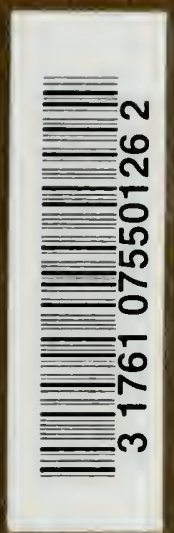

- INN VDF IORONIO ( GIRph 







\title{
HANDBUCH
}

UER

\section{BIOCHEVISCHEN ARBBITSUETHODEN.}

\author{
BEARBEITET FUN
}

Prof. Dr. E. Abderhalden, Berlin - Priv.-Doz. Dr. D. Ackermann, Würzborg - Prof. Dr. Hans Aron, Mfanila - Prof. Ur. Baglionl, Rom - Prof. Pr. phil. Bartelt, Peking - Prof. Dr. Battelli, Genf - Prof. Dr. J. Biehringer, Brannschweig - Dr. phil. Carl Brahm, Berlia - Priv.-Doz. Dr. Theodor Brugsch, Kerlin - Prof. Dr. Chodat, Genf - Prof. Dr. Cramer, Edinburgh - Prof. Dr. M. Dennstedt, Hamburg Prof. Dr. Felix Ehrlich, Breslau - Prof. Dr. med. Embden, Frankfurt a. M. - Prof. I)r. St. Faust, Wurzburg - Priv.-Doz. Dr. Frledenthal, Nicolassee-Berlin - Prof. Dr. E. Friedmann, Berlin - Priv.: Joz. Dr. Fuhrmann, Graz - Prof. Dr. Wm. J. Gies, New-York - Priv.-Doz. Dr. Grube, NeuenahrBonn - Prof. Dr. Oiof Hammarsten, Upsala - Priv.-Doz. Dr. Hári, Budapest - Dr. M. Henze, NeapeI - Priv.-Doz. Dr. Hildebrandt, Halle a. S. - Priv.-Ioz. Dr. Rudolf Hoeber, Kiel - Prof. Dr. Jacoby, Berlin - Prof. Dr.Johannsson, Stockholm - Dr. phil. R. Kempf, Berlin - Prof. Dr. Kobert, Rostock Priv.-Doz. Dr. Kostytschew, St. Petersburg - Prof. Dr. William Kuester, Stattgart - Prof. Dr. Kutscher, Marburg - Prof. Dr. Leo Langstein, Berlin - Prof. Dr. Loeb, Berlin - Prof. Dr. Jacques Loeb, Berkeley (Kalifornien) - Prof. Dr. London, St. Petersbnrg - Prof. Ur. Leonor Michaelis, Berlin - Prof. Dr. Franz Müller, Berlin - Priv.-Doz. Dr. M. Nierenstein, Bristol - Prof. Dr. Osborne, New-Haven, Conn. - Prof. Dr. W. Palladin, St. Petersbarg - Geh. Rat Prof. Dr. E. Pflüger, Bonn - Dr. pbil. Pringsheim, Berlin - Prof. Dr. Röhmann, Rreslan - Dr. phil. und med. Peter Rona, Ferlin - Prof. Dr. Rosenfeld, Breslau - Priv.-Doz. Dr. Franz Samuely, Freiburg i. B. - Prof. Dr. A. Scheunert, Dresden - Prof. Dr. Schittenheim, Erlangen - Prof. Dr. J. Schmidt, Stattgart Dr. Schmitz, Frankfurt a. M. - Prof. Dr. Fr.N.Schulz, Jena - Prof. Dr. Schulze, Zürich - Prof. Dr. Slegfried, Leipzig - Priv.-Doz. Dr. Lina Stern, Genf - Prof. Ur. Steüdel, Berlin - Hofrat Prof. Dr. J. Stoklasa, Prag - Dr. Eduard Strauß, Frankfurt a. M. - Prof. Dr. Tappeiner, München - Geh. Rat Prof. Dr. Tollens, Göttingen - Priv.-Doz. Dr. Völtz, Berlin - Priv.-Doz. Ur. Weiser, Badapest J. Wetzel, Berlin - Prof. Dr. Wiechowski, Prag - Prof. Dr. Wilistäter, Züich - Prof. Ir. E. Winterstein, Zürich - Pris.-Doz. Dr. Edgar Zunz, Brüssel.

HERAUSGEGEBEN VON

PROF. DR. EMIL ABDERHALDEN, DTREKTOR DES PHYSIOL. INSTITUTES DER TIERARZTL. HOCHSCHULE, BERLIN.

DRITTER BAND.

-

SPEZIELLER TEIL.

MIT 413 TEXTABBILDUNGEN.

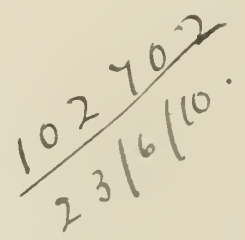

URBAN \& SCHWARZENBERG

BERLIN

N., FRIEDRICHSTRASSE $105 \mathrm{~b}$
WIEN

I., MAXIMILIANSTRASSE 4

1910. 


$$
\begin{aligned}
& \text { QH } \\
& 324 \\
& A_{3} \\
& \text { Bd. } \\
& \text { Spcz.T. }
\end{aligned}
$$

A L L E RECHTE VORBEIIALTEX.

Copyright, 1910, by Urban \& Schwarzenberg, Berlin. 


\section{Inhaltsverzeichnis.}

Fermente

Seite

A. Methoden zur Darstellung von Fermenten. Vion Prof. Ur. Leonor Michaelig. Berlin 1

Darstellung ron Hefepreßsaft . . . . . . . . . . . . . . 3

Darstellung des Invertins . . . . . . . . . . . . . . 7

Darstellung des Pepsins . . . . . . . . . . . . . . . 8

Extraktion der pankreatischen Fermente . . . . . . . . . . . 9

Darstellung des Labfermentes . . . . . . . . . . . . . . . 10

Die Dialyse . . . . . . . . . . . . . . . . . 10

Allgemeines über die Anfbewahrung der Ferment präparate. . . . . . . 12

Die Klärung von Fermentlösungen . . . . . . . . . . . . . . 14

B. Methoden zur qualitativen und quantitativen Verfolgung der Fermentwirkung.

Von Prof. Dr. Leonor $11 \mathrm{ichaelis,} \mathrm{Berlin} \mathrm{.} \mathrm{.} \mathrm{.} \mathrm{.} \mathrm{.} \mathrm{.} \mathrm{.} \mathrm{.} \mathrm{.} \mathrm{.} \mathrm{.} \mathrm{.} 16$

1. Der qualitative Yachweis der gebräuchlicheren Fermente . . . . . . . 16

1. Koblehydratspaltende Fermente . . . . . . . . . . . . 16

Diastase . . . . . . . . . . . . . . . 16

Invertase . . . . . . . . . . . . . 16

Zymase . . . . . . . . . . . . . . 17

Emulsin . . . . . . . . . . . . . . . . 17

2. Proteolytische Fermente. . . . . . . . . . . . . 17

Pepsin . . . . . . . . . . . . . . . 17

Labferment . . . . . . . . . . . . . . . . 19

Trypsin . . . . . . . . . . . . . . . . . 19

Paparotin . . . . . . . . . . . . . . 2.2

3. Lipase . . . . . . . . . . . . . . . . . . . . 2.2

2. Allgemeine Grundsätze bei der quantitativen Bestimmung der Fermente. . . 24

Beispiel für die quantitative Bestimmung eines Ferments . . . . . . . . 28

Einiges über die Methoden zum ständigen Verfolgen der Fermentwirkung. . . 31

Elektrische Wanderung der gelösten Fermente. . . . . . . . . . 38

C. Darstellung von Oxydasen und Katalasen tierischer und pflanzlicher Herkunft.

Methoden ihrer Anwendung. Von Prof. Dr. R. Ubodat, Genf. . . . . . . . . 42

Oxygenasen. . . . . . . . . . . . . . 42 
Seite

Nachweis von peroxydartigen Verbiudungen in den Uxydationsfermenten. . . 43

1. Jodstärkekleister . . . . . . . . . . . . . . . . . . . . . 43

2. Barytwasserprube . . . . . . . . . . . . . . . . . . . . . . . 44

Nachweis von peroxydartigen Verbindungen in der lebenden Ptlanze. . . . . 14

Peroxydase . . . . . . . . . . . . . . . . . . . . . . 45

Messung der Aktivitit der Peruxydase. . . . . . . . . . . . . . . . . 19

Oxydasen. . . . . . . . . . . . . . . . . . . . . . 52

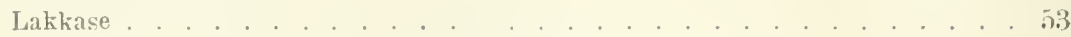

Bestimmung des oxydationswertes der Lakkise. . . . . . . . . . . . . 51

Tyrosinase . . . . . . . . . . . . . . . . . . . . . . . . . . 5 5

Messung der oxydativen Kraft der Trrosinase . . . . . . . . . . . . (i己

Katalase . . . . . . . . . . . . . . . . . . . . . . 65

Gewinnung der Katalase. . . . . . . . . . . . . . . . . . . . . . . 66

Messung der katalytischen Kratt. . . . . . . . . . . . . . . . . . 69

Anhang: Aldehydase. . . . . . . . . . . . . . . . . . . 72

Verdaunge. . . . . . . . . . . . . . . . . . . . . . . . . . . . 75

A. Operative Technik zum Studium der Verdaung und der Resorption. Tom Prof. Dr. E. S. London, St. Petersburg . . . . . . . . . . . . . . . . . . . Tis

Allgemeine Bemerkungen. . . . . . . . . . . . . . . . . . . . . . 15

1. Operationsiaum . . . . . . . . . . . . . . . . . . . . . 76

2. Aseptische und antiseptische Maßregeln . . . . . . . . . . . . . . 76

3. Instrumente . . . . . . . . . . . . . . . . . . . . . . T

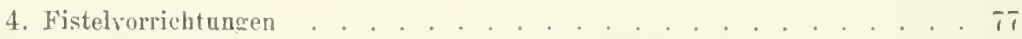

5. Verschiedenartige für die Versuche nötige Vorrichtungen . . . . . . . 79

6. Grundlagen der Operationsmethodik zur Intersuchung des Verdaunngsprozesses . . . . . . . . . . . . . . . . . . . . . . . S.2

7. Operations- und Versuchsmethodik . . . . . . . . . . . . . . 8t

1. Erölthung und śchließung der Bitnchhöhle . . . . . . . . . . . . 84

2. Pflege der Tiere nach der Operation . . . . . . . . . . . . . 85

A. Polyfistelmethode . . . . . . . . . . . . . . . . Sn

B. Dauerisnlierungsmethode . . . . . . . . . . . . . 9;

I. Speichelfistel . . . . . . . . . . . . . . . 96

II. Osophatgusfistel . . . . . . . . . . . . . . . (1)

III. Magentistel . . . . . . . . . . . . . . . . . 100

IV. Drüsenblindsiicke . . . . . . . . . . . . . . 102

х) Fundusblindsack (kleiner Magen) . . . . . . . . . . 102

§) Pylorusblindsackmagen. . . . . . . . . . . . . . . 106;

ү) Pylorussatckmagen . . . . . . . . . . . . . . . . . 1015

¿) Totaler Magensack . . . . . . . . . . . . . . . 107

в) Brunnerdrüsensack . . . . . . . . . . . . . 107

V. Pankreastistel. . . . . . . . . . . . . . 107

VI. Gallenfistein . . . . . . . . . . . . . . 110

1. Gallenblasenfistel . . . . . . . . . . . 110

2. Endständigre Chnledochustistel . . . . . . . . . . . . 111

3. Kontinuitätsfistel des Dnctus choledochus. . . . . . 112 
III. Thiry-Vellasehe Fistel . . . . . . . . . . . . 113

VIII. AuBere Gastrojejuno (resp. ileo)anastomose . . . . . . . 113

IX. Ecksche Operation. . . . . . . . . . . . . . . . 111

1. Kanüleneinlegung in die șjeichelgänge . . . . . . . 117

2. Exstiruation der s.childdrüse . . . . . . . . . . . . 118

3. Exstirpation der Banchsjeicheldrüse . . . . . . . 118

4. Exstirpation der Nebennieren . . . . . . . . . . . . 119

5. Verschiedene Manipulationen an Blutgefißen . . . . 11!)

6. Anlegung einer Fistel des Ductus thoracicus . . . . 120

B. Methoden zur Untersuchung der Verdaungsprodukte. Vun Privatdozent Dr. Edgard Zunz, Briissel . . . . . . . . . . . . . . . . . . . 122

A. Allgemeine Technik . . . . . . . . . . . . . . . . . . 12.2

I. Terdaungsversuche in Hand des Tierexperimentes . . . . . . . . . . 12²

a) Allgemeine Betrachtungen . . . . . . . . . . . . . . . . . . . 120

b) Verdaungsversucbe bein intakten Tiere . . . . . . . . . . 123

1. Schlundsondenverfahren . . . . . . . . . . . . . . . . 123

2. Isolierung des Magens und des Dünndarnes jost mortem . . . . 12T

c) Vorherige operative Eingriffe erheischende Versuche . . . . . . . 129

1. Terfahren. welche das Entweichen run Verdaungsprodukten rom Jagen nach dem Darm rerhindern . . . . . . . . . . 130

х) Lnterbindung des Pförtners . . . . . . . . . . . 130

¡) Verschließung des Pförtners rom Jagen her . . . . . . 131

ץ) TerschlieBnng des Pförtners rom Duodenum ber . . . . 133

2. Verfahren zur Gewinnung der Endprodukte der Magenverdauung . 131

3. Verfahren zur direkten Einfiihrung von Nährstoffen in das Duodenum 137

4. Terfahren zum studium der Darmrerdaung an isolierten Darmschlingen . . . . . . . . . . . . . . . . 139

х) Ohne vorherige Anlegang einer Varmtistel . . . . . . . . 139

¡) Mit vorheriger Anlegung einer Darmfistel . . . . . . . 143

j. Verfahren zur Termeidung des Zuflusses ron Pankreassaft und Galle in den Darm . . . . . . . . . . . . . . . . 146

II. Verdannngsversuche im Reagenzglase . . . . . . . . . . . . . . 148

a) Allgemeine Technik . . . . . . . . . . . . . . 148

I. Brutschränke . . . . . . . . . . . . . . . . . 149

Brutschränke für Gasheizung . . . . . . . . . . . . . . . 149

z) mittelst Wasser geheizte Brutschränke . . . . . . . 150 d'Arsonvalsche Brutschränke . . . . . . . . . 154

¡) Jittelst Jletallröhren geheizte Brutschränke . . . . . . 156

¡) Brutschränke für elektrische Heizung . . . . . . . . . 15ॅ

II. Thermostaten . . . . . . . . . . . . . . . . 161

b) Terfahren zur V'ermeidung der Anhäufung der Terdaunngsprodukte . 165

1. Allgemeine Jialysierverfahren . . . . . . . . . . . 165

Dialysator nach Grabam . . . . . . . . . . . . . 165

Dialysator nach B. Proskaner . . . . . . . . . . 166 
Dialysitur nach W. Kühne. . . . . . . . . 167

Dialysator nach Wrobleski . . . . . . . . . . 167

Dialysierapparat von Waymonth Reid . . . . . . . . 168

Dialyse nach Gürber . . . . . . . . . . . . . . 169

Dialysator nach siegfried . . . . . . . . . . . . . . . . . . . . . . . . 171

Dialyse nach Jordis . . . . . . . . . . . . . . . 171

Jiffusionshïlsen von Schleicher d schiill . . . . . . . 172

Dialyse in Kollodiumsäckchen . . . . . . . . . 172?

Dialyse in Schilf- und Zelluloseschlïinchen . . . . . . . 175

lialyse nach Pascueci . . . . . . . . . . . . . 177

lialyse nach Wiechowski . . . . . . . . . . . 177

Dialyse nach ran Calcar . . . . . . . . . . . . . . . 178

2. Sivezielle Dialysierverfahren zu kïnstlichen Verdanungsversuchen 183

Dialysator nach kironecker . . . . . . . . . . . . 183

Dialysator nach Sheridan Lea . . . . . . . . 185

Dialysator nach P'upe . . . . . . . . . . . 186

13. Spezielle Technik . . . . . . . . . . . . . . . . . 189

I. Gewinnung der Vordaunngssifte. Darstellung der Fermente und ihre Anwendung . . . . . . . . . . 18!

a) Allgemeine Betrachtungen . . . . . . . . . . . . 189

b) Speichel . . . . . . . . . . . . . . . . . . . . . . 190

Gewinnung . . . . . . . . . . . . 190

Im speichel enthaltere Fermente . . . . . . . . . 190

Diastase (1'tyalin, Amylase) . . . . . . . . . . . . 191

c) Mlagensaft . . . . . . . . . . . . . . . . . . . . 192

Gewinunng . . . . . . . . . . . . . 192

Im Nagensaft enthaltene Fermente . . . . . . . . . . 193

Magenlipase oder Magensteapsin . . . . . . . 198;

Pejsin . . . . . . . . . . . . . . 193

Reindarstellung des Pepsins aus Schweinsmagenschleimhaut nach

l'ekellaring . . . . . . . . . . . . . . 194

Darstellung des Pepsins aus Hundemagensaft nach Pekelharing 195

Pepsinlösung nach schrumpl . . . . . . . . . . . . 196

Pseudopepsin . . . . . . . . . . . . . . . . 196

lablerment oder ('hrmosin . . . . . . . . . . . . 197

Paraclymosin . . . . . . . . . . . . . . . 199

Propepsin und Prochymosin . . . . . . . . . . . 199

d) Darmsaft . . . . . . . . . . . . . 200

Gewinnung . . . . . . . . . . . . . . 200

Im Darmsatte enthaltene Fermente . . . . . . . . . 202

Diastase, Invertase, Maltase . . . . . . . . . . . . . . 202

laktase . . . . . . . . . . 203

Lipase . . . . . . . . . . . . . . . . . . 203

P'seudopepsin oder Pepsin der Brumerschen Druisen . . . . . 203

İrepsin . . . . . . . . . . . . . 203

Enterokinase . . . . . . . . . 204 
sekretin . . . . . . . . . . . . . . . 205

Arginase . . . . . . . . . . . . . . . . . 206

Nuklease . . . . . . . . . . . . . . . . . 206

•) Pankreassaft . . . . . . . . . . . . . . . . . . . 206

Gewinnung ron proteolytisch unwirksamem Pankreassaft . . 206

Gewinnung eines spontan aktiven Pankreassaftes . . . . . . 210

In Pankreassafte entbaltene Fermente . . . . . . . . . . 210

Pankreasdiastase . . . . . . . . . . . . . . . . 210

Pankreassteapsin oder Lipase . . . . . . . . . . . . 211

Trypsin . . . . . . . . . . . . . . . . . . 211

Nuklease . . . . . . . . . . . . . . . . 213

f) Galle . . . . . . . . . . . . . . . . . . . . . 213

1. Einwirkung bei der Verdauung der Fette . . . . . . . . 213

2. Einwirkung bei der Terdauung der Proteine . . . . . . . . 214

3. Gewinnung der Galle . . . . . . . . . . . . . . 214

g) Kombinierte Verdanungswirkungen . . . . . . . . . . . . 214

h) Verdanungsfermente pflanzlicher Herkunft: Papain . . . . . . 215

II. Isolierang der Abbauprodakte der Verdauung . . . . . . . . . . . . 216

a) Allgemeine Betrachtungen . . . . . . . . . . . 216

b) Isolierang der Abbauprodukte der Verdaung der Kohlehydrate . 216

1. Nachweis der verschiedenen Abbauplodukte der lioblebydrate in einem Verdaungsgemisch. . . . . . . . . . 216

‥ Quantitative Bestimmung der unzersetzten Stärke. der gebildeten Dextrine and Zacker in einem Verdaungsgemische . . . . 217

3. Isolierung der Dextrine . . . . . . . . . . . . 218

c) Isolierung der Abbauprodukte der Verdaung der Fette . . . 220

Feststellung der aus Fettemulsionen abgespaltenen Fettsäuren 220 Gleichzeitige quantitative Bestimmung der Seifen und Fettsänren in einem Verdanungsgemische . . . . . . . 221 Untersuchung der Abbauprodukte der Verdauung der Fette nach Levites . . . . . . . . . . . . . 2 221

Feststellung des (iesamtfettes . . . . . . . . . . 2222

Verfahren von Volhard-Stade zur Feststellung des Grades der

Fettspaltung durch Lipase . . . . . . . . . . . 223

Bestimmang von Seifen neben Fettsäuren in Verdanungsgemischen nach Pflïger. . . . . . . . . . . . 225

Glyzerin . . . . . . . . . . . . . . 226

d) Isolierung der Abbaaprodukte der Verdanung der Proteine . . .227

Verfahren zur Cntersuchung der Abnabme der Genuinität der Proteine . . . . . . . . . . . . . . . 227 Quantitative Messung proteolytischer spaltungen mittelst der Formoltitrierung nach sörensen . . . . . . . . . 22T

Bestimmung der in einem Verdaungsgemenge rorhandenen Proteosenmenge . . . . . . . . . . . . . . 230 Lntersuchung der Stickstoffrerteilnng zwischen den rerschiedenen Grappen von Proteosen und anderen Spaltprodukten der Proteine 230 
Maslams Verfabren zur Bestimmung des Proteosengehaltes einer

Verdauungslösung . . . . . . . . . . . . . . . . 237

Fällung der Proteosen mittelst Gerbsiure . . . . . . . . 238

Isolierung der Proteoseu . . . . . . . . . . . . . . . 239

Darstellung der Proteosen nach E. P. Pick . . . . . . . 239

Hetero und Protoalbumose . . . . . . . . . . . . 939

Heteroalbumose . . . . . . . . . . . . . . 240

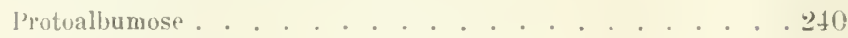

I'roteosenfraktion A. . . . . . . . . . . . . . 240

Thioalbumose . . . . . . . . . . . 241

Albumose $\mathrm{A}^{\mathrm{II}}$. . . . . . . . . . . . . . . 241

Protensenfraktion $\mathrm{B}$. . . . . . . . . . . . . . . . . .

Albumose $\mathrm{B}^{\mathrm{I}}$. . . . . . . . . . . . . . . . 2 1 . .

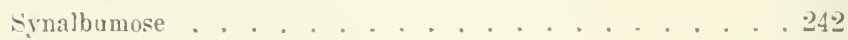

Albumose $\mathrm{B}^{11}$. . . . . . . . . . . . . 24

Proteosenfraktion ( . . . . . . . . . . . . 243

Darstellung der Proteosen nach Haslam . . . . . . . . 243

Darstellung der Protıalbumose und der Heteroalbumose nach Adler 244

Eigenschaften der Proteosen . . . . . . . . . . . 246

Tryptıphan . . . . . . . . . . . . . . . . . . . . . . . . . .

1. Isolierung nach Hopkins und Cole . . . . . . . . 446

2. Quantitative Bestimmung nach Levene und Rouillier. 248

Naehweis des Vorhandenseins basischer Spaitungsprodukte in einer

Verdaunugslösung . . . . . . . . . . . . 249

Bestimmung des Ammonialss . . . . . . . . . . . . . 249

Plasteine und Koalgulosen . . . . . . . . . . . 24!

Physikalisch-chemische Verfahren zur Lntersuchung des Abbalues

der Proteine . . . . . . . . . . . 251

e) Isolierung der Abbanprodukte der Verdauung der Nukleoproteide 253

f) Isolierung der Abbauprodukte der Verdaung der Phosphatide . 255

C. Methoden zur Untersuchung des Speichels und des Inhaltes des Verdaungssehlauches und der Fäzes der Pflanzenfresser. Von Prof. Dr. A. Scheunert, Dresden. . . . . . . . . . . . . . . . . . . . . . . . .

1. Untersuchung des speichels . . . . . . . . . . . . . . . 25̆

A. Gewinnnng . . . . . . . . . . . . . . . . . . . 257

B. Allgemeine Eigenschaften. . . . . . . . . . . . . . 258

C. Organische Verbindungen . . . . . . . . . . . . . . 258

1. Proteinsubstanzen . . . . . . . . . . . . . 25s

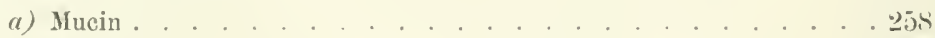

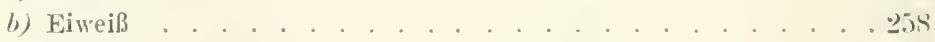

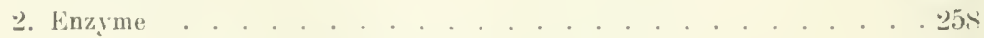

3. Andere organische Verbindungen . . . . . . . . . . . 25!)

D. Anorganische Verbindungen . . . . . . . . . . . . . . . 259

I. Salze der Rhodanwasserstotlsiure . . . . . . . . . . . . . . . 25!

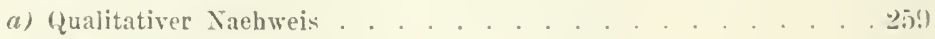

b) (quantitative Bestimmung. . . . . . . . . . . . . 260 
II. Chlorige Seite

III. Nitrite . . . . . . . . . . . . . . . . . . . . . .

IV. Ammoniak . . . . . . . . . . . . . . . . . . . . . . . . . . . .

Speichelsteine, Zahnstein . . . . . . . . . . . . . . . . . . . . . 26

2. Tntersnchuner des Darminhaltes und der Fäzes der P’tanzentresser. . . . . 263

I. Analytische Bestimmungen in frischen Magen-Durminhalten und Fäzes der Phanzenfiesser . . . . . . . . . . . . . . . . . . . 263

1. Trockensubstanz . . . . . . . . . . . . . . . . . 264

2. Bestimmung stickstıffhaltiger Bestandteile. . . . . . . . . . . 264

3. Untersuchung aul' anorganische Bestandteile (Analyse der Asche) . 266

4. Trennung der lïslichen von den unlislichen liestandteilen und Analyse der löslichen Bestandteile. . . . . . . . . . . . . . . . 266

a) Lntersuchung der gelüsten Bestandteile . . . . . . . . . 267

b) Untersuchung der ungelïsten Bestandteile . . . . . . . . .267

II. Anderweitige Verarbeitung des frischen Jaterials . . . . . . . . . 267

IIl. Konservierung des frischen Jaterials . . . . . . . . . . . . . . 268

IT. Vorbereitung von Magen-Darminhalteı und Fäzes zur Analyse (Trocknen,

Zerkleinern) . . . . . . . . . . . . . . . . . . 268

V. Analytische Bestimmnngen iu getrockneten Jaterial. . . . . . . . . 70

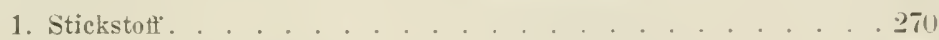

2. Bestimmung der stärke. . . . . . . . . . . . . . . . . 270

3. Bestimmung der l'entosane . . . . . . . . . . . . . . . . 273

4. Bestimmung der Rohfaser. . . . . . . . . . . . . . . . 273

a) Weender-Verfahren . . . . . . . . . . . . . . . . . . . . . . . . . . . . . . .

b) Verfahren nach Holde-Fleiss . . . . . . . . . . . . . . 27.

c) Glyzerin-S̈chwefelsäureverfahren von König . . . . . . . . . 2 75

5. Zellulosebestimmungen . . . . . . . . . . . . . . . . . 276

Die Methode ron Lange und ihre Modifikationen . . . . . . . . .

K. Darmgase . . . . . . . . . . . . . . . . . . . . . . . . . 281

Anhang: Untersuchung ron Darmkonkrementen . . . . . . . . . 281

Intermediärer Stoffwechsel

A. Fraktionierung von Organen und Darstellung von wirksamen Organextrakten.

Von Prof. Dr. W. Wiechowski, Prag. . . . . . . . . . . . . . . . . 2S?

A. Vorbereitung der Organe (Entfermung des Blutes) . . . . . . . . . . . . 283

B. Die ,zellnläre Dialyse durch Dampf organischer Flüssigkeiten . . . . . . 285

C. Das Zerkleinern der Organe . . . . . . . . . . . . . . . . . . . . . 286

D. Allgemeine Methode zur chemischen und biologischen l'ntersuchung iiberlebender

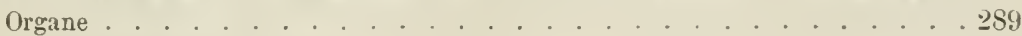

I. Das Trockneu . . . . . . . . . . . . . . . . . . . . . 289

II. Die Extraktion. . . . . . . . . . . . . . . . . . . . . . 293

III. Das Zerkleinern der Zellen . . . . . . . . . . . . . . . . . . . . 297

E. Die Herstellung ron Alkohol-(Aceton-)Material . . . . . . . . . . . . . 299

F. Weitere Verarbeitung der zerkleinerten Organe . . . . . . . . . . . . . 300

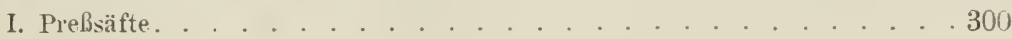


11. Extrakte.

1. Indifferente Extraktion

๔) Kochsalzlösung bzw. Wasser . . . . . . . . . . . . . . . 303

ङ) Glyzerin . . . . . . . . . . . . . . . . . . . . . . . . . . . . . . . . . . . .

ү) Athrlalkohol . . . . . . . . . . . . . . . . . . . . . . . . . . .

״. Extraktion durch Aul'sehließung (Entmischnng) der Urganzellen . . . 305

x) Mechanisch-physikalische Aufschließungsmethoden. . . . . . . . 305

11) Gefrieren und wieder tuftaten . . . . . . . . . 305

h) Die Zertrïmmerung der Zellen . . . . . . . . . . . . . . .306;

c) Die Ilialyse gegen destilliertes Wasser. . . . . . . . . . . 306

d) Fntmischung durch Zusatz geringer, niebt eiweißfällender Mengen Athylalkohol . . . . . . . . . . . . . . . . . . 308

e) Aufschlieben durch Auskochen dor trgane . . . . . . . . . 30S

(5) Chemische Aufschließnngsnethoden . . . . . . . . . 308

(1) Nazeration und lïnger dauernde Autolyse . . . . . . . . . 308

b) Papain . . . . . . . . . . . . . . . . . 309

c) Trypsin . . . . . . . . . . . . . . . . . . 309

d) Pepsin . . . . . . . . . . . . . . . . . . 309

๑) Salzlüsungen . . . . . . . . . . . . . . . . 310

f) Alkalien . . . . . . . . . . . . . . . . 311

g) Säuren . . . . . . . . . . . . . . . . 312

ff. Fraktionierung der Extrakte, l'relisäte oder Kollaturen . . . . . . . . . 312

Salzfïllung . . . . . . . . . . . . . . . . . . . . 313

х) Ammonsulfat . . . . . . . . . . . . . . . . . . . . 313

ק) Calciumchlorid . . . . . . . . . . . . . . . . . . . 313

\%) Kaliumacetat. . . . . . . . . . . . . . . . . . . . 313

๖) Uranylacetat . . . . . . . . . . . . . . . . . . . . . . . . . . . . . . . .

§) Säuren . . . . . . . . . . . . . . . . . . . . . . 314

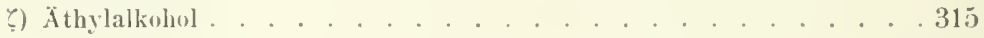

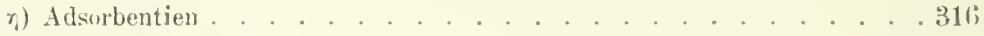

if) Dialyse gegen destilliertes Wasser. . . . . . . . . . . . . . . 317

II. Konservierung des Materiales während der Arbeit. . . . . . . . . . . . 317

1. Autiseptika . . . . . . . . . . . . . . . . . . . . . . 318

2. Die Reaktion . . . . . . . . . . . . . . . . . . . . . . . . . . 319

3. Temperatur . . . . . . . . . . . . . . . . . . . . . . . . 319

4. Schädigende stoffe . . . . . . . . . . . . . . . . . . . . . 319

l). Die künstliche Durchblutung resp. Durchspülung von Organen. Von Prof. Dr. Franz $\|$ üller, Berlin . . . . . . . . . . . . . . . . . . . . . . 321

Yorbereitung des Tieres . . . . . . . . . . . . . . . . . . . . 321

Operationstechnik . . . . . . . . . . . . . . . . . . . 32)

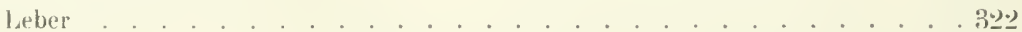

Niere . . . . . . . . . . . . . . . . . . . . . . . 3

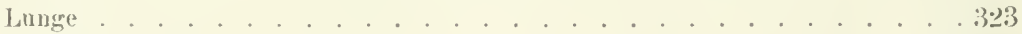

1) . . . . . . . . . . . . . . . . . . . . . . . . 4 
Seite

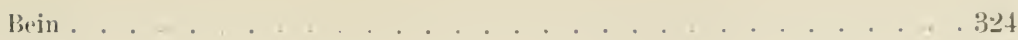

$11 \mathrm{er} \%$. . . . . . . . . . . . . . . . . . . . . . . . . . . . . . . . . .

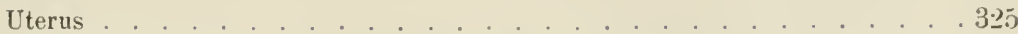

Zusammensetzung der Durchspiilungstliissigkeit . . . . . . . . . . . . . . 325

Prinzip der Durchspïlangsapparate. . . . . . . . . . . . . . . . . . . 327

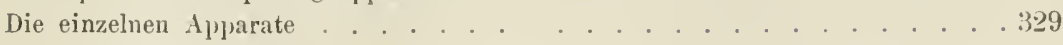

1. Froschherzapparate. . . . . . . . . . . . . . . . . . . 329

(1) Nach Williams-Dreser . . . . . . . . . . . . . . . . . 30!

b) Der Jacobjsche Alparat . . . . . . . . . . . . . . . . . . . . . . . . . . .

2. Apparate für das säugetierherz . . . . . . . . . . . . . . . . . . . . . . . . . . . . . .

(1) Der Langendorifsche Apparit . . . . . . . . . . . . . . . . . . . . . . . . . . . . . .

b) Ter Brodiesche Herzapparat . . . . . . . . . . . . . . 335

3. Apparate zur künstlichen Durchblutung anderer Orgune als des Herzens. 338

a) Apparat von Jacabj . . . . . . . . . . . . . . . . . . . . . . . . . . . . . . . . . 339

b) Durchblutungsapparat von Brodie . . . . . . . . . . . . . . 351

c) Durchblutungsverfabren von Hevmann und Kochmann . . . . . . . 3556

C. Stoffwechseluntersuchungen an überlebenden Organen. Ton Professor Dr.

s. Baglioni, Rom. . . . . . . . . . . . . . . . . . . . . 358

A. Allgemeines . . . . . . . . . . . . . . . . . . . . . . . . . . . . . . . . . . . .

1. Theoretische Begrändung. . . . . . . . . . . . . . . . . . 358

2. Allgemeiner Yersuchsplan . . . . . . . . . . . . . . . . . . . 359

3. Einige allgemeine praktische Winke . . . . . . . . . . . . . . 361

B. Spezielles . . . . . . . . . . . . . . . . . . . . . . . . . . . . . . . . . . . . . . . . . . . . . . . . . .

1. Lunge . . . . . . . . . . . . . . . . . . . . 363

2. Leber . . . . . . . . . . . . . . . . . . . . . . . . . . . . . . . . . . . . . . . . .

Methode von Salaskin . . . . . . . . . . . . . . . . . 364

${ }^{\circ}$ Kraus . . . . . . . . . . . . . . . . . 365

" $"$ G. Embden und K. Glässner . . . . . . . . . . . 365

, K. Grube . . . . . . . . . . . . . . . 367

3. Darmschlinge . . . . . . . . . . . . . . . . . 368

Jethode von G. Salvioli . . . . . . . . . . . . . . . . 368

Embden und Glässner . . . . . . . . . . . 369

4. Niere . . . . . . . . . . . . . . . . . . . . . . . . . . . . . . . . . . .

Methode von bunge und Schmiedeberg . . . . . . . . . . . . 369

, Jacobj und v. Solieranski . . . . . . . . . . . . 371

Verfahren ron skutul . . . . . . . . . . . . . . . 371

Methode ron Sollmann . . . . . . . . . . . . . . . . 373

5. Muskelsystem: Herz . . . . . . . . . . . . . . . . . . . 374

Langendorffs Verfthren . . . . . . . . . . . . . . . 375

Skelettmuskeln . . . . . . . . . . . . . . . . . . . . . . . . . . . . . . . . . .

Methode von M. v. Frey und M. Gruber . . . . . . . . . . . . . . 378

. Embden und Glässner . . . . . . . . . . . . . 38:

6. Zentralnervensystem . . . . . . . . . . . . . . . 38? 
D. Die Fermente des Kohlehydratstoffwechsels in Tier- und Pflanzenwelt. Vou Prof. Dr. Martin Jacoby, Berlin. . . . . . . . . . . . . . . . . . 385

Glykogenspaltende Fermente . . . . . . . . . . . . . . . . . . 38.,

Die Bestimmung des diastatisehen Fermentes nach Wohlgemuth . . . . . . 386

Dextrinasen . . . . . . . . . . . . . . . . . . . . . . . . . . . . . . . .

l) Malz-Diastase . . . . . . . . . . . . . . . . . . . . . . . . . . . . . . . . . . .

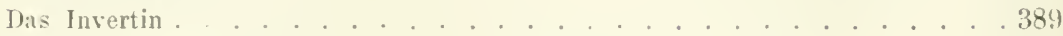

D) Es Emulsin . . . . . . . . . . . . . . . . . . . . . . . 391

Die Zymase . . . . . . . . . . . . . . . . . . . . . . . . . 393

Trennung von Fernent und Coferment der Zymase. . . . . . . . . . . . 396

bic Laktaridase. . . . . . . . . . . . . . . . . . . . . . . . . . . . . . . . . . .

Ile tierische Glykolyse . . . . . . . . . . . . . . . . . . . . . . . . 399

Die Glykolyse bei den hüherm PHanzen . . . . . . . . . . . . . . . 400

E. Die Fermente des Fettstofivechsels in Tier- und Pflanzenwelt. Vun Prof. Dr: Martin Jacoby, Berlin. . . . . . . . . . . . . . . . . . . 402

Die Abrahme der Atherlöslichkeit des Fettes im Blut . . . . . . . . . . . 40.2

Die Jonobutyriuase des Blutserums. . . . . . . . . . . . . . . . . . $4(0)$

lie Esterspaltung in den tierischen Organen . . . . . . . . . . . . . 403

Die Neutralfetspaltung in den tierischen trganen. . . . . . . . . . . . . 403

bie Rizinulipase . . . . . . . . . . . . . . . . . . . . 405

F. Die Fermente des Eiweißstoffwechsels in Tier- und Pflanzenwelt. Yon Prof. Dr. Martin Jacoby, Berlin . . . . . . . . . . . . . . . . . . 407

Die proteolytischen Fermente del tierisehen Organe . . . . . . . . . . . . 407

Die Fermische Gelatinemethode . . . . . . . . . . . . . . . . . . . . . 408

Die Polypeptidspaltung durch tierische Organe nach Abderhalden . . . . . . 409

Die Isolierung von fermenten nach Rosell . . . . . . . . . . . . . . . 409

Die lsolierung des proteolytischen Leherfermentes nach Hata . . . . . . . . 410

Die Isolierung des proteolytischen Lenkozytenfermentes nach . bohmann und

Lockemann . . . . . . . . . . . . . . . . . . . . . . 411

Die optische Untersnchung der Polrpeptidspaltung in Geweben. . . . . . . . 412

Jie proteolytischen Fermente der ptlanzlichen Futtermittel. . . . . . . . . . 412

bas proteolytische ferment des llaters . . . . . . . . . . . . . . . . . . 413

Die Eiweißspaltung in Keimpflanzen. . . . . . . . . . . . . . . . . . 414

Das peptisehe Enzym der Gerste . . . . . . . . . . . . . . . . . . . 416

Die Abspaltung von Tryptophan durch proteolytische l'flauzenfermente . . . . 416;

Die peptolytischen Fermente der Planzen. . . . . . . . . . . . . . . . . 416

Das Papayotin . . . . . . . . . . . . . . . . . . . . . 417

Die Wirknngen des Papains bei hoher Temperatur. . . . . . . . . . . . . 417

bie Polypeptidsjaltung durch Papayotin . . . . . . . . . . . . . $41 \mathrm{~S}$

Anhang: Das Sekretin . . . . . . . . . . . . . . . . . . 418

T)arstellung und l'rüfung des sokretins. . . . . . . . . . . . .418

Das Prosekretin. . . . . . . . . . . . . . . . . . . . . . . 41 !

Die seliretinähnlichen Wirkungen des C'hulins . . . . . . . . . . 419 
G. Die Fermente des Nukleinstoffwechsels und deren Wirkung. Von Prof. Dr.

Alfred scluit ten helm, Erlangen . . . . . . . . . . . . . . . t2(l)

Allgemeine lBenerkungen. . . . . . . . . . . . . . . . . . . . $4: 20$

1. Nuklease . . . . . . . . . . . . . . . . . . 421

Allgemeiner Nukleasenachweis durch $x$-tlymonukleinsaures Natrium . . 421

Spezieller Nachweis der aufspaltenden Nuklease und Isolierung $\operatorname{der} \mathrm{Ab}$ -

bauprodukte . . . . . . . . . . . . . . . . . . 42?

Darstellung and Eigenschaften der Nukleasen. . . . . . . . . . . 424

2. Purindesamidasen . . . . . . . . . . . . . . . . . . 424

Nachweis der Fermentwirkung . . . . . . . . . . . . . . . . . 124

Darstellung und Eigenschaften der Puriudesamidasen . . . . . . 4: ;

3. Xanthinoxydase . . . . . . . . . . . . . . . . . . . . 129

Nachweis des Ferments . . . . . . . . . . . . . . . . . 428

Darstellung und Figenscliatten der Kauthinoxydase . . . . . . . . . 429

4. Urikolytisches Ferment (Harnsäureoxydase) . . . . . . . . . . . . . 430

Nachweis der Irikolyse . . . . . . . . . . . . . . . . 430

Eigenschaften des Ferments . . . . . . . . . . . . . . 432

H. Weitere Fermente des intermediären Stoffwechsels mit EinschluB der Methoden zur Untersuchung der Autolyse von Organen. Ton Prof. Dr. Martin Jacoby, Berlin . . . . . . . . . . . . . . . . . . . . 4 433

Das Salkowskische Terfahren zur Untersuchung der Antolyse . . . . . . . . 433

Die Autolyse von Preßsäften . . . . . . . . . . . . . . . . . . . . . 434

Die direkte Beobachtung der Antolyse . . . . . . . . . . . . . . . . . . 434

Die Enteiweißnng und die Untersuchung der șaltungsprodukte bei der Antolyse $13 \pm$

Die phỵsikalisch-chemische Untersuchung der Autolyse . . . . . . . . . . . 436

Die Heterolyse . . . . . . . . . . . . . . . . . . . . . . . . . . . . 436

Die aseptische Autolyse . . . . . . . . . . . . . . . . . . . . . 437

Die Säurebildung bei der aseptischen Antolyse . . . . . . . . . . . . . . 439

Die Milchsäurebildung bei der Autolyse. . . . . . . . . . . . . . . . . 439

Die Gasbildung bei der Autolyse . . . . . . . . . . . . . . . . . . . 440

Die Arginase . . . . . . . . . . . . . . . . . . . . . . . . . . 411

Die Spaltung des Kreatins und des Kreatinins, sowie die Kreatinabspaltung in

den tierischen Organen . . . . . . . . . . . . . . . . . 441

1. Methoden zur Bestimmung der Atmung tierischer Gewebe. Von Prof. Dr.F.Bat telli

und Privatdozent Dr. Lina Stern, Genf. . . . . . . . . . . . . . . . . . . 444

I. Der Gaswechsel in Gegenwart von Sauerstoff . . . . . . . . . . . . . . 444

A. Untersuchungsmethoden des respiratorischen Gaswechsels ganzer Organe $14 \pm$

1. Die Organe oder Gewebe sind in situ am lebenden Tier, die Nervenverbindung und die natiirliche Zirkulation sind intakt . . . . . . . 444

a) Die Vorbereitnng des Versuchstieres . . . . . . . . . . . . 445

b) Die Blutentnahme und die Gasanalrse . . . . . . . . . . . . 140

c) Bestimmung der im Organ zirkulierenden Blutmenge . . . . . .445

d) Terfabren, um die Tätigkeit des zu nntersuchenden Organes zu

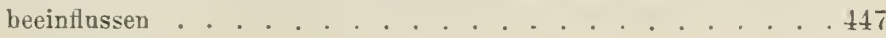



Respiratorischer Gaswechsel in den Muskeln . . . . . . . . 148

parotis. . . . . . . . . . . . . . 448

Submaxillaris . . . . . . . . . . . . . . . 449

Pankreas. . . . . . . . . . . . . . . . . 449

Niere. . . . . . . . . . . . . . . . 44 . .

barm . . . . . . . . . . . . . . . 149

Gehirn. . . . . . . . . . . . . . . 449

2. Die kïnstliche Durehblutung ganzer, vom Kïrper losgetrennter Organe 450)

13. Untersuchung des Gasweehsels frigmentierter Gewebe. . . . . . . . . 450

1. Zubereitung der Gewebsfrigmente . . . . . . . . . . . . . . . \$2ّ

2. Aplarate znr Untersuchung des respiratorischen sitoftwechsels fragmentierter Gewebe . . . . . . . . . . . . . . . . 45 ?

Der Apparat rom Tissot für länger dauernde Untersuchangen des respiratorischen Gaswechsels überlebender Gewebe . . . . .453

Mikrorespirometer von Thunberg. . . . . . . . . . . 45

C. Atmung der in Flissigkeiten suspendierten (iewebe. . . . . . . . . . 460

1. Schiittelapparat . . . . . . . . . . . . . . . . . 460

2. Einleiten der Gase in die Flaschen. Jessung der Gase . . . . . . 461

3. Zubereitung der Gewebe . . . . . . . . . . . . . . . 464

4. Die Zusammensetzung der Suspensionsthissigkeit . . . . . . . . . . 467

5. Die Ilauptatmung. Der fundamentale Atmungsprozeß; das Pnein; die hemmenden Substanzen in den Geweben . . . . . . . . . . . 468

6. Die akzessorische Atmung. . . . . . . . . . . . . . . . 47

7. Der Einfluß der verschiedenen Substanzen . . . . . . . . . . 473

II. Entwieklung von Kohlensäure in Abwesenheit von sauerstott . . . . . . . 47

1. Die kïnstliche l)urchblutung ganzer überlebender Organe . . . . . . . 4it

2. Die kïustliche Dnrchblutung des ganzen Tierkörpers unter Ausschlnß von Siluerstott" . . . . . . . . . . . . . . . . . 475

3. Intersuchnng fragmentierter Gewebe . . . . . . . . . . . . . . 47

4. Bestimunug der in den Geweben präformierten Kohlensïure . . . . . . 477

K. Methoden zur Bestimmung der Atmung der Pflanzen. Von Prof. Dr. W. Palladin und Priv.-Doz. Dr. s. Kostytschew, St. Petersburg . . . . . . . . . . . 47!

1. Bestimmung der ron den Phanzen gebildeten Kohlensänre. . . . . . . . 480

Pettenkofersche Röhren . . . . . . . . . . . . . . 480

Alparat von Blackmann . . . . . . . . . . . . . . . . . 483

Anordnung von Puriewitich . . . . . . . . . . . . . . . . . . 484

Appamat von Chudiakow . . . . . . . . . . . . . . . 484

, Polowzow . . . . . . . . . . . . . . . 485

1I. Bestimmung des von den Pllanzen absorbierten sanerstoffes..... . . 488

Apparat von Wolkoft und Mayer. . . . . . . . . . . . . . 488

III. Gasometrische Methoden zur gleichzeitigen Bestimmung der abgeschiedenen Kohlensiiure und des absorbierten sauerstofles . . . . . . . . . . . . . 49()

Apparat von Godlewski . . . . . . . . . . . . . . . . . . . $49(1$

Polowzow-Richter . . . . . . . . . . . . . . . 49. 


\section{Apparat von Bonnier und Mangin}

IV. Die anä̈robe Atmung und deren Produkte . . . . . . . . . 504

Apparat von Bardeleben . . . . . . . . . . . . . . . .504

. . Kostytschew. . . . . . . . . . . . . . 505

n Nobokich . . . . . . . . . . . . . . . 507

Y. Die Atmung der abgetöteten Pflanzen . . . . . . . . . . 510

VI. Atmungschromogene und Atmungspigmente . . . . . . . . . .513

L. Methoden zur Bestimmung der Exkrete bei der Atmung der Bakterienzelle.

Yon Hofrat Prof. Dr. stoklasa. Prag . . . . . . . . . . . .516

I. Anaërobiotische Atmung . . . . . . . . . . . . . . 517

II. Aërobiotische Itmung . . . . . . . . . . . . . . . . 517

Apparat von W. Hesse . . . . . . . . . . . . 518

. ${ }^{\circ}$ E. Godlewski . . . . . . . . . . . . . 519

Jodifikation von Krzemieniewski . . . . . . . . . . . 52.2

Apparat für anaërobe Atmung ron .J. Stoklitsa . . . . . . . . . 524

Bestimmung des Alkohols nach Stoklasa und Ernest. . . . . 528

Die quautitative Bestimmung des Alkohols . . . . . . . 528

Apparat fur aërobe Atmung von J. Stoklasa . . . . . . . . . 532

ron R. Kolkwitz . . . . . . . . . . . . . . . 534

. .. Pfeiffer und Lemmermann . . . . . . . . . . . 536

, . Minkman . . . . . . . . . . . 536

M. Physikalisch-chemische Untersuchung von lebenden Zellen und Geweben. Von

Priv.-Doz. Dr. Kudolf Höber. Kiel . . . . . . . . . . . . . . . . . 538

1. a) Die Innenspannung von Zellen. . . . . . . . . . . . . . . 538

1. Der Hämatokrit roı Koeppe . . . . . . . . . . . . . 539

2. Das Trichterröhrchen von Hamburger . . . . . . . . . . . . 510

Plasmolyse . . . . . . . . . . . . . . . . . $ّ 11$

b) Die Innenspannung von Geweben . . . . . . . . . . . . . ว42

Wägung des Gewebes . . . . . . . . . . . . . . . 542

Plethysmographisches Verfahren . . . . . . . . . . . 543

Kryoskopie . . . . . . . . . . . . . . . . 54t

‥ Die Durchlässigkeit von Zellen . . . . . . . . . . . . . . 541

Plasmolytisches Verfahren.............. . . 54t

Cytolytisches Verfahren . . . . . . . . . . . . 54.

Kryosknpisches Verfahren . . . . . . . . . . . . . 546

Wägungsverfahren . . . . . . . . . . . . . . 547

Durchlässigkeit für Farbstoffe . . . . . . . . . . . . 547

Mikrochemisches Verfahren . . . . . . . . . . . 5 48

Anhang: I'ber die Bestimmung von Lipoidlöslichkeiten und Teilungskoeffi-

zienten . . . . . . . . . . . . . . 54

a) Bestimmung ron Lipoidlöslichkeiten . . . . . . . . . . 5 54?

b) Bestimmung von Teilungskoeftizienten . . . . . . . . . . 549 
Der Rulestrom; Eintiuß ron Elektrolyten . . . . . . . . . . . . 551

liataphorese.................. . . . . . . . . . . . . . . . .

Biologische Gasanalyse. Von l'rof. Dr. Franz Jliiller, Berlin . . . . . . . . . 5๊j

Einleitung. . . . . . . . . . . . . . . . . . . . . . . . . . . . . .

Yorbereitungen . . . . . . . . . . . . . . . . . . . . . . . . . . .

Einriclıtung des Analysenzimmers . . . . . . . . . . . . . . . . 5อว

Reinigung des Glases und der Glashähne. . . . . . . . . . . . . 556

Fornn der Glashähne. . . . . . . . . . . . . . . 558

kautschukverhindungen . . . . . . . . . . . . . 559

Reinignng der Gummisehliuche . . . . . . . . . . . . . . . 560

Reinignng des quecksilbers. . . . . . . . . . . . . . . . 560

Quecksillerwanne . . . . . . . . . . . . . . . 563

Aiehung der Glasröhren . . . . . . . . . . . . . . 564

Aichung vou Gasmessern. . . . . . . . . . . . . . . 56

Allgemeine gatsanalytische Yethodik. . . . . . . . . . . . . . 569

Probenentnabme und Transport der Gasproben. . . . . . . . . . . 56?

Aufbewahren von Gasproben . . . . . . . . . . . . . . . . . 571

Abmessen der Gasproben. . . . . . . . . . . . . . . . . . 573

Allgemeines . . . . . . . . . . . . . . . . . . . 573

Abmessen ïber Wasser. . . . . . . . . . . . . . . . 57t

. Quecksilber . . . . . . . . . . . . . 5

A. Nach Bunsen. . . . . . . . . . . . . . . . . . . . . .

1. Alte Metbode . . . . . . . . . . . . . . 57

2. Nach Geppert verbessert. . . . . . . . . . . . . . . 57!

B. Thermobarometerprinzip . . . . . . . . . . . . . . . . 581

C. Prinzip ron Petterson . . . . . . . . . . . . . . . 5st

1. Nach Hempel . . . . . . . . . . . . . . . . 58t

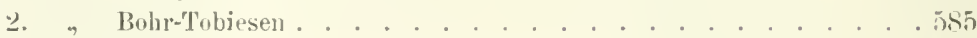

3. Nach Haldane . . . . . . . . . . . . . . 587

Reduktion der Gasvolumina auf den Normalzustand bei $0^{\circ}$ und $760 \mathrm{~mm}$. 1)ruck 588

Spezjelle Irethoden . . . . . . . . . . . . . . . . . . . 599

Einleitung . . . . . . . . . . . . . . . . . . 599

Kohlensäurebestimmung . . . . . . . . . . . . . . . . . . 1800

I. Koblensäurebestimunng in großen Gasmengen bei relativ hohem Kohlensäuregehalt . . . . . . . . . . . . . 600

a) Nach Bunsen . . . . . . . . . . . . . . 600

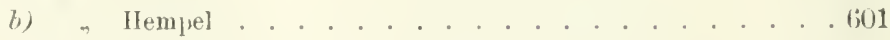

c) $n$ Petterson . . . . . . . . . . . . . . 1502

II. Kohlensiiurebestimmung in großen Gasmengen bei relativ geringem $\mathrm{CO}_{2}$ Gebalt . . . . . . . . . . . . . . $60^{2}$

1. Nach Petterson'schem I'rinzip (ohne Korrektion für Druck- und Temperaturänderungl . . . . . . . . . . . . 602 
(1) Methode von Petterson und Palmuvist. . . . . . . . (j) 2 2

b) Methode voll Tigerstedt und Sondin . . . . . . . . . . 605

lic: Genaughkeit der Pettersonsehen Methode. . . . . . . . . . (;09

(1) Nach Tigerstedt und Sondén . . . . . . . . . . . 1;09

b) Nach Petterson-l'almqvist . . . . . . . . . . . . . (;10

2. Nach dem Therumbarometerprinzi], im Apparat wn Zuntz-(ieppert . li10

3. Barytmethode . . . . . . . . . . . . . . . . . . li11

(1) Nacl Saussure-Hesse . . . . . . . . . . . . 611

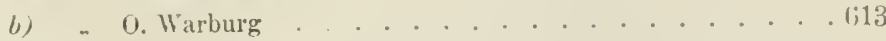

4. Gewichtsanalyse durch Bestimmung des Gewichtsverlustes nach vorheriger vollkommener Trucknung des Gases odel der Gewichtszunabme einer zuvor gewogenen tbsorptionslösung . . . . . . . . . . . 1;1t

I. Kohlensäurebestimmung in kleinen Gamengen . . . . . . 614

1. Nach Bunsen-Geppert . . . . . . . . . . . . . (;14

2. Petterson-Tobiesen . . . . . . . . . . . 6160

3. Petterson-Haldane . . . . . . . . . . . 617

II. Kuhlensäurebestimmung im Wasser . . . . . . . . . . . . (1919

(1) Gewinnung der $W$ asserpoben . . . . . . . . . . . 1;19

b) Bestimmung der Kohlensäure . . . . . . . . . . . li21

1. Gebundene liohlensäure . . . . . . . . . . . li21

Tolumetrische Bestimmung (besonders auch fiir $\mathrm{CO}_{2}$ in festen Körpern) . . . . . . . . . . . $\$ 21$

․) Freie Koblensäure . . . . . . . . . . . . . . . . 621

Quantitative Bestimmang nach Trillich . . . . . (5:2)

3. Freie und halbgebundene Kohlensäure . . . . . . 6.2)

Sauerstoflbestimmung

1. Verbrennungsanalyse . . . . . . . . . . . . . . 6 6.2)

1. Mit Kupferspirale (nich Kreussler) . . . . . . . . . . . . . 62-)

‥ Durch Explosion. . . . . . . . . . . . . . . . . 6ะ3

B. Absorptionsanalyse . . . . . . . . . . . . . . . . . . . 624

1. Absorption mit pyrogallussaurem Kali . . . . . . . . . . . 1524

2. $\rightarrow$ mit Phosphor . . . . . . . . . . . . 6:6

3. . durch Kupferlisung . . . . . . . . . . . . . . . 627

4. . durch Natriumthiosulfat . . . . . . . . . . 628

5., mit Chromchlorï . . . . . . . . . . . . 628

C. Sauerstoftbestimmung im $\mathrm{W}^{2}$ asser . . . . . . . . . . . . . . . . . . . . 629

1. Reichardtsche Einrichtung . . . . . . . . . . . . . . . . . . . 629

2. Sauerstoff-Analyse mit Auskochen, Tenax-Apparat von F. C. G. Müller 630

3. Winklersche Methode . . . . . . . . . . . . . . . . . 1334

Bestimmung in verunreinigten Wässern . . . . . . . . . 635

Stickstotfbestimmung . . . . . . . . . . . . . . . . . . . . 637

Kohlenoxydbestimmung . . . . . . . . . . . . . . . . . . . . 637

I. Kleine Jengen Ǩohlenoryd in großen Jengen Laft . . . . . . . . . 637

t. Absorptionsanalyse . . . . . . . . . . . . . . . . . . . 637 
(1) mit Blut. . . . . . . . . . . . . . . . . . . (133-

(1) mit Jodsäure. . . . . . . . . . . . . . . . . . (it1)

B. Verbrennungsanalyse . . . . . . . . . . . . . . . . (itl

IJ. Giößere Menen Kohlenoxyd in großen Mengen Lnft . . . . . . . . liti

A. Alsorptionsmethoden . . . . . . . . . . . . . . . . . lith;

a) Salzsaure Kupferehlorürlisung . . . . . . . . . . . . . . . (if6;

b) Inumoniakaliselhe Kuplerehloriurlïsung . . . . . . . . . . liti

l. Verbrennumganalyse . . . . . . . . . . . . . . . . . . 647

1. Nach Bunsen-Geppert . . . . . . . . . . . . . . (647

๖. Grisoumeter natch Corpuillon . . . . . . . . . . . . . . . . 1;47

3. Verbrennung in der Matinkil,illate . . . . . . . . . . . . . (if!)

Grubengasbestimmung (Jethan) . . . . . . . . . . . . . . . . . . . . (if!!

Wasserstollestimmung . . . . . . . . . . . . . . . . . . . . . . lint

1. Explosionsmethode (Bunsen) . . . . . . . . . . . . . . (iint

2. Verbrennungsmethode in Grisoumeter . . . . . . . . . . . . . . liăt

3. Fraktionierte Verbrennung nach Hempel . . . . . . . . . . . . (i.)t

4. Absomption mit Palladium (Hembel). . . . . . . . . . . . . . (j,j)

Stickoxydulbestimmung (Litchgis) . . . . . . . . . . . . . . . . . 65.J

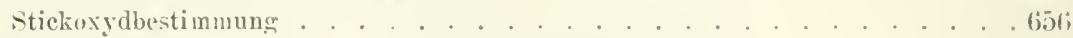

Bestimmung schwerer Kohlenwasserstofỉe und von Acețlen . . . . . . . . . 6ál;

Schwefelwasserstollbestimmung . . . . . . . . . . . . . . . . . . . . . . . 65

Bestimmung der Blausäure . . . . . . . . . . . . . . . . . . . . . . . . 65ั

Die Gewinnung und Analyse kleiner Gasmengen (Mikroanalyse). . . . . . . . 6.jk

Apparat von Brodie und cullis . . . . . . . . . . . . . . . . . . . (j.)s

.. Krogh . . . . . . . . . . . . . . . . (561

Das Mikrorespirometer (Thunberg) . . . . . . . . . . . . . . . . . . bit

Die Gewinnung und Analyse der Blutgase . . . . . . . . . . . . . . . . . 66t

Vorbereitungen zur Blutgasgewinnung. Blntgewinnung und Abmessung. . . (66.)

Verschied’uheiten der Blutgaszusinmensetzung bei Verglejchung verschiedener lBht-

prohen desselben Tieres zu verschiedenen Zeiten . . . . . . . . . . . . . . . . . . . . .

Dis Prinzip der Blutgaspumpenmethude . . . . . . . . . . . . . . . libs

Fehlerquellen bej der punpemmethode. . . . . . . . . . . . . . . . . . 669.)

Die Genauigkeit der Gaspumpenmethodik . . . . . . . . . . . . . . . 67̄1

Analyso der Blutgase. . . . . . . . . . . . . . . . . . . . . . 673

Verchleich der Genanigkeit des analytischen Ilethoden . . . . . . . . 676

Die versehiedenen Blutgaspumpen . . . . . . . . . . . . . . . . . . 677

Die verbesserte: Plligersehe Pumpe nach Kuntz. . . . . . . . . . . . . 1977

Die Pнupe vou Boh" . . . . . . . . . . . . . . . . . . . . . . . . (57!

Die Pumpe you Bareroft . . . . . . . . . . . . . . . . . . . 680

Pumpe zar Eutgasung kleiner Blutmeugen . . . . . . . . . . . . . . . 6ik2

Cheurische Methoden der Blutgasgewinnung . . . . . . . . . . . . . . 683

Die verschiedenen Ferricyanidappatrate und ihre llandhabung. . . . . . 685

1. Der Apparat von Haldane in der neuesteu Form mach 13:arcroft . . (65.)

b. Der lierricyanidapparat nach Franz Miiller . . . . . . . . . . . (i88

('. Baterufts Ditlerenzuethude . . . . . . . . . . . . . . . . . . (j)1] 
1). Moditikation ron Barerofts Apparat nach ]'lesch zur Bestimnung der Kohlenoxydkapazität

E. Reihenanalyse

Absolute Genanigkeit der Ferricyaniduethod. . . . . . . . . . . . . . 697

Die Bestimumng der Absorption and der Spannung von Gasen in l3lut . . . . . (j99!

A. Methoden mit konstanter Durchleitung von Gas . . . . . . . . . (j:!)

B. Methoden. bei denen das blut von eiuer gemessenen Gasmenge bei einem bestimnten Fruck das Mlaximum des Jöglichen aufnimnt. . T(x)

('. Methodıu, bei denen ein Gasremisch mit den Blut bis zum Spannungsausrgleich geschiittelt wird. bei denen die Gassjannung durch Analyse des Schïttelgases, die entsprechende Gasmenge durch Analyse des Blutes bestimut wird. . . . . . . . . . . . . . . . $7(0)$

1. Nach Luewy-Zuntz . . . . . . . . . . . . . . . . T(j)

2. Nach Bohr . . . . . . . . . . . . . . . . . . 703

Methode zur Messung der Mlutgasspannung im zirkulierenden Blut . . . . T(13)

Die Blutkörperchenzählung und Hämoglobinbestimmung. Von Prof. Dr. Frunz

M ïll er, Berlin . . . . . . . . . . . . . . . . . . . . . T0i

1. Die Fehlerquellen . . . . . . . . . . . . . . . . . . 70,

1. Sedimentieren . . . . . . . . . . . . . . . . . 107

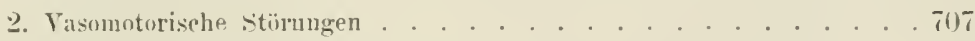

II. Die Blutkörperchenzählung . . . . . . . . . . . . . . . . . 714

III. lie Bestimmung des Blutfarbstottes. . . . . . . . . . . . . . . . . T19

Allgemeine Bemerkungen. . . . . . . . . . . . . . . . . . 719

Die einzelnen Kämoglobin-Bestimmungsapparate, Hämometer. . . . . . T20

A. Einfachere Apparate für die Bedïrfnisse der Praxis . . . . . 720

1. Farbenvergleichung nach Ehrlich-Tallqvist . . . . . . . T.20)

․ Gärtnerscher Hämophotograph . . . . . . . . . . . . . . T㒸)

3. Apparat von P. Grützner . . . . . . . . . . . . . . 72.2

4. Keillämometer von Plesch . . . . . . . . . . . . . 7ət

5. Gowerssches Hämoglobinometel (Haldane) . . . . . . . . 7.2t Sablis Hämatinometer . . . . . . . . . . . T: (;)

b. Die komplizierten Blutfarbstottbestimmungsmethoden . . . . . 726

1. Ver Mieschersche Hämometer . . . . . . . . . . . . 7206

2. Die kolorimetrische Doppelpijette von Hoppe-seyler . . . . . T2!)

3. Das Chromophutometel von Plesch . . . . . . . . . . 730

4. Jas Spektrophotometer von Hüfner . . . . . . . . . . . 736;

bie sugenannte objektive Hämoglobinonetrie. . . . . . . Tł1

Die Bestimmung des spezifischen Gewichtes, der Trockensubstanz und der Vis-

kosität des Blutes. Von Prof. Dr. Frinz Jiiller, Berlin. . . . . . . . . . . T42

1. Bestimmung des spezitischen Gewichtes . . . . . . . . . . . . . . 742?

1. Pyknonetrische Methode . . . . . . . . . . . . . . Tt兰

2. Arüometrische Methode . . . . . . . . . . . . . . . 743

2. Bestimmung der Trokensubstanz des Blutes . . . . . . . . . . . . . . 743

3. Bestimmung der Viskositiit des Blutes. . . . . . . . . . . . . . . . . T 43 
1. Prinzip der Jlethoden. . . . . . . . . it3

?. Aplarat von Hirsch und Beck. . . . . . . . . . . . 74t

3. - Determann . . . . . . . . . 745

t. .

5. . . Münzer-Bloch . . . . . . . . . . . 746

(i. Die (icnanigkeit der Resultate . . . . . . . . . . it7

Die Bestimmung der Blutmenge. Ion Prof. Dr. Franz Jïller, berlin . . . . . its

1. Direkte Bestimmungsmethode der im Körper vorhandenen Blutmenge . . . . T48

2. Indirekte Bestimmungsmethoden der im Körper vorhandenen Blutmenge. . . Tó1

(a) Infusionsmethode . . . . . . . . . . . . . . . 751

b) Aderlißmethode ................... . . . . 758

c) Kohlenoxydmethode . . . . . . . . . . . . . . . . . . . . 759

3. Bestimmung der pro Zeiteinheit umlanfenden Blntmenge . . . . . . . . . T61

a) Messung des Answurfsvolumens des Ilerzens . . . . . . . . . . . 761

b) Bestimmung der pro Zeiteinheit zirkulicrenden Blutmenge ans dem sauerstoffverbranch

A. Nachweis und Bestimmung der Eiweibabbauprodukte im Harn und in den Faeces.

Von Dr. phil. n. med. l'eter Rona, Berliu . . . . . . . . . . . . . T6.

Ammoniak . . . . . . . . . . . . . . . . 760

Nachweis . . . . . . . . . . . . . . . . . 760

Quantitative Bestimmung des Ammoniaks im Ilarn . . . . . . . 76ã

nach Folin. . . . . . . . . . . . . . . . 760

nach Krïger-Reich, modifiziert von Sehittenhelm . . . . . . . 767

nach schafter. . . . . . . . . . . . . . . . 769

nach Nencki und Zaleski . . . . . . . . . . . . . 769

nach A. Steyrer . . . . . . . . . . . . . . . 771

nach Sehlosing . . . . . . . . . . . . 672

nach lionchèse-Ifalfatti . . . . . . . . . . . . . . .773

Harnstofí . . . . . . . . . . . . . . . . . T7t

Ejgensehlaften . . . . . . . . . . . . . . 774

Nachweis . . . . . . . . . . . . . . . . 774

Dastellung des Harnstofls aus dem Harn nach Salkowski. . . . . . 774

Isolierung von sehr geringen Mengen von Harnstofil aus Blut, Galle, Milch oder aus Organen nach Hople-Serler . . . . . . . . . . . . 775

nach Gottlieb. . . . . . . . . . . . 766

Methode von Ilörner-Sjö̈uist . . . . . . . . . . . . . . . 776

Jethode von Folin . . . . . . . . . . . . . . . 788

Verfahren von Pfliger-Bleibtreu . . . . . . . . . . . . 781

Kreatin . . . . . . . . . . . . . . . . 783

Eigenschaften . . . . . . . . . . . . . . 783

Nachweis. . . . . . . . . . . . . . . . . . 783

Darstellung nach Neubauer-Salkowski . . . . . . . . . . . . Ts3

l)arstellung nach Folin . . . . . . . . . . . . . . . 784

(quantitative Bestimmung nach Folin . . . . . . . . . . . . 787

Bestimınung des Kreatins neben dem Kreatinin . . . . . . . . . . 791 
Darstellung des Gramtkreatinins aus den Jluskeln nach Welser . . F(9) Verfahren vou MrJanhy . . . . . . . . . . . . . . . . . . . 792

Bestimmuner des Kratins und Kreatinins in Autulysenversuchen . . . . . 792

Bestimmung des Kreatinins im lilute. . . . . . . . . . . . . . . . . 7!3

Sichwefel . . . . . . . . . . . . . . . . . . . . . . . . . . .

. . . . . . . . 791

Bestimnumg ves Gesamtschwefels nach salkowski . . . . . . . . . . 794

Bestinmung des Gesamtichwriels nach Modrakowski . . . . . . . . 794

Bestimmung des (irsamtschwefels nach Neumann und Meinertz . . . . 795

Anwendung der Peroxydmothole nach Modrakowski . . . . . . . . . 795

Anwendung dor Peroxydmethode nach folin . . . . . . . . . . . . 796

Anwendung der Peroxyduethode nach dbderhalden und Funk. . . . . 796

Bestimmung des (iesamtschwefils auf nassem Wege nach schulz-Konschegg 797

Gesamtschwefeliure

Bestimmung nach Salkowki . . . . . . . . . . . . . . . 797

Bestimmung nach foulin . . . . . . . . . . . . . . . . . 798

Xtherscbucfelsiuren . . . . . . . . . . . . . . . . . . . . 799

Direkte Bestimmune nach Salkowski . . . . . . . . . . . . 795

Indirekte Bestimmung bzw, direkte Bestimmung der anorganischen sulfate nach Folin. . . . . . . . . . . . . . . . . . . 799

Direlste Bestimaung der Atherschwefelsaiuren nach Folin . . . . . . 799

Noutraler siehwetel.

Bestimmung nach Sillkowski . . . . . . . . . . . . . . . 800

Bestimmung nach Ifess . . . . . . . . . . . . . . . . . . . 800

Bestimmung der Thioschwefelsäure nach Salkowski . . . . . . . . . 801

Bestimmung der Thioschwefelsiure nach l'resch . . . . . . . . . . . 801

Rhodanwasierstofi

Nachweis und Bestimmung nach I. Junk . . . . . . . . . . . 802

Nacluwis nach Bruylants . . . . . . . . . . . . . . . 802

liestimmnng nach lang . . . . . . . . . . . . . . . . 802

Bestimmung nach Edinger und ('lemens . . . . . . . . . . . . 802

Schwefelwasserstoft' . . . . . . . . . . . . . . . . 803

Eiweiß und nächste Lmwandlungsjrodukte . . . . . . . . . . . . . . . 803

Nachweis ron Eiweiß im Harn . . . . . . . . . . . . . . . . . . 803

Der Bence-Jonessche Eiweißkürjer . . . . . . . . . . . . . . . . 804

Trennung des Albumins und des Globulins . . . . . . . . . . . . 80

Bestimmung des Glubulins . . . . . . . . . . . . . . . . . 806

I. Bestimmung des Eiweißes . . . . . . . . . . . . . $80 j$

1. Gewichtsanalytisch nach ścherer . . . . . . . . . . . . 805

๖. Jethode nach Esbach . . . . . . . . . . . . . . 806

3. Verfahren von Deroto . . . . . . . . . . . . . 806

4. Methode von Roberts . . . . . . . . . . . . . 806

11. Nichtliangulierbare, biuretgebende Abbaujrodukte des Eiweißes . . 807

Nachweis nach Hotmeister . . . . . . . . . . . . . . . . 807

nach Salkowski . . . . . . . . . . . . . . . 807 
Sacheis tes atejte

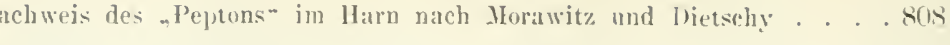

Nachweis nach Deroto und Bang . . . . . . . . . . . . . 808

Nachweis von Mucin und mucinähnlichen Substanzen nach Hammarsten S09 nach Spaeth. . . . . . . . . . . . . . . . . . 810

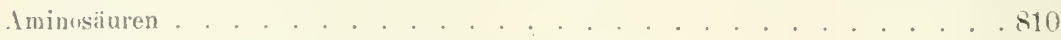

Isolierung der Aminusïureu ans dem lrin . . . . . . . . . . . . . . . 810

Isolirrung des Cystins im Urin nach Gaskell . . . . . . . . . . . . . 8i1

Isolierung des Cystins im Urin nacb Coldmann und Baumann . . . . . . 811

Jie Naphtalinsulfochloridmethode zur Isolierung der Aminosäuren . . . . . d12)

lie Formolmethode zur Bestimmung der Aminosäuren im Harn nach Henrịue.

und sörensen . . . . . . . . . . . . . . . . . . . . . . . . . . .

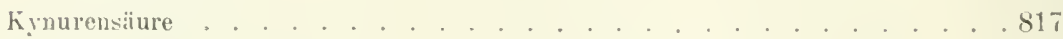

Eigenschafters . . . . . . . . . . . . . . . . . . 817

Nachweis . . . . . . . . . . . . . . . . . . . . . . 817

l)arstellung nach Hofmeister . . . . . . . . . . . . . . . . . 818

l)arstellung nach latl' . . . . . . . . . . . . . . . . . . . . . . . . 818

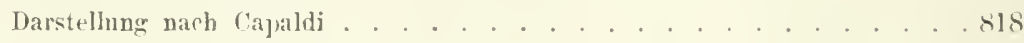

Sïuren unbekannter Konstitution . . . . . . . . . . . . . . . . . 819

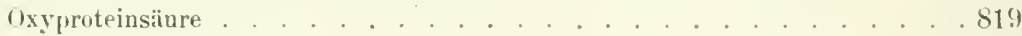

Antoxyproteinsäure . . . . . . . . . . . . . . . . . . . . . 820

Alloxyproteinsäure . . . . . . . . . . . . . . . . . . . . . 821

Quantitative Bestimmung der (1xyprotcinsïurefraktion nach Ginsberg . . . 8.2

Quantitative Bestimmnng der Proteinsïuren in l3lnt nach Browinski . . S22

Uroferrinsĭure . . . . . . . . . . . . . . . . . . . . 823

Sänre voll Hári . . . . . . . . . . . . . . . . . . . . . S23

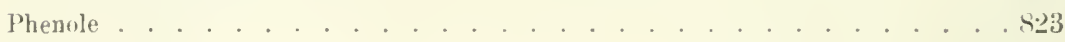

Phenol . . . . . . . . . . . . . . . . . . . . . . . . . . . . . . . . . . . . . . .

Nachweis und lsolierung . . . . . . . . . . . . . . . . . . . . 82t

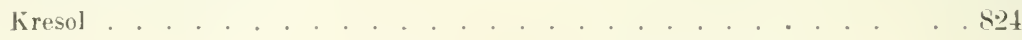

Trennung des Phenols von p-Kresol . . . . . . . . . . . . . . . . 8.24

Nachweis . . . . . . . . . . . . . . . . . . . . . 82.)

Quantitative Bestimmung des Phenols in Harn nach Kossler und Penny . 82.)

Brenzkitechin . . . . . . . . . . . . . . . . . . . . 827

Nachweis . . . . . . . . . . . . . . . . . . . . . 827

Darstellung nach Baumaun . . . . . . . . . . . . . . . . . . . 8.7

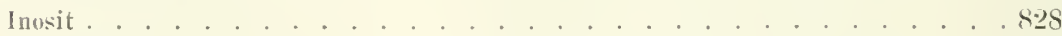

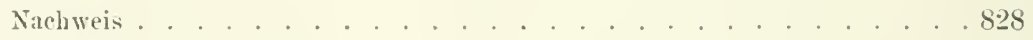

Isoliernng nach Boedeker und cooper Lane . . . . . . . . . . . . . . 828

Isolierung nach Rosenberger . . . . . . . . . . . . . . . . . . 899

Hipunrsiure . . . . . . . . . . . . . . . . . . . . . . . . . . 8 89

Eigenschaften . . . . . . . . . . . . . . . . . . . 829

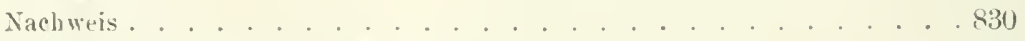

Isolierung nach Bunge und Schmiedeberg . . . . . . . . . . . . . . . 830

Bestimmnng nach Jaresreld und stokvis . . . . . . . . . . . . . . . 830

Bestimmung nach Henriques und sörensen. . . . . . . . . . . . . . . . . 831

Bestimmung nach W. Wiechowski . . . . . . . . . . . . . . . . 831 
Bestimung nach R. Cobn

liestinmung nach A. Ilagnus-Jery . . . . . . . . . . . . . . 833

Homugentisinsäure

Eigenschaften.

Darstellung nach E. Jeyer . . . . . . . . . . . . . . 835

birstellung nach Wulkow and Baumann . . . . . . . . . . . . 83.5

Darstellung nach (iarrod . . 835

Bestimmung nach E. Baumann . . . . . . . . . . . . . . . . 836

Bestimmung nach Denigès. . . . . . . . . . . . . . . . . 836

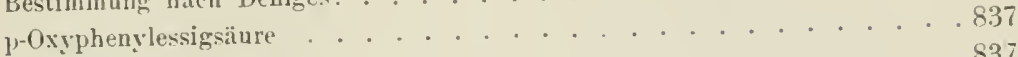

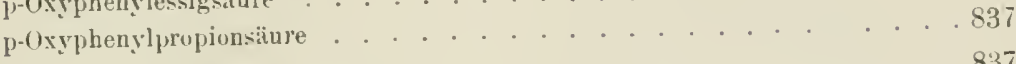

Indol und Indolderivate . . . . . . . (5.

ludol, sikatol -

Eigenschaften, Nachweis . . . . . . . . . . . . . . . . . . . . . . . . . . . . . 84

Indoxyl . . . . . . . . . . . . . .

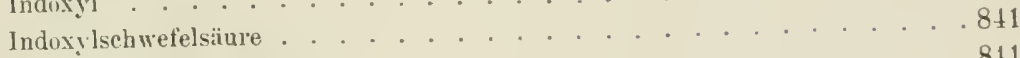

Darstellung nach Baumann . . . . . . . . . . . . . . . . 811

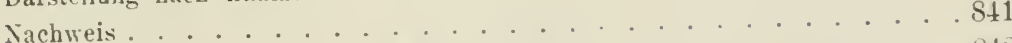

Bestimmung nach Obermeyer, Wang, Ellinger . . . . . . . . . . . 842

Bestimmung nach Bomma . . . . . . . . . . . . . 843

Bestimmung nach Imabuchi . . . . . . . . . . . . . . . . 84.

Indol-Pr-3-Essigsïure . . . . . . . . . . . . . . . . . . 845

Indigrot (Indirubin, Indigpurpuriu) . . . . . . . . . . . . . . . 84う

Anhang: lbersicht über die Stickstoftverteilung im Haru . . . . . . . . . . 846

Verfahren nach Pfaundler. . . . . . . \$ $\$ 6$

Verfahren nach Krïger und śchmid . . . . . . . . . . . . . . 847

Nicht dialysable stickstotthaltige Bestandteile des Harns . . . . . . . . . . 848

Bestimmung der Chondroitinschwefelsäure nach Pons . . . . . . . . . . $8 \pm 8$

Intersuchung der adialysablen sitofte nach Hofmeister. . . . . . . . . . 849

nach Abderhalden und Pregl . . . . . . . . . . . . . . . . 850

nach Salkowski . . . . . . . . . . . . . . . . . 850

Farbitotie im Harn . . . . . . . . . . . . . . . . . . . 850

1. Gallentarbstotte . . . . . . . . . . . . . . . . . . . . . . . . . . . . . .

?. Urobilin . . . . . . . . . . . . . . . . . . . . . . . . . . . . . .

Darstellung nach Jaftë . . . . . . . . . . . . . . . . . . . . . . . . . . . . . 85

Darstellung nach Méhu und Fr. Miiller . . . . . . . . . . . 85̆

Tarstellung nach Garrod und Hopkins . . . . . . . . . . . . . . $85 \pm$

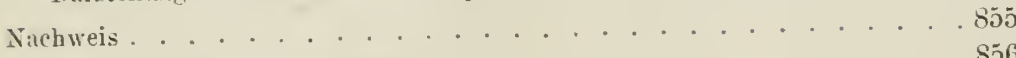

Bestimmung nach Hoppe-Seyler . . . . . . . . . . . . . . . . . \$ă6

Bestimmung nach Charnas . . . . . . . . . . . . . 856

3. Urochrom . . . . . . . . . . . . . . . . . . . . . . . . . . . . . .

Dilstellung nach Garrod . . . . . . . . . . . . . . . . . 857

Darstellung nach Ifohlweg . . . . . . . . . . . . . . . . 858

Isolierung nach Domkrowski . . . . . . . . . . . . . . . . . 858

Schätzung del Uruchrommenge nach Klemperer . . . . . . . . . . . S59 
4. Uromein . . . . . . . . . . . . . . 859

Isolicrung rach staal . . . . . . . . . . . . . . . . . . . . . .

Nachweis . . . . . . . . . . . . . . 8601

Darstellung nach Rosin . . . . . . . . . . . . . . 860

5. Uroerythrin (Purpurin) . . . . . . . . . . . . . . 860

6. Hiimatoperphyrin . . . . . . . . . . . . . . . sti1

Vol. auch Nachtrag S. 1347.

B. Die Darstellung organischer Basen aus Harn. Ion L'rof. Dr. Fr. K nt:cher, Harburg 863 Historisehe Ubersicht . . . . . . . . . . . . . 863

Verfahren von Lutf-Grifliths zur Darstellung toxischer Basen aus Harn in der

Iodifikation von Albu . . . . . . . . . . . . . . . . Sijt

Ausbeute an toxischen Harnbasen bei Infektionskrankheiten . . . . . . . soft

Formeln der von Griffiths entdeckten Basen .. . . . . . . . . . . Sib.

Verfahren nach Brieger zur Datrstellung organischer Harnbasen . . . . . 865

Base $\mathrm{C}_{5} \mathrm{H}_{7} \mathrm{NO}_{6}$. . . . . . . . . . . . . . . . . . . . 866 ;

Verfahren уон Baumann und Udránsky zur Darstellung ron Tetra- und Penta-

methylendianin. . . . . . . . . . . . . . . . siti

Verfithren von loewy und Neuberg . . . . . . . . . . . . . Stis

Verfahren von Kutscher und Lohminn . . . . . . . . . . . . 8íl)

Verfahren von R. Engeland . . . . . . . . . . . . . 875-877

Histidin-Nachweis im IIarn . . . . . . . . . . . . . 871, 876

Isolierung des Methylguanidin . . . . . . . . 871, 872, 876, 879

.$\quad$ Dimethylguanidin . . . . . . . . . 871, 872, 876, 879, 8801
$. \quad . \quad . \quad .873,880.881$

". Y.Methypyridin . . . . . . . . . . . . . 875, 881

. Gynesin . . . . . . . . . . . 873, 88:3

"

. , Reduktonovain ............. 875, 852

". Norain .............. . . 881, 88\%

.. Vitiatin ............... $875,882,883$

. kinosin . . . . . . . . . . . . . 883

Base $\mathrm{C}_{15} \mathrm{H}_{36} \mathrm{~N}_{8} \mathrm{O}_{13}$. . . . . . . . . . . . . . . . . . . . . . . . . . .

Imidazolaminoescigsiiure . . . . . . . . . . . . . . . . . . . 877,883

Nethode zur Bestimmung des Trimethylamins im Harn nach de Filippi 877, 878, 879

Eigenschaften und charakteristische Verbindungen einiger Ilarnbasen . . . .879

C. Nachweis, Bestimmung und Isolierung der Abbauprodukte des Nukleinstoffwechsels im Harn und in den Fäzes (Purinbasen, Methylpurine, Marnsäure, Allantoin). Anhang: Untersuchung der Harnsteine. Von Prof. Dr. Allred schittenhelm, Erlangen . . . . . . . . . . . . . . . 88t

A. Porinbasen, Methyłpnrine, Harnsäure . . . . . . . . . . 884

A. Bestimmung der llarnsiiure und P'urinbasen in l'rin . . . . . . . . . stis

Kupfersulfat-Bisulfatmethorle nach Kïrüer und schmid. . . . . . . 89.)

Silberlällung der llarnsäure nach Lndwig-Salkowski . . . . . . . . . S8S

festimmung der Puriubasen nach Camerer und Arnstein . . . . . . 888

Amnonfillung der Harnsïure nach Hopkins . . . . . . . . . . 8 8 !) 
Ausführung naeh llopkins . . . . . . . . . . . . . . 88 !

Folinsehe Moditikation . . . . . . . . . . . . . . . . . 889

Wörners Moditikation . . . . . . . . . . . . . 890

B. Isolierung und Ifentitizierung der Harnsïure und Purinbasen im l'rin . 890 Bestimmung ron Koftein und Theobromin im I'rin. . . . . . . . 8(1)

r. Bestimmung der Puriubasen in len Fïzes . . . . . . . . . . . . .893

(2uantititive Jethode nach Kriiger und sehittenhelı . . . . . . 8\%)

Dirstellung und Identifizierung der Purinbasen . . . . . . . . 8914

B. Allantoin . . . . . . . . . . . . . . . . . . . . . . . . .

Wiechowskis Methode zum Nachweis von Allantoin im Tierhan . . . .898

Wiechuwskis Methode zum Nachweis von Allantoin in Jenschenluarn . . .900

Allantoinbestimmung, Moditikition von Abderhalden und Einbeck . . . . . 902

Anbang: Intersuchung der Harnsteine . . . . . . . . . . . . . .903

Uratsteine . . . . . . . . . . . . . . . . . . . . . . . . . .

Oxalatsteine . . . . . . . . . . . . . . . . . 903

Phosphatsteine . . . . . . . . . . . . . . . . . 904

Kirbonatsteine . . . . . . . . . . . . . . 904

Gipssteine . . . . . . . . . . . . . . . . 90t

Xanthissteine . . . . . . . . . . . . . . . 904

Cystinsteine . . . . . . . . . . . . . . . . . . . . . . . . . . . . . .

Tyrosinsteine . . . . . . . . . . . . . . . . . . . . . . . . . . .

Urostluealitlse, Fettsteine . . . . . . . . . . . . 90:

Cholesterinsteine . . . . . . . . . . . . . . . 90:

D. Nachweis, Bestimmung und Isolierung von Aceton, Acetessigsäure und $\beta$-Oxy-

buttersäure. Von Prof. Dr. Gustav Em bien und Dr. Ernst Sehu itz. Frankfurt a. II. 906

I. Nachweis, Bestimmung und Isolierung von Aceton . . . . . 907-9920

1. Nachweis von Aceton . . . . . . . . . . . . 908-912

a) nach Legal . . . . . . . . . . . . . . . . . . . . . . . . . . . . . .

b) nach lieben . . . . . . . . . . . . . . . . . . . . . . . . . . . . .

c) nach Gumning . . . . . . . . . . . . . . . . . . . . . . . . .

d) nach Frommer . . . . . . . . . . . . . . . . . . . 909

e) nach Penzoldt . . . . . . . . . . . . . . . . . . 910

f) nach Rẹnold . . . . . . . . . . . . . . . . . . . .911

g) nach Stock-Fröhner . . . . . . . . . . . . . . . . . . 911

2. Quantitative Bestimmung des Acetons. . . . . . . . . . . . 91"2

a) Ausfiihrung der Bestimmung des Gesamtacetons am Harn . 913-915

b) Bestimmung des Gesamtacetons im Blut und in Organen . . . . .915

c) Bestimmung des Acetons in der Atemluft . . . . . . 915-917

๔) Verfahren von Geelmuyden . . . . . . . . . . 916

¡) Verfahren von Fr. Voit . . . . . . . . . . . . 916

\%) Verfthren ron L. Schwarz. . . . . . . . . . . .916

б) Verfahren vou .Joh. Mï̈ller . . . . . . . . . . . . . . 917

3. Isolierung des Acetuns . . . . . . . . . . . . . . . . 918

(1) Isolierung des Acetons in Substanz . . . . . . . . . . . 918

b) Isolierung des Acetons in Form kristallisierender Verbindungen . .918 
х) Tsoliorung des Acetons als p-Nitrophenylhydrazon . . . . . . 919

(5) Isolierung des Acetons als Dibenzalaceton . . . . . . . . 919

II. Nachweis und bestimmung der Acetessigsiure. . . . . . . . . (\$20-924

1. Nachweis der Acetessigsiiure . . . . . . . . . . . . . 921-923

(1) Realktion von Gerhardt . . . . . . . . . . . 921

b) Reaktion von Riegler . . . . . . . . . . . . . . 921

c) Reaktion von Arnold . . . . . . . . . . . . . . . . 422.2

‥ (quantitative Bestimmung der Acetessigsäure. (Getrennte Bestimmung ron

Acetcssigsinnre und Aceton) . . . . . . . . . . . . 923

Methode von Embden und scluliep . . . . . . . . . . 923

(1) In Harn . . . . . . . . . . . . . 923

b) Im Blut . . . . . . . . . . . . . . . . . . . .

Methode von Folin . . . . . . . . . . . 924t

III. Nachweis, Bestimmnno und Isolierung der -1)xybuttersiure . . . !2 $24-939$

1. Nachweis der j-Oxubuttersäure . . . . . . . . . . . (1)-927

a) Durch therführung in $x$-Crotonsäure . . . . . . . . . . . . 925)

b) Durch İberführung in Acetessigsäure . . . . . . . . . 9066

2. Bestimmung der faxybuttersäure . . . . . . . . . . . 928-937

1) Durch Therfïhrung in $\alpha$-Crotonsiinre . . . . . . . . . . 928

b) Anf polarimetrischem Wege . . . . . . . . . . 928-!34

ж) nach Bergell . . . . . . . . . . . . . . . . . 928

() nach Black . . . . . . . . . . . . . . . . . . . . .

y) nach Yagnus-Jevy . . . . . . . . . . . . . . . . . . . 929

כ) Eigenes Verfiluren . . . . . . . . . . . . 930

c) Durch Oxydation zu Aceton nach Th. Shatfer. . . . . . . .934

3. Kolierung der

E. Methoden zum Nachweis weiterer im Urin vorkommender Verbindungen mit Einschlub der wichtigsten körperfremden Stoffe. Von l'riv-Doz. Dr.

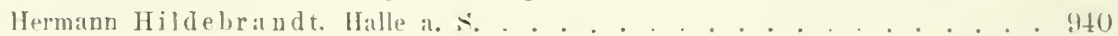

A. Allgemeiner Teil . . . . . . . . . . . . . 940-9.53

B. spezinller Teil . . . . . . . . . . . . . . . . $933-993$

Atherschwefelsïuren . . . . . . . . . . . . . . 95-958

(ilykokollpararinge . . . . . . . . . . . . . . 958-969

Geparte Gilykuronsänren . . . . . . . . . . . 969-981;

Veränderungen :um Jolekiil durch Oxıdation resp. Reduktion . . 987-993

fresantstoffwechsel. . . . . . . . . . . . . . . . . $94 \mathrm{tt}$

A. Methoden des Stoffwechselversuches im allgemeinen . . . . . . . . $994 \mathrm{tt}$.

(1) Stoffwechselversuche beim Menschen . . . . . . . . . . . . 9!14 ft:

a) Stoffwechseluntersuchungen an erwachsenen Individuen (Eiweiß-liohlelydrat - Fettstofiwechsel: Nukleinstoftwechsel, Sulzstoffwechsel. Wasserstoflwechsel). Ton Priv.-Doz. Jor. Theodor lirugseh, lierlin. 
a) Las Kalerienbediulnis

(1) Berechnung der lost aut Grund des minimalen Eiweißledlarfes und nach dem Gesetze der Isulynamie der Xahrungsstofle . . . . 99.

c) Auswahl del Nahrung . . . . . . . . . . . . . . . 996

1) Analyse der Nahrungsmittel . . . . . . . . . . . . 99

4) simmeln der Ausscheiduniren . . . . . . . . . . . . . 998

f) Analyse der Ausscheidungen . . . . . . . . . . . . . 1000

list . . . . . . . . . . . . . . . . 1000

Eirbioclienes. . . . . . . . . . . . . . . . . 1001

Ilam . . . . . . . . . . . . . . . . 10(1)

schweiß . . . . . . . . . . . . . . . . . 1001

(1) Einteilung des Sitofiwechselversuches in Perjoden . . . . . . . 1001

II. Ausnutzungsversuche (Resorptionsversuche) . . . . . . . . . . . 101)2

III. Eiweiljstollwechselversuche . . . . . . . . . . . . . . . . 100.)

IV. Kollehydrat- und Fettstoflivechselversuche . . . . . . . . . 10J9

V. Nukleinstoffwechselversuche . . . . . . . . . . . . . . 1011

V1. Salzstoftiwechsel . . . . . . . . . . . . . . . . . 1013

VIl. Wasserstoftwechsel . . . . . . . . . . . . . . . . 1014

ङ) Stoffwechseluntersuchungen am Säugling. Von Prof. Dr. l.eo Langstein.

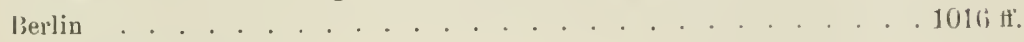

Milchgewinnung . . . . . . . . . . . . . . . . 1015

Versuclisanordnung . . . . . . . . . . . . . . . $1016 \mathrm{ff}$.

Gesautstoffwechsel . . . . . . . . . . . . . 1027

r) Stoffwcehselversuche an Hunden, an Wiederkäiuern und an Vögeln.

Gewinnung der sensiblen Ausscheidungen. Von Priv.-Do\%. Dr. Vïltz.

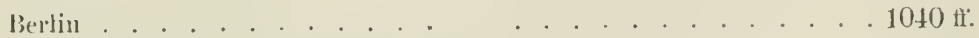

1. Stofliwechselversuche an IIunden . . . . . . . . . . . 1040

2. Stolfwechselversuche an Wiederkäuern . . . . . . . . . . 10.0.t

3. Stotiwechselversuche an Vögeln . . . . . . . . . . 10.58

Untersuchungen an Seetieren. Yon Dr. M. Henze. Zoologische Station. Neapel . 106it

I. Methodik der stoffivechseluntersuchungen an Wassertieren . . . . . . . . . 1065)

1. Respiratorischer Gaswechsel . . . . . . . . . . . . . . . . . . . 106 .

(1) Bestimmung des Sauerstulls . . . . . . . . . . . . . . 1060̃

1. Titrimetrische Methode nach 1. W. Winkler . . . . . . . 1065

2. Titrimetrische Methode nach schützenberger und Risler . . . . . 1068

Apparat zur Jitration des Samerstofls . . . . . . . . . . . . 1070

'Titerstellung der Natriumbỵdrosulfitlösung . . . . . . . . . . 1072

b) Bestimnung der Kohlensäure . . . . . . . . . . . . . . 1073

1. Titration der Kohlensänre . . . . . . . . . . . . . . 1073

״. Bestimmung der Gesantkollensäure durch Anskochen . . . . . 107t

3. Gasvolumetrische Koblensïurebestimmung . . . . . . . . . . 1076

c) Methoden der gleichzeitigen Hestimmung ron Sincrstotf, Kohlensäure und stickstotf . . . . . . . . . . . . . . . . 1076

d) Bestimmung der Koblensäuretension des Wissers . . . . . . . . . 1080

e) Mikrochemische Gašlnalyse . . . . . . . . . . . . . . . 108? 
13. Jethodik der Versuchsanordnung. Respirationsapparate . . . . 1082

(1) Vernons Versuchsanordnung. . . . . . . . . . . . 105.

b) Versuchsanordnung nach Piitter . . . . . . . . . . . 108t

c) Respirationsapparat fon Joylet und Regnard . . . . . . . . 1084

d) Respirationsapparat von liounhiol . . . . . . . . . . . 1084

c) Respirationsapparat naclı Zuntz . . . . . . . . . . . . . . 1087

f) Versuchsanordung mit [nrehliuftung nach ['iitter . . . . . . 1050)

.9) Ilikrorespironeter nach Thunberg . . . . . . . . . . . . . . . 1091

( . Bestimmung der Iusscheidungsprodukte . . . . . . . . . . . . . . 10122

a) Feste Bestandteile . . . . . . . . . . . . . . . . 1092

b) Bestimmung des Kohlenstulls. whleher gefösten organisehen substanzen untspricht . . . . . . . . . . . . . . . . 1093

c) liestimmung der stickstoflhaltigen Verhindungen . . . . . . . . . 109.

d) lestimmung des tmmoniaks . . . . . . . . . . . . . 10!5

p) Bestimmung der Nitrite . . . . . . . . . . . . . . . . . . . 1090;

f) Bestimmung gotsforminer Ausscheidungsprodukt . . . . . . . . . 1097

I). Außere Linflisse, welche bei stuttwechseluntersuchungen in Frage kommen 1098

(1) 'l'emperatur . . . . . . . . . . . . . . . 109ה

b) Licht . . . . . . . . . . . . . . 1099

c) Nanerstotlzehrung des Wassers . . . . . . . . . . . . . . . . 109?

(l) Sirmbiose und Parasitismus. . . . . . . . . . . . . . 1101

11. Allgemeine Erfahrungen ïber das Arbeiten mit seetieren . . . . . . . . 1101

a) Fesselung dep f'iere . . . . . . . . . . . . . 1101

b) Blutentnahnte . . . . . . . . . . . . . . . . . . . . . . . . . . .

c) Aufsammlung von Exkreten und sekreten . . . . . . . . . 110;

d) Exstiruationen . . . . . . . . . . . . 1107

c) Plyysiolugische löisungen . . . . . . . . . . . . . . 1107

Anhang: Chemische und physikalische Notizen ibber seewasser . . .110k

a) Zusammensetzung des seewassers . . . . . . . . . . . 110s

b) Gasgchalt und Absorptionskoefizienten des seewassers für die atmosphärischen Gase . . . . . . . . . . . . 110

c) Die sogenannte ... Alkalinität des Seewassers . . . . . . 110!

(7) Die lieaktion des reewassers . . . . . . . . . 1110

c) Spezifisches Gewicht . . . . . . . . . . 1111

f) Gefrierpunkt des seewassers. . . . . . . . . . . . 1111

(1) Elektrische teittähigkeit . . . . . . . . . . . 1112

1) Temperatur des Seewassers . . . . . . . . . 1112

i) Küntliches seewasser. . . . . . . . . . . . . 1112

B. Methodik des Encrgiestoffwechsels. Von Prot. 1)r. I. E. Johansson, Stocklolm 1114 fll.

I. Stotf- und Energieumsatz . . . . . . . . . . . . . . 1114

1. Die Komponenten des Stottwechsels. . . . . . . . . . . 1114

2. Physiologicehe Verbremungswerte . . . . . . . . . . . 1115

3. Schema des stoffwechsels . . . . . . . . . . . . . . . 1116;

4. Die einzelnen P'osten in Stuflwehsel . . . . . . . . . . . . . . 1118

э. Verbrennungsprodulte . . . . . . . . . . . . . . 1122

(i. Bilanzen des Körpermaterials . . . . . . . . . . . . . . 112t

7. Imsitz und Verbrenung im Kinger . . . . . . . . . . 112. 
II. Koeftizienten der Eiweiß-, Fett- und liohlehylnutwerbrennumg

1. Die Kurttizienten der Eiweißverbrennung. . . . . . . . . . . .112i

2. Knetlizienten dor Fett- und Kohlelydratverbrennung . . . . . . . 1131

3. Die Zuverlissigkeit der kalorischen kiretizienten . . . . . . . . . 11:31

4. Die sauerstoltaufnahme und die Kohlensäureabgabe als Indikatoren der Verbrennung im Kï̈rper. . . . . . . . . . . . . . 1133

11I. Versuchsanordnungen . . . . . . . . . . . . . . . . 113\%

1. Lntersucliung der Nahrung bei frei gewillilter Kost . . . . . . . 1135

2. Man bestimmt die Nenge und die Zasimmensetzung der Nahrung. den Harn- und Kotstickstoff and die Kohlensii ureabgabe . . . . . . . 11:31;

3. Jan bestimut den Sanerstoftiverbratuch. die Kohlensäureabgabe und die stickstoffausscheidung mit dem Harne. (Yersuchsanordnung nacb Zuntz.) . 1135

4. Man bestimmt den stickstoff, den Koblenstoff und die Verbrennungswärme der Kust. des Kotes and des Harnes, die Koblensäureausscheidung and die Wärme:tbgabe des Körpers (einschließlicb der geleisteten Arbeit). . 1140

๖. Vollständiger Bilanzversueh . . . . . . . . . . . . . . . . 1141

IV". Respirationsapparate . . . . . . . . . . . . . . . 1143

Typus 1: Regnault und Reiset ............... . . 1144

, ․: Pettenkofer und roit. . . . . . . . . . . . 1149

, 3: Verfahren ron Zuntz . . . . . . . . . . . . 115.)

Y. Kalorimeter . . . . . . . . . . . . . . . . . $115 \mathrm{~s}$

1. Absorjtionskalurinieter oder Kalorimeter für kunstante Temperatur . . 1159

Eiskalorimeter . . . . . . . . . . . . . . . . 1159

Yerdanpfungskalorimeter . . . . . . . . . . . . . . . 1159

D'Arsonvals selbstregulierende Kalorimeter für konstante Temperatur . 1160

Selbstregulierender Wasserkalorimeter von Lefére . . . . . . . 1161

Respirationskalorimeter von Atwater. Rosa nd Benedict . . . . . 1161

Kalorimeter ron Ilarcet . . . . . . . . . . . . 1163

‥ Strablungskalorimeter . . . . . . . . . . . . . . 116t

Luftkalorimeter ron d'Arsonval . . . . . . . . . . . . . 1164

Differentialkalorimeter nach ditrsonval . . . . . . . . . . 1167

Lnftkalorimeter mit Korrektionsapjarat von Rubner . . . . . . . . 1167

Kompensationskalorimeter von Haldane . . . . . . . . . . . 1168

Thermo-elektrische Strablungskalorimeter . . . . . . . . . 1169

3. Anemokalorineter . . . . . . . . . . . . . . . 1170

Methoden beim Arbeiten mit sensibilisierenden fluoreszierenden Stoffen. Von

Prof. Dr. H. $r$. Tap peiner, Yünchen . . . . . . . . . . . . $1171 \mathrm{ff}$.

Lichtquelle . . . . . . . . . . . . . . . . . . . 117 2

Belichtungsgefäße . . . . . . . . . . . . . . 1174

Auswahl der Stoffe und Fonzentration derselben . . . . . . . . . . 1176

Die wichtigsten Methoden der künstlichen Parthenogenese. Von Prof. Dr.

Jacques Loeb, New-York . . . . . . . . . . . . . . . . . . $1179 \mathrm{ff}$.

1. Die Jethoden der künstlichen Parthenogenese beim Seeigelei . . . . . 1179

2. Tariationen dieser Methode . . . . . . . . . . . . . . 1181

3. Entwicklungserregung olne Jembranbildung . . . . . . . . . 1182

4. Versuche am seesternei . . . . . . . . . . . . . . 118?

๖. Kïnstliche Parthenogenesen am Molluskenei . . . . . . . . 1183

6 .

. Annelidenei . . . . . . . 1183 
Die wichtig sten Methoden der Immunitätsforschung. Von Prof.' Dr. Leonor M i c h a elis: Berlin

Herstellung und Nachweis von Antikörpern . . . . . . . . . . . . 118.,

I. lie Eiweißrizipitine . . . . . . . . . . . . . . . 118.

1. Wie Wahl des Yersuchstieres . . . . . . . . . . . 118

2. Die Methodik der Injektionen . . . . . . . . . . . . . . 1181;

3. Die Injektionsintervalle . . . . . . . . . . . . . . . . . . 1186

4. Gewinnung des Prïzipitinserums und Aufbewahung . . . . . . . 1187

э. Prüfung des l'rizipitins . . . . . . . . . . . . . . . . . 118!

(quantitative Eiweißbestimmung mit der Prizipitinmethode . . . . 11!11

II. Die Hämolýsine . . . . . . . . . . . . . . . . . . . . 11!)1

Der Nachweis des Hämolysins . . . . . . . . . . . . . . . . . 119:3

Del Nachweis der Hämagghtunine . . . . . . . . . . . . . . 1194

III. Jie Mtethode der Komplementablenkung . . . . . . . . . . . . . . 1194

IV. Lie Wassemannsche Serumreaktion . . . . . . . . . . . .11!1

Anhang: Antiköruer, welche als Formente wirken . . . . . . . . 1203

I) ic wichtigsten Methoden heim Arbeiten mit Pilzen und Bakterien. Von Dozent

Franz Fuhrmann in Graz . . . . . . . . . . . . . . . . 1204

Einleitung . . . . . . . . . . . . . . . 1204

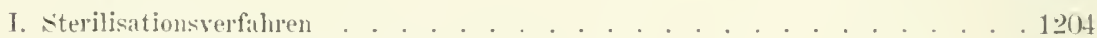

(1) Sterilisation durch trockene Wärme . . . . . . . . . . . . 1205

b) Sterilisation dureh feuchte Wärme . . . . . . . . . . 1206

Sterilisation in strömenden Dampf . . . . . . . . . . . 1206;

Sterilisation im erlitzten Dampf . . . . . . . . . . . 1207

c) Sterilisation durch Filtration . . . . . . . . . . . . . 1209

11. Nährsubstrate . . . . . . . . . . . . . . 1212

a) Feste Nährsubstrate variabler Zusammensetzung . . . . . . . . . 12120

Kirtoffelnührböden . . . . . . . . . . . . . 1213

Brotnährbüden . . . . . . . . . . . . . 1 . . . . . . . .

b) Flïssige Nährsubstrate schwankender Zusammensetzong . . . . . . . . 1215

1. Blutsernu . . . . . . . . . . . . . 1215

2. llitch . . . . . . . . . . . . . . 1216

3. Fleischbrihe . . . . . . . . . . . . . . . . . . .

4. Mistdekukt . . . . . . . . . . . . . . . . . . . . . .

э. Wiirze . . . . . . . . . . . . . . . . . . . . .

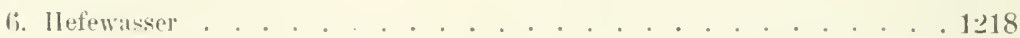

7. Abkochungen von Frichten . . . . . . . . . . . . 1219

8. Heuinfus . . . . . . . . . . . . . . . . 1219

c) Flïsige Nïhrsubstrite von konstanter chenischer Zusimmensetzung . . . 1219

(1) Gillertige Niilısubstrate . . . . . . . . . . 12201

1. Nihhrgelatine . . . . . . . . . . . 1221

‥ Nähragar . . . . . . . . . . . . . . . 12220

e) Nïhrsubstrate fiir die Gewinumg und Zucht bestimmter Mikroorganismen 1:23

Anhang: Al,füllvorrichtungen . . . . . . . . . . . . 1227

behailter fije steriles Wasser . . . . . . . . . . . . 1228 
III. Reinzuchtmethoden .

1. Jas Gelatine-I'lattenverfahren . . . . . . . . . . . 1230

?. Der Agarplattenguß . . . . . . . . . . . . . . 12:33

3. Reinzucht ron einer Zelle unter Kontrolle . . . . . . . . . 12:33

IV. Anä̈rnbe Zurht und Kultur in bestimmten Gaven oder Gasgemischen . . . . 12:3S

Kultur in hoher schicht. . . . . . . . . . . . . 1234

Kultur in ther Buchnerröhre . . . . . . . . . . . . 1034

Zuchtapjarat für Eprouvettenkulturen . . . . . . . . . . . 1239

Anä̈rnlue I'lattenkultur . . . . . . . . . . . . . . 12:3!

Eprourettenkultur im Wasserstott . . . . . . . . . . . 1 1243

Plattenkultur in Wasserstoff . . . . . . . . . . . . 1244

Plattenkultur in Gasstrom . . . . . . . . . . . . 124t;

Y. Bestandteile von Pilzen und Bakterien . . . . . . . . . . . . 1247

A. Jikroehemische Methoden zum Nachweis der Bestandteile von Bakterien und

l'ilzen . . . . . . . . . . . . . . . . . 1247

(1) Zell wandbestandteile (Zellulose, Pektin. Chitin. Kallose) . . . . 1248

b) Zellinhaltsstofte (EiweiBstotte. Nukleine, Volutin. Glykogene, Fette) . 1250

B. Herstellung der PreBsïfte . . . . . . . . . . . . . 1 20.5工2

( Nachweis und Gewinnung einiger Enzyme ron Pilzen und liakterien . . 12.tst

1. Proteolytische Enzyme . . . . . . . . . . . . . . . 10.4t

‥ Kohlenhydratspaltende Enzyme . . . . . . . . . . . 105!

1). Anhang: Gewinnung won Bakteriopurpurin und Bakteriochlorin . . . 1:2 (j-2)

VI. Jethoden zum Nachweis und zur Bestimmong einzelner Umsetzungsprodukte in

Pilz- und Bakterienkulturen . . . . . . . . . . . . . 1206

(a) Nachweis gasförmiger L'msetzungsprodukte . . . . . . . . 106 0

b) Nachweis gelöster Unsetzungsyrudukte . . . . . . . . . . 1264

Indolnachweis . . . . . . . . . . . . . . . . 1264

Nitritnachweis . . . . . . . . . . . . . . . 1265

Jachweis von siiurebildung . . . . . . . . . . . 1265

Säurebestimmung in Kulturen . . . . . . . . . . . . . . 1267

Alkalibestimmang in Kulturen . . . . . . . . . . 10198

III. Das Tierexperiment . . . . . . . . . . . . . . . 12lis

Die wichtigsten Tiere und ilıre Zucht . . . . . . . . . . 126158

Tierhalter . . . . . . . . . . . . . . . . . 1271

Wägung und Tempcraturmessung . . . . . . . . . . . . . 12 . . . . . . . .

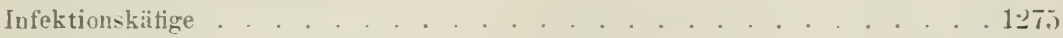

Injektionsspritzen . . . . . . . . . . . . . . . . 107s

Narknse . . . . . . . . . . . . . . . . . . . . . . . . .

Infektionsmethoden . . . . . . . . . . . . . . 1281

Dosierung des Impfmateriales . . . . . . . . . . . . . . . . . . . . . . . . . . . . .

Beobachtung und Sektion . . . . . . . . . . . . . . 1293

VIII. Gewinnung and Züchtung pathogener Jikruben . . . . . . . . . . . 1296

Micrococcus meningitidis cerebrospinalis . . . . . . . . . . . . . 1297

Micrococcus aureus (Rosenbach) Mig. . . . . . . . . . . . . . 1297

Micrococens gonorrhoeae (Neisser) Flïgge . . . . . . . . . . 1298

J'seudomonas aernginnsa (śchröter) Mig. . . . . . . . . . . . . . 1299 
liacillus coli Escherich.

Bacillus suipestiter

Bacillus typhosus (iattky

lacillus uedematis Liborius

Bacillus tetani Nicolatier

1302

bacterium anthracis (Koch) Mig.

Bueterium arisepticum

liacteriun diphtheriae (Loeftler) Mig.

lacterium influenzae (IR. P'feiffer), Lehmann und Neumann.

lacterium mallei (Loeffler) Mig.

J'estbicterium

Bacterium jneumoniae Mig.

Biscterium suicidum

lacterium tuberculosis (Koch) Mig.

Nierosjira comma (Kónch) Schrötter

Actinomyers hominis.

IX. Gewinnung und Züehtung verschiedener, nicht pathogener Mikroorganismen . 131t

Eiweißspaltende Bakterien . . . . . . . . . . . . . . 1314

Harnstutbakterien . . . . . . . . . . . . . . 131;

Nitrifikationsbakterien . . . . . . . . . . . . . . . . . . . . . .

Denitrifizierende likterien . . . . . . . . . . . . 1317

Schwefelbakterien . . . . . . . . . . . . . . . . . . 1318

l'urpurbakterien . . . . . . . . . . . . . . . . . . . . .

l'hotogene I3akterien . . . . . . . . . . . . . . . . 1319

Erreger der Jethan- und Wasserstoff'gärung der Zellulose . . . . . . 1320

Essigbakterien . . . . . . . . . . . . . . . 132-2

Milchsäurebakterien . . . . . . . . . . . . . . . 13202

Buttersäurebakterien . . . . . . . . . . . . . . . . 13:3

Gewinnung ron spirillen . . . . . . . . . . . . . . . 13ㅆt

Strahlenpize . . . . . . . . . . . . . . . 135

Sehimmel pilze . . . . . . . . . . . . . . . . . . 13:-5

X. Wethoden der bakteriologischen Wasser-, Boden- und Luftuntrrsuchung . . 1;32.;

Wisseruntersuchung . . . . . . . . . . . . . . . . 13:5

lodenuntersuchung. . . . . . . . . . . . . . . . . . 1331

lulltuntersuchung . . . . . . . . . . . . . . . . 1332

Nethoden zur Herstellung bestimmter Wasserstoffionenkonzentrationen. Von l'rof. Dr. Leonor Mi ichaelis, Berlin . . . . . . . . . . . . . . . . . . 1339

Acetatgemiseh . . . . . . . . . . . . . . . . . 1342

Am noniungemische . . . . . . . . . . . . . . . . 1344

Phosplatgemisehe . . . . . . . . . . . . . . . 1345

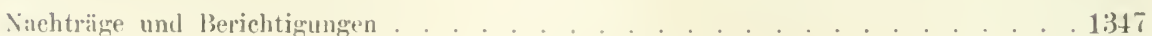

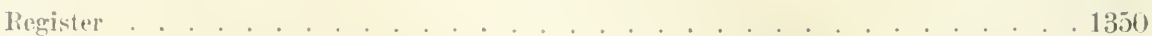




\title{
Fermente.
}

\section{A. Methoden zur Darstellung ron Fermenten.}

\author{
Von Leonor Michaelis, Berlin.
}

Bisher ist noch kein Ferment auch nur in annähernd reinem Zustande dargestellt worlen. Bei der Herstellung ron Fermenten handelt es sich bis: hente immer noch darum. Lösmngen oder feste Präparate zu beschaffen, die die Wirkung des Fermentes besitzen. Wieriel selbst in den stärkst wirksamen Fermentpräparaten der Masse nach anf das wirhliche Ferment kommt. dariiber fehlt uns bis jetzt jede schätzmng. aber alles spricht dafür. dal selbst die besten trockenen Fermentpräparate zum grofien Teil aus den unrermeidlichen Verunreinigungen bestehen. häufig eiweibartiger Natur. In trockenen Fermentpräparaten ist dieses Eiweil oft zum größten Teil in rlenaturiertem, mü̈slichem Zustand enthalten. Löst man ein solches Präparat in Wasser. so geht manchmal nur ein rerschwindender Anteil des Pulvers in Lösung, obwohl die Lösung kräftige Fermentwirkung zeigt. Stellt man aus der klaren Lösung etwa durch Fällung mit Alkohol wieder ein festes Präparat her, so ist das meiste daron wiederum unlöslich. gleichzeitig erleidet man grofe Verluste an Ferment, so daß auf diesem Wege die Tremung der Verunreinigungen ron dem eigentlichen Ferment sehr bald ihre (irenze hat. Es gibt ïhrigens auch eiweibhaltige Fermentpräparate. weIche vollkommen löslich sind.

I)ie Fermente könmen ans den sie produzierenden ()rganen auf zweierlei Weise gewonnen werlen. Entweder benutzt man das sekret des lebeuden Organes. welches wie speichel direkt orler wie Magensaft durch Fisteln gewonnen wird. Insofern ist die Methode der Fermentgewinnung identisch mit der Methode der operativen I'hrsiologie. (oder aber man gewinnt die Fermente durch Auslangung der isolierten Organe. Nan mnf dazu aber die ()rwane des in gesundem Znstande geschlachteten Tieres nehmen; die Organe menschlicher Leichen zeigen meist keine Fermentwirkmg mehr.

I) Methode. die man einschlagen muß. un aus cinem ()rgan Fermente zu gewinnen, hängt ron der Extrahierbarkeit des Fermentes ah. Es gibt Fermente. die olne Schwierigkeit durch Wasser. dem nötigenfalls 
weedguete Antiseptica. wie C'hloroform orler 'Tolnol. zugesetzt sinul. extrat-

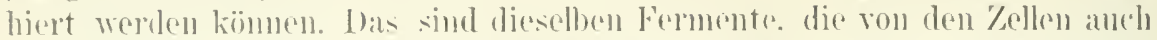

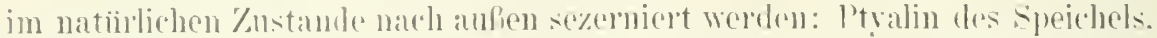

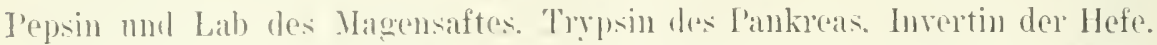
Jedoch sind tie fedingungen der Extraktion mounstiger als die ver natiir-

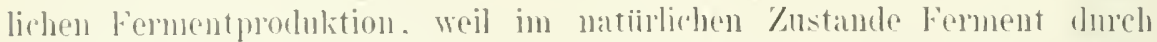
Tembildung stets machgeliefert werdron kann. während ans den toten oromen

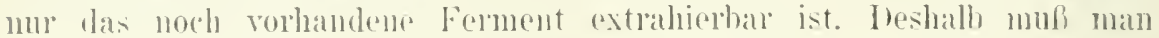
hei den Extraktionsmethoden die Aushente möglichst zu erhöhen suchon.

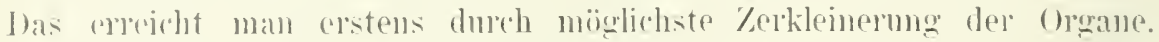

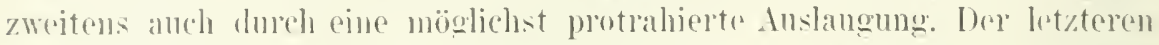
ist allerdings bej viclen Fermenten dureh die geringe Halthatheit in liosung

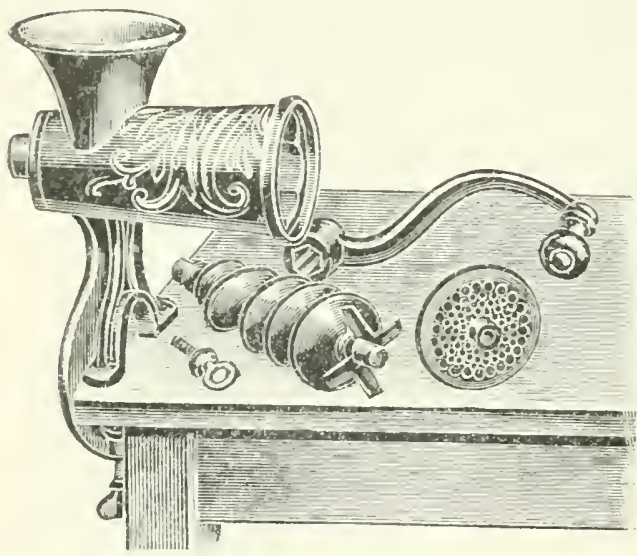

l*ig. 1.

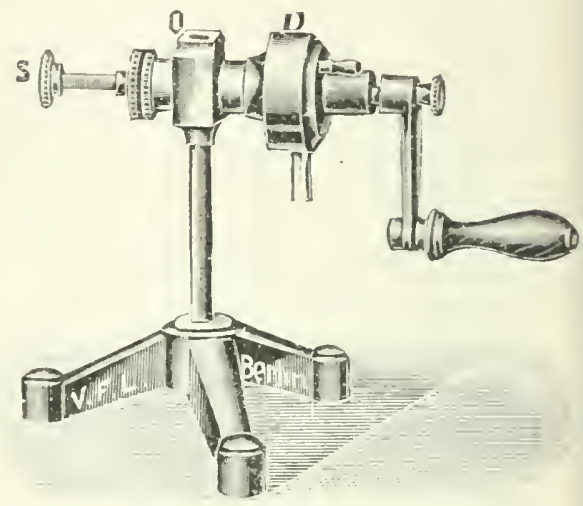

Fig. 2.

fin 7iel acsetzt. Anwendum des Sohiittelappluates ist bei manchen Feymenten dabei zu vernedden ans dem suäter anf S. 1:3 angefiilnten Grunde.

Fine aweite lisse ron fermenten ist diejenige. Welche menter natiolichen Bedingumgen von den Zellen iberhanpt nicht nach auben hin sozer-

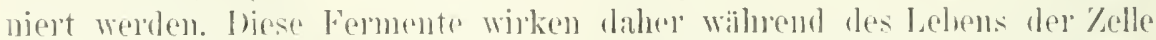

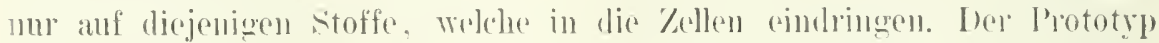

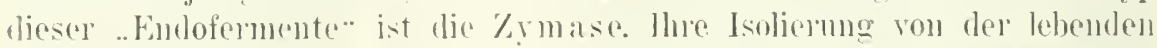

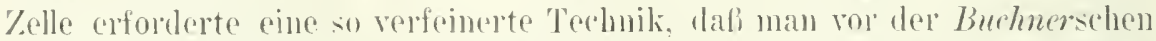

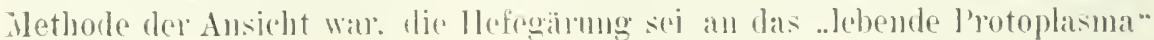
sebunden.

In Grunde ist also zunärehst immel das Wesentliche. Wemn man Fer-

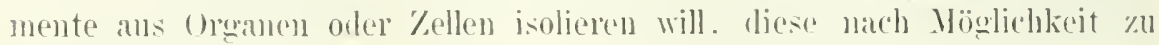
zerkleincril.

Fiir dic erste. wöber \%erkleinelum benutze man \%. B. ein Wiegenesser oder die gewïhnlichen (Fig. 1) Fleischhathmaschinen. oder feiner,

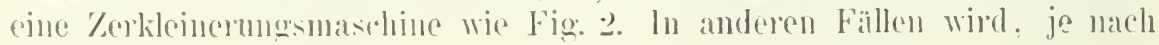




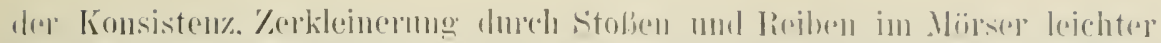

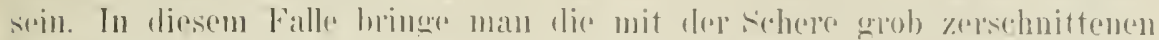

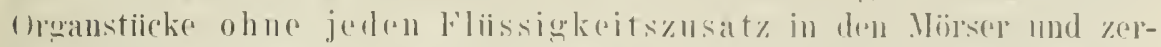

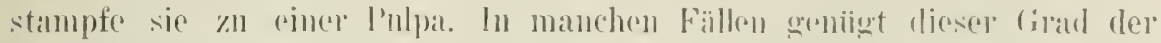

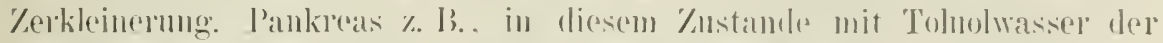
Autolyse iblorlassen, liefert einen trypinhaltigen lixtrakt.

In anderen Fällen bedarf es weiterer \%erkloinermug. wtwat wenn man

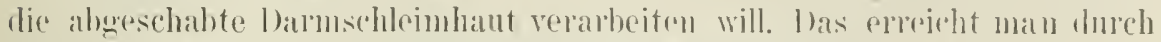

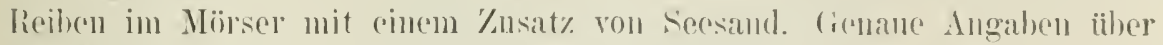
die Jengenverhältnisse in allgomeinen lassen sich nicht machen; man

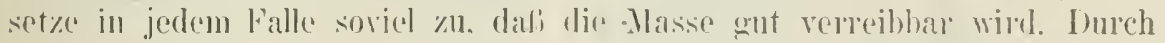

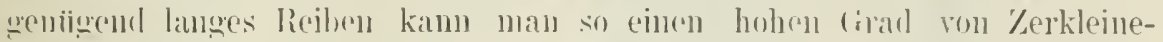
rung erreichen. Inas \%erkleinerte (iewebe wird dann wienler mit Chloroformuasser orler 'Toluolwasser extrahiert (Chloroform 1 auf eno Wasier, Tolnol chenso). Biu derartiges Verfahren ist \%. B. zur (iewinumg der invertinartigen Fermente der Hefe greignet.

In auderen Fällen wirl man nach mongegangene? wholer \%erkleinerung die I'ulpa anf (ilasplatten oder Tontelleren ausbreiten mod durch ainen warmen Luftstrom oder in einem craknierten Exilkkator iber schwefelsilure bei zinmertemperatur oder bei :370 rasch trockinen. Nach einge-

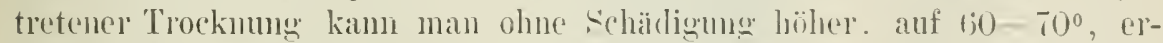
hitzen. Das getrocknete Gewche lälist sich in Wiirser leicht zerklemern and weiterhin. wie gewöhnlich, extrahieren.

Noch arölieren Effekt hat einr lieihe ron Hothorlen. ron denen die älteste und rerbreitetste lie ron Buchner ${ }^{1}$ ) ist: diese möge in ihrer ursprünglichen Anwendungsweise für die (iewinnung der Kymase ans der Hefe nïher heschrieben werden.

\section{Darstellung von Hefepreßsaft.}

Im besten wird obergärige Hofe als Iusgangsmaterial rerwendet, die man als einen dickflüssigen Brei von Bierhranereien bezichen kann. Ine (iewinnung des P'refsaftes zerfüllt in folgende I'rozeduren, welche zum Teil mit den eigenen Worten ron Buchner beschrieben werden sollen: 1. Waschen der Hefe, 2. Entwässern der Hefe, :3. Vischen mit Sand und Kieselgur. t. Zerreiben unter Zerreißung der Zellmembranen, 5. Auspressen der teigförmigen Masse.

1. Xan bringe die ans der Branerei hezogene Hefe anf ein Haarsieb und shlowemme sie mittelst aufgegossenen Wassers durch das Sieb hindurch in hohe (refäBe (25) Inhalt) mit Wassel. (rröhere Bestandteile (Hopfen) bleiben schon so auf dem Siehe znriick. Nachdem die Hefe sich zu Boden gesetzt hat, hebert man das Wasser ah. Dieser ganze Waschprozeß wird :3-tmal wiederholt, his das Waschwasser klar und farblos bleibt.

") Ed. Buchner, Hans Buchner und Martin Hahn, Die Zymasegärung. MIünchen und Berlin, R. Olklenbourg, 1903. 
Schlieblich koliert man die Itefe durch ein Nesseltuch anf einem Filtrierrahmen. Der Waschprozel dauert fïr 2 leg llefe 1 stunde.

2. \%ur Entwässerung bringt man die gewaschene Hefe in ain beutelförmig gefaltetes Koliertuch und hierauf noch in ein l'rebtuch. die weiter unten nïher beschrieben werden. Iban bringt man das canze in die ebenfalls weitel' nuten zu beschreibende lrvdraulische P'resse und unterwerfe es jinuten einem Inrucke von 50 Atmosphären. Es resultiert da-

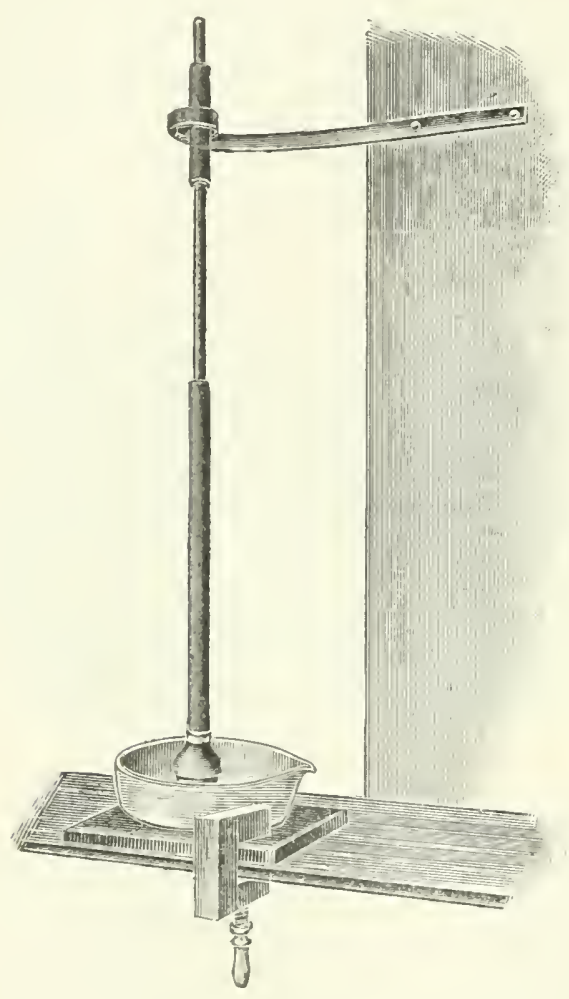

Fig. 3.

bei ein Hefekuchen ron etwa $70 \%$ Wassergehalt. der im Bruch noch selhbran und nur an den Rändern schon etwas weili getrocknet erscheint.

2). Iliese uetrocknete Hefe wiol in riner sehr grolien Porzellanschale mit Gmarzsand velmischt, der durch ein sieh ron oon Masehen pro chadratzentimeter hindurchgesangen jst, mul fermer mit hicselgur, mol zwar auf $1000 g$ entwissierte

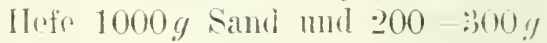
Ki ieseleur. Ilieses wird zunïclsst mit den Hïndel gremengt und durch ein grofes Siel) (9) Maschen anf $1 \mathrm{~cm}^{2}$ ) eneschlagen.

4. Zur Zerreibung kommt das staubtrockene, fast weilie I'ulver in l'ortione'n ron :300- $400 \mathrm{~g}$ in eine groblice I'orzcillanschale ron $40 \mathrm{~cm}$ Durchmesser: dieselbe ist dured eine Holzfassme mit dem Tische fost resbunden: das P'or\%ollanpistill

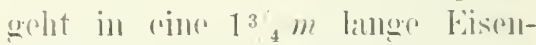
stange iiber (fosamtgewicht skg). die durch die Ose oines an der Wamel des Arboitsrammes federoml

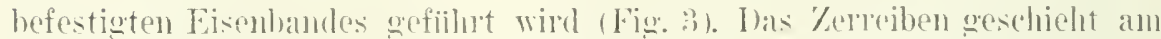
besten mit dor Iland. Ls muli solanger fortersetzt werden. bis dir toig-

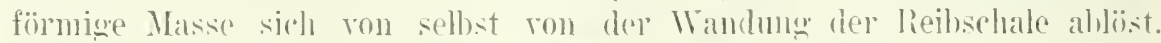

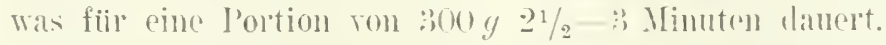

5. Zum Zwerke des Anspressens wird die teigförmige Masse. entsprechend 1 kigllefe, nummehr in ein starkes, hammwollenes, nicht appretiortes Prefituch aingeschlagen, wie as als wassordichtes Segeltuch Verwen-

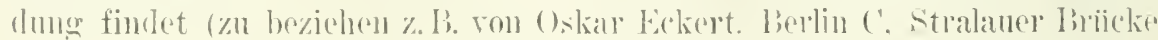
Nr. 3). Dieses Tuch wird ror dem Gebranche mit kaltem Wasser giviudlich dnrehtränkt und damn in der hrdranlisedien Presse bei so Atmosphären 
Druck von dem ïberschiissigen Wassel hefreit. Als I'resse (Fig. t) hedient man sich der hydraulischen Presse, die zin diesem Zisecke jetzt im Handel unter dem Namen der Buchnerpresse zu haben ist. Die auszupressende Ifasse wird in las 'Theh eingeschlagen, auf die Prefplatte gelegt und mit einem vielfach durchlöcherten Hohlaylinder ans Staliblech ungeben, und dalsuf die rertikale Spindel mit der Iland angerogen. I)en Ilauptdruck er-

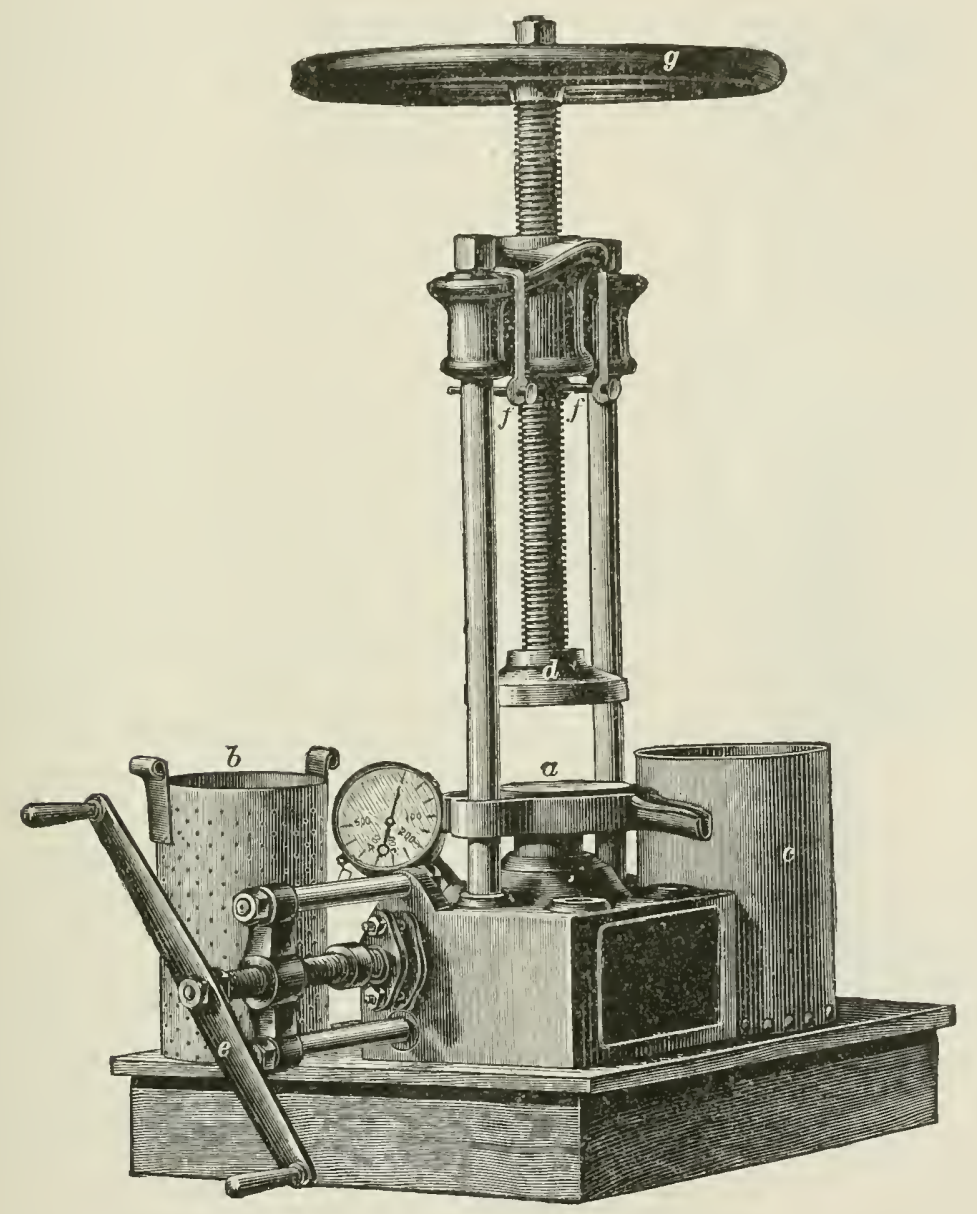

Fig. 4.

reicht man dinn durch Anziehen der horizontalen spindel. Der erreichte Atmosphïrendruck jist an dem Manometer abzulesen: man steigert diesen langsam von $50 \mathrm{zu} 50 \mathrm{Atmosphären} \mathrm{mnd} \mathrm{hält} \mathrm{ihn} \mathrm{durch} \mathrm{öfteres} \mathrm{Nachziehen}$ auf der gewïnschten Höhe konstant. Die Pressen sind fïr einen In'uck von :300 Atmosphären gebaut. Iler abfliebende I'relisaft tropft direkt ans der Presse anf ein Faltenfilter und von da an in ein dureh Eiswasser gekiihltes 


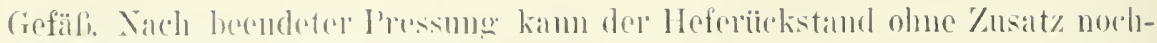

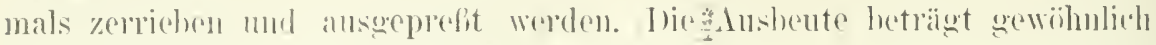
fiir 1 k\% llofe too his sogat $500 \mathrm{~cm}^{3}$.

Eine weiterr Ilothode. den intrazollulären Inbalt zu gewimuen. stellt

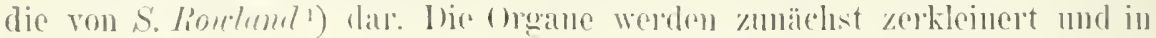

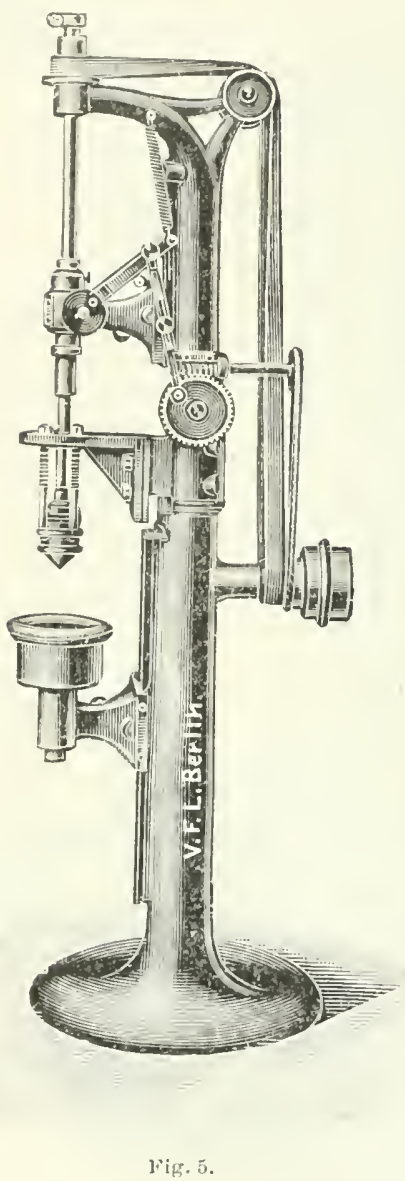

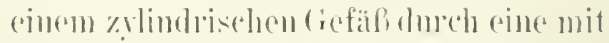

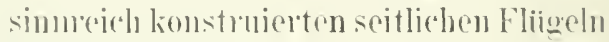

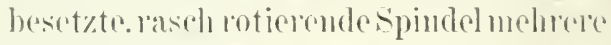
Stumlen zerricheru. dam mit Kieselgur his zur Konsistruzaines trockenen I'ulvers

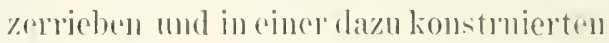
Filtrepresse answedlitekt. Skiz/2u des Apparates finden sich in der Originalarbeit.

Ine besonderen fïr Iuslatugmen des Inhaltes rom lakterien wereguet ist

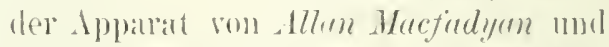

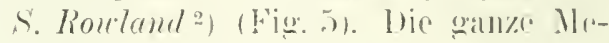
thorlo sei für das ()hjekt hosduriebert. fiid das die Infor'als sie amwandten. fïl die \%erkleinesume von Tyjulnshatlen.

10 Bonillomkiiblbelen werlen mit

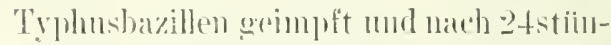
liwem Infenthalt im bintshamk gut zentrifuniolt. Die Inkteriemmasse wird

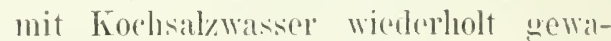
schen. zentrilugiert mul rasch getrockunt. indem sio anf dio oborfläche rines (bamberlandfilters ausowneitet mud huft

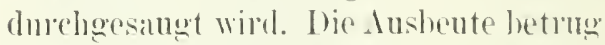

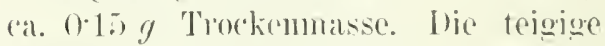
Masse wirl vou den Filter alogeloist und in das konische ciefiilides nebenstehenden lpparates gehracht.

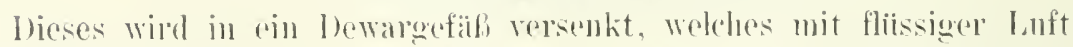
gefüllt ist. Fin Vollkomus ans stahl mit clektriselsem Antrieh rotiert immerhalb des mit der weforenen bakteriemmasse gefüllten Hohlionus,

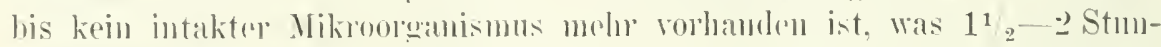

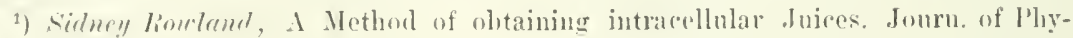
siology. Visl. 207. p. $53(1901)$.

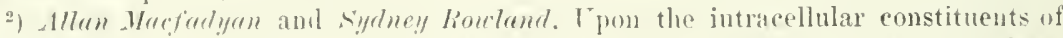
the typhoil hacillus. 11 . Apparatus and Methols. Zentralbl. f. Bakteriol. Abt. I. Bal.34. ร. $765(1903)$. 
den erfordert. Die aufgetaute Ilasse wird im Mrhatmörser mit physiologischer Cl Na-Lösung verrihut und gröhere korpuskuläe Elemente abzentrifugiert, so dali eine opaleszierende Iösung übrigg hleibt.

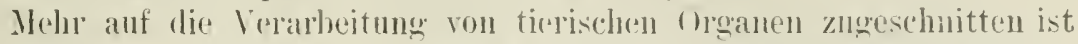
die \%erkleinerungsmethorle von Wierhowshi ${ }^{1}$ ), die an anderer stelle beschricben ist.

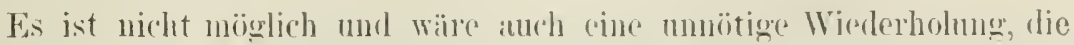
Darstellung aller gebriuchlichen Fermentpriparato zu beschreiben. Als typische Beispiele mögen dic folgenden geniigen:

\section{Darstellung des Invertins.}

\section{Verfallen vou W. A. Osborne. ${ }^{2}$ )}

$1 / 2 \mathrm{~kg}$ Prelihefe wird zunächst mit $1 / 216 \%$ igem Alkohol angerieben, nach $16-2+$ Stunden abfiltriert. Es gesclicht dies hauptsächlich, nm rlie Eiweibkörper zu koagulicren. (Hente diuffe das nicht meln nötig sein. da man nötigenfalls nach L. Michuelis ${ }^{3}$ ) nachtrïglich das Eiweif leicht durch Kaolin entfernen kann.) Der gut ahgesangte Riickstand wird mit 500 $\mathrm{cm}^{3}$ Chloroformwasser (i) $\mathrm{rm}^{3}$ Chloroform auf $1 / \mathrm{H}$ asser) 6 Tage lang unter häufigen Umschiitteln bei $: 30 \quad 35^{\circ}$ erhalten, dann durch grofe Faltenfilter gebracht und das Filtrat gleich in 1 l-Gefälien anfgefangen, die zu drei Vierteln mit 96\% $\%$ igem Alkohol grofillt sind. Der in dem Filtrat sich sofort bildende Niedcrschlag wird zuletzt auf ein Filter gebracht, mit Alkohol grewaschen, im Vakumm unter Schwefelsäure retrocknet. Zul Reinigung von den Aschenbestandteilen erwies sich die I)ialyse am wirksamsten.

\section{Verfahren nach L. Michaelis.}

Die Alkoholbehandlung des vorher beschriebenen Verfahrens. welche die Entfernmng der Eiweißkörper zum Hauptzweck hatte, kann auf folgendem Wege umgangen werlen, welcher daranf beruht, dafj Kaolin alle Ei"reißkörper: nicht aber das Invertin adsorbiert: $100 \mathrm{~g}$ I'reßhefe werden mit der nötigen Menge Sand zerriehen. Es ist nicht nötig. die rollkommene Kerreibung. wie zur Inastellung der '/ymase, anzustreben. Dam wird die Masse :-6 Stunden mit $200 \mathrm{~cm}^{3}$ Chloroformwasser $\left(1 \mathrm{~cm}^{3}\right.$ auf $100 \mathrm{~cm}^{3}$ Wasser) geschiittelt und dann durch Filtrieren oder scharfes Zentrifugieren der flüssige Extrakt vom Bodensatz getrennt. Fs ist nicht nötig, völlige Klarheit des Extraktes schon jetzt anzustreben. Dann werden je $100 \mathrm{~cm}^{3}$ Extrakt mit 15 20 g Kaolin portionenweise unter schiitteln versetzt. Man achte darauf, daß die Reaktion andentungsweise sauer ist;

1) Wilh. Wiechoushi, Eine Jethode zur chemischen und hiologischen Untersuchung überlebender Organe. ILofmeisters Beitrïge. Bd. 9. S. 232 (1907).

2) I. A. Osbarne, Beitraige zur Kenntnis des Inrertins. Zeitschr.f. physiol. (hem. Bi. 28. S. 399 (1899).

$\left.{ }^{3}\right)$ L. Vichaclis, Die Adsorptionsaffinitäten des Hefe-Invertins. Biochem. Zeitschr. 7. 488 (1911)8). 
nötigenfalls säure man mit rinigen Tropfen $10 \%$ iger Essigsäure an. Dam filtriere man. indem man die ersten Anteile des Filtrates immer wieder aufgieft, bis das Filtrat vollkommen wasserklar ist. Eine leichte gelbliche Färbung bleibt bei manchen Hefearten bestehen.

Die weitere Reinigung durch bialyse, wenn erforderlich, s. weiter unten.

\title{
Darstellung des Pepsins
}

\author{
uach Pelelharing. ${ }^{\text {) }}$
}

\section{a) Aus Hundemagensaft.}

Der filtrierte Magensaft des llundes, der ganz frei von Galle soin muli, wird 20 Stunden lang bei möglichst niederer Temperatur gegen destilliertes Wasser dialysiert. Dann wird die tribe Flïssigkeit zentrifugiert. der ans fast reinem Pepsin bestehende Bodensatz mit ein wenig Flïsiokeit anf ein Filter gebnald, mit etwas destillertem Wasser gewaschen. ahgeprefit und im Exsikkitor getrocknet.

\section{b) Aus Schweinemagensaft. ${ }^{2}$ )}

Ine Fundusteile von 10 Schweinemägen werden rerhackt und mit 67

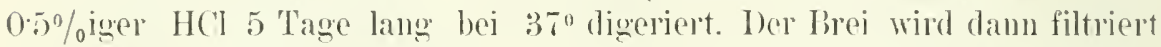
nnd gegen destilliertes Wasser his zum Entstehen einer Trübung dialysiert. (In Peronnentschlänchen dauert das 24 Stunden.) i)er entstanclene Niederschlag wird jotzt durch Zentrifngieren abgeschieden mol 1 Stunde mit :0 bis $40 \mathrm{~cm}^{3} \quad 0 \% 20$ iger $H$ ('] bei $: 30$ digeriert, wobed or sich klar löst. I)ie Lösmg, die beim Erkalten triib wird. wird gegen destilliertes Wasser dialysiort. Es bildet sich wieder eine Triilumg, die bei weiterem Ibalysieren teilweise in Lösung geht. Purch /ufïgen von Hl ('l bis zu einem Gehalt von $0.02 \%$ fällt der Xiederschlag wieder ans. Er wird anf ein Filter gebracht, mit wenig Wasser gewaschen und ïber Schwefelsäme getrocknet.

\section{Extraktion des Pepsins durch Glyzerin nach v. Wittich. ${ }^{3}$ )}

Die ron den tieferen Schichten freipräparierte Iagenschleimhant (Achwein. Kaninchen) wird möglichst zerkleinert, mit Wasser ein wenig gewaschen und dieses aborgossen. Der wenig fenchte Riidckstand wird mit Glyzerin ïbergossen. Natch wenigen Stmoden lat das Glyzrin stark peptische Eigenschaften. Wie Extraktion kamn oft wiederholt werden. Fïulnis tritt nicht ein. I'm ein festes Fermentpräparat darans abzuscheiden. fïlle man den Glyzerinansug mit Alkohol.

1) C. A. Yekelharing, Mitteilungen über l'epsiu. Zeitschr. f. physiol. ('hem. BA.35. S. 8 (1902).

2) C.A. Pelelharing, Uluer eine nene Bereitungsweise des Pepsins. Zeitschr. für physiol. ('hem. Bd. 22. S. $233(189697)$.

3) $x$. Wittich, Thes eine nene Methode zur Darstellung künsticher Verlanungsflüssigkeiten. P'flügers Arehiv. Bd. ㄹ. S. 193 (1869). 
Zu dieser letzteren Darstellungsant von I'epsin ist zu bemerken. daf leicht eine Beimengung von peptolvtischen \%ellfermenten erfolnt. Die mit derartig bereitetem ..P'epsin" angestellten Versuche sind nach den Erfahrungen von E. Abderhalden ans dem genannten frrunde nicht eindeutis.

\section{Extraktion der pankreatischen Fermente.}

(i) Dit Flyzerin nach $x$. Wittich. ${ }^{1}$ ) Zerkleinertes l'ankreas (z. 13. rom lind) wird mit (ilyerin ibergossen. Sohon nach wenigen Stunden zeigt der Extrakt anylolytische und tryptische Wirkung. Nach mehrwöchentlicher Extraktion tritt starke Autodigestion ein.

b) Ebenso extrahiert Hommursten las I'ankreas mit $0.0: 3 \%$ igem Ammoniak, fällt das Filtrat mit verdiimnter Essigsäure und lïst den Niederschlag in Sodalïsmng. Dietz. ${ }^{3}$ )

c) Extraktion der pankreatischen Formente nach I'otterin ${ }^{2}$ ) und

l'ankreasdrüsen rom Schwein werden in einer Fleischhackmaschine fein \%erhackt, dann das l'rodukt mit absolutem Alkohol so lange behandelt. bis den Gewebeteilen das Wasser entzogen ist. I)ann wird nochmals mit der Maschine zerhackt. Nachdem dann der Alkohol durch Filtration müylichst entfernt ist. bringt man den Riickstand in einen Soxhletschen Extraktionsapparat und entfettet mit Ẍther vollständig. Dann bringt man den Inhalt del Extraktionshiilsen auf ein grobes Nutschenfilter, saugt den Ather ab und trocknet im Luftstrom. Das erhaltene I'ulver zeigt die fermentativen Wirkungen des Pankreas.

Man kam nach Dietz die Lipase ron dem Trypsin folgendermafen tremnen: Yan breitet das Fermentpulver auf ein grofes Nutschenfilter in diimner schicht aus, iibergielit mit kaltem Wasser und saugt stark ab. I)as Auswaschen geschieht so lange, bis das Filtrat mit verdiunnter Essigsäure keinen Niederschlag mehr gibt. Das Wassel darf mit dem Ferment nicht lange in Beriihrung sein. weil es sonst aufquillt und das Filter verstopft: deshall gibt man immer nur kleine P'ortionen Wasser zu mud läßt diese vollständig absangen, bis man neues zufügt. Damn trocknet man das Ferment mit Alkohol und Ẍther. Zum Schlusse wird das Ferment noch durchgesieht. Was Ferment ist seines proteolytischen Anteiles anf diese Weise fast röllig beraubt und ist. als Lipase betrachtet, haltbarer und wirksamer als vor dem Auswaschen mit Wasser. Diese Lipase ist absolut unlöslich, es ist also nur möglich, mit dufschwemmungen des P'ulvers zu arbeiten, während das Trypsin glatt in Lösung gelıt uncl als völlig klare Lösung rerwendet werden kann.

$\left.{ }^{1}\right)$ i. Wittich, Ċber eine nene Methode zur Darstellung künstlieher Verdanungsflüssigkeiten. P'flügcrs Archir. Bd. 2. S. 193 (1869).

$\Rightarrow$ Potterin, Comptes rendus. T. 137. p. 378 (1904).

3) Dietz, Uber eine unkehrbare Fermentreaktion im heterogenen Srstem. Zeitschr. f. physiol. Chem. Bd. 52. S. 286 (1907). 


\section{Darstellung des Labfermentes}

uach Hammarsten.

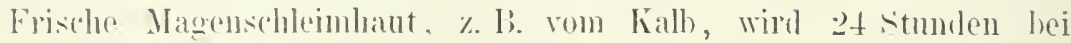

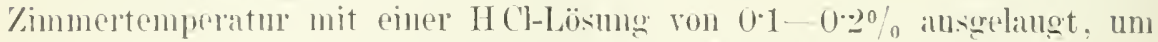
das \%onogen des Fermentes gleichzeitien in Ferment mmznwandeln, dam genau neutralisiert mol filtriert. Un ein festes Labpoijparat zu bekommen, kamm man diese Lösmg mit Alkohol fällen. ler Niedersohlag ist zu einem klemen 'Teil wieder in Wasser löslich mod zeigt wioder Labwirkmug. Jedes

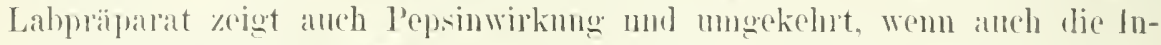
tensität dieser beiden Wirkmoren nicht immer palrallel zu gehen braucht.

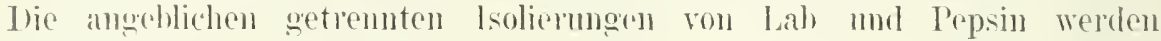
hestrittell.

Die gehränchlichsten Fermente sind meist in guter Form im Handel erhätlich. Sach meinen Erfahrmugen kamm ich folgende Präparate empfollen:

l'epsin. Das l'epsin der l'harmakopöie ist gut wilksam: mall beachte, dab es zur Herstollumg des gesetzlich vorgeschriebenen Titers mit entsprechemdan Mangen Zucker, meist Milduzneker, verrliimnt ist, was die Hanptmasce dieses Priparates ansmacht. Ein P'epsin, whehes frei ron Kohlehydratbemengungen ist, ist als Pepsin. purissim. non Grïbler an bozichen.

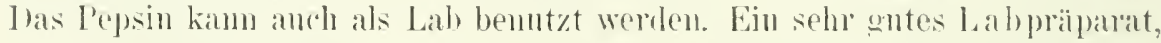
wohl aus hiblbermagen, ist vou Grübler erhältheh. I)aselhst ist auch lliastase, ferner steapsinsolution, ejue Lipase. zu hekommen. Vou kïuflichem Invertin möchte ioh abraten. Als lipase sind hesombers zu runpfehlen entölte Ricinussamen, zn beziehen in Form ciner plastischen Emulsion ron der Chemischen Fabrik anf Iktien. Charlottembum.

'Typsin. Das beste l'räparat ist Pancreatium absolutum der Mktien-

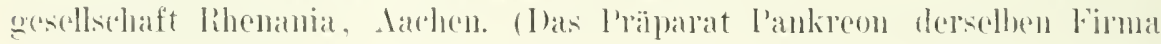
ist tamminhaltie! ')

\section{Die Dialyse.}

Man elhiblt anf die oben geschilderte Weise Extrakte, welche auber dem Ferment noch zahlreiche andere Substanzen enthalten. Mitmuter geniigt ein Fxtrakt in diesem /ustande den gestellten Anfordermen. Will man weiter reingen. so kam man zunähehst von der Eigenschaft der Fermente Gebranch matchen, bei der lialyse dureh tierische Membramen nicht zu diffmudieren. Als Ilalysiermembrane möchte ich die sogenanuten .Fischblasenkondome“ des Handels vor allen anderen empfehlen. Es sind getrockncte Bhlindlaime von

${ }^{1}$ ) Nenerdings fahriziert die Berliner Falrik organotherapentischer I'räparate Dr. Fresend und Dr. Redlich, Berlin XW.. ein gutes Trypsinpräparat, welehes in Wassel restlos böslich ist. In Wasser gibt es eine leicht opaleszente Lösung, die durch etwas Sola ganz klar wird. 
Schafen. (Line empfehlenswerte Marke ist als ... Nr. f" von Hermann lieinhold, Berlin, Bernburgerstr. 14 zu beziehen.) Sie werden einfach auf einem Glasstab aufgespießt (Fig. (i) nnd wie nebenstehend in cin Glasgefäß eingehängt. Die Füllung geschieht ann schonendsten folgendermaben. Man giefo z.1nichst $20-30 \mathrm{~cm}^{3}$ der lösung in den schlauch und fuille lamm aufien destilliertes Wasser so hoch auf, daf es das innere Nivean ïberragt. Dann fiille man innen wieder eine schicht von 5 cm Höhe auf, gielie anfen Wasicer entsprechend nach und so fort. Man fülle die sichläuche nicht mehr als halb voll und ïberzeuge sich nach der Füllung, dafie sicht schliefien. Das Anfenwasser wird tiglich 2-3mal ernenert, indem der Schlanch fuir kurze Zeit herausgehoben wird. Die Möglichkeit des Verschlusses mud mehr Requenlichkeit hietet mehenstehender kleiner Ipparat (Fin. 7), hei

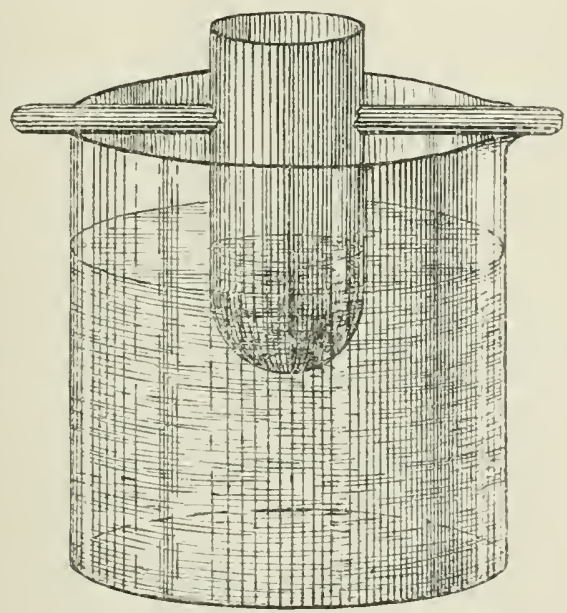

Fig. 6.

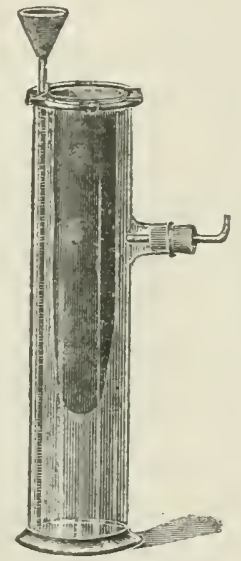

Fig. 7 .

dem man das Aubenwasser, wenn man will, durch ständiges Tropfen zirkulieren lassen kann. In allgemeinen diirften die rohen Fermentpräparate so salzarm sein, daß die Dialyse gegen im ganzen $t$ omal gewechseltes destilliertes Wasser in Lanfe von 2 - : Tagen allen Anspriichen freniuge leistet. Man gebe in die Fermentlösung und in das Wasser etwas Toluol. Ton komplizierteren Iialysiervorrichtungen kam man für diese Zwecke absehen.

Ein weiterer Anspruch auf Peinigung der Fermentlösung wird dahin gehen, auch die nicht dialysierenden Stoffe vom eigentlichen Ferment zu tremen, also vor allem Eiweibstoffe. Eine allgemeine Methode gibt es hierfür nicht und nur in einigen Fällen gelingt eine teilweise Entfernung des Eiweiljes, so beim Trypsin in gewissem Malje dadurch. daf das Pankreas der Selbstrerdanmo für längere Zeit unterzogen wird. In einigen wenigen Fällen ist es möglich, durch geeignete Adsorbenzien die Lösung von stö- 
lenden Kolloiden zn befreien. wenn es nämlich ein Adsorbens giht, das Eiwcib wohl, aber nicht das Ferment adsolbiert. So kam mall Hefeinvertin durch schiitteln mit Kaolin olme Verlust reinigen, loch ist das ein dusnahmefall. Mlle Methoden. die sonst auf dem ...Mitreiben* der firmente

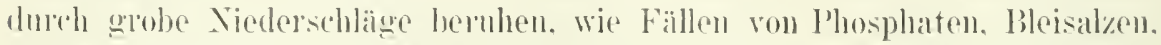
laben eigentlich noch nicht Biirorerecht in eince exakten Methodologie der Fermentreinigmo, so interessante liesultate in rein sachlicher Ieziehmog sice galiefert haben.

\section{Allgemeines über die Aufbewahrung der Fermentpräparate.}

Im trockenen \%ustande sind die Fermentpü̈latrate dulehans halthats.

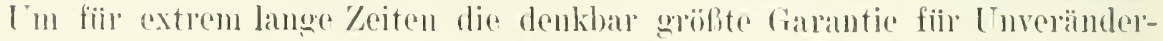

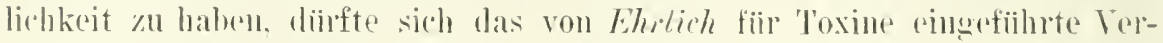

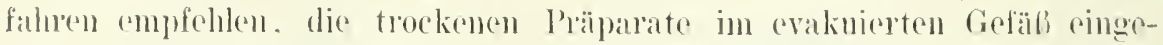
sehmolzen und dancend vor Lieht geschiitzt an einem kiihlen (orte anfzuhewahnen. liir gewöhnliche /wecke verbürot jedoch die einfache trockenc Aufberahrung Unveränderlichkeit fiur lange \%eit.

In Losmugen ist die Haltharkeit viel beschrinkter. Immerhin lassen sich, wrun die mus selten erforderliche wirklich absolute I nveränderlichkeit im höcdsten Simm nicht anestrebt wirl, die meisten liermentlösungen mindestens fiir viele Tage, manche sogar fïr einige Wochen moter /usatz der ondele zu besprechenden Inesinfektionsmittel in Eisschrank anfbewahnen. Man mul dann mur darauf achten, dab die Fermente eine bestimute lieaktion

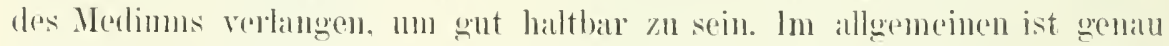
nentrale Reaktion das beste. Bei den meisten pflanzlichen l'ermenten ist aine spur sanrel lieaktion ehel als alkalische lieaktion elwiunscht: efwa

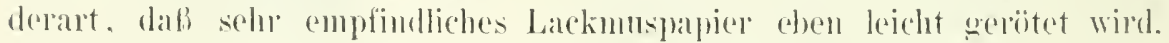
wie es das destillierte Wasser des Laboratorimms gewöhmlich von selbst tut. Von tierischen Fermenten scheint das Lab besonders empfindlich zn sein

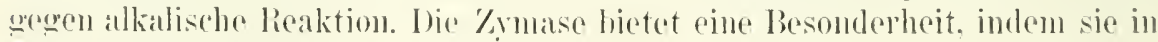
Form des Hefeprofisiftes ïberhaupt nicht zu konservieren ist und sofort zum Virsuch benutzt werden muli. Das bemht nach A. Harden und W. Yomm") daranf, dali das Coenzym so besonders empfindlieh ist, während die eigentliche bymase sich relativ gut hält. Kommet es darauf an, die denkbar

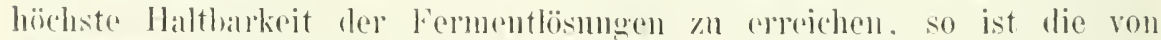
Morgenroth $\left.{ }^{2}\right)$ fiil das Lab angegebene Methode zu empfehlen. Sie ist fiil viele formente und Toxine hranchbar.

Fine abgewogene Menge des festen Präparates wird mit einer Vischung von Cilyzerin und $10 \%$ iger lochsalzlösung (fiir gewöhnlich kamm man statt

1) A. Horden und W: Young, The alcoholic ferment of yeast juice. Journ. of Physiol. Vol. 32. Nr.1 (1906); P'roe. Roy. Soe. Vol. 77 B, p. 405 u. Vol. 78, p. 368 (1906).

2) Korgemoth, Ưher den Antikörper des Labenzyms. Zentralbl. f. Bakteriol. Bd. o․ S. 349 (1899) und: Zur henutnis der Lahenzyme und ihrer Intikörper. Zentralbl. f. Bakteriol. Bl. 느. S. 7உ1 (1900). 
der Kochsalzlïsung anch Wasser nehmen) zu steichen Teilen versetzt, einen

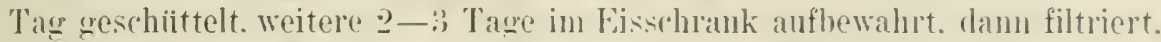
in kleine. braune Fläschehen eingefuillt und der Korken nit P'araffin oredichtet. Diese stammlïsmon sind auf Lis aufbewalnt anferordentlich halthar: je konzentricrter', um so besser.

Wemn man sich ats einem trockenen Fermentpriparat an verschicdenen 'Jagen exakt vergleichbare Lösungen fü quantitative hwecke herstellen will, so beachte man. dali viele festen Fermentpräparate zum überwiegenden 'Teile aus wasserunlöslichen Verumreinigumgen bestehen. wolche das gesante. in ihnen enthaltene Ferment nur selı allmählich an das Wasser abgeben. Man bekommt daher bei nicht restlos löslichen Prïparaten niemals Lösungen von völlig gleichartiger Zusammensetzung. wenn man das l'ulver nicht mindestens 24 stmolen mit dem Wasser in Berihlung läßt. Auch miissen die äuferen Redingungen. namentlich die Tenperatur während des Auslangens des Präparates einigermalen koustant gehalten werden. Es ist nämlich ein festes Fermentpulver durch eimmalige Auslaugung niemals zu erschöpfen, sondern es scheint sich ein fieichgewicht herzustellen, welches von der Temperatur abhängig ist. Will man also z. B. eine jederzeit reproduzierbare Trypsinlösumg bereiten. so rate ich zu folgendem Verfahren. Man hält sich eine möglichst große Menge eines käuflichen 'Trypsinprïparates vorrätig, entnimmt einen Tag vor Anstellung (ler cigentlichen Versuche 0.09 g desselhen und löst es in 20 $\mathrm{cm}^{3}$ Wrasser, indem man es während der ersten 2 Stunden öfter umschüttelt und damn bis zumn nächsten Tag in Eisschrank stehen läft. Am nächsten Tage wird die Lösung filtriert, die ersten Tropfen des Filtrates werden rerworfen, um eine etwaige Adsorptionsaffinität des Filtrierpapieres zum Ferment erst abzusättigen. I)iese Lösung brauche man nur für eimen, höchstens für zwei Versuchstage. Im allgemeinen diufte eine solche Iethode der Aufbewahrumg in Lösung für lïngele \%eit vorzuziehen sein. Energisches Schuitteln von Fermenten im schuttelapparat ist dagegen zu vermeiden. weil viele Fermente darlurch erheblich an Wirksankeit einbiben. So berichten Alderhalden und Guggenheim '), daf Tyrosinase sowie dic peptolytischen Fermente de: Hefeprelsaftes durch 48 stiindiges und auch kiirzer dauerndes schuitteln ihre Wirksamkeit einhiißen. Es tritt bei letzterem dabei eine Tribung ein. Auch sonst wird ein solches Torkommen berichtet. Wabrscheinlich beruht diese Erscheinung auf derselben Lrsache, aus der eine Eireiliosung beim starken schütteln koaguliert: es bilden sich fortwährend neue oberflächen, an denen eine irreversible .Häutchenbildung." stattfindet. Es wäre das also eine auf Adsorption an der (J)erflärhe beruhende Verändermo. Sach Signe und Sigral Schmidt-_ielsen $\left.{ }^{2}\right)$ ist Lablösung gegen schiitteln ganz

1) E. Abrtrhalden und Y. Guggenheim, Versnche ïber die Wirkung der Trımsinase ete. Zeitschr. f. physiol. Chemie. Bd. 5t. S. 3.52 (1908).

$\left.{ }^{2}\right)$ signe und rigral sichmidt-Yielsen. Zur Kenntnis der ..Sehüttelinaktirierung" des Lahs. Zeitschr. f. physiol. Chemie. Bd. 60. S. 4 206 (1909). 
besonders empfindlich, so dah es sthon in wenigen Minuten weitgehend zerstort werlen kamu.

bei rostlos lïslichen Fermentpräparaten lassen sich rergleichbaro

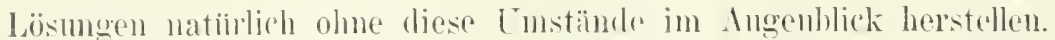

Ton l)esinfektionsmitteln, wolde die Fermente in allgemeinen nicht solädigen mud ihe llirkung nicht merklich hemmen. wirl man mit foluemler Auswalil stets auskommen:

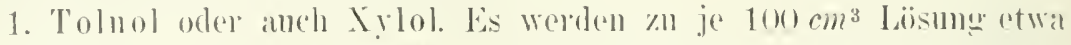

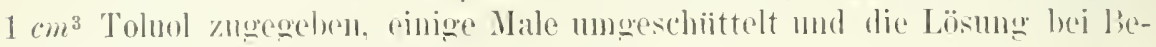
larf mit l'ipettru entrommen.

2. ('hlolofolm, weleles oft elemso wirksam mol fïr die spätrere Entmahme beynemere ist. Man nehme anf $10\left(0 \mathrm{~cm}^{3}\right.$ Flissigkeit uicht mehr als atwa $1 \mathrm{~cm}^{3}$ (hloroform, schiittle die. Fliissigleit damit gut dumelo und verschlielie dir Flasede sehr wnt, weil somst die obelen Sehichten an Chloro-

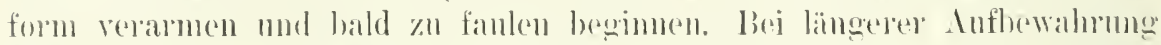

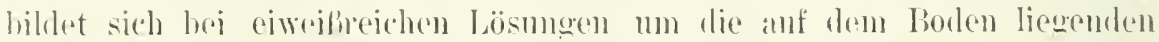

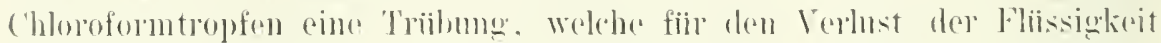

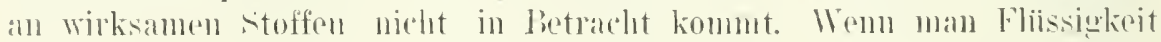

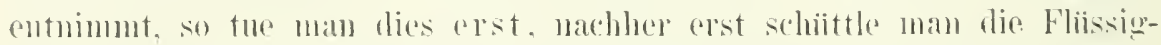

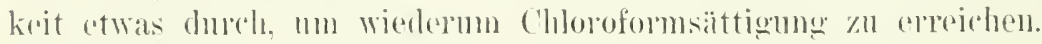

:). Thymol, welloes man in fester Folm. etwas zerrieben. in die Fliissigkeit eintränt.

Ther dir Mrothode des Einfrierens liexent hei Fermentlösungen allseitige Erfahrungen noch nicht vol. \%ur Inflowalumug vou Phutserum. Exsudaten 1 . del. ist dies die ideale Methode. As Ipparate sind im fiebrauch der Eiskasten .. Frigo" von Lautenschläger und aine von mir ange-

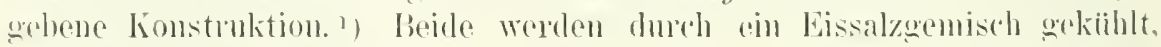
welches täglich einmal aruenert wird. Während aber die Fiweibiörper des s'ormos, auch wem sie otwa 1 Jahr lang eingeforen waren, nach dem Inftanen wieler watt in Lösmy gehen, woben Fistrakte ans (towanen und

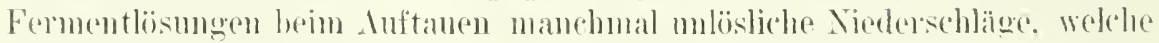
wohl einen Teil del wirksinnen Fermente anthalten diirftert.

Mit ainer dieser Methoden wird man in allen Fïllen anskommen.

\section{Die Klärung von Fermentlösungen.}

Mitunter ist es notwendie. amnihernd klare Fermentlisungen zu baben. ()ft macht das keine schwierigkeit uml kam durch einfaches Filtrieren dureh ein gewöhnliches Filter oder Amoh eine Chamberlandkerze orreicht werden. Nutzt das nichts, so hilft in aimzelnen Fällen cin geeignetes Alsomptionsmittel. nämlich dam. wemn es gelingt, ein Adsorptionsuntel atusfindig zo machen, welehes das Ferment nicht mitreilit. In manchen

1) Zu hezichen von len Tereingten Fabriken für Laboratoriumshedarf, Berlin X. Näheres darïher siehe in dem Kapitel .. Aetholen der Inmunitätsorschung". 
Fällen gelingt das vollkommen. Invertinlösungen kann man dureh beliebign weit getriebenen Znsat\%, von Kandin, wenn erforderlich, vollkommen klïren, ohne Fermentverlust. Auch stärkere l'epsinlösungen werden durch kleine Iengen Kirolin (\% li. $1 \mathrm{~g}$ auf $50 \mathrm{~cm}^{3}$ lliissigkeit) nicht stark al)geschwäicht. Die Jenge des notwendigen Minimums an liaolin läbit sich allemein nicht angeben; je konzentrierter die lïsung an Ferment ist. um so geringer ist der relative Verlust durch die Adsorption. Die meisten anderen Fermente werden bei einer derartigen Klämng erheblich beeinträchtigt. Dureh sehr kleine Ilengen Kaolin oder Tierkohle läßt sich aber oft ein Vorteil für den yualitativen Fermentnachweis doch gewinnen. indem bei klaren lösungen der Nachweis einer kleineren Formentmenge oft sicherer ist als der Nachweis gröferer Mengen in tribler Lijsung.

I) Fälle. wo es auf besondere Klarheit der Fermentlösung ankommt. sind: der polarimetrische Nachweis der Fermentwirkung (Invertin peptoJytische Fermente) und die Aufhellungsreaktionen (Ricin-, Edestin- und Kaseimmethode bei proteolytischen Fermenten). 


\section{B. Methoden zur qualitativen und quantitativen Ver- folgung der Fermentwirking.}

Von Leonor Michaelis, lierlin.

\section{Der qualitative Nachweis der gebräuchlicheren Fermente.}

Die Fermente lassen sich allein mit Hilfe der von ihnen bewirkten sperifischen Einwirkmo auf das angepalite substrat nachweisen. Li hanWalt sich also nur dartm, für jedes ferment ein pratischen Zwecken geniigendes substrat zn finden mud die Bedingungen der Fermentwirkung. wir 'lemperaturoptimum, lieaktionsoptimum, zu kemnen.

\section{Kohlehydratspaltende Fermente.}

Das amylolytische Ferment im Speichel oder in anderen Kïrperfliissigkeiten sowie die pflanzliche Diastase werden in folgender Weise nachgewiesen. Eine etwa 1\% ige Lïsmg von stärke, welehe durch Kochen herwestellt ist. wirl hei (angenähert) neutraler lieaktion mit etwas von der Fermentlisume versetzt. Zimmertemperatur reicht zur Einleitung der Reaktion aus, allenfalls kimn man die Reaktion bei $37^{0}$ vornehmen, um sie zn beschleunigen. Entuimmt man in Abständen von einigen Mlinten P'roben. so fürben sie sich, mit einigen 'Tropfen 5ofach recdünnter Lugolsches liosung versetyt, nicht mehr rein blau, sondern der lieihe nach die znnächst entnommenen l'moben violett. die späteren rot, welbbram, schlienlich gar nicht mehr (d. h. die hellgellbe Eigenfarbe des Jods bleilot bestehen). Gleichzeitig arhält man bei Anstellmog der Trommorschen l'robe lieduktion nilch kurzem, (inmaligem Aufkochern.

Invertase wird in folgender Weise narogewiesen. I be Fermentlïsmo wird hei nentraler, lieber aber otwas samer als alkaliseher lieaktion mit

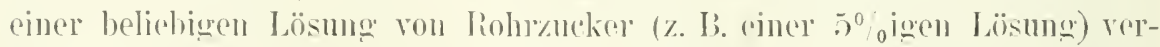
sotzt. Es oreniignt dazn der käufliche Würfelzucker. Beobaclutet man die Inehmo dieser Lösme im Polarisationsapparat gleich nath der Ansetzung. so kamn man nach Verlauf von oinigen Vimuten oder bei selur weringen Fer-

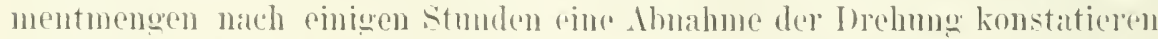
infolge der Bildung ron Invertzucker. Ilis I)rehumg wird bei geriügend 
langer Einwirkung sowar eine Linksderhung, in Maximun etwa dren dritten 'Teil der urspringlichen liechtshlehumer nach links. Fileichocition mit drem Begimn der Inrehumgänderungr libt sich mit Hilfo der Trommerschen l'robe lieduktion nachweisen. Bei langem linchen und langem Stehen in der alkalischen Lösung liefert der Tiohrzucker spontan geringe Menern rednzieleuden /uckers: mau koche daher nur kur\% und beachte nur kröftige lieduktionswirkungen.

Zymase lälit sich rein ynalitativ sehr anfach in folgender Weise erkennen. Gin .. Gï̈rungrsöhrehen* wird mit einer Mischung voun 1 T'oil 5) $1 \%$ igrer Tiohr- oder Traubenzuckerlösung und 2 Teilen der Fermentlösung gefïllt (Fig. s), derart, dab der lange schenkel ohne Lufthlase ist. Tach Aufenthalt ron Minuten oder wenigen stumden bei $20-50^{\circ} \mathrm{C}$ fiilt sich der liingere schenkel des Gäimugsoöhrchens mit Kohlensäuregas. Man heachte, daß nur ganz frische l'relsäfte gärungskräftig sind, ältere. inaktive säfte aher durch Zusatz von frischem, gekochtem Prebsaft reaktiviert werden können.

Emulsin erkemnt man leicht daran, laf es in einel wässeligen Aufschwemmung von Amrgedalin Blausäuregeruch auftreten läßt.

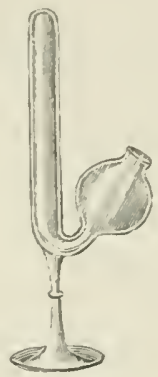

Fig. 8.

\section{Proteolytische Fermente.}

Pepsin läBt sich in rerschiedener Teise arkemen. Ich nemne folgende Methoden, wohei die frïher vielfach rerwendete Methode der ...Mettschen Röhrchen", mit coaguliertem Eiweif gefïllte Crlaskapillaren als iiberholt nicht näher beschriehen werden soll:

a) Man hält sich Fibrinflocken ans Rinderblut vorrätig. Sie rerden liergestellt, indem Blutgerinnsel solange in fließendem Wasser grewaschen werden. bis die Blntfarbe verschwunden ist. Wenn nötig, zerkleinere man die Gerinnsel in stiicke ron etwa Bohnengröfe. Damn werden sie in rlyzerin aufbewahrt. sie halten sich sehr lange. Tnmittelbar ror dem fiebrauche wasche man einige Flocken in flieljendem Masser, bis das Glyzerin ainigermaßen entfernt ist. Man rersetze nun eine solche Fibrinflocke mit der zu priffenden Fermentlösung und grebe soviel stark verdinnter Salzsäure hinzu, dali die Lösung Kongopapier eben deutlich blïut. Im allgemeinen wird dazu soviel H Cl nötig sein. daf die Lïsung eine ${ }^{1}{ }_{30}$ normale H Cl-Lösung darstellen wiirde. Eine Kontrolle enthält dieselbe Flissigkeitsmenge und dieselbe HCl-1Jenge, aber kein Ferment. In der Kontrolle tritt nu eine Verquellung ein. in der Fermentprobe im Laufe einiger Stunden eine vollkommene Lösung. Beste Temperatur etwa : $7 \%$. Desinfektionsmittel ist iiberfluissig:

b) Nachweis mittelst Gelatine. Eime durch Erwärmen hergestellte Lösung von 10\% gewöhnlicher Gelatine in Wasser wird in noch flüssigem Zustande in kleine Reagenzgläschen gefüllt, so daf sie nur etwa ein Drittel 
des Cilases eimnimmt. Diese Gläser lasse man arstarren. Die in ähnlicher Weise wie oben angesinente Fermentlisung wird anf die Gelatine geschichtet nul nach einigen Stunden oder an nächsten Tage konstatiert. dab die frelatine gan\% odler zum l'eil verflüssigt ist. Man lasse diese l'ro-

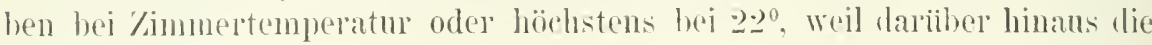
Gelatine selumilzt.

a) Den beschricbenen Methorlen bei weitem rorzuziehen ist die Ri-

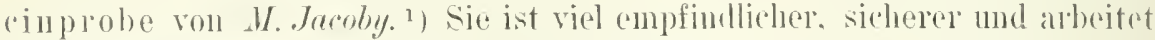
erheblich sohneller. Sie bornht daranf. dabi ein in den Ricinussanen entbaltence Giweibkörper hei der fiir die Pepsinverdaume erforterlichen sancen lieaktion muloslich ist, und zwat anlierordentlich foine Flocken bildet, die durch die Wirkung des l'epsins rasch greböt werden. Dieser Eiweilikiirper luat iblorgens nichts anderes mit dem sonst als.. Rizin" henannten Toxin zu tun, als dab er anch in den Ricinussamen vorkommt. Deshalb

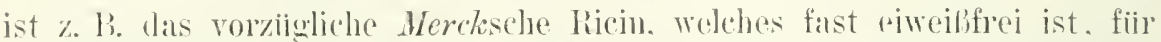
diese I'robe nicht zu gehratehen. Man beriche .. Iicin nach Jacoby" von den Chemisehen Werken auf Aktien, C'bartottenburo. Man gebe go dieses Pulvers in $50 \mathrm{~cm}^{3} 3^{0} /$ ige Na C'l-Lösung, schiittle einjge Vinuten stark durch. stelle das Gemisch auf eine Stunde in ciu lawwimes Wasserbad von ca. 40 " und filtriere dann ab. Von dem völlig klaren Filtrat wird je I Volnmteil mit $1 / 3$ bis $1 / 2$ Volumteil $1 / 10$ normaler II (1-lösung versetzt. Es entsteht eine Trubung, die nach einger \%eit zur bildums sehr feiner Florken fuilıt. Man grebe die salzsäure in Portionen hinzu. solange, bis eine kräftige Tribung entsteht. In C̈berschub der säure löst sich die Tribung wieder. Jas mub rermieden werden. I)ieses Reagens hiilt sich mehrere Tage. Mau versetze z. B. $5 \mathrm{~cm}^{3}$ der gut durchgeschiittelten licinaufschwemmung mit $1 \mathrm{~cm}^{3}$ der Pepsinlösung. Schon bei Zimmertemperatur, norh schneller im Wasserbade von $37^{0}$ tritt eine Aufhelhng und bald rollständige Kiärung der Fluissigkeit ein. Sunontan findet dies niemals staft, wofern man nicht

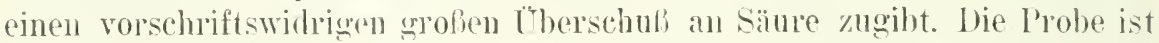
äuberst empfindlich: es lassen sich mit ihr dic geringsten Spuren vou Pepsin nachweisen. sie ist eine wirkliche Bereicherung dor Methodik.

Der rorzug dieser Methode besteht noch dazu darin, dath das Fortschreiten der lieaktion ohne /ufigung eines Indikators erkannt werden kann.

d) Die Edestinmethode nach Fuld und Levison. ${ }^{2}$ ) Edestin ist numekehrt wie Ricin in saurer Lösumg löslich, in schwach alkalischer mü̈slich. Man kann es daher aus der angesinterten Lösung durch passende Nlialimengen ausfällen. Sicherer gelingt die Ausfällung aus der samren Lösung durch Chlor-

$\left.{ }^{1}\right)$ H. Jacoby, Beziehungen zwisehen Terdaumgs- nnd Lahwirkung. Binchem. Zeitsclır. Bi. 1. S. 53 (1906). Ferner: E. Solms, Cber eine nene Methode der ynantitativen Pepsinhestimmung und ihre klinische Verwendmig. Zeitschr. f. klin. Med. Bd.64. S. 159 (1907).

2) E. Fuld und Louis A. Lerison, Die Pepsinhestimmung mittelst Edestinprolie. Biochem. Zeitschr. Bl. 6. S. 473 (1907). 
natrimu in Substan\%. Die Dethoule gestaltet sich themnach folgendermalien: Van stelle sich eine Lösung von 1 juro mille Edestin in 1/30 Nolmal-Sal\%s̈̈nre her, im ibbrigen verfähnt man wie bei der liscinnethode. Yachdem das

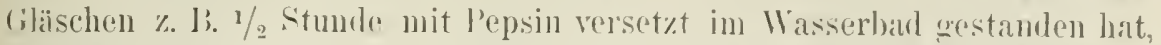
rersetyt man eine entnommene I'robe mit rotwa ('hlornatrium in substanz. Voch vorbandenes Edestin wirl ausgefält. die I'rpsinwirkung änliert sich also in dem Anshleiben der (INit-Fällung.

Labferment wird in folgender Weise nachgewiesen: Ian verdinne wewiohnliche rohe orler gekochte Miloh mit a Teilen Wasser und versetze

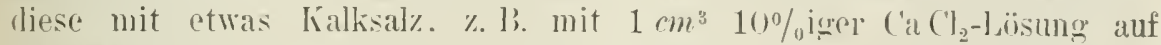
$100 \mathrm{~cm}^{3}$ verdünnter Vilch oder $20 \mathrm{~cm}^{3} \quad 5 \%$ iger Lösumg von (alciumatectat auf $100 \mathrm{~cm}^{3}$ Vilchverdimnung. Fs darf durch den Kalkzusat\% keine Ausfüllung entstehen. Ifie Fermentlösung wird flurch sorla bzw. verdiunnte Essigsäure. wem nötig, anfs genaneste gegen Lakmuspapier neutralisicrt. Bringt man die Vilchverdiunnung mit der Fermentlïsung znsammen, so tritt mach Vinuten, bei sehr greringem Fermentgehalt virlleicht erst nach einer Stunde oder später plötzlich cine Ausfällung des Kascins ein. welche das Milchfett mitieibt und die Flüssigkeit klärt. Ist man im Zweifel, ob eine Iusfällung demnoch durch eine geringe sämrewirkung znstande gekommen ist. so wiederholt man den Versuch mit rorher gekochter Fermentlissung. I) Fällung mub alidann ausbleiben.

Trypsin läbt sicln in folgender Weise nachweisen:

a) Erstens kann nan die Verdaung einer Fibrinflocke zum Nachweis benutzen. I)ie lieaktion mulf leicht alkalisch sein, und das hat den C'belstand, dali dalrei. namentlich bei älteren Fibrinflocken, leicht spontan starke Verquelluncen eintreten können. Ich rate daher, die Fibrinflockenmethode als solche nicht anzuremblen. aulier in der ron Jacoly trmpfohlenen Form (s. das Kapitel ..Fermente des intermediären Stoffwechscls" von 1. Jacoby) in Kombination mit (ielatine.

b) Fine vorziigliche und schmelle Methode ist die haseinmethode, welche fast gleichzeitig von Gross ${ }^{1}$ ), Fuld ${ }^{2}$ ) und mir ${ }^{3}$ ) beschrieben wurde. Irh führe sie folgendermalien als: Es werden $0.1 \mathrm{~g}$ Kasein (nach Hammarsten, berogen von Kahlbaum) in wenig Wasser mit 10 Tropfen $10 \%$ iger Sorlalïsung unter Erwärmen gelöst und mit destilliertem Wasser auf $200 \mathrm{~cm}^{3}$ aufgefiillt. Hiervon werden etwa $5 \mathrm{~cm}^{3}$ mit $1 \mathrm{~cm}^{3}$ der Fermentlösung. Welche möglichst klar sein mub, versetzt, ins Wasserbad ron $37^{0}$ gestellt und ron 5 zu 5 Xinuten Prö̈bchen mit einer I'ipette entnommen. Diese werden mit Essigsäure versetzt. Fülit kein Kasein mehr ans, so hat das 'Trypsin gewirkt. Es kommt nun darauf an, dali man die richtige .Ienge Essigsiure

1) Gross. Die Wirksamkeit des Trypsins und rine einfache Methode zu ihrer Bestimmung. Areh. f. exper. I'athol. Bı. 58. S. 157 (1908).

2) E. Fild, Die Wirksamkeit des Trypsins und eine einfache Methode zu ihrer Bestimmung. Arch. f. exper. Pathol. Bd. 58. S. 468 (1908).

$\left.{ }^{3}\right)$ L. Wicharlis und M. Ehrenreich, Die Adsorptionsanalyse der Fermente. Biochem. Zeitschr. Bd. 10. S. 283 (1908). 


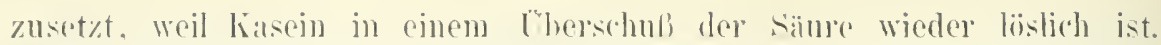

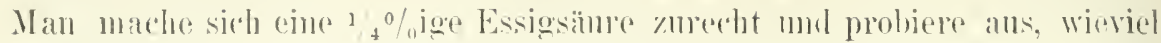
Tropfen mall zu dem finch bereiteten Kasein-Fermentgemisch, in dem

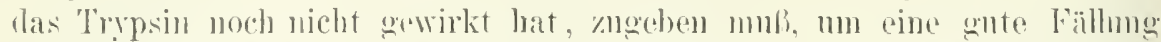

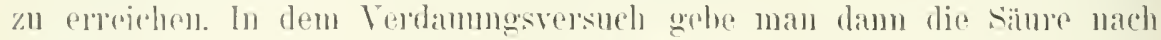

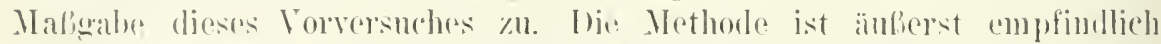
und gelut so rasch, dali \%usat\% ejues Desinfektionsmittels nicht in Finge

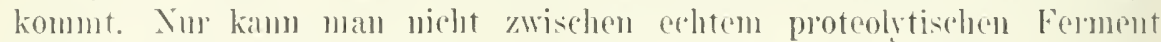

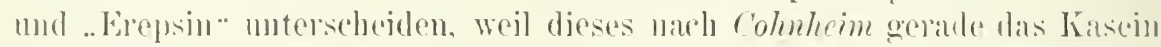

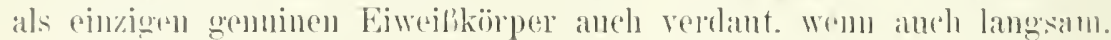

(c) Von diesen Fohler frei ist die serenuplattenumethode vou

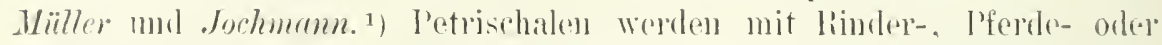
Hammelserum etwa ${ }^{1 / 2} \mathrm{~cm}$ hoch gefiillt mol in ainem Thermostaton hei for trehalten, bis sio vollkommen erstant sind. Statt des Thormostaten kann man einen einfachen Trockensuhank anf ra. $70^{\circ}$ einstellen. bio Fer-

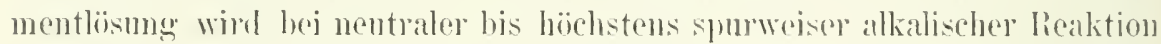
in einzelnen 'Tropfen anf die l'latte gobracht und in dinem Thermostaten

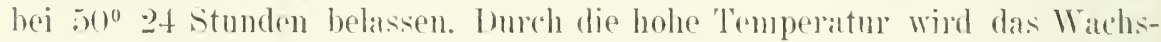

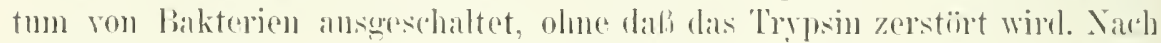

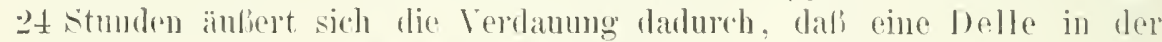
betupften Stello del l'latte antstanden ist.

d) 'loppsin kamm auch daran erkannt werden, dali es hej längerel

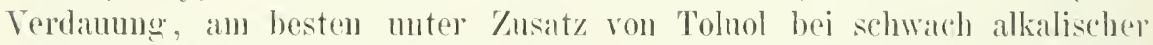
Reaktion jeden beliebigen Fiweibkïrpes, der Tyrosin enthält, mutes Bildung von leicht erkembaren 'Tyosinkristallen spaltet. Man kiull \%. B. rine $5^{0}$ oige Jïsme von Witte-l'epton benutzen.

Am besten geeimet simd mach E. Abderhalden mud A. Schittenhelm 2)

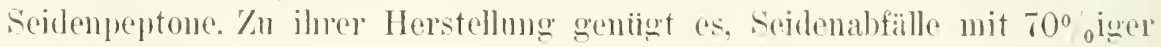
Sohwefelsäme in der Kälto zu hỵdrolysieren. Die Seidenpeptone sind nieht alle gleicenertig. Ins von den Autoren verwendete l'rïparat hatte ein Molekulargewicht vou fios. liste sich sehe leicht in Magensaft mol enthicht tro\%o Tyrosin. oft fiel Tyrosin hej der Verdammeg schom nach riner stumbe atus. biesa l'epton ervies sich als besonders vorteilhaft, mu die peptolytischen Fermente des mach Boldyreff" gewommenen Magensaftes fiir klinische /werke nachzuwcisen. Die Reaktion mub leicht alkaliseh sum. Del urobe Vorteil

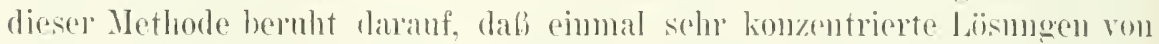

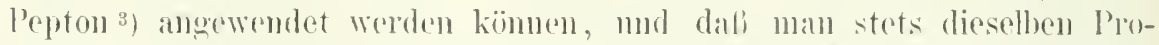
dukte zur Verfügmog hat. Ferner kamm dor Verlanf der Verdammo direkt

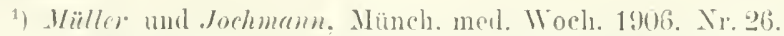

$\Rightarrow$ E. Abuterhalden und A. Schittohelm, Uber dis Vorkommen von peptolytiselien Fermenten im llageninhalte und iluren Nathweis. Zeitsehr. f. physiol. Chemie. Bd. ju. S. 230 (1909) und Uber den Xarhweis peptolytischer Fermente. Ehenda. Bd. 61. S. 421 $(1909)$.

3) l'epton "Tiorhe“, zu bezichen bei Hoffmann-La Roche of Cie., ('hem. Fabrik, (irenzach (Baden). 
durch Verfolgung der Trovinabsheidung kontrolliert werlen. Durch Filtrieren und Wägen des ahgeschiedenen Tyrosins oder Abzentrifugieren

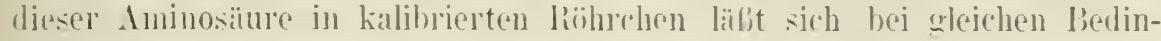
wnugrn die Vethode anch zu eines" "quantitativen gestalten.

e) Ferner kann man zum Xarhweis tryptischer Fernente auch die Spaltung areeigneter l'olypeptide narh E. Abderhalden benutzon. Inen Eintritt der spaltung erkennt man entweder durch das Auskristallisieren schwer liislicher Aminosïnren ${ }^{1}$ ) oder rlurch die Inrehungsinderung im I'olarisationsapparat. $\left.{ }^{2}\right)$

Für den ersten \%weck ist sehn geeignet das Gilycrl-l-tyrosin. Man rersctze $\%$ B. $5 \mathrm{~cm}^{3}$ der auf Ferment zu priffenden Lösung mit $0 \% 2$ g (ilycyl-l-trosin nud 2 Tropfen Tolnol. Nach mehrstindigen Aufenthalt im lirutschrank beginnt eine Tribung aufzutreten. die nach einiger Zeit zur Mscheidung der unter dem Mikroskop leicht erkenubaren liristalle von Tyrosin führt.

Für den zweiten \%weck kann man ebenfalls Glucrl-l-tyrosin verwenden oder besser d-Alanyl-glycin. welches keine unlöslichen P'rodukte liefert und klar gelöst hleibt. Yan versetze z. B. $15 \mathrm{~cm}^{3}$ der zu priifenden klaren Fliissirgkeit hei spurweise alkalischer Reaktion mit $1 \mathrm{~g}$ des Dipeptids. fülle die Vischung in ein Polarisationsrohr von geeigneten Dimensionen cin. lese die 1)rehung ab und halte es im Brutschrank bei :370. In geeigneten Intervallen, je nach dem Fermentgehalt in. Ininuten orler Stunden. lese man wieder ah und konstatiere die Drehungsïnderung.

Bekamtlich geht die heutige Auffassung dahin. in dem Trypsin ein Gemisch von Fermenten anzunehmen. und es gibt aulierdem Fermente im Darmsaft. in Hefeprefsäften und an anderen orten. welche im Cregensatz zum I'epsin die gemeinsame Eigenschaft haben. dab sie bej saurer lieaktion nicht oder schlechter wirken als bei alkalischer Reaktion. IIan kann die einzelnen Fermente, wo sie gemischt rorkommen. nicht tremen. IVan kann somit auch nur ron einem Nachweis der verschiedenen Wirkungen sprechen. Dis proteolytische Wirkung läßt sich am schnellsten durch die Iethode der Serumplatten nachweisen. wohei jedoch zu bedenken ist, daf die Empfindlichkeit dieser Methode nur mäßig grob ist, die Spaltung ron liasein ist nicht ganz auf eine Stufe damit zu setzen. weil sie, wenn anch schwach. auch von den ereptischen Fermenten gegeben werden soll ${ }^{3}$, weJche sonst nur die nicht mehr koagulablen Ëweilbö̈rper abbauen. Ler direkte Yachweis der Erepsinwirkung weschieht durch die Spaltung ron Peptonen bis

1) Literatur darïher in den einzelnen weiterhin zitierten Arbeiten ron Abderhaiden und Nitarbeitern.

2) E. Alderhalden und A. H. Kölker. Die Verwendung optisch-aktiver Polypeptide zur Prüfung der Wirksankeit proteolytischer Fermente. Zeitschr. f. physiol. Chem. Bd. j1. S. $29 \pm(1907)$.

3) ('ohnheim, Umwandlungen des Eireißes durch die Darmwant. Zeitschr. f. physiol. (bem. Bd. 33. ¿̇. 451 (1901): Weitere Vlitt. ïber Erepsin. Ibidem. Bd. 35. $13+(1903)$. 


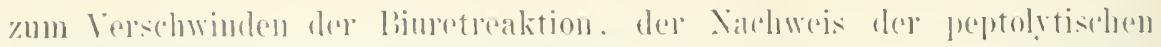

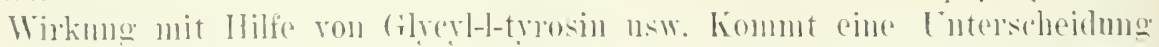

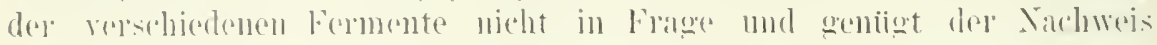

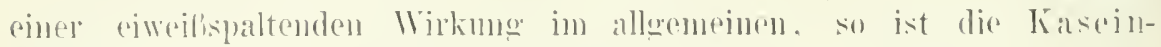

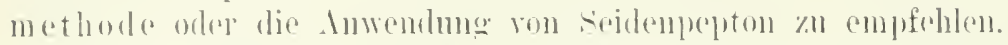

soll andrepseits festorstellt werlen. ol ain protenlytishes Ferment mit einem zweitru illentisch ist. so kamm man sich muter l'mständen mach

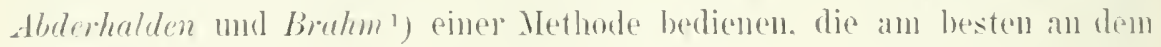

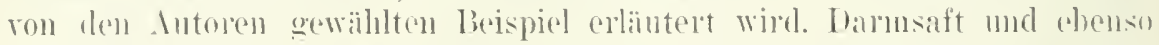

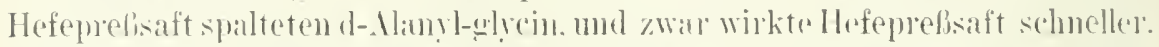

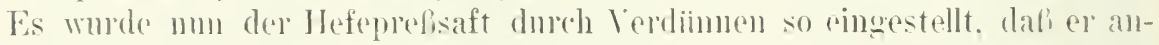

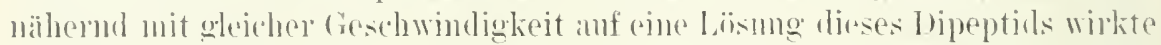
wie dop Darmsaft. Dann wurlen die so reloleichbar gemachten Fermentlösmoren in ihrer Wirkmog anf oin anderes substrat gepriift. und zwal auf Glyeyl-l-lencin. Es zeighte sich hier amäherndr rilejchhojt heider Forment-

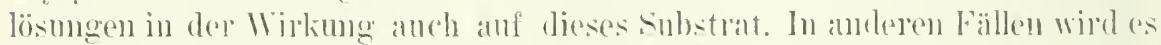
gewili möglich soin natelzuweisen, diu zwei fermentlösungen. die anf ain

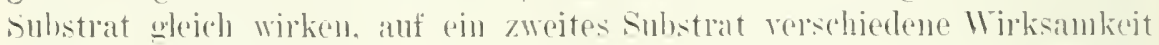
haben. In einem solehen Fall wird man die Idoutitat der bejden fermente sicher verucincul kömment.

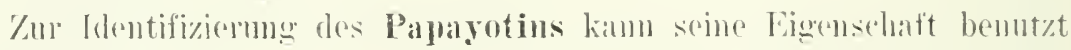

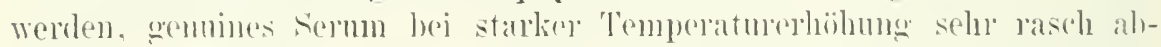

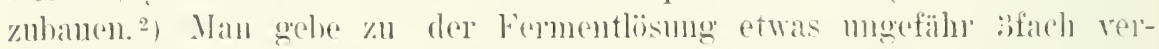

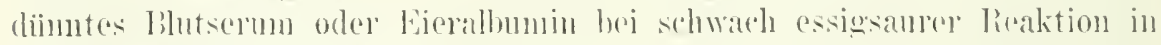
ein Leagrmylas, koche das wank sofolt langsan auf. filtriere von

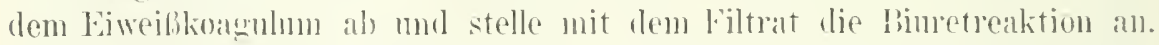
Bei Gegenwart rou l'apayotin giht das filtrat moch in starken Voreliinnumen ane selur intensive, rote biuretreaktion.

Lipase wird in der Weise natelgewiesen. dali man sie anf die binnlsion eines Neutralfettes wirken lälit mud dir butstehmo freier Fottsïme

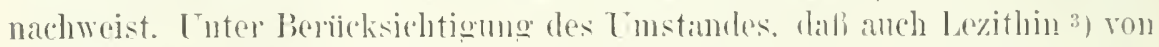
den Lipasen gespalten wirl, scheint mil dieses nim\% hesonders geeignet.

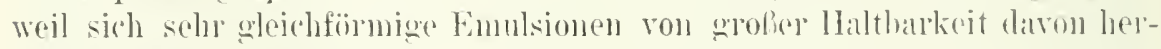
strllen lassen. Diese Emulsion wird bei den Xentralfetten daburell hergestellt, dak das fott mit den anderen Fliisigheiten rerroben wird. livin

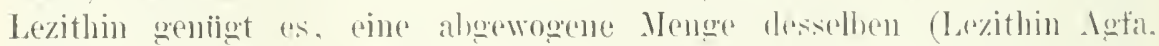

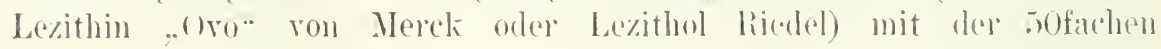

1) E. Abderhalden und C. Brahm, Zur lienuntis der fermentativen I'olypeptilspaltung. 11. Mlitteilung. Kcitschr. f. physiol. ( hem. Bal. 57. S. 34르 (1908).

") ('. Merenne, II. Bouton und E. Iozersti, Sur la digestion hrusque de lovalbumine et du sérum sanguin par la papä̈ne. Soe. de hiologie. T. 60. p. 309 (1906). Ferner: D. Tonescu. Uher rine eigenartige Verdaumg des llühner- mul Serumeiweiß dmeh l'apa:n. Biochem. Zeitschr. Bd. ‥ S. 17 (1907).

3) I'unl Mayer, Cher die spaltung der lipoiden Substanzen durch Lipase. Biochen. Zeitschr. Bd. 1. ร. 33 (19)(16). 


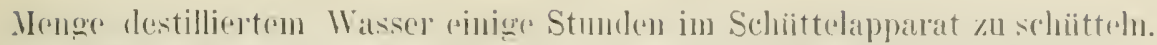

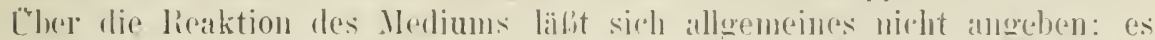
giht lipasen (pflanzlicher). wolche nur bei selur deutlich saurer lieation

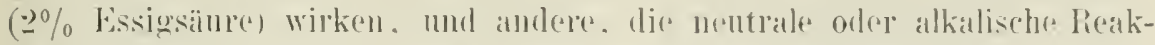
tion aforlern. Im \%weifelfalle set\% man dahel das lieaktionseremisch in

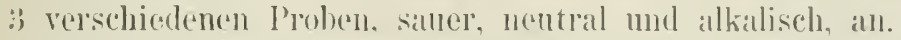

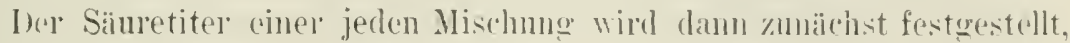
indem einc abgemessene I'robe mit oleichom Volumen absolutem Ilkohol versetzt wird, um die in Wassel unlöslichen Futtsiumen in Iösung zu

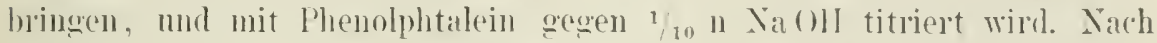
Ahlanf von stunden orlel 'Tagen wird an einer zweiten l'robe diese Titua-

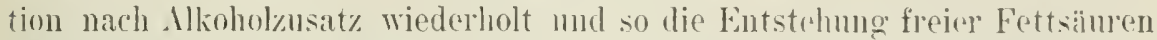
nachocwicsen. Man beachte. dafi rine ausbleibende Fermentwirlung unter Lmstänen durch \%usat\% von Mangansulfat in (rang gesetzt werden kann, welehes nach ('onnstein und Hoyer ${ }^{1}$ ) hei pflanzlichen Lipasen. als Aktirator wirkt. Jan nelme auf etwa $10 \mathrm{~cm}^{3}$ i)lemulsion $5 \mathrm{~cm}^{3}$ riner Lösung von Mns() (4:1000). Als Iesinfiziens verwenten Connstein und Hoyer ('hloralhydlet.

Ein Leispiel iiher die Mengenverhälntusse eines Lipasenachweises (nach

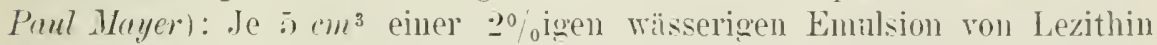
...gfa* werden mit $1 \mathrm{~cm}^{3}$... Steapsin* (Grïblev) in Reagensglas rersetzt, und je eine solche Probe is, 20 mul to Stunden im Brutscluank bei $37^{\circ}$ helassen, sowie eine Kortrolle ohne Sterpsin.

I anach werden die Prohen muter \%usatz vou reichlich $99 \cdot 66^{0}$ igem Alkohol guantitativ in ein liecherglas iblerefiihrt und mit $1 / 10$ Jormalnatronlange titriert, unter Anwendung einer methylalkoholischen Lösung von I'henolphtalein als Indikator. Es wird zunächst del säuretiter der Lösung ohne Ferment bestimmt, welcher ïbrigens im frischen Zustand mol nach dem Anfenthalt im Inutschrank del gleiche ist mol anf dem Fettsäuregehalt dos Lezithins mol des Ferments beruht. El beträgt fiil $5 \mathrm{c}^{3}$ der Lozithiuanfschwemmung \%. B. $0 \% 3 \mathrm{c}^{3} \mathrm{~m}^{3} \quad 8 / 1011-\mathrm{Na}\left(\mathrm{H}\right.$. fiil $1 \mathrm{~cm}^{3}$

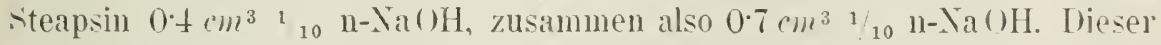
IV ert wir! bei den ibrigen l'roben abgezogen. So fand sich z. H.:

$$
\begin{aligned}
& \text { Nach is Stumden: } 1.0 \mathrm{~cm}^{3} 1 / 10 \mathrm{~m}-\mathrm{XaUH}
\end{aligned}
$$

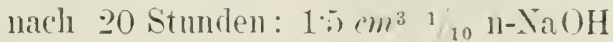

Titer nach Abzu世 der ursprïnglichen Azidität.

Ein anderes Beispiel nach Comstein und Hoyer mit Verwendung von Ricinuslipase: $5 g$ Lipase (Ricinusiamen) werden mit 10!/ Wasser,

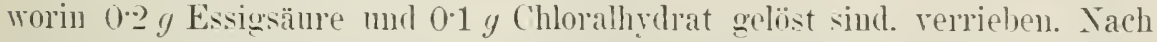
2t stmulen ist zirka $80 \%$ der theoretisch möglichen Fetsäure in freier Form vorhanden und durch Titrition nachweishar.

1) Connstein, Hoyer und Wartenhry, Cher fermentative Fettspaltung. Ber. d. l)eutsch. chem. Ges. J@. 35. S. 3988 (1902). 
Bei der l'ankreaslipase lïßt sich nach Jietal) auch die smothetisiorende Wirkmong leicht machwejsen. Ms besonder's geeignetes substrat dafuir empfiehlt Jletz ein Gemisch von wenig n-Buttorsiate mol viel Iso-Amrlalkohol. Man rersetze dis Gemisch nit Ferment und verfolge an l'röbehen

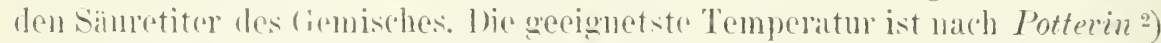

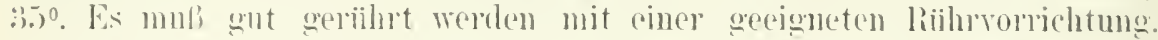

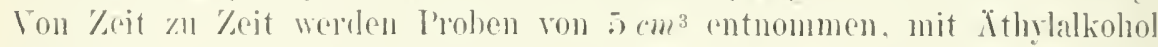
resetzt mul gegen Barytlange mit l'henolphtaloin als Indikatol titriert.

\section{Allgemeine Grundsätze bei der quantitativen Bestimmung der Fermente.}

Es kann sich immer mon moln relative quantitative liestimmungen mit bezun auf ejue willkiuldohe T'estlösmo des Fermentes handeln. Diese

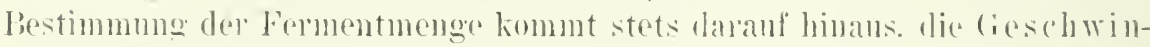

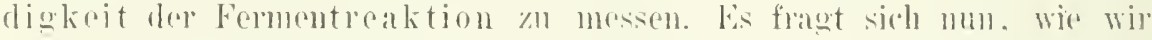

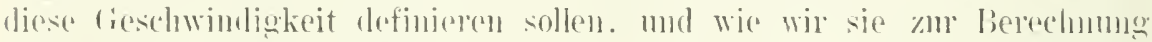

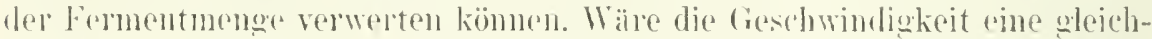

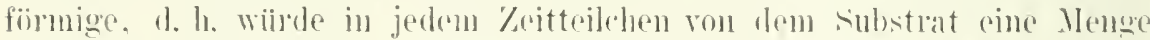
mmgerotzt, welehe nur von der Konzentration des Fermentes ablüngig ist. minh aber mit der lionzentration des substrates valuiert. so wäle dic Ge-

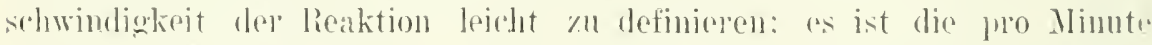
mugestzte substratmenge. In dor Tat wibt es Fille, wo mit gewissen Fin-

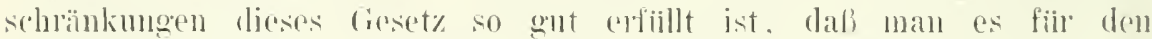
vorliegronden hwek gebranchen kann. Besonders trifft dieses für das

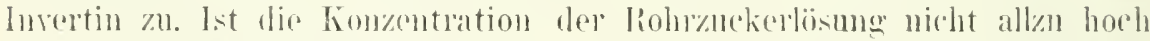
(iiber 1/2 normal) nud nicht allzu gering (unter $1 / 6$ normal), so wiod im Anfang do lieaktion, nämlich his otwa zm Erreichmo des fiuften Teiles

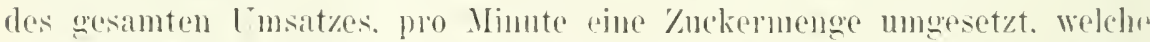
fast mabhängig von dep Zuckerkonzentration ist mul der Fermentmenge seln angenibluert einfan proportional ist. \%ur Dofinition einer Invertinlösung geniogt es daher, ome Ingabe etwa nach folgendem schenlat zu machen: Die fermentlïsune invertiert in einer ca. halburmalen liohr-

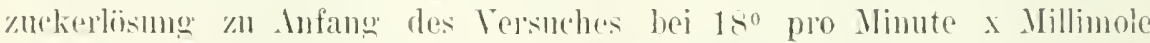
liohmoncker: alsdann ist rine zwoite Fermentlïsmo, welche muter gleichen

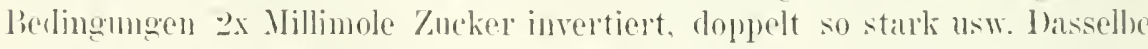
wilt auch fiir die Maltase nach V. Hemi ${ }^{3}$ und fiir die polrpeptidspaltenden Fermente der Hefe nach Alderhalden mul Micharlis $\left.{ }^{+}\right)$. sofern man wirklich nur den dufing der lieaktion herücksiohtigt.

1) Diefz, l'her eine mukehrbare fermentreaktion in heterogenen System. Zeit-

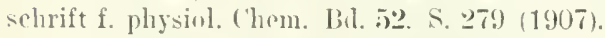

2) Potterin, comptes rent. T. 137. p. $378(1904)$.

3) Ir. Henri, Lois générales de l'aetion des diastases. Paris 1903.

4) E. Abderhalden und L. Nichaelis, Der Verlanf der fermentativen I'olypeptidspaltung. Zeitschr. f. physiol. ('hem. Bu. .2. s. 326 (19)7). 
In den meisten Füllen ist aber die Beziehnum zwischen Fermentmenge und lieaktionsgeschwindigkeit komplizierter und ist ferner die lieaktionsgeschwindigkeit nicht so einfuch zu definieren, wril die I'msat\%geschwindigkeit solhst zu Anfang des Versuches eine ungleichförmige ist oder schwierig zu relfolgen ist. In allen diesen Fällen ist es prinzipiell rerkehrt, wenn man die in gleichen Zeiten erreichten L'msitze versehiedenen Betrages zur Berechnung der Fermentmente rerwerten wollte. E. wibt \%wei einwandfreie Vethoden.

Die erste heruht darauf, daf man die \%eiten miteinander vergleicht, welche zur Erreichung eines bestimmten L'msatzes erforderlich sind. Findet man \% B. dal eine bestimute Fermentlösung in einer gan\% bestimmten substratlösmng. sagen wir 1 g des substrates. in 10 Minuten spaltet und finden wir. dal', in einer zweiten Fermentlösung die spaltung von 1 g Substrat 20 Xinuten erfordert. so können wir schlielien. dalf die lionzentration des Katalrsators in der zweiten Lösung halb so grob ist als in der ersten. Wenn wir aber finden, dali in rer ersten Fermentlösung in 10 Vinuten $1 \mathrm{~g}$ Substrat ungesetzt wird. in der zweiten in 10 Minuten ?.g Substrat, so könnell wir daraus im allgemeinen nicht schlieben, daf die zweite doppelt soriel Katalysator enthïlt als die erste.

Die zweite Iethode besteht darin. dali man durch Probieren in Serien diejenige Verdünnug der zu priffenden Fermentlïsmg bestimmt. welche in einer passend gewählten. beliebigen \%eit denselhen Imsatz herrorbringt wie die Testlösung des Fermentes. Findet man z. B. . dali die 1ofache Verdiinnung der zu priifenden Fermentlösung zu jeder beliebigen Zeit in dem L'msatz Sehritt hält mit der Testlösung. so können wir mit sicherheit schließen. dali die zu prifende Fermentlösung 10mal soriel Ferment enthält als die Testlösung. Voraussetzung ist dabei, dal die Reaktion des Mediums die gleiche ist, und dal auch sonst das Milieu in beiden Fällen durchans rergleichlar ist. Das lïft sich angenähert immer erreichen.

Dagegen ist es allgemein ein prinzipieller Fehler. aus den verschiedeneu C'msitzen, die zwei Fermentlösungen nach Ablauf einer gegebenen Zeit hervorrufen. yuantitative Schliisse auf die relativen Fermentmengen zu ziehen. Nur das eine lälit sich schlielien, daß die langsamer wirkende Lösung weniger Ferment enthält als die andere.

Erste VIethode. Vergleichung der Zeiten. welche zur Erreichung des gleichen Umsatzes notwendig sind.

I iese Methode bedarf einer gauz hesonderen Besprechung. aus welcher sich ihre Anwendbarkeit ron selbst ergibt.

I)er Anschaulichkeit halber führen wir die Erörterung an einem Beispiel einer einfachen, nicht fermentativen, aber doch katalytischen Reaktion durch, an der Inversion des Rohrzuckers durch Säuren. Für diese gilt das Gesetz. dali die zur Zeit t gespaltene 'Zuckermenge in folgender Teise ron der" Konzentration der H-Ionen und ron der Anfangsmenge des liohrzuckers, a, abhängig ist: 


$$
\mathrm{k} .11 . \mathrm{t}=\ln _{\mathrm{ll}} \frac{\mathrm{a}}{\mathrm{a}} \mathrm{x} \text {. }
$$

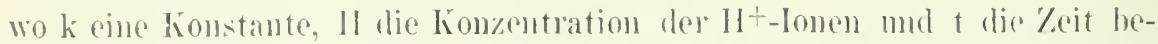
dentet. Wenu wir mun, gemäli mserer Mothode, die Anfangsmenge a des Lohymokers immer gleich machen wod inmor bis zm Errejohmm desselhen Limsatmes a abwaten, so ist des Ausdruck lu $\frac{a}{a-x}$ eine liomstante (C). und wiı liönnten schejhen:

$$
\text { k. II } . t=c^{*}
$$

oller

$$
H=\frac{(}{k . t} .
$$

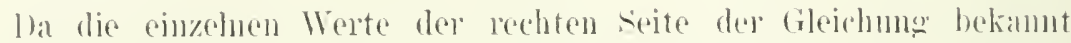
sind haw. durell den forsuch bestimmt werelen kïmen, so kïmnen wir darans die konzentration der It -lonem, II. beredmen. Insofern gestattet

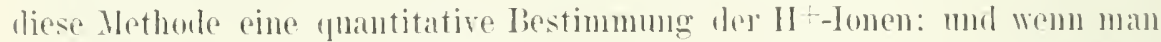

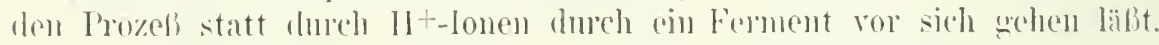
sn ist es ähnlich. Wie kompliziont anch der der rechten seite des rilei-

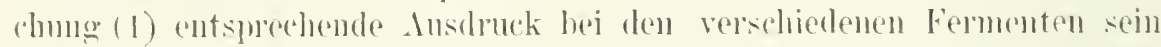

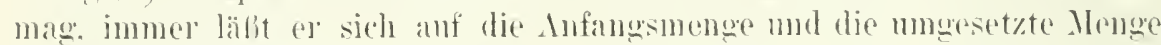
des sulstrates loziehen (immer ist ef cime .. Fumktion von a mol x"). mut wemn wir a mul a komstant wählen, so wird dio rechte seite der dibei-

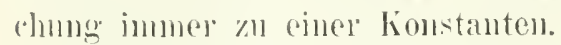

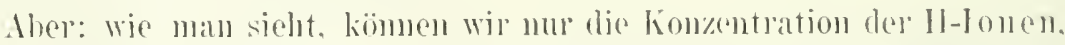

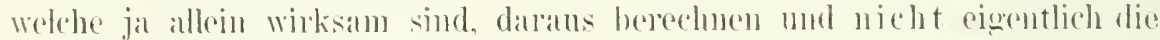

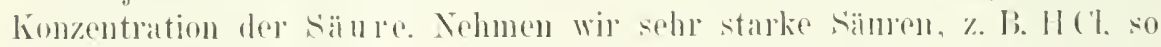
wird allerdings die Lomzentuation der ll-fonen angenähert proportional der

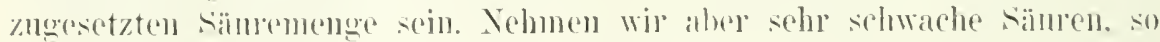

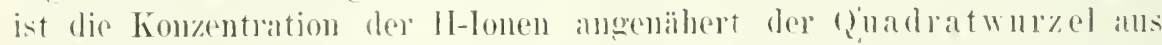

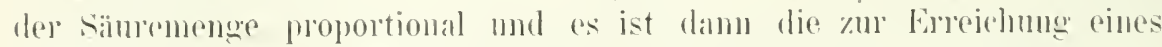

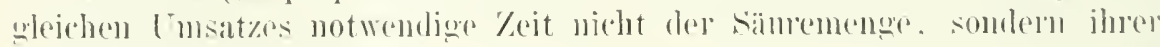

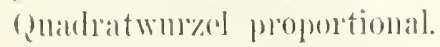

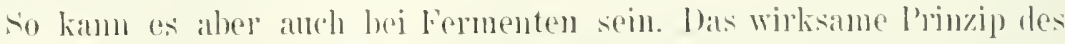

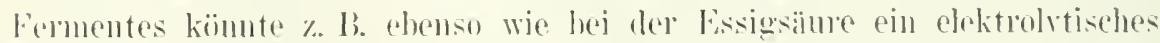

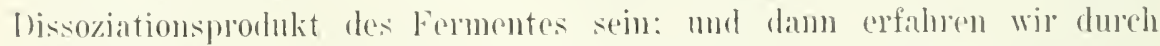
diese Methode nidat die lionzontration des wanzen Fermentes, sondern die Lonzentration jenes wirkamou Ibssoziationspodnktes desselben. Wir verlangen aher die Menge des Fermontes sollost zu crfaluren. Daher ist diese Wethode mu nit entspreduender Vorkemutnis der bigenart des Fermentes zu benutzen. Ist die Fermentwinkmo der Fermenturemge einfach poportional, wie os beim luvertin der Fall ist. so verhalton sich die \%eiten

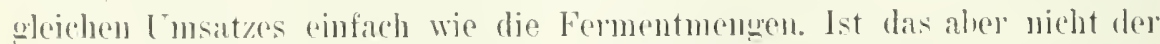
Fall. so empfiehlt as sich nieht, diese Methode anzmwendem. In einigen Fällen, wo dio Verhälnisse Häbre bekannt sind, läbt sich die Methode 


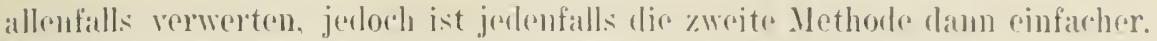

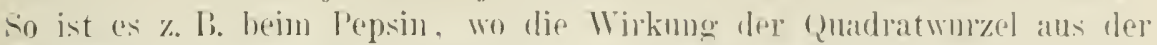
fermentmenge matrh dem Srhätz-Borissouschen liesetz proportional ist, wje as oben fiil die Essigsiure bei der \%orkelinersion anseinandergesetzt

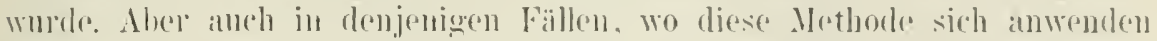

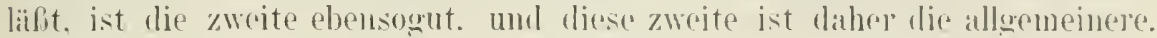

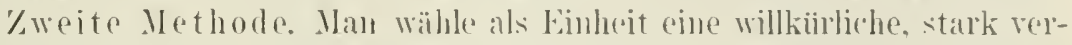

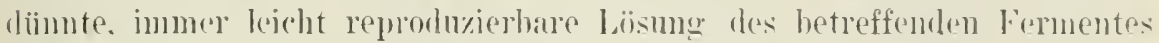
und rerdiune die zu motersuchende Fermentlösung durch Probieren so weit. dah sic die weiche Wirksamkejt hat wie diro Testlösung. I)ann muli der

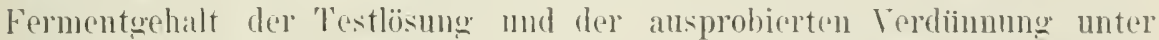
allen Cmständen mleich sein, wenn dic äufielen Bedingung(m, wie Roaktion des Medimms, Temperatur usw. enleich sind. Daraus lälit sich dann der Fermentegehalt der zu priffenden Lösung leirht herechnen.

Es landelt sich also nur darum, für jedes Ferment ein gooignotes substrat zu finden, bej dem ain beliebiger Punkt des Lmsatzes grona fest-

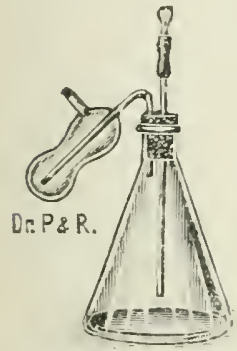

Fig. 9. gostellt werden hann. Fï die einzelnen Fermente lassen sich folgende Punkte des Imsatzes dazu benutzen:

Bei amylolytischen Fermenten kann man len Punkt wählen. wo die anfinglich blaue Jodreaktion der Stärke gerade rein rot geworden orley besser gerarle eben farblos geworden ist. ${ }^{\prime}$ )

lei Invertin kam man \%. I). den Punkt wählen. wo in einer 50 ${ }_{0}$ igen Rohrmckerlosumg merade eine Irehungsverminderung um 10 eingetreten ist.

Bei der Zymase kann man den P'unkt mählen. wo z. 15. gerade $0^{*}, \mathrm{C}_{2}$ entwickelt sind. Man kam dam nicht einfache Gärungsiohrchen henutzen. sondern Kölhchen von folgender Form (Fig. !), welche man etwa von Stunde zli Stunde wägt.

Die hier\%u nötige gewichtsanalytische Bestimmung der Gärkraft wird nach Buchner in folgend(l' Weise ausgefïhrt: In ein Erlenmeyersches Kö̈l)chen ron $100 \mathrm{~cm}^{3}$ Inhalt werden je $20 \mathrm{~cm}^{3}$ Prebsaft, $0^{\circ} .2 \mathrm{~cm}^{3}$ Toluol und $8 \mathrm{~g}$ fein gepulverter Rohrzucker portionsweise eingetragen und durch L mschiitteln raseh gelöst, dann wird der Verschluf anfgesetzt und der canze Ipparat wewogen. Der Verschlub hesteht zweckmälig ans einem sog. Fürventil nach Meissl. Jieses ist ein kleines Waschflïschchen. mit $1-2 \mathrm{~cm}^{3}$ konzentrierter Schwefelsäure beschickt zum Trocknen der ausströmenden Kohlensäure mnd auf der anderen seite mit einem Bunsenschen Schlauchrentil versehen, welches den Austritt, nicht aher den Eintritt ron fiasen gestattet. Dieses limsenventil wird hergestellt, indem man einen $5 \mathrm{~cm}$ langen schwarzen (iummischlauch von $0.5 \mathrm{~mm}$ Wandstärke, del einseitg durch ein Glasstäbchen rerschlossen ist, in der Mitte duch einen $1 \mathrm{~cm}$ langen Längsschnitt

1) Wohlgemuth, Uher eine neue Methode zur quantitatiren Bestimmung des diastatischen Ferments. Biochem. Zeitschr. Bd. 10. S. 1 (1908). 
mit sehr schartem Messer aufschlitzt. Die Beriicksichtigume dor gelöst bleibenden ('o, ist nubht nötig. da die liemanigheit der Methode nicht grob

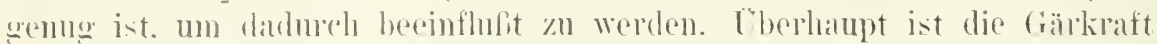
von so viden Vebenumstïnden abliängig. dali diese Methode besser zur

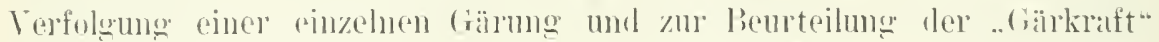
oines l'refsaftes. als zu einel wirklich puantitativen Restimmung der /ymase berutat werilen kilm.

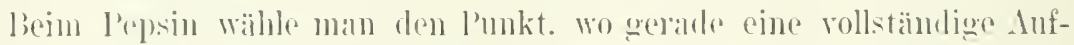
luellung des licins oder groude das Verschwinden des Edestins eingetreten

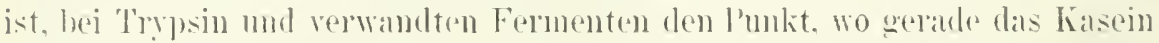
vollkommen versohwmden ist. Bei Lab ist der geoignete l'mukt dio \%eit, in dey die Ausfockung ebun eintritt: dieser \%eitpunkt läbt sieh selu wenau angeben. Man wähle als 'Testlïsmog eine recht hohe Terdiinnung. welche

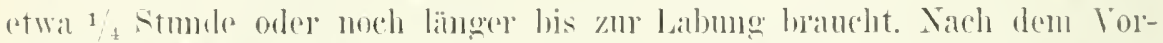

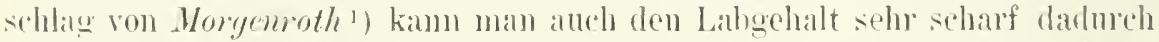
definieren. dab man diejonige Verdiimmug angibt, wo das Ferment. It stmmden hei sehr kalter Fissohranktemperatur mit fle Milchrerdiinmmg zu-

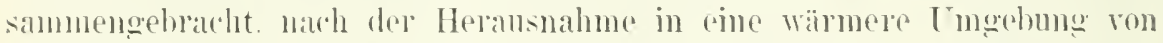
$: 37^{0}$ iberhaupt in absehbarel \%eit (etwa 2 Stumden) noch cierimumg hervolruft. liei Lipatsen wähle man als Endpmbt die Erreichumg einer beliebigen. bequem gelewenen Aziditait.

l)ie Jusfiihrum derartiger Versuche ist fast iiberall nach dem gleichen schema zu machen mol es genïgt die genane beschroibung eines beispieles.

\section{Beispiel für die quantitative Bestimmung eines Ferments.}

Es sei z. l: die Aufuabe gestellt. eine hestimmte Lismo anf ihren lichalt an Pejsin zu prïfen.

1. Man stelle sich in oben angegehenel Weise die saure licinanfschwemmung her.

๖. Man löse $0^{\circ 2}$ g T'epsin (z. B. las l'röparat der l'harmakopöe) in $100 \mathrm{em}^{3}$ Wasser mol probiere in einem Vorversuche. Wieviel Kubikzentimeter noitig sind, $105 \mathrm{~cm}^{3}$ der licinanfschwemmmo im Wassephad von : $\mathcal{S}^{\circ}$ in einer angenehmun \%eit aufzuhellen. Nan habe \%. l. gefunden.

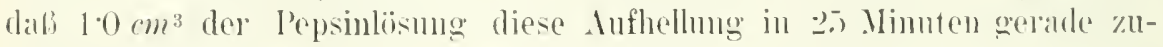
stande hingen. wihrend $\left(0 \cdot 9\right.$ cmo $^{3}$ dies nicht volliommen tum.

1) Vorgenroth, Zentralhl. f. Bakteriol. BAl. 26. S. 349 (1899) und Bel. 27. S. 721 $(19)(1)$.

Dic Angahe, man solle destilliertes Wasser nehmen. ist für den Fall gelacht. daß die zn prifende. unhekamnte Fermentflissigkeit in fast salzfreier Lisung gegehen ist nder so stark verdünnt werden kann, daß der Salzgehalt minimal ist. Ist der salzgehalt höber (z. B. wenig rerdünnter. weil schwach fermenthaltiger Magensaft), so nehme man üherall statt destillierten Wasiers eine Lösung. welche in ihrem Salzgehalt wenigstens ungefähr dieser Flinsigkeit 'ntspricht. Anf dem Lmstand, daß dieser Bedingung nur beschränkt Genüge getan werden kann. beruht eine kleine l'nsicherheit. weldhe jedoch gegenüber anderen unermeidlichen I nsicherheiten, z. B. hei der Erkennung des Endpunkts. meist wenig ins Gewicht fallen dürfte. 
:. Man stelle sich vou der unhekannten, zu mntersuchenden Fermentlösmog Verdïmungen her in folgender Weise:

Jan fülle \& lieagenzoliser mit je $1 \mathrm{~cm}^{3}$ destilliertem Wasser. Man mehme damm eine trockene l'ipette von $1 \mathrm{~cm}^{3}$ Inhalt, entnehme $1 \mathrm{~cm}^{3}$ der umhekannten Fermentflïssigkeit und webe sie in das erste Riohrehen. Die l'ipette sei auf vollkommenes Amsblasen reecht. Man blase sie in das Rearenzglas ans, remische nut, indem man mehrere Male mit lerselhen I'ipette aufzieht und ausblist. Jann entnchme man $1 \mathrm{~cm}^{3}$ der Mischung mit derselben Pipette und iblertrage sie in das zweite Reagenzgläschen. Man mische chenso und iibertrage wieder $1 \mathrm{~cm}^{3}$ in das dritte lieagenzgläschen und so fort. Solange wirl stets die groiche l'ipette benutzt. Yun setze man zu jedem dieser Rïhrchen $5 \mathrm{~cm}^{3}$ der licinaufschwemmung. Das kann mit einel l'ipette ron $2.5 \mathrm{~cm}^{3}$ geschehen, ans der man je 5) $\mathrm{cm}^{3}$ ablüßt. Las Einfüllen der Ricinlösmg in die sämtlichen Gläser werde rasch vorgenommen. so daß es im ganzen eine halbe Minute nicht iiberschreitet, am besten in einem mit Eiswasser gekiihlten Wasserbad. Man notiere die \%eit und setze alle Riohrehen auf einem Gestell (Fig. 10) in ein Wasserbad, dessen Temperatur man entweder durch geeignetes einfaches liegulieren der Erhitzung oder durch einen automatischen Regulator möglichst konstant hält. auf :3̊?. Man notiere die \%eiten, zu denen die Ricinlösung in den verschiedenen I'roben gerade aufgehellt ist. Dasjenige Röhrchen. welches „2) Jinuten verbraucht, ist ron derselben Fermentkonzentration wie die Testlösung, die als willkürliche Einheit

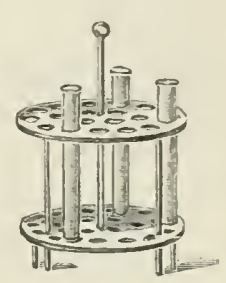

Fig. 10. angenommen wal. Es sei in unserem Versuche das dritte Röhrchen der lieihe, mit der Verdünnung 1 : s. Tamn ist die ursprïnglich zu priffende Fermentlösung smal so stark wie eine Lösung von $0 \cdot 2$ - g des angewandten Testpräparates in $100 \mathrm{~cm}^{3}$ Wasser, entspricht also einel Lösumg von $1.6 \mathrm{~g}$ des T'est-Pepsin in $100 \mathrm{~cm}^{3}$ Wasser.

Die Reaktion mul; in allen Röhrchen genau greich sein. Wenn nun die zu prifende Fermentlisung eine wesentlich andere Reaktion hat als die 'Testlïsung. wenn also z. B. natïrlicher Magensaft mit einel neutralen Lösung eines festen I'epsinpräparates verglichen werden soll. so neutralisiere man den Magensaft vorber genau und beribksichtige die dadurch geschaffene Anderung des Volumens.

In diesem Falle, wo es sich um eine direkte Aufhellungsreaktion handelt, erkennt man den gewiuschten Endpunkt der Fermentwirkung direkt. Bei anderen Yethoden. z. B. Trypsinbestimmung mit der Kaseiuliethode, cntnimmt man mit einer Pipette ron Zeit zu Zeit Pröbchen und setzt das geeignete Reagens, in diesem Falle also z. B. stark rerdiunte Essigsïure, zu.

Auf die hier beschriebene Meise wirl unter anderem auf die einfachste Weise das höchstwichtige Postulat erfïllt. dab das Gesamtrolumen in allen Pïhrchen das gleiche ist. 


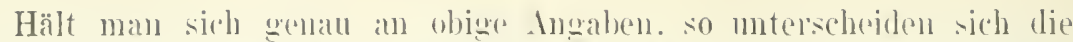
rinzehen böhrehen der Vorsuchseihe derart. dab jedes folgende dic Häifte

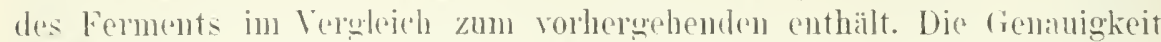

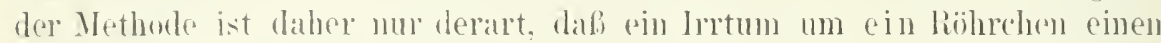

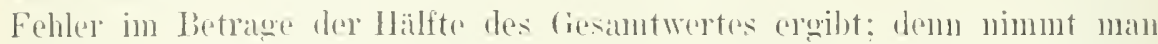
\%. li. das : R. Rönchen als jlentisch mit der 'Testlosmug an. so ergibt sich

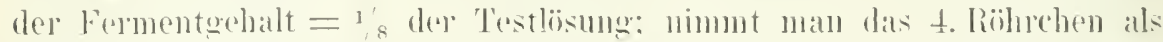

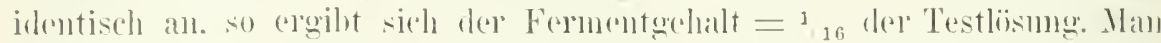
kamm aber anch foincre Abstufungen der einzehen liöhehen machen. num muli einc solche Reihe immer eine weonnetrische sein. Wemn der Abstand

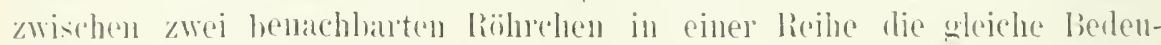
tuno laben soll. In obiger lieile ist die Verdiinumo nach l'otenzen ron

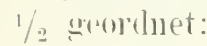

$$
1:{ }^{1}{ }_{2}:{ }^{1 / 4}: 1_{4}^{1 / 8}:{ }^{1} / 6 \ldots
$$

Nan kann anch mach I'otenzen von $2 / 3$ oreluen:

$$
\text { 1: } 2 / 3: 4_{9}: 8 / 27: 16 / 41 \ldots 11 \leqslant 11 \text {. }
$$

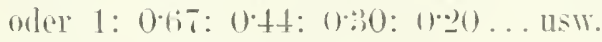

oder anch noch feines mach l'otenzen rou ${ }_{4}^{3}$ :

$$
1: 3_{4}^{3}: 9_{16}: 2_{64}: 81 / 256 \ldots 11511 .
$$

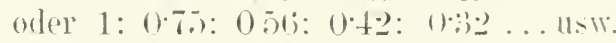

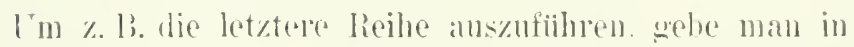

Riohnchen 1:

Fermentlösmo $1 \cdot 11$

+ Masser lïhrchen :):

Finenthisume 0\%

+ Wasser

\section{lïhrehen :3:}

Fermentlösmag o ori nsw. + Wasser (1)+4

In alloemeinen wird man zmächst vine gröbere lieihe mod damm. wems es die I'mstainde erfordern, innerhalh der vorlänfig festoregenten (i)en\%en immer frinele lieihen ansetzen, und man wird darin soweit gehen. wie es die Empfindlichkeit der Methode, hesonders die Möghichkeit riner exakten Erkennmo des Endpunktes der Reaktion gestattet. I'm das Instellen solcher Reihen verschiedener Empfindlichkeitsorenze

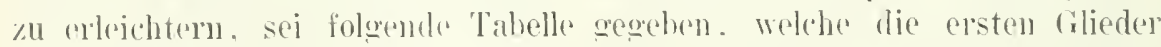
verschiedener weometriseher Reihen enthält. dede llorizontalneihe ist eine

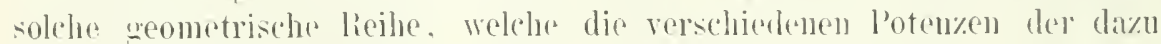

\begin{tabular}{|c|c|c|c|c|c|c|c|c|c|}
\hline & ()$^{t e}$ & $1^{\mathrm{te}}$ & $\ddot{\theta}_{t e}$ & $3^{t e}$ & $t^{t e}$ & $5^{t \theta}$ & $6^{+t}$ & 7 te & 8 te \\
\hline & \multicolumn{9}{|c|}{ Potenz } \\
\hline $0 \overline{1}$ & $1 \cdot(x)$ & 0.000 & 0.9 & 0.125 & $0.0(; 25$ & $(0.0312$ & (1).0156 & 0.00786 & 0.00393 \\
\hline 0.6 & $1 \cdot 1)(0$ & 01600 & 0.360 & 0.216 & 0.130 & (1) $078 \mathrm{~s}$ & 0.0167 & $0 \cdot 0.280$ & 0.0170 \\
\hline $15 \cdot 7$ & $1 \cdot 00$ & 0.700 & 0.490 & $0 \cdot 343$ & $0 \cdot 2+0$ & $1)^{16} 16$ & $0 \cdot 118$ & $0 \cdot 0824$ & 0.0576 \\
\hline 0.8 & $1 \cdot 00$ & 01800 & $(1)(i+1)$ & (1) 512 & 0.410 & $0: 3: 3$ & $0 \stackrel{2}{2} 2$ & 0.210 & () 16 is \\
\hline 09 & 100 & $0: 900$ & 0.810 & $0.7 \cdot 23$ & 0.656 & $(1.590$ & 0531 & 0.175 & $0 \cdot 430$ \\
\hline
\end{tabular}
aehïrigen Kahl der linken Kolumme enthält.

Tabelle. 
Man kinn nun natiolich imnerhalb einer joden solchen geometrischen Reihe alle cilieder mit ainem bestimmten Fatitn multiplizieren: so entspricht \%. B. die lieilie

$$
1 \cdot 00 \quad 0.500 \quad 0.50 \ldots \ldots
$$

indem man jedes Cilied nit is multipliziert. folgender lieihn:

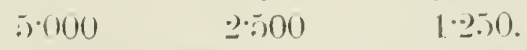

Der ...eometrische Mhstanl" der eimzelnen (ilieder der multiplizierten lieihe ist damm der gleirhe wie der der urspringlichen.

Die Zahlen in der Tabelle sind dreistelliw angegehen: man wird in praxi gewöhnlich nur zweistellige Zahlen branchen.

IItu kamn nun nach dem Vorschlag von Fuld) diese Reihen auch anders konstruieren. Fuld geht von dem I'rinzip ans, wemn man die starkste Verdünnmo als 1 bezeichnet, in der Reihe so aufzusteigen. dafi man auf jeden Fall zu dem 10fachen Multiplum gelangt, und zwar nicht einfach den ganzen Zahlen von 1-10 entsprechend, welche ungleichwertige .. geometrische Zwischenrüume" zwischen sich fassen, sondern mit Hilfe von geometrischen Reihen. Will man die Rieihe von der Terdiinnung 10 bis 1 in 10 Cilieder teilen, so benutzt man eine geometrische lieihe mit dem Exponenten $\overline{10}$ : will man sie z. B. in 4 trlieder teilen, so benutzt man eine solche mit dem Exponenten $\left.\right|^{3} \overline{10}$ nsw.

Folgende Tabelle nach Fuld gibt solche Reihen, auf eine Dezimale

\begin{tabular}{|c|c|c|c|c|c|c|c|c|}
\hline 10 flieder & 9 Glieder & 8 Glieder & I Glieder & 6 Glieder & 5 Glieder & 4 filieder & 3 rilieder & 2 Glieder \\
\hline 1.0 & 1.0 & 1.0 & 10 & 10 & $1 \cdot 0$ & 1.0 & 1.0 & 1.0 \\
\hline $1 \cdot 3$ & $1 \cdot 3$ & $1 \cdot 4$ & $1 \cdot \tilde{o}$ & $1 \% 6$ & $1 \cdot 8$ & $2 \cdot 1$ & $3 \%$ & 100 \\
\hline $1 \cdot 7$ & $1.8=$ & $1 \cdot 9$ & $2 \cdot 1$ & 25 & $3 \cdot 2$ & $4 \cdot 6$ & $10^{\circ} 0$ & \\
\hline $2 \cdot 1$ & 2.4 & $2 \cdot 7$ & $3 \cdot 2$ & 4.0 & 56 & 10.0 & & \\
\hline 28 & $3 \cdot 2$ & 3.7 & 46 & 63 & $10 \cdot 0$ & & & \\
\hline 36 & $4 \cdot 2$ & $5 \cdot 2$ & $6 \cdot 8$ & $10 \cdot 0$ & & & & \\
\hline 46 & 56 & $7 \cdot 2$ & $10 \cdot 0$ & & & & & \\
\hline 60 & 75 & 100 & & & & & & \\
\hline $7 \cdot 7$ & 100 & & & & & & & \\
\hline $10 \cdot 0$ & & & & & & & & \\
\hline
\end{tabular}
berechnet, wieder.

\section{Einiges iiber die Methoden zum ständigen Verfolgen der Fer- mentwirkung.}

Für gewisse Zwecke ist es notwendig, den Ablanf einer Fermentwirkmg schritt fuir Schritt zu verfolgen. Benntzt man dazu chemische Methoden, so mub man dem Fermentgemisch ron Zeit zu Zeit Proben ent-

1) E. Fuld, Zur Theorie mul Technik des sog. Morgenroths-Versuchs. Biochem. Zeitschr. Bd. 4. S. 54 (1907). 


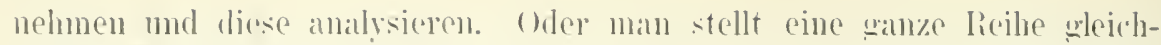
artiger fiemische von forment und Substrat her. mterbicht die Ferment-

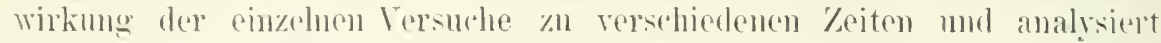
die einzelnen lersuche. Als beispiel für eine solehe Methode sei die Tul-

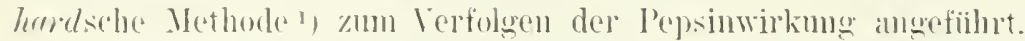

bie Volhorlsche Methode erestaltet sieh folgendermalien:

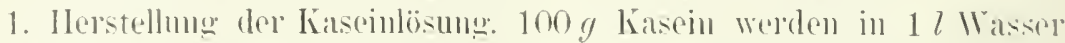

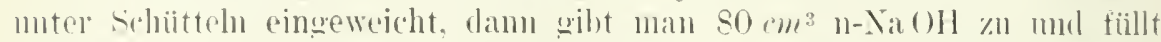

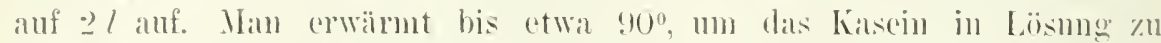
bringen. nach dem dhkiblen rersetyt man mit otwas Toluol. Die Lösung ist gut halthar.

-. Vorbereitumg zum Versuch. In einer langhalsigen Flasche, die mit

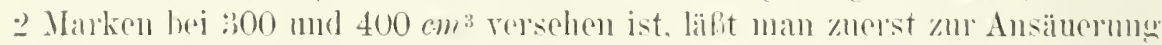
genall $11 \mathrm{~cm}^{3}$ n-HC'l-Lösumg cinflieben, fiillt auf $1.50 \mathrm{~cm}^{3}$ anf und gilit

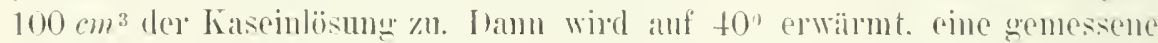

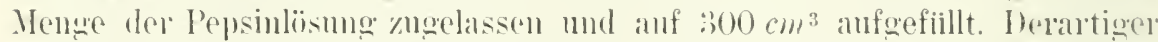
Kolben stellt man eine wanze lieile auf und moterbicht die Verdammg zu rerschiedenen Zeitpunkten.

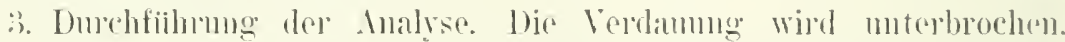

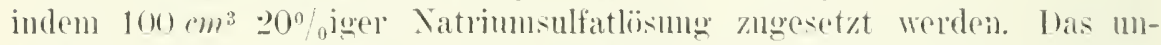
verdante Kasein fällt dabei ans. Fs wird abfiltriert und je 100 onler $200 \mathrm{~cm}^{3}$ des Filtrats mit $\frac{1}{10}$ n-NaOIl gegen Phenolphtalein titriert. Fon der Aziditait ist die vorher hestimmte Azidität der Kaseinlösung albzzidacn, sowie die Azidität der l'epsinlösung. So roült man den Zuwahs des sümetiters. der auf der Bildung der salzsamen l'eptone beruht. Das ausfallende liasein hat nämlich die Eigenschaft, HC'l zu hinden; finden sich aber Teptone in dere Lösmo, so tritt eine Konkmrenz zwischen dem Kasein mul den Peptonen

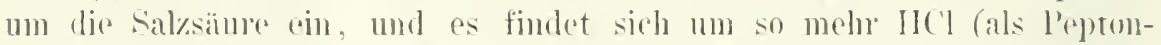
hydrochlorid) in lisung, je mehr l'epton im Vergleich zum Kasein volhanden ist. Man kam so dio Azidititszunahmen als Maßstalo fün den Kaseinabliau betracliteri.

Liei manchen physikalischen Ifthoden kam man jedoch den Fortand der lieaktion an einer einzigen l'robe verfolgen. Von den letzteren

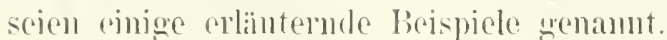

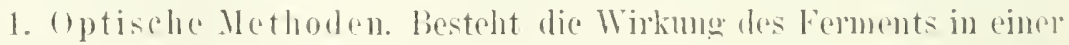

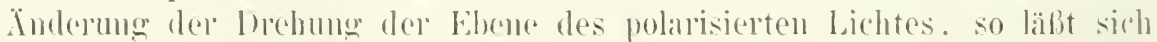
der Vorlanf im lobarisationsapparat selbst verfolgen. to ist es hei du spaltumg der sacelaurose durch Invertase, bei der Spaltmong der optisch aktiven mod der lazentischen. astrmmetrisch spaltbaten Polypeptide dureh

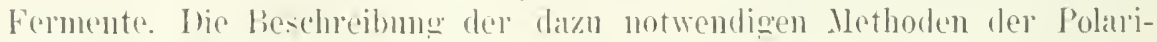
sation vel. bil. I.

1) Volhard, ther eine nene Methode der quantitativen l'epsinhestimmung ete. Müuchener med. Wochensehr. 1903. S. 2I29. 1907. Heft 9. - Löhlein, Cber die Volhardsclue Methode ete. Hofimcisters Beitr. Bd. 7. 2. 120 (1905). 
Fermente: Metholen z. qualit. u. quantit. Verfolgung d. Fermentwirkung. :;:;

Weitere Einzelleiten bei der V'erfolgung der Fermentwirkungen auf polarimetrischem Wege sollen an einigen lieispielen beschrieben werden, die dem Hanptanwendungscehiete der Iethorle entstammen, der fermentatiran Hydrolyse des liohruckers und der fermentativen Polypeptidspaltung.

İei dem Beispiel des lioluynckers besteht zu Anfangr eine starke Rechtsdrehnng, welche sich zmächst schnell. damn immer langsamer verringert, den Nullpunkt iiberschreitet und in eine Linkidrehung iibergeht. Die Link:drehung riihrt daher, dali der Invertzucher, das heift das Gemisch ron 1 Iol. Glukose und 1 Vol. Fruktose. einen rechtsdrelienden (Glukose) und einen linksdrehenden Kï̈rper (Fruktose) enthält, von denen der linksdrehende stärker dreht. Wenn eine Lösung ursprïnglich so viel Rohrzucker entluält, daß sie a Grad nach rechts dreht. so dreht sie nach vollkommener Spaltung a. $(0.4266-0.005$ t) (riad nach links, wo t die Temperatur der Flissigkeit hedeutet. Hiernach kann man sich im voraus berechnen, welche Enddreloung man zu erwarten hat. Hat z. B. die Lösung zu Anfang eine Rechtsdrehung ron $10^{\circ}$ bei einer Temperatur ron $20^{\circ} C^{\prime}$. so ist die zu erwartende Drehung nach idealem Abschluß der Hydrolyse $4 \cdot 17^{\circ}$ nach links. Im ganzen durchläuft also der Apparat einen Winkel ron $14^{1} 17^{\circ}$. Es entspricht dann jeder Grad der In'ehungsabnahme während des Versuchs der Spaltung des $1+1$ iten Teils der urspriinglichen Rohrzuckermenge. Auf diese Weise kann man berechnen. welche Bedeutmg jede beliebige Änderung der Drehnng hat.

Iniese Betrachtungen lassen sich leicht auch auf andere Methoden der Verfolgung der Fermentwirkung ïbertragen, z. B. auf die Verfolgung der Leitfähigkeit, des Ciefrierpunkts usw.

Ganz entsprechende C̈berlegungen erfordert die Spaltung optisch aktiver Polypeptide. dibeitet man z. B. mit d-Alanyl-glycin, so hat dieses Ausgangsprodukt die spezifische Drehung $[\%]_{\mathrm{D}}=+50^{\circ}$ : von den beiden Spaltprodukten dreht das d-.llanin $+2 \cdot 4^{2}$. das flycin $0^{\circ}$. I)ie I)rehung muls also ursprünglich im Verlauf der Spaltung abnehmen, und zwar mul zum Schluf die Drehung fast gleich 0 werden. Die Drehungsverhältnisse werden am einfachsten nach E. Abderhalden und A. H. Koelker ${ }^{1}$ ) durch folgendes Schema ansgedriickt:

$$
\frac{\frac{+2 \cdot 4^{0}}{\text { d-Alanyl- }}-0^{0}}{+50^{\circ}}
$$

Und ähnlich z. B. bei Tripeptiden:

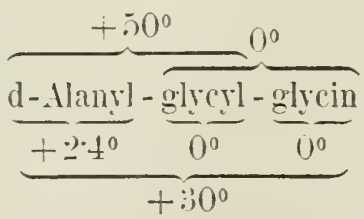

1) E. Abderkalden und A. H. Koelker, Weiterer Beitrag zur Lienntnis des Verlaufs der fermentativen Polypeptidspaltung. V. Mitteilung. Zeitschr. f. phỵsiol. Chemie. Bđ̀. óう. S. 416 (1908; 
Im letzteren Fall kïmute das Ferment anf verschedene Weisen wirken.

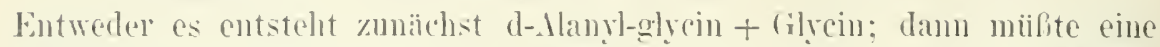
Zmahme der liechtsdrehmog cintreten: oder es wird zmuäehst d-Alanin abgespalten: dam milite cine starke Abnalme der Drehung eintreten. Es zeigte sich bei Versuchen mit llefeprefisaft. dah sofort eine Abnahme der brehmo eintrat, es mul also zuer'st das d-Alanin aboespalten worden sein.

Ein ähnliches schema für ein Tetrapeptid ist:

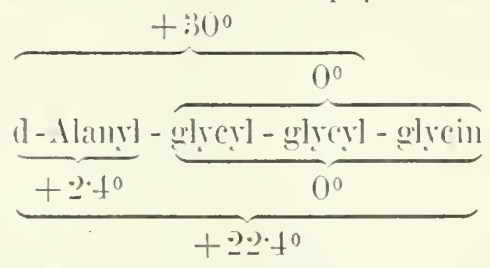

Schlieblich muf man noch bei der Bereclunng der Yersuche beriicksidhtigen. dah oft die Fermentlïsungen eine geringe Figendrehme hesitzen. I)iese muf in thzug gebracht werden.

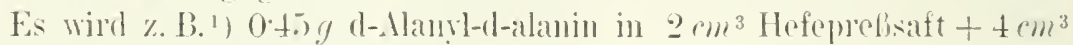
phrsiologischer ('I-Na-1,ösmog welijst.

$$
\begin{aligned}
& \text { I) rehung zu lieginu }-1: 350^{\circ} \\
& \text { mach .5 Minuten - 1\%:? } \\
& \begin{array}{lllll}
. . & 15 & . & & -099^{\circ}
\end{array} \\
& \begin{array}{llll}
. & 31 & . &
\end{array} \\
& \text {.. (ii) .. }+0.02^{\circ} \\
& \text {. } 80 \text {. } 8 \text { + }+0.090
\end{aligned}
$$

Jie zu erwartende schubdrehung nach rollkommener spaltung ist num. wie ans anderen Versuchen mit gröberen Fermentmengen hervorgeht und in fast rölliger lbereinstimmung mit diesem Versuch selbst. +0*100. I) Eeser Eudwert kamm also dureh direkte beobachtung ermittelt werden. oder er kamn anch nuter Beriiclisichtignng des theoretischen Endwerts und der Eigendrehung der Fermentlïmmg berechnet werden. Es wird also im

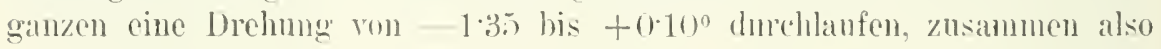
$145^{\circ}$. Bezeichnen wir die Enddrehung als (o. so wiirde also der Verlauf (liese: Versuchs in folgender Weise ungerechnet werten miissen 2):

Zeit in Nlinuten:

0

5

1.)

$: 31$

6.)

80 mmgerechnete Irehung:

$$
\begin{aligned}
& 1.45 \\
& 1: 3: 3 \\
& 1.09 \\
& 0.00 \\
& 0.08 \\
& 0.01
\end{aligned}
$$

1) E.. Abderhalden und I. II. Korllier, Die Verwendung optisch-aktiver Jolypeptide zur Prüfung der Wirksamkeit protenlytischer Fermente. Zeitschr. f. phỵs. 1 hem. Bd. $\overline{3}$. S. 294 (1907).

2) E. Abderhalden und I. Wichaelis, Der Verlanf der fermentativen Polypeptilspaltung. Zeitschr. f. plụsiol. Chem. Bd. ప̃2. S. 326 (1907). 
Die gröbte schwierigkeit und doch mit das Widhtigste fiir eine reorhnerische Verwertmog ist die liestimnnng der Anfangsdrehung in solchen Fïllen, wo die Fermentwirkmg stark ist mod die walue Anfangsdrehmo his zur Ineendigung der ersten dhlesung schon roündert ist. Man verglciche in solchen Fällen die theoretisch zu berechnende Infangshelnung mit der wirklich

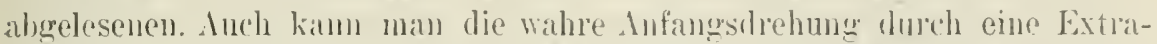
polation korrigieren, indem man die Annahme zngrmude legt, dab für seho kleine Zeitintervalle die umgesetzte Ironge der \%eit proportional ist. Ein schematisches Reispiel:

\begin{tabular}{|c|c|}
\hline $\begin{array}{l}\text { Zeit: } \\
\text { (1) }\end{array}$ & $\begin{array}{c}\text { beobachtete brehung: } \\
\vdots\end{array}$ \\
\hline $1 / 2$ Minute & $1 \cdot(0)^{\prime \prime}$ \\
\hline 1 . Minute & $1^{\circ}(0) j^{\prime \prime}$ \\
\hline $1^{1} / 2$ Minute'n & $1 \cdot() 4^{\prime \prime}$ \\
\hline - Minuten & $1 \cdot 0.00$ \\
\hline $21 / 2$ Minuten & $100^{\circ}$ \\
\hline
\end{tabular}

Hier wird also imnerhall) der ('rsten $21 / 2$ Minuten nit gleichförmiger (ieschwindigkeit pro halhe Vinute eine I) rehmesabnahme von 0.020 bewirkt. Man kam daraus durch Extrapolation schliefien, daf die wahre Irehung zu Anfang $=1 \cdot 10^{\circ}$ war.

Statt die reinen optisch-aktiven I'olypeptide der Fermentwirkung aus\%wet\%en, kam man auch razemische P'olypeptide benutzen, da ron Abderlalden nachgewiesen wurde, dali von diesen durch Fermente nur die eine Form gespalten wird. Dadurch ïberwiegt die Drehnng der ungespaltenen Antipodenform im Laufe der Fermentwirkung immer mehr. Während also bei den optisch-aktiven I'olypeptiden die rorher hestehende Irehumg in rielen Fällen so gut wie vollkommen rerschwindet, begimnt hier der Velsuch mit einer Drehung ron $0^{0}$ und endet mit starker lyehung. Ein Beispiel dafür sei der Arbeit ron E. Abuerhalden und A. H. Koellier ${ }^{1}$ ) entnommen:

\begin{tabular}{|c|c|}
\hline Zeit: & I) rehungswinkel: \\
\hline 10 Minuten & $-0.08^{\circ}$ \\
\hline 1 Situnde & $-0 \cdot 08^{0}$ \\
\hline 2 stunden & $-0.09^{0}$ \\
\hline $5 \quad$. & $-0.12^{0}$ \\
\hline 20 & $-(0 \cdot 2 \cdot 00$ \\
\hline & $-0 \cdots 27^{0}$ \\
\hline
\end{tabular}

1) E. Abderhuden und A. H. Kotlker, Zur Kenntnis des Verlanf der fermentatiren Polypeptidspaltung. Zeitsehr. f. phys. Chem. Bd. 54. S. 363 (1908). 


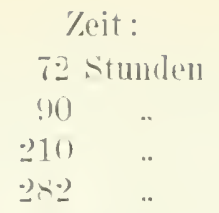

I) rehungswinkel:

$-0 .+20$

$-0.56 i^{0}$

$-(0) \cdot 14^{0}$

$-1 \cdot 00^{0}$

$\therefore$. I essungen der elektrisclen Leitfïhigkeit') wurden ron Ir. Henri und Laryzier des Bancels ${ }^{2}$ ) nud ron II. M. Baryliss ${ }^{3}$ zur Verfolgung der proteolytischen Wirkung benutzt.

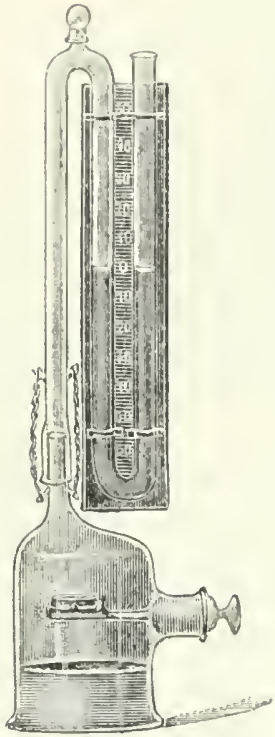

Fig. 11. Das Verdanungsgentisch wird direkt in das Leitfühigkeitsgefïß eingefüllt. Es werlen dian nach der in Bd. I beschriebenen Nethode in Intervallen bestimmungen rorgenommen.

:3. Gewichtsallalytische Methoden sind damm möglich, wem die Fermentwirkung mit Gaseutwicklung verbunden ist, mo man das Gas frei entweichen lïlit. Wahin gehört die bei der ..\%ym ase" beschriehene Methode des Wïgens des Gïrungskölhchens. Wind fermer cin spaltprodukt, z. B. Tyrosin. Willrend der Fermentwirkung abgeschieden, so kann es, wie oben schon criähnt (S. 21), auch unter bestimmten Bedingungen zur quantitativen Verfolgung der Fermentwirkung dienen (Ablerhalden). Auch kïmnte man etwa frei werdendes Tryptophan kalorimetrisch relfolgen (Abderhalden).

4. Manometrische Methoden sind anwendbar, wenn die Fermentwirkung mit Gasentwicklung verbundem ist, und man das (ras nicht entweichen, sondern anf ein Manometer wirken libl.

l'ïr diesen Zweck ist z. li. der von $\mathrm{W}^{\prime}$. Loeb ${ }^{4}$ ) heschriebene Apparat zur Bestimmung der $\mathrm{H}_{2}$ (), Zersetzung durch die Katalise geeignet (Fig. 11). bas Zersetzungsgefiib besteht aus einen starkwandigen Gilasgefäi, das sich zu einem schmalen lohr verjüngt und in ein (nnecksilbermano-

1) E. Volhord, Über eine nene Mcthode der quantitativen l'epsinhestimnung etc. Nïnchener med. Wochenschr., 1903. S. 2119 4. 1907. H. 9. - Löhlein. Uther die Volhardsche Iethode etc. Infimeisters Beitr. Bd. 7. S. 120 (1905). - S. Kïtner, Münchener med. Wochenschr. 1903. S. 2185.

$\left.{ }^{2}\right)$ I. Henri und Largrier des Bancels, Loi daction de la trypsine sur la gélatine. Compt, rend. soe. de Biol. Bu. 55. s. 5633 (1903).

3) W'. M. Bayliss, The hineties of 'Tryptic Action. Arch. des sciences biolog. Vol.11. p. 175 (1906) und: Researches on the Nature of Enzyme-Action. 1. On the Canses of the Rise in Electrical Conductivity under the Action of Trypsine. Jouru. of Physiol. Vol. 36. p. 221 (1907).

*) Wr. Loeb, Zur Werthestimmung der Katalasen und Oxydasen in Blut. Biochem. Zeitsehr. Bi. 13. S. 339 (1908). 
meter fortsetzt. Her- und Abstellung der Luftkommunikation gesehieht rermittelst des mit eincr Offnung versehenen Holmes. Die Füllung geschicht in folgender Weise: Nach Entfernung des Stiojsels werden 25) $\mathrm{cm}^{3} \mathrm{H}_{2} \mathrm{O}_{2}$ Lösung in das Zersetzungsgefäf und das entsprechend verdünnte blut in abgemessener Venge mittelst Pipette in das Schälchen gebracht, dieses auf den Teller des gnt eingefetteten Stöpsels gesetzt und letzterer bei hori\%ontaler Stellung des l'ellers in den Schliffansat\% geschoben. Man stellt den Apparat in das Wasserbad, so daß das Zersetzungsgefäl rom Wasser bedeckt ist und wartet den Temperaturausgleich ab. Dann wird die Piirette mit dem Apparat rerbunden, auf 0 gestellt und nach Abschluf der Luft die Konstanz der Einstellung kontrolliert. Dann läßt man durch eine Inrehung das Schälchen in die $\mathrm{H}_{2} \mathrm{O}_{2}$-Lösung fallen, schïttelt einmal durch und liest in Zeitintervallen den Druck ab.

\section{Der Einfluß der Temperatur.}

Alle Fermentreaktionen haben einen sehr großen Temperaturkoeffizienten, so daß es durchaus notwentig ist, bei einer quantitativen Verfolgung der Fermentreaktioneu die Temperatur sehr konstant z.u halten. Für sehr genaue Versuche wird man sich zu diesem Zwecke des Ostualdschen Wasserbades bedienen. In manchen Fällen ist es, wemn man gleichzeitig größere Reihen ansetzt, und die Verfolgung des Fortganges der Peaktion polarimetrisch stattfinden soll, durchaus angängig, wofern man bei Zimmertemperatur arbeitet, von dem Wasserbade abzusehen. Man fuihrt diese Bestimmungen folgendermaßen aus: Die Polarisationsröhren werden, bis zu 6 Stiick gleichzeitig, in einem gut temperierten Raum, etwa dem Wägezimmer, senkrecht der Reihe nach aufgestellt und anferdem daneben ein mit Wasser gefüllter Zylinder, welcher etwa die gleiche Form hat wie die I'olarisationsröhren. In diesen wird durch eine Korkbohrung ein Thermometer gefïhrt, an welchem man die Konstanz der Temperatur verfolgen kann. So kann man praktisch Konstanz der Temperatur ohne Wasserbad eireichen, wenn es die Beruemlichkeit erfordert. Häufig muß man aber den Ablauf der Fermentwirkung im Polarisationsrohr bei erhöhter Temperatur verfolgen. Zu diesem Zweck sind bei guten Polarisationsapparaten eriärmbare Wassermäntel angebracht, deren Temperatur sich beliebig regulieren läßt.

Im iibrigen richte man die Genauigkeit der Temperaturregulierung konform der sonstigen erreichbaren Genauigkeit ein. Um den Endpunkt einer Aufhellungsieaktion zu bestimmen, wäre es ïberflüssig, die höchsten Anspriiche an Konstanz der Temperatur zu stellen; es liegt in der Yatur dieser Reaktionen, daß ihre Genauigkeit oft nicht besser als auf etwa höchstens $10 \%$ des Gesamtwertes zu erreichen ist. Bei einer derartigen Reaktion, besonders wenn sich die Dauer nur auf etwa $1 / 2-1$ Stunde erstreckt, kommt man mit primitiver Temperatmregulation in einem Wasserhad von mittleren Dimensionen aus. Man stelle in dasselbe einen Einsatz. 
für 12 lieagrnzghiss mit cinem Griff (Fig. 10, s. 29). Durch gelegentliches schwenken ron oben nach unten an diesem (iriff kamm man für stämligen Wïmeanstanseh in Wasserharl sorgen. Wie Ginstellung geschicht dureh einen cinfachen Bunsenhrenner: nach Errechung der arewiinschten Temperatur fächle man mit der Flamme gelegentlich alle par Minnten unter ständiger Kontrolle des 'Thermometers. lei einiger l'bung kann man danit sehr gnte Konstanz der Temperatur erreichen. lienutzt man eine solehe Vorrichtumg hälufiger, so lohnt es sieh. las Wasserhad mit einem Temperaturegulator \% versehen.

Dic Rewnlierung der Temperatur bei einem sich iiber kurze Zeit erstreckenden Versuche durch einen gewöhlichen Brutschank ohne Wasserbad ist gau\% illusoriseh, weil die ciefüfie in Luft erst nach sehr langer \%eit die 'Temperatur der" Lmgebung annebmen.

\section{Elektrische Wanderung der gelösten Fermente.}

Wemn es sich daum haudelt. nur die Wandermugs richtung geloster Fermente und ähnlicher sitoffe zu ermitteln. so hedient man sich dazu

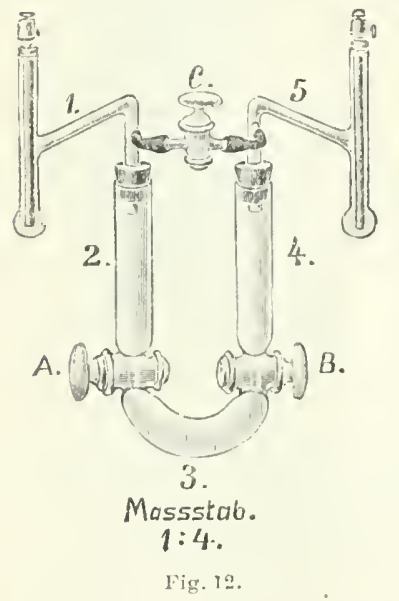
eines L-Rohres, welches dureh iromel eine geeignete Einrichtmge gestattet, mach geniigendem Durcligang des Strones die Flïssigkeit um die Anode, mm die kathode mol nach Vüglichlieit anch die der fiefälmitte getremt \%u erhalten. Ton den empfohlenen ipparaten's möchte ich folgende Konstruktion nïher beschreiben, welche sich mir gerade bei Fermenten gut bewiht hat ${ }^{2}$ (Fig. 1).

Iin Ithohr ist dureh zwei Glashähne 1 mond $B$ mit weiter bohrung in drei lianme geteilt (2.3, f). I)meh (immmistopfen sind Aufsit\%e ron der in der \%eichnung siebtharen Fonn dimnit verbunden, die muter sich durch einen mit Giashahu a muterhrochenen Weg kommmizieren. Ms Elektroden werden ron oben in die seitlichen Aufscitze diunne Metallstreifen his anf dn Boden der kugelfömigen Erweiternng hineingesteckt. Wolches Metall man dazn wählt. wirl sogleich ersichtlich sein.

1) Dechold. Wie elektrische Ladung von Toxin mod Antitoxin. Münchener med. Wochensehr. 1907. Ni.39. - Fidd and Tengue. The electrical charge of toxin aud antitoxin. Jomm. of experim. Med. Vol. 9. p. $\$(5$ (1907). - I. Ilenri, Compt. rend. soc. de liol. 1907. 20. April. - Lendsteiner und I'anli, 25. Kongreb für inuere Medizin. Wien. 1908. S.57.

2) L. Viehantis, Elektrische Üherführung ron Fermenten. Binchem. Zeitschr. Bd. 16. ¿. 81 (1909). 
Man hahe nun \%. B. die Aufgabe, die durch Ilialyse elektrolytfrei gemachte Lïsung irwenl cines Fermentes y untersuchen. Dam verführt man folgendermalien:

Entweder man arbeitet mit qanz reinem destillierten Wasser und wählt dann Platinelektroden. Yan bringt dann zunäehst die Fermentlïwung in den mittelsten Abschnitt des [-Rohres (3), schlielít die Hähne $A$ und $B$, spült die seitlichen Gefäle 2 und $\dot{f}$ gut aus. füllt sic mit destilliertem Wasser, setzt die Aufsätze anf. fuillt dieselben luftblasenfrei mit destillieltem Wasser. indem zunächst der Hahn o geöffnet ist. Nachdem man den Ipparat durch eine Stativklammer hefestigt. in seine definitive Stellung gebracht hat, und das Nireau der Fliissigkeit sich gut reguliert hat. sehliebt man den Hahn $c$ und steckt die I'latinelektroden in die seitlichen öffnungen, zum Schlnli öfnet man rorsichtig die seitlichen Hähne. Ist das spezifische Gewicht der Fermentlösung nicht merklich hïher als das des Wassers. so dafj man Konvelitionsströme durch Erschiitterungen zu befürchten hat, so kann man das spezifische (iewicht der Fermentlösung durch Zusatz von ganz wenig Glyzerin orler '/ucker erhöhen.

Diese Methode leidet an dem Lbelstande. da\} die sehr geringen. unrermeidlichen. im Laufe der Zeit zunehmenden Terumreinigungen des Trassers durch (') ${ }_{2}$ und Alkali aus dem (ilase zur Folge haben, dals die Reaktion an den Polen unter der Wirkung des Stromes im Lanfe eines Tages merklich alkalisch an der Kathode und sauer an der Anode wird und die Peaktionsveränderung sich ron hier merklich auch in die von den Ėlektroden entfernten Gebiete ausbreitet. Mitunter haben aber die geringsten Inderungen deï Reaktion grole Wirkungen auf die Wanderungsrichtung. T'm die Anderung der Reaktion zu rermeiden, habe ich rorgeschlagen. folgende Inordnumg zu treffen:

Man fülle die Fermentlösung in das Mittelgefäß, schliefe die Hähne. fülle die anderen Räume mit destilliertem Wasser, setze die Aufsätze auf. fülle sie mit destilliertem Wasser und achte darauf. daß keine Luftblase in den Aufsätzen bleibt. Jetzt fiille man in diejenige Öffnung, die zur Anode werden soll. durch ein Trichterchen eine Messerspitze festes Cl Xa ein. derart, daf der größte Teil desselben in die kugelförmige Erweiterung hineinfïllt: und in den zur Krathode bestimmten Aufsatz fülle man ebenso etwas $\mathrm{CuCl}_{2}$ in Substanz ein. Als Anode benutze man ein streifchen silberblech, als Kathode einen Kupferdraht. Jetzt schlielie man Hahn $c$ und öffne die Hähne $A$ und $B$ und schalte den Strafenstrom von 110 Volt für 8 bis -4 Stunden ein. Die Anordnung ist dann folgendermafen:

\begin{tabular}{|c|c|c|c|c|c|}
\hline + sither & $\begin{array}{l}\text { Cl Na- } \\
\text { Löisung }\end{array}$ & Wasser & $\begin{array}{l}\text { Ferment- } \\
\text { lïsung }\end{array}$ & $\begin{array}{c}\text { Wasser } \\
t\end{array}$ & $\begin{array}{l}\text { Cu Cl } \mathrm{Cl}_{2}- \\
\text { Lösung }\end{array}$ \\
\hline
\end{tabular}

Iie Wirkung der Anordnung ist folgende. An der Anode geht Silber als Ion in Lösung, wird aher sofort ron den daselbst befindlichen C-Ionen 
zu mü̈slichen Cl Ig grebunden. welches als Tribumerscheint. An der liathode wird metallisches Kónpfer abeschieden. Eine Verämderung der nentralen lieaktion tritt ako nicht ein.

Häufig kommt es diurauf an. die Wandermugsichtung bei Gegenwart ron Neutralsalzen mud besonders bej Gexenwart von s̈̈uren oder Alkalin \%u elmitteln.

Till man \%. B. das Ferment in (iegenwart ron $1 / 100$ n ('l $\mathrm{K}$ untersuchen. so wiirde sich eine Anordnung empfehlen. die man entsurechend dem rorstehenden schema in nummehr leicht relständlicher Weise so ausdricken. kimn :

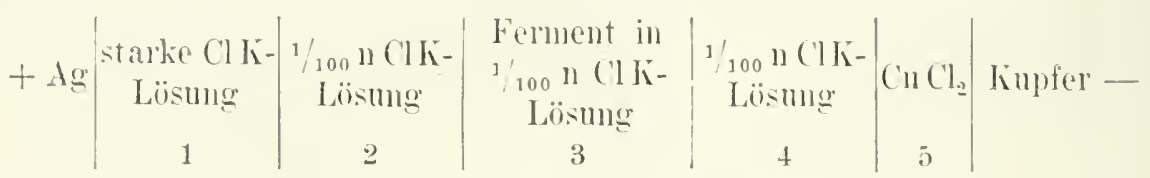

Jie Zusammensetzung dieser Anordnung geschieht folgendermalien: Jie Lösung des Femments in ${ }^{1}{ }_{100}$ n (1) le wird in das Mittelgefäf gelnacht. die seitlichen Jähne dann geschlossen, die seitlichen Rämme ansgewaschen. mit $1 / 100$ n ClK gefiillt, die Anfsätze anfgesetzt. ebenfalls mit $1 / 100$ u ('lli gefüllt. dam in die Anodenseite ('I in substan\%, in die hathodenseite Cn (l, in Substanz eingebracht. I)ie Menge dieser Salze muls jetzt etwas rejchlicher bemessen werden, weil hei dem stälieren Stroun, der durch die bosser leitenden Flïssigkeiten geht. diese Salze soust ror Mbhruch des Versuches erschöpft sein kömnten und dannit oine Inderung ler Reaktion eintreten wiirde. Inum werden dic netallischen Eblektoden wie ohen eingefuilurt. Die Silberelektrode darf nicht zn diim sein. Weil sic bei dem stärkeren Strom sonst in wenigen Stunden aufgezehrt sein könnte.

Will man die Wanderumg des Ferments in samel lösmng, z. l?. in $1,{ }_{100} \mathrm{n} \mathrm{H}$ (1) untelsuchen, so verfahre man folgendermafien:

\begin{tabular}{|c|c|c|c|c|c|}
\hline$+\lg$ & stiuke HCl & ${ }^{1} 100 \mathrm{n} \mathrm{II} \mathrm{(1)}$ & $\begin{array}{l}\text { Ferment in } \\
1 / 100 \mathrm{n} \mathrm{HC} \\
3\end{array}$ & $1 / 100 \mathrm{ll} 11$ (') & C $\begin{array}{c}\mathrm{Cu}\left(\mathrm{I}_{2}\right. \\
5\end{array}$ \\
\hline
\end{tabular}

Man fülle das Mittelgefäb mit der lösmug des Ferments in ${ }^{1 / 100} \mathrm{n} \mathrm{H} \mathrm{Cl}$. fiille die seitlichen Crefüle und die Aufsätze chenfalls mit $1 / 100 \mathrm{H} \mathrm{HCl}$, unterschichte an der Anode mit einer l'ipette, die man bis anf den Boden des Kugelansatzes einfiilut, lise liissigkeit mit $1 \mathrm{~cm}^{3} 10^{0}{ }_{0}$ igen $\mathrm{H} \mathrm{Cl}$, gebe in das Kathodengefüb ('n $\mathrm{Cl}_{2}$ in Substanz und verfahre weiter wie oben. so wird der sïuregehalt in allen lïumen des eigentlichon L'Tiohnes einigermaßen konstant gehalten.

Dab der in dem Kingelgefäb so reichlich enthaltene Elektrolyt dureh Diffnsion sich in stïrenden Mengen bis in die Riinme des L-Pohres

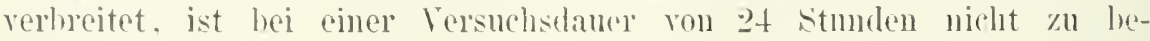
fiirchten. 
Die Entnahme der Fliissigkeiten nach Beendigung des Stromdurchgangres geschicht in der Weise. daf man zunächst den Strom unterbricht und sofort die seitlichen Hähne $A$ und $B$ schlieft. I)ann ziehe man die Elektroden heraus und lifte nacheinander die Gummistopfen, indem man die obere Öffnung des Aufsatzes mit dem Finger verschliefit. den Gummistopfen herauszieht und die in dem Aufsatz enthaltene Flïssigkeit abseits ausfliefen lïßt. Man gebe acht, daß bei dieser Manipulation keine Fliissigkeit aus den Aufsïtzen in die Seitengefülie des ['-liohres grelangt (es darf kein $\mathrm{CuCl}_{2}$ und kein $\mathrm{Ag}(\mathrm{Cl}$ hiniibergeraten) und entleere einzeln den Inhalt der drei Räume des L-Riohres. Man iiberzeuge sich durch geeignete Indikatoren, daß keine Inderung der Reaktion eingetreten ist. Daun prüfe man die Flïssigkeiten auf ihren Fermentgehalt. wenn nötig. nachdem nan erst die Reaktion auf die für die Fermentwirkung erforderliche Stufe bringt. 


\title{
C. I)arstellung von 0xydasen und Katalasen tierischer und pflanzlicher Herkinft. Methoden ihrer Anwendung.
}

\author{
Yon R. Chorlat, Genf.
}

Inie Fermente, welche an den in der lebenden Zelle sich abspielenden (xydationsprozessen. positir oler negatir, beteiligt sind. künnen ihrer spezifischen Funktion nach in folgente Hauptgruppen eingeteilt werden ${ }^{1}$ ):

I. Oxygenasen, stickstoffhaltige Körper. Welche den molekularen Sanerstoff unter l'eroxydbildung aufuehmen.

II. Peroxydasen, welche das ()xydationsremögren der bei der hier in Betracht kommenden Verdinnmo an und für sich trïgen Peroxyde aulierordentlich erhöhen. Die bisher als oxrdasen bezeichneten Fermente sind nichts anderes, als (mehr oder weniger trembare) (iemenge ${ }^{2}$ ) ron Oxygeuasen und peroxydasen.

III. Katalasen ${ }^{3}$, welehe das Hydroperoxyd katalytisch unter Sauerstoffentwicklung zersetzen.

\section{Oxygenasen.}

Als (Oxrgentsen bezeichmen Chodat und Bach den supponierten eiweilihaltigen oder organischen Anteil der bisherigen Oxydasen. der als I'eroxyd bihlender Körper sich mit den Lnftsanerstoff addierend, sich mit ihm zu einem Kürper der allgemeinen Formel $\mathrm{F}\rangle_{0}^{0}$ verbiulet. Vit anderen Worten, es sind fermentartige körper, die sirh mit dem sanerstoff der Luft zu anem I'eroxyd rerbinden kïnnen. Sie werden, wie andere fermentartige Kïrper, durch Hitze zerstört, dureh starken Alkohol gefïllt, kömnen vergiftet

${ }^{3}$ ) 1. Barh nnd $R$. (hodat, ther den gecenwärtigen Stand der Lehre ron den pflanzlichen Oxylationsfermenten. Biochem. Centrall. Bd. 1. S. 417 (1903).

2) R. Chodat und A. Bach, Yntersuchungen über die kolle der Peroxyde in der (hemie der lebenden Zelle. Y. Zerlegung der sog. Oxydasen in Oxygenasen und Peroxydasen. Ber. d. Dentsch. chem. Ges. Ju. 36. S. 606 (1903).

$\left.{ }^{3}\right)$ O. Loex. ('atalase a new enzym of ceneraloceurrence. L. S. Department of Agrienlture. Rep. No. 68 (1901). Katalase ist kein eigentliehes Oxylationsferment, spielt aber bei den sich in der lehenden Zelle ahspielenden Oxydationsprozessen eine wichtige Rolle. Deshalb muß dieses Ferment hier anhangsweise herücksichtirt werden. 
und geschädigt werden. Sie unterscheiden sich von gewöhnlichen I'eroxyden nur dadurch, daß sie wahrscheinlich hochmolekulare Kürpere sind, Albuninstoffe orler Vorstufen der Albuminstoffe orler sonstige komplizierte organische Verbindungen, die dem chemischen \%ellnotabolismus ihren L'rsprung rerdanken. Es sind ziemlich unbestiundige Köirper: Aber anch jedes I'eroxyd kann als (xygrenase fungieren. ${ }^{1}$ )

Die eigentlichen Oxygenasen sint in den sog. ()xydasen in loser orler fester Verbindung mit unbekannten Substanzen, die den Charakter einer P'eroxydase hahen. enthalten. Folglich ham man jede ()xyenase durch ein anorganisches oder organisches P'roxyd elsetzen mol aus ihr in Verbindung mit einer Peroxydase ein Sistem P'eroxyl-peroxylase konstruieren. welches einem (oxydationsferment gleichwertig ist (z. B. Lakkase, siehe unten).

\section{Nachweis von peroxydartigen Verbindungen in den Oxydations- fermenten.}

Man bediene sich folgenter Reagenzien:

\section{Jodstärkekleister.}

Zum Xachweis eignet sich gewöhnlich das Jodstïrkepapier; da die Pflanzenschnitte meistens saner reagieren und die Jodausscheidmng, wie hekannt, nicht direkt aus Jodkalinm, sondern ans Jodwasserstoffsüure stattfindet, so gehen die Abdrïcke ron Pflanzenschnitten direkt die Jodreaktion. Ler Yersuch miblingt sehr oft mit Pflanzensäften, weil dieselben ungesättigte orler reduzierende Terbindungen enthalten, die das Jod absorbieren. ${ }^{2}$ -

Da diese Reaktion anch mit Nitriten zu erzielen ist. so empfiehlt es sich jedesmal, die Bismarckbraunreaktion (Griessche Reaktion) der Nitrite auf ILtaphenylendiamine zu rersuchen oder eine andere für diese Körper ('harakteristische Reaktion zu probieren. ${ }^{3}$ )

Der Saft und die Pflanzenstiicke ron Clavaria flara. die rasch und stark auf eine sanre Jodkaliunstärke reagieren, enthalten (frischer Saft!:) keine Spur von Nitriten. Die durch Alkolol ans Russula foetens gefüllte ()xyenase ${ }^{4}$ ), welche die Jorlprobe intensiv gibt, enthält ebenfalls keine spur ron Nitriten. Die gegenteiligen Angaben ron $d s o$ beruhen anf einem [rrtum. ${ }^{5}$ )

') A. Bach und R. Chorlat, II. Über Peroxydbildung in der lebenden Zelle. Ber. 1. Dentsch. chem. Gesellsch. Jg. 25. S. 2466 (1902). - R. Chodat und A. Bach, Tntersuchungen ïher die Rolle der Peroxyde in ler Chemie der lebenden Zellen. I. Berichte d. Deutsch. chem. Ges. J@. 35. S. 1275 (1902).

$\left.{ }^{2}\right) P_{i}$. Chodat und A. Bach, Untersuchungen etc. III. Oxydationsfermente als pernxyderzeugende Körper. Berichte d. Dentsch. chem. Gesellsch. Jg. 3j. S. 3945 (1902).

3) R. (hodat und A. Bach, Untersuchungen. 1. c. VII. Einiges üher die chemische Satur der Oxydase. Berichte d. Deutsch. chem. Gesellsch. Jg. 37. S. 37, 38 (1904).

$\left.{ }^{4}\right)$ h. Chodat, Les ferments oxrdants. Schmeizerische Wochenschr. f. Chemie und Plarm. Nr. $46-48$ (1905).

$\left.{ }^{5}\right)$ Aso, Which compouml in certain plant juice can liberate iodine from potassium indid? Beihefte \%. Bot. Ceutralh. Bul.15. S. 205 (1903). 


\section{Barytwasserprohe lha (0II) ${ }_{2}{ }^{1}$ )}

Beim biehandehn des frisch ausgepreften. stark oxydaschaltigen Saftes von Lathriea squamaria ${ }^{2}$ ) mit einem Luftstrom unter tropfenweisem \%usatz von 1\% igem liartwasser erhält man einen Barytniederschlag: (lia() $)_{2}$. Welcher nach Answaschen und Zersetzen mit verdiunter Säure (Escigsinure) dic bekannte Hydroperoxydreaktion mit Titanschwefelsämre ${ }^{3}$ ) nicht zeigt. dagegen .Jodkaliumstärkepapier sofort und sehr intensir blïut. I) erhaltene Lösmg gibt mit dem Griesschen Reagens keine Reaktion anf salpetrige Sïure. Die sofortige Jolauscheidung aus Jodkilium kimu daher nur von einem acylierten Hydroperoxyd herriilnen.

\section{Nachweis von peroxydartigen Verbindungen in der lebenden Pflanze.}

\%u ihrem Nachweis eignen sich besonders gut die jungen Kartoffeln. an deren leripherie Oxydationsfermente vorkommen (siehe miten).

Diimsschnitte. welche den peripherischen Zellschichten von frischen Kartoffeh entnommen sind (die Schnitte mïssen in der \%one, die unterhalb des dimnen hramen Periderms liegt, gemacht werden), werden heluffs Entfernung des von den zerstörten Zellen herstammenden Saftes in Detmers physiologischer ${ }^{4}$ ) Salzlösmng ansgewaschen, auf einen (lhjektträger gebracht und unter dem Mlikroskop mit Jodkaliumlösung $(5-10 \%$ ) hehandelt. Nach einiger Zeit nehmen die im Innern der Zellen befindlichen Stäkekörner die für lie Jodstärke charakteristische Färbung an. Die Zellen behalten dabei iln normales. Aussehen und auf Zusatz ron hypertonisehen Salzlösungen plasmolysieren sowohl die gefärhten wie die mugefïrbten \%ellen in ganz normaler Weise. Da die Plasmolyse als eines der sichersten Kemneichen des Lehens anzusehen $\mathrm{jst}$, so ist damit die Peroxylbildung anch in der \%elle nachorewiesen.

Je nach dem \%ustande der Versuchsobjekte Alter. Oxydase- und Wassergehalt, Frische) sind zur Hervorrufung der Blatürobung der Stärkeköner mehr oder weniger konzentrierte dodkalimulösungen erforderlich und die Färhung tritt mehr oder weniger rasch ein. Wendet man schwach hypertonische Jodkaliumlïsungen an, so heobachtet man gleichzeitige lBlaufïrhmo und I'lasmolyse. Bei Velsuchsobjekten. welehe Guajactinktur nur langsan blüuen (siche unter Lakkase). bleibt, die Jodstärkereaktion häufigr aus.

1) I. C'hodat und A. Bach, Untersuchungen über die Rolle der Pernxyle in der Chemie der lehenden Zelle. I. Zerlegung der sog. Oxydasen in Oxygenasen und Peroxydasen. Ber. d. Dentsch. chem. (ies. Jg. 36. S. 606 (1903).

2) Worzelparasit, in Frühling zu sammeh.

s) Betyer und rilliger, Berichte 1. Dentseh. chem. Gesellsch. Jg. 33. S. S58 und $1569(1900)$.

t) Detmer, I'flanzenplyysiologisches F'raktikum. II. Aufl. S. 2 (189.)). 


\section{Peroxydase. ')}

Vorkommen: Peroxylase ist im Pflanzenreich sehr verbreitet. Es gibt kaum eine höhere l'flanze, in welcher dieselbe absolut fehlen diufte. Den meisten I'ilzen fehlt sie jedoch vollkommen. ()) sie im tierischen ()rganismus eine ähnliche Verbreitung hat, bleibt zurzeit noch unsicher, da das Himoglohin als Peroxylase fungieren kann, und es ist deshalb strittig, ob die Peroxydase als solche im Organismus der höheren 'Tiere sich findet. Genane quantitative Bestimmmngen stehen noch aus; aber es ist leicht zn demonstrieren, dali dieses Ferment in den nicht griinen Teilen reichlicher vorhanden ist als in den gefïrbten Organen der I'flanze.

Darstellung 2 : $5 \mathrm{~kg}$ Meerrettiwwureh werden mittelst der Hackmaschine fein zerkleinert, einige Stunden sich selbst ïberlassen, un die enzymatische Glykosidspaltung zu vervollstindigen, und dann einige Tagre mit starkem Alkohol $\left(96^{\circ} \%_{0}\right)$ extrahiert, welcher die ätherischen öle auflöst. Die rote alkoholische Flïssigkeit wird abgegossen, der Riickstand wiederholt mit $80 \%$ igem Alkohol gewaschen. abgeprebt und schlieflich das liesiduum mit $40 \%$ igem Alkohol $(10 l)$ rersetzt und 5 Tage stehen gelassen; die ahgeprefte Fliissigkeit wird hierauf filtriert und mit weniger als dem doppelten Volumen starken Alkohols rersetzt, d. h. solange eine starke Tribung entsteht.

Der weife oder grauweilie Niederschlag wird in ein wenig destilliertem Wasser gelöst, mit starkem . Ilkohol wiederum ansgefällt und über Schwefelsäure im Vakuum ron Alkohol und Wasser befreit.

Sind genügende Vorrichtungen rorhanden. so ist es ratsam, vor der Fällung die $40 \%$ ige alkoholische Fliissigkeit rorerst im Vakum bei $30^{\circ} \mathrm{C}$ einzuengen und erst, wenn dieses Filtrat bis auf ein Drittel konzentriert ist, mit starken Alkohol zu versetzen.

Will man Alkohol sparen, su kann ebenfalls eine sehr aktive Peroxydase durch folgendes Verfahren bereitet werden:

Es werden fein zerkleinerte Meerrettigwurzeln 1 Stunde in einem geschlossenen Crefäfie sich selbst ïherlassen und dann abgepreßt (A): der Kuchen wird nun mit Wasser versetzt, so daf das Flüssigkeitsniveau wenig über die Wurzelmasse sich erhebt und so während 10-20 Stunden stehen gelassen; damn wird ein zweites Mal abgepreßt $(B)$; der Riickstand wird noch einmal mit Wasser digeriert und nach der gleichen Zeit abgepreßt $(C)$.

Die :3 Fliissigkeiten $(A, B, C)$ werden miteinander gemischt und graduell und langsam mit starkem Alkohol rersetzt, bis sich ein erster Niederschlag zeigt. Dieser Niederschlag setzt sich leicht ab. Dann wird mittelst

1) Peroxydase wird auch Leptomin (Raciborski) oder Peroxyddiastase (Bertrand) oder indirektes Oxydationsferment (Bourquelot) genannt. - Der Tame wurde ron Linossier gewählt. Compt. rent. de la Soc. de biol., Paris. T. 5. p. 373 (1898). F. Batelli und L. Stern, Über die Peroxydase der Tiergewebe. Biochem. Zeitschr. Bd. 13. S. 44 (1908).

$\left.{ }^{2}\right)$ Bach und C'hodat, Ber. d. Deutsch. chem. Ges. Jg. 36. S. 600. IV. Üluer Peroxydase (1903). 
eines Hehers die dariber stehende Flissigheit abgehoben nud diese noch eimmal mit starkem Alkohol $\left(96^{\circ} 0\right)$ versetyt. Dor erste Ninderschlag ist sehr wenig wirksam lkamn abed zu pualitativen Versuchen Verwondung finden); der zweite setzt sich langsam ah und haftet als weiber, gummi-

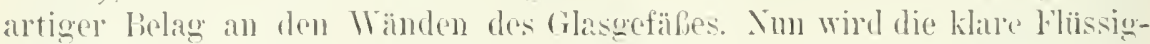
keit durch bekantieren cutfernt. Der wmmöse, weife Nicherschlalg wird mit $40^{0}$ igem Alkohol dig(riert nud nochmals al)geschieden. ${ }^{1}$ )

Die Ausbente betriget $10-20 \%$ on.

Dureh beide Methoden aber. durch die erstere am sehnellsten und sichersten. gelangt man zu einer kistallinisch weilien Masse, die sich gan\% rorzightich sowohl zu qualitativen wie zn quantitativen I'ntersuchnugen

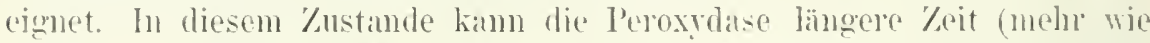
- Jalne) muerändert an einem trockenen (H'te und in Inunkeln anfbewahrt werden (wem möglich im Exsikkator iiber schwefelsime). Es gilt dies besonders für das nach der ersten Vorschift bejeitete Ferment.

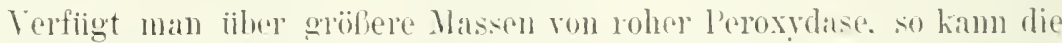
lieinigung nach der erwithnten llethode melnubls wiederlolt werden. Dadurch befreit man die Pepoxylase von den Zuckeraten und anch von Mineralsubstanzen. Die gereinigte Perosydase ist mu cin amorpher bramer

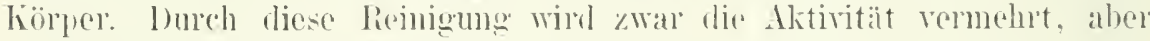
nicht in dem oleichen Mabe wie dic honzentration. ${ }^{2}$ )

biese anorphe l'erostalse ist viermal alktirer als die kristallinische l'eroxydase. $\left.{ }^{2}\right)$ Inuch Inalyse läbt sich die Peroxydase noch writer reinigen. Dabei verlient man so seln an Substanz, dab die Methode nur einen beschränktenl Wert hat. $\left.{ }^{3}\right)$

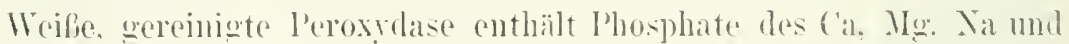

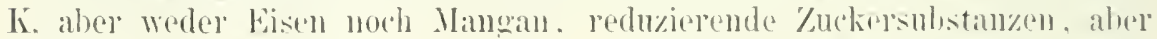
keine Eiweibstoffe. Wie oben gezejot. kann man diese weilie l'eroxylase

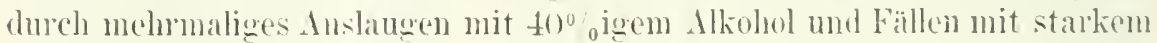
$90 \%$ igem. Alliohol reinionem.

Eigensohaften: Wie sn darestelle lerosylase ist eine wenig hroposkopische, wasserlisliche Masse, welehe Eiweilorationem nicht zeigt.

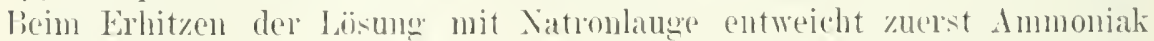
und damn eine nach I'rridin riechente Base. Mit gepulvertem Kali rej-

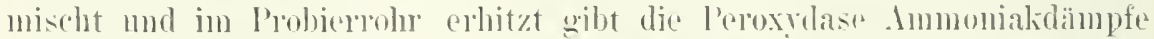

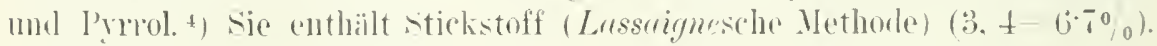

1) E. r. Stoeklin, Contribution à létule de lat peroxylase in R. C'hodat. "Travaux

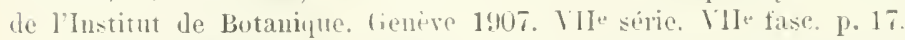

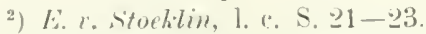

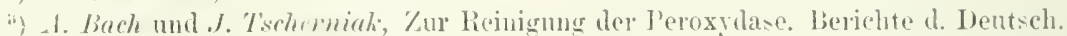
chem. (iesellsch. Jg. 41. S.234ว (1908).

^) A. Boch, Uther den Stickstoffehalt der oxytationsfermente. Berichte d. Deutsch. chem. Gesellsch. Je. 31. S. 2.20(1908). - 1. Jach und R. r'hodat. Lntersuchungen. IV. Uher l'eroxydase. Berichte d. Jeutseh. chem. (iesellsch. Jg. 36. S. 600 (1903). - E. de stochlin, fontribution à l'étude de peroxylase in ('hodut. Traraux. Genere 1!ut. p. 2- 
I) urch siedehitze lälit sie sich lïhmen, wird aber. falls sice nur kurze \%eit gekocht worden ist. nach einigen Stunden zum Teil regencriert.")

In Gegenwart ron Hydroperoxyl oder eines anderen l'eroxydes rermag I'eroxydase die gleichen stoffe zu oxydieren. welehe auch durch Lakkase oxydiert werden. ${ }^{2}$ )

Die (Xxydation des Jodwasserstoffes durch Hydroperoxyd wird aukerordentlich beschlennigt: es werden Phenole und Polyphenole oxydient und öfters kondensiert:

Hydrochinon zu (hinon. $\left.2 \mathrm{C}_{6} \mathrm{H}_{4}(1) \mathrm{H}+\mathrm{O}_{2}=2 \mathrm{I}_{2}()+2 \mathrm{C}_{6} \mathrm{H}_{4}\right\rangle_{(1)}^{()}$.

Prrogallol жu P'urpurogallin rein kristallisiertes rotes liondensationsprodukt),

Guajakol zu Tetraguajakol

$$
4 \mathrm{C}_{6} \mathrm{H}_{4}() \mathrm{H} .0 \mathrm{CH}_{3}+\mathrm{O}_{2}=\left(\mathrm{C}_{6} \mathrm{H}_{3} .0 .0\left(\mathrm{CH}_{3}\right)_{4}+2 \mathrm{H}_{2} \mathrm{O}\right.
$$

Orthophenrlendiamine zu Dianinophenazin:

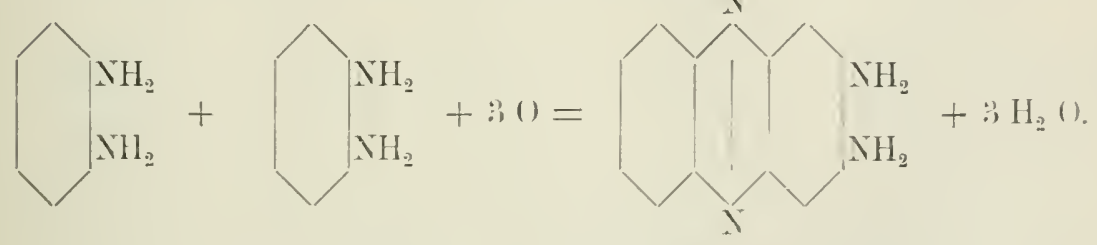

Eines der besten Reagenzien auf Peroxrdase sind die Kresole. Mit einer verdiinnten Lösung ron o-Kresol gibt Peroxydase in Gegenwart von Hydroperoxyd eine griine (bei konzentrierten Lösungen schmutzigbraune), mit m-Kresol eine fleischfarbene und mit p-Kresol eine milchig-trïbe. opaleszierende Reaktion. Die Wirkung auf o-hiresol und p-Kresol ist ganz besonders stark und spezifisch. Dabei ist aber immer ratsam, nicht zu konzentrierte Hydroperoxydlösungen resp. Kresollösungen für diese Versuche zu verwenden, da beide in allzu starker Konzentration auf Peroxydase mehr oder weniger lähmend oder schädigend wirken. Es eignen sich $01-1^{\circ}{ }_{0}$ ige Lösungen von Hỵdroperoxyd und $1{ }^{\circ}{ }_{00}$ ige Kiresollösungen für qualitative Lintersuchungen am besten. ${ }^{3}$ )

1) R. Chodat und A. Bach, Tntersuchungen. I. Zerlegung der sog. Oxydasen etc. Berichte d. Deutsch. chem. Gesellsch. Jg. 36. $\therefore .606$ (1903). - Dieselbèn. Untersuchungen. III. Oxỵdationsfermente als peroxyderzeugende Förper. 1. c. Ibid. Jg. $3 \bar{j}$. S. 3943 (1902).

2) Woods, Lnited States Depart. of Agriculture. Mr.18. p. 17 (1902). - Aso. On Oxidizing Enzyms in the regetable Body. Bulletin of the College Agriculture, Tokyo. V. 2. p. 231 (1902). - Bach und Chodat, l. c. IY. Über Peroxydase. Berichte d. Dentsch. chem. Gesellsch. Jg. 36. S. 600 (1903).

3) R. Chodat, Tourelles recherches sur les ferments oxydants. Archires des Sciences naturelles. IVo Période. T. 24. p. 2 (1907). Sur le mode liaction de la Trrosinase. - Derselbe, La spécificité de la Tỵrosinase et son actions sur les produits de la dégradation des corps proteiques. Ibid. T. 24. p. 172-194 (1907). 


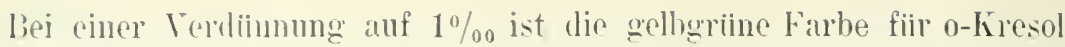
noch sthr stark, resp. die milchigweilie 'Tribung' fiur p-líesol, bei 1/1000u sind beile Reaktionen noch seln deutlich. I)ie Grenze der Sichtharkeit liegt zwischen 10.000 und 100.000. Die Sensibilitit der Guajakprobe ist eine noch feinele: abel sie längt von so vielen Vebenumständen ab, dab diesclbe allein keinen sicheren Schlub gewährt. Inferilem sind o-Kresol mud p-líresol chenische Kïrper, die in gröfter Reinheit zu erlangen sind: ilue lösungen $\left(1^{0 /}, 0\right)$ sind anch ziemlich haltbar.

Iiei Lntersuchungen iiber ()xydationsfermente ${ }^{1}$ ) achte man genau laranf, daß die lieagenzien nicht selten peroxydient sind. Es gelingt manch-

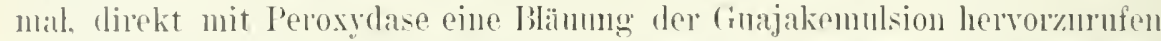
orler ebenfalls dilekt P'rogallussäure zu oxydieren, oder es färben sich andere, noch susiblere lieagenzien fast sofort durch die zugesetzte l'eroxidase. Es laibt sich seln leicht feststellen, dab entweder der Alkohol peloxydhaltig ist, oder das (ruajakhar\% sich an der ()berfläche oxydiert lıat. orler es hat sich die l'vogallussämre an der Luft ein wenig verändert.

Will man die Guajakprobe anwenden, so ist darauf zu achten, dab für jeden Versuch diue nene alkoholisehe Lösme bereitet werden mulf; das Guajakhar\% mul ron der äuberen oxydierten Schicht durch schaben hefreit werden. Zum Nachweis ron Peroxyd in Alkohol kam folgenderweise verfahren werden. Aus dem Alkolıol wird eine Guajaktinktur bereitet und mit Wasser zu cinel sog. Guajakemulsion gemischt. Setzt man l'eroxydase linzu, so wird sich die Guajakemulsion sofort blau fälben, falls der IIkohol peroxylualtig ist, bleibt die blaue Farbreaktion aus, so kömmen die Reagenzien als peroxydfrei betrachtet werden. Ha auferdem die (inajakenulsion an der Luft sich rasch oxveliert, so dab sie sich nach kurzer Keit bei '/usat\% von I'eroxydase allein schon bläut, so empfiehlt es sich, zu qualitativen Versuchen l'yrogallol oder Kresol zu verwenden, die viel mehu zurerläissin sind.

Da Wasserstoffsuperoxyd ron Katalase (siehe unten) rasch zersetzt wird und in den meisten I'flanzensiften stark zur Wirkung lommt. so ist es absolut notwendig, in solchen Fällen, wo es gilt, die Höhe des Peroxydasemusat\%es zn messen, in lehenden oder erfrorenen oder auf eine andere Weise ohne Hitze getöteten I'flanzen oder Tierorganen sich eines l'eroxyis zu hedienen, welches wasserlöslich ist. Es eignet sich dazu besonders gnt das dem Hydroperoxyd am näichsten stehende Ithylhydroperoxyd $\mathrm{C}_{2} \mathrm{H}_{5}($ ). () (1). $\left.{ }^{2}\right)$

$100 \mathrm{~g}$ Diäthylsulfat werden mit $115 \mathrm{~g}: 30 \%$ iger Hydroperoxydlösung, [75) G Kaliumbydroxyel und $600 \mathrm{~cm}^{3}$ Wasser bis zum Versehwinden des Diäthylsulfats geschiittelt und das angesiucrte lieaktionsprodukt aus dem Luftbarl iilerdestilliert. Nich zweimaligen Cberdestillieren unter vermin-

1) R. Chodat und A. Bach, Entersuchungen. VII. Uher die chemische Natur der Oxydasen. Berichte d. Dentsch. chem. Gesellsch. Jg. 37. S. 36 (1904).

$\left.{ }^{2}\right)$ Baeycr und rilliger, Ber. l. Dentsch. chem. Gesellsch. Jg. 34. S. 738 (1901). liach und 'hodat, Untersuchungen etc. IT. Üher Katalase. Ibid. Jg. 36. S. 1758 (1903). 
dertem Druck ergibt das erhaltene P'rodukt (20.5 $g$ ) hei der jodometrischen Bestimmung $2 \cdot 7 \%$ X 7 thylhydroperoxyd. Mit dem Titanschwefelsänrereagens wiht es nicht die mindeste Gelbfürbung: es ist also völlig hydroperoxydfrei. Es enthält neben viel Alkohol eine Spur Essigsäiure.

\section{Messung der Aktivitat der Peroxydase.}

A. Dnreh die ()xydation von Progallussäure. ${ }^{1}$ )

Es wird in $35 \mathrm{~cm}^{3}$ Wasser 1 g reine I'yrogallussäure gelöst und zu je 10 solchen Lösmngen wachsende Iengen von Peroxydase oder ein konstantes Volumen Wasserstoffsuperoxyd zugesetzt. Etwa in folgender Weise:

\begin{tabular}{|c|c|c|c|c|}
\hline $\begin{array}{c}\text { Pyrogallol } \\
\text { I. }\end{array}$ & $1 \mathrm{~g}$ & $\begin{array}{c}\mathrm{II}_{2} \mathrm{O}_{2}, 1 \% \\
10 \mathrm{~cm}^{3}\end{array}$ & $\begin{array}{c}\text { Peroxyclase } \\
0.01\end{array}$ & $\begin{array}{c}\text { Purpurotallin } \\
0.021\end{array}$ \\
\hline II. & $1 .$. & 10 & 0.02 & 0.042 \\
\hline III. & $1 .$. & 10 & $0.0: 3$ & 0.066 \\
\hline IN. & $1 .$. & 10 & 0.04 & 0.086 \\
\hline V. & $1 .$. & 10 & 0.05 & 0.102 \\
\hline VI. & 1. & 10 & 0.065 & 0.123 \\
\hline VII. & $1 .$. & 10 & 0.07 & $0 \cdot 145$ \\
\hline VIII. & 1. & 10 & 0.08 & $0 \cdot 166$ \\
\hline IX. & $1 .$. & 10 & 0.09 & 0.162 \\
\hline $\mathrm{X}$ & 1. & 10 & 0.010 & 0.162 \\
\hline
\end{tabular}

Die Wischung soll $50 \mathrm{~cm}^{3}$ betragen. Gleich nach dem Zusatz von Peroxydase bräunt sich die Flïssigkeit, bald nachher triibt sie sich und Purpurogallin fängt an. sich abzuscheiden. Man lasse die Versuchsflaschen 12. Stunden stehen; der Bodensatz wird auf gewogene Filter abfiltriert. mit $50 \mathrm{~cm}^{3}$ destilliertem Wasser gewaschen. Die Filter werden im Trockenschrank bei $100^{\circ}$ getrocknet und gewogen.

In einer zweiten Reihe ron Versuchen läßt man die Quantität des Wasserstoffsuperoxyds variieren mit einer gleichbleibenden Venge I'eroxydase:

\begin{tabular}{|c|c|c|c|c|}
\hline $\begin{array}{c}\text { Pyrogallol } \\
\text { I. }\end{array}$ & $1 g$ & $\begin{array}{c}\mathrm{H}_{2} \mathrm{O}_{2}, 1^{\circ} \% \mathrm{O} \\
\quad 1 \mathrm{~cm}^{3}\end{array}$ & $\begin{array}{c}\text { Peroxydase } \\
0.10\end{array}$ & $\begin{array}{c}\text { Purpurogallin } \\
0.0205\end{array}$ \\
\hline II. & $1 .$. & $\stackrel{-2}{ } \quad$. & $0 \cdot 10$ & $0.0 \pm 2$ \\
\hline III. & 1. & $3 \quad$. & $0 \cdot 10$ & 0.060 \\
\hline IV. & 1. & $t$ & 0.10 & 0.078 \\
\hline V. & $1 .$. & 5 & $0 \cdot 10$ & 0.099 \\
\hline 11. & $1 .:$ & 6 & $0 \cdot 10$ & $0 \cdot 1 \geq 1$ \\
\hline III. & 1 & 7 & $0 \cdot 10$ & $0 \cdot 141$ \\
\hline VIII. & 1. & 8 & $0 \cdot 10$ & $0 \cdot 168$ \\
\hline IX. & 1. & 9 & $0 \cdot 10$ & $0 \cdot 168$ \\
\hline $\mathrm{I}$ & 1. & 10 & $0 \cdot 10$ & $0 \cdot 163$ \\
\hline
\end{tabular}

1) R. C'hodat und A. Bach, Lntersuchungen über die Rolle der Peroxyde in der ('hemie der lebenden Zelle. 1. e. Berichte d. Deutsch. chem. Gesellsch. Jg. 36. S. 607 (1903). - Dicselben, Biochem. Zentrallı. Bd. 1. S. 417 (1903). 
Inrch diese Versuche libt sich leicht beobachten, dah die Wirkung ler I'eroxylase sich in einem bestimmten Verhältuis zum Wasserstoffsuperoxyd verhält. In diesem Versnche war zufülliọ das Verhältuis in ganzen Zahlen ansgedriekt. $1 \mathrm{cg}$ Peroxrdase alitivierte genau $1 \mathrm{~cm}^{3}$ Wasserstoff-

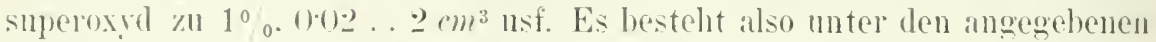
Bedingmeng zwischen I'eroxydase und Wasserstoffsuperoxyd ein honstantes Verhälnis. Eine (yuntität n l'eroxydase aktiviert eine Quantität m Wasser-

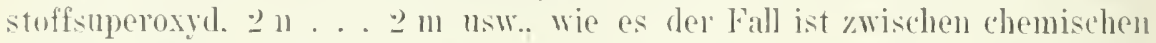
Verhiudumen. Es zuget dies also. daf beide sich zu einem chemischon

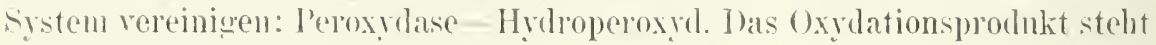
num zu diesem Srstrm in direktem Verhältuis bis zu einer Grenze, ïber weleho die Masse des (oxydationsproduktes konstant bleibt. Es lälit sich num aber zeigen, dafi diuse obere firenze auch ron der Masse des rorhandenen.

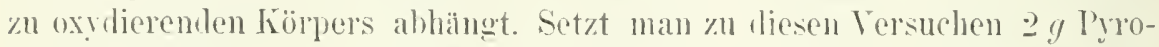
wallussiume statt $1 \%$ so bleibt das Verhältuis zwischen l'eroxydase mud Wasserstoffsuperoxyd bestehen. abor die Quantität des (Oxylationsprodulites steight:

\begin{tabular}{|c|c|c|c|c|}
\hline & lyrogallol & $\mathrm{H}_{2} \mathrm{O}_{2} 2 \mathrm{zn} \quad 1_{0}^{\circ}$ & l'eroxplase & Purpurogallin \\
\hline 1 & 1 & $10 \mathrm{~cm}^{3}$ & $0 \cdot 10$ & $0 \cdot 166^{\circ}$ \\
\hline B & 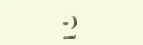 & 10 & 0.10 & $0.20: 3$ \\
\hline$c^{\prime}$ & ;) & $10 .$. & $(v \cdot 10$ & $(1.205)$ \\
\hline 1) & 4 & 20 & $(j \cdots)(0)$ & $0 \cdot 401$ \\
\hline
\end{tabular}

Mit gereiniotor l'eroxydase (Stoctilin und Chodat) kann unter ähnlichen Bedingmoen die Lushente an I'urpurogallin erliöht werden. Es liahen

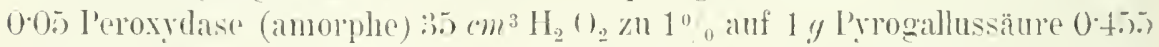
l'mpurogallin geliefert. Was zu (1) 1 l'eroxydase 0?!)10 Purpurogallin entspricht.

In all diesen Versuchen ist daranf zn achten, dalf die Konzentration des Masserstoffsuperoxyds nicht zu hoch steigt. Fis hat sich mämlich gezeigt, dab, je mehl die Poroxydase gereingt ist, sie mu so mehr dureh zu

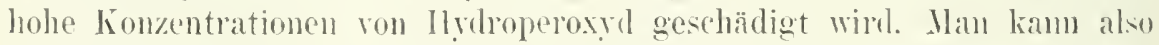

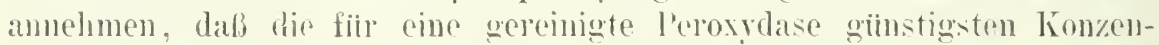
trationen für eine weniger roine nicht zu hoch fallen werten. so dadi die Konzentration ${ }^{1}$ ) ron $0 \cdot 1-0^{\circ} \% \%$ als für die meisten Versuche ginstig angenommen werden liams.

Die schädliche Wirkmng ciner zu hohen $\mathrm{H}_{2}\left(\mathrm{O}_{2}\right.$-Konzentration hommt in folgender 'Tabelle klar zum Insdruek ${ }^{2}$ ):

Peroxydase

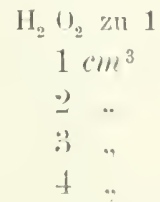

l'urpurogallin gef.

berechnet

0.05

$1 \mathrm{~cm}^{3}$

0.0

$(0.5)$

$0 \cdot 05$

$+$

$0 \cdot() 178$

$(1.016$

$0 \cdot(1)=1$

$0.0: 3 \cdot 2$

(1) $+1, i 6$

$0 \cdot()+8$

0.0601

0.06 it

1) Berechnet anf das totale Volumen des Gemisches

") Chorlat in stoeklin, 1. c. S. 35 . 


\begin{tabular}{|c|c|c|c|}
\hline $\begin{array}{c}\text { Peroxydase } \\
0^{\circ}()_{i}^{-}\end{array}$ & $\begin{array}{c}\mathrm{H}_{2} \mathrm{O}_{2} 2 \mathrm{zH} 1^{\prime \prime} \\
5 \mathrm{C}^{\circ} \cdot \mathrm{m}^{3}\end{array}$ & $\begin{array}{l}\text { l'urpurogallin gef. } \\
0 \cdot 080-2\end{array}$ & $\begin{array}{c}\text { bererhnet } \\
0 \cdot()<0\end{array}$ \\
\hline $0 \cdot 0$ & (j).. & $0 \cdot(9 !): 3 \cdot 2$ & 0.096 \\
\hline $0 \cdot 0 \overline{5}$ & 7 & (1).1181 & $0 \cdot 112$ \\
\hline $0 \cdot 0 \%$ &.. & 0.0956 & $0 \cdot 11:-$ \\
\hline $0 \cdot(05)$ & $!$ & $008 \div$ & $(0 \cdot 11 \stackrel{2}{-2}$ \\
\hline 0.05 & 10 & 1007.2 & $0 \cdot 112$ \\
\hline $0 \cdot 05$ & 11 & 11.0467 & 0.112 \\
\hline$(0 \cdot 0.5$ & 12 & $0 \cdot(0-1.5): 3$ & $0 \cdot 112$ \\
\hline 0.05 & $1: 3$ & $0 \cdot()++2)$ & $0 \cdot 11 \geq$ \\
\hline $0 \cdot 05$ & 14 & $(1 \cdot(): 396$ & $0 \cdot 112$ \\
\hline 0.05 & 15 & 0.0:3อล & $0 \cdot 112$ \\
\hline $0 \cdot 0)$. & 16 & (1).(0:3:3!) & $0 \cdot 112$ \\
\hline$(0.05)$ & 17. & $0 \cdot 0: 3+1$ & $0 \cdot 11: 2$ \\
\hline 0.05 & $18 .$. & & \\
\hline
\end{tabular}

I'yrogallussäure in starker Konzentration iibt ebenfalls einen nachteiligen Ënflub auf die Aktivierung der I'eroxydase aus, wenn sie zu lange mit dem Ferment in Beriihrung kommt. Hat man solche Bestimmungen auszuführen, so tut man gut, das Ferment zuletzt als Wasserlösung zuzusetzen.

Den oben angegebenen krörterungen zufolge kömnte man nach Buch vorläufig das Aktivierungsvermögen eines I'eroxydasepräparates folgendermaken definieren: Von dem im Exsikkator anfbewahrten Präparate werden ca. 0:30 g genau abgewogen und in :30 $\mathrm{cm}^{3}$ Wasser gelöst. $5 \mathrm{~cm}^{3}$ dieser Lösung werden mit ïherschiissigen Hydroperoxyd, on cm $^{3}$ 1\% iger Ilydroperoxydlösung und 1 1 g I'yrogallol zusammengebracht: das entstandene P'urpurogallin wird mach 12 Stmonden auf ein tariertes Filter gehracht, mit $200 \mathrm{~cm}^{3} \mathrm{Wasser}^{\circ}$ gewaschen, bei $105^{\circ}$ bis zur Gewichtskonstanz getrocknet und gewogen.

Andrerseits läbt man $10 \mathrm{~cm}^{3} 1 \%$ iger Hydroperoxydlösung mit ïberschiissiger Peroxydase (ํ. $\mathrm{cm}^{3}$ der obigen Lösung) auf $1 \% \mathrm{~g}$ Prrogallol einwirken -- das Volumen der Reaktionsfliissigkeit beträgt in beiden Fällen $100 \mathrm{~cm}^{3}$ (modifiziert nach Chodat) - und verführt weiter wie oben.

Ist a die mit IIdroperoxydiberschuf angewandte Peroxydnenge und m die entstandene I'urpurogallinmenge, b die mit Peroxydaseïberschuli angewandte Hỵdroperoxydmenge und n die dabei entstandene P'urpurogallinmenge, so ist $\frac{\mathrm{bm}}{\mathrm{n}}$ die Hydroperoxydmenge, welche mit a-Peroxydase in Reaktion trat, und $\frac{\mathrm{hm}}{\mathrm{an}}$ das Aktivierungsvermögen des untersuchten Peroxydasepräparates. ${ }^{1}$ )

1) A. Bach, Über die Wirkungsweise der Perrỵdase bei der Realition zwischen Hydroperoxyd und Jodwasserstoffsäure. Ber. d. Deutsch. chem. (iesellsch. Jg. 37. S. 3787 (1904). 


\section{Oxydasen. $\left.{ }^{1}\right)$}

Es sind his jetzt viele Oxydationsfermente in Pflanzen- mnd Tiersäften mol (Moanen aufoefunden worden. Hore Wirkung anf rerschiedene chemisobe Verbindungen ist beschrieben worden. ohne dalb die Autoren die spezifische Tätigkeit der ron ihmen mutersuchten Oxylationsformente in Vergleich zu anderen besser bekannten l'ermenten klar ror Angen gehabt hahen. So wird öfters von (oxydase ans l'ilzen. Ferment ans Leber odre

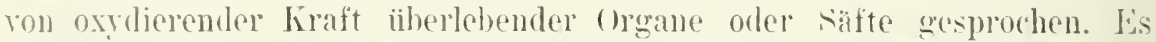
sind das physiologische Begriffe: die Biochemie kamm diese Angaben verwerten, dadurch, dab diese Beobarlitungen der Ausgangspunkt ron logiseh und kritisch durchgefühten Lutersuchungen werden kïmmen. Ita jedoch die meisten dieser Angaben jeder Methodik cutbeluren oder sich anf zu rage Fermentbegriffe beziehen, so miissen sie hier unberiickichtint bleiben.

Ls sei hier nur kn1\% angegehen, wolde lieagenzien gebrancht werlen, num die oxydative Fermentwirkung der Pflanzensüfe oder Tierorgane zu charaliterisieren.

Viele Pflanzensäfte oder (organe färben sich an der Luft: ebenfalls Tiersifte. Werden diese Säfte oder (Hoane rorerst durch liochen von ihren Fermenten befreit, so bleibt die Färbmg ans. Es werlen muter anderem durch den Luftsanestoff muter Farhstoffhildung oxvdiert (sog. Atmungspigmente von Palladine 2 ):

(iclb, gelberiun, damn blan: Viele Boletusarten. ${ }^{3}$ )

Blan: Iilut von ('ephalopoden. ${ }^{4}$ )

Rot, später violett bis schwarz: l'ilze, \%. L. liussula nigricans (Terlschwamm), A lmillaria mellea (Hallimasch), l'salliota eampestris (Champignou). Amanita l'ubese ens (l'erlschwamm) ete. P'hanerogamen: Weizenkeimlinge, Weizenkleie (Schwar\%brot) ${ }^{5}$ ). Kartoffelknollen, Tpfel. Finchtfleisch der Nub ete. viele Stengel und Plätter, z. R. ron Vicia Faba (Saubolme), Lathrus niger. Silphium sp. ete. 'Tegumente vieler Insekten, Sekret les 'Tintenfisches, die llant mehrerer Kaltbliiter.

1) schoenbein, Basler Verhandl. I. S. 229 ; II. S.9: III. S.697; V. S.34 ete. (1855 lis 1867). - Bertrand. Sur le latex de larbre ì laque. Comptes liendus de l'deadémie des sciences de I'aris. T. 118. p. 1215 (1895). - Derselbe. Sur la lacease et le pouroir oxyclant de cette diastase. 'T. 120. p. 266 (1895). - loersellie, Sur la présence simultance de la lacease et de la tyrosinase dans les champignons. T. 12:. p. 1132 (1896). I) erselise, Laque et lacease. Archives de Physiologie. T. 20, 1. 23 (1896).

$\left.{ }^{2}\right)$ H. Pralladime, Die Atmungspigmente der Pflanzen in Hoppe-seylers Zeitsehr. f. physiol. Chem. Bal. 5.). \&. 208 (1908).

$\left.{ }^{3}\right)$ Bertrand. Sur le blenissement de certains champignons. Comptes rendus de l'Acad. des Sciences. T.1333. p. 12333(1901). - De rselbe, Amm lustit. Pastenr. T.12. p.179 (1902) und schon früher genan beschrichen und erkannt durch schocnbeins U'ntersuchungen. Visle Basler Verhandl.

4) Pirri et Poitier, I'résence d"une Oxydase..... dans le sang des acéphales. comples rentus Acad. Se. 'T. 122. S. 1314.

5) Boutron.r. Sur les causes yui produisent la couleur du pain bis. Comptes rendus de l'Académie des sciences de Paris. T. 120. p. 934 (1895). - Bertrond et H. Muttermileh, la mode de coloration du pain his, Annal. Institut Pasteur. T. 21. p. 833 (1907). I'. še, Contribution à l’étude des applieations thérapeutipues des oxydases. Paris 1905. 
liraun, dann schwar\%: Vilchsaft von lihus vernicifera und lihus succedanea L. f. (Anwendung: Bereitung (les japanesischen Lacks.))

Fuchsinrot: Saft mehrerel Jacobiniarten (wunderschöne Reaktion iuf Luftsauerstoff). ${ }^{2}$ )

(ielh, dam schwar: l'ilze (Hygrophorusarten); Phanerogamen (Monotropa), Frichte der Viburnum Lantana.

Fs ist ein leichtes, in den meisten Fällen aus der intakten I'flanze durch kochendes Wasser resp. durch Alkohol das Chromogen (Leukobase) auszuziehen und aus anderen l'flanzen oder Tieren ein Ferment ohne Chromogen in der Kälte zu bereiten (siehe unten), welches in fiegenwart von Luftsanerstoff das Chromogen zı einem gefärbten Körper zı oxydieren vermag, z. B. aus Russula delica gewinnt man einen Saft, der sich nicht spontan fürbt, der aber, dem gekochten Saft von Russula nigricans zugesetzt, die Tyrosinreaktion giht. Der Saft von Amanita vaginata, der sich ehenfalls nicht spontan rötet, giht die charakteristische Färbung mit dem gekochten Auszug aus Amanita rubescens.

Es ist nun späteren Untersuchungen vorbehalten, zu zeigen, inwieweit allen diesen Farbreaktionen spezifische Oxydationsfermente entsprechen. In mehreren Fällen ist heobachtet worden, daß bestimmte chemische Substanzen durch Pflanzenansziige oder Organbreie oder -extrakte zu ebenfalls bestimmten Kürpern oxydiert werden olme Farbenumschlag, z. B Alkohol zu Essigsïure, an der Luft durch Azeton-Daneressigbakterien. ${ }^{3}$ ) So Salizylaldehyd zu Salizylsäure, Benzaldehyd zu Benzoesäure durch Leber-, Lungen- und Milzextrakte (s. unter Aldehydase). Hier spielt jedoch der Luftsauerstoff heine liolle.

Zwei dieser (Xxydationsfermente sind zurzeit etwas besser bekannt. Lakkase und Tyrosinase. Inwieweit die Aldehydase als spezifisches Oxydationsferment gelten kam, ist vorläufig nicht zu entscheiden.

\section{Lakkase. ${ }^{4}$ )}

Darstellungsweise: Dem Nilchsaft ${ }^{5}$ ) von Rhus vernicifera oder Rhus succedanea wirl das $t$ - Jfache Tolumen starken Alkohols zugesetzt: der entstandene Niederschlag wird auf einem feinen Tuche mit starkem Alkohol gewaschen, bis die abfließende Flïssigkeit sich nicht mehr durch Zusatz ron Wasser triibt (Fehlen ron Harz: Lakkol): das Präzipitat wird dann mit kaltem Wasser ausgelaugt; es löst sich zum größten Teil bis auf ein schwärzliches Residuum, das durch Filtrieren entfernt wircl. Das klare, wïsserige Filtrat wird hierauf mit dem zehnfachen Volumen Alkohol

1) Bertrand, La laccase et le pouroir oxydant de cette diastase. Comptes rendus de l'Académie des sciences de Paris. T.118. p.1215 (1894).

$\left.{ }^{2}\right)$ J. Parkin, On a brilliant pigment appearing after injury in species of Jacolinia. Report of the Brit. Assoc. for the adrancement of Science, p. 818 (1904).

${ }^{3}$ ) Buchner und Gaunt, Uber die Essiggärung. Liebigs Annalen. 349. S. 140. (1906).

$\left.{ }^{4}\right)$ Yoschida, Chemistry of lacquer. Tokyo Journ. Chem. Soc. Vol. 43. p. 472 (1883).

5) Bertrand, Sur la laccase. Comptes Rendus de l'Académie des sciences de Paris. T. 118. p. 1215 (1904). J. Parkin, On a hrilliant pigment appearing after riguny in species of Jacobinia in Report of the Brit. Assoc. for the adrancement of science. p. 818 (1904). 
rersetzt. Her nen entstandene Niedershlag wird num von der Fliissigheit getremnt. gesammelt und in Valkum ïber schwefolsüre gretrocknet.

Iriewohl hei den höheren Pflanzen sehr rerbreitet, lïbt sich Iakkise aus densulben mu schwer isolieren. Pilze eignen sich viel hesser dazn.

liussula foetens und Laetarius rellerens sind besonders gute Materialien.

A. Aus liusinlat foetens:

Es werlen glog linssula foeteus fein mekleinert. Hie schlemime P'ilzmasse wiol ansogeprelit und der visköse salft direkt in Nkohol fliefien gelassen. Ier reichliche Niederschlag wird gesammelt. auf Touplatten rasch getrocknet. Dieses lonferment ist zum göbten Teil in Masser mulisslich. In Löisng geht num sowohl Lakkase wie Tyosinase. Letztere kamn ron ersterer durch Hitze getrennt rerden: Man lasse die Fermentlisung im Wasserbal hei $65^{0}$ eine stumde lang stehen. Die Tyosinase wird dabei zerstört und dic Lakkase nur wenio abgeschwïcht.

B. Als Lactarius vellereus $\left.{ }^{1}\right)$ :

Ier Saft kann als Tohferment verwertet werden. Dic l'ilze werden gepreft und der Saft in Flaschen mter \%usat\% eines Antiseptikmms (Chloroform. Toluol) im Inukeln aufbewahnt.

Inreh Fällen mit Alkohol gelangt man zu eincl Rohoxydase wie oben.

C. Ans (lavalia flava:

Auf dieselbe Weise. wie oben. läht sich eine Lakkase. die aber frei ist ron Tyrosinase, gewinnen.

Bestimmmug des oxydationswertes der Lakkase.

A. Volumetrische Methode dureh Messume des Volumens samerstoff, das in der \%eiteinheit und in fegenwart cince hestimmten Menge des zu oxydierenden Kïrpers anfgenommen wir (l. ${ }^{-1}$

Fis werken 10 - 20 $\$ 0 . \mathrm{cm}^{3}$ del Fermentlösmng mit Wasser zu

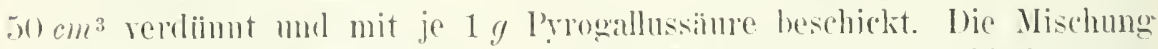
wird num in ler Waschflasche mit einem Endioneter in Verbindung gesetzt. Wic ans Bertrunds I'ntersuchungen bekamt ist, wird bei der oxrlation der Pyogallussänre nicht nur sauerstoff anfgenommen. sondern zugleich Kohlensäme ahgegeben. Es müssen also beide Gase volumetrisch oder gravinetrisch hestimmt werden. Als behälter henutzt man tine mit Glashähnen vershene zugeschmolzene Glasflasche von bekanntem Inhalt. Sach Füllen mit kohlensänrefreier Luft wird der behälter dureh das his an den Boden reichende /uleitungssohr mit den Reagenzien beschickt nud mit einem Mefinyarat verbunden, welcher ohenfalls kohlensäurefreie Luft entlält. Her Apparat hesteht aus einem graducerten Mebrohr und einem

1) R. Chorlat und A. Barh. Tntersuchungen. III. Oxydationsfermente als peroxydareugende körper. Burichte d. Tentsch. chem. (iesellsch. Jg. 35. S. $3944(1902)$.

$\left.{ }^{2}\right)$ R. Chodat und . I. Bach, Intersuchungen. 1. c. 36. S. 605 (1903). 
Niveaurohr und ist mit (buecksilher heschickt. Nach x stunden wird das absorbierte Sauerstoffrolumen unter Beriicksichtignng der bei Iseginn und am Sichlusse des Versuches ahgelesenen T'emperaturen und Barometerstïnde bestimmt, und das sämtliche (ias durch Hehen des Niveaurohres in den Behïlter ïhergefiihrt und die vorhandene Kónlensüure gravimetriseh bestimmt.

B. (irarimetrisch durch die Menge des ausgeschiedenen l'urptrogallins's:

Yier Erlenmeyerkolhen werden mit je 1 g Pyrogallussïure und wachsenden Mengen einer Lakkaselösung beschickt: das Volumen wird bei allen Versuchen auf $40 \mathrm{~cm}^{3}$ gleichgestellt.

\begin{tabular}{|c|c|c|c|c|}
\hline & $A$ & $B$ & $c^{\prime}$ & I) \\
\hline Pyrogallol & $1 g$ & $1 y$ & $1 \%$ & $1 g$ \\
\hline Lakkaselösung & $10 \mathrm{~cm}^{3}$ & $20 \mathrm{~cm}^{3}$ & $: 30 \mathrm{~cm}^{3}$ & $40 \mathrm{~cm}^{3}$ \\
\hline Wasser & $30 \quad .$. & $\underline{0} 0$ & $10 \ldots$ & \\
\hline
\end{tabular}

Nach 24 Stunden (resp. 30 Stunden, to Stunden) wird die Quantität des abgeschiedenen Purpurogallins nach der oben unter Peroxydase (S. 49) angegebenen ITethode bestimmt. Die Wirkungsweise der Lakkase bei den benutzten Konzentrationen läßt sich annähernd genau durch den Ausdruck $a x+b$ formulieren, wobei a die Quantität des abgeschiedenen Purpurogallins bei der Konzentration $1, x$ die Konzentrationen $1,2,3$ ete. und b eine Konstante bedeuten.

\begin{tabular}{|c|c|c|c|c|}
\hline Nach 24 Stunden & $A$ & $B$ & $C^{\prime}$ & $D$ \\
\hline Gefunden & $0 \cdot(18:$ & $0 \cdot 130$ & $0 \cdot 159$ & $0 \cdot 211$ \\
\hline $\begin{array}{l}\text { berechnet } \\
(b=0.41)\end{array}$ & 0.082 & $0 \cdot 123$ & 0.167 & $0 \cdot 210$ \\
\hline $\begin{array}{l}\text { Nach } 72 \text { Stunden } \\
\text { gefunden }\end{array}$ & $\begin{array}{c}E \\
0 \cdot 15: 30\end{array}$ & $\begin{array}{c}F \\
0 \cdot 2 \cdot 230\end{array}$ & $\begin{array}{c}G \\
03135\end{array}$ & $\begin{array}{c}H \\
0 \cdot 3660\end{array}$ \\
\hline berechnet & $0 \cdot 15: 30$ & 0.2268 & $0 \div 3025$ & $0 \% 3780$ \\
\hline
\end{tabular}
werden:

Zu dieser Bestimmung kann statt Pyrogallussäure p-Ḱresol gebraucht

Lakkasehaltiger Laktariussaft wurde während einer Stunde bei $60^{\circ}$ erhitzt, bis sich keine Reaktion auf Tyrosin mehr zeigte. Die Lösung war schwach sauer. Zu 4 Proben (je $10 \mathrm{~cm}^{3}$ ) einer gesättigten Lösung ron p - Kresol wurden steigende Iengen der Lakkaselösung hinzugefügt, wie folgt:

\begin{tabular}{|c|c|c|c|c|c|}
\hline & \multirow[b]{2}{*}{ Lakkase } & \multirow[b]{2}{*}{ Wasser } & \multirow[b]{2}{*}{ p-Kŕesollösung } & \multicolumn{2}{|c|}{ Niederschlag } \\
\hline & & & & I. & II. \\
\hline$A$ & $10 \mathrm{~cm}^{3}$ & $: 30$ & 10 & $0 \cdot 0 \div 10$ & $0 \cdot 019$ \\
\hline$B$ & $20 \quad$. & 20 & 10 & 0.0285 & $0 \cdot 029$ \\
\hline$C^{\prime}$ & 30 & 10 & 10 & 0.0425 & 0.0375 \\
\hline$D$ & to . & 0 & 10 & $0 \cdot 0+31$ & 0.0482 \\
\hline
\end{tabular}

1) R. Chodut, Loi d'action de 1\%)xydase. Archires des sciences phrsiques et naturelles. T. 19. Nai (1905). 


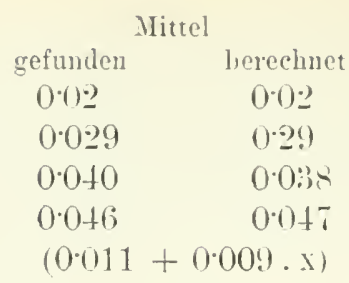

Man verfährt. wie oben, und wïscht den Niederschlag mit $50 \mathrm{rm}^{3}$ Wasser. (Nach 13. Zahorshi. Botanisches Institut. Genf.)

Eigenschaften. Lakkase hat die oleiche qualitative Mirkung wie das Fermentsystem: Peroxydase-Hyalroperoxyd (l'eroxylase-(Jygenase).

Es oxydiert direkt an der Luft: (majakemulsion. P'urpurogallin, Guajakol. Hydyochinon, angesäueltes Jodkalium unter Abscheidung vou Jod verwandelt den Milchsaft von Rhus vernicifera oder Rhus snceedanea (Iackhamm) zu schwarzen japanesischem orler toukinesischem Lack. wobei cin aromatischer Körper, Laccol' ${ }^{1}$. kondensiert wirl. o- und p-Kresol etc. etr.

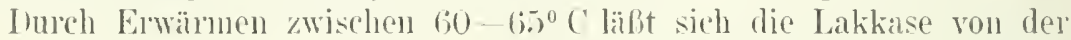
gewöhnlich beigemischten Ty'osinase tremn: sind beide Fermente zugegen. so gewinnt die Wirkung der Lakkase bei schwach saurer Reaktion die ()berhand: wird die Lösung alkalisch gemacht. so kommt die Tyrosinasereaktion zum Torschein. ${ }^{2}$ )

Dabei ist aber zu beachten, dafie saure lioaktion nur mit Vorsicht vorgenommen werden darf. da eine ansegerägt saure Reaktion die Wirkmo (ler Lakkase stark hemmt. ${ }^{3}$ )

Um die lieinheit einer Lakkaselisung zu hestimmen, verfahle man. wie folgt:

Zu einer $1 \%$ igen oder $05 \%$ igen p-Kresollisung setze man einige Kubikzentimeter der Lakkaselösung: man verteile die Mischung in viel lieagenzglaiser: A enthält obengenannte Mischung, $B$ mit /usatz ron Spuren ron Essigsiure bis zur schwad saulen Reaktion, $C$ wird schwad allialisch gemacht (nit kohlensaurem Natron), l) ebenfalls alkalisch, ahel" mit 'Musat\% von Glykokoll (spmen!). Ist nur Lakkise vorhanden untel Ausschluf von 'Tyosinase, so wird A milchig-weib, $B$ ebenfalls mit stärkerer 'J'ribung. C und I) reagieren viel sehwächer. Bei Terumreinigung mit 'Trrosinase färben sich $C$ und $D$ gell resp. rot.

Inwieweit die sog. Indophenoleaktion in den Pflanzen nud Tieren auf das Vorhandensein von Lakkase zuriickzufïhre'n ist. ist noch nnentschieden. ${ }^{4}$ )

1) Bertrand, l. c. Comptes rendus. T. 118. p. 1215 (1896).

2) ('hodut et Zahorshi, Sur les rélations qui nuissent la lacease et la tyrosinase. Arehives des Sciences physiques et naturelles. Janual und März 1909. p. 90 et 305.

s) G. Bertround, Recherches sur linfluence paralysante exercée par certains acides sur la laccase. Bull, de la Soc. chimique P'aris. l'e série. T. 1. p. 1120.

4) Röhmann und spitzer, I'ber Oxydationswirkungen tierischel Gewele. Ber. d. Deutsch. chem. Gesellsch. Jg. 28. S. 567 (1895). - Spitzer, Beobachtungeu üloer die oxylative lecistungen tierischer Giewehe. I'tügers Archir. Bd. 71. S. 596. 
\%ı diesem Behufe wird folgende Lösung öfters von den Tierphysiologen in Anwendung gebracht:

\begin{tabular}{|c|c|}
\hline $\begin{array}{l}\text { Paraphenylendiamin } \\
\text { \%-Naphtol }\end{array}$ & aa. $1 . t=1.5$ \\
\hline Soda & \\
\hline Wasser & $100 y$. \\
\hline
\end{tabular}

An der Luft wird diese Lösung nach und nach violett, dann blau; aber diese Färbung kommt mur langsam zustande: Indophenolreakt ion. Sie wird dureh I'flanzensäfte oder Organextrakte. wie Speicheldrïsen, Milz, Knochenmark, Thymus etc. beschleunigt. Gewisse wirksame Pflanzenextrakte widerstehen der Siedehitze, so daf es fraglich scheint, ob die Beschleunigung dieser Reaktion wirklich auf Oxydation zurïckzuführen ist.

\section{Tyrosinase.}

Vorkom men: Uieses Oxydationsferment scheint sehr verbreitet zu sein. Von ihm rührt die Schwarzfïrbung vieler Pflanzensäfte (Vicia Faba etc.), die Rotfärbung vieler Pilze her (Psalliota campestris, Boletus sp., Armillaria Mellea. Russula nigricans), die später in schwar\% übergeht (Weizenkleie, Kartoffelschalen). Tyrosinase ist auch bei Arertebraten, speziell in Insektenlarren (Tenebrio molitor, Lucilia Caesar), in dem Sepiablut, in der Tintendriise vieler Cephalopoden, in den melanotischen 'Tumoren von Pferden. in der Haut von pigmentierten Fischen und Kröten (Melaninbildung) festgestellt worden.

Nachweis: Da nit dem Ferment in den meisten Pflanzen auch zugleich Tyrosin zugegen ist, so läft es sich nur indirekt nachweisen. Am einfachsten ist es, ron dem Safte zu einer $1 \%$ on- $1 \%$ igen p-Kiresollösung zuzusetzen; ist Tyrosinase vorhanden und ist der Saft durch doppeltkohlensaures Natron in Utherschul, neutral oder hesser alkalisch gemacht, so geht die farblose Lösung in Gelb und dann in ()rangegelb oder Rot iiber; fïgt man einer anderen P'robe an Anfang des Versuches eine Spur von Glykokoll zu, so wird die Reaktion beschleunigt und die rote Farbe kommt gleich zum Torschein. ${ }^{1}$ )

D) arstellung: $A$. Kartoffeltrrosinase. ${ }^{2}$ ) Kartoffelschalen ( $\bar{b}$ bis $8 \mathrm{~kg}$ ) werden nach Befeuchten mit Alkohol mittelst einer Hackmaschine zu einem dicken Brei zerrieben und so rasch wie möglich ausgepreßt. Man lasse den bräunlich gefärbten Saft direkt in ein Glasgefäß flielien, das zur Hälfte mit starkem Alkohol (94\% $\%$ igen) gefüllt ist. Den roluminösen Niederschlag lälit man absetzen; die klar gefärbte alkoholische Flïssigkeit wird mittelst eines Heber's soweit wie möglich entfernt, der Bodensatz auf ein Filter gebracht und noch feucht mit der nötigen Menge destillierten Wassers unter Zusatz von Toluol 1 Tag stehen gelassen; hierauf wird filtriert und

1) R. Chodat et W. Stanb, Nourelles recherches sur les ferments oxydants. Archires des Sciences physiques et naturelles. IVo période. T. 24. p. 188 (1907).

2) W'. Staub, Nourelles recherches sur la Tyrosinase in Chodat, Travaux de l'Institut de Botanique de l'Université de Genère. 8 o série. I. fasc. (1908). 
die klare Flissigked mit starkem Alkohol rersetzt. Der Niedersthlag setzt sich leicht ab: dureh Inkantieren läbt ex sich von dor dariber stehenden Fliissigkeit leicht tremnen.

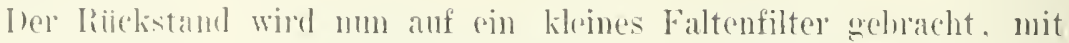
Alkohol gewaschen und noch fencht anf poriosen Porzellanschalen ibber

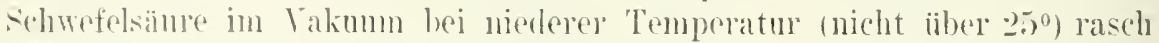
getrocknot.

biesel trockene Iiickstand list sich rollkommen in Wasser, oxydiert sich nicht an der Luft, enthält somit keinen oxydablen Körper ('Tyrosin ete.). I)ie Iösung enthält keine Lakkase, bläut also frische Guajakemulsion nicht. wohl aber ist darin Peroxydase vorhanden, was durch /usatz von Hydroperoxyd zur Guajakemulsion sich gleich zeist.

Lösmogen vou Tyrosinase in Wasser halten sieh hej /usatz ron Tolnol ziemlich lang (mehrere 'lage). aber die lloikmo nimmt langsam ab. Es ist jedenfalls besser. die Lïsmb immer frisch zu bereiten.

B. Jilztyosinase. Bekanntlich enthalten viele I'ilze Lakkase und Tyrosinase. Am bequemsten ist. Latetarins velle reus in Laubwälern zu sammeln; dieser P'ilz. der selı lejeht zu erkemen und in Mittelouropa der arobite mul zugleich einer der verbreitetsten ist. ist kreideweib, ziemlich zerbrechlich, mit dieken Lamellen an der Tuterseite des trichterförmigen Hutes mul gibt beim Inschneiden einen reichlichen weifen oder schwarh gelblichen Milchsaft, weleher seharf schmeckt. Ton diesem Pilz kïmen leicht jo kg in pinem Valchmittag gesammelt werden. Die l'ilze werdens so rasch wie möglich zerstiickelt, an hesten mittelst einer Hackmaschine, wie sie gewöhnlich in Kiiehen geblancht wird. Die schleimige Masse wird stark geprebt, der dunkle Saft mit starkem Alkohol versetzt. Wer oeichliche Niederschlag wirl auf einem Tuch gesammelt und die Lösung abfiltriert. Der noch fenchte Niederschlag wird hierauf mit Wasser versetzt und zwei 'Tage unter Kusaty von Tolnol digeriert. Die filtrierte Flissigkeit wird nun wieles durch Alkohol gefällt, der Niedersohlag gewonnen mut eventuell noch eimmal gereinigt. Die Lakiase ist durch diese Behandhung viel meln alngeschwälot als die 'Tyrosiuase.

Man kann anch die rohe Fermentmasse anf Touplatten rasch trocknen mud zur späteren Extraktion der Trrosinase verwenden. Mit der Zeit verschwindet die Lakkase zum gröbten Teil mol die Wasserextraktion der rohen Oxydaso liefert dureh /nsitz von Mlkohol ein sowohl ron Lakkase wie rom l'eroxydase frejes ferment, das die lieaktionen einer gereingten 'Yrosinase liefert (siche unten).

Es werden ron der liohtyosinase bog fein zerriehen und mit 500g Wasser t8 stmolen mazerieren gelassen, hierauf filtrient. I)as Filtrat wird mit 2 $/ 90^{\circ}$ igem Ilkohol rersetzt, sehr kur\% \%eit stehen gelassen, abdekantiert mol der Niedersehlag in wenic Wasser gelist und mit dem dreifachen Volumen stanken Alkohols rescetzt. Hel Niedorshlag wird, wie oben, behandelt und getrocknet. Er ist frei sowohl von I'erosydase wie von Lakkase (A).

1) Cotle, l'résence de la tyrosinase chez le ., Suberites Domuneula" in Comptes renlus Soc. Biolog. 'T. 55. p. 137 (19013). 
I) Fe liissigkeit. die ron dem sofortigen Viederschlag abrlekintiert wurde. wird num 2t Stunden stehen gelassen. Es setzt sich ein zweiter Niederschlag ab. Er wird abgetremt, sofort in Wasser grelöst und mittelst starken Alkohols prizipitiert $(B)$. Dieses I'rïparat hat die grleirhen Eigenschaften wie $A$. aber nicht stärker.

C. Tierische Tyrosinase. 1. Ans Suberites (lomuncular) (Schwämmen). Frischer Suberitessaft wird mit dem dreifachen Volum starken Ilkohols $(90 \%)$ rersetz.t. Der crefällte Viederschlag löst sich zum Teil in kaltem Wasser mul enthält die Trrosinase.

2. Aus Tintenfischen. ${ }^{1}$ ) Beim öffnen der Tintentasche vermeile man. die Tintendriise 7.1 rerletzen: man schabe die anhaftenden Tintenpartikelchen ab. Yon anßen liift sich die Lage der Irüse durch eine dunkelblane Farbe, die sich scharf ron dem umgebenden Gewebe abhebt. leicht bestimmen. I)as kleine (Iraan wird abgeschnitten und mit sand rerrieben: der entstandene Organbrei wird mit Chloroformwasser rersetzt und durch ein Tonfilter ron den schwarzen Teilchen befreit. Die klare Lösung enthält die gesuchte Trrosinase.

D. Rohtyrosinase (Pilzsubstanz). Zu Versuchen auf Trosin kann man sich anch einer Rohtrrosinase. wie sie in den Pilzen selbst enthalten ist, bedienen. Es werden zm richtigen Zeit Pilze aus der Familie der Asterosporen gesanmelt (August bis (Oktober). Lie besten sind:

$$
\begin{aligned}
& \text { Russula delica, } \\
& \text { Russula Queletii. } \\
& \text { Russula andantiaca, } \\
& \text { Russula lepida. } \\
& \text { Russula integra. }
\end{aligned}
$$

Alie enthalten außer Trrosinase anch Lakkase: es wird die gefärbte Epidermis sowohl rom Hut wie ron dem stiel abgenommen: der l'ilz wird hierauf in dïnne Scheiben zerlegt und bei Zimmertemperatur so rasch wie möglich getrocknet. Die Aufbewahrung geschieht an trockenem ()rte in weiten Gefäßen mit iiberfallendem Deckel.

In wohlverschlossenen Gefäßen verfaulen die Pilze ziemlich leicht. da dieselben nicht sterilisiert werden können.

Von den grob gepulverten Pilzen nimmt man gewöhnlich $1 \mathrm{~g}$ anf $50 \mathrm{~g}$ Wasser, lipt 2 stmden mazerieren und filtriert. I bie Lösung kann unter Zusatz von Toluol einige Wochen aufbewahrt werden.

E. Fohtrrosinase als Glyzerinauszug. Ter von der gefärbten Epidermis befreite Pilz wird in kleine Stiicke zerlegt und mit dem doppelten Gewicht chemisch reinen Glyzerins $\left(30^{\circ}\right.$ Beaumé) versetzt. Die Xrischung wird anfangs täglich mehrfach geschïttelt, nach einiger Zeit 16 Tagen) filtriert und im Dunkeln aufbewahrt.

1) Gessurd, Tyrosinase auimale. Compt, reud. Soc. Biolog. T. J4. p. 1305 (1902). Siehe auch $0 . r$. Fïrth und schneider, ľber tierische Trrosinasen und ihre Beziebungen zur Pigmentbildung. Beitr. z. chem. Physiol. u. Pathol. (F. Hofmeister). Bd.1. S. 229 (1901). 
Für saubere nud mzweidentige Tntersuchungen kann ansschlieflich die mittelst der unter Ziffer A mul $B$ bezeichneten Jethoden dargestellte Trosinase benntzt werden. Bis jetzt ist nur mit Methode $B$ eine Tyrosinase zil priparieren. die zugleich frei sowohl ron Lakkase wie ron Peroxydase ist. Die erwähnte Kartoffeltyosinase hat, wiewohl schwach. vor der mureinen Pilztrosinase, wie sie von den meisten Forschem bis jetzt benutzt wurde, den Vorteil. von Aminosäuren frei zu sein, obschon sie and weren del Gegenwalt vou Peroxylase nicht als physiologisch rein bezeichnet werlen darf. I)agegen ist die nach Nethode $B$ erlangte Tryosinase sowohl ron T'eroxylase wio von Iminosämen frei. Aus diesem Frumde sind alle mit nurriner 'Trosinase angestellten Versuche zu revidieren und die Angaben ler meist(u Autoren als sehr zweifelhaft anzusehen.

Eigenschaften: Tyosinase ist ein oxydationsfement, das spezifisch auf Trrosin eine oxydierende Wirkmog hat: es vermag woder eine reine Lakkase noch das System Mydroperoxyl T'eroxydase Tyrosin zu oxylieren. In jedoch beide hesser bekannten (Oxvasen anf die relschiedenen P'henole wirken kömmen, speziell auf l'yogallol, Phenol, Kilesol ete., so ist das Resultat, wem beide zugegen sind, je nach der relativen Menge der zwei Fermente und del Masse des zu oxydierenden Kärpers ein verschiedenes. Will man mun weiter gehen in dem studium del spezifischen Wirkmug ded Oxylationsfermente, so ist es mumgänglid notwendig, die Fermente in der Reinheit zu erhalten, in del sie unzweidentige Resultate liefern kïnnen. Da anferlem, wie unten gezeigt werden soll, die Aminosämen, der Tyrosinase zngesetzt, die Wirknng derselhen nicht nur heschlemigen, sondern anch in anderer Wrise beeinflussen kïmnen. d. h. andere Farbeneaktionen hervorbringen kömmen, so lassen sich Iflanzensäfte oder Pilzsïfte nicht liurzweg mit Tyrosinaselösungen identifizieren. Es läbt sich ja leicht dantum, dab, da in jeder wachsenden Pflanze durch den chemischen Metabolismus Aminosämren sich bikden, diesclhen je nach der relativen Menge nud Artmischmor die supponierte Tyrosinasewirkung verschiehen kömnen.

Anch in dem Falle, wo es heibt, die 'Trosinasewirkmo' anf Tyrosin zu studieren, eignen sich mmeine Fermente in keiner Weise. Demm anch hier kïmmen beimengmeng von Aminosämen schädlich wirken, indem sic dic Reaktion verlanssumen oder eventuell nicht his zmm Eutpunkt gehen lasseu kömmen.')

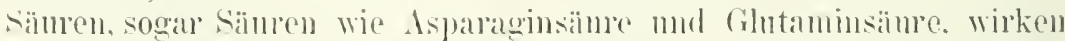
hemnnend. Genane Untersuchungen iiber die dureh Kusatz von sïnren bewilkte Hemmmng stehen noch alls.

Jedenfalls ist sicher, dah reme Trosinase an hesten anf Tyrosin wirkt. wenn die Lösmng nentral ist (Chodut mul Zahorshi).

Lälit man das Felment anf eine p-Kesol-( $\left.{ }^{1} 1000^{-1} / 100\right)$ lösmng wirken. so wird in neutraler oder sehr schwach alkalischer Lösmug ('Musatz rou

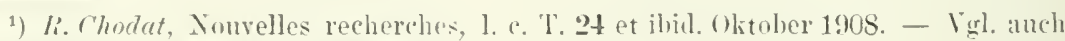
E. Abdrhatden und H. Guggenhrim, Ther die Wirkung der Trrosinase aus Russula delica ete. Zeitschr, f. physiol. ('hem. Bil. 54. S. 35:- (1908). 
$0.05-0.1 \%$ igem $\mathrm{YaHC(})_{3}$ ) die Fliissigkeit rasch goldgelb mul mit der Zeit orangegelb. aber nie rot. Solange die Reinigmug der Tyrosinase nicht soweit fortgeschritten ist. dab eine rote lieaktion nit p-Kresol ansbleibt. so mub dieselbe als mit Aminosäuren reruneinigt hetrachtet werden.

Spuren von (ilykokoll. Alanin. Leucin ete. geniigen (1/100000), um diese grelhe Farbe rasch in liot iiherzufiihren. War die Lösung am Anfang schwach alkalisch, so geht die schö̈n kirschrote Farbe (man lasse die Reagenzglisser ruhig stehen) ron unten nach ohen in Violett und zuletzt in Blat iiber. Je nach der Stärke der 'Tyrosinase nimmt der Umschlag von liot in Blau 2 Stunden bis 1 Tag in Anspruch. Lüsungen von p-Kiesol zu 1/100000 zeigen noch diese schöne Reaktion. Lösungen ron 1\% igem Kiresol rerlangsamen die Reaktion; sie konmt am besten zustande hei einer Kionzentration von $1 / 2000$. Die rein blane Endfarbe zeigt einen metallischen, schillernden, roten (fuchsinartigen) Dichroismus.

Prrogallussüure wird ebenfalls oxydiert. Die rotgelhe Farbe ist der durch Lakkase herrorgerufenen ganz ähnlich: l'urpurogallinbildung wurde aher bis jetzt nicht sicher beobachtet. Trrosinase rermag weder Guajak noch Guajakol zu oxydieren.

Es werden anch durch reine Tyrosinase oxydiert (in Gegenwart ron Glykokoll oder anderen Aminosäuren mit Farbenumschlag wie beim pKresol):

Tyrosinhaltige Polypeptide, wie l-Trrosinanhydrid. Glycyl-l-tyrosinanhydrid, Glycyl-tyrosin. d-Alanyl-glycyl-l-tyrosin. l-Lencyl-glycyl-l-tyrosin, Tetrapeptid aus Seide (1 l-Trrosin, 1 d-Alanin und 2 Glykokoll) (nach Chodat und Alderhalden). Die Farbemreaktionen sind jedoch nicht dieselben wie mit Tyrosin. Da aber diese Untersuchungen nicht mit reiner Tyrosinase (auler deu von Chodat ausgefuihrten) ausgeführt worden sind, sind die betreffenden Angaben nicht ganz eindentig, da die Terunreinigung mit unbekannten Gemengen Aminosïuren die spezifische Reaktion verschieben kann.

Phenylalanin gibt keine Farbenreaktion und wird wohl sonst nicht angegriffen.

Es ist bei solchen Lntersuchungen auf Polypeptide auch darauf zu achten, dab der Tyrosinase kein peptolytisches Ferment anbaftet. Die fegenwart eines solchen ist, wie folgt, nachzuweisen: 1. durch Bestimmung des Drehungsrermögens im Polarimeter (falls asymmetrische Körper zugegen sind; 2. durch Zusatz ron peptolytischen Fermenten (Trypsin) und Tergleichung der Reaktionen mit und ohne dieses Ferment.

Es läßt sich auf diese Weise leicht dartun, daß die erwähnten tyrosinhaltigen Polveptide als solche oxydiert werden. und daß der Oxydationswirkung keine hydrolytische Spaltung vorangeht.

Wie gesagt. wird l-Trrosin ron reiner Tyrosinase zuerst in einen schün rosaroten Kiörper umgewandelt; spïter geht die Farbe in Schmutzigviolett iiber und zuletzt entsteht ein schwarzer Niederschlag, der sich mit del Zeit ausscheidet und absetzt. Dieses schwarze Endprodukt ist Melanin genannt worden (vide: Zur Kienntnis der melanotischen Pigmente und der 
fermentativen Melanimbildung rou O. $ґ$. Fïrth und E. Jerusulem, Biochem. Zeitsehr.. 190\%. Bd. 10. S. 1:31).

Durch dieses Verhalten agen die Mboumprodukte der Mlbminstoffe lälit sich Tyrosinase zur Luterseheidung der peptischen von der tryptischen

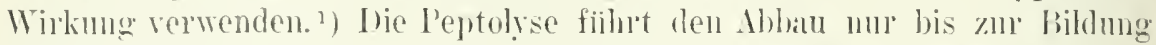
ron P'pentonen. bei der treptischen Verdamury entstehen dagegen Aminosänun. nnd besonders friihzojtig wirl nach Abderhalden Tyrosin frei.

Versetzt man eine peptonisierte Lösung ron tyrosimbaltigem Fiweil mit 'Tyosinase oder nur mit l'ilzextrakten, die Tyosinase neben Aminosänren enthalten, so nimmt das femisch eine grine his blangribe farlut an. die nicht in Bram und sehwar ibergeht. Ist aber die Verbanung weiter fortgeschritten und ist Tyrosin alowespalten worden, so nimunt das bigestionsgemisch rasch die charakteristische rotbrame mud bramschwarze Farbe an, die Tyrosin in Gegenwat ron Tyrosinaso gibt.

\section{Messung der oxrdativen Kraft der 'Trosinase.}

Genane Methoden zul' Destimmung del Wirkungsweise do 'Tyrosinase fehlen noch.

O. ¿. Fürth und E. Jerusalem benutzten zwej Methoden:

a) Methodr der sodimentierumg. Dabei crfolgt die schätzung der gehildeten Melaninnenge nach dem Volmmen der entstundenen l'ignontfailnume.

b) Methode der spektrophotometrischen M(ssumg. I)a bekantutlich zwishen Konzentration einer Farlstofflösung mol ihrem Extinktionskoeffizienten für cinen bestimnten spektralbezirk l'roportionalitit bestcht. gुe-

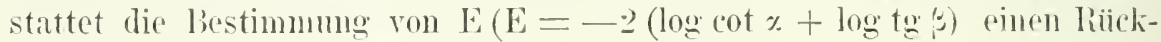
schlub anf die relative Menge gobildeten Melanins.

Die mitueteilten liesultate lassen aber diese zwei Methoden nicht als erwinscht betrachten. Noeh mohr: Dio Bildmog des Melanins ist kein primïres lrorlukt; durch rerschiedene Bedingungen, \%. B. durch Zusat\% ron Aninosïnen, kann dessen Bildmo verlangsant oder sogar anfoghoben werden. Ine Bedingmuen der Therfiihrung des roten ()xylationsproduktes des 'Tyosins in Melanin sind zurzeit vollständig mbekannt.

Die Keitdaner der Melininbildumg ist auberdem ziemlich lang. so dab dabei eine Schidigmne des Fermentes anzunchunen ist.

Weniger ungenan ist dic Moluminhestimmmosmethode, die A. Bach

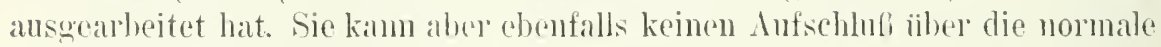
Fermontwirkung geben, da sic anch nur ain sekmndäres ()xvdationsprolukt zu bestimmen verman.

(2) Methode von Bach. ${ }^{2}$ ) In eine Reihe von 8 liechergliisern gibt man

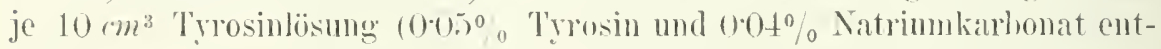

1) 1. W. Harlay, De lapplication de la tyrosinase ferment oxydant du Russula delica à loitule les ferments proténlytiques. Paris 1900 . (Thise de l'kecole de phamacie faite sous la direction du l'rof. Bourrpuelot.) - ('hodut und sitaub, l. e. 3 et seq.

2) A. Bach, Üher die Wirknngsweise der Tyrosinase. Berielite d. Deutsch. chem. (iesellseh. Jg. 41. \$. 221-22.2 (1908). 
haltend), steigende Mengen Formentlösung und Wasser bis auf 5 () $\mathrm{cm}^{3}$. I le Glüser enthalten der licihe nach $0.5,1,15,2,5,10,15), 20 \mathrm{~cm}^{3}$ Fermentlösung. Die Reaktionsomische werden -2t stunden bei '/immertemperatur

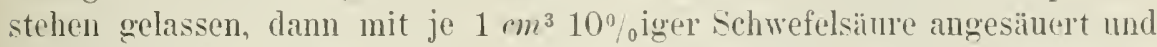
mit 0.002 n-Permanganatlosumg bis zur Huffübung titriert. Gleichzeitig mit der ersten lieihe wird eine zweite lieihe von Giass'n unter wenau rleichen Bedingungen mit den Reagenzien beschickt. Irie Tritration erfolgte hier slach 48 stunden.

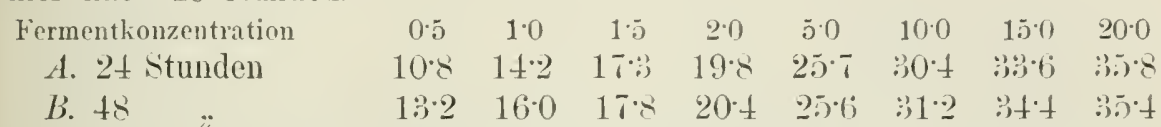

Es ist dies eine logarithmische Kurve: die Menge des Reaktionsproduktes steigt mit der Fermentmenge, renn auch langsamer als letztere: die lieaktion kommt um so schneller zu einem Stilstand. je gröfer die Fermentkonzentration ist.

d) Methode von Chodat und Staub. ${ }^{1}$ ) Bei einer anderen Wethore bestimmt man die Wirkungsweise kolorimetrisch. Fs werden 0\%g Bismarckbraun, $05 \mathrm{~g}$ Korallin in $250 \mathrm{~cm}^{3}$ absolutem Alkohol gelist $(P)$.

Da bei dieser Methode die Rötung der Tyrosinlösung bestimmt werden muf und es sich gezeigt hat. daf andere Farbennuancen am Anfang und später zu beobachten sind, so haben grenannte Autoren zwei skalen hergestellt.

\section{Skala für Spätreaktionen.}

Ton der alkoholischen Farl)-

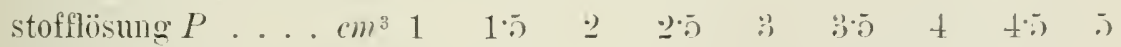

$\begin{array}{llllllllll}\text { Absoluter Alkohol . . . } 19 & 18 \% & 17 & 17 \% & 17 & 16 \% & 16 & 15 \% & 15\end{array}$

II. Skala für Anfangseaktionen.

Von der alkoholischen Farbstofflösung $P\left(m^{3} \quad 0 \cdot 1 \quad 0 \% 3 \quad 0 \% 3 \quad 0.4 \quad 0 \%\right.$ Absoluter Alkohol ...................... 19.9 19.2 $19.7 \quad 19.6 \quad 195$

Zur Synthese der Trrosinase.

Es ist oben gezeigt worden. wie man die Lakkasewirkung durch die eines Systems Peroxydase--Hydroperoxyd ersetzen kann. Es läßt sich aber Tyrosinase durch dieses Srstem nicht ersetzen. Tyosin wird dabei nicht oxydiert, d. h. durch Hydroperoxyd unter Zusatz von Peroxydase.

Nun läßt sich aus der Wurzel ron Vicia Faba und aus dem Stengel vou Philodendron monsteroides eine Peroxydase ausziehen. die in Verbindung mit Wasserstoffsuperoxyd die charakteristische Rötung des Trrosins sowie die Tyrosinasereaktion auf p-Kresol liefert.

Durch anhaltendes Erhitzen auf 100 wird diese Peroxydase zerstört (es ist die gewöhnliche Peroxtlase), aber es bleibt in der Lösung ein in der Siedehitze bestïndiger Körper, welcher, einer Perorrdase aus Meerrettig. zugesetzt. die charakteristische Tyrosinasereaktion liefert.

$\left.{ }^{1}\right)$ W. Staub, Nonvelles recherches sur la Trrosinase, I. c. 
I) a 'Trosin schon im Extrakt vorhanden ist, so verliime man den gekochten Saft von Keimlingswureln ron Vicia Faba. damit die Konzentration des Tyrosins vermindert wird. Einem Teil der Lösung setzt man eine resätigte Tyosinlösmg, dem anderen das entspechende Quantum Wasser mul zuletzt beiden P'robieroläsern einige Tropfen einel $1^{0}$ oigen Hydroperoxydiosmug zu. Es cutsteht keine Farbenreaktion; fïgt man aber noch hejden Versuchen $1 \mathrm{~cm}^{3}$ einer Meerettigperoxydaelösmg (1::0) z.11, so wirk die tyrosinhaltige lösung rasch und intensiv rot. die andere riel spätrel und seliwächer.

I). Zu einer p-Kresolläsung $\left(0 \overline{5}^{0}{ }_{0} \mathrm{ig}\right)$ fïgt man einige Kubikzentimeter des gokochten saftes von Vicia laba-Keimlingswuzeln. Ilese Mischung wird in 4 lingenzgliser gleichmäbig rerteilt (A. B, C, D). $B$ wird durch Kusatz von verdïnnter Fssigsäure schwach sauer, ('und $D$ werden alkalisch gemacht. Allen 4 Versurhen wird $1 \mathrm{~cm}^{3}$ einer l'eroxydaselösung zugesetzt und hierauf mit einigen 'Tropfen einer $1 \%$ igen Lösung Hrdroperoxyds beschickt und zuletzt noch zu $I)$ eine spur (ilykokoll addiert. In A und $B$ entsteht die milchig-tribe Lakkasereaktion, in $C$ die gello Trosinasereaktion, in $D$ die schönste Farbe, wie sie durch genuine Trrosinase hervorerufen wirl. $\left.{ }^{1}\right)$

Diese Versuche lassen sich nur so denten, daf im gekochten saft der Keinlingswomeh ron Vieia Faba cin ko-Ferment enthalten ist. welches dem System Peroxylase-Hydroperoxyd zugesetzt, ihm die Tyrosinaseeigenshaften velleiht. Somit ist dadurch eine Synthese der Tyrosinase grmacht worden, durch welche die Einsicht in das Wesen der Tyrosinase erleichtert wirl.

Wenu behauptet wurde. dafi Lakkase gleidwertig ist dem System: I'eroxylase-Hyrlroperoxyd, so ist Tyrosinase äquivalent einem system: I'eroxylase-Hydroperoxyd + ho-Ferment.

Bestäigt sich diese Anschaumosweise, so ist nummehr das weitere Problem für das System I'roxydase-Hydroperoxyd, weitere Ko-Fermente zu finden, durch wolche die spezifische Wirkung er. verschohen werlen kanu.

Anmerkung. Als (rikase bezeichmen butelli und Stern ') ein bekanntes (Oxylationsferment, welches in Gegenwart von Samerstoff llarnsäme untel Entwikkung vou kohlensäure zu Allantoin oxydiert. Bej der Darstellung des Fermentes verfalne man auf folgende Weise: los Giewebe (Niere des Iindes oder Leber des I'ferdes) wird fein zerriebon, mit 25 Tolumen leicht alkalisch gemachten Wassers versetzt und wälrend 15 Minuten ungeriihrt. Das Ganze wird durch ein Tueh gepreft und zentrifugiert. Man erhält anf diese Wreise eine tribe Fliissigkeit, zu der man num $2 \cdot 5$ Volumen Alkohol hinzusetzt. In ïbrigen reffïht man in folgender Weise: Schnell zentrifugieren, den Bodensat\% mit Xther waschen und denselben an der

1) R. Chodat, Sur les rapports qui unissent les deux principaux ferments oxydants, les laccases et les tyrosinases. Archives des Sciences physiques et naturelles. ITo période. T. XXVII. p. 90 (1909).

¿) F. Batelli und L. Stern, Untersuchungen über die Trikase in den Tiergewehen. Biochem. Zeitschr. Bd. 19. S. 219 (1909). (Hier die Literatur.) 
Luft trockuen. Je lïnger die Dauer der Einwirkung des Alkohols auf die Fliissigkeit ist, um so mehr wird dic Urikase algeschwächt.

2-3g eines solchen Priparates kïnnen in 1 Stunde $0.20 \mathrm{~g}$ Harusäure zersetzen, im reinen Sauerstoff ist die Menge der zersetzten Harnsäure 2-3mal so groß. - Der durch Hamsäureoxydation bedingte respiratorische Quotient $\frac{\mathrm{C}_{2}}{\mathrm{O}_{2}}$ ist gewïhnlich 2

$$
\mathrm{C}_{6} \mathrm{H}_{4} \mathrm{~N}_{4} \mathrm{O}_{3}+\mathrm{H}_{2} \mathrm{O}+\mathrm{O}=\mathrm{C}_{6} \mathrm{H}_{4} \mathrm{~N}_{4} \mathrm{O}_{3}+\mathrm{CO}_{2} \text {. }
$$

wenu frisches Gewebe benutzt wird. Das Optimum der Temperatul der Urikasewirkung liegt zwischen $50-55^{\circ}$. Wie bei anderen genuinen ()xydasen (Oxygenasen) hat der Zusatz ron $\mathrm{H}_{2} \mathrm{O}_{2}$ oder des Äthylhydroperoxyds keinen Eiufluf auf die Oxydation der Harnsäure.

\section{Katalase. ${ }^{1}$ )}

Vorkommen: Katalase scheint keiner höheren Pflanze zu fehlen. bei Pilzen ist sie stets rorhanden: ob dieselbe bei gerrissen Bakterien fehlt. scheint zweifelhaft. da gewisse Spezies, wie Diphtheriebazillen. Staphylokokken u. a.. eine starke $\mathrm{H}_{2} \mathrm{O}_{2}$-zerstörende Eigenschaft besitzen. Bei Tieren ist sie fast überall nachgewiesen worden. Nach ilrer katalytischen Kiraft können die Gewebe in absteigender Reihe geordnet werden: Leber, Niere, Magenschleimhaut, Speicheldriisen, Lunge. Pankreas, Hoden. Herz, Iluskel. Hirn. Auch in solchen Geweben, die kein Blut enthalten oder nur in minimalen, kaum nachweisbaren Quantitäten. wie Knorpel. Glaskörper, Linse des Auges und Fettgewebe, ist Katalase nachweisbar.

Zum Nachweis der Katalase in der lebenden Pflanze verfahre man, wie folgt:

Ein Elodaeablatt wird in 5\% ige $\mathrm{KNO}_{3}$-Lösung, der man $\mathrm{H}_{2} \mathrm{O}_{2}$ zu $1{ }^{\circ} \%$ zugesetzt hat, gebracht. Lnter dem Mikroskop beobachte man. wie aus den schwach oder stärker plasmolysierten Zellen, deren Hautschicht unversehrt, folglich um den abgerundeten Protoplasmaballen scharf abgerundet ist. Gasblasen entströmen.

Öfters kann man auch heobachten, wie aus einer plasmolysierten Zelle, deren Protoplasina noch strömt, durch Katalyse des Hydroperoxyds Gasblasen ausgeschieden werden.

Ebenso lehrreich ist folgender Versuch: Es werden mit je $25 \mathrm{~cm}^{3}$ Roulinscher Nährfliissigkeit beschickte Erlenmeyerkolben, die in ïblicher Weise sterilisiert worden sind. nach Zusatz ron steigenden Mengen Hydroperoxyd mit sporen aus Reinkulturen ron Penicillum glaucum, Sterigmatocystis nigra und Rhizopus nigricans geimpft und im Thermostaten bei 220 sich selbst ïberlassen.

Der Hydroperoxydzusatz (ron einer 10\%igen Lösung) beträgt 1 bis $2+m g$ aktiven sauerstoff in der ersten Versuehsreihe, 5-50 $\mathrm{mg}$ in der

1) A. Bach und $R$. Chodat, Lntersuchungen über die Rolle etc. VI. Katalase. Ber. d. Deutsch. chem. Gesellsch. Jg. 36. S. 17j7(1903). - O. Loeu, Katalase a new Enzyme of general occurence. 1. c. Dep. Agric. Report. p. 68 (1901). 
zweiten. Zur Kontrolle werden einerseits Kolben ohne Hrdroperoxidznsaty inohuliert, andrerseits nichtinokndierte Mischungen von Ilydroperoxyd und Raulinscher Flissigheit im Thermostaten stehen gelasson.

Dabei ergibt sich, dab Hydroperoxyd anf die Entwicklung der I'ilze zwar hemmend wirkt. dab aher nach einer gewissen Inkubationsperiode. welche mit der Pilzart und dem Hrolroperoxydzusatz variert, die sporen Iycalinmfüden anssenden, welche sich zuerst mit (iasbläschen bedecken und dann eine danejude Gasentwicklnng veranlassen. Diese wächst mit dem Wrahstum des Mreelimmballens und hört auf, wemm in der Nährfliissigkeit mittelst 'Titanschwefelsäme kein Hydroperoxyd mehr nachweishar ist. lie I'ilze, aus sporen gezogen (Sterigmatocystis mol lihizopus), kommen indessen unter sporenbildung zu voller Entwicklumg, wähend die Nährflissigkeiten noch reichlich Hydroperoxyd enthalten. Sterimnatooystis nigra vermag sich sehr gut in einer Nährflissigkeit mit konstantem Peroxydgehalt von 0.68\% Hydroperoxyd (Ersatz des I'eroxydrerlustes durch \%usatz von neuem Hrdroperoxyd) zn entwickeln. Da wïhrend der ganzen Zeit, ron dem reitpunkte der liejunng der sporen his zur sporenbildung ans dem I'ilz, d. h. ans seiner Oburfliche Sanel'stoffulasen entbunden werden, so läßt sich diese Gasentwicklung nur anf die in der lebenden Pflanze enthaltene Katalase zuriickfiihren. Latalase ist sonit nicht ein postmortales Ferment. sonderu eime mit der belenstatigkeit verbundene Fermentausscheidung.

\section{Gewinnung der Kítalase.}

A. Zur Gewinnmo ron Pilzkatalase (Chodut-Buch) bediene man sich der Reinkulturen ron Sterigmatorstis nigla in Raulinseher Flïssigkeit. Sterigmatoeystis kam man sich zu jeder Zeit reschaffen. indem man unter ciunc Glasglocke zerstoliene Galläpfel fencht liegen läßt. Nach kurzer Zeit bemerkt man das sporentragende Mycelimm. das nm mittelst eines sterilisierten Platindralutes in eine sterilisierte Ranlinsche Lösung iibertragen werden kann. Die Pilzhänte werden mit (ilas zu cinem Brei zorstoben und mit einer Spur ron Tatrimmkarbonat enthaltemlem Wasser verieben.

The klar filtrierte Jliissigkejt (man warte nicht, his die I'ilzhänte nit Sporen bedeckt sind) wird mit Alkohol gefällt und in ibblicher Weise rasch gewonnen.

Durch Extraktion von zerriebenen 'Tabaksblätern mittelst chloroformihaltigen Wassers mu Fällen durch /usatz vou Ammoniumsulfat im lbelschuf gewinnt man einen Niederschlag, welches vou der dariber stehenden Flissigkeit abfiltriert und durel Dialyse von dem Ammoniumsulfat befreit, sich als stark katalaschaltig erweist (Loew).

B. Bintkatalase (Hämase, Usturald-Scnter $\left.{ }^{1}\right)$. Defibriniertes Blut wird mit dem zehufachen Vohm kohlensamen Wassers gemischt. ïber Nacht

1) G. Senter, Das wasserstoffuperoxydzersetzende Enzym des Blutes. Zeitschr. f. physik. Chem. Bd. 4t, s. 257 et ser. (1903). 
strhen gelassen, am anderen Inorgen zentrifugiert und filtriert, um die Fluissigkeit von den festen Bestandteilen zu trennen. Ihie katalytische Substanz ist fast ausschlieflich in die lijsung ïbergegangen (sie scheint aber im lebenden Körper an das Stroma gebunden zu sein).

Gleiche Volumina des Himoglobin und Katalase enthaltenden Filtrates und $9.1 \%$ iger Alkohol werden gemischt, die Mischung wird schnell zentrifugiert und die Alkohol-Hämoglobinlösung rom entstandenen Niederschlag abgegossen. Der rotbraune Niederschlag wird dann zwei- oder dreimal mit einem Alkohol-Wassergemisch gewaschen, um das Hämoglobin vollkommen zu entfernen, dann wird er zunïchst mit Filtrierpapier und darauf im Takuum iiber Schwefelsäure getrocknet. um den Alkohol vollkommen zu entfernen.

Der getrocknete Xiederschlag wird dann zu einem feinen Pulver zerrieben.

C. Leberkatalase. $2 \mathrm{~kg}$ Schafsleber werden gleich nach dem Tode mittelst einer Hackmaschine zerrieben. Der dicke Brei wird mit etwa 2 l ('hloroformwasser ${ }^{1}$ ) beschickt. Nach 24 stiundiger Mazerierung wird die rotbraune Flïssigkeit abgepreft. durch ein Tuch filtriert und mit dem rierfachen Volumen $94^{\circ}{ }_{0}$ igen Alkohols gemischt. Der entstandene kopröse Niederschlag wird abfiltriert und hevor er trocken geworden ist, auf eine poröse Platte ausgebreitet und rasch iiber Schwefelsäure in Vakum getrocknet (A).

Ein reines Produkt wird dann durch nochmalige Fällung des Alkoholfiltrates durch überschiissigen Alkohol $(B)$ getronnen. Das weife Pulver ist aber wenig wirksam.

Es werden auf diese Weise etwa $200 \mathrm{~g}$ Rohkatalase erhalten.

Durch Mazerieren mit Chloroformwasser und Fällen mittelst 99\% igem Alkohol gewinnt man ein helleres Produkt, das aber eine geringere Wirksamkeit zeig't. Werden $0.5 \mathrm{~g}$ dieser Pohkatalase mit $30 \mathrm{~cm}^{3}$ destilliertem Wasser 1 Stunde digeriert und dam filtriert, das Wasser mit wenig Chloroform geschüittelt, so liefert das Filtrat eine sehr wirksame und wasserhelle Lösung ron Katalase. ¿ Tropfen dieses Extraktes vermögen in wenigen (ㄹ) Jinuten aus $1{ }^{\circ}{ }_{0}$ igen $\mathrm{H}_{2}\left(\mathrm{O}_{2}\right.$-L L̈̈ungen $\left(30 \mathrm{~cm}^{3}\right) 30-40 \mathrm{~cm}^{3}$ Sanerstoff $\mathrm{zu}$ entbinden (siehe unten).

D. Gekrösekatalase. ${ }^{2}$ )

fiekröse rom Schwein. vom Rind und Speck eignen sich weniger zur Gewinnung trockener Katalase: hingegen erhält man durch Terreiben ron etwa :50 $\mathrm{g}$ Schweinefett mit $150 \mathrm{~g}$ destilliertem Wasser in einer Reibschale. worauf auf Talcum venetum filtriert wird, eine neutrale. klare Lösung. die sehr aktiv wirkt.

Eigenschaften. Katalasen haben nur die Eigenschaft. Hrdroperoxyd katalytisch unter Sauerstoffentwicklung zu zersetzen. Andere Peroxyde.

1) F. Teuhaus, Contribution à l'étude des ferments oxrdant: le l"action combinée de la peroxydase et de la catalase. Genère 1905. - Batelli et stern, Prẻparation de la catalase animale. Soc. Biologie. L VII. p. 264 (1901).

2) Leo Liebermann, Beiträge zur Kenntnis der Fermentwirkung. Archir f. d. ges. Phỵsiol. Bd. 10t. S. 203 (1904). 
auch tas ithylhydroperoxyd ${ }^{1}$ ). werden ron hitalase nicht angegriffen. Sie iibt keinen oxydierenden Einfluli aus, kann also nicht als cigentliches oxydationsferment gelten. Von ihr wird aus Wasserstoffsuperoxyd nur moleknlarer suluerstoff frei gemacht. Ine ihr ron Locw u. a. zugeschriebenen oxydierenden Eigenschaften beruhen auf Vermureinigung mit Peroxydase. Anch die L'mwandlmog von Sehwefel zu S(hwefelwasserstoff ${ }^{2}$ ) findet nicht statt.

Durch die Katalase wird auch die oxydationswröfie der oxygenase nicht im mindesten herabgesetzt.

Aus den sehr genanen Lutersuehnugen senters geht herror, dab die Katalasereaktion in erster Amäherung proportional der Konzentration des $\mathrm{I}_{2} \mathrm{O}_{2}$ verläuft, insofern als die Konzentration zwischen $\mathrm{m} / 300$ !nnd ${ }^{\mathrm{m}} 1000$ variert. Bei stärkeren $\mathrm{H}_{2}\left(\mathrm{O}_{2}\right.$-Lösungen hesteht im Gegenteil diese strenge l'roportionalitä nicht mehr; die Reaktion verlänft relativ schneller in rerdiunteren Lïsungen, obwohl der Lnterschied ein kleiner ist.

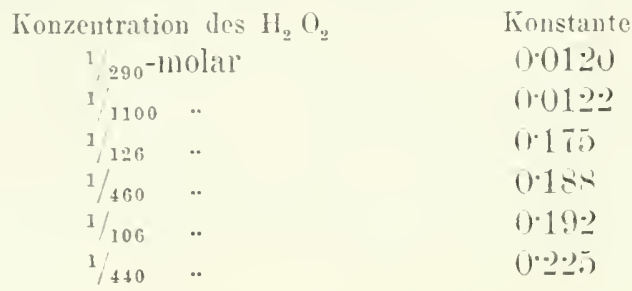

Stärkere Konzentrationen wirken schädigend auf das Ferment.

Dabei ist auch Riicksicht 20 nehmen auf lie Temperatur. Zwischen () und $10^{0}$ ist die zerstörende Wirkung einer mäbig konzentrierten Peroxydlösung auf das Ferment sehr schwach.

Der Ceschwindigkeitspnotient für $10^{\circ}$ Temperaturerhöhmng ist etwa $1 \%$ ) Minuten.

liei $\left(55^{0}\right.$ verliert eine verdimnte Bhut- oder Leberkatalase ihre Wirksamkeit in 15 . Vinuten vollstinndig; bei $5 \bar{a}^{0}$ ist die Zersetzungsesech windigkeit bedeutend kleiner; nach stimdigem Ehitzen bei dieser Temperatur hat eine

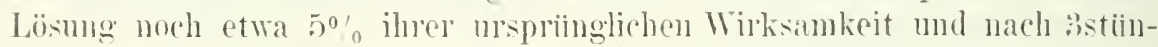
digem Erhitzen hei $4 \bar{\nu}^{\circ}$ noch etwa $60^{\circ}$ or der mrïnglichen Eigenschaft.

Es ist also ratsam, die Uessungen hei niederen Temperatmen rolzumehmen. Bei $0^{0}$ bleibt eine Formentlösmg wochenlang fast muerïndert. Katalase aus Gekrösefett ist gegen Ilitze widerstandsfähiger, wie solehe ans l'flanzensäften. Erstere wird zwischen $60-70^{0}$ zerstört, letztere zwischen 40 bis $.00^{n}$.

1) Bacyer und rilliger, Athylhyltroperoxyd. Berichte d. I)entsch. chem. Gesellsch., Jg. 34. S. 738 (1901). - Bach und rhodat, Intersachungen ete. V1. Cber Katalase. Ebenda. Jg. 35. S. $1758(1903)$. - F. Batelli et $1 l^{110} \mathrm{~L}$. stern, Recherches sur la catalase dias l'organisme animal. Fstrattu dall' Arehivio di Fisiologia. Vol. 2. Fas. IV (19) (0) (arec Bibliographie) (1905).

2) Pozzi-Escot, l'ropriétés ratalytiques des hỵdrogénases. Bull. de la soc. chim. Paris. [3.] T. 27. p. 280 (1902). 
I) Sïuren bewirken eine sehr starke Verzögerung der Katalyse, olne dab dadurch das Ferment danernd geschïdigt wird. Nach 2-3stiindiger Inkubationszeit mit der Säure und darauffolgender Ventralisation der , Täure mit Alkali wirl die katalytische Kraft wieder hergestellt.

Salze haben auch eine verzögernde Wirkung: Xa Cl wirkt viel weniger verzögernd als Kalimmnitrat oder kaliumchlorat.

Giftwirkung ihht Blausiune aus. Wie ist gleiclufalls keine dauernde. Wird durch einen Lnftstron die Blansäure entfernt, so erholt sich das Ferment, wenn auch nicht vollstiindig.

\section{Messung ler katalytischen Kraft.}

Zu Vorrersuchen oder zu Vergleichsuntersuchungen läpt sich die fermentative Wirkung einer Katalaselösung in der Weise berechnen. daß man in passender Weise den entwickelten Sanerstoff mißt.

1. In ein mit Mohrscher Bürette versehenes Gefäß mit doppelten Hähnen und Riöhren gießt man 5- $10 \mathrm{~cm}^{3}$ der Katalaselösung: hierauf läßt man durch das Öffnen eines Hahnes $30 \mathrm{~cm}^{3}$ einer 1\% $1 \%$ igen Hydroperoxydlösung zufließen. Die sich entwickelnde Sanerstoffmenge wird mittelst eines in Verbindung stehenden Eudiometers gemessen nach 1, 2, 5, 10 Vinuten. Ist die bestimmte Zeit rerflossen (mit dem Chronometer zu messen), so wird der zum Eudiometer fïhrende Hahn geschlossen und durch Senken der Quecksilberkugel das Niveau äquilibriert. Da der Versuch in sehr kurzer Zeit zu Ende ist und in einem Raum mit konstanter Temperatur vorgenommen werden kann, so ist eine Barometer- und Temperaturkorrektur z.ll solchen Untersuchungen kaum nötig. ${ }^{1}$ )

Der Liebermanusche Apparat²), der etwas kompliziert ist, kamn jedoch gute Dienste leisten und hat sich gut bewähnt (siehe Fig. 13). (Fabriziert bei Bender \& Holbein. Zürich und Miunchen.)

In die Abteilung A (Fassungsraum ca. $25 \mathrm{~cm}^{3}$ ) kommen mit Hilfe einer Pipette nach Entfernung des bei $E$ eingeschliffenen Manometerrohres $D$ und bei geschlossenen Hähnen $a, c$ und $d 5 \mathrm{~cm}^{3}$ einer verdïnnten Fermentlösung; hierauf wird der Hahn auch bei $b$ geschlossen und der Apparat umgekehrt Damn werden bei geschlossenen Hähnen $e$ und $f^{\prime}$ bei $F 5 \mathrm{~cm}^{3}$ einer $3 \%$ igen (resp. $1 \%$ igen) Lösung von Wasserstoffsuperoxyd in die Abteilung $B$ gehracht (Fassungsraum ca. $30 \mathrm{~cm}^{3}$ ), worauf Hahn g geschlossen wird. In die Abteilung $C$ (Fassungsraum ca. 2.5 $\mathrm{cm}^{3}$ ) kommen nun 5 $\mathrm{cm}^{3}$ einer gesättigten Kóchsalalösung, worauf auch Hahn h geschlossen, der Apparat wieder umgekehrt und auf passende Art in ein Stativ geklemmt wird. Nun wird das sowohl nach aufwärts wie nach abwärts von 0 in Nillimeter geteilte. bis 0 mit Quecksilber gefüllte Manometerrohr $D$ anfgesetzt. Die Hähne $i$ und $b$ werden

1) E. Maliffi, La Catalase daus les tissus des différentes espèces animales. Genère. Thèse de médecine. 1904. p. 31.

$\left.{ }^{2}\right)$ Leo Liebermann, Beiträge zur Kienntnis der Fermentwirkungen. Ffü̈gers Arehiv f. Physiologie. Bd. 104. S. 179 (1904). Fig. ?. 


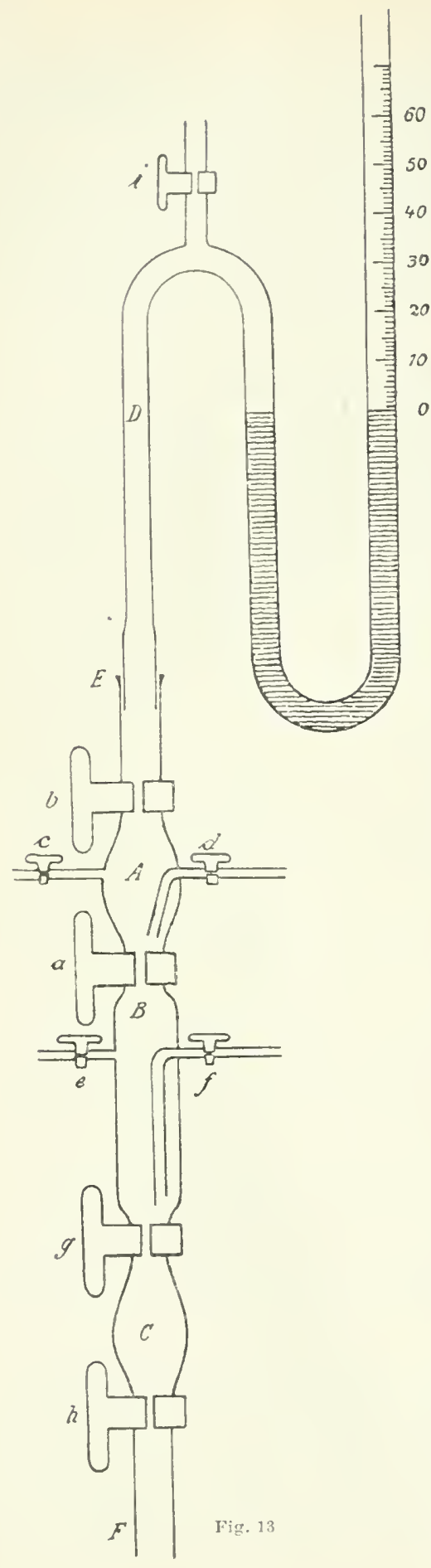

behufs Druckausgleichung geüffnet, dann wirl $i$ wieder geschlossen. Der schliff bei $E$ sowie sämtliche Hälne sind sorgfültig einzufetten. Bezïglich letzterer soi noch erwähnt, dab die Hähne b, a.!! und hetwa mit $1 \mathrm{~cm}$ weiten Bohrmgen verschen sind, um den Fliissigkeiten einen bermemen und raschen Durchflus zn ermöglichen.

Das Manometerrohr ist, soweit die Villimeterteilung (100 mm nach auf- und ahwirts) reicht, genam kalibriert, so lab clas Volum in linbikzentimetern für jecten Millimeter ans der Kalibriermustabelle abgelesen werlen kann.

Mischen sich nun die beiden Fliissigkeiten bei greöfnetem Hahn a in der Abteilung $B$ und findet (iasentwicklung statt, so steigt das (yuecksilber im Manometer, mo es kam num fiur jede beliebige Zeitlaner des Versuches das Volumen des entwickelten Gases bestimmt werden. Hierzu ist es nur nötig, dasselbe jedesmal auf gleiche T'onperatur $\left(0^{\circ}\right)$ und gleichen Druck $(760 \mathrm{~mm})$ zin reduzieren.

Die Abteilmu $C$ dient dazu. einer thersïttigma mit Gas rorzuhengen. Sie wird darum mit riner gesättigten kochsalzlösmo hescluickt. Sie bezwerkt zweitens ein rollkommeneres Inurdmischen des in $B$ befindlichen Fliissigkeit. indem sic nach einer bestimnten Versuchsdaner nach $C$ faillt, wemn Hahn g geöfnet wird. Endlich wird durch das rasche Inurcluflielion der Flïssigkeit einer Thersittigmg rorgebengt, und gleichzeitig worden die an den Wänden haftemlen Gasblasen zum Verschwinden gebracht.

Diese Vethoden sind jedoch zu unvollkommen. um dadureh zu absoluten Werten zu gelangen. Sie können nur zu Vorgloiehsversuchen dienen, d. h. um die aktive Masse in einem bestmmten 
(quantum Ferment oder () gan und in einer bestimmten Versuchsocit zu schät\%en.

Bei solchen Experimenten ist es natiulich unumgänglich notwendig. fiir jede Kategorie von Versuchen bestimmte Tormen zu wählen. In den $B$ rıtelli- und Stemschen Versuchen wird die aktive Masse auf $1 \mathrm{~g}$ Substanz und 1 Minute Zeit reduziert; z. B.: .) cm³ einel Leberemulsion zu zooo hahen in der ersten Minute 25 $\mathrm{cm}^{3}$ Sanerstoff entbunden. Nun enthalten diese $5 \mathrm{~cm}^{3} \mathrm{O} \cdot(1025)$ ()rgansubstanz; folglich wiirde $1 \mathrm{~g}$ desselben ()rganbreies in der ersten Minute $10000 \mathrm{~cm}^{3}$ Sanerstoff in Freiheit gesetzt haben.

Diese volumetrischen Methoden haben den Cbelstand, dali einerseits Chersättigung mit Sauerstoff eintritt. renn das die Fliissigkeit enthaltende Gefäl nicht geschiittelt wird, während andrerseits beim Schiitteln der Einflub der Gefäbwände cinen unberechenbaren Faktor darstellt.

I a die nach den angegebenen Methoden bereiteten Katalasen so wirksam sind, daf ihre verdünnten Lösungen in Wasser nur Spuren organischer Substanz enthalten, so läßt sich die katalytische Kraft durch Titrierung mittelst verdïnnter $\mathrm{K}$ In $\mathrm{O}_{4}$-Lösung messen, indem daduch die jeweilige Konzentration der verdiunten Lösmng des Wasserstoffsuperoxyds hestimmt wird.

Sorgfältige Messungen (Senter) haben nun dargetan, daß die Reaktionsgeschwindigkeit in sehr verdiunten ( ${ }_{4}^{4} 0_{0}$-molaren) $\mathrm{H}_{2} \mathrm{O}_{2}$-Lösungen proportional der Fermenthonzentration ist.

Die Reaktion wird nach Senter ${ }^{1}$ ) in mit Glasstöpseln rersehenen Erlenmeverflaschen von $: 300$ resp. $1000 \mathrm{~cm}^{3}$ Inhalt ausgeführt; 100 resp. $400 \mathrm{cin}^{3}$ Fermentlösung ron passender Konzentration werden in einer dieser Flaschen einige Stunden im schmelzenden Eise vorgekiihlt und darauf 100 resp. $400 \mathrm{~cm}^{3}$ vorgekiihlte $\mathrm{H}_{2} \mathrm{O}_{2}$-Lösung hinzugefiigt. Die Temperatur wird sofort nach der Mischung gemessen, 11 sicher zu sein, daß sie wirklich $0^{n}$ beträgt; die eimzehnen Proben - 35 resp. $100 \mathrm{~cm}^{3}$ - werden ron Zeit zu Zeit entnommen. in rerdïnnte schwefelsäure gegossen. wodurch die Reaktion vollständig unterbrochen wird, und daranf mit $1 / 500^{-m o l a r e r} \mathrm{~K} / \mathrm{HO}_{4}$ Lösung titriert.

\section{Tabelle nach Senter.}

\section{t (Minuten) $\mathrm{H}_{2} \mathrm{O}_{2} \quad 0.4343 \mathrm{Kj}$}

Wasserstoffsuperoxydkonzentration immer ${ }^{1}{ }_{4 i t}$-molar (in der Mischung), $400 \mathrm{~cm}^{3}$ Katalaselösung mit $400 \mathrm{~cm}^{3} \mathrm{H}_{2} \mathrm{O}_{2}$-Lösung gemischt und $100 \mathrm{~cm}^{3}$ titriert.

1. 1 Vol. Fermentlösung in :300 Vol. Mischung:

\begin{tabular}{|c|c|c|}
\hline 0 & 42 & - \\
\hline 10 & $40 \%$ & 0.0017 \\
\hline 20 & 304 & 0.0023 \\
\hline $40^{1 / 3}$ & $3+4$ & $0 \cdot(0) \cdot 3$ \\
\hline $85^{1} / 2$ & 26.0 & 0.107 \\
\hline 116 & $21 \cdot 2$ & $0.00 \geq 8$ \\
\hline 160 & $16 \cdot 0$ & $0.00 \div 8$ \\
\hline $19 t^{1}=$ & $12 \cdot 5$ & $000 \div 9$ \\
\hline
\end{tabular}

1) r. Sentcr, 1. c. (rol. Fußnote 1, S. 66). S. 25. 
V. 1 Vol. Fermentlösung in 120 Vol. Mischung:

\begin{tabular}{|c|c|c|}
\hline (1) & $4: 37$ & - \\
\hline $6^{1} / 6$ & 408 & 00049 \\
\hline $15^{1 / 6}$ & $86 \%$ & $0.005 t$ \\
\hline 25 & $\$ 1.0$ & 00068 \\
\hline$f()^{1}{ }_{6}$ & $24 \div 4$ & 60068 \\
\hline 6.$)$ & $16: 1$ & $0.007=$ \\
\hline $10 \pi$ & $7 \cdot 8$ & 0.007 \\
\hline
\end{tabular}

VII. 1 Vol. Fermentlösung in to) Vol. Mischung:

\begin{tabular}{|c|c|c|}
\hline 0 & $4: 7$ & \\
\hline $5^{1 / 3}$ & $3: 37$ & $00 \geq 14$ \\
\hline $10^{1 / 2}$ & 257 & 00226 \\
\hline 15 & $20 \div 3$ & 0.0218 \\
\hline $26 j^{1 / 3}$ & $12 \div$ & $0 \cdot 0218$ \\
\hline$: 7^{1}{ }_{3}$ & $6 \% 3$ & 0.0236 \\
\hline
\end{tabular}

I ie Konstanten $k_{1}$ sind muter der Amnahme berechnet. dalf die lieaktion proportional der jeweiligen $\mathrm{H}_{2} \mathrm{O}_{2}$-Konzentration verlänft, d. h. dalj die Zersetzungsgeschwindigkeit $\frac{d c^{\prime}}{d t}=k_{1} c_{t}$ ist. wo $C_{t}$ die Konzentration des $\mathrm{H}_{2} \mathrm{O}_{2}$ zurzeit $\mathrm{t}$ ist. Inreh Integration erhalten wir $\mathrm{k}_{1}=\frac{1}{\mathrm{t}_{2}-\mathrm{t}_{1}} \ln \frac{\mathrm{C}_{1}}{\mathrm{C}_{2}}$ oder t:3 $43 \mathrm{k}_{1}=\frac{1}{\mathrm{t}_{2}-\mathrm{t}_{1}} \log _{\mathrm{C}_{2}}^{\mathrm{C}_{1}}(1)$, wo $\mathrm{C}_{1}$ und $\mathrm{C}_{2}$ zwei anfeinanderfolgende Beol)achtmigen bedenten mul $t_{2} t_{1}$ die inzwischen rerflossene Zeit (rgl. Ostwald-Luther, Physiko-chemische Mesingen. S. 45.)).

\section{$\mathrm{A} N \mathrm{NH}$ A.}

\section{Aldehydase. ${ }^{1)}$}

Vorkommen: Sie ist bis jetzt nur im Tierreich gefunden worden.

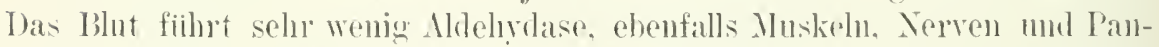
kreas; Leber, Lmor und Milz wirken sehr energisch. Dieses Ferment kann mit dem vorangehenden nicht verglichen werden, da fuir seine Wirkmug die Gegenwart des Luftsanerstoffes nicht nötig, ja sogar nachteilig ist.

Darstellung: Vom Schlachthaus bezogene frische Rindsleber wirl zerhackt, mit (kuarzand zerrieben, der Brei mit destilliertem Wasser, dem 'Tolnol in l'bersehno mgefiigt ist, mindestens einige Stunden stehen gelassen mol hänfig durchgesehiittelt. I)ann wird das Extrakt rom Riickstand dnrch Kolieren und Filtrieren getremt.

1) Jaquet, Recherches sur les oxydations organiques dans les tissns. Mémoires Soc. biolog. S. 50. (1892). - Helous et Biermis, Ponvoir oxydant du sang. Sore hiolog. T. 46. S. 536. - Martin .Jacoby, ther das Aliehyd oxydierende Ferment der Leler und Nehemniere. Zeitschr. f. physiol. Chem. Bd. 30. S. 135 (1900). - J)erselbe, Ciher die (1xydationsfermente der Leber. I"irchors Arehir f. pathol. Anat. 11. 1'hysiol. Bd. 157. S. 255 (1899). 
Das so gewonnene dunkle. aber völlig klare Filtrat wird mit soviel gesättigter Ammonsulfatlösung versetzt, daß $25 \%$ ige Sättigung mit diesem Salz erreicht wird. Dabei werden hier, wie auch fernerhin, immer, wenn Ammonsulfat in Anwendung gezogen wird, soviel Tropfen verdinnter Sodalösung hinzugetan, daß die Fliissigkeit schwach alkalisch reagiert und deutlich nach Ammoniak riecht. In etwa 24 Stunden setzt sich dann allmählich ein geringer Niederschlag ab, der abfiltriert wird.

I)as Filtrat wird in gleicher Weise auf :3:3 $1 / 3 \%$ ige Sättigung mit Salz gebracht, der Niederschlag wiederum nach 25 Stunden durch Filtrieren entfernt. Das so erhaltene wasserklare, ziemlich dunkle Filtrat wird auf $60 \%$ ige Sättigung mit Ammonsulfat gebracht. Dabei entsteht ein massiger Niederschlag, der sich meistens in 24 Stunden vollständig absetzt.

I)ieser Niederschlag, welcher die Aldehrdase enthält, wird nach 24 Stunden abfiltriert. mit entsprechender Salzlösung ausgewaschen und damn in destilliertem Wasser aufgenommen, wobei er sich nur unrollkommen löst. Frïhestens nach einigen Stunden wird wiederum filtriert. las klare Filtrat wird mit $95 \%$ igem Allkohol soweit rersetzt, dab gerade ein gut abfiltrierbarer Niederschlag entsteht. Dieser Niederschlag hat sich nach einigen Minuten bereits alogesetzt und wird nun sofort von der Fliissigkeit durch Filtrieren getrennt.

Es geniigt, Alkohol in einer Quantitït znzusetzen, daß die Konzentration desselben höchstens $: 30^{\circ}$ o betrïgt. Der abfiltrierte Niederschlag wird sofort mindestens 5-6mal mit kleineren IIengen destillierten Wassers, dem man einige. Tropfen verdünnter Sodalösung zufiigt, extrahiert. Die Ausziige werden vereinigt.

Am besten läßt man den Niederschlag, um das Ferment vollständig in Lösung zu bringen, fein rerteilt über Tacht mit Wasser stehen.

Man hat nunmehr bereits eine helle Flïssigkeit, die aber regelmäßig Eirreiß enthält.

Sie wird bei schwach alkalischer. durch Soda hergestellter Reaktion mit einer verdïmnten Lösung ron Cranylacetat bis zum Entstehen einer abfiltrierbaren Trübung gefällt. der Niederschlag ebenso wie der mit Alkoholfällung gewomnene behandelt.

Es resultiert eine wasserklare Flüssigkeit, die kräftig Salizylaldehyd zu Salizylsïure oxydiert.

Eigenschaften: Aldehydase soll keine Eiweißreaktion geben. Sie dialysiert schwer oder gar nicht. geht aber durch Chamberlandfilter. sie löst sich in Wasser, wirkt am besten in nentraler Lösmng, alkalische oder saure Reaktion wirkt hemmend. Sie ist mit Alkohol, mit Uranylacetat fällbar, sie lïßt sich durch Ton filtrieren und rerbleibt bei der Dialyse im Pergamentschlauch. Die Aldehydase ist in 20\% igem Alkohol dentlich löslich. Sie wird durch geringe Mengen freier Süure, aber auch durch freies Alkali. anscheinend an wenigsten durch Ammoniak ihrer oxydierenden Wirkung beraubt. Die Aldehỵdase wird bei ihrer oxydativen Wirkung nicht verbrancht. 
Kileme Sodamengen beenträchtigen bereits die Oxydation des Salizylaldehych, bei $0 \% 5 \%$ leidet sie schon erheblich. bei $0.7 \%$ werders nur noch spuren oxyliert, bei $1^{0}$ o findet keine ()xylation mehr statt: \%usat\% von $0 \cdot 1 \%$ Sa ()ll steigert die (xydation. bei $0 \% \% \%$ kommt sie schon nicht mehr znstande: Ganz geringer Salzsäurezusatz vermindert nicht den frad der Oxydation, bei einer lionzentration von $1^{0}$ o werden nur noch spmen von Salimbaldehyd oxyliert. Iiei bo wird am meisten Salizylsiure gebildet, bei 75" wird das Ferment nicht vollstäntig zerstört. Durch Kochlitze wird es vollstïndig zerstiint.

Mrlehrlase oder biastase oxydo-reductrice von Abclous ist keine ()xydaso in simne von Bertrand, Chodut und Bach. Inren Sanerstoffhedarf nimunt sie aus den vorhandenen anorganischen oder organischen reduzierharen Verbindungen, z. L. chlorsanem Kali, silpeter etc. Der Inftsauerstoff hemmt dic oxydirenende Kraft der Mdehylase; reiner Sanerstoff ist nordh schädlicher: $\left.{ }^{1}\right)$

\%ur Messung der oxydieronden Kraft bedient man sich einer kolorimetrischen Methode. Ine aus salizylaldehyd gebildete salizylsäure wird mittelst Eisenchlorid oder Fisenammoniakalann kolorimetrisch bestimmt.

lis sind nicht nur die Bedingungen der oxylation durh dieses Ferment, sondern aurh das von Medredew 2) aufgestellte Wirlinugsgeset\% so sonderbar, dab alle derartigen Angaben dringend einer eingehenden Revision bediirfen.

1) Abelous et _lloy, Influence des diverses conditions sur l'oxydation de l'aldéhyd salicylique par les organes et les extraits d'organes. Comptes rendus de l'Acad. Sc. T. 136. S. 1573 . Soc. Biol. '1. 53, p. 891 (1903). - Hid., Sur l'existence dans l'organisme animal dine liastase à la fois oxylante et réductrice. Ibid. T. 5j. p. 1355 et 1356.

") Jedredew, Über Oxydationskraft der (iewebe. Pflügers Archiv. Bd. 6j. S. 249 (1897). 


\title{
Verdauung.
}

\section{A. Operative T'echnik zum Studium der Terdaumg und der Resorption.}

\author{
Yon E. S. London.
}

\section{Allgemeine Bemerkungen.}

Zweck biologisch-chemischer Lutersuchungen iiber Verdaung und Resorption ist dic Aufklïrung der chemischen Reaktionen bei lebenden ()rganismen. Diese oder jene Ergebnisse chemischer Reaktionen resultieren aus den letztere begleitenden Lmständen. Will man daher biologisch-chenische Studien richtig angelegt betreiben, so miissen für dieselben ganz gleiche Verhältnisse wie bei lebenden Organismen geschaffen werden. Solche Terhältnisse in vitro zu erzeugen. ist jedoch ausgeschlossen, und es bleibt deshalb dem Forscher nichts anderes iibrig. als zu Untersuchungen an lebenden Tieren Zuflucht zu nehmen. Cuntersuchungen in vitro kömnen blof Orjentierungszwecken dienen.

Tntersuchungen an Tieren ïber Verdaumer und Resorption unterscheiden sich in solche an vivisezierten und an operierten Tieren. Inurch jede Vivisektion wird die normale Tätigkeit des Organismus von (irund aus erschiittert. Die durch operationen herbeigefülıten Veränderungen schwächen sich dagegen gewöhnlich mit der Zeit ab und der (Organismus kehrt dank der ihm innewohnenden Anpassungsfähigkeit zu der normalen Tätigkeit zurïck. Deshalb soll man, wo es nur angeht. Untersuchungen an operierten Tieren stets solchen an vivisezierten vorziehen.

Gegen das vorhin Angeführte wird schwerlich jemand etwas einwenden wollen und doch gilot es wenig Institute, an denen die Verdauungs- und Resorptionsfragen in vivo oder wenigstens mittelst in vivo gewonnener Säfte studiert werden. Grund dieser Erscheinung ist meiner Ansicht nach in erster Reihe die Vermutung, daß die Einrichtung für solche Versuche mit sehr bedeutenden Auslagen verbunden ist. und in zweiter Ricihe das Feblen einschlïgiger literarischer Anleitungen ïber die bei solchen Arbeiten notwendige Technik. 


\section{Operationsraum.}

Die fiij ['ntersuchumeen an Tieren (als passendstes Material kommen

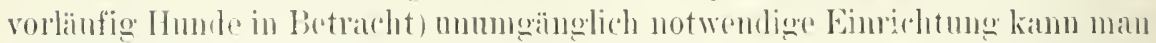
keinesfalls als kostspielig hezeichnen. Sind ansicichende dlittel vorhanden. so kitum es selbstredend nichts schaden, den Operationstam dhenso sehön einzurichten. wie in den musterhaften chirmrgischen Kliniken, aber unbedingt

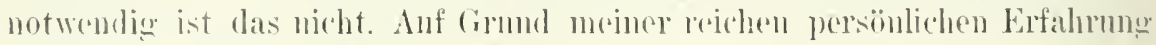
darf ich nämlich hohaupten. dall im gewöhnlichen Lokal mit gleichem Jarfolge operiert werden kann. wie im best eingerichteten operationssaul.

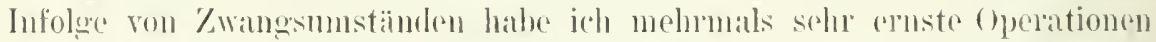
in dem bei meinem Laboratorinm befindlichen Hundezimmer, in dem ständign mehrere operierte Hunde muterebebraht sind, mol wo deshalh von ciner asej-

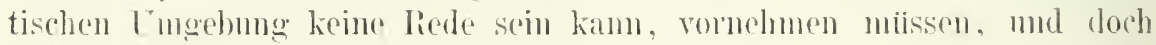
latte dies fuir meine ()perationen keine nachteiligen Folgen. Steril, und zwar genallest, mulu nur das sein, was mit dem eigentlichen operattionsfelde in unmittolhare Beriilurung kommt. Leinlaltung der wei-

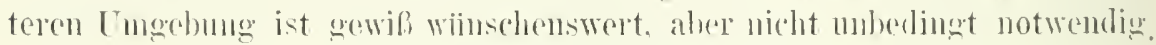

\section{Aseptische und antiseptische Maßregeln.}

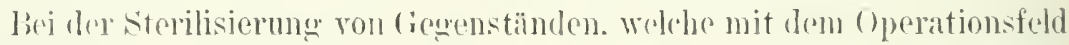
in Berïhrung kommen, hat man sich nach den allgemein iiblichen liegehn der chimmegischen Aseptik und Antiseptik zu rixhten. Instrumente und Seide siede man in 1\% iger Sodalïsmg nud halte sie damn wïhrend der (Iperationszeit in $2 \%$ iger liabolsämelösung. Watte mod Verbandstoffe sterilisiere man im Autoklaven. Die llände reinige man mit Seife, warmem Wassel mul Biirste und tauche sie damn anf einige Minuten in $1 \%$ ige Sublimatlïsmo und wasche endlich mit Alkohol. Während der Oporation selbst. wem die Hände zufällig mit nicht sterilen Cexemständen in Berïhrung kommon, diirfen diese mit Sublinat grereinigt werden.

Die Vorbereitung der Hunde zur (operation geschind anf folgende Weise. 2t stunden ror der Operation muls die Verabreichung ron Futter eingestellt werden. Anwendmo von Ahfiihrnitteln (Kalomol) ist ganz iiber-

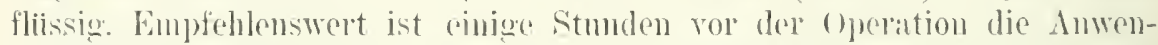
dung dines Wannenbates. Was aber auch muterlatsen werden kamu. Wenn grobe Cimstande damit verbunden sind. Ith persönlich hathe in den letzten 4 Jahre bei Hunden darom Abstand genommen mol zwall selbst bei Lus-

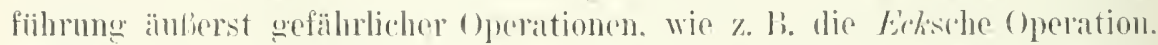

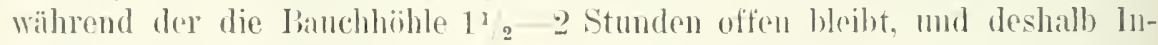
fektion leicht möglich ist.

Am besten schiitzt man die bauchlöhle vor ron anlion eindringenden Infoktionen durch sorgfiltige llantdesinfektion um das operationsfeld. Dir Hatare $n$ m die angemerkte schnittstelle müssen möghichst weit hermun sorgfïltigst abrasiert werden. Die entbliblite Hant wird peinlichst mittclst Biiirste, scife und warmem Wasser gewaschen mud sodamn reichlich 
mit $1 \%$ iger Sublimatlösmug. Alkohol und Ither begrossen. Wonarh der Hund der ganzen Länge nach mit Handtiichern zugedecht werden muf (ich verwende $t$ stiick) und nur ein Spalt für den Schnitt zwischen ㅡ Handtiichern offen gelassen wird.

\section{Instrumente.}

Es soll die VIinimalzahl der nötigen Instrumente angegethen werden.

1. Skalpeil. spitze

2. Scheren mit Knopf. mittelgrof. ohne nach Cooper. hleine

Inzisionsschere Richter,

:. Pinzetten nach Waldeyer, hreite schmale

Hakempinzette mit Schraube

t. Kornzangen nach Charrière. 2 stiich

und zugleich Sarlellialter

万. Arterienklemmen nach Péan mit Lappenverschluf $2+\frac{1}{4}$ Richelot. aufwärts gebogell is

6. Knopfsonden aus Neusilber rerschiedener Breite. b

i. Hohlsonden

8. Akupressurpinzetten nach Allis

9. Unterbindungsnadel nach Leopold

10. Nähnadel, ganz gebogene, rerschiedener Grölie . 12) runde für die Darmwand . . . . 12

Untersuchungsnadeln gerade für Blutgefïße 12

11. Nadelhalter nach Martin oder anderen . . . 1

12. Haken nach Prince, messerförmig . . . . . :

13. Löffel nach Volkmam.

1.. Ecksche Scheren .

16. Langes Seziermesser

17. Injektionsspritzen

18. Leithaken

19. Thermokauter

\section{Fistelvorrichtungen.}

Fistelröhren. Die Röhren sollen entweder aus reinem silber oder aus Neusilber gemacht werden. IIan mulj eine Sammlung von dreierlei Arten ron Röhren haben:

1. Einfache Fistelröhre(Fig. 14). Sie besteht aus einer zylindrischen Röhre mit einem an einem Ende fixierten breiten, ovalen Rande und einem beweglichen Ring. dessen Öffnung dem Unmfang der Röhre genau ent- 
spricht. I)ieses Modell hat London an stelle des üblichen (Fig. 15), welches sich als mpraktisch erwiesen hat, eingefiilnt.

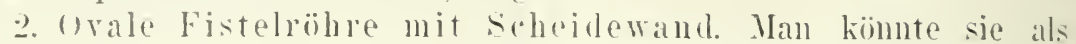
..zweikammerig. bezeichmen. Dieses Modell (Fig. 16) hat London fü den berlarf del I'olyfistelmethode erfunden. Wie aus der Fig. 16 ersichtlich, besteht dirselhe aus einer ovalen Röhre mit einem an einer Extremität der-

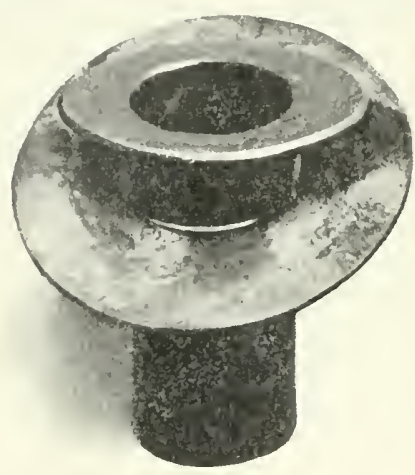

Fig. 14.

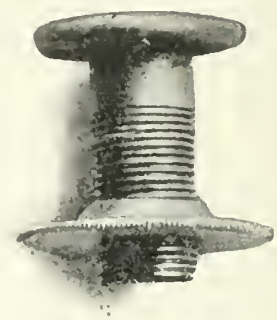

Fig. 15

selben fixierten. chenfalls ovalen. breiten liand: die genan in der Mitte der liöhre befestinte Scheidewand tritt an beilen Enden dersellen iiber deren Rand hervor, wobei der $0 \% \mathrm{~cm}$ hohe Vorsprum an Stelle des breiten Randes von einer bis zur anderen seite desselhen sich erstreckt: der äuliere Ring ist beweglich.

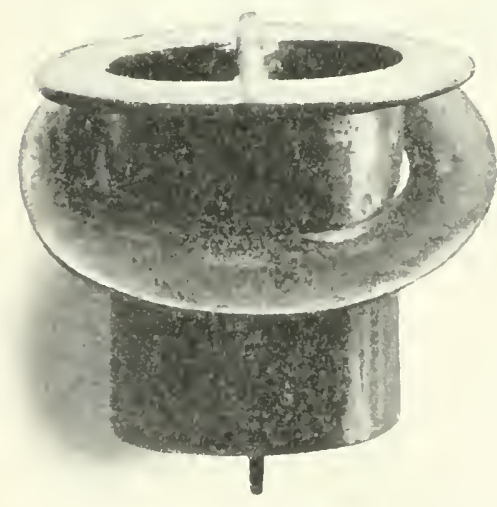

Fig. 16.

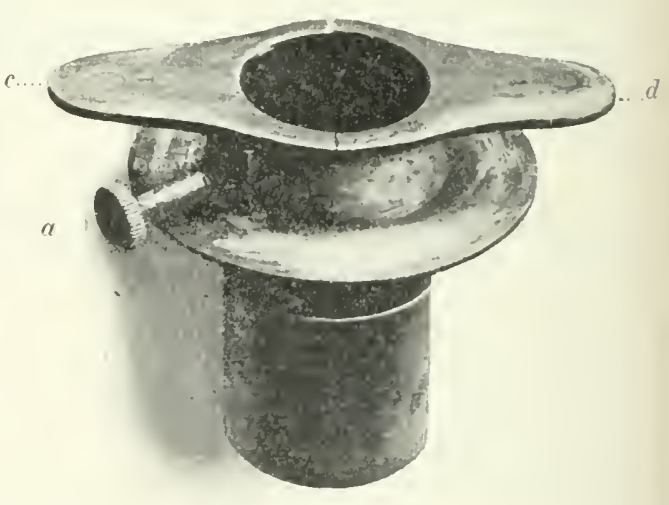

Fig. 17.

:\%.roleghare Fistelrahre (Fig. 17). Nir besteht ans zwei Hälften. die zusammengesetzt ein ganzes liohn bilden: der bewegliche ling ist mit cince schraube (a) versehen, welohe das \%nsammenhalten beider Hälften bedingt. Dieses Modell findet nur in sehr soltenen Fällen Anwendmo.

Es ist notwendig. einen Vorrat ron liölnen verschiedener cröbe zu besitzen. Es kamn nämlich eine Fistelröhre nur in dem Falle als ..gut" 
bezeichnet werden, wenn sie eine rollkommene Ausscheidung des an den Ort der Fistel gelangenden ('hymus gestattet. Nun besitzt jeder einzehe Hund bestimmte Dimensionen seines Darmlumens, deren $\mathrm{Ab}$ schätzung im voraus unmöglich ist. Dementsprechend ist es ratsam. vor der Operation mehrere Fistelröhren verschiedenen Kalibers vorzubereiten. d. h. dieselhen mit den ïbrigen Instrumenten zusammen zu sterilisieren und davon bei Besichtigung des Darmes das für den betreffenden Fall an besten passende Exemplar zu wählen. Wonach man sich bei der Wahl der Röhrengrößse richten muf, wird weiter unten bei der Beschreibung der Operationstechnik erläutert.

Die Erfahrung hat gezeigt, daß folgende Dimensionen am zweckmäßigsten erscheinen. Alle IIaße sind in Villimetern angegeben.

1. Fistelröhre für den Magen.

Lumenweite . . . . . . 22

Röhrenlänge . . . . . . 40

Breite des inneren Randes . 10

Breite des äuferen Ringes . 12

๖. Einfache Fistelröhre für den Darm.

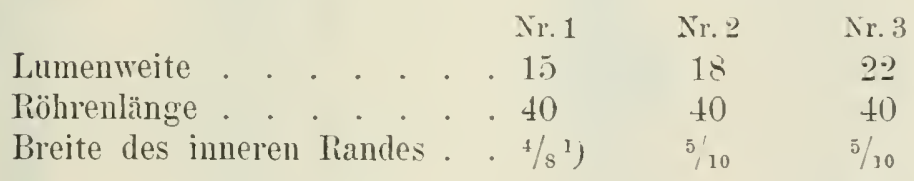

3. Zweikammerige Fistelröhre.

\begin{tabular}{|c|c|c|c|}
\hline Lumenweite & $\begin{array}{l}\text { Nr. } 1 \\
15 / 251)\end{array}$ & $\begin{array}{l}\text { Nr. } \\
18 / 30\end{array}$ & $\begin{array}{l}\text { Nir. } 3 \\
22{ }^{\prime} \\
35\end{array}$ \\
\hline Röhrenlänge . . . . . . . & 40 & 40 & 40 \\
\hline $\begin{array}{l}\text { Höhe des inneren Scheiderand- } \\
\text { vorsprunges }\end{array}$ & $: 3$ & 4 & 5 \\
\hline $\begin{array}{l}\text { Höhe des äußeren Scheidewand- } \\
\text { vorsprunges }\end{array}$ & 4 & 6 & 8 \\
\hline Breite des inneren Randes. & 5 & 6 & 7 \\
\hline
\end{tabular}

Zerlegbare Fistehröhren müssen im allgemeinen gleiche Dimensionen haben wie die einfachen; es muß nur hervorgehoben werden. daß die Lünge der Fliigel (Fig. $17 c$ und $d$ ) $2-21 / 2 \mathrm{~cm}$ betragen muß.

\section{Verschiedenartige für die Versuche nötige Vorrichtungen.}

1. Ballonapparate. London hat zwei Arten ron Ballonapparaten ausgearbeitet. welche allen Forderungen der Polyfistelmethode entsprechen:

1) Über dem Strich ist die Breite des schmïleren, unter dem Strich diejenige des weiten Randes angegeben. 
a) knicfürmigg gehogener (Fig. 18),

b) gerater (Fin. 19).

Diese Ballons werden von der (ienossenschaft r'ussisch-amerikanischer (ium miwarenmanufaktur (Nt. Petershurg. K. Hulm, Morskatja :3t) angefertigt. Im allgemeinen sind sie ziemlich gut und beynem: es erweisen sich aher nicht sämtliche Exemplare in gleichem Malie danerhaft: sehr häufig bilden sich Löcher in den Ballons, so dab letytere die Luft nieht mehr halten kiomen. Ihe Erfahrung hat gezeigt, dab es sehr niitzlich erscheint, die Ballons vermittelst (immmileims mit einer homlongummikappe zu umbiïlen.

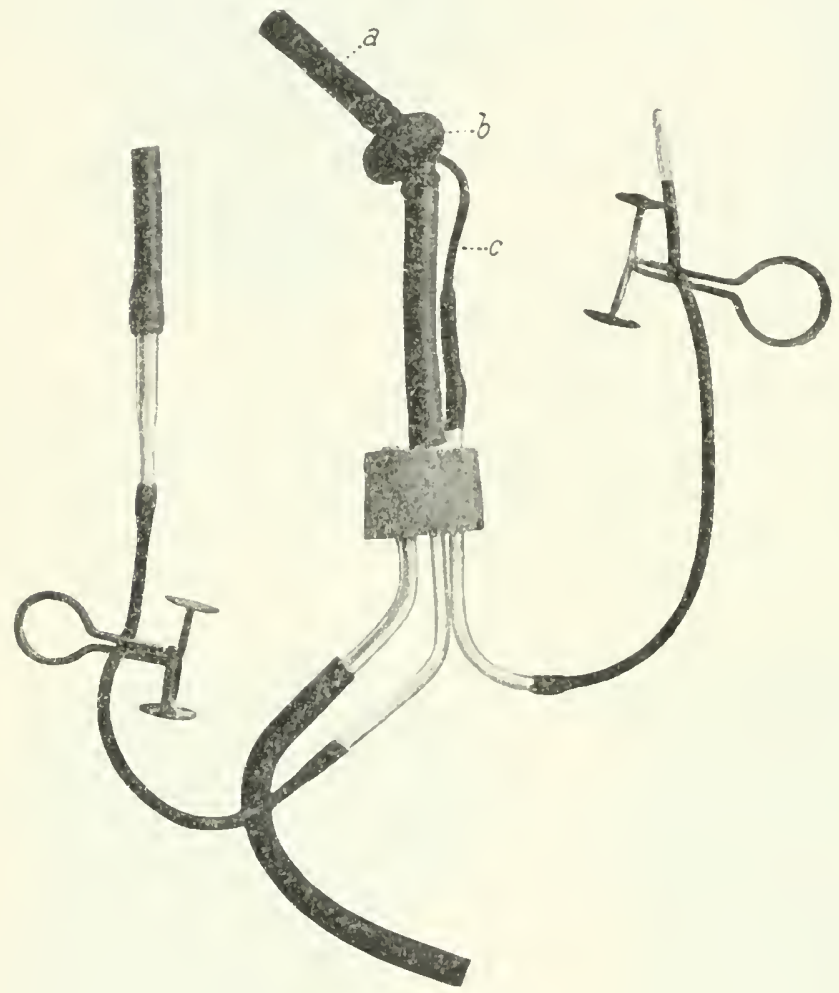

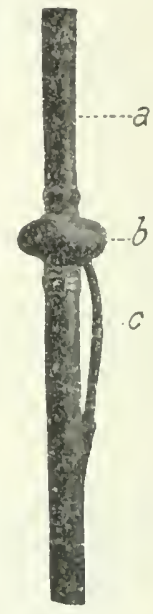

Fig. 19.

Iig. 18.

Diese rermehrt die Festigkeit des Ballons. ohue seine Dehnharkeit zu rerminder'n.

Der Ballonapparat (Fig. 18-19) ist aus folgenden Teilen zusammengesetzt: einer dickwandigen (iummiröhre (11). durch welche die Injektionem in den Darm ausgefiilnt werden; einem Batlon (b), welcher im Darmlumen durch die liöhre (c) anfgeb]äht wird. T"m einen klaren Einblick in die Art der Anwendung des Ballonapparates zn gestatten, wird hicr die Fig. 18 beigefïgt. Sie reigt. wic die Rïhren a und $c$ des Ballonapparates durch Vermittlung von Glasröhren, welche cinen in die Fistehöhre einge- 
steckten Pfropfen durelıbohren, mit der änlieren Tungebung in Verbindung stehell.

Cher die Ausriistung des Ballonapparates sollen folgende praktische Bemerkungen hinzugefiigt werden. Ler Pfropfen, welcher ron den Glasröhren durchbohrt wird, mul' aus Kork, nicht aus Gummi gemacht werden, denn ein Gummipfropfen läßt sich sehr schwer in die Fistelröhre derart einpassen, daß er dieselbe dicht schlieft und keine Flüssigkeit durchlält. Der Korkpfropfen wird noch vor der (Iperation eingepafit, samt der Fistelrïhre in Wasser anscekocht und ca. 5 Tage lang in der Rö̈hre gelassen; im Verlanfe dieser Zeit rerdichtet sich derselbe und nimmt eine konstante,
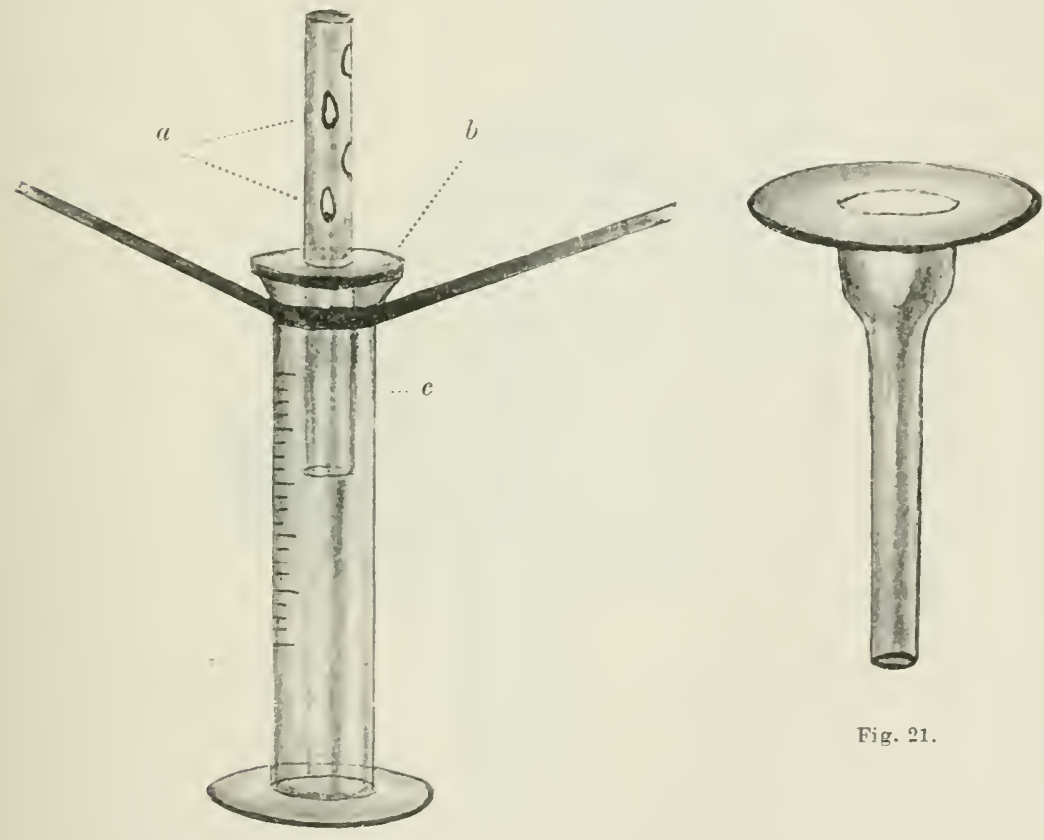

Fig. 21.

Fig. 20.

dem Lumen der Fistehölre genau entsprechende Form an. I)ann bohrt man Öffnungen, durch welche die Glasröhren dicht durchgestochen werden. Für das zum Ballon führende Gummiröhrchen wählt man ein enges Glasrohr (2 $\mathrm{mm}$ ), fuir das zu Injektionen dienende Gummirohr nimmt man dagegen ein etwas weiteres Glasrohr $(3 \mathrm{~mm})$ und für das Ableitungsrohr, welches zur Ableitung der auf der Strecke zwischen dem aufgehlähten Ballon und der Fistelröhrenscheidewand ins Darmlumen sezernierten Säfte dient, wird ein möglichst weites Glasrohr ausgewählt $(4 \mathrm{~mm})$.

2. Ableitungsgummirohr für den Magen- resp. Darmsaft (Fig. 0). Diese Torrichtung wird folgendermaßen zubereitet: Man nimmt ein dickwandiges Gummirohr mit der Lumenweite von $3-5 \mathrm{~mm}$ und brennt 
in dessen obere Hälfte mit vinem glihhenden llaht viele Seitenöffnumgen in einem solchen Nbstand roneinander durch (ii). daf die Elastizität des Rohres nitht rermindert wird, wonach man die betreffende Rïhre fiir einige Minuten in l'etrol eintaucht. I)amn nimment man eine dicke, elastische Gummischeihe ron $5-6 \mathrm{~cm}$ im Diameter (b) und fiihrt durch die in deren Zentrum gemachte Öfnumg das erwïhnte fimmmirohr muterhall, der durehgebranten Löcher ein. Endlich steckt man ins mutere Ende des

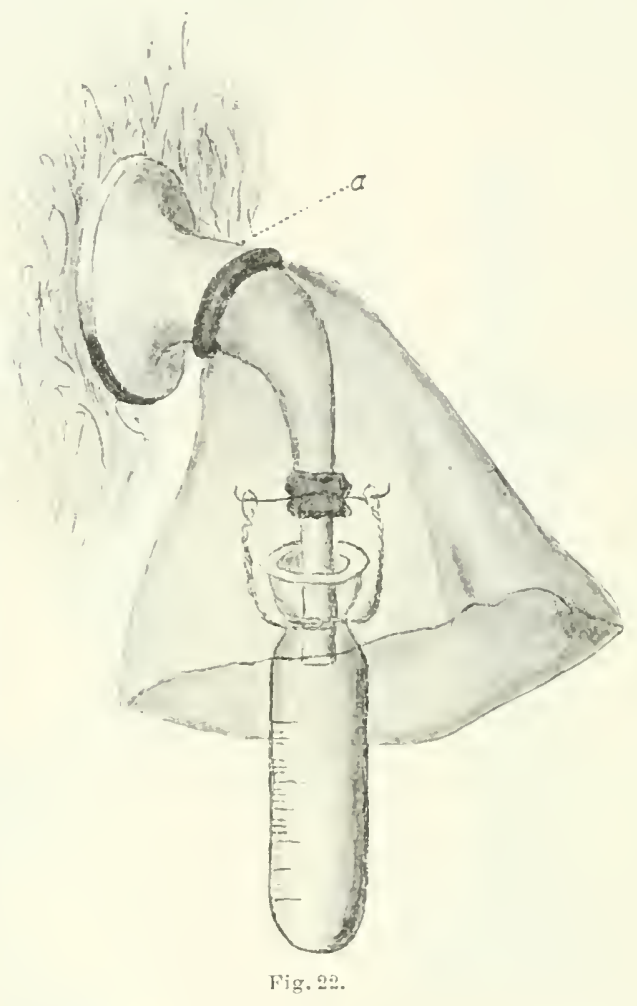

Gummirohres eine Gilasröhe von entsprechender Weite ein (c) und die Vorrichtung ist fertig.

O. Speichchröhren. Man soll zwcierlei Trichterröhren ans Glas besitzen: gerade (Fig. 21) und gebogene (Fig. …2).

4. Gilas- und Gummiröhren verschiedenor lircite.

5. I'fropfen aus gutem Kork.

6. Mendelejeffscher Kitt (vgl. S.97).

\section{Grundlagen der Operationsmethodik zur Untersuchung des Verdauungsprozesses.}

Zur Verarheitung der Nahrungsstoffe bedient sich die Natur spezifischer Fermente. welehe von speziellen Driisen zubereitet werden. Am Ent- 
stehungsort sowic im entsprechenden Ausfülnungsgange befindet sich das Ferment in relativ reinem Zustande; sobald es aber das Lumen des Aus-

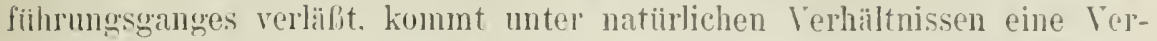
einigmug mit anderen Fermenten resp. verschiedenartigen fremulen sitoffen zustande. Folglich arscheint es notwenelig, un die Arheit einer bestimnten Iniise zu verfolgen, deren Ausfïhrungsgang von den umgrbenrlen Teilen kïnstlich zu isolieren. Solange es sich um einen Driisenapparat handelt, dessen Sekret, bevor es nach aulien sezerniert wird, sich in einen gemeinschaftlichen Ausfiihrungsgang sammelt, bietet die Isolierung des letzteren von der Lmgebung lieine Schwierigkeiten. Es existicren aber Verdauungsdriisenapparate, welche ihr Sekret durch zahlreiche. mikroskopisch foine, auf einer grolien (Oberfläche der Vordaumgstraktuswand zerstreute Ansfiihrungsüinge alsondern. Für solche Fïlle haben die Experimentatoren Thiry $\left.{ }^{1}\right)$ und Heidenhain ${ }^{2}$ ) das Primzip der operativen Isolierung der sezernierenden Oberfläche angewandt. Wer isolierte Wandahschnitt wird zu einen Blindsack rernäht und durch eine Fistelöffnung mit der Aufenwelt in Verbindung gesetzt.

Da die anf operativem Wege isolierte sezemierende Oberflïche von dem Zusammenhang mit dem ïlrigen Terdaumgstraktus ausgeschlossen wird, ist es klar, daß für experimentelle Zwecke nur ein Teil der phrsiologisch tätigen Oberfläche isoliert zu werden braucht, da ja dessen Tätigkeit iiber die Gesamtoberfläche Aufschluli gibt. Erscheint der isolierte Bezirk ron deu umgebenden Teilen gänzlich losgetrennt, so emanzipiert er sich ron der Unterordnung der funktionellen Harmonie des Verdaumngtraktus, fängt an, selbständig, unabhängig von seinem Ganzen zu funktionieren und kann infolgedessen uicht mehr als Zeiger dieses Ganzen dienen.

Auf Grund dieser Tatsache benutzte J.P. Purlow ${ }^{3}$ ) als Crundlage der Operationsmethodik ein neues Prinzip, nämlich die operative Isolierung eines Teiles des Ganzen unter Erhaltung der sekretorisch-nervösen Verbindung zwischen den einzelnen Teilen. insofern dies in jedem einzelnen Falle möglich erscheint. duf diesem (irundprinzip hat Pawlow eine Reihe Operationen ausurearbeitet, durch welche die Möglichkeit gegeben wurde, in viele bis dahin dunkle Fragen der Verdaumgsdriisenphrsiologie Licht zu bringen.

Aber auch diese Grundlage kann keine erschöpfende Bedeutung beanspruchen, indem das Prinzip cler operativer Isolierung der Terdaumgsdriisenausfïhrungsgänge an und fiir sich eine Quelle der Invollkommenheit dieser Methodik für die Entersuchung der Physiologie der Verdaumg in sich birgt.

1) Thiry, Sitzungslıer. d. Wiener Akad. 1864.

3) Heidenhain, Üher dic Absonderung der Fundusdrüsen des Magens. Pfiugers Archiv. Bd. 19. S. 148 (1879).

3) J. P. Paclow, Zur chirurgischen Methodik der Untersuchung der Nagensekrction. Verhandl. d. Ges. russischer Arzte zu St. Petershurg. S. 151 (1894). 
Erstens schafft die stetige Abfuhr der süfte nach außen im Verdaumgstraktus und zugleich auch im Gesamtorganismus abnorme bedingungen. Zweitens ist es plausibel, daß die normale trheit eines ()romes nehmen wir als Beispiel das Pankreas oder die Leber — miter gleichzeitigen Ausschlufi von P'rodukten der 'Tätigkeit der hetreffenden Irïse rom Yerdaunosprozeli zu verfolgen, gleichwertig einer Lntersuchung von Verhältnissen erscheint, die unter exklusiven pathologischen Bedingungen stattfinden kïnnen. 1)rittens schränkt uns die genamnte Methode die Erforschung der Verdauung nur auf diejenige der rekretionstitigkeit der Verdaunngsdriisen ein, olne für die Untersuchung des Verdanungsprozesses sellst. insofern in demselhen physikalische resp. chemische Faktoren tätig sind, einen weitcren liahmen zu schaffen.

All das Gesagte bewegte London, einen nenen Weg der Erforschung. des Verdaungsprozesses anzutreten, indem er seine Irothodik auf cinem neuen Prinzip gründete, das von dell erwihnten Fehlern frei sein soll. Es ist das Prinzip der operativ-mechanischen Isolierung von $\mathrm{Ab}$ schnitten des Verdaungstraktus. lieses Prinzip besteht darin. dak las Tier im Bereiche des Verdaungstraktus einer (Jperation unterworfen wird. welche nacher im Laufe des Versuches die lsolierung eines beliebigen Abschnittes des Verdauungstraktus gestatten soll, wobei die durch die Versuchsverhältnisse hedingten Verluste an Körpersäften dem Mranismus während des Versuches ersetzt werden können und sämtliche Nagendarmfunktionen auberhalb der Versuchszeit rollkommen normai ablaufen. Da die Untersuchung des Verdaumosplozesses nach diesem Prinzip die Anlegung einer mehr oder weniger grolien Zahl von Fisteln voraussetzt, gall London seiner Methode den Xamen ..Polyfistelmethode" oder ..'Temporärisoliermasmethode" zur Unterscheidmor von der friiheren llethodik, welche auf dem Prinzip der permanenten Isolierung basiert (Lauerisolierungsmethode).

Zur allseitigen Lntersuchung des Verdaumgsprozesses ist selbstrepständlich die Anwendung beider Ilethoden erforderlich.

\section{Operations- und Versuchsmethodik.}

Im Wiederholungen zu rermeiden, sollen hier vor allem einige (Iperations- resp. versuchsmethorlische Angahen angeführt werden, welche zu den meisten weiter unten zu behandelnden Fällen Bezug hahen.

1. Eröffnung und Schliebung der Banchhöhle.

Ahgesehen von einigen speziellen Fällen mub die Eröffnung der Bauchhöhle in allen ibbrigen Fällen ausnahmslos lings der Linea alla geschehen. lei der Schnittfïhrung durch die Hant muli man darauf hedacht sein. daf die weibe Linie der Haut bei den Hunden fast niemals mit derjenigen der Muskelwand zusammenfällt: letztere zicht melu nach links. gerade in der IIittellinie des Körpers, mol lïßt sich gewöhnlich leicht abtasten. Xachdem 
die Haut und die Aponeurose der Linea alba durchschnitten sind, kommt man auf eine Schicht des subperitonealen Fettgewebes. das in Form von Falten nach imnen herabliängt. Der operateur und der Assistent fassen dasselbe an symmetrischen Stellen mit I'inzetten, riehen es aulierhalb der Wunde hervor, und der Operierende macht nun einen Schnitt zwischen den Pinzetten, weteher nach der einen oder anderen Seite verlängert wird. Zuletzt werden die Falten nach außen gezogen und an der Basis alggeschnitten.

In der Regel kommt dabei keine Blutung zustande, so daß eine L'nterbindung der Gefïlie entbehrlich erscheint. Einmal aber. augenscheinlich infolge einer (iefäbanomalie, trat an Stelle der abgeschnittenen subserösen Falte eine Blutung nach der Operation auf, welche den Tod des Hundes zur Folge hatte. Un solchen Vorkommnissen rorzubeugen, ist es zweckmälig, jedesmal zu kontrollieren, ob nicht irgend ein bedeutendes Gefäß in die Schnittwunde zu liegen gekommen ist. Man vernäht die Schnitträndel schichtweise. Die Hautnaht wird mit Kollodium bestrichen.

\section{Pflege der Tiere nach der Operation.}

1. Nach säntlichen Bauch- resp. Fisteloperationen bleiben die Hunde 2 Tage lang ohne jede Nahrung. Am :3. Tag bekommt ein mittelgrofer Hund viermal täglich je $100 \mathrm{~cm}^{3}$ Milch: am 4. Tag viermal je $100 \mathrm{~cm}^{3}$ Milch und $50 \mathrm{~g}$ feingehacktes Fleisch: dann vergröliert man, entsprechend dem Zustand des Tieres nach und nach die Tahrmngsmenge, bis die normale Ration erreicht wird. Es mul; iherhaupt hervorgehoben werden. dab, insofern es sich um die Erforschung der Verdaunng handelt, die Hunde mit leichter und gut rerdaulicher Nahrung gefiittert werden miissen: Milch, Schabefleisch und Weißbrot. Sonst ist es selnr schwer, die Iniät derart zu regulieren, dal der Verdaungstraktus im uötigen Momente leer erscheint.

๖. Zum Ausstreichen der Wunde sind am besten die desinfizierenden und adstringierenden Salben zu empfehlen. Am besten gebraucht man folgende Salbe: Menthol 0.1 . Acidi salicylici $0 \%$. Zinei oxydati, Amyli tritici aа. 60 , Vaselini, Lanolini aa. $15 \cdot 0$.

\section{A. PoIyfistelmethode.}

a) Historisches. Die Polvfistelmethode ist von E.S. London $\left.{ }^{1}\right) 1905$ in Angriff genommen und ron ihm technisch ausgearbeitet worden.

b) Das Wesen der IIethode. Die Polyfistelmethode besteht darin. dalb der Verdaunngstraktus durch Anlegen von Fisteln in eine Reihe von-

1) E.S. London, a) Zum Terdauungschemismus im tierischen Organismus unter physiulogisehen und pathologischen Verhültnissen. Zeitschr. f. phys. Chemie. Bd. 4 j. S. 381 (1905). - b) Ein reiner Prlorusfistelhund und die Frage über Gastrolipase. Ibid. Bu. 50. S. 125 (1906). - c) Methodische Angahen. Ilid. Bd. 51. S.211 (1907). - d) Zur Technik der Eckschen Operation. Ilbicl. Bd. 51. S. 467 (1907). - e) Weitere methodische Angahen. Ibid. Bd. 53. S. 246 (1907). 
einander abgorgenzter Abschnitte zerlegt wind. Diese Methode dient erstens dazu, das schicksal vershiedenartiger. Substanzen bei ihem fortschreiten durch oinzelne Absehnitte des Verdamngstraktus zu verfolgen und zweitens zur Gewimnung der im Laufe der Terdaumg abgesonderten Säfte (fial!e. Pankreassaft. Dillmsaft).

Ijic Ansführmg der Polyfistelmethode ist nur dadnrch moiglich weworlen. dab es gelang, die Fistel derart amznlegen, dab sie während des Versuches auch tatsäldheh einen Teil des Terdaumestraktus rom anderen ahtremut. Diese Möglichkeit wude durch Ausabeitung einer Methode der Anlegung ron Fistelröhren mit weitem Lumen gegehen.

Es sei zmuächst diese Methode im allgemeinen geschildert. Inf die zol verschiedenen Darmabschnitten gehörenden I)etails wind an entsprechender stelle eingegangm.

r) Nethode der Anlegung von Fistelröhren mit weitem l.umen am Darm.

1. Man merkt sich die Solnittlinie und legt eine bentehaht nach Lembert, d. h. ohne die schlemhant mit der Sadel zu durehstechen. um sie herum an. I)ic Schnittlänge muf derart berechnet warden. daf der innere Rand del Fistelröhre mit seinem queren, d. h. kïrzesten l)urhmesser in die Schnittwunde eingefiihrt werlen kann. Die Nahtstiche miissen mïglichst klein und hänfị sein. Die Distanz zwischen beiden parallelen Tahtreihen darf z mm nicht ïbersteigen. Der letzte Ausstich kommt gegeniiber dem ersten Einstich zu liegen.

2. In ler Mitte der leutelnaht wird mit dem Skalpell ein Selnitt his \%ur Submukosa genacht, daranf die Mnkosa ebenfalls mit dem Skalpell durchstochen und anf der ibrigen sitrecke nit der Schere anfgesehnitten. indem man durely sie gleichzeitig zur Schommog des Nahtfadens die Mnkosa-submukosa herauswölbt.

3. Del (Iperatem und der Assistent fassen (ersterel mit der linken Hand) mit den l'inzetten die schnittänder in der Mitte und der Operierende schieht mit der rechten Hand die Fistohöhlo mit dem kïrzesten Inuchmesser ilnes immeren liandes in den l)an hinein, indem er, die Wunde an ihrem distalen Ende mechanisch erweiternd, den ganzen imeren Rand ins Larmlumen einzufihmen sucht. Dank solcher Manipnlationen wird die minimale lomension der Darmwunde erreicht.

4. Der Ein- resp. Ansstich des Farlens, welche ros lem Finfiihren der Fistelrölne nebeneinandel lasen, erscheinen jetzt voneinander entfernt; infolgedessen wirl die Bentelnaht mit derselhen Vadel, welche ans diesem Grunde vor dem 'buknoten des Fadens von diesem nicht abgenommen werlen darf. bis zur Stelle des ersten Einstiches fortofühut. Her Faden wirl znerst in einen chirurgischen, daranf in einen einfachen Knoten gebunden. I labei erscheinen die Sehleimhautrïnder nach anken vorostiilpt. vie miissen mittelst einer kleinen schere oder eines Iollinumnsehen Löffels vollkommen entfernt werlen. I)alauf wird der Farlen in entgegengesetzter

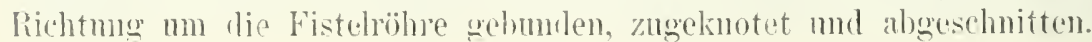


5. Man zieht das Omentum majus hervor, legt einen liand desselhen auf den Fistelröhrenrand auf, durchschneidet es mit dem skalpell in der Richtung des [)iameters und schiebt die Schnittrïnder lïngs der äuferen Riölrenwand bis zur Berihlrung mit dem I)arm herab. Hier wird das Netz in Falten gelegt und ron beiden Seiten an div Jarmwand angenäht. $/ u$ diesen Zwecke bedient man sich langer Fürlen und runder, nicht schneidender Nadeln. IIan macht 2 Nahtstiche. indem man nur die Muskularis fabt.

b. Jie Darmschlinge sant der Fistelröhre wird in ein Iulltuch eingevickelt und auf die Seite geschohen. Der äufere Fistelring wird auf diejenige Stelle der Bauchwand aufgelegt, an cler man die Fistelröhre nach außen durchfiihren will. und entsprechend dessen Diameter wird ein Hantschnitt gemacht. Der Schnitt mul möglichst nahe an die Linea alba gefiihrt werden. um die Fistelröhre in mehr vertikale Lage zu bringen. I)ies ist besonders wichtig bei zweikammerigen Röhren, bei denen bei mehr horizontaler Lage das Hinïberfliefien von einer Kammer in die andere längs der Schleimhaut ermöglicht wird. Ohne den Ring abzunehmen, wird dann unter Kontrolle der Finger der linken Hand die ganze Dicke der Bauchwand durchschnitten. Der Diameter des äuferen Ringes erscheint als der richtigste Zeiger für die Schnittlänge: Macht man einen längeren schnitt. so bleibt nach Durchfiihren der Fistehöhre freier Raum ibrig. wohin der Darminhalt gelangen und relschiedene Komplikationen (Abszesse, Geschwiire etc.) herrol'ufen kann; andrerseits ist es sehr schwer, die Fistelröhre durch einen engeren spalt durchzufiihren. Die giinstige Schnittlïnge ist dadurch ausgezeichnet, daß die Fistelröhre nach dem Durchschneiden von der Haut dicht umfaft wird.

7. Die Enden des Fadens, mit dem das Netz an den Darm angeheftet war. werden mittelst einer großen. mäßig grekrïmmten Yadel unter Kontrolle des linken 'Zeigefingers in der Entfermung' ron $1-2 \mathrm{~cm}$ rom eutsprechenden schnittende, in $1-1^{1}{ }_{2} \mathrm{~cm}$. Distanz roneinander durch die Bauchwand geführt. Der" Operierende schiebt dann dureh den Schnitt der Banchwand einen Pérnschen sehieber durch und führt dessen Spitze unter Kontrolle des linken Zeigefingers aus der Schnittrunde der Linea alba heraus. Darauf senkt der Assistent die Darmschlinge samt Fistelröhre resp. Netz rorsichtig in die Bauchhöhle ein. I)er Operierende fafit den Fistelrand mit dem bereit liegenden Péanschen Schieber. Mit einem zweiten Schieber wird der entgegengesetzte Fistelrand gefaßt. wenn aher die Fistelröhre ron grobem Kaliber ist. nimmt man einen dritten und einen vierten Schieber zu. Hilfe. Man hilft sich nach Bedarf mit einer anatomischen Pinzette und zieht die Fistelröhre nach außen hervor. Die Fadenenden werden ad maximum angezogen und iiber einem Mullpolsterchen geknotet. Es ist ratsam, zu kontrollieren. ob nicht etwas in der Bauchhöhle in die Fadenschlinge geraten ist. In der Regel ist es nicht der Fall; loch ist mir ein Hund 20 stunden nach der Operation dadurch zugrunde gegangen, dab eine Darmschlinge rom Faden mitgefabt wurde. Iiese ging in Gangrän über und hatte eine Peritonitis zur Folge. 
8. Ile Banchruncle wird zugenäht: auf die Fistelıöhre wird der äulsere Fing angelegt und dariber kommen noch -) Gummiringe (abgeschnittene Stilcke eines Gummischlauches von einem : Bmal engeren Lunen als die Fistelgöhre). Es ist sehr wichtig, darauf zu achten. dalf die Ringe in richtige lage kommen. Wenn die Cummiringe den äulieren Fistelröhrenring zu fest an die Hant andrücken, so daß letzterer alle Beweglichkeit einbiißt, so fiihut es pewöhnlich zu dem Resultat, daf der vom inneren Fistelröhrenrand zusammengeutetsehte I)armabschnitt gangrüuesziert. die Gangrïn anf den diu Fistelöhre ungebenden Bauchwandbezirk sich aushreitet. was das Heransfallen der Fistelrihhe zur Folge hat. Dies geschieht gewöhnlich am 3 . his 4. Tag nach der operation. Wenn keine anderen schweren Komplikationen vorliegen, erscheint es möglich, den Hund zu retten. indem man eine zerlegbare Fistelröhre von gröferen Dimensionen (Fig. 17) als dic herausgefallene einführt. Dieses Vorgehen fuhrt aber nicht immer zum Ziel. da die Gangrïn häufig progressiven Verlauf zeigt und auberdem durch Zufliefen von Chỵmts unterhalten wird. Falls aber der äußere Fistelring zu hoch iiber der Haut gelegen ist, kaun dies das Abreißen der an die Banchwand angehefteten Darmschlinge zur Folge haben (bei den Bewegungen des Tieres), was zu aner tödlichen Peritonitis. hervorgerufen durch Einfliefien von Darminhalt in die Bauchhöhle. führen kam.

bie richtige Lage ellangt der äubere Ring in dem Falle, wenn er. an der Haut gut anliegend, demnoch freie Beweglichkeit in der ganzen Zwischenstrecke ron $1 / 2-2 / 3 \mathrm{~cm}$ besitzt.

An folgeuden Tag nach der Uperation wirl der untere Gummiring und nach 2-:3 Tagen anch der obere Gummiring abgenommen und der äufere Fistelring an die Fistehöhre in der Entfernung ron ca. $1 / 2-1 \mathrm{~cm}$ (je nach der Dicke der Bauchwand) von delen Rand angelötet. Cleichzeitig werden die zur Befestigmng der harnschlinge an die Bauchwand angelegten Nähte entfernt.

Die Hautnaht wird erst an 7 . bis 10. Ta! nach der Operation entfernt.

d) Iesonderleiten der Methodik der Fistelanlegung in rerschiedenen Darmabschnitten.

\%) $1 \mathrm{~m}$ kompliziertesten erscheint die Anlegung ler l'ylorusfistel. An diese Stelle wie iberhaupt ans Duodenum pabt nus eine grofe. zweikammerige Fistelröhre.

lievor man zur Prozedur der Fistelanlegung selbst schreitet, ist es notwendig, zwei konstant hestehende Bauchfellalten zn durchschueiden. welche ron beiden Seiten dos Pylorusringes nach der Leber ziehen. Es ist darauf zu achten. daß das seitens des Inodenums zichende Band grewöhnlich mehr oder weniger hedentende Gefäbe enthält, die bei der I)urchtrennung geschont worden niissen. In manchen Fällen trifft man außerdem noch cinige fadenfömmige bïnder, die an besten dbenfalls durchschnitten werden. Der zweite Vorhereitungsakt besteht darin. daf man denjunigen Teil des Gallenganges alprëpariert resp. heraustremnt. Welcher in der Dicko 
der Duodenalwand his zu seiner Eimmindungsstelle in das Darmlumen gelegen ist, ohne selbstrerständlich den Darm zu eröffnen.

Beide heschriebenen Vorlsereitungsakte sind in folgender Beziehung wichtig. Die Durchtremung der Bänder verleiht dem Pylorusteil des Nagens resp. Duodenums gröbere Beweglichkeit, wodurch die Befestigung der letzteren an die Bauchwand erleichtert wird. Dies ist besonders wichtig bei Hunden mit rorstehendem Thorax. I)er zweite $\Lambda \mathrm{kt}$ erscheint deshalb ron Wichtigkeit, weil er die Möglichkeit gibt, die erste Papille vom Rande der Fistelröhre weiter nach riickwärts zu schieben, was bei kurzem Duodenum von hesonderer Bedeutung ist.

Es gilt iiberhaupt als liegel, dah der Darm mit der Zeit sich etwas proximalwärts zu verschieben pflegt. Wenn also die Papille zu nahe an die Fistelscheidewand zu liegen kommt, kann sie mit der Zeit jenseits derselben sich verschieben, so daß das Sekret dieser Papille (Galle und Pankreassaft), anstatt durch die anale Kammer nach außen abzufliefen, sich den durch die orale Kammer heraustretenden Magenausscheidungen beimengt.

Zum Zwecke der nöglichst bedeutenden Entfernung der ersten Papille vom Fistelröhrenrand ist es vorteilhaft, mit der analen Befestigungsnaht denjenigen Bezirk des Duodenums mitzufassen, aus welchem der Gallengang herauspräpariert war. Die orale Befestignngsnaht zieht durch die Serosa resp. Muscularis des P'ylorusteiles des Magens in dem Abstand von 1 - $2 \mathrm{~cm}$ vom Pylorusring.

Bekanntlich miindet der erste Pankreasgang in der Regel in die gleiche Papille mit dem Gallengang ein. indem er in den letzteren unweit der Papille durchbricht. Es kommen aber verschiedene Anomalien ror; es kann z. B. der Pankreasgang oberhalh der Gallenpapille einmiinden, auch kommt ab und zu aufer den heiden Hauptgängen noch ein akzessorischer Ansfiihrungsgang vor, welcher gerade an der für die Fistel bestimmten Stelle eimmïnden kann. Alle diese Anomalien, wenn sie auch selten sind, müssen in Betracht gezogen werden. Am einfachsten ist es dann, den abnormen Gang zwischen zwei Ligaturen zu durchschneiden.

Um Beimengungen der Ausscheidungen der ersten Papille zu vermeiden, ist es vorteilhaft, einige Wochen vor der Pylorusfistelanlegung eine Transplantation der genamnten Papille rolzunehmen. sammen:

Die Operation ${ }^{1}$ ) setzt sich aus folgenden einzelnen Momenten zu-

1. Am Duodenum werden zwei Ḱlemmpinzetten angelegt; die eine am Pylorusende, in einiger Entfernung von der Eimmiindungsstelle des Gallenganges, und die andere im Zwischenraum zwischen der Papillaröfnung und dem zweiten Pankreasausführungsugang.

$\left.{ }^{1}\right)$ E. S. London, Weitere methodische Angaben. Zeitschr. f. physiol. Chemie. Bil. 62 (1909). 
2. $1 \mathrm{~cm}$ von der Eimmindungstelle des Gallenganges in das I)udoum anternt wird der erste Kuoten derjenionen Naht angelent, mit welcher späterhin der Inodenallappen angenäht werden soll.

$\therefore$ Der mit provisorischer Ligatur rersehene Lappen wird ans den Dnotenmo in der Weise herausgesehnitten, daf die Papille in einger Entfermung rom Lappemrunde zu liegen kommt.

t. Die Rïnder des Inodenaldefektes wrolen zn der herangezogenen ersten Jejunnuschlinge zugenäht, anf welche Weise der entstandene lefekt am besten erainzt wird.

5. In den Lappen wird die eine oder die andere Schlinge des Dundenums orled des iibrigen Darmteiles - am besten die zur Defektergänzung dienonde erste Jejunnmschlinge - herangezogen und mit dem rechten liand des Lappens durch cine fortlaufende Naht vereinigt; darauf wird noben der Naht eine Öffum in die I)armwand eingeschnitten, in welehe ler linke Lappenrand lineingestiilpt und reunäht wird.

\%wecks Beseitigung der limeimengung der Siffe aus der ersten Papille zum Magenbrei wurde noch in anderer Weise verfahren. Lang ${ }^{\prime}$ ) hat z. l'. vorgeschlagen, den (rallengang samt dem ersten Pankreasgang zu unterbinden mud die Gallenblase in eine Darmschlinge einmünden zn lassen. E. Zun $z^{2}$ ) hat eine besondere Kintile beschrieben. Cohnheim. und Dreyfus ${ }^{3}$ ) legten an Juodenum nahe beieinander zwej Fisteln an mnd liefen den Hund wälurend des Versuches anf einer schiofen Ebene stehen.

Anwrudnug der l'ylorusfistel. Die Prlorusfistel rerfolgt dreierled \%wecke:

1. Die Bestimmmng der Verlaumng resp. Resolption im Magen, zn welehem '/wecke das Exkret ans der oralen Fistelhälfte aufgefangen wird; 2. die Frforselung des Absondermosganges aus der ersten Papille (Galle und Pankreassaft), wozn die anale Fistelhälfte (der Ballon befindet sich in der Vitte zwischen der crsten mnd zweiten I'apille) dient; 3 . die Untersuchung der Gallensekretion, zu welchem \%weck der esste pankreatische Gang während der (I)peration unterlumblen wircl.

Tersuchsanstellung an Pylorusfistellund (Fig. 2:3). Behufs lieguliernug der Pylorustätigkeit spritzt man durch die Röhre $C$ des Ballonapparates vou Zeit zn Zeit entweder des rom selben Hund in einem Vorversuch gewonnenen Dagenhrei oder Prodnkte der Pepsinverdaumg in vitro

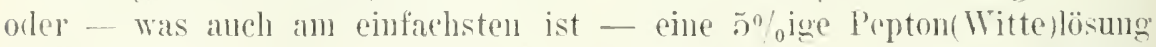
in '/o normalen Salzsimrelösme. \%ur Herstellung der Pepsinverlaumugsmodukte verfährt man in der Weise, dab man 100-200g fein gemahlenes Fleisels

1) Lang, Other Eiweißrerdaung und Eiweißresorption im Magen des Hundes. Biochemisclie Zeitschrift. Bd. 11. S. 20.25 (1906).

2) K. Zunz, Eine Kaüzle zı ('holedochoenterotomie. Zeitschr. f. biolog. Technik mul Methodik. Bal. 1. S. $13 t$ (1908).

$\left.{ }^{3}\right)$ ". C'ohnheim und Ireyfus, Zur l'hysiolngie und Pathologie der Nagenrerdanung. Zeitsch. f. physiol. (hemie. Bd. 58. ‥ 50) (1908). 
mit $500 \mathrm{~cm}^{3}$ natiulichem oder künstlichem Magensaft bei $: \mathfrak{B}^{\circ} \mathrm{C}$ binnen 12 his 2t stmnden rerdanen lälit. Jan läbt den Verdaumesbrei durch ein feines Sieb und spritzt denselhen portionenweise je nacl Bedarf ins iluodenum. Der in das Gefül) $d$ fliefende saft (lialle + Pankreassaft) wird, wenn es darauf ankommt, zum Injektionsbrei zugefügt. Zur Sicherheit fürbt man den Injektionshrei mit Methylenblau. Läit der Ballon zufällig nach, so bemerkt man dies gleich an Blauwerden der aloflielienden Säfte.

5) Die mittlere Dnodenalfistel wird in der Vitte der ersten und zweiten Papille angelegt. Der Darmschnitt mul derart ceführt werden, dali dic scheidewand näher an die erste als an die zweite Papille zu liegen komnt, indem die Darmwand, wie ohen angedeutet, mit der \%eit sich

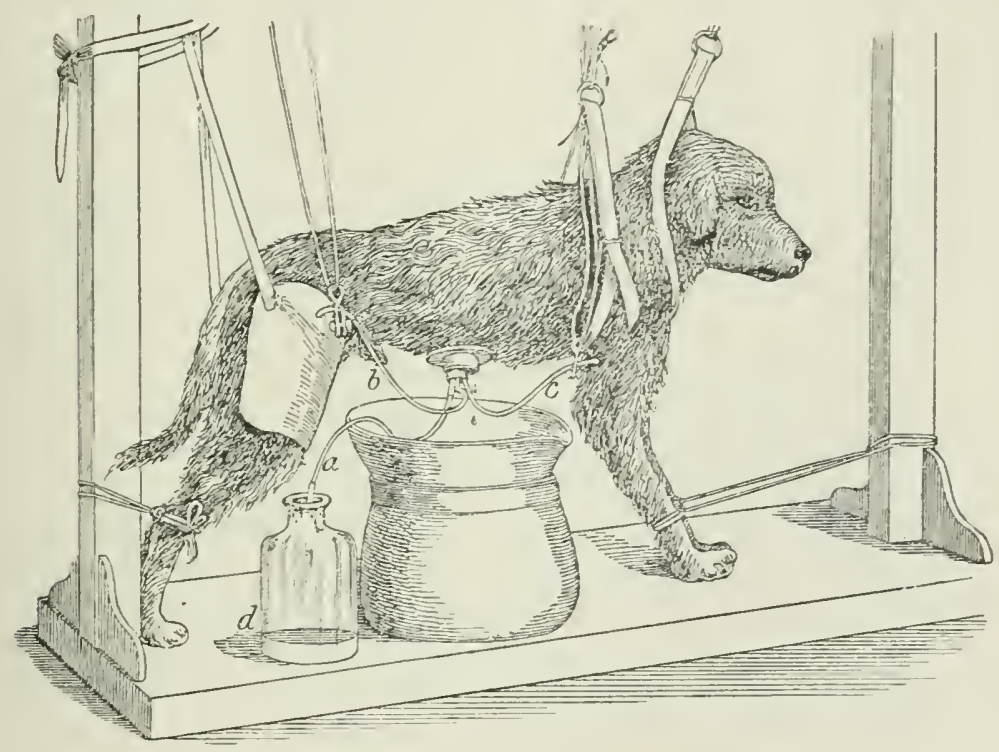

Fig. 23.

proximalwärts rorzuschiehen pflegt, so dab die zweite Papille entweder auf das Nireau der scheidewand gelangt und infolge der Peristaltik der einen oder anderen Seite derselben halanciert, oder aber sie stellt sich proximal von der Scheidewand fest.

Anwendung der mittleren Juodenalfistel. Lie mit dieser Fistel verfolgten Zwecke sind zweierlei Art: 1. Die Bestimmung der aus der ersten Tapille stammenden Säfte für den Verdaunngsprozeß und 2. die Verfolgung der Pankreassekretion ans der zweiten Papille.

Versuchsanstellung. Dem ersten Zreck entsprechend sammelt man den aus der oralen Fistelhälfte heraustretenden Chymus, während für den zweiten die aus der analen Hälfte kommenden Säfte aufgenommen werden. Zum Regulieren der Pylorustätigkeit leitet man in das untere Inodenum 
im arsteren Falle den in einem Vorversuch am selben Hund gewomenen Brei orler einen kinstlichen Fleischverdaumgsbrej unter Zufïgung von aus frïheren Tersuchen wewonnenen Sïften aus beirlen Papillen. Die Säfte lassen sich gauz gut kouservieren, wenn man sie auf flachen. breiten Tellern bei einer 'Temperatur von $20-205^{\circ} \mathrm{C}$ eintrocknen läbt. Die Trockensubstanz wird damn noch im Exsikkator üher Schwefelsäme wasserfrei gemacht. Solche Trockensäfte behalten ihe Verdaumoskraft unendlich lang. Will man aus der 'Trockensubstanz den natiirlichen Saft herstellen. so achte man darauf, dab der Saft der ersten Papille in Mittel nach den mehrfachen Untersuchungen vou London und Polou:zowe $\left.{ }^{1}\right) 0 \% 0 \%$ X und der l'ankreassaft der zweiten Papille $0.19 \%$ N enthält.

Handelt es sich um das Studium der P'ankreassaftsekretion, so rerführt man ander's. I)er aus der oralen Fistelläilfte herausfallende Brej wird mittclst einer Pravizspritze durch das Finlejtungsrohr in den I)arm weiter hefördert. Vor dem Einspritzen wird der Brej durch ein feines Sieh durchgelassen und mit Dethylenhlauläsmg gefïrbt. Der zwischen je zwei Einspritzungen ansgeschjedene Pankreassaft wirl abgenessen und. wenn es nur auf Quantumbestimmumgen der Pankreassekretion ankommt. zmm Einspritzungshei hinzugefiigt. Soll aber der Saft noch zu irgend welehen anderen Untersuchungen dienen. so mub er durch entsprechende Mengen rou Voratssaft ersetzt werlen. Nur bei einem solchen Verfahren bekommt man gename. als Norm waltende Daten. Bei der iblichen Methode (Pankreasfistel) verläuft der Verdanmosprozeß anormal, weil der während des Versuches sich absondelude Saft dem Verdaunngstraktus entzogen wird.

;) Die untere I) uodenalfistel wirl gewöhnlich 5- 6 cm muterhalh des zweiten Pankreasoanges angeleot. in welchem Falle die Operation war keine Schwierigkeiten darhietet. Wenn es aber winschenswert erscheint. die Fistal weiter muten anzulegen. ist es nötig. diejenige Mesenterialfalte anzuschueiden. welche den muteren 'Teil des lmodenums resp. den Anfangsteil des Jejunums an die Wirbelsänle (Plica duodeno-jejunalis) befestigt.

Auch hier mul eine zweikammerige ristelröhre angelegt werden.

Anwondung. Inie mit diesej Fistel verfolgten $/$ wecke sind zweierlei

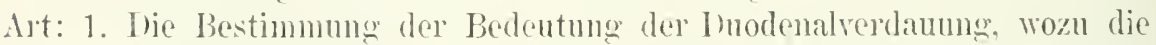
aus der oralen Fistelkammer aufgenommenen P'rodukte der Analyse unterworfen werden; 2. zur Gewinumng des Saftes, wulcher von den dnorlenalen Iniisen abgesondert wird. zu welchen Zwecke der aus der analen Fisteloffuung abfliefende Saft gesammelt wird; letyterer stammt aus dem zwischen Ballon und scheidewand eingerahnten larmabschnitt.

Versuchsanstellung. Inicselha wie hei der mittlemen I)uodenalfistel.

d) Die ibrigen Fisteh werden nach den oben erwähuten allgemeinen Regeln angelegrt. Es sej nur noch hemerkt. dah die Ileozökalfistel am Ende des Ilenms t-5 cm entfernt rom Coekmm anzulegen ist.

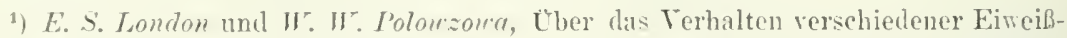
arten im Magen und oleren Duodenum des Hundes. Zeitschr. f. phỵsiol. (hem. Bul. j̃. S. 113 (1909). 
ミ) Lnter dem Namen ... Liesorptionshmud" soll cin Hund verstanden werden, hei dem ein beliebiger Darmabschnitt, vielleicht auch der ganze I)arm, ron dem ()rte der zweiten oder soga der ersten Papille bis zum Coekum zwischen zwei Fisteh heranswesondert wird, nachden vorher der zweite Pankreasgang unterbunden worden war, so daß auberhalb der Versuchszeit der Jarm nuter den für denselben normalen Ernälnungsverhältnissen sich befindet und nur während des Versuches dem Einfluk der von oben zufliefenden Verdanungsä̈fte entzogen wird (Speichel, Magen- resp. Pankreassaft, Galle). lie Vorzïge, welche diese Methode der Heraussonderung von Darmabschnitten vor rler Thiry-I'ellaschen. welche weiter unten ihre Beschreihung findet, hat. sind ohne weiteres klar: erstens wird der zur Untersuchung von normalen Verhälnissen hestimmte Iramabschnitt den normalen anatomisch-physiologischen Pedingungen nicht entzogen, zweitens ist dadurch die . Iöglichkeit gregeben, einen Darmteil beliebiger Länge zu isolieren.

Abgesehen davon, welchen Darmabschnitt wir zwischen zwei Fisteln zul isolieren winschen, muls in die proximale Fistel eine zweikammerige Fistelröhre eingeführt werden, welche allein das isolierte Darmstïck vor dem Hineinfließen von aus den oberhalb dessellsen liegenden Bezirken stammenden Säften zu verhüten vermag. Die zweite anale Fistehöhre kann auch einfach sein. Der Resorptionshund kann auch selbstrerständlich mehrere Fisteln haben.

Anwendung. Der Resorptionshund wird gebrancht, wenn es wiinschenswert erscheint, 1. die Resorptionserscheinungen im Darm zu untersuchen und 2. die Wirkung des Darmsaftes zu verfolgen. Wenn man dessen Einfluf möglichst zu beschränken wiinscht, benutzt man die Atropininjektion.

Als Nebenprodukt wird während des Versuches Darmsaft aus dem Darmabschnitt, welcher sich zwischen der Fistelröhrenscheidewand und dem Ballon befindet, durch das Ableitungsrohr (c) ausgeschieden.

Tersuchsanstellung. Die Ausriistung des Hundes ist aus der rorliegenden Abbildung (Fig. 24) klar. Man leitet die Versuchsflïssigkeit durch das Rohr in den Darm und nimmt sie damn in ein Kölbchen auf. welches, falls es sich auch um Darmsaftwirkung handelt, mit Eis beschickt sein mub.

Will man vergleichen, wie sich die Resorption rerschiedener Darmteile verhält, so muß man die zu vergleichenden Abschnitte durch zweikammerige Fistelröhren trennen. Als Beispiel soll der Fall (Fig. 25̆ und 26) angegeben rerden, in dem London ${ }^{1}$ ) und Sivré rergleichende Untersuchungen iiber die Resorption in der oberen und der unteren Darmhälfte ausgefïhrt haben. Es waren dem Hunde : Fisteln angelegt. Eine ron den Fistelröhren (eine doppelte, mit einer Scheidewand, ${ }^{38} / 22 \mathrm{~mm}$ im Querschnitt) wurde in den unteren Teil des Duodenums eingefiihrt; die zweite derselben Art, nur in etwas kleineren Dimensionen - 30/20 mm, wurde in die markierte Yitte und die dritte endlich mit rundem Lumen ( $22 \mathrm{~mm}$

$\left.{ }^{1}\right)$ E. S. London, Weitere methodische Angaben. Zeitschr. f. physiol. Chem. Bd. 60. S. 191 (1909). 
im (unerselnitt). ohne Scheidewand, in den Endteil des Inodenmms, einige \%entimeter rom Coekmm entfernt, angelegt. Die Ansriistung des Hundes zum Versuch ist leieht alus den zwei heiliegenden Zeichnungen z.n ersehen. die das Aussehen des Hundes während des Tersuches ron zwei Seiten aus darstellen. Die Zeichnung 2.) stellt den Hund ron der rechten seite dar. Ilier ist die Fistehröhre, welche in las Inodenum angelegt war, zu sehen; a bedentet dic Röhre, durch welche man den Ballon aufbäht; b, die Röhre. durch welche die Versuchsfliissigkeit in das Jejunum eingeleitet wird: c die Röhre, llurch welche in die schale $e$ der Inarmsaft abflieft, welcher während des Versuches von der Schleimhaut des Darmteiles. der sich zwischen der scheidewand der Fistel und dem Ballon befindet. abgesondert wird. Die Fliissigkeiten. die sich oberhall der l'istel sammeh. flieben in das

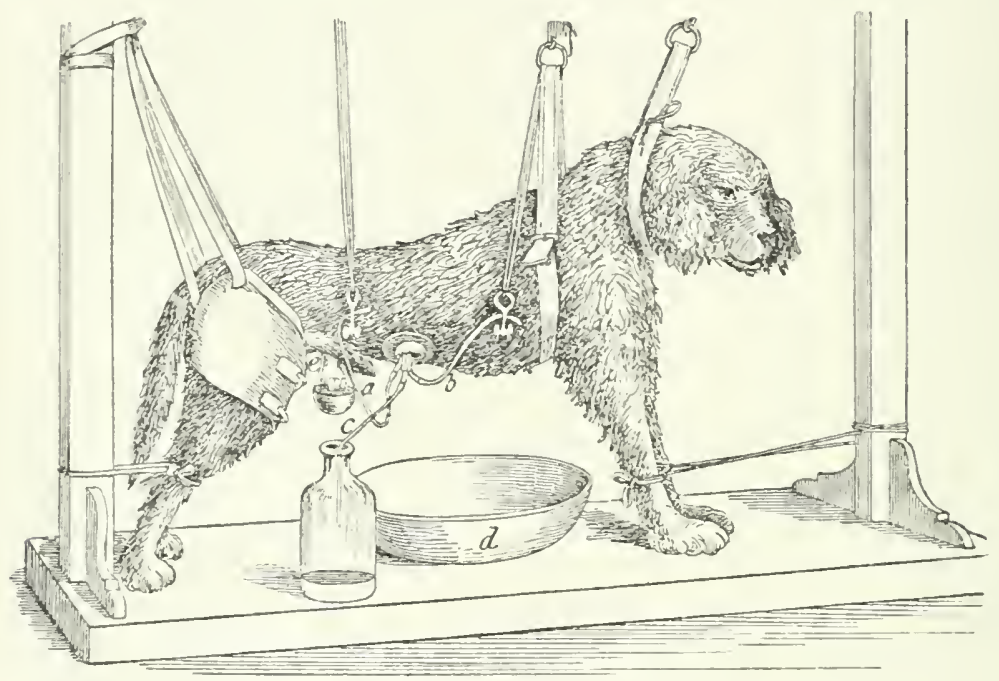

F'ig. 24

Gefäl $d$ ab. der Wand der proximalen Fistelhälfte entlang. Die unresorbiert gebliehene Versuchsfliissigkeit liuft dureh die Rïhre, $f$ (Fig. 26 ) in das (ivfäl $l$ ab) die Röhre $f$ befindet sich in einem liorken, der im I'roximalteile der mittleren Fistel eingesetzt ist. In die distale Hälfte der letztgenamnten Fistelröhre ist ein Pfropfen mit drei Röhren eingebracht worden: $g$ fiur das Aufblähen des Ballons: $h$ rum biuleiten der Versuchsfliissigkeit in die untere Iälfte des Darmkanals nud $i$ zmm Alfliefien der Absonderungen der Schleimhaut des Darmteiles. welcher sich zwischen der Scheidewand der Fistelröhre und dem Ballon befindet, in das Gefäfi $m$. Der unresorbiert gebliebene Teil des in die untere Darmhälfte eingesprityten Versuchsmaterials scheidet sich in das an der dritten Fistel angehängte kï̈lbchen $k$ aus (Fig. 2.5 n. 2015). 
Wir wollen noch einige Fragen beantworten:

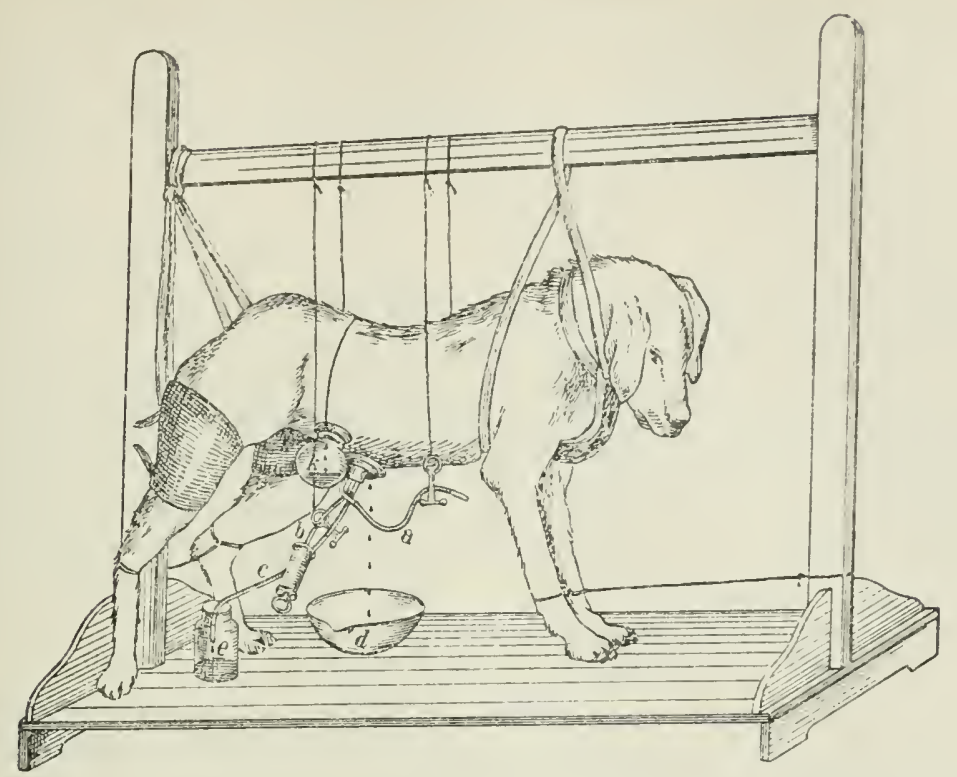

Fig. 25.

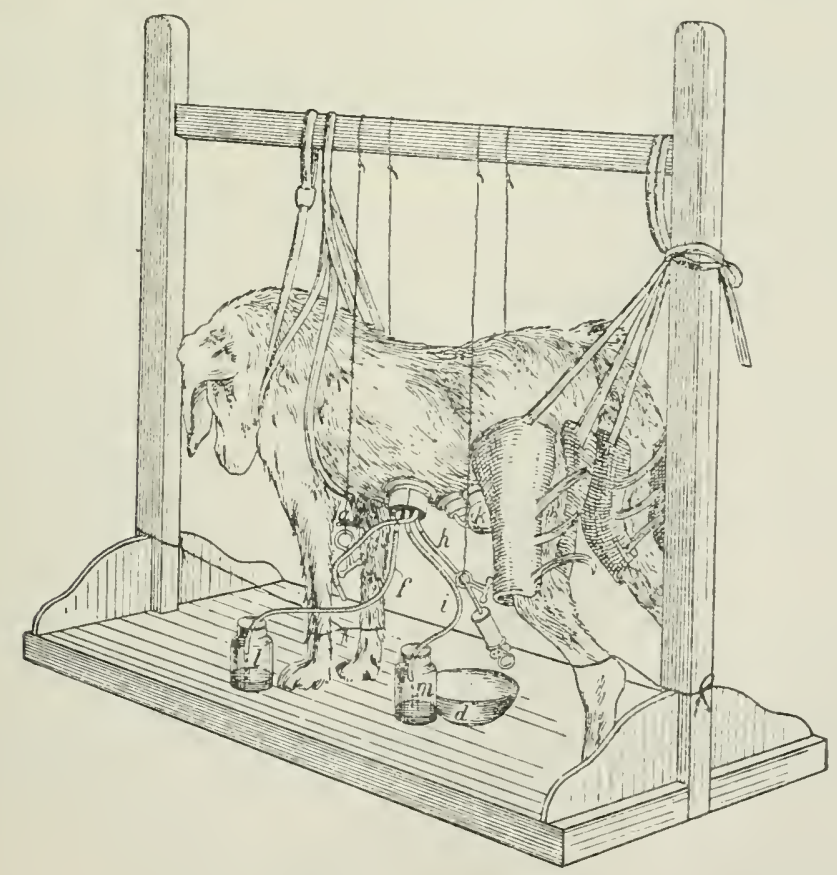

Fig. 26.

1. Wieviel Fisteln können im Maximum einem Hunde angelegt werden ? 
Die groblite /allul, mit del ioh es zu tun hatte, war his jetzt vier. Es ist aber nicht ausceschlossen. dali noch mehr Fisteln angelegt werden kïmnen. Jedenfalls ist es vorteilhafter, bei einer und derselben (Operation alle Fisteln anzulenen, als je eine Fistel bei jeder ()peration. Im letzteren Falle hat man bei den weiteren ()perationen mit dem Net\%, welches an den friuheren Fistelstellen verwablst. Schwierigkeiten.

2. Wie lange leben die Fisteltiere, wenn kein Zufall ihrem Leben ein Ente setzt?

Ich besitye Fistelhunde. dic sehon ror $t$ Jahren operiert worden sind und sich vorliufio im besten Zustande befinden.

Iha Schlimmste ist, dab sich dic Fistel nach melneren Monaten, sogar nach Jahren bei einigen Tieren trichterfoirmign rom I)am abtremut. so dab die lontinuität des loarmlumens sich vollkommen hersteilt. und das Tiel fiir Experinente au der ansfallenden Fistel mutanglich wird. Der Hundeoromismus kitmpft in dieser Weise siegreich gegen linsere Eingriffe.

\section{B. Danerisolierungsmethode.}

\section{Speichelfistel.}

a) Historisches. Zuerst wurde die Methode der Danerfistelanlegung durch Einloilung einer metallischen Kaniile ron Cl. Bernard ${ }^{1}$ ) 18.56 ausgefiihnt. Schiff 2 ) modifizierte 1867 die Methode in der Weise. daf er den ahpräparierten Speichelgang durchschnitt und das zentrale Encle in eine Inndhöhlenwandioffnmo (inmöhte. Glinsti ${ }^{3}$ ) hat 1895 diese Schiffsche Methode bedentend renbessert.

b) Operative Technik.

1. Mau sucht die Öffunng des betreffenden Ganges an der Mundschleimhaut anf. Die Cil. submaxillaris mündet ins Frenulum linguae ungefähr $0.5 \mathrm{~cm}$ iiber dem Mundhöhlenboden. Man erkemnt die Stclle an deren Farhe die röter ist als die der umgebenden schleimlant. Die Parotis mindet in der oberlippe in einer Entfermumg von $1 \mathrm{~cm}$ rom $/$ wisehenpunkte am Zahmand zwischen dem ersten und zweiten Backzahn. Ianeben befindet sich die Mïndung der ()hbitaldriise, ein wenig tiefer im Munde, entsprechend dem dritten Backzahn. In den betreffenden speichelgang wird, $11 m$ iln während der Operation leichter ror Augen zu behalten, eine entsprechend feine Kuopfsonde eingefiilnt, die Schleimhant um den Speichelgang in Imkreisdiameter vou ${ }^{3 / 4}-1 \mathrm{~cm}$ umschnitten und der letztere bis zu einer Tiefe von ca. $0.5 \mathrm{~cm}$ abpräpariert. In die frei hängende Schleimhant wind cine ligatme angelegt.

2. In der Nähe des enthlößten Suejehelganges wird die Mundhöhlenwand mittelst eines scharfen skalpells durchstochen. I)urch die gebildete Öffnung,

1) C. Bernard, Legons sur la physiologie expérimentale. 1850.

2) Schiff, Leçons sur la physiologie de la digestion. 1867.

3) Glinsti, Zur Methodik des Studinms der Spcichelsekretion. Verhandi. d. Ges. russischer Arzte zu St. Petersburg. S. 340 (1894). 
weldhe durch Abschnoiden des liandes noch etwas veroübert wirl, wind die frei hängende Schleimhant mittelst der erwähnten Ligatur durchgezogren und durch Nähte an die äuliere Mundhöhlenwand befestigt. Beim Durchziehen des solneimhautstïckchens achte man darauf. dafj der speichelgang nicht torquiert wird. Es folgt das Vernähen der Sclleimhatutwunde.

Handelt es sich um den 1). Stenonianus, so wird der pröiparierte schleimhautlappen cinfach auf die Haut der betreffenden Wange wenäht. Soll aber der I). Bartholinianns orler Whartoniaums transplantiert werden, so ist es ratsam, zuerst die heiden zusammen auf die äuliere. Fläche des Mundlülıleubodens abzuleiten, da dieselben ganz nahe nebencinander an Fremulum linguae liegen und nicht ohne Schwierigkeit getrennt werden könmen. I)ic (Orientierungssonde wird in den D. Whartonianus einreführt. Man wartet ab, bis die Wmule verheilt ist und unterbindet den nicht in Petracht kommenden Speichelgang.

c) Postoperative Behandlung. Die Transplantation der Speichelgänge fällt am riimstigsten aus bei Verwendung mittelstarker seide und dichten, knotenartigen Nähten. Sollte die Heilung der Wunde nicht per primam, sonderu per secundam intentionem erfolgen, so entsteht eine Narbe, welche zn einer Verengung der Öfnung des Ganges führt. ['m diesem Mißerfolg vorzubengen, ist es notwendig, den Speichelgang möglichst oft mit einer entsprechenden Knopfsonde zu bougieren.

Es kommt auch ror, daß das transplantierte Schleimhautstück ahreißt oder in die Mundhöhle hineingezogen wird. Ist das einmal geschehen, so ist die Operation als für immer miflungen zu betrachten.

Ist die Operation gelungen, so mub man ron Zeit zu Zeit die der Fistelöffnung anliegenden Borken aufweichen und die Durchgängigkeit des Kanales priffen, indem man bei dem Hunde speichelahsonderung durch Darreichen von Zwieback oder Eingießen von Säurelösung in den Mund hervorruft.

d) Anwendung.

1. Aufsammlung ron Speichel aus einer bestimmten Drïse unter normalen Umständen.

2. Verfolgung der Speichelsekretion unter verschiedenen Bedingungen.

3. Studien der Gehirnfunlitionen mach der Methode von , bedingten Reflexen* (Parlow).

e) Versuchsanstellung. An der Hautstelle, an welcher der Speichelgaug einmindet, wird ein mit einem Schirm aus durchsichtigem wasserdichtem stoff versehener Trichter (Fig. 22) vermittelst Mendeljectfschen Kittes ( $100 \mathrm{~g}$ Kolophonium, $25 \mathrm{~g}$ gelbes Wachs, $40 \mathrm{~g}$ Eisenmennige, $\mathrm{Fe}_{2} \mathrm{O}_{3}$ ) befestigt; auf den Hals des Trichters wird ein Häkchen aufgrekittet und anf das letztere ein graduierter Zylinder. Die Hautstelle, an der der Trichter angekleht werden soll, wird vermittelst einer. Schere ron den Haaren befreit (nicht rasiert!) und mit dem geschmolzenen, aber bis zur teigigen fionsistenz abgekiihlten (um Ekzem zu vermeiden) Kitt beschickt und nun wird 
der 'Trichter angeklebt. Vor dem Abmehmen des Trichters wird der Kitt mit einem erhitzten Metalstah rorsichtig angewärnt.

Anhangsweise soll hier auch die 'Technik der temporïren Fistelanlegungangefiihrt werden.

Dem narkotisierten resp. kurarisierten Tiere macht man zweeks Isolierung des Luctus Whatonianus und l)uctus Bartholinianus an der unteren Seite der Schnauze, parallel dem Cnterkieferrande in einem Abstand von ungefäh" $1 \mathrm{~cm}$ ron demselben einen :3-4 cm langen Schnitt, hevinnend 2 cm vom Kinnwinkel. Man separiert die Faszie und schueidet den M. mylohyoideus durch. Man präpariert dann vorsichtig den durchschnittenen Muskel und findet darunter auf dem M. genioglossus die Ausführungsgänge der submaxillaren und sublingrualen 1)rise. Ier I). Whartonianus unterscheidet sich ron dem I). Bartholinianus dadureh. dab er dicker ist und näher der Nittellinie liegt. Will man die Ansfihlungsänge deutliches hervortreten lassen, so bringt man in den Mund des Tieres irgend ein Reizmittel. z. B. schwache Silzsäure. Man legt an den blobgelegten Gang peripherisch eine Ligatur an, schneidet den Gang soviel an. dal die hereitliegende Kaniile leicht eingefïht werden kann. I)ie ringefuihte Kaniile wird mit einer ligatur lefestigt.

Behufs Isolierung des D. Steuonianus macht man einen $3 \mathrm{~cm}$ langen Hantschnitt in den mittleven Teil der Linie. welche den nnteren (b)rmuscheband mit der Basis des ersten Backzahnes vereinient, und findet leicht den Ausfiihrungsgang auf den M. masseter.

Anwend 1119:

Studium der Speichelabsonderung unter nervösen und vaskulären Einfliissen.

Versuchsanordnung. Dic Kanile, welche in den Ausfiihrungsgang eingefiihrt worden ist, wird mittelst Kautschukröhre mit einem langen. anf einer Skala horizontal liegenden Glasrohre verbunden. Während des Versuches notiejt man von \%ejt zu \%eit das Nivean des Speichels in liohr. das, sobald es gefuillt ist, lurch ein anderes lohl ersetzt wird. Anstatt die liönr immer zu wechseln, kann man auch ander's verfalnen: man schaltet ror dem Gilasrohr ein seitliches Abflubrohr ein, durch welches man jerlesmal die angesammelte Fliissigkeit ablaufen läßst.

Die Speichelabsonderung läßt sich auch registrieren, und zwar in verschiedener Weise. Entwoder libst man nach (C.Ludwig' ${ }^{3}$ den Speichel aus der Kanile in ein Wassermanometer mit leichtem Hebel fliefen. oder man läBt nach Bayliss und Startiny ${ }^{2}$ ) Speicheltropfen anf eine kleine Glimmerscheibe fallen. Welche mit dem Hebel einer Mareyschen Trommel rerhunden ist; die Kapsel wird durch ein Kautschukrohr mit ciner zweiten

$\left.{ }^{1}\right)$ C. Ludwig, Lehrbnch der Phrsiologie. 1861

2) Zitiert nach J.I'. Parlou, Tieyerstents Handbuch der physiologischen Methodik. 11. Teil. 2. Abt. S. $180(1908)$. 
Tronmel verbunden, deren Ilebel an einer langsam rotierenden Trommel die fallenden Tropfen verzeichnet. Popielski1) photographierte das sich in dem Rohr forthewegende Niveau der Flïssigkeit.

\section{II. Ösophagusfistel.}

(1) Historisches. (\% Bernard ${ }^{2}$ ) war der erste. der die Ösophagusfistel cingefuihrt hat. Am Hunde technisch ausgearbeitet hat sie Purlou: b) Operative Technik.

1. Es wird ein Hautschnitt längs des inneren liandes des linken II. sternocleidomastoideus, von der unteren Kehlkopfgrenze angefangen, $10 \mathrm{~cm}$ weit abwärts gefiihrt.

2. Man isoliert die Speiseröhre in der Mitte des Hautschnittes in einer Strecke von $5 \mathrm{~cm}$. legt an beiden Enden des isolierten Abschnittes je eine Gummischlauchligatur an und durchschneidet in der Mitte.

3. Die Ösophagusabschnitte werden in die Winkel der Hautwunde gebracht und dort mit den naheliegenden Halsmuskeln und mit der Haut rernäht. wobei man darauf achtet. daß die Ösophagusöffnungen nicht verengt werden. Die zwischen den Ösophagusenden liegenden Gewebe werden schichtweise vernäht. I)ie Hautbriicke, welche die eingenähten Enden trennt, soll nicht weniger als $4-5 \mathrm{~cm}$ betragen. Diese Brücke kann auch von vornherein unverletzt gelassen werden, in diesem Falle aber ist die Operationsausführung schwerer.

c) Postoperative Behandlung. Es ist für den Erfolg der Operation sehr wichtig. daß in der Postoperationsperiode keine Eiterung eintritt; denn ist dies geschehen, so verbreitet sie sich sehr rasch. I)eshalb muß die Operation möglichst rein gemacht werden und nach der Operation muß die Wunde bis zur vollen Verheilung mit $0 \cdot 1 \%$ iger Sublimatlösung mehrere Male im Tage gewaschen werden.

Die Fütterung des Tieres geschieht in der ersten Zeit nach der Operation durch die Magenfistel. Nachdem aber die Wunde völlig geheilt ist, beginnt man mit der Fütterung durch den unteren Ösophagusabschnitt mittelst einer Magensonde. Wird der ösophagotomierte Hund zm Gewinnung ron größeren Magensaftmengen gebraucht, so müssen ihm reichlichere Quantitäten von Wasser resp. Kochsalz zugeführt werden.

Es kommt nicht selten vor, dal trotzdem während der Operation ein genügend großer Zwischenraum zwischen beiden Ösophagusenden gelassen worden ist, letztere sich mit der Narbung einander nähern. so dab sich eine Kontinuität des Ösophagus einstellen kann. In einem solchen Falle bleibt nichts anderes übrig. als eine quere Exzision in die Hautbricke zu machen und die Wundränder der Länge nach zu vernähen.

Ist die Wunde völlig geschlossen, so lockert man die Verbindung der Ösophagusenden mit den umgebenden Gewehen durch einfache Traktion mittelst den in die Öffnungen eingeführten Fingern.

$\left.{ }^{1}\right)$ Popiclski, Dissertation. St. Petershurg. 1896.

2) Cl. Bernard, Leçons de phỵsiologie opératoire. 1875. 
(rewöhnlich wind die Ösophagotomie mit einer Ilagenfistel kombj-

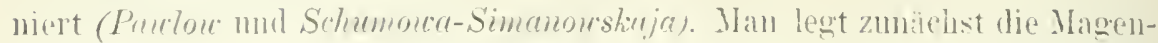
fistel an und schreitet zur Ösophagotomic mur dam. Wenn die Magenfistel gut verwalchen ist. $\left.{ }^{1}\right)$

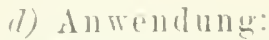

1. Studium der" Mundverdamumg.

2. Anfsammlume vou Magensaft, weleher durch scheinfiiterume herrol'ur(tufen wird.

e) Versuchsanstellung: Handelt es sich num Abshäitzung der Yundverdanung, so gribt man den 'Tier eine bestimmte speise per os und nimmt liv aus del oberen ()sopluagusoffumg heransfallenden Entleerungen auf.

Zu Gewinmung von gröberen Mengen Magensaft verfährt man folgenderweise: Der Hund wird in das Gestell getan, die Magenfistel geoffnet, der Magen mehrmals grimollich mit Wasser ausgespiilt mo minter der Iagenfistel ein Trichter mittelst rimmischläuchen befestigt. Der Trichter 'uthält Cilaswolle, welche dazn dient, den schleim zmrickzuhalten. I)as Trichterrohr wirl durch anen Gummischlanch mit dem für dio dufnahme des Magensaftes bestimmten Gefäli verbunden. Man stellt vor das Tier eine schate mit ' ${ }_{2}$ kg in kleine Stüche geschnittenem Fleisel. I) Ilund schluckt gierion die Fleischstiicke, welche aher hald durch die ohere Ösophagusiffumng in dieselhe Schale heransfallen, vom Hund wirder vershluckt werden. wieder herausfallen usw. Die scheinfiitterung kam mehrere stunden dauern. Während der ganzen Zejt seheidet sich Magrensaft al).

Nicht inmer gewinnt man bei der Scheinfiittermog reinen Magensaft. da sich oftmals in den Magen Dammäifte (Galle, Pankreas- und Darmsaft) eroben. Die Peinengmen won Duodenuminhalt libt sich ohne Sehwierigkeit

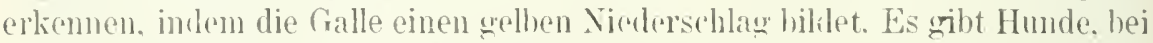
denen dic leimengung von Darnsäften als Regel gilt; andrerseits aber gibt us solche, hei denen die I)armsüftoheinengung ganz ausfällt. Der Manensaft, der sonst wasserklar ist. nimmt bei der Gallenbeimengung eine gethe Farine an. Zn1 Entfärbung benutzt man mit woten Erfolg Tierkohle.

\section{Magenfistel.}

(1) Historisches. Bussow $\left.{ }^{2}\right)$ und Blondlot $\left.{ }^{3}\right)$ waren die ersten, die eine Magenfistel zmm studium der Magenphysiologie angewendet haben.

b) () perative Technik:

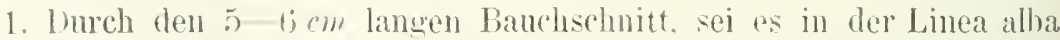
(zu scheinfuitterungsrersuchen), sui es an einer anderen stelle, z. B. lïngs der lippenlinie, wird die vordero Magenwand mit zwei Fingern nach aulien hervorgezogen. Man musticht mit einer Bimtohaht die Linie des heabsichtigten Schuittes.

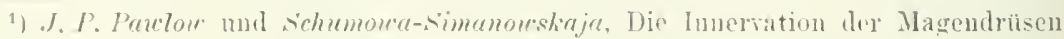
beim II unde. Arch. f. Anat. u. Phrs, 1895.

2) Bassor, Bulletin de la Socirté des Naturalistes de Noscou. T. 16 (1842).

3) Blondlot. Traité analytique de la dicestion. p. 2022 (1842). 
2. I) deh den gemachten Schnitt wird die untere Scheibe der Fistelröhre in die Magenhöhle eingefuhrt; die lieutehaht wird zugezogen mud iiber Mullpolsterchen areknöptt.

3. Man zieht dureh die Seromuseularis der der Srheihe anliegenden Magenwand einander werenüber + Füden, deren Enden mittelst einer Varlel an entsprechenden Stellen durch dic Bauchwand gezogen werden. Sach \%uzichen der 4 Nähte wird dic Röhre in der Wunde fixiert. Wemn nötig, legt man uocll Hilfsnälite an.

c) P'ostoperative Bebandlung. Iank der desinfizicrenden Wirkung der Macrensalzsïnre verlänft aewöhnlich die postoperative Periode ohme irgend welche Komplikationen, so dall keino hesondere Pflege der Wunde erforderlich ist. Nach ungefähr :3 Wochen ist die Fistelkaniile schon mit einer derben Narbe ungehen.

d) $\mathrm{Anw}$ wendung:

1. Die Magenfistel wird häufig als Hilfsistel benutzt, weil sie zur Orientienung dienen kann. ob der Magen leer ist.

?. Will man reinen Magensaft aus del Magenfistel beim nicht ösophagotomierten Hunde bekommen. so rurfäht man folgendermaßen: Мan öffnet die Fistelkanïle, spiilt den Magen griundlich mit warmem Leitungswasser aus und gibt dem Hunde 20 -30 Stijcke Sehnen mit Fett allmählich zu verschlucken. Die zugofïhrten unverdanlichen Stiicke kommen bald ricter durch die Fistelöffnung ganz nach außen. Sobald alle Stïcke herausgefallen sind, verschließt man die Fistelöhre mit einem Kork, welcher mit ziner bogenfömigen Glaskaniile versehen ist. Tach Verlauf ron 5-6 Minuten heuinnt die Ausscheidung les Magensaftes. Sie dauert ca. 11/2-2 Stunden. 1)er so crewonnene Mageusaft ist mit Speichel rermengt. Ebenfalls nicht selten wird der Magensaft durch die aus dem Dnodenum kommenden transpylorischen Säfte vermmeinigt. Zur Gewinnumg ganz reinen Magensaftes eignet sich die Methorte also nicht.

3. Zum Studium des Magenchemismus rerführt man je nach den Versuchsbedingungen.

e) Versuchsanstellunщ. Hancielt es sich un das studium des Eutleerungs- resp. Verdaumgsvorganges, so verfähnt man in folgender Weise: I) Hund wird ins Gestell getan und seine Fistelkanüle geöfnet. Ist der Magen leer, so behommt man aus der Fistelöffnung entweder keine Ausscheiduug oder nur geringe Nengen von alkalischem schleim. Es kommt auch nicht selten ror, daf im nïchternen Magen $20-30 \mathrm{~cm}^{3}$ schleimhaltiger saurer Magensaft aufgefunden werden. Fin solcher Safterguf aus der Fistelöfnung ist fast die Regel, wenigstens bei gierigen Hunden. wenn man das Öffnen der Fistel rornimmt, nachdem del Hund mohr als 5-10 Minuten aufgestellt war mud folglich auf das Futter gewartet hat. Es soll deshalb die Fistelkaniile möglichst rasch geöffnet werden, sobald der Hund ins Gestell getan worden ist. Gleich mach dem Schliefen der Kaniile soll die Füittermng erfolgen.

Nach einer bestimmten Zeit, wenn die Magenverdaumg unterbrochen werden soll. öfnet man die Fistelkaniile und lïfit den Mageninhalt in das 
untergestellte Gefüß fließen. Ist der Magrminlalt broigg oder fliissign. Was gewoilnlich in der späteren Verdaumosperiorle der Fall ist, so greht die Ansscheidung ron selhst vor sich. Ist abel die Speise noch wenig angegriffen, so mub man sich gleich von Anfung an damit helfen, die rechte liaurhwandseite (die Fistel wird gewöhulich an der linken Seite angelegt) stark mit der Hand zu drizcken, mud zwar in der lichtung zur Fistel. Die Massage der batuchwand heginstigt aber die Fistelexketion nur so lange, als der Magen noch mäfig gefiillt ist. Bleibt die giinstige Wirkung der Massage aus, so nimmt man die Entleernug mit den kleinen Finger der rechten Hand ror. Die letzten Reste des Magenimhaltes werden mit reichlichen Wasserausspiilmmen entfernt. Wie Ausspiilmog geschicht am besten in der Weise, dab man einen 'Trichter mittelst eines langen Gmmmirohres mit der Glaskaniile des Fistelrohrkorks vereinigt mol $1 / 2-1 / \mathrm{Wasser}_{2}$ in den Magen eingiebt. Beim Öffnen der Fistelrohre ergiebt sich daraus das Wasser, welches die Speisereste mit sich reißt. Man wiederholt die Ausspiilumg, his das Wasser ganz klar ist.

Kommt es nicht auf die quantitative Ciewimung des Mageninhaltes an, sondern wiinscht man nur eine l'robe desselben für qualitative Bestimmungen zu erhalten, so verfährt man folgendermaßen: Man schliefit die Fistchöhre mit einem Kork, in dessen Mitte eine hogenförmige, weite Glaskaniile mit einem durch einen Schicher greschlossenen Gummischlauch angehracht ist. Aus dieser Röhre werden zu verschiedenen Zeiten während der Verdaumng bej Abklemmung des Schiehers fiir die Analyse P'ortionen genommen. Bei diesel Versuchsanordnung kommt in der Hauptsache nur derjenige 'Teil des Mageninhaltes zur Untersuchung, welcher sich während des r'rohenehmens zufällig in der Nähe der Fistel befindet. rur Kontrolle verfïlıt man deshalh noch anders. Mam läbit zu einer hestimmten \%eit den ganzen Magenimhalt durch die Glasröhre herausflielion. vermischt ihn gut, entuimmt ane P'robe und bringt den Rest dem Hunde per os oder per fistulam zuriick.

\section{Drüsenblindsäcke.}

\section{э. Fundusblindsack (kleiner Magen).}

(c) Historiscles. Die ('peration ist von Heidenhuin') in Angriff genommen und ron Purlow 2) wesentlich verbessert worden.

b) Operative Terhnik:

1. Iner pylorische Teil des Matgens und die Kardia werden durch (immmischlänche rom l)uodenmm resp. Osophagus abgeschniurt. Man achte dahej daranf, dab die Magengofïbe nicht verletzt werolen. Der (immmischlauch wind rorsichtig zwischen der Magenwand und den Gefäben des omnentum durchgefiihrt.

1) Heidenhain, Uber die Absonderung der Fundushrïsen des Magens. Iffügers Archiv. Bu. 19. S. $148(1879)$.

2) J.P. I'arlow, Zur ehirurgischen Nethodik der Untersuchung der Magensekretion. Verhandl. d. Ges. russischer Arzte zu St. Petershurg. S. 151 (1894). 
2. Man führt eimen \&-10 cm oder melı (je nach der Giröle des Magens) langen schnitt an der vorderen Magenwand durch Serosa und Iluscularis, parallel der Längsachse tles Magens, augefangen 1-ə Finger weit von der Grenze zwischen dem prlorischen und dem Fundusteil des Magens; dam führt man an der hinteren Magenwand einen symmetrischen Schnitt, ebenfalls nur durch Serosa und Muscularis. I)ie letztere kontrahiert sicl und läbt ganz deutlich in der Schnittlinie die in der Subserosa quer verlaufenden Gefäle erkennen.

:3. Die Gefïfe, welche sich durch den schnitt hervorwölben. werden an den Rändern der Serosa-Musculariswunde mit je ? Ligaturen. die nur $5-6 \mathrm{~mm}$ ron einander entfernt sind, umstochen und unterbunden.

t. Der Assistent ergreift die Subserosa samt Serosa an der Curvatura major mit 2 Klemmpinzetten und der operateur öffnet die Magenhöhle mittelst einer Schere zwischen den Schiebern, saugt den Mageninhalt (Magensaft, schleim, Speichel usw.) mittelst Mulltampons aus und spiilt den Magen noch zweimal mit $0 \% \%$ iger Salzsäurelösung aus. Dann führt man den Schnitt durch die iibrige Mukosa und Submukosa bis zum Ende des Schnittes, inden die Gefäße selbstrerständlich zwischen den Kinoten geschnitten werden. Man erhält also einen Magenwandschnitt von einer Dreieckform mit möglichst geschonten Vagusfasern.

5. Es folgt die Durchschneidung und Lospräparierung der schleimhaut an der Lappenbasis. Der Operateur umhiillt den Zeigefinger der linken Hand mit Mulle, legt darauf die Lappenbasis der Serosa und fiihrt einen oberflächlichen Schnitt längs der ganzen Lappenbasis. Dann faßt der Assistent mit 2 Pinzetten die Ränder des Schnittes an einer Ecke, hebt dieselbe ab, damit der Operateur die Submukosa anschneiden kann; gleichzeitig zieht der Assistent die angeschnittene Submukosa auseinander. So entfaltet der Assistent dem Operateur allmählich den Weg fïr den Schnitt his zur zweiten Ecke. Es entsteht dabei Blutung, zu deren Stillung auf die Schnittlinie ein längrlicher Gazetampon fiù :3-5 Minuten gelegt wird. Erweist sich die Submukosa beim Abhehen des Tampons noch nicht röllig aufgeschnitten, so fiihrt man das Skalpell noch einmal rasch der Schnittlinie entlang und legt nochmals einen Gazetampon in den Schnitt ein. Dann werden unter allmählicher Abhebung des Tampons die blutenden Gefäfe einzeln gefaßt und unterbunden. Die Submukosa erweist sich auf $3 / 4-1 \mathrm{~cm}$ nach jeder seite hin abpräpariert.

6. Die Submukosa eines jeden Schnittrandes wird mit der Serosa der Rïnder des ersten Schnittes folgendermaßen zusammengenäht. Die Endund Yittelpunkte der Schleimhautlappen werden durch 4 Schieber markiert. Der Schnitt wird also in + Teile geteilt, entsprechend den anzulegenden + Tahtreihen. An jeder Seite wird nämlich der freie Magenrand, und zwar dessen Muscularis samt Serosa mit der Submukosa der entsprechenden Schleimhautlappenhälfte rernäht. I)ie erste Naht kommt auf die Submukosa, ganz am Ende des betreffenden Randes, und auf die Serosa-Muscularis an der Seite des entsprechenden Péans, wo sich auch der anzunähende Schleim- 
hautrand befindet. Die nächste Naht anf der Submukosa wird nïhel zur Yitte der schleimhautkante auf die terosa, weiter ron den l'áans längs dem Rande nach der betreffenden Höhle zu gelegt. so werden $T$ bis \& Nïhte his zmm l'éan. Weleher sich in der Mitte des lappensehleimhantrandes befindet. dicht neben einander angelegt. In derselhen IV cise verden Sïhte an jeder Hälfte beider Ränder des scheidenschnittes wemadnt. Intlurch entsteht eine kuppelförmige Einwölbmg beille Vagenteile. Zwischen den letztren bleibt eine : $-4 \mathrm{~cm}$ breite Bricke ans Muscularis, Subserosit und Serosil bestehen (Fig. 27). Die Brieke wird nit $4-5$ yuer durrhgefiihrten Fïden znsimmengezogen und, wemn nöitg, noch durch llilfsnähte hefestigt. Dadurch werden beide Vagenteile von eimander viollig getremut.

†. Der Hauptuagen wird durch Yilute wanz geschlorsen; der nenformierte .. kleine" Vagen wird zu einem Blindsack vernäht, wohed eine

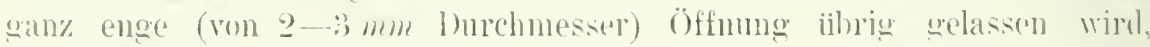

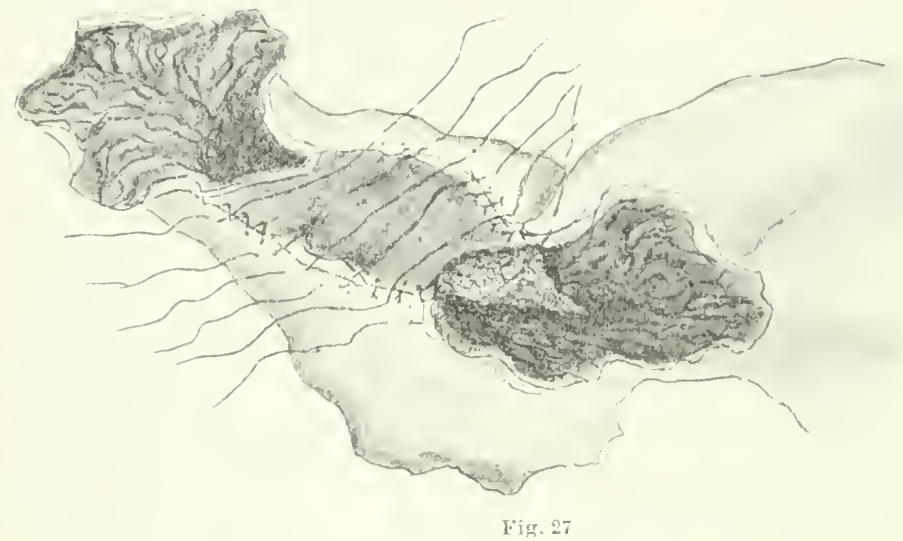

welche in die ditte der Banchwand beim Schlieten dersulben dingreuäht wird.

c) Postoperativa Behandlung. Sechon ann näthsten 'Tuge nath dar ()peration füngt man an, das sekret des kleinen dagens abzuleiten. wozu

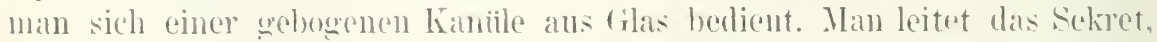
solatuge der Hund in Froiheit hleiht, zweimal täglieh nach aulen. Sohald der Hund sich soweit erlolt hat, dafi es ihm nicht schwer wird, im fiestell lange zu stehen, leitet man den Kileimmageninhalt durch die in Fig. 어 alugrebildete liöhre ab.

Bei den Kileimmagenhunden kommen meduere homplikationen ror:

1. Heftige Korrosion der Wunde. In diesem Falle whïlt man die besten Resultate, wenin man die obun angegebene salbe (siche S. sii) anwendet.

2. Prolaps des kloinen Magens. Inese Komplikation ist qewöhnlich eine Folge der ersten mut wird dadurch herrororerufen. dab die Narhe. 
welehe den kleinen Magen umgibt, wegen der Andauung gelockert wird. Es greniegt eine zufällige Steigerung des intrabdominalen Inruckes, damit ein rölliger P'rolaps zustande kommt. Der Y'rolaps erfolgt meistenteils in der Nacht, wenn der Hund sich im Käfig hefindet.

ficwöhnlich gelingt es ohne Schwierigkeiten, durch Massage den prolabierten Blindsack zu reponieren. Der Prolaps aber kann sich nach kurzer Zeit wiederholen, weshill eine radikale Operation erforderlich erscheint. Jan reseziert aus dem kleinen Magen ein keilförmiges Stiick und rerengert die Offnung. ther auch diese Operation führt nicht immer zum Zicle. Ist dies aber der Fall, so eröffnet man die Bauchhöhle und näht den kleinen Magen an die Bauchwand oder an den grofen Yagen.

d) Anwendung:

1. Gewinnung von reinem Magensaft.

2. Vergleichende Versuche ïher den Sekretionsrorgang hei Verdaumng rerschiedener Substanzen. I)ie absoiuten Zahlen, die hoi den Versuchen erhalten werden, hahen kaum eine physiologische Verwertung, wohl aher grewissermaßen die Verhältnisse zwischen den einzelnen Zahlen.

e) Versuchsanstellung.

Bevor der Kileimnagenhund zum Versuche kommt, mul, el nach Purlow einigen Vorversuchen unterworfen werden.

1. Bei leerem Magen, wenn die saure Sckretion granz ausbleibr, neckt man den Hund mit Speise und hestimmt die Magensaftmengen, welche einerscits durch die Magenfistel aus dem Ilanjtmagen und andrepseits durch die Öffnung des Kleinmagens nach auhen fliefen.

2. Ian fïhrt dem Hunde per os eine magensafterregende IFleisch oder Liebigs Fleischextrakt) oder eine magensafthemmende (Butter, Eirotter usw.) Speise zu. Vach 1 -2 stunden entleert man den grofen Yagen. spiilt denselhen mit Wasser nach und sammelt den Saft aus beiden Fisteln. Liefern dahei beide Fisteln Saftmengen in gewissermassen konstanten Verhältnissen, so wird der Hund zu weiteren Untersuchungen als tauglich anerkannt. Der positive Ausfall der Probe heveist. dab die Vagusiste durch eine heide Magenteile vereinigende Brücke geschont sind.

Die Hauptrersuche werden so angestellt, dali man dem nüchternen Hunde eine speise verabreicht und die kleine in Fig. 20 abgebildete Vorrichtung einfïhrt und je nach $1 / 4$ Stunde das Mefigefüß wechselt. Außer der Quantität des Saftes hat auch dessen Verdaumgskraft Bedeutung. Die aufgesammelten Saftproben werden, falls sie nicht direkt zur Terdaungssprüfung kommen können. bis dahin anf Eis aufbewahrt, weil in der Wärme die Verdauungskraft leidet.

Hierzu sei Folgendes bemerkt:

Ian kann nicht mit Sicherheit ausschliefen. dal ein Teil des während dieser Prifungen sich absondernden Iagensaftes ins Duodenum ühergeht. Es ist ebenfalls noch nicht bewiesen, daß die konstanten Verhältnisse. welche sich bei den erwähnten Priifungen erceben, auch dam vorhanden sind, wenn der Hauptmagen sich in Verdauung befindet. 
biesc Fragen könnten selbstverständlich nur dureh sperielle Ĺntersuchungen an einem isophagotomierten Keimmagenpylorushund entschieden werilen, d. h. an einem Hund, hei welchem eine (osophagus-. Magen- und Pylormsfistel und ein likeinmagen rorhanden sind.

\section{(৬) Pylorushlindsackmagen (Schemjalin ${ }^{1}$ ).}

In allgemeinen wirl der kleine Magen am pylorischen 'Teil des Magens in derselben Weise angelegt wie am Fundnsteil, nur missen folgende l'mukte berilcksichtigt werden:

1. Man fïhre den Längsschnitt, welcher den Pyloruslappen abtrennen soll, an der Mittellinie zwischen der Curvatura major und minor. Ist der Lappen nicht geniigend breit, so hat man beim Vernähen desselben \% cinem Blindsack Schwierigkeiten, weil die Nähte wegen der Muskelkontraktioncen zn angespannt sind und häufig durchschnciden.

2. Damit die Peritonealanheftmogen der Magendarmorenze nicht \%u stark gezert werden, ist es vorteilhafter. die operation gleichzeitig vorzunehmen. Zuerst bildet man den Kleinnagen und nïht dessen freie Öffnung in den Fundusmagen. Nach :-4 Wochen. wem der Hund sich gan\% erholt lat, öfnet man die Banchhöhle seitlidh, tremnt den Kleinmagen vom Fundus ab, vereinigt iln aber mit letzterem durch :3 Nälite, schlielit die Funduswomde und läbt den Pylorusmagen in die Bauchhöhle minden.

\section{ү) Pylorussackmagen (Kresteff 2 ).}

1. Beiläufig $4-5 \mathrm{~cm}$ fundalwärts vom l’ylorns fiilurt man $2 \mathrm{~cm}$ lange Sehnitte durch die Serosa und Muscularis der vorderen und hinteren Magenwand, zwei parallel der kleinen Ĺurvatur verlaufende, in einer Entfernung von 1-2 cm von derselben. Löst man nun die Schleimhant von der unschnittenen Serosa-Muscularis ab, so bleibt die letztere als Bricke, welche den kinftigen lylorusmagen mit dem Fundusmagen vereinigt.

๖. An die Schnittstellen legt man 2 Klemmpinzetten an, wobei letztere an der kleinen hurvatur unter der Serosa-Muscularishrieke geleitet werden und schneidet mit einer Schere die ganze Nagenwand durch. l)ie entstandenen Wunden des Fundus- resp. Pylorusteiles werden durch Nähte geschlossen. Die isolierte serosa-Museularisbricke bleiht intakt.

:. Der Pylorusring wird zwischen 2 Klemmpinzetten ganz durchgetrennt.

4. Das Dnodenum wird entweder direkt mit der Pylorusöffnung in den Magenfundus cingenäht, oder aber es wird diese öffnung vernäht mud eine seitliche Gastroenterostomie gemacht.

Anwendung mol Versuchsanstellung.

Die beiden Pylorussickmägen unterscheiden sich in bezng anf die Anwendung und Versuchsanstellumg in nichts vom Fundussackmagen.

1) Schemjakin, Liexcitabilité spécifique de la muqueuse du canal digestif. Arch. des sciences hiologiques. T. 10. p. 87 (1903).

$\left.{ }^{2}\right)$ Krestefr, Contribution à l'étude de la sécrétion du suc pylorique. Revue médicale de la Snisse romande. Bu. 19. S. 452 (1899). 


\section{万) 'Totaler Magensack (Frémont ${ }^{2}$ ).}

Die Operation ist ron Frémont rorgeschlagen worden und besteht darin, daf' der ganze Magen rom ïbrigen Verdaungstraktus isoliert wird. Es werden zwei totale Querschnitte gemacht, einer an der frenze zwischen Speiseröhre und Magen und der andere zwischen Magen und Irodenum. Das Öophagusende wird mit dem Duodenum zusammengenäht und auf diese Weise die Kontinuitït des Verdauungsrohres wieder hergestellt. Die IIagenwmden werden rernäht und eine Iagenfistel. wie oben beschrieben, angrelegt.

Anwend ung. Der totale Magensack kann zur Crewinnung von größeren Quantitäten ganz reinen Magensaftes gute Dienste leisten. Zum Studium des normalen Ganges der Magensekretion eignet er sich selbstrerständlich nicht. Dasselbe lälit sich auch von Hepps Modifikation sagen. Hepp ${ }^{2}$ ) empfiehlt, unter rollkommener Schonung der Nor ragi den Ösophagus ron der Lardia abzuschneiden und mit dem I uodenum zu verbinden. Ferner wird der Iagen am anderen Fnde rom Pförtnerteil abgeschnitten. Die Magenwunden und die Prloruswunde werden vernäht und am Magen wird eine Fistel angelegt. Da bei dieser Operationsart die Yn. vagi geschont werden, nähert sich die sekretionstätigkeit des Magensackes mehr der Yorm als beim Verfahren ron Frémont: doch ist der normale Verdauungsgang zu sehr gestört, als daß das Verfahren für die Yorm gültig sein könnte.

\section{ミ) Brumnerdrüsensack (Paulox ${ }^{3}$ ).}

1. Nan macht an der Grenze zwischen Magen und Darm einen 3 bis $4 \mathrm{~cm}$ langen Längsschnitt dureh Serosa und Muscularis, präpariert letztere vorsichtig von der Schleimhaut rundum ab. unterbindet den Schleimhautzylinder an zwei Stellen in einer Distanz ron $1 / 2-3 / 1 \mathrm{~cm}$ und schneidet zwischen den Ligaturen durch.

2. Die Schleimhautstümpfe werden magen- resp. darmwärts eingestiilpt und über den Stïmpfen die Submukosa vernäht.

3. Es folgt Zunähen der Serosa und Muscularis am Längsschnitt.

4. Man durchschneidet das Duodenum etwa $1 \mathrm{~cm}$ oberhalb der Einmündungsstelle des Ductus choledochus. Der untere Duodenumabschnitt wird blind remaiht und durch eine Gastroenterostomie mit dem Magen rereinigt, der obere stark verengt und mit seiner Offuung in der Bauchwunde befestigt.

\section{Pankreasfistel.}

(1) Historisches. Paulow 4 ) und nachher Heidenhain ${ }^{5}$ ) hahen zuerst die operative Technik der Anlegung einer danernden Pankreasfistel aus-

1) Frémont, L'estomac expérimentalement isolé. Bull. de l'Acad. de méd. T. 34. p. 509 (1895).

2) Hepp, Comptes rendus de la Société de Biologie. Vol. 58 (1905).

3) J.P.Partou, Die physiologische Chirurgie des Verdaunngskanals. Ergebnisse (ler Physiologie ron Asher und Spiro. Bd. 1. S. 246 (1902).

4) J.P. Parlou, Neue Methoden der Anlegung pankreatischer Fisteln. Yerhandl. d. St. Petersburger Naturforscher. Bd.11. S. 51 (1879).

$\left.{ }^{5}\right)$ Heidenhain, Hermanns Handb. d. Phỵs. Bd.. 
gearheitet. London', modifizicute diese Methode. Diese Modifikation sei hier angerehen. Nachdem Schepoualnitiou enteleckt latte. dali der l'ankreassaft in zymogrenen \%ustande ans der Driise ansugeschieden und inu durch die Kinase der Papillenschleimhant aktiviest wirl, fing man an, die in

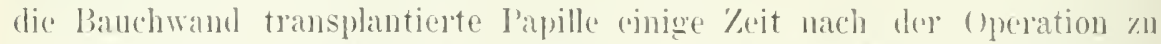
entfernen. lie beste Methode bei Ausfiihnung dieser Manipulation ist von Bublin ${ }^{2}$ ) roreschlagen worlen. l)ie operative Technik wird also in dre

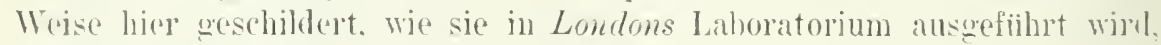
und dio postoperative Entfermung der transplanticeten Papille in der Meise. wite es Bablin tut.

b) Operative Technik.

1. Man zicht las luodemun hervor, lent es nach rechts hin und sucht mit riner Hohlsonde den zweiten Pankreastrang anf. Letzterel he-

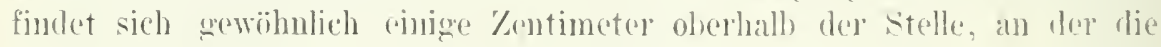
Pankreasdriise sich rom Inodenum entfernt.

2. Nan unterbindet temporär das louodenum um ¿ $\mathrm{cm}$ dies- und jenscits der Kinmiindungsstofle des lankreasoanges mit diinnen (iummischlänchen. bie binmindungstelle des Ganges wird zirkulir mnschnitten und der ats-

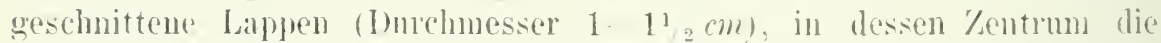
Pankreaspapille sich befindet. mit Mull umbunden, um dic ungebenden Gewele vor Infektion zu schiitzen. und heiseita olegt: die Inodenalwumle wire! veruäht.

3) An der rechten lianchwand, in einer kintfernnne von $3-4 \mathrm{~cm}$ rom Banchschnittrande, wirl mit rinem Messer eine $1 / 2$ cm breitr öffunng gemacht.

t. Man legt ober- und muterhalb der Naht 2 Ligaturen an. die z.mn Fixieren des buodenums an der Bauchwand dienen.

5. Mau legt an ansegechnittenen Darmstick durch die Serosa muscularis 2 Füden an. mittelst welehor das Larmstidek durch die kleine seit-

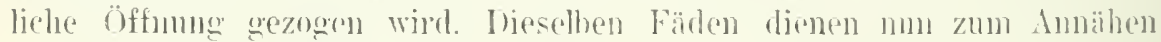
(munterblochene Nabt) des I)armstiickes an die anliegende Haut.

¡. Es folgt Knoten der Befestigmesänden mul Schliehen der liauchliohle.

c) P'ostoperative Behandlung. Solon am zweiten Tage nach der ()peration fünt gewihnlich der l'ankreassaft an, sich abzusondern. 1)ic

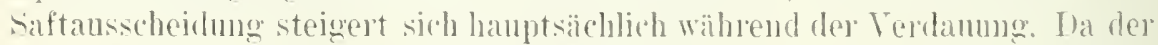
saft eine reizende Wirkung anf die Bauchhant ansibt und letztere zerfrilit. so ist es erstens notwendig, während ler Vordanmossogit den Hund im Gestell zu halten und zwritens anberhalh dor Verdamungseit. Während

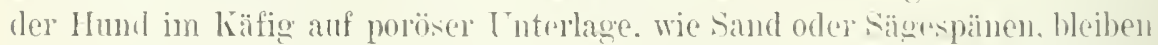
muli, ron \%oit zu \%eit die Jianchhant mit Wasser zu reinicen. Man fütere den Hond während diesel \%eit mit Jilch mol Brot unter Zufügung von

1) E. A. london. Ine Arbeit ist nicht publiziert.

2) Brelskin, Zur linge der Sekretion der l'ankireasdrüse. Nachrichtent der militärmedizinischen Akademie zu St. I'etershure. S. 23 (1904). 
Soda. Vach $7 \rightarrow$ Tagen unternimmt man die Entferunne der I'apille. I)ie

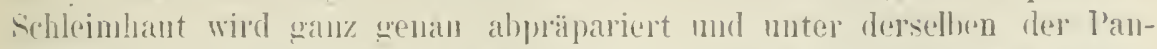
kreascane durelswdnitten; die Ränder des Ganges werden an die Ränder der Hautwunde angenält. Solange die l'apille da ist, hat man nicht zu befiirchten, dab der (rang obliteriert; sobald aber lie Papille algeschniten ist, mub man jerlen 'lag 1-onal den Gang mittelst einer passenden Kinopfonde hougieren. da sonst rine (M)literation des kianals eintritt.

d) Anwendung.

1. (iewinnung von reincm zynogenen Y'ankreassaft.

2. Studimm der lankreassaftsckretion muter vershiedenen bedingungen. Cher den normalen (rang der I'ankreassaftsekretion vermögen, wie oben (s. 92) ansgefuihrt, die Versuche am Pankreasfistelhund keinen zurellissigen Aufschlub zu geben. Im hesten studiert man die normale l'ankirassaftsekretion an Hand der Polvfistelmethode (s..9ㄹ).

c) Versuchsanstellung. Tan fiihrt in den Pankreasqang eine passende feine Metall- oder Glaskaniile ein und sammelt den ausflieljenden saft in einem Gefälo. l)ie Glaskanïle wird durch ein um den Rumpf gebundenes Kautschukrohr befestigt. AnBer der Versuchszeit hraucht man keine hesonderen Waßnahmen anzuwenden, da der narbige Gang dank seiner Elastizitït und der Anspannung der umgebenden Gewebe geschlossen wird.

Unter den verschiedenen Modifikationen der Isolierung des Pankreasganges (Smotzky $\left.{ }^{1}\right)$, Solooloff $\left.{ }^{1}\right)$, Foderì ${ }^{2}$ ) u. a.) sei nur noch die ron Parclow 's) ansgeführte erwähnt. Es liandelt sich um die Fistel des ersten Pankreasganges. Ilie Operation unterscheidet sich nicht von der eben beschriehenen, nur mul selbstrerständlich eine Trennung des I'ankreasganges rom Ductus choledochus stattfinden. Das geschieht in folgender Weise. Nachden die Niindungspapille samt ungebendem Darmstiick herausgeschnitten ist, wobei notwendigerweise der Gallengang durchschnitten wird, wird der in der Darmwand gebliebene Gallengangsalıschnitt von Seite der Schleimhaut aus aufgeschnitten, wodurch eine neue Miundung fiir den Gallengang geschaffen wird. Iie Darmwand wird nun wie gewöhnlich geschlossen und die Papille, wie oben beschrieben, in die Banchwand transplantiert.

Die Operation kann kaum Inwendung finden, weil man aus dem so isolierten Pankreasgang entweder gar keinen Saft bekommt oder höchstens wenige Tropfen. Um einen größeren Saftahfluß zu erzielen, kann nach Paulow folgendermaßen verfahren werden. Man unterbindet während der Operation den zweiten Pankreasgang; man erhält dann :3-4 Wochen eine ausgiebige Sekretion. da der gesamte Pankreassaft infolge der reichlichen

1) Vgl. J. P. Parlor, Die operative Methodik des Studiums der Verdanungsdrüsen in Tigerstedts Handluch der physiologischen Methodik. II. Teil. 2. Abt. S. 150 (1908).

$\Rightarrow$ Foderi, Lntersuchnngen zur Naturlehre des Nenscheu und der Tiere. 1896.

$\left.{ }^{3}\right)$ J.P. Parlou, Ergebnisse der Physiologie ron Asher und sipiro. 1902. 
Anastomosen zwischen beiden Gïngen jetzt durch den transplantierten Gang sezernjert wird. Sobald aber der unterbundene Ausfiihrungsung sich reponiert lat. vermindert sich wieder die Sokretion durch die transplantierte Papille. bleibt aher gröfer als vorher, so dals man z. I). hei lirotfüterung ein par Kubikzentimeter Saft bekommt.

\section{Gallenfisteln.}

\section{Gallenblasenfistel.}

(1) Historisches. Dastrel) War der erste. der diese ()peration ausgefiihrt hat. Dam wurde sic ron verschiedenen Autoren verbessert.

b) Operationstechnik:

1. Der lanchschnitt in der Linea alba beginnt $4-5 \mathrm{~cm}$ unterhalh des schwertfortsatzes.

2. Man ergreift rorsichtig mittelst 2 Schieberu die Gallenblase und zicht dieselbe durch den Bauchwandschnitt heraus.

2) Man preßBt den Blaseninhalt möglichst quantitativ durch den Ductus choledochus ins Inodenum und legt eine Fistel in lerselben Weise an. wie sit oben (S. \&6) bei Beschreibung der I)armfistelanlegung geschildert wurde.

4. Man leitet die Fistehöhre durch aine. wie bei der Darmfistel. speziell angelegte passende öfumng zwischen dem Schwertfortsatz und dem Anfane des erwähnten Bauchschnittes. Auch hier bedient man sich mit Vorteil des Omentums mol der Hilfsfäden. Es folgt Anlegen der äuberen Scheibe und Befestignug derselben mit Gummiringen.

Dastre zieht ror. diese Operation zweizeitig auszufïhren. Es sollen 4 Fïden durch die Gallenblase durchgeführt werden, mit deren Hilfe die Blasenkuppel in den Extrabauchschnitt gebracht wird. Durch einen Schnitt wind die Blase eröfnet, des Schnittrand ringsum angenäht und in die Fistel eine temporäre Glasöhre eingefïhrt, mm den Verschlub der Fistel zu verhindern. Das Glasrohr wird mit den Hantühten verknipft. Nach 5 - 11 Tagen wird die untere Bauchwunde wieder reöffnet, die Gallenblase an einer Stelle durchschnitten und nachdem die Fistelrölue die Glasröhre ersetzt hat, wird der frische Bhasenschnitt vernäht. Fs liegt aber kaum ein Grund vor, die operation, welche ganz leicht auf einmal ausgeführt werden kann. zweizeitig zu machen.

c) Postoperative Jiehandlung. Die postoperative Periode verlüuft ohne irgendwelche Komplikationen.

d) Anwendung. Die Gallenblasenfistel bei ununterbundenem Ductus choledochus kann nur zur (iewinnung ron Galle dienen. Will man die Gallenblasenfistel zum Studium der Gallenabsonderung benutzen, so mub man die () preration mit der [nterbindung des Ductus choledochus beginnen, um den Zutritt der Galle ins Inodenum zu verhindern: man unterbindet nämlich den

) Dastre, Opúration de la fistule liliaire. Pecherches sur la bile. Archives de Phrsiologie. Vol. 2 (1890). 
Ausführungsgang an 2 Stellen, die 2-3 $\mathrm{cm}$ roneinander entfernt sind. und schueidet zwischen ihnen ein Stiick heraus. Fs rersteht sich olne weiteres, dab ein Gallenblasenfistelhund mit einem unterbundenen D. choledochus uns ïber die normale Gallensekretion keinen Aufschluf liefern kann. weil (ler Verdauungsprozel und der Stoffwechsel überhaupt bei einem solchen Hunde wegen des völligen Ausschlusses der (ialle als anormal betrachtet werden muf. Es ist zwar von T'schermak ${ }^{1}$ ) ein Verfahren vorgeschlagen worden, die Unterbindung des $\mathrm{V}$. choledochus nicht an der Einmündungsstelle desselben in die Darmwand vorzunehmen, sondern näher der Leber zu, und zwar zwischen den Ästen des Ganges. In diesem Falle soll ein Teil der fralle aus der Leher durch die Äste. welche zwischen der Ligatur und der Darmwand sich befinden, sich ins Darmlumen ergiefien. durch die höher liegenden Xste in die Blase resp. in das Fistelrohr. Dieses Verfahren ist aber noch zu wenig aufgeklärt, als daß man es für Studien über den normalen Gallenabsonderungsvorgang benutzen könnte.

\section{Endständige Choledochusfistel.} worden.

a) Historisches. Die Operation ist ron P(utlow ?) ausgearbeitet

b) Operative Technik.

1. Man zieht das Duodenum möglichst weit in den Bauchschnitt hervor und sucht an demselben den weißlichen Streifen auf, welcher dem in der Darmwand verlaufenden Teile des D. choledochus entspricht. Die ovale Auftreibung dieses Streifens entspricht der Papille, worin der Gallengang und gewöhnlich auch der erste Pankreasgang mininden.

2. Nan präpariert vorsichtig das Pankreas von der angedeuteten Stelle ab, wobei man besonders darauf achtet, daf die hier reichlich rerlaufenden Gefäße nicht rerletzt werden; die letzteren werden, insofern ihnen eine Verletzung bei weiterem Gange der Operation droht, unterbunden. Der Pankreasgang wird zwischen 2 Ligaturen durchschnitten.

3. Die ovale Auftreibung wird ron 3 Seiten umschnitten, so daf sich ein zungenförmiger Lappen (Fig. 28) bildet, welcher seitens des Pylorus mit der Duodenalwand verhunden bleibt und in der Mitte die Gallengangpapille trägt. Der Lappen wird nach oben umgeklappt und mit seiner Serosa mit der Darmserosa vernäht, so daß die Gallengangpapille auf der äuferen Darmfläche befindlich sich erweist.

4. Man entfernt sorgfältig die Schleimhaut an der Basis des umgestiilpten Lappens und vernäht die aufgefrischte Stelle, Submukosa resp. Muscularis zu Submukosa resp. IIuscularis (Fig. 29). Die ührige Wunde wird wie gewöhnlich. Serosa zu Serosa, geschlossen.

$\left.{ }^{1}\right)$ Tschermak, Eine Methode partieller Ableitung der Galle nach außen. Pfiügers Archiv. Bd. 82 (1900).

$\left.{ }^{2}\right)$ Vgl. J. P. Paulow, Die operative Methodik des Studiums der Verdauungsdrüsen in Tigerstedts Handbuch der phỵsiologischen Methodik. II. Teil. 2. Abt. S. 150 (1908). 
7. Man näht den Inams in dio mediane Banchwmde in der Weise ein, dab die Nähte dip Papille mit der Mindung des I). choledochus in cinem ()al mmaben.

c) Postoperative Behaudlumg. (iewöhnlich verheilt dic banchwmule in 11-12 Tagen. Heilt abel die Darmwumble nicht gut und bleibt (2inc Dormfistel zuriick. so bleibt uichts anderes ibrig, als die letztere zu shliefen. wobej man darauf achten muls. dab die Darmschleimlant nicht in die Naht kommt. Nachden die Wmole rerheilt ist. kann es passicren, dalj dìn sich allmählich retrabieremde Varbe das barmstijek mit del Fallengangsiffumm zu stark \%uriekznzichen anfängt.

ln diesem Falle ist es nötig. von \%eit zu \%eit ans dey Tarbe cin (Tralstück auszuschneiden und len schuitt zur vernähen.

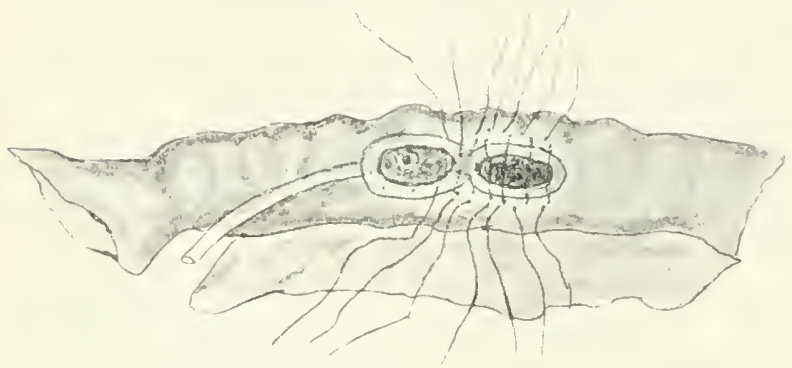

Fig. 28

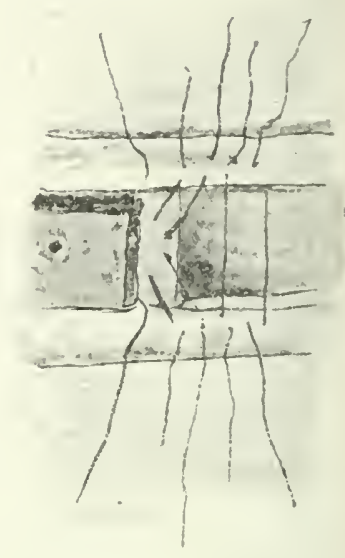

Fig. 29

(1) In we nd nug. Die endstundige ('holedochusfistel hat vor der Gallenblasonfistol den Vorteil, dalis die Gallenabsondermug dureh die in der Papille befindliche Vorrichtung resuliert wird. Doch vermag ein in dieser Woise operierter Hund keine für die normale (rallensekiction giiltigen Daten zu liefern, weil die Verhälnisse hier keine normalen sind. (Die Methode, die sich dazn am besten eignet, ist oben [S.89-.9(1)] angegehen.)

e) Versuchsanstellung. Die Cralle wird durol einen an der betreffenden Banchwandstelle mit (smmmischlänchen fixierten T'richtor in einem kïlbchen gresammelt.

\section{Lontinuitätsfistel des Ductus choledochus.}

11) Historisches. Die Fistel ist ron Lewascheu vorgeschlagen worden.

b) bic operative Teehnik motersoleidet sich dmoh nichts rou der hei vler Gallenhlasenfistel gehrinchlichen. Nur wird anstatt der Gallenblase der I). (choledochus sclhst fiil die Fistelanlegmo benutzt. In der Fistel lälit man ein T-fömiges, ans zwei zusammenfüghanen schenkeln bestelnendes Röhrchen ('inheilen.

[ie Anwendung und Versuchsanstellung ist dieselbe, wie bei der Gallenhlasenfistel. 


\section{Thiry-Vellasche Fistel. ${ }^{1)}$}

a) Historisches. Inie Mothode ist zuerst ron Thiry ausceführt und ron Tella modifiziert worden.

b) Operative Technik:

1. Man zieht ans der Bauchhöhle das I)nodenum und die erste Jejunmmschlinge hervor und legt an beide Darmschlingen kilemmen an, wobei das Inodenum unterhalb der Eimmindungsatelle des zweiten l'ankreasganges abgeklemmt wird.

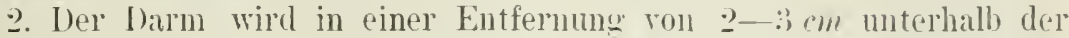
nberen und oberhalb der unteren Kilemme durchschnitten und die herausgesonderte Schlinge in ein Mulluch eingehiillt.

:3. Das l)uodemum wird dem Jejunum genähert und mit demselben entweder durch Gerade- oder durch seitenanastomose mit oder ohne Anwendung des Murphyschen Kinopfes (ersteres erscheint einfacher) zusammengenëlit.

4. Die Enden der isolierten Schlinge werden in beide Enden der Banchwunde eingenäht.

c) Postoperative Behandlung. I)ie Hautnaht geht fast immer auseinander infolge der unvermeidlichen Verschmierung derselben durch bakterienhaltige Absonderungen aus den I)armöffnungen. Die Wunde wird ron Zeit zu Zeit durch sehwache Sublimatlösung desinfiziert und heilt ganz gut.

(l) Anwendung:

1. Zur Gewinnung ron Darmsaft. Zn diesem Zwecke wird in die Darmschlinge eine Ableitungsröhre eingeführt (siehe Fig. 20). Die Röhre iibt eine Reizung aus und bewirkt Sekretion. Der so gewonnene Darmsaft ist kein normaler Saft; nur in seltenen Fällen ist er hlutfrei. Bei Anwendung der. Polyfistelmethode gelingt es. wie oben erwähnt (siehe s. 9:3). größere Quantitäten von reinem Darmsaft während der Verdaum!g' als Nebenprodukt zu gewimnen.

2. Zur Erforschung der Resorptionserscheinungen. Es lïlit sich ïbrigens rermuten, daß diese Operation anch für den genamnten Zweck keine Verwendung mehr finden wird, indem durch die Polrfistelmethode die Möglichkeit gregeben ist, jeden beliebigen Darmabschnitt zn isolieren, und zwar mit Erhaltung seiner normalen phrsiologisch-anatomischen Beziehungen zu dem gesamten iibrigen I)arm.

e) Versuchsanstellung. In die ohere oder untere Öffnung, erentuell in beide zugleich, wird ein Rohr ron dem in Fig. 20 abgebildeten Typus eingefiihrt und die Ausscheilung in einem am Bauch fixierten Gefälie aufgefaugen.

\section{VIII. Äußere Gastrojejuno- (resp. ileo)anastomose.}

Die klinische Methode der Gastroenteroanastomosenbildung kann im Laboratorium kaum Verwendung finden, es sei denn, daß die Untersuchung

1) Tella, Untersuchungen zur Yaturlehre des Menschen und der Tiere. Bd. 12. 
der mit diesel Uperationsmethode zusammenhängenden Erscheinungen be\%werkt wirl. Für Laboratorimmszwecke mul die Inastomose derart ausgeführt werden. dalf der" Verbindungsichlaneh nateh aufen zu liegen kommt.

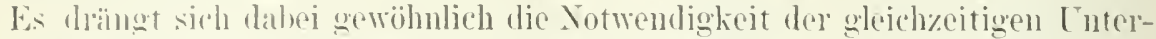
brechung der Kommmikition zwischen dem Magen und dem I)uodenum auf.

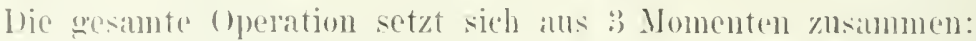

1. lie Zerunetshome des l'ylorusringes mittelst des Doyenschen binterotrytors und die Anlegring der Ligatme anf die genuetsolite stelle mit machfolgender serïser Xaht des l'ylorusteiles des Magens mit dem Lufang (les Inodenums: (W. Rokitzlit).

2. Anlegung der Fistelröhre an den prolorischen Magenteil. wobei dieselloe durch einen spericllen schnitt der rechtell Banchwand nach aulien gefofihrt wird.

:) Anlegnng der F"istelröhre an die betreffende Inarmschlinge: dic liöhro wird ebenfalls dureh eine spezielle Öfnumg der linken Bauchwand nach anben gefiihrt.

t. Lie Bandhwunde wird geschlossinu. In die Fistehöhren werden I'fropten mit gebogenen Glasröhren eingefiihnt, wek he mittelst eines Gummischlauches vereinigt werden.

Am besten macht man die Operation in zwei sitmungen. \%nerst leat man die Fisteh an, und wem diese rerlesilt sind. tremut man den Magen vom Duorlenm, intem man in folgender Weise verfährt: Van führt

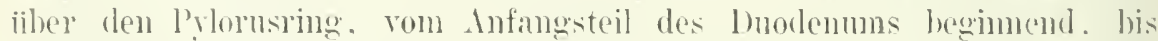
ב. 5 rm jenseits (magenwärts) des Ringes (inen schnitt dureh die serosa und lluscularis, list die Schlemhatut. welche intakt geblieben ist. mit einem stmupfen Instrumente ab, muterbindet sie an zwei stellen mol schneidet zwischen den Ligatnren durch. Mam stiilpt die Sä̀le ein mol vernäht die Serosa-Yluseularisbriiclie.

Die Anwend nug diesere Operation und die Versurhsansfühung kïmen auberordentlich rerschiedenartig sein, doch lassen sich dic Einzelheiten zurzoit noch nicht inscinimdersetzen, weil die Methode sich noch in Entwieklung bofindet.

\section{Ecksche Operation.}

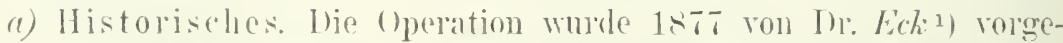
schlagent. Stolnition ${ }^{2}$, Massen und P'atlow ${ }^{3}$ ), Queirolo ${ }^{4}$ ). Rothberger nud "Vinterberg ${ }^{5}$ ) un! Guleke ${ }^{6}$ ) modifizierten sie. Bei allen diesen Autoren

1) Ech, Militï-mediz. Inırn. Bd. 130 (1ลั7\%).

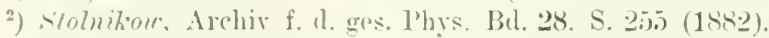

") Massen et l'aulorr, Sur nue modifiention daus lopération de la fistule d'Erk entre la veine porte et la reine cave inferienre. Archires des sciences hiol. T.2. p. 581 (1893).

4) (Jurivolo, anlrschotts Entersuchungen. Bd. 15), S. 228 (1895).

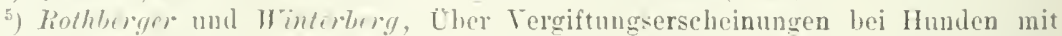
Ficlischer Fistel. Zeitschr. f. experim. P'itl. n. Ther. Bu. 1. S. 312 (1905).

6) N. Guleke, Zur Technik der Eckschen Fistel. Zeitschr. f. experim. Path. u. Ther. Bil. 3. S. $706(1906)$. 
aber gab die (operation eine zu grofe Sterblichleit $(60 \%)$. Endlich hat London ein Vorfahren angegehen, welches die Siterblichkeit his auf o helabsetzt. I)iese Methode sei hier ausführlich beschrieben.

b) Operative Technik:

1. Man macht der Limea alba entlang einen Bauchschnitt, welcher, rom Schwertfortsatz anfangend, bis zur hintersten Grenze der Bauchwand zieht. Ihie subperitoneale Falte wird abgeschnitten. Der rechte Schnittrand wird mit einem Mulltuch iherdeckt.

¿. Inden der Operateur mit seiner linken Hand den mit der Serviette bedeckten Iiand der Schnittwunde zuriickhailt, führt el die rechte Hand in die Banchhöhle ein, schiebt sämtliche Darmschlingen behufs Freilegung der Tena cava resp. Tena portae nach der linken Hälfte derselben hin. iibergibt sie dem Assistenten, welcher zu gleicher \%eit beide Hände in die Banchhöhle einführt und die ihm rom (operierenden gereichte Iarmmasse in eine Mullserviette einhiill. /ur Erzielung des regelrechten operationsganges ist es notwendig, daß der Assistent bis zum Schlub der Operation seine Häude ans ler Bauchhöhle nicht herausnimmt, indem er mit einzelnen Fingern diese oder jene Teile des Operationsfeldes entsprechend den Anzeigen des Operateurs rorrickt oder zuriickschiebt.

3. Mit einer flachen Hohlsonde wird derjenige Teil der T. portae abpräpariert, welcher in ler Mitte zwischen der V.pancreatico-dnodenalis und den nach der Leber ziehenden Ästen liegt. Nit Hilfe einel Aneurysurnadel wird damn ein langer Faden unter den isolierten Vemenabschnitt gelegt. Die Fadenenden werden mit einem Schieber gefabt und auf die äuberen Decktiicher zur Seite galegt. Dabei müssen folgende zwei Umstände beachtet rerden: erstens. dab in die Ligatur tatsächlich die Vena portae mud nicht etwa einer der zur Leber sich begebenden Äste zu liegen kommt; zweitens, dab beim Jurchfïhren der Aneursmanadel die Vene selbst nicht verletzt wird. Bei ungeniigender Aufmerksamkeit werrlen diose Fehler leicht gemacht. Hat man in Simne, den Blutstrom von der Vena cava nach der Vena portae abzuleiten. so wird der Faden unter die erstere gefiihrt.

t. Nun folgt das Entfernen des lockeren Bindegewebes ron der Vena portae und deren Zusammennähen mit der T. cava. Zu diesem Zwecke ist es notwendig. möglichst feine. runde, nicht schneidende Vadeln und entsprechend feine Seide zu vrwenden. Der erste Einstich wird in die Tena portae. $0 \% \mathrm{~cm}$ unterhalb der Einmündungstelle der V. pancreatico-duodenalis gemacht, wobei die ganze Dicke der Venenwand durchstochen wird: in dieser Weise rerfäht man auch im weiteren. Es entsteht dabei immer eine geringe Blutung, welche aber auber acht gelassen rerden kann; vielmehr mub möglichst schmell del Ausstich durch die Wand der V. cara gemacht werden. Es ist gleichgiiltig, on man die Nadel durch die ganze IVanddicke der T. cara durchfiihnt oder nur die Adrentitia derselben in die Naht faßt; cinfacher und schneller erscheint es, die ganze Ibicke durchzustechen. Die Naht wird nit beilen in die Tiefe der Bauchhöhle einge- 
senkten Zeigefingern zusammengezogen und in einem einfachen, nicht chimmischen Knoten zweimal nacheinander gebunden. Ibie Blutmog steht dadureh still; ist dies nicht dex Fall, so driickt man ganz leise mit einem kleinen Mnllampon an. Das freje Fadenende. welches eine genügende Länge besitzen mub. wind mit einem schiebes gefalt. Hiesel wirl anberhalb der Wunde nach der linken Seite gelegt (eventuell nach der rechten; es ist konditionell und mulizur späteren (orientiermug gemulit werden). Mit dem zweiten Fadenende fälnt man fort, die Tonenwände durch eine fortlaufende Nalıt auf einer Strecke von $5-6 \mathrm{~cm}$ zu veremigun. Das Fadenende wird ebenfalls

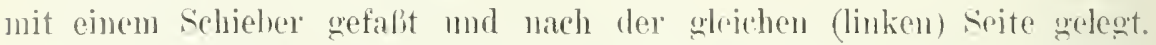
Falls die Nahtstiche eine Bhutung hervorufen. sucht der zweite Issistent diese ebenfalls mittelst 'Tupfern zu stillen.

5. Die Scherendrähte werden gerale gezogen md die Schere anf das lecktuch gelegt, indem man letzteje in den freion hamm zwischen beiden schicberbunchen fixiert. J)ie rechte, fiir die V. portae hestimmte Nadel wird mit einem schieber festgehalten. der zweite Assistent falst den silberfaden in (aner Entfermung ron $20-5$-5 $\mathrm{cm}$ ron des Narlel mud hält ihn gestreckt. den bewegungen des Operierenden folgend mol hamptsächlich dafiur sorgend, dab an demsolben kejue biegmog zustande kommt, denn letztere kam beim Durchgehen durch dio dïme Tenenwand dieselbe zelreilien und tüdliche Bhtung hewirken. I le Narlel wird in der Entferinumg von $1 / 2 \mathrm{~cm}$ von der Nahtlinie und ron $1 / 2-3 / 4 \mathrm{~cm}$ vom Nahtende ein- und höher oben an der symmetrischen stelle ansofiihnt. Man macht den schiebex auf und falit zunärhst die Narlel, darauf anch den Falden selbst muterhall derselben, indem man ihn vorsichtig nach voln durchstibt. Der Assistent schieht dabej mit den Wunem der rechten Hand die Leber von der vorriickenden Sadel zurick. Sowohl die Nadel wie der l'aden miissen den Fingern des Assistenten entang gleiten, welcher mit lejehten Bewegungen derselben den Faden heranzieht, un lessin Heranstueten zu erleichtern.

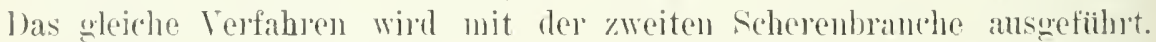
Wem man dabei vorsichtig vorgeht, so entsteht keine blutung; falls sie abel doch zustande kommt, gelingt es leicht, diesclbe mittelst 'lupfern zu stillen.

(i. In der Entfermung von $6.5 \mathrm{~cm}$ von den dureh die Venen durchgefïhrten Scherentäden wind die zwate fortlanfende Nalit angelogt. Die freien Farlenenden werden mit den schicbes gefalit mol nach der rechten seite der Banchwand geleort.

7. Her Operatem führt den linken Keigefinger unter das proximale Fadenende der oberen Naht proximalwäts ron den scherenbranchen, indem er mit demselhen auch das freic Ende des mroximalen Fadens der muteren Saht zurickolrängt, während er mit der rechten Hand die Scherenbranchen herauszieht und dieselben zur glejehen Zeit gerade streckt. I)er Assistent hat dafür zos sorgen, daf die Schere derart in der Mitte zwischen der oberen und unteren Naht durchgeht, dab nirgends fremdes Gewehe mitgerissen wirl. Mlühhlich zieht der Operateur die schere nach aubu, 
indem er dieselbe zunächst nach rorn in den freien liaun der Bauchhöhle rorruickt. In der Regel erfolgt dieser Akt olne irgend eine Blutung; falls jedoch eine solehe zustande kommt, wird sie mittelst Tamponade gestillt.

8. Die freien Enden der oberen resp. unteren Naht werden zugeknotet und die an die $\mathrm{V}$. portae angelegte Ligatur fest gehunden.

Die Operation kann dadurch vereinfacht werden. daß man anstatt spezieller Scheren nach der Amerikaner Methode den Thermokauter anwendet. ${ }^{1}$ )

c) Postoperative Pflege. 2t Stunden nach der (operation kann mit der Fiittermo des Hundes begomnen werden. Anfänglich gibt man rur Milch, dann aber Vilch und Brot: es diurfen geringe Fleischmengen zugesetzt werden. Will man einen Echschen Hund lïngere Zeit am Leben erhalten. so muf eiweibreiche Diüt vermieden werden: es gibt nämlich Hunde, die diese nicht ertragen und entweder periodischen Anfällen komatösen Charakters anheimfallen oder einfach kachektisch werden und nach (6--8 Wochen ohne sichtbare änBere Ursache zugrunde gehen.

d) Anwendung. Isolierung der Leber rom portalen Kreislauf. Es muf aber in Betracht gezogen werden. daf rollkommene Isolicrung dabei kaum erlangt werden kann, aus dem einfaclien (irunde, weil das Netz fast regelmäfig mit der Leber verwïchst und ein Kollateralkreislauf sich herstellt. hängำ.

e) Die Versuchsanordnung ist von dem zu rerfolgenden Zwecke abhàngig.

Die beschriebenen Operationen besitzen eine direkte, unmittelbare Bedeutung fuir die Erforschung der Verdauungs- resp. Resorptionserscheinungen. Zur allseitigen Beleuchtung der zwischen den Verdaungsorganen und den iibrigen Drïsenorganen bestehenden Verhältnisse sind Operationen an diesen letzteren selbst notrendig. Diese Operationen bilden den Gegenstand der nachfolgenden Auseinandersetzungen.

\section{Kanüleneinlegung in die Speichelgänge.}

Der Ductus Whartonianus und Ductus Bartholinianus werden folgentdermaßen aufgefunden. Nan fïhrt einen Hautschnitt an der unteren Seite der Schnauze, parallel dem Rande des Lnterkiefers, $1 \mathrm{~cm}$ ron ihm entfernt, angefangen $1 \frac{1}{2}-2 \mathrm{~cm}$ rom Kinnwinkel in einer Länge ron $3-4 \mathrm{~cm}$. Die Faszie wird absepariert und der Mrylohyoideus quer durchschnitten. Wenn man nun die Ränder des durchschnittenen Muskels von dem unterliegenden Gewebe genau abpräpariert, so treten auf dem I. genioglossus die Ausfuilnrungsgänge der submaxillaren und sublingualen Drüisen hervor.

1) Kommt es auf völlige Isolierung der Leber an, so unterbindet man noch zuletzt die Art. hepatica (siehe unten S. 119). Im letzten Falle sterben die Hunde 1 bis 2 Tage nach der Operation im komatösen Zustande. 
Del Juctus Whatonianns liegt nähel der Vittellinie. Sollten die Insfiilumnesgänge nicht genügend dentlich hervortreten, so bringt man irgend eine reizende Substanz in den Mund des Hundes. wodureh die Speichelabson-

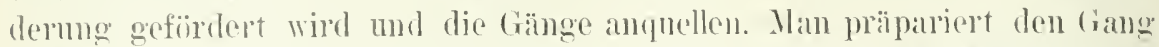
(ine strecke weit ab. schmeidet ihn auf die Hälfte seines ['mfanges an mul fühnt mit Hilfe aines Leithakens die pascend, Kaniile ein, woranf die Befestignng derselben mittelst einer Ligatur folgt.

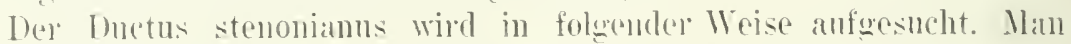

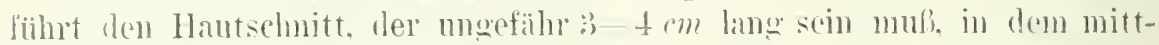
leren leil derjenigen Linie, welche den mutren hand der () hrmuschel mit der basis des emsten backenzahnes vorbindet. Es tritt direkt del dusfiihmunggang hervor. indem derselbe auf dem M. masseter liegrt. Inreh Einführmm iloend eines lieiznittels in die Mundhöhle wird der Gang mit sipeichel gefiillt mod dadmoh erkembarer gemacht.

\section{Exstirpation der Schilddriise.}

Am Halse des Hundes wird ein Mediansehnitt ron 4 - im Länge gemacht. der ummitelbar unterhalb des Ringknoryels seinen Infang nimmt. Beim Auseinanderichen der Ilauträndel wird die oberflächliche Halsmuskulatur bloferelegt. Mittelst des Skalpelsticles resp. der Sondr worelen die ancinanderliegenden häinder der Mn. sterno-hyoulei zwecks Freilegung der Trachoa getrennt und mit stumpfen Ihaken anseinandergezogen: lie beidersoits der Inftröhre liogenden schilddriisen treten dabei dentlich hervor.

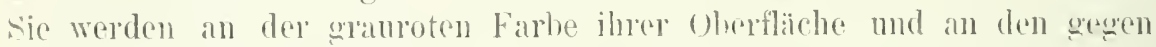

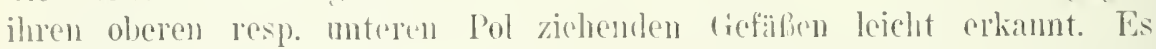
wird jede briise fïr sich mittelst cines sehiobers ans ler liefe der Wunde hervorgezugen, wobei sorgfältiog ron den momehenden Geweben resp.

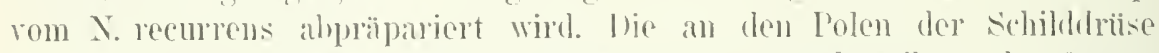
liegenden Gefibibiudel werlen möglichst weit von derselluen als vanzes mnterbunden mol die Intise sellost mit einer sichere mmittelbar an ihrer () berfliche losgetrennt.

Liese operation aeschieht meistens ohue lihtrerlust. In manchen Fällen aber, wo die Kapselvenen besonders stark entwickelt ersebeinen, ist nachfolgende Ibutumg mïglich, zu deren stillung man zu Anlegung vou starken Ligaturen an kiaffenden Crefälien onleoifen muli.

\section{Exstirpation der Banchspeicheldrïse.}

1)urch einen in ler Mittellinie der Banchwand gefiihrten Sehnitt wild der obere 'T'eil des Duodenums hrovorwezogen. dem dic banch-

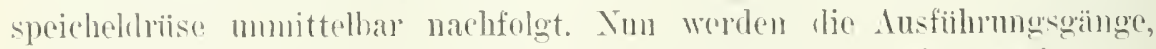
deren rahl zwischen eins und deei (anch mehr) variert, abpräluariert.

Der eine Homptansfiilnungegane ist konstant und befindet sich linkerseits in der Entfermung you ca. $1 \mathrm{~cm}$ von del Abgangsstelle des schwan\%- 
andes der Drüse vom buodenum. Manchmal ist er so oberflitehlich gelecren, dab er sofort in die Angen fällt, in anderen Füllen aber versteckt er sich

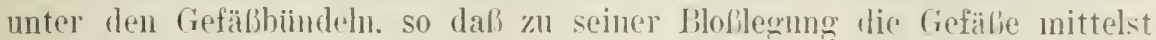
eincr sonde vorsichtio unter Verhiitung von Blutung nach der einen oder auderen Seite verschohen werden miissen. Der zwcite Lusfiihrungsgang ist in der Mehrzahl der Fälle zu treffen und findet sich unterhalh der l'apille, in welche der Gallengang einmünlet. Zu seiner Freilegung werden dir den frallengang umgebenden (iewebe abpräpariert, derselhe in der Iuodenalwand bis zur knopfförmigen, der Papille entsprechenden Auftreibung verfolgt, und nun kommt der feine, weibliche Pankreasgang zum Vorschein. l)er dritte Ausfiihrungsgang ist sehr unheständig und ist in drer Mitte zwischen den beiden beschriebenen gelegen. In die isolierten Auffihrungsgainge werden starke Ligaturen angelegt. I)arauf folgt die Interbindung sümtlicher zwischen dem 1)nodenum und der Pankreasdrüse ziehenden (iefüßbindel, wonach alle Ansfïhrungsgainge resp. -liefäßse oberhalb der Ligaturen durehschnitten werden und die Inrise anf stumpfem Trege. am besten mit den Fingern aus dem Peritonealiiberzug heransgeschält wird.

\section{Exstirpation der Nebennieren.}

Die Yehennieren stellen lïngliehe. etwas plattgedriickte. gelblich schimmernde (rrgane dar. Sie liegen am medialen Rande der Nieren. und zwar gregen das thorakale Ende derselben, inden sie das letztere in den meisten Fällen brustwärts überragen. Yan öffnet die Banchhöhle an der Yedianlinie, schafft die Darmschlingen von der betreffenden Seite ab), sucht das die Nieren umgebende fetthaltige Bindegewebe an den Lendenmuskeln. wo die Yebennieren eingeschlossen sind, auf. präpariert das Bindegewebe ab. unterbindet und schneidet die Yebennieren ab. Die operation ist franz blutlos.

\section{Verschiedene Manipulationen an Blutgefäfien.}

Von den Manipulationen, zu denen man bei der C'ntersuchung der Verdaumg resp. Resorption greifen mub. rerdienen am meisten Interesse folgende: Ligatur des einen oder anderen Gefüßes, Injektionen in das Blut und Blutentuahme.

Im häufigsten bietet sich die (relegenheit der T'nterbindung der Leberarterie. wenn es wïnschenswert erscheint. wie oben erwähnt. die Ecksche (1)eration durch Ausschluf der Leber aus dem arteriellen Blutkreislauf zu komplizieren.

Die 1 . hepatica stellt einen Ast der A. coeliaca dar, welcher leicht zu finden ist, wenn man ron der $\mathrm{\Lambda}$. coronaria rentriculi sinistra ausgeht. Man schiebt die kleine Magenkurvatur nach links (rom Hunde ans geerechnet). wobei die $A$. coron. ventr. sin. gespannt wird. verfolgt dieselbe bis zu deren Vereinigungsstelle mit der A. lienalis unl steigt weiter in der Richtung der 
Lorta lieranf; hier findet sich die A. hepatica. welche mmittellatr an ilurer Abgangsstella von der $\Lambda$. coeliaca an zwei Stellen unterbunden wird.

Intravenöse Injoktionen sind an berpemsten entweder in die Ohrrenen, wemn es sich mu geringe Flissigkeitsquantitäten handelt, ausznfiihren oder in die ïnbere Jugularvene, wenn es wiinschenswert arscheint. himen kur\%er 'Zeit grobe Mengen ron Flüssigkeit in den Blutkreislauf einzu-

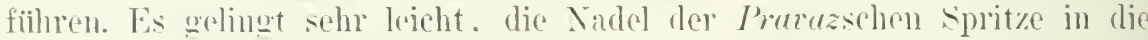
(H)rene einznfiilnen. Ian brancht dazu mur. nachdem die Haut rasiert und mit desinfizierenden Lösmoen (Seifenwasser, Sullimat. Alkohol. Ither) gewaschen ist. die Vene muterhall, der zum linführen bestimmten Stelle mit dem Finger anzudriicken. Etwas schwieriger steht es mit der bemutzung der. V. jugularis axterna. obgleich hei einiger thung auch diese Operation einfach erscheint. Her Hund mul entwerler durch Festhinden an den Tisch oder durch Fixieren in den Gestell in seinen Bewegungen beschränt worden. Man drïckt mit flach angelegten lingern anf den unteren Halsteil, $n$ in del betreffenden Vene Bhutstanumg hervorzurufen. Wobei die Vene ansehwillt und zienlich dentlich hervortritt. Wenn der Gang der Vene festgestellt ist. drïckt der Assistent deren nuteres Ende mit einem Finger an. Der Experimentator sticht die Spritzennadel (sie kann ron bedentenden Dimensionen sein) in die Hant senkrecht ein, senkt sie dann aufwärts und durchsticht die Vene selbst. Der Gehilfe bäbt die Vene frei und num wird die lnjektion ausgefiïhrt.

Für die Bhutentziehnug kann jede beliebine Arterie oder wiedermm die änfere Jugularrene gebrancht worden. bei Benutzung der letzteren kann man anf zweierlei Art rorwehen: entweder sticht man in die Vene in der Kopfrichtme eine feine Nadel ein und sangt das Bhnt mittelst der Spritze an. oder aber man wendet eine weitlumige Nadel an, so dab. falls der Hund im (iestell steht, das Blut ans derselhen spontan ausflieft. Selbstrerständlich mul der moterhalb der Finstichstelle liegende Venenabschnitt während der ganzen Zeit an die nmgebenden festen Teile angedrïekt werden.

\section{Anlegung einer Fistel des Ductus thoracicus.}

Der louctus thoracicus variiert in seinem Torlaufe beim Hunde sehr. Aus der zwischen den l'feilem des Zwerchfells gelegenen Milchzisterne stammend. bildet er einen mefähr gänsefederstarken Kanal, der. an der Aortenwand oralwärts verlanfend, sich von der t. Rippe abwendet. die grofen Brusthöhlenarterien krenzt and in 2. Interkostalrann in die linke V. subclaria eimmimlet. Im den Ductus aufzusuchen. verfïhrt man folgendermalien: An der linken Ilalsseite führt man an änberen Rande des M. sternocleidomastoideus einen $\bar{i} \overline{c m}$ langen schnitt, angefangen von der Claviculi- 
grenze. Man prïpariert das Unterhantgewebe ah, bis die V. jugnlaris externat hervortritt. Die Vene wird abwilrts präpariert — wobei man darauf achte, daf die Seitenäste nicht verletzt werden - , bis man zm I. subclavia kommt. Hier in der 'liefe der 1 . carotis sncht man die Finmündumgstelle des D. thoraciens anf, indem man das nmgebende Isindegewehe sorgfïltig prïpariert.

Handelt es sich um eine temporïle Fistel, so verklemnt man die Eintrittsstelle des Ductus in die Vene mittelst aines Schiehers. Weiter unten wirl in einer Entfernung von ca. $1-1 \frac{1}{2} \mathrm{~cm}$ an den inzwischen aufgeschwollenen Ductus eine kleine feine Kilemmpinzette angelegt. Der zwischen den Klemmpinzetten befindliche Ductusteil wird bis anf die Hälfte angeschnitten, durch den Schnitt eine feine Glaskaniile eingefiihrt und dam mit einer Ligatur befestigt. Beseitigt man die nutere Klemme, so füngt sofort die Lymphe an, abzufliefen. I'm die Lymphexkretion zn beschlemigen und alsundanter zu machen, macht man dem Hunde von Zeit zu Zeit Massage und kiinstliche Extremitätsbewegunger. Es ist vorteilhafter, grolie Hunde zu wählen, obschon zwischen Kö̈pergewicht und Lumenbreite des Ductus sich kein direkter Zusammenhang konstatieren läbt.

Will man eine Danerfistel anlegen. so verfähnt man anders. Man sncht znerst die Eimmindungsstelle des Ductus thoraciens anf, unterbindet alle Seitenäste der $\mathrm{V}$. jugularis ext., welche sich iiber $2-3 \mathrm{~cm}$ rom Ende derselben befinden, unterbindet weiter die V. subclavia und iiberliaupt alle Venen, die unterhalb der Eimmiindungsstelle des Dnctus sich vorfinden, läßt die $V$. jugularis ext. anschwellen, unterbindet sie in einer Entfernung vom Ende von 2-:3 cm und führt in deren aufgeschnittenes Lumen eine entsprechende dickwandige Gummikaniile ein und muterbindet. Die Kimiile wird-beim Schliefen der Hautwunde in derselhen an den Hauträndern durch Nähte befestigt. Glaskaniilen oder diumwandige Gummikaniilen sind zu diesem Zweck untauglich, erstere weil sie die Venenwand zu verletzen vermögen mul letztere, weil sie bei der Vernarbung der Hautwunde zusammengedrïckt werden.

Die Kaniile muf mehrmals täglich bougiert werden. Die Hantwunde heilt nur langsam. Bei antiseptischer Behandlung kann Eiterung leicht rermieten werden. 


\section{B. Methoden zur Untersuchung der Verdanumgs- produlite.}

Von Elgatod Kunz, Briissel.

\section{A. Allgemeine Technik.}

Man kann die Verdamung an Hand des Tielexperimentes oder durch versuche in lieagenzolase studieren.

\section{Verdaumgsversuche an Hand des Tierexperimentes.}

\section{(1) Mllemeine Betrachtungen.}

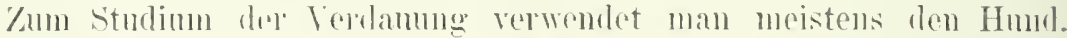
Andere Tiere (Katze. Solwein. I'ferd usw.) worden aber andel dazn benutzt.

Das Versuchstier soll sich im nibchternen \%ustande befinden. Man giht

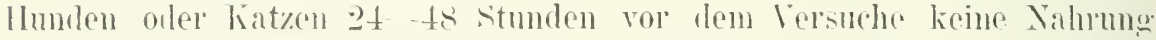
melne, läbt sie jedoch nach bolichen trinken. liwi lianimelen oder Meerschweincheru mub das Fasten noch länger danern. Während diuser Fastens-

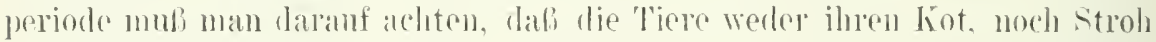

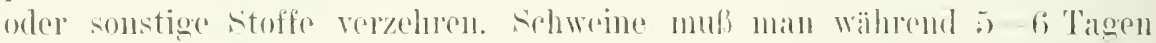

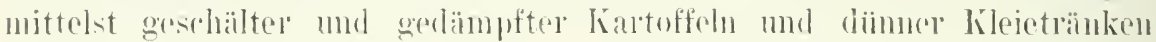

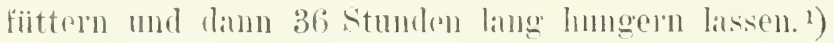

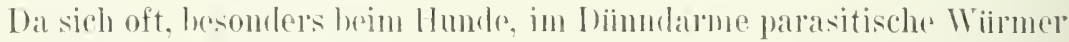

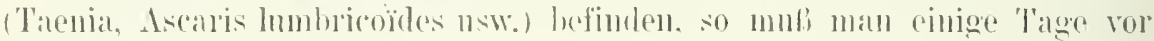
drum Versurhe mittelst louredichung vou Intholmintika das Tier daron zu

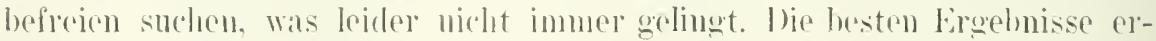

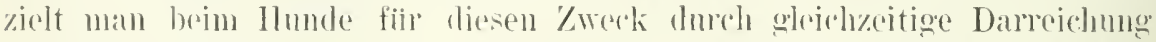

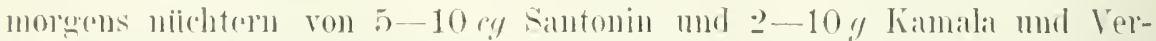

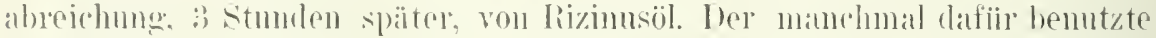
(iranatwnzoddekokt wirkt oft reizend anf den Darm des Humdes mol ruft viel loichter Erhorehen helrop als Kamala.

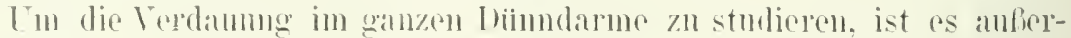
dem ratsam, während des Fastens et-Le Stumden vor dem Versuche mittelst

1) E. Liitsch, \%ur Kenutnis der. Verdaunng ron Fleisch im Magen und Düundarm des Srhweines. Inaug.-I)iss. Leipziq 1909. $54 \mathrm{~S}$. 
Karlsbader Salz den Darm von den Nahrungsïberbleibseln zu reinigen. Hunden ron 5-10 kig gibt man zu diesem Belufe mittelst der Schlundsonde eine Lösung von 5 g Karlshader salz in $200 \mathrm{~g}$ Wasser, Tieren ron gröferem Gewichte entsprechend mehr. ${ }^{1}$ )

In nachfolgender Besprechung sind die Verdaunngstersuche heim Tiere. je nachdem sie einen rorherigen operativen Eingriff erfordern oder nicht, eingeteilt.

I'm jede weitere Fermentwirkung nach dem Auffangen des Magenoder des Darminhaltes zu verhindern. muf man diese Inhalte. falls sie nicht sofort untersucht werden, auf Eis oder besser im gefrorenen Zustande aufbewahren.

\section{b) Verdaumosressuche heim intakten Tieve.}

Beim intakten Tiere kann man eine gewisse Zeit nach einer gegrebenen Iahlzeit oder nach Verabreichung eines festen oder in Lösung befindlichen Stoffes den Mageninhalt mit Hilfe der Schlundsonde gewinnen. Bei diesem Verfahren erhält man natïrlich nur Auskunft ïber die eigentliche Magenrerdauung. Ein und dasselbe Tier kann aber zu mehreren Vergleichsrersuchen dienell.

Un gleichzeitig Magen- und Darmrerdauning heim nichtoperierten Tiere zu studieren. muß man letzteres einige

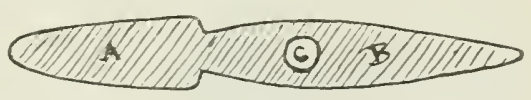

Fig. 30 . Zeit nach der Mahlzeit töten und sofort zwischen Tnterbindungen Ifageninhalt und Darminhalt trennen.

1. Schlundsondenverfahren. Falls das Versuchstier die untersuchten Stoffe nicht rerschlingen will, so mub man sie mittelst der schlundsonde in den Magen einführen, was sich aber nur bei Lïsungen oder bei Aufschwemmungen fein zerhackter Feststoffe in destilliertem Wasser oder einer ander'en Fliissigkeit ausfiihren läft. ${ }^{2}$ )

Zu dirsem Zwecke ist es empfehlenswert. sich eines die Gestalt nebenbeistehender Fig. :30 zeigenden Beifstiuckes zu bedienen. Es besteht aus einem mit einem Handgriff At rersehenen abgerundeten oralen Holz- oder Hartgummistïck $B$. in dessen Nitte sich ein rundes Loch C' befindet, durch welches man die mit einem Trichter am äuferen Ende rersehene weiche Kautschuksonde einfiihren kann, dessen Länge und Breite je nach dem Tiere wechseln.

Zur Einfuihrung der Sonde in den Magen muf das Versuchstier sich in aufrechter stellung befinden. Ein am hesten auf einem Stuhl sitzender (rehilfe nimmt den Pumpf oder die hinteren Glieder des Versuchstieres

1) P. Nolf' et Ch. Honoré, Influence des conditions de l'absorption intestinale de l'azote alimentaire sur l’élimination urinaire. Arch. int. de Pbssiol. T. 2. p. 85-115 (1904).

2) A. Cahn, Die Verdaung des Fleisches im normalen Magen. Zeitschr. f. kliu. Med. Bl. 12. S. $3 t-t t$ (1887). 
zwischen die Knnice. hïlt die oberen Gliedler mit einer Hand und das Maul mit der anderen. Das Reißstiok wird so zwischen den Zühnen oder den Kiefern angehracht. dals die Öffnung $C$ der Nitte der Mundhöhle entspricht. mud daf man durch diese Bohrung das runde Ende der Sonde iber den \%mngenricken hinweg leicht bis zur hinteren liachenwand schieben kann. Jamn wild die sonde langsan bis in den Magen geschoben.

Dahei muf man mit grolier Sorofalt vorgehen. damit der Jagenschlamch nicht in die luftröhre gelangt. Was besonders bein Kanincher ricmlich leicht erfolgen kimn. Man erkennt dies daran. dab bei jeder Iusatmung Luft durch die Sonde hinausuetrieben wird. liei einiger I'bung läbt sich übrigens die Sonde in der Lnftröhre fiihlen. (oft werden dann die Lippen blan und zeigen sich Atemstïrugen. Falls dies der Fall ist, so mulb man die sonde sofort herauszichen und rorsichtig versuchen, sie in die speiseröre zn bringen. Manchmal mus man dazu dic lage des Beilstiickes etwas verindern.

Befindet sich die Sonde in der speiscröhre, so ersicht man meistems ans deren rerschluckter Länge, ob sie his in den Magen gelangt oder nicht. sobald man im Magen zu sein graubt. gieft man almählich die Flüssigkeit in den 'lrichter: sie fliebt meistens ziemlich rasch in den Magen. Enfolgt kein MhfluB oder hört der Ahfluß plötzlich auf, so ist entweder der Schlanch noch nicht in den Magen gelangt, oder die öffnumg seines imneren Fudes ist durch irgend eine Trsache (hrimmung des Schlauches sellost im Magen, Falten der Magenschleimhaut usw.) rerstopft. Durch volsichtiges Hin- mnd Herschichen der Sonde gelingt es dann wewöhnlich leicht, sie in den Magen zu bringen oder die Öffnmmg ihres immeren Endes zu befreien. und sofort läuft die Flïssigkeit rasch in den Magen. Einige Sekunden, nachdem die Flissigkeit den Trichter völlig verlassen hat, werden die Sonde und das Beilistiick for'tgenommen. Nun lälit man das Versuehstier bis zum knde des Versuches sich frei hewegen.

Falls das Versuchstiel feste Nahrmeg nicht fressen will, so wirl es in anfrerhter Stellung durch rinen frehilfen in der oben beschrichenen Weise gehalten. Statt des Beibstiokes hringt man einen geeigneten Mundsperrer zwischen boirle Kiefer. Ine Nïhrstoffe werden allmählich in kleinen Mengen und vorzngsweise im fenchten Zustande bis an den hinteren Gammen eingefïlurt, mon den Schlnckreflex horvorzurufen, wodurch das Versuchstier dic Nahımmg verschlingen mulo. $\left.{ }^{2}\right)$

Lum den Inhalt des Magens zu gewinnen, führt man nach der für den Tersuch festgestellten Zeitdaner die Sonde in der soeben beschriebenen Weise in den Magen und grefit in den Trichter ein genau abgemessenes Volumen destillierten Wassers. Whe der 'Trichter' ganz leer geworden ist, senkt man ihn rasch. um Mageninhalt sowie mogsetztes Wasser aushebern zu können. Jarauf wäscht man den Magen melnmals mit bekannten Wasser-

1) E. Zunz, Contribution à l’étude de laction de la morphine sur la digestion de la viande chez le chien. Mém. cour. et antr. mém. publ. par l'Acad. roy. de méd. de Belgitue. 'T. 20. Fase. 3. p. 1-30 (1909). 
mengen aus, welche man sofort aushebert. Wenn das eingefïhrte Wasser ohme Beimischung von Jageninhalt ausfliefit, nimmt man die Sonde heraus.

Cakn zieht dem Aushebern die Benutzung der nebenhei abgebildeten Iagenpumpe (Fig. 31) vor. Die Schlundsonde soll unten offen und mit mehreren seitlichen Lö̈hern rersehen sein. Der Nageninhalt wird nach beliebiger Frist mit der Magenpumpe ansgesangt. Durch wiederholtes Ein- und Auspumpen ron Wasser soll schließlich der gesante Mageninhalt vollständig erhalten werden.

Das Schlundsondenverfahren besitzt seln viele Nachteile. Yan ist nie sicher, besonders nach Terabreichung ron Feststoffen (Fleisch, Brot usw.), den Mageninhalt völlig zu entleeren und erluält meistens nur einen mehr oder minder grolien 'Teil davon, welcher je nach der Lage der' Sondenöffnung im Magen von den verschiedensten Magengegenden stammen kann. La aber die Zusammensetzung des. Nageninhaltes nicht iiberall dieselbe ist ${ }^{1}$ ), so bekommt man mittelst der Schlundsonde nur sehr unsichere Ergebnisse. ${ }^{2}$ ) Bei den Auswaschungen des Magens kann ein Teil des eingegossenen Waschwassers in das Duodenum dringen und dabei eine gewisse Menge rom Mageninhalt mitreißen. Die Auswaschuigen vermehren die Irrtiimer bei der Schätzung der Nenge des Mageninhaltes bedeutend. I)azu kommt noch, daß die Finführumg der Schlundsonde manchmal von unangenehmen oder selbst schmrerzhaften Empfindungen begleitet wird, was den sekretorischen Prozeß vielleicht stört. ${ }^{3}$ ) Bei der Einführung der sonde können Brechbewegungen oder Zusammenziehungen der Bauchwand ausgelöst werden, wodurch möglicherweise die Darmsekrete in den Magen treten. oder die Arbeit der Magendriisen beein-

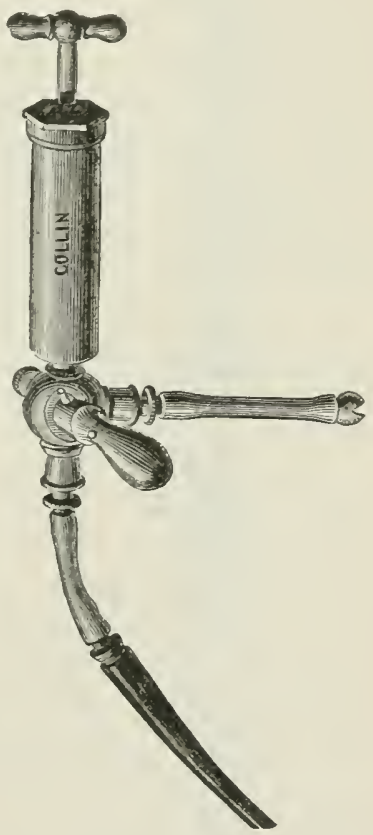

Fig. 31 . träclıtigt wird.

Das Schlundsondenverfahren kann eigentlich nur zu Vergleichsuntersuchungen ïber die Aufenthaltsdauer rerschiedener Nährstoffe im Magen bei ein- und demselben Tiere dienen.

1) Ellenberger, Zum Mechanismus der Magenverdauung. Pfïgers Arch. f. d. ges. Phrsiol. Bd. 114. S. 93-107 (1906). - A. Scheunert, Zum Mechanismus der Magenverdauung. Ebenda. Bd. 114. S. 61-92 (1906). - P. Grïtzner, Ein Beitrag zum Mechanismus der Magenverdauung. Ebenda. Bd. 106. S. 463-522 (1905).

2) F. Penzoldt, Beiträge zur Lehre ron der menschlichen Verdauung unter normalen und abnormen Verhältnissen. Deutsch. Arch. f. klin. Med. Bd. ̄1. S. $335-582$ (1895). Die Magenverdauung des Menschen unter rerchicdenen physiologischen und physikalischen Einflüssen. Erlangen und Leipzig 1901.

$\left.{ }^{3}\right)$ J.P. Paulow; Die Arbeit der Verdauungsdrüsen. Wiesbaden 1908. 
I'm beim Menschen aus dem I'ylorus- und Fundusteil des Magens gesondert Speisebrei zu gewinnen, hat Komad Sichin) folgendes Verfilnen ersonnen, dessen beschreibung hier wörtlich nach dem orginal wiedergegeben wirl.

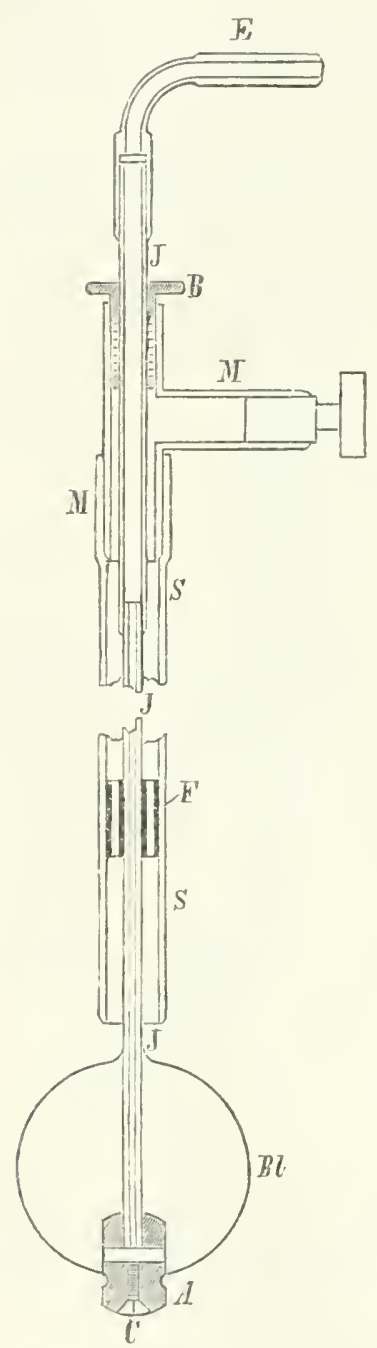

Fig. 32.

Man hedient sich der nebenhei (Fir. : : : abgelildeten Aspirationsmanometersonde. Liese besteht aus :- Tiöhren, von denen die engere in der weiteren liegt. Ine weitere lioihe $s$ bildet cin ca. $100 \mathrm{~cm}$ langer wejeher und möglichst biegsamer Uagenschlauch von a. 1:3 mm lichter Weite mit ainer rumden endständigen öfmung. Nach ohen ist an diesen Schlanch ein Yletallroln $M$ angesetzt. das ein rechtwinklig absehemles, durch ('incin stöpsel luftdicht rerschliefbares Ausflufrohr trïgt. In axialer Izichtung schliefit eine Stopfluiichse $B$ das Metalhrohr ab). dureh die ein oben rechtwinkliw abehogenes diinnwamliges Messingrohr \& rou $4-5 \mathrm{~mm}$ lichter Weite geführt ist. Dieses in der Stopthïichese verschiebhare Iletallrohr setzt sich immerhath des Magenschlauches fort durch einc diinne aber hinlänglich feste Röhre $J$ von :) mm Lichtung. die narle Art der Seidenkatheter" angefertigt ist. Am unteren Ende des Magenschlancles besitzt die imnere Riönle eine Fiihrung 7 . in Gestalt zweier ineinander liegender Zylinder. vou denen der änbere fest in die Imnenwand des Nagenseblandehs eingedassen ist und den

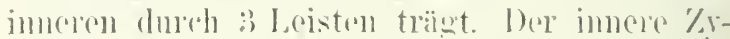
linder ist die eigentlielle Fiihrung fïr die lmomeröhre. Dhese ïherragt de'n Vagenschlauch num

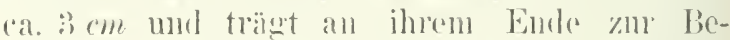
schwermug ainem in dor Gröbe dem äulieren schlauch entsprechenden zylinder I ans silher. durch den molurere Bohrlïcher z.l ihrem L.mmen führm. Nahe ann unteren. abgermuleten Ende des Silberzylinders ist eine seiclite ringförmige limne. In dieser ist eine dimme Jembran befestiet. die, ein silickehen $B L$ von $3-4 \mathrm{~cm}$

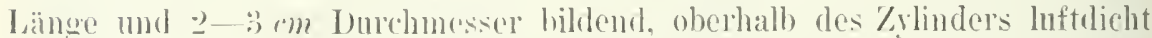
festemebur(m ist. J)ieses Säckehen kommuniziert also mit der lichtung der Innenröhre und bildet den druckempfangenden Ballon. Der Silber-

$\left.{ }^{1}\right)$ h.sick, Intersuchungen über die Saftahscheidung und die Bewegungsworgänge im Fundus- und l'ylorusteil des Mageus. Deutsch. Arelu. f.klin. Ned. Bd. S8. S. 169 bis 223 (1906). 
zylinder ist bis anfen durchbohnt und kann dureh eine schranbe C' huftdicht verschlossen werden. so dafi die Wasserfiillung des Imenrohres auf keine Schwierigkeiten stiblt.

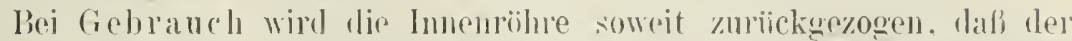
Sillory linder auf der unteren öffnung des Sehlatuches aufsteht und dir (kollabierte) Membran zum gröbten 'Teil im sichlauch verschwindet. Die obere Öffnung des Schlauches ist durch einen stipsel fest rerschlossen. Der l'atient liegt in rechter seitenlagr mit ganz wenig erhöhtem oberkïrper (er stiitzt sich leicht auf den rechten killonbogen). Die Einfiihrung der Aspirationsmanometersonde geschieht in derselben Weise wie die eines gewöhnlichen Magenschlauches. Manchmal scheint es vorteilhaft zu sein. wenn man bein Fintritt des Schlanches in den Magen leichte roticrende Bewegmigen - Drehmug im ganzen um ca. $360^{\circ}$ - vornimmt. Der Schlauch scheint sich dadurch eher in der gewiinschten Weise abzubiegen. sobald nämlich ein grifieres Stïck dessclben die Cardia passiert hat, biegt sich der beschwerte Sondenkopf stark nach abwärts, gleitet der kleinen Limratur entlang mol gibt dadureh dem Schlandhe eine auf den Pylorus hinstrebende Richtmng. Ist das sondenende gentïgend weit in diesem Sinne vorgedrungen, so wird das Imnenrohr rorsichtig durch die stopfbiichse $(1-2 \mathrm{~cm})$ vorwärts geschoben, wodurch der Ballon röllig aus tere Minndung des äuberen Schlauches hervortritt. Daraufhin wirl der Ballon in der oben angegebenen Weise mit Luft bzw: Wasser gefüllt und die Innenröhre mit den Vanometer in Terlindung gesetzt. das den positiven Nagenimnendruck und die Druckschwankungen angibt. Hat die Druckmessung ein entsprechendes liesultat ergeben. so wird die Verbindung mit dem Manometer gelöst, der Stopfen ans dem Ansfubrohr entfernt. und man kann nun Mageninhalt fust genau von derselben Stelle, an der man zuror den I) ruck gemessen hat, aspirieren. Im besten geschieht dies dadurch, daß eine schwach wirkende sangpumpe muter Zwischenschaltung einer Flasche mit doppelt durchbohrtem Stopfen angeschlossen wird. Der Mageninhalt fliebt in die Flasche. Ist es gelungen, aus dem Iryorusteil des Magens Speisebrei zu erhalten, so wird man sofort nach Alschlub dieser Ausheberung demselben Individum in sitzender Stellung einen gewöhnlichen Jagenschlauch einfïhren und auf dieselbe Weise Mageninhalt aspirieren. Bei einiger Llbung gelingt es, so rasch hintereinander die erste und zweite Portion des Magensaftes zu gewinnen, daf die Zeitdifferenz anf ein Minimum (1-2 Ninnten) zurüickgeht. Eine selnr wichtige Vorbedingung zmm Gelingen des Versuchs ist das Fernbleiben von Wiirgen oder von Brechbewegungen, wegen der damit verbundenen sturken Aktion der Bauchpresse und der extremen Inspiration mit Verschlul der Glottis. Alle diese forcierten Bewegmmen miissen natiirlich den Mageninhalt durcheinander riitteln und auf diese Weise eine Untersuchung getrennter Magenabschnitte auf ilnen Chemismus rereiteln.

2. Isolierung des Magens und des Dïnndarmes post mortem. I)as Versuchstier verschlingt die Nahrung oder bekommt sie mittelst der 
Schlmulsoude oder hai Auwendmug des Mundsperrers. Währemb der fïr die Verlanung festgestellten \%eitdane bewegt sich das Versuchstjer frei. I)am will es auf das brett sebracht und dusch Chloroform oder bessey durch Nackenstich mol alejehzeitiges öffnen der Karotiden rasch getoitet. Sofort wird die lianchhöhle geöffnet, ohme dahej die Lage der Eingeweide zn ver-

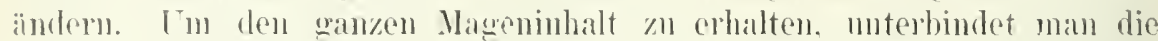

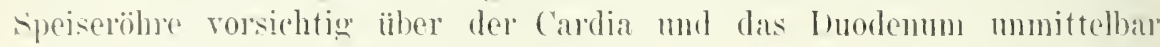
muter dem Pförtner. Man tronnt solann den Magen von der Spejscröhre

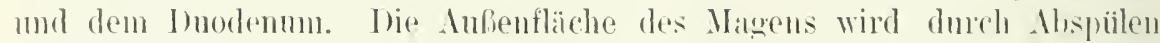
mittelst destilliortem Wassej oder physiologischer Kochsajzlösmen rom anhaftemlen libut befoeit und nachher mittelst Filtrierpapier ahgetrocknet. Dium ïfnet man den Magen. fänot sejnen Inhalt in einer Pormellanschale ant, spuilt die Migenschlembat mehrmals mit destillie:tem Wasser oder physiologischer Kochsalylismmg ah und fügt dio Waschwässer dem Mageninhalte hoj, $\left.{ }^{1}\right)$

Im heim Humde den Inhalt des Magenfmulus mol des leförtuerteiles

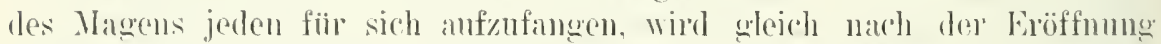

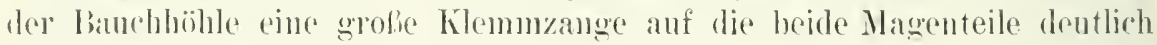
tremende Furche welegt, wäbrend wleichzojtig ein Gehilfe eine andere Klemmzange auf den I'förtner anbringt: damn unterbindet man die speiseröhre iiber der C'ardia. Nach Tremmng des Gresamtmagens von der Speiseröhre mul vom bnodenum und nach griindlichem Nbspiilan der äuberen Magenoberfläche öffnot man zuerst den l'fürtuertail des Magens, fïngt seinen Inhalt in einer Porzellanschale anf mul wïscht diesen Magenteil gubindlich ans. Danach wird der Magenfmulus weoffuet, seju Inhalt in emer anderen l'orellauschale anforemgen und das durch Auswaschen der Schleimhaut des Magenfumdus phaltene Waschwasse dazu gegossen. ${ }^{2}$ )

liejn Schweine kam man den Magen mogefihr in der Nitte ab-

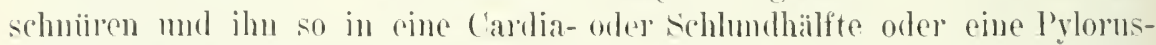
oder Funduspylorushilfte teilen. ${ }^{3}$ ) beim schweine und heim Pferde kann mans anch durch gloichzeitiges Anlegen zweier Luterbindungen den Magen in :) Abschutte tremen: Candia, lundus, Pylorus beim schweine; Pars oesowhagea, Fundusdrisemregion. Pylorusdriisemregion heim Pforde. ${ }^{4}$ )

Der Inhalt des ganzen biinndarmes, des obersten Diimdarmes

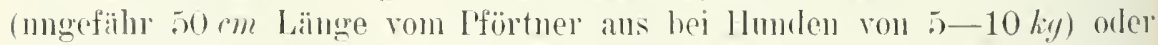
mehrerey Dimmlanmteile wiod anf dieselbe Weise wie der Mageninhalt zwischen L'uterbindumen gefabt. Das Bht wird ron der äuberen Darm-

1) A. schmilt-1/ülheim, Untersuchungen ïher die Verdanung der Eiweißkorper. Arch. f. Anat. u. Physiol., physiol. Altt. S. 39-58 (1879).

2) E. Yunz, Nonvelles recherches sur la digestion de la viande crue et de la viande mite chez le chien. Ném. cour. et autr. mém. publ. par l'Acad. roy. de méd. de Belgrique. T. 19. fasc. pag. T (1907).

3) Ellenberyer und r. Ilofmeister, Die Magenverdaumng der Schweine. Arch. f. wiss. u. prakt. Tierheilk. Bd. 12. S. 126-146 (1886).

4) E. Lütsch, loc, cit. - E. liosenfeld, Cher die Eiweißrerdaung im Magen des Pferiles. Inaug.-Diss. Ieipzig 1908. $55 \mathrm{~S}$. 
oberfläche abgespült und dor Inhalt des gesamten l)iunndarmes oder der verschiedenen Darmteile nebst den dazn grehörigen Waschwässern gesondert zur Intersuchung gebracht. Da wiederholte Auspü̈lungen des gesamten Iüinndarmes orler der isolierten I)armschlinge nicht immer geniigen, um den Inhalt völlig zu erhalten. so muf man nach den Auswaschungen den Larm der Länge nach aufschneiden und die Schleimhaut durch leichtes Abstreichen und Abspülen rom sie bedeckenrlen Belag befreien. ${ }^{1}$,

Die Isolierung des Magen- und des I)ünndarminhaltes post mortem gibt Aufschlïsse iiber den Inhalt dieser Organe oder ilnrer Teile zu verschiedenen \%eitpunkten der Verdaumng somie über die Dauer des Verbleibens der Nährstoffe im Magen, nicht aber über das Endprodukt der Magenrerdaung.

\section{c) Vorherige operative Eingriffe erheischende Versuche.}

Yachfolgend sind die einen vorherigen operativen Eingriff erheischenden Verdaungsversuche je nach dem Zwecke der operation angeordnet.

Falls der eigentliche Verdaumgsversuch gleich nach der Operation oder kurz daranf erfolgt. wie bei der Lnterbindung des Pförtners oder hei Einfïhrung von Flissigkeiten in isolierte Darmschlingen. so soll man dem Tiere kein Iorphin-Atropin subkutan einspritzen wegen dessen Einfluf auf die Vervenzentren und auf die Verdaumngsprozesse. Die Operation wird bei nicht zu starker Narkose mittelst des X̂ther-Alkohol-Chloroformgemisches ausgefïhrt.

Un bei der Laparotomie die schädliche Wirkmng der Abkïhlung des Magendarnkanales möglichst zur vermeiden, soll man sich eines heizbaren Operationstisches bedienen. Als solchen kam man den durch Elektrizitait erwärmten Carvalloschen Operationstisch anwenden oder bloß einen grofen, ïber einer Heizschlange befindlichen Krasten aus Weißblech, der das auf dem Brette fixierte narkotisierte Versuchstier aufnimmt und dessen aus rerschiebbaren Blechplatten bestehender Deckel eine berqueme Regulierung (ler Imnentemperatur auf $: 3-40^{\circ} \mathrm{C}$ ermöglicht. ${ }^{2}$ ) Dieses Verfahren ist dem manchnal empfohlenen Operieren in einem mit auf $: 3 \bar{\tau}-40^{\circ} \mathrm{C}$ erwïrmter physiologischer liochsalzlösung gefïllten Thermostaten vorzuziehen, denn bei letzterer Versuchsanordnung ist es keineswegs ausgeschlossen, daf die in die Banchhöhle eindringende Kochsalzlösung auf die Yerdauungsprozesse einen Einfluß ausïbt.

1) Ellenberger und I. Hofineister, Die Darmverdanung und die Resorption im Darmkanal der Schweine. Arch. f. wiss. 11. prakt. Tierheilk. Bd. 14. S.137-171 (18S8). - Dieselben, Uher die Terdamng des Schreines. Arch. f. Physiol. u. Anat, physiol. Abt. S. 137-153 (1889). - Dieselben, Die Verdaunng ron Fleisch bei Schweinen. Ehenda. S. 280-298 (1890). - E. Zunz, Über die Verdaunng und Resorption der Eireißkörper in Magen und im Anfangsteil des Dünndarmes. Beitr. z. chem. Physiol. u. Pathol. Bd. 3. S. 339-364 (1902).

$\left.{ }^{2}\right)$ O. . Fürth und J. Schütz, Ein Beitrag zur Methodik der Versuche üher Fettresorption aus isolierten Darmschlingen. Beitr. z. chem. Physiol. u. Path. Bd. 10. S. 461 bis S. 4 i2 (1907). 
Mul, man wäluend der Operation einen 'Teil des Magrens oder des Darmes anlier der Banchhöhle freilegren. so breitet man ihn auf mit warmer phrsiologischer Kochsalzlösung getränkten hompressen ans, welche niitigenfalls mit dieser Iösung berieselt werden. Dabei soll möglichst vermieslen werden. dafi Kochsalzbisung in die Banchhöhle dringt, weil daluroll vielleicht oin Einflub anf die Verdanungsprozesse hedingt sein kiillnte.

Bleibt das 'Tier nach der I.aparotomie anf dem lirett, so mulb dies stets in einem sehr stark geheizten Raume, dessen Temperatur mindestens 25-300 C heträgt. geschehen. Anberdem soll man die Bauchwunde mittelst Watte hederkt halten und den Banch mittelst öfters ernenerter warmer Decken gegen Frkältmo sehütyen, da diese sonst die Verdammgsprozesse stirell kann.

1. Verfahren, welehe das Entweichen ron Verdanungsprodukten rom Magen nach dem Darm verhinderm. Man kam das Entweichen ron Verdaumesprodukten rom Magen nach dem I arm durch Unterbindung des Iförtncrs, durch Verschließung des l'förtners von Magen her oder durch Verschliefung des Pförtners rom Dnodenum har verhindern.

\%) Lnterbindung des l’fürtners. Beim nïchternen. leicht narkotisierten 'liere wird die Banchwand in der Linea alba oder etwas rechts daron geöffnet, ein Faden um den l'förtner gelegrt und unterbunden. Man rersehlieft die Banchwand sorofältig durch Nähte. Nach einiger Zeit läbt man das Tier dic Nährstoffe verschlingen oder verabreicht sie ihm mit der schlundsomle. Nach der fiir den Versuch festgestellten \%eit wird das Tier getritet, die Banchwand geöfnet, die speiseröhre iiber der Cardia unterbunden und del Magenimhalt mit den schon beschriebenen Kautelen anfugefangen. ${ }^{1}$ )

Jieses Verfahren ist keineswegs einwanlfrei. Narkose und Laparotomic hewirken wahrscheinlich eine Terminderung der Magentätigkeit. Selhst wemn die zwischen der Laparotonic md der Verabreichung der Nahrung verflossene Zeit geniigend ist. damit diese schädlichen Einfliisse nicht mehr bestehen, so kamn noch die Interhindung des I'förtners die normale Innervation und Bhtrelsorgung des Magens stören. Es bestoht aulierlem die Gefahr des Erbrechens und der Beimengmug von resschlucktem speichel, wodurch Versure ibluer die Magentesorption störend beeinflubt werden kïnnen. Die Einfiihsung vom Speichel in den Magen bewirkt natiirlich beim Hunde eine Zmmahme der Magensaftmenge, der Aziditït mol des Verdanmossermïgens des saftes. ${ }^{2}$ )

1) M. Tappriner, ther Resorption im Magen. Zeitschr. f. Biol. Bal.16. s.497-507 (1880). - II. Mecule-smith, Die Resorption des Zuckers mul des Eiweißes im Magen. Areb. f. Anat. u. Physiol., physiol. Alut. S. $481-496$ (1854).

2) Ahert Fromin, Aetion de la salice sur la sécrétion et la digestion gastrique. compt. rend. hebul, des séane de la Soce de Biol. 'T. 62. p. 80-81 (1907). 
(5) Verschliebung des I'fürtners rom llagen her. Man legt beim Versuchstier (meistens Hund) in unmittelbarer Nähe des I'fürtner's eine Magenfistel an. in die eine durch einen liork verschliefbare Kaniile eingefuilnt wird. Beim von dieser Operation völligr geheilten Hunde, d. h. einige Wochen nach der (Iperation, wird im nïichternen Zustande durch die Magenfistel ein Gummiballon in das Duodenum gebracht und grleich unterhalb des Prylorus aufgehlasen, wodurch man den Vlagen rom l)uodenum leicht und rollständig alsschlielien kann. ${ }^{1}$ )

Die richtige Iusführung des IIagendarmabschlusses mittelst der Kautsclunkblase wird auf folgende Weise erzielt. ${ }^{2}$ ) Tach Entfernung der Kintuile aus der Nagenfistel geht man mit dem Zeigefinger durch die Fistel in den P'ylorus hinein. die IIuskulatur des P'ylorus zieht sich um den vordringenden Finger zusammen. und man fühlt eine deutliche ringförmige Lmschniurmug. Hat nan sich so über die Lage des Pförtners orientiert, so bringt man den :3-tmal gefalteten Kautschukbeutel auf die Kuppe des Zeigrefingers und driickt ihn an den Eingang des Pylorus. Infolge der eiutretenden Kontraktion wird die Blase erfabt und durch leichtes Nachschieben. mn ein Zuriickweichen zu vermeiden. gelangt der Ballon in clas Duodeuun.

Der Kautschukballon ist mit einem kurzen stiele versehen, in dem cin iiber ein eingekerbtes kurzes Glasröhrchen gestiilpter Gummischlauch eingeschohen und iiber dem stiele festgebunden wird: iiber diese Stelle wird ein ca. $30 \mathrm{~cm}$ langer, weiterer Bindfaden befestigt. Nach der Einfiihrung wird die vorher nebst dem Schlauchstiicke luftleer gemachte Blase gefiullt. indem in die Öffnung des Gummischlauches ca. $25-30 \mathrm{~cm}^{3}$ Wasser gespritzt werden. Man schließt dam den Schlauch durch eine Kilemme und sucht den Ballon an dem Schlauche durch den Pförtner hervorzuziehen. Zeigt sich der Widerstand, den der gefïllte Ballon dem Herausziehen entgegensetzt, geniigend grob. so bringt man am Kautschukschlauch nahe ann Stiele des Ballons eine Ligatur an und schneidet das jetzt bedeutungslose Schlauchstiick ab. den Ballon an dem zur Befestigung angebrachten Bindfaden festhaltend. Nachdem man sich vom richtigen Sitze des Ballons üherzengt hat. wird die Kanïle wieder in die Fistel eingefuihrt und ein durchbohrter Kautschukpfropfen in die Kanïle fest eingesetzt. In die Bohrung ist eine mit Kautschukschlanch und Klemme versehene Glasröhre eingepaljt. Dieser Stopfen befestigt zwar sofort die Fäden, die bis zu diesem Augenblicke stets gespannt gehalten werden miissen. um aber ein spïteres Hinabgleiten des Ballons in das Dnodenum zu verhiiten, hefestigt man die heraushängenden Fäden noch besonder's an der Kaniile. Nun ist der Iragen nach dem Harme hin durch die gefiillte Kautschukblase vollständig abge-

1) H. Tappeiner, loc. cit. - B.r. Anrep, Die Aufsaugung im Magen des Hundes. Areh. f. Anat. u. Phy̧siol., phrsiol. Abt. S. 50t-514 (1S81).

2) Irar . vegall, Versuche über die Resorption des Zuckers. Inaug.-Dissert. München 1888. - J. Brandl, Über Resorption und Seliretion im Magen und deren Beeinflussung dureh Arzneimittel. Zeitschr. f. Biol. X. F. Bd.11. S. 27i-307 (1892). 
schlossen. Der Krautschukstopfen sitzt dicht in der Kaniile, so daß zwischen Fistelrand und Kaniile kein Tropfen des Iageninhaltes ausgepreft werden kann. Bei der Befestigung des Ballons muf man ein zu starkes Anziehen des lieutelstieles vermeiden, dem sonst wird ein Teil der Darminnenfläche iiber den Ballon gestiilpt, was die Lntersuchnngen iiber Magenverdaunng stören kann. Der Kautschukballon soll nach Oguta nicht allzu stark mit Wasser ansgerdehnt werden, demn sonst wird der bisweilen beobachtete Fintritt der Brechbewrgungen begiustigt.')

Sach $v$. Anrep soll der in den Magen eingefiihrte Gummischlanch während 10-15 Minuten eine starle Magensaftsehretion herrorrufen, was jedoch bestritten wird. ${ }^{2}$ ) Da diese Frage noch nicht als endgiiltig festgestellt anzusehen ist ${ }^{3}$ ), so soll man ${ }^{1}{ }_{4}{ }^{1}{ }_{2}$ stmule nach erfolgtem Magendarmabschluf warten, ehe durch die len Kantschukpfropfen durchbohrende Gasröhre die zu untersuchende Lösung oder Anfsehwemmung in den llagen eingespritzt wird. Damn rerschlieft man mittelst einer Klemme den an der Glasrïhre befindlichen kautschukschlauch.

Während der ganzen Daner des Versuches bleibt das Tier auf einem brette befestigt. Damit as sich dabei ohme Narkose vollkommen ruhig rerhält, sowie um das durch die Inwesenheit eines Frendkiorpers (Kantschukblase) hervorgerufene, manchmal eintretende Erbrechen zu vermeiden, stellt Brondl das Irett schrïg, so dab das 'Tier gleichsam in hängender stellumg sich befindet. Hle Stiitzpunkte, die es in dieser lage nötig hat, miissen sorgfältig gepolstert scin, damit schmerzempfindungen durch bruck oder Zhig ansgeschlosien sind.

Tach Verlauf der Versuchstauer wird der Mageninhalt entleert. Dies gelingt aber nie völlig, da die Lage der Fistel in der Nähe des Pförtners den Abfluf erschwert und da die zahlreichen Falten der Magenschleimhant stets Flissigkeit zuriickhalten, welche man indes trilweise noch durch Ausspülungen des IIagens mit destilliertem Wasser erhalten kamn.

Sachdem man den Mageninhalt so volstïndig wie möglich entnommen hat, wird der Stiel der Kautschukblase durchschnitten. wodurch ihr Inhalt sich entleert. Damn wird der leer gewordene Pallon durch den Pförtner und die Fistel horansgezogen, nm ihn aus dem Magen zn entfernen.

U'm, ohne die Jenge des Gesamtmageninhaltes genan zon kemnen, die Gröhe der Kesorption in dem Magen zu schätzen. bedient sich r. Tappeiner des folgenden Verfahrens: Am knde des Versuches wird eine bestimmte Menge einer ihrem schwefelsïuregehalte nach bekannten Natriumsulfatlösung in den Magen gespritzt, der Hund mit dem Brette hochegehohen und dreimal kurze Zeit tiichtig geschiittelt, um eine gleichmälige Mischung

1) M. Oyata. Uher die Verlanung nach der Ansschaltnug des Nagens. Areh.f. Anat. 11. Physiol. Physiol. Aht. S. 89-116 (1883).

2) J. I'. F'arlou', Dir Arbeit der Verlauungsdrüsen. S. 110. - I'. Leconte, Fonctions gastrointestimales. La Cellule. T. 18. p. $283-322$ (1900).

${ }^{3}$ ) A.schiff, Zur Frage der mechanischen Erregbarkeit der Magensaftsckretion Zeitschr. f. klin. Nled. Bd. 61. S. 220-230 (1907). 
der Natriumsulfatlösung mit dem Mageninhalte zu erziclen. Nach jedem Schiitteh wird eine Probe des Mageninhaltes aus der Fistel abgrelassen. unrl diese Probefliissigkeit dann auf ihren Gehalt an Schwefelsäure und an der Versuchssulstanz untersucht. Der annähernd gleiche Schwefelsäuregehalt der drei Proben gibt eine Kontrolle fiir die durch das Schiitteln er\%ielte gleichmälige Mischung des Natriumsulfates mit dem Mageninhalte. Aus dem Gehalt der Proben an Schwefelsäure (S) und Versuchssubstanz (V) und aus der an Ende des Versuches als Natriumsulfat in den Nagen eingefiihrten Schwefelsäuremenge (S') läßt sich die Gesamtmenge der im Magen vorhandenen Substanzen berechnen. Nimmt man nämlich an, daß wïhrend der kurzen Zeit des Schiittelns keine in Betracht kommenden Mengen von Natriumsulfat resorbiert werden. so entsprechen in den Proben und also anch im Gesamtmageninhalte am Ende des Versuches die gefundenen $\mathrm{H}_{2} \mathrm{SO}_{4}$ Mengen $\mathrm{S} \%$ den Versuchssubstanzmengen $\mathrm{V} \%$ und die nicht resorbierte Menge der Versuchssubstanz ergibt sich aus der Gleichung: $\mathrm{S}_{0} \%: \mathrm{Y}^{\circ} \%=\mathrm{S}^{\circ} \mathrm{x}$.

Die Verschließung des Pförtners bei einem Magenfistelhunde durch Einführung einer mit Wasser gefüllten Kautschukblase in das Duodenum besitzt mehrere Nachteile. Vielleicht kann sie eine Reizung der Magenschleimhaut bewirken. Die Verletzung der Magenwand durch die Magenfistel übt eine mehr oder minder beträchtliche Einwirkung auf die Magenbewegungen und dadurch vielleicht auf die im Magen vor sich gehenden Verdauungsprozesse aus. Andererseits können mehrere Versuche an dem gleichen Tiere in mehrtägigen Zwischenräumen angestellt werden.

v) Verschließung des Pförtners vom Duodenum her. Unter vorsichtiger schwacher Narkose wirl beim Versuchstiere die Bauchwand durch einen 1 oder $2 \mathrm{~cm}$ rechts von der Linea alba gefuihrten, $15-20 \mathrm{~cm}$ langen, 1-2 cm unter dem Rippenbogen beginnenden Einschnitt geöffnet. Man unterbindet die Speiseröhre unmittelbar über der Cardia, ohne die großen Gefäße der Nagenoberfläche zu verletzen, bringt 2 Fäden unter das Duodenum und öffnet es mittelst des Thermokanters. Dieser Einschnitt muf lang genug sein, um die Einführung eines in der Mitte durchbohrten Gummistopfens zuzulassen. In der Bohrung steckt eine $25-30 \mathrm{~cm}$ lange Gummisonde, welche den Stopfen ungefähr $5 \mathrm{~cm}$ lang iiberragt. so daß ihr inneres Ende sich im Magen befindet, wenn der Stopfen am Pförtner sitzt. Der andere Teil der Sonde mißt wenigstens $15 \mathrm{~cm}$ und ist $5 \mathrm{~cm}$ vor seinem äuheren Fnde mit einer Schraubenklemme versehen. Durch den Einschnitt der Duodenalwand und den Pförtner führt man die Sonde in den Magen und bringt dann den Stopfen his an den Pförtner; wo er mit Hilfe der unter das Duodenum gelegten Bindfäden befestigt wird. Tach der nur kurze Zeit in Anspruch nehmenden Operation'. bei welcher weder in Magen noch Darm Blut gelangt, rerschließt man die Bauchhöhe, indem man die sonde durch eine kleine Öffnung nach anfen leitet.

1 -2 Stunden nach der Operation. wemn das Tier nicht mehr unter dem Einflusse der Narkose steht, versieht man die Sonde mit einem Trichter und gießt in dieselbe die in den Magen einzufuilnrende Lösung oder Auf- 
schwommung, welche she leicht in den Magen läuft. Die Kilemme wird l'asch deralt aeschlossen, daß die sonde gefiillt heibt. Dies erlaubt, nach hestimmten \%eitabschniten einen Teil des Magenimbltes aufunfangen. Is gentigt, die Kilemme loszuschrauben: nu ist es nötig, zuerst mugefihn $20 \mathrm{~cm}^{3}$ Flibsigheit abfliefen zu lassen, was die in ler sonde verbliebene Mene ibertrifft. Anf diese Weise ist man sicher, dab die aufgrofangene Flïssigkeit wirklich ans dem Magen herrihrt. Im Ende des lersuches wilul das Tier getiotot. Der noch im Magen vollandene Inhalt wird mit lev nötigen Vorsicht anfurefangen, wobei man sich zugleich iiherzeugt, dals hei der Uperation der Magen umerletzt gehlicben ist. $\left.{ }^{1}\right)$

Die wen beschriehene Versuchsanorohumg orlanbt, wiederholt Anteilo vom Mageninhalte zu gewinnen. (1) diese wirklich der mittleren Zusammensetzmug des Mageninhaltes in den rerschierlenen untersuchten \%eitpunkten entsprechen, ist aber, nach den Beohachtungen von Ellenberyer und seinen Mitarbeitern sowie von Grïtzner, keineswegs völig sicher. Andere mehr oder minler herechtigte Einwände kïnnen noch erhoben werlen. Die Unterbindmog der speiseröhre und des l'förtuers stört vielleicht etwas die normale lmorvation mol Bhutversorwme des Magens. Die Einfuihrung diner sonde in den Jagen führt möglicherweise zn einer stäkeren Ilagensaftabsonderumg, was indes bestritten wirl. Die Nirkose mul die Latparotoule können, trotz allen Vorsichtsmabregeh, lie Magentitigkeit vielleicht sekmulär beeinflussen.

2. Verfahren zur Gewinumgg der kindprodukte der Maganverdaumne. Im beim llunde die Endprodukte der Magenverdamung zu gewinnen. werden in möglichster Xähe des l'förtuels zwei seitenständigne, einige \%entimeter roneinander cutfernte Inodenalfisteh nach PaulouDrastre2) angelegt und mit Duodenalkiniilen versehen. Die dem Magen an mïhsten liegende Fistel dient zum Auffanwen von Magen- odes Inodenalinhalt, die andere zmm Finspritzen von Salzsäure oder anderen stoffen ins mutere Inorlenum. '/ur genamen Erforschmng der Magentitigkeit miissen die Fisteln so gelegen sein, daf der ('holedochnsang nud der obere Ansfühnungsgang der Banchspeicheddrise unter der vom Magen am nächsten gelegenen Fistel minden, was indes ziemlich solwwer zn er\%ielen ist.

Mehrere Wochen nach der ()peration wird in einem Vorversuche das

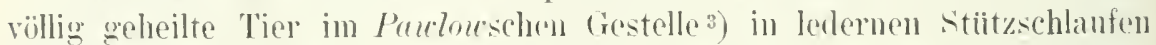
anfegestchlt. Man fiittelt es mit derselben Salıum wio beim aigentlichen Versuche. Die vom Magen entleerten Massen werlen in einem in eine Kältemischmmg gebetteten Gefäß aufgefangen mol mit dem (ilasstab um-

1) E. Znnz, l'ber die Verdauung und Resorption der Eiweißkörper im Magen und im Anfangsteil des Inündaums. Beitr. Z. chem. I'hysiol. u. l'ath. Bı. 3. S. 339-364 (1902).

$\left.{ }^{2}\right)$.J. I'. Parlon, Die phrsiologische Chirurgie des Verdaumeskanals. Ergebn. d. Phrsiol. Jg. 1. Aht. 1. S. 277 (1902), - O. Cohnheim, Zur 'Teehnik der Duodenalfistelı. Zeitschr. f. biolng. 'Technik und Methodik. Bil. 1. S. 268-276 (1909).

3) W. I. Boldirefr. Le travail périndique de l'appareil digestif en dehors de la digestion. Areh. des se. hiolog. de St. I'étersbourg. T. 11. p. 27 (1905). 
groriint. Sie gefrieren rom Rande her rasch zn einem Eiskhmpen, der in gofroreuem Zustande bis zum weiteren (iebrauche aufgehoben wirl. Sobald dir Eutlecrung anfhört, werden $50 \mathrm{~cm}^{3} \mathrm{Wassel}$ machgerelen und ramit der Ilagen tiichtig durchgeschiitteIt. Zum schlusse wirl noch eine Magenspiilung mit Hilfe der Schlundsonde ansugefïhrt. l)as so wewomene, in Kälemischumgefroren aufbewahrte Verdauungsporlukt wird zu dem eigentlichers, -) Tage später erfolgenden Versuche benutzt. Dafür wird es aufgetaut, zur Befreiung von wröberen Stiicken durch weitmaschige (iaze filtriert mud auf Kö̈pertemperatu erwärnt. Man kann auch die im Torsersuche rom Magen entleerten Massen ron 5 zu j̃ Minuten sammoln mud ummittelbar fuir kure \%eit in kochendes Wasser bringen, um das Ferment abzutöten. Ilan heht dieses Terdaumgsprodukt auf Fis auf.

Beim eigentlichen Versuche rerschlingt der am Gestelle sich befindende Hund dieselbe Nahrung wie bein Vorversuche. Sobald samer Mageninhalt in die Duodenalfistel eintritt, wird ein nach dem Prinzip der Tamponkaniile mit einem Ballon aus Kondongummi armierter Nelatonkatheter in den abfïhrenden Duodenalschenkel eingeführt und daselbst nicht zn weit vou der Kaüile entfernt aufgebläht.

Die Aufb]ähung des Ballons mul, mit grolier Sorgfalt und Vorsicht geschehen. Schon die blolie Beriihrung der Dnodenalschleimlant durch den eingefiihrten Ballon unterbricht während einigen Jinuten die. Magenentleerung. Bläht man den Ballon zu stark auf, so kam sogar die Magenentleerung eine ginze halbe stunde aufhören und ïberhaupt nicht mehr regelmäßjg in Crang kommen. Es geniigt zum rollständigen Darmabschlusse eine rerhältnismälig geringe Ballonfüllung. Zur Fiillung des Ballons darf nicht Wasser relwendet werden, sonst wird der anf diese Art ein ganz erhebliches Gewicht erreichende Ballon als lästiger Fremdkörper empfunden; der Hund wird oft muruhig, die Magenentleerung wird ganz unregelmäbig oder hört anf. Mit dem spiegel sieht man im frunde der Kanüle peristaltische Darmbewegungen - offenbar zur Weiterschaffung des Ballons.

Hat man den Ballon unter diesen Kantelen eingeführt und sich nach wenigen Minuten rom geregelten Fortgang der Magenentleerung üherzengt, so schreitet man nun dazn. das aufgetaute, auf Körpertemperatur erwärmte Verdauungsprodukt des Vorrersuches portionsweise nach Maßgabe des austretenden Mageninhaltes durch den Katheter hinter dem Lallon in den Darm zu spritzen. Es empfiehlt sich, die Masse durch Methylenblau zu fürben und sich häufig zu vergewissern, daß kein Rückfluß in die Kianüle stattfindet.

Um den phrsiologischen Vorgang in rollständig exakter Weise nachzudhmen, miißte man nach jedem einzelnels entleerten schul eine gleichgrobe Verdaumosproduktmenge in das Duodenum eintreten lassen. Da dies aher nur schwierig erreicht wird, so begnügt man sich damit, nach bestimmten Zeiten (5 his 15 Jinuten) oder nach einer abgezählten Anzahl einzcher schiisse (15) bis 20 ) eine annähernd entsprechende Menge des 
Verdauungsproduktes einzuspritzen. Luf eine solche Einspritzung tritt regelmïlig rasch der reflektorische Pförtnerschlub ein. welcher je nach der Verdaumgsperiode :3 bis 10 Minuten anlä̈lt.

Das rom Magen schußweise Entleerte wird, wie in Vorversuche, in einem in Kältemischung sich befindenden Ciefüß aufgefangen.

Die von Tobler vorgeschlagene portionenweise Einspritzung des beim -2 Tage vorher angestellten Vorversuche erhaltenen Verdanungsproduktes in den abfïhrenden Duodenalschenkel nach MalBgabe der rom Iagen entleerten Mengen soll das Zustandekommen des rom Dnodenum ans durch sauren oder fetthaltigen Chymus ausgelösten Chemoreflexes. der das periodische Öffnen und Schließen des l'förtners beim normalen Tiere regelt. ermöglichen und anf diese Weise die sonst beim Bestehen der Duodenalfistel rascher wie normalerweise vor sich gehende Vagenentleerung verhüten. ${ }^{1}$ ) Trotz diesen scharfsinnigen. von Tobler vorgeschlagenen Vorsichtsmabregeln erfolgt indes stets hej den Duodenalfistelhunden die Hagenentleermo rascher als bei den Normaltieren.

Die Toblersche Versuchsanordnung beriicksichtigt indes einen anderen, wahrscheinlich keineswegs unwesentlichen Umstand. Die während der Magenverdauung of erstaunlich groben abgesonderten Magensaftmengen bewirken nämlich eine beträchtliche Terausgabuug des Organismus an Fliissigkeit und Mineralstoffen, insbesondere an Salzsänre ${ }^{2}$ ), so dal, es als sehr wahrscheinlich erscheint. daß während einer Verdanungsperiode die in den Darm ergossene salzsiure rasch zuriickresorbiert wird und so dem Blute die Beständigkeit seiner Zusammensetzmng gesichert bleibt. Die etwaige Beeinträchtigmng der Magensaftabsonderung im Magen bei den Fisteitieren durch größere Nagensaftrerluste nach außen wird durch die Einspritzung von der Menge nach den bach anfen fliefenden Breimengen ungefïhr entsprechenden Chymusmengen in den Darm möglichst vermieden.

Bis jetzt ist die Toblersche Versuchsanordnung das beste Verfahren. um das Endprodukt der Iagenverdaumg zil gewimnen. Indrerseits gibt sie aber keineswegs völlig richtige Aufschliisse ïber die Zeitdaner des

1) Z. Oppenheimer, Uber die motorischen Verrichtungen des Magens. Deutsch. med. Wochensehr. Bd. 15. S. 125-128 (1889). - A. Hirseh, Beitrïge zur motorischen Funktion des Margens heim Inunde. Zentrall)l. f. klin. Ned. Bd. 13. S. 993-995 (1892). - Derselbe, Weitere Beitrïge zur motorischen Funktion des Magens, nach Versuchen an Hlunden mit I armfisteln. Ihisl. Bd. 14. S. $73-77$ (1893). - J. ron Mering, Ǔber die Funktion des Magens. Therapeut. Monatsh. Bd. 7. S. $201-204$ (1893). - Horitz, Nudien n̈ber die motorische Tätigkeit les Mlagens. Zeitschr. f. Biol. Bd. 32. S. 313-369 (1895): Bd. 42. S. 565-611 (1901). - ). Marlacir, Le passage pylorinue. Ia Cellule. T. 14 p. 2.5-53 (1898), - A. Serdjukow, Inang.-Dissert, St. l'etershurg 1899. - s.J. Linturarew, Inaug.-Dissert. St. letershurg 1901. - A. J. Schomiahine, Physiologie de la région pyloripue de lestomae du chien. Arch. des sc. hiolog. de st. P'étersbourg. T. 10. p. $87-170(1904)$.

2) M. I'fundler, C"ber eine neue Methode zur klinischen Funktionsprüfung des Magrens und ileren physiologische Ergebnisse. Deutsch. Arch. f. klin. Mediz. Bi. 6j. S. $254-284(1900)$. 
Verweilens der verschiedenen Nährstoffe im Magen. weil die Magenentleerung sich nicht wie beim normalen Tiere rollzieht. ${ }^{1}$ )

3. Verfahren zur direkten Einführung von Nährstoffen in das Duodenum. Im Nährstoffe unmittelbar in das Doorlenum mit Umgehung des Magens einzufiihren, wird dem Versuchstiere (meistens Hund oder Katze) in nächster Yähe des I'förtners eine mit einer Kaniile versehene Magenfistel angelegt. Erst wenn das Tier von dieser Operation völlig geheilt ist, kann man die eigentlichen Versuche anstellen.

Um jeden Verlust der in den I)arm eingeführten Stoffe zu vermeiden. wird der Pförtner mittelst des durch die Fig. :3:) schematisch reranschaulichten durchbohrten Cummiballons $A$ verschlossen. In die eine der beiden Öffnungen $B$ wird ein kurzer Ring cingebunden, dessen Lichtung mit einem doppelt durchbohrten Stopfen verschlossen wird. Durch den Pfropf laufen zwei Gummikatheter, der engere $C$ derselben endet im Hohlraume der Kautschukblase, der andere $I$ ) dagegen, welcher weiter und länger ist, durchsetzt auch die Öfnning am anderen Ende des Beutels $E$ und ragt mit seinem freien Ende $\overline{5}-6 \mathrm{~cm}$ iiber denselben hinaus. An dem Orte, wo er den Ballon verläßt, wird der Katheter $D$ in die Wand des Bentels dicht eingebunden.

Die Kautschukblase wird leer durch den Pförtner geschoben, dann durch die in ihre Höhlung mïndende Röhre $C$ so weit mit Wasser gefiullt bis sie sich an die Wand des Duodenums fest anlegt, wonach der liatheter $C$ mittelst der Klemme $F$ rerschlossen wird. Dann wird die, nötigenfalls in einem fliissigen Breie mit Wasser verriebene. in einem vorgelegten Kiolben befindliche Speisenmasse unter Quecksilberdruck durch den Katheter $D$ in den Darm eirgebracht, der in dieser Röhre verbleibende Speiserest durch etwas Wasser nąchgespiilt und hierauf endlich die freie Irïndung des Katheter's $D$ mittelst der Kilemme $G$

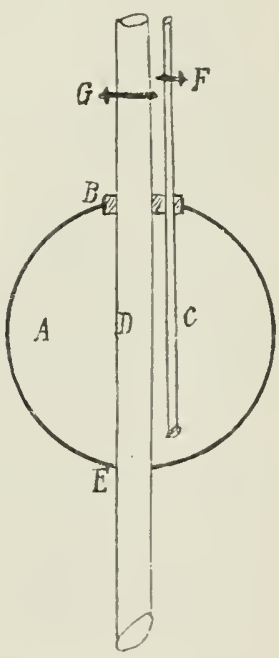

Fig. 33. geschlossell. $\left.{ }^{2}\right)$

Man kamn den während der Verdaumng sich bildenden Iagensaft in einem vor der Fistelöfnumg hängenden Bentel aufnehmen und diesen so oft entleeren. als el sich mit Magensaft füllt.

1) L. Tobler, Uber die Eiweißverdaung im Magen. Zeitschr. f. physiol. Chem. Bd. 45. S. 185-215 (1905). - G. Lang, C̈ber Eiweißrerdaumg und Eiweißresorption im Magen des Humles. Biochem. Zeitschr. Bd. 2. S. 225-242 (1907). - Otto Cohnheim, Zur Spaltung des Nahrungseiweißes im Darm. 2. Mitteil. Zeitschr. f. physiol. Chem. Bd. 51. S. 415-424 (1907). - Derselbe, Beobachtungen über Magenrerdaunng. Münchener med. Wochenschr. Bd. 5̇. S. 2581-2583 (1907).

2) M. Ogata, Über die Verdaung nach der Ausschaltung des Magens. Areh.f. Anat. 1. Phỳsiol., phụsiol. Altt. S. 89-116 (1883). 
Nach del festrestellten Versuchszeit wird das Tier getötet und die Bauchhöhle geöfnet. I) : muterbundene Ibimndarm wird herasgenommen. Seine änßere oberfläche

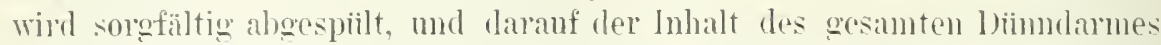
oder jeder der gebildeten Darmschlingen gosondert aufgefangen.

Dieses Verfahren erlaubt. die Inumverlaumg ohne jeden operativen Eingriff in den Darm sollost mud olue jede Nalkose zn studieren. Dio Einfiihrung des Gmmmilallons hleibt aber vielleicht nicht ohne Einfluf auf dic T)armyololaume.

Tom sich möglichst den Bedingungen. unter welchen normalerwejse der Fintritt der Fliissigkeiten rom Magen in den Darm ror sich geht. \%u nïhern und un nicht in einel vorherigen Operation eine Magenfistel anlegen zu mïssen, bedient sich $I$. Nolf folgenden Verfahrens: Mittelst des listomis wird ein schnitt in die Hant in ler Linea alba in der Höhe des Magens gemacht. Mittelst des Thermokinters wirl dam die Bauchwand geöffuet. Ilas Xet\% wird mittelst des \%eigefingers durchlohnt. und nun zieht man den präprlorischen Magenteil in die Wunde. In diesen herum wird ein starker Faden golegrt, welcher ihn später umschniren mul: die Koronar- und die gastroepiploüschen Artrien müssen sich anberhalb dieser Ligatur hefinden. Dureh einige Nïhte befestigt man die vordere Magenwand an die Wunde. so dab der anf diese Weise frei-

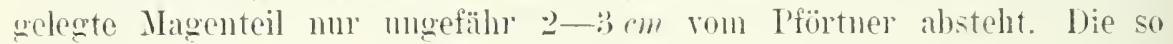
freigelegte Jagenwand wird mittelst des Thermokanter's der Länge nach durchbohrt. Durch diese Bohrumg führt man bis in die Nähe des Iförtners das dicke Ende einer mmgebogenen Crlaskaniile ain. so dab diese im Magen bleibt. Mit dem hintel Jem an die Banchwand befestigten Magenteile liegenden Faden wird num die Einschnürung der Kaniile umbunden. olne dabej die Magenwand zu stark zusammenzndrieken, so dal das dicke Ende der Kaniile fast vor dem Eingange des l'förtnel's befestigt ist. Das freie änbere Ende der Kantile wird mittelst einer Kantschnlä̈hre mit den die in den Inan emzuspritzende Lösung enthaltenden Trichter verbunden.

Die so eingefuihte Flissigkeit mnh also durch den Pförtner flieben. mm in den Darm zu gelangen. Die Raschheit des Eintrittes in das I) uodenum wird durch die Höhe, auf welehe man den Trichter iiber den I'förtner anbringt. beeinflubt. saure Flissigkeiten treten stets sohwieriger in das Duodenum als alkalische. \%ur Ereichmo gleicher Einfuligeschwindigkeit hedarf es einos zwei- bis dreimal groileren hrolostatischen Druckes bei samren als bej alkalischen Fliissigkeiten.

Man kam mittolst dieses Verfahrens wïhrend längerer \%eit einen mit ziemlich gleichbeibender Raschheit vor sich gehenden Fliissigheits-

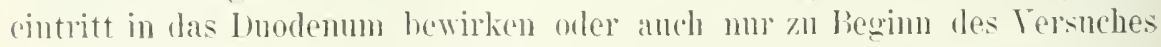
ein bestimmtes (puantum Flüssigkeit in den Dam eintreten lassen.

Fach der in roraus fiir den Versuch festgestellten Zeitdauer wirel das Tier rasch getötet, die Bauchhöhle geöffnet mud der Inhalt des 
(iesantelinudarmes oder mehrerer durch Vuterbindungen isolierter Darmteile mit den nötigen Kantelen jeder füir sich anfocofangen. ${ }^{1}$ )

Bei dieser Methode bleibt der Darm unverletzt und die Darmverdaumng erleidet nicht, wie beim Ogataschen Verfahren, von der Einführunog des fummiballons herrihlende etwaige störungen. Die in der Sähe des l'förtners anf der Magenwand liegende Interbindume und die zum Einführen der Kianïle in den Magen nötige Tarkose und Lafrarotomie bleihen indes möglicherweise nicht ohne Einflub auf die Darmverdaumug.

t. Verfahrenzum Studium der l)armverdaumg an isolierten I) armschlingen.

x) Ohne vorherige Inlegung einer Darmfistel. Tm die Verdaunng im ganzen Dimndarme ohne Intervention der Galle und des I'ankreassaftes zu studieren, wird unter leichter Narkose die Bauchwand in der Linea alba oder $1-2 \mathrm{~cm}$ rechts davon geöffnet. Der I iinndarm wirl gleich ibber der Ileocöcalklappe muterbunden. Ein Faden wird am Inodenum unter der Eimmïndumg des Choledochusganges und des ¿2-:3 cm davon entfernten Hauptausfiihmungsganges des Pankreas gelegt. Mittelst des Thermokauters macht man eine kleine öffnumg inmitten des zwischen diesen Faden und dem Iförtner befindlichen Duodenalteiles. In diese öffnung bringt man eine an ihrem ïuferen Ende mit einer Kilemme rersehene diune Kantschukröhre, deren inneres Ende man in den Diinndarm abwärts fülıt, oder das mit einem Hahn rersperrbare Ansatzstück einer spritze. Man schnirt den Faden auf das Duodenum, so daß die Kautschukröhre oder das Ausatzstiick der Spritze fest in der Darmschlinge sitzt, damit bei Einspritzungen kein Verlust erfolgt. Nun spritzt man die auf Körpertemperatur erwärmte, untersuchte Lösung (orler Aufschwemmung) in den Darn und schlieft dabei nötigenfalls so oft die Klemme oder den Hahn, als man die Spritze wieder einfiillen muli. L'm die gesante Lösung dem Darm abzugehen, wird zuletzt eine geringe Luftmenge eingespritzt, relche die in der Rölne geblichene Flïssigkeit in den Darm treibt. Die Kilemme oder der Hahn wird dann geschlossen und die Pöhre oder das Insatzstiick vorsichtig ans dem Darme herausgezogen, während gleichzeitig ein Gehilfe den am Duodenum liegenden Ligaturfaden fest anzieht, so daß das duorlenale Ende des Diinndarmes endgiiltig abgeschlossen ist. Die Bauchwand wird durch Nähte vereinigt. Nach Ablauf einer bestimmten \%eit wird das Tier durch Nackenstich getötet und der Inhalt des Dïnndarmes mit den nötigen Vorsichtsmaßregeln aufgefangen.

Dieses Verfahren erlaubt Magen- und Darmverdaumg zu rergleichen, indem man einen zweiten Faden am Duodenum in unmittelbarer Nähe des Pförtners anlegt. die speiseröhre umittelbar iber der Cardia unterbindet, die mit der Klenme oder dem Insatzstiicke versehene Kautschukröhre nach Fïllen des Diinndarmes in den Magen bringt, die Versuchsflissigkeit in dieses Organ spritzt und den duorlenalen Faden unterbindet.

1) P. Nolf, De labsorption intestinale de la propeptone chez le chien. Bull. de la Classe iles Sciences de l'Acad. roy, de Belgique. p. 1149-1202 (1903). 
Falls man nur die Darmverlaumng untersuchen will, so kann man. nach $P$. Yolf $^{\prime}$ und $C h$. Honoré ${ }^{1}$, durch eine im Duodenum angelegte Öffnung eine dicke Glaskaniile ins Jejunum einfiihren. daranf den Darm unterbinden und den so vorbereiteten Darm mittelst Naht an der sofort wieder abgeschlossenen Bauchwand befestigen. Das änlere Ende der Kaniile steht mit einer mit einer Kilemme versehenen Kautschukröhre in Verhindung. Nachdem sich das 'Tier ron der Operation und der dafiir nötigen Narkose erholt hat, fiihrt man die auf $40^{\circ}$ erwärmte, untersuchte Nährstofflösung in den Darm. schließt die Klemme, tötet nach der Versuchsfrist das Tier und füngt den Dünndarminhalt auf. Dieses Verfahren erlaubt, während des Versuches neue Einspritzungen in den Darm zu machen sowie die Einfuihrung mit jeder beliehigen Raschheit zu bewerkstelligen. Es ruft aber leichter Störungen der Innervation und der Blutversorgung des oberen I)inndarmteiles hervor als die zuerst beschriebene Methode.

Um die Darmverdaumng und Resorption verschiedener Lösungen bei ein und demselhen Tiere zu untersuchen, wird eine gemessene Schlinge an beiden Enden abgebunden und beiderseits dicht an den Ligaturen eröffnet. Werden mehrere solche Vergleichsrersuche an einer Reihe von Tieren angestellt. so soll man stets Darmschlingen derselben Lage benutzen, denu verschiedene Stellen des I)ammohres hesitzen fuir die gleiche Fliissigkeit keineswegs dasselbe Resorptionsvermögen und dieselbe Einwirkung. ${ }^{2}$ ) In jeder der beiden Öfnungen der Darmschlinge wird eine mit Gummischlauch und Klemme versehene Glaskanüle eingebunden. Die schlinge wird zuerst dnrch einen Strom körperwarmer physiologischer Na Cl-Lïsung, Ringerlösung oder der zum Versuche dienenden Flïssigkeit so lange griundlich ausgespiilt. his die Fliissigkeit ganz klar abfließt. Zur Entfernung der dann noch in der schlinge rorhandenen Spiilfliissigkeit wird die äuliere Oberfläche der Darmschlinge mehrmals sanft gestrichen. Die Ausspiilung erlaubt zwar die Darmschlemhaut röllig zu reinigen. bleibt aber vielleicht nicht ohne Einwirkung auf diese. so dab man sich dazu nur derselhen Fliissigkeit, wie der zum ersten Versuche benutzten, bedienen soll. Auferdem kaun beim zur gänzlichen Entfermung der Spiilfliissigkeit nötịen. selbst vorsichtigen Anstreichen die Darmwand leicht mechanische Verletzungen erleiden. Sach der Answaschmo der Darmschlinge wird die an einer der beiden Kraniilen hefindliche Klemme geschlossen, die Schlinge wieder in dic Bauchhöhle gebracht. durch die andere Kaniile die untersuchte Fliissigkeit in die Darmschlinge eingespritzt, die an dieser Kaniile sich befindende lilemme rugemacht und dann die Bauchwand geschlossen. Yach Ablauf der beah-

1) Influence des conditions de labsorption intestinale de l'azote alimentaire sur l'élimination azotée urinaire. Arch. int. de J'hysiol. 'T. 2. p. $85-115$ (1905).

$\left.{ }^{2}\right)$ Irannois et Ri. Lípine, sur la manière différente lont se comportent les parties supérieures et inférieures de lintestin gréle au point de rue de l'absorption et de la transsudation. Arch. de physiol, norm. et pathol. 3. Reihe. T.1. p. 92-111 (1883). - Carl Voit und J. Baner, C̈ber die Aufsaugung im Dick- und Dünndarme, Zeitschr. f. Biol. Bd. 5. S. $536-570(1869)$. 
sichtigten Versuchsdauer wird die Schlinge wieder hervorgezogen und durch sanftes Streichen ihrer äuferen Oberflïche die noch vorhandene Flüssigkeit durch eine der Kianilen (ntleert. Xun wäscht man die schlinge wieder mit Kochsalzlösung, Ringerlösunğ oder der zum nenen V'ersuche dienenden Flïssigkeit und füllt darauf die Schlinge mit letzterer. Auf diese Weise kann man nacheinander 6 bis 8 Lösungen untersuchen. Höber empfichlt die sonst etwas miihsame Reposition der Darmschlinge durch Riesezieren des Netzes am Anfange des Versuches zu erleichtern. Iiese oft wiederholte Reposition der dem Bauch bei jeder Entleerung entzogenen Schlinge verursacht leicht mechanische Verletzungen und fiihrt manchmal sogar zu einer Zerrung oder abmormen Lagerung des Mesenterimms, so daf die lilutzufuhr gestört oder verändert wird. L'm dies zu vermeiden. kann man die eimmal gefuillte schlinge während der ganzen Versuchszeit in stetig mittelst phrsiologischer oder Ringerlösung benetzte Tüicher auferhalb der Bauchhöhle liegen lassen: dabei befindet sie sich aber sicher unter abnormen Bedingungen. ${ }^{1}$ )

Das Vorhandensein der inneren Enden der heiden Glaskanïlen in der Schlinge stört vielleicht die Verdanungsprozesse. Um diese etwaige Fehlerquelle zu beseitigen und trotzdem die Darmschlinge ror dem Versuche ausspiilen zn können, wird die in einer bestimmten Länge abgebundene I)iinndarmschlinge quer durchschnitten. Der Ort der Durchschneidung mufs derart gewählt werden, daf die am Mesenterialrande verlaufenden großen Gefäße geschont bleiben. Auferdem kamn man noch vor dem Durchschneiden beiderseits das äuferste zur Schnittfläche führende Blutgefäß umstechen. Nach der Durchspiilung mittelst körperwarmer physiologischer Kochsalzlösung, Ringerlösung oder am besten derjenigen Fliissigkeit, die zum eigentlichen Versuche dient, wird die Schlinge an beiden Enden zugebunden. Kur Einführung der Tersuchsflïssigkeit in die Schlinge wird die mit der spritze selbst oder durch einen kurzen Kautschukschlauch mit einer Bïrette rerbundene Kaniile einer Pravazschen Spritze möglichst schief durch die Darmwandung eingestochen. Legt man durch dreimaliges Umstechen einen Faden um die Kaniile, und zieht man diesen beim Herausnehmen der Kaniile zu, so geht bei der Einspritzung der Fliissigkeit kein Tropfen verloren, demn der schiefe Stichkanal wird bei größerem Innendruck zusammengepreft mol schließt ventilartig. Wührend der Einspritzung muß die Lanïle festgehalten werden, damit sie nicht die Darmschleimhaut verletzt und eine Blutung hervorruft. ${ }^{2}$ ) U'm keine Verletzung der Darmwand der Schlinge

1) R. Heidenhain, Nene Versuche über die Anfsaugung im Dünndarme. Fffügers Areh. f. d. ges. Physiol. Bd. 56. S. 576-631 (1894). -- M. Katzenellenbogen, Der Einfluß der Diffusibilitat und der Lipoidlöslichkeit anf die Geschwindigkeit der Darmresorption. Ebenda. Bd.114. S. 522-534 (1906). - R. Höber, Über Resorption im Dünnlarm. I. Mitt. Ebenda. Bd. 70. S. 624-642 (1898). II. Mitt. Ebenda. Bd. 74. S. 246-271 (1899). - Derselbe, Die physikalische Chemie in der Pbysiologie der Resorption. der Lymphliktung unl der Sekretion. Physikalische (hemie und Medizin. Bl. 1. S. 294- 419 (1907).

$\left.{ }^{2}\right)$ Feory Friedländer, Über die Resorption gelöster Eiweißstoffe im Dünndarme. Zeitschr. f. Biolog. Bł. 33. S. $263-287$ (1896). 
zn bewirken. kann man anch nur eines der beiden Enden der Schlinge nach der Ausspoilung znschlieben; in das andere wird eine Kautschnkrölıre oder das Insatzstiick ciner Spritze angebracht mol dureh einen die Schlinge umschniirenden Faden darin festgehalten. Nach der Einspritzung der untersuchten Fliissigkeit wird die Röhre oder das Ansatzstïck rasch aus der Schlinge gezogen, während man gleichzeitig den Faden fest zuschniirt. so daß dann dic gefüllte Schlinge beiderseits geschlossen ist. Aufer den rorhin sehon erwähnten Einwänden gegen die Ausspiilnng hietet die soeben heschriehene Versuchstechnik noch als Fehlerinelle eine von der burchschneidnng des larmes oberhall, und nnterhall, der eigentlichen schlinge herriihrende, etwaige Beeinträchtigung der Verdaumgs- und Resorptionsprozesse in der schlinge.

Zum Vergleiche der Verdaumg und Resorption verschiedener Lösungen in Dïnndarme eines und desselben 'Tieres kam man sich anch zwei odel mehrerer zwischen Lnterbindungen isolierter Schlingen gleicher Länge bedienen. Bei solchen Versuchen mub besonders darauf geachtet werden. dalf das Mesenterinm keine Drehung erleidet damit die Blutversorgung in den rersehiedenen Schlingen normal bleibt. ${ }^{1)}$ Es ist rorzuziehen. beim 1 oder \& Tage vorher mit Abfiihrmitteln behandelten Tiere keine Auswaschung der abgebnndenen Darmschlingen vorzmehmen. Mittelst des Thermokanters wird die I armwand zwischen den die zwei benachbarten Schlingen begrenzenden Fäden eröffnet, so dab man durch diese Öffnung eine Kautschukröhre oder das Ansatzstiick einer spritze zuerst in die eine und daranf in die andere Schlinge cinfïhren und auf diese Weise die Versnchsfliissigkeit in die eine Schlinge und gleich nachher in die andere einspritzen kann.

Bei allen Verfahren zur Untersuchung der Verdaumng in isolierten Diinndarmschlingen kömmen beim Abbinden der Schlinge sowohl der Kreislanf des Bhutes und des Lymphe als die Innervation V'erandermgen erleiden mol dadurch die Verdanungsprozesse mehr oder minder gestört werden. I ie zu diesen Versuchen nötige Narkose wirkt wahrscheinlich etwa in demsolben Simne. Das Herrorholen der Darmschlinge aus der Bauchhöhle und die anderen Manipulationen am Larm und am Meschterium bewirken Veländermaen der Beweglichkeit des Darmes.

Will man die in Diekdarme vor sich gehenden Verdaumgs- und Resorptionsprozesse untersuchen, so fiihrt man durch das Rektum eine Schlundsonde in den Dickdarm ein. Ḱnapp hinter dem (ü̈um und distal an einer noch gut erreichbaren Stelle wird je eine Ligatur angelegt, das innerhalh ulieser Ligatnren liegende stäek des Dickdarnes losgetremnt mond durch Warmwasserausspiilungen und leichtes Ansstreichen grindlich gereinigt. Jann wirl an einem Ende dieser Dickdarmschlinge eine Ligatmr durch

$\left.{ }^{1}\right)$ (i. Lenbuscher, Studien ïber die Resorption seitens des Darmkanales. Jenaische Zeitschr. Bd. 18. S. 808. - E. Waymouth lieid, ()n intestinal alisorption, especially on the alsorption of serum. peptone and glneose. Mhilosoph. Transact. of the Roy. Soe. of Lundon. Series B. Vol. 192. p. 211 -297 (1900). 
den Mesenterialansatz hindurchgefuihrt und fest geschniirt, so dali die Ilickdarmschlinge verschlossen ist. Im anderen Ende dieser Schlinge wird eine Kautschukröhre oder das Ansatzstiick einer Spritze angebracht und mittelst eines die Schlinge umschnïrenden Farlens darin fest gehalten. Sobald die Versuchsfliissigkeit in die I)icklarmschlinge eingespritzt ist, wird die liöhre oder das Ansatzstiick bei gleichzeitigem festen Zuschniiren des Fadens rasch aus der Schlinge gezogen, so dab dann die Inickdarmschlinge beiderseits verschlossen ist. Ias Ausspiilen des Dickdarmes scheint selbst bei 1 oder 2 Tage vorher mit Abführmitteln behandelten Hunden oder Katzen unentbehrlich. ${ }^{1}$ )

3) Mit vorheriger Anlegung einer Darmfistel.

Bei der Thiryschen Darmfistel wird das eine Ende eines abgetrennten Darmstiickes durch eine Naht verschlossen und das andere mit der Bauchwand vernäht, so dah eine Dauerfistel gebildet wird. T'm mehrere Versuche über die Terdaunng im Dünndarme hei ein und demselben Tiere anzustellen, bedient man sich heutzutage nur noch der V'ellaschen Veränderung der Thiryschen Darmfistel. In der Thiry-Tellaschen Fistel werden beide Enden des isolierten Darmstïckes in die Bauchwand eingenäht, so daß beide nach außen mïnden. Bei dem Einnähen der beiden Fistelenden in die Banchwunde soll man dabei durch eine schniirstiefelartig angebrachte Naht das Lumen der Darmenden stark rerengen, um den sonst immer drohenden Darmwandprolaps zu verhiiten. ${ }^{2}$ )

Bei den Versuchen an Tieren mit Thiry-V'clascher Darmfistel mue man zunächst feststellen. welche Inhaltsmenge der Darmabschnitt faßt. und welche Menge Spülfliissigkeit notwendig ist. um den Darm von einem bestimmten Volumen der eingeflossenen Versuchsflüssigkeit röllig zu befreien. Die Kapazität des isolierten Darmabschnittes bleibt indes nicht stets dieselbe; sie nimmt érheblich ab, wenn der Hund längere Zeit zu Versuchen nicht benutzt wird und nimmt hingegen zu, wenn die Versuche rasch aufeinander folgen. Werden aber nach dem Beispiele ron $r$. Scanzoni die Versuche in gleichmäbigen Zwischenräumen angestellt, z. B. alle :3 Tage, so bleibt die Kapazität ziemlich beständig. ${ }^{3}$ )

1) II. J. Hamburger, Versuche über die Resorption ron Fett und Seife im Dickdarm. Arch. f. Physiol. u. Anat. Physiol. Abt. S. 433-46t (1900). - Felix Rench, Untersuchungen über die Größe der Resorption im Dick- und Dünndarme. Ebenda. Bı. 86. S. $247-258$ (1901).

2) L. Thiry, ther eine nene Methode, den Dünndarm zu isolieren. Sitz.-Ber. d. Wien. Akad. d. Wiss. Math.-naturw. Kl. 1. Abt. Bd.50. S. 77-96 (186t). - L. Vella, Tenes Verfahren zur Gewinuung reinen Darmsaftes. S. Moleschotts Tntersuchungen zur Naturlehre. Bi. 13. S. 10 (1882). - O. Cohnheim, Üler Dünndarmresorption. Zeitschr. f. Biol. Bu. 36. S. 129-153 (1898).

$\left.{ }^{3}\right)$ Gumilen'shi, Uber Resorption im Dünndarm. Pfiagers Arch. f. d. ges. Pbrsiol. Bd.39. S. 5ૅ6-592 (1886). - F. Röhmann, Über Sekretion und Resorption im Dünndarm. Eluenda. Bd. 41. S. 411-462 (1887). - Friedrich $\iota$. Scanzoni, Über die Resorption des Traubenzuckers im Dünndarm und deren Beeinflussung durch Arzneimittel. Zeitschr. f. Biol. Bl. 33. S. $461-474(1896)$. 
Lnmittelhar vor jedem Versuche soll man die Darmschlinge mit der mutersuchten Lösung mehrere Male durchspiilen. Sonst bleibt bei Beendigung des Versurhes eine nicht mbeträchtliche Flissigkeitsmenge an den Wänden haften. Während. wenn die Darmwand schon rorher mit derselben Fliissigkeit bespiilt war. dieser Fehler sich mehr oder minder antheben läft. ${ }^{1}$ )

Zur Cutersuchung der Vertanme bei Anwendung Vellascher Fisteln hestehen \%wei Verfahren. je nachdem man den isolierten Darmabschnitt während der ganzen Zeit des Versuches mit der untersuchten Lösung speist oder ihn nur zu Beginn des Versuches damit fïllt.

In ersten Falle werden in beiden Fistchn kleine. in ler Mlitte von (incre liohre durchsetzte und seitlich cinen Ansatz tragende. dïnne Gummiballons leer cingefiilnt mud dam rom seitlichen Ansatz eines Spritze aus mit ('a. Q $0 \mathrm{~cm}^{3}$ Wasser refüllt, so dab sie (inen vollkommenen Abschlur bilden mu die Fistel nur mehr ron den die Kautschukheutel durchsetzenden heiılen Riöhren zugänglich bleilt. Diese beiden Röhren werden sodann mit kleinen, mit Thermonetern rersehenen Lirbigsehen Kiihlern verbunden. durch deren Yantel auf $t 0^{\circ}$ erwirmtes Wasser flieft. Der eine Lieligsche Kiihler endigt in einem Wassermanonneter. so daf die aus dem Darmathschnitte anstretende und durch die Atmungsbewegungen und I'eristaltik auf- und absteigende Fliissigkeit anf Kürpertemperatur bleibt. Der andere Kïhler führt zu dem die anf Körpertemperatur erwärmte mntersuchte Lösmmg enthaltenden Gefälie, ans dem diese Lösung muter einem turch Mariottesche Flaschen bestaindig gehaltenen Irucke von $40 \mathrm{~mm} \mathrm{Ig}$ in die Fistel stetigr zufliefien kinn, so daf heide Kiihler aigentlich als Erwärmer dienen. Durch die soeben beschriebene Versuchsanordnung wird der Druck im Einflufgefäbe geregelt und hlcibt hestïndig. Indrerseits wird beim langsamen Zuflieben der auf Körpertemperatur erwärmten Flïssigkeit cin Abliihlen in dem zuführenden (iummischlanch rermieten. Mamit die Tersuchsfliissigkejt während des ganzen Versuches muter einem bestïndigen Druck von to $\mathrm{mm}$ Hg bleibt. muf natïlich auch schon ror dem Versuche das Ianometer des zweiten Erwärners demselhen Drucke ausgesetzt worden. um ein Thertreten der Füllnngsfliissigkeit in das Ianometer zu verhiiten. ${ }^{2}$ )

Inn nach Beendigmer des Versuches die mtersuchte Lösung aus dem I armstïcke zu entfernen. werden beide Ballonröhrchen abgeklemmt und von den gleichfalls ahgeschlosicnen Erwärmern abgenommen. Nun länft zu-

$\left.{ }^{1}\right)$ I. И. Hamburger, Uher den Einfluß des intraintestinalen Druckes anf die Resorption im Dünnilarm. Arch. f. Anat. u. Physiol. Physiol. Abt. S. 428-464 (1896).

2) Gumilerski, loc. cit. - reseunzoni, loe. cit. - Einst Fansteiner, Über Resorption ron Pepton im Dïmularm und deren Beeinflussung durch Nedikamente. Zeitselur. f. Biol. Bu. 33. S. $475-488$ (1896) - I I. r. Talpeiner, Ther die Beeinflussming der Resorption der Fette im Dünnlam durch Arzneinittel. Nach Arheiten von 1 . Eschenbach, L. Lichtuitz und rmeiner mitgeteilt. Zeitschr. f. Biol. Bul. 45. S. 223-24!) (1903). - Yut Eschenbach, Ther Becinflussung der Resnrption der lette im Lünndarme durch Arzneimittel. Inang.-Diss. München 1897. - L. Lichtwitz, Čber Beeinflusiung der Resorption der Fette im Dünndarme durch senfiil. Inaug.-Diss. Leipzig 1901. - rimeiner, Die Resorption ron Fett und seife im Dümndarn. Zeitschr. f. Tiermediz. Bd. 6. S. 134 (1903). 
nïchst aus beiden wiorler greöffneten Rïhrchen so viel Flissigkeit aus, als

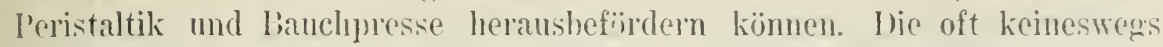
greringe, damn noch in der barmschlinge vorhandene lösungsuenge wind durch Lufteiublasung mittrist Spritze von der eiuen listel aus entfernt. lann erst kommt die Ausspülumg mittelst eines genau bramuten (puantums Kochsalzlösung, welche entweler anch unter Quechsilberlinck mit dem Apparate orler einer Spritze refolgt. Die nicht mehr von sellst ansfliefende Fliissigkeit wird alsdamu mittelst luftemblasungen antfernt, so dafi nach Herausnahme der Kautschukbentel nur wenige Tropfen Fliissigkeit noch aus den Fisteln herrorkommen. Nach $v$. Seanzoni soll die Eintlecung der schlinge und ihre Ausspiilung kaum mehr als \& Minnten beanspruchen, so dal' die während dieser Zeit noch stattfindende Resorption das Ergehmis des Versuches num unwesentlich becinfluft.

Wird die Thiry-Vellasche Fistel nur einmal zu Beginn des Versuches gefiillt, so werlen zuerst die Kautschukballons, wie oben beschrieben, in bcisle Enden der Fisteln eingefiihrt. Durch die zentrale liöhre ciner dieser Grummibentel wird die auf liörpertemperatur relurachte lïsung mittelst einer spritze in die Schlinge befördert, worauf diese Kautschukröhre mittelst einer Kremme rerschlossen wird. Die zentrale Riölne des anderen Ballons ist mit einen Licbigschen Kïhler rerbunden. durch welehen auf 40" erwärmtes Wassel flickt und dessen inneres Rohr offen bleiht. I)adurch kann die zeitwoise durch die Bauchpresse oder durch Zusammenzichmg der Darmmuskulatur heransgedrickte Fliissigkeit nach Belieben answeichen und heim Nachlassen des abnormen Inuckes wieder in die Fistol zuriekfliefen, ohue unter Körpertemperatur zu simlen.

Zum dichten Verschlusse der Thiry-T'ellaschen Fistel kann man auch eine, nach Art des Pflizgerschen Lmoenkatheters mit ciner ans Fischhlase des Karpfens helgestellten, zum Iufblasen ringerichteten, elastischen Menhrane versehene liöhre benutzen. ${ }^{1}$ )

Bei den an Tieren mit Thiry-Tellascher Fistel angestellten Versuchen geschieht die Aufsangung weit rascher und rollkommener als hei den Versuchen mit durch Tuterbindung in situ isolierten Damsehlingen. Die physiologischen Verhältuisst sind weit bessel im erstelen Falle als im zweiten gewahrt; die Versuche werlen ohne Narkose angestellt. Nach Höbe soll sich indes fast immer einione Zeit nach der Terheilung ein teilweise wenigstens auf dic abnorme berïhrme der Oberfläche der Darmscbleimhaut mit der Luft zuriickzuführender katarrhalischer /ustand der Darmschleimhaut vorfinden. Solbst bei peinlichster Ausfihrmng aller Vorsichtsmabregeh golingt an Schlusse des Versuches die rollständige Entleerung der Schlinge keineswers mit absolutel Sicherheit. Wie Blribtreu es hervorhebt. bleibt beim Iusspiilen einer Thiry-Vellaschen Fistel leicht ein Teil der Fettsubstanz als zäher Schleim an der Darmwand haften, wodurch

1) Tetsu Hattori, Uber Resorption ron Seifen ans isolierten Darmschlingen. Inaug.Lisselt. (ireifsmald 1905. 
hisweilen eine viel gröfere Resorption als die tatsächlich bestehende vorretänscht wird. Die Finfïhrung dej Kautschukblase in die beiden Enden der Fistel crzeugt manchmal die Absonderung einer geringen Menge einer dicken schleimigen Masse: in anderen Fällen ruft sie jedoch war kine sekretion hervor: jedenfalls kann sie auf die Verdaungs- mnd Resorptionsprozesse ('inwirken.')

5. Verfahren zur Termejdung des Zuflusses von l'ankreassaft und Galle in den Dalm.

'Zur Vermeidung des Zuflusses des Pankreassaftes in den Dar'm werrlen beim Hunde die Ausfiihrungsä̈nge des Pankleas zwischen 2) L'nterbindungen durchsehnitten. Man mulj die Operation unter peinlichster Asepsis ausfïhren. Zur Eroffnung der Banchwand wird ungefähr $2 \mathrm{~cm}$ unter der letzten Rippe ein $2 \mathrm{~cm}$ rechts von der Linea alba anfangender, :3 his $5 \mathrm{~cm}$ langer Einschnitt gemacht. Juf diese Weise sieht man gleich das Duodenum. Der meistens $1^{1}$, bis $2 \mathrm{~cm}$ oberhalb des Beginnes der freien Portion des rechten Pankreaslappens meln oder minder tief befindliche Hauptausfïhrungs: gang wird zwischen zwei so nahe wie möglich an der Darmwand sich befindende Unterbindungen durchschnitten. Iiese L'nterbindnngen müssen oberhalb der Tereinigung der zwei Aste, aus denen der Hauptgang herrorgeht, angebracht werden. Dann wendet man den pylorischen Teil des Dnodenums und des Pankreas und schneidet den in den Taterschen Divertikel gemeinsam mit dem Ductus choledochus einmüindenden Nebenausführungsgang der Bauchspeicheldriise zwischen 2) Unterbindungen durch. Manchmal besteht auferdem ein zwischen dem Haupt- und dem Tebengang mindender, bisweilen ziemlich breiter. mittlerer, dritter Ansführungsgang und mitunter sogar nach Hess und Sim noch ein aus der Pars lescendens des Pankleas entspringender vierter Gang. Derartige Gänge müssen selbstrerständlich auch zwischen 2 Unterbindungen durchschnitten werden, denn es hestehen anastomotische Verbindungen zwischen dem Hauptgang und den verschiedenen Nebengängen. Die Banchwand wird soløfältig durch Nähte vereiniot. bei der ()peration muf die Pankreasdriise stets in mit körperwarmer physiologischer Lösmg benetzten sterilisierten Tiichern eingehüllt bleiben. Sie darf keine Verletzung erleiden. sonst entsteht leicht die den 'Tor hervorufende Fettgewehsnekrose. Gleich nach der Operation erfolgt stets eine mehr oder minter betrïchtliche Gewichtsabnahme: nach einigen Tagen jedoch nimnt in den meisten Fällen das Gewicht allmählich zu. 1 m schlieflich zur Norm zuriickzukehren, obgleich die Pankreasdriise bei gelungener Unterbindung aller Ausfïhrungsiange stets eine erhebliche sklerose aufweist. In einigen Fällen indes sinkt das Gewicht langsam bis zum nach \& Tagen his 1 oder \& Monaten oder sogar einer längeren Zeitdauer eintreten-

1) H. Bleibtren, Zur Mechanik der Untersuchung der Fettresorption im Jarme. Dentsche med. Wochenschr. Bd. 32. ¿. 1233-1235 (1906). - Otto Cohnheim, C̈ber die Resorption im ìinmlarm und der Bauchhöhle. Zeitschr. f. Biol. Bu. 37. S. 443-48= (1899). - R. Hïber, Die physikalische Chemie in der Physiologie der Resorption, der lymphbildung und der Sekretion. S. 305. 
den Tod; die Sklerose der Driise ist in diesen Fällen riel ausgeprägter als sonst. ${ }^{1}$ )

U'm den Zufluf der (ialle in den Darm zn rermeiden, kann man (eine Gallenblasenfistel nach dem Dastreschen ${ }^{2}$ ) Verfahren anlegen.

Will man aber die durch das Abfliefen der (iesantgalle nach auben verursachten etwaigen Störungen verhiiten und nu die Verdaumng im oleren I iinndarme bei Abwesenheit der Galle stndieren oder bei einem Duodenalfistellunde das Produkt der Nagenverdaumg ohne Beinischung der Galle erhalten, so kann man den Gallengang und den oberen Pankreasgang zwischen zwei Unterbindungen durchschneiden und eine Cholezystenteroanastomose machen; die I)armverdaumn ist damn nicht beeinträchtigt. ${ }^{3}$ )

Fine andere Operation, welche denselben zweck erzielt, ist die durch Londont) angegebene Transplantation rer ersten Inorlenalpapille.

Statt der Cholezystenteroanastomose und der 'T'ramsplantation der' ersten Duodenalpapille kam man auch beim Hunde. nach Durchschneidung des Yebenausfïlnungsganges des Pankreas zwischen zwei Ligaturen, den Ductus choledochus in unmittelbarer Nähe seiner Eimmindung in das Dnodenmm unterbinden, ihn durchschneiden und ihn in eine kleine an ciner Schlinge des Jejunums angebrachten Öffnmı durch Nähte vereinigell. ${ }^{5}$ )

1) Edyard Zunz et Léopold Hayer, Recherehes sur la digestion de la viande après ligature des canaux pancréatiques. Mém. couronn. et autr. mém. publ. par l'Acad. roy. de méll. de Belgique. Coll. in $8^{0}$. T. 18. fase. 7 , 71 pages (1904). - D ieselben, Sur les effets de la ligature des canaux pancréatiques chez le chien. Bull. de l'deal. roy. de méd. de Belgique. $4^{\mathrm{m} \theta}$ série. T. 19. p. 509-5う5 (1905). - I'go Lombroso, Contrilution à la connaissance de la fonction du pancréas. Areh. ital. liologie. T. 42. 1. 336-340 (1904); De l'ahsorption des graisses ehez les chiens arec couduits pancréatiques liés. Compt. reml. hebl. d. séane. de la Soe. de Biol. T. 56. p. 396-397 (1904): De la lipolyse dans le tube digestif des chiens arec conduits pancréatiques liṕs. Ibid. T. 56. p. 398 (1904); Sur l'absorption des graisses après l'ahlation du pancréas dont les couduits ont èté précèdemment liés. Ibill. T. 56. p. 399 (1904); Olservations histologiques sur la structure du pincréas du chien après ligature et résection des contuits pancréatiques. Ibid. T. 57. p. 610-611 (1904): Sur la structure histologique du pancréas après ligature et section des conduits pancréatiques. Journ. de physiol. et de pathol. génér. T. 7. p. 3-12 (1905). - O. lless, Die Ausführungsgänge des Pankreas. P'flügers Arch. f. d. ges. Physiol. Bd. 118. S. 536-う38 (1907). - O. Happel, ťber die Folgen der Unterbindung der Ansführungsgïnge des Pankreas heim Hund. Inaug-Dissert. Marburg 1906. 17 S. - K. Sim, Der Einfluß experimenteller Pankreasgangunterbindungen auf die Nahrungsresorption. Inaug.-Dissert. Jarburg 1907. 29 S. - A. Xiemann, Die Beeinflussung der Darmresorption durch den Abschluß des Panlireassaftes. nebst anatomischen Untersuchungen ïber die Histologie des Pankreas nach Unterbindun seiner Gänge beim Humle. Zeitschr. f. exper. I'athol. u. Therapie. Bd. 5. S. $466-477$ (1909).

$\left.{ }^{2}\right)$ A. Lastre, Opération te la fistule biliaire. Arch. de physiol. norm. et pathol. うัme série. T.2. p. 714-723 (1890).

3) G. Lang, Über Eiweißrerdaung und Eiweißresorption im Magen des Hundes. Biochem. Zeitschr. Bl. 2. S. $225-242$ (1907).

4) E. S. London, Zum (hemisunus der Verdauung im tierischen hörper. XIII. Mitteilung. Weitere methodisehe Angahen: Zeitschr. f. physiol.Chem. Bd.5̈3. S. 24tC-250 (1907).

$\left.{ }^{5}\right)$ E. Zunz, Nourelles recherches sur la digestion de la riande crue et de la riaude cuite chez le chien. Ifém. couromn. et autr. mém. publ. par l'Acarl. roy. de médec. 
Zu dieser choledorhoenterostomie bedient man sich der in der Fig. 3t schomatisch ahgebildeten Kaniile. Sic besteht aus eimer $2-0 \mathrm{~cm}$

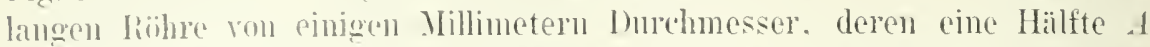
mit einem (rewinde an ihrer äulieren Oberfläche versehen ist. Wïhrend dic andere Hälfte $b$ glatt ist nud ringsum :; Einschuirungen $C$ von $1 \mathrm{~mm}$ 'Tiefe anfweist. Im Eule $D$ der Kanüle, da wo der Schraubengang anfüngt, besteht aine klome, runde foste l'latte $I$. wolche das äubere Ende der

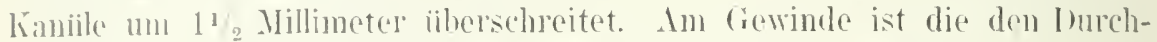

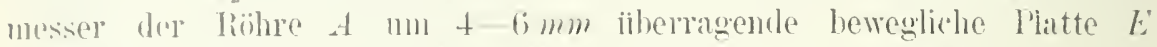
allgeschrambt. Las andere Ende $F$ der Kaubile ist abgeschrägt.

ber Ductus cholerlochus wird in der Nähe seiner Einmindung in

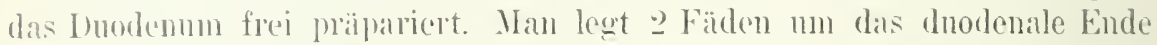

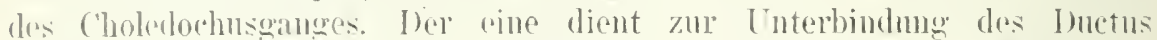
choledochus in mmittolbarer Nïhe des Inodenums. Finige Millineter

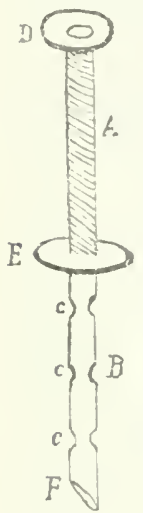

Fig. 34 .

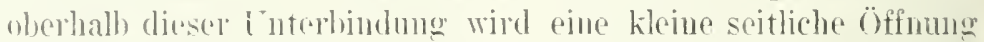
im choledochnswange angebracht. Durd diese öfnumg steckt man den olatten Toil B der Kimiile in den Inctus choledochus unel bofestigt iln dauin. indem man den zweiten Faden anf eine der Einschniirungen des 'Teiles $B$ der Kantile fost zuschniirt. Jann wird der ('holedochusqune zwischen der in del Nähe des Dnodemuns lisgonden Interhindung nud dem Eintritte der Kaniile in den fiang durchschnitten. Nun wird mittelst des Thermokanters in der zm Choledochoenterostomie wewählten Darmsichlinere eine den Eintritt der l'latte $U$ in den Darm ellambende kleine offumus gemacht. Sofort schroubt man die I'latte li anf solcho Meiso an, dab die Darmwand zwischen den beiden Platten I) mel E' lefestigt bleibt. Die Kianiile mol

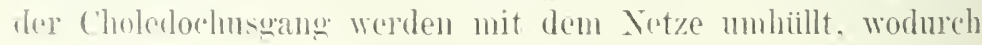
die Hrilung selor begiinstigt wirt.

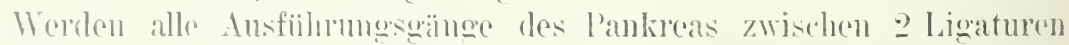
durchschniften. nunl strllt man nachher eine fiallenblasenlistel her oder erfolgt daum rimo ('holegstenteroanastomio, so treten weder balle noch Pankeassift in den ballu ein.

Sobald die durch die rersehiedenen zur Vermeidung des Zuflusses

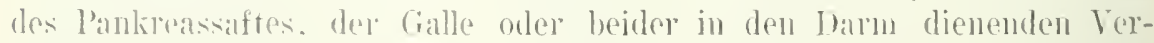
fihmen operierten Tiore sich ron den Folgen dos operativen Eingriffes erholt haben, kiann nan sie zu den Versuchen bemutzen.

\section{Verdaumgsversuche im Reagenzglase.}

\section{(1) Allanemeine Technik.}

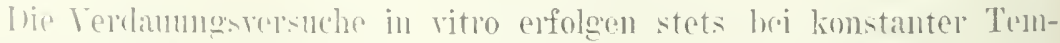
peratur, meistens hei Köppertemperatur, in einem Brutapparate.

de Belugique. T. 19. fasc. T. p. 30 (1907). - Derselbe. Fine Kanüle zur (holedochnentrustomie. Zeitschr, f. bolog. Technik n. Methodik. Bal. 1. S. 134-135 (1908). 
Die zu verdauenden Stoffe. in festem, gelöstem oder flüssigem Zustande, werden mit der Verdaunngsfliissigkeit und meistens einem Antiseptikum in gut rerschlossenen Kolben oder Eprouretten in den Brutraum gebracht. Nach der im voraus festgestellten Versuchszeit wird das Verdauungsprodukt quantitativ oder qualitatir mittelst der später zn beschreihenden Methoden untersucht. Man kann auch zu bestimmten Zeitpunkten dem Verdaungsprodukte Proben entnehmen und auf die Anwesenheit oder die Menge gewisser Stoffe priffen.

Als Brutapparat bedient man sich entweder eines IBrutschrankes oder besser eines Thermostaten.

I. Brutschränke. Ein guter Brutschrank mulf folgenden Anforderungen entsprechen: 1. Er muf den Schwankungen der äulier en Temperatur mighlichst wenig unterworfen sein: ‥ der Wärmeverlust durch strahlung und durch Konvexion mul auf ein Minimum beschrïnkt sein: $\therefore$ der Brutschrank mus mit einem möglichst empfindliche'ı automatischen Thermoregulator versehen sein.

Der Luftram der Brutschränke wird entwerler durch ihn umgebendes Warmwasser oder durch eine darin befindliche erwärmte Ietallröhre greheizt. Zur Heizung des Wassers oder der Netalhö̈hre benutzt man am besten Gas oder Elektrizität.

Brutschränke für Gasheizung. Da der Gasdruck oft ziemlich beträchtliche Schwankungen anfweist, so schaltet man bei der Anwendung ron Gas zur Heizung ron Brutappa-

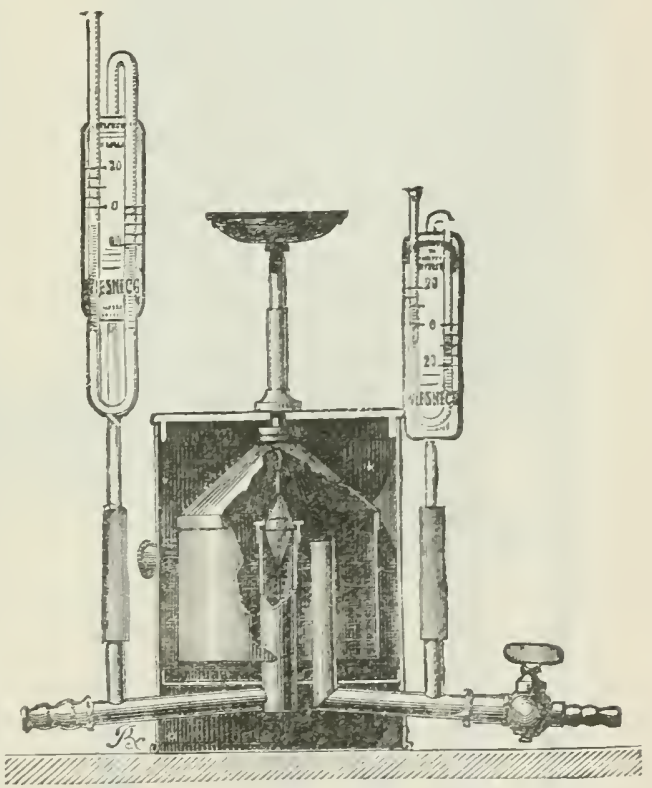

Figr. 35.

raten manchmal einen Ciasdruckregulator in den frasstrom ein. Dazu kann man den in Fig. 3.5 abgebildeten .Yoitessirschen Apparat oder einen anderen ähnlichen benutzen.

Bei allen Gasdruckregulatoren wird der Gasverhanch dadurch geregelt. daß das Cias durch eine Öfnung strömt, deren Durchschnittsebene beim Sinken des Gasdruckes zunimmt. Das im Apparat strömende Gas hebt mehr oder minder eine Glocke, welche einen sich durch einen festen Ring hewegenden metallischen Kegel mitreißt.

Indes empfiehlt es sich nicht, sich der auf den frastrom selbst eingestellten Gasdruckregulatoren zu bedienen. sondern nur solche Brutschränke anzuwenden. in denen ein Gasdruckregulator direkt angehracht ist. da dieser viel 


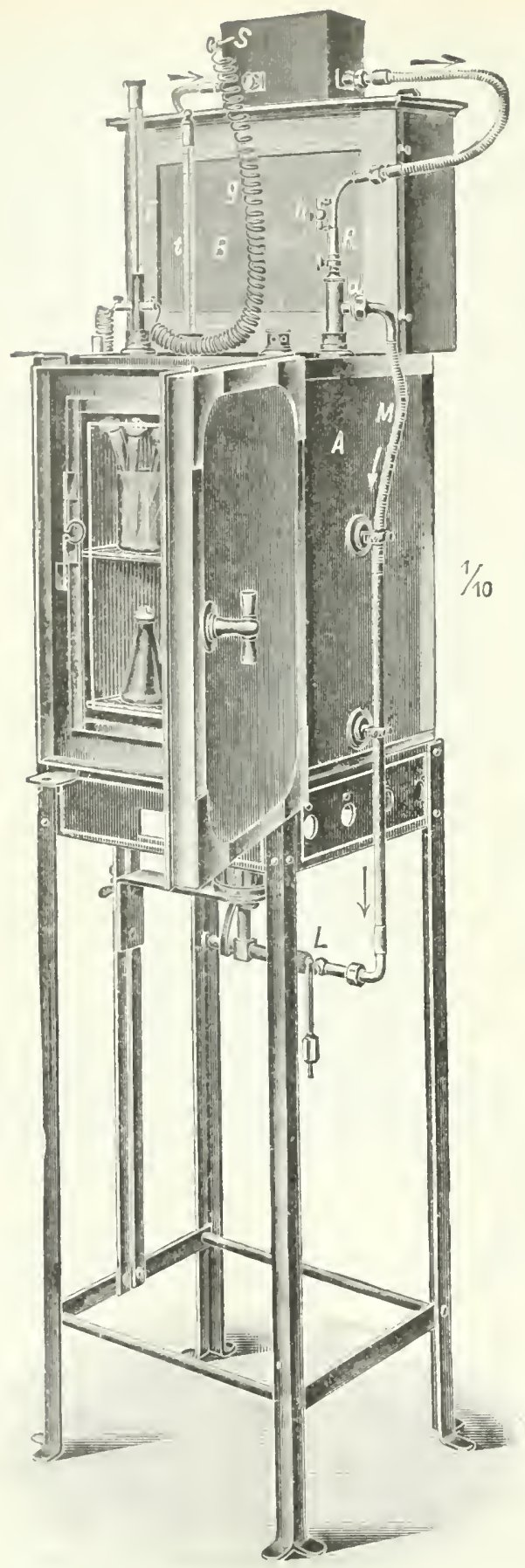

empfindlicher ist"und anf Gasdruckschwankungen wesentlich selmenler leagiert wie der Moitessiersche und älmnliche frasdruckregulatoreu.

\%) Mittelst Wasser geheizte brutschränke. Die Apparate. in denen Wasser zur I'ïmorerteilung dient, bestehen aus einem ans Kupfer oder Stahlblech angefertigten doppelwandigen. üherall dichi verschlossomen Wasserbehälter, dessen äuliere oberfläclie mit Filz, Asbest oder besser mit Filz und darriber mit linoleum bekleidet ist. Stahlblechapparate sind keineswegs zu emufehlen, weil sie infolge des Durchrostens des Bleches dureh Oxydationen ziennlich rasch unbranchbar werden. In der oberen Wand des Wirmehehälters hefinden sich die fiir 'Thermoregulator und Thermometer nötigen Öfnungen. Fin aulin angebrachtes II asserstandrohr mit Tentilanslanf gibt die Jöhe des Wassers im Behälter an.

ITie es die Fig. sho veranschaticht, fïhren Doppeltüren zom Brotraume, cine innere einfache Glastiile und eine aufiere doppelwandige Vetalltiire. Der durch diese boppelwände hegrenztr lianm ist mit Luft gefiillt. Die äulierc (therfläche ree Metalltiire ist mit frilz und daruber mit Linolenm belegrt. Iloc äulere Tiure schließt in Falzen; diese sind mit Sattelfilz gefiittert.

Der Lautenschlägersche Brutapparat nenester Konstruktion besityt eine Wämeverteilungsvorrichtmug, wodureh nicht 
nur der dirckte Eimfluh der Flamme auf den Innenraum aufgehoben wird, sondern aulierdem anch die geringste Wärmesteigerung am Boden sofort durch das in Bewegung befindliche Wasser direkt zu dem empfindlichen Teil des in einer Metallhiilse mit Zirkulationsvorrichtung enthaltenen Thermoregnlator's gelaugt.

Als brenner soll man den in der Fig. 37 abgrebildeten Kochschen sicherheitsbrenner anwenden. Er besteht aus einem rechtwinklig gebogenen

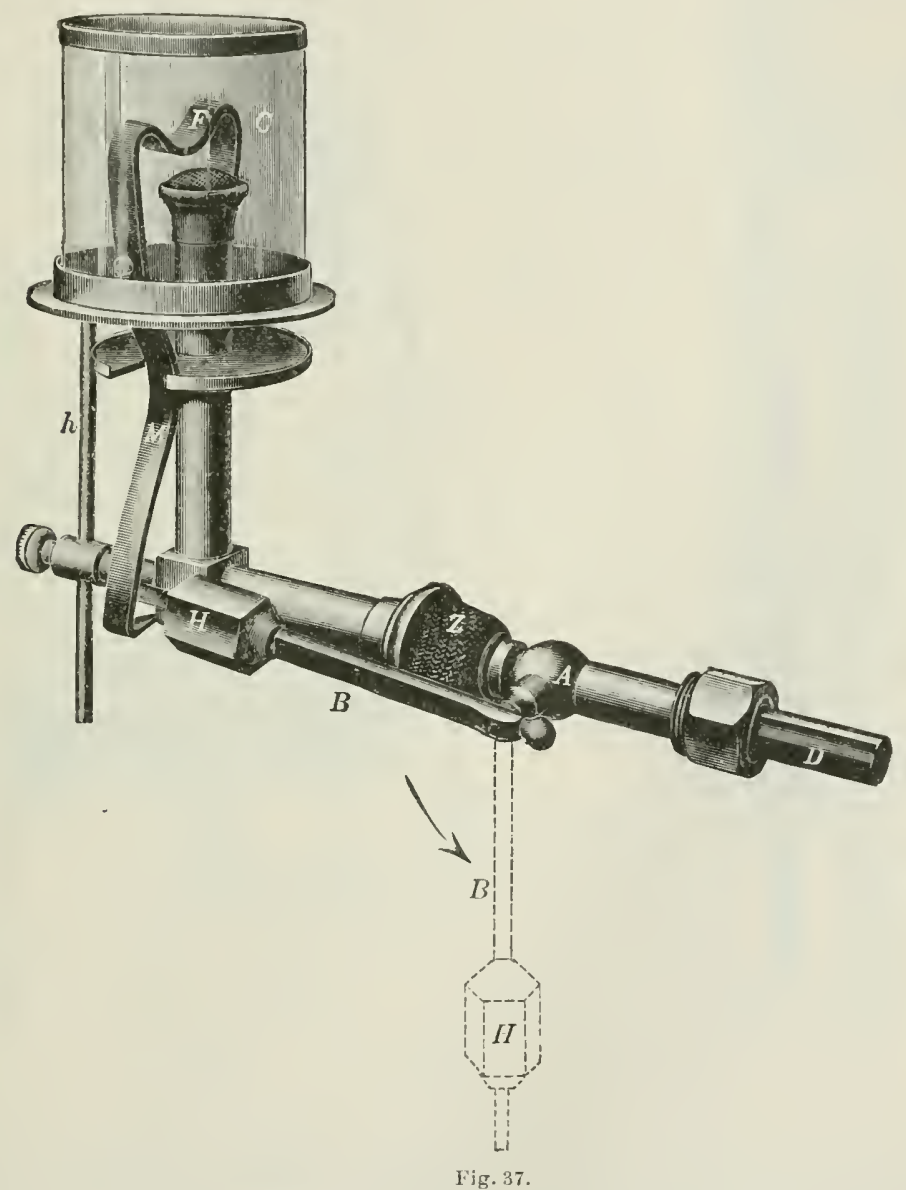

Brenner mit Drahtnetzerschluh, welcher eine ebenfalls mit Drahtnetz umgebene Mischungsdiise $Z$ besitzt. Über der Bremerkappe befindet sich eine Feder $F$, die aus cinem Doppelstreifen - Stahl und Yessing - hergestellt ist. Die Ansdehnung der Feder $F$ wird anf einen Hebelarm II iibertragen, der, sobald die Flamme bremnt, den Hebel $B$ mit Gewicht $H$ in wagrechter Stellung auf die Cnterlage $U$ hält, wodurch der Hahn $A$ auf bleibt. Erlischt die Flamme, so kiihlt sich die Feder $F$ ab und ver- 
sehiebt den Hehelarm $M$ : dadurch wird dem Hebel $B$ die Unterlage $U$ entyogen: (r) fällt infolge der Gewichtsbeschwermng herab und nimmt die vertikale Stellune an, in welcher der Hahn $d$ die Gaszufuhr verschlielit. Beim Auheizen wird ier Hebelarm $B$ so lange in wagrechter Stellung gehalten. his die Feder $F$ durch die angezindete Flamme geniigend erhitzt ist und die Tuterlage I das rewicht $H$ festhält.
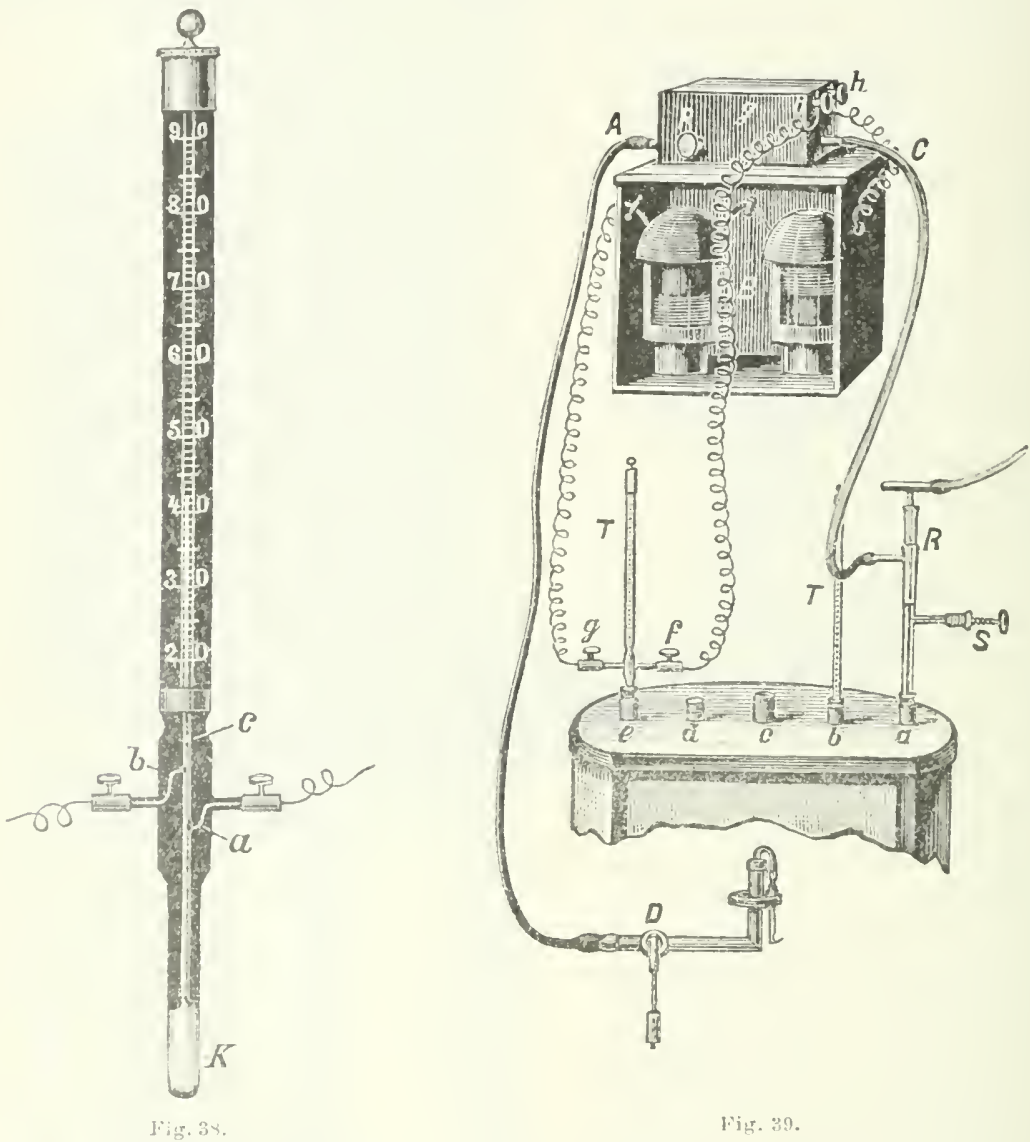

Zmm Konstanthaltun der Temperatul in den 11 assorbutschränken hrdient man sich entweder eines elettrischen Thermoregulators oder wints: (quecksilherthermoregulators.

Dore Lantenschlägersche elelitrische Thermoregulator besteht ans cinem Konstanthermomoter, einem (iasschliefier mit Elektromagnet und Vorlage sowie eincm Bremer.

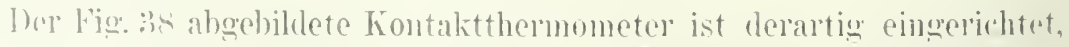
das in die lufterere Kapillare zunäclast zwe Platindrähte eingeschmolzan

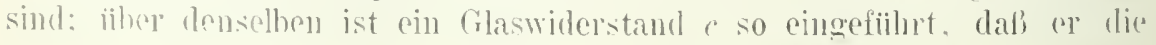
Kápillare niedet rollständig verschließt, sondern für das aufsteigende (pueck- 
silber noch Raum läbt. Durch diese künstliche Verengerung reift der (Quecksilberfaden beim Zurïcksteigen bei c ab und bleibt oberhalb des Widerstandes stehen. während die unterhalb) $c$ befindliche Säule in die Kugel $k$ zuriucktritt.

Bei der Tätigkeit des Thermometers reminimen sich beide Querksilbersäulen nicht, sondern dic unter $c$ befindliche gelangt nur his zum Poldraht 7 . wodurch stromschluf eintritt und die (iasflamme bis anf eine regulierbare lieserveflamme ahgeschlossen wirl. Sinht nun die Temperatur. so rerläft die Säule den l'oldraht $l$, wodurch stromöffnung eintritt und die Hauptgaszufuhr wieder frei wird.

Wie die Fig. :3! es zeigt, ist das Thermomoter $T$ mit einer elektrischen Batterie $B$ und einem Gasschliefier $G$ verbunden. Dieser sperrt bei Stronlath-

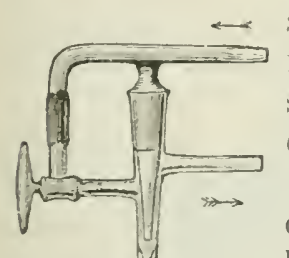
schluf die Hauptgaszufuhr bis auf eine regulierbare Reserreflamme ab und stellt bei stromöffnung den freien liasdurchgang wieder her.

Del Gasschliefier $G$ besteht ans einem Hebelarm mit Eisenker'n. welcher" bei Stromabschlue an die im Imnenramm angebrachten Elektromagnete gezogen wird. Die Lage des Hebelarmes wird dadurch rerindert. und folglich die Hauptgaszufuhr his auf eine Reserveflamme abgeschlossen. Hiese ist dureh die Schraube $R$ fur rerseheclene Temperaturen einstellbar.

Ijie Quecksilberthermoregulatoren kïmnen in zwei truppen eingeteilt werden. je nachdem die Gaszufuln lediglich diureh die Ausdehnmo einer relativ dïmen Quecksilbersäule geregelt wirl, oder dureh die ron Dimpfen leicht siedender Fliissigkeiten rerursachten Fig. 40. Auf- und Abwärtsbewegungen eincr

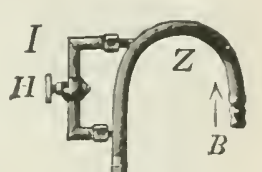
relativ dicken Quechilbersäule.

Die ersteren ermöglichen keine sehr genaue Einstellnng des Brutschrankes und miissen fiir Terdaumesrersuche röllig verworfen werlen. Hierher gehören der in Fig. t) abgebildete Reichertsche Qnecksilberregulator. der Thermoregulator nach Schenck. der Thermoregulator nach Chancel usw.

Die anderen Thermoregulatoren (nach Lothur Meyer, Soxhlet usw.) halten hingegen die Würme auf Bruchteile eines Grades genan gleichmälig. Einer der zweckmäßjgsten ist der Spiralthermoregulator nach Lantenschlüger (Fig. 41), weleher vom Luftdruck unahhängig ist. und bei denı die 
Lecoreflamme anroh dinfaches Drehen des auf einer Nehemü̈hre befindliehen lahnes /I fir rerschiedene Temperaturen einstelloar ist. Er bosteht ans (incm ohen dureh cinen Metallkopf $T$ mit stopfluiehse versehlossenen Glas-

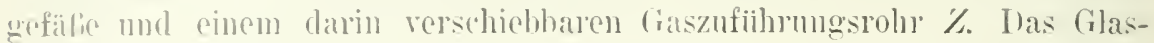
wefiali teilt sich in rimen unteren liegnlierram $R$ mit eingeschmolzener (ilasspirale $S$ und einen Gastamm $G_{x}$. ron dem das Gasahfühumgsrohr 1 zum linenner geht. Das Zuführungsohr besitzt eimen Notanslauf $N$ und andigt unten mit einem schlitzförmignen Inssehnitt $l$. Del Regulier-

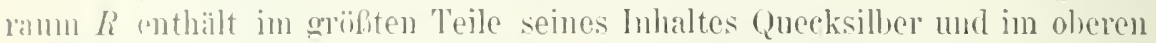
iihrighleibenden Teile eine je nach der zn erzielenden "Temperatur gewïhlte

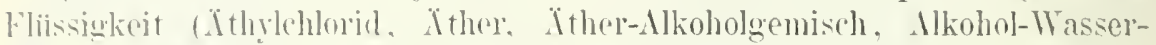
gremisch. Wasser, Inilinöl-Wassorgemisch, Aniliuöl) mud deren Dämpfe.

I)iesc Fliissigkeiten drieken bai den hestimuten Wärmegraden die

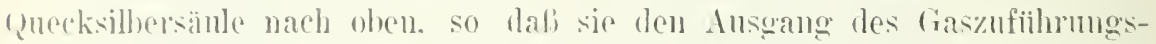
rohles verschliebt und das (ias nur durch das Notloch $N$ entweichen und die lieserveflamme speisen kaun.

Die lnbetricbsetzumg des Lautenschlügerschen Spiralthermoregulators ist folgende: Ine (ilaskioper wird in den Wasseram des Brutapparates eingefiilnt und in eine Mrtallhiilso mit Zirkulationsvolrichtmo so gestellt, dal) el sich nicht beweren kam. A wird mit dem Premer. $B$ mit der Gakidung rerbundem. Sobald das Thermometer im Wasserram des Appalates cine 'Temperatml anyeigt, die nugefäln $1 \%$ bis $2{ }^{\circ} \mathrm{C}$ unter dem einzustellenden Wirmenad liewt, beohachtet man den bremer und schiebt langsam mul rorsichtip das Rohr Z so tief in das Quecksilher hinein. bis der Schlity $L^{r}$ vollstïndig verschwindet und nur durch die Notöffnumg $n$ (ias zmm lbenme gelangen kamn. l)er Schlitz $U$ des Metallrohres ist nicht sichthar, Man kam bei ganz allmählichem Einsehieben des Rohres an

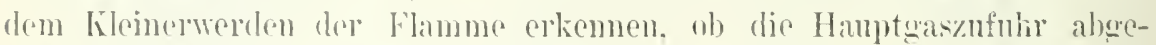

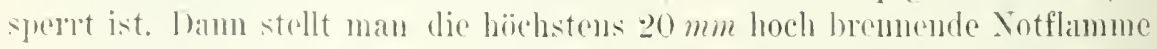
dureh lowehen des Hahnes $H$ anf diese Höhe ein. I)er bremer selbst mub mindestens $150 \mathrm{~mm}$ fom Boden des Brntaploalates entfornt sein. Steigt die "Temperatul noch, dam ist entweder die Notflamme klemer zu stellen oder ras mit 'Teilumg verselsene Gasufübrungspoh' $Z$ nm $1 \mathrm{~mm}$ und nach liedarf noch weiter einzustellen. Fällt dagegen die Temperatur mter den

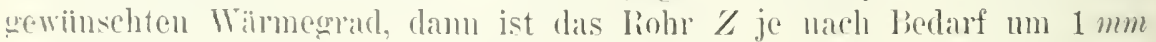
oder mehr nach oben zu relschichen.

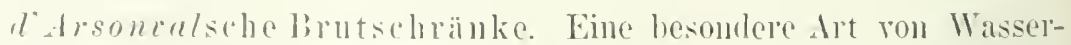

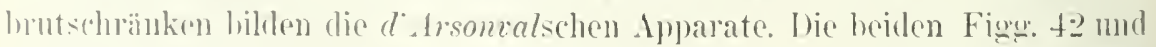
4:) veramsehanlichen dieses Srstem. Iner Jirutschank besteht ans einem inmeren luftramme. Welcher iiberall durch ״n Metallwände begrenzt ist. \% wischen diosen befindet sich eine Wasserschicht. Inese Metalloppelwand

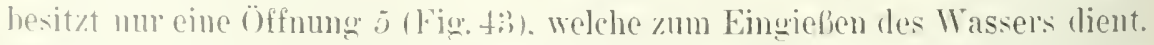
Man dan mu kur volher zun sieden erwillmtes Wasser henutzen, dem die im gewibulichen Massu enthaltenen Luftblasen werden heim Elwärmen frei, verindern die Höhe der Fliissigkeit mol verhindern die Regulierung 
des Apparates. Die iubere Metallwand ? ist muten durch eine biegsame stahlplatte 3 abgeschlossen. Sie dient als Jecke fuir eine Kammer 10, in die eine Ansatzröhre 12 eindringt. Inrch diese strömt das lias zu, das damn durch die liöhren 13 und 1.3" den Bremnern zugefülurt wird. Mittelst eines Gewindes kann man das Ende der Ansatzröhre 10 del l'latte entfermen oder nähern. Lm den Apparat für : $\tau^{\circ} \%$ B. zu regeln, entferut man die Ansatröhre 10 von der Platte 3, so daf das Gas hej

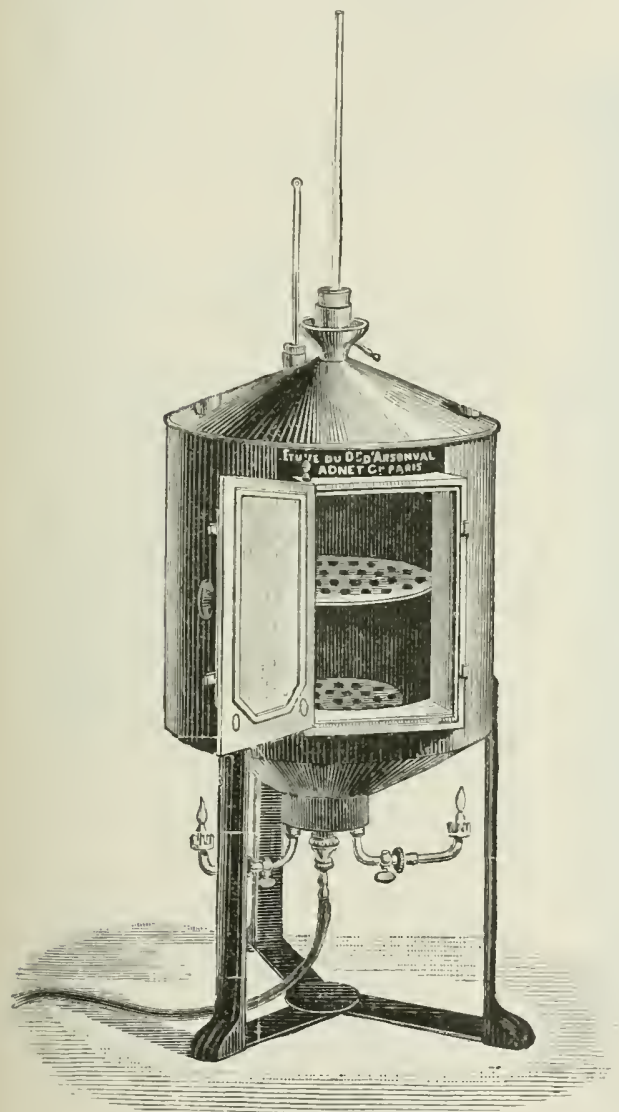

Fig. 42. voller Flamme brennt. Wenn im Luftraume des Brutschrankes die 'Temperatur : $36^{\circ}$ erreicht, so nähert man die liöhre 10 der' 'latte 3 , um die Höhe der Gasflammeetwas zu vermindern. Sofort wivl ric Öffnung s)

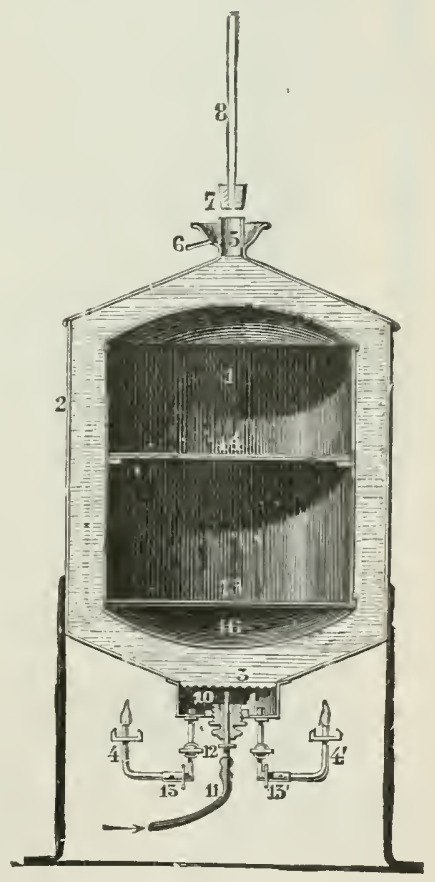

Fig. 43.

mittelst eines mit einer Glasröhre 8 versehenen Stopfens relschlossen. Lnter dem Einflusse jeder Temperaturerhöhung dehnt sich das in der Doppelwand enthaltene Wasser, steigt in die Röhre 8 und drickt die Platte 3 nieder, wodurch die Gasflamme kleiner wird. Es muf darauf geachtet werden, daß die Höhe des Wassers in der Röhre $S$ nicht durch Abdampfen sinkt, sonst nimmt die Temperatur im Brutraume zu. Ein Nachteil dieses Apparates ist, dab die Elastizität der biegsamen Platte mit der Zeit ahnimmt, wodurch die Einstellung des Brutschrankes leidet. 
(5) Mittelst Metallröhren geheizte Brutschränke. Als solche benutyt man meistens den Rourschen Brutschrank. Wie Fig. $4 t$ zeigt. besteht dieser Iirutschrank ans einem mit einer Glastiir vorn verschliefibaren Hol»chranke, dessen untere und obere Wand mit einer Kupferplatte relsehen ist. Dieser Schrank steht auf Fiife iiber einer Glasrampr. In Brutshrinke hefinden sich eine Reihe sonkrechter, gegen die immere

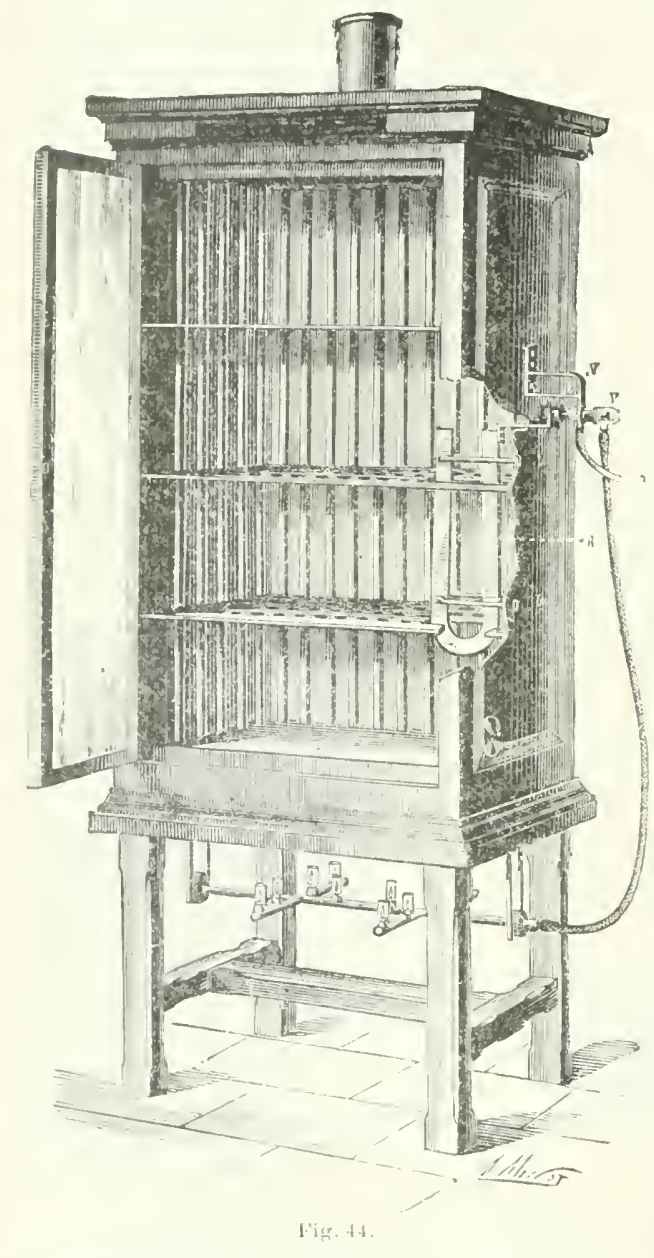
Seite der Holzwinde gelegener Kupferröhren. durch welche die rom Verbremmmgsase herrihrenden Gase strömen und anf diese Weise durch Strahlung cine gleichmälige brwärmung der' im limtschanke enthaltenen Luft elzielen. Zur Veutilation dienen kleine öfnumgen im nuteren 'Teile der scitenwinde sowite eine mit einer limran Liohre versehene öffmomg in der Decke des lintschrankes.

Der dureh die Figg. t. muml 46 velansehamlichte Rouxsehe Metallthermoregulator besteht aus einem durch Lïten cinel äufieres! Zinkplatte $\not z$ mit ainur inneren stahlplatte 1 herestellten U-förmigen oder geralen stabe. Inas dureh die liölure $C$ z:11strömmule (ras tritt in den Vemtilkasten $E$ mond wird durch die liobre $C$ fortgetricben. Mittelst der den Ventilkasten $E$ mit dem Netallstabre vereinigenden Schrambe $I$ wiril der V'entilkasten mehr voler minder dem stale milhe gechracht.

sinkt lie Temperatur des Ifodiums, so zieht sich die Zinkplatte molur als die stahlplate murick, so daf das U-fömige [oppehnetallsystem sich zo iffnen stroht. Wilhrend in geraden Stabe beide Jetallplatten sich in der Nähe der Ventilklappe von cinander" zn entfernen streben. In beiden

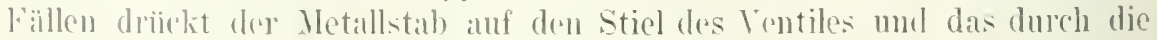
liobne $C$ in Ventilkasten $E$ eintretende Gas wirl in melo oder minder errolier Venge durch die liöhre I) strömen. un dem Gashrenner zuznfliefien. Ian erhöht die crö̈fe der Gasflamme. indem man mitteist der 
Schraube den Ventilkasten dem Vetallstabe nähert. und rermindert sie hingegen, indem man den Ventilkasten ron der Ietallschraube entfernt. Wenn der Thermoregulator das Ventil völlig schliefít, so tritt das Gas durch die kleine öffnung $v$ direkt von der kïhre $C$ zur Röhre $D$, wodurch das Frlöschen des Ciasbrenners vermieden wird.

そ) Brutschränke für elektrische Heizung̨. In diesen Brutschränken wird die zum Erwärmen nötige Heizung mittelst eines auf der Bodenwand befindlichen widerstandsfühigen Leiters, den der elektrische strom durchlïuft, erzielt. Diese IViderstände kömnen entweder aus einem zwischen zwci Emailschichten sich befindenden brahte oder aus mit Amiant gewebtem Vetallgewebe oder aus die Winde des Brutschrankes iiberluufenden sole-

RÉGULATEURS BI-AÉTALLIQTES IE M. LE !) IRTIX.

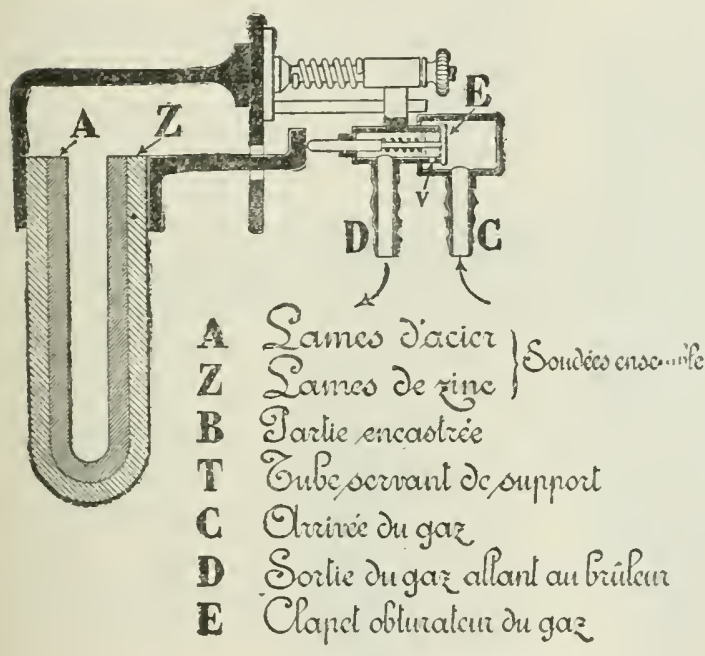

Fig. 45.

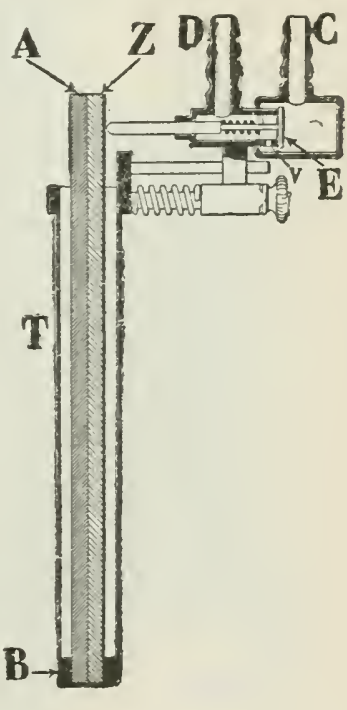

Fig. 46 .

noïlartigen Irähten bestehen. Am Boden des schrankes befindet sich ein Riadiator. werden.

Zur Regelung der Temperatur kïnnen mehrere srsteme ancerrandt

Bei Benutzung des Pouxschen Doppelmetallthermoregulator's verwendet man die in Fig. $4 \bar{i}$ abgebildete Anordunng. Der Tnterbrecher I schickt den elektrischen strom ohne Vermittlung des Regulators direkt in den Radiator $H$, so dali der elektrische Strom auf den Radiator $H$ auf solche Weise einwirkt, daf er ihm nur die zur Erhaltung einer konstanten Temperatur nötige Kalorienzulage bringt. Der änfere elektrische strom länft durch den bipolaren Cnterbrecher $B$. Einer der P'ole dieses Tuterbrechers $B$ steht in direkter Verbindung mit einem der beiden Enden der Radiatoren. Uer andere Pol ist mit den unipolaren Interbrechern $C$ verbunden. Der Unterbrecher $I$ erlaubt, einen beständigen Strom in den Radiator $H$ zu 
selicken. I)er [uterbrecher C gestattet, den strom entweder durch die Becher I/ des Jiegulators oder direkt durch den Regulierungsiheostat $R$ zum Iídliator $H$ zu senden. I)ic Station $r$, lessen elektrischel Miderstand sehr grop ist. wird mittelst des nur eine sehr kleine Strommenge durchlassenden liouxschen I)oppelmetallthermoregulators il in 'lätigkeit gesetzt.

REGTLATEUR ÉLECTRIOIE POUR CHAMBRE-ÉTLTE

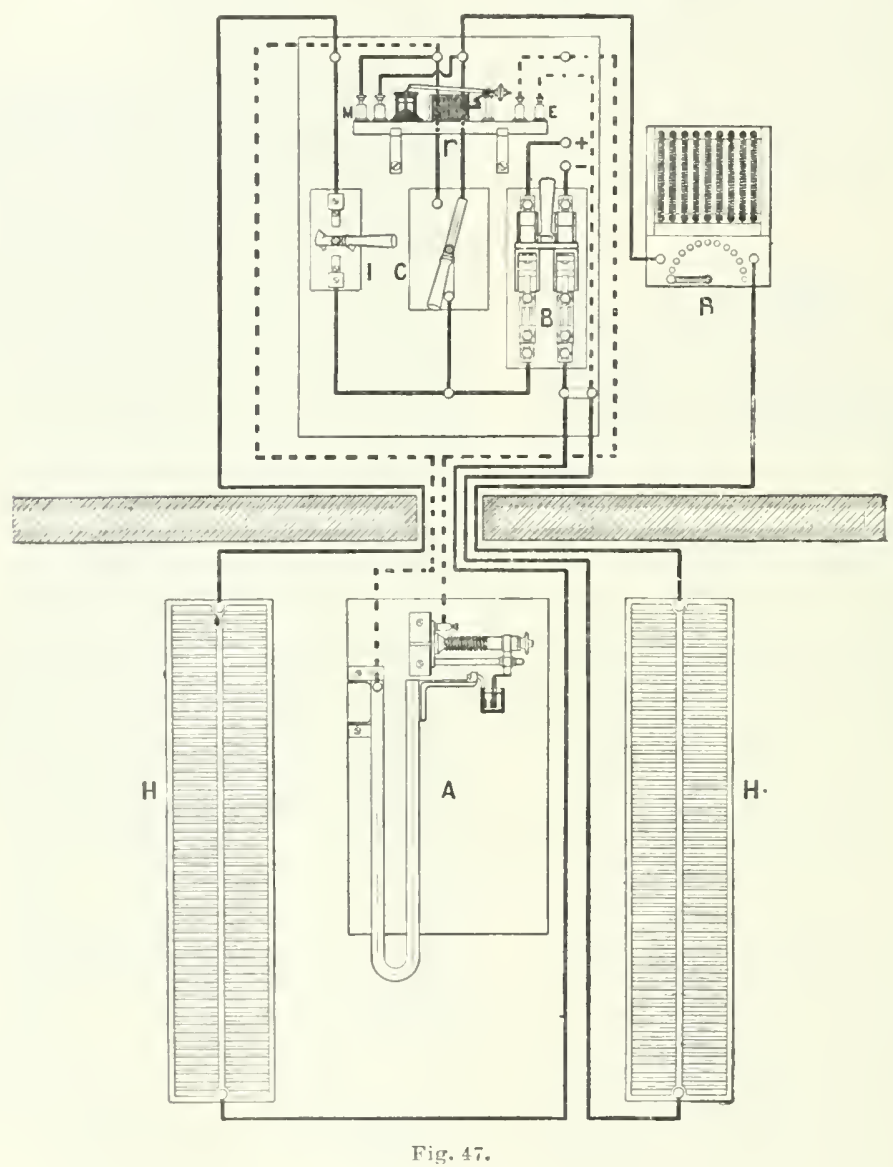

Suln empfohlenswert sind die Maurysehen brutschränke für elektrische Heiznng. Einen solchen zeigt Fig, t8. Die Mnordnung des Heizsrstems wirl durch die Fig. 4 !) reranschaulieht.

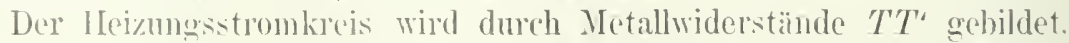
Fr liegrt wagrecht im unteren 'Teile des Apparates. I)er elektrische strom. in dem die. Jonlekraft entsteht. wird durels zwei parallele Widerstinde greleitet, ron denen der eine mit dem speziellen Relais $R$ verbunden ist. 
das den zum Thermoregulator $H$ gehenden Alyweigungsstrom unterbricht oder wierlerherstellt.

Die Regehng der Temperatur hängt rom Ricais und rom Regulator ab. Als eigentlicher Thermoregulator dient eine elektrolytische Liöhre, deren Form je nach dem Brutschranke verschieden ist. Diese liohre hesteht aus einem wagrechten, an Lnde verschlossenen 'Teile und aus einem senkrechten T'eile. Sie wird mit Quecksilber gefüllt. Wemn unter dem Einfluli der 'Temperaturerhöhung das Quecksilher sich ausdchnt, so nimmt die Höhe der im senkrechten Teile vorhandenen (Quecksilbersïule zu und das Quecksilber steigt in eine enge Glasröihre. welche mittelst eines gekitteten I'fropfens auf das offene Ende der elektrolytischen liöhre befestigt ist. Uher dieser engen Röhre befindet sich eine nach mien wurch eine Platinspitze endigende $\mathrm{Mi}$ krometerschraule I: Durch Drehen der Mikrometerschraube kann man diese Platinspitze mehr oder minder in die enge Glasröhre senken. Der Temperaturgrad des Brutschrankes wird durch den Kontakt zwischen Platindraht und Quecksilber geregelt. Der Regulator wird ron einem sich vom Erhitzungsstrom abzweigenden Strom durchströmt. Diesen $\mathrm{Ab}$ zweigungsstrom erhält das Relais $R$. Letzteres besteht aus zwei Rollen diimen Drahtes, in deren Achsen sich zwei an den Enden eines nicht mehr im Gleichgewichtszustande befindlichen Wagebalkens hängende

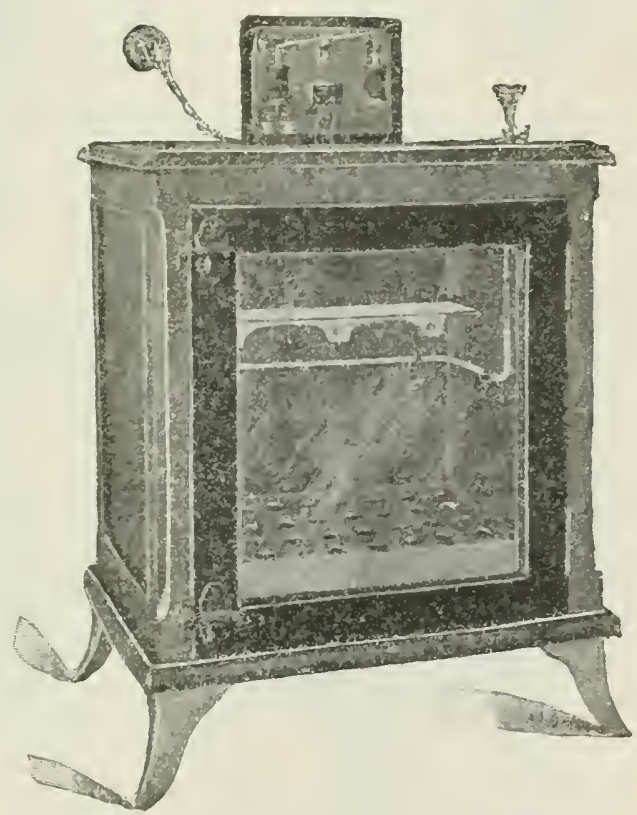

Fig. 48 .

Kerne aus reichem Eisen senkrecht verschieben können. Im Ruhezustand neigt sich der Wagebalken der Seite des Kernes zn, auf den ein Kupferdraht gelötet ist, der als Brücke zwischen zwei kleinen Eisenbechern $\mathrm{CC}^{\mathrm{C}}$. deren Boden mit Quecksilber versehen ist, dient.

Eine Abzweigung des Heizungsstromes auf einem sehr wenig Widerstand leistenden Stromkreis wird durch diese zwei Becher geleitet. Sobald die Temperatur sich zu erhöhen strebt, dehnt sich das Quecksilber aus, wodurch die Höhe der Quecksilbersäule im Regulator steigt. In einem gegebenen Augenblicke kommen Quecksilber und Platinspitze in Beriihrung. Sofort wird der der Metallröhre des Regulators zugefiihrte Abzweigungsstrom nach den Rollen abgelenkt, welche dann die Kerne aus weichem Eisen anziehen. Ton diesen Kernen steigt derjenige, welcher die Brüicke trägt. 
wihrend dev andere hingegen sinkt, so dab der Wagehalken wargecht zu liwen komut. Dadurch länft aber dam der Heizmosstrom nicht meh\% Jurch den wenig Widerstand leistenden stromkreis der Qneckilberbecher, smulern dnuch einen zugesetzten Widerstand, welcher die Joulekraft rer-

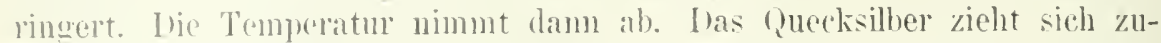

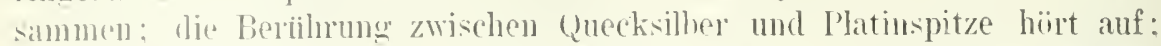
der Wagel)alken neight sich und dic Bribke zwischen den zwai quecksilher-

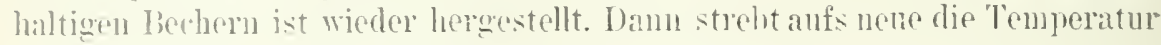

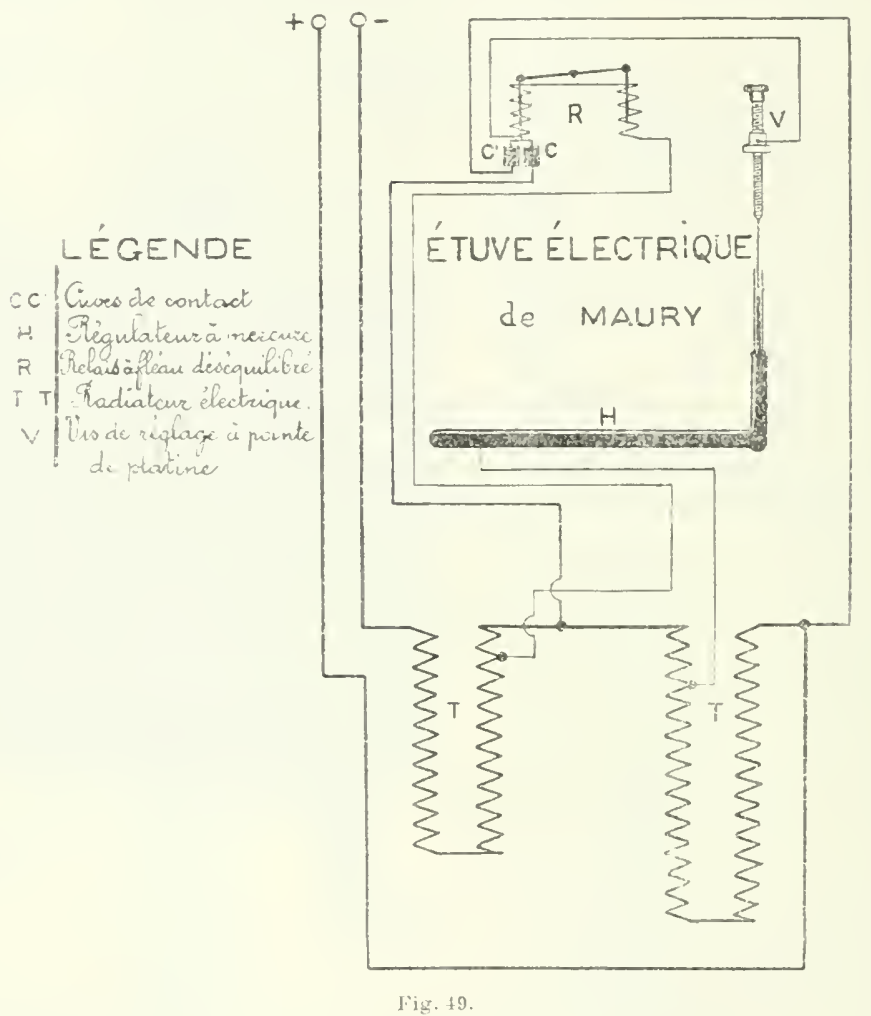

sivh zu ahöhen. his dey chen heschriehene Merhanismus wieder tatig wird mind so weitel.

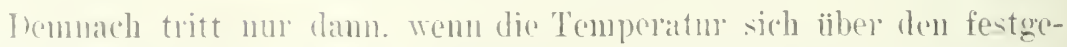

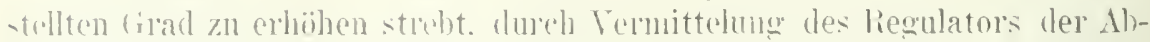

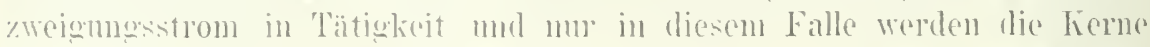
ats weichen Eisen innitten rop hollen angezogen. Ino stäke des Abzweiwungsstrones unfalit nur wenige Millimpere, was fiir die Aufrechthaltumg

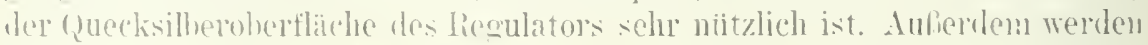

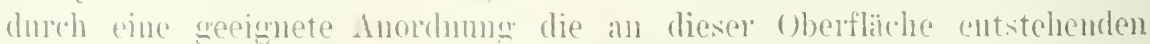
Finterbrechungsfunken anf ein Vinimun gebracht. 
llie Empfindlichkeit des Regulators ist sehr groß, dem die Temperatur schwankt nur um 1/4 (irad in der inneren Luft des Brutschrankes. Das Murrysche Erhitzungs- und Regelungssystem eignet sich ebenso gut für (ileichstrom als fuir Wechsclstrom.

Man kann anch die elektrische Heizung mittelst eines liegulators regelı, welcher mit einer einc Quecksibersïnle höher oder niedriger stellenden leicht siedenden Fliissigkeit arbeitet.

II. Thermostaten. I'm linngere Zeit eine anf weniger als $1 / 10 \mathrm{Grad}$ hestandige Temperatur zu halten. wie dies oft hei Verdaungsversuchen nötig ist, kann man Brutschränke nicht henutzen. Es ist nämlich völlig unmöglich. ein festes und fliissiges System mit erheblicher Wärmekapazitit mit einem Gasmedium seh" geringer Wärmekapazitiit in stets rasch eintretendem Gleichgewichte zu halten.

Deshalb soll man die Thermostate den Brutschränken bei allen Verdauungsversuchen vorziehen. Der Fig. 50 abgebildete Ostwaldsche Thermostat besteht ans einem emaillierten Gefäße, welches ron einem Wärmeschutzmantel aus Filz umgeben ist und auf einem Dreiful ruht. Dieser Metallbehälter ist mit Wasser gefiillt, in welchem man bei langem Gebrauch etwas Jodquecksilber in Leinwandbeutelchen bängt. um die Wasserverunreingumg durch Bakterienbildung zu verhindern. Ein durch einen geeigneten Motor in 'Tätigkeit gesetzter Fliigelriihrer' oder anderer Riihrer bewirkt eine stetige Mischung des Wassers, wodurch die örtlichen Temperaturdifferenzen im Thermostaten ausgeglichen werden.

Die Versuchskolben oder -Röhren tauchen völlig oder teilweise in die

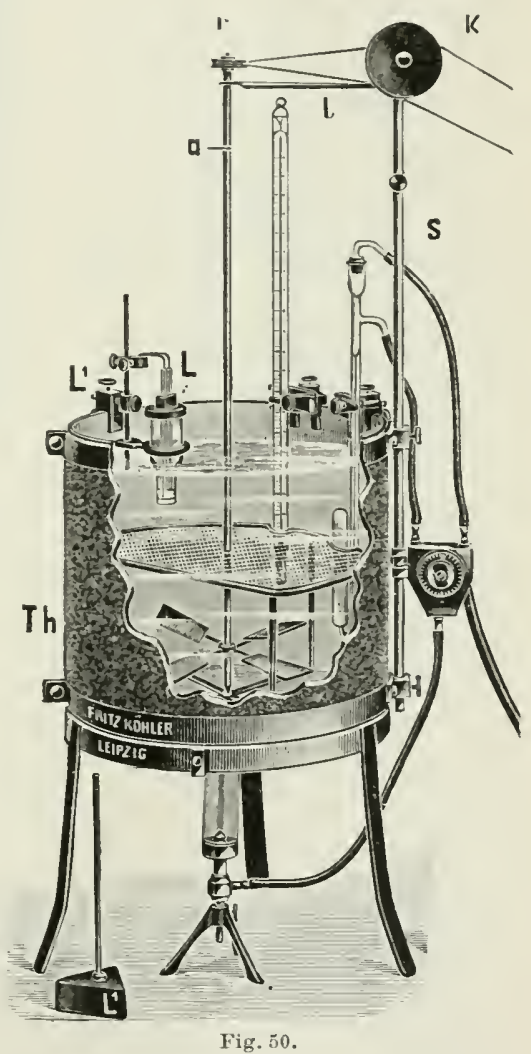
erwärmte Wassermasse. Durch hesondere Schüttelvorrichtungen können die in den Kolben oder Eprouretten enthaltenen Versuchsflïssigkeiten einer hin- und hergehenden Bewegung oder auch einem vollstïndigen Rotieren unterworfen werden.

U'm das sich verdunstende Wasser zu ersetzen, bedient man sich eines Konstantniveaus, wie das in Fig. 51 gezeichnete. Dazu wird der Thermostat mit einer $10 \mathrm{~mm}$ großen, unter dem Nirean liegenden Bohrung versehen, in welche die Verbindungsröhre des Konstantniveaus geschraubt 
wirl. Inas verstellbare Niveanrohr $I^{\top}$ gestattet ein Einstellen des Wasserspiegels in gleicher Hïhe seines seitlichen bohrungen. Durch das mit der Wascrleitmo verbundene Einlanfstick $E$ fliebt Wasser, so dall es den velolenen Inlalt ersetzt. 1)er I'berschub des zufliebenden Wassers wird dureh dic öffmmon des Niveamrohnes abgeleitet.

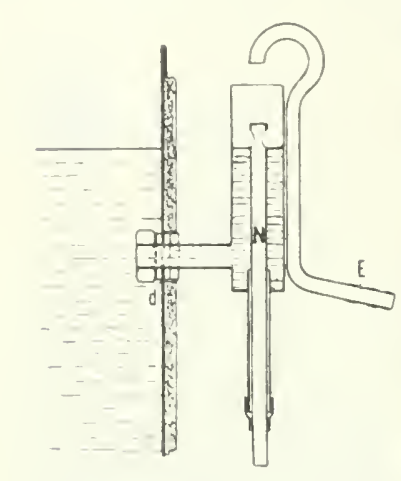

Wig. 51.

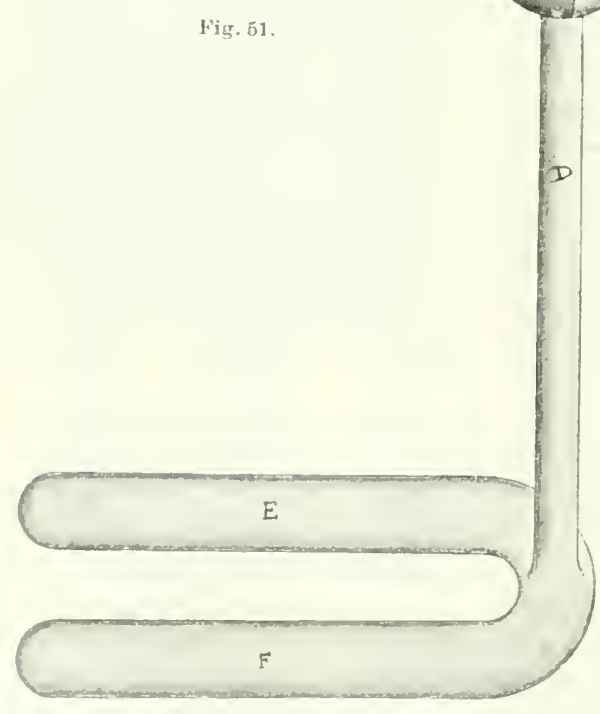

Fig. 52 .

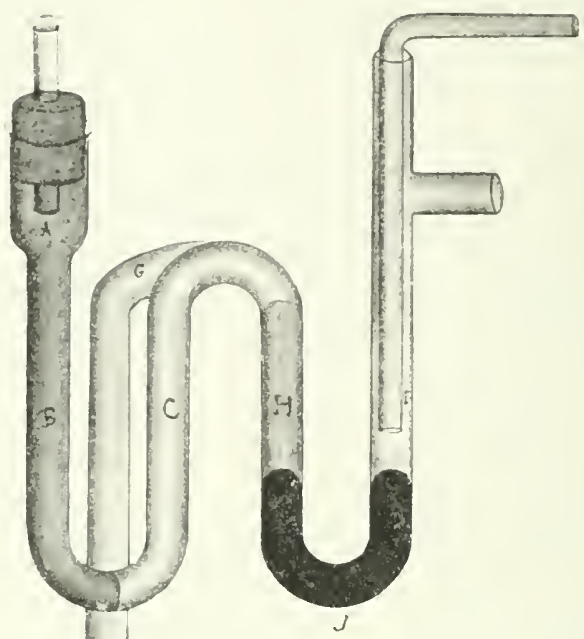

Der deul Thermostat erwämende Gasbrenner ist mit 2 Ableitmugen der Crasleitmug verbunden, wovon dis cine dem geringen Gasstrome der beständigen Flanne Durcheang liefert. während die zweite, auf derem Laufe die Regulierungsvorrichtung geschraubt ist, zeitweise die auberdem nötige Hilfscasmenge zum Gasbrenner strömen läßt. IDie Timperatm des Wassers wechselt also zwischen ¿- Grenzen, welehe man einander so viel wie möglich nähcrı muli. I ine wird dureh einen 'Toluolregnlator erzielt. Inter diesen ist zul'zeit der empfehlenswerteste der durh O. Dony-Hénault beschriebene, welchen dic Fig. 52 veranschaulicht.

I)ieser liegulator besteht ans einer in Wasser eintauchenden senk-

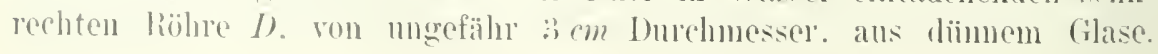


Sie endigt unten durch eine $\mathbf{U}$-förmige wagrechte oder irgend eine andere der Gestalt des Behälters passende liöhre F:F. Die größte Iasse des als Regulierflüssigkeit dienenden Toluols muß sich an Boden des Behälter's in der Nähe der der Wirkung des Erwärmens unterworfenen W'and befinden. Dic Röhre $D$ rerengt sich ohen etwas und endigt durch die fast wagrechte liöhre $G$ in einem aus 4 senkrechten liöhren $A B$. $C$. $H$ und $I$ zusammengestellten System.

Der vorher mittelst der Wasserpumpe von Luft befreite Regulator wird mit Toluol gefiillt, so daß die Flïssigkeit keine Gasbläschen enthält. Dann wird der Regulator in den Thermostaten gelegt und dieser ungeführ auf die gewiinschte Temperatur gebracht. Sobald dies erreicht ist, gielit man in die Röhre $I$ zuerst genügend konzentrierte NaCl-Lösung, um die Röhre $H$ völlig zu füllen und nachher die Quecksilbersäule $J$. welche die NaCl-Lösung in die Röhre $H$ treibt, darauf wird mittelst Filtrierpapierstreifchen die Röhre $H$ sorgfältig getrocknct. Las die Röhre $A B$ füllende Toluol wird abpipettiert und durch konzentrierte NaCl-Lösung ersetzt. Damn wird die Frweiterung $A$ der Riöhre $B$ durch einen Kautschukpfropfen rorsichtig geschlossen, in dessen Vitte eine mit einem Kiautschukansatz und einer Kilemme versehene Kiapillarglasröhre sich befindet, durch welche der Flïssigkeitsüberschuf leicht ausfließen kann. Im geeigneten Augenblicke wird die auf dem Kautschukansatz befindliche Ḱlemme geschlossen. Nan trocknet Pfropfen und Kautschnkansatz. Lm einen völlig dichten Verschlul des liegulators zu erzielen, werden Pfropfen und Kautschukansatz mit einer Gummilackfirnisschicht überzogen. Das zwischen den beiden NaCl-Schichten $B$ und $H$ eingesperrte Tolnol kamn nicht entweichen. so daß. wenn der Thermostat in einem Zimmer sich befindet, deren Temperatur keinen grofen Schwankungen muterworfen ist. und die Temperatur des Thermostates sehr lange Zeit unverändert bleibt. Ein Temperaturunterschied von $1^{0}$ in Zimmer berîlit eine mittlere Yeränderung der 'Temperatur des Thermostaten von $0^{*}\left(1^{\circ}\right.$. Tm diese Temperaturschwankungen noch zu verringern, mub man entweder den im Wasser nicht eintauchenden Teil des Regulators mit einer den Wasserverlust vermindernden Hülle versehen oder den größten Teil des Systems $B C H I$ in ein Wasserbad eintauchen lassen.

Ein Vorteil des Dony-Hénaultschen Regulators über die Ostucaldschen Toluohregulatoren ist, daß man ihn nach dem Einfüllen ohne Neueinfüllung nacheinander auf sehr rerschiedene Temperaturen bringen kann. ['m die 'Temperatur des Thermostaten zu emiedrigen, entnimmt man den

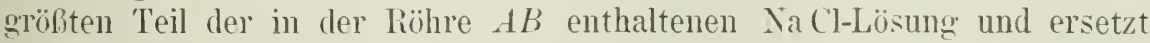
sie durch Toluol. Beim Erhöhen der Temperatur dringt wegen seiner geringen Densität das sich ausdehnende Toluol durch die in $A B$ euthaltene Fliissigkeit. $\left.{ }^{1}\right)$

1) O. Dony-IÍnault, Sur le réglage rigoureux de la température. Bull. de la Soc. roỵ, des Sc. méd. et nat. de Bruxelles T. 62. p. 188-196 (1904). 
Der (hurch Foì') verändelte Kenzo Sutosche Regulator ist äuberst (mpfindlich. Er erlanbt die T'emperatur des Thermostaten mehrere Wochen lang ohne andere Verïnderungen, als höchstens tägliche Schwankungen von 0.0.- 0.030 zu erhalten. Der Fousche Apparat ist ein Fliissigkeitsregulator, hei walchem Potrolem als Fliissigkeit verwendet wird.

Wie Fin. 5:) zeigt, besteht der Fousche 'Thermoregulator aus einer wagrechten, hufuisenförmigen höhre, deren drei seiten eine Länge von $20 \mathrm{~cm}$ mul einen inneren Durchmesser von $t \mathrm{~cm}$ haben. Ans dem mittleren schenkel steigt senkrecht eine lïhre $A$, welche mit der Röhre $B$

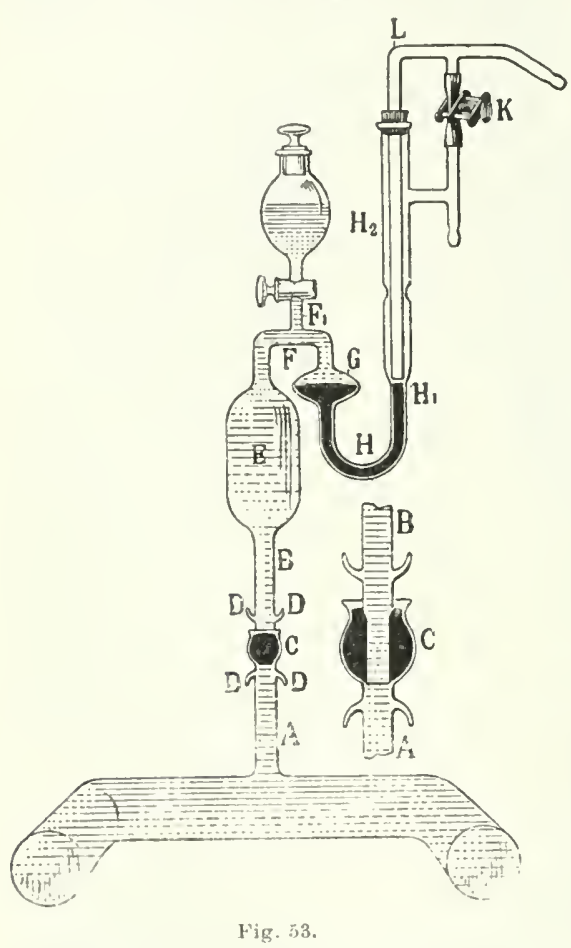
luftdicht rerbunden ist. Jie Terbindungsstelle ist mit cinel (necksilherschicht $C$ umgeben; auberdem kamn man noch eil (iummiband in dem Haken $D$ befestigen. lie liöhre $B$ trïgt eine $5 \mathrm{~cm}$ breite und $10 \mathrm{~cm}$ hole Erweiterung, ïber welche sich die liöhre $B$ wagrecht biegt. An der Biegung zweigt sich senkrecht eine durch einen Hahn $F^{\prime}$ geschlossene Riihre; oberhalb des Hahnes elweitert sich diese liöhre trichterförmig und wird dmeh einen Glasstopfen verschlossen. Die Riöhre $F$ biegt dann wieder senkrecht und endigt in einel Erweiterung $G$ von $4 \mathrm{~cm}$ Querdurchmesser und $11 / 2 \mathrm{~cm}$ längendurchmesser. Diese Erweiterung $G$ dient zur Aufnalume des in der Röhre $H$ enthaltenen Quecksilbers, wenn bei Erlöschen der Flamme des Thermostaten das Quecksilber mach dem Inuern des Regulators zu flieben strebt. Die quecksilberhaltige Röhre $H$ wirl bald kapillar und biegt nach ohen, um bei $H^{1}$ sich wieder zu (rweitern. Die das Gats einfiihremde liöhre $L$ dringt in die löhre $H^{2}$ bis zmr öfnung der Kapillare $H$; sie hat unten eine wagrechte offnung ron 2 mm Inrchmesser. In einer strlle der Röhre $H^{2}$ besteht eine Verengerung. um Verschichungen der liölue $L$ zu vermeiden. Die Verbindung $A-B$ bezweckt, den Untausch des das l'etrolem enthaltenden Crefübes $A$ zu ermöglichen, so daß letzteres entsprechend der Form des Thermostaten durch ein anderes ersetzt werden kam. Die Erweiterung $E$ ist angehracht, damit der Ipparat die Temperatur

$\left.{ }^{1}\right)$ ('. Foà, Eine Methode graphischer Kegistrierung einiger Gürungsvorgänge. Bio(dem. \%eitschr. Bd. 11. p. 382-399 (1908). 
der hoch gelegenen Stellen des Thermostaten annimmit. L'm den Forischen Thermoregulator mit Petroleum zu füllen, gießt man es zuerst in die Röhre $A$; dann nimmt man den oberen Teil des Regulators, hält ihn etwas greneigt und füllt die Frweiterung $E$, indem man eine geeignete, mit Petroleum gefüllte I'ipette bis zum Hahn $F^{\prime \prime}$ einfuihrt. Anf diese Weise führt man das Petroleum in die Erweiterung $G$ ein. in welche man schon vorher reines Quecksilber gegossen hat. Wenn der ganze Apparat gut gefüllt ist und in den Thermostaten grebracht wird, dehnt sich das Petroleum aus und sammelt sich im Trichter. Sobald die gewïnschte Temperatur erreicht ist, schließt man den Hahn $F^{\prime}$ und stellt die kleinste erforderliche Flamme durch Drehen der Schraubenklemme $K$ her.

\section{b) Verfahren zur Vermeidung der Anhäufung der Verdaungss- produkte.}

Die Anläufung der Verdauungsprodukte verlangsamt allmählich bei den Verdauungsversuchen in vitro die vor sich gehenden Prozesse und hebt diese schließlich auf. Um die entstehenden Abbauprodukte aus der Verdauungsfliissigkeit zu entfernen, bedient man sich der Dialyse. Man kann die Dialysiervorrichtungen in für alle biochemischen Untersuchungen anwendbare und in speziell für Verdanungsrersuche ersonnene cinteilen.

\section{Allgemeine Dialysierverfahren.}

Zur Dialyse benutzt man verschiedene Membranen: Pergament (Grahum, v. Wittich, Kühne, Proskauer usw.); Kollodium, Schilf, Zellulose (Metschnikoff, De Waele): in Lezithin oder Cholesterin getränkte Seide (Pascucci); tierische Membranen, wie Schweineblase (Hoppe-Seyler); mit verdünnter Salzsäure von den morganischen Salzen befreite Membran des Hiihnereies (Botkin); an einem Ende geschlossene Teile der Darmröhre oder von der Gefäßwand (Charrin und Moussu); Blinddarm von Schafen (Wiechouski): Speiseröhre, Amnios (can Calcar) usw.

Die dialysierenden Eigenschaften dieser verschiedenen Membranen für ein und denselben Stoff sind keineswegs stets dieselben. Das Dialysiervermögen der tierischen Membranen wechselt ziemlich stark mit dem Alter des Tieres sowie auch mit der Tierart, ron welcher sie herstammen. Dieses Vermögen nimmt mit dem Alter des Tieres meistens ab und ist gewöhnlich größer bei Pflanzenfressern als bei Fleischfressern. ${ }^{1}$ )

Dialysator nach Graham. Der Fig. 5t abgebildete einfache Grahamsche Dialysator besteht aus einem runden, mehr oder minder tiefen, mit destilliertem Wasser gefüllten Glasgefïße, in das ein Glas-

1) Botkin, Zur Frage von dem endosmotischen Terhalten des Eiweißes. Virchou's Arch. f. pathol. Anat. Bd. 20. S. 39-42 (1860). - Charrin et Monssu, Influence des dialyses ou filtrations intra-organiques sur les principes toxiques. Compt. rend. hebd. des séanc. de la Soc. de Biologie. T. j2. p. 694-696 (1900). 
zolinder taucht, dessen untere öfnung mit feucht iiber\%ogenem und festgebundenem l'eroanentpapier verschlossen ist. Dat: Pergamentpapies lïbt die Kristalloide durehtreten. nicht aber die Kolloide. Vor dem Gebranche muli man sich der Dichtigkeit des Pergamentpapiers durch Mufoielien von Wiscep versichern.

Umo zu repmeiden, dals zwischen der P'eromentmembran und der

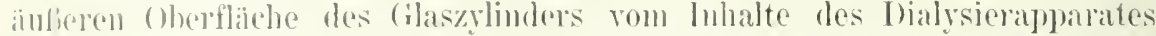
wegen deren Falten orler durch Kapillaritiit iiher die Ligatur heraustritt oder

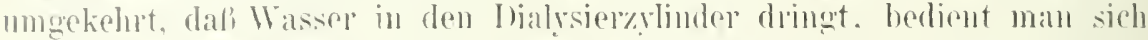

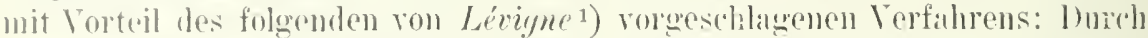

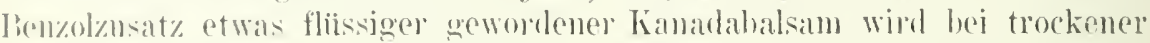
Jereamentmembran in die Furche gegrossen. Des' Balsam dringt iberall жwischerl Gias mol Membran mol verkiobt (ilaswand mod Vembram auf der ganzon Beriihrmugsflïche zusammen. Nach testiindigem stehen ist der balsam fest gewor-

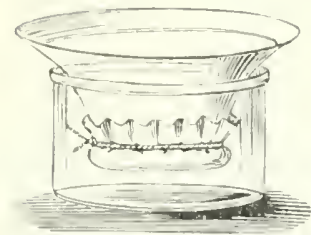

Fig. 54.

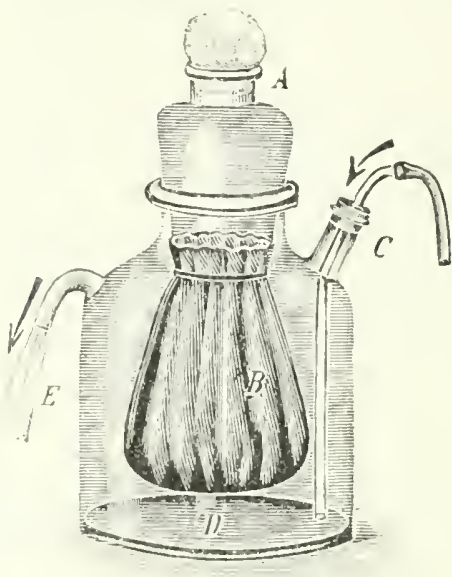

Fig. 55 .

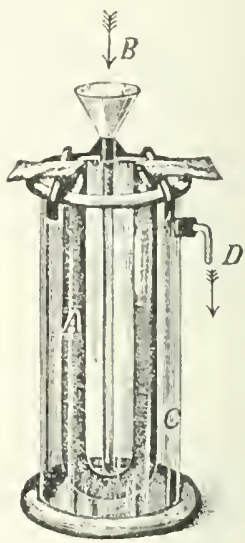

Fig. 56.

den, das Suhaften ist allgemein und die Dialysierapparate können angewendet werden. Wegen der Verdunstmog der in diesen Apparat gebrachten Lïsung kamn man don Grahomschen Inidysator nicht zu Verdammgsrersuchen anwemden.

Dialysator nach B. Proskuner. Der erwähnte Nachteil besteht

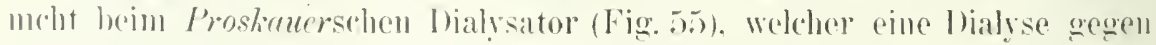
strömendes Wasser sowje die Sterilisiermg des Dialssitors erlaubt. Ihe

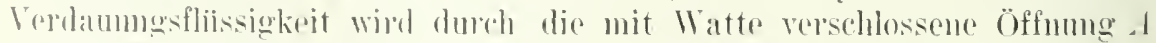

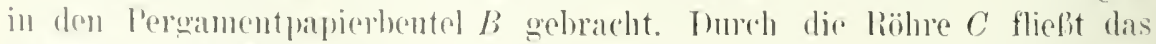

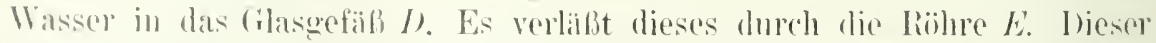
Aprarat kimm in den Broutschrank gestellt werden, so dal dam die Verdammg nuter bialyse mit stetiger Ernenerme des anlien befindlichen IViscirs erfolgt.

1) Hemi Luerigne, Recherches sur le passage de lacide urique et des sels a travers des memluranes incrtes. Thèse de Lyon 1905. p. 28. 


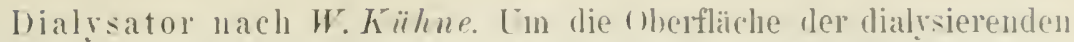
Ilembran zu veroüljern. hat kïhne die Inwendung von Dialysierschläuchen aus I'eromentpapier empfohlen. Wie die Fig. of es reranschaulicht, hat ḧ̈hme einen Apparat ersonnen. welcher erlaubt, unter stetigen kineuern des Wassers die I lialyse zu bewerkstelligen. Die dor Verdaumg unterworfene Fliissigkeit wird in den l)ialysierschlauch $A$ gebracht und der ganze Apparat in eimen Brutschrank gebracht, so dal' das Wascer durch den Trichter $B$ allmählich in das refiali $C$ fliefit und del Wasseriberschul, dureh die Nebenröhre $D$ ahfliel't.

Der Dialrsierschlanch mul\} stets zuerst anf seine Dichtigkeit geprift werden. wozu man iln mit Wasser füllt. Timnt er an einer oder mehreren Stellen, so mul' man die am wassergefiillten schlauch angemerkten Stellen nach dem Trockuen aufupfen, wozu man am besten die ron Jordis empfohlene, mit Alkohol und Ther passend rerdiinnte Mischung gleicher Teile Kólodium und honzentrierter Schellacklösung (1:1) benutzt.

Lm den Dialssierschlauch dicht zu verschließen. werden die offenen Schlauchenden entweder mit starken Fïden zugebunden oder hesser zwischen zwei mit Gummiringen verbundénen Glasstäben zusammengeprebt.

Di alysator na ch Wroblesti. Zur Dialrse in beständigen Strome ron sterilisiertem Wassel untel Telmeidung jeder Infektion der

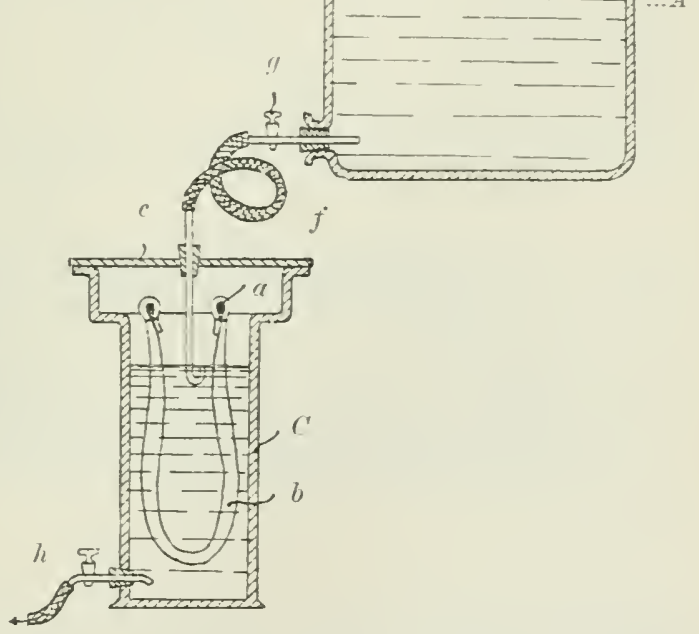

Fig. 57 . dialysieren den Flüssigkeit empfiehlt Wroblesti den in der Fig.ji abgebildeten Apparat. Dieser besteht ans einer hochstehenden, mit Wasserverschlub $B$ rersehenen. Mariotteschen Flasche A. deren Auslaufrohr (Harnrohr) g durch den schlauch $f$ mit einem diinnen Röhrchen verbunden ist, welches in die Bohrung des den Zrlinder $C$ dicht verschlielienden Deckels $c$ luftdicht eingesetzt ist. In dem Zrlinder (' befindet sich ein an den zwei Glasstïben a anfgehängter Pergamentschlauch b, in den man die zu dialysierende Fliissigheit bringt. Der Zyhinder $C$ hat unten ein mit einem Hahne versehenes Abflußrohr $h$, durch welches die äubere Flissigheit abfließt. In demselben Jaße wie dieser Abflub erfolgt. strömt Wasser aus der Mariotteschen Flasche in den 
\%rlinder C: Vor dem Gehranche sterilisiert man den resamtapparat und (as Wasser. ${ }^{1}$ )

Dialysierapparat vou Wuymouth Reid. Un die relative Diffusibilitat verschiedener Stoffe durch Pergamentpapier moter den gleichen 'T'mperatul-. Druck- und Flüssigheitsufuhrbediugmgen zu verogleichen. empfiehlt sich dio von Waymouth Reid angewandte Dialysiervorrichtung, welche durele die Fig. os veranschaulicht wird:

Fin mehrere Liter Wasser enthaltender, dureh die punktierten Linien in der Fiw. is angezeigter Kupferbehälter wird durch eincn groben Bunsenhrenner erwiant und durch cinen kleinen. von einem Motor getriebenen Acluranhenriihrer (I'l) geriihnt. In leicht eine beständige Temperatur zu erbalten, befindet sich der bumsenbrenuer dicht unter der Schraube. Im

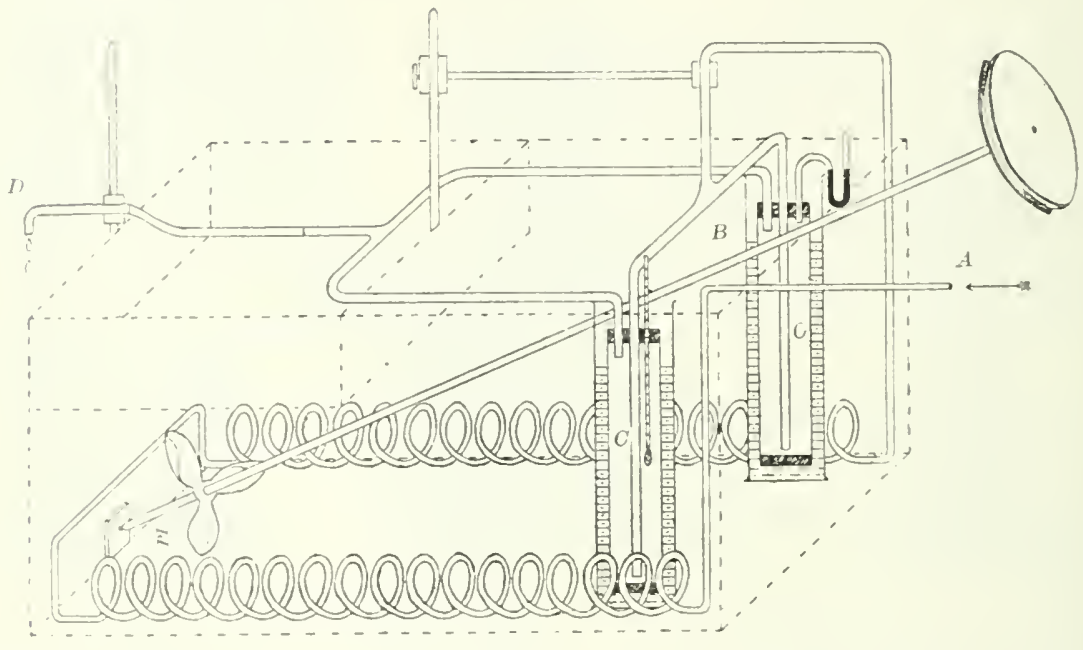

Fig. 58 .

Wasserbade hefindet sich rin Schlangenohr aus diimem liupfer. welches an cinem Ende (1) Wasser von der Wasseleitmo crhält, wähend das andere Ende dic zwei Dialysierzylinder $\left(C^{\prime}\right)$ speist. Dor Wasserstrom erwärmt sich im schlangenohr. wird dnreh ein T-liohr $B$ ron oben bis anf dron boden der beiden Ibatysieszytinder $(C)$ geleitet, fließt oben ans dem Dialysierzylinder ab und wind schlieflich durch das rerstellbare liohr I) nach anfen (rebracht. Die D)ialysiersehlänche hängen in den Dialysierzylindern: sie werlen wasserdicht mit Kantschukstopfen verschlossen. Wie \%rlinder selbst sind durch dreifach durchbohrte Stopfen rerschlossen. Imeh je zwei dieser öffnungen achen die Finflub- und Abfluböhren des Wasserstromes: in der dritten dringt auf der einen Seite ein 'Themometer, auf der an-

1) 1. Wrohleski, Zur Vialyse. Zeitschr. f. angew. Chemie. S. 692 (1894). 
deren ein Nanometer ein. Durch Verïndermo der Höhe des äuferen Ansflubrohres $D$ wird der in den Dialysierschläuchen bestehende Druck geregelt.

Beim Vergleichen del Diffusionsgeschwindigkeit zweier Substanzen mulb man vorher die Dicke des I'ergamentpapieres mit Hilfe eines Zeißschen Mebapparates fuir Deckgläschendicke bestimmen. Aulierdem enpfiehlt Waymouth Reid. sich durch Vorver'suche mit Glukose von der gleichen l'ermeabilität der beiden Dialysierschlänche \%n iil)er\%engen. ${ }^{2}$ )

Dialyse nach Gïrber. Ein absolut sicherer Verschlub der P'ergamentdialysierschlänche läßt sich nach Gürber nur auf folgende Weise erzielen: Ein etwa $50 \mathrm{~cm}$ langes, gut eingeweichtes und anf seine Dichtigkeit geprïftes schlauchstiick wirl gleichschenkelig znsammengelegt, dann der eine Schenkel anfgeblasen und die zu dialssierende Fliissigkeit darin eingefïllt. wobei man sorgfältig zu vermeiden sucht, dals von ihr in oberen Drittel desseblben etwas hängen bleibt. Hierauf drïckt man diesen Teil des geöffneten Schlanches wieder zu, faltet ihn der Länge nach fächerförmnig mit dem entsprechenden Teil des anderen Schlauchschenkels und gewinnt so einen festen Papierstiel. Dieser wird ungefähr in der Nitte kräftig gedreht, dann die obere Hälfte um die untere geschlungen und der so gebildete Knäuel in ein kleines Stiick feuchtes Pergamentpapier gewickelt, um bei den jetzt anzulegenden Drahtschlingen ein Durchschneiden des sichlauches zu verhïten. Man legt eine Drahtschlinge von $1 \mathrm{~mm}$ starkem Messingdraht möglichst nahe der Umbiegungsstelle des Papierstieles und die andere $1-2 \mathrm{~cm}$ davon entfernt.

Der so erhaltene, iiherall gut verschlossene, gefiilte Dialysierschlauch wird mit der gewïnschten Wassermasse in einen durch einen fimmmistopfen verschlossenen Glaszylinder gebracht, welcher anf einer Schiittelmaschine befestigt wird, so dal die Flissigkeit in stetiger Bewegung bleibt, wodurch die Wand des ganzen Schlanches fortwährend bespiilt und ausgenutzt wird. Dieses Schütteln bezweckt außerdem noch folgendes: Beim ruhigen Stehen miissen die diffundierenden Stoffe nicht nur durch die Schlanchwand hindurch, sondern aus der dieser nächsten Fliissigkeitsschicht in immer entferntere schichten weiter oder ans entfernteren in diese herandiffundieren. Dabei kann es vorkommen. dali auf beiden Seiten unmittelbar an der Diffusionsmembran der osmotische Ausgleich nahezu eingetreten ist. während er sonst für die ganze Fliissigkeit noch lange aussteht, da die diffusible Substanz nicht in dem Maße hinzı- oder hinwegdiffundiert, wie sie durch die Nemloran hindurchgeht. Werden aber die Flïssigkeiten durch Schütteln fortwährend mechanisch gemischt, so haben die Vorgänge der Diffusion nur durch die Dialysiermembran hindurch stattzufinden und verlaufen 1 mn un so rascher, weil dann stets der gröbtmöglichste osmotische Unterschied hergestellt wird. $\left.{ }^{2}\right)$

1) E. Waymouth Reid, A liffusion apparatus. Joum. of Physiol. Vol.21. p. 85 bis 100 (1897).

$\left.{ }^{2}\right)$ A. Gürber, Die Salze des Blıtes. I. Salze des Serums. Verh. d. phrsik.-meil. Ges. zu Würzburg. Bd. 28. 21 \$. (1894). 


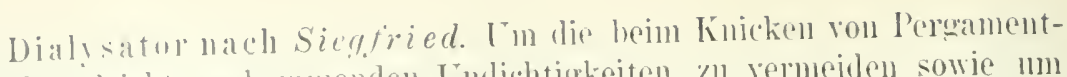

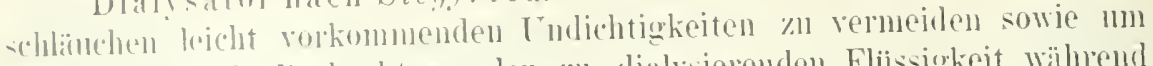

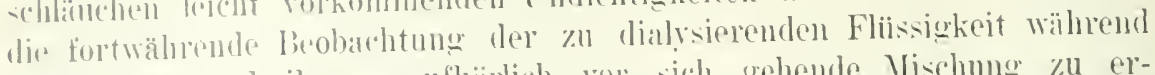
der Jhalyse mul ihne manfhörlich vor sich gehende Mischung zu erlauben, so dalf dann keine Diffusion immerhalb der klizssigkeit selbst ent-

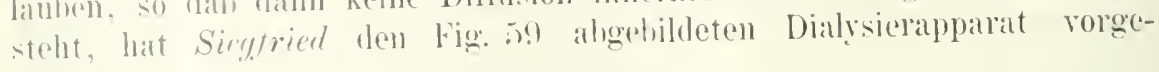
schlagents.

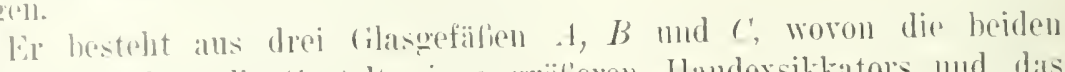

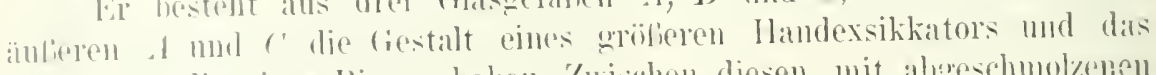
mittlen $b$ die eines Ringes hahen. \%wishen diesen, mit abgeschmolmenen

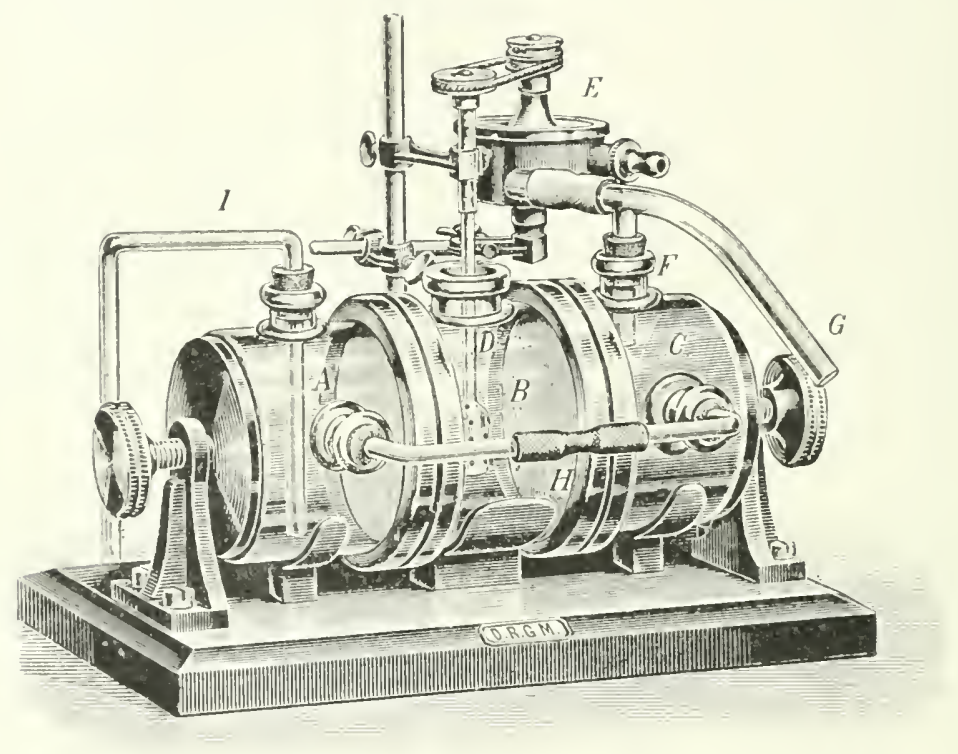

Fig. 59.

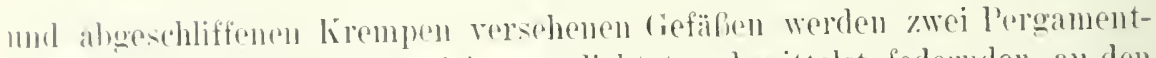
papiersobeihen, dhuch (immmiringe gedichtet und mittelst federnder, an den Krompen anliegender, durh vier schranben zusammengeprefiter Messingrimge wassoldicht befestigt. Dureh diese I'ergamentpaparecheihen vird der Inhalt

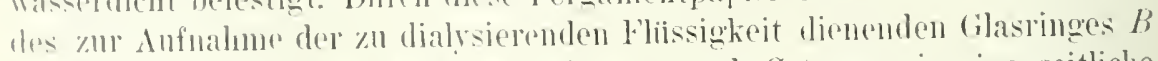
abgegremzt. Die beiden änberen fiefailie it und $C$ tragen je eine seitliche mul eine ohere liöhre. I)ie suitlichen. rechtwinkelig gehogenen Giasübren

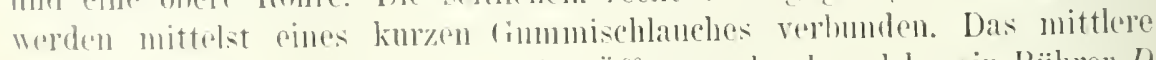

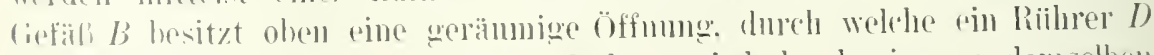

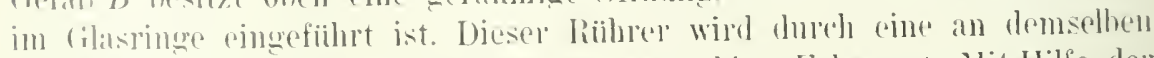
liestolle wie der Aphalat hefestigte Wasserturbine E' bewegt. Mit Ililfe der anf die obere Öffnumg $F$ des ciefalles $C$ anfgesetzten T-Röhre wird das 
aus der 'Turbine flieliende Wasser in den Dialysierapparat geleitet, wähend der Clberfuli durch das uach muten gebogene linde $G$ der T-Riöhre narh auben tritt. Das in das liefibli $C$ einflieliende Wasser dringt das Wasser aus diesem Gefälie durch die Verbindungsröhre $/ /$ in clas ficfuili $A$, aus wclchem es durch die liöhe I nach auben gebracht wirl. $\left.{ }^{1}\right)$

Dialyse nach Jordis. Jordis zufolge soll man die P'roumentschläuche nicht anfhängen, soudern lose zugebunden in ein grolies flaches paraffiniertes Gefïl auf einen Rost aus Gilasstäben :3 $\mathrm{cm}$ ïber dem Boden legen. Werden dann die Enden der schlïuche an zwei oberhalh des Fliissigkeitsniveaus befindliche Stäbe gehunden. so kamn man jederzeit leicht Prohen entuehmen. besteht ein /uflubroh im Niveau und ein vom Boden ausgehendel Uberlauf, so kann die Dialyse gegen fliefendes destilliertes Wasser erfolgen.

Jordis hat den durch beifolgende Zeichmung (Fig. (i0) illnstrierten, filterprebähulichen Dialysator ersonmen: Holzringe $r$ von $\vdots \mathrm{cm}$ Breite, 15) $\mathrm{cm}$ innerem Durchmesser und 2-:3 cm Dicke werden nach einander mit ver-
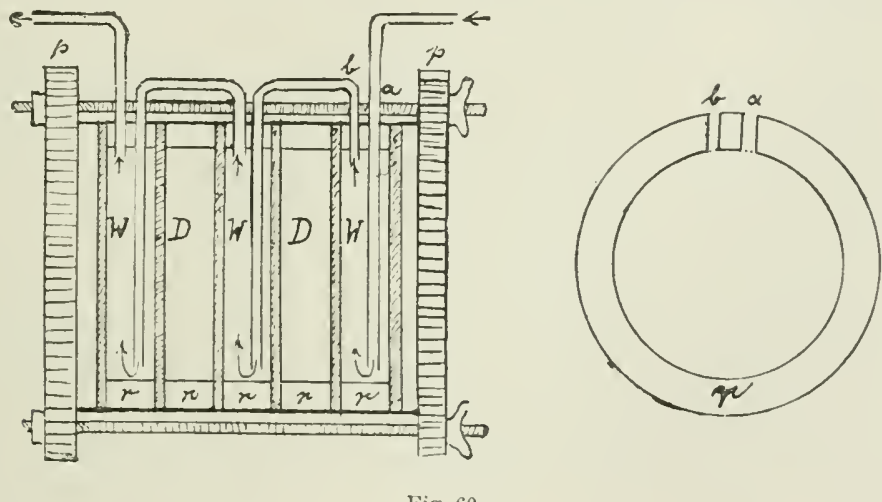

diimnter Salzsäure, verdiimuter Iauge, wieder verdiunter sïure und endlich Wasser ausgekocht und dam getrocknet. Lufttrocken kommen sie in ein ringförmiges Blechgefäb, worin sic anf dem Sandhade in Hartparaffin gesotten werden. bis keine Blasen mehr entweichen. Beim Erkalten zieht sich fast alles Paraffin ins Holz. Daher legt man die Ringe noch einmal kurze Zeit in eben geschmolzenes Paraffin, wodurch nach dem Abkïhlen auf dem Holze eine glänzende Schicht bleiht. welche mit einem Glisstabe röllig geglätet wird. Die Ringe haben zwei Bohrungen " und $b$ ron je $1 \mathrm{~cm}$ Durchmesser. Nun bespannt man eine Anzahl n-Ringe beiderseits mit nassem Pergamentpapier. zu welchem Zwerke eine kleine Rimne auf dem Rande fiur den Bindfaden eingeschnitten ist. Diese $n$-Ringe legt man zwischen $(n+1)$ unbespannte. indem je ein : $\mathrm{mm}$ dicker Ring aus Gummi dazwischen gesetzt wird. spannt mittelst Fliigelschraben zwischen zwei Eisenringen p ein und lälit trocknen. Danach fiillt man den am Ende befindlichen, mit

$\left.{ }^{1}\right)$ M. riegfried, Ein Dialysierapparat. Ber. d. Deutsch. chem. Ges. Bd. 2. S. 1825 bis $1826(1598)$. 
l'erwament hespannten limg mit Wasser und priff seine äuliere Seite anf Undichtigkeiten. Die betreffenden stellen werden markiert. Indem man nm jeden ling eimmal ans Ende der lieihe setzt, kimm man nach und nach sämtliche Dialysatorflächen prifen. wenn man es nicht vorzieht. eine kleinere Fassung für einen einzelnen Ring zu verwenden. welche schneller fördert. Anf die markierten Stellen gibt man nach dem Trocknen ein wenig gewähnliches Hühnereiweif und koaguliert es vorsichtig iber einer kleinen Flamme. Schlieflich setzt man vor die Eisenringe eine runde Holzscheibe. daranf eine fummischeibe, dam einen leeren ling. abwechsehnd mit einem bespannten unter Zwischenlage rou (inmmiringen und zieht die spannselnauben fest an. Das Srstem ist dam rollkommen dicht. Aus einer rorgelegten hochgestellten Zehnliterflasche lälit man durch eine, den Zufluh regelnde Kiapillare destilliertes Wasser in der genannten Weise durch die Wasserkammern W strömen, welche die Dialysieräume $D$ einschlielien, und erzielt so eine sehr schnelle Dialsse, wenn man die $10 \mathrm{l}$ auf 12 stunden Ausflubzeit einstellt. Die in der Zeichnung fortgelassenen Öfnungen $a$ und $b$ :un den límmern I) werden mit liorkistopfen rerschlossen. Bei Inbetriebsotzmg mul man in $D$ und $W$ die atgemessene, berechnete Fluissigkeitsmenge einfiillen, weil sonst wegen der Dehnbarkeit der Membranen keine gleiehmäbige Fïllung erzielt wird und beim Füllen einer weiteren liammer die lïsung ans schon gefïllten zum 'Teil herausgedriickt werden wiirde. Lei $: 3 \mathrm{~cm}$ Dicke fassen die Ringe je ca. $1 / 2$ l Flïssigkeit.

Der Ipparat wird auf ein $20 \mathrm{~cm}$ breites brett von passender liange gestellt, auf welches zwei Leisten aufgenagelt sind. deren Innenkante entsprechend weggehobelt wurde. Er hat den Vorzug. vollkommen abgeschlossen zu sein und doch jederzeit Probeentnahmen zu gestatten. Die Zahlul der Kimmern und die fröble der linge kann natiirlich behebig sein. Auch ist es möglich, in einem grölieren Srstem durch Einlage ron fiummischeiben, wie sie an den Enden benntzt werden, kleinere Gruppen abzusondern mnd so verschiedene liolloide oder I'roben verschiedener lieinheit - in der lichtung des Wasserstromes) hintereinander in demsellen Apparate zu haben. ${ }^{1}$ )

I) iffusionshïlsen rou sohleicher is sehiill. Lm die Ibalyse geringer sulstanzmengen in kleinen Wasservolumen zu ermöglichen, hat die Firma schleicher is schiill zu Diim Dialysierhiilsen aus Persamentpapier in den Handlel gehracht. Solehe kümen bei Terdauungsversuchen, wo man nur mit geringen Fliissigkeitsmengen arbeiten muli, angrwandt werden. Indes soll man in den meisten Fïllen den Dialysierhülsen dir weiter unten besprochenen schilf- oder hollodiunsïcke rorziehen.

Dialyse in Kollodinmsätekchen. Zur aseptisehen Dialyse tierischer Flüssigkeiten kam man sich bei $115^{\circ}$ (' sterilisierter liollodimmsäckchen hedienen. ${ }^{2}$ )

$\left.{ }^{1}\right)$ E.Jordis, Ein neuer Hialysator. Zeitschr. f. Elektrochemie. Bd. 8. S. 67T bis $678(1902)$.

2) C. Delezenne, Aetion des sels de calcium sur le sue pancréatique préalablement dialysé. Compt, rend. hebd. des séanc. de la soc. de hiologio. T. 57. p. 503-525 (1905). 


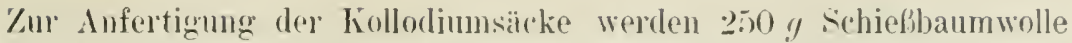
in einem (iemische von 300 ; Ither und 700 g absolutem dlkohol aufgelöst. Man nimmt eine änborlich gut gereinigte (ilasröhre (Fig. 61) entsprechenden Durchmessers, welche an einem Ende I geschlossen ist und in der Nähe des anderen frejen Endes $B$ eine lunde Elweiterung $C$ anfweist. Man taucht wïhrend 2-_; Sekunden die liöhre in die Kollodiumlösung, so dalo die liöhre sich darin nur bis zur Mitte der Erweiterung C', wie es die Linie $D$ zeigt, befindet. Lamn nimmt man die Röhre von dieser lösung heraus und läbt sie moter stetigem Undreben an der Luft trocknen, bis man nur noch den Alkohol, den Xther jedoch nicht mehr riecht, was in emigen Sekunden der Fall ist. Nun wird die Röhre wieder in die Kollodiumlösung bis zur Linie D während ¿-:; Sekunden eingetaucht, worauf man sie unter stetigem Emrihren an der Luft bis zum rölligen Verdunsten des Athers trocknen läst. Man kann diese Prozedur ein drittes Ial wiederholen. Die mit den Kollodiumsacke umhiillte Röhre wird einige Zeit in kaltes Wasser eingetaucht. Dann wird der Kollodiumsack mittelst eines Messers rorsichtig bis zum Ende $E$ der Erweiterung (' von der (ilasröhre getrenut, wor'auf man den Sack durch den so dargestellten Ping greift und wie einen Handschuhfinger umdreht und von der als Mandrin dienenden Röhre wegnimmt. ${ }^{2}$ )

Nocard taucht einell am Ende abgerundeten Glasstab in der Größe des gewüuschten Kollodiumsackes in geschmolzenes Paraffin. Nach dem Erstarren des Paraffins bringt man den Sack in Kollodium. Man läßt au der Luft unter stetigem Hehen trocknen. Schließlich taucht man den Glasstab in das paraffinlösende heife Wasser, wodurch der Kollodiunsack isoliert wird.

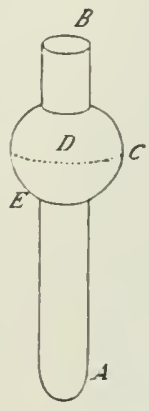

Fig. 61 .

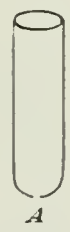

Fig. 62

Ein anderes Verfalıren, um Kollodiumsäcke anzufertigen, besteht darin, daf man einen Glasstab entsprechender Größe ungefähr $1 / 2$ Minnte in das Kollodium und darauf einige Sekunden in Chloroform eintaucht. Das Chloroform läst die durch die Ätherdämpfe bewirkten kleinen Bläschen, welche sich manchmal in der Wand des sackes befinden, und welche bei der Sterilisierung die Zerreißung des Kollodiumsackes hervor'ufen könnten. Außerdem wird auf diese Weise die Kollodiumschicht härter. Gleichzeitig rerhindert man, dab das Kollodium dem Glase zu fest anhaftet. Diese Prozedur wird einoder zweimal erneuert, worauf man den Kollodiumsack in der oben beschriebenen Weise rom Glasstabẻ abnimmt. ${ }^{2}$ )

Man kaun sich auch einel am Ende ot mit einem kleinen Loche versehenen Glasiöhre (Fig. 6:) bedienen, welche man in eine ziemlich

1) Gütige Mitteilung des Her'u Prof. Dr. C. Delezenne (Paris).

2) Alfied Blumenthal, Contribution à l'étude expérimentale des modifications morphologiques et fonctionuelles des globules blanes. Mém. cour. et autr. mém. publ. par l'Acad. roỵ de méd. de Belgique. T. 5̇s. fasc. S. p. 1-5̄ (1905). 
dicke Leimlissme bei :37-40 ('eintaucht mod nachher trocknen lälit, so lab die Offnung a mit eine dimnen Leimschicht geschlossen ist. Die so vorbereitete liahne wird. wie oben beschrieben. in Lollodinn eingetaucht an der Luft gelassen his zum Verdunsten des Ithers muter stetigem Lindrohell und dann noch in Chloroform eingetaucht: diese Prozedur wird zweibis dreimal wiederholt. J)ann wird die mit dem Kollodiunsacke versehene Riohre in heiles Wasser gebracht. worin der Leim sich verflissigt. Dadurch marcht sich der Kollodiumsack allmählich von selbst von der liöhre los. indem sein Ende sich rom Ende $A$ des (ilasröhre entfernt mud der sack auf die änbere (Glaswand rutseht.')

Von diescu + Verfahen ist ersteres für biochemische Zwecke entschieden vor\%uziehen. Bei Anwendung einer guten Kollodiumlösung kann man leicht sïcke jeder beliebigen riröle bereiten.

Zur Sterilisierune der Kollodimmsicke wird. wie

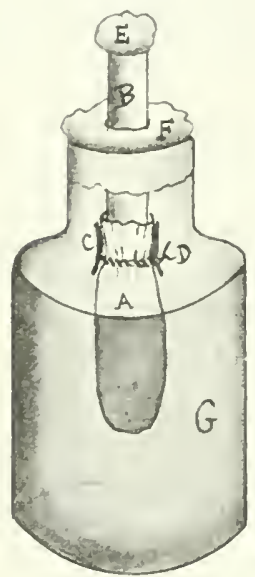

Fig. 63. nehenstehende Fig. 6:' es reranschanlicht, der Kollodimmsack $A$ an eine (ilasröhre $B$ gebunden, indem man den den Kollodiumsack beendigenten Ring mit einem Pergamentpapierring $C$ umhiillt und diesen mittelst des Fadens $D$ anf der liöhre $B$ befestigt. Der l'ergannentring hat den \%weck, jede \%erreilung des Kollodiumsackes bein Festschniiren zu verhinder'ı. In das lnnere des sackes wird destilliertes Wasser oder phrsiologisehe Lösung gegossen. Das obere Ende E' der Glasröhre $B$ wird mit einem Wattepfropfen verschlossen. I)er an der Glasröhre befestigte Kollodiumsack wird dann in eine destilliertes Wasser oder phrsiologische Lïsung enthaltende Fin- his zweiliterflasche $G$ gebracht. deren oberes Ende $F$ mit Watte rerschlossen wird. Ine Höhe der Fliissigkejt im Kollodinmsacke und in der Flasche muli die gleiche sein.

Die so bereitete Flasche wird in Autoklaven bei $115^{\circ} \mathrm{C}$ während ${ }_{4}{ }_{4}$ Stmude erwärmt. Dann entfernt man aseptisch die im sacke enthaltene Fliissigkeit, gielft die zu dialysierende Lösung hinein und verstopft rasch mieder das Ende $E$ der Giasröhe $B$ mit Watte.

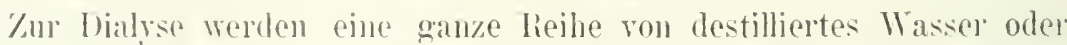
physiologische lismug enthaltenden, sterilisierten, mit Watte verschlossenen Fin- his '/weiliterflaschen beniitzt. Dee' sterilisierte Kollodiumsack wird in eine dieser Flaschen gebracht, diese sofort mit Watte rerschlossen und bei ('iner 'l'emperatur mele $10^{0}$ gelassen. Sach einigen stunden wird der Kollodiumsark in eine andere mit physiologischer Lösung grefiillte Flasche gehracht. Inese l'rozedur wird bis zur Vollendung der I)ialyse mehrfach winderlolt. ${ }^{2}$ )

1) (Gïtige Mitteilung des Herrn l'rof. Dr. .J. Bordet (Brüssel).

2) Gritiere Mitteilung des Herru Prof. Dr. ('. Melezrnne (Paris). 
Zur Sterilisiermon des Kollodimmsackes empfichlt es sich, destilliortes Wassel in den sitck und in die ihn enthaltonde Flascho zu giefen, während zur I)ialyse von tierischen Süften oder Verdaumesfliissigkeiten man elucr physiologgische Kochsalzlösung atmwenden soll.

Falls man die Kollodiumsïcke zu Versuchen in vivo vepwendet, wird der gefuillte Sack dicht unterhalb der Glasroihn mit Seide zugebunden. von der Gilasröhre getrennt und an oberen Ende aulien mit lollodiun gedichtet. Die äubere Oberläche des völlig verschlossenen Sackes wird mit sterilisiertem destillicrtem Wasser oder mit physiologischer Lösmor ausgewaschen und unter strengster Asepsis in die biuchliohle oder einen anderen Teil des ()rganismus gebracht.

Die Permeabilität der Kollodiumsäcke wechselt sehr je nach ihrer liereitung; Proteine dialysieren nur sehr langsam durch diese Säcke. $\left.{ }^{1}\right)$

Ein Nachteil der Kollodiumsäcke ist ihr Adsorptionsvermögen für gewisse Fermente (Amylase, P'epsin usw.) und vielleicht auch fiir andere Stoffe. ${ }^{2}$ )

Un die Widerstandsfähigkeit der Kollodiunsäcke zu erhöhen und um die Ibialyse der Fermente durch die Ḱollodiummembran zu verzögerı. empfiehlt es sich, das Kollodium mit Lecithin und Cholesterin zu vermischen. Die Kollodiummembran schwängert sich zues'st mit den Fermenten, was eine ziemlich lange \%eit beansprucht, und läßt erst danı die Fermente durchtreten. ${ }^{3}$ )

Dialyse in Schilf- nnd Zelluloseschläuchen. Auber dem Peroramentpapier und den Kollodiumsäcken werden noch Schilfschläuche zur Dialyse verwendet. Zur Herstellung der Schläuche werden möglichst dicke Schilfrohre von Phragmites commun is inre segmente greteilt und diese $1 / 4-1$ Stunde in kochendes IVasser gelegt. An rinem Segmentende wird hierauf durch sorgfältiges Abschmeiden eine Strecke der die Höhlungen der Internodien auskleidenden innersten Membran freigelegt und der kleine Membranzylinder mit einem Seidenfaden zugebunden. An diesem zugebundenen Ende legt man nun einen diinnen Glasstab mit abgerundeten Enden an und

1) El. Metschnikoff, E. Rour et Tanarelli-Salimbeni, Toxine et antitoxine cholériques. Ann. de l'Inst. Pasteur. T. 10. p. 257-282 (1896). - A. Kodet et Guéchoff, Essai dapplication de la méthode des sacs de collodion à la connaissance des produits toxiques des bacilles dEberth et coli. Compt. reud. hebd. des séanc. de la Soc. de Biolog. T. 52. p. 962-965 (1900). - Sur les propriétés des sacs de collodion et leur rôle en bactériologie. Ibid. T. 52. p. 965-967 (1900). - Milton C'rendiroupoulo et Armand Ruffer, Note sur la dialyse des produits solubles élaborés par le bacille pyocyanique dans les saes de collodion. Ibid. T. 52. p. 1109-1110 (1900). - A. Rodet et J. Hoitessier, Sur la perméabilité des membranes de collodion. Ibid. T. 54. pag. 1047-1049 (1902).

2) F. Strada, Sur la filtration de quelques diastases proténlytiques au travers des membranes en coliodion. Anu. de l'Inst. Pasteur. T. 22. p. 982-1009 (1908). A. slosse et $I$. Limbosch, Note sur l'adsorption des ferments digestifs par le collodion. Bull. d. 1. Soc. roy. des Sc. mél. et nat. de Bruxelles. 'T. 67. p. 132-136 (1909).

3) H. Bierry et $G$. Schaeffer, Dialyse et fixation sur sac de collodion de la lactase et le l'émulsine animales. Compt. rend. hebd. des séanc. de la Soc. de Biolog. T. 62. p. $723-725$ (1907). 
bewent ihn mit leism Inrucke in der lichtung des Rohres. Dahej löst sich dic imnore Membran von der Schilfwand ah und berindet sich schlieblich in gan\%er Ausdehnung anf dem sio vor sich herstiilpenden Gilasstabe. Sofort willl (lel stab heransgezogen. Anf diese lVeise kann man schläuche von

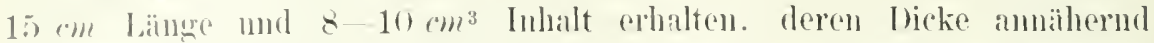
(ros mum entspricht mol welche fast mur ans reiner \%ellulose bestehen.

[m] die Schilfschlänche zu sterilisieren, fiihnt man in das offene Ende des schlandhes eine kleme (ilasröhre ein mol befestignt diese vorsichtig mit seide an dor Wand des sirchehens. Letyteres wind dam mit destilliertem Wasse efoullt. Hierauf wird die Gissöhre mit Watte verschlossen. mit dem daran hänuenden Schilfsacke in eine destilliertes Wasser enthaltende Fasche gebracht mul dew Schilfsack nach domscolben Verfahren, wie es fiu die Kollodimmsicke angegeben wurde. sterilisiert. Narh dem Sterilisieren entnimmt man aseptisch das in dem Schilfsack enthaltene Wasser mod ersetyt es duroh die \% dialysicrende Fliissigkeit. I) Dialsse erfolgt in derselben Weise, wio bei Vorwendung von Kollodimmsäcken. Falls man das Sohnilfsäckchen zn Versuchen in vivo völlig versehliefien will, wird es dicht unterhalb der Glasröhre mit Seide zngebunden, an oberen Ende anben mit Kollodimn gedichtet und ganz anf dieselbe Weise wie die liollodiumsäcke zu dem ähnlichen /wecke behandelt.

Die Schilfschlainche kïmen nur zmr Dialyse von kleincn Flissigkeitsmengen gebraucht werden. Xach Philippson sind sie fiir Glykogen, fiir gerimuare l'roteine, fiir Ileteroalbumosen, 'Jrypsin und den gerimmngshemmenden liestamlteil des Blutegelextraktes nicht durchässig. während l'epsin in sipuren durchzutreten soheint.

Die Zellulosesäcke dos Handels (Lemne in Paris) besitzen dieselben Ë̈unschaften betreffs dor Dialyse wie die Schilfsäcke.

Lm die Dichtigkeit der. Schilf- md \%elnlosesäcke vor ihem Gehranche zu priifen, empfichlt de Waule ${ }^{1}$, in den vorher angefeuchteten Säcken eine wisslige $1 / 200-1 / 300 \%$ ige Methylviolett-oder (ientianaviolettlösung einzugieben und damn den Sack $1 / 4-1 / 2$ Stmole in einer Wasser entlualtenden breiten Eprouvette zu lassen; das Wasser der Eprouvette mul fablos bleiben. Dann wïscht man den Schilf- oder Zellulososack wut aus. Falls er gefürbt. bleibt, so bewirkt dies keinen Nathteil fiir seine dialysierenden Eigens(liaften. ${ }^{2}$ )

1) Giitige briefliche Mitteilung des Herrn Dr. de Wrarle (Gent).

2) E\%. Motschnikoff, Sur la lutte des cellules de lorganisme contre linvasion des microbes. Anu, de l'Inst. Pastenr. T. 1. p. 321 - 336 (1887). - I'olbelsky, Contribution it lètude de l'immunité vis-it-ris du hacillus sultilis. Ibid. 'T. 12. p. $427-446$ (1898).

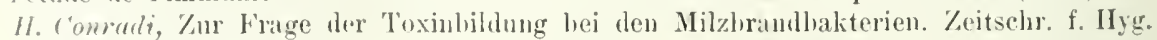
11. Infektionskinkh. 13d. 31. S. 287-316 (1899). - P. Ihilippson, Cber die Verwentharkeit der Schilfschläuche zur Dialyse. Beitr. z. chem. Physiol. n. Pathol. Bal. 1. S. 80-82 (1902). II. Ine Wraele. Xote sur l'immunité confirée par la mithode des sacs de celluluse et sur les produits microliens dialysants. Zentralhl. f. Balkt. P'arasitenkunde 11. Infektionskrankh. 1. Abt. Orje. Bd. 42. ‥ 6336-642 n. $760-770$ (1906). 


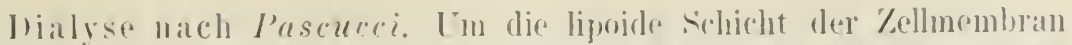
nachzuahmen. lïst P'ascueci Lecithin in heiliem .llkohol, läßt his zum sirup

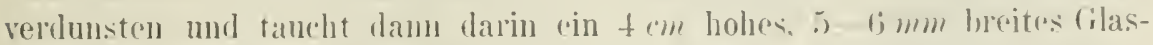
röhrehen, dessen eine öffunng mit feinem, wrilem seidenstoff üher\%ogen ist. Dee sobilenstoff wird anf diese Wrose durch Lecithin gretränkt. Yach der Impriagnation mmgibt man das lährehen, da, wo die Seide befestigt ist, mit ereselmolzenem Wachs. trocknet das liohrehen bei $37^{\circ}$ und bewahrt es im Vakuum iiber schwefolsäme anf.

Durele Fintanchen des mit Seidenstoff iiberogenen Glasriblnchens in vorsichtig geschmolzenes ('holesterin oder in rurch Lösen ron Lecithin mul Cholesterin in dem gewiuschten Gewichtsverhältnis und nachlıerigem rölligen Ëndunsten dargestellte Lecithin-('holesteringenische erzielt man kïnstliche ('holesterin- oder ('hol'sterin-Lecithinmembranen. ')

Dialyse nach Wriechowsti. Zur Dialyse von Organemulsionen bedient sich Wiechousti angeblich ans , lem Binddarm ron schafen hergestellter sogenannter Fischblasenkondome. Wegen der Dürre dieses Iaterials beginnt oft beim Anfüllen mit Wasser infolge des starken In'uckes nach einiger Zeit auch aus dichten schläuchen an einzelnen dümeren Stellen Wasser herauszusickerm. Ina aber die Schlänche während der I)ialyse keinen solchen lyruck anszuhalten haben, muf man die Prifung anf Dichtigkeit anf andere Weise vornehmen. Yan fuillt die in Wasser eintauchenden schläuche mit Lackmuslisung und läßt sie darin

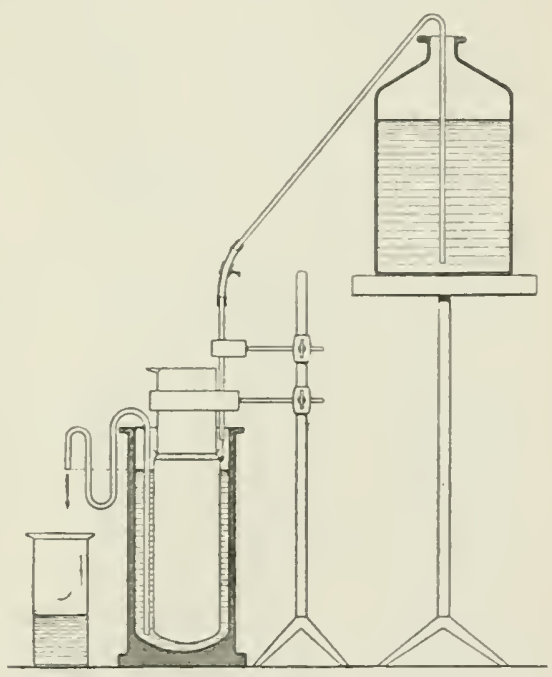

Fig. 64. längere Zeit: färbt sich die äufere Flïssigkeit. so ist das stïck unbrauclibar.

[n mit möglichst wenig Flüssigkeit auszukommen. den Fortgang der Dialyse beifuem heurteilen zu kümnen und die Verarbeitung der I ialysationsfliissigkeit zu erleichtern. empfiehlt Wiechousli die schläuche his an den Boden von so eng gewählten (ilaszylindern zn bringen, dafi die Schlänche darin eben Platz haben, ohne die Wände zu berühren. Der Abfluf wird durch eine dreimal U-fürmig gebogene Röhre, die auf den Boden des Zylinters reicht. so geregrelt, daf immer genan so viel Fliissigkeit

1) 0. Prscucci, Dic Zusammensetzung des Blutscheibenstromas und die Hämolrsse. II. Mitteilung. Die Wirkung von Blutgiften auf Membranen aus Lecithin und Cholesterin. Beitr. z. chem. Physiol. u. Pathol. Bd. 6. S, 5๊2-566 (1905). - s. G. surart, ťber die Permeabilität küustlicher Lipoidmembrane für I'rofermente. Biochem. Zeitschr. Bd.6. S. $358-365(1907)$. 
yom boden des rylinders abliuft. als oben zufliebt (Fig. 6t). Ihas

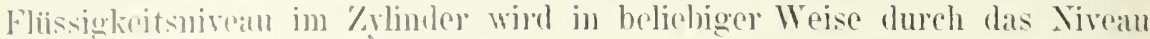

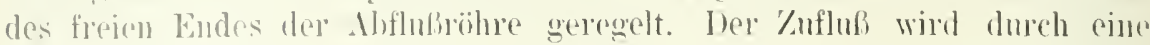
lilemmu enerencelt. $\left.{ }^{1}\right)$

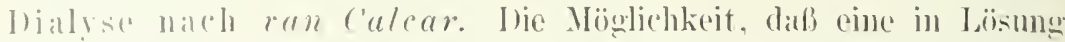

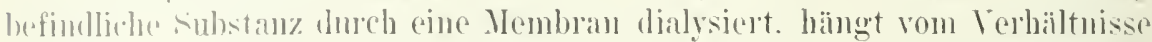
des Molekularvolunems zur Jorenwejte ler Membran ab. Demuacl elklärt

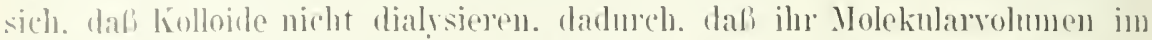

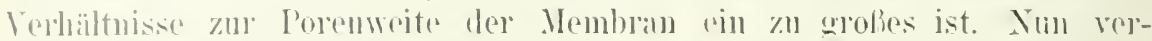
arölicet man die l'orenweite riner tierischen Membrun willkiirlich in einem ganz hestimuten Malke durch Erhöhung ihner syammug. Wählt man eine

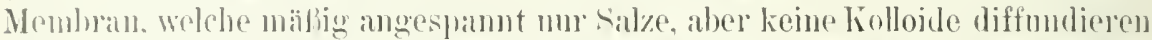
liblit, so crziclt man dadurels, dab man der Menbran allmählich eine immer

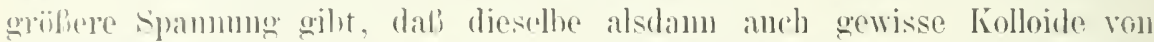
varhïlnismäbig klejuen Molekularvolumen diffundieren lälit, während sio

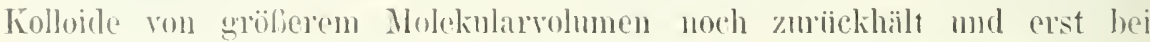

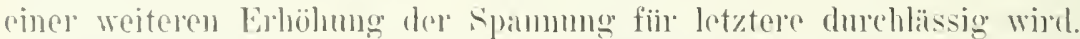

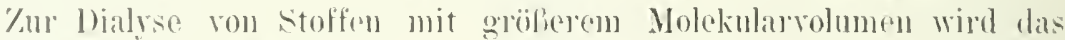
frische menschliche Amnion nach ean Calcar folgrondermaben bereitet:

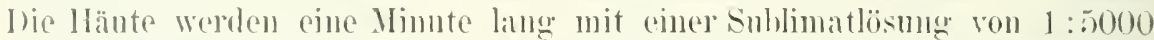
tïchtig absespiilt mol sodann in physiologischer Kochsalzlisung währent

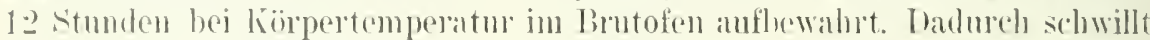
die bedeckende Epithelsehioht mol berginnt an einigen stellen schon (2ingermaben sich von der Untersehieht abzulïsen. I) anm wird die llant

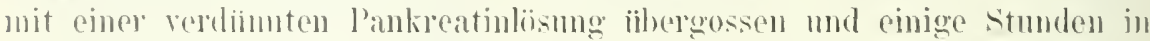
den Brutolen gelegt, mn darauf wieder während einiger Stmoden in eine erwälute salzlösmmg zu kommen. Cbergießt man num die Häutr noch

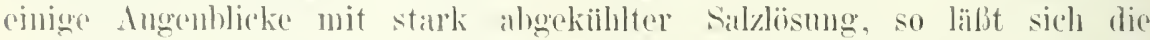

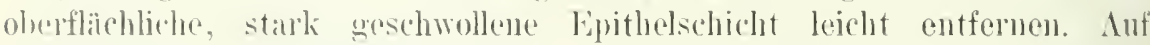

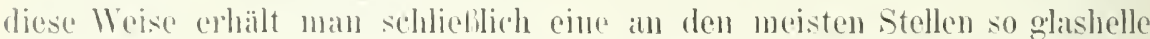
Hant, dali man, wemn man schwaryo buchstaben dammer legt, fast nicht

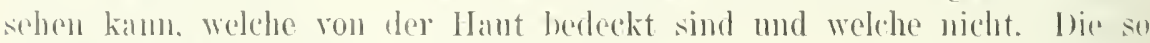
beroiteten Ilïute worden in ajuer Glyzerinlösmmgr oder anch in sterilem. destilliertem Wasser oder in salzlösumg iiber ctwas (hloroform anfbewaht.

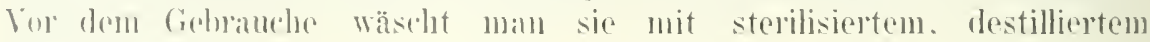
Wassej ans.

ean Calcar verwendet die Amnionlänte auf eine wanze Amahl Arten

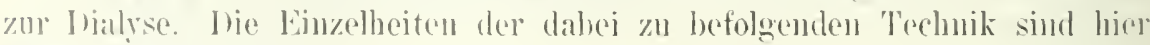
mitril wiederorechen.

/ul Anfertigmug (ines sackfömigen bialysators ans Amnionhant nimmt num eine zylinderformige Glasiobre I (Fig. (i.s), die an einem Ende $F$ souber abgermolet mul efwas narls anhen mogebogen ist, und

$\left.{ }^{1}\right)$ W: Wirchoustri, Eine Methote zur chemischen und biologischen I'ntersuchung überlebender Orgune. Beitr. z. chem. I'hysiol. U. Pathol. Bd. 9. S. 232-246 (1907). 
befestigt dieselbe mit dem Fude $E$ nach oben in der K'lemmschraube $K$ des Stativs $S$. Hierauf legt man das zu benutzende Amnionhäutchen $H$ auf rlie Öffnung der Röhre, und zwar so. dafi es iiberall ungeführ gleich weit herunterhïngt. Mittelst des in der lílemme $K^{2}$ befestigten Reagenzglases $R$ drïckt man das Häutchen mehr oder minder tief in die Köhre $A$ hinein. Auf dem Rande $E$ des Zylinders $A$ bildet dann das Häutchen $H$ Falten, welche mit der Hand so gleichmäßig wie möglich iiber den liand $E$ verteilt werden. Wie die Figgr. $6 t^{\circ}$ und $6 \mathrm{i}$ es reranschanlichen, befestigt man damı das Häutchen so fest wie möglich mittelst des Fadens $D$ um die zylinderförmige Röhre 1 . Der ïberflïssige Teil der Membran wird abgeschnitten und das Reagenzglas $R$ aus der Rïhre $A$ lrerausgezogen. Inrch Fiillen des sackfïmigen IDialysators $H$ mit Wasser wird er auf seine Dichtigkeit gepruift.

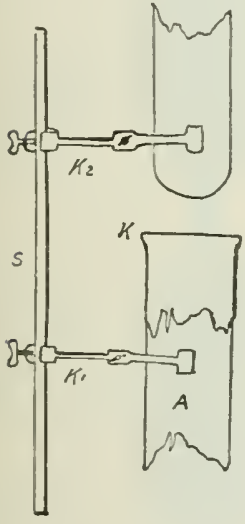

Fig. 65 .

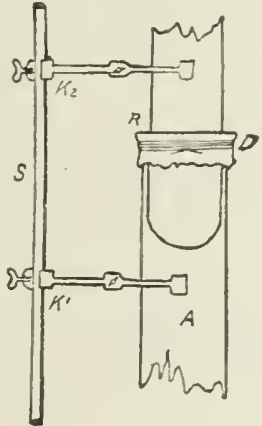

Fig. 66 .

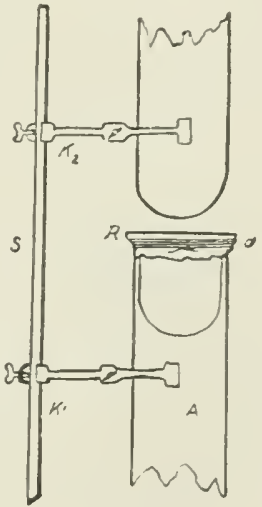

Fig. 67.

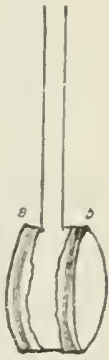

Fig. 68.

Zur raschen bialsse benutzt ran c'alcar den in Fig. 6r abgebildeten Dialrsator. welcher aus einem an beiden Enden ausgebogenen Zrlinder $C$ besteht, aus dessen Wandmitte eine senkrechte Röhre $R$ länft. İber die Öffnungen des Zylinders werden die Amnionhäute befestigt. Ist die Entfernung $a b$ sehr grofi, so hat man einen Dialysator von grofem Rauminhalte bei verhältnismäßig geringer dialssierender (oherfläche. Bei schr kurzer Entfernung $a b$ erhält man hingegen einen Dialssator ron geringem Inhalte und sehr grofer Dialysationskapazität. Nan bringt ihn in ein offenes Gefail, so daß das Xiveau in Zylinder (' $R$ und im Gefälie gleich ist. Die lehnung der Membran ist damn rerhältnismällig gering, wenn das spezifische Gewicht der zu dialysierenden Flissigkeit ron dem des Wassers nicht sehr rerschierlen ist.

Lm ohne Druck, jedoch bei gespannter IIembran zu dialsieren. bedient man sich folgenden Apparates (Fig. 69). Auf dem mit den zwei Hihnen $K^{\prime}$ und $K$ rerselienen Kolben $A$ ist eine ron innen geschliffene Röhre $B$ angebracht, welche an ihrer Unterseite einen eingeschliffenen 
F. $\%$ unz.
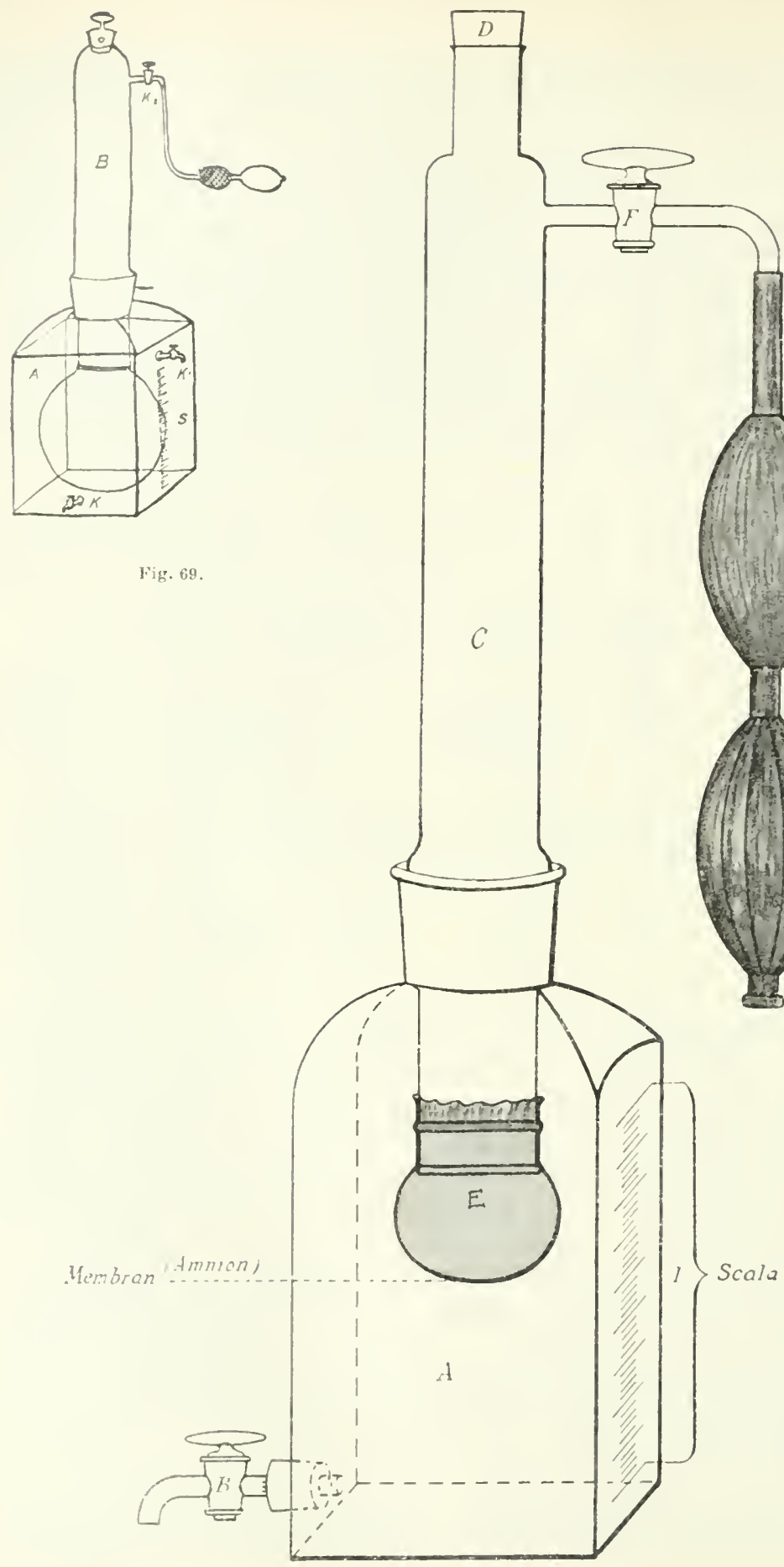

Nig. 70. 
Rand hat. woran man die Amnionmembran hefestigt. Die Rölue $B$ wird oben mit einem Stropsel geschlossen, wihrend oben an der Seite noch cine durch den Hahn $K^{2}$ \%u schliefiende dïnne Glasrölire angebracht ist. mit welcher ein Gebläse in Verhindung stcht. An der einen Seite des Kollonens d befindet sich anlierden die skalat $S$.

Mann bringt in die Riöne $B$ eine eventuell durch Dialysieren anf l'ergamentpatjier schon von Salzen befreite Kolloidlösung und setzt diese liöhre auf den mit destilliertem Wasser oder physiologischer lösung fast vällig gefiillten Kolben $A$. Dam wird mittelst des Gebläses die Membran bis zu einem bestimmten Grade gespanıt, wobei der Flïssigkeitsüberschuli ans dem Kólben $A$ durch den Hahn $K$ abfliefien kann. Je nach dem Spannungsgrade der Membran sind ihre Poren mehr oder minder weit und können Kolloide von nicht zu großem Nolekularvolumen dialysieren. Zn bestimmten Zeitpunkten kann man $K$ und $K^{\prime}$ öffnen, um durch den Hahn $K$ einen Teil der Fliissigkeit aus dem Kolben abzulassen und zu untersuchen. Alsdann fiillt man $A$ anfs nene aus einem Behälter durch $K$, worauf man mit Hilfe des Geblïses den Inalysator muter Ablesen der Skala auf sein urspriingliches Nivean zuriickfiihn't.

Gelingt es nicht, ein in $B$ befindliches I'rodukt bei einer gewissen Spannung der Membran zu dialysieren, so erhöht man sie unter Kontrolle der Skala. IDie Grenze. imnerhalb welcher ein Stoff durch die Ammiosmembran dringt, mub natiirlich fuir jedes Häntchen anfs nene bestimmt werden.

Ans Fig. 70 läbt sich etwas genauer ersehen, wie die Amniommembran $E$ an der in Lílben $A$ eindringenden Riöhre $C$ befestigt ist.

Fig. 71 zeigt die zmm bialysieren unter erhöhtem Drucke mod gespannter Membran benutzte Vorrichtung.

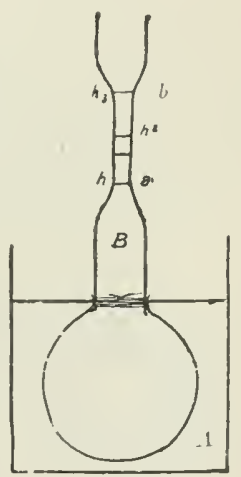

lig. 71 . in welcher man sowohl die erhöhte Spannumg als den erhöhten Druck dadurch erzielt, daß man das Nivean in Dialysator höher setzt als in dem umgehenden Gefäße. In der Mitte der Liöhre $B$, an welcher das dialysierende Amnioshäutchen befestigt ist, befindet sich ein ausgezogener'Teil $a b$ geringeren Durchmessers als die iibrige Riölı'c. Dies erlaubt. bei gleichbleibendem Volumen zu dialysieren. Dialysiert man nämlich eine Mischung dialysierbarer und nicht dialysierbarer Stoffe, wie Serum z. B., so kommt es manchmal nach einiger Zeit ror, daß die Salze in solcher Menge durch die Membran gedrungen sind, dab so ungefähr Gleichgewicht entstanden ist, oder dali sie bei fortgesetzter Ernenerung der Fliissigkeit in $A$ gröbtenteils aus $B$ verschwundell sind, so dab Wasser so lange ron $A$ nach $B$ dringt, bis der hydrostatische Druck in $B$ gleich der osmotischen spannung geworden ist. Auf den Teile $a b$ der Röhre $B$ kann man sehr leicht das Steigen der Fliissigkeit ablesen. Beim ersten Steigen in der Röhre $a b$ erhöht man das Niveau, z. B. von $h$ bis auf $h_{2}$. und kontrolliert jetzt fortwährend den 
Apparat. Siteigt trotzdem das Niveau noch in der liöhre $a$ b, so erhöht mau as auf $h_{3}$. bis zuletzt das steigen röllig aufhört, wodurch erwiesen wild, daf die osmotische Spannung der nicht dialysierbaren Produkte in B Ilem hrdrostatischen Drucke gleich geworden ist.

Dialwient man eine Flissigkeit, die neben Salzen, die durch die Annionhaut und das Pergament leicht dringen, einen Stoff enthält, der wohl duch die Ammionhaut. nicht aher durch das Pergament geht. und will man letzteren stoff in möglichst reinem Zustande salzfrei erhalten, so verwendet man rorteilhaft den in der Fig. T. wiedergegebenen van calcarschen Apparat. Die Riohre $B$, an welcher die Imnioshant befestigt ist, befindet sich in einer etwas weiteren Röhre $A$, an deren unterem Ende ein I'eramentsack P' festuebunden ist. Man bringt das Ganze in das Gefiiß C, welchem durch die liöhre $d$ frisches, destilliertes Wasser zugefiihnt wird, wibluend der Wasseriberschub dureh die Rïhre $e$ abfliebt. Das Niveau der Rïhre $B$ befindet sich bei $n_{2}$. das von $A$ bei $n_{1}$, dis Nivean des mugebendenen Gefäbes C' bei $n$.

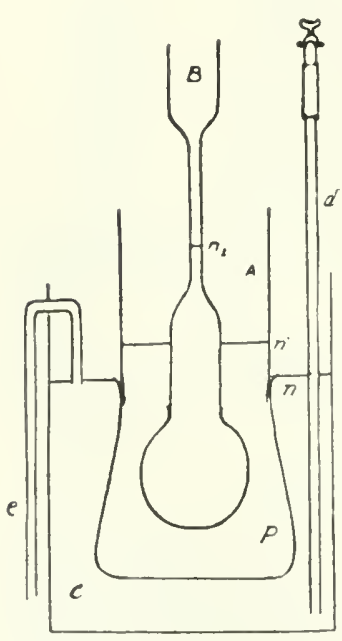

Fig. 72.

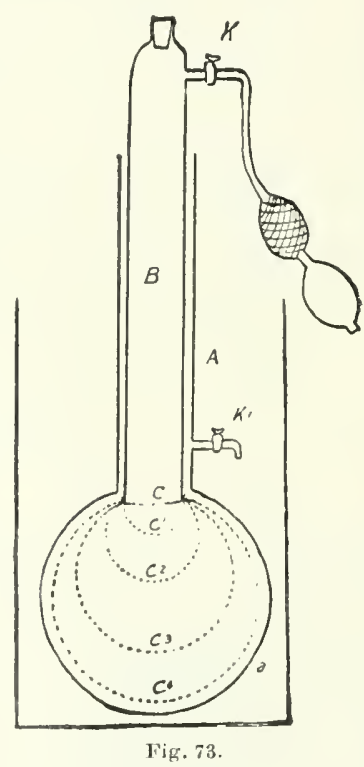
sobald der Inhalt des Pergamentsackes $A$ salzfrei geworden ist. enthält dieser Bentel dann den durch lergament nicht dialssierbaren Stoff in reinem $/ 41-$ stande.
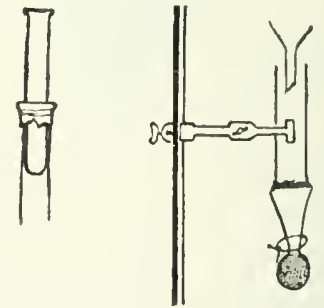

Fig. 74.

'/ur raschen Dialyse vou Flissigkeiten, die sich sehr schmoll zersetzen, hat ran ralcar den Apparat der Fig. 7:) ersonnen. An der mit einem Hahne $K^{\prime}$ versehenen liöhre $f$ ist der mit der zu dialysierenden Fliissigkeit grefiillte Ammionsack e hefestigt. Dalauf setzt man die Riohre $B$, an weleher sich eine zur bialyse ginzlich mgeeignete Kautschukmembran $c$ befinclet. Das ohere Ende ist mit einem Stopfen geschlossen mud hat oben (ancu mit rinem Geblisse verbundenen Hahn $K$. Man fiillt die Riohre $B$ mit Wasser und blast mittelst des Geblises die Membram o bis $c^{1}$ orler $c^{2} . c^{3}, c^{4}$. bie flitssigkeit strigt in 4 zwischen der Ammiosmembran und der 
Kantschnkmembran. Nan läbt den C̈berflul) durch den Hahn $K^{1}$ ablaufen mul erhält anf diese Weise zwischen $a$ und $c^{4}$ eine sehr diune Fliissigkeitsschicht bei selır grofier Dialysieroberfläche $"$.

Un iiberall geschlossene Säckchen aus Amnionhäutchen zu hereiten. legt man eine Inmionhaut iiber die öfnumg eines liöhrehens und schieht lie Amnioshaut mit einem gläsernen Stahe in das Röhrchen; dann wirl es mit einem um das Röhrchen gelegten Faden befestigt. I larauf bringt man das Rïhrchen in eine Klemme und giefit das zu benutzende Material (Jurch einen Trichter hinein (Fig. 74). Schlieflich wird das gefiillte Säckchen mit einem Faden gebunden und der iiberfliissige Teil der Imnionhaut abgeschnitten. Diese Sïckchen können, wie die Kollodium-, Schilf- oder Zellulosesïckchen, mit infektiösem Materiale als Inhalt in eine körperhöhle gebracht werden. ${ }^{1}$ )

\section{Sperielle Dialysierverfahren zu kinstlichen Verdanngs- versuchen.}

U'm die bei der natiirlichen Verdaumg ror sich gehenden Vorgänge möglichst nachzuahmen. hat man besondere Dialysierapparate angewandt.

Dialysator nach Kronecker. Die Abbildungen 75 und if zeigen die von Kronecker rorgeschlagene Einrichtung, um die Verdaumg einer verhältnismälig großen Menge von Nahrungsstoffen möglichst schnell zu vollenden, die Produkte derselben mittelst Dialyse zu trennen und das wirksame Ferment möglichst ungemindert zu erhalten.

Dieser Apparat besteht aus den eigentlichen Diffusionsapparat und aus dem Verdauungsofen. Letzterer besteht ans einem zxlindrischen Blechbehälter $i$ ron $18 \mathrm{~cm}$ Höhe und $20 \mathrm{~cm}$ Durchmesser. welcher mit Wasser gefiillt ist, dessen Temperatur der Wärmeregulator $h$ konstant erhält Ein Messinghahn $g$ erleichtert die Entleerung des Topfes. Der Deckel hat 2 Öffnungen. In der zentralen. etwa $95 \mathrm{~cm}$ breiten öffnung wirl ein tubuliertes frlas $e$ von $10 \mathrm{~cm}$ Höhe und $9 \mathrm{~cm}$ Durchmesser mittelst des auf $10 \mathrm{~cm}$ Weite ausgebogenen Randes festgehalten. Durch das andere enge Loch reicht das (Quecksilbergefäß des Regulators in das Wasserbad.

Das Ausflulirohr mit dem Glashahne $f^{\prime}$ ist im Tubulus des Cilases hefestigt und durchsetzt mit Hilfe eines Korkes wasserdicht die Hïlle des Yerlauungsofens. In dem Glase $e$ hängt ein spitzwinkliger Trichter, dessen Ausflußröhre abgeschnitten und dessen Wand $2 \mathrm{~cm}$ unter dem oberen Rande von einer Anzahl pfenniggroßer Löcher (d) durchbohrt ist. In dem Trichter liegt lose ein Faltenfilter aus Pergamentpapier, welches bis zum Rande reicht.

1) R. P. can ('alcar, Über die Konstitution des Diphtheriegiftes, eine nene Methode zum Nachreis der Toxone. Berl. klin. Wochenschr. Bd. 42. S. 1028-1031 (1904). - Derselbe. Uber Dialyse und einzelne ihrer Anwendungen. Ebenda. Bd. 42. S. 1368 bis 1372 (1905). - Derselhe. Ilialyse. Eiweißchemie und Immunität. S. $11 \mathrm{ff}$. Leiden und Leipzig 1908. 
Wie Wolfhïgel es empfiehlt, soll man nicht die Falten des P'eroatmentfilters bis zur spitze des Trieliters laufen lassen. nud umb man, um Ginlisse ganz zu relmeiden, das T'eroanentpapier zuvor aufenchten. Ebenso ist es latsan. don P'ergamentfilter num bis zu \%weidrittel semer llöhe

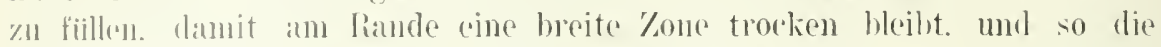
innere Fijscigkoit nitht nach anlien iberwatern kann.

L’m dio gebildeten Verdaumosprodukte mittelst der Dialyse möglichst schuell ans dol Lösmog fortzuschaffen. ist auf dem cilase e cine Mariottesche

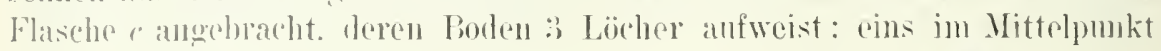

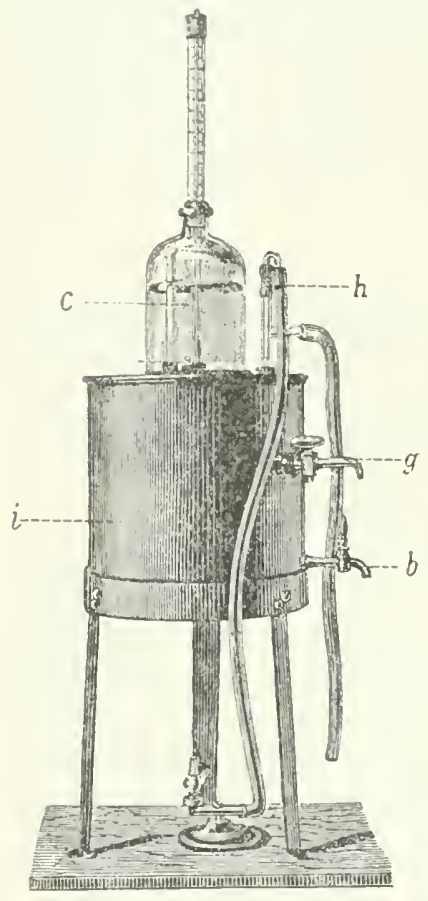

Fig. 75.

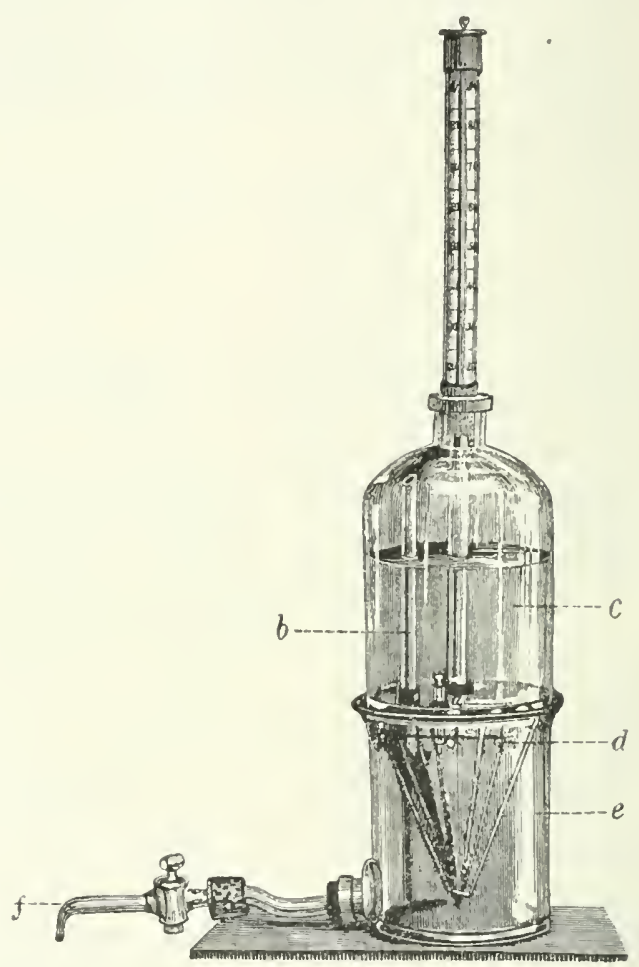

Fig. 76 .

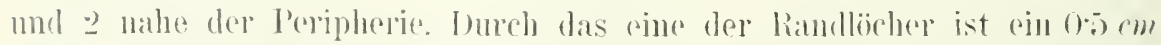
weites cilasröhrohen a wasserdidht gesteckt. so dab es esm lang ju den

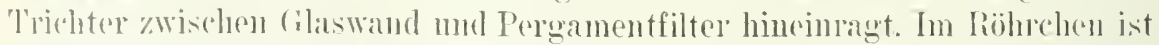
ein answezogenos Glasstäbrhen als konisches Ventil heweglich. Das spitze Funde desselben ragt muten otwas ziber das Röhrohen hinaus, so dali es von der Wand des 'Triditers gehohen wird, sobald man die Flasehe anf das I)iffnsionsglas stellt. Fin striglohl l, stopft das zweite liantloch und endigt mit sehräg alygeschnitener Viindung etwa 2 c'm muter der oheren Flaschemwand.

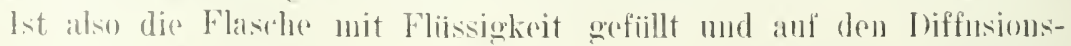

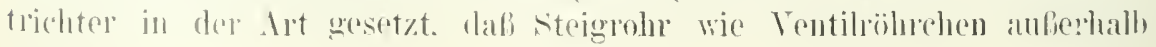


des Filters bleiben. so riunt der Inhalt solange in Trichter und rilas, bis die Steigrohrmündungen durch das Fliissigkeitsnireau gesperrt werden. Dann wird durch den Donek der äuberen Luft. welche sich mit der im Flaschenraume enthaltenen nicht ausgleichen kann. die Fluissigkeit verhindert, durch das Ventilröhrchen ansmtreten. bis das Niveau. durch irgend einen Umstand zum sinken gehracht. Luftblasen dureh das steigrohr dringen lüft. so wird der Fliissigkeitsspiegel unter denn 'Trichterranle. an der löcherreihe konstant erhalten. Durch diese Lörher wird der Austansch der Fliissigkeit innerhalb und aulierhalb des Trichter's im Cilase begïnstigt. Während der Diffusion findet ein lebhafter Kreislauf statt. inden die Fliisigkeit innerhall) des Trichter's wegen den anfgenommenen Terdannosprodukten schwerer als die anferhalh befindliche durch die mutere Trichtermitndung herabfält und dimnere Lösung durch die Löcherreihe eintreten lïlt. Will man die Fliissigkeitsnenge auberhalb des Filters günzlich erneuern. so braucht man nur durch den Ausflubhahn $f$ das Diffusat zu entlecren: es füllt sich dam ans der Vuriotteschen Flasehe das Srstem mit verdiunter Sulzsïure. Fin durch die Mariottesche Flasehe in den Trichter hineinragender 'Thermometer gestattet die Beaufsichtigung des Verdaumgsrammes.

Will man das Wasser auferhalh des Dialysators oft werliselı. so mulb man dafür sorgen. daf der verbrauchte Wasservorrat in der Mariotteschen Flasche jederzeit ersetzt werden kann. Lazu stöpselt man in den Hals der Flasche statt des Thermometers einen Trichter. dessen Trichterrohr von oben her durch einen in Kautschukrohr gehiillten (ilasstab luftdicht schlielit. Ist die Flasche leer und im Diffusionsglase der Wasserspiegel etwas gesunken, so liiftet man den Glasstabstïpsel und fiillt die Flasche durch den Trichter in wenigen Sekunden. Ian braucht nur darauf zu achtent. dilis der Einfiilltrichter gestöpselt wird. heror die Fliissigkeit sich dem Filterrande so nahe gehoben hat. daß sie iiher denselben hinweg zu dem IDiffundate $z$ steigen droht. ${ }^{1}$ )

Dialysator nach Sheridan Lea. Im Kroneckerschen Apparate können zwar die dur'h Pergamentpapier dialssierbaren Verdaungsprodukte entweichen, aber die unaufhörlich beim lebenden Tiere vor sich gehenden Bewegungen des Magens und del (iedärme werden keineswegs nachgeahmt. Tun dies zu erreichen, bedient sich A. Sheridan Lea des in Fig. 77 abgebildeten Ipparates. Inieser besteht aus einem zylindrischen Gefülie $A$ von $6.5 \mathrm{~cm}$ Höhe und ('a. 1.) $\mathrm{cm}$ Durchmesser, welches mit 3 öffnumgen $B, C, D$ versehen ist und aus einem mit Wasser gefuillten Kupferbehälter $E$. in welchen sich eine Schlangenröhre $G$ befindet. die durch die Öffnung (' mit dem Gefïle $A$ in Verbindung steht. Durch diese schlangenröhre kann man einen Wasserstrom ron $F$ iiber $H$ und ' nach dem Gefäbe $A$ flieben lassen. Das Wasser füllt las Grefäl $t$ bis zur Höhe

1) Hugo Kronecker, Ein Verdauungsofen mit Diffusionsapparat. Beitr. z. Anat. u. Physiol. Festgabe für Farl Luduig. S. 130-133. Leipzig 1874. - G. Wolfthägel, Uber Pepsin und Fibrinserdaumg ohne Pepsin. Ptügers Arch. f. 1. ges. Phỵsiol. Bd. 7. S. 1Re his $200(1873)$. 
den Öffnumg $b$, ron wo es durch die liöhre $I$ abfliefit. Inrch Regulierung ler Flanme des Bemuers $J$ und der Wasser\%ufuhr in der sehlangenröhre kann man die Wassertemperatm im ciefïbe $A$ anf $40^{\circ}$ ( halten. Im \%entrum des (iefäbrs 1 befindet sich ein zweites zylindrisches Gefäl $K$, dessen unteres Ende $I$ mittelst eines von cincr Glasröne durchbohrten liautahukpfropfens gesehlossen ist. Diese (ilasröhre ist mit der Glasröhre $M$ rerbunden. In (iefälse $K$ befindet sich der Dialysierschlauch $V^{r}$ aus Ierganentpapier: weleher mittelst der auf der Winde O liegenden Schnur I' piner fortwälnend alternierenden Bewegnng von unten nach oben und ron ohen nach unten unterworfen ist. In den Dialysator 1 bringt man die zu verdanenden stoffe mod die Verdannosfliissigkeit. In Gefälie $K$ hefindet sich

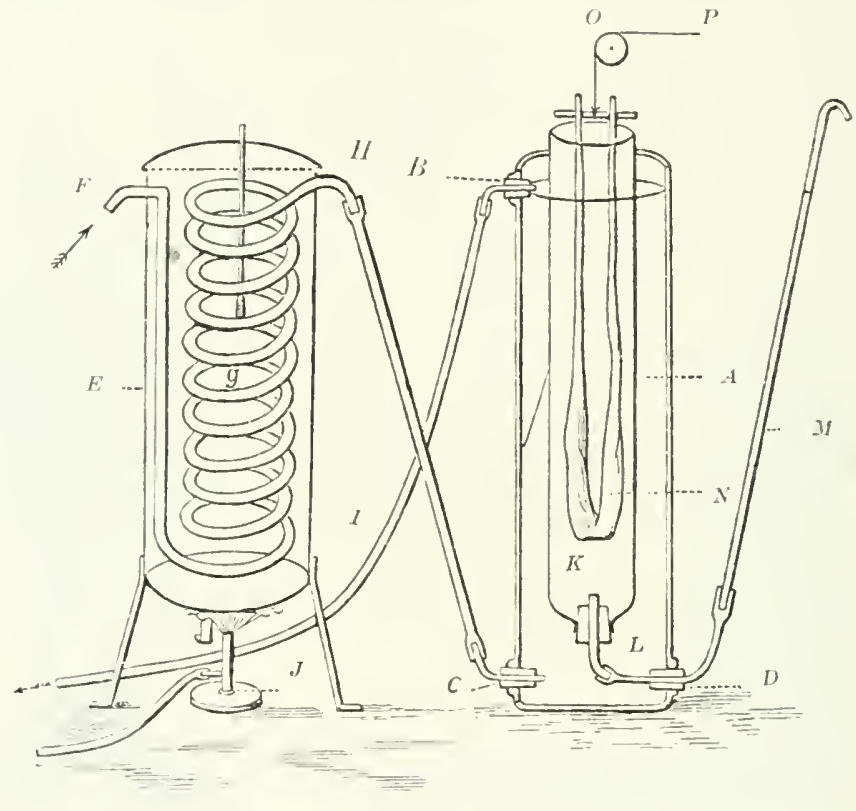

l'ig. 7 i

dieselbe Lösung. aber ohne liermente. Yach Sheridan Lea soll die Mischumw dus luhaltes des Dialysielschlauches eine selu vollkommene sein. Pupo zufolge sind jedoch die bewegmen keineswegs energisch genug und almen

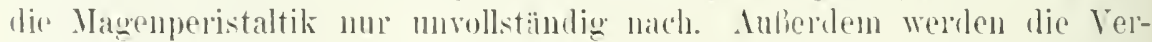
danungsiifte keineswegs wie in lebenden Organismus stetig zngefiihrt und (menert. ${ }^{1)}$

Dialyator nach Pupo. T'm sich hei den Vorsuchen in vitro den bei der natiortichen Verdamme hestehenden Berlingungen möglichst zu nähern.

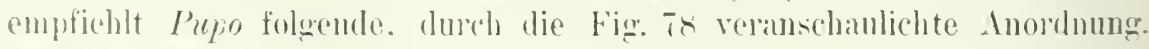

1) A. Sheridun Leu, A comparative study of artificial and natural digestion. Joum. of l'hysiol. Vinl. 11. p. $226-263$ (1)!(1)). 
In einem mit :3 Offuungen versehenen líolben $A$ vou $: 30 \mathrm{~cm}$ Länge und $16 \mathrm{~cm}$ Durchmesser hïngt wagreclit ein l'erganentpapierbentel $B$ von umgeführ $200 \mathrm{~cm}^{3}$ Inthalt. Eine der beiden öfnumgen dieses Sackes ist mit der $10 \mathrm{~cm}$ langen und $4 \mathrm{~cm}$ breiten Giasröhre $h$ verbunden. Diese Gilasröhre $h$ ist an ihrem inneren Ende mit einem Musselintuch geschlossen und an ihrem äuferen Endle mit einem I'fropfen. durch welchen die Glasröhre $f$ in die Röhre $h$ dringt. Die andere öffnumg des Perganentheutels ist mit der Röhre $p$ rerbunden. Diese Röhre endigt auferhalb des refülies $A$ durch den 2 - :3 cm höher als die Öffnung der Röhre $f$ liegenden Trichter $k$. Veben des liöhre $p$ treten durch denselben I'fropfen aus dem (iefäbe it der 'Thermometer $t$ und die durch eine Kautschukröhre mit

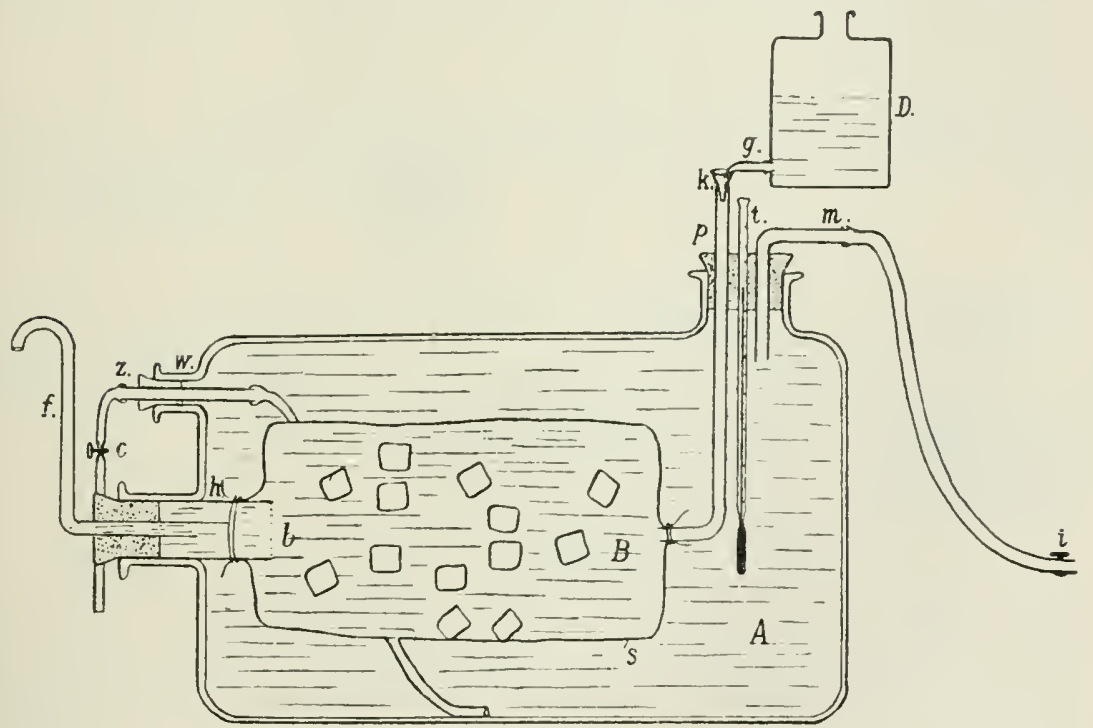

Fig. 78.

einem voll einem Motor in Tätigkeit gresetzten Blasebalge verbundene Röhre $m$. Die zu verdauenden Stoffe werden in den I'ergamentpapierbeutel gelegt. Der Verdauungssaft wird durch den Trichter $k$ in den Pergamentsack gebracht, während die den eigentlichen Dialysator $B$ umgebende Fliissigkeit durch die Öfnnung $w$ in das Gefäl $A$ eingegossen wird. Sobald dieses Gefäl gefüllt ist, wirl die Öffnung $u$ mit einem durch die Röhre $Z$ durchbohrten Pfropfen geschlossen. Diese Riöhre Z wirkt als Sangröhre. sobald die Ḱlemme $c$ geöffnet wird. wodurch man das Gefül i ausleeren kann. I)as (iefäb A liegt auf einem mittelst Bunsenbrennem auf $40^{\circ} C^{\circ}$ erwämten sandbade. Um den Verdaumgssaft alhnählich zu erneuern. 


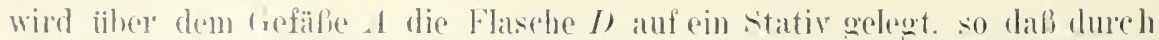

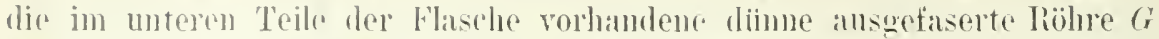
die Verdanmesflïsigkeit $k$ abtropft. Man kamn die in der Flasde $D$ befimdliche Flissigkeit mittelst einer Gasflamme erwärmen. Was iilmigens nicht abolut notwendig ist. dem der langsam abfliebende Verdannossaft erwäme sich beim Wischen mit der in Dialssator enthaltenen Fliis simkeit.

IBei jeder liewegmo des Blisbalges erhöht sich der Druck im Gofäbe $A$, wodnrch des l'orgamentheutel in allen Richtungen zusammengedrickt wird mod die zu verdanenden Stoffe sich mit der Verdaumosflüsigkeit gut rermischen. Wegen der voriihergehenden Volmmenahnahme des sackes $B$ strebt die Verdanungsfliissigkeit in die liiblne f zn stejgen. Man kamu

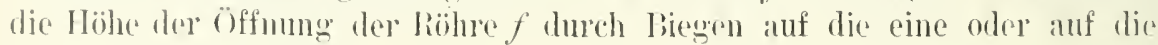

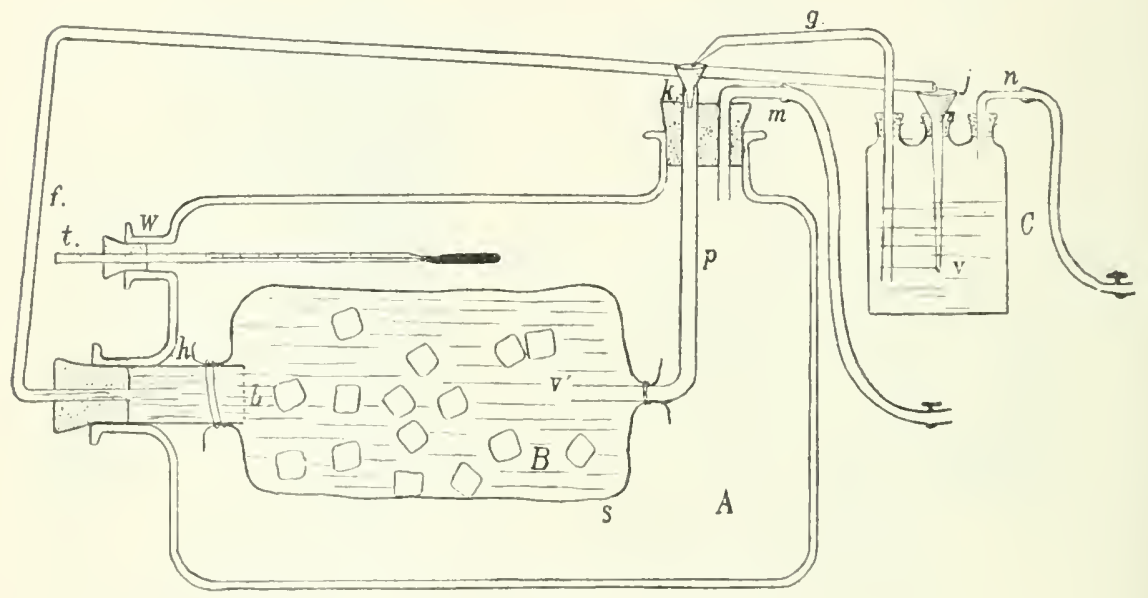

Fig. 79

andere seite etwats verïndern, so dab bei den maximalen sehwamkmoen die Fliissigkeit gerade his zur Öfnumg der liölure f gelangt. Da aber die manlhörlieh laugsam ror sieh gehende Zufulur von Verdamugssaft das. Volmmen der in Perganenthentel $B$ entlualtenen Flïscigkeit stets vergröbert, so wirl ein 'T'ail diesor Fliissigkrit durch die lïhre $f$ ' wegretrieben und in einem Gefälie gresanmelt. Das Musselintuch verhindert die Weo-

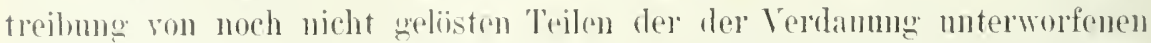
Stoffe. so dab auf diese Weise nur die vom Verdamungssaft gelösten Produkte ansueschieden werden. In Pruposchen Apparate werden die Tomwandlungskïrper nicht nur durch Dialyse. sondern anch mechanisch wergetrieben. Anberdem strömen stets nene Verdanungsialtmengen zu. 
welche, wegen der maufhörlichon Bewewungen des l'ergamenthentels. in innigste Berührum mit den zu verdauenden Stoffen gebracht werden.

Falls man die reitweiso entfernten Verlaumarspoodnkte den Pergamentbentel wieder zufiihren will. so mulj man den socben beschriebenen Apparat etwas verindern mud ihm die aus fig. ja zu erschende fiestalt geben. Die Röhre f wirl mit dem Trichtel ; des den wälnend den Versuchen dem I'ergamentbeutel $B$ zuströmenden Verdaumessaft enthaltenden Kolbens ( verbunden. Dieser Kolhen hesitzt anferdem zwei andere durch Kiatschukpfropfen geschlossene öffnungen. I)uroh eine dieser Öffnungen gecht die Röhre $g$. welche in den Trichter $k$ allmälhlich die in Kolben $C$ enthaltene Fliissigkeit giefit. Durch die andere öffumg geht die Röhre $n$. welche mittelst einer liautschukröhre mit dem Blasbalge in Verbindung

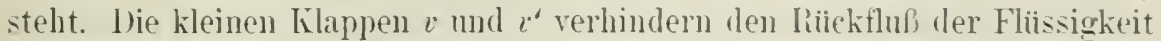
zu den Trichtern. Da bei jeder Drehumg des liarles des Blasbalges ein oder zwei Tropfen Flissigkeit durch die Röhre $g$ in den Trichter $;$ und in die Röhre p gejagt werden. so besteht ein unaufhörlicher Kreislauf zwischen der Flissigheit des I'ergamentbentels $B$ und der Flasche $C$. Der Thermoneter $t$ befindet sich in der öffnung $w$ statt neben den Röhren $p$ und $m .{ }^{1}$ )

\section{B. Spezielle Technik.}

\section{Gewinnung der Verdauungssäfte, Darstellung der Fermente und ihre Anwendung.}

\section{(1) Allgemeine Betrachtungen.}

\%u den Verdauungsversuchen soll man die Verdammgssäte selbst den ans den entsprechenden Driisen dargestellten Extrakten rorziehen, dem Verdaumgssäfte und Drïsenextrakte hesitzen keineswegs dieselben enzymatischen Figenschaften. Die Extrakte enthalten nämlich oft intrazelluläre Fermente. welche keineswegs an der phrsiologischen Wirkung der Sekrete der Verdammgsdriisen Teil nehmen und infolgedessen leicht zu ganz unrichtigen schlïssen führen kïmnen.

Da es nicht immer möglich ist. die Verdanmgssäfte mit genïgender Asepsis anfzusammeln. so soll man sie durch sterilisierte (hamberland- oder Berkelerkerzen filtrieren, bein Filtrieren in sterilisierte, mit Watte rerschlossene Kölbchen anffangen und auf Eis anfbewahren. S. Dsierzgorsti sowie Kastle und Loewenhart zufolge soll aber bei einer lerartigen Filtration eine beträchtliche Schwächmug des Fermentgehaltes des Filtrates elfolgen. Dies ist hesonder's der Fall. wemn man um geringe Flïsigkeitsmengen dieser Filtration unterwirft. denn nach Dsicrzyoushi enthalten die ersten

1) Carlos Pupo, Recherches expérimentales sur la diggestion artificielle de l'albumine. Thèse de (ienère. 39 pages (189!). 
l'ortionen des Filtrates fast gar keju Ferment, die folgenden erst mehr: ${ }^{1}$ )

Falls man die Verdammgssifte der Kerzenfiltation nicht monterwerfen kamn. so mul man sie mit einer geringen Menge eines Antiseptikums relsetzen. Wozn man 'T'hymol, Kampferpulver, C'alonel, chloroform. Senfiil usw: je nach den L'mstïnden gebrancht. Am empfehlenswertesten

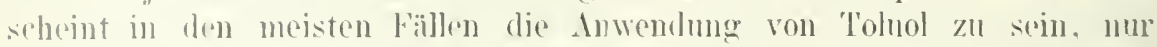

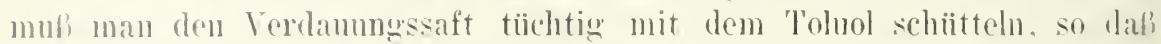
(r) damit gesittigt wird: atherden soll eine 'Toluokchicht ijher dem Safte stohen.

Bei den Verdamugstersuchen in vitro ist es meistens ratsam, sellst

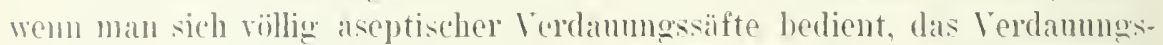
gemisch, ohe man es im brutappäate dem Veroanmosprozesse muterwirft. mit Toluol zu versetzen. Nur bei der Anwendung von l'epsin in Gegenwart von silzsaume kam man. falls die lersuche keine zu lange Zeit beanspruchon. den 'Toluolzusatz weglassen. Diese Antiseptika bleiben indes nieht immor ohme schädlichen Einflul anf die Wirkmng der verschiedenen bumme, so dalf man keinen Chersehui davon anwenden darf. Man soll sie atuch je nach den Emstïnden vorschioden wïhlen. $\left.{ }^{2}\right)$

Man soll sich immer durch besondere bakteriologische Kontrollversuche rom der dbwesenhejt lehender Bakterien in den Verdaumgsgemischen an Ende oder wïhrend des Versuches ïherzengen.

Bei lieendigme der Versuche muf sofort jede enzymatische linknug

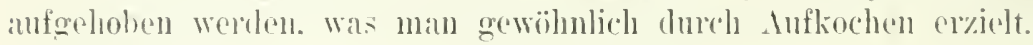

\section{b) Speichel.}

Gewimnung. '/mu Gowimnen des Speichels hedalf es beim Menschen keiner besonderen Voreschtungen.

Beim Tiere kamm man ihn durch in die ansgeschnittenen Iusführungswïngr der speicheldriisen eingehnndene Kaniilen oder nach dem Verfalnen von Glinslit erhalt(rn."3)

In speichel anthaltene Fermente. Beim Menschen enthält dev

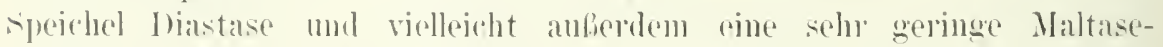
menge. In speichel des Hundes fehlt die Diastase wahrscheinlich völlig.

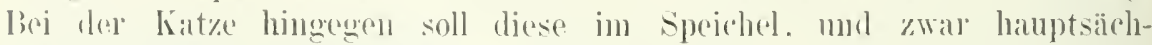
lich in Submaxillatisperehel vorhanden sein. beim l'ferde soll nach

1) S. Isierayouski, sur la filtration des substances albuninoüdes à proprictés actives. Areh. des se. hiolog. de st. P'etershourg. T. 4. p. 225-240 (1896). - J. H. Kasfle and .1. S. Lowenhart, concerning lipase, the fatt splitting enzyme, ant the reversilility of its action. Amer. Chem. lourn. Vol. 24. p. 491-52.) (1901).

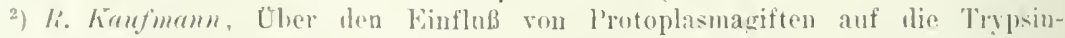
rerdanmeg. Zeitsehr. f. physiol. ('hemr. Bil. 39\%. S. $434-457$ (1903).

3) Versnche über die Arheit der Speicheldrüsen, mitgeteilt durch J. I'. I'arrlor. lerh. d. Gesellseh. russischer Crate zu St. Petershurg. 1895. - \%it. nach.J. I'. I'rurlou, Die

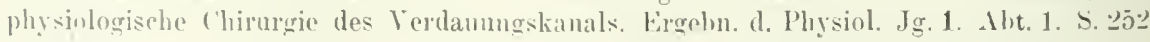
$(1902)$. 
H. Goldschmidt im speichel, wenigstens im Parotisspeichel. die Diastase 1 m als Zymogen sich vorfinden. ${ }^{1}$ )

I iastase (I'tralin. Amylase). Bis jetzt besteht noch kein vijllig sichereVerfalluen. mm das Ptralin in reinem zustande zon isolieren.

Ian benutzt noch oft die alte dureh J. Cinhneim angegebene Vethode. Der menschliche speichel wird nit verdianter I'hosphorsänre und daun mit ('alciumhydroxyd versetz. Der sich bildende Tricalciumphosphatniederschlag reilit das Ptralin mechanisch mit. Der abfiltrierte Niedelschlag wird mit Wasser ansgewaschen. Wohei das l'tyalin vom Wasser geliist wirul. Aus dieser Lïsung fällt man schlieflilich rlas Ptyalin mit Alkohol. Durch wiederholtes Auflösen in Wasser und Fällen durch Alkohol kamn man das I'tralin reinigen. ${ }^{2}$ )

Genticr setzt zum Speichel so lange 98\%igen Alkohol. bis sich ain flockiger Nierlerschlag bildet. I)ieser wird abfiltriert, in wenig destilliertem Wasser aufgelöst, mit einigen Tropfen einer Mercurichloridlösung versetzt, un das vorhandene Fiweil) zu beseitigen. In Filtrate wird der Cherschub ron Mercurichlorid durch schwefelwasserstoff rerjagt. Die nach dem Ahfiltrieren vom Mercurisulfid iibrig bleibende Flüssigkeit wird bei einer $40^{\circ} \mathrm{C}$ nicht ibbersteigenden Temperatur zur Trockene verdampft und dann mit Alkohol behandelt. Ler in Alkohol unlïsliche Teil des Trockenriickstandes wird in wenig destilliertem Wasser aufgelöst. filtriert, dialysiert, um die anorganischen Salze wegzutreiben, schließlich mit absolutem (lkohol gefïllt. wohei sich das I'tyalin in Flocken ausscheidet. ${ }^{3}$ )

Um das Ptyalin zu erhalten, wird nach $S . W^{r}$. ('ole $e^{4}$ mensehlicher speichel mit starkem Alkohol rersetzt. Nach zweitiogigem Stehen filtriert man den Niederschlag und wäscht denselben mit absolutem Alkohol aus. Der spontan abgetrocknete Niederschlag wird dam bei $40^{\circ} \mathrm{C}$ mit destilliertem Wasser ausgezogen. Dieser Auszug wird abfiltriert. Thas so erhaltene Filtrat bildet eine sehr wirksame neutrale Ptyalinlösmug und enthält nur Spuren ron Proteinen. Ian kann diese Ptyalinlïsung durch Dialyse gecten destilliertes Wisser weiter reinigen.

1) P. Grützner, Notizen über einige ungeformte Fermente des Süugetierorganismus. Pflïgers Arch. Bd.12. S. 285-307 (1876). - Lafayctte B. Mendel and F'. I'. Índerhill. Is the saliva of the dog amylolytically active? The Journ. of biol. ehem. Vol. 3. p. 13 bis 143 (1907). - Harald Goldschmidt, Zur Frage: Ist im Parotidenspeichel ein Ferment rorgebildet rorhanden oder nicht? Zeitschr. f. physiol. Chem. Bd. 10. S. 273-293 (1886). - W. Mestrezat, Origine physiologique du pouvir saccharifiant de la salive. Compt. rend. hebd. des Séane, de la Soc. de Biol. T.63. p. 736-738 (1907). - Derselbe, Origine du ponvir saccharifiant de la salire chez l'homme. Bull. d. l. Soc. chir. de France. Série 4. T. 3. p. $711-713$ (1908). - A. J. Carlson and J. G. Ryan, The diastase in eat's salira. Amer. Journ. of Phrsiol. Vol. 22. p. 1-15 (1908).

$\left.{ }^{2}\right)$ J. C'ohnheim, Zur lienntnis der zuckerbildenden Fermente. Firchou's Arch. f. pathol. Anat. Bd. 28. S. 2\$1-253 (1863).

$\left.{ }^{3}\right)$ Charles E. Simon, A text-book of physiological chemistry for stulents of medicine and physicians. 2d edition. london 1905. p. 12⒊

4) Contributions to our linowledge of the action of enzymes. Part I. The influence of electrolytes on the action of autolytic ferments. Journ. of Plysiol. Vol.30. p. 202-220 (1903). 
Als dinfachere Vothole. mm einc wirksame neutrale Ptralinliosung zu

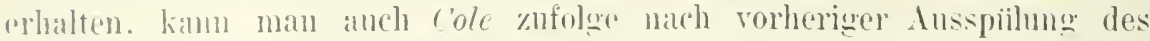
Mmuls mit hoiliem destillierten Wasier während 1 Mimute mefälu heilies destilliertes Wasser im Mumb halten mol glojeh dalauf diese Fliissigkeit gegen oft ermenertes destilliertes Wasser dialysieren. Iniese I'tyalinliismog anthilt indes eine gejunge Mncimmenge.

1)as l’traliu scheint an kräftiosten bei nentraler oder änferst schwach samm lieaktion zu wirken. Ine Wirkmeg der speichelamylase wird vom mmgebenden Modimn stark beeinfluht. Die Speichelamylase soll nur bej (iegremwart dines Phosphates ihe Wirksankeit ausiben und jedenfalls nicht

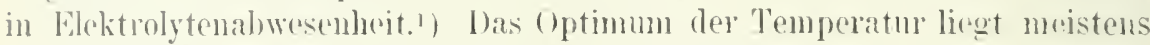
low rilkil 500 fiu die monschliche Amylodextrinase. $\left.{ }^{2}\right)$

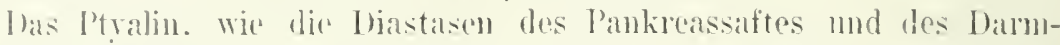
salles, fülnt Stälke in l)extrine und Zncker iiber; der dabei statffindente Vorang ist noch keineswegs in semon Eimzelheiten sicher festegestellt. Es

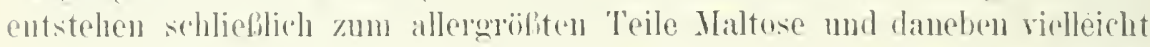

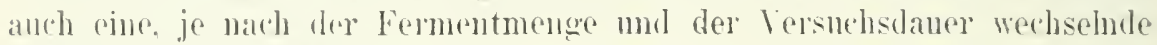
Menge voul Isomaltose. $\left.{ }^{3}\right)$

\section{(.) Magensaft.}

Gewinnung. Man orhält leicht remen Magensaft durch Verabreichumer

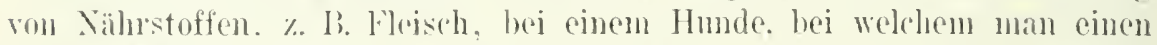
kleinen Magen nach dom l'urlowsehen Verfaluen isoliert hat. Diese operation ist an anderer stalle sehon beschrivben.t)

Eillins bereitet mittelst hoilien destillierten Wassers oder 0 to nigrer

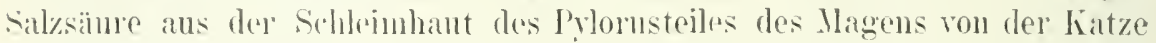

1) II. Roger, sur le rîle des phosphates daus la sacelarification salivaire. Compt. rend. helud. d. Séanc. de la soce de Biol. T. 6ij. p. 374-375 (1908).

2) A. stosse und /l. Limbosch, le laction du ferment salivaire dans ses rapports aver la température du milieu. Areh. int. de Physiol. 'T. 6. p. 36.5-380 (19018).

3) 1. Srhlesinger, Zur liemunis der diastatischen Wirlang des menschlichen sueichels nelst cinem kmzen AbriB der (ieselsichte dieses fiegenstandes. Firchows Arch. f. pathol. Anat. Bul. 12\%. S. 14t;-181 u. 340-363 (1891). - W. E.bstein und C'. Schulze, 'ber die linwirkung ler Kullensäne anf die diastatischen Fermente des 'Tierkörpers. libenda. Bd. 133t. S. 475-500 (1893). - E. Kïlz mul J. Yogfl. Welche Zuckerarten entstehen hej den durh tierische Fermente hewirkten Ahban der Stärke und des Glykogrens. \%eitscher. f. Biolng. Bal. 31. S. 11R-124 (1894). -- M. ('. Trbb, On the transformation of maltose to dextrose. Jum of l'hysiol. Wol. 15. p. 421-432 (18!4). - II. Y. I'rmon, The conditions of action of pancreatic remin and diastase. Ebenda. Vol. 27. p.171-19!9 (1901). - H. Röhmam, Zur Lemutuis der Glukose. Ber. d. Dentsch. chem. lies. Ba. 27.

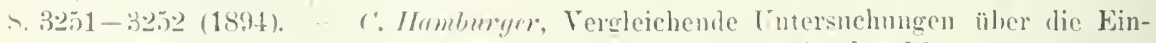
wirkung des speichels. des l'ankreas- mul larmsaftes sowie des Blutes anf Stärkeklejstel. l'flügers Arch. f. d. ges. Physiol. Bd. 60. S. 543- 597 (1895). - F. Kübel, Üher

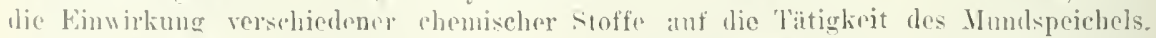

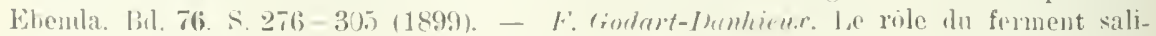

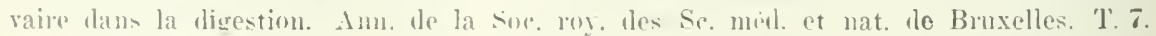
filser. 1. 1r. 1-132. (1898).

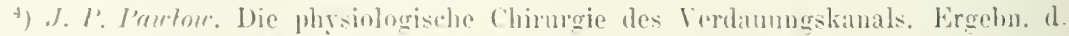
lhysiol. og. 1. Aht. 1. S. $258(1902)$. 
oder von schweine (boj diesem Tiere anch ans dem (ardiateile) ein Extrakt. welches ein Vagensckertin enthïlt. Wird heim IIme oder bei der Katz. die Cardia unterlunden, und fïhrt man rom lnodenum aus eine hanïle in den Magen, welehe man nahe an l'fürtner unterlindet. und fiillt nan ferner den Magen mittelst einer in cinem mit der líaniile verbumlenen behälter befindlichen salzlösung, so bewirkt dam die intravenöse Einspritzung der das Iagenselietin enthaltenden neutralisierten bxtrakte nach 10 Vinnten eine

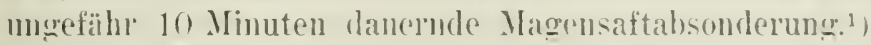

Im Vagensafte enthaltene Fermente. Der Magensait enthäl cine nur auf emulgierte Fette wirkende Magenlipase und ein proteolytisches Ferment. das I'epsin. (ob anferdem noch ein besonderes Labferment besteht. orler oh dic den Lahfermente mu! dem l'epsin zugeschricbenen Wirkungen einem und demselben Enzrme zukommen. ist eine viel unstrittene Frage. Ieshalh wird man hicr die I)arstellung des Labfermentes nach Hemmarstrn rorfinden, ohne dalf dadurch irgendwie dieser Punkt benrteilt werden soll. Dies ist auch der Fall für das Glaeßnersche l'seudopepsin des l'Ylormsteiles des Magens.

Magenlipase oder Magensteapsin. Bis jetat besteht kein Verfahren zur Isolierung der Jagenlipase.

\%u Versuchen mit der Magenlipase benutzt man den aus dem kleinen Magren eines nach Paulou operierten Hundes stammenden Magensaft. Man kimm anch das, nach swiundlichem Auswaschen der Magenschleimhaut, durch /usat\% des gleichen Gewichtes wasserfejen Glyzerins zur Magenschleimhaut und fünftägigem Stehen in Thermostaten bei oft wiederholtem Umschütteln erhaltene Cityzerinextrakt der Magenschleimhaut anwenden. was indes keineswegs zu empfehlen ist.

Die Magenlipase ist nicht schr widerstandsfühig. sie scheint am besten hei leicht saurer Reaktion zu wirken, wenigstens bei Vlenschen und Hunden. ${ }^{2}$ )

Pepsin. Pelielhuring hat Verfahren zur Reindarstellnng des P'epsins aus der Schweinsmagenschleimhant angegeben und aus dem reinen. nach

1) J. S. Edkins, The chemical mechanisu of gastric secretion. Journ. of Physiol. Vol. 34. p. $133-144$ (1906).

") Cash. Über den Anteil des Magens und des Pankreas an der Verdauung der Fette. Arch. f. Physiol. u. Anat., physiol. Alit. S. 323-333 (1850). - Ogata, Die Zerlegung neutraler Fette im lebendigen Magen. Ebenda. s. j15-j18 (1881). - Franz Vollard, Uber das fettspaltende Ferment des Magens. Zeitschr. f. Klin. Meul. Bd. $¥ 2$. S. 414-4:9 (1901); Bd. 43. S. 323-333(1901). - Albert Fromme, Čber das fettspaltende Ferment der Magenschleimhaut. Beitr. z. chem. Physiol. u. Pathol. Bd. 7. \&. 51-76 (1906). - F. Laqueur, Uber das fettspaltende Ferment im Seliret des kleineu Mageus. Ebenda. I3d. 8. S. 281-284 (1906). - E. S. Loulon, Zum Chemismus der Terdanung im tierischen Kïrper. 7. Vitt. Ein reiner Pylorusfistelhmul und die Erage über Gastrolipase. Zeitschr. f. phrsiol. Chem. Bd. 50. S. 125-128 (1906). - E. S. London und M. A. Wersilorea, Zur Frage über die Spaltung emnlgierter Fette im Magendarmkanal des Hundes. 13. Mitt. Eluenda. Bd.56. S. 545-550 (1908). - Friedrich Heinsheimer, Experimentelie Lntessuchungen über fermentative lettspaltung im Magen. Deutsch. med. Wochensehr. Bd.32. S. 1194-1197 (1906). - $\therefore$ J. Lerites, Üher die Verdaung der Fette im tierischen (rganismus. Biochem. Zeitsehr. Bd. 20. S. 220-223 (1909). 
I'aulour abaltenen Hundemagensafte. AuRerdem besteht eine Vorschrift von

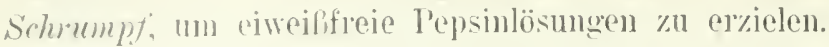

lieindalotellume des I'epsins aus sthweinsmagenschleim-

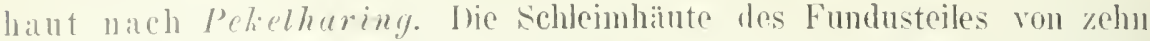

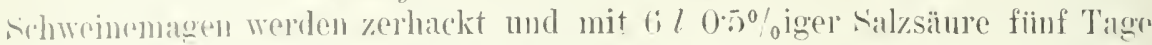
lang hei :37" C rerlaut. Hel so hereitete Infus wirel dann filtriert. Dazn

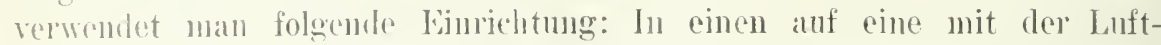
pumpe verbunlene liasche gestellen 'Triehter wirl eine otwat zentineterdicke. lonisch abgeschliffene, von zahlorichen öffunngen perforierte Ebonitjlatte gelegt. Diese wird mit fenchtem Filtrierpapier hedeckt und dann wird. während die luft ans eler Flaseho herausgesangt wird, ein diuner lirej von in Wasser fein zerpebenen Filtrierpapier darauf gegossen. Durch die so elhaltene, $7-1$ i) $\mathrm{cm}$ dicke. feste schicht wird damn die zu filtrierende libssig-

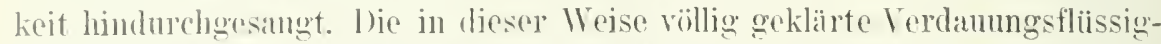
keit wird dann in l'eroamentpapiersoluäuchen in ein grobes refäb nit strömendem Leitungswasser gostellt und etwa ?2 stunden dialysiert. Del Iam tribe gewordrne l)alysatorinhalt wirl zentrifngielt, um den ans Pepsin bestehenden Niedersdulag (a) nud die ohen schwimmonte rlibsigkeit zu tremen. letztere wirel mit hasischem libiacetat mol Immoniak hehandelt. "nolureh sich ain volmuinöscr. leicht filtrierbarer Niederschlag bildet. Diesel Niedorschlag wird vom libler gemommen und mit eimer gesätigten ()xalsïmrelösung versetzt. Her dicke Brei licfert damn hald eine gelbbrame Flissigkeit, welche durch Filtrieren leicht rom Bleiacetat zu befreien ist. l)ieso stark saure, völlig klare Flussigkeit wirl 24 36 stunden geopen strömendes Leitungswassel dialysiert. Das hierbei im Dialysator ansgefällte lepsin (b) wind mittelst der Zentrifuge von ler Flissigkeit (c) getrenut. Die Pepsinportion b wirl mit del zuerst ansgeschiedenen Pepsinportion a veleinigt, in möglichst wenig $0 \% 2 \%$ inel Salzsäme bei $: 7^{\circ}$ C gelöst und bei derselben Temperatur filtriert. Die vollig klare, gelblicl gefïlote Lösung wiol in die \& 1ofache Menge destillienten Wassers gegossen und vorsichtig mit äulierst verdiumter Natron- und Kalilange versetzt. bis empfindliches Kongopapier nicht meh' gebläut wind. '/u' möglichst volständigen Ansscheidung des l'epsins beilet die Flïssigleit eine Nalelt iiber im Eis-

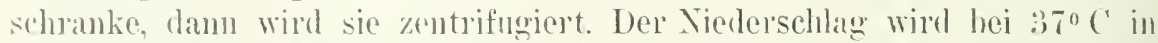

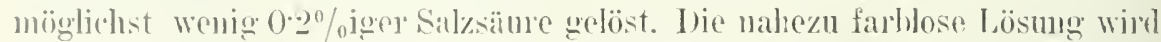
bei :3" C filtriert mol dam in einem klemen Dialysatorschlath in destilliertes Wrasser gestollt. In I)ialysator setzt sich dam das Tepsin in kleimen, gruppenweise zusammenhaftenden, durchsichtigen, ziemlich stark

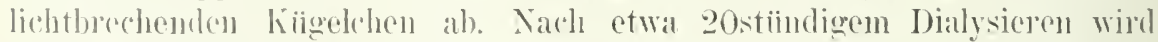
dieser Vioderschlaw abfiltriert, oinmal mit destilliorten Wasser iibergossen und nach vorsichtigrm Auspressen des Filters zwischen Filtrierpapiar vom Filter abgehohon und iiber schwefelsäure ofler Clilorcalcimm hei rimmertemperatur etrocknet und fein zerrieben. Das so beleitete Pepsin stellt ein aschefarhiges, nieht oder kaum hygroskopisches l'nlver dar". 
Die rom Ijleioxalat ahfiltrierte. dialysierte und dann ron ausgeschiedenen l'epsin hefreite Lösung enthïlt noch eine erhebliche Pepsinmenge, wolche bei sättigung dieser Lösung mittelst Ammonsulfats sich in klehrigen, leicht zu filtrierenden Flocken absetzt. Dieser Niederschlag wird durch ein gehärtetes filter filtriert, woron es sich als eine zähe zusammenlïngende Masse leicht abnehmen lïßt und im feuchten \%ustande ohne Wasselzusatz in einen Dialysatorschlauch gebracht, welcher in strönendem Wasser aufgehängt wird. Das Wassel dringt in den schlauch hinein und löst den größten Teil des Niederschlages innerhalh ət Situnden, worlurch das Pepsin ron einem Teil der Verdauungsprodukte der Vagenschleimhaut und rom zugesetzten Ammonsulfat befreit wird. Diese Flissigkeit wird mit Salzsäure versetzt bis zu einem Gehalt ron $0.02 \%$ Salzsäure und nun einen Tag lang gegen Salzsäure derselben Konzentration bei ciner nicht weit iiber $0^{\circ} \mathrm{C}$ betragenden Temperatur dialysiert. Der dabei entstandene Pepsinniederschlag (c) wird abgesaugt und wie oben beschrieben behandelt: Auflösen in $0 \cdot 2 \%$ iger Salzsäure bei $: 7^{\circ} \mathrm{C}$. Filtrieren, Gieljen in das \&- bis 10fache Volumen Wasser, Zusatz ron Alkali, bis Kongopapier nicht mehr gebläut wird, Zentrifugieren, Lösen in $0 \cdot 20{ }_{0}$ iger süne usw. Schließlich wind die gereinigte substanz im Exsikkator bei Zimmortemperatur getrocknet und zerrieben. Dieses Pepsin entspricht röllig dem durch Dialtrse sowie mittelst ammoniakalischer Bleiessiglösung und Oxalsäure erhaltenen.')

Darstellung des Pepsins aus Hundenagensaft nach Petielharing: Dialysierschläuche aus Pergamentpapier werden mit 0\%\% iger Salzsäure grefüllt und melırere Tage gegen fliefendes Wasser dialysiert, um die sonst ron der Schlauchwand an Wasser abgegebenen, nicht unerheblichen Calciumsulfatmengen vorerst zu entfernen. In den so bereiteten Pergamentschläuchen dialrsiert man gegen die wenigstens zofache Menge destillierten Wasser's etwa 20-2t Stunden lang bej einer nicht weit über U0 C gelegenen 'Temperatur den durch die Scheinfiitterung nach dem Parloxschen Verfahren beim uleichzeitig eine Ösophagus- und eine Magenfistel tragenden Hunde erhaltenen frischen Magensaft. Die tribe Flïssigkeit wird dann zentrifugiert, der gröbte Teil der oben schwimmenden Flissigkeit ahgegossen, der Bodensatz und dic noch rorhandene Fliissigkeit auf ein kleines Filter gebracht, mit wenig destilliertem Wasser gewaschen, abgeprebt, rom Filter abgehoben und im Frsikliator getrocknet. Auf diese Weise erhält man vollkommen farbloses Pepsin. falls der Magensaft ohne jede Gallenmischung bleibt. Man kamn letztere rermeiden, indem man sich eines ösophagotomierten und gastrotomierten Hundes mit kleinem Magen nach Pauclow bedient, erhält abev dann zu wenig Magensaft, um eine wesentliche Pepsinmenge daraus zu bereiten.

Wind die rom mittelst Dialyse gefüllten Pepsin getrennte Flïssigkeit mit Ammonsulfat halbgesättigt, so entsteht ein nicht unheträchtlicher Pepsin-

1) C.A. Pehelharing. Cher eine nene Bereitungsweise des Pepsins. Zeitschr. $\mathfrak{l}$. phrsiol. Chem. Bd. 23. S. 233-24t (1896). - J. H. A. Gexin, Pepsin und Chrmosin. Ehenda. Bd. 54. S. 31-79 (19.17). 
nimlerschlage. I m diestos l'epsin zu reinigen. wird es, wie oben heschrieben.

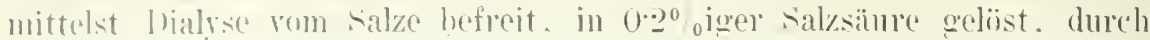
Diallse wieder gefällt, ahfiltriert und getrocknet.')

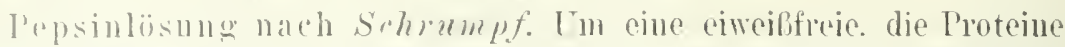

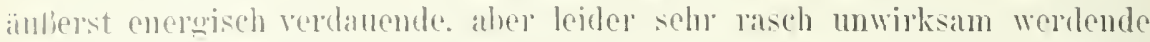
l'opsinlisung zu berejten, rerfïlnt man mach Schrumpf auf folgende Weist: Man priburiert sehleimhänte rou möglichst frischem schwememagen ab.

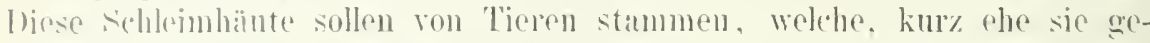

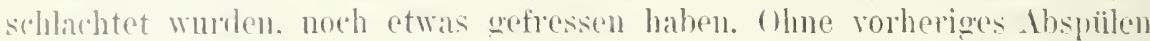
des ilmen anhaftenden schleimbelags werden diese schleimbaute wamz fein

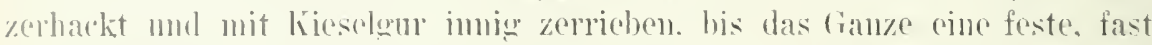
trokene Masse darstellt. Jiese wirel mittelst der Buchnerschen Prosse bei wanz allmählich bis zu etwa 100 Amosphälen westejortem Druck ausgeprofit. Der so erhaltene, leicht getriilete l'rebsaft wirl sofort dureh eine

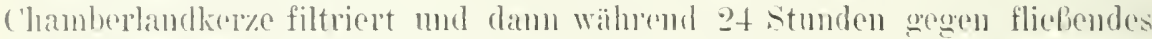
Wasser dialysiert. Eine geringe Cholesterimmenge wird in etwa $10 \mathrm{~cm}^{3}$

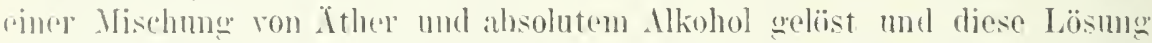

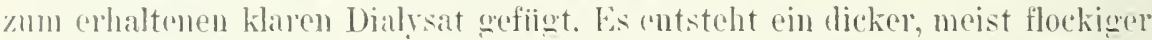
Niederschlag. der sehr rasch abzentrifugiert, abfiltriert. in der urspriinglichen Wassermenge anfoeschwemmt und dam öfters mit kleinen Ither-

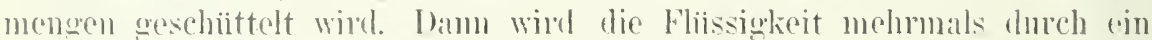
Sangfilter oder besser durch eine Kitasatoker\%e filtriert, wodurch man sebliefilich eino ganz klaure P'epsinlissmog erhält. $\left.{ }^{2}\right)$

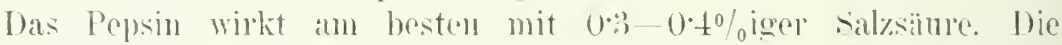
optimale Temperatur scheint $: 39^{\prime \prime}$ zil scin. IBoi nicht zu lanese danernden Versuchen ist ein Intiseptikum\%sat\% nieht absolut notwentier. Bej landdancruden Versuchen hingegen empfichlt es sich. Tohnol oder oin anderes Antiscptikmm anzumenten.

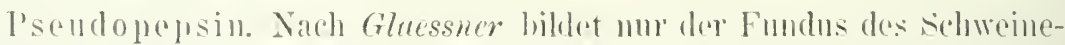
magens orhtes P’usin, whihremd hingegen sowohl Fumdus als l'yloms das anch in sehwath alkalisther Lösune wirkende. Tryptophan er\%ergende mol gexenteilig zum l'ropepsin mit Cranylacetat nicht mit ausfallende P'sendopepsin absondern. Hemmach enthalten die aus dem l'ylonusteile des siohweinematens bereiteten Fxtrakte mur l'sendopepsin.

bas Bestehen dres Pendopepsins wird von Rered angenommen, ron

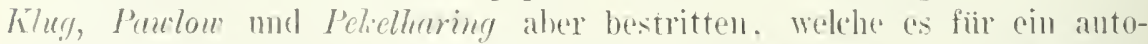

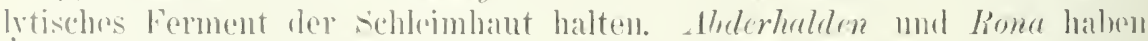

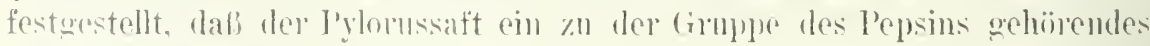

1) C'. 1. l'elelharing, Mitteilungen über Pepsin. Zeitschr. f. plysiol. Chem. Bd, 35.

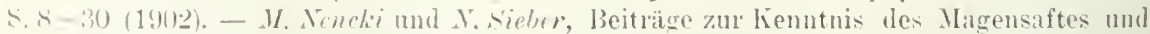
dep chemischen Zusimmensetzmng der Fuzyme. Ehenda. Bd. 32. S. 291-319 (1901). -

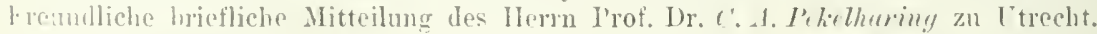

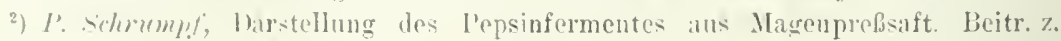

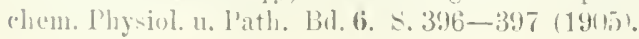


proteolytisches Ferment enthält, jerlorh uirht entichiralen. ol) dieses Enzym mit dem Pejsin identisch ist oder nicht.')

Labferment oder ('hymosiu. \%ur Reindarstellung dieses Enzyms benutzt man das Hommustonshe lerfalıen. Un cinc wirkiane chrmosinpeiche Magenschleimbantinfusion zu rehalten, nimnt man Iabmaun von

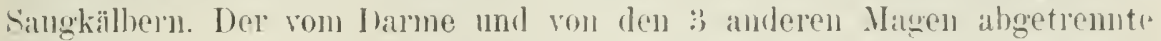

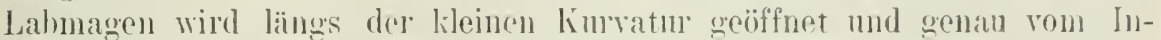

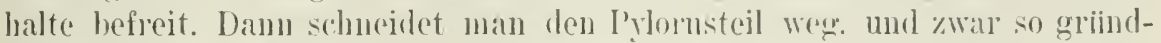

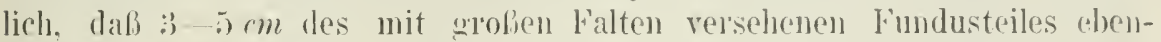
falls mit wegeschnitten worden. I)ey (xrund liorzu liegt darin, dafo der

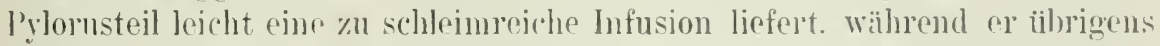
äıner an Chymosin als del Fumbusteil ist. Die iibrowe Magenselnleimhant wird griundlich mit kaltem Wasser abgespiilt. so dafi alle Schleinflöckehen und sichtbaren Partikelchen. auch dic. Welche sich zwischen den Falten vortinden. gänzlich entfernt werden.

Nun schaht man die Driisenselicht ab). Wägt die Masse und zerteilt sic in 10 - onmal ihres frewichtes einel $0 \cdot 1-0 \% 2 \%$ igen Salzsime. Nach 24-48stimdigem stehen bei etwas iber $0^{\circ} \mathrm{C}$ botragender Temperatur filtriert man die Fliissigkeit. Eine solche Infusion mulj nach der Neutralisation mit $\left.\mathrm{Na}_{2} \mathrm{C(}\right)_{3}$ und darauffolgendel Verdiinmmog mit dem ?ofachen Wasservolumen die Gerinmum ganz frischer Milch in dem Verhälnisse $1: 10$ bei $37-38^{\circ} \mathrm{C}$ in 1 Vinnte hervorlufen. Wirkt sie weniger kraftig, so miligliickt meistens dic Darstellung des Chrmosins.

Nachden man sich ron der kriftigen Wirkung der neutralisienten Infusionen iberzengt hat, geht man zu der fraktionierten Fällung mit Magnesimmkarhonat iiber: Jiese weschicht derart, dal jo $100 \mathrm{~cm}^{3}$ Infusion mit $1-1 \frac{1}{2}$ g Magnesiumkalponat versetzt und wähend .o Minuten mehrmals damit geschiittelt werden. Damn wird rasch filtrielt und das Filtrat auf I'(p)sin und Chrmosin orepriift.

Da das im Filtrat enthaltene Magnesiumsalz die Wirkung des Cluymosins hegiinstigen kamm, so soll man bei der I'rifung anf Chỵmosin nie meln als $1 \mathrm{~cm}^{3}$ vom Filtrate zu je $10 \mathrm{~cm}^{3}$ Mileh setzen oder einen T'eil des Filtates mit dem gieichen Wasservolumen verdiumen und crst liese Lösung benutzen. Bringt unter diesen Lmstinden das Filtrat bai $38^{\circ} \mathrm{C}$ die Vilch

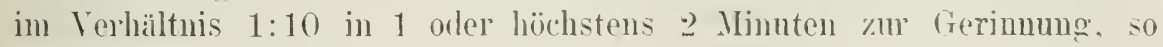

1) K. Glaessner, ther die irtliche Verbreitung der Profermente in der Magenschleimhaut. Beitr. z. chem. Physiol. u. Pathol. Bd. 1. \& $24-33$ (1902). - Felir Reach, Zur Kenntnis der Verdanungs- nnd Resorptionssorgange im Magen. Ehenda. Bd.4. S. 139-14t (1904). - F. Klug, Üher das Ferment der Pylorusschleimhaut. Pyïgers Arch. f. d. ges. Physiol. Bd. 93. S. 281-292 (1902). - C. i. Pekelharing, A propos de laction de la pepsine. Arch. des Sc. hiolog. de St. Pétersbourg. T. 11 (supplément). p. 36

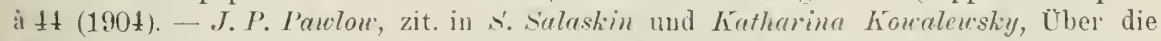
Wirkung des reinen Hundemagensaftes anf das Hämoglobin resp. Globin. Zeitschr.f. phrysiol. Chem. Bd. as. S. 567-584 (1903). - Emil Abderhalden und Peter Rona, Zur Kienntuis des proteolytischen Fermentes des Pylorus- und iles Duodenalsaftes. Ebenda. Bd. 47. 3. $359-361$ (1906). 


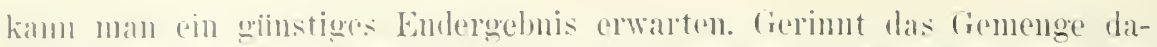

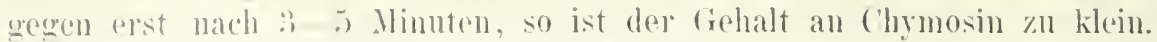

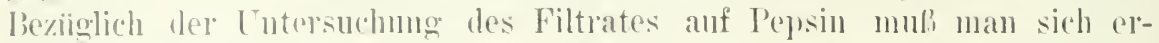
immern. dak das im Filtrat enthaltene Jagnesiumchlorid die F'epsinverdaumer rrsthweren kitno. I'm diesen etwaigen schädlichen Einfluli möglichst zu vermeden, wird ror der Pepsinprohe das Filtrat mit t, 6 oder \& Tolmuima

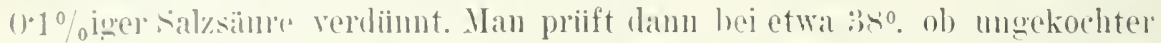

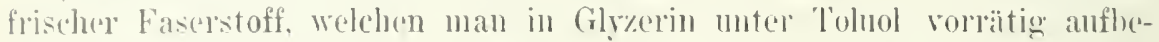
walnem kann, in kumer \%eit verdant wirel oder nicht dureh das Filtat

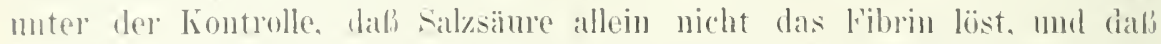
Salzsimue mit demselben Magnesumbloridgehalte die Wirkmon des zugerscetzten l'epsins nicht himlert, noch wesentlich repö̈grert. Wind dic Pepsin-

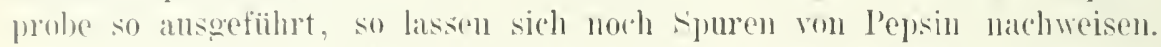

bie Fällumg mit Magnesiumkarbonat wire so langro wiederholt, bis man rin Filtrat erhäl, welches bei kräftigre labung eine Fibrinflocke bei lörpertemperatm in latufe eimer stunde nicht merkhar verdaut. Ciewöhulich ('lreicht man dies mit :) Föllungen in $1 \frac{1}{2}$ stunden.

Die Wirkung des Magnesiumkarbonats beruht teilweise anf Nienlerreilien des Pepsins und teilweise anf der alkalischen lieaktion. Welche nad lingerer \%eit sowohl die l'epsin- wie die Labwirkmg vernichtet. Wem man, da die l'epsinpoben immer einice \%eit dancrn, die Gefahr einer zu langlanemden Eimwirkung der alkalischen lieaktion anch anf dis Chymosin rermeiden will, so kann man eine Vorprohe mit etwa $100 \mathrm{~cm}^{3}$ Infusion anstellen, mu clie nötige Amzahl von Fällungen und die etwa erfordorliche \%oit zu ermitteln mul erst dann die llamptportion bearbeiten. Das zuletzt erzielte Filtrat wird sogleich mit silzsäure neutralisiert. Es kann dann ohne schadon et Stmoden oder länger in der Kälte stehen, che man die Bearbeitung fortsetzt. Dazu wird das Filtrat angesänert und ron nenem auf I'psin gepriift, dies mit liicksicht anf die Angaben I'arlows fïl den llundemagensaft, dab das gelähmte Pepsin durch die Noutralisation roaktiviert werlen soll, obgleich diese Purlowschen Angaben, Hemmorsten zufolge, allerlings nicht fiir die Kallssmagreninfusionen zu gelten scheinen.

las anguänerte, keine Pepsinwirknng mehr besitzende Filtrat wird mit einel lïsung ron cholesteriu in Alkohol und etwas Cithel rersetzt, mmittelbal und winlerholt mugeschiittelt. Das ausgefällte ('holesteriu, wolches dinen 'Teil des Chymosins niedereibt, währond dic Chymosimeste mehst den rotwaigen l'epsinspmen in Lösmeg bleiben oder zerstört werden, wird auf ein Filter gesammelt. mit Wasser ausgewaschen, in Wasser anfgeschlïmmt, mit Ther rersetzt und leicht geschiitelt. bis das Cholesterin

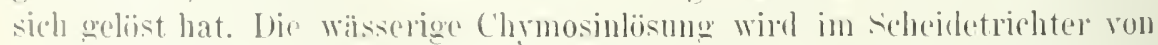
dor Xthorschicht getrenut und machliel filtriert. Diese letzte l'hase der Chrmosingewinnmo milighicht leider sehr oft, was arwili trilweise von der

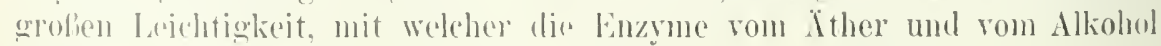
in diesen fermontarmen Lösungen zerstönt werken, herriilnt. 
Statt Cholesterin zu benut\%en, kann mall anch das keine I'epsinwirkung mehr \%eigende, krätig aber auf Milch wirkencle Filtrat mit Bleiessig fällen, den Niederschlay mit selur vordünnter tohwefelsänr zerlecen. die saure Fliissigkeit abfiltrieren und sie mit riner Loisume ron Stearinseife in Wasser relsetzen. Das Chymosin wird von den Fottsiiuren mit niedergrepissen und, wenn letztere in Wasser verteilt und durch schiitteln mit Xther entfernt werden, bleiht rlas Enzym in dor wasserigen Lïsung zuriek. ${ }^{1}$,

Lei den Versuchen mit Lahferincent soll man mach Fuld senföl als Antiseptiknm anwenden. $\left.{ }^{2}\right)$

P'ar'achmosin. Wio mittelst schweinrmagen bereiteten Pepsinpräparate des Handels enthalten cin sich durch scoine Eịcenschaften rom grewöhnlichen Labfermente etwas unterscheidendes Ferment, das l'arachymosin, welches das Labenzym des Magens des schweines und des Menschen darstellt, wïhrend das Chrmosin sich im Fundusteile des Labunagens rom Kialbe und rom s'chafe regelmäligg findet. ${ }^{3}$ )

Propepsin und Prochymosin. Zur Tremung dieser beiden Profermente von den bereits gebildeten Furmenten sowio von einander werden nach Glaessner schweinemagen abgespiilt und sorofältion von schleim und Valnumgsresten befreit. I)ann wird die schleimhaut dos Fundusteiles ron der Muskulatur abpräpariert, nochmals mit flieliendem Wasser mehrere stunden lang gewaschen und darauf zu feinem Breie zerhacht. Der Schleinlıanthrei wird mit der doppelten Gewichtsmenge destillierten Wassers und mit Natriumkarbonatlösung bis zur deutlich alkalischen Reaktion rersetzt. Nun fïgt man Toluol zur Fliissigheit und schiittelt sie vorsichtio. so dalo ras Toluol sich, wenn auch nur in geringem Grade, darin löst, während der gröbte Teil des Toluols dafiir aber die (oberflïche bedeckt und gegen das Eindringen von Keimen schiitzt. Die Gesamtflissirkeit bleibt alsdann wïhrend : + Wochen bei $40^{\circ} \mathrm{C}$. Nach dieser Zeit wird del alkalische Auszug filtriert, mit Kochsalz bis zu einem Gehalt ron $1^{\circ}{ }^{\circ}$, damn mit so viel verdinnter Essigsüure versetzt, dah ein größtenteils aus Mncin bestehender flockiger Niederschlag ausfällt: dabei muß man jeden Essigsäureiiberschulj vermeiden, wozu man die benötigte Essiosäuremenge in Vorversuchen genau ermittelt. Der Niederschlag wird abfiltriert. Zum Filtrate setzt man allmählich Natriumkarbonat bis zur schwach alkalischen Reaktion und nachler tropfenweise rerdiinnte Lranylacetatlösung. Der die beiden I'rofermente enthaltende dickflockige Niederschlag wird fluch Zentrifugieren

1) Olof Hammarsten, L.chrbuch der physiologischen Chemie. 6. Aufl. Wiesbaden 1907. S. 363. - Derselbe, Zur Frage nach iler Ilentität der Pepsin- und Chrmosinmirkung. Zeitschr. f. physiol. Chem. Bd. j6. S. 18-80 (1906). Freundliche briefliche Mitteilung des Herrn Prof. Dr. Olof Hammarsten zu Lpsala.

$\left.{ }^{2}\right)$ E. Fuld, Cher Hilchgerinnung durch Lab. Ergebn. d. Physiol. Bu. 1. Abt. 1. S. $468-504$ (1902).

3) Irar Bang, Cher I'arachymosin, ein nenes Labferment. Pfflügers Arch. f. d. ges. Physiol. Bd. 79. S. 425-441 (1900). - Gcorg Becher, Cntersuchungen über das Zeitgesetz des menschlichen Labfermentes nnd dessen quantitative Bestimmung. Beitr. z. chem. Physiol. u. Pathol. Bd. 7. S. s!-119 (1936). 
von der l'lissiokeit getrenut unel dam mit kleinen Jengen von mittelst

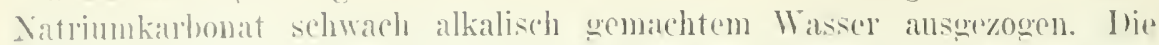

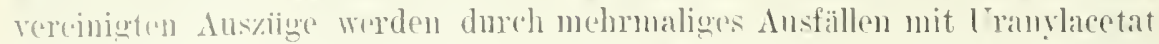

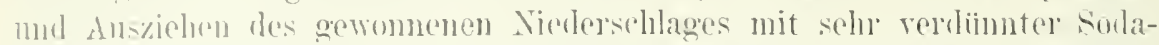

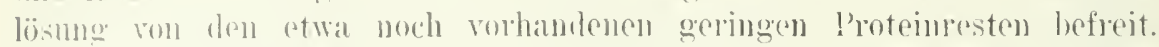

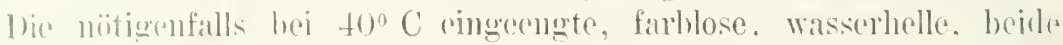

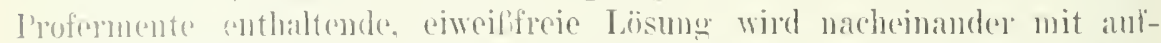

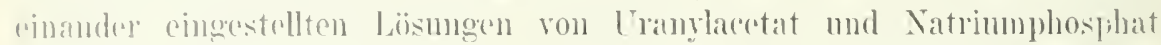

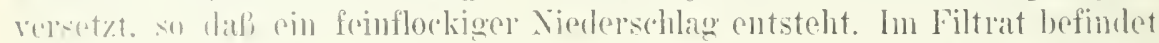

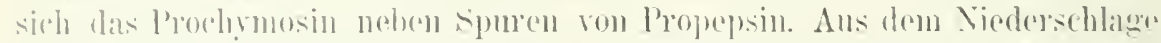

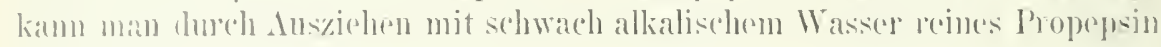
('rlıalt('). $\left.{ }^{1}\right)$

\section{(1) Dilmsilt.}

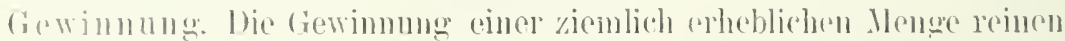

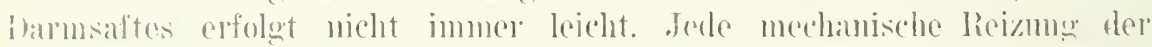

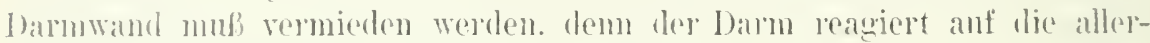

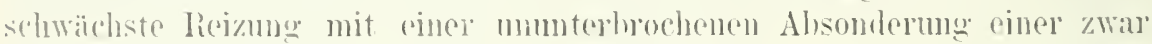

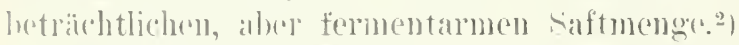

licin seit 2t Stmulen nitchtermen Hundo bewirkt die intravenöse

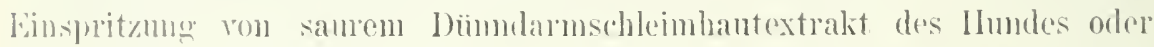

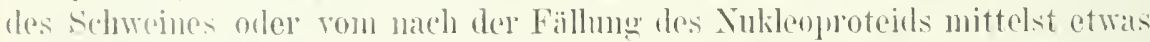

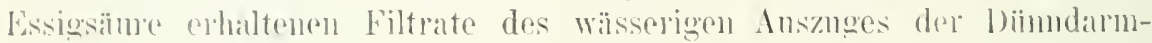
schleimbantzellen oine mehr odel minder arobe Fliissigheitsalssonderung in

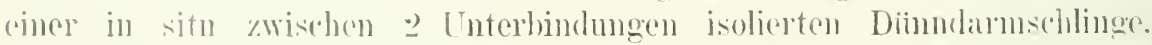

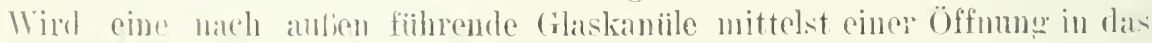
untere Ende ler sohlinge befestigt, so kimm man den abgesonderten Saft

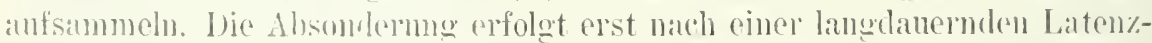

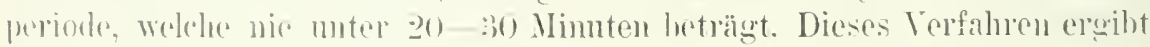

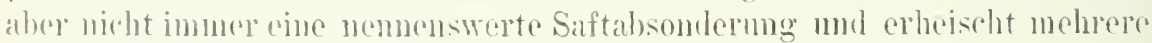
Ti(re, falls manl viel Dalmsaft erhalten will.3)

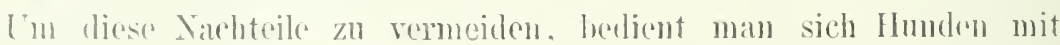

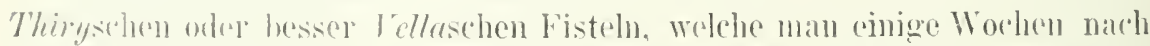
der Oneration zu diesem Zwecke verwenden kam. Sach Delezeme mul

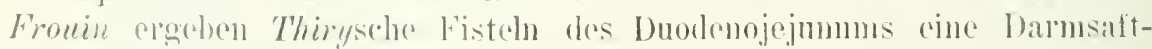

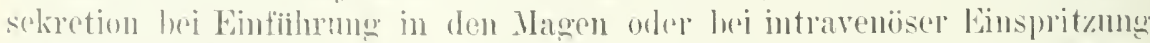

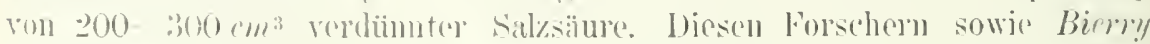
nurl Fromin znfolepe sutleren Thirysehe Fisteln des Dnodenojejunnus nach

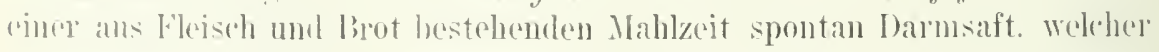

K. Ciluesure, ther die Vorstnfen der Magenfermente. Beitr. z. rhem. Physiol. 11. P'athol. Bi. 1. S. $1-2: 3(1902)$

2) IT. H. simeitsch, Absonderung des Darmsaftes, Hang.-Dissert. St. P'etersburg 1904.

3) F. linttus:i, l'roprietà chimiche e fisiologiche delle cellule epiteliali del tubo galstroentericu. Areh. di fisiologia. T. 1. p. $413-472(1904)$. - F. Bottazsi et L. Goblurioli,

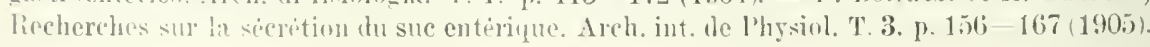




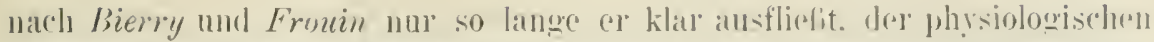
sekretion entsplech("n wiirle.2)

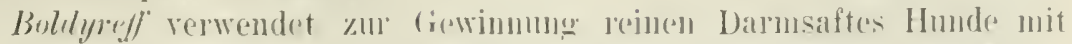

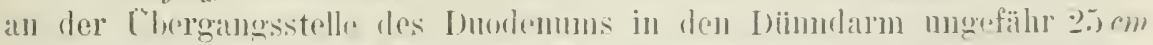

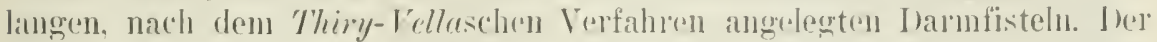
inn niichternon \%ustande periodisch alle zwei stunden wälıend zirka

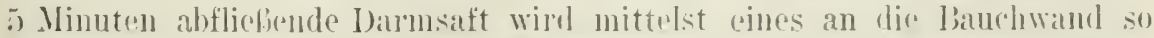

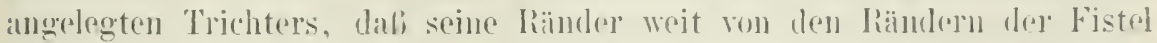

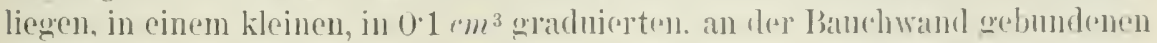

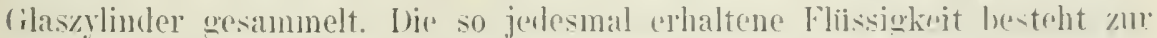

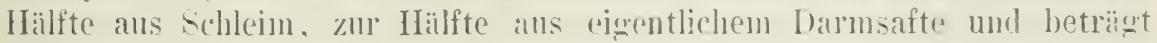

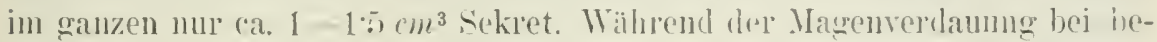

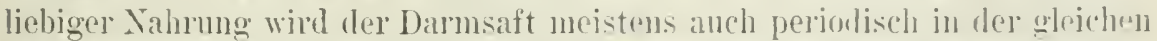
Menge abgesondert, aber die Absouderungsperioden treten viel selteuer und

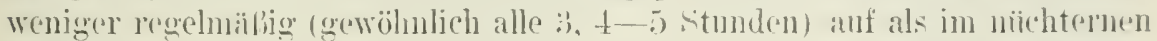
Zustande; hisweilen, wemn frejlich selten, wiru im Vurlanfo dey ganzon Magenverdaumo gar kein odel fast kein I)armsaft ahgesondert. In dem erhaltenen Darmseklete soll man stets den diimnfliissig('u saft dur'(h) Mlgrielien vom Schlein tremene. Der dam zuriekbleibendr. Darmsaft ist selu wirksam. ${ }^{2}$ )

Fou spritzt $40-\bar{x}) \mathrm{cm}^{3}$ riner 20 igen Salzsilurelösung in das eine Ende einer Téllaschen Darmschlinge: diese Fliissigkeit fliefst sofort alurh das andere Ende der Schlinge ab. Einige Iinuten mach dem Mbflefen der Salzsäurelösung hegimnt eine Iarmsaftabsondermng. Sobald lie rekretion aufhört, wiederholt man die Salzsïureeinsputzung. Anf diese Thise kam man nach Foì bej einem Hunde von $10 \mathrm{~kg} 10-1.5 \mathrm{~cm}^{3}$ Darmsaft $\mathrm{m}^{\mathrm{ro}}$ Stunde gewimen. ${ }^{3}$ )

l)er nach (inem der soeben beschriehenen V'rfahren erhaltene Darmsaft wird abfiltriert, zentrifugiert. $11 \mathrm{~m}$ ihn von Zelltriimmern des Inarmepithels zu hefroien. und dam anf eine sterilisierte chamberland- oder

1) C. Delezcnne et A. Fronin, La sécretion physiologique du suc intestinal. Action de lacide chlorhydrique sur la sécrétion dnedénale. Compt. rend. hebd. d. séanc. de li Soc. de Biol. 'T. 56. p.319-322 (1904). - A. Frouin, Action du suc intestinal sur lit sícrétion entérique. Ibid. T. 5S. p. 702-70t (190.)). Compt. rend. de l'Acal. des Sciences. 'T. 140. p. 1120-1121 (1905). - H. Birry et A. Fronin, Roble des éléments cellulaires dans la transformation de certains hyllates de carbone par le suc intestinal. Ibid. T. 142 . p. $1565-1568$ (1906).

2) II. . . Boldyreff, Das fettspaltende Ferment des Darmsaftes. Zentrallh. f. Physiol. Bu. 18. S. 460-461 (1904). - Derselbe. Jie Lipase des Darmsattes mul ihre Charakteristik. Zeitschl. f. physiol. Chem. Bd. j0. S. 39t- 413 (1907). - Derselle, Über den Übertritt der natiurlichen Mischung des Pankreas-, des Darmsaftes nnd der Galle in den Magen. Zentralbl. f. Physiol. Bd. 18. \$. $457-460$ (1904). - Le travail périodique de l'appareil digestif en dehors de la digestion. Arch. des Sc. hiolog. de St. Pétersbourg. T. 11. p. $1-157$ (190.5).

3) Corlo Fori, Sull erepsina del sncco enterico e sulla scomparsa di alcuni fermenti intestinali in un .. ansa del Vella" da lungo tempo isolata. Areh. di fisiologia. Vol. .). p. $26-33(1917)$. 
Jierkoleykrye in amen sterilisierten. otwas Kampferpulver enthaltenden liolhen filtriert. Fr wird im Eisschrank auflewalnt.

\%um liwinnen wirksanen Darmsaftes soll man mm Tieje henutzen,

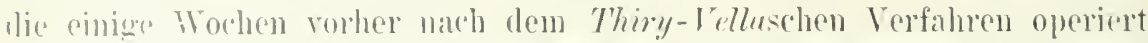

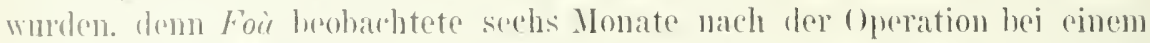

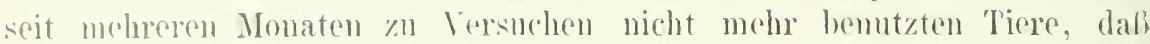
der aldesonderte saft keine Enterokinase mehr und nur wenigr Erepsin (s)thiclt, sowic dali die nach dem weiter unten heschriebenen Verfalren ron Bayliss mol sturling behandelte lommwand kein Sekretin zu rogeben schiom. Tiri Ilunden mit doppelter Thiryscher Fistel des Dundenums heohachtete anch Froum. dab lie Sekretion des Darmsaftes mit der seit der. ()peration verflossenen \%eitlaner abnimmt; el betrachtet die anfing-

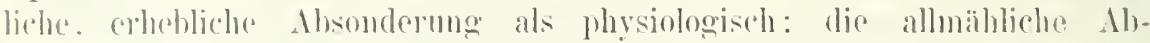

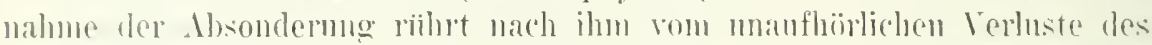
sirklotes her. $\left.{ }^{1}\right)$

Das (Jptimum der Wirkme des Damsatfes selowint dam erzielt zu werlon, wemn man die Versuehe bei Anwendmeg einer mit Kolnlensäure Hiberosätigten Alkalilïsung anstellt. Wozn man die Verlammgstliissigheit

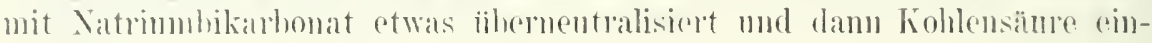
l(itor. $\left.{ }^{2}\right)$

Im Darmsafte enthaltene Fermente. In Darmsaft enthït folopule Fermente: eine Iliastase, eine Invertase, eine Maltase, manchmal rine Laktase, eine anf amulgiertes Fett einwinkende Lipase. das I'epsin ader Psendopepsin dor Brumerschen Drisen, das Frepsin, die Enterokinase, das sekrotin (oder l'rosekretin), eine Iroinase, eine Nuklease.

Diastase, luvertase, Maltase. Diese Fermente scheineil in

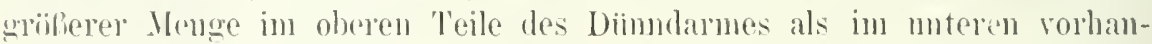
le lell zil seill.

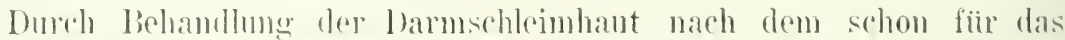
I’yalin orwähnten o. Cohuhromschen Verfahren kamn man sie eingermaben isolierent.

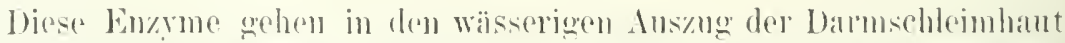

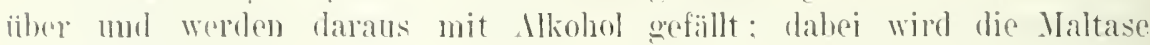
l(i)lit zerstiirt. $\left.{ }^{3}\right)$

1) r. Fod, loce cit. - Llloet froum. Sur les variations de la sécrétion du suc intestinal. compt. rend. hebl des siance de la soc. le Biolog. T. 58 . p. (553-655 (1905).

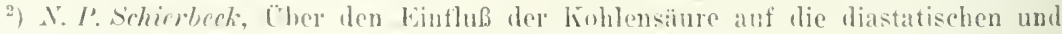
peptumbililenden Fermente in tierischen Organismus. Skand. Areh. f' l'hysiol. Bd. 3. S. $344-390(1892)$.

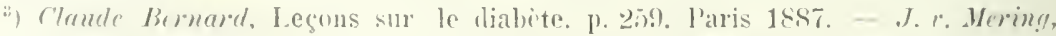
EinfluB ron diastatischen Fermenten auf stärke, Jextrin mol Maltose. Keitschr. f. plysiol. ('benie. Bd. 5. S. 185-192 (1881). - F. Rïhmam, Ther Sekretion mul Resortion im

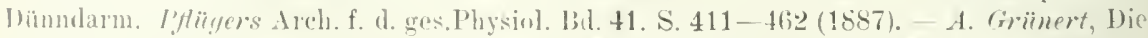
formontatim Wirkung des lö̈udarmsaftes. Juang.-Dissert. Dorpat 1890. - K. Miura,

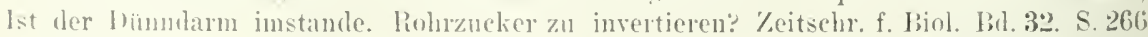

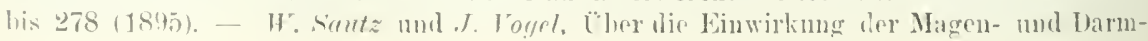


Iaktase. Läbt man die Darmschleimhant von ('arnivoren und (omnivoren während „2-t lagen mazrieren. so enthält der Ausmg stets Laktase. I)je Iarmschleimbant der Herbivolen, mit Insuahme des Kaninchens, eroibt hingeren bei dieser I'pozedur nur im jugendlichen Alter laktaschaltige lixtrakte. ')

Lipase. Fs hestrht noch kein Verfahren. un dieses Ferment $z u$ isolieren. Nach Boldyrefl spaltet die Lipase nur emulgiertes Fett mol emulwiert nur schward dlas Fett. Dio. Dammlipase scheint haltharer zu sein als das l'ankreassteapsin. Ihre Wirkmug wirl nicht durch Gallowsatz verstärkt.2)

Pseudopepsin oder l'epsin der Brunnerschen Driisen. Ton einen wirksamen duszug del Brumerschen I)riscen zu beleiten. entfernt man mach Glaessner die Lieberkïhnswen Drïsen tunlichst dureh Abschaben mit den Skalpell. Dann sterilisiert man die Oberfläche der noch bestehenden Sohleimhant dureh kochendes Tassel und unterwirft die erhalten'u schleimhautreste einer anhaltenden Verkaumg mit schwach alkalischer Lösung hei Brutwärme, wodurch das noch anhaftende l'epsin sicher zerstört wild.

Dieses Verfahren ist indes nicht zu empfehlen. denn es wird dabei keineswegs die Mitwirkung der Kellfermente der Darmwand mit siclserheit vermieden. Veshalh muf man sich daranf beschränken, nur den aus einem Hunde mit Fistel des oberen Teiles des Inimdarmes stammenden I'vlorussaft anzuwenden. ${ }^{3}$ )

Erepsin. Die durch einen Wasserstrom gut gereiniogte Darmschleimhaut eines seit ¿t Stunden niichternen, durch öffnen beider Karotiden und Verbluten getöteten Hundes wird abgeschaht und während mohrerer stunden in eine durch Natriumkarhonatzusatz leicht alkalisch gemachte $9 \%$ ige Ja Cl-Lösung webracht oder wiederholt mit Wassel ausgezogen. Die so erzielte Fliissigheit wird filtriert. $\mathrm{Zu} 2$ Teilen des Filtrates setzt man :) Teile einer wässerigen gresättigten Ammonsulfatlösmug. wodurch (las Erepsin gefällt wird. Dieser Niedersclılag wird abfiltriert. das Filtrat in destilliertem Wasser aufgeschwemmt und unter Zusatz ron Toluol oder

schleimhant auf einige Biosen und anf Raffinose. Elhenda. Bd. 32. S. 203-307 (1895). Friedr. Krïger, Untersuchungen iilier die fermentative Wirkung des Dünudarmsaftes. Fibnda. Bd. 37. S. $229-260$ (1899). - E. Weinlrend. Ulher las Auftreten ron Invertin im Blıt. Ehenla. Bd. 47. S. 27!)-288 (1905). - Em. Bourquelot, Sur les propriétés physiologiques du maltose. Compt. rend. de l'Acad. des Sciences. T. 97. p. 1000-1003 (1883). - L. E. shore and H. C. Tebl. On the transformation of maltose to dextrnse. P'roced. of the I'hysiol. Soc. 25. June 18:12. in Journ. of I'hysiol. Vol.13. p. 19-20. 1. Falloise, Distribution et origine des ferments ligestifs de l"intestin grêle. Areh. jut. de Plysiol. T. 2. p. $299-321$ (19(5)

$\left.{ }^{1}\right)$ R. II. Achers Flimmer, On the presente of lactase in the intestine of animals and the adaptation of the intestine to lactose. Jumrn. of Phrsiol. Tol. 35. p. 20-31 (1901).

$\left.{ }^{2}\right) 11$. X. Boldyreft, loc. cit.

$\left.{ }^{3}\right)$ K. Ailcessner, Uluer die Funtion der Brumnerschen Drïsen. Beitr. z. ehem. l'hysiol. und l'athol. Bil. 1. S. 105-113 (1902). - Emil Abderhalden und I'oter Kona, \%ur lieuntuis des proteolytischen Fermentes des Pylorus und des Luolenalsaftes. Zeitschrift f. physiol. ('lem. Bd. 47. s. 359-361 (1906). 
('hloroform dureh llialyse von Ammonsulfat befreit. Wïluend der Dialyse

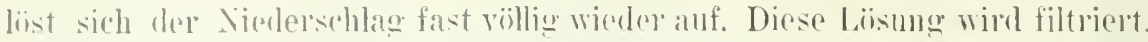

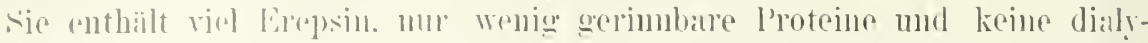

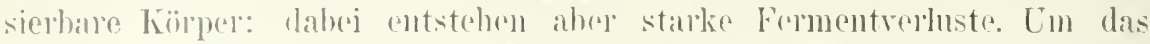

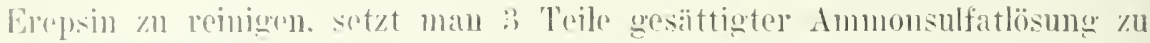

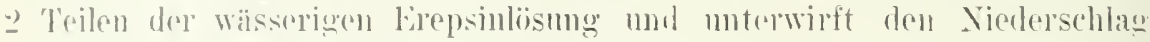
der Dialyse: dieso I'rozedur wird mehrmals wiederholt.

Dats Erepoin wirkt rigentlich nur anf die Produkte der Magenver-

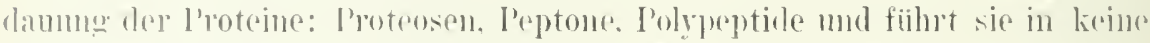
Jimetreaktion mehr darbintrude stoffe. Ije Erepsinspaltung arfolgt viol latsher auf P'eptone und Polypeptide als and I'roteosen.

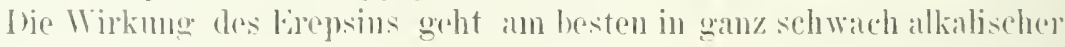
lieaktion vol sich. $\left.{ }^{1}\right)$

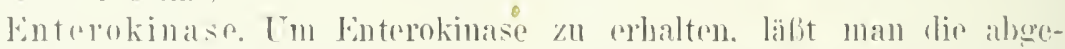
schabto Darmschleimhaut cines mugefähr of stunden nach einer aus rohem Pferdefleische bestedenden Mahlzeit dmoh Ansehmeden beider Karotiden und

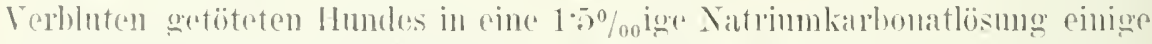
\%eit ma\%erinen. Diese Mazeration wird dam abfiltriert mul das filtrat

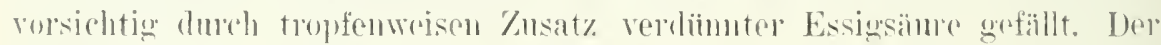
Nirderschlag enthält dic Nukleoalbumine, einen groben Teil der Kinase sowic das Frepsin. Zmm (iobrancho wird 1y des trockenen Niederschlages

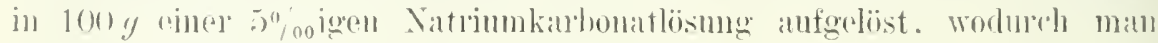
vine stark wirksume Kinaseliosumg erzielt.

Im die Enterokinase ohne Erepsinbeimischumg zu genimnen, fällt

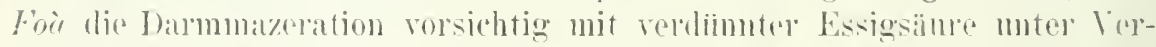

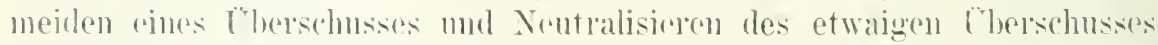
mit Jatriumkarbomat. Wol auf ein Filtel gebrachte Niederschlag wird mit angesindertem Wassel gut ausgewaschen. D)as erhaltenc saure Filtrat nelst den samen Waschwisson enthält Enterokinase und kein Erepsin. Vor dem tiebramehe muli man dieses Filtrat mit Natrimmkarbonat leicht alkalisch machen. Man kann dieses Verfahren anch anwenden, mm die Futerokinase vom Erepsin in ans einer Thiry-lelluschen Fistel chaltunen l)armsifte zn tromento $\left.{ }^{2}\right)$

$\left.{ }^{5}\right)$ ctto Cohnheim. Die l'mwandlung des Eiweißes dureh dio Darmwand. Zeitsehr. f. plysiol. ('hem. Bul. 33. S. 451 - 465 (1901). - Lejselle. Weitere Nitteilungen üher

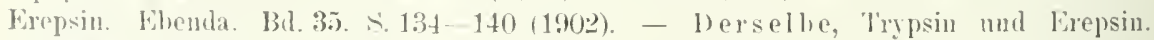

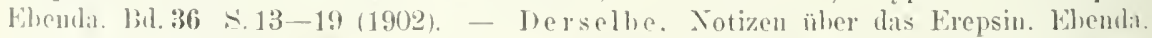
Bu. 47. S. 2866 (1906). - Derselbe. Zur spaltumg des Nahrungseiwejßes in Darm.

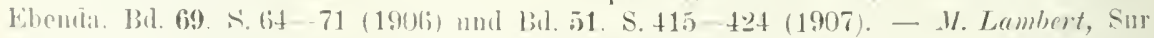
la fermentation érepsique. Compt. rend. lielud. des. séanc, de la soe, de Biol. T. 5j. p. 416

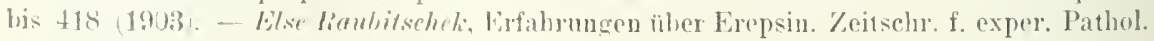
18. Pluarmakul. Bel. 4. S (675-680 (1907).

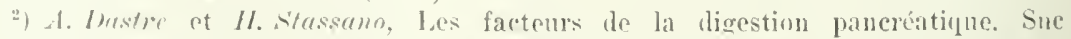
pancréatique. kinase et trypsine. Areh. int de l'hysiol. T. 1. p. 86;-117 (1904). - Corlo Fon, Sulla digestione pancreatica ed intestinale delle sostanze proteïehe. Arch. di fisiol. Vul. 4. p. 81-97,1906i). 


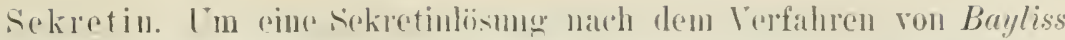
und Starling zu bereiten, wird ain seit es stmulen fastender Hund durch Öffuen der bejden Karotiden und Verbluten wetötot. Man entuimmt das Inodenmm mod das Jejunmm. Wäsolut mittelst eines Wasserstromes die innere Oberfläche des biumbarmes, schneidet den (notnomnenen Diinndarmteil in s- $10 \mathrm{~cm}$ lange Stïclie. Welche man macheinander ioffnet. Damn schabt man die Schloimbant mod zermalmt alluablich den so erhaltenen Brej mit reinem Sande mud etwas $0.4 \%$ iger Salzsïure in einem Jürser. Narbdem die wam\%e Schleimlaut so buhandelt wurde, setzt man zum die Schloimhautzellen enthaltenden Sandbrei 2-:3mal sein Volumen $0 \%$ \% Salmsäure. Yarh einem einige Vinnten bis 1/2. Stunde danernden stehen erhitzt man Sand mul Flïssigkeit in ajuer Por\%ellanschale zum Sieden. Während des siedens fügt man tropfenweise starke Natronlange zur Fliissigkeit, so lange bis sie alkalisch zu werden anfüngt, worauf man sie mit verdünntel Fssigsäure leicht ansïuert, mm die Nukleoalbumine zn fällen. Sachdem die neutrale oder leicht sanre Flissigkeit während 10--15 Minnten zum Sieden erhitzt wurde. filtriert man Flissigkeit und sand durch ein Tuch. Las Filtrat wird nochmals auf cinem I'apierfilter filtriert, worauf es röllig klar sein mul. Ist dies nicht der Fall, so filtriert man nack dem Erkalten dic Fliissigkeit nochmals: dann erzielt maĩ stets ein klares Filtrat. Diese Fliissigkeit kann zum (iewinnen proteolytisch inaktiven I'ankreassaftes beim Hunde intravenös eingespritzt werden. Lm sekretin von allen sipuren von Gelatine und Eiwejh zu hefrejen. versetzt man diese Fliissigkeit mit einem Gemische absoluten Alkohols und Athers; das Sekretin bleibt in Lisung mnd wird durch Verdampfen gewonmen. Cm eine ron den den Blutdruck orniedrigenden Stoffen befreite Sekretinlösung zu elzielen, wird der Inodenojejunalschleimhauthrei mit ahsolutem dkohol statt mit Salzsäure zermalmt. bieser Brei wird im Soxhletapparat mehrmals mit siedendem absolntem .lkohol hehandelt. Durch Filtration wird die alkoholische Lösumg voun ungelösten Riichstande getremnt. Dieser Rïickstand wird in $0 . \%$ iger Salzsäme aufgeschwemmt, zum sieden erhitzt unter \%ufuigung znerst von Natronlauge lis zur leicht alkalischen Reaktion und dam ron Fssigsïne bis zur neutralen oder kaum sauren lieaktion: schließlich wird in der oben heschriebenen Weise filtriert.

Delezenne läßt die Duodenaljejunalschleimhant während 12_- o o Stunden lri einer $10^{0}$ nicht ïbersteigenden Temperatur in $0 \cdot 4-0 \%{ }_{0}$ iger salzsäure mazerieren. neutralisiert alskann die Mazeration, bringt sie kuze Zeit zum sieden und filtriert sie. Durch Kochen der Dïnndarmschleimhaut während riniger Minnten mit : - t Teilen physiologischer Kochsalzlösun sowie durch halbstiundiges Erhitzen auf $s\left(1^{\circ}\right.$ erhält man Sekretin enthaltende Extrakte. $\left.{ }^{2}\right)$

1) U. M. Baylis.s and E. H. starliny, The mechanism of pancreatic secretion. Journ. of Phrsiol. Vol. 28. p. 325-353 (1902). - Dieselbe, Die chemische Koordination der Funktionen des Kürpers. Ergelın. d. Physiol. Bd. j. S. 66t-697 (1906). - C. Delezenne et $E$. Pozerski, Action de l'extrait aquenx d'intestin sur la sécrétine: études préliminaires sur quelques procédés dextraction de la sécrétine. Compt. rend, hebl. d. séanc. de la Soc. de Biol. Vol. 56. p. 987-989 (1904). - C. Delezenne, Lactivation du suc pancréatique par les sels et la spéciticité du calcium. Ibid. T.58. p. 1070-1073 (1906). 
Iroinaso. Dieses Ferment hat ähnliche Lösungsverhältuisse wie das Frepsin. Indes enthalten gereinigte Erepsinbsungen nicht immer Arginase.

Inklease. Vich Foir enthält der I)armsaft eine die Nukleinsiumen in Nukleinbasen nul Phosphorsiome spaltendes Ferment, wenn anch num in geringer Ilenger. ${ }^{1}$

\section{c) Pankreassaft.}

Del aus dem Hanptausfiihrungragang des Pankleats beim Humde mit dor nïticen Vorsicht entmommene Saft rerlant die I'roteine meistens nicht: dizu muf or erst durch die Euterokinase des Inamsaftes aktiriort werleu. Insmahmsweise erhält man indes. selbst unter diesen brodinguneren, proteolytiseh wirkamen Saft. Dey proteolytisch muirksane Saft scheint das 'prypin nur als Proferment ouler Zymogen zu enthaten; ob dies anch der Fall fül die anderen Fermente (Diastase, Lipase) ist. kam als wahrwheinlich betrachtet werden. ist aber noch nicht endgiltig festgestellt. ${ }^{2}$ ) fowinnmog vou poteolytisch nnwirksamem Pankleassaft. /ann Gewinnen inaktiren P'ankeassaftes wird der seit est stunden niichterne Hund riner loichten Narkose mittelst des Alkohol-Ither-('hloroformonemisches muterworfen. Die lianchwand wiod mittelst eines $1-2 \mathrm{~cm}$ links ron do Mittellinie anfongenden. $2 \mathrm{~cm}$ untriblh der letzten lippe fralalle $z$ diesor rerlatenden Einschnittes eriffuet. Tnter genaner Asepsis wirl der boj der limmiindnng des Choledochnsganges in das Dnodenum sich be-

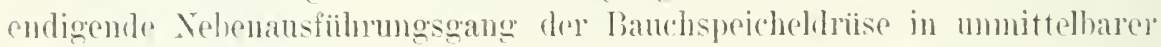
Silhe des I armes muterbunden. Gleich daudeh wird der Hauptausfiihrmos-

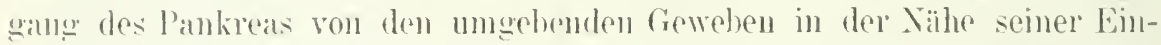
miindung in das Dnodenmm frejogelegt. wozn man meistens die dariber liegen-

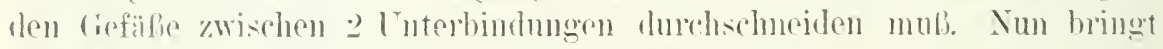
man - Fiiden mter den Hamptausfiihnugesang des l'ankreas mud unter-

1) C. Fon, Sulla nueleasi del suren intestiuale. Areh. di fisiol. T. 4. p. 98-100 (1906).

2) J. I'. I'anlour et schepowalnikoff, (razette clinique de Botkin (1900). - C. Delezeme et a. Fronin. La sierétion physiologinne du pancréas ne posséde pas d'action digestive propre vis-itris de lalbumine. Compt, rend, held. des séanc. de la soce de Biolog. T. 54.

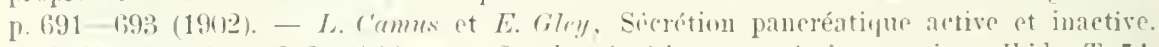
lhid. 'T. 5t. p. $241-243(1902)$. - Sur la sécrétion pancréatique actire. lbid. T. 34. p. $895-896$ (19)(12). - De la séerétion d"un suc paneréatique protéolytique sous: l'influence des injections de sérétine. Ihid. T.54. p. 649-650 (1902). - W. M. Baylis.s

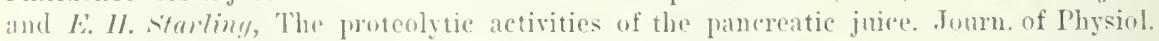
liol.30. p. 61-83 (1903). - L. Popnirlski, Cher dio Grumleigensehaften des Pankreassafters. Zentralhl. f. I'hysiol. Bd.17. S. 65-70 (1903). - O. I'rym, Milz und l'ankreas.

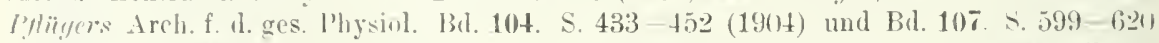
(190\%). K. עays, Weitore Beiträge zu1 lienntnis der Trypsiun irkung. 111. Mitteilung. Ino Wirkme des frisehen Ilumdepankreassaftes. \%eitschr. f. physiol. themie. Bd. 4!! $\therefore 189-2(11$ (1906) - B. I'. Babhin, Einige (irumdeigensehaften der Frmente des Pankreassaftes. Kentrallh. f. d. aes. l'hysiol. n. Y'athol. d. Stoffwechsels. Bt.1. S.97-108 (1906). - II. Tonath, I'ber Aktivjerung mul lieaktivierme des l'ankreassteapsins. Ein Beitrag

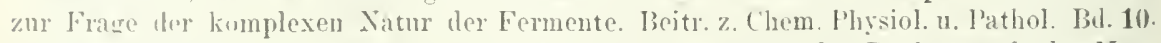
S. 390()$-410(1907)$. - J. Wohlgemuth, (ntersuchmoen über den Pankreassaft des Menschen. H1. Mitteilung. Uher das Labfernent. Biochem. Zeitechr. Bul. ‥ S. 350-350 (1907). 
bindet diesen mittelst eines dieser Fäiden in munittelbarer Nähe des Darmes. Damu matht man rine bleine

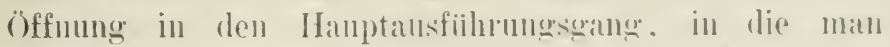
eine sterilisierte Kaniile einfuilut mud nittelst des zweiten Fardens darin befestigt.

Dazn empfiehlt es sich, sich einer Irotallkanuile A zu bedienen, welche. wie Fig. so es zoigt, mit einer Glastöhre $C$ dureh eine Kautschulröhre /; verbunden ist. Das froie Ende der Glasröhre wirl mit einem nirht zu festen Wattepfropfen $D$ rersehen. Die Glaspölure ' 'mit der daran befestigten Kaniile wird in die durch den Wattepfropfen $F$ verschlossone Eprourette $E$ gebraht. Die Eprourette und die darin liegende Kaniile werden im Autoklaven bei 115) 1:2(10 sterilisiert.

bei der Operation hiilt ein (iehilfe die liprouvette $E$ : wagrecht und nimmt den sie rersehlielienden Wattepfropfen ab. Vittelst einer sterilisierten P'inzette greift man die Glasprihne ( rorsichtig an ilurem äuferen Ende an und zieht sie mit der danit verbundenen Kaniile vorsichtig aus der Eprouvette heraus. Sobalol die Kaniile il im Hauptausfïhrungsgang des Pankreas befestigt ist. wird die Banchwand sorgfältig durch Nähte vereinigt, indem man durch sie die lautschukröhre $B$ auf solche Weisi führt. daßs sie nirgends Druck erleidet. und dals ihr Lumen iiberall frei bleibt.

Yor der Eröffnung der Banchwand wird eine Vena jugularis freigelegt und darin eine dureh eine Kautschukröhre mit graduierter Bïrette rerbundene Glaskaniile befestigt. Kaniile and Bïrette enthalten eine sekretinlösung. Die Halswunde wird dureh Xïhte rereinigt. Man kann auch das sekretin, wie Delezenne es rorsehlïgt. in dic Fußschlagrene einspritzen.

Wenn die Batuchwand wieder verschlossen ist. füngt man an, die Sekretinlösung intravenïs einzuspritzen. Man kann alle $10-15$ Yinuten einige Kúbikzentimeter dieser Fliissigkeit einspritzen. wie Bayliss nud Sturling es rorschlagen. Dieses Verfahren hat abor den Nachteil, daß, falls die nene Sekretineinspritzung nach dem völligen Stillstand der durch die erste Sekretineinspritzung hervorgernfenen Pankreassaftsekretion gemacht wird. die ersten Teile

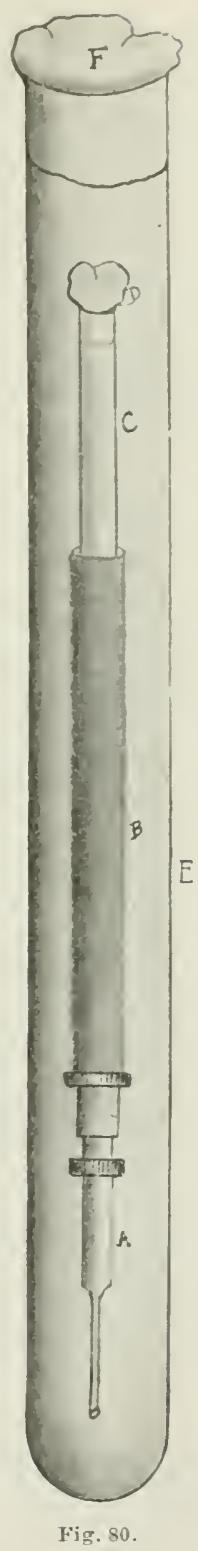
(1 cm: ungefähr) des nun ahgesonderten saftes manchmal eine geringe proteolytische Wirksamkeit aufweisen. $\left.{ }^{3}\right)$

1) H. M. Bayliss and E. H. starling, The mechanism of pancreatic sceretion. Journ. of Phycsiol. Vol. 28. p. 32.5-353 (1902). - L. Camus et E. Gley. De la sécrétion dun 
selbst wem man die Sekretincinspuitzungen so anfeinander folgen lailit, dali die saftahsondermong nie aufhört. in welchem Falle der saft nath aingere \%eit wälond des ganzen lersuches inaktiv bleibt. beobachtet man

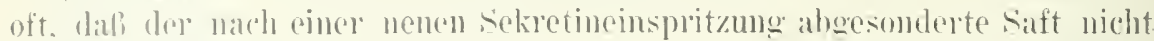
diesclhe thesitat und wahlseheinlich anch nicht dieselbe Wusammensetzung besityt als der vor dieser Finspritzung arhaltene.

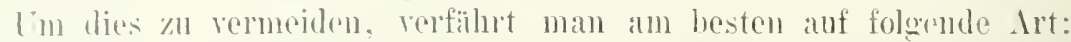
Mall berritet im volums eine ande licihe von mit Watte lose velschlossenen sterilisiorten \%entrifngiemöhuen vou je mindestens $40-50 \mathrm{c}^{3} \mathrm{~m}^{3}$ Inhalt. Van contnimnt don die (ilascöhre (' schliefenden Wattepfropfen $D$. hrinet diese

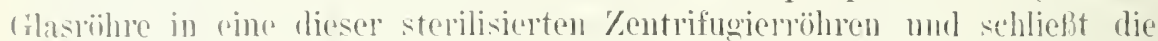
\%entrifuerererihne lose mit Watte, so dab die Luft entweichen kamm. Nun lälit man die sekretinlösung in die Vena jngularis oder fomoralis

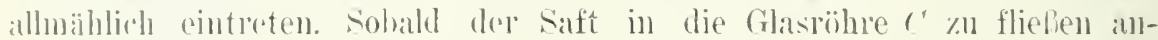
tängt. wird der biutrittshahn der die Sckretinlosung enthaltenden Bürettu

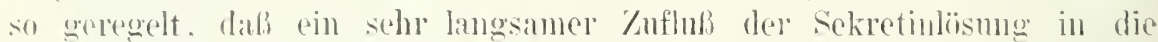
Vune erfolgt. In ihrem oheren bube ist die Bibutte mittelst eines Kantschukpfropfons areschlossen, durch welchen eine Gilasröhe bis in den unteren Teil del biirotte dringt, so dab die in der Bïrette enthaltene Fliissigkeit. wie ans eince Mariotteschen Flasehe, stets unter demselben loruck in dis Vene einflielit. Der Zufluli soll so geregelt sein. dab der Eintritt vou $50 \mathrm{~cm}^{3}$

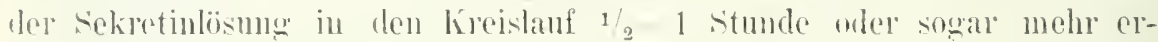
fordert. Inf diese Weise bekommt man stets einen völliọ klapen saft, dessen Absondermug stumbenlang dauern kam ohne wesentliche verände-

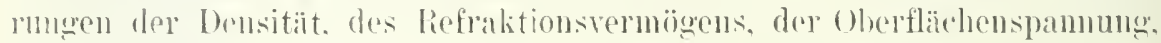
des osmotischen l)ruekes nud der cuzymatischen Wirksamkeit. Wie so er-

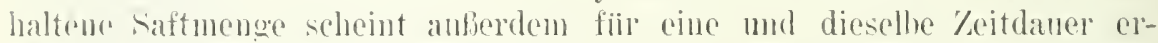
hoblicher zn sein als bei aler Einspritzung relatis grober sekretimmengen

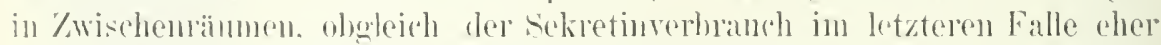
"rhehlicher als in ersteren ist. Dieses Verfahren rerhindert fast völlig.

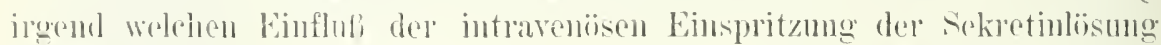

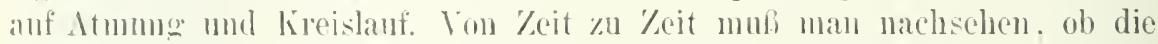
Fliissigkoit noch in die Vene flieht. und nötigenfalls den langsanen Eintritt

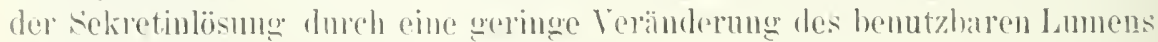
des bintrittshahmes wiellop herstellen. ")

Da die asten l'ortionen dos dureh ciekretineinsuritzung ephaltenen saftes fast immer cinc meln oder minder erhebliche proteolytische Wirk-

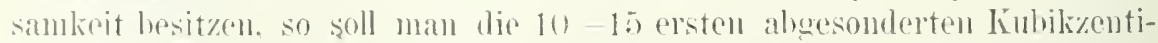
moter des saltes nicht benutzen. Xachdem diese aste Saftmenge ansere-

sur pancreatique proneblytique sons linflucnee des injections de sécrétine. Compt. rend. hebud. des seance de la soce de Biol. T. 5t. p. 649-650 (1902). - Variations de lactivite protenlytique du sue pancriatique. Jumro de physiol, et de pathol. génér. T.9. p. 987 his

1) F. Zum: I propos lu mole liaction de la sécrétine sur la sécretion pan-

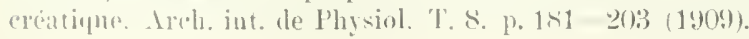


schieden wurde, entummt man die \%entrifugierröhre. in welche dic Glasröhre $C$ eindringt und arset\%t sie durch aine andere sterilisierte Zentrifugicröhre, in wetche man entwerler etwas 'Toluol oder hesser etwas Kanpfer gehracht hat, nund welche durch Watte lose rerschlossen ist. Jedesmal. wemn eine Zentrifugierröhre $z 2_{3}{ }_{3}-3 / 4$ ihrer Höhe ron Pankreassaft gefüllt ist. wird sie durch eine nene ersetzt. Die \%entrifugierröhren werden mit Watte verschlossen. Der so erhaltene Saft wird währond 10-15 Minuten zentrifugiert, wonach man gleich die zwei oberen Drittel seines Inhaltes is einen Toluol oder Kampfer enthaltenden, mit Watte verschlossenen. sterilisierten Kolben gielit, welcher in Eisschrank aufbewahrt wird. Dieser proteolytisch unwirksame Saft soll möglichst rasch benutzt werden, um scine Figenschaften viollig $\mathrm{zu}$ erhalten und um jede etwaige spontane Aktivierung zu vermeiden.

Cm den inaktiven Pankreassaft zn aktivieren, setzt man Darmsaft oder eine ungeführ 05\% Natriumkarbonat enthaltende Enterokinaselösung hinzu. Es besteht sowohl für die Enterokinase als für den inaktiven Pankreassaft eine Aktivitätsschwelle; eine gegehene Pankreassaftmenge benutzt zu ihrer Aktivierung un eine gegebene Kinasemenge. Die Iktivierung erfolgt rascher bei $: 37^{\circ}$ als bei $20^{\circ}$. Die optimale Enterokinasemenge ist keineswegs stets dieselbe. Ein knterokinase- oder Darmsaftüberschuf kann die proteolytische Wirksamkeit des Pankreassaftes vermindern. Nach Purlou setzt man zum inaktiven Pankreassaft $5 \%$ Darmsaft. Das Verdaumngsvermögen des Pankreassaftes und des Darmsaftes zeigt keine ron der Nihrungsart herriihrenden konstanten Veränderungen. Indessen soll Frouin zufolge je nach der Diät die zur Aktivierung des Pankressaftes nötige Darmsaftmenge mehr oder minder beträichtlich sein. Nach Fleischdiï muß man beim Hunde dem inaktiven I'ankreassaft $1 / 500$ bis $1 / 1000$ seines Volumens an Darmsaft zusetzen, nach Brotdiät aher $1 / 20$ oder sogar $1 / 10$.

Ian kann den inaktiven Pankreassaft auch durch Calcimmsalze akti-

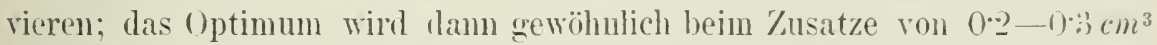
ciner 2 -Normalmolekularlösung eines löslichen Kalksalzes für 2 c $^{3}{ }^{3}$ inaktiven Pankreassaftes erreicht. Auferdem bewirken manchmal andore Metalle sowie einige Aminosäuren anf direkte oder indirekte Weise die Aktivierung des Pankreassaftes; das Calciun allein scheint aber eine spezifische Wirkung zul hesitzen. ${ }^{1}$ )

1) O. C'ohnheim, Trypsinogen und Fnterokinase. Arch. des sc. biol. de St. Pétershourg. T. 11. Suppl. p. 112-116 (1904). - A. Dustre et II. Stassano, Sur la question de savoir sil y a pour le mélange pancréatique actif un optimum ou un seuil. Compt. rend. hebd. des séanc. de la Soc. de Biol. T. 55. p. 317-319 (1903). - C. Delesenne, Activation du sue pancréatique par les scls. Ibid. T. j9. p. $476-478$ (1905). - Sur le rôle des sels dius l'activation du suc pancréatique, spécificité du calcium. Ibid. T. 59. p. 478-480 (1905). - Action des sels de calcinm sur le suc préalablement dialysé. Ibid. T. 59. p. 523-525 (1905). - Liactiration du suc paneréatiqne par les sels et la spécificité dn calcium. Ibid. 'T. 60. p. 1070-1073 (1906). - Albert Frouin, Sur l'actirabilité des sucs pancréatiınes de fistules permanentes chez des animaux soumis à des régimes différents. Hiil. T.63. p.473-4it (1907). - Carlo Fò̀, Sulla diggestione pan- 
(reminumereines spontan aktiven Pankreassaftes. Der nad der intravenösen Einspritzmog von Pilokarpin. Wittepepton, I’ụsostigmin orler Mnskinin abgesonderte l'ankreassaft wirkt sehon vou selhst anf serommene I'roteine. Fiir Humle von 5--10 ky spritzt man pro Tier-

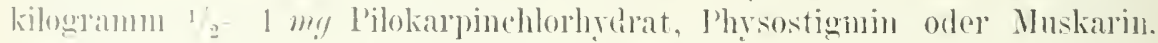

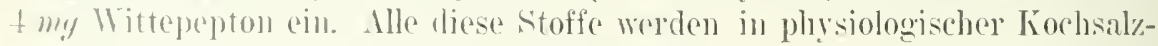
liismug (2elisst. ${ }^{\text {) }}$

In Pankleassafte enthalteno Fermente: lor Pankreassatt

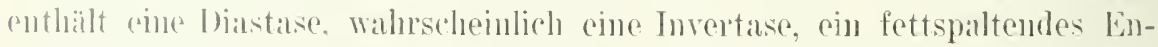
zymo, das 'Trypsin oder Trypsinowen, ein Labfermont, ein erepsinähnliches Enzym. vielleicht anberdem noch eine Maltase und eine Glutinase sowe in manchen Fällen aine Iaktase. Ila die meisten dieser Fermente bis jotzt mu elurel ihrt Wirkung bokimnt und keineswegs isoliert sind. so ist das bestrhen einiger nicht nit voller sicherheit festgestellt. "2)

l'aukleasdiastase. Man kann die rankreasliastase ans dem

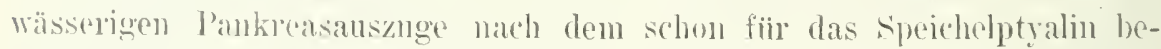
schriebenen J. Cohnheimschen Verfahren einigeruaben isolieren. \%um

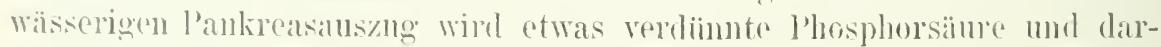
auf Kalkwasser his zur nentralen oder schwah alkalischen lieaktion gefiigt. Die Diastase wird von dom ontstehenden Calcimphosphatnierlerschlig teilweise mitgerissen. Der Nioderschlag wird ahfiltrient und mit

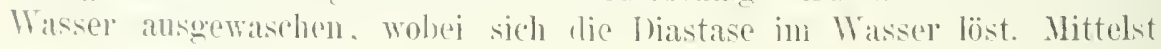

rreatica ed intestinale delle sostanze proteiche. Arch. di fisiol. Vol. 4. p. $81-97$ (1906). 1I.J. Hamburger et E. Ilekma, Sur le sue jutestinal de lohomme. Journ. de physinl. pt

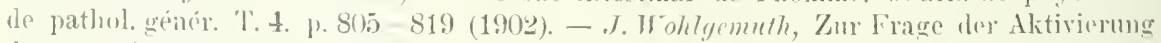
les tryptischen Ferments im mensehlichen Körper, vorlänfige Mitteilung. Biochem. Zeitschi. Bd. 2. p. 264-270 (1906). - E. Zanz, Contribution à l'étule des propriétés

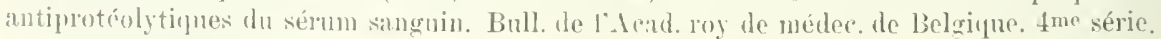
T. 19. 1). $729-761$ (1905). - Kecherehes sur lactivation du suc pancreatique par les sels. Bull. de la Soc. roy des Sc. méd. et mat. de Bruxelles. 'T. 64. p. 28 -5j und 9S-118 11906); Ann. de la Swe rog. des Se. méd. et nat. de Bruxelles. T. 16. fase. 1. p. 63-273 $(1907)$.

i) E. Wertheimer, sur les propriétés digestives du sue pancréatique des animanx à jeun. Compt. rend. hobl. des séanc. de la sone de liol. T. 53. p. 139-141 (1901).

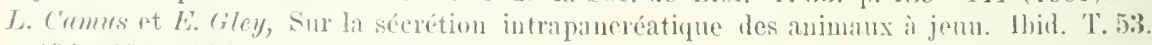
p. $191-196$ (1901). - L. Gley, sur le mode d'action des substanees antiroagulantes du groupe de la peptone: Artinu de ces substances sur les sérétions. ('inquant, de la Soe.

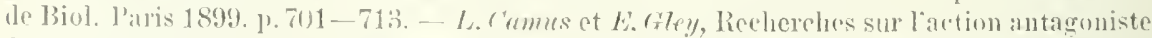
de latropine et de divers excitants de la sécretion pancreatique. Ireh. des se. biolor. T. 11. Suppl. p. $201-210(1934)$. - J fon-Jules Leprege. De l'action de quelques alciloides sur la secretion pancréaticus. The the de lille 1904.

$\Rightarrow W$. IL. Buyliss and E. $I I$. Sturling, The protenlytic activities of the pancreatic

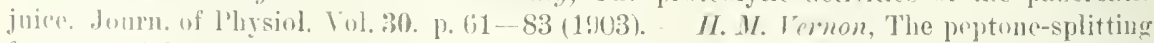
fermente of the panereas and intestine. Ihid. Vol. 30. p. 330-369 (1903). - Derselbe, Dils Torknnmen ron krepsin im Pankreals. Zeitschr. f. physiol. ('hem. Bd. 50. S. $440-441$ (1906). H. Bierry ot E. F. Terroine, le sue panereatique te scerétine contient il de la maltase?

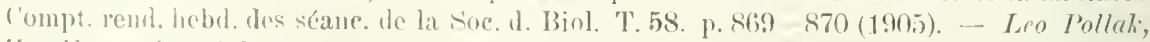
Zur lrager dex cinheitlichen mul spezifischen Natur des Pankreastrypsins. Beitr. z. chem. P'hysiol. 11. Pathol. Bd. 6. S. 9.)-112 (190.3). 
Alkohol wird sie aus ihrer wässerigen Lösung gefältt. Durch mehrmaliges Auflösen in Wasser und Fïllen mit Alkohol wirl die Pankreasdiastase gereinigt. Schlieblich wird sie über Schrefelsäure getrocknet.

IIan kann auch aus dem I'ankreas ein Gilyzerinextrakt hereitun. diesen mit Alkohol fällen und den abfiltrierten Viederschlag mit Wasser auswaschen, wobei sich das Ferment löst. Aus ihrer wässerigen Lösung wird dann die Diastase mittelst Alkohol gefällt. Der so erhaltene Niederschlag wird mit Alkohol ausuewaschen und iiber Schwefelsälure getrocknet.

Pankreassteapsin oder Lipase. Der Pankreassaft spaltet Neutralfette in Fettsïmren und Glyzerin. Andrerseits kann ('r das Fett emulgieren.

Bis jetzt besteht noch kein Verfahren, un das Pankreassteapsin rein darzustellen. Nach Cumnstcin soll man bei Verdaunngsversuchen mit ['ankreassteapsin sich ausschlieblich des Saftes selbst oder der frischen zerkleinerten Driise bedienen.

Loevenhart zermalnt 10 Gewichtsteile der frischen Banchspeicheldriise rom Hunde, (ochsen orler Schweine mit 1 Teil sand und fügt zum so crhaltenen Breie 100 Teile destillierten Wassers. Dieser Juszug wird durch Leinwand abfiltriert. Pro $100 \mathrm{~cm}^{3}$ des Filtrates setzt man $20 \mathrm{~cm}^{3}$ einer gesättigten Uranacetatlösung. Lie so erhaltene Flïssigkeit reagiert gewöhnlich sauer. Nan neutralisiert sie gegen Lackmus durch Zusatz einiger Tropfen einer gesättigten Lösung von Tatriumkarbonat und Tatriumphosphat. Dann fïgt man $5 \mathrm{~cm}^{3}$ einer gesättigten Tatriumphosphatlösung zu je $100 \mathrm{~cm}^{3}$ der Flüssigkeit. Der dabei erzielte Niederschlag wird zentrifugiert, filtriert und an der Luft auf dem Filter getrocknet. wozu einige Tage erforderlich sind. Solange als der Niederschlag feucht hleibt, muß man iln von Zeit zu Zeit mit Toluol bespritzen, um jede Fäulnis zu rermeiden. Die erhaltene Trockensubstanz wird in einem Mörser zu einem P'ulver verrieben. Dann wird dieses Pulver mehrere stunden mit Xither in einem Soxhlctschen Extraktionsapparate ausgezogen, wieder zermalmt. durch ein feines Sieh geschiittet und an der Luft getrocknet. Iuf diese Weise erhält man ein die Lipase enthaltendes Pulver. Zum Gebrauche bereitet man eine möglichst homogene Aufschwemmung von $1 \mathrm{~g}$ dieses Pulvers in $.50 \mathrm{~cm}^{3}$ destillierten Wassers.

Das Pankreassteapsin ist nicht sehr widerstandsfähig; es wird leicht durch Sïmen zerstört. ${ }^{1)}$

'Trypsin. Es besteht noch kein völlig sicheres Verfahren zur Reindarstellung des Trypsins vder seines Zymogens, da man bei allen Methoden von der Drïse ansgeht und nicht rom Pankreassafte sellst.

Nach Kïhne wird frisches Pankreas mit Glaspulver und absolutem llkohol zermalnt. Ier bleibende Niederschlag wird mit eiskaltem Wasser

1) Irithelm Connstein, Uber fermentative Fettspaltung. Ercebu. d. Physiol. Bd.3. Abt. I. S. 194-232 (1904). - A.s. Loevenhart, Are the animal enzymes concerned in the hydrolysis of rarious esters identical? Journ. of biolog. Chemist. Vol. 2. p. 427-460 $(1907)$. 
behandeIt und die so elhaltene wässerige Lösmng mit Alkohol gefiillt. Man wiederholt melnmals das Iuflösen in Masser und die Mlkoholfïllung. Dev Niculerschlag wird schliefich mit Wasseffeiem Alkohol ausoewaschen und daranf in Wasser aufgelöst. \%u dieser Lösung fïgt man 1\% ige Essigsilure, filtriert, erwärnt das Jiltrat cinge Zeit anf $t^{0}$. filtriert und alkaliniert die wieder erwïnute Flïssigkeit merklich. Nach Entfernung rlureh Filtation des dabei ctwa entstehenden Niederschlages wird die Flüsighoit bei too eingedunstet. um das Typosin zur Mbscheidume zu bringen, und nachher der Inilyse unterworfen. Das in lösnng befindliche 'Trysin wind durch wiederholte Fällung mittelst Alkohol gereinigt.

Martin Jacoby zerlackt Banchspeicheldrisen rom limde mo üherläft

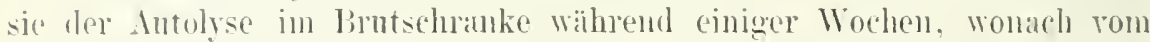
molösten ladickstanule abfiltriert wirl. Das Filtrat bleibt noch während rinjere Minuten im loutschranke. Damn wirl os mit Immonsulfat versetzt, mn ane Salzhonzentration von 6.5\% zu erreichen. Nach mehrstindigem Strelen filtriert man mol sïttigt das Filtrat mit Ammonsulfat. Der dabei

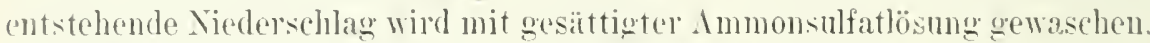
dialysiort und schlieflich in 1\% $1 \%$ iger Na Cl-Lösung gelöst.

Mreys was auf mehrfache Weise durch verschiedene Iussalmungsmethoden bestrebt, aus l'ankreasestrakten ein eiweilfrejes wirksames Trypsinpriiparat hermstellen. Diese Velfahren ergehen aber leider nicht stets dieselhen Eruebnisse. Im meisten empfiehlt Mays die fraktionierte Magnesiumsulfatfüllung. d. h. die vollständige Sättgung des vom bei llabsättigung mit Iagnesinmsulfat antstandenen Niuderschlage ahfiltrierten Filtrates, orler die sattigung mit Ammonsulfat von vorher his zur Sittignug mit lochisal\% rersetzten Pankreasextrakten. Man erhält dahei oft nur einen nehr oder minder guolien 'Teil des Enzyms. Man soll die Anssalzung bei $40^{0}$ (' anstellen. IBei der weiteren Reingung der so daryostellten Präparate ist es schwierg. eino Mbuahne der Mirksumlieit des Trypsims zu rermeiden.

Schuarschitd hat nach folgender Vorschrift eine wirksane, keine Bimetreaktion darbietende Trypsinlösung lereitet: Rinderpanklas werden zu feinem livei zerhackt, mit wenig Nitlimmbikarlomat versetzt und mit

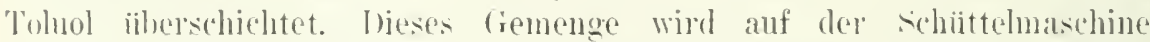

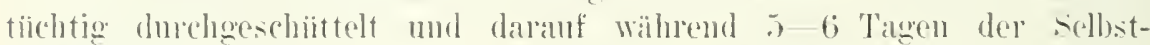
verdanmeng iberlassen. Lam wird koliept und bis zmm Eryelen einer klaren Flissigkeit filtrient. Ietztere wird. nm dic l'roteine zu entfernen. mit gesibtinter Cranylarectatlösung nud daun sofort. un die lieaktion alkalisch zil ehalten. mit Xatrimmphosphat versetzt. Der das 'Tryesiu rethaltrude roluminöse Niederschlan wird abtiltriert und damn in der lieib-

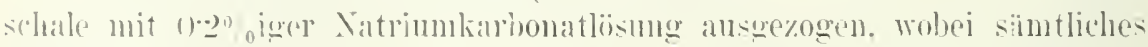
Forment in dio lösung iiberowt. falls man den Niederschlag mindestens

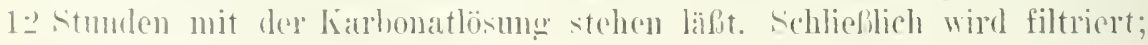
das Filtrat (nutluält das Trypsin. ${ }^{1}$ )

4. Kïhne, Uher das Trypsin-En\%ym des Pankreas. Verh. d. Naturhist.-Nled.

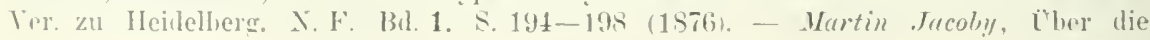


Suklease. Rimulspankeas oder Hundepankreas wird mit Sand und Kieselgur zerrieben mod in der Buchnorshen l'resse greprebt. Der gewomnene Saft wird mit Ammonsulfat gesättigt, der dadureh rutstandene, die Nuklease enthaltende Niederschlag abfiltrient und mit Alkohol mod Ither ausgewaschen. Dieser Nukleaseniederschlag löst sich leicht in destilliertem Wasser.

Sowoln der inaktive l'ankreassaft als der durch Euterokinasezusat\% ahtivierte verflïssigen zwar (Abderhalden und Srhittenhelm, Fovi) die gallertige Nukleinsäure, spalten sie aber nicht in Nukleinbasen und I'hosphorsïure, obgleich die Vukleinsäure unzweifelhaft eine Verïnderung erleidet. ${ }^{1}$ )

\section{f) Galle.}

1. Einwirkung bei der Terdaunger der Fette.

Der Zusatz einer geringen Gallenmenge kann die fettspaltende Wirkunw des Pankreassteapsins erheblich verstärken, was grölitenteils von den gallensauren Salzen herriihrt. ${ }^{2}$ ) Hingegen wird die Wirkung der Magen- und Darmlipase durch (iallenzusat\% kaum gesteigert. ${ }^{3}$ ) Aulierdem besitzt die Galle ein keineswegs unbeträichtliches Lösungsvermögren für die Fettsäuren und die Seifen.*)

chemische Natur des Ricins. Arch. f. exper. Pathol. u. I'harmakol. Bd. 46. S. 28-40 (1901). - Karl Mays, Beitrïge zur lienntnis der Trypsinwirkung. Bd. 38. S. 428-512 (1903).

- Moritz schrarzschild, Ther die Wirkungsweise des Trypsins. Beitr. z. chem. Physiol. II. Pathol. Bd. 4. S. 155-170 (1904).

1) Fritz Sachs, Über die Nuklease. Zeitschr. f. phrsiol. ('hem. Bd. 46. \$. 337-353 (1905). - Emil Abderhalden und Alfred Sehittenhelm, Der Ab- und Aufbau der Nukleinsäuren im tierischen Organismus. Ehenda. Bu. 47. S. 452-457 (1906). - C. Foù, Sulla uucleasi del suce intestinale. Arch, di fisiol. Vol. 4. p. 98-100 (1906).

$\left.{ }^{2}\right)$ IL. Nencki, Über die Spaltung der Sänreester der Fettreihe und der aromatischen Verbindungen im Organismus und durch das Pankreas. Arch. f. experim. Pathol. u. Pharm. Bd. 20. S. 367-38t (1886). - B. K. Rachford, The influence of bile on the fat-splitting influence of panereatic juice. Journ. of Physiol. Vol. 12. p. 72-94 (1891). - R. Magnus, Die Wirkung synthetischer Gallensäuren auf die pankreatisehe Fettspaltung. Zeitschr. f. physiol. Chem. Bd. 48. S. 376-379 (1906). - O. $v$. Fïrth und J. Schiitz, Über den Einfluß der Galle anf die fett- nnd eiweißspaltenden Fermente des Pankreas. Beitr. z. chem. Physiol. 1. Pathol. Bi. 9. S. 28-49 (1907). - A. S. Locrenhart and C. G. Souder, On the effect of bile upon the hydrolrsis of esters by pancreatic juice. The Journ. of biol. Chem. Vol. 2. p. 415-425 (1907). - H. Donath, Uher Altivierung und Reaktivierung des Pankreassteapsins, ein Beitrag zur Frage der komplexen Natur der Fermente. Beitr. z. chem. Physiol. 11. Pathol. Bil. 10. S. 390-410 (1907). - Melle L. Kálaboukiff et E. F. Terroine, Sur lactiration des ferments par la lécithine. I. Action de la lécithine sur la lipase pancréatique. Compt. rend. hebd. des séanc. de la Soc. de Biolog. T. 63. p. $372-374$ (1907).

3) F. Laqueur, Üher das fettspaltende Ferment im Sekret des kleinen Magens. Beitr. z. chem. Physiol. u. Pathol. Bd. 8. S. 281-284 (1906). - W. Boldyreff, Die Lipase des Darmsaftes und ihre Charakteristik. Zeitschr. f. physiol. Chem. Bd. 50. S. 394-413 (1907). - Melle L. Kalaboukoff et E. F. Terroine. Sur lactivation des ferments par la lécithine. II. Action de la lécithine sur les lipases gastrique et intestinale. Compt. rend. hebd. des séane. de la Soc. le Biolog. T. 63. p. 617-619 (1907).

4) E. Pflïger, Fortgesetzte Untersuchungen über die in wasserlöslicher Form sich vollziehende Resorption der Fette. Arch. f. d. ges. Phỵsiol. Bd.88. S. 299-338 (1902). - 
2. Viurirkung bej Verdaumg der Proteine.

sowohl die Hundegalle als die menschliche Galle enthalten eine geringe Ience vinns Fihrinflocken auflösenden proteolytischen Fermentes, welehes

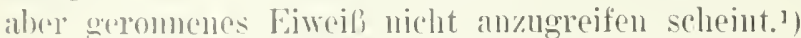

bisweilen rerstärkt die Calle etwas die Trypsinwirkmo; diese Wirkum schoint indes sich nur anf schon proteolytisch wirksanen Pankieassaft zu bezichen, so dab sie wahrshemlich nicht auf der Inwescuheit einer der Enterokinase ihnlichen Substanz in der Galle heruht. ${ }^{2}$ )

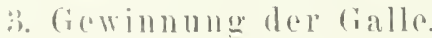

In Galle zu gewimen. Kam man eine Fisted der Gallemblate nach

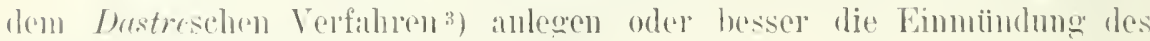
Choledochuseranges mach andien liihnem.4)

\section{(i) Combinierte Verdaumgswirkungen.}

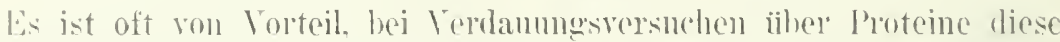
zunest wähend ciner njeht zu langen /eitdanej dor peptischen Verdaumw mittelst Magensaftes zu muterwerfen. das Verdammgsgemisch dam mit

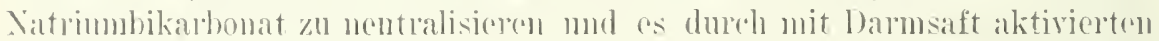

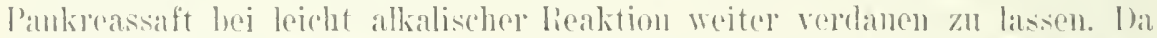

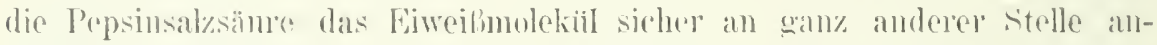
greift als das Trypsin. so worden walrscheinlich durch die Magemsaftrerdammog dem 'Trypsin manehe Itomeruppierumgen des I'loteinmolekïles zu-

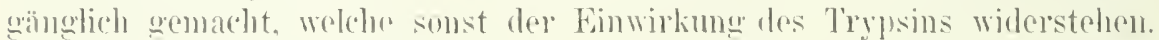

T'm den tiefsten Abban der Proteine zu erzielen. scheint es an beston

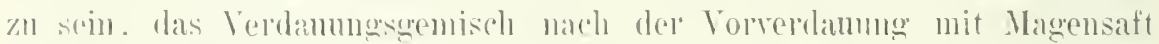
zmerst mol dam mit aktivichtem l'ankreassaft mit bamextrakt oder Erepsinlïsme zu versetzon.

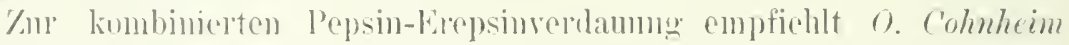

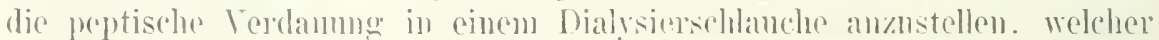

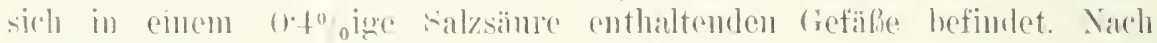

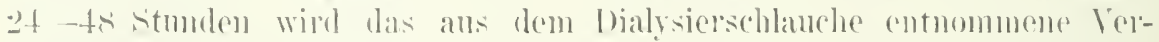
daumugsemisch mittelst Vatrimulikarbonat bis zur leicht alkalischem lieaktion

Inerselbe, Cher die Bedentung der Scifen fiir die liesorption der Fette. Ehenda.

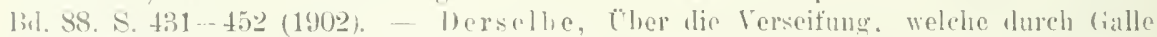

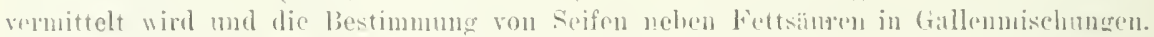

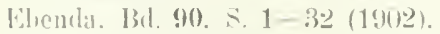

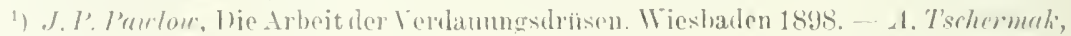
Notiz ïlore das Verdaumesvernö̈gen der mensehlichen (ialle. \%entralbl. d. I'lysiol. Bul. 16. $\therefore .32 !)-330)(1902)$.

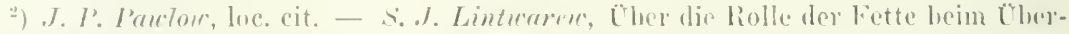
ganer dos Mageninhaltes in den Darm. Inang.-1)issert. St. [etershurer 1:101. Zit. uach

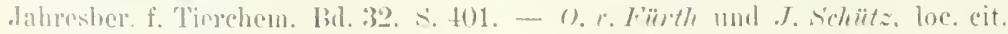

$\left.{ }^{3}\right)$ A. Irestre, Operation de la fistule biliaire. Areb. do physiol. norm. et pathot.

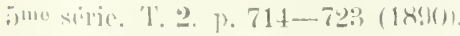

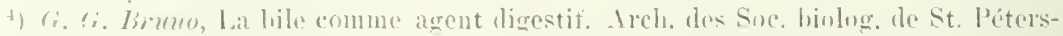

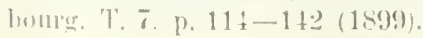


versetzt, Kohlensïme durchgeleitet. mul lam die Frepsinlösumg hinzugefiigt. Man kann anch das beim Hunde ans einer Dnodenalfistel mach dem Tobler-Cohnheimschen Verfahren erhaltone Verlauungsormiseh mit Satriumbikathonat lis zur schwach alkalisclen lieaktion versetyen. Kohlen-

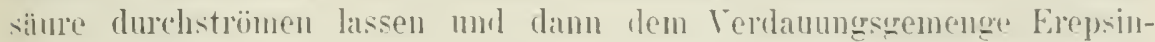
liisulng zusetzen. ${ }^{1}$ )

\section{h) Verbaumaslemente pflamblicher Herlinft: Papaim.}

Tuter den Pflanzenfermenten henutzt man oft das im safte der Carica papaya enthaltene protenlytische Froment, wolches man l'apain oder l'apayotin nemut.

Im das Papain zu isolieren, füllt man die durch wiederholte Fxtration des Saftes mit Wassel erhaltene Flissigheit mit Ilkohol. Irej so (ariclte Nicderschlag wird in Wasser auforelost und entweder durch llialye geremint

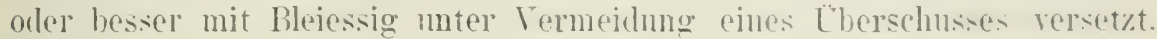
abfiltriert und das Fitrat mit schwefelwaserstoff behandelt. im laknum etwas eingedampft und tropfenweise Alkohol his zum Anfang der Fällung des l'apains dazu grefiigt. Damn wird rom mit den ersten niedergeschlagenen l'apainteilen mitgerissenen Bleisultid ahfiltriert. Las hlare Filtrat eleribt num mit Alkohol einen woilen Papainuierlerschlag. ?)

Meistens bodient man sich Handelspräparaten (l'a])ain mul ['apayotin). welche man als -2 50/ige filtrierte Lösung in phrsiologischor Flibsigkeit oler Wasser lienutzt.

Bei $40^{n}$ geht die Verdaume mittelst l'apain sehr schwer rol sich und ist sehr unvollstündig, falls man nicht wiederholt frisches Ferment zusetzt. Die same lieaktion scheint an rorteilhaftesten fuir die remdanende Wirkun des Papaius hei Zimmertemperatur zu sein.

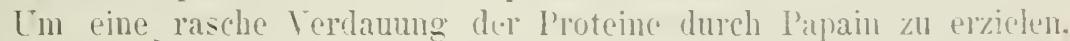
werden die kurze Zait bej Zimmertemperatur orlep im Brutranme gelasienen Gemische rasch auf $80-90^{\prime \prime}$ C whitzt: diu cigentliche Veldaumg tritt elst währonl des Emämens anf. Je linger man das Eiweilipapain-

1) Otto (ohnheim, Zur spaltung des Nahrungseiweißes im Inime. Zeitschr. f.

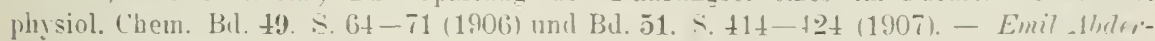
hulden und Berthold (Juplor, Weiterer Beitrag zur Frage nach der Terwertung ron tief

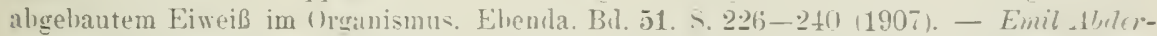
halden und Peter Rona, Weiterer Beitrag zur Frage nach der Tertretung von tief ahgehantem Eiweiß im Granismus. Ehemla. Bl. 5ㄹ. S. 507-51t (1907). - Emi Ahder-

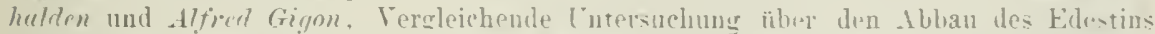
llurch Pankrearsaft allein und chreh Magensilt und l'ankreasaft. Ebenta. Bil. 5is. $\therefore$ 119-125 (1907). - E. Zunz, Contribution i l'étode de la digestion et de la résorption des protéines dans l'estnmac et daus l'intestiu rrèle chez le chien. Iém. eour. et autr.

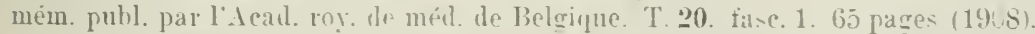

") Ad. Wurtz et E. Bouchut. Sur le ferment digestif du Cariea papara. Cumpt.

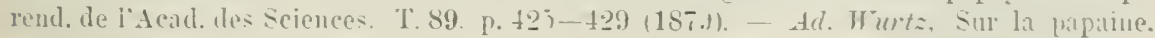
contribution it l'histnire les ferments sulubles. Ihitl. T. 93. p. 1379-1381 (1880). - sur

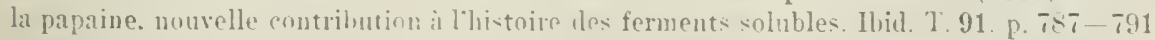
(1ぷン). 
memiseh bei Zimmertenperatur oder im Brutrame bei to libt. else man (e, pliitzlich auf $80-90^{\circ} \mathrm{C}$ bringt, desto geringer ist die dann entstehende Vordanume. Wird salzsinue dem Papainproteingemische beim Vormischen zugrefiigt, so hehält das I'apain sein mspringliches Verdaumugsvermögen. Wirrl die salswïnce erst später dem Papainproteingemische zngesetzt, so hindert sio jede weitere lbmahme des enzanatischen Vermögens, bringt es aber nicht zur urspringlichen Höhe zuriick.')

\section{Isolierung der Abbauprodukte der Verdauung.}

\section{a) Alleremeine Betrathitungen.}

Ehe man dic Isulierung der Terdaumbsprodukte vornimnt. mub man jede weitere anzmatische Wirkmog durch lufkochen des Verdaumossgemenges antheben.

(Jft empfiehlt es sich, die Verdanumg in Thermostaten ohne Ihialyse vol sich wehen zu lassen und erst nach der fiir den Verdanumgsprozeli bestimmten \%(itdanel die l)ialyse nach einem der schon beschriebenen Verfahren zur 'T'rennmug der dialysierbaren und der nicht dialysiorbaren Sualumodukte \% grobanchen. Das zmm sieden erhitzte Veroummosprodukt wird vom moerdaten Reste nul den gerimbaren substanzen abfiltriert.

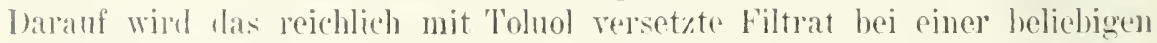
"Jemperatur (zwischen $0^{\circ}$ und $40^{\circ}($ ) der Lialyse unter täglichem orler beständigem Wechsoln des in I lalysator enthaltenen Wassers so lange unterworfen, his aine dem lialysat entnommene und eingedampfte l'robe keinen liiickstand oder höchstens Spuren davon hinterlälit. ${ }^{2}$ )

\section{b) Isolierumen der Abbauprodukte der Terbaumg der hohlehgdrate.}

Zn den Versuchen ibler Verdammg der Kohlehydrate bedient man sichl Starkekleisters, Brotes usw.

1. Nachwojs der rersehiedenen Abhauprodukte der liohlehydrate in rinenterdanungsgemische.

Fis besteht bis jetzt noch kein völig cinwandfreies Verfahren жu l'rennumg der verschiedenen, bei der Verdamme der Kohlehydrate ent-

1) O. Emmerling, Uher die Eiweibspaltung durch Papayotin. Ber. d. 1)entsch. chem. fies. Bu. 24. S. (995-6.19) und 1012 (1902). - Emil Abderhalden und Iutaka Teruachi, Tergleichende l'utersuchungrn üher einige proteolytische Fermente pflanzlicher Ilerkunft. Zeitschr. f. physiol. (lem. Bd. 49. S. $21-25$ (1906). - C. Delezenne, M. Mouton rt 1:. l'ozerski, Sur l'allure anomale de quelques protéolyses produites par la papaine. compt. reud, hehul, des séduc. de la Soc. lle Bjol. T.60. p.68-70 (1906). - Sur la ligestion hrusque de lovalbumine et du sérum sanguin par la papaine. Ibid. T. 60. p. 309-312 (19(16). - 1). Jonescu, Uher eine eigenartige Verlauung des Hühner- uml les Serumciwnj Jurch l'apaiu. Biochem. Zeitschr. Bd. 2. S. 176-187 (1906). - Fritz Sachs, Über die Verdaumg von rohem IJühnereiweiß dureh Papain. Keitschr. f. physiol. ('hem. Bd. 51. s. $488-505(1907)$.

3) Emil Ahderhalden und Béla heimbold, Der Ibbau des Edestins aus Baumwollsamen lurch Jaukreassaft. Keitschr. f. physiol. Chem. Bd. 46. S. 159-175 (1905). 
stehenden Spaltumgsprodukte. Unter diesen mutersiheidet man das mit Jod sich blan färbende Amylodextrin. das sich mit Jorl rotbram fürbende Erythrodextrin, das sich mit Jorl nicht färbende Arhroodextrin. Maltose und Glukose.

Die Jodreaktion eloibt, sellost bei dnwendung einer sehr verdiunten Jodjodkalilismug, nicht inmer völig sichere krgehnisse iiber die \%usammensetzung eimes resschiedeno Dextrine enthaltenden Gemisches. dem die iiberwiogende I)extrinart kam die Reaktion der anderen verhinderm. Falls viol Amylodextriu und nur wenig Erythrodextrin im Verdaumgsgenische vorhanden ist, so erhält man eine blaue lieaktion. Mit der 'muahme der relativen Erythodextrimmenge wird die Farbe stets mehr violett. Ebersteigt die Errthodextrinmenge erlublich lie Amrlodextrinmenge, so sicht man un die rothraune Farhe des Erythodextrins.

Man kamn die verschiedenen lextrine durch fraktionierte Fällung mittelst Itzbaryt und die \%ucker durch Daustellung ihrer ()sazone charakterisieren. I as Verdanmosenemisch wirl zum Sioden gehracht, $n$ m die liastase zn zerstören nud nachher filtriert, um es von den noch rorhandenen ungelösten stärketeilen zu befreien. Dann fïgt man allmählich so lange eine kaltgesätigte wisserige Itzbarytösumg hiuzu. wolche unter fliissigem Paraffin bei Vermeiden jerler direkten Beriilnumg mit der Luft anfhewabrt wird, bis eine mit verdiunnter Essigsäme angesäuerte alofiltrierte Probe der Verlammosfluissigkeit bei '/usatz der Jodjolkalilösung keme violette Färhung melı, sondern eine rotbrame gibt. Nach Abfiltrieren des dam völig gefällten Amylodextrins fiihrt man den alluïhlichen Xtzbarytzusat\% so lange fort, bis eine angesinuerte abfiltrierte I'robe der Verdaunngsfliissigkeit keine rote Färbung mehr mit Jod gibt. Nach Abfiltrieren des so elzielten Erythrodextrimniederschlages wird Alkohol zmm Filtrate gegeben: entsteht alsdam eine Trübung, so ist Achroodextrin vorluanden. Die Anwesenheit reduzierender Zuckel wird durch die Trommersche und die Fehlingsche Probe erwiesen. Zur Feststellung der anwesenden Zuckerarten mub man einen Teil der Verdaunngsfliissigkeit zur Darstellung ihrer (Gazone rerwenden. ${ }^{1}$ )

2. Quantitative Bestimmung der unzersetzten Stäre, der gebildeten Dextrine und Zucker in einem Verdaungsomische.

Zur quantitativen Bestimmung der in einem gegebenen Iugenblicke der Verdaung der Kohlehydrate bestehenden Menge ron Stärke, Dextrinen und /ucker bedient man sich am besten folgenden Verfahrens. welches sich anf clie Erfahrungen von London und Polowzowa sowie von Slosse und Limbosch stiitzt: Das gesamte Verdaumgsgemisch wird mit 1/10-Normalnatronlauge oder 1/10-Normalschwefelsäure je nach den Lmständen genau nentralisiert, unter '/usatz von etwas Essigsäure zum Sieden erhitzt und filtriert. Un die Filtration zu beschleunigen, kann man sie im Brutschrank bei $40^{\circ} \mathrm{C}$ rornehmen. Nan erhält so ein Filtrat $a$ und einen Riuckstand $b$.

1) J. Moreau, Étude expérimentale de la marche de la saccharification de l'amidon. Ann. de la Soc. ruy des Sc. méd. et nat. de Bruxelles. T. 12. Fasc. 3. p. 1-117 (1903). 


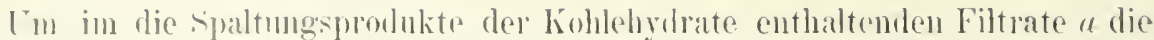
bextrimmenge und die Zuckermenge, jede fiir sich zu ermittelı, muli man

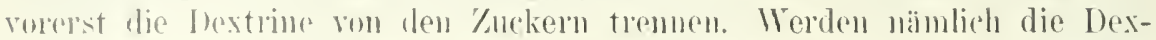
trine während 10 his 12 Minnten mit dorehlingschen läsung zum sieden ehhityt. so kümmen ledwierende Zuckel aus den Dextrinen entstehen. Diese

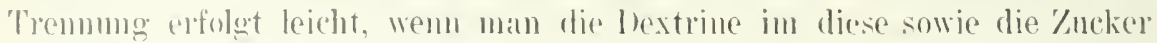
enthaltemen Filtrate a dureh Zufügunger ron 20 Vohmima Alkohol fällt. Das

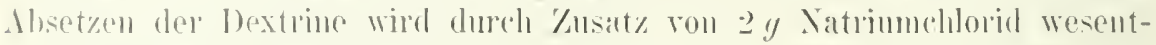

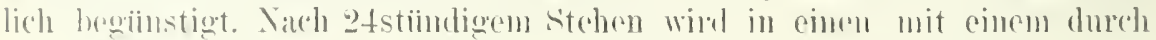

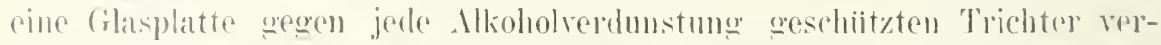

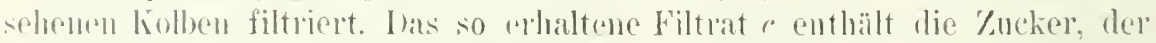
Nicderschlag d die Dextrine. Man dampft das Filtrate auf dem llaserbade zur Troelieme rin, löst den líickstand in destilliertem Wasser auf

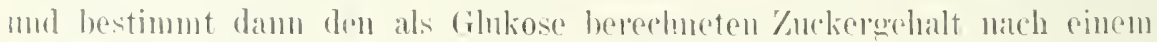

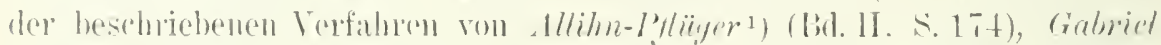

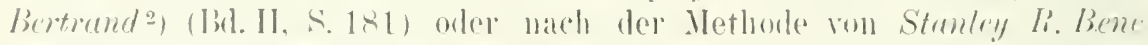

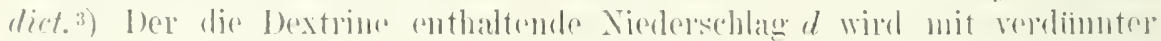

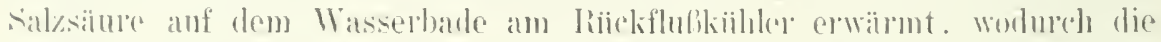

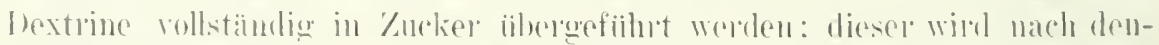

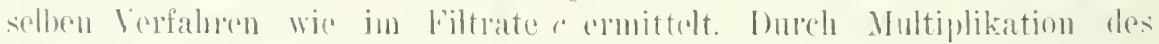

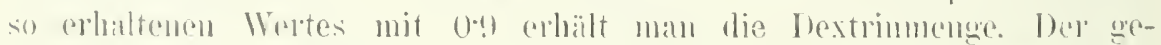

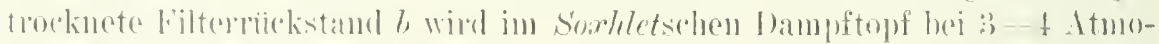

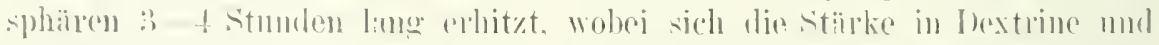

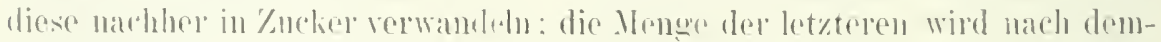

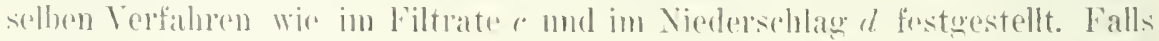

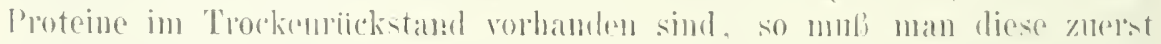

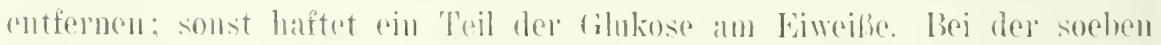

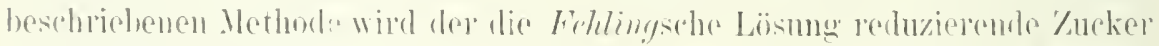

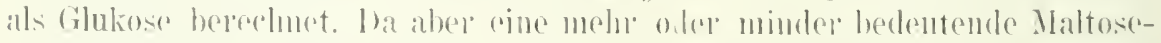

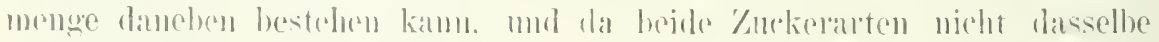

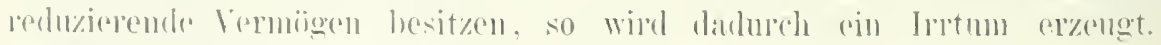

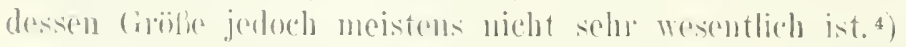

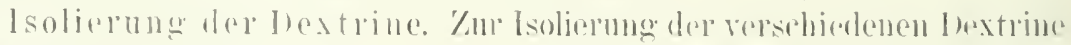

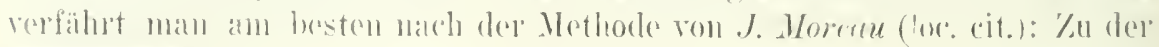

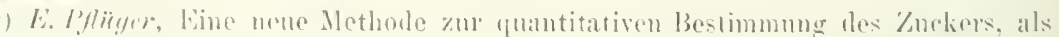

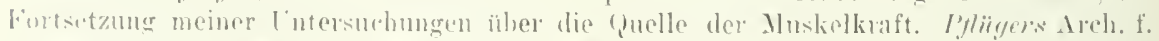

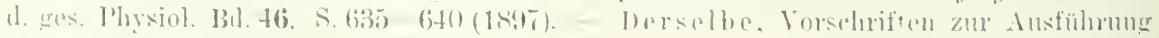

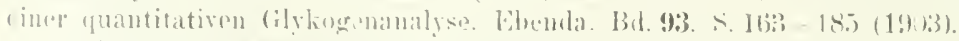

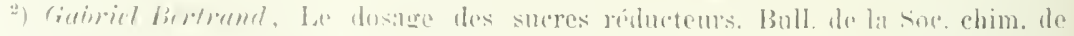

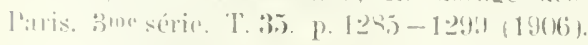

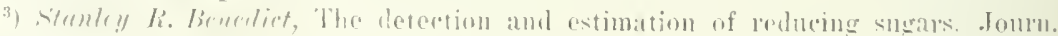

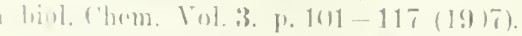

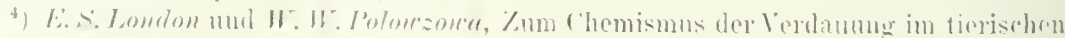

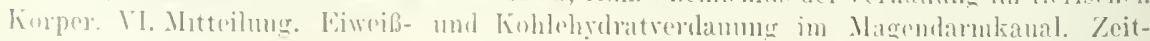

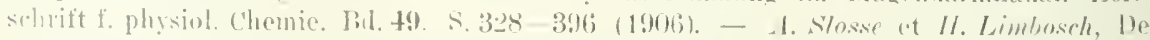

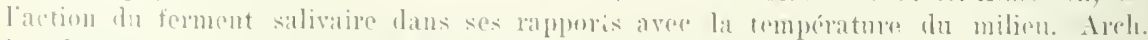
int. de physiol. 'T. (b. p. 36.5-34r) (1!) 
neutralisierten, bei \%usatz ron Essigsiure abgekochten, abfiltrierten und wieder nentralisierten Verlaumurslösung setzt man allmällich eine gesiittigte wässerige It\%barytlïsmog hinzu. Nach jorlem \%usat\% werden einige lubikzentimeter der Flissigkeit abfiltriert und mit Jodjodkalium versetzt. sobald man eine rothraune Firbung erhält. filtriert man die Hanptmasse der Fliissionkeit. Der Niederschlag a hesteht aus Imylorlextrin und etwas Frythrodextrin: er dient zur lyarstellun des Amylodextrins. Zum Filtrate b, wird allmählich ron der Itzharytlisumge weiter zugesetzt. bis eine abfiltrierte Probe sich bei Znfiigung der Jodjodkalilïsung nicht mehr rot fürbt: dann trennt man durch Filtration den aus den yröbten Teile des Errthrodextrins hestehenden Viederschlatr a rom das Achroodextrin und die reduzierenden Zucker enthaltenden riltrate $d$. Im letzteren fïllt man durch Alkoholzusatz das Arhloodextrin und trennt diesen Niederschlag $r$ durch Ihfiltrieren oder Ahgiefien rom die reduzierenden Zucker enthaltenden Filtrate $t$.

Ine drei Viederschlägne $u$, c und $e$ werden jeder fïr sich in mittelst Essigsäure angesäuertem Wasser aufgclöst.

Die Amrlodextrinlösung (I) wird mit Itzharytlösung sol lange rersetzt. his eine Probe der abfiltrierten Fliisigkeit bei \%usatz der Jodjodkalilisung rotbraun wird. dann filtriert man den Amylodextrinniederschlag und löst ihn nachher wieder in angesiuluertem Wasser auf. Ine Fällungen mit Itzbarytlösung und die Anflisungen in Wassel werden melumals wiederholt. Wenn keine spur mehr von Errthrodextrin sich hei der Jodprobe nachweisen lillit. fällt man dureh Alkohol das Anylodextrin. un es rom in lïsungr bleibenden Barsumacetate zu tremnen.

'/u1 Errthrodextrinlösung (c) setzt man Atzharytlösung bis zum Erscheinen einer rotbramen Farhe beim Versetzen einer ahfiltricrten Probe der Flissigkeit mit Jorljodkalibsung. I)ann filtriert man rom amylodextrinhaltigen Niederschlage ab. Zum erhaltenen Filtrate fiigt man Xtzbarytlösung bis zur Abwesenheit jeder roten Färhung hei Jodjodkalizusitz zu einer abfiltrierten Probe der Fliissigkeit. Der entstandene Viederschlag wird abfiltriert. in angesäuertem Wasser anfgelöst und die Fällungen mit Itzharytlösung sowie das nachherige Iuflösen in Wasser werden mehrmals wiederholt his zum durch die Jodprobe ancezeigten Vershwinlen jeder Imylodextrinspur sowie zum völigen Feh!en reduzierender zucker in der nach der Fällung des Frrthrodextrins bleibenden Flüssigkeit. Dann fällt man mit Alkohol das Errthrodextriu, um es rom Barrumacetat zu trennell.

Dic Ichroodextrinlösung (e) wird durch Fällung des Errthrodextrins mittelst Itzbarytlösung. Abfiltrieren. Fällung des Achroodextrins mittelst Alkohol. Auflösen der Niedurschlïge in angesïuertem $\mathrm{W}$. sser und mehrfaches Wiederholen dieser Gesamtprozedur rom anhaftenden Erythrodextrin sowie ron jeder Spur eines reduzicrenden Zuckers befieit. Schlieblich wird das Arhroodextrin aus seiner wii-serigen Lösung durch .tlkohol gefüllt und auf diese Weise rom Barrumacetat getremnt. 


\section{(c) Isoliegung der Ibbauproblukte der Verdanumg der Fette.}

7ur [ntersuchung der Fettverdaumg benutzt man meistens das von

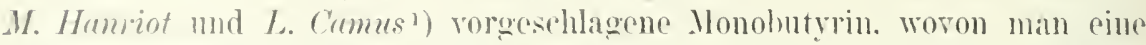
1\% ige wisserige lösmlng frisch hereitet, stearinsanres oder ölsaures Natıon usw. Als natiirliche l'ette nimmt man (Olivenöl. Kubhutter, Rinderfett, Sehweinefett usw. I) ie Neutralfette missen absolut frei von Fottsïuren sein. Als Emulsion hedint man sich der Mileh oder kïnstlicher, mit Hilfe ron (immmi alubicum bereiteter (Olivenemulsion oder einer Eigedbwasseremulsion (:) Vigelb anf 100 cm $^{3}$ Wassep). Im eine selur fein rerteilte Emulsion zu bewerkstelligen. mentralisiort man das stets freie Fettsäme enthaltende küufliche Olivenöl oder Rizinnsïl mit der eben dazn erforderlichen Menge ${ }^{1 / 10}$ normaler Natronlange und rermischt gut Lauge und öl durch s.'shittelm. ${ }^{2}$ )

Feststellumg dor ans fottemulsionem abespaltenen Fettsürem.

Falls man bei Versuchen in vitro mit Fottemulsionen mur die lenge der algespaltenen Fettsämen ermitteh will. so geniigt es nach Beendigung des Verdammgeprozesses. die Fliissigkeit mit $1 / 10$ oder $1 / 20$ mormaler alkoholischer Xatron- oder Lalilange muter Anwendung ron Phenolphtalein bis zur Nentralisation zn repsetzen. Zur Vermeidung jeder Hydrolyse wälrend

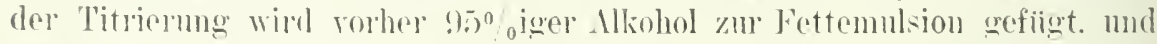
Jwal $50 \mathrm{~cm}^{3}$ Alkohol auf $20 \mathrm{~cm}^{3}$ Emmlsion. Auferdem soll man stets fiontrollversurhe anstellen mit der wirksamen Lipase ohne Zusat\% der der Verdaunng muterworfonen Fettemulsion einerseits und mit der ausgekorhten

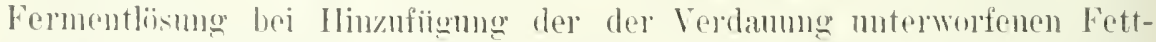
cmulsion andereseits in demselhen Verhälnisse als heim eigentlichen Versuche. Beide Kontrollfliissigkeiten werden in Ien Thermostat gleichzeitig mit dem Versurhegemische gehracht mid zun derselhen Zoit wie letzteres titriert. Inie dahej etwa rerbranchten Langenmengen werden von der zur Nentralisation des eigentlichen Verlaunngsepmenges angewandten ab)erogen. ${ }^{3}$ )

$\left.{ }^{1}\right)$ W. Homriot et $L$. Camus, Sur le dosage de la lipase. Compt. rend. de l'Aead. des Sriences. T. 12t. p. 235 - 237 (1897). - Compt. rend. hebd. des séanc. de la Soc de Biol. 'T. 49. p. 124-126 (1897).

") Aristides Kunitz, Ther l'ankreassteapsin und über die Reaktionsgesehwindigkeit der mittelst Enzyme lowirkten Fettspaltung. Zeitschr. f. physiol. Chem. Bd. 46. S. $48 \div-491(190)$ ) $)$.

$\left.{ }^{3}\right)$ Aristirles hanitz, Beiträtge zur Titration ron hochmolekularen Fettsäuren. Ber. d. Dentsch. whem. Ges. 131.36. S. 400-404 (1903). - A. S. Loevenhart and George Peiree, 'The inhiliting effect of sorlinm fluoride on the action of lipase (second paper). Journ. of liolog. (hem. Vol. ‥ p. 397-413 (1907). - A. S. Loerenhart and C. G. souder, On the effect of hile upon the hyllolysis of esters by pancreatic juice. Ibid. Vol. 2. p. 415-425) (1907). - Otto r. Fürth und Julius Schütz, U'ber len Finfluß der Galle auf die fettund ciweißspaltenden Fermente des Pankreas. Beitr. z. chem. P'hysiol. n. Pathol. Bd. 9. S. $28-49(1907)$. 
Gleichzeitige quantitative bestimmung der Seifen und Fett-

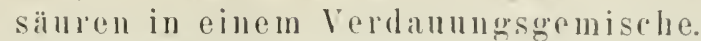

'/ur gleidheitigen quantitativen Bestimmung der Seifen und Fettsänren in einer Verdanungsfliissigkeit korht man diese nach \%usat\% der mehrfachen Nkohohnenge, filtriert. wïscht den Niederschlag mit Nkohol, verjagt den Alkohol aus dem Filtrate. macht die als reifen rorhandenen Fettsïuren durch Salzsïure frei, erhityt wieder, läht erkalten, filtriert die erstarrten Fettsämen, wischt sie so lange mit destillierten Wasser aus, his in der Waschflitssigkeit kein Chlor nehr nachweisbar ist, löst sie auf dem Inftrockenen Filter in Ither nud bestimmt nach Nlknlobusatz die gesante Fettsämrenmenge mit 1/10 oder 1/20 110rmaler alkoholiselier Natronorler líalilauge hei Anwendung des l'henolphtaleins als Indikator.')

Untersuchung der Abhauprodukte der Verdaumm der Fette llach Levites.

Zur Untersuchmog der bei der Verdaumng der natiirlichen Fette entstandenen Produkte erwälmt man dic Veldanungsfliissigkeit anf dem Wasserbarle bis zum Schmelzen des Fettes, bringt sie dann auf Eis bis \%um Erstarren des Fettes, entnimmt die erstarrte feste Fetthruste, wäscht sie mehrmals mit Wasser aus mol löst sie in Ither oder Petrolemmäther auf (Lösung I). Falls man durch blobes Erwärmen mud nachfolgendes Erstarren die Fette nicht aus der Verdaumngfliissigkeit entnelnmen kann, wie dies heim Torhandensein einer erheblichen Gallen- oder schleimmenge der Fall ist, so wird der Verlaumgshrei im Schittelapparat mit ${ }^{\prime}$ ther ausueschittelt und somit rom gröbten Teile des Fettes befreit: die Atherschicht (Lösung I) wird ron der Wasserschicht getremnt. Letztere oder die nach Wesschaffen des erstarrten Fettes ïbrig bleibende Flïssigkeit wird langsam auf dem Wasserbade bis zur 'Trockene eingerlampft und im Soxhletschen Extrahtionsapparate mit Ither oder l'etroleumäther ausgezogen. wodurch man die ätherische Lösung II erhält. Beide Atherlösungen I und II werden vereing't. Nach Verdunsten des Athers mud Befleien der Reste des Lösmugsmittels durch Einleiten von Kohlensïure wird der ans dem Nentralfette und den freien Fettsämren bestuhende Rückstand gewogen und danach in Ilkohol aufgelöst. Mit $1 / 10$ nornaler alkoholischer Natron- oder Kalilauge wird num bei l'henolphtaleinanwesenheit die Sämrezahl hestimmt und darams werden auf (irund des mittleren IIolekulargewichts die freien Fettsïuren in Prozenten ausgedrickt. Der nach der Atherextraktion im Soxhletschen Apparate hinterbliehene feste Riichstand wird mit wässerigem Alkohol verrieben, mit einer genau bekannten salzsïuremenge angesänert. ringedampft und im Soxhletschen Extraktionsapparate mit Ather auswezogen. Die so erhaltene ätherische Lösmo III enthält die in Verdanumgsemische als

1) O. $r$ Fürth und J. Schütz, Fin Beitrag zur Methodik der Versuche üher Eettresorption aus isolierten Darmschlingen. Beitr. z. chem. Physiol. u. Path. Bd. 10 S. 462 lis $+79(1907)$. 
sejfen vorhambruen Fetts̈̈men. Man lälit den Xther rerdunsten. wägt den liïchstand und list ihn wathher in Alkohol anf. In der alkoholischen Lösung titrielt man die Menowe dor als Soifen in Verdaumosuemenge hefindlichen

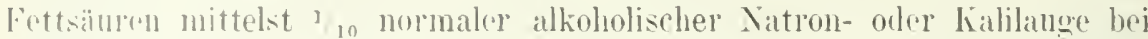
P'henolphtaleingegrnwart. Dieses Terfahren kann nur dann angewandt werden. wonn keine anderen stoffe (Proteine, Kohlehydrate) als Fette dem Vel(limmosprozesie unt(rworfen werden. ${ }^{1}$ )

\section{Feststellung des Gesamtfettes.}

Lin ainem Velolumugstemenge das Gesantfott zu entzichen, wird

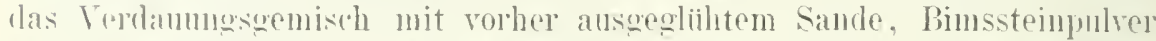

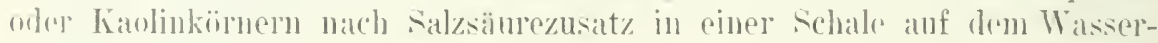

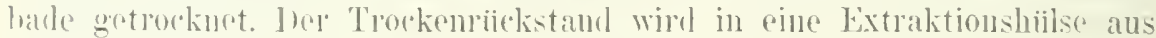

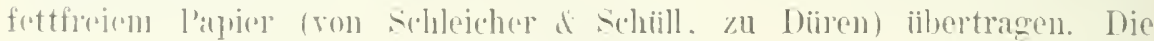

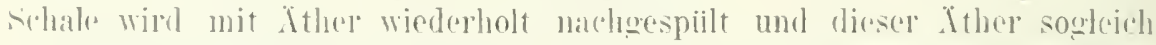
dureh rinen trorkenen l'apierfilter oder hesser durch rinon Aslestfilter in den die Extlatitionshiilse enthaltenden Extralitionsapparat gegossen. Nach

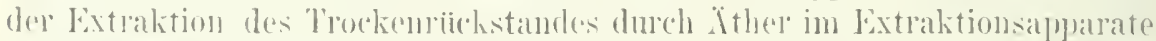

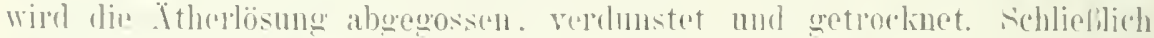

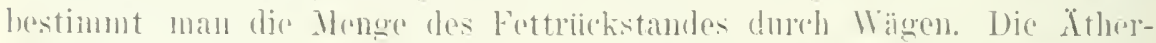

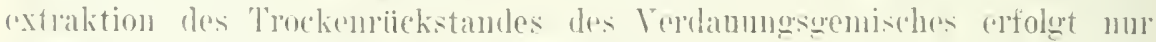

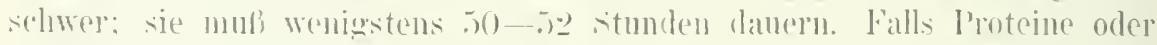
\%ellelenente in Velolaumosgenenge rorhanden sind, so mul man sie

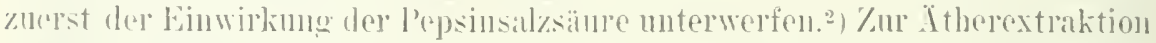
hedient man sich mit Vorteil statt des Sombletschen Extraktionsapparates

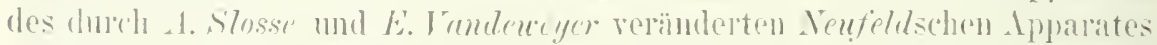

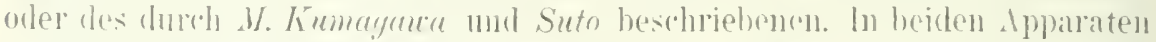

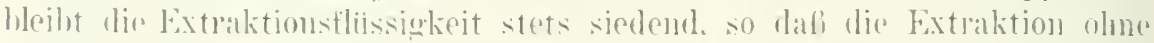

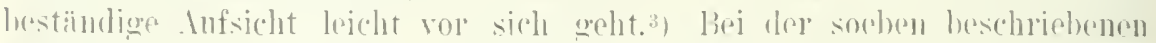
Methorle werelen die seifon zerlent. so dali man mur dio freien und als

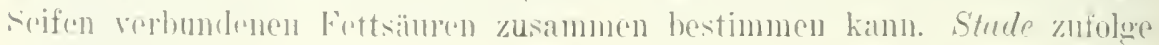

1) s. Lerifes, Uther die Vordanung der Fette in tierischen (Iromismus. Zeitschr. f. physiol. (hem. Bil. 49. $\therefore$. 273-285 (1!)06).

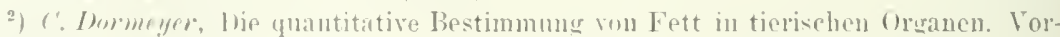

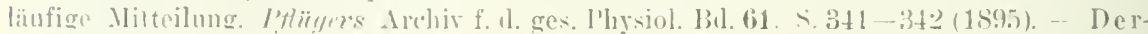
selbe. I) qe quantitative Bestjmmmng son Fetten. Seifen nul Fettsänr'll. Fihenda. Bul. 65 ‥ (1)-108 (1896). - Jos. Nokinn, Nene Beiträge zur Fetthestimmung in tierischen Ge-

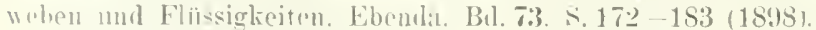

$\left.{ }^{3}\right)$ A. stosse, L'albminin peut elle se transformer en graisse par simple macération. Areh. iut de Phrsinl. T'. 1. p. 345-358 (19)4). - Recherches expirimentales sur la formation de la eraisse aux dépens de l'albumine. Anu. de la soc. roy. des Se. méd. et nat. the Bruxalles. T. 13. fasc. 2. p. 1-39. - 1. Slosse et E. Iandereyer, Etude analytique de lablinentation dou groupe de 33 nurriers hruxellois. Mém. cour. at autr. mém. publ.

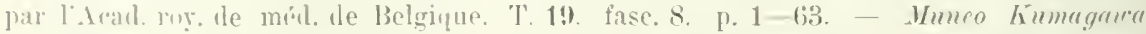
mul henzo suto, Ther die Bestimmung les Fetturelaltes tierischer Hï̈siglieiten nach

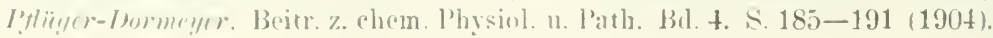


werden bei der Itherextration des anf Kaolin getrockneten Verlaunnesgemisches erhehliche Mengen rou Noutralfetten nicht extrahiont: auberlem werlen die Fottsiuren leichter vollständig extrahiert als die Neutralfette. so dal) man bei diesem Verfalnren leicht eine zor erhehliche Prozentzahl als

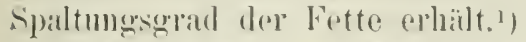

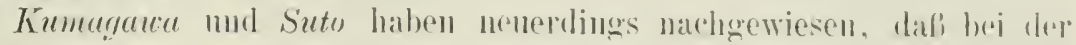
Atherextraktion von Gemischen, welehe anlore Feotte moch andere Stoffe enthalten, das Neutralfett keineswegs allein puantitativ isolicert wirl. Die

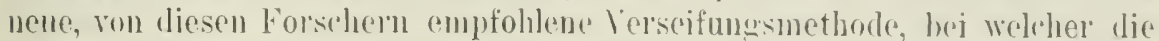
Menge der hohen Fettsämen ynantitativ bestimmt wird, davon das Gewicht der etwaigen mrerseifharen substanzen (cholestron usw.) abge-

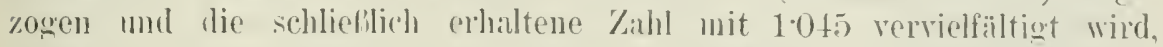
um ans den gefmulenen hohen Fettsämen die Nence des Neutlalfottes zu berechnen, kömnte vielleicht gute Tienste bei liosorptionsiersurhen iilrev Fettstoffe leistem, gibt aber lieine Infschliisse iiber die bei dor Vorlanumg ror sich gochenle spaltung (ler Fette. ${ }^{2}$ )

Wie ans dem Vorherogenenden erhellt. ist es also keinesweos leicht. die absolut'n Mengen der als Teutralfett, als freie Futtsïnen und als Seifen in eincm Terdanungsgenische rorhandenen Fettstoffe renan zu ermitteln. Deshalb labben Tolhard und Stade das unten beschriebene Vel-

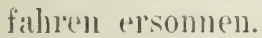

Verfahren vou Volhurd-Stude zur Feststrllung les firades

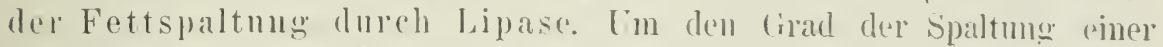
Fettemulsion durch die Lipasen der Verdaumosscklete zu ermittelı, müssen nach Vollhard keincswegs alle im Verdaunugsonemische vorhandenen Nontralfette und lettsäuren quantitativ der 'Titration zugänglich remacht werden.

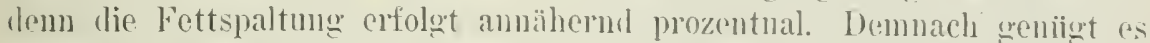
rinen beliebigen 'Teil des Fettäthers zn titrieren und zu verscifen. um darans den I'rozentgehalt des Öthers an Fettsäuren festzustellen. Bei del Ausschïttelung aliquoter Mengen des Verdaumngsemisches hetragen narh Stade die bei Ermittlung des prozentischen Verhälnisses alogespaltener Fettsïuren heobachteten Cutelschiede bei stets derselbru schuttelzeit höchstens $3 / 2 \%$, bei verschiedenen schiittelzeiten indes his $20 \%$.

Bei dem Irolhard-Straleschen Verfahren wirl eine gewisse Menge $\left(20-50 \mathrm{~cm}^{3}\right)$ des Verbaumgsonisches in einc Flasche ron uuge fälly $150 \mathrm{~cm}^{3}$ Inhalt gehracht, welche nötigenfalls rlam duch Eintauchen in haltus Wasser

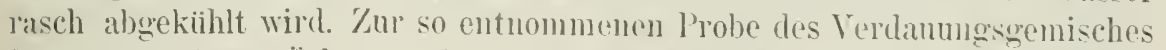
fïgt man $75 \mathrm{~cm}^{3}$ Xther sowic $2 \mathrm{~cm}^{3}$ (bei Versuchen mit (ler Magenlipase) oder mehr (bei Versuchen mit l'ankreassteapsin) Alkohol, rerschließt gut

1) Ir. Stade, Untersuchnngen über das fettspaltende Ferment des Magens. Beitr. z. chem. Physiol. u. Path. Bd. 3. S. 2 ?) - 321 (1903).

2) M. Kumagawa und $K$. Śuto. Ein neues Verfahren zur quantitatiren Bestimmung des Fettes und der unverseiflaren Substanz im tierischen Material nebst der Kritik einiger gebrätuchlichen Metholen. Ahhandhung I. Biochem. Zeitschr. Bd. 8. S. 211 lis 347 (1908). 
mud schiitelt wïhend mehrerer Vinuten, bis der oben anfsitzende Äther cinen intensiv gellen Farbenton zeigt, wodurch hewiesen wind. dab Nentralfort wie lettsïnen in genitgender Menge extrahiert sind. I)ie Fettspaltmong hönt fast sofort im Angenblicke der Athereinwirkung auf. so dab beim Schüttelrapahen die \%erstörung des Fermentes durch Kochen iiberfliissig ist. Wer Zusat\% rou Alkohol zum Xther beschlemigt die Schichtung nud relondedet die Bilduno von Emmlsionen. Solald sich nach Beendignug

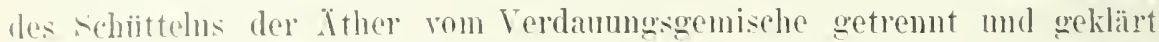
liat. werlan $50 \mathrm{~cm}^{3}$ desselben in ein Köblbehen abgegossen, mit $75 \mathrm{~cm}^{3}$

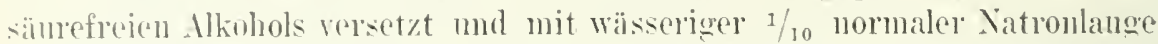
suf l'henolphtalein titriert, wodurch man den Gehalt an freien Fottsäuren (Welt I) hustimmt. I'm sämefreien Alkohol zu erzielen. wirl der Ilkohol in 5-Literflaschen in durch Dampfzuleitung erhitzten Wasserbale gekocht und mit $1 / 10$ normaler Natronlange gegen I'lenolphtalein nentralisinet. 1)anach werlen $10 \mathrm{~cm}^{3}$ normaler Satroulange dem Gemische zugesetzt und die Köblbehen ¿ stunden auf kochendem Wasserbade unter dem Riickflußkijhler oder ot Stmulen gut verschlossen bei Zimmertemperatm gelassen. wodurch die noch in dem femische entlaltenen Nentralfette völlig verseift werden. In durch die Verseifung das Glas angegriffen wird. besonders heinn lonchen. so empfichlt es sich, die zur Verseifung dienenden

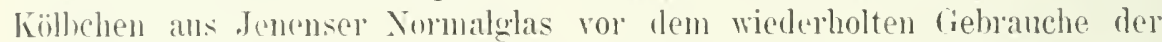
Einwirkmne strimenden I)ämpfen ansznsetz('n, his daß das an ihren Wänden kondensiogende Wasser ohne Alkaligehalt abfliedst. Nach der Verseifung enthält das fiemisch das gesamte extrahierte Fett in Form ron Natrouseifen mul anfordem einen Cherschul an frejer Natronlange. Man fiigt damn $10 \mathrm{~cm}^{3}$ nolmaler schwefelsume zur verseiften Flissigkeit. Ein Teil

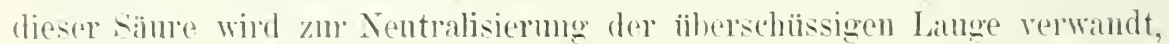
der andere Trail treiht aus den dureh die Verseifme gewonnenen Satronseifon die Fettsäuren ans. deren Jenge (Wert II) man nittelst $\%$ o normaler Natronlange anf l'henolphtalein titrinetrisch emittelt. Ans den heiden

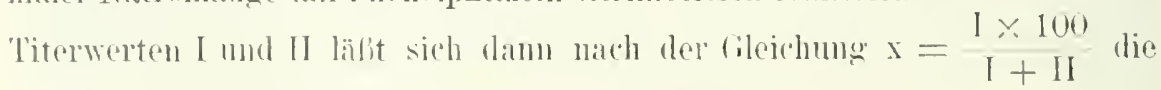
Crröba der Fettspaltumg in l'rozenten berechmen.

I) a emulgierte Fettr (\%. li. Eigell)) anch ohne Fermentemwirkmg in geringem Grade gespalten werden. so soll man stets bei den Versuchen iiber Fett-

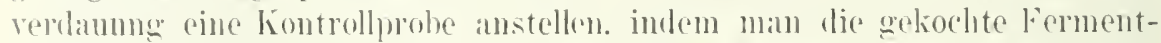
lösung (Magensift. J'ankiteassaft) anwendet. I)as Volhard-Studesche Verfahren

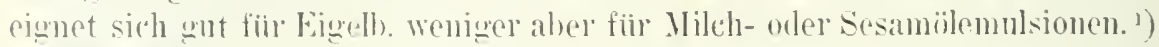

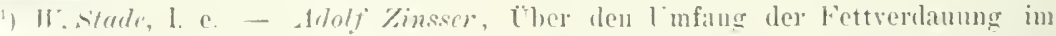

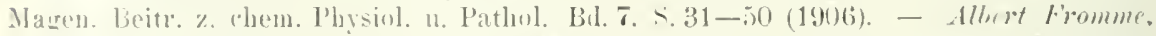
fore das fotspaltende Ferment der Magensehleimhant. Ehenda. Bu. 7. 5. $51-76$

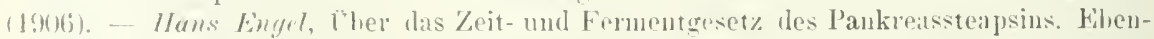

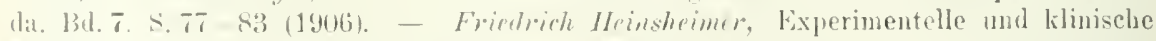
studien ïher fermentative Fettspaltung in Magen. Arlojten aus dem pathologischen Institut zu Bordiu. zur Fejel der Vollendung des lustitutsuenbanes lierausgegeben rou

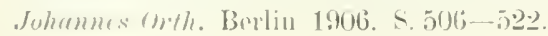


Bestimmunge vou Seifen neben Fettsäuren in Verdauungsgemischen nach Ifflüger. Pflüger hat nacherewiesen, dah ans del'

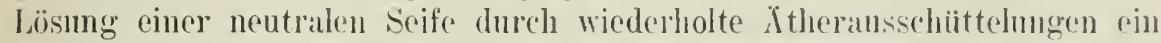
grofer 'l'eil der vorhandenen Fettsämen infolge der dabei vor sich gehenden Hydrolyse ent\%ogen werden kann. Demuach kann man ans einem femengr. ron Seifen und Fettsiuren die letzteren durch Itheraussehiittelung keineswegs fluantitativ genau bestimmen. Tn den dabei sich ergebenden Fehler zur vermeiden, empfiehlt Pfliuger folgende Ilethode, welche auf der völligen Fällnug der Seifen mittelst Kochsalz bei $0^{0}$ beruht: Das Verdauungsgemisch wird in 2 Hïlften verteilt, woron die cine filtriert wird, die andere hingegen nicht. In der ersten Hälfte wird die Menge (ler in Lösung befindlichen Fettsïuren bestimmt. I)ie filtrierte Flüssigkeit wird in 2 gleiche Portionen verteilt. Der erste Teil wird mit Salzsäure angesïuert und mit Ither ausgeschütelt. Der Itheranszug liefert die resamtmenge $a$ der im Verdammosprodukte in Lösung befindlichen freien und in Seifen gebundenen Fettsämren. I)er andere 'Teil wird mit $\mathrm{NaCl}$ gesättigt, wozu man zu $50 \mathrm{~cm}^{3}$ Fliissigkeit $500 \mathrm{~cm}^{3}$ gesättigter $\mathrm{NaCl}$ lösung und $15 \mathrm{~g} \mathrm{NaCl}$ fiigt. Nach 15 stiindigem Stehen auf Eis wird bei $0^{0}$ filtriert. Der Niederschlag wird mit siedendem Alkohol aufgenommen; in rer so erhaltenen alkoholischen Lösung stellt man die Menge $b$ der ausgesalzenen freien Fettsäuren fest. Nach Abschluf der Titration wird der Alkohol aus der neutralen Scifenlösung verjagt, letztere mit Salzsälure angesäuert und mit Ather ausgeschütelt. Dieser A therauszug gibt bei rer Titrierung dic Gesamtmenge $c$ der durch die Anssalzmng ansgeschiedenen freien und gebundenen Fettsäuren. $c-b$ - entspricht der Menge d der in den geelösten Scifen enthaltenen Fettsäuen, $a-(c-b)$ der Gesamtmenge $e$ der freien gelösten Fettsäuren. Um den ganzen Betrag der Seifenbildung zu erfahren, wurden in der zweiten Hälfte des Verdaumngsgemisches ohne jede Filtration die Seifen in der ohen beschriebenen Weise ausgesalzen. Der so erzielte Niederschlag wird mit sierleudem Alkohol aufgenommen; durch Titration ermittelt man dic Venge $f$ der ausgesalzenen freien Fettsämren des Gesantrerdaumngsgemisches. Nach der 'Titration wird der Alkohol weggejagt, der Ritickstand mit Salzsïure angesäuert und mit $X$ ther ansgeschiittelt. Der Atherauszug gibt bei der Titration die Menge $g$ der ausgesalzenen freien und gebumlenen Fettsïuren der Gesantverdaunngsfluissigkeit. $g-f$ entspricht der resantmenge $h$ der in den gelösten oder ungelösten Seifen enthaltenen Fettsïmen. Zieht man von der Gesantmenge der Fettsäuren der Seifen $h$ die Menge $d$ der in den gelösten Seifen befindlichen Fettsäuren ab, so erfährt man dic Menge $i$ der sich aus der iibersättigten Lösung niederschlagenden Seifen. ${ }^{1}$ )

1) E. Fÿ̈rger, t'ber die Bedeutung (ler Seifen für die Resorption der Fette nebst cinem Beitrag zur Chemie der Seifen. Areh. f. d. ges. Physiol. Bd. 88. S. $431-452$ (1902). - Derselbe, Uber Kalkseifen als Beweise gegen die in wässeriger Lösung sich rollzichende Resorption der Fette. Ehenda. Bd. 89. S. 211-226 (1902). - Derselbe. Uber die Verseifung, welche durch die Galle rermittelt wird, und die Bestimmung ron Seifen nehen Fettsäuren in Gallenmischungen. Ebenda. Bd.90. S. 1-32 (1902). 


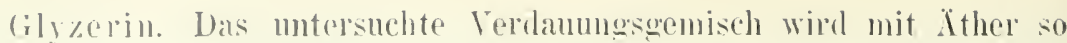
lange estrabiert, bis der ither Fett ibernommen hat. Der flissige oder broige Riickstanl wird nach otwager vorsichtiger Eimengumg anf dem Wasselbaule bei nicht zu hohel 'Temperatur mehrmals mit Alkohol extrahiert. Jie Nlkohollösung wind filtriert und das Filtrat in einem Becherglas anf das Wassorhad gebracht. um den Ilkohol zu verjagen. I'm Glyzerinverlust heim Eintrocknen zn rermeiden. wird dabei die Wand des Becherolases wiederholt mit klemen Mengen Wassers abgespritzt. Nachdem die qanze Jlissigkeit anf cinge Kubikzentimeter eingeengt ist. Wirl sie mit Wasser aufgenommen.

L'm die Anwesenheit ron (ilyzerin nachznweisen. geniigt es, dio wässerige lösmu mit Borsäme zn erhitzen, wobei sich ans dem Glyzerin Akrolrin biklet, welches dirch den stechenden Geruch und durch die Fähigkeit seiner Gase mit Silbernitrat getränktes Filtrierpapier zu schwil"zen l(icht erkembar ist. ${ }^{1}$ )

\%ur (plantitativen Bestimmung des (rlyzerins werden 25 $\mathrm{cm}^{3}$ des nach der Therextraktion zuribkbleibenden Verdaumugremisches mit Alkohol auf $100 \mathrm{~cm}^{3}$ Gesamtrolumen gebracht. mehrmals mogeschiittelt, nach Stehenlassen filtriert. Vom Filtrate griefit man $80 \mathrm{~cm}^{3}$ in ein Becherglas und verjagt den Alkohol anf den Wasserhade unter wiederholtem Alspritzen der Wand des Becherglases nit wenig Wasser. Wenn nun noch einige Kubikzentineter Flissigkeit in becherglase vorhanden sind, wird sie mit Wasser in ein Mabioilhchen von $25 \mathrm{~cm}^{3}$ Inhalt gegossen und destilliertes IVasser his zur Marke hinzugefügt. Die Fliissigkeit wird alsdam wiederholt mit Petrolither ansesehiittelt. Von der wisserigen Flissigkeit entnimmt man 10 c'me $^{3}$, welehe nochmals muter Beohachtung der oben angegebenen Kantelen anf lem Wasselbal eingeengt und nachher anf $10 \mathrm{~cm}^{3}$ mittelst Hinzufiomng destillierten Wassers gebracht werden. Vou dieser wasserigen lösmg dienen je $5 \mathrm{~cm}^{3}$ zur quantitativen Restimmmog des Glyzerins mach dem durch Stritar, Herrmann sowie Tangl und Weiser otwas verinderten (Bd. II. S. 2) s6) schon heschriebenen Jodidverfahren von Zrisel und Finto. ${ }^{2}$ )

1) A. Wohl und ('. Ycuberg, Uher die Darstellung des Akroleins. Ber. d. Dentseh. chem. Ges. Bd. 32. S. 1352 - 1354 (1899). - J. Wohlgemuth, ther den Sitz ler Fermente im Iühnerei. Zeitschr. f. physiol. Chem. Bd. 44. S. 540 -545 (1905). - loeselle, Cher dis Vorkommen vou Fermenten in Hühnorej. Festschrift zur Ehre des 60. Gehurtstages von kirnst Solkourki. Berlin 1904. S. 433-441.

$\left.{ }^{2}\right)$ s. Keisel mul li. Finto. C'ber ein nenes Verfaluen zur Bestimmung des Gilyzerins. Koitschr. f́. d. landw. Versudiswesen in Österreich. Bd. 5. S. 729 (1902). - J)ieselhen. Bestimmung des Rohglyzerins im Weine mittelst der "Jodidnethode". Zeitsehr. f. analyt. Chem. Bd. 42. S. 549-578 (1903). - H.J.stritar, Kur Methoxyl- und Glyzerinhestimmung. Lithenda. Bd. +2. S. 579-590(1!03). - Awgust Herrmann, Uher die Bestimmung des Glyzerins im Harm. Beitr. z. chem. P'hysiol. u. P'athol. Bil. 5. S. 422-431 (1904). Fronz Tangl und Stephan Wriser, iber den Glyzeringehalt des Blutes nach Untersuchungen mit dem Zeistschen Jodidverfahren. Pflügers Archiv. f.d. ges. Physiol. Bul 115. S. $152-174(190(5)$. - Felir Reach, Versuche üher die physiologische Veresterung der Fet1siuren. \%eutralbl. f. d. ges. Physiol, u. Pathol. d. Stoffwechsels, N. F. Jg. 1907. Nr. 20. 


\section{(d) Isolierung der Ahhauprodukte der Verdaumng der Proteine.}

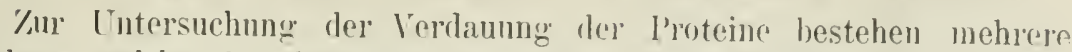
Verfahren. welche den Grad der Spaltung und die Mengen der verschirdenen Gimppen ron Spaltprodukten zu hestimmen strohen.

Vorfahren zur Lutersuchung der Abnahme der Genuinitit der I'roteine.

Bei der Vernichtung der Genuinitiit der l'roteine verschwindet die rerinnharkeit. Lm den in einem Verkauungsgemisch noch grenuinen Anteil der Proteine zu bestimmen, wirl dieses der Hitzekoagulation in schwach essigsaurer Lösung unter $\mathrm{NaCl}$-\%usat\% unterworfen. I) urch Filtration trenut man die geronnenen l'roteine und hestimmt nach Kjeldahl den stickstoffgehalt des die gerommenen noch genuinen Proteine enthaltenden Niederschlages sowie des die nicht mehr gerinnharen l'roteine nud ihre spaltungsprodukte enthaltenden Filtrates. ${ }^{1}$ )

Man kann sich auch dazu der im I. Bande (s.686) schon beschriebenen Enteiweifiungsmethode von Michelis und Rona bedienen. bei welcher allerdings ein Teil der Proteosen mit den I'roteinen bei der Mastixfällung niedergeschlagen werden. ${ }^{2}$ ) Die liestimmung des Stickstoffgehaltes des Filtrates nach Kjeldahl erlaubt also nur eine Schätzung des beim Verdauungsprozesse gelösten Sitickstoffes. $\left.{ }^{3}\right)$

Quantitative Messung proteolytischer Sipaltungen mittelst der Formoltitrierung nach Sörensen. Nach Sörensen mul man eine proteolytische Spaltung als eine Hydrolyse mit Bildung von Karboxyl- und Aminogruppen betrachten, so daß eine rationelle Messung der Spaltungsgröbe auf eine ynantitative der durch die studierte Proteolyse gebildeten Karhoxy- oder Aminogruppen ziclen soll. Nach einen die Aminogruppen in Methylengruppen verwandehden Formolzusatze kann man titrimetrisch den Gehalt an Karboxylgrmpen vor, nach oder während der Proteolyse hestimmen. Die so nachgewiesene Zmmahme der Karboxlgruppen stellt dann den Grad der Proteolyse dar und kann durch die entsprechende Menge 1/5 normaler Barytlösung ansgedriickt werden. Nimmt man nun an, daf für jerle freigeworlene Karboxylgruppe eine Aminogruppe entwickelt wird, so kann man den Grad der I'roteolyse in Jilligramm Stickstoff ausdricken. indem man die verbrauchte Anzahl Kubikzentimeter der $3 / 5$ normalen Itzharytlösung mit $-2 \cdot 8$ velvielfacht.

$\mathrm{Zu} 20 \mathrm{~cm}^{3}$ der untersuchten Verdaumngsflissigkeit werden $10 \mathrm{~cm}^{3}$ einer frisch hereiteten Phenolphtalein-Formolmischung (50 $\mathrm{cm}^{3}$ Handelsformo]

1) C. Oppenheimer und H. Aron, Oher das Verlaalten des genuinen Serums gegen die tryptisehe Verdanung. Beitr. z. chem. Physiol. u. Pathol. Bd.4. S. 279-299 (1904).

${ }_{2}^{2}$ P. Rona und L. Wichartis, Beitrag zur Frage nach der kolloidaien Natur ron Albumosenlösungen. Binchem. Zeitschr. Bł. 3. S. 109-115(1907). - Diesclben, Über die Löslichkeitsrerhältnisse von Alhumosen und Fermenten mit Hinblick auf ilure Beziehungen zu Lecithin und Mastix. Ebenda. Bd. 4. S. 11-20 (1907). - E. Zunz, Contribution ì l'étude des proténses. Arch. int. de I'hysiol. T. 5. p. 245-2う̌6 (1907).

3) H. Aron und I'. Klempin. Stulien üher die proteolytischen Enzyme in einigen pflanzlichen Nahurungsmitteln. Biochem. Zeitschr. Bd.9. S. 163-18t (1908). 


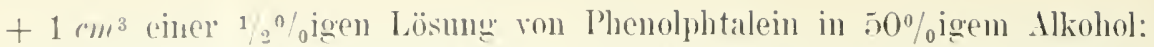
die Mischung wird mittelst baryt- oder Natronlange genan nentralisiert) oder $15 \mathrm{~cm}^{3}$ einer Thrmolphtalein-Formolnischmo $\left(25 \mathrm{~cm}^{3}\right.$ Alkohol $+50 \mathrm{~cm}^{3}$ Handelsformol $+5 \mathrm{~cm}^{3}$ ainer $1 / 2 \%$ igen alkoholischen Thymolphtaleinlösmu: die Dischme wird genan nentralisiert) gefügt. Dann rersetzt man die Fliissigkeit mit $2 / 5$ normaler Atzbarytlïsmg unter Umschütteln bis zur Rotfärlung bei l'henolphtaleinanwendung, his zur deutlichen hauen Farbe bei Fehranch von Thymolphtalein, fïgt nachträglich noch einen bekamten Uber-

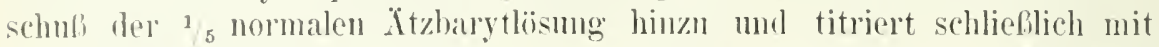
$1 / 5$ normaler Salzsïure zurtïk. Die 'Titrierungen erfolgen bis zum Erhalten derselben Farbe wie in einer Kontrollfliissigkeit, welche $20 \mathrm{~cm}^{3}$ destillierten Wascors statt der untersuchten Verdaungsfliissigkeit enthält. Die bei der T'itrierung der Kontrollösmng etwa verbranchte Menge der 1/5 normalen Atzlarytlösmıg wird von der zun Nentralisieren der Verlaumugstliissigkeit nötigen abgezogen. Die den Verdaum wsflisssigkeiten in rolaus zugesetzten Salzsïme- oder Dlkalimengen miissen selbstverständlich hei der Berechmmg ler Analyse in Betracht gezogen werden.

Falls keine Karbonite orler I'hosphate in dem Verdanumgsgemische rorhanden sind, so kann man es ebensogut mittelst 1/10 normaler Yatronlange als mittelst Xtzharyt titrieren. Die Natronlange ist der Barytlosung bei der Titrierung von phenylalaninreichen Mischmugen rorzuzichen. Bei der 'Titrierung gewisser P'roteine und ihrer ersten spaltmigsprodukte soll man die 1/10 nomale Natronlange statt der 1/5 normalen Atzbarytlösung verwenden, un die Ansfïllung schwer löslicher Barytrerbindungen, besonders beim Gebrauche von 'Thymolphtalein, zu umgehen.

Ins Prolin $=\%$-I'yrrolidinkarhonsïure lraucht bei der P'henolphtaleintitriermug $110180 \%$ mol hei der 'Thymolphtaleintitrierung nm $82 \%$ der berechneten Barytmenge. Dor dadureh bewirkte Fehler ist ohne Berleutung, w'mu das Prolin, wie in den meisten Fällen, nur einen kleinen liruchteil der gesanten Aminosïuremenge ansmacht; ist es hingegen in reichlicherer Inenge vorhanden, so kann man die Formoltitriermo nicht anwenden.

Bei der 'Titriermo' mit Natronlange und P'henolphtalein verbrancht Tyrosin 105\%\% der berohmeten Natronlange, bei der Thymolphtaleintitriernng 1:37:5\%. Boi Anwesenheit gröferer Tyrosinmengen ist demuach dic Nethode mbrauchbar. Beim Vorhandensein kleiner Mengen darf man die Titriermug mur mit Natronlange mo l'henolphtalein vornehmen. Anch hei der Formoltitriermo der bei einer gewöhnlichen Proteinspaltmuge entstandenen Mischung vol Iminosiumen kaun las anwesende Tyrosin einen Fohler verumachen. Dersollon ist alber gewöhnlich nur klein und geht iiberdies nach Sörensen in entgegengesototer liichtung von der der iibrigen

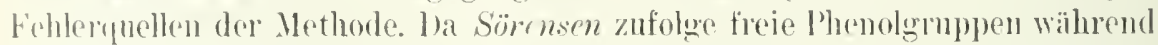
ter l'roteolyse wilnrscheinlich nieht gehildet werlen, ist dieser Fehler vorans-

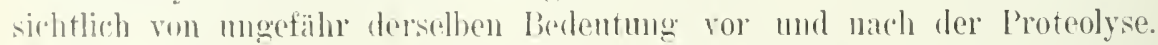
Wie dem anch sci. der l'mschlag ist bei Trostonawescuheit weniger scharf als solnst. 
Die Guanidinsalze verhalten sich anch nach Formolzusat\% als vollständig nentrale Verbindungen. Nenn in dem Protejumolekiil das Arrinin mit den ïbrigen Iolekïlteilchen nur durch srins. Imino- oder Karboxylgruppe verkniipft ist, wïlnend die Guanilingruppe auch im Protreinmolekiil frej ist. wird die Passivität der Guanidingruppe dem Formol gegeniiber keinen Fehler verursachen. Findet sich aber im I'roteinmolrkiil (ine Guanidingruppe mit einer Karboxylgruppe anhydridartig verbunden, so wird die spaltung riner solchen Bindung sich rer Messung bei der Formoltitrinerung entrieh(')

Die natiirlichen Proteinlösmeng haben oft eine mehr oder minder stark gelbe oder brïunlichgelbe Farbe. Daher ist es zweckmäBigr, wenn auch meistens nicht notwendig. die Kontrollösung durch Zusat\% einimer Tropfen von schwachen Lösungen passender Farhstoffe ähnlich zu fürben. Zu diesem Zwecke dignen sich je nach der Farhe des Verdaunngsgemisches Lösungen von $0 \cdot 2$ g Tropäolin 0 . Tropäolin 00 oder Bismarchbraun in $1 l$ Wasser. sowie Lösungen ron $0 \cdot 02$ g Methylyolett in 1 l Wasser. In einigermafen stark gefürbten Flüssigkeiten ist die Phenolphtaleintitrierung der 'Thymolphtaleintitrierung rorzuziehen.

Das Sörensensche Verfahren ist besonder's dann anwendbar. wenn dit ersten Spaltungsprodukte der Proteine in weitere durch die Wirksamkeit der proteolytischen Fermente iiheroführt werden.

Bei tief dunkelbraun gefärbtem Verdaungsgemische hommt es. w']n auch nur selten. vor, dal selbst nach der Verdinnung mittelst destillierten Wassers die Formoltitrierung nicht genïgend scharf und genau ausgeführt werden kann. In diesen Fällen mul man durch Fällung in salzsanrer Lösung mit einigermaßen reichlichen Mengen silbernitrat die untersuchte Flissigkeit entfärben, ehe man die Formoltitrierung ausfïhrt. $20 \mathrm{~cm}^{3}$ der Verdauungslösung werden, in einen Kolben von $50 \mathrm{~cm}^{3}$ Inhalt gegossen und durch Zusatz ron Salzsäure oder Natronlauge und destilliertem Wasser auf 2.5 $\mathrm{cm}^{3}$ Gesamtrolumen und auf die Acidität einer 1/10 normalen säurelösung ungeführ gebracht. Danach werden zirka $4 \mathrm{~cm}^{3}$ einer ungefähr 2-normalen Baryumchloridlösung ( $2+4$ g reines $\mathrm{BaCl}^{2}+\mathrm{H}^{2} \mathrm{O}$ pro Liter Lösung) zugesetzt und darauf unter oft wiederholtem Schiitteh tropfenweise zirka $20 \mathrm{~cm}^{3}$ einer ungefähr ${ }^{1 / 3}$ normalen Silbernitratlösung (56.7 $g$ reines $\mathrm{Ag} \mathrm{NO}^{3}$ pro Liter Lösung). Tachdem der gehildete Schaum sich bei kurzem Stehen gresetzt hat, wird kohlensäurefreies Wasser bis zur Marke zugesetzt und ïberdies + Tropfen Wasser. deren Volumen ungefähr dem Tolumen des von $20 \mathrm{~cm}^{3} \mathrm{der}^{1 / 3}$ normalen Silbernitratlösung her'iihrenden Silberchlorids entspricht. Nach gutem Schütteln wird durch ein gewöhnliches Filter (ron $11 \mathrm{~cm}$ Durchmesser) filtriert. indem man darauf achtet, möglichst viel ron dem Niederschlag auf das Filter zu bringen. Das im Anfang tribe Filtrat wird vorsichtig auf das Filter zuriickgegossen. Mlit einer passenden Menge $\left(15--30 \mathrm{~cm}^{3}\right)$ des schließlich erhaltenen. völlig klaren Filtrates wird dann eine Formoltitrierung mit Phenolphtalein als Indikator in der oben heschriebenen Weise ausgefiihrt, indem die eventuell im roraus zugesetzten 
Säme- bzw. Basenmengen mit in liechnung gezogen werden. Bai dieser Versuchsanorhung entsteht dadurch ein Fehler, dab his $20 \%$ des ciesantstickstoffes mit dem sibherchlorid gefällt werden. Will man diese stickstoffmenge bestimmen, so werden Filter und Niedersehlag dreimal mit zirka ${ }^{1} 5$ normaler Iaryumchloridlïsmog gewaschen, indem man das Filter jedesmal völlig leer laufen läßt nnd darauf volständig mit der Waschflüssigkeit füllt. Inabej mub man besonders daranf achton, den obersten Rand des Filters sorgfultig zu waschen, selhst wem die Waschwisser ein wenig getribt werden, denn der dadureh entstandene Fehler ist weit kleiner als der durch ein morolständiges Waschen verursachte. Schließlich wird die stickstoffmenge im Filter und Niederschlag zusammen mach Kjeldahl bestimmt. ${ }^{1}$ )

liestimnung ler in einem Verdaumgsuemische vorhandeuen l'roteosenmenge. Lm die in einem Genische ron Verdaumgspuodukten ler Proteine vorhandene Proteosenmenge zu bestimmen, fügen $K$. Baumann und A. B̈̈mer zu je $100 \mathrm{~cm}^{3}$ der vorher neutralisierten mol rom Nentralisationsniederschlag duch Filtrieren hefreiten Fliissigkeit $2 \mathrm{~cm}^{3}$ einer durch Vermischen von 1 Tolmmen konzentrierter Schwefelsïure mit + Volumina destillierten Wassers erhaltenen verdïnnten schwefelsäure. I)je so angesäuerte lösung wirl dam in der Kalte nit feingepulvertem Zinksulfat gesättigt, so dali sich nach 24 stïndigem Stehen Zinksulfatkristalle wieder ausscheiden. Der Niederschlag wird dam anf ein Filtel gebracht mol mit einer schwach angesänerten kaltgesättigten Zinksulfatlismng gewaschen. Bei diesem Verfahren kanu man den Albmmosenstickstoff mmittelbar nach Kjelduhl hestimmen. ${ }^{2}$ )

Lntersuchung der Stichstoffrerteilung zwischen den verschiedenen Gruplen von Proteosen und anderen Spaltprodukten der l'roteine. Com den quantitativen Verlanf der peptischen Eiweilsspaltung bei Verdauungsversuchen in vitro und in vivo zu verfolgen, kann man sich der Untersuchung der Stickstoffrerteilung zwischen den verschiedenen so entstandenen Produktenfraktionen nach folgendem Verfahren bedienen. ${ }^{3}$ )

Die Gesamtrerdaumosflissigkeit bzw. davon in bestimmten Zeitpunkten entnommenc Proben oder der Magen- oder Darminhalt werden zuerst durch Filtrieren von den etwaigen noch vorhandenen mogeosten

1) S. I. L.sörensen, Études enzymatiques. I. Compt. renıl. des trav. du lah. de Carlsberg. 'T. 7. fasc. 1. - Ierselle, Enzymstudien, Biochem. Zeitsehr. Bil. 7. S. 45-101 (1907). - S. I'. L. sürensen und II. Jessen-Hansen, Uber die Ausführung der Formoltitrierung in stark farligen Flüssigkeiten. Biochem. Zeitsehr. Bı. 7. S. 407-420 (1908).

$\left.{ }^{2}\right)$ K. Batmann und A. Bömer, Ober die Fällung der Albumosen dureh Zinksulfat. Keitschr. f. Untersuch. d. Xahrungs- 12. Genußmittel. Bi. 1. S. 106-126 (1898).

$\left.{ }^{3}\right)$ E. Zunz, Uber Ien quantitativen Verlauf der peptischen Eiweißspaltung. Zeitsehr. f. physiol. Chem. Bd. 28. S. 132-173 (1899). - Derselbe, Contribution à l'étude de la ligestion peptique et gastrique des substances alluminoiles. Amm. He la Soc. roy. de Scienc. méd. et nat. de Bruxelles. T. 11. fase. 1. p. 1-188 (1902). - Derselbe, Uber die Verdaunng und Resorption der Eiweißköpes im Magen und im Anfangsteil des Dünndarmes. Beitr. z. chem. Pḩ̣siol. u. Pathol. Bd. 3. S. 339-364 (1902). 
mud greronmenen l'roteinen befreit. Falls solche anwesend sind, so werden sie mit einer ziemlich erheblichen Menge konzentrierter schwefolsiure vorsetzt und bis zur völligen lïsung stehen gelassen. I)mrh rorsichtiges Erwärmen auf dem Wasserbade kanm man das Auflösen etwas beförleru. Ier Stickstoffgehalt dieser schwefelsamen lösung der l'rotoino wirt nach Kjelduhl festgestellt. Man bostimmt ehenfalls nach Kjeldahl den sitichstoffgehalt eines grenau bekannten 'Teiles des Filtrates $\left(10 \mathrm{~cm}^{3}\right.$ \%. 1).), dessen M(enge man genau abmißt. ${ }^{1}$ )

Damn erhitzt man das eventucll mittelst verdiunter ksigsäure leicht angesäucrte Filtrat " zum Sieden, um die noch gelösten P'roteine zur Gerinnung zu hringen, filtriert, wäscht mit etwas heilsem Wasser das auf dem Filter gebliebene geromnene Eiweif, setzt die Waschwässer zum rom gerinmbaren Stickstoff befreiten Filtrate b und mibt das Volumen dieser Gesamtflïssigkeit $b$. Num bestimmt man den Stickstoffgehalt einer $10 \mathrm{~cm}^{3}$ les Filtrates a entsprechenden Menge des Filtrates b nach Kjeldahl; der zwischen den so erhaltenen Stickstoffmengen bestehende Untersinied ergibt den als gelöstes aher noch gerinmbares Eiweil, rorhandenen stickstoff.

Danach nentralisiert man das Filtrat $b$ sorgfïltig durch tropfenweise Zufïgung einer verdïnnten Natronlauge oder Natriumkarbonatlösung und filtriert vom aus Acidalbumin bestehenden entstandenen Neutralisationsniederschlag ab, wodurch man das Filtrat $c$ erhillt, dessen stickstoffgehalt nach Kjelduhl bestimmt wird. Der Unterschied zwischen dem Stickstoffgehalte der Filtrate $b$ und $c$ ergibt den in Nentralisationsniederschlag enthaltenen Stickstoff. Manchmal verbleiben indes noch geringe Acidalbuminmengen in Filtrate $c$, welche schon durch eine geringe Menge gesättigter Zinksulfatlösung gefällt werden und also die in der ersten Proteosenfraktion grefundene Stickstoffmenge etwas zu hoch ausfallen lassen.

Da die Fällungsgrenzen der einzelnen Proteosenfraktionen an Verdauungslösungèn bestimmt wurden, welche etwa $2 \%$ gclöste und verdaute I'roteine enthielten, so muß das Filtrat $c$, ehe es der Fraktionierung unterworfen wird, je nach liedarf durch Einengen oder Verdïnnen auf diese Konzentration gebracht werden. Hierauf säuert man das Filtrat $c$ durch Zusatz von 2 $\mathrm{cm}^{3}$ verdiunnter Schwefelsäure (1 Volumen konzentrierter Säure auf + Volumina Wasser) auf je $100 \mathrm{~cm}^{3}$ Flissigkeit an und stellt das Gesamtvolumen der Flüssigkeit fest, um zu ersehen, in welchem Verhältnisse dasselbe zu $10 \mathrm{~cm}^{3}$ des ursprünglichen Filtrates a steht. Nun fiigt man zum Filtrate $c$ das gleiche Tolumen einer kaltgesättigten, durch Zusatz von $2 \mathrm{~cm}^{3}$ verdiinuter schwefelsäure auf je $100 \mathrm{~cm}^{3}$ angesäuerter Zinksulfatlösung, wodurch die I'rotoalhumose (oder die I'rotoalbumosen) und

1) L. Tobler, Über die Eiweißverdaunng im Magen. Zeitschr. f. physiol. Chem. Bd. 45. S. 185-215 (1905). - E. Zunz, Contribution à l"étude de la digestion gastrique de la viande crue et de la viande cisite chez le chien. Ném. cour. et autres mém. publ. par l'Acad. roy. de méd. de Belgique. T. 19. fasc. 3. p. 1-36 (1906). - Nourelles recherches sur la digestion de la viande crue et de la riande cuite chez le chien. Ibid. T. 29. fase. 7 . p. $1-30$ (1907). 
die Heteroalhumose in Gestalt feine Flocken wefällt werden. welehe sich zirmlich schnell anf dem Boden des die Flissigheit enthaltenden Gefälies absetzen. [ In absolut klare Filtrate zu erziclen, ist es gut, die Fliissigkeit einige 'Tage an cinem kihhlen Grte stehen zu lassen. Fiir die folgenden l'roteosunfuktionen ist diese Vorsichtsmaliregel norh mehr erforderlich, da

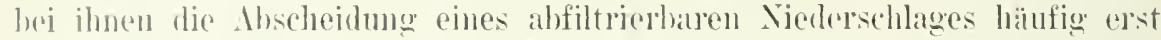
mach lïngrom stehen erfolent. Das Filtrieren darf ejst damn begimnen, wenn der Viederschlan sich vollständig odep wenigstens zum gröblen 'Teil an Boden des Gefïles allgesetzt hat. Tun dem lerlust von Fliissiglieit durelo Verblunstung rolzubengen. empfiehlt as sich, die Filtration an ainem kiilılen orte vorzunelnmen. Der 'lichter mit dem doppelten oder dreifachen Filter steht unnittelbar in dem die filtrierende Flissioncoit anfnelumenden liolben und wird sologualtig mit einer Glasplatte bedeckt gehalten. Wirol 'Talk anf das Filted' gebrateht. so erhiilt man schon mach 1-

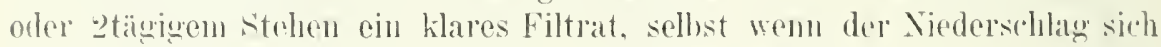
noel keineswegs völlyg an boden des Gefüfies abgesetzt hat. Iom klaren

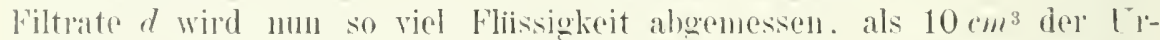
spunuslösung entsplicht. und damn den Stickstoff nach Kjoldohl hestimmt. ber lutersehed zwischen dem Gesantstickstoff des Filtrates $c$ und den Stickstofferohalt des Filtrates $d$ rergiht den in der l'potoalhumose coder l'rotoalbumosen) und der Heteroalbunose enthaltenen Stickstoff. Hei Lnteysuchume des Mareninhaltes kömmen Spuren von schleim rorlanden sein, deren man sich nicht dureh Gerimnumg entledigen kann. Disser schleim wird mit der ersten Proteosenfraktion niedergerissen. Hed dadurh bewirkte fehler ist indes, da es sich stets nur mu versehwindend geringe Mengen handelt. nu' mbedentend. Bej den Versuchen mit Hafereiweib fügt man

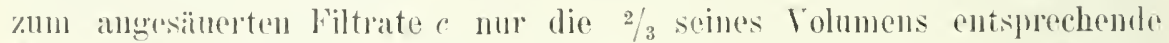
Ilenge an gesiltigter samrer Zinksulfatlösung, 110 durch in $100 \mathrm{~cm}^{3}$ des (remiselies $40 \mathrm{~cm}^{3}$ der Zinksulfatlösung enthalten sind. ${ }^{1}$ )

\%um Filtrat d setzt man die zur Fillumo der zweiten l'roteosenfraktion (b)uteroalbumose A) nötige Zinksulfatmenge. Dafiir mul man zun Filtrat d

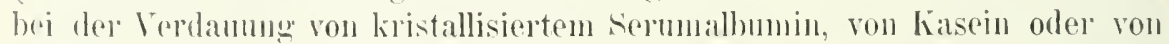
Fleisch die Hälfte seines Volumens an gesittigter saurer Ziuksulfatlösumg

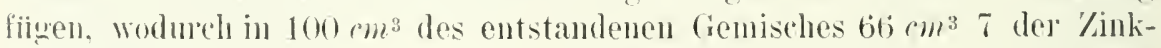
sulfatlösung enthalten sind. Fiir das Hafereiweil werlen zunn Filtrated die t seines Volumens entsprechende Menge an gesiltigter samrer Kinksulfatlösung gefiigt, wodmoln in $100 \mathrm{~cm}^{3}$ des remisches $60 \mathrm{~cm}^{3}$ T der Zinksulfatlösung enthalten sind. Wie Banzhaf und Gibson es deutlich nachegewiesen haben, dalf nan in diesen Fällen nicht vou ${ }^{2}{ }_{3}$-Kinksulfatsättigung sprechen. ${ }^{2}$ ) Fiil das kristallisierte Eieralloumin werden zum Filtrate d die ${ }_{2}$ s seines Volumens ("utsprechende Menge an gesättigter samer Zinksulfat-

1) Ernst Rosenfeld, Cber die Eiweißverdaunng in Magen des l'ferdes. Inaug.Dissert. Leipzig 1908, $54 \mathrm{~S}$.

2) Bdwin.J. Bunzhaf and Robert Banks Gibson, The fractional precipitation of autitoxic serum. The Jouru. of hiolog, Chem. V'ol. 3. p. 253-263 (1907). 
lösung gefïgt. Wodureh in $100 \mathrm{~cm}^{3}$ des (iemisclues $70 \mathrm{~cm}^{3}$ ler Zinksulfatlösıng enthalten sind. Für das P'sendoglohulin, das Euchlobnlin und das Serunglobulin werden zum Filtrat d die $23 / 2 \pi$ ihres Volmmens entsprechonden Mengen an gesïtigter samer '/inksulfatlisumg gefiigt, wodurch in $100 \mathrm{~cm}^{3}$ des Gemisches $7: \mathrm{cm}^{3}$ dor Zinksulfatlïsung enthalten sind. Vitch geniigendem Stehen und nach vorsichtigem wie oben vorgenommenem Filtrieren bestimmt man nach Kjeldahl den Stickstoffoehalt eines $10 \mathrm{~cm}^{3}$ der Trsprungslösung entsprechenden Teiles des neuen Filtrates e. Der Unterschied zwischen dem stickstoffrehalte des Filtrates d und dem des Filtrates $e$ ergibt den Stickstofforehalt der Inenteroalbumose 1 .

Dem Filtrate e wird nun die zur Ausscheidung der dritten ['roteosenfraktion (I)euteroalbumose B) genügende Menge gesiittigter angesiuertor Zinksulfatlösung zugesetzt. Diese Menge entspricht für das kristallisicrte Serumalbunin. las liasein. das Fleisch unl das Hafereiweil den ${ }^{\prime} 3$, für das kristallisierte Eieralbumin den ${ }^{13}{ }^{17}$, fiil das seroglobulin. das Englobulin und das I'seudoglobulin den ${ }^{2} / 5$ des Volumens des Filtrates e, wodurch von $100 \mathrm{~cm}^{3}$ des entstandenen Gemisches resp. s6.7. 8:3 und s.) $\mathrm{em}^{3}$ ans Zinksulfatlösung bestehen. Suhtrahiert man len Stickstoffgelalt eines Tolumens des nach den ohen angeführten Regeln erhaltenen neuen Filtrates $f$, welches $10 \mathrm{~cm}^{3}$ dor ursprünglichan Lösung gleichkommt, ron dem entsprechenden Tolumen des Filtrates $e$, so erhält man den stickstoffgrehalt der Deuteroalbumose $\mathrm{B}$.

Zur Fällung der vierten Proteosenfraktion (Deuteroalbumose (') wird das Filtrat $f^{\prime}$ mit reinstem, kristallisiertem. feingepulvertem Zinksulfat gesättigt. Damit sich das salz vollständig aufliost, wird die gesiittigte Flïssigkeit während 2-3 Stunden einer Temperatur von ca. $40^{\circ}$ ausgesetzt und \lann an einem kalten ()rte stelıen gelassen. Nach vollständiger sättigung der Fliissigkeit scheidet sich der Uberschuß an Zinksulfat sehr schnell in Gestalt schöner Kristalle ab. Das Volumen der Lösung mub ror dem Eintragen des Zinksulfates wie auch nach erreichter Sättigung genau festrestellt werden. Beide Bestimmungen sind nötig, um bei den Analysenberechnungen die geringe, durch Zusatz des Zinksulfates bewirkte Volumensteigerung des Filtrates $f$ beriicksichtigen zu können. Der Unterschied zwischen dem Stickstoffgehalt des nemen, mit Zinksulfat gesättigten Filtrates $g$ und demjenigen des Filtrates $f$ ergibt den stickstoffgehalt der vierten Proteosenfraktion (Deuteroalbumose (').

Die zunehmende Verdimmung der auf cinander folgenden Filtrate sowie die fortschreitende. durch Ausfillen der Protensen bedingte Abnahme an Stickstoffgehalt macht bei den Stickstoffbestimmungen fïr die späteren Filtrate die Terwendung einer entsprechend zunehmenden (bis zu $100 \mathrm{~cm}^{3}$ ansteigenden) Fluissigkeitsmenge erforderlich. Es ist daher nötig, die Proben der Filtrate e, $f . g$ und $h$ zunächst in Wasserbad auf ein geringes Volumen einzudampfen und dann erst nach dem Erkalten mit der KjelduhlSchwefelsäure zu versetzen. Die Gegenwart größerer Zinksulfatmengen hat den Nachteil, die Oxydation etwas zu rerlangsamen. 
Ein kleiner Felnler wird anschemend darlureh ringefiidnt, dab das allordings soln weringe Volumen dor vershiedonen Niedersehläge gleidh Null angesetzt wird. Nun ist aher das Volumen der Niederschläger, wemn man das imbibierte Wasser in Abzug bringt, dem Gesantrolum(n der Fliissigkeit gearenibur stets ein so geringes, dab der ans seiner Vernachlïssionng bervorgehende Felnler in der Regel nur einige Tausendstel oder höhstens anigre Hundertstel I'rozente erreicht nud jedenfalls kluner ist als der Fahlel: der sich ans den sohwiorigkeiten, die Niederschlïgr völlig anszuwaschere. orgibt.

Als ane erustlicher ius Ange zu fassende Fehlorquelle mub hingegen das oftmalige Almessen kleiner Fliissigkeitsmengen angeschen werlen, da die Abmossmgsfehler bei der Berechung der stickstoffwerte eine erheblicho Vorvelfältigung erfahren. Selbstrerständlich ist der so entstandene Fehler bedentender fiir die letzten Filtrate als fiir die ersten. Wenn man von ainer genijgenden Flissigkeitsmenge ausgeht, kam man den dadureh bewirkten Intum gröbtenteils vermeiden, inden man das friltrat $c$ in 4 Portionen teilt, rovon jede der drej ersten $1 / 5$, die letzte $2 / 5$ des Filtrates $c$ entsprechen. In der ersten Portion fällt man nur die erste I'roteosenfraktion, in der zweiten die erste nud die zweito Fraktion, in der dritten die drei ersten Proteosenfraktionen, in del vierten die Gesamtproteosen. Letztere dient anferdem zur natherigen Fälung der I'eptone und der anderen durch l'hospholwolframsäme oder I'ikrinsäure fïllbaren Verdaumgsprodukte.

Falls man dron Stickstoffuchalt der rerschiedenen l'roteosenniedersclubize selbst statt den stickstoffgehalt der anf einander folgenden Filtrate nach Kjeldahl feststellt, so mub man, mm die sonst durch das Auswasehen der Niederschlïge repursachte erhebliche Steigerung des Volumens der Filtrate und die durch die so eingetretenen Volumenänderungen mötig gemachten Volumenhestimmungen und T'mochnmgen zu verneiden, die von dem gremenen l'rotein und rom Neutralisationsuiederschlaug abfiltrierte Flissigkeit in gleiche P'ortionen einteilen und den Stickstoffgehalt, der ans der ersten P'roteosenfraktion allein, ans den ersten mul zweiten l'roteosenfraktionen zusammen, aus den $\ddot{3}$ ersten l'poteosenfraktionen und ans den (issamtproteosen bestehenden, "lurh Hsangen von jeder Hiissigkeitsspur befleiten Niederschläge nacheinander nach Kjeldahl bestimmen. Auf diese Wrase ermittelt man die (puantitit jeder einzelnen Proteosenfraktion durch dbzielien des Stickstoffochaltes des vorhergehenden Niederschlages rom stickstoffgehalte des betreffenden Xirelerschlages. AnBerilem muli man noch den Aschegrehalt jeder der verschiedenen, völlig trockenen Viederschligge bestimmen mol ihn rom cievichte der hetreffonden Trockensubstallz ahzielen. ')

1) E. s. London und .1. Th. sulime, Kum (hemismus der Vordanung im tierischen Körper. II. Nitteilung. Eiweißerdaumg im Magendarmkanal. Zeitschr. f. physiol. (hem. Bal. 46. S. 209-235 (1905). 
Das proteosenfreie Filtrat $y$ kann zur Bestimmung der anderen Verdammgsprodukte direkt gebraucht werden. Leider lälit sich bis jetzt das nur die Peptone niederschlagende ausgezeichnete Terfahren von Siegfried dazu nicht verwenden und mul man die P'eptone entweder durch l'hosphorwolframsäure oder durch Pikrinsänre fälleıı.

Durch Phosphorwolframsäure werden aulier den Peptonen noch dis Hofmeisterschen l'eptoide sowie gewisse Endprodukte, wie Histidin, Arginin und Lysin abgeschieden. Zur Bestimmung des durch Phosphorwolframsäure füllbaren Stickstoffes setzt man zum proteosenfreien Filtrat y die Hälfte seines Volumens an verdünnter schwefelsäure (1 Volumen konzentrierte Scliwefelsäure, 4 Volumina Wasser) und dann tropfenweise unter stetigem Schiitteln so lange eine 10\% ige wässerige Lösung kristallisierter Merckscher l'hosphorwolframsäure, bis die entstandene Trübung nicht mehr zunimmt. Man muß jeden ['berschul an Phosphorwolframsïurelösung tunlichst vermeiden, denn manche durch diese Säure gefällte stickstoffhaltige Stoffe, wie z. B. die Diaminosäuren, lösen sich teilweise wieder in einem Reagenzüberschusse auf. Wie Pfaundler es gezeigt hat, geben mit Phosphorwolframsäure verschiedenen Handelsursprunges bereitete Lösungen nicht dieselben Ergelnnisse. Man läßt die erhaltene trübe Fluissigkeit erst $t$ bis 6 Stunden bei einer Temperatur ron $40^{\circ} \mathrm{C}$ und hierauf 1 - Tage bei niederer Temperatur stehen, worauf mit iblicher Vorsicht filtriert werden kaun. Das klare Filtrat $h$ ist blafsiolett gefürbt und darf sich anf Zusatz eines Tropfens der Phosphorwolframsäurelösung nicht meln triiben. Das Volumen des Filtrates $y$ vor der Zugabe der verdïnnten schwefelsäure und der Phosphorwolframsänre sowie das Volumen des Filtrates $h$ miissen selbstverständlich festgestellt werden. Der nach $K$ jeldahl bestimmte stickstoffgehalt des Filtrates $h$ ergibt den in den durch Phosphorwolfransiure nicht fällbaren Verdauungsprodukten enthaltenen Stickstoff. Durch Abziehen dieser Stickstoffzahl rom Stickstoffgehalte des Filtrates $y$ ermittelt man den in den Peptonen und den anderen durch Phosphorwolframsäure fällbaren Verdauungsprodukten enthaltenen Stickstoff. Die Oxydation der zu analysierenden Fliissigkeiten wird durch die Anwesenheit ron Phosphorwolframsäure ziemlich erschwert. Um den Stickstoff nach dem Kjeldahlschen Verfahren bei Phosphorwolframsäureanwesenheit zu bestimmen, empfiehlt es sich, von der Kosselschen Methode Gebrauch zu machen. $250 \mathrm{~cm}^{3}$ des Filtrates $h$ werden in einen Erlenmeverkolhen ron $1 l$ Inhalt aus Geräteglas (Schott und Gen., Jena) gebracht, welcher gleichzeitig zur Oxydation und zum darauf folgenden Destillieren des gebildeten Ammoniaks dient. Zu dieser Flüssigkeit setzt man $50 \mathrm{~cm}^{3}$ konzentrierter Schwefelsäure. Ian rerdampft vorsichtig auf freier Flamme bis zum anfänglichen sieden. Nun läßt man die Flïssigkeit fast völlig erkalten und setzt ein aus $10 \mathrm{~g}$ Kaliumsulfat und $1 \mathrm{~g}$ Kupfersulfat bestehendes feines Pulver sowie $50 \mathrm{~cm}^{3} \mathrm{Kjeldahl-Schwefel-}$ säure hinzu. Hierauf erwärmt man die Fliissigkeit sehr vorsichtig so lange, bis sie klar geworden ist und bis der auf dem Boden des Kolbens bestehende Niederschlag deutlich gelb geworden ist, was anzeigt, daß die 
oxydation völig beendet ist. Xach Erkalten des Kolbeninhaltes rerdinnt man ihn mit destilliertem Wasser und reduriert vorsichtig die Wolfam-

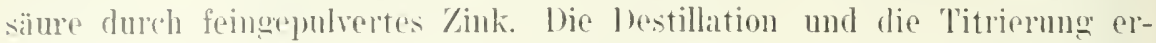
folgen wie eswrihnlich. Boi aller Vorsicht darf man indes den Resultaten der stichistoffbestimmmo nach Kjaldahl bei Gegenwart grober Phosphor-

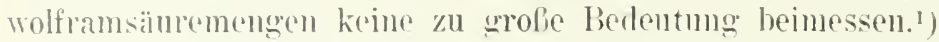

statt die l'eptome in allumosenfreien liltrat $g$ mit Phosplorwolframsïure zu fällen. kam man sic mittelst l'ikrinsäme niederschlagen. Dazn wird auf 10 'Teile Filtrat 1 'Teil verdiumter schwefelsäure (1 Volmmen kom\%entriortel Schwefelsäure, 4 Volmmina destillierten Wassers) hinzugefuiut mul l’ikrinsiume im Cherschusse. Dieses Cemenge wirl zur Lösmug der Pikrinsäme eine kume \%eit bej to (' gehalten und nach dem Abkïhlen filtriert. Inan erzielt sofort ein klares Filtrat $h$. wenn man die mit l'ikrinsilure relsotzte Hliissigkeit anf pinen doppelten oder dieifachen. 'Talk enthaltenden Filter gielit. Das liltrat $h$ wird mit Xthor wiederholt kriftig auscosohiittelt. mu die Pikrinsïme zu entformen. Dann hestimmt man nach Kjeldahl den Sitickstoffechalt des Filtrates $h$. Wodureh man den durch l'ikrinsäme uicht fällbaren Stickstoffteil ermittelt. Inrch Alziehen dieser Stickstoffzahl rom Stickstofferehalte des Filtrates g stellt man den als l'ejtone und andere durch I'ikrinsäure in den proteosenfreien Flissigkejten vorhandenen Stickstoff fest. Ije J'ikrinsïnme fällt die l'eptone meistens völlig. manchmal jedoch nu teilweise, sowio auberlem keine Bimetreaktion gebende. Stoffe (wahrscheinlich das Lysin und viellejeht noch andere Substanzen), aber weder das Arginin noch das Itistidin. Fis wiol immer im proteosenfreien Filtrat y viol weniger Stickstoff duch T'ikpinsinure niedergeschlagen als durch l'hosphorwolframsämre.²)

Ian kam anch zur Fällung del Teptone das proteosenfreie Filtrat y

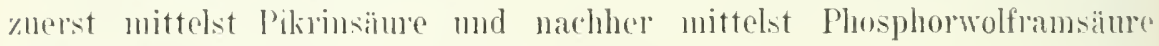
in der oben beschriehenen Weise rersetzen. ${ }^{3}$ )

1) Fr. Hofmeister, Ǔber Bau und Gruppierung der Eiw eißkörper. Ergehn. d. Hhysiot. Bd. 1. Alt. I. S. 759-802 (1902). - - r. Gumlieh, Ther die Ansseheidung des Stielistoffes im Harn. Zeitschr. f. physiol. Chem. 13d. 17. S. 10-34 (1892). - W. Hausmam, Üher die Verteilung des Stickstuffes im Eiweißmolekïl. Ehenda. Bd. ㄱ․ S. 95-108 (1899). W. (ivelemitsch, U'ber das Arginin. Ehenla. Bd. 27. S. 178-215 (1899). - G. Wetzel, Die organisehen Substanzen der Sehalen von Mytilus und l'imna. Ehenda. Bd. 29. S. 386 bis 410 (1900). - M. Pfannllor, ther ein Verfahren zur Bestimmung des Amidosïurenstickstoffs im Ilarne. Ehenda. I3d. 30. S. 74-89 (1900). - Fr. Kutseher, Ǔber die Terwendung der Phosphorwolframsäure hei quantitativen Bestimmungen der Spaltungsprodukte des Liweißes. Ebenda. Bd. 31. S. 215 -226 (1900). - A. Kossel, Uher die Bestimmung des Harnstoffes im Harn (nach Versuchen des Iferrn II. sehmied). Verhandl. d. Berl. physiol. (ies. 27. Juli 1894 in Arch. f. Anat. 11. Physiol. Physiol. Abt. S. 552 553 (1894).

K. Banmann und A. Bömer. Cher die Fällung der Albumosen dureh Ziulsulfat. Zeitsehr. f. Lnters. 1. Nahrungs- แ. Genußmittel. Bi. 1. \$. 106--126 (1898).

$\left.{ }^{2}\right)$ Felir Reach, Zur Kenntnis der Terdaunngs- und Resorptionsvorgänge im Magen. Beitr. z. ehem. P'hysiol. u. Path. BA. 4. s. 139-144 (1903). - E. Zunz, Nourelles recherehes sur la digestion de la viande dans l'estomac et dans la première portion de lintestiu grêle chez. Ie ehien. Anm. de la Soe. roy des Sc. méd. et nat. de Bruxelles. T. 12. fase. 3. p. 8(1903).

$\left.{ }^{3}\right)$ Ernst Rosenfeld, loc. cit. - Ermst Lötsch, Zur Kenntnis der Verdauung von Fleiseh in Nagen umd Dïmmlume des Schweines. Inaug.-Diss. Leipzig 1908. 54 S. 
Da der prozentige stickstoffgehalt der verschiedrnen I'roteosen und der anderen Abbauprodukte der I'roteine keineswegs der gleiche fiur allo diese Stoffe ist. so ergildt sich ans der Feststellumg der Stickstoffverteilung \%wischen den verschiedenen Verdaungsprodnkten nur eine annïhernde Schätzung (ler relativen Mengen dieser Stoffe. $\left.{ }^{3}\right)$

Haslams Verfahren zur Bestimmung des l'roteosengehaltes einer Verdanungslösung. Xach Haslum soll bei dem einfachen Mussalzen der l'roteosen eine ziemlich betrïchtliche l'roteosenmenge durch die I'eptone oder andere Körper in Lösung gehalten werden, während andrerseits im Proteosemniederschlage andere Stoffe mitgerissen werden. Un dadurch hewirkte, ihm zufolge sehr erhebliche Irrtiiner z.n rerliiten. empfiehlt Haslum zur Bestimmung des I'rotensengehaltes einer Verdauungslisimg folgendes Verfahren. Die von d'n geromnenen und einfach gelösten l'roteinen sowie vom Acidalbumin befreite, genan neutralisierte Verdaumoslïsung wird durch gepulvertes Natriumsulfat anf dem Wasserbade allmählich gesättigt. Nach fünfstindigem Stehen in Brutofen bei : $: 7^{\circ} \mathrm{C}$ wird filtriert. Der von Filter abgenommene Niederschlag wird in einer Schale mehrmals mit gesïttigter Natriumsulfatlösung bis $4 \overline{5}-\overline{5})^{0}$ (' umgeriihrt. I) erhaltenen Waschwïsser werden filtriert. Man muli diese Umrihhungsprozedur so lange fortsetzen, bis der Zusatz des gleichen Volnmens konzentrierter schwefelsäure zu einer Waschwasserprobe nur eine äuljerst schwache brimmung hervorruft, wodurch gezeigt wird, dal fast keine organischen Stoffe mehr in Lösung gehen. I)ie auf den Filtern. in der Umriihrungsschale und auf der zum Umrühren benutzten Spatel zuriickgebliebenen Proteosen werden in Wasser gelöst. durch Natriumsulfatlösung wefällt und lurch mehrmaliges L'mrühren mit gesättigter Natrinmsulfatlösung auf dieselhe Weise behandelt. Die Gesantproteosen werden dam in Wasser gelöst. mit gepulvertem Vatriumsulfat ausqesalzen und nach vierstündigem Verbleiben im Brntofen filtriert. Der Proteosenniederschlag wird wieder gelöst, ausgesalzen und filtriert. Diese Anssalzungen und Anflösungen werden so lange fortgefuihrt, bis der nach jeder Aussalzuny nach Kjelduhl bestimmte Stickstoffgehalt des Filtrates keine Änderungen mehr erfährt, wodurch bewiesen wird. dal die Trennung der Proteosen ron deu Peptonen und iibrigen Verdamungsprodukten vollendet ist. Yun stellt man nach Kjeldahl den Stickstoffurehalt der in Wasser gelösten l'roteosen fest und fügt zum erhaltenen Risultate die bei dem Reinigungsverfahren in Lösung gegangene I'roteosenstickstoffmenge, was den (iesamtgehalt der Verdauungsiösung an I'roteosen ergiht. En die in Lösmng gegangene Proteosenstickstoffmenge zn berechmen, wird ler mittlere Stickstoffgehalt der letzten nach der Aussalzung erhaltenen Filtrate mit dem Gesamtvolumen der Waschflüssigkeiten und Filtrate vervielfacht. Dieses:

1) E. Zunz, De la quantité dlalbumoses contenue daus l'estomac du chieu après ingestion de viande. Ann, de la Snc. roy des Se méd. et nat. de Bruxelles. T. 13. Fase. 1. p. $1-10$ (1904). 
leidel seln vial \%eit raubende $11 n d$ etwas verwickelte Verfahren gibt nach Hrstrum desto menanere liesultate. je morofer der Proteosengebalt der Verdanumplisung ist. Enthält diese mehr als $60 \%$ l'roteosen. so soll der Irrtum $20 \%$ nicht ibersteigen. Sind hingegen wenger als $20 \%$ l'poteosen im Terdammesgenische vorhanden. so erhïlt man wahrscheinlich keine selur armanen Erochnisse. $\left.{ }^{2}\right)$

Fiallung ler Jrotcosen mittelst Ferbsäule. Man verwendet vielfach die Gerbsämre als Fïllungsmittel der Proteosen. Nach Eiffront werlen 50 g ferbsäure in $500 \mathrm{~cm}^{3}$ destilliertem Wasser aufgelöst; zu dicser lösung fiigt man zuerst $50 \mathrm{~cm}^{3}$ einer normalen Satronlauge, dann eine geniigende Menge destillierten Wassers, um das Gesamtrolumen der Fliissigkeit anf $1 \mathrm{l}$ zu hringen, schlieblich noch $15 \mathrm{~cm}^{3}$ einer $10 \%$ igen Weinstriusäurelösmug. $/ \| n$ der ron den geronnenen und einfach gelösten Proteinen sowie rom Tentalisationsuiederschlay befreiten Flüssigkeit fïgt man eincu grofen C̈berschuß dieser Gerbsäme-Weinsteinsäurelösung. Nach 12stindign stehen filtriert man dnch einen stickstofffreien Filter, wischt 5 fimalnit der ferhsämre-Weinsteinsäurelösmy aus und bestimmt nach $K j$ jeldahl den stickstoffuehalt des Niederschlages. Die von Effront rorgeschlagene Gerbsïure- Weinsteinsïurelösung fällt nun tatsïchlich sämtliche Proteosen. während die echten Peptone zum gröbten Teile der Fällung entgeben und nur dureh l'hosphorwolframsïure niedergeschlagen werden. Sie fïllt aber, auber' den l'roteosen, auch noch Körper, die keine Biuretreaktion mehr wehen und von denen mm ein Teil durch Phosphorwolframsäure gefält wirl. Dieses Verfalnen ist also nicht zu empfehlen.

Steudel mol hutscher haben die Gerbsänre zur Beseitigung der kolloilalen liostandteile rorocschlagen. Man fält die neutratisierte ofler wewen Latckmopapier ganz schwach alkalisch reagierende Flissigkeit mit 200 iger Wässeriger Cierhsäurelösung. I'nul Mey konute mittelst dieses Verfahrens die r'roteosen bis anf spmen fïllen, njeht aber die l'eptome.

Nach Hedin soll die Inwendung eines lbersehnsses einer ans $70 \mathrm{~g}$ Gerbsiume. $50 \mathrm{~cm}^{3}$ Visessig. $100 \mathrm{~g}$ NaCl umd die zum Erhalten eines Gesamtvolmmens von 1 l nötige Menge destillierten Wassers bestehende Flissigkeit kemeswegs die Peptone und die iibrigen Verdaumbsprodukte der I'roteine fällen, also nur die Proteosen. I)urch Abziehen des nach Kjeldahl hostimmten stickstoffuchaltes des mach der (ierbsämefällung erhaltenen Filtrates vom stickstoffurehalte der von den geromenen mud einfach gelisten l'roteine sowio rom Acidalbumin befreiten Fliissigkeit ermittelt man len als lroteosen vorhandenen Stickstoff.

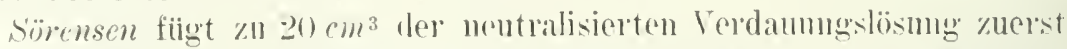
־ $\mathrm{cm}^{3}$ nommaler, dureh Esigigsumezusatz lackmus gegentiber neutralisierter

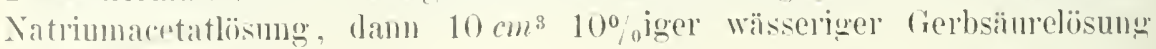

1) S. N. P'incus, On the precipitation of proteids with anhydrous sulfate of sodium. The Jomm. of Physiol. Vol.37. p. 57 65 (1901). - H. C. Hrislam, The separation of proteids. I. The Jouru. of Physiol. Vol. 32.2. p. 207-298 (1905). 


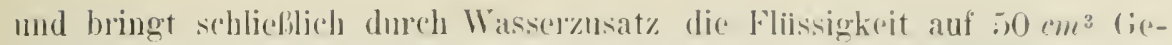
samtrolmmen. Nach tïchtigem siohteln und nachlorigem stehen his zum

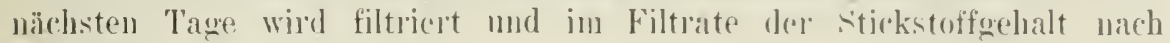
Kjolluhl festgestellt. ')

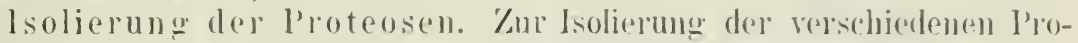
teosen aus den l'rodukten der V'rodaumg der l'poteine kann man sich des I'ickschen oder des Haslamschen Verfahrens bedienen. welche beide auf die fraktionierte Fällung mittelst Ammonsulfat mul Alkohol bermben, ods. der auf der Inwendung des Eisenammonalauns fubenden Adlerschen Methode. Sach Pick kimn man die l'roteosen in + Fruppen einteilen, wovon die erstere aus der Protoalbmose mo der Heteroalbumose, dir zweite (T'roteosenfraktion A) aus der alkoholfällbaren Thioalbumose und aus del' alkohollöslichen Albumose $\Lambda^{\text {II }}$, die dritte (Proteosenfraktion $B$ ) aus der Albumose BI, der Symalbmmose und der Albumose liII mol die vierte aus der Albumose C bestehen. Vielleicht ist sogar die \%ahl der I'roteosen noch größer. 2) Nach Haslam hingegen soll man nur 5 Proteosen muterscheiden. die Heteroalbumose, die in gleichen Teilen Alkohol und Wasser unlöslichen ж-Protoalbumose und $\boldsymbol{x}$-Deuteroalbumose, die larin löslichen ;-Protoalbumose und p-Deuteroalbumose.

Darstellung der Proteosen uach E. P. Pick. Die entsprechend den durch E. P. Pick anfgefundenen Fällungsgrenzen getrennten 4 verschiedenen Proteosenfraktionen werden jede fiir sich durch Alkoholzusatz in weitere Fraktionen zerlegt, diese durch wiederholte Fïllung mit Alkohol von bestimmtem Prozentgehalte von den benachbarten Fraktionen möฒlichst vollkommen getremt mud durch Fällumg mit essigsaurem barțt rom anhaftenden Ammonsulfat hefieit.

Hetero- und Protoalbumose. Lie Verdaumgsflissigkeit wird zuerst von den geromnenen oder gelösten Proteinen und vom Nentralisationsniederschlag befreit. Die so erhaltene neutrale Flissigkeit wird mit dem gleicheu Volumen gesättigter Ammonsulfatlösunģ gefällt. Der entstandene Niederschlag wird abfiltriert mul mit einer aus gleichen 'Teilen Wasser mol gesättigter Ammonsulfatlösung bestehenden Flïssigkeit gründlich gewaschen und nachher in heiben Wasser gelöst, m eine möglichst konzentrierte, wässerige, neutrale Lösung zu erhalten. Diese Flïssigkeit wird mit dem doppelten Volmmen $95 \%$ igen Alkohols versetzt. Worauf man sie

$\left.{ }^{2}\right)$ J.Effront, Über die Bestimmung ler Verdaunnesproilukte des Pepsins. Chemiker-Keitung. Bd. 23. Nr. 7 (1899). - H. Stendel und Fr. Kutscher, Zur Kenntnis von Liebigs Fleischextrakt. Zentralbl. f. Pbysiol. Bd. 19. S.504--508 (1902). - Paul Hey, Zur henntnis der l'epsinrerdauung. Zeitschr. f. physiol. C'hem. Bil. 48. S. 81-84 (1906). - S. G. Hedin, Investigations on the proteolytic enzymes of the spleen of the ox. Journ. of Physiol. Tol. 30. p. 155-175 (1904). - s. P. L. Sïrensen, Enzymstudien. Biochem. Zeitschr. Bu. 7. S. 45-101 (1907).

2) E. Zunz, Dic fraktionierte Abscheidung der peptischen Verdauungsprodukte mittelst Zinksulfat. Zeitschr. f. physiol. Chem. Bd, 27. S. 219-249 (1899): Action des alhumoses secondaires et des peptones sur l'or colloïlal. Bull. de la Soc. roy. des Sc. méd. et nat. de Bruxelles. T. 64. p. 174-186 (1906). 
in lev lï̈lte his zum vïlligen Absetzen der Viederschläge stehen läßt. ber durch dbegielen ron der dariber befindlichen alkoholischen Lösung hefrede Niederschlag dient zur barstellung der Heteroalhmmose. die abgenossene Fliissigkeit zur Darstellumg der Protoabmmose.

Hoteroalbumose. Her gut abgenebte Niederschlag wird in $100{ }_{0}$ iger wässeliger Lösung mit verdïnnter Schwofelsïnre nentralisiert und mit dem gleichrn Volumen gesuttigter Immonsulfatlösung gefïlt. I)ie sich in Gestalt aines fosten linchens an dor Flïssigkeitsoberflïche abscheidende Heteroalbumose wird abgeloben, sorgfïltig anf dem Touteller ron der Flïssigkeit befreit, wolist und ans ca. 10\% iger nentraler Lösung wie rorher ansgesalzen, ahweprefit, das Cianze nochmals wiederholt. Man versetzt die so wewonnene Proteose in 10\% iger wisseriger Lösung mit dem halben Volumen $955^{\circ}$ igen Ilkohols. Der gut abgepreßta Niederschlag wird in heißem Wasser gelöst. filtriert mud wienler mit dem halben Volumen $95 \%$ igen Alkohols gefällt. biese l'rozodur wirl ein drittes Mal wiederholt, woriuf der Niederschlag zulest mit $: 320 / 0$ igem, dann mit $95 \%$ igem $11 \mathrm{kohol}$ und endlich mit $\mathrm{X}$ ther gewaschen wird mud nachher getrocknet. Das 'Trockmen soll his zur Gewichtskonstanz in trockenen Luftstrome bei einer $95^{0}$ nicht iberstrigenden Temperittur erfolgen: diese Vorsichtsmabregel mul man fiir alle l'roteosen beachten.

Protoalhumose. Aus der abgegossenen alkoholischen Lösmug wird ler Alkohol im Vakmmm abdestilliert, der Riichstand getrocknet. in Wasser gelist und lie otwa $10^{\prime \prime}$ ige, mit schwefelsiure nentralisierte lösung wielerholt durch das gleiche Volumen gesätigter Ammonsulfatlïsung gefällt. abfiltriert mol in Wasser anfgelöst. Manchmal entsteht bei vorsichtion \%usatze repdinnter Essigsime eine Tribung oder die Alscheidmng rines Niederschlages. bam mul man solange Essiustiule zusutzen, bis (ine Probe der vom entstandenen Niederschlige abfiltrierten Iösung anf rolsichtigen sinnezusaty krine Triibmg mehr giht. Tm die Ammonsulfatresto zu entfernan. wird die Fliissigheit mit einer gesättigten lösmor essigsamen Barrums muter Trumeiden cines lbersehusses versetzt. Man filtriert und setzt zum Filtrate wisserige Ammonimmkarbonatlismog. Welche den in Lösmo gebliebenen liart fällt. Falls die Filtration de mit essigsaurem Barvt rorsetzten Flüssioked selbst nach längerem Stehen kein völlig klares Filtrat elgibt, so kilm man jedoch die Ammonimmkabonatlösmog den liltate zusetzen, wodurch dioses stets leicht klal abfiltrierbar wird. Das Filtrat wind rorsichtig anferekocht, rom sich eventmell nachträglich noch ansscheidenden barrumkarhonat abfiltriert und darauf anf dem IV asserbade his zur siruprlicke eingerlampft. Iter erhaltene liiickstand wird in fio\% igem

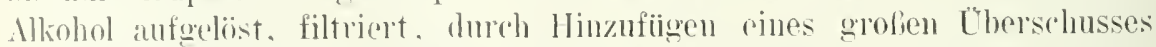

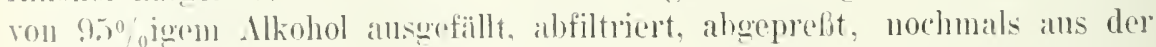

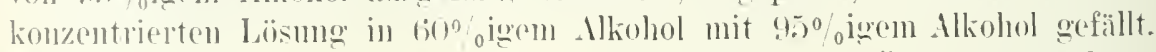
schlieblich wird der anf dem Filter mit Alkohol mud Ither gewaschene

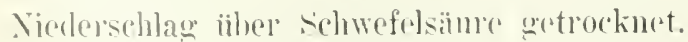

Proteosenfraktion 1. Das nach Zusat\% vom qleichon Volumen gesïtigter Inmonsulfatlösmng zu des von den gerommenen oder gelösten 
l'roteinen und vom Icidalbumin hefreiten Fliissigheit erhaltene Filtrat wird nit dem halben Volumen gesittigter Ammonsulfatliismng gefällt. Ier so entstandene Niellersehlag wird ahfiltriert und mit eince ans zwei bolumina gesïttigter Ammonsulfatlisung und einem Volumen destillierten Wassers bestehenden Flïssiokeit gewaschen, und dauans eine nöglichst konzentrierte wiisserige nentrale bösumg bereitet, zu welcher man dam das doppelte Volumen 95\% igen Alkohols fiigt. Del Niederschlag dient zur Darstellung del

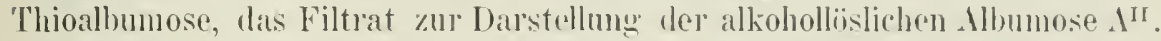

T'hioalbumose. Mit dem abfiltriertem Niederschlage wird eine ŏ- bis $10 \%$ ige wïsserige Lösumg dargestellt, welche behufs Abscheidung von der ersten Fïllung etwa entgangenen liesten der Heteroalbumose mit dem gleichen Volmmen gesättigter Ammonsulfatlisung gefült und vom entstandenen Viederschlage abfiltriert wird. Wum Filtrate setzt man nun die Hälfte seines Volumens gesïttigter Ammonsulfatlösumg, filtriert, löst den Niedejschlag in ungefähr derselben Wassermenge wie hei der Ausgangslösung und wiederholt mehrmals die anfeinander folgenden Operationen, nämlich Zusatz eines Volumens gesüttigter Ammonsulfatlïsmigr, Abfiltricren, Zusatz eines zweiten Volumens aesittigter Ammonsulfatlösmng. Filtrieren, Iuflïsen in Wasser so lange, bis die Thioalbumose von den anhaftenden Teilen del Nachbarfraktionen möglichst rollkommen gereinigt ist. Die wässerige Lösung des auf die beschriehene Weise orhaltenen, die Molischsche Reaktion nicht mehr gebenden Prïparates wird mit essigsaurem laryt versetzt. In Filtrate fällt man das iberschissige Barvum mit kohlensamem Ammon, koclut das barytfreie Filtrat anf. filtriert es eventuell vom sich noch ausscheidenden Buryumkarbonat, konzentriert es auf dem Wasserbade und fällt die Lösung mit $95 \%$ igem Alkohole im Ubel'schusse. Der flockige Niederschlag wird nut abgeprebt, nochmals aus konzentrierter wïsseriger Lösung mit ilkohol gefüllt, abfiltriert, mit Alkohol und Ither gewaschen, getrocknet.

Albumose II $^{\text {I }}$. Die nach Fïllung der Lösumg der Proteosenfraktion A mit dem doppelten Ilkohoholumen erhaltene alkoholische Lösung wird im Vakum zur Trockene eingedampft, der Rückstand in Wasser grelöst und die etwaigen Reste der Protoalbumose ans der etwa 10\% imen Lisung durch Fälung mit dem gleichen Volumen gesättigter Ammonsulfatlösung bei nentraler Reaktion entferut. Ius dem ammonsulfathaltigen Filtrat wird dic Albumose $\mathrm{A}^{\mathrm{II}}$ durch weiteres Zufiigen eines halben Volumens gesïttigter Ammonsulfatlösung ausgefällt. Nach seinem völligen Absetzen wird del Niederschlag nochmals gelöst und mit dem :3-tfachen Volumen 9.̆o oigen Alkohols gefïllt. Der Trockenriickstand des Alkoholfiltrates wird wiederum von Protoalbumoseresten und ron beimengungen, die dem alkohollöslichen Anteile der Fraktion B angehören, durch Aussalzen in dem friberen Verhältnis hefreit. Ijese Prozedur wird mehrmals wiederholt. Wenn sich aus dem nummehr erhaltenen Produkte durch Zufïgen des 2-3fachen Alkoholvolumens keine alkoholfiillbare substanz mehr entfernen lälit, so wird nach Verdumsten des Alkohols der Trockenrickstand mit essigsaurem Baryt und Immonimmkarbonat wie bei der Thioalbumose aschefrei gemacht. Die salz- 


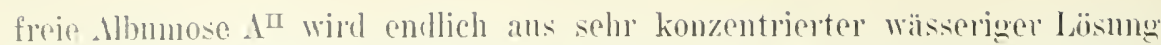
dureh rinen aroben Alkoholiiherschub gefillt, dev Viederschlaw abfiltriert.

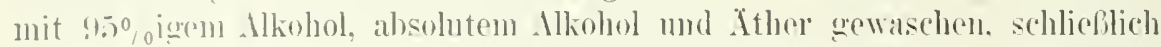
in trockencon luftstrom einige 'Tage bei einer 950 C nicht iibersteigenden T'emperatur getrockurt.

T'roteosenfraktion I3. Das nach der Fällung der l'roteosenfraktion A

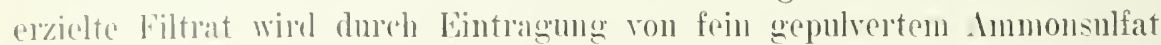

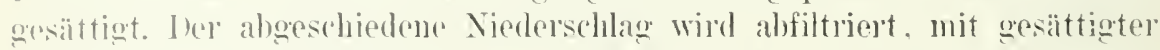
Ammonsulfatlismmg gewaschen, in Wasser anforöst. mn eine 5-10\%

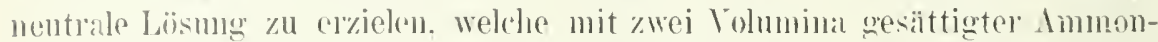
sulfatlissung grefällt, rom arlaltenen etwaigen Niederschlage abfiltuient und mit eneulvertem Immonsulfate gesättigt wird. Diese l'rozerlur wird so lange wiederholt, bis alle mitgerissenen lieste der anderen l'roteosenfraktionen entfent sind. I)ie so geremigte Faktion B wird in etwa 6 - $10 \%$ oger Wässeriger liokme mit dem doppelten Volmmen 95\% igen Alkolols gefüllt: es entsteht zmüichst eine Triibmug der alkoholischen Iösmng, die sich nach mehrstindigem stehen als leichter Niederschag absotzt (Abmmose B ${ }^{\mathrm{I}}$ ). I)as alkoholische Filtrat wird nummeh" mit einel dem vierfachen Volumen des urspriinglichen Flissighteitsmenge entsprechanden Ilkoholmenge versetzt. so daf eine efwa $75 \quad 81 \%$ ige Aliohollismoge entsteht, wodureh die Abumose $B^{\text {II }}$ oder Symalbumose fällt. Im alkoholisehen Filtate ist noch die alkohollöslive dihmmose $B^{\text {III }}$ rorhanden.

Allomose $B^{I}$. Diese l'roteose wird durch wiederholtes Anflösen in

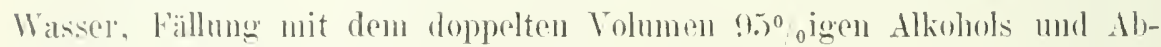
filtrieren von der symalbmmose getrenut, wobei sie salmfrei chalten wird mud nach dem Auswaschen mittelst konzentrierten Alkohols und Ather oleich wetrocknet werden kimn.

syualbumose. Diese Proteose wirl in Wassel anfugelös mud durch wiederholte Alkoholfällung, Auflösen und Abfiltrieren ron den nitgerissenen

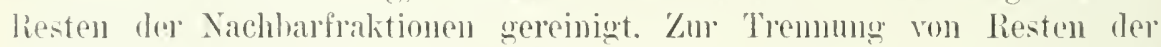
l'noteose Bir empfiehlt as sich. 6.5-70\% Jurolı Alkoholfällmog gereinigte Synallumose wird in wässeriger läsmug durch Fällung mit asigsamem baryt in der oben heschriebenen Weise von anhaftend('m Ammonsulfat befreit, aus konzentriertej Lösung mit großem

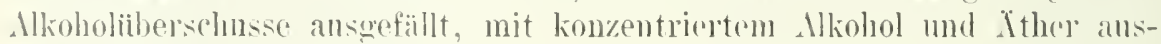
erewachen, dam getrocknet.

Albumose bin. Das nach Austälung der Fraktion B B $^{\text {II }}$ erhaltene alkoholische filtrat wird anf lem Wasserbade zur Trockene eingedampft.

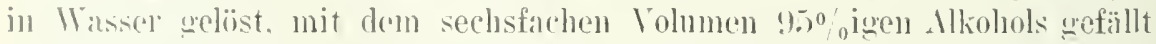
umel filtrient. loas none alkoholisehe Filtrat wirl eingedampft. wiederholt auf dirse Wrise grereingt. damn die wässerige Lösmng duch Fïllung mit essigsamrm bayt in der oben beschriebenen Weise rom anhaftenden Immonsulfat hefreit, aus komzentrierter Iösmug mit großem Alkoholiiberschusir atusgefällt. mit konzentriertem Alkohol und Ther ansgewaschen, selulieflich getrocknet. 
Proteosenfration C. Die nach Ansscheidung aller I'roteosen durch Ammonsulfatsättigung in neutraler Lösung erhaltene flissigkeit wird mit $1 / 20$ ilıres Volumens an ammonsulfatgesüttigter, 1/20-Normalschwefelsänre gefällt. Nach melntägigem Stehen hat sich dio Proteosenfraktion C so fest am Loden des Gefïlies abgesetzt, dali man die ïherstehende Lïsung bequen abgielien kann. Die Mlhumose (' wird wieder in Wasser gelöst, die Lösung mit Immoniak neutralisiert. hehufs Reinigung ron der Nachbarfraktion I' mit Ammonsulfat in der Hitze wesätigt, vom entstandenen Niederschlage abfiltriert, wie oben mit säure gefällt. Das erhaltene l'rodukt wird mehrmals einer derartigen leinigung unterzogen, bis durch Salzsättigung bei neutraler Reaktion keine P'roteosenausscheidung mehr zu erzielen ist. Die gereinigte Proteose C wird dann rom anhaftenden Salze in üblicher Weise befreit und nachher his zur Gewichtskonstanz in trockenen Luftstrome bei einer 950 C nicht iilsersteigenden Temperatur getrocknet. ${ }^{1}$ )

l)arstellung der Proteosen nach Haslam. Za der von den geronnenen und gelösten Proteinen sowie rom Acidalbumin befreiten Lösung der Verdaumgsprodukte setzt man das gleiche Alkoholvolumen. Der Niederschlacr enthält die Heteroalbumose, die \%-Protoalbumose und die \%-Deuteroalbumose: im Filtrate befinden sich die -Protoalbumose und die - - Seuteroalloumose.

Ler mit 50\% igem Alkohol answewaschene ahfiltrierte Niederschlag wird in einer der Lrsprungslösmng entsprechenden Wassermenge aufgeschwemmt, worin die \%-Protoalbumose und die \%-Denteroalbumose sich anflösen, die Heteroalbunose aber nicht. \%um ron der Heteroalbumose abfiltrierten Filtrate setzt man wieder ein Volumen Alkohol, filtriert. Wäscht den Xiederschlag mit 50\% igem dlkohol und schwemmt ihn in Wasser auf. wobei eine neue Heteroalbumosemenge unlöslich bleibt. Die Heteroalbumose wird mit heifem Wasser gewaschen und die Waschwïsser mit der die \%-Protoalbumose und die $x_{\text {-I }}$ euteroalbmmose enthaltenden Flüssigkeit rereinigt. Diese Alkoholfällung und narhherige Anflösung wird so lange wiederholt. bis dẹ Zusatz des gleichen Volumens konzentrierter Schwefelsäure zum Filtrate stets dieselbe Färbung gibt. Dann löst man die gefüllten $x$-Protoalbumose und \%-Leuteroalbumose in Wasser auf, füllt die $\%$-Protoalbumose dureh Znsatz ron 1 Volunen gesïttigter Ammonsulfatlösung zum Filtrate und die -Denteroalbumose durch Sättigung des nach Abfiltrieren der $\boldsymbol{x}$-Protoalbumose erhaltenen Filtrates mit gepulrertem Anmonsulfate. Sowohl die x-l'rotoalbumose als die $x$-I) lenteroalbumose werden durch nacheinander folgende Aussalzungen und Auflösungen so lange gereinigt. bis der nach jeder Aussalzung nach Kjolduh bestimmte stickstoffgehalt des Filtrates unverändert bleibt.

1) E. P. Pick, Ein neues Terfahren zur Tremung ron Albumosen und Peptonen. Zeitschr. f. physiol. Chem. Bd. 24. S. 246-275 (1897). - Derselbe, Zur Kenntnis der peptischen Spaltungsprodukte des Fibrins. I. Teil. Ebenda. Bd. 29 S. 219-287 (1899. - Derselbe. II. Teil. Die sogenannten Jeuteroalbumosen. Beitr. z. chem. Physiol, u. Pathol. Bil. 2. S. 481-513 (1902). 
Die nach Fällum der Heteroalhmmose. der $x$-l'rotoalhmose mnd der x-[henteroalbumoso hleibende allioholischo Lösung wird bei to- $50^{\circ}$ auf dem Wasserharle verdampft, um den Alkohol wegzutreiben und zum Volumen der l'rsplungsösmo zu bring('u. Dann setzt man zur wässerigen Fliissigkeit las gleiche Voluman gesiattigter Ammonsulfatlösmo, worlureh die p-l'rotoalbumose niedergeschligen wird. Nach dem Abfiltrieren der F-Frotoalbumose sätiont man das erhaltene Filtrat mit gepulvertem Ammonsulfate. wodurch man die s-1)nteroalbumose fällt. Die Reinigung der P-Protoallommose und del 's-beuteroathmose erfolent anf diesclhe Weise, wio die der s-l'rotoalhrmose und dej \%-Denteroalbmose. ${ }^{1}$ )

larstellung der l'rotoalbumose und der Heteroalbumose nalh Adler. Das nentralisichte Verdammgsgemisch wird mit der gleichen Menge gesättigter Immonsulfatlösmme versctzt. der ahfiltrierte Niederschlag znerst mit einer Mischung gleicher 'Trile destillierten Wassers und wässeriger gesättigter Ammonsulfatlösung, später mit gesättigter Ammonsulfatlösung bis zum Verseluwinden der Binctreaktion gewaschen. Die unofïlten Protoalbumose und Heteroalbumose werden in Wasser gelöst und mit Ammonsulfat versetzt, bis die lösnng genan $5 \%$ dieses Salzes (rnthält.

Dej erhaltenen Lösung wird nun vorsichtig eine mïBig konzentricrte

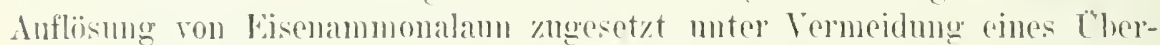
solusses. Nachdem sich dor hellgelbe Nicderschlag a gut alogesetzt hat. was bisweilen einige Tage cofordert, wird or abfiltrient. mit $5 \%$ iger wäsorerger Ammonsulfatlismng bei $t 0^{\circ} \mathrm{C}$ gewaschen, in Wasser anfoeschwemnt mud mit konzentriertem Ammoniak rersetzt. l)as Filtrat von dem in der Wiarme gnt ansgewaschenen Eiscnoxylhychate wird nit schwefelsänre neutralisiert. wiorler gronan anf einen Febalt von $5 \%$ Ammonsulfat gebracht und aber-

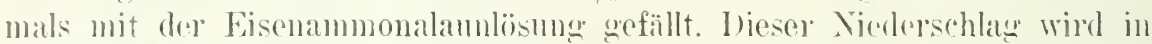
starkem Immoniak gelöst, vom Gisenoxydhydrat abfiltriert. mit volständieg

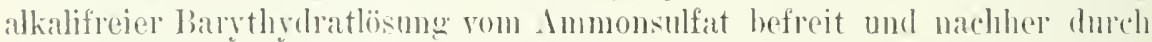
Ammonkarbonat der Barytiberschub entfernt. Jie schlichlich so erhaltene l'lissigkeit wind in Vakum oingedampft. Der in Wenig Wasser mol einigen

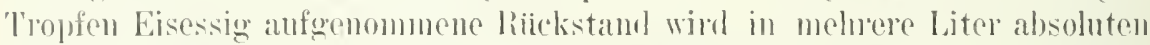

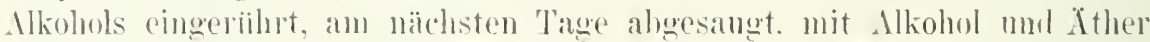

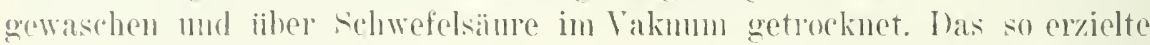
l'rodukt entspricht der J'rotoallonmose. Kum völigen T'uoknen wird die l'jotoalbumose his zul Gewichtskonstan\% im trockenen Luftstrome bei 950 C' gertiocknet.

L'm den durch den geringen Cberseluub des Eisenammonalams in

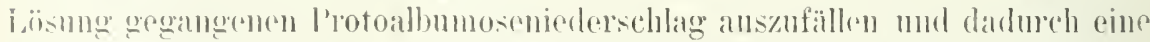
erentuelle Velumemigmmg des Heteroalhmmoseniederschages zu verhiiten, fiigt man mit $5^{0}{ }_{0}$ Ammonsulfat versetztes wäseriges Ammoniak zur nach

1) H. (. Hastam, The separation of proteids. Hart I: Jomn. of Physiol. Yol. 32. f). $267-298$ (1905). - l'art II: Hbirl. Vol. 36. 1). 164-176 (1907). 
Fällung und Abfiltrieren des Protoallumoseniederschlages a bleibenden Fliissirrkeit b. Die so entstandene \%wischenfïllun wird abfiltriert. I)as nene Filtrat wird mit feingepulvertem Eisenammonalann muter tiichtigem Riihren rersetzt und nacher dazn konzentriertes Ammoniak gefügt. bis die lieaktion der Yischung nur noch schwach sauer ist. I)er entstandene Niederschlag wird alfiltriert, mit 5\% \% iger wässeriger Ammonsulfatlösung loci $40^{\circ}$ ( $^{\prime}$ getwaschen. in Wasser aufgeschwemmt und mit konzentriertem Ammoniak versetzt. Das Filtrat von dem in der Wärme gut ausgewaschenen Eisenoxydhydrat wird mit Schwefelsiume nentralisiert. auf einen Gehalt ron $5 \%$ Ammonsulfat gobracht und wieder inittelst feingepulverten Eisenammonalaun und Zusatz von Ammoniak bis zur schwach sauren lieaktion gefällt. Der Niederschlag wird im starken Ammoniak gelöst, rom Eisenoxydhydrat abfiltriert, mit Barythydrat von Ammonsulfat und mit Ammonkarbonat vom Barytüherschusse befreit. Die dann erzielte Ileteroalbumoselösung wird in Vakuum unter $40^{\circ} \mathrm{C}$ eingedampft. Der Riïckstand wird in Wasser unrl Eisessig gelöst. in einer grolien Menge ahsoluten Mlkohols eingeriihrt. am Ilïchsten Tage abgesaugt, mit Alkohol und IIther ausgewaschen und iileer Schwefelsäure im Vakuum getrocknet. Die so erhaltene Heteroalbumose wird schließlich im trockenen Luftstrome bei 9.50 (' bis zur Gewichtskonstanz getrocknet. Im völlig reine Präparate zı er\%ielen ist es zweckmäßigg. die Heteroalbumose einer drei- his viermaligen Fällung mittelst Eisenammonalaun zu unterwerfen, namentlich wenn grögere Quantitüten zur Verarbeitung gelangen. Dadurch wird aber das Verfahren etwas umständlich.

Deshalb ist es nach Adler fuir die larstellnng der Heteroalbumose vorteihafter, das Eisenammonalannerfahren mit der E. P. Pickschen Iethode zu kombinieren. Das yon den geronnenen oder geliisten I'roteinen und rom Yeutralisationsniederschlag befreite peptische Verdanung:gemisch wird mit dem gleichen Volumen gesättigter Ammonsulfatlösung gefällt. Der entstandene Niederschlag wird abfiltriert, mit einer aus gleichen Teilen Wasser und gesättigter Ammonsulfatlösung bestehenden Fliissigkeit gründlich ausgewaschen und nachher in heibem Wasser gelüst. um eine müglichst konzentrierte wässerige neutrale Lösmng zu erzielen. Dies Flïssigkeit wird mit dem doppelten Volumen $95{ }^{0}{ }^{\circ}$ igen .1 kohols rersetzt. Worauf man sice in der Kälte bis zum völligen thsetzen des Niederschlages stehen lälit. Der durch Abgiefien von der dariiher befindlichen alkoholischen Lösung befreite Viederschlag wird in Wasser gelöst und mit Ammonsulfat rersetzt, bis die Lösung genau $5^{\circ} \%$ dieses Salzes enthält. Ina die Heteroalbumoselösung alsdann noch Protoalbumose enthält, so wird sie nach der oben beschriehenen Eisenammonalaummethode wie eine Lïsmng beider sogenannten ..primären“ Proteosen behandelt. Es ist nun sehr wichtig, die Fällung des ersten Eisenniederschlages (P'rotoalbumose) rechtzeitig zu unterbrechen. da sonst, namentlich bei mehr als $5 \%$ Proteosen enthaltenden Fliissigkeiten. ein Teil des zweiten Niederschlages mit in den ersten geht. Dieses kombinierte Verfahren ergibt Adler zufolge eine viel erheblichere Ausbeute als 
lic Fisenammonalanumethode allein und erlanht anfierdem eine wesentliche \%eiter'sparnis. $\left.{ }^{1}\right)$

Eignschaften der Proteosen. Die rerschiedenen Proteosen sind noch keineswegs genigend scharf ronciunder getremnt, un durch ihue physikalischen und chemisehen Eigenschaften sicher charakterisiert zu werder.

Erwihnt sei jedoch. daf die l'rotoalbumose mol die Heteroalbumose den Farbonmmehlag ron einer nach Zsigmondy dangestellen hochroten kolloidalen Iösung in Violett hei \%/sat\% von einer 10\% igen Kochsal\%lïsmng verhindern. Während alle anderen Proteoson hingegen die kolloblale hochrote Goldlisung olmo jeden Elektrolytzusatz an sich blan färben. bie Heteroalhmose hesitzt diese schuitzende Figenschaft in viel hïherem frade als die I'rotoalbumose.

Mle Proteos(2n ergehen die Tyndalsche Erscheinumg und scheinen demuall kolloidaler Natur zu seiu.

Die Heteroalbumose mol die sinalbmose hewirken die Flockung des Mastix ohno Elektrolytzusatz. die anderen l'roteosen nicht.

1)mrh \%usatz von Chondroitinschwefolsäure mol Essigsime nach dem J'onsschen Verfahren worden alle Proteosen nichergeschlagen. Diese Reaktion ist viel empfindlicher fiir die l'rotoalbumose, die Heteroalbmose und die sirnalbmmose (1 fïr 9000 oder 10.000 ) als fiir die anderen l'roteosen (1 fiir fo() bis 1 fiil 6000$)$.

Allo T'roteosen rermehren die Refraktionshahl des Massers.

I)meh /usat\% cince 1" "igen ammoniakalischen Clupeinsulfatlösung werden die Heteroalbmmose mul die Protoalbmmose gefällt, die anderen l'roteosen aber ni(cht."2)

'Tryptophan. 1. Isolierunge nach Hoplins und cole.

'/um Isolieren des Tryptophans unter den Verdaumusprodukten der Proteine bedient man sich des Verfahrens ron Hoplins und Cole.

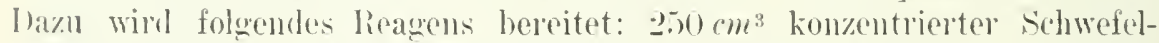
säure worden mit $4750 \mathrm{~cm}^{3}$ destillierten Wassers rermischt. In einnu

1) Kudolf Alller. Die Ileteroalhumose und l'rotoalhumose des Fibrins. Ein Beitraf zur Kemutnis der primären J'rodnkte des kiwcißabhanes. Inang.-1)iss. Leipzig 1907.

(iiitige Nitteilung des Herrn Ir. Rudolf Adler zu Larlsbad.

$\left.{ }^{2}\right)$ A. Hunter, The reaction with protamine as a means of distinguishing primary from secontary proteoses. l'roc. of the I'hysiolog. Soc. 22. Fehr. 1908 in Jomrn. of l'hysiol. Vol.37. p. I - VI (1908). - ('h. Pons, Quantitative Untersuchungen iiber dic Ausscheidung der (hondroitinsehwefelsäure. Beitr. \%. chem. Y'hysol. u. I'harmakol. Bd, 9. S. 393-400 (1907). - Sur l'acide sulfochondroitique et sa présence daus l'urine normale. Anu. de la Soc. de méd. de (iand. T. 86. p. $288-292(1906)$. - $R$. Zsigmondy. Die hochrote Goldlisung als Reagens anf Kolloide. Zeitschr. f. analyt. Chem. Bd. 40. S. 697-719 (1901). - Ex Zunz, De lemploi de l'or colloidal pour caractériser les albumoses primaires. Areh, int. de Physiol. 'T. 1. P. 427-439 (1904). - Action des albumoses secondaires et des peptomes sur loor colloidal. Bull. de la Soe my. des Se med. et nat. de Bruxelles. T. 64. p. 174-186 (1906). - Conntribution à l'étude des protéoses. Areh. int de Physiol. T. 5. 1. $245-256(1907)$. 
Mörser verrihht man $50 \mathrm{~g}$ Quecksilhersulfat mit einem Teile der verdinnten schwefelsiure, fümt die so erhaltene Iufschwemmung zun Hauptteil der verdïnnten Sïure und schïttelt die Gesantflïssigkeit tüchtigr. Yun wirl uine neue Portion von $50 \mathrm{~g}$ des Quecksilbersalzes mit einem Teile des Sïnre verriihrt, zum Hauptteil gefügt und dieser geschüttelt. Diese I'rozedur wird bis zum rollständigen Zusatze in Portionen von je $50 \mathrm{~g}$ der $500 \mathrm{~g}$ Irerurisulfat zn der verdïnten Schwefelsüure fortgefuihrt. Cach einigem stehen filtriert man dann das lieagens.

Die lösung der Verdauungsprodukte der l'roteine wird nit diesem Reagens bei Anwesenheit von ungeführ $5 \%$ iger Schwefelsäure versetzt, wobei nur Cystin und Tryptophan fallen. Bei langem Stehen wirl indes das Tyrosin auch teilweise niedergeschlagen. Yach 12stündigem oder längerem Stehen wird der erhaltene Niederschlag so lange mit $\bar{\delta}_{0}^{0}$ iger Schwefelsäure ausgewaschen. bis die Waschfliissigkeit mit dem Millonschen Reagens keine rote Fürbung nehr in der Külte gibt. wodurch nachęerriesen wird, da\} alles etwa mitgerissene Trrosin wieder gelöst wurde. Danach wird der Niederschlag in Wasser aufgeschwemmt unl bei Zusatz ron $20{ }_{0}^{\prime}$ iger Schwefelsäure mittelst Schwefelwasserstoffes hehandelt. Yach dens völligen Sïtigen der Flïssigkeit mit letzterem erwärmt man sie einige Zeit auf dem Wasserbade und sïttigt sie wieder mit Schwefelwasserstoff. Nun filtriert man den Viederschlag. schrremmt ihn in Wasser auf und behandelt ilm wieder nit Schwefelwasserstoff. Iiese Prozedur wird t-5mal wiederholt. Die vereingten Filtrate werden auf dem Wasserbade vorsichtig erwärmt. um den Schwefelwasserstoffüberschul wegzutreiben. Nach dem Erkalten der Flüssigkeit setzt man $5^{0}{ }_{0}$ ihres Tolumens an Schwefelsüure hinzu und versetzt sie allmählich unter sichütteln mit der (quecksilbersulfatlösung bis zum Erscheinen eines geringen bestïndigen Niederschlages. Nach $1 / 2$ stündigem Stehen wird rasch abfiltriert. Das Filtrat enthält kein Cystin mehr oder höchstens spuren daron. Z/u diesem Filtrate setzt man nun einen Uhersthuf des Quecksilhersulfatreagenzes. nm das Tryptophan zu fällen, wozu jetzt viel weniger Reagens nötig ist als bei der Behandlung der Gesamtlösung der Verdaunngsprodukte der Proteine. Nach einigem Stehen filtriert man und wäscht den Niederschlag zuerst mit verdünuter Schwefelsäure und nachher mit Wasser ans. Das Quecksilher wird durch Schwefelwasserstoff niedergeschlagen. Das Filtrat wird durch rorsichtige Hinzufügung heifer Itzbarytlïsung bei Vermeidung jedes Cherschusses von der Schwefelsïure hefreit. Yan erwärmt alsdann die Fliissigkeit einige Zeit anf dem Wasserbade und filtriert sie nachher vom Bartumsulfat ah. Zum Filtrate setzt man ungefähr $1 / 2$ Volumen $90 \%$ igen Alkohols und dampft es auf dem Wasserbade ein. Während des Eindanpfens mub man ron Zeit zn Zeit geringe Alkoholmengen zum Filtrate fügen. Das Eindampfen wird so lange fortgesetzt. bis nach dem letzten Alkoholzusatze beim Abnehmen vom Wasserbade sich in der Lösung Kristalle zeigen. Liese werden auf der Sangpumpe abfiltriert. mit $90^{\circ}{ }_{0} \mathrm{igem}$ Alkohol ausgewaschen und dann in wenigh heifiem Wassel aufgelöst. Zu dieser Lösung setzt man das gleiche 


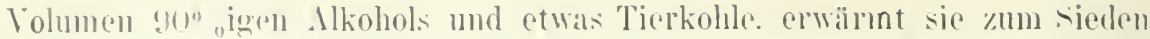
und filtrielt sie noch heil ab. Ins Filtrat wird anf dem Wasserhade unter \%usaty rou Alkohol von \%eit zu Zeit aingedanpft bis zmm Erscheinen rines Kiristallbries bein Erkalten. Ije so erhaltenen Tryptophankristalle werden

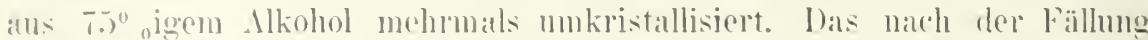
des Cystins und des 'Tryptophams in der Verdamumgsflissigkeit durch

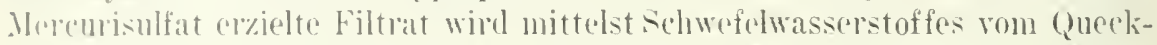
silber bufreit und kilm nach Abfiltrieren rom Quecksilhersulfid mit l'hos-

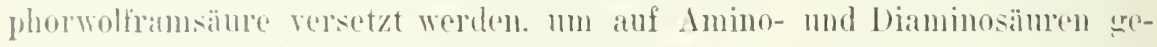

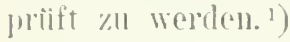

2. (? Inatitative Bestimmung des Tryptophans nach Lerene nul Rovillier.

bas Verfahron vou Hoplizus und Cole erlaubt keine genaue quanti-

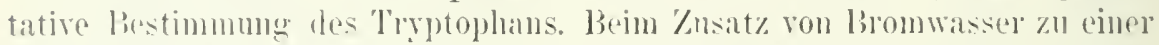
Tryptophanlïsung fürbt sich diese purjur. Diese Fülumg wächst zuerst in Intensität mit dem Bromzusatze: sobald sie aber ihr Maximmm errejelt hat, relschwindet sic plötzlich bei Zufiigung eines weiteren Tropfons les libomwassers. Diese Eigensehaft henutzen Leene mul Rovilles folgendermalen zur guantitativen Bestimmmong des 'l'yptophans: Die Lösumg der

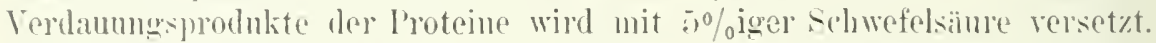
loum fụ̈t man so lange von der Hopline-Coleschen Meremisulfatlösung hinzu, bis del Kusatz ron 1 'Tropfen blomwasey zur oben sehwimmendien

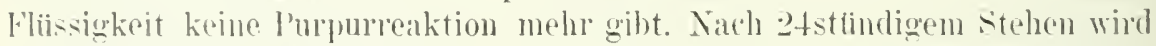
filtriert. Der Nimlerselulag wird in höchstens bis -2\% schwefelsäure enthaltendem Wasor anfueschwemunt, durch Schwefelwasselstoff zersetzt, abfiltriert. Has Filtrat wind anf deu Wasserbade erwärmt, mo den Nelhwefelwassolstoff zu reltreihen und auf cin genalu bekinntes (iesamtrolumen gohracht. $1.5 \mathrm{~cm}^{3}$ dirser loiisigkeit werden in einer Eprourette mit $2 \mathrm{~cm}^{3}$ Amylalkohol rersetzt. Enter tiichtigem sichüteln fiigt man tropfenweise

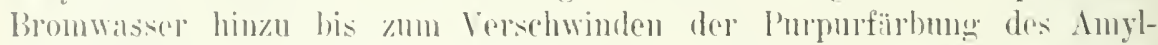
alkolsoles. Für versehiedrue l'roben einer und derselhen T'rytophanlïsung

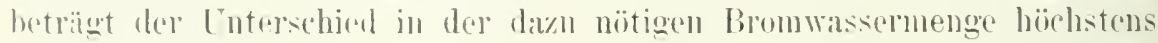
(1). $0.1 \mathrm{rm}^{3}$. In einem alinnoten Teile des mach dem Vertreihen des

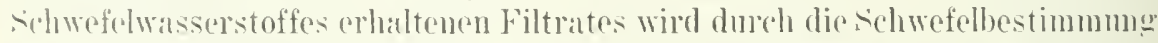
dic in der 'Tryptophanlibsug vorhandeme Cystimuenge ermittelt. Man be-

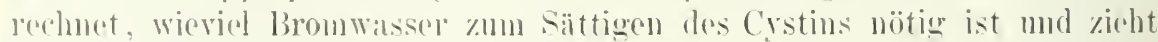
den so erhaltenen Wert vou der bej der 'Titriermog der cystimhaltigren 'Tryptophanlösung verhranchten Bromwassermenge ab. Auf diese Weis" orfïhnt man die Inzahl der Kiubikz'ntimeter Bromwasser. welche nötig ist, 110 das 'T'ryptophan zu süttigen. Yor jeder Inalyse ist es ratsam, das Prom-

1) F. Crowland Hopkins and siyduey Hr. Cole, A Contribution to the Chemistry of proteids. T'art I. A preliminary study of a hitherto mudeseribed product of tryptic digestion. Journ. of l'hysiul. Tol. 27 . p. 418 4⿻上丨 (1901). 
wasser mittelst Cystiu- und 'Tryptophanliosungen bekannten fielaltes auf' ('ystin und auf 'lyptophan zn titrieren.")

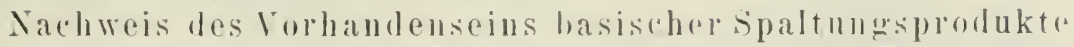
in einer Verdaumugslisung. Das Verdanungsgenisch wird mit l'hosphol-

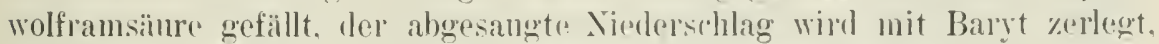
der Hydrolyse dureh $: 3: 3 \%$ ige Schwefelsime muterworfen und ron nenem mit l'hosphorwolfamsäure grefïllt. Bleiht bei der Spaltume der Proteine odel

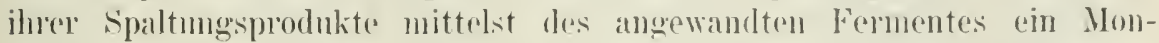
aminosiunren entlualtendes l'olypeptid ïbrig. so mïssen die Monaminosiumen im letzten Filtrate vorhanden sein. Was man durch dir Bestimmung des Stickstoffes dieser Fliissigkeit nach Kjeldnhl ermitteln kamn. Wegen der teilweisen Löslichkeit des l'hosphorwolfunsämeniederschlagrs der Hexonbasen kann indes eine geringe stickstoffnenge in dats letztele l'iltrat iblertreten, was man beriuckisichtigen muli. ${ }^{2}$,

Restimmung des Ammoniaks. Inas bei der Veldaumg der l'roteine frei gewordene Ammoniak wirl nach dem Verfaluren von $\boldsymbol{H}$. Nemrki

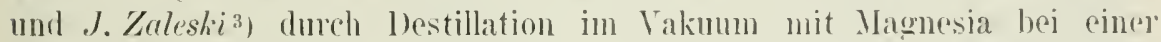
$40^{0}$ nicht übersteigenden Temperatur elmittelt. Von der erhaltenen Zahl 1113 man sowohl das in dem untersuchten P'rotein vorgebildete Ammoniak als auch die sich wïhrend derselben Zeitdauer in einer nur ans dem Verdanumgsafte bestehenden Kontrollflissigheit gelohlde Ammoniakmenge abziehen.") Man kann sich auch des Schittenhelmsthen ${ }^{5}$ ) oder des Folim-

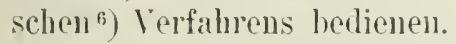

Plasteine und lioagubsen. Proteine werden mit künstlichem oder natiolichem, nach dem Puulowschen Verfahron erhaltenen Magensafte 13 Tage der Verdaumg mterworfen. Damn wird das vom gerimubaren Eiweiße und rom Nentralisationsuiederschlage in iblicher Weise befreite. einen starken Proteosengehalt aufweisende Verdanungsemisch konzentriert. mit Sal\%säure bis \%u $05 \%$ \% mgefïhr angesinert und mit naturlichem, nach J'axlow's Methode gewonnenem Magensafte oder mit einer Lablösung ver-

1) P.A. Lerene and $C$. A. Rowillier, (1n the quantitative estimation of tryptophan in protein clearage products. Journ. of biolog. Chem. Vol. 2. p. 481-4S4 (1907).

2) O. Cohmheim, Zur Spaltung des Nahrungseimcißes im Darme. Zeitschr, f. physiol. Chemie. Bd. 49. S. $64-71$ (1906) und Bd.51. S. $414-424$ (1907). - C. Foì, Sull erepsina del succo enterico e sulla scomparsa di alcuni fermenti intestinali in un ..ansa del Vella" da lungo tempo isolata. Arch. di fisiol. Vol.5. p. 26-33 (1907).

3) U. Nenchi und J.Zaleski, Über die Bestimmung des Ammoniaks in tierisehen Flüssigkeiten und Gewehen. Zeitschr. f. phỵsiol. Chemie. Bd. 33. S. 193-209 (1901).

4) S. Dzierzgourski und s. Salaskin, Über die Ammoniakabspaltung bei der Einwirkung vou Trypsin und Pepsin auf Eiweißkörper. Zeitsehr. f. Physiol. Bd. 15. S. 249 bis $25+$ (1901). - E. Zumz, Sur la digestion peptique des substances albuminoides. Ann. de la Soc. roy. d. Se. medl. et nat. de Bruxelles. T. 11. Fase. 3. p. 1-26 (1902).

5) A. Schittenhelm, Zur Methode der Ammoniakbestimmung. Zeitschr. f. physiol. Chem. Bd. 39. S. 73-S0 (1903).

$\left.{ }^{6}\right)$ O. Folin, Eine nene Methode zur Bestimmung des Ammoniaks im Farne unl anderen tierischen Flüssigkeiten. Zeitschr. f. physiol. Chemie. Bd. 37. S. 161-176 (1902). 


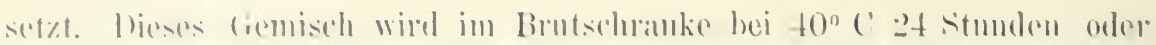

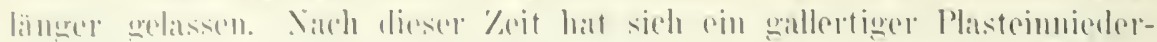

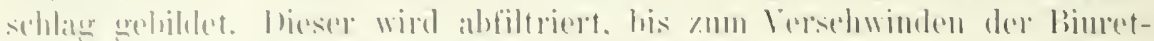

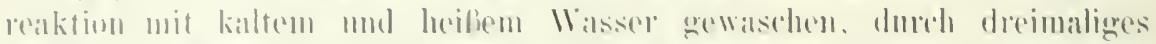

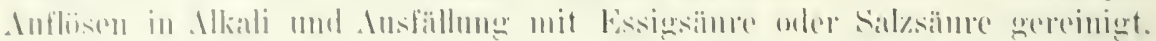

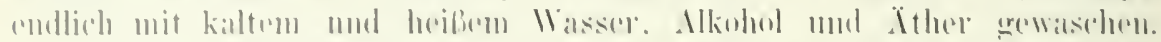

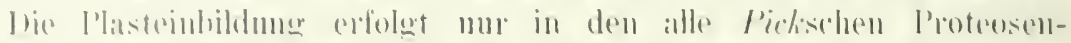

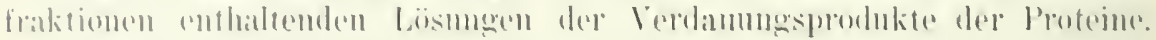

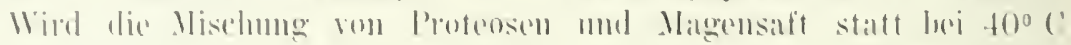

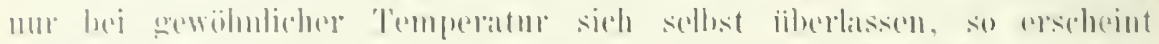

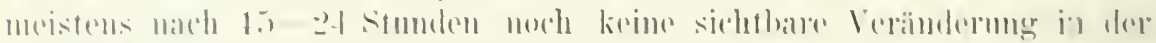

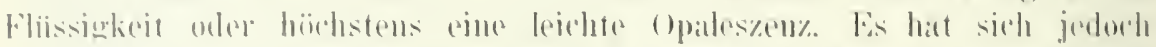

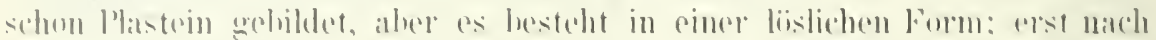

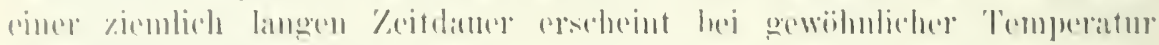

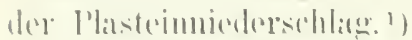

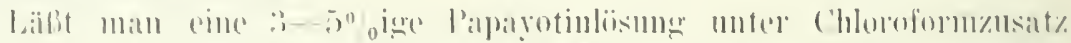

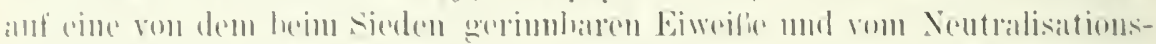

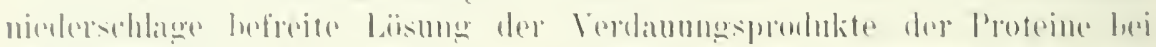
40" (

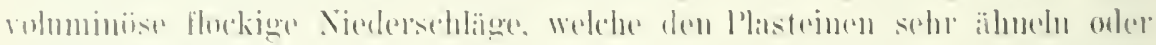

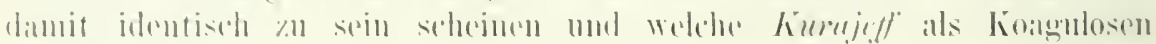

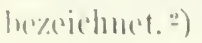

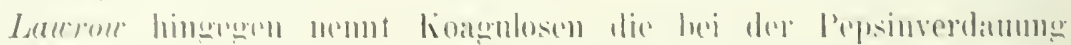

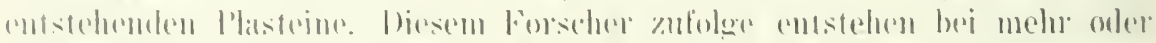

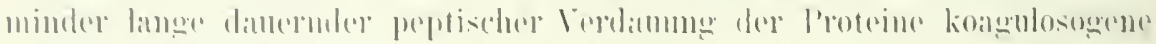

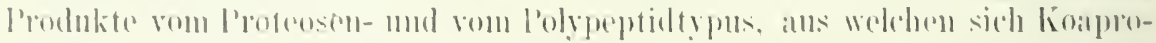

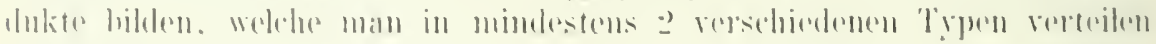

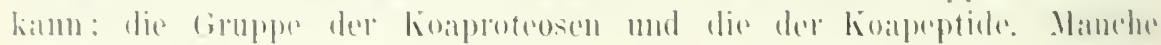

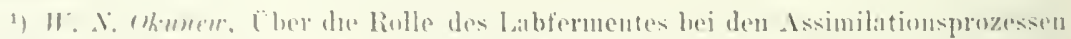

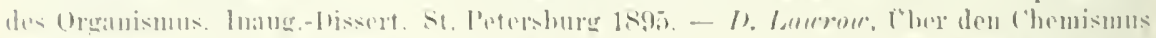

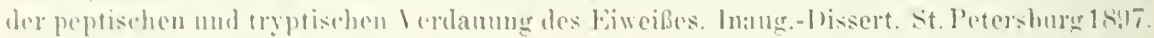

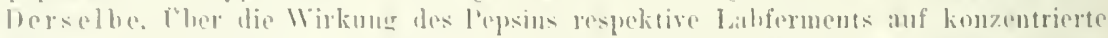

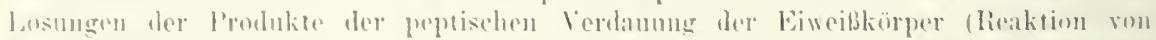

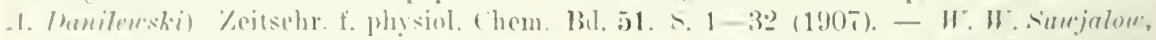

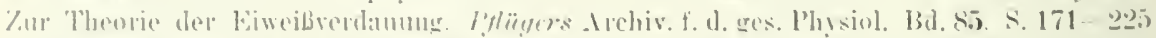

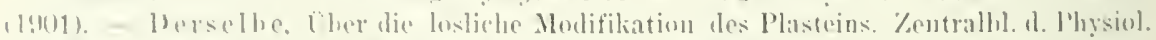

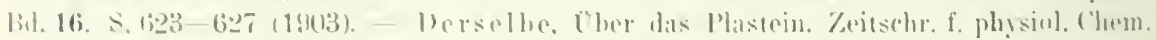

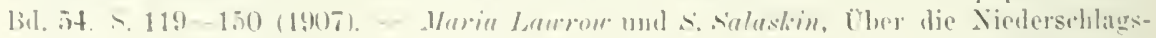

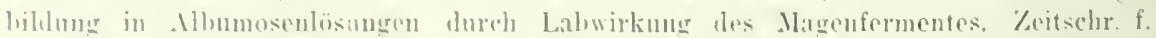

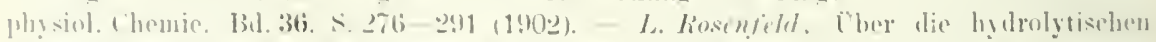

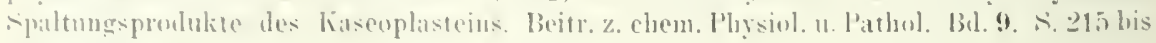
$2: 31(1907)$.

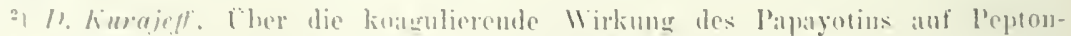

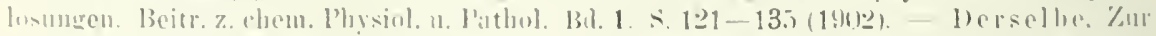

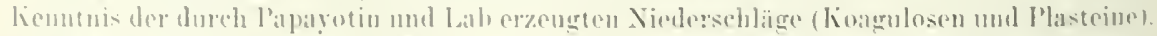

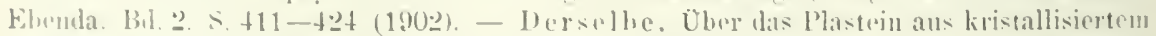

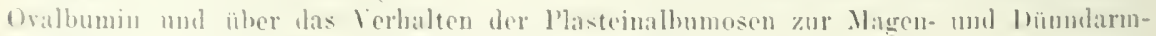

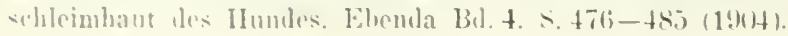


dieser koagnlosogenen Produkte werden leirht ans ihren lisinngen mit den Proteosen bei der fraktionierten Ausfällung von Lösungen der Ver(lammosprolukte mitgerissen. ${ }^{2}$ )

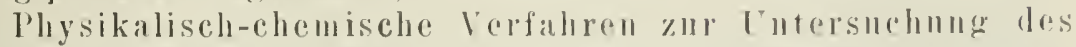
Abbanes der l'roteine. Man hat anf verschiedene Wrisen velsurbth die Inlantitativen Vorgïnge bei der Verdauung der Proteine anf physikalischrleenischem Wege zir verfolgen. Solche Verfahren kïmen aber nur hoi spaltungen von :uluerst einfachen Verbindungen zuverlissige liesultate regreben.

Jie Iessung der Xnderung des optischen Inedumesvermögens der lösung eines bestimmten optisch-aktiven l'olypeptides bei fromentzusat\% erlaubt den Nbban von Stufe zu Stufe zu verfolgen. ${ }^{2}$ ) Dies ist anch der

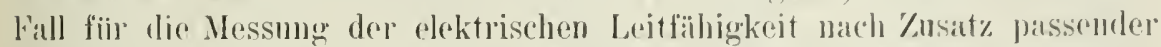
Vengen Natrimmhydroxyd bei der lirepsinspaltung des Glycyl-pylycins oder hei irgend einer enzymatischen Wirkung auf ein ähnliches einfiches Abbauprorlukt der Proteine. $\left.{ }^{3}\right)$ Diese Verfihren eignen sich besonders zomn Studium der Wirkmog der Abderhaldenschen peptolytischen Fermente: ${ }^{4}$ )

Bei der eigentlichen Verdaunng del Proteine (nnd dies gilt aurh fiir die Kohlehydrate) messen aber alle physikalisch-chemischen Ifothoden das liesultat der verschiedenartigsten nebeneinander ninhergehenden, sich in ihrem Eragebnis manchmal kreuzenden chemischen Vorgänge. Mit Oppen-

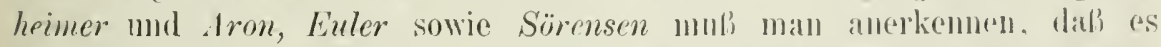
gewölntich ganı willkürlich ist, die gemessene Kudermng irgend eimer physikalischen kigenschaft als den Umfang der Spaltung proportional

1) D. Lawrou, Zur Kenntuis der Koagulosen. Zeitschr. f. physiol. Chemie. Bil. 533. S. $1-7$ (1907); Bd. 56. S. 342-362 (1909); Bı. 69. S. 520-5:32 (1909).

2) E. Aluderlateden und A. II. Kocller, Die Verwendung optiseli-aktiver l'olypeptide zur Priffung der Wirksamkeit proteolytiseher Fermente. Zeitsehr. f. physiol. ('liem. Bal. 53. $\therefore .294-310$ (1907). - Derselbe, Weiterer Beitrag zur Kemntnis des Verlaufes der fermentativen Polypeptidspaltung unter versehiedenen Bediugungeus. Ehenda. Bd. ̄̃os. S.363-38! (1908). - Derselbe, Weitrer Beitrag zur Kémutuis les Verlaufes der fermentativen Polypeptilspaltung. (V. Nitteilung.) Ehonda. IBd. 50. S. 416-426; (1908). - E. Abdevhalden und $L$. Michaelis, Der Verlanf der fermentativen l'olypeptidspaltung. lihenda. Bd. 52. S. 326-337 (1907). - Ko Ahderhalden und A. Ciyon, Weiterer Beitrag zur lienntuis des Verlanfes der fermentativen l'olypeptidspaltung. Vihenda. Bil. 53. S. $294-310$ (1907).

3) Hons: Euler, Fermentative Spaltung von I)ipeptiden. Zeitschr. f. physiol. ('hen. Bil. 51. S. $213-2.25$ (1907).

4) Emil Abdchadden und Florentin Modigreerenu, ither das Vorkommen ron peptolytischen Fermenten im Mageninhalte nue ihr Nachweis. \%eitschr. f. physiol. ('luem.

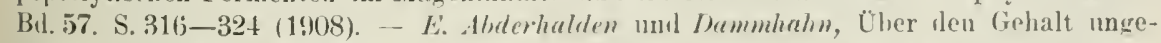
kinimter um gekeimter Simen versehiedener l'flumzenarten an peptolytischen Fermenten.

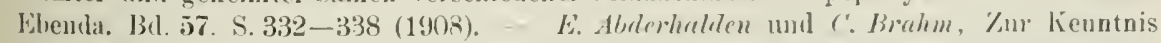
des Verlanfes der fermentativen l'olypeptidspaltung. VI. Mitteilung. Ehenda. Bil. 57.

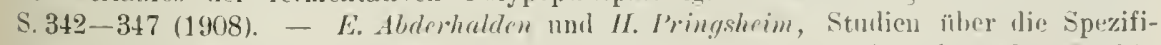
zitait der protenlytisehen Fermente bei verschiedenen l'ilzen. Ehenda. Bd. 5!). \$. 249-25.j (1909). - E. Aludwhalden, G. C'aemmerer und L. F'ineussohn, Zur lieuntuis des Verlanfes der fermentativen l'olypeptilspaltumg. VIl. Mitteilnng. Ehenla. Bul. 59. S. 292 bis 319 (1909). 
anzusehen, und dal) dies sogar höehst mushrscheinlich ist. denn sowohl das verschwindende Ausgangsmaterial als fast alle aufretenden spaltprodukte berinflusien diese Figenschaften. ${ }^{2}$

Diese Kritik scheint mir ehenso das Kugsehe Verfaluren der spektro-

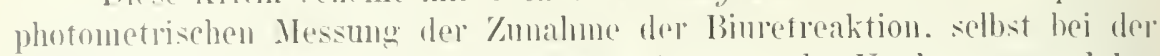

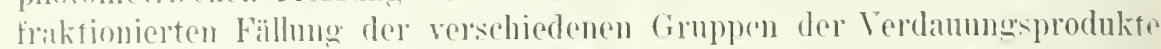
der I'roteine. zu treffen. als die Messung ler optischen Drehumg. die

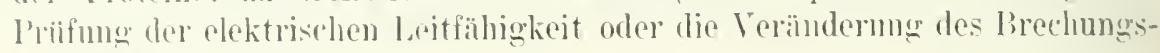
vermigugns. 2)

Spriggs hat nachgewiesen, dah die Viskositït einer Lösmmg von

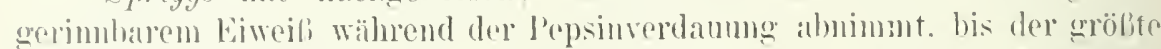

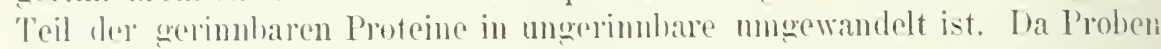
derselhen Fiweiflosmng, mit versehiedenen I'epsinmengen behandelt. zur \%eit der gleichen Viskositit dieselhen l'rozente gerimbares mol monerimbates l'potein enthalten, kann man mittelst fül jedes Protoin eigens dazu experimentell festgestellten Kurven wiihrend dep Vertammog des betroffenden I'poteins den ciehalt an gerimbarem mod mgerinmanem liweif visknsimefrisch foststellen. bei der troptischen Verdanmmg nimut anch dic

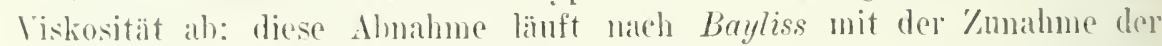
elektrischen Leitfähigkeit keineswegs parallel. In konzentriorten Lösungen dey Spaltungsprodukte der Proteine bewirken alle proteolytischen linzyme Heray zufolge eine Zumahme del Viskositat. Demnach seheint die viskosimotrisene Yethode bei der Entersuchmog der Syaltung der l'roteine nur mntel den ron simiggs festgestellten bedingungen bienste leisten zu kiinn(1). $\left.{ }^{3}\right)$

1) ('. oppenheimer und H, Aron, Über das Verhalten des genuinen Serums gegen die tryptische Verlaumng. Beitr. z. chem. Physiol. u. Pathol. Bu. 4. S. $279-299$ (1904). s. I’. L. sörensen, Enzymstudien. Biochem. Zeitsehr. Bd. 2. ‥45-101 (1907).

") F. Kluy, Intersuchungen üher Pepsinverdanung. Iflügers Areh. f. d. ges. Physiol Bd. 60. S. 43-70 (18:95). - T)erselbe. Beiträge zur l'epsinverdamumg. Eibenda. Bid. 6j) S. $330-342$ (1897). - L. Schïtz, line Nothode zur Bestimmung der relativen l'epsinmengen. \%eitschr. f. physiol. Chen. Hal. 9. S. 577-590(1887). - A. Gärber, Wie beeinfluß1 die Verlaumg das brehmngsvermogen riner Eiweißlösung: Festschr. d. physik.-med. Ges. z. Würzburg 1899 - M. OKer-Islom, Die elektrische lecitfähigksit und die ciefrierpunktseniodrismug als Indikatoren der Eiweibspaltmg. skand. Areh. f. I'hysiol. Bel. 13. S. 359 374 (1!102). - Vietor Ifenri et Larguer des Burcels, Loi do lastion de la

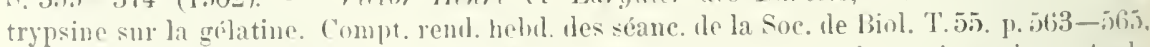
$787-789$ et $860-868$ (1903). - W. M. Baylise, The kinetics of tryptic action. Areh. dex sci. liolog. de st. l'étersh 'urg. T. 11. Suppl. P. 261 - 291 (1904). - Researches on the nature of enzumo action. I. On the canses of the rise in elertrical conductivity under the action of trypsin. Journ. of l'hysiol. Vol. 36. p. 22-21-252 (1908). - F. Ohermayer unt

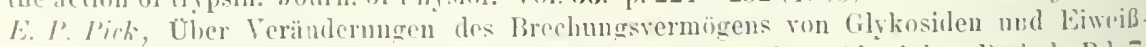
köpen dureh Formente. Sämren mul Bakterien. Beits, z. chem. l'hysiol u. l'athol. Bd. T S. $331-380$ (19)66).

${ }^{3}$ ) F. I. Smriggs, Eine nene Methole zur Bestimmung der Pepsinwirkung. Zritschr. f. physiol. ('hem. Bu. 35. S. 46.5-494 (1902). - R. O. Ilerog, ther proteolytische Enzyme. Ehenda. Bd. 39. S. 304-312 (1903), - W. M. Bayliss, loc. cit. 


\section{e) Isolierung der Ahbauprodukte der Verdaunng der Nukleoproteide.}

Die aus einem Fiweißanteil und einer Nukleinsäure bestehenden Nukleoproteide werden sowohl durch l'epsin als durch Trressin in die der protenlytischen Finwirkung dieser Enzyme unterworfenen Eiwcilie und in Nuklein gespalten. Letzteres wirl dann wieder in Eiweib und Nukleinsäure qespalten. Srhlieblich wird die Nukleinsäme durch dic Nuklogse in ihre cinzchen Bestandteile zerlegt: I'hosphorsäure. Nuklem- oder Purinhasen. Pyrinidinbasen usw:

Die L"ntersuchung der die Spaltungsprornkte der Xukleoproteide enthaltenden Verdaumgsgemische erfolgt nach den in den Ahschnitten iiher den Ahbau der Nuklemsänren und die Isolierung der Abbauprodukte der P'roteine schon beschriebenen Verfalnen.

Falls Proteine im Verdaumgrggemische rorhanden sind. so werden sie zmerst durch vorsichtiges Erwärmen bei Essigsïurezusatz oder durch Ausfällung mit Alkohol in der Kiilte niedergeschlagen.

Im proteinfreien Filtrate wird dam die unzersetzte Nukleinsäure wefällt. Ein Teil der Nukleinsäure scheidet sich schon bei der Neutralisation der Verdaumnsflüssigkeit und nachherigem vorsichtigen Eindampfen ab. In neutrabisierten klaren Filtrate wird die noch vorhandene Nukleinsïure durch verdünte Schwefelsänre, durch Alkohol unter Zugabe von Natriumacetat, durch Zusatz ron gelistem Kupfersulfat oder durch eine 50 oige wässerige Lösmng ron Nercuriacetat bei genan nentraler Reaktion gefällt.

I'm die durch Vercuriacetat gefällte, mit Spuren ron Proteosen oder vielleicht anch von Hexonbasen vermnreinigte Nukleinsänre in reinerem \%ustande zu erhalten, wird dieser Niederschlag abfiltriert und auf dem Filter mit etwas Wasser, dem etwas Mercuriacetat zugesetzt ist, griudlich ansgewaschen. Dann wird der Niederschlag in Wasser aufueschwemmt. das Quecksilber durch.Schwefelwasserstoff abgeschieden, rom Schwefelenecksiber abfiltriert, anf dem Wasserbade eingeengt, schlieblich in absolutes Ilkoholitthergemisch gegossen, wobei eine feinflockige Füllung entstelit. Solange der Alkoholäther noch wasserhaltign ist. geht immer ein Teil der Füllung wieder in Lösung, den man indes durch Einengen der Alkoholiitherfliissigkeit und erneutes Eingielien derselben in absoluten Alkoholäther zurïckgewimmen kamı.

Wird die derartig mit Qnecksilberacetat rorbehandelte. nukleinsäurefreie Verdaumgslösung neutralisiert. so kann man darin the Proteosen und die anderen spaltungsprodukte des Proteinenanteiles des Yukleoproteides nach den frïher beschriebenen Verfahren nachweisen und isolier('n.')

In der von der unzersetzten Nukleinsäure befreiten Fliissigkeit kann man die abgespaltene l'hosphorsäure durch Eindampfen und Teraschen mit soda und salpeter oder durch Versetzen mit Magnesianischung und Behandlung des entstandenen Niederschlages ron phosphorsaurer Ammoniak-

1) F. Cimber, Ľber die fermentatice Spaltung der Nukleoproteide im Stoffirechsel. Zeitschr. f. klin. Ned. Bd. 43. S. 252-303 (1901). 
magnesia in iblicher Weise nud Wägrn der Phosphorsäure als prophosphorsame Magnesia nachwrisen.1)

Narh beseitigen ler etwa noch vorhandenen Nukleinsinne mittelst Sehwefelsume kamn man das Filtrat mit Bleiacetat fällen, wieder filtrieren, das neue Filtrit mit soluwefelsäure vom Blei befreien, filtrieren, das num chlaltene liltrat durch Ibdampfen vom schwefelwasserstoffiiberschul befreien. I)am fällt man die Nuklembasen mittelst Silbemitrat und einem Immoniakïberselnuss( $\left.{ }^{2}\right)$

ln durels Schwofelsinre von der nicht gespaltenen Nukleinsänre befrejten Filtrate kann man anch die Purinbasen direkt mit der Quecksilbersulfatlisung ron Kossel mul Putten fällon, welche man dureh Erhitzen

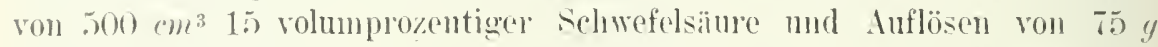
(2urksilheroxyd in der heiben Fliissigkeit bereitet. Der entstandene Niederschlag wirl abgesaugh, in Wasser aufgeschwemmt und unter Zusatz ron etwas salzsïme mit Schwefelwasserstoff zellegt. Damm wird filtriert mul das libltant dureh Imrehleiten von luft voun Schwefelwasserstoff befreit. banacl wind as mit ammoniakalischer Siberlisung gefült. Dej Silberniederschlag wird ahfiltriert. gut ausgewaschen, in Wasser aufgeschwemmt und unter \%usat\% ron Salzsiure in ller Wäme \%ersetyt. Las Chlorsiber wird abfiltrirrt, durch das Filtrat noch einge Schwefelwasserstoffblasen weleitet und dam wiobler filtriert. Das letzte filtrat wird eingedampet, woduch sich die salzsanren P'minhasen kristalliniseh ansschejden. Jie ansgeschiedenen Kristalle werden mit Alkohol und Ather getrocknet und durch dir ron Buriun angegebene mod von P'auly veränderte Diazoreaktion als l'mrimbasen rharakterisiert. Zum Instellen dieser Reaktion wird folgendes Reagens fristh lalgestellt : - y feingepulverter sulfanilsinue werden mit :) $\mathrm{cm}^{3}$ Wassel

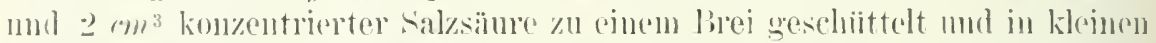
Portional innerhall) einer Minute mit einer Lösmog von $1 \mathrm{~g}$ frischem Kalimmitrat in $1^{-2} \mathrm{~cm}^{3}$ Wassel versetzt. Wobei mah jeden Zusat\% mit kaltem Masseg gekiihlt wiod. Mic sulfanilsiure geht gröbtenteils raseh in Lösmmer mol an ihre Stelle tritt bald cin dichter, weiber, kristalliniseher

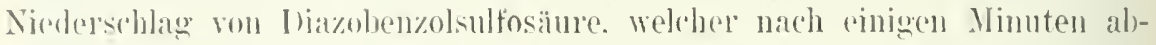
gesangt mol mit wenig. Wasser ansgewaschen wird. Ije zu prifende lösumg

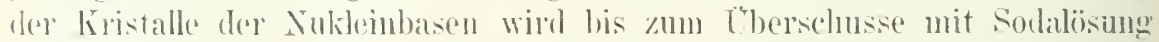
versetyt und damu mit :s $5 \mathrm{~cm}^{3}$ der Burim-l'unlysehen Diazohenzosulfosïnrolosmug. Nach Verlanf von längstens einigen Minutru, meistens aber sofort, entsteht rine arelibe bis rote Farbe ${ }^{3}$ )

1) T. Araki, (Ther enzymatische \%ersetzung der Nukleinsiure. Zeitschr. f, physiol. Chem. Bd. 38. S. 84-97 (1903). … M. Nakayama, iluer das Erepsin. Ehemda. Bd. 41. S. $347-36 \cdot 2(1904)$.

$\left.{ }^{2}\right)$ r. Foù, Sulla nueleasi del suceo intestiuale. Areh. di fisiol. Vol.4. p. 98-100(1906).

${ }^{3}$ ) A. Lossel und A. J. I'atten, Zur Inalyse der Hexonbasen. Zejtselur. f. plysingl. ('hem. Bu. 38. S. 39-45 (1903). - II. I'auly, I'ber die Konstitution des Histidins. Ehenta. Bu. 42. 5. 508-518 (1904). - F. sachs, ther die Nuklease. Fhenda. Bd. 46. S. $337-353$ (1905). - k. Burian, Diazoaminoverbindungen der Imidazole und der Purinsulstanzen. Ber. d. Deutselh. chem. Gesellsch. Bal. 37. ‥ 696-707 (1904). 
Wird die iibrig gebliebene Nukleinsänre durch Alkohol muter Zusat\% von Natrinnacetat gefällt, so versetyt man das dourch Mlulanpfen auf dem Wasserbade rom Alkohol hefreite Filtrat mittelst ammoniakalischer Silberlösung und Kúnfersulfat-Iisulfit. um die Purinhatsen zn isolieren. Wird die muzersetzte Nukleinsäure als kiupfersal\% gofällt, so wirl in Filtrate mittelst der Kupfersulfat-Bisulfitmethode auf freie Purinbasen gefalmdet. ')

\section{f) Isoliernng der Lhbauprodukte der Verdaunng der Phosphatide.}

Unter dem Einflusse des Pankreassteapsins, der Darm- und der Magenlipase werden die als wässerige Emulsionen benutzten I'losphatide gespalten. Am besten bekannt ist der Abbau des Lezithins. Es wird in Glyzerinphosphorsïure, freie Fettsäuren und (bolin zerlegt. Nach Sloutzolf scheinen die Abspaltungen des Chobins und der Fettsäuren mahhängigg voneinander zin erfolgen. Stussano und Billon znfolge wird durch mittelst Enterokinase aktivierten l'ankreassaftes kein Cholin aus frisch bereiteten Lezithinen abgespalten. Nach Bergell wird durch Darmsaft Lezithin leicht und schnell unter Cholinbildung gespalten.

Zur Bestimmung der abgespiltenen Fettsäuren werlen diese an Ende des Versuches mit $1 / 10$ oder $1 / 20$ normaler Kalilauge und Phenolphtalein als Indikator titriert. I)urch 2 besondere liontrollkölbchen mul man die Reaktion des Gemisches von Lezithinemulsion und Fermentlösung ror der enzymatischen Einwirkmo feststellen, im ersten ohne Vorbehandlung, im zweiten nach brwärmen und Zusatz ron $9.5 \%$ igem sïurefreien Alkohol. In + anderen Kontrollkölbchen wird die Lezithinemulsion zur vorher aufgekochten Fermentlösung zugesctzt. Yon diesen 4 Kontrollkïlbchen werden ¿ sofort titriert, und zwar wieder das eine ohne jegliche Vorbehandlung, das andere nach Zusatz von o(1)\%igem Alkohol und Erwärmen. Die 2. letzten Kontrollkölbchen mit erwärmter Formentlïsung hleiben ebensolange in Thermostaten. wie die Hanptversuchskölhchen und werden gleichzeitig mit diesen titriert. und zwar wieflerum das eine ohne Vorbehandlung, das andere nach Zusatz von 95\% wärmen. Luf diese Weise ermittelt man die tatsächliche Abspaltmng ron Fettsäuren ans den zum Versuche angewandten Lezithin.

IIan kamn anch nach den Volhard-Stadeschen Verfahren die Ienge der durch Fermentwirkung frei gewordenen säuren sowie die llenge der noch im unzersetzten Lezithin vorhandenen säuren feststellen und aus den beiden so ermittelten Zahlen die prozentige Abspaltung der Fettsäuren bei der Lezithinverdaunng in Prozenten der Fettsiumen des Lezithins berechmen.

Zur Untersuchung anf murerändertes Lezithin wird das Verdaunngsprodukt mit starkem Alkohol rersetzt und der Niederschlag abfiltriert. Filtrat und Niederschlag werden bei $50-60^{\circ}$ eingetrocknet. Die Riick-

1) E. Abderhalden und A. Schittenhelm, Der Ab-und Aufban der Nukleinsänren in tjerischen Organismus. Zeitschr. f. physiol. Chem. Bd. 47. S. $452-457$ (1906). 
stände werden vereinigt, in Sodhletshen Apparate mit wasserfreiem Ither answagoen und damn mit 9.\%\%

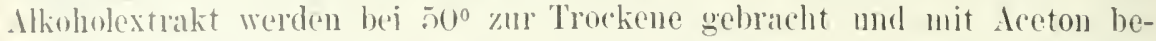
landelt. wodurch in den Acoton die Fettsämen sowie die atwa rorhandemen Fette und Ilkaliphosphate treten, wïhrend die Hamptmasse des Lezithins als Riickstand bleibt. Dieser wird abfiltriert mol in Ather gebracht. In der so erzielten lösmng kam man mittelst Phosphorsïmemul Stickstoffhestimmung die dnwesenheit des lezithins nachweisen. biuses Verfahren (rlauht aber keineswegs, das muersetzte Lezithin quantitativ zu erhalten, demin nach Kumagura und Suto wird das Lezithin alls dem Itherextrakte dureh Leeton nicht ymantitativ gefiilht.

Im Cholin und Cilyzerinphosphorsäure nachzıweisen, wird die fermenthaltige Lezithinemulsion bei to-50 anf dem Wasserbade cingetrocknot mud der liückstand mit salzsïmohaltigem leeton ausgezogen. Iie Acetonliosmng wird abfiltriert, nentralisiert, bei $40^{\circ} \mathrm{zur}$ Trockene gobracht, dor Iitickstand in Wasser gelöst, abfiltriert und mit Krauts Jodwismutkaliumeagens gefällt. Nach 10-12stïndigem stehen wind der Niederschlag auf dem Hilter gesammelt, mit silberoxyl zursetzt, mit Alkohol ansgezogen, das Cholin daraus mit alkoholischem Platinchlorid gefällt. Jas Filtrat der Fällung mit Krouts Reagens wird eingedampft, angesimort, mit Slkohol amsegogen und im dikoholextrakt der von der (ilyzerinphosphorsïme stammemile Phosphor hestimmt. ')

1) Irter Bergell, Ïber die Spaltung des Lezithins durch den bei rollständigem 1)irmverschluß ahgesonderten Darmsaft. Zentrahl. f. allg. Pathol. n. pathol. Anat. Bal. 12. S. 633-634 (1901). - H. stassemo et Billon, La licithine n'est pas dedouble par le sue pancriatique mene kinase. Compt. rend. helul. des srane. de la Soe. de Biologie. T. 15. p. 48\% 483 (190:3). - La lécithine puse ingérée so retrouve inaltérée dans la lymphe

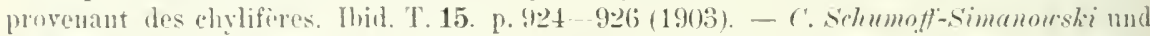
I. sirber, Das Verhalten des Lezithins zu fettspaltenden Fermenten. Zeitschr. f. physiol.

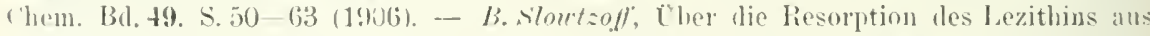
dem Darmkanal. Beitr. z. chem. Physiol. und Pathol. Bal. 7. S.509-513 (1906). -

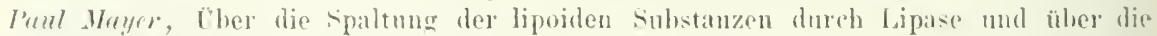
"ptischen Antipoden des natürlichen Lezithins. Biochem. Zeitschr. Ba. 1. S. 39-.22 (1906). - Uher lezithinzuckrr sowie üher tas physikaliseh-chemische Verhalten des Znckers im Blut. Ehenda. Bd. 1. S. 81-107 (1906). - I. Kumagarn und K. suto, Ein ncues Verfahren zur quantitativen Bestimmung des Fettes und der unverseifharen Substanz im tierischen Material nohst der kritik einiger gebränchlichen Methoden. I. Abhandlung. Ehremla. Bd. 8. S. $211-347$ (1908). 


\section{('. Methoden zur Lntersuchung des speichels und des Inhaltes des Verdaunngsschlanches nud der Fïzes der Pflanzenfresser.}

Von $\boldsymbol{A}$. Schennert. Iresden.

\section{Untersuchung des Speichels.}

\section{A. Gewinnung.}

Wie besonders die Untersuchungen Paulous gezeigt haben. ist die Zusammensetzung des Speichels ron den verschiedensten Einfliissen psrchiwher und mechanischer Art abhängig: man wird daher bei der fewinnung von Speichel zn Intersuchungszweeken je nach den Lmständen, nnter denen sie erfolgt. verschieden zusammengesetyte Sekrete erhalten. "bber die Gewimung lassen sich daher nur canz allgemeine Angaben machen.

Das Sekret bestimmter Speieheldrüsen wird hei Tieren ilurch Anlegen ron Fisteln all die Ausführungsgänge ( $\mathrm{rgl}$. Bd. III. S. 96) gerronnen. Germisehten Mundspeichel geminnt man nach Anlage einẹr Ösophagusfistel derart, daß man das Tier anf irgend eine dureh die Versuchszweeke bedingte Weise zur Speiehelseliretion reranlaßt und den aus der Fistelöffnung austretenden abgesehluekten Speichel auffängt. Durch Torzeigen von Nahrung kamu so psyehischer Speichel, durch Einbringen harter Gegenstände in das Naul Gleitspeichel usw. gewomnen werden. Auch durch Injektion speicheltreibender Mittel (Pilokarpin) oder elektrisehe Reizung kanu Speichelsekretion herrorgerufen werden. (iemischten mensehliehen speichel gewinnt man dureh Kaven anf Wattebausehen oder Sehrämmchen und Eutleeren des im Nunde sich ansammelnden Speichels oder Aus(lrürken der Schwämmehen ${ }^{1}$ ). ferner durch Ausführen ron Kau- und Saugberregungen hei gesehlossenem Munde"). sehließlieh auch dureh clektrische Reizung mit einem galranisehen Strom ron 05-1 Milliampire. wobei die Elektrode des liohlenpols in die linke Hand genommen und mit dem Drahtende des Zinkpols die Zunge bestrichen wird. ${ }^{3}$ )

Mensehliches Parotisseliret erhält man leicht durch Finführung einer Kianüle ron entspreehendem lumen in die (bei Selbstrersuchen mit Hilfe eines Spiegels) leieht auffindbare Mündung eines Parotidenganges.

1) G. Sticker, Ein einfaches Verfahren, größere Mengen ron Mundspeichel zu ge"innen. Nünchner Med. Wochenschr. Jg. 1897. S. 227-228.

-) Jarcein, Zur klinischen Pathologie des Speichels. Wiener Med. Presse. Jg. 1892. S. 568 .

अ) H. llieminger, Beitr. zur lienntuis des mensehlichen Mundipeichels ete. Diss. W ürzhurg. Jg. 1893. S. 42.

A bderhalden. Handbuch der biochemischen Arteitsmethoden. III. 


\section{B. Allgemeine Eigenschaften.}

bie Reaktion des frisch sezcrnjerten phrsiolngisehen speichels ist stets alkalisch.

Ther das Verbalten rerschiedener Indikatoren graen speichel sowie seine liealstion hei hrankheiten rel. hej Ireminger mul Flechseder.")

Jor Speidel ist stets durch feste Partikelchen getrübt, lie sich bei der mikirnsopisclen l'ntersuehung als Speisereste. ahgestoBene Hund- unl Zungenepithelien. letritus efe. erweisen. Fermer enthät er sogenamte speichelkorperehen (leukozytem?). kemhaltige, ein gekiontes l'votoplasma lesityende /cllen mit amöhoiler Bewegung. Fine Trenmung des Speichels von diesen Bestandteilen kann durel Sedimentiermug oder dureh Filtration (Wattehausch) erzielt werden. Der sich hoim längeren stehen des Speichels an dur Luft abscheilende, dine Trülung hervorrufende Nierlershhag hesteht aus (al ( ()$_{3}$. welehes aus dem Ca(IIC() $)_{2}$ les speichels dureh liohlensäureabgabe entsteht.

Uher die Bestimmung des spezifisclsen Gewichtes ${ }^{1}$ ), ler elektrischen Leitfähir. keit. der (iefrierpunktserniedrigung, der Viskosität des Sipeichels rgl. die betreffruden Kapitel dieses Worlies und die zitierten Originalarbeiten. ${ }^{2.3}$ )

\section{Organische Verbindungen.}

1. I'oteinsubstanzen.

(1) Juzin. Jas Speichehmuin wird dmeh Ansämeru des Speichels mit

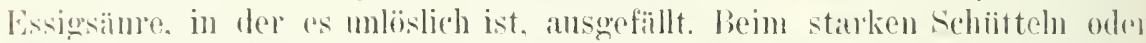

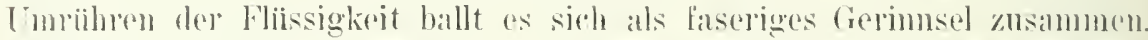

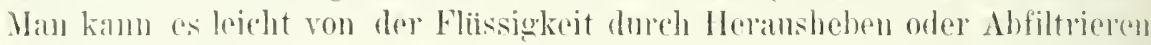
(quantitative Mrothode bei Inwendung gewogener Filter) tremen mul mit

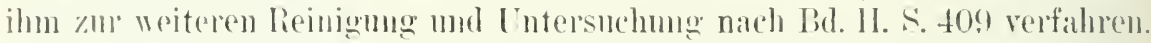
\%ur Identifizicrung geniigt es, durch droistiindiges liochen in 10\% iger H('l am lïichflubkibley den Aminozucker ans ihm athuspalten mod diesen nath

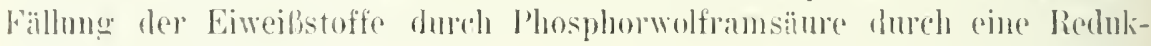
tiomsprobe matehzmwerisen.

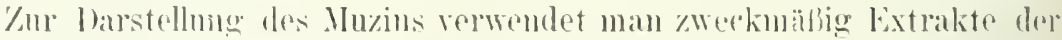
(il. mandilmbaris (submaxillaris). (Vorl. Bul. 1I. s. +10.)

b) Eiweib. Das neben Muzin im Speichel enthalteme native Eiweil

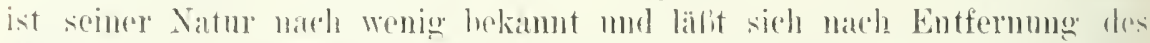
Murins darin mit den bekamuten lieaktionen mathweisen und durch koagnlation entfernem.

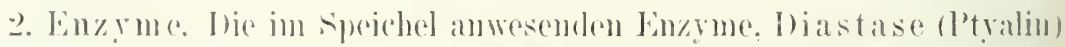

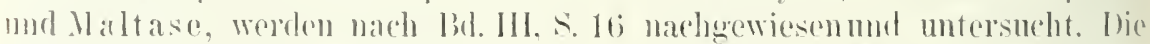

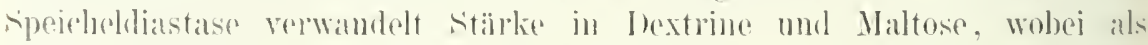

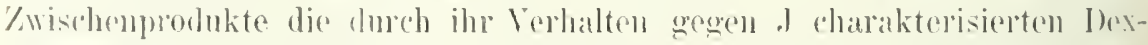

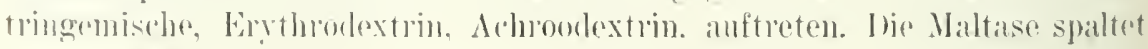

1) I. Flecleseder, Wor gemischte Speichel des Menschen. sein noumales Verhalten mul seine Veränderungen in hrankheiten. Zeitsehr. f. Heilkunde. Ba. 27. Aht. f. inmere Hol. S. 231-296 (1906).

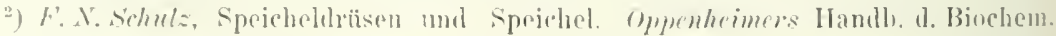
13i1. :3 1. 1.27.

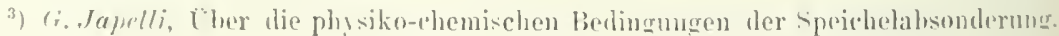

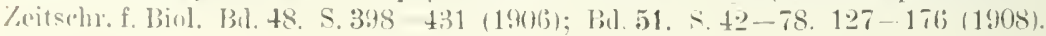




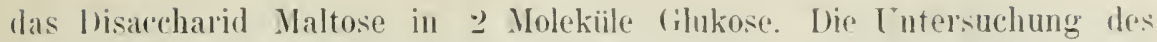
speichels auf (1xydasen erfolgt nach I3d. III. S. fi) ff. Lit. findet sich bui Srhulz, l. ce.

3. Nachweis anderer organischer Verhindungen. Besonders im Speichel liranker ist noch eine Anzahl anderer organischer Verbindungen aufgefunden worden, z. B. Harnstoff, Harnsäure, Aceton, Traubenzucker, Leucin. Über den Nachweis dieser liörper vgl. die betreffenden Kapitel dieses Werkes, üher ihr Vorkommen berichten Dieminger und Fleckseder u. a.

Die von Rosenlach ${ }^{1}$ ) beschriebenen Farbenreaktionen dürften anf seinem Eiweißgelaalt heruhen und nach den Untersuchungen ron Rosenthal ${ }^{2}$ zu urteilen. keine Bedeutung für die Speicheluntersuchnng besitzen.

\section{Anorganische Verbindungen.}

\%ur Untersuchung auf gelöste anorganische Verhindungen wird es in den meisten Fällen nötig sein, die Eiweißkörper des Speichels vorher zu entfernen. Zum Nachweis und zur Bestimmung der ( ()$_{2}$ und des Ammoniaks bedarf es dessen nicht. Zur Enteiweißung süuert man, sofern nicht besondere Methoden (vgl. unten) erforderlich simbl. mit Essigsäure an, filtriert das ausueschiedene Muzin ah und (ntfernt das Eiweiß im Filtrat durch Koagulation. Es kommen in Frage:

Kationen: K. Na, (a, $\mathrm{Mg}, \mathrm{NH}_{4}$.

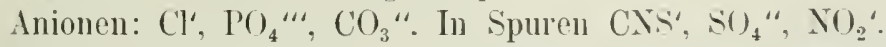

Finer genaneren Besprechung bediirfen nur einige wenige Bestimmungsmethoden, deren Ausfïhrung; zum Teil von dem bei der quantitativen und yualitativen chemischen Analyse üblichen Verfahren abweicht.

1. Salze der Rhodanwasserstoffsäure.

il) Qualitativer Nachweis. Vorsichtiges Einengen des Speichels anf die Hälfte oder ein Drittel seines Volumens leistet häufig gute Dienste.

1. Nachweis als Ferrirhodanid. Die blutrote Farbe des Ferrirhodanids dient auch zum Nachweis des Rhodanalkali im Speichel. Ian fügt zu dem mit $\mathrm{HCl}$ angesïuerten speichel einige Tropfen einer $10 \%$ igen Ferrichloridlösung. Bei Gegenwart von lihodanalkali tritt die durch Ferrirhodanid herrorgerufene hlutrote Farhe auf (in Ather löslich).

Eine praktische Modifikation dieser Reaktion stammt von Gscheidlen ${ }^{3}$ ). der Filtrierpapier mit salzsäurehaltiger Ferrichloridlösung tränkte, trocknete und als Reagenzpapier verwentete. lin Tropfen rhodanalkalihaltigen Speichels auf solches Papier gebracht ruft darauf einen roten Fleck hervor.

‥ Eine noch gröbere Empfindlichkeit ist der Reaktion von Soler $u^{4}$ ) eigen. Jodsämre wird durch rhodanhaltigen Speichel reduziert und dahei

1) U. Kosenbach. Ut ber einige Farbenreaktionen des Mundspeichels. Zentralbl. f. klin. Med. Bd. 12. S. 145-148 (1891).

$\left.{ }^{2}\right)$ J. Rosenthal, Uber Farbenreaktionen des Mundspeichels. Berl, klin. Wochenschr. Jg. 1892. S. 353.

$\left.{ }^{3}\right)$ K. Gscheidlen, Rhodannachweis. Malys Jahresber. Bd.4. S.91 (1874).

$\left.{ }^{4}\right)$ L. Solera, Über eine eigentümliche Reaktion des Speichels. Malys Jahresher. Bd. 7. S. $256(1877)$. 
Jod frej. welches durch stärkekleister (Blaufärbung) nachewiesen werlen

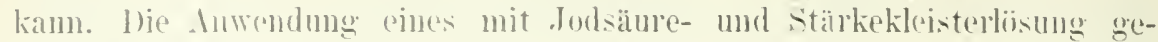
tränkten heagen\%papieres ist anch hier zn empfehlen.

3. lieringere praktische Betentung als die sul 1 und 2 genannten liahen tie Reaktionen ron P'olluccil) und ('olasanti ${ }^{2}$ ) gewonnen. I'ollacei hat die Eigenschaft der Rholanide. mit geringen Mengen Mercurosilzen Mercurialkalirhodanid und metallisehes buechilher zu gehen, zum lihodannachweis im speichel verwendet. In ein selazilchen hringt man etwas falomel nul gibt 10-12 Tropfen Speichel hinzn. Bei Anwesenheit ron Rhodanalkali tritt Dunkelfarbung unter Alscheidung ron metallisehem IIg ein. Colasanti hat mehrere Reaktionen angegeben, von denen die eine anf dem Anfreten einer smaragdgrünen Fïrbun beim Versetzen rhodanbaltigen speichels mit rerdinnter líupfersulfatlösung. die andere auf der Redulition rou Goldchloridlüsungen $1: 100$ () durch verlünnte Sulfocyanatlisungen heim Frwärmen in alkalischer lösung (Kusatz ron gesättigter $\mathrm{Na}_{2}\left(\mathrm{O}_{3}\right.$-Lösnug beruht. In letzterem Falle tritt violette Färlonng dor lösung durch kollovidales Gold cin.

b) ()uantitative Bestimmmu!

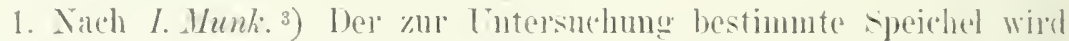
filtriet. zur Trockne gedampft und der Trockensiickstand molnmals mit Alkohol anserzogen. Anf diese Weise erreicht man eine vollständige 'Tremung der Fiweilisubstanzen ron Rhodansalzen. da anber diesen nu noch Chlorile. in das alkoholische Extrakt ïberohen. Der 'Trockemrïckstand des Alkoholextraktes wird mit Wassel aufgenommen, mit HNo, angesäuert mol durels silbernitrat. Chloride und Thodanide vollständig ansgefällt. Del Niederschlag wird anf einem Filter gesanmelt und im Wassertrockenschrank getrocknet.

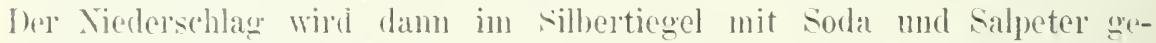
schmolzen. wobei der schwefel des lihodanids zn sehwefolsäme oxvliert

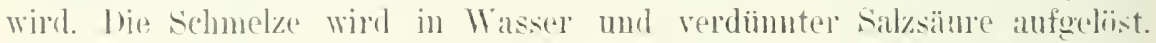
klar filtriert und in dieser Lösmon die Fällnng der schwefelsilume mit Ba('1. vorgenommen. Wunk emptichlt zur Entfermmgr ïherschiissiger salpetersäne die sehmelzo mehmals mit HCl anf dem Wassorbade einzmdampfen mud damn es'st mit $\mathrm{H}_{2}()$ anfzmehmen mod mit lia (1 $l_{2}$ zu tällen.

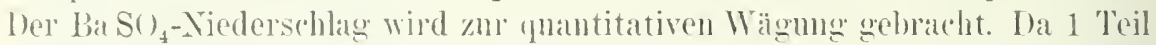

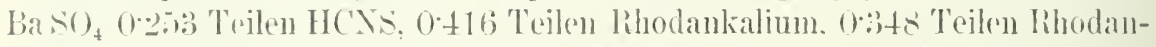
matrium entspricht. läbt sich der Rhodanalkaligehalt des speichels leicht berechusen. Dia Methode gibt recht gename Werte, wie mehrfache Vachpriifungen \%. B. von Krïger eroeben hahen. ${ }^{4}$ )

2. S. Leng ${ }^{5}$ ) hat eine llethoule vorgeschlagen. die sich zu gleichzeitiger Bestimmung der (hloride und Rhodanide eignet. Der enteiwejbte und filtrierte Speichel wird in zwej gleiche Portionen greteilt und in einer l'ortion mit $n$ Ag $\mathrm{N}()_{3}-\mathrm{L}$ ösung nach Volhard titrimetristh die Gesantmenge ler Chloride nul Rhodanile ermittelt. Die andere I'ortion wirl unter Zusatz ron chlorfreiem salpeter in einer I'latiuschale verascht und in

1) E. Pollacei, Narhweis der Rhoulanwasserstoffäure im Speichel. Aun. chin. mal appl. Bu, !) \&. 162. Zit. mach .Halys Jahresher. Bu. 34. S. 425 (1904).

") G. C'olusanti, Zit, nach Malys dahresher. Bill. 19. S. 72-7t (1889).

3) J. Kunk, Phys-chem. Nittcilungen. Tirehous Areh. 134. 69. S. 350-369 (1877).

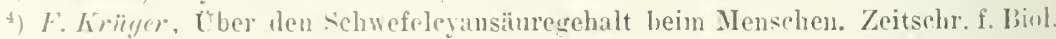
Bil. 37. $\therefore .62-24(1898)$.

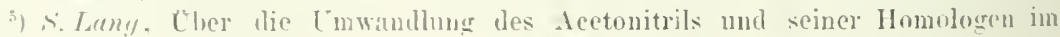
Tierkinper. Arh. f. exper. Y'ath. u. Pharm. Bd. 34. S. 2253 (1894). 
In mit Wasser anfgenommenen Sehunclze der ('hlorgehalt ermittelt. Lurch berechnung läßt sich der Gehalt an Thineyansäure leieht ermitteln.

:). Sipektrophotometrische Bestimmung. Sehr schnell und mit grolier (ienauigkeit lïbt sich der Rhodangehalt des Speichels mit Hilfe des Spektrophotometers hestimmen. Tezmer 1), (ler mit dem Höfnorschen Instrument arbejtete, hat foluendes Vorfahren erproht:

Nach cutsprechender Verdiummog des Speichels mit Wasser (das Spektrophotometer liat fiir Rihodanillïsungen von 0.0015-0.0025\% Salz-

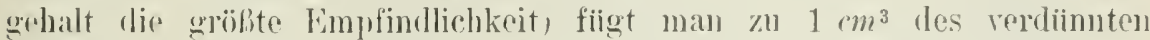
Speichels :; 'Tropfen rerdiumter Eisenchloridlösmng. schiittelt un and filtriert durch cin kleines Filter. Das Filtrat wird in den Mbsorptionstron gefiillt mol der Extinktionskoeffizient bestimmt (Doppelbestimmung mit je 10 Ablesungen). Näheres vgl. Spektrophotometrie Bd. I. A.631. Da der Extinktionskocffizient $\varepsilon=\log \cos ^{2}$ o und das Absorptionsverhältnis I für Ferrirhodand mach Tezners Bestimmungen 0.00:3 betrïgt, lälit sich die Konzentration c del Lösung gemäß der Formel $c=\Lambda$. $\approx$ oder $c=-\log \cos ^{2}$ o $0 \cdot 00: 3$ herechuen, wobei o der abgelesene Winkel ist. Dir Methode lälit sich aufjerordentlich rasch und mit sehr geringer Speichelmenge $\left(1 \mathrm{~cm}^{3}\right)$ ausführen (Fehlergrenze ㄴ $0.0015 \mathrm{mg}$ ). Über Anwendung des Glanschen Spektrophotometers zur lihodanbestimmung vgl. Wroblewshi. ${ }^{2}$ )

4. Die kolorimetrisehe Bestimmung ist mehrfach angewand worden, gilut aher lesultate, die an Genauigkeit bedentend hinter denen der geschilderten Methoden zuriekstehen. Das alte Terfahren von Oehl ist neverdings von Fleckseder ${ }^{3}$ ) in folgenter Weise ansgeführt worden. Benötigt dazu werden zwei gleiche, genau in liubikzentimeter geteilte Eprouvetten. In die eine werden $0.5-2 \mathrm{~cm}^{3}$ klaren Speichels (Sedimentieren oder Filtrieren), in die audere die gleiche Menge einer $01 \%$ Rhodankialiumbösung gebracht und zu heiden ein gleiches Volumen einer $10 \%$ igen Eisenchloritlösung, die etwas $\mathrm{HCl}$ enthält, gegeben. Durch Unschütteln wird Vermischung und gleichnaißige Fïrhung der Flüssigkeiten erzielt. Die Lösung, welche eine tiefere rote Farbe zeigt, wird dann mit soviel Wasser verdünt, bis ibre Farbe mit der der anderen unverdünnten ïbereinstimmt. Der Rhodangehalt des Speichels läßt sich durch einfache Derechnung ermitteln. Fine kolorimetrische Bestimmung kann natiurlich auch unter Anwendung eines der üblichen Kolorimeter ausgeführt werien.

Ausführlicheres über Phodanbestimmung findet sich bei rillain. ${ }^{4}$ )

II. Chloride.

\%ur quantitativen Bestimmumg der Chloride empfiehlt sich das oben angergebene T'erfahren von Lany oder dic Methode ron Munk. (Lit. sub I Z) 1 und ๖.)

1) E. Tezner, Variations phys. de la composition de la salive. Areh, interuat. de I'hys. T. 2. ก. $153-191$ (1905).

2) A. Wrobleuski, Anwendung des Glanschen Spektrophotometers anf die Tierchemie. Quantitative Bestimmung der Rhodansalze in Speichel. Krakau. Akad, d. Wiss. Bil. 96. S. 389 (1896).

3) R. Fleckseder, Der gemischte Speichel des Menschen, sein normales Verhalten und seine Terïnderungen in Krankheiten. Zeitschr. f. Heilk. Bd. 27. Abt. f. innere Med. S. $231-296(1906)$.

4) E. Villain, Über das Vorkommen und ten Nachweis des Rhodans im Menschenund Tierkörper und seine toxikologische und pharmakologische Bedentung. Diss. Frejburg 1903. 


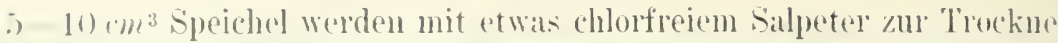

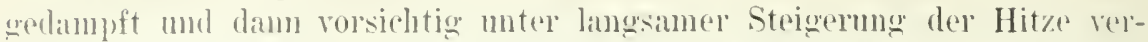
kollt und schlieflich iiber freier Flamme rasch gegliht. Die weibue Schnelze

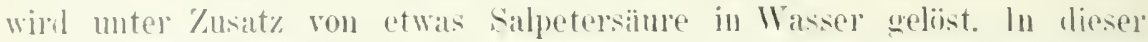

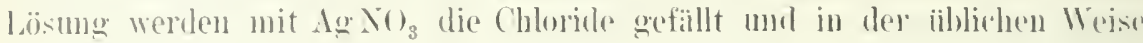

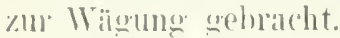

HI. Nitrite. Zum Nachweis der Nitrite in Speichel künnen verschiedene lieilktionen verwendet werten, die in der qualitativen chemischen Analyse zu grlochem \%wecke dienen. In ganz frischem speichel fallen sie häufig negatir aus.

(1) Mit $\mathrm{H}_{2} \mathrm{SO}_{4}$ angesäuerter speichel giht mit .lolzinkstärkekleisterlösung Blanfarbung infolge Anftretens blauer Jodstärke durch in Freiheit gesetztes Jod. I)ie .Jod. zinkstärkekleisterlosung wird so hergestellt, daß zunäehst 1 y Stärke mit etwas destilliertem Wasser verriehen wird. Diese Anfsehwemmung gibt man in ein Becherglas, fïgt cine Lösmng vou $5 g$ Zinkehlorid in $25 \mathrm{~cm}^{3} \mathrm{Jl}_{2}()$ hinzu und kocht bis zur hösung der Stärke: das l'rodukt wird daun mit $20 \mathrm{~cm}^{3} \mathrm{II}_{2} \mathrm{O}$ und 60 g / Zinkjodisl rersetzt, gemiseht und kanm dann zur Realition verwendet werden.

b) Mit Sehwefelsäure angesïuerter Speichel gibt mit schwefelsaurer m-l'henylendiaminlösung bei Anwesenheit ron Nitriten Gelh- lis Bratufärbung (Bismarckluam). \%ur Herstellnug der Lösung werden $5 \mathrm{~g}$ m-Phenylendiamin mit schwefelsäure bis zur schwach sauren Reaktion vorsetzt und auf $1 /$ aufgefiillt. Ihe Lösung soll farblos scin.

c) $x$-Naphtylanin-Sulfanilsäurelösung gilit mit nitrithaltigem Speichel, anf 8$)^{n}$ (rwärmt, dentliche Rosafürhmo. Zur Bereitung des Reagens wirl $1.0 \%$ g Sulfanilsäure in $150 \mathrm{~cm}^{3}$ einer $30^{\circ}$ igen Essigsäure gelöst; 2. 0.1 g $\alpha$-Naphtylamin puriss. mit $20 \mathrm{~cm}^{3}$ Wasser gekocht. Es bleibt hierbei ein hanvioletter Rüekstand mugelöst. von dem dir ühersteliende klare Flüssigkeit algegossen und mit Lösung 1 vermiseht wird. Die Anflowahrung soll in Flïsehchen mit paraffinierten Stopfen erfolgen. Die Realitiois ist äußerst empfindlich.

IV. A m moniak. Der Nachweis freien Ammoniaks gelingt mit Nesslersehem lieagens. Quantitativ kann der Gebalt an Ammonium durcl Destillation mit IIg an un luffangen les ibbergehenten $\mathrm{NH}_{3}$ in einer säure ron lekanutem Titer lestimut werden. Auch das richlösingsehe Verfahren eignet sieh zur Ammoniakbestimmug im sipeichel.

V. Ciase des speichels. Uher Methoden der frewinumg der speichelgas. $\left.(1)_{2}, \mathrm{~N}_{2}, \mathrm{CO}_{2}\right)$ vgl. Külz [Parotidensekret] $\left.{ }^{1}\right)$. I'flïger |Sulmaxillarsekret $]^{2}$ ).

$$
\text { sipeichelsteine und Kahnstein. }
$$

Die in den Ausführungrsgingen der Speicheldrïsen (Gl. parotis, mandibularis |sul-maxillaris], sullingualis) oder seltener in den Drüsen selbst krankhafterweise eingelagerten Konkremente lıaben im allgemeinen cine ähnliche qualitative /nsammensotzuner und bestehen ans organischen und anorganischen Restandteilen. Uber die organisehen liestandteile ist wenig bekannt, sie simb unter dem Mikroskop zum Teil als leeiber rerschiedener Bakterienarten oder als Epithelien, Speichelkörperchen u. dgl. zu erkenuen. Ihe anorganischen Bestandteile sind auBer Wasser hauptsächlich Phosphate und liarlumate des Ca mul Mg, von denen stets die Ca-Salze, und zwar meist die l'buspliate, seltener die Karbonate in üherwiegender Jenge vorhamlen simd. Xehen diesen finden sich noch geringe Mengen löslieher Salze; Rhodanide finden sich nicht.

1) R. Külz, Über den Gabrehalt menschlieher Selirete. Zejtschr. f. Biol. Bd. 2:3. $\therefore 3: 010-328(1887)$.

2) E. I'flüger, Die Gase des Speichels. P.thïgers Archiv. BA. 1. S. 686-690 (1868). 


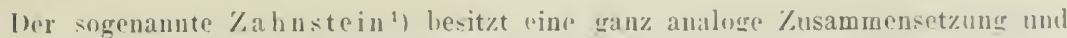
liesteht in ler Hauptsache ans Caleimphosphat orler Calciunkinlonat.

Zur Untersuchung wird dureh dusziehen iler zerkleiuerten lionkremente mit Wasser eine Trenumg der wasserlöslirhen von den wasserunlöslichen Bestanlteilen liewirkt. Dje Lösung kinn der qualitativen chemisehen Inalyse unterworfen werden.

Die unlöslichen Bestandteile lassen sich durch Behandlung mit verdinuter salzsïure, wobei ( $O_{2}$ unter $A$ ufbransen entweicht, in lösnng bringen. Nach dem Abfiltrieren ron ungelösten (organischen) Bestanlteilen siml daun in der Lösung die l'rolon auf (ia, Mg, $\mathrm{PO}_{4}^{\prime \prime \prime}$ vorzunehmen.

Bei der (quantitativen Analyse ist mit ahgewogenen Vengen. die rom Ergehnis der yualitativen Vorprohen und der Menge des vorhandenen Materials abhängen. analog zu verfahren und bei der Alscheilung der einzelnen Verhindungen zur Wägung und bei der Bestimmung der ('), die Nethorlik der quantitativen Mineralanalyse anzuwendeo. Vergleiche Aschenanalyse Bu. I. Quantitativ können feruer ermittrlt werlen: Wasscrgehalt. Asche. Nenge der in $\mathrm{H}_{2}()$ löslichen und mloslichen Bestandteile, Y-liehalt ler organischen Substanzen (Kjeldahl).

\section{Untersuchung des Darminhaltes und der Fäzes der Pflanzenfresser.}

Der Inlaalt des Verdaumgstraktus der I'flanzenfresser ${ }^{2}$ ) oder mit wemischter Sahrung wefütterter Ommi- und harnivoren stellt eine mehr oder weniger diumbleige Masse dar, deren Konsistenz. wesentlich ron der Menge der in ihr enthaltenen Holzfaserteile abhängig ist. und deren Wassergehalt je nach dem Abschuitte des Terdaumngsschlauches. dem sie entstammt, valliiert.

Im Magen rom Pferd und Schwein finden sich 60-70\%. im Dünndarm und ('aekum 90-98\% Wasser, im Kiolon nimmt der Wassergehalt allmählich ab. im Rektum heträgt er $7 \bar{j}-85 \%$. Der Inhalt der Vormägen (mit Ausnahme des Psalters) und des Drisenmagens der Wiederkäner ist stets sehr wasserreich und enthält $80-900^{\circ}{ }_{0} \mathrm{H}_{2} \mathrm{O}$. Der Wassergehalt des Kotes entspricht im allgemeinen lem des Rektums. Pferd (70 bis $80 \%$ ), und ist nur beim Rinde oft ron dünnbreiger Beschaffenheit.

\section{Analytische Bestimmungen in frischen Magen-Darminhalten und Fäzes der Pflanzenfresser.}

In frischen Inhalten und Fïzes kömen ron analỵtischen Bestimmungen nur die der 'Trockensubstanz, del' stickstoffhaltigen Körper und gewisser anorganischer Bestandteile ansgeführt rerden, da zum (ielingen anderer liestimmungen, $\%$. B. der der stärke. der Rohfaser etc. die Zerkleinerung der zu analysierenden Substanzen unbedingt erforderlich ist, diese aber mit feuchtem Material nicht vorgenommen werden kamn. In allen solchen Fällen hat der :malytischen Bestimmung eine Ëntrocknung des Lntersuelungsmaterials rorherzugehen. Ferner kam in frischem Material eine ynantitative Trennung: der gelösten von den ungelösten Bestandteilen vorgenommen werden. Hieran

1) C. Wittmann, Lntersuchungen über Zahnstein und dessen chemische Znsammensetzung bei unseren Hanssängetieren. Diss. Leipzig 1908.

2) Über die Methodik. die sich in vielen Fällen dem Gange der Fnttermittelanalyse anschließt, rgl. auch $J$. Körrig. Die Entersuchung landwirtschaftlich und gewerblich wichtiger Stoffe. Berlin. Paul Parey. 


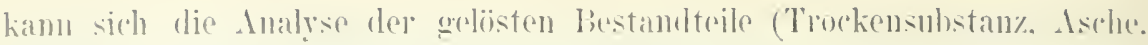
stichstoff. lïsliche liohlehydrate etr.) ansoluliefien.

Fied allen Amalsisen frischen Materials ist die Probeentualume von

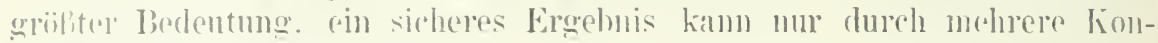
trollamblyen mhalten werlen.

\section{Trockensuletanz.}

lou Magen-barminhalten empliehlt es sich. 10-20) a abzuwïgent.

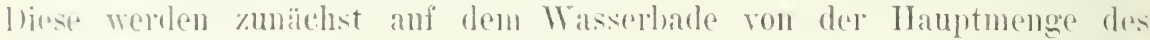

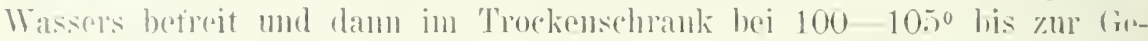
wichtikonstany gratrockinet.

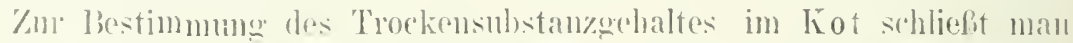
sich dem bei der Futtemittelanalyse greibten Brauche an: otwa jo liot werlen bej $100^{\circ}$ bis zur Gewielitsomstanz getrocknet, was mejst nach $\therefore$ - situmlen erreicht ist.

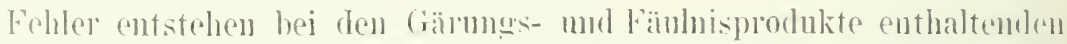
lalminhalten mud den Fïzes dadurch, dafi sich aufer dem Wasser ande noch andere sulstanz(n) velflichtigen (Fettsïnren. aronatischr hörper. Ammoniak etc.l. Soll dies vermieden worlen, so mub bei möglichst nirdriger 'Temperatur ïher wasserentzichenden Mitteh gretrocknet worden. In lisat\% der Luft dureh ein indifferentes lias. $\mathrm{H}_{2}$. ('H, $\mathrm{N}_{2}$ cotc.. ist in solehen Fiillon zu empfehlen.

\section{Bestimumung stirkstolfhaltigner Bestandteile.}

(1) ficsamtstickstoff. \%ur Y-lestimmmug bedient man sich dor

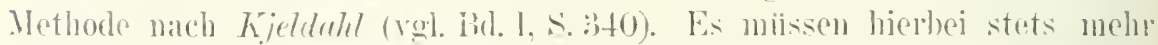
als 2) liontrollanalysen ansgefiilnt werkn. zn denen je nach dem Wassergehalt 2-10y der fenditen substan\% verwendet werden sollen.

b) Bestimmung des Eiweilies und Nichteiweifes im hot del

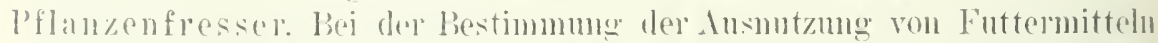
ist es ibhlich. den stickstoff dev Futtermittel anf .. liohpmotein" ummuechnen

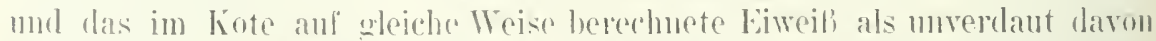

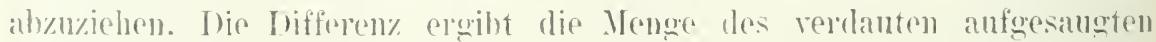

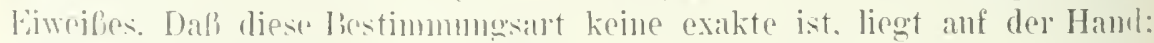

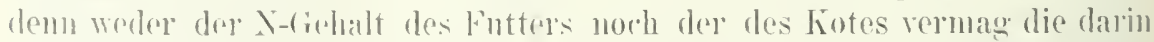

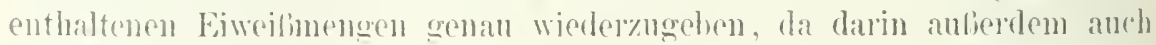

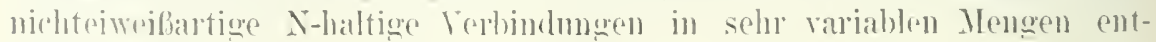
haltens sind.

Stutzer hat eine Methorle ansogaldeiter, die gestattet, in Futtemittoln wenigstens annähernd genan die Menge des whklichen Eiweiles, .. des liein-

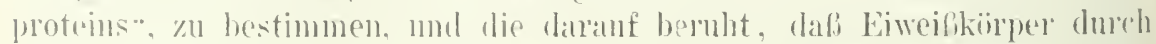

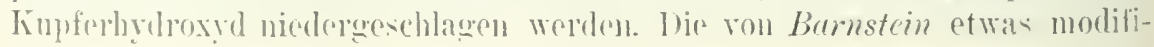




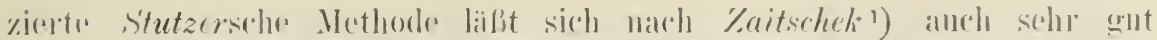

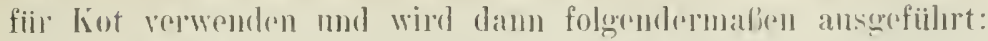

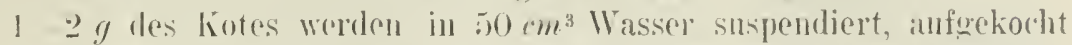

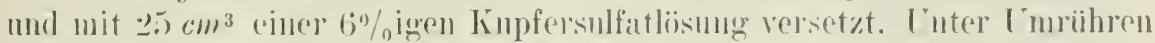

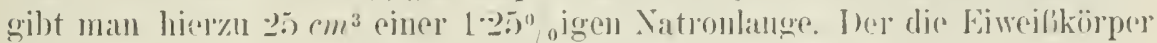

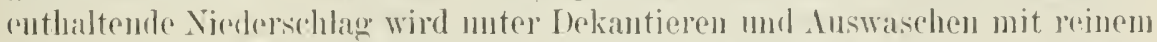

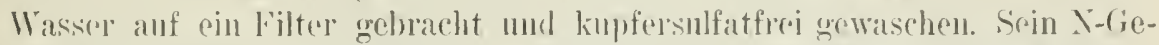
laalt giht mit (0.5.) multipliziert. den Eiweilogehalt (Reimprotein) del substanz

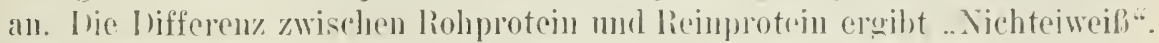

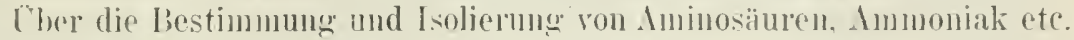
vel. Bid. III. Mbschnitt: Stoffwerhsolendprodukte.

(2) Bostimumug der im kote enthaltenen, aus den Stoffwechsiplodukten stammenden Stickstoffmengen. Kahlreiche eingehende [utersuchumgen Stutzers und anderer Antoren berechtiscen zu der Ammahne, dab die in Kote der Pflanzenfressel vorhandenen, durch kiinstlichen Magnensaft löslichen Stickstoffmengen als Mafh des mit dem liote

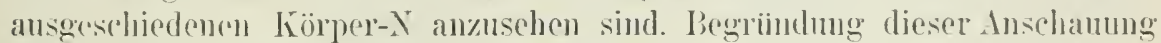
siche in den () loiginalartikeln. 1, 2, 3, 4, 5)

Von Bedeutung für die Ansführung der von Stutzor ausgearheiteten Methode ist die Vertrendung ganz frischen líntes, da dieser beim Trocknen unter gewöbnlichen Bedingungen rine etwa $6^{3}$, betragende Erniedrigung seines Verdaulichkeitskneffizienten erleilet. ${ }^{6}$ ) Eintrocknen bei $15-20^{\circ}$ ruft nut einen geringen Fehler hervor, loch ist ein fehlerfreies Konservierungsverfahren vorzıziehen, das darin besteht, daß man pro $100 \mathrm{~g}$ liot $1 \mathrm{~cm}^{3}$ schwefelliohlenstoff zufïgt und das Gemisch in luftricht schließenden Glasstïpsclflaschen anfliewahrt. ${ }^{5}$ )

Zur Ansführung der Bestimmung ${ }^{4}$ ) verfährt man wie folgt:

*) Bereitung des kïnstlichén Magensaftes. Es empfiehlt sicl hierzu ein Extrakt von Schweinemagenschleimhant derart zn hereiten, daß von einer größeren Anzahl (am besten 6) Mägen die Schleimhänte ahpräpariert und gut zerkleinert werden. Zum Schleimhantbrei werilen $15 /$ Wasser und dazu $300 \mathrm{~cm}^{3} 10 \%$ iger H ('l gegeben. Unter ifterem Umschïtteln bleibt tas Gemisch 24-30 Stnnden lang del Extraktion äherlassen. Jann wird das Extrakt erst durch Flanell koliert, dann dureh Papier klar filtriert und sein (ichalt an Salzsïure durch Zugahe der titrimetrisch (Phenolphtalein) leicht zu ermittelnden Menge anf $0 \cdot 2 \%$ gebracht. Zur besseren Konservierung empfiehlt stuzar den Zusatz einer möglichst kleinen Chloroformmenge.

${ }^{1}$ A. Znitschek, Zur Methodik der Bestimmung des Stickstoff- und Fiweißgehaltes ler Fäzes. Fflügers Areh. Bu. 98. S. 595-62.2 (1903).

$\left.{ }^{2}\right)$ A. Stutser, Einige Beobachtungen über Proteinverdanung. Zeitschr. f. physsiol. ('hemie. Bil. 10. S. 153-169 (1886).

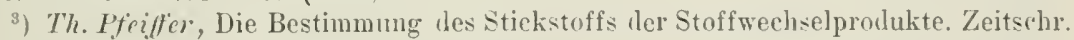
f. physiol. ('hemie. Bıl. 10. S. $560-576$ (1886).

4) A. Stutzer und E. Verres, Untersnchungen üher die Wirkung der Enzyme der Magenschleimhaut und des Bauchspeichels auf regetabilische Eiweißstoffe. Biochem. Zeitschr. Bil. 9. S. 127-162 (1908).

$\left.{ }^{5}\right)$ A. Stutzer, E. Merres und L. Seiller, Die Untersuchung des liotes auf Gehalt an Stickstoff, der in Form ron Stoffwechselprolukten darin enthalten ist. Biochem. Zeitschr. Bi. 9. S. 310-317 (1908).

$\left.{ }^{6}\right)$ ( Beger, Uher den Stickstoffgehalt und die Löslichkeit stickstoffhaltiger Bestantule in l'epsinsalzsäure sowohl in frisehem wie in präpariertem Hammelknt. Zeitschr. f. phỵsiol. Chemic. Bil. 40. S. 176-181 (190304). 


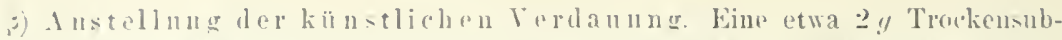
stanz entsprechemle Nenge liot wird mit $250 \mathrm{~cm}^{3}$ des kïnstlichen Magensaftes übergosien und nach dem Erwärmen auf $37^{\circ}$ hierzn allmählich soviel H('l gefügt. his eine honzentration mn $1^{\circ}$ o 11 ( 1 erreicht ist und dann 12. Stunden stehen gelassen. Danach wirul das lieloste rom l'nselösten ahfiltriert und in letzterem der stickstoff bestimmt. Jie I)ifferenz zwischen dem $X$ des frischen liotes und dem ungelöst gebliebenen $\mathrm{X}$ uilut den Y-fiehalt der im liote enthaltenen Stoffwechselprodulite.

\section{Untersuchung anf anorganische Bestamiteile (Analyse der As(lie).}

ber pualitativen und puantitativen Bestimmung anorganischel lel-

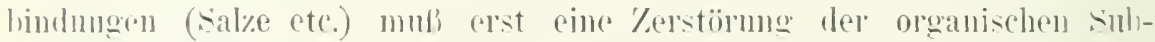
stamen vorherohen, die teils auf nassem Wege. teils durch Verasthmo

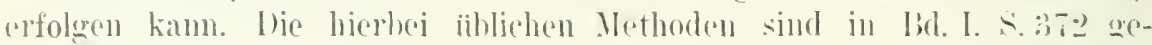
schildert.

\section{Trennung der löslichen von den unlöslichen Bestandteilen mul Analyse der löslichen Bestandtrile.}

Kommt es darauf an. in yuantitativ abgewogenen Mengen die geliisten vou den ungelisten bestandteilen zu tremen. so kann num die Filtration dureh gewogene, quantitative Filter gewählt werlen. Von den wasserämeren In-

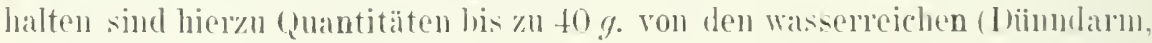
Cackum) bis zu ? g an ampfehlen. Bei der Entmahme dieser Portionen ist die groblo sorefalt daraut zu lexen. dab man wirkliche Mittelproben erbält. bie Filtration findet im Eisschank, das Auswaschen mit eiskaltem Wassel

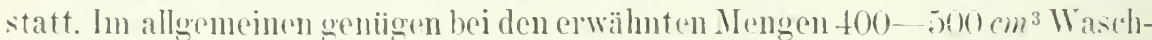
Wasser zum grüullichen Iuswaschen. Ilas auf $.000 \mathrm{~cm}^{3}$ aufgefülte Filtuat enthält dio gelösten Inteile (Kohlehvdrate. Fiweiblerivate) in solcher lionzentration. dab in 100 resp. $50 \mathrm{~cm}^{3}$ genane analytisehe liestimmumgen atusgefïilut werlen kïmnen. Die Filtration danert bei den sauren Mageninhalten

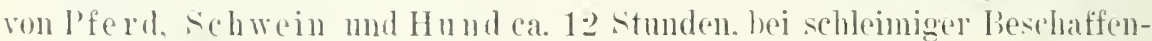
heit mul alkalisther liogktion der Inhalte und bei den Inhalten der viej Wiederkän'rmägren oft hedentend länger.

Handelt es sich lerliglieh darum, einen 'T'eil der Inhaltsflissigheit

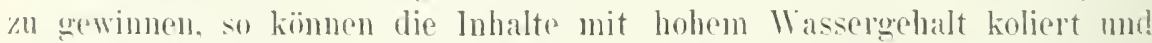
dann filtriert werden. Bei wasseramen Material (7. R. Magenimhalt von I'ferod mud schwein) bediont man sich mit Tolteil del l'resso (Handpresse oder hydraulisohe I'resse). Die ansegeprebte Flissigkeit läbt man entweder absutzen oder man zentrifugiert sie. In beiden Fällen mul das

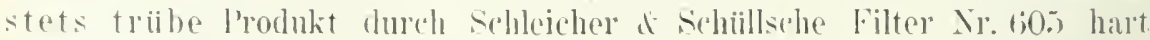
ofler extrahart in Eissolnank klar filtrient werten. Mehrmaliges Gielien des anfänglich fast immer triben Filtrates anf dasselbe Filter ist erforIerlich.

Soll im Inhalt cines Iarmabshnittes die Nenge der gelösten Stoffe hestimmt werilen, ohne dab in abgewogenen Mengen. wie soeben geschildert, die Trennumgr vorsenommen werlen kann, so verfährt man wio folgt: das im gesamten Inhalt enthaltene. 
ans der Trockensubstinzlostimumug herechnete Wasser sej a. Man gewinnt dam durel Anspressen und Filtrieren klare Inhaltsflüssigkeit. Von dieser werden $10 \mathrm{~cm}^{3}$ gewogen $\mathrm{b}$ und hierin der Wassergehalt ermittelt $P$. Wis muß sich dann verhalten: Wassergehalt der $10 \mathrm{~cm}^{3}:$ Trockensubstanz der $10 \mathrm{~cm}^{3}=$ Cresimtwassercehalt $: \mathrm{x}:$ also $c:\left(1-c^{\circ}\right)=\mathrm{a}: \mathrm{x}$ oiler $x=\frac{a(b-c)}{c}$.

11) Votersuchung dor geliosten linstandteile.

y) Trorkensubstan\%. Je nach der Konzentration der Flissigkeit

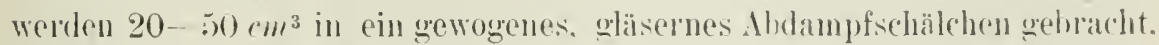
zmöachst auf dem Wasserbad, dann im 'Trockenofen hei 100 10.50 getrocknet mid dann gewogen.

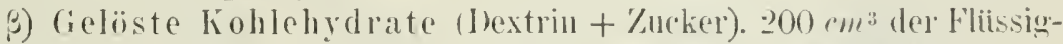
keit werden im offenen stehholben unter /usat\% ron $20 \mathrm{~cm}^{3} 25^{0}$ iger $\mathrm{HI} \mathrm{Cl}$ :) Stunden auf dem siedenden Wasserbade rolitzt. Hiedurch werden die höheren Kohlehydrate hydrolysiert mol der dabei entstandene \%ucker kium nach einey der iblichen Methoden bestimmt werlen (vgl. Mid. II. S. 11! ff. und S. $167 \mathrm{ff}$.). Fis empfiehlt sich stets. im lieaktionsprodukt die mit Phosphorwolframsäure föllbaren substanzen zu fällen und im neutralisierten Filtrat die \%uckerbestimmung vol\%unchmen (vol. unten unter stäkebestimmung, S. 271).

y) Reduzierende Kohlehydrate. '/m' Znckerbestimmung werden $100 \mathrm{~cm}^{3}$ des wässerigen Filtrates, bei konzentrierten hösmgen entsprechend weniger, mit Salzsiiure und Phosphorwolframsäure ron den damit fällbaren Substanzen befreit, das Filtrat genau neutralisiert und auf ein bestimmtes Volumen gebracht. Fs kann dies sowohl durch Auffiillen als auch durch Eindampfen anf dem Wasserhade geschehen. Wie Zuckerbestimmmo erfolgt nach einer der iiblichen Methoden.

i) Stickstoff. Kur Analyse nach Kieldahl (vorl. Bd. I, S. :3t0) verwendet man $50 \mathrm{~cm}^{3}$ les wässerigen Filtrates (bei konzentrierte Lösun! entsprechend weniger). Man kann diese zunächst nach /usatz von etwas schwefelsäme im Verbremmungskolben auf ein kleineres Volumen eindampfen oder auch direkt mit 20 ' $\mathrm{cm}^{3}$ konzentrierter $\mathrm{H}_{2} \mathrm{SO}_{4}$ und (puecksilher verbrennen.

s) Ciber die Ausfiihrung der Untersuchung anf Fineiliahbauprodukte. Fermente, Salze etc. vol. die die Intersuchmog dieser Substanzen behandelnden Kapitel dieses Werkes.

b) Vntersuchung der ungelösten Bestandteile.

Die auf dem Filter zurïckgebliebenen ungelösten Bestandteile könmen in ihrer Fesamtheit getrocknet und gewogen werden. Zur Analyse werden sie, wie weiter unten geschildert wird, vorbereitet und verarbeitet.

\section{Anderweitige Verarbeitung des frischen Materials.}

Sollen Magen-Darminhalte der Pflanzenfresser von koagnlablen Fiweißkorpern befreit werden, so kam, falls die Anwendung der von Rona und Michaelis ausgearheiteten 
Methulen del Euteiweißung (Mastix, liaolin) angängigr ist, rel. Bl. I. S. li86, der gesamte

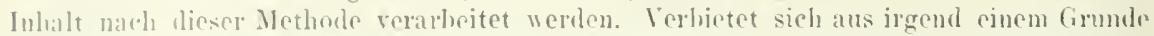
die Anwrudung dieser Methoden. so muß wor der Hitzeknagulation hei stäirkereichem Matrial erwarnt werden. Beim Anfkochen tritt eine Verkleisterung der Starkekürnehen

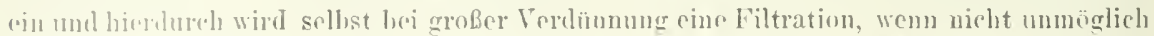

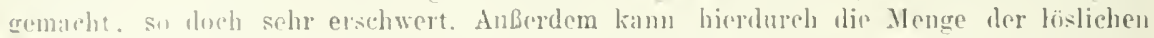
linhlehydrate aine steigermng erfahren mul die Bestimmung derselhen illusoriseh werden. lis emptiehlt sich daher zmä̈ldst. wie olon hesehricben, durch Anspressen und Zentrifuginem dir gelosten Bestandteile zn gewinnen mol in disesen damn die Hitzekoagulation, dio äbrienens in desen Fällen besonders schwierig ist, auszufühnen.

Uber die Isolierung flüultiger. Substanzen (Fäulnis- und Gärungsproduktel aus baminhalten durch Destillation und Wasserdampfostillation rgl. Bil. I11. Alsehnitt: Stoffuechselendprodulite.

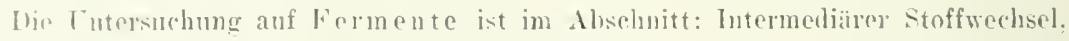
dir auf lerdanungsprodukte s. 12.2 ff. geschildert.

\section{Konservierung des frischen Materials.}

Frisches Material mit geringem Wassergehalt kamm muter absolutem Ilkohol anflewaht waden. Kur Analyse ist dam der Alkohol abzudestillieren und das lostillat anf stickstoffhaltige liasen $\left(\mathrm{XH}_{3}\right)$ zu prifen. Stark wasserlaltige suhstanzen (Kot ron hindern. I)aminhalte der I'flanzenfresser)

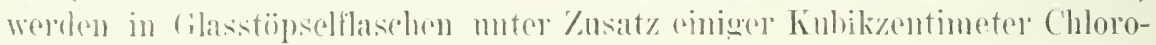
for'm anflicwahrt.

Lipi del lionserviemome ist stets zu beriickichtigen, dab in barminlaalten fordanmesfermente enthalten sind, durell deren Wirkmog weitgohoude Visäulerungen in der \%usammensetzung der Inhalte hervorgerufen wrolen hïmnen. Fine lïngere Infbewahrung soldher Inhalte. in denen Verdaumespodukte von Eiweih oder Kohlehylraten bestimmt werden sollen. ist. anch womn sie in Eisschrank elfolgt, deshalh besser zu muterlassen.

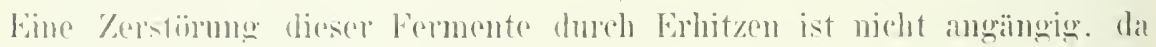

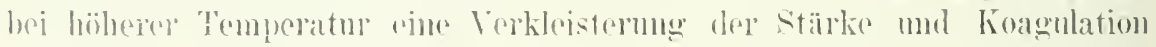

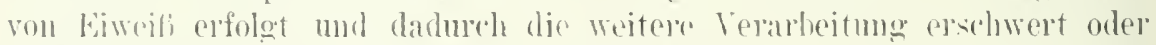

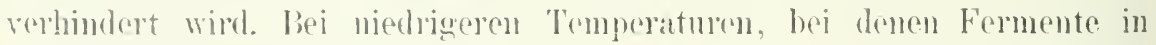

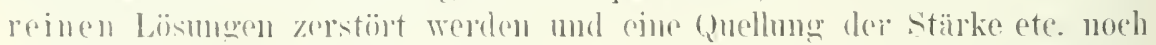
nircht stattfinden wiirde, werden in solehen, dio versehiedensten gelösten substanzen, Verdanungspodukte efe. enthaltenden lösungen die Fermente

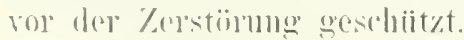

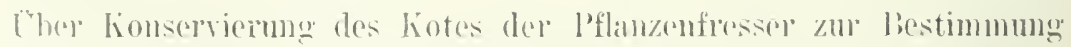
der in ihm enthaltenen stichitoffhaltigen stoffwechselprodukte rol. s. enón.

\section{Vorbereitung von Magen-Darminhalten und Fäzes zur Analyse (Trocknen, Zerkleinern).}

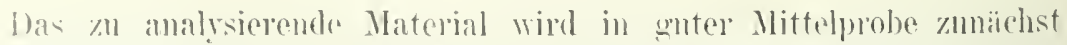

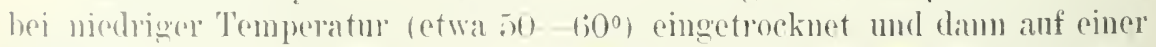
Handmithlo wrob geschoten. I) as geschotone Produkt wird hierauf rer- 


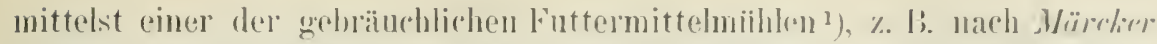

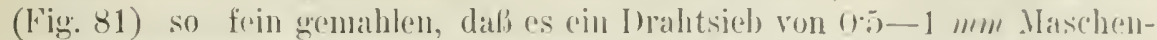
weite detzteres Mals wird rom Verband der landwirtschaftlichen lensuchs-

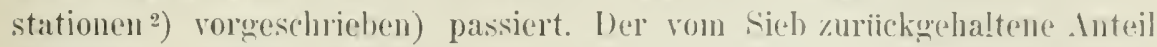
wird stets nochubls gemahlen, his auch er die nötige Feinheit eloreht hat.

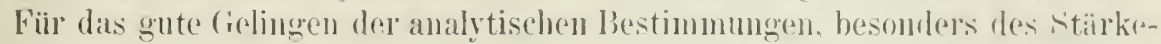
relaltes und der Rohfaser in zellulosereichem Material. ist sine moijglichst feine Zerkleinerung merläßich. Das so vorbereitete Analysemmaterial wim in flachen Gefälien oder anf Papier in diimer Schicht ausgebreitet mul meter öfterem Lmribren 1-2 Tage offen stehen gelassen, um es lufttrorken zu machen. '/ul' Iufbewahrung füllt man es dann zweckminilig in I'ulverflaschen mit eingeriebenen stopfen, als Aufbewahrungsraum diene das Temperaturund Feuchtigkeitsschwankungen nicht unterworfene Wägezimmer. Bei Vernachlässigrung dieser Vorsichtsmafregeln können besonders bei den manchmal Fenchtigkeit leicht annehmenden Darminhalten Schwankungen im Wassergehalt und damit Beeintrïchtigung der Analysenresultate eintretert.

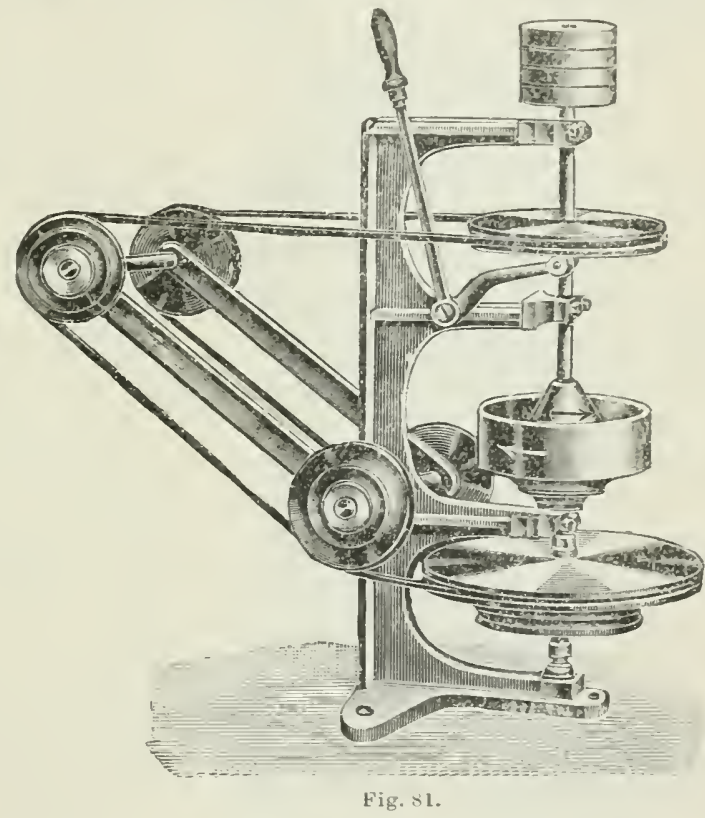

Besondere Maliregeln zur Vermeidung von Stickstoffierlusten bei der Trocknung ron Fäzes und I)ickdarminlalten. Kot und die fliichtige stickstoffrerbindungen enthaltenden Inhalte des Darms verlieren, wie zahlreiche Tutersuchungen gezeigt haben, (ainen recht er-

${ }^{1}$ ) Die algebildete Mühle (mit Motorantrieb) leistet uns seit Jahren bei cler Verarbeitung der Magen- und Darminhalte sovie auch der Futtermittel der P'llanzenfresser ansgezeichnete Dienste. Bei schwierig zu zerkleinerudem Material (Heu. Häcksel). welches lange danerndes Mahlen erfordert, ist allerdings eine Verumreinigung des Mahlgutes durch abgeriebene Teilchen der stählernen Mahlscheiben nicht zu vermeiden. Ihre Entfernung gelingt mit Hilfe eines starken Elektromagneten, ist aber sehr langwierig. Andere geeignete Mühlen sind Bd. I, S.15 u.16 abgebildet und beschrieben. Für die rorliegenden Zwecke eignen sich besonders anch hugelmühlen.

$\left.{ }^{2}\right)$ Beschlüsse des Terbandes landwirtschaftlicher Versuchsstationen. Landw. Versuchsstat. Bd. 60. S. 383 (1901). 
halichen 'Tril ilues stickstoffes bei der Ëntrockmung. wobei as eleich-

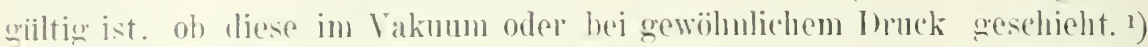

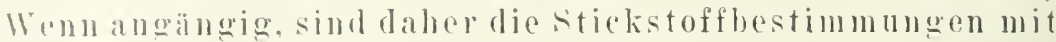
flischom Interial auszufïhron. Ist dies nicht möglich. so missen

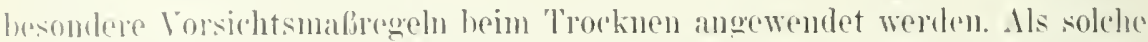
sind das Fintrocknen nach /usat\% von schwefelsäme oder Weinsäure zu

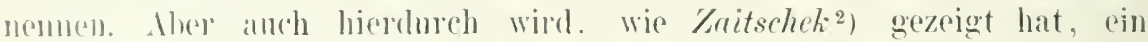
grewisser X-Verlust, der allerlings solu gering ist, nicht verhindert. Ferner worden Verlusto fast vermjeden, wenn hoi duwendung eines Vakummapparates das entweichende Ammoniak oder andere fliichtige Basen durch sä̈ure absolbiort werden und das entweichende Wasser komdensiert und anfgesammelt winl. I'ber Vorbereitung groblierer Kotmengen zu Analyse vol. hei strigel. ${ }^{3}$ )

\section{Analytische Bestimmungen im getrockneten Material.}

1. Stickstoff. Bei der Bestimmung nach Kjoldahi (Bd. I, S. 340) werden zweckmïßig $1-2 g$ der getrockneten Substanzen rerwandt. Uber die Stickstoffhestimmung in liot vergleiche dis Vorhergesagte.

2. Lestimmung der Stäke. Die in Wasser unlösliche Starke wird hekanntlich durch gecignete Igenzien (iiberhitzter Wasserdampf, verdiimute siluren. diastatisehe Enzvne ete.) hydrolytisch respalten und dabei in lisliche produkte (Dextrine. Zucker) iiberoführt. Die analytische liestimmum

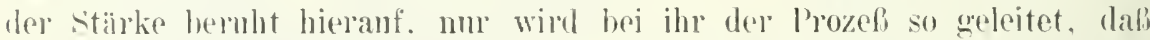
als alleiniges Fudprodukt (ilukose entsteht, deren Menge quantitativ bestimmt und lamm dalans die Stäkemenge berechnet wird. Am meisten ist die Inwendmug der von Märcher und Morgent) vorgeschlagenen Modifikation des Anfschliebrelfahrens zu empfehlen. Nach cigenen vielfachen Erfahrungen ist das zweckmäfigste Verfahren folgendes:

2-:3 g der feingemahlenen Substanz werden mit :30-40 $\mathrm{cm}^{3}$ Wasser in aincon Metallbecher gut rerrührt und dieser mit dem Deckel bedeckt ıur Verkleisterung seines Inlabltes in ein kochendes Wasserbarl (grober Blechtopf mit beckel) eine Stunde ling oingestellt. Alsdam läbt man auf

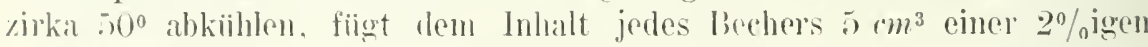

1) Anmerkung. Nach Zaitschek wal der N-Verlust, Ien der Lot bein Troeknen relitt. im Durchschuitt

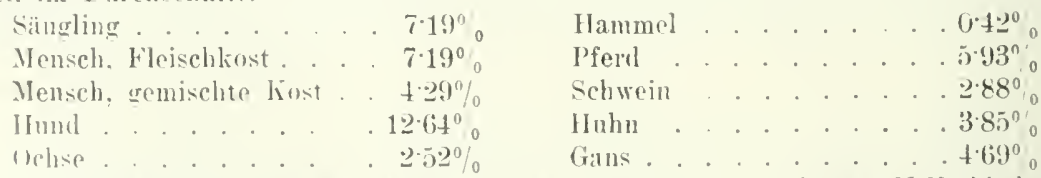

Hauptsälhlich ist dieser $\mathrm{N}$-Verlust auf das Konto flüchtiger $\mathrm{N}$-Verbindungen lesenders vou Ammoniaksalzen zn setzen, doch kömnen nach o. Kollner (Landwirtseh. Versuclsstation. Bit. 47. S. 288: Bd. 50. S. 256) wahrscheinlich auch noch durch Zersutzine anderer Verlindungen. z. B. Harnstoff, solehe Verluste entstehen.

2) A. Zrritschek, Zur Nethodik der Bestimmung des Stickstoff- und Eiweißgehaaltes der Facers. Pylügrre Arehiv. Bol. 98. S. $595-622$ (1903).

3) 1. Strigel, Allgemeiur Methodik der Analyse organischer Stoffe. Oppenheimers Ilanthuth der Biochemie. Bel. 1. S. 1 (190)8).

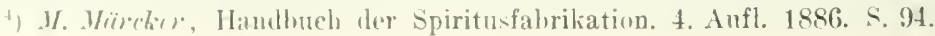


Diastasemafschwemmmog (Diastase Derek puriss, andere l'räparate enthalten häufig Zneker!) zu mol verrö̈lurt den Inhalt unter dbstreichen der an den (iefübwinden haftenden Trile der angewandten Substanz gut. Ian stellt dann den Motallbecher in das Wasserbarl zuruick mucl hält mummedr die 'Temperatur eine hallos stumdo lang anf $6(0)-70^{\prime \prime}$, nn bei dieser der Diastasewirkung wiinstigan T'emperatur eine Verzuckermug der verkleisterten

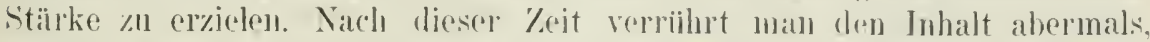

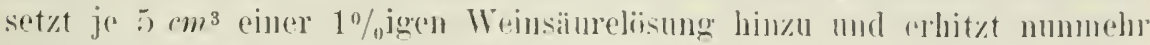

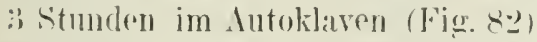
hei rinem Druck roul : 1 tmosphïlren. ler Zusat\% der Woimsïuro (a)folgt. um schwach saure Reaktion zn er\%ielen, ist diese nicht vorhanden, so wird die gebildetr Inextrose leicht zerstört. Das wleiche ist der Fall. wemn der I)ruck in Antoklaven iiber :) Atmosphären steigt, die I hauce des Erhityens hat unter richtigen Verhältnissen keinen Einfluli. Nach dem Erkalten wird der Autoklas geöffnet und der Inhalt der Metallbecher durch Faltenfiltel. (stïrkefrei!) in Stelskolhen filtriert. ber Filtrierrickstand wird mit horhendem Wasser nachgewaschen mod unter dem Mikroskop mit Jorllösung auf Stärke greprifift. Sind noch Stärkekörṇchen odter gröhisere, sich blaufärbende Teilchen zngegen. so ist der Aufschlub movollstiindig und der ganze Prozeb so oft zu wirderholen, bis die Reaktion newaltiv allsfällt. Bläumng vereinzelter kleiner Teikchen wird iibrigens in

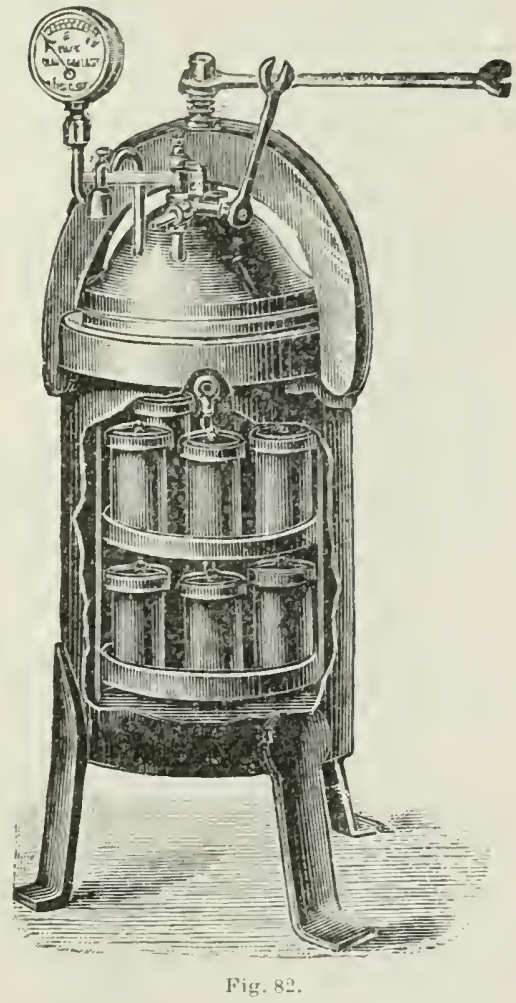
gewissen Fällen stets heobachtet, dem dualysenresultat tut dies nach unseren Erfahrmagen keinen Abbruch. In den meisten Fällen wird somit der dreistiindige Aufenthalt im Autoklaven geniigen. In einzelnen Fiallen, z. B. bej den sehr eiweiBreichen Darminhalten des Hundes. habe ich den Prozeh 3 -imal wiederholen miissen, ehe alle Stärke aufgeschlossen war. Ihe vereinigten Filtrate, die zirka $-200 \mathrm{~cm}^{3}$ hetragen sollen. werden dann mit soviel H ('l versetzt, dali eine $2 \%$ \% ige Lïsung entsteht mol werden :3 Stunden anf dem siedenden Wasserbade erwärmt, un die Inversion z.n vollenden. Zur Zuckerbestimmung entfernt man nach Ellenberger-1) die noch in

1) Lllenberger und Ilofine ister, l'ber die Verdamngssäfte und die Verdaunng des I'ferdes. III. Magenverdaumng. Arch. f. wissensch. u. prakt. Ticheilk. Bi. 8. S. 395-414(1882). 


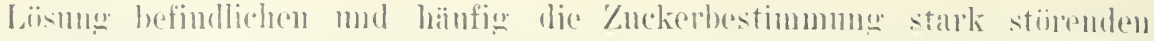

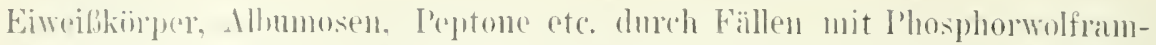

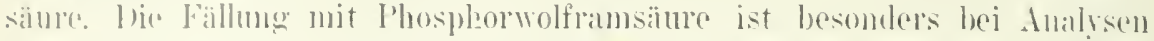

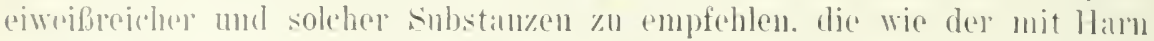

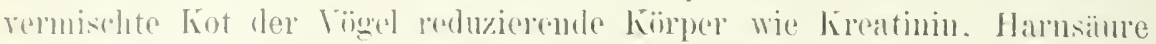

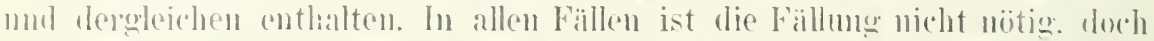
leistet sic besmulers bei späterer Anwendung der titrimotrischen /uckerhestimmunesuotholen stets gute bienste, da durch sie anel substanzen,

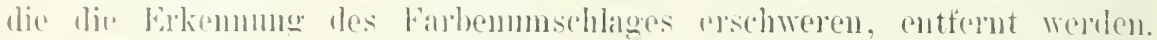

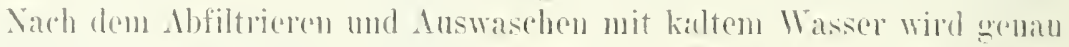

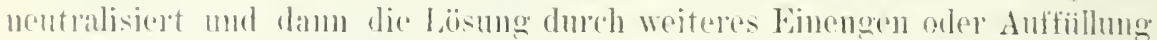

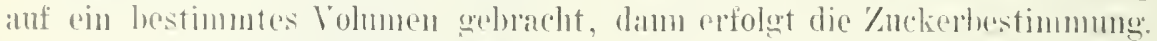

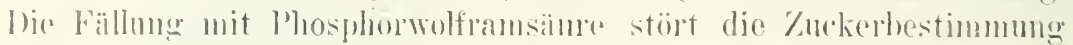

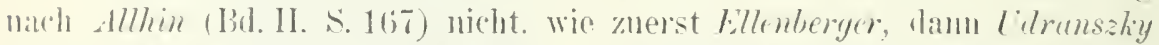
mul Korh, Ireiser und Zaitschet') nachgewiesen haben. Natch museren

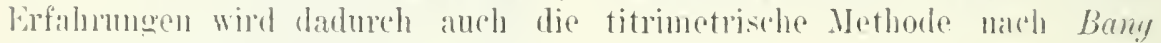
(Iid. II. s. 170) nicht gestiint.

bie gofundene /urkermenge wirl dureh Multiplikation mit (1)! anf stialle mogerechnet.

Falls die analysierte Sulstanz l'entosane enthailt. kann mit der geschilderten Methode der wahre Stäkegehalt nicht ermittelt werden, da die Pentosane teilweise in l'entusen grespalten werden. Ist es erforderlich. den hierdureh entstehenden febler zu

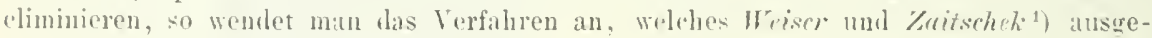
arbeitet mul als branchbar erwiesen hathen.

Die nach dem Aufschluß erhaltene /uckerlisung wirl in zwei gleiche leile 1 mul 2

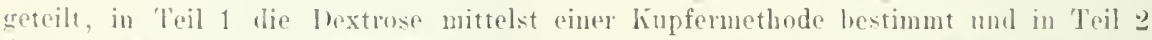
die Pentosen nach Tollens ermittelt (Bul. I1, S. 123). Un nach Tollens auch aus Dextrose bei Destillation mit $12^{\circ}{ }_{0} 11 \mathrm{Cl}$ eine geringe Menge Furfurol entsteht. wird lie in vorliegenden Falle ermittelte Pentosenuenge zu grob sein. Es muß um den wahren Wer zu erhalten, von ihr die Menge Pentose alugezugen werden. die der aus ler vorhandenen bextrose gebildeten Furfurohmense ('utspribht. Rocine Inextrose ergibt $(1) 36^{0}$, Furfurol oder $0.65 \%$ Pentosen (Tollens, Weiser und Zaitschel). Man lringt dies in Anrechnung, intem man $0.65 \%$ fler in Tejl 1 hestimmten lextrosenunenge von der in l'eil 2 ermittelten l'entosenmenge abzeht. Dio Nifferenz ergibt die wirkliehe l'entosenmenge, die von der in 1 luestimmten lextrosenmenge alugezogen, den wahren Dextroseugehalt der l'urtion 1 ergilut.

Diese Berechumugsant ist nul' zulässig, wenn l'entose und hextrose das gleiche liednktionsrermögen gegenüber lüupfer besitzen. Boi der Hydrolyse der Pentosane entsteht stets ein Gemiseh von drahinose mol Xylose mul es ist. un das Reclulitionsrermögen dirses l'entosengrmisches kennen zu lemen. zmlissig, den Nittelwert des Reduktionswormögens heider /uckerarten zu rerwenden. Dieser zeigt aher nach Wrisor und Zetitschels nur ganz geringe Alweichungen ron dem fü Dextrose ermittelten Werte. Fis ist also praktisch unbedenklich. die l'entosemmenge direlit als bextrose zu betrachten und in der Berechnurg als solehe zu verwenden. Anch der liehler, der dadureh entsteht, laß man bei der Berechnumg des aus der Dextrose entstehenden Furfurols die gesante Menge reduzierender Substanzen als luxtrose ansiebt, währent doch ein 'Teil davon ans l'entosen besteht, ist so geringfügig. dafo er praktisch nicht ins Cewicht fällt.

2) M. Weiser und A. Zartscheh. Beitr. zur Methodik der Stärkehestimumug und

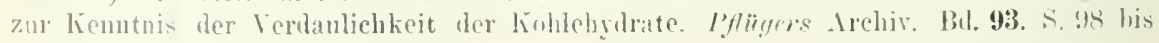
127 (19)2), (llier anch lit.) 


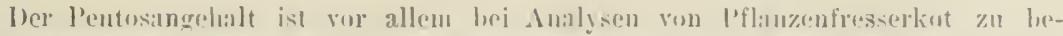

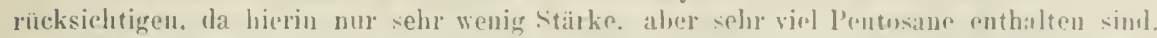

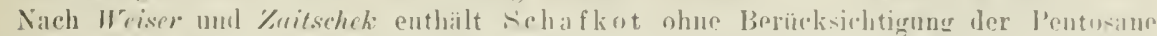

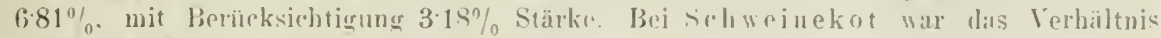

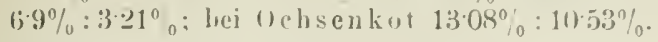

:). liestimmung der l'entosane. Zur Bestimmung der Pentosane

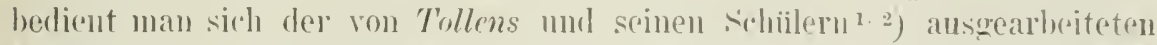
Methode. Diese heruht darauf, lab man das bei der Inestillation mit II C'l aus der Sulstanz entstehende Furfurol quantitativ bestimut und hieraus die lentosenmenge mit Hilfe eines empirischen Vorfalırens berechnet. [ a in den pflanzlichen Stoffen unbekannte fiemische rou l'entosanen vorliegen und die Furfurolbildung aus den darans bei der Hydrolsse entstehenden Pentosen keineswegs quantitativ erfolgt, so ist dic lostimmmng nur als eine annähernd genaue zu hetrachten.

Die Ansführung der Bestimmung, zu der 2-5y luftrockener Sulıtanz rorwemlet werden sollen, schließt sich vïllig der für die Bestimmmg der I'entosen gültigen Ifethode (Destillation mit H Cl rom spez. (iew. 106 uud Bestimmung des entstandenen Furfurnls als Furfurolphlorogluzil) an, die in Bd. II, S. 128 geschildert ist. Die Umrechnung des gewogenen l'hlorogluzidniederschlages anf Pentosane erfolgt nach der ebenda angegehenen Tahelle.

Boi Gegenwart ron Methylpentosimen wird hei gleicher Behandlung nebenbei Methylfurfurol gebildet und dieses dimn als Methylfurfurolphlorogluzid gefält. Infolge der Beimengung lieses Lïrpers zum Phlorogluzilniederschlag wird die Bestimmung der l'entosane unmöglich gemacht. Uber die Tremung les Methylfurfurolphlorogluzids $\mathrm{rgl}$. Bd. II, S. 13J. ebeuso rgl. daselbst Reaktionen auf Pentosen und Methylpentosen.

4. Bestimmung der liolifaser.

Als Rohfaser bezeichnet man den in verdiuntem Alkali und Sïnre unlöslichen Inteil pflanzlicher Stoffe. Die Rohfaser hat daher eine sehr variable \%usammensetzung und enthält neben der Zellulose auch noch Ligninsubstanzen, Hemizellulosen, Pentosane etc.

Sämtliche bisher ausgearbeitete Bestimmungsmethoden der Rohfaser erfüllen die Ansprïche, die der Chemiker an eine exakte analytische Methode stellen soll, nicht und sind auch noch selir weit von einer solchen entfernt. Es kommt das daher, daf diese Methoden versuchen, aus einem sehr komplizierten Substanzgemisch ein einfacheres Substanzgemisch darzustellen. Dies erfordert aher eine Zerstörung gewisser anderer Bestandteile des urspringlichen Gemisches, und um das zu elreichel, miissen stets so eingreifende Mittel verwendet werden, daß auch die Bestandteile des Endproduktes stets mehr oder minder angegriffen nnd zerstört werden.

a) Weender-Verfahren. Zur Bestimmung der Rohfaser bedient man sich noch sehr häufig des alten W'eender-Verfahrens von Henneberg

$\left.{ }^{1}\right)$ E. Kröber, Untersuchungen üher die Pentosanbestimmungen mittelst der Salzsäure-Phloroglnzinmethode nebst cinigen Anwendungen. J. f. Landmirtsch. Bd, 48. S. 357 bis 384 (1900).

2) B. Tollens, Über die Bestimmung der Pentosen und Pentosane. Zeitschr. f. physiol. Chem. Bel. 36. S. 239-243 (1902). 


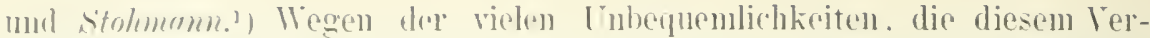
fahlen in soiner mrspringlinhen Form anhaften, wird as wohl allgemein

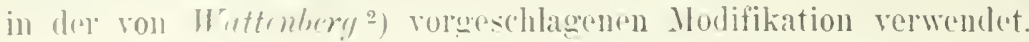

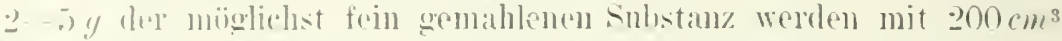

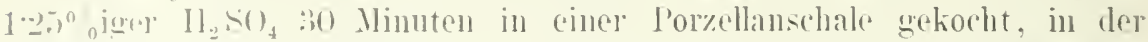
innen dureh einen cingebrannten Streifen diu Grenze eines $200 \mathrm{~cm}^{3}$ hetragenden Volmuens angezoigt ist. Inuch Zusat\% von liochendem IVasser wird das Flibsigkeitsolmmen konstant 'rhalten. Man sangt dann die noch heilie.

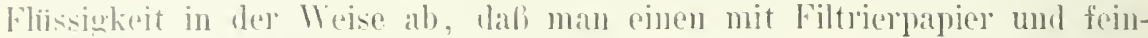
maschiger Kioliergaze iiberspanten (ilastrichter. der mit ejuer sangpumpe in Verbiudume steht. in die schale pinstellt und lir l'mmpe wirken lälit.

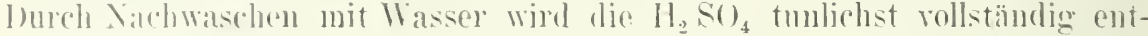

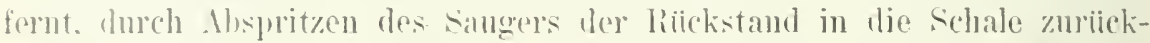

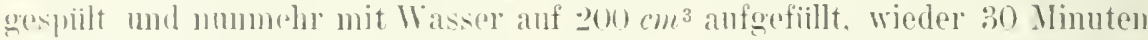
gekocht und ahersangt. Hicruach wiederholt man das Kochen mit $200 \mathrm{~cm}^{3}$ 1.2.00 „iger Koll unl nach abermaligem Absangen mit $200 \mathrm{~cm}^{3} \mathrm{H}_{2}$ O. Man

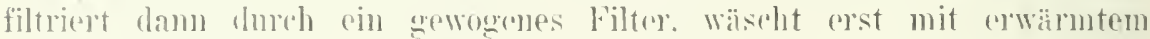
Alkohol, damm eincm erwïmten Gemisch von Alkohol mul Sthel und

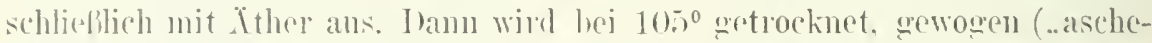
haltign liohfaser"), das Filtor rerascht und die Asche rom liewicht der aschehaltigen liohfaser ahgezogen (..aschefrejo liohfaser.).

Ilan kann in verhälnismäßig knrzer \%eit hei gheichzeitiger Verarheitung mehrerer I'ortionen eina ziemlich große Anzahl rom Rubfaserbestimmungen nach dieser Meihode ansführen. \%eitranbend wirl sie nu dadurh, daß häufig, besonters bei Analyen der Inhalte des l'flanzenfresserdarmkanals. zahlreiche Kontrollen noitig sind, um ähereinstimmende Resultate 7.1 erhalten. Wie Mlethede besitzt zahlreiche Fehlerguellen, dir man dureh peinliches trieiten zu umgehen hesirebt sein muB. Beim Kiochen in den offenen Schalen kümen Teile Jer Substuz am Raule ankleben und dem weiteren dufschluß entzogen werden. Jer Wisserzusitz, das Absaugen dureh die Filtriergaze kann zal Fehlern führen. Ferner kinnen sich muter den gerade herrschenden Bedingmagen gewisse substanzen der Anflosung durch $\mathrm{ll}_{2} \mathrm{SO}_{4}$, lioll entzimen ete., wie dies z. B. für das blabtin der elastischen Fasern des Fleisches srilt $\left(1 / a n^{3}\right)$ und hei der dualyse eiweißreicher substanzen (Dimndarminhalt ron schwein mul Hund) häufig rorkommt.

Fs ist lesbalb manchmal sehr schwer, konstante Resultate zu erziclen. Bei großen Versuchsreihen, in donen die gefumelen Rohfaserworte zu Vergleichen dienen xulleu, müssen die Bestimmungen schablonenmäßig und unter ganz gleichartigen Bedingungen rou einem Analytilier ausgeführt werden.

Beim Wremilo-Verfahren ist ferner zu heachten, daf die dabei gewonnene Rohfaser außer \%olnlose anch noch amlere Stoffe, z. B. Ilemizellulosen nnd hesonders I'entosane. enthält. und daß ein Tiril der schwer löslieben Zellwandhestandteile durch die Behandlung mit kOIJ in lasume grebracht werden können. Bei Versuchen, z. B. Aus-

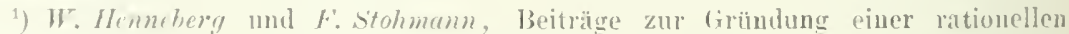
Fütterung der Wiederkiner. Branns'liweig 1864.

2) Wattenbrig, line vereinfachte Ilethode der Weendor-Rohfiserbestimmung. J. f. Liandwirtseh. Bel. 28 (1881).

${ }^{3}$ ) Mann, Zur \%ellubsebestimmung im Kote. Areb. f. Hrg. Bul.34 (1899).

4) Cher Fohlerquallen der Alahode verl. auch bei H. Lohrisch, Ubre die Bedentung der Zellulose im Haushalte des Menschen. Zeitschr, f. phisiol. Chem. But. 47. S. 200 his $2520(1906)$ 
mutzungsversuchen, hei denen die Pentosane gesomiert bestinmt werden, ist alsu das IVender-Verfahren nicht anwendhar.

b) Verfahren nach Moldefleiss. ${ }^{1}$ ) Diese Vethorle ist (donffalls eine Modifikation des I'cender-Verfahrens. Man bedient sich dabei des nebenstehend ahgebildeten Lpparates (Fig. 8:3). I)ie Bestimmung wird in cinem hirnenförmigen, oben offenen, unten sich konisch verangernden Gefäb vorgenommen, dessen untere Öffnung durch einen Asbestpfropfen verschlossen ist, der durch kräitiges Ansaugen einiger Fasern von ausqeglihtem und zweckentsprechend vorbereitetem Filtricrasbest hergestellt wirl (sie he Iid. I S. 408).

Zur Analyse hringt man dureh die obere Öfnumg der anf einer Sangflasche aufgesetzten (ilasbirne die gewogene Substanz ( $(g)$ ), gilbt hierzu $200 \mathrm{~cm}^{3}$ einer kochenden rerdiunten Schwefelsäure, die man sich aus $150 \mathrm{~cm}^{3} \mathrm{H}_{2} \mathrm{O}$ und $50 \mathrm{~cm}^{3} 5^{\circ} \%$ iger $\mathrm{H}_{2} \mathrm{SO}_{4}$ hergestellt hat und selickt dann ebenfalls durch diese öffnung vermittelst cines bis auf rlen Boden reichenden Glasrohres Wasserdampf aus dem Dampfentwickler durch dic Fliissigkeit. I'm Abkïhlung und dadureh Termehrung des Fliissigkeitsrolumens in der Birne zı vermeiden, umwickelt man dieselhe mit einem Tuch. Nach halbstiüdigem Durchleiten muterbricht man die I)ampfauleitung durch $\mathrm{Ab}$ ziehen des verbindenden Schlanches, schließt die Sangflasche an eine Luftpumpe an und sangt die Fliissigkeit durch die Ashestlage ab. Man wieder-

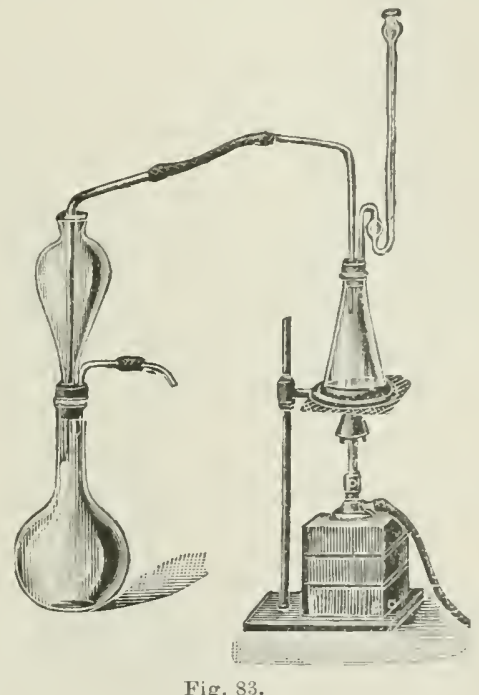

Fig. 83 .

holt dann den ganzen Prozels zweimal mit $200 \mathrm{~cm}^{3}$ Wasser, damn mit $200 \mathrm{ccm}$ einer $1.25 \% \mathrm{KO}) \mathrm{H}$ und wiederum zweimal mit Wasser. Hierauf wisscht man mit Alkohol und Ẍther, wie eben unter a) geschildert, aus, trocknet hei $105^{0}$ und bringt den trockenen Riiickstand samt Asbestpfropfen in eine Platinsehale, trocknet nochmals bis zur Gewichtskonstanz und wägt. Hierauf wird verascht, die Platinschale samt Inhalt gegliiht und von neuem gewogen. Durch Subtraktion des letzten Gewichtes vom zuerst ermittelten crhält man das Gewicht der .. aschefreien Rohfaser”.

c) Glyzerin-Schwefelsäureverfahren von König. Eine weit sicherere Nethode ist das von $J$. Küniy ${ }^{2}$ ) ausgearbeitete Verfahren. Dieses

1) Holdeffiss, Eine algekürzte Methode der Rohfaserbestimmung. Landwirtsch. Jahrb. Jg. 18\%7. Suppl.

2) J. König, lie Zcllmembran und ihre Bestandteile in chem. und physiol. Hinsicht. Laudwirtsch. Versuchsstation. Bd. 65. S.jó-110 (1906). 


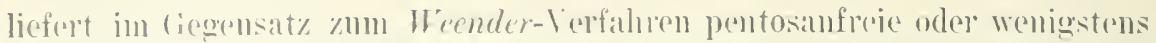

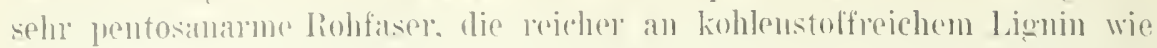

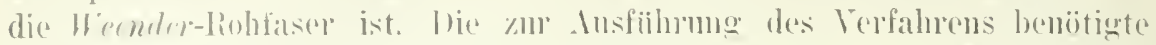

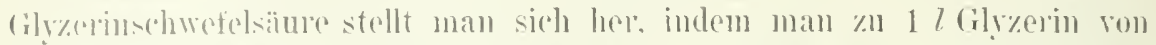

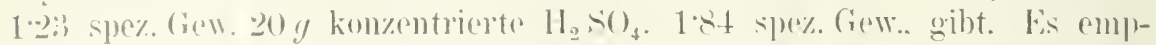
fichlt sich. das känfliche Glyzerin stots mit dem Mriometer zin priften, da

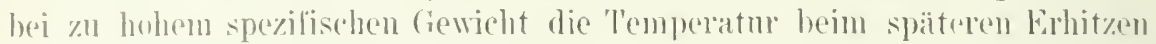

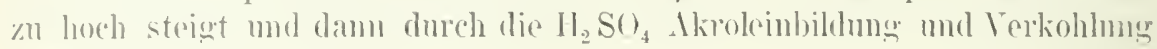
howilkt wilrl.

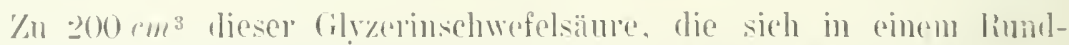
kolben (zweckmäbig weithalsig) orler in einer Por\%ellansehalo befincien. giht

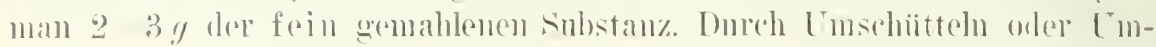
riihnen verteilt man dieselbe gut mud kocht dam nicht \%u lebhaft unter liückflulioler erhitzt im Autoklaren bei :) Atmosphären 1 Stmule lang ('lemperatur

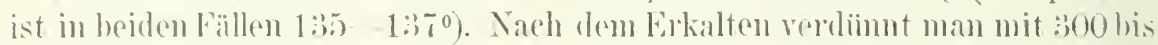
$400{ }^{2} m^{3}$ Wasser, kocht nochunals anf mol filtriert hoib thuch einen croorh'l'iegeel an der Luftpmmpe als. Aufere dem von König rmpfohlenen l'latin-

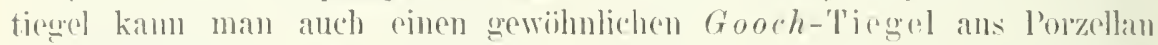
mit Asbestfïllung vorwenden. Tritt math einiger Keit Verstopfung rim, so kann man den Niederschlag mit einem Suatel vorsichtig von der Mitte dep

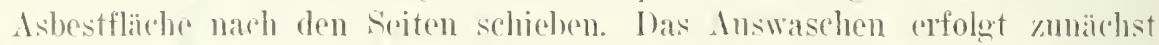

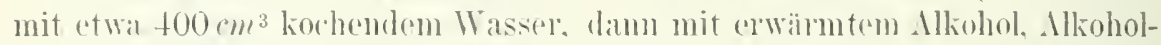
äther uncl schlieflich Xther, bis das Filtat farblos ablänft. Der Goorh-

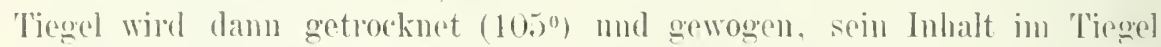

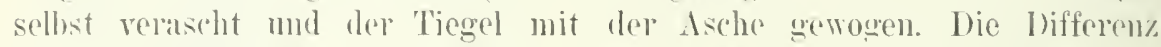
zwischen beilen Wägungen wibt das Gewicht der aschefocien Robfaser.

Besonders bei rasch filtrierenden Reaktionsgemischen ist die Kömigsehe Methode sehr raseh und begnem anszuführen. Vor allem liefert sie aber genane und übereinstimmende lisultate. Vorlredingungen hierfür sind gute Zerkleinerung, sorgfiltige Bereitung der (ilyzerinschwefelsäme und genanes Winhalten der Kohzeit. Die Wirlinug les (i) yzerinschwefelsünregemisches ist so eingreifend, daf mach meinen Frfahrunes hei eruenter behandlung ron mit dem Vesfalnen hergesteller Rohfuser eine abermalige, nieht unberlentende Substanzverringermug eintritt.

Andere Rohfaserbestimmungsmethoden, äher die boi Lohrisch ${ }^{1)}$ und Kïnig $^{2}$ ) nachzulesen ist, hilhen keine allgemeinere Verbreitung gefunden unt reichen, was Leiehtigkeit der Ausführung oder Genanigkeit der liesultate aulangt. nicht an die geschilderten heran. Fine nühere Schilderung soleber Vorfahren erïbrigt sieh also.

๘. \%ellulosebestimn unger.

liei den Ausnutzungsversuchen pflanzlicher Nahrungsmittel im tierischen Organismus hat von jeher das Velualten des wichtigsten liohfaserbestandteiles ..der \%ellulose" ein grofies Interesse heansprucht. \%ellulose wird in Magen und I bimndarm der Tiere mit einhöhligem Magen nioht

1) II. Lohrisch. I'her dir Bedentung der Zellulose im Hanshalte des Mensehen. Zeitschr. f. physinl. Chem. Bd, 47. S. $200-2520$ (1906).

*) J. König, l)ie Intersuthung lanılwirtschaftlicher und gewerblich wichtiger Stoffe. Berlin. Paul Parey. 


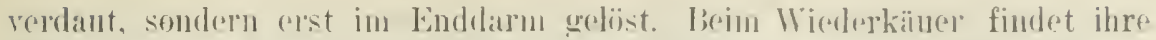

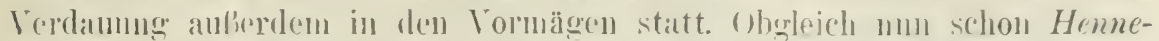

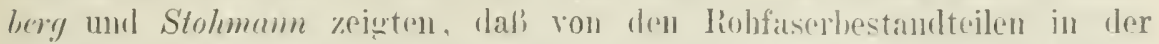

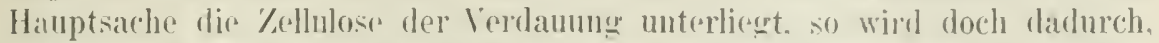

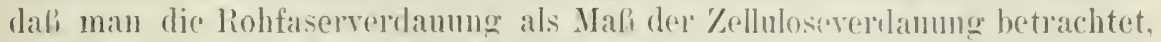
eine rewisse Insicherleit in die Reurteilung der \%ellulosererdanung gebraclit.

Man ist deshalh öfter's hestreht wewesen. Methoden der Kollulosehestimmung anszuarbeiten. lem quibiten 'Teil dieser Methodrn kann eine praktische Berleutung nicht zuerkannt werden, cia sie entweder zu umstandlich oder fïr quantitative Zwoke iiberhaupt ungeeignes sind.

lis beruht dies anf demsolben Grunde, der oben bei der Bespreclumg der liohfaserbestimmungsmethode angefuihrt worden ist. Wir kennen kein Mittel, /ellulose in irgend einer Form quantitatir abzuscheiden. Stots wird man die anderen Substanzen, mit denen die \%ellulose meist innig vermischt ist, auf irgend eine Weise zerstören müssen, um dic \%ellulose von ihnen zn befrejen. Da diese Substanzen (Eiweili. Stäke. I'entosane. Hemizellulosen, Lignin etc.) aher meist ebenfalls gogen die verschiedensten Agenzien sehr resistent sind, ist man genötiont. zu sehr eneroisch wirkenden Mifteh zu greifen. Soi es num, dab man sich Bromwassers, des C'hlorgrenisches, honzentrirerter Kalilange oder ähnlicher Wittel herlicnt. man wird in keinem Fallo sicher sein, ol, einerseits tatsächlich alle anrleren Substanzen zerstört sind und wird andrerseits auch nie wissen, oh nicht doch 'Teile der \%ellulose ebenfalls zerstürt worden sind.

Es seien im Hinblick anf diese Unsicherheit hier nur die Methoden ancefuihrt, die sich ron den anderen wenigstens durch raschere und bequemere Handlabung auszeichnen. Es sind dies besonders die, die sich der Auwendung hochkouzentrierter Kalilange als Lösungsmittel der anderen Substanzen bedienen. Von der Wiedergabe der Methoden von $F$. Schultze. W. Hoffmeister, H. Wïller etc. soll deshalb hier abgesehen werden. ${ }^{1}$ )

Die Methode ron Lunge ${ }^{2}$ ) und ihre Modifikationen.

Diese Methorle beruht auf einer Ingabe Hoppe-Seylers ${ }^{3}$ ), nach der \%ellulose selbst duch schmelzemles Ilkali keine erkennhare Veränderung erleidet. sofern die 'Temperatur $200^{\circ}$ nicht ibersteigt. Die Ausfiihrung der Methode ist folgende: Von der fein zerkleinerten Sulstanz werden $10 \mathrm{~g}$ in eine tubulierte, mit Glasstopfen rersehene Retorte gefillt, 30- 40 y Itzali in Stangen und :30- $40 \mathrm{~cm}^{3}$ Masser hinzugefiigt. Die Retorte wird mit einem Glasstopfen rerschlossen und in einem Ölbade erhitzt, dessen Temperatur

1) Vgl. hierüber H. Lohrisch, Ǔber die Bedeutung der Zellulose in Hanshalte des Menschen. Zeitschr. f. phys, ('hemie. Bd. 47. S. 200-252 (1906).

$\left.{ }^{2}\right)$ G. Langr, Zur quantitativen Bestimmung der Zellulose. Zeitschr. f. physiol. (hemie. Bd. 14. S. $283-288$ (1890).

*) F. Hoppe-seyler, Cher Huminsubstanz, ihre Entstehung und ihre Eigenschiften. Zeitschr. f. phrsiol. Chem. Bd. 13. S. 66-121 (1889). 
durch ein Thermometer gemessen wird, welehes so tief in las Ölbad cintaucht, dafi sich seine (necksilherkngel mit dem Boden der lietorte in elcicher 'l'iefe befindet. Die 'T'mperatur wird langsim mud vorsichtig. es tritt starkes schäumen ein. bis anf $180^{0}$ gestrigert mul eine stumde lane aul dieser Jöhe ughalten. Nach dieser \%eit ist der Inhalt der lietorte zu einer festen hasigen Masse cingetrocknet. Nach Mbkiilnlen auf mngefähl suo wird mit heiben Wasser der Retortoninhalt anfunommen mud mter solofiltigem Inswaschen in ein liecherowas geloracht. wo mau ihu voll-

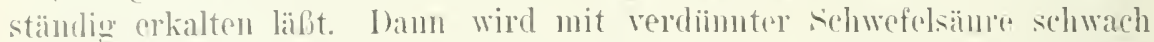
ancesiuert. Wobei ein oft roichlicher Niodersohlag entsteht, der anch ausgefällte Zellulosepantikelehen enthalten soll. Inueh schwaches Alkalisieren mit Nitronlange. Welches nmmmehr vorgenommen wird. sollen alle anderen ausqefallenen substanzen auber Zellulos wieler in Lösmg gebracht werden. Die alkalische Flïssigkeit wïd hieranf unter V'rwendung von saugpumpe

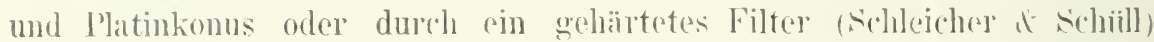
quantitativ abfiltriert und mit heiliem und kaltem Wasice sorgfialtig nachgewaschen. Ilierauf wirl der Riickstand vom Filter entferut. mit Ilkohol digeriert, anf rin gewogenes quantitatives Filter gebracht. mit Alkohol

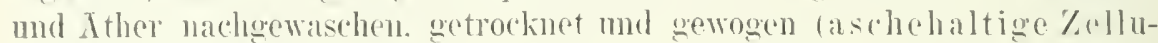

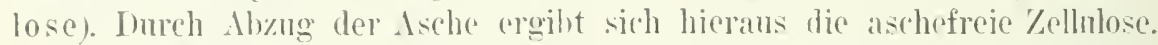

bie Methode vou Lange kaum streng yenommen als quantitative Mothode nicht hezcichnet werden. Dic Voraussetzung, dill hochkonzentrierte Konl die \%cllnlose nicht beeinflusse, ist cinte irrige, wie schon ans den Befunden ron Bumcke und Wolffenstein $\left.{ }^{2}\right)$, die \%ellulose mit $: 30 \% 0 \mathrm{Xa}(\mathrm{H}$ hydrolysierten ${ }^{2}$ ). hervorgeht. Ferner ist die Anmahme, dafi der beim Ansäneln mit $\mathrm{H}_{2} \mathrm{~s}\left(\mathrm{O}_{4}\right.$, und dem navfolgenden Alkalisieren vorbleibende liuick-

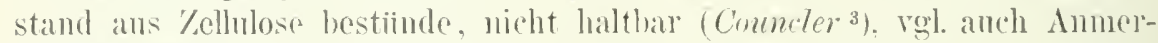
kung -). Jan erhät daher mit dem Langeschnoln Verfaluen stets etwas zu wenig Zellulose, da cin T'eil verloren weht. Anch wir beobachteten hei ciner Nachpriffung des Terfahrens. bei dem reine l'apierzellulose zur V'erwendung

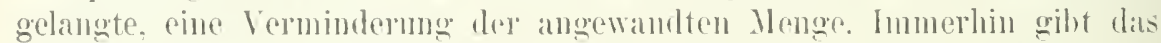

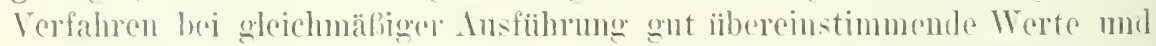
ist zu liestimmungen, bei denen es sich num die Erlangung einiger Vergleidhswerte handelt, wohl anwendhar.

Zmr Anfertignng grölierer Amalysenserien. die sich hei AnsniitzmosStoffwechsel- mol Verdammesversuchen hänfign mötig machen, ist das Ver-

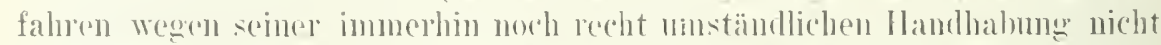
geeignet. Infolgedessen haben Simon murl Lohrischt) eine Modifikation

1) G. Pinmele und h. Wolfienstin, ther Zellulose. Ber. d. Deutseh. chem. Ges Bd. 32. S. $24913-2507(1899)$.

2) Die Autoren hydrolysierten durch ca. achtmaliges, je einstiundiges Konchen mit

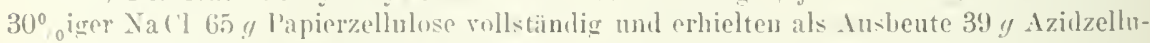
lose (lisslich in kalter NaOH. ansfallhar dureh verdiumte Sehmefelsimre).

3) ('. Councler, Cher \%ellulosehestimmungen. Chem. Ztg. Bd. 24. S.368-369 (1900).

4) 11. Lohrisch, Uber die Bedentung der Zollulose im Haushalte des Menseherr. Zeitschr. f. physiol. Chemie. Bil. 47. ¿. 200-20.52 (1906). 
vorgeschlagen, dic. hequem mud lasich ausfiihnbar. sirh besonders fuir

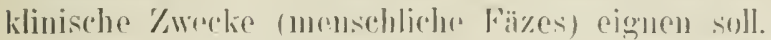

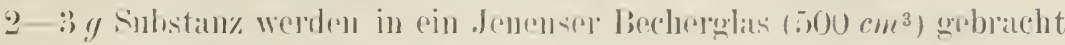

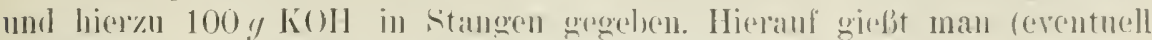

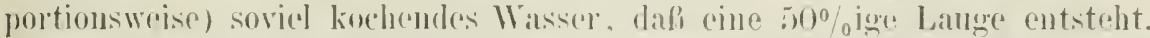

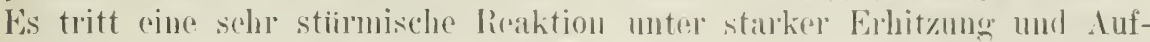
kochen cin. bei der eine eneroische Finwirkngy del Lange anf die Sulstanz zustande kommt. Die meist tiefloranne lösmug elotot man noch eine Stunde auf dem Wasserbad, lïbt erkilten und fiigt zur Aufhellumg portionsweise $5 \mathrm{~cm}^{3}: 30 \%$ iges $\mathrm{H}_{2}()_{2}$ Perlydrol (Merck) hinzu. wobei abermals Erhitzen und Aufschïmmen cintritt. Sollte die Lïsung nummah noch nicht hellgelb geworden sein, so fïhrt ein nochmaliges halbstiundiges frwirmen anf dem Wasserbade zum Ziele. Nach dem Erkalten fügt man das halbe Volumen (zirka $\left.70 \mathrm{~cm}^{3}\right)$ Alkohol $(96 \%$ ) zur Ausfällng gelöster /ellulose limzn. Mischt sich Alkohol mond lauge nicht, so genügt der \%usat\% ron $90 \mathrm{~cm}^{3}$ Fisessig, um die Mischung zu reranlassen. Andere Stoffe als \%ellulose fallen hierbei nicht aus, da die Fliissigkeit zu stark alkalisch ist. Inch stärke füllt, wie ich mich ïherzengt habe, nicht ans. Man filtriert dann durch ein gehürtetes Filter (Schleicher d Schiill, Nr.575) ohue Saugpumpe ab, wäscht mit heißem Wasser aus und bringt elen Niederschlag rom Filter in das Becherglas zuriick und dann auf ein gewogenes fuantitatives Filter. Answaschen erfolgt erst mit reinem heiben, damn mit Essigsäure angesäuertem Wasser. Nach nochmaligen Auswaschen mit heifiem Wasser, Alkohol und Ither erfolgt 'Trocknung', Wägrung und Aschebestimmung..

Dieses Verfahren hat gegeniiber lem urspriinglichen Langeschen den groben Vorteil der bequemen Ausfuhrbarkeit, verbiudet aber damit den größeren Nachteil, dab ilın eine nene, und zwar sehr erhehliche Fehlerquelle in Festalt des $\mathrm{H}_{2} \mathrm{O}_{2}$-(iebranchs anhaftet. Wie ebenfalls Bumclie und Wolfienstein zeigten, gelingt es mit $\mathrm{H}_{2} \mathrm{O}_{2}$ leicht. Zellulose in Hydralzellulose iiberzufïhren, die ihrerseits wieder durch Akali in rellulose und die erwähnte Azidzellulose gespalten wird. Auch Matthes und Streitberger 1) fanden bei einer Nachpriifung des Känigschen Verfahrens der Zellulosebestimmung, dals $\mathrm{H}_{2} \mathrm{O}_{2}$ in alkalischer (ammoniakalische1') Lösumg Zellulose angreift. Bei Nachpriifmo ${ }^{2}$ ) des Simon-Lohrischschen Verfahrens konnten wir keine branchbaren liesultate erlangen, fanden vielmehr, dafi die Resultate je mach den gerade herrschenden zufälligen Bedingumgen, der jeweiligen Wrirkmo des $\mathrm{H}_{2} \mathrm{O}_{2}$, der Daurr des Erwärmens, der Abkiihlung und der Filtration bedeutenden sichwankungen unterworfen sind.

Untepwirft man schon aimmai nach Simon-Lohrisch helındelte Zellulose nochmals dem Terfahren, so tritt eine ganz erhebliche. (a. $200_{0}^{\circ}$ und mehr betragende V'rminderung (2in. ${ }^{3}$ ) Zn1 Zellulosebestimmumg in Magen-,

$\left.{ }^{1}\right)$ H. Hatthes und F. Streitherger, ther die Zusammensetzung der Kakao-Rohfaser. Ber. d. Deutsch. chem. Ges. Bd. 40. S. $4195-4199$ (1907).

") A. Schounert und E. Lötsch, Vermag der Hund Rohfaser oder Zellulose zu verdaueu? Bioch. Zeitschr. Bd. 20. S. 10-21 (1909).

$\left.{ }^{3}\right)$ Scheunert, Grimmer und Lätsch, noch vicht publizierte Mitteilungen. 


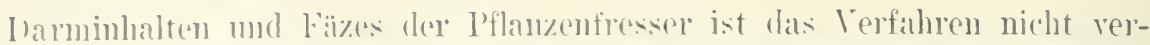

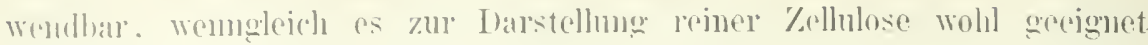
sein mag.

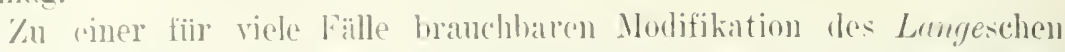

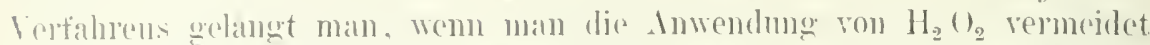
und im iihnjogn :ihnlich wie simon und Lohrisch rerführt. Djese Modifihation, dir uns bei einigren lutersuchumgen gute Dienste greleistet luat, fïhren wil wie folgt ans:

1-2g Substan (fein gemahlen) worden in einem Jenonser Becherolas mit $100 \mathrm{~cm}^{3}$ Wasser (Laboratorimmsemperatur) verriilut, nach und nach 100 y tangentiali eingetragen und dieses dureh vorsichtiges schüteh

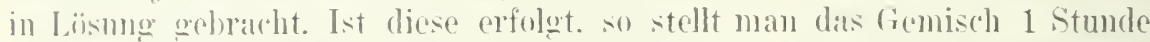
auf (as siedende Wasserbad. Damn filtriert man heif durch pin gehätetes

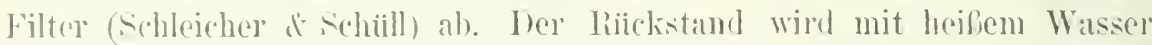
so lange gewaschen. bis das Filtrat gegen Lachmms nahezu nentral reagiert. 1)ann wind er von dem wehäteten Filter anf cin crewogenes quantitatives gebracht. hier solange mit heifem Wasser wewaschen. bis das liltrat neutral

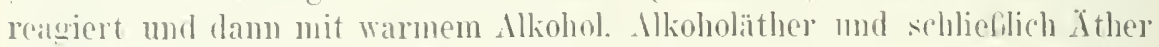

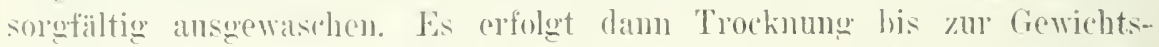
koustam\% hei $105^{\circ}$ und Wägung. Nan erhält nach Alzun des Filtrierogewichtes aschehaltige \%ollulose. Iurch Veraschen des Filters und Wügung ler Asche berechnet man sich dureh subtraktion die aschefreic \%ellulose.

Das Verfahren gibt wht ibereinstimmende Welte. Mbsolute Werte veluagescbensowenig wie dio anderen Methoden zu geben. auch diufte bej ihm infolge dor milden behandlumg eno selativ mueine /ellnlose erhalten werdan. Fs ist aber zu Verglei chsowecken hei stäkearmen

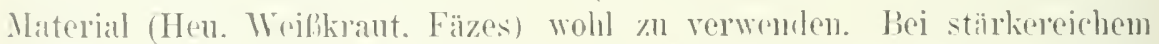
Material diufto eine Vorbehandlume mit Jiastase nötig sein. Bei mehrmaliger Behandlune derselben Kollulose nach dem Verfahren tritt mur eine Vermindrime vous $5-7^{0} 0$ ein.

Es sei betont, dal es sich empliehlt, sich, eho man pines der Verfahren

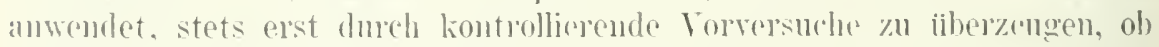
es ancly fiir den heabsichtigten Horeh hranchbar ist. Vor allem ist anch

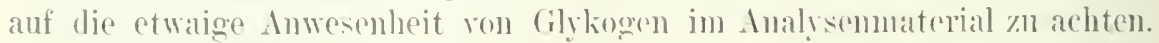

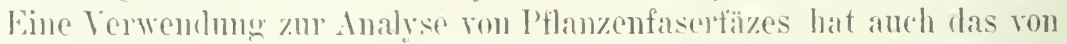

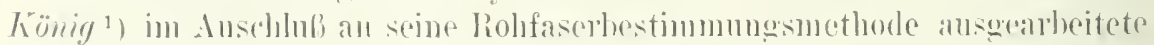

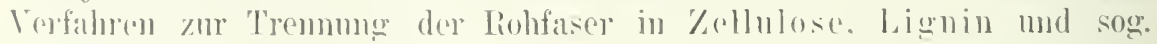

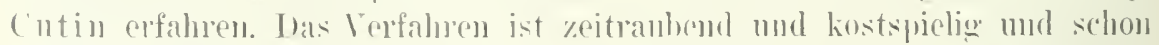

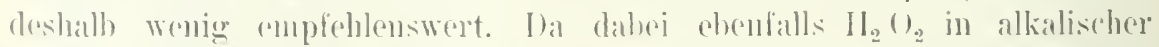

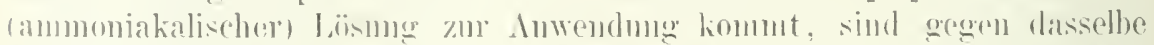

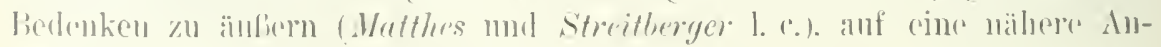

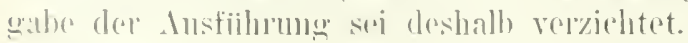

¿) J. König, lie Zellmemliran und ilure Bestandteile in chemiseher mul physiologischer Hinsicht. Iandwirtsch. Versuchsstat. Bel. 65. S. 55-110 (s. 1906). 
6. Fett. Ther Nachwris, Bestimmune und Tutersuchung des Fettes rgl. Bal, II, S. 200. Dem lee der F'uttermittelanalyse gen̈btem Branche entsprechent wid die fiesamt-

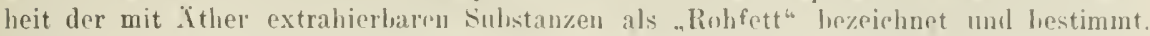

\section{Darmgase.}

Die Analyse der Darmgase $\left.{ }^{1}\right), \mathrm{CO}_{2}, \mathrm{~N}_{2}, \mathrm{H}_{2}, \mathrm{CII}_{4}$, erfolgt nach IBI. III, Alsschnitt Gasanalyse. Besondere Apparate zum Auffancon mul zur Analyse solelier (ias finden sich hei Ad. Schmidt ${ }^{2}$ ) und $N . Z u n t z^{*}$ ) beschrieben.

\section{ANHANG.}

\section{Untersuchung von Darmkonkrementen.}

Die Darmkonkremente ${ }^{3}$ ) hahen eine üheraus rerschiedene Zusammensetzung, so daß sicb hestimmte mul in allen Fällen auwendbare Regeln für ihre Tntersuchung nicht gehen lassen. Stets enthalten sie sowohl orgunische als auch anorganische Bestandteile, deren Mengenverhältnis sehr wechseln kam. Da in schr vielen Fä̈len die Hauptmenge der organiseben Bestaniteile aus Resten pflanzlicher Nahrung (IIafersteine der schottiscben Laudbevölkerung, Phytokonkremente der Pflanzenfresser) oder aus Haaren, Wolle u. dgl. (Piliknnkremente. Haar-, Borsten- und Wollbälle ıles IJundes, des schweines und der Wielerkïuer ete.) besteht, giht die mikroskopische Untersuchung of wichtige Anfsehlüsse ïler Herkunft und Zusammensetzung, z. B. anch hei Koprolithen. Abgesehen von diesen mehr als Fremulkörper anzusehenden Bestandteilen kommen in Darmkonkrementen aurh organische Verbiudungen, z. B. Fette und Seifen, vor (IIafersteine, Darmgrieß, Larmsand), aucl, l'rotein, Farlıstoffe finden sich darin. Zur Erkennung dieser Beimengungen sind hesondere chemische Methoden (Reaktionen auf Fett, l'rotein: fermer Untersuchung des Atherextraktes und Verseifung) anzuwenden.

Unter den anorganisehen Bestandteilen nehmen Phosphate, md zwar hesonders häufig Magnesiumammonimmphosphat, die erste Stelle ein. Die Enterolithen des Pferiles bestehen bis zu $90^{\circ} \%$ ans dieser Verbindung. AnBerdem kommen noch Phosphate und Karlnnate von Ca und Mg nnd in sehr geringer Henge lösliche Chloride. Sulfate sowie mit der Nahrung aufgenommene unlösliche mineralische Bestandteile, $\mathrm{Sio})_{2}, \mathrm{Al}_{2} \mathrm{O}_{3}$ u. dgl., vor. Zur Untersuchung kocht man die zerkleinerte Substanz mit Essigsiure aus und loringt dadurch die Phosphate und Karbonate ete. in Lösung. in ler sie dann qualitativ nachgewiesen und quantitatir lestimmt werden kïnucn. Der unlösliche Rückstand besteht aus organisehen Bestandteileu (Mikroskop!) und dem erwähnten $\mathrm{Si} \mathrm{O}_{2}, \mathrm{Al}_{2}()_{3}$ etc.

Uher Untersuchung der aus den Anfangsiliusen des Darmes stammenden lionkremente (Gallensteine, Panlireassteine 1. dgl.), die gelegentlich im Darmlumen angetroffen werden, rgl, an anderer stelle.

1) Vol. A. Scheunert, Verdaunng. IV. Oppenheimers Handh, d. Binch. Bd.3. II. S. 140 (1909).

") Ad. Schmidt, İher die Beziehung der Fäzesgärung zor Darmgärung und zu dem Flatus, Areh, f. klin. Med. Bd. 67. S. 545 (1898).

$\left.{ }^{3}\right) X . Y u n z$, Cber eine Nethmle zur Aufsimmlung und Analsse ron Darm- und Gärungsgasen. Arch. f. (Anat. u.) Physiol. Jg. 1899. S. 579. 


\section{Intermediärer Stoffwechsel.}

\section{A. Fraktionierung von Organen und Darstellung von wirksamen Organextrakten.}

Von W. Wiechowski, I'rig.

Die im folgenden zu beschreibenden Mothoden heziehen sich nur auf die Gewinnunge fermentativ wirkender (bzw. nicht kochbostimliger) Organextrakte und anf die Darstellung der Orqaneiweibiöper. Die als ..Holmone" (Sturling) bezeichneten, fiur innere Sekrete gehaltenen, wirksamen

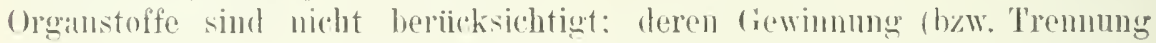
von den ()'ganproteinen) ist infolge ihrer gröfieren Stabilitit, inshesondere auch Lochbeständigkeit weit leichter als die der Organfermente. Dagegen können die beschripbenen Methoden gegebenenfalls zum Aufsuchen von Antikïrpern in den Organen oder zur Abtremung .. hindender Gruppen" Anwendung finden.

Fiir die Methodik dieses Teiles biologischer Forschung ist noch weniu greschehen. Mit Lusmahme der Mathoden. die dureh den muter I) beschriehenen allgenein verwendbaren Gang ermöglicht sind. bleihen die zahleeichen angrebenen Verfahren weit hinter dem zurick. was insbesonlere in quantitativer Bezichung ron der (iewimmung der Orwanfermente mud -proteine verlangt werden mulb. Es gelingt zwar mit den meisten der zu besprechend'n Methoden zn wirksanen Orwanextlakten oder zu mehr minder einheitlichen Eiweifstoffen zu gelangen: die Ausbenten stehen aber nicht nur moist in keinem Vrabiltnis \% den in Arbeit genommenen dateriahnengen. sondern man bleiht auch ïher die Grölie der Verluste im Cnklaren. da die Intersuchuma dej verworfenen Antrile nicht vorgenommen wurde oder wegen der Xitur des Vurfahrens nicht mïglich war. Wie gezeigt werden wird. wurden vielfach Wege heschritten, die zn einer woitgohenden schitdignug der Fermente führen. so daf, was schliefilich erhalten wurde. ein geringer, der Zerstörung enteangener liost wall. Dassellhe gilt ron der Darstellung dar Organnoteine. Aurh hierbei wurlen oft Extraktionsmittel verwendet. die dematurierend wirken.

I) (Arund fiir diese Mangelhaftigkeit der Methodik. die sich in der (ieringfitigigkeit unserer Kenntuis ron der Organzusammensetzung reflek- 
tiert, liegt nicht nur in rer iheraus grolien Labilitüt Ies . Iateriales sondern anch in der $\Delta$ rt suiner Kompliziertheit. in der emulsionsartigen Ibeschaffentheit der ()rounsubstan\%. welche don einfachsten nicht eingreifonden Fraktionierungsersuchen schwere Hindernisse in den Wey legt. Die freien und fest gebundenon Lipoide. die an Masie die Lipoide meist noch iibertreffenden Extraktivstoffe im älteren Simne, zu denen anch dire niclit mehr ausgeschwemmten P'rodukte der postmortal weitergehenden Zelltiitigkeit zugezailhlt werden mïssen. erschweren nicht mur die liewinmme. sondern es schädigen gerale die letzteren nachweislich die Wirksankerit bzw. Ansheute der Fermente. Ehe man daran gehen kann. die Grganfermente ..rein“ dar\%ustcllen, ist es notwendig, deren Figenschaften, Empfindlichleiten, Konservierungsfïhigkeit. Verhalten gegen alle anzuwendenden Eingriffe und Reagenzien festzustellen. wie ich es in Gemeinsehaft mit $H$. Iriener ${ }^{1}$ ) fuir das urikolytische Ferment getan habe. sie auf (irmud der gewonnenen Eifahrungen sukzessive von allem wirkungslosen billast zu befreien und quantitativ und ungeschwächt in einer Eiweili-lipoid-extrakt- und salzarmen Lösıng zunäehst zu konzentrieren. Laß hierfiir Methoden unerläßlich sind, welche jederzeit den Wirkungswert der gewonnenen Fraktion an dem des Ansuangsmateriales messen lassen. welche stets die Feststellung gestatten. ob die Trennung vollständig ist. d. h. kein Ferment in dem zu verwerfenden Anteil mehr enthalten ist, berlarf keiner Begruindung. Auch für die Darstellung der organproteine muls die Fordering aufrecht erhalten werden, dab die Eiweilie vollständig und in unverändertem \%ustand abgesclieden werden. Systematische Stmlien hieriiber sind nach Methode I) leicht durchzufiilhren.

Die ang̨efihhten (iesichtspunkte mögen als frundlage für die allgemeine Beurteilung der zu beschreibenden llethoden dienen. Kritische Bemerkungen im einzelnen sind jeder Vethode heigefiigt.

\section{A. Vorbereitung der Organe (Entfernung des Blutes).}

Jede Anfteilung der Organe hat mit der Gewinnung eines unveränderten und reinen. il. h. einheitlichen Untersuchungsmateriales. der ()rqanzellen, mit der Trenmung derselhen von den allen Organen gemeinsamen Bestandteilen: Blut. Bindesubstanzen, (iefïlie, Ausfïhrungsgänge zu beginnen. Inshesondere sollen die ()rgane nur unmittelbar nach dem Torde des Tieres und in völlig blutfrejem Zustande in Arheit genommen werden.

Die Entfermung des Blutes gelingt hefriedigend nur durch Ausspiilen der Organe anf dem Wege der (iefübe. Das hie und da geïbte Answaschen der zerschnittenen (Organe ist muzulïssig. Es fiihnt nicht nur nicht zum Zicle. sondem arbeitet naturgemäf auch mit Verlusten an löslichen Organbestandteilen. Zudem lassen sich (bis auf das Kunochenmark)

') Wr. Wiechorski und H. Wiener, Über Eigenschaften und Darstellung des harnsäurezerstörenden Fermentes etc. Beitr. z. chem. Phrs. u. Path. Bd. 9. S. 247 (1907). 


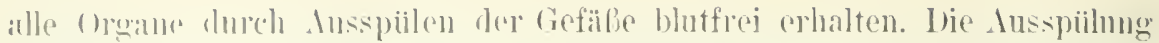

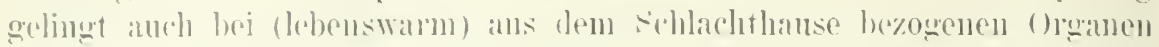

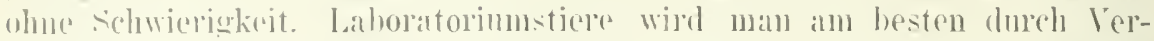

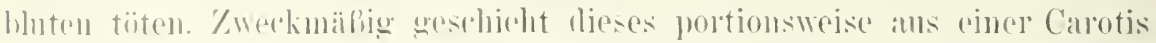

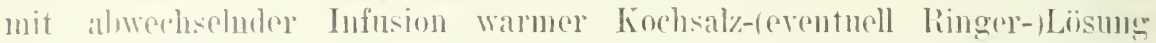

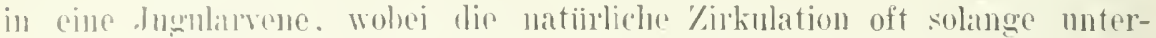

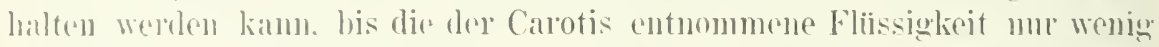

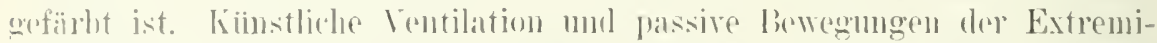

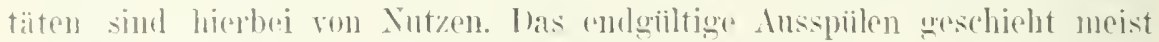

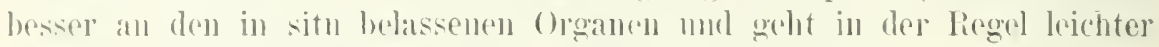
in retrogralep lichtumg, d. l. per veluan vor sich.

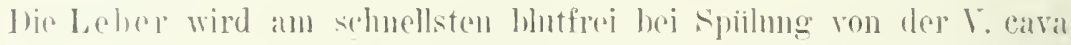

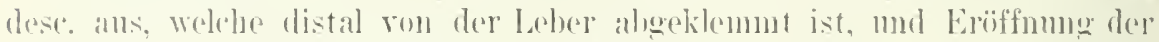
Vena portar. Lälit man dieso jutakt, kilemmt dio Cava distal von den Nieren-

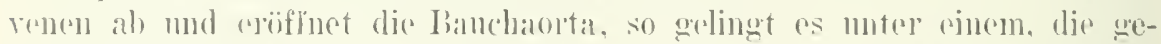

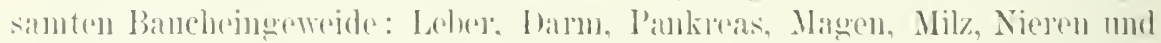

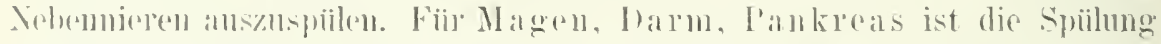

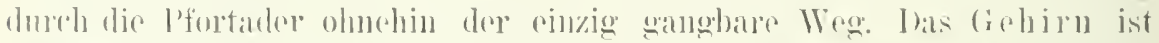

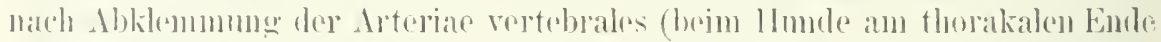

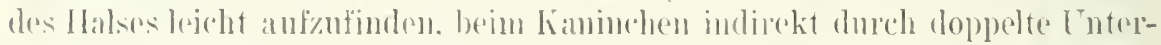

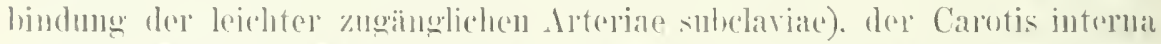
dere anen Seite: der Carotis "xterna mol Irter. oceipitalis der anderen Seite, rom der Carotis commmis dieser Seite kopfwälts son den Arter. thyreoblea

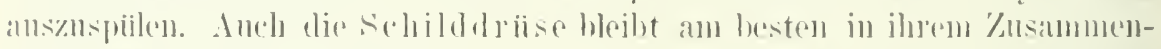

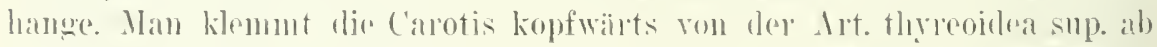

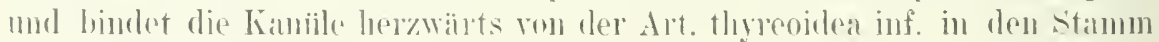

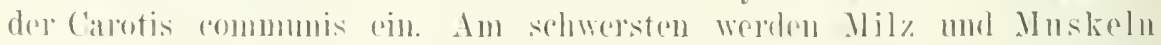
blutfrei. Letztere sind wohl num an Labolatoriunstioren vollstiudien blutferi zu

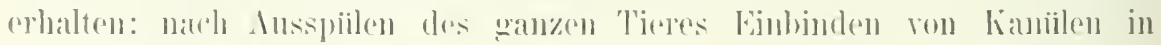

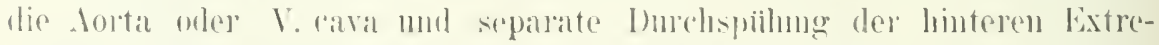

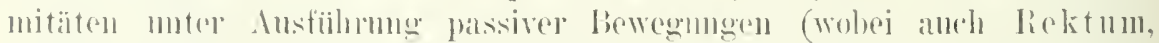

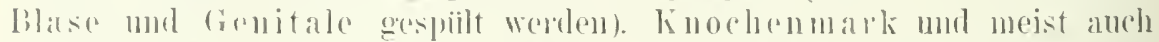

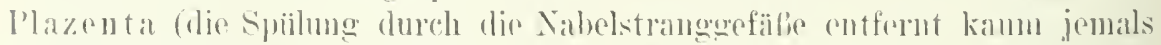

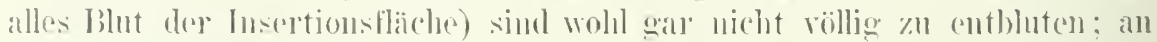

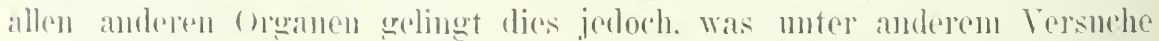

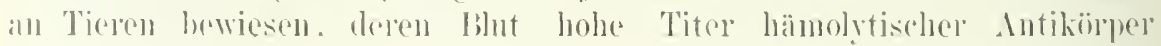
anfwies.

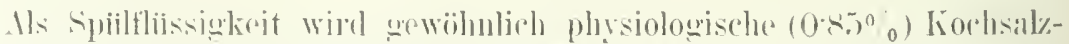

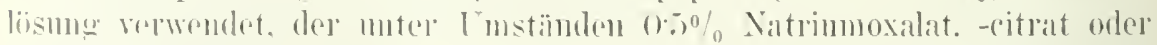
-fluorid zugasetzt worden kann. Doch bieten im allgemeinen gerimmugs-

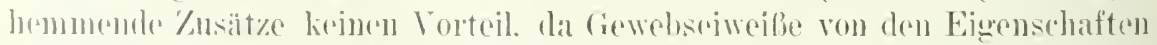

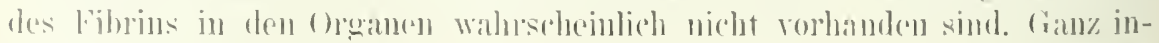

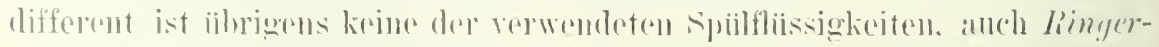

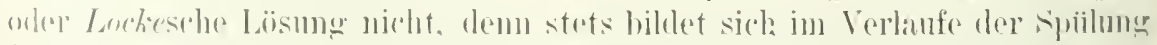

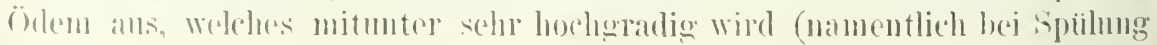




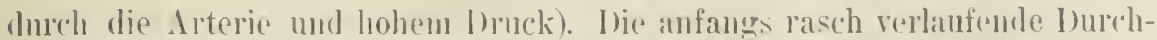

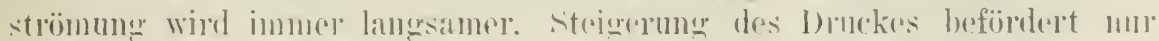
die Aushildung des Ödems und ist anch deshalh nirht zu empfehlou, weil

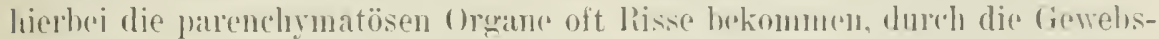

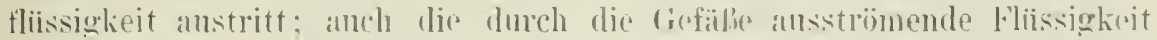
enthält damn oft schon Organeiweil). Derartigr linhste vermeilet man am

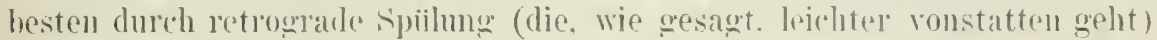

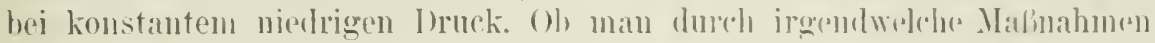
das öhlem völlig vermeiden kam, ist mir nivht bekannt. velsuehen hëmute man eincu weringen Halnstoffznsatz zur spiilfliisvigheit. F'iir manche Fiille

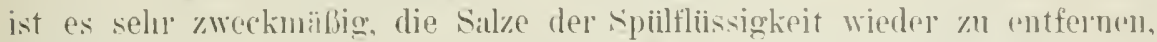

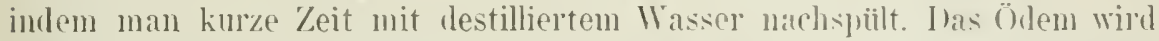
hierdurch meist noch dentlicher: die Spïlnng lialit sich jedoch gut zu Eurle fïhren. schmolles Irheiten bei niedriger 'Temperatur ist allemal angmoint.

lel nächste Ikt der Verarbeitum ist bei allen Mrothorlen eine mehr

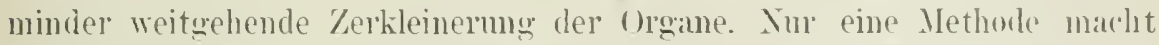
hiervon eine Ausuahme, da sie Saft aus unzerkleinerten ()roanen gewinut; sie soll daher zunächst besprochen werden.

\section{B. Die „zelluläre Dialyse“ durch Dampf organischer Flüssig- keiten.}

\section{(R. Dubois ${ }^{1}$ ). Dastre ${ }^{2}$ ).}

Die Organe werden in dïnme Scheiben zerlegt und diese unter einer evakuierten Glasglocke iiber einer Schale dem Dampf von Chloroform, Ither, Toluol etc. in der Kälte ansgesetzt. Die Dämpfe dieser Flissigkeiten lösen sich in den Zellipoiden und verdrängen Wasser aus den Zellen. relohes, mit Eiweißstoffen. Fermenten. Salzen usw, beladen, exsudiert und in die Schale tropft. Doch ist das Wesentliche des Vorganges keine hlobe ...Deshydratation", vielmeh" werden durch die Einwirkung der lipoidlöslichen Stoffe sonst semipermeable Membranen für Inhaltsstoffe passierbar, so dab eine Art Entmischung stattfindet und alles Wasserlösliche erhalten werden kömnte. Dasselbe wird erzielt durch Eintauchen von Uroanen in die hetreffenden Fliissigkeiten. Am Boden des Gefäßes sammelt sich in Tagen Organsaft an. Eine Hundelebel lieferte in 4 Tagen $70 \mathrm{~cm}^{3}$ Saft. Diesel wurde gegen Fluornatrim dialysiert, er verwandelte Stärke in Maltose und diese in Glukose und zeigte keine glykolytische sowie keine proteolytische Wirkung gegen Fibrin und gekochtes Eierklar. ${ }^{3}$ )

1) R. Dubois, La dialyse cellulaire par les rapeurs etc. Compt. rend. soc. Biol. T. 53. p. 93 und 126 (1901). - Die erste Mitteiluug hierüber ehenda 1884.

p. $3 \pm$ (1901).

2) A. Dastre, De la diillyse coloroformique ete. Compt. rend. soc. Biolog. T. 53.

$\left.{ }^{3}\right)$ J. Permilleux, Untersuchungen üher einige Fermente der Leber. These de Paris. 1904; zit. nach Jalys Jahrb. 
Lis ist nicht mutersucht. ob alle Fermente der () ruane anf diese Weise

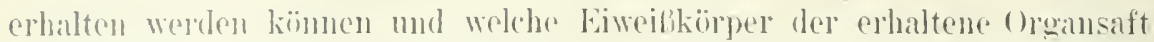
enthilt. Fin Vachtril der I'rozedur ist ihre lange Daner. Welehe die Inter-

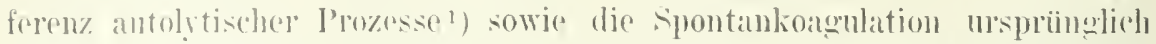

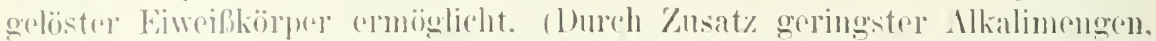

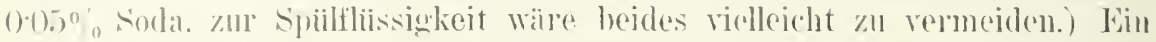
Vorteil do Mothorle ist, dal der ()rounsaft konzentriort erhalten wird.

\section{Das Zerkleinern der Organe.}

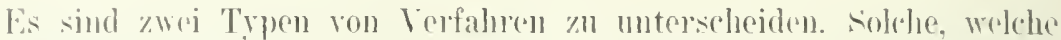

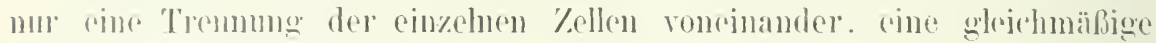

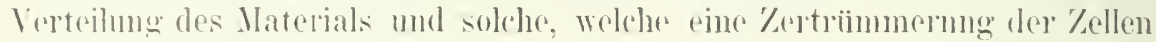
scolbst anstrehen.

1. Da es fiir alle Fälle zwrekmäbig ist, an einem romhejtlichen Aus-

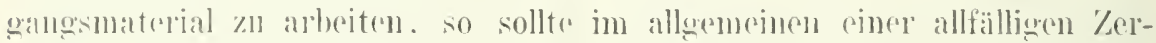

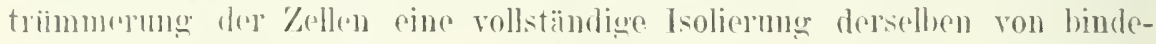
gewerigen Intejlen. Bhtgefäßen. Driisengäingen vorangehen. Bei worchen

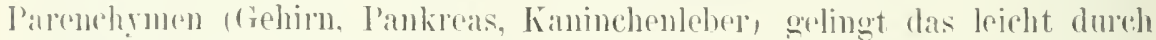
Anskneten der intakten Orone auf emom diinnmaschion Drahtsieh mit

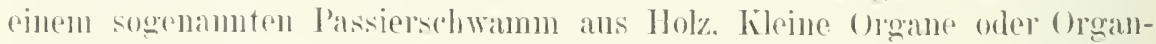

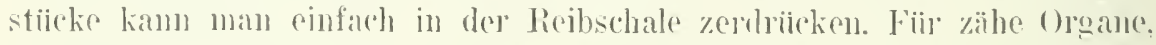
die das mumittelhan nicht zulassen (inshesondere Muskel. Innge. Thrreoidea, Niere, l'rostata), kam mit Vortril ein rorlaufiges Kerouetschen zwischen Walzen andewendet werden. P'rinzipiell ist das Zerdrieken den selmeidenden

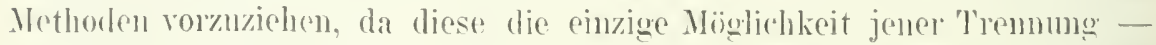

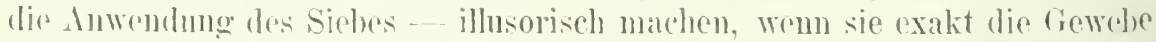
zorschunden. (iroh) mit dem Wiegemesser oder dor Fleischharkmaschino (heliebiger Tonstruktion) zerhleinertes Material lälit sich ebenso durch Siebe prosin oder mach ontsprechemler Vordïmung durch etwa 1stiindigos Schïteln anf der Maschine so weit verteilen, daf beim Auspressen der Masse durch

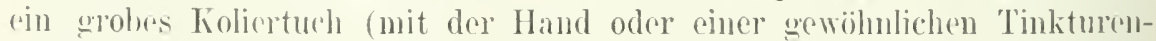
ofler Fuchtpresses) oin zwar verdiunter, aber in wesentlichen rinheitlicher Zellbrej erha]ten wird. Von den sehmeidenden Apparaten arbeitet die Kossel-

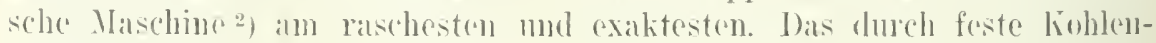

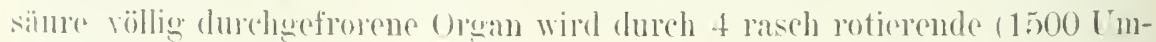
(rohmugen in der Minnte) Frisemesser in cimen foinen schmee und beim Anftanm in einen gleichmäligen Brei rerwandelt (Fig. 84 u. 85 ). Iscoeseco ${ }^{3}$ )

$\left.{ }^{1}\right)$ Nach li. (Kiari (Arch, exper. Path. u. 1'harm. 13d. 60. S. 256 [1909]) beschleunigt die Gegreuwart flürhtiger lipoidlöslicher Stoffe die Autolyse mul beht deren Latenzzeit anf.

2) A. Kossel, Beschreibung einiger Apparate. Zeitschr. f. physiol. Chemie. Bil. 333. S. $5(19() 1)$.

$\left.{ }^{3}\right)$ II. Iscoresco, De la présence de la catalase etc. Compt. rend. sor. Biol. T. $\mathbf{6 0 .}$ p. $22+(1506)$. 


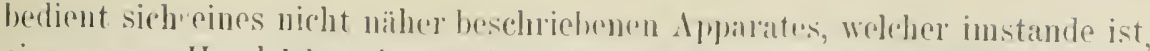

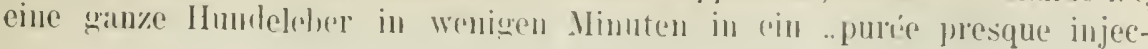
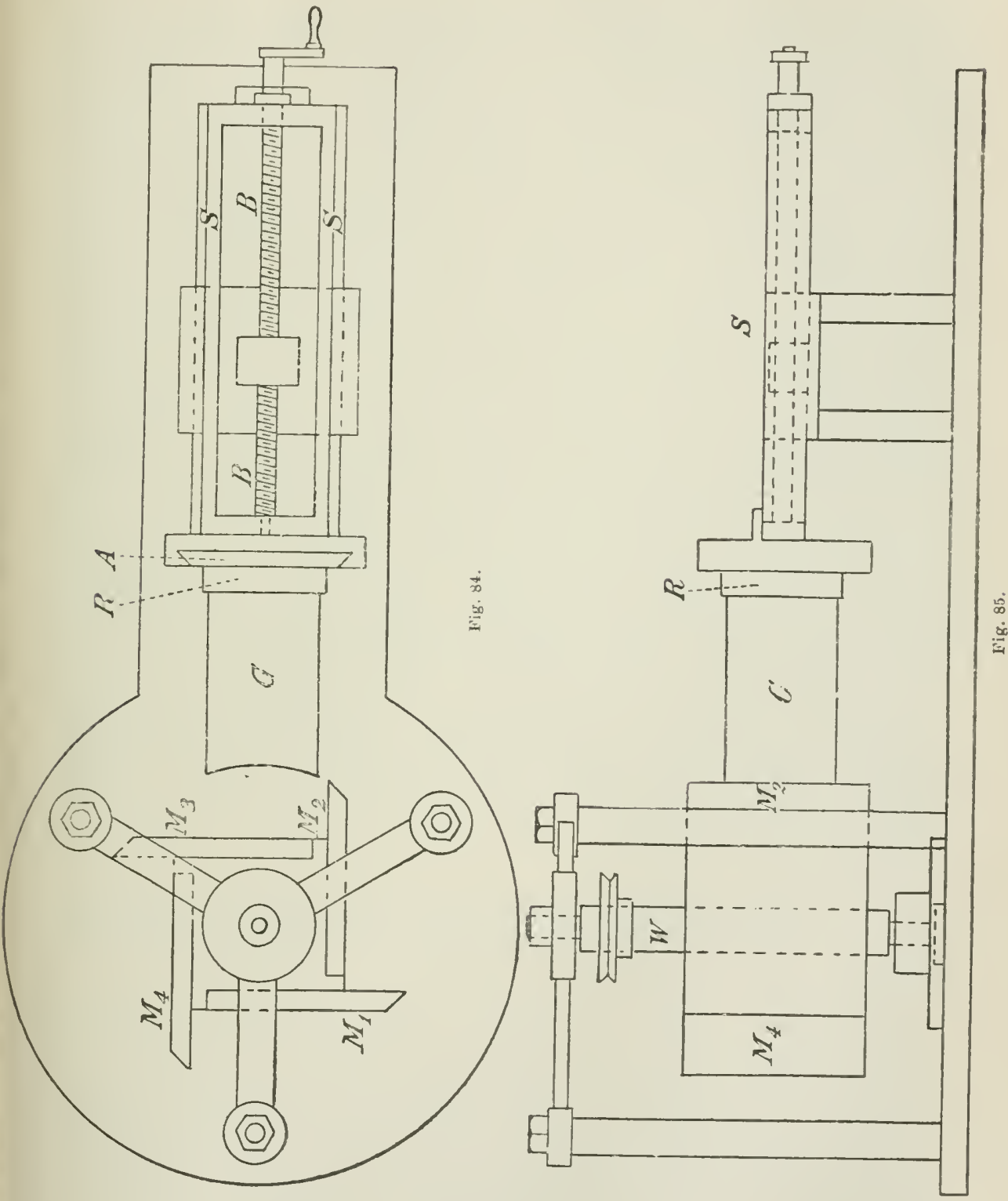

table" zu rerwandeln. Anch einige andere derartige Apparate. welche auljerdem steriles Arbeiten gestatten, sind angegeben. 
Il. D) je \%ertriinmerung der \%ellen, die dom Gesagten zufolge zweckmälig erst an ..gesiebtem” Material vorgenommen winel, geschioht

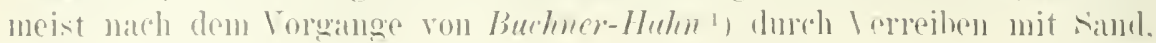

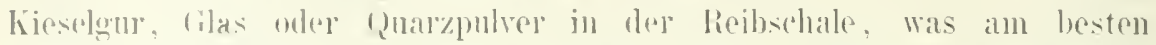
maschinell geschieht. Loulund ${ }^{2}$ ) hat hier\%u einen oigenen Apparat ange-

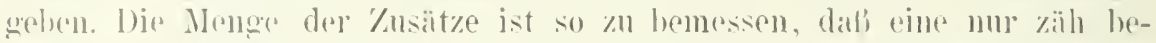
wegliche Masse dutsteht. da bei geringeren /usätzen in dem diinnfliissigen

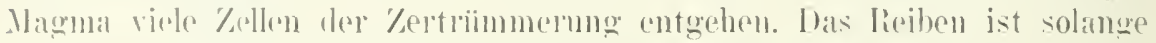
fortzusotzen, bis die mikroskopische lutersuchmog gefüblex Ansstriehe die voillige Ermielung des gewiuschten biffektes erweist. I)en Nachtril dieses

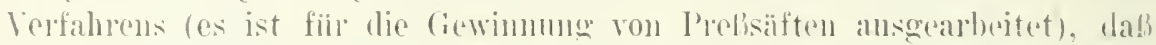
die gemathten \%säitze von mü̈slichen Oroanfaktionen nicht getrennt

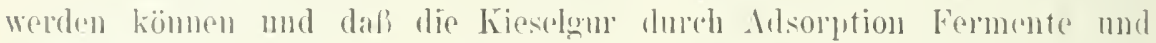

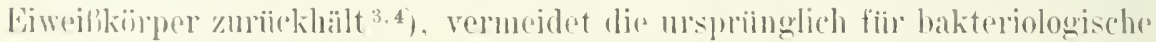

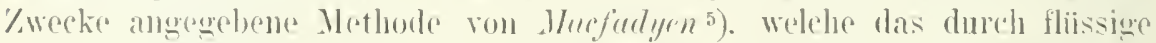
luft damerud tief geforen gehalteme Maturial maschinell in der lieibschale olne \%usat\% pulvert. Diese Methode wurle mit selur gutem bifolge -

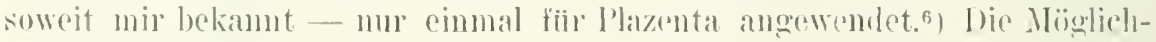

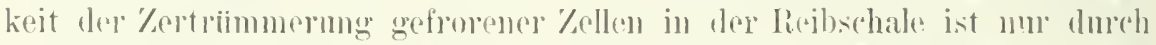

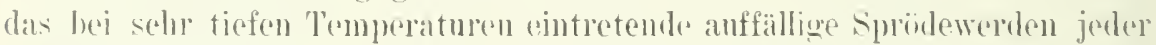
substan\% gegeben. In kleinen (bei gerjugen Substanzmengen) wird man

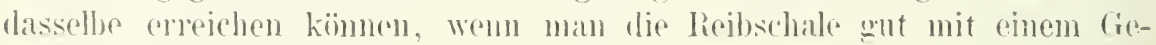
misch von fester Kohlensäme mol dreton kiihlt mol sich eines l'istills mit hölzernem Handgriff bedient, wenigstens sollen auch anf diese Wreiso Bak-

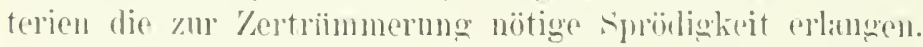

Ehe die Extraktion mo Fraktionierme des zerkleinerten Materiales

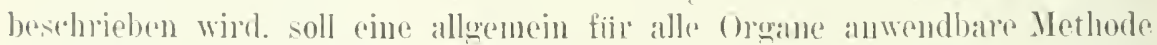

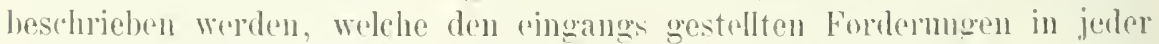
Einzelleit zu antsprechen gostattet. bzw. ans der Notwendigkeit, jene zn erfiillen, hervolongungeren ist.

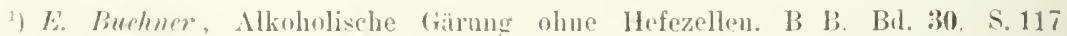
(1897). - E. Buchmer und Rump, sbenda. Bd.30. S. 1110, 2668; Bd.31. S. 209, 1084. $1090,1,331$.

2) S. Rowland, A method of obtaining intracellular juices. Journ. of plysiol. Vol. 27. p. $533(19) 1)$.

$\left.{ }^{3}\right)$ S. G. Ifelin, A rase of specific alsorption of enzymes. Biochem. Journ. Vol. 2. p. $81(1907)$.

4) L. Lecrontier, Gimploi de la presse de Buchner pour la préparation des tissus. Arch. intern. de phys. T. .j. p. 328 (1907).

5) A. Yacfarlyen. Upon the inmunising effect of the intracellular contents of the typhoil bacillus as obtained loy the disintegration of the organism at the temperatur of

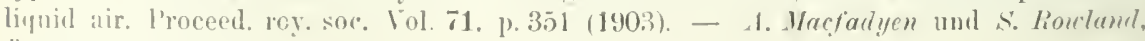
Uther die intrazellularen Toxine ete. Zentralhl. f. Balkt. Bd. 38 (1904).

$\left.{ }^{6}\right)$ P. Bergell and W. Liegmam, Über die in der I'lazenta enthaltenen Fermente. Müuchener med. Wuehensehr. Bd. 52.) S. 2.211 (1905). 


\section{Allgemeine Methode zur chemischen und biologischen Unter- suchung überlebender Organe (W. Wiechowski ${ }^{1}$ ).}

Die Methode ist l. c. in etwas anderer Werise beschrichen. Hier sind z.nm erstenmal weitere bifahrungen und Verbesserungen verwertet, wie sie sich beim drbeitun nach derselben in pharmakologischen Institnte eler deutschen I'niversität in Pragr argeben hahen, wie ïberhaupt auch andere (hisher unveriffentliehte) Einzelheiten der in diesem Kapitel besprochenen (iegenstände Eroubuisse des genannten Lathoratoriums sind.

I lie Wethode beruht auf der Beohachtung, dab vorsichtiges und rasches Trocknen der ()rgane dureh Luft weder kiweikkörper noch Fermente (auch nicht die Lipoides in irgend einer Wrise verändert, virhnehr sie fiir lïngere Zeit in dem 'Zustande konserviert, in dem sie sich zur \%oit des Todes des Tieres befunden hahen. Ferner hat sich gezeigt, daf sich die getrocknetern Organe gleichfalls ohne lie geringste schädigung mit flüchtigen Lïsurıssmitteln extrahieren lassen. was nicht nur eine sonst unmögliche Fraktionierung ermöglicht, sondern auch die weitere Verarbeitung des Materials anf Eiweif und Fermente sehr wesentlich erleichtert. Gestalt und Fürbbarkeit der ()rganzellen ändern sich durch diese Prozeduren nicht, wohl ist aber mit der Möglichkeit zu rechnen, daß die Beständigkeit der einzelnen Zelle auch durch das Trocknen allein vermindert wird. Nachweisbar ist das fuir Wrythrozyten, welche nach dem Trocknen ihren Farbstoff rollstïndigr all isotonische Lösungen abgeben; hier wirkt also das Trocknen in älnlicher Weise aufschlieliend wie das Gefrieren (siehe weiter unten) oder der Znsatz geringer Mengen Alkohol. Die getrockneten und extrahierten Zellen lassen sich mit Leichtigkeit in einer líugelnühle oder unter /uhilfenahme ron organischen Fliissigkeiten in der unten beschriehenen Farhenreibmiihle oder sonst wie vollständig zertrïmmern. So erhält man ein haltbares, genan meßbares und, was das Wichtigste ist, unverändertes lusgangsmaterial: Eiweib und Fermente frei von Lipoiden und Extrakt in Form weifer bis hellgraubrauner Pulver. Auferdem läft sich auch der Lipoidextrakt unverändert (unerhitzt) gewinnen und zu entsprecheuden studien iiber die Berleutung der Zellipoide als „, bindende Gruppen" oder Antikörper benutzen.

1. Das 'Trocknen bewerkstellige ich jetzt nicht mehr wie 1. c. angegeben in einem grolen Thermostaten bei ca. $37^{\circ}$ (was his 4 . Stunden in Anspruch genommen lıat), sondern hei Zimmertemperatur durch einen kräftigen Luftstron. Nachdem Versuche mit einem Fligelexhaustor gezeigt hahen, dafi hierdurch die Trocknung auf 20 -30 Minuten bei Zimmertemperatur herabgedriickt werden kann, wurde uns der in Fig. sli, 87 skizzierte Trockenapparat ron der Firma Janka in Prag gebaut und hat sich bei zahlreichen Versuchen in jeder Richtung hewihrt. Diese Art des Trocknens hat gregenüber der früher geiibten nicht nur den Vorteil der Schnelligkeit.

1) Wr. Wichouski, Eine Methole zur chemischen und biologischen Untersuchung üherlebender Organe. Beitr. z. chem. Plys. u. Path. Bd. 9. S. 2:32 (1907). 
Die beliehig niedrig zu wïhlende Temperatur verhindert absolnt jecle Verinderung, was nicht für alle Zwecke bei der friiheren Methode, die höhere T'emperaturen rerwendete. röllig gewihrleistet war. Insbesondere wriden die den Fiweilikörpern und Fermenten gegeniiber scheinbar labileren Lipoide völlig konserviert, wofür der ('eruch des Produktes zu sprechen scheint. Dic bei niedriger 'Temperatur getrockneten Organe haben durchaus den spezifischen cieruch der frischen bewahrt, während bei höherer l'emperatur getrocknete keinen frischen, sondern mehr an Backwaren erimermlen, gelegentlich sogar ranzigen Geruch anfweisen und behalten. Allerdings verändert sich ler frische Geruch der kalt getrockneten Organe, wenn sie an del Luft liegen, nach ejniger Zeit auch; schliebt man an das Trocknen jedoch sofort die "ioluolextraktion (siehe weiter unten) an, so lälit sich dies fast rüllig vermeiden, die getrockneten und extrabierten (rrgane behalten lüngere Zeit den spezifischen Gernch der frischen, der jerlen Geiibten sofort die Tierart erkennen läßt. Das Wesentliche des Trocknungsprozesses, die Ursache, warum er so schnell ror sich geht und die Grundhedingung für befriedigende Resultate ist: diinnste Schicht, $d$.h. dem Luftstrome größte Fliclue darbieten. Je diinner die schicht, desto rascher kommt man zum Ziele. desto besser wird konselviert. Dickere schichten überziehen sich rasch mit trockenen K'rusten, welche die 'J'rocknung darunter liegender 'T'eile verzögern. Die Forderung geringer Schichtdicke ist natiorlich nur an möglichst fein verteiltem Material zu erfüllen.

Da es aus mehreren Grïnden unzweckmäßig ist, die Salze der spuilfliissigkeit beim Trocknen bis zur Sättigung zu konzentrieren. spiile ich prinzipiell nach dem Blutfreispiilen mit 0.85\% iger Kochsalzlösung diese wieder mit destilliertem Wasser aus. Die hierauf grob zerkleinerten ()rgane werden durch feine Messingdrahtsiebe passiert (siehe B). Der erhaltene, ganz gleichmälig feine Zellbrei wird unter Verwendung eines elastischen. bajonettförmigen Malerspatels diinnst auf Glasplatten ausgestrichen. Für grölere Organe brancht man daher viel Flächenraum, z. B. für die Leber eines zirka $25 \mathrm{~kg}$ schweren Hundes $1.5-200 \mathrm{~m}^{2} . \Delta \mathrm{m}$ gleichmäßigsten wird die Verteilung, wenn man die dimnflïssige Masse über die schrïg gestellten Platten fließen läßt, den strom mit dem Spatel so regulierend, dab er die ganze Breite der Platte eimnimmt, und schlieblich die senkrecht gehaltenen kurze Zeit abtropfen lïßt. Die hierzu nötige Konsistenz des Zellbreies kann man unbeschadet der Trocknungslauer erentuell durch Hinzufiigen von destilliertem Wasser herstellen. Die so beschickten Platten kommen in die einzelnen Fächer des folgenden Apparates (lig. 86 und 87). Fin in seinen Dimensionen beliebig zu wählender parallelepipedischer Metalkasten, dessen Grundflïche mit der Plattengrölie iibereinstimmt. ist lerart in ganz niedrige Fächer geteilt, daf die diese trennenden horizontalen Btechwände abwechselnd an der hinteren und vorderen Vertikalwand luftlicht abschlieben, während sie an den entsprechend entgegengesetzten Stellen dieser Wände bis auf mehreve Zentimeter froi endigen. Der hinten in das oberste Fach durch einen elektrisch angetriebenen Zentrifugalventilator geleitcte Luft- 
strom von :30-40 $\mathrm{m}^{3}$ pro Minute ist daher gezwungen, in Zickzackwege alle Fächer zu passieren und die daselbst gelegrenen Platten zu bestreichen; er tritt schlieflich aus dem untersten Fache durch eine die ganze Breite und IIöhe desselben einmehmende öffnumy der vorderen Kastenwand aus. I'm die einstreichende Luft von Staul zul befreien. wurden in das oljerste Fach. unmittelbar unter den Infteinfall, entsprechend grolie Schalen, dic teilweise mit konzentrierter Schwefelsïure gefüllt sind, in eine Reihe gestellt und vor diese anlierdem eine mit Vaseline bestrichene Glasplatte gelegt. Dieses Verfahren ist, wie die Erfahrum lehrte, besser als die Anbringmng eines Wattefilters, das. wenn genügend dicht, die Intensität des Luftstromes stark herabsetzt. Alle Verbindungen, insbesondere die Kastentüre, miisseu gut gedichtet sein, - da sonst viel nutzbarer Luftstrom verloren geht. Zweckmäßig köunte man das unterste Kastenfach als heizbares Wasserbad einrichten, um größere Flïssigkeitsmengen bei niedriger Temperatur abzudampfen, in ähnlicher Weise wie es Faust getan hat. Faust ${ }^{1}$ ) gibt an, dab die Temperatur einer Flüssigkeit, die sich auf dem siedenden

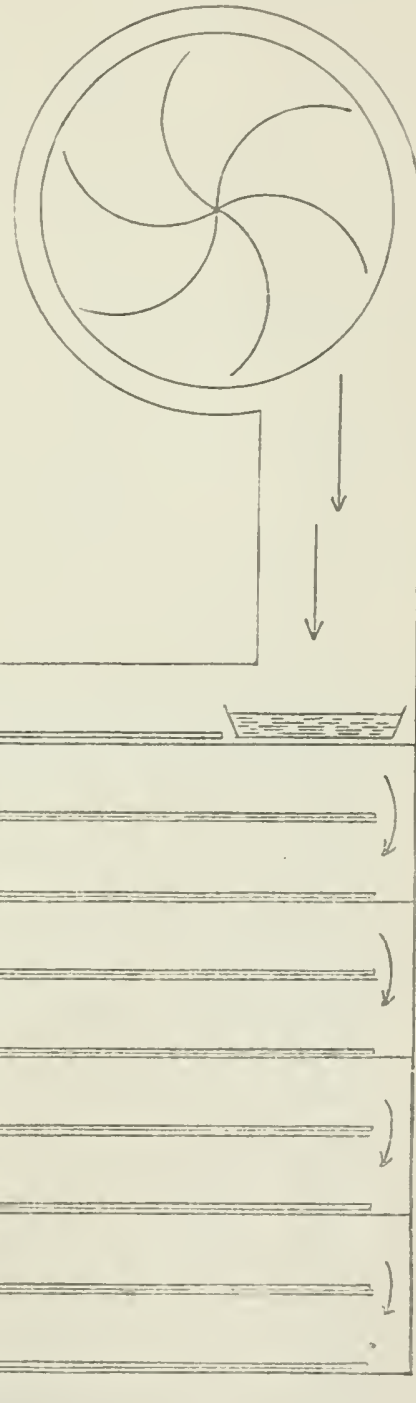

Fig. 86.

Wasserbade befindet, infolge Uberleitens eines so kräftigen Luftstromes nicht S. 248 (1904).

1) E. S. Faust, Über das Fäulnisgift Sepsin. Arch. f. exp. Path. u. Pharm. Bd. $\mathbf{5 1 .}$ 


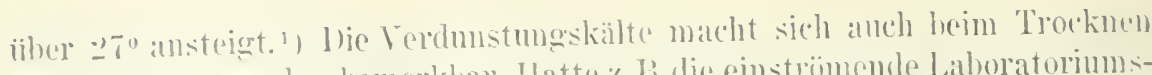

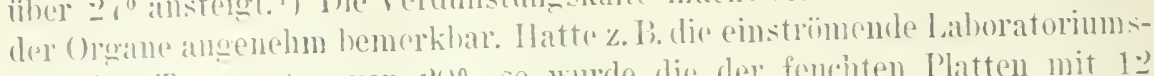

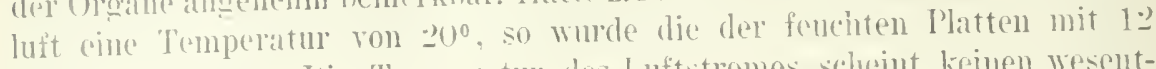
bis $15^{0}$ gemessent. Die Temperatur des Luftstromes scheint keinen wesent-

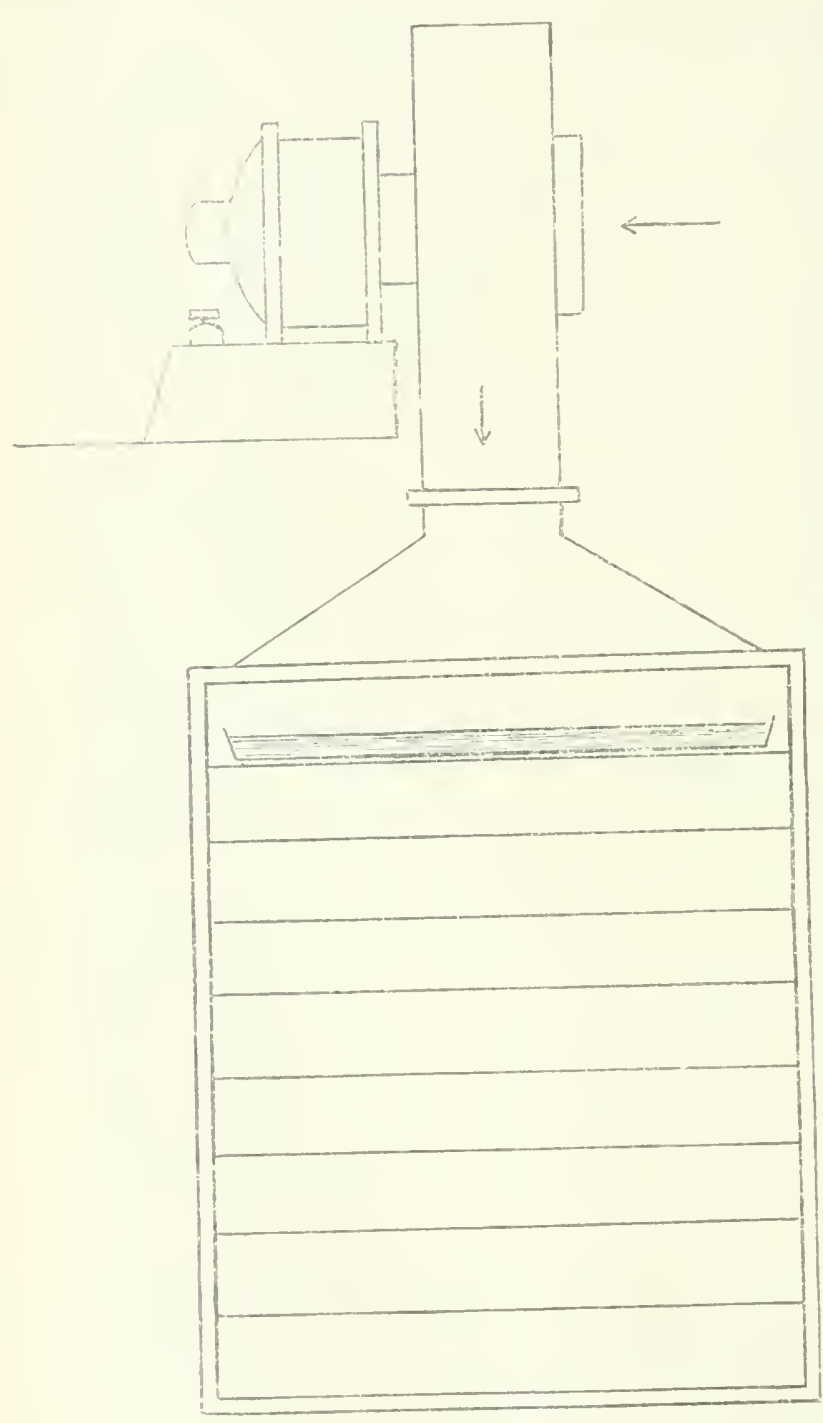

Fig. 87. lichen Finfluh anf die 'Trocknungsdatuer zu baben. Bei ("iner Tomperature voll t5o (alls dem libechmanted des relucizten laboratorinumsofous (ntmomues, liomnte keine nemmensworte Vorkiilzmus dor T'rockinungedaurer hrohachtet werden. Ich glatuhe daher, dali man anch stark gohiihlte Luft henutzen kalmu und wiirle die Aufstellung des Ipparates in (in) Kinllerlokide mit dancrut niedriger 'T'mp)(ratur enupfollen. sind die l'atten diinn gestrichum wewesell, so ist ber liasteninhalt in 15 bis :i) Minuten völliw trochin und didlurch konser' viert. Blutsorum trocknet num dann lïnger als (etwa 45 Minuten. Wemm (s nimht in dimuer. sollderen in dickerschichte (in Schalen) (ringehracht wurde. lije trockenen l'latten werden mittelst anes hroiten und fustrn Anstrucherspatels ohime schwiorigheit ahoreklat\%t und das Material inl"orm kleines trockinel selumppen rom fiernche der frischen Urame erhalten. Nath einem 2tstiindigen Lufenthalte im Es-

1) Laboratorien, welche eimen Faustschen Apparat besitzen, kimnen natmremals denselhen auch zum Organtrocknen in ler Kälte benutzen. 


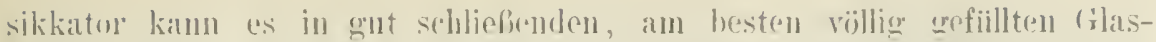

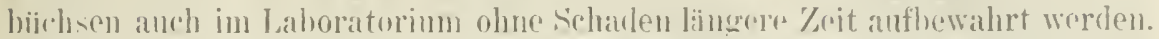
linsere ist es judoch. das so konservirete Material sofort der Extraktion dor

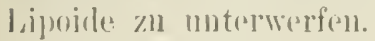

II. Inic Fxtraktion habe ich fribler (l. (.) unter emem mit der

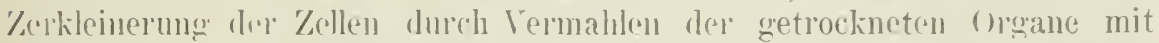

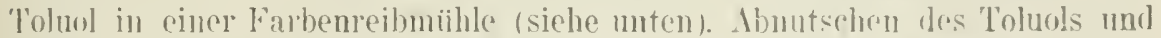
iifteres Wirslerholen dieses Volganges an den auf der Nutsche zuriokbloblenden Masson vorgenommen. Eino antomatische Fixtraktion des gemihlonen futos war wegen der Ilichtigkeit dessellon, die nur di* Vakumfiltration zulieli, nicht möglich. Wer Wunseh, heide Akte zu trennen, d. h. wohl extrahierte, aber mzertrimmerte \%ellen zur Litersuchung zu bekommen und dic Benuemlichkeit mul Tollständigkeit einer automatischen Extraktion nicht zu entbehren, führten dazu, neuerdings das getrocknote Material vor der \%ertrimmermo der Zellen mit Toluol zu extrahieren, la sich gezeigt batte. dab das Tolnol auch auf nicht wanz fein zermahlenen ()ronen wirkt. bie gehränchlichen Extraktionsapparate für Extraktion fester Massen. als deren Vorbild der Soxhletsche gelten kann, waren deshalh nicht zu verwenden. weil bei ihnen das Extraktionsgefäl) iiber dem (rhitzten Kolben angebracht, mitsant seinem Inhalt bis nahe an den Siedepunkt der Fxtraktionsfliissigkeit dauernd erhitzt wirl (bei Toluol gegen 100\%). die Fxtraktion aber kalt rorgenommen werden muß, will man Eiweißkörper und Formente nicht schwer schädigen. Ich habe daher den in Fig. S8 wiedergegehenen Extraktionsapparat konstruiert ${ }^{1}$ ). dessen Wesen darin besteht, daf. das Fxtraktionsgefäf weit aus dem Bereiche der siedenden Extraktionsfliissigkeit geriickt und durch ein ans zwei Kü̈hlern hestehendes Küihlsystem vou ill getrennt ist. Der Ipparat ist infolge des Ersatzes jedes Korkrelschlusses durch Quecksilbersicherheitsverschliisse absolut dicht zu erhalten und sehr leicht zu handhaben. Thas zweischenkelige Extraktionsgefäf ist durch zwei Glocken ('/n- und Ablanfglocke) mit "zwei entsprechenden, aber rerkehrten Glocken des Kühlsystems beweglich in Verbindung gesetzt. Am untereu Ende. wo das schmale Ablaufrohr anfsteigt, befindet sich ein Hahnanslab. I) bese beiden Öffumgen werden durch einen Wattebausch verschlossen. das Gefülj etwa bis zur Hälfte mit der Extraktionsfliissigheit gefiillt und hicranf das zn extrahierende Material eingefüllt. Das gefiillte Gefïl. wird nun derart an die Kühlanlage angesetzt, dab zunächst beide Zulaufglocken von unten nach oben röllig ineinander geschoben werden; damn wird das Ciefäb nm seine Längsachse soweit gedreht und aach rechts geneigt, daß die beiden Ablaufglocken ihereinander zu stehen kommen (Zuund Ablaufglocke fler Kïhlanlage sind in der Vertikalen $1 \mathrm{~mm}$ roneinander entînt). worauf (las Extraktionsgefäl soweit gesenkt wird. daß nun auch die Ablaufglocken ineinander geschoben erscheinen und hier durch das in der Ablaufolocke der Kühlung befindliche Quecksilber der Terschluß hergestellt ist.

1) Hergestellt ron den rereinigten Fabriken für Laboratoriumsbedarf in Berlin. 
In dieser stellung wird das Gefäß durch eine Klemme fixiert. Hierauf wird in die Zulaufolocke des Extraktionsgefüßes (uecksilber gegossen his Versehluß hercestellt ist. Der Kochkolben wird nach Beschickung mit Flüssig-

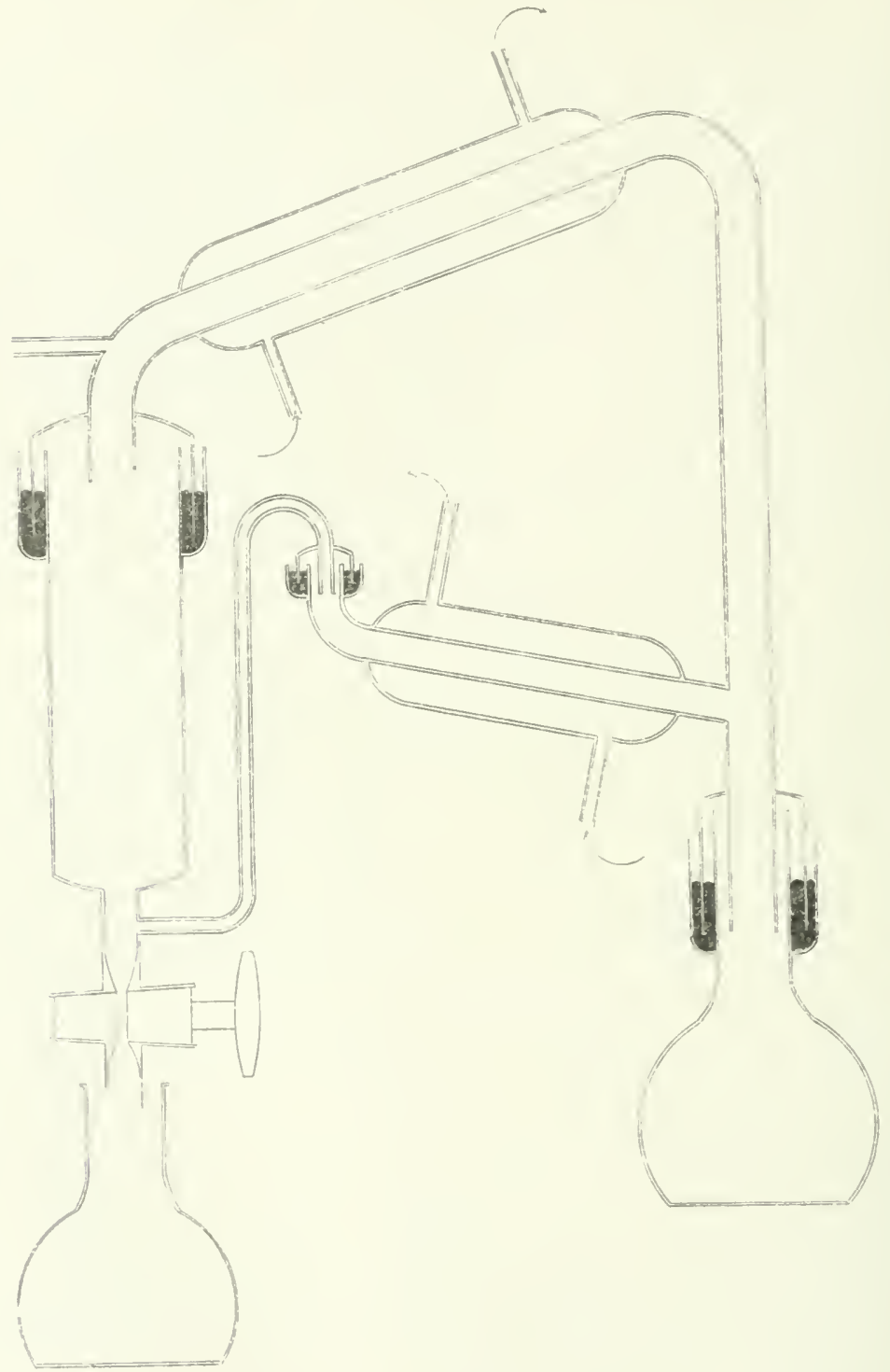

Fig. 88 .

keit und etwas Bimsstein zur Vermeidung des siederer»nges durch Einschieben seiner Verschlufglocke in die der Kühllanlage ron muten an dieve angesetzt und ohne Klemmenfixierung anf ein mit Asbestpapier helegtes. 
Drahtnetz gestellt. I)as hielauf zum Verschlnli in die Kolbenglocke cingrefiillte (Quecksilber wird, um seine Verlampfung zu verhindern, mit einer geringen Mentre (ilyzerin bedeckt. ${ }^{1}$ ) Das Kühlsrstem lat die Form eines Dreiecks: es hestuht aus cinem oberen zun Extraktionsgefüf abstrigonden. dem Zulanfkiilıler, und ans einem untron zum Kolben absteigenden. dem Ablanfkiilıler, deren Seelemrohne sich am Extraktionsegrfäß in spitzen Winkel treffen, wo sie die beiden Verschlnbglocken tragen. an den entgegrengesetzten Enden aber durch das senkrechte Dampfleitungsrohr miteinander verbunden sind. Das Kühlwasser läuft aus dem oberen in den unteren Kühler. Die Seelentohre sind so weit gewählt, dal Kondensflüssigkeit sie nicht verschlichen kann. Auberdem ist aber das Dampfleitunssoln in seiner gamzen Ansdehmung weiter im Lumen als die Seele des Ablaufkiihlers. hierdmo'n wird erreicht, dafi der Hauptstrom des Dampfes durch das senlirecht aufsteigende Leitungsiohr scinen Weg in den Zulaufkïlsel nimmt und nur ein geringerer Nehenstrom in das Ablaufrohr eintritt, wo el nach wenigen Kentimetern Wegstrecke durch die Kïhlung kondensiert wird. Aulerdem verhindert das den Ablanfkiihler verschliebende angefiillte Extraktionsurefäß die Ausbreitung des Dampfes durch den Ablaufkiihler. Tersuche haben abel gezeigt, dak ohne Ablaufkühlung der heife Dampf, das ganze Ablaufrolu anfiillend, das Extraktionsgefïß trotz dessen Entfernung rom Feuer stark erwïmt, außerdem aber nur eine kurze strecke im senkrechten Dampfleitungsroln anfsteigt, so daß, hei dem hohen sierlepunkt des Toluols wenigstens, die Anlage einfach wie eine Rïckflubkiihlung wirkte und kein Destillat in das Extraktionsofefif gelangte. Der Ablaufkiihler verhindert das im Zusammenhange mit del geringeren Weite des Ablaufrohres und dessen Abschluf durch das Extraktionsgefäls: der Dampf entweicht durch das senkrechte Leitungsrohr, wird im 'Lulaufkiihler kondensiert, die Fliissigkeit tropft auf das Extraktionsmaterial, passiert dieses und grelangt durch die Secle des Ablaufkïhlers in den Kochkolben zuriick. Da das nmgebogene Ende des Ablaufrohres des Extraktionsgefäßes nur wenig niedriger liegt als dessen obere Öffuung, so bleiht das Gefäß danernd gefïllt; die Extraktion erfolgt kontinuierlich und nicht intermittierend. (In verschiedenen Versuchen hat sich die intermittierende Extraktion, die unschwer eingerichtet werden komnte, nicht bewährt.) Das Extraktionsgefäl darf natmgemäb nư soweit mit Extraktionsmaterial gefüllt werden, dab die Flïssigkeit dieses dauernd vollständig bedecken kann. Das ganze System steht nur an der Glocke des \%ulaufkiihlers mit der Auljenluft durch ein kurzes ragrechtes Rohr in Terbindung, wo ein Natronkalk- bzw. Chlorcalciumröhrchen vorgeschaltet werden kann. Nur völlig wasserfreie Flissigkeiten diirfen als Extraktionsfliissigkeiten verwendet werden. (Toluol ${ }^{2}$ ) ist mit $\mathrm{CaCl}_{2} \mathrm{zu}$ trocknen, Aceton

1) Dabei bleibt der innere (Quecksilberspiegel unbedeckt, hier sammelt sich aber hald Kondensflüssigkeit an, so laß anch hier kein Hg verdampfen hann. Hier darf kein Glyzerin vorhanden sein, weil es die Extraktionsflüssigkeit rerunreinigen würde.

2) Kilares, jedoch wasserhaltiges Toluol destilliert trübe, da sich hierbei das Wasser abscheidet. Das zu extrahierende (Irgan nimmt das Wasser begierig auf, wodurch die Massen schmierig werden. 
gleichzoitio mit ('alciumchlorid und Kaliumkarbonat.) Nacholem die katrak-

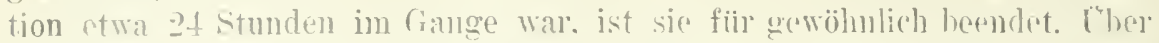
den Fortgang beleht nur anfangs das Anssehen der ablanfoudun Flüssigkeit, die bald farblos wird. spätre die Prufmo kleiner Flïssigkeitsprohar anf lijokstandsfreiheit, die man. ohne die Extraktion zn muterhrehen. heim Ilahnatslaf des Rxtraktors jeder\%eit entuehmon kam. Will man nach beenduter 'Toluolextraktion noch eine solehe mit absolutem Alkolinl oder' Aceton anschliefien, so brancht man mur die Flissigkut im Kochkulhen zu wechsoln, dessen Glocke nichloger als der Hals ist. so dafi man erkich-

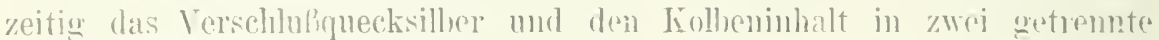

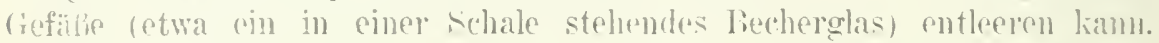
Soll nicht weiter extrahicht werden. so wind das kxtraktionsocefäß durch den Hahnauslaf groh entleert. in der dem Einsetzen entsprechenden Weise ahgenommen. das Versohluli-Hg der Zulanforlocke ausgeschiitet und schlielilich ras frefäb beim Hahnauslab mitteist Stopfens mit einem Absangkolhen wrybunden. I)as mugabogene Fude des Ablanfrohres wird mit einem kleinen Iioristöpsel geschlossen und nun scharf abgesaugt. bis das Material völlig frocken ist. Dann stïlpt man ibe! las abgenommene Extraktionsoroül eino passende Glasbiichse mo entleert durch Stiimen die gesamte extrahierte Masse. Hat man dafiur gesorgt. dip Masse ror der Extralition mit einem Wattebausch zu bedecken, so dient dieser bein Absaugen mud Trocknen als Filter; das durch das Tolnol sterilisierte ()roan lälit sich dann nach Futfernung des Wattebausches auch stril anflewaluen. Was unter Lustän.len hei der weiteren Vrarbeitung antiseptische /usätze remoiden liebe. In entsprechend langen Fxtraktionsgefülien lassen sich, wofern man auf das Extrakt keinen Wert legt, heunem mehrere Grane gleichyeitin. extrahieren, indom man diese in evontuell grokiinte Schlejchel-schiillsche Extraktionshiilsen füllt, die letzteren ineinander sterkt mol das ganze sistem in deu halh gefiillteu Extraktor versenkt. Als Extraktionsflissigkeiten rerwendet man am bosten aromatische Kohlenwaserstoffe (Tenzol, Toluol, Avlol). INie aliphatischen Kohlenwasserstoffe sowie Ather, 'Totrachlorkohlenstoff, Chloroform, Schwefelkohlenst off sind nicht so zweckmäing. Es macht den Findruck, als oh die aromatischen Extraktionsmittel viel mehr einzudringen remörhten. Wit'l'oluol nehmen die getrorkneten wrgane eine tief

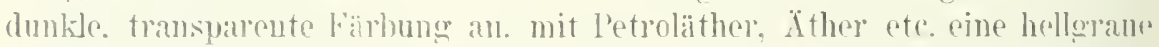

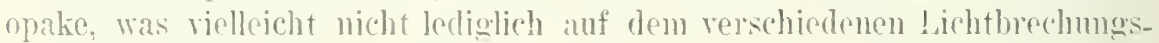
vermöen herulien mag. (rebrontlich kïnnte man als Extraktionsmittel anch andere aromatische riöroer wie Anilin orler ätherische (̈) (Terpentinöl) bemmtzen, dic ebenfalls. "ie uns Versuche geleht haben, die trockenen ()rerme nicht schädigen. Narh der Extraktion mit solchen mit Wasser nieht mischbaren fliissigkejen gehen die ()roun an mit Wasser mischbare, organische Lösungsmitteh noch grofärhte Extrakte ab. Am hesten eignet sich für diese Extraktion das Areton oder aurh Alkohol, die bei Vermeidung von Wascerspumen (Vorschalten eines Ca ('b-liolnes), wio die Versuche gezeigt haben. wader die Eiweilikirper koagulieren. noch die Fermente irgendwie 


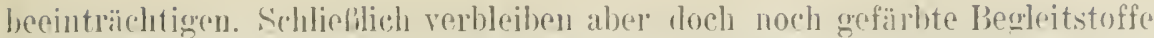
der Oloumeiwcilie zuriick, welche zmm 'l'eil wenigstens wasserlöslich murl dialysabel sind, so dib nach der I)ialyse (sieho weiter nuten) fast ungefiirbte Extrakte "rlalten welden. Kommt es laranf an, die Extrakte durels Hit\%e unverindret, nativ zu grwinnen, so geht man in der eingangs elwähnten Weise vor Mahlen mit der hetreffenden Flissigkeit in dor Farbommihle und Abmutschens und gewinnt die gelösten Stoffe nicht dureh Abrampferm, sondern Weghlasen des Läsungsmittels in den beschriehenen 'Trockenappatrat. So kann man anch die nativen (O)ganlipoide zur Lintersuchmug bekommen.

III. las \%erklejnevil der \%ellen läbt sich, falls diese trocken und entfettet, infolgr( dessen spröde sind, anch ohne besondere I pyarate in der lieibschale leicht ausfïhren. Mit lorteil lassen sich natiirlich hierzu die verschiedenen 'Треи von Kugelmilhlen mit Porzellantrommel (Biichse) verwenden. Recht gut lassen sich die trockenen \%ellen. insbesondere wenn sie entfettet sind. " unter Zuhilfenahme von Toluol in einer Farbenreibmiihle zerreiben. Die

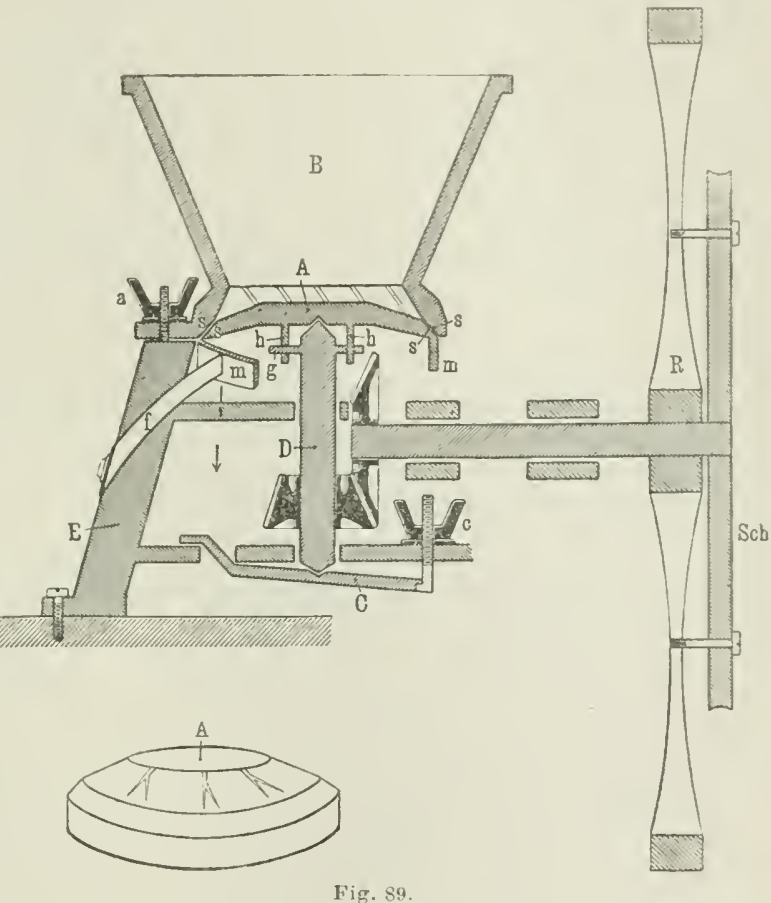

Konstruktion des anch fiir andere Zwecke, zum Vermahlen fester substanzen in Flissigkeiten gut rerwendbaren Apparates ist folgende ${ }^{1}$ ) (Fig. 89): Die abnehmbare Scheibe $A$ wird durch den Hebel $C$ und die Achse $D$ mittelst der Fliigelschraube e nach oben gegen den gleichfalls abnehmbaren, durch drei Fliigelschrauben (a) auf einem Gestell (E) fixierten Konus oder Zylinder (B) gedriickt. Die Beriihrungsflächen sind etwa $2 \mathrm{~mm}$ breite schräge Schliffe $(s s)$, gegen die sowohl an Konus als an der Scheibe kleine Rimnen führen. Die Richtung der Zylinderrinnen und Scheibenrinnen kreuzen sich, indem die ersteren in der Drehrichtung

1) Diese Mühlen sind in jedem Farbwarengeschäft erbältlich. Dieselbe Konstruktion haben dic Salbenmühlen der Apotheker. Auch werden derartige \ü̈hlen mit Hartporzellanreibflächen von den meisten Werkstätten für Laboratoriumsbedarf geliefert. 


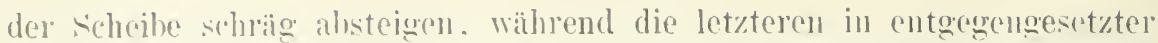
Richtung verlanfen. Die scheibe A balanciest auf der durch Kalnuraliiher-

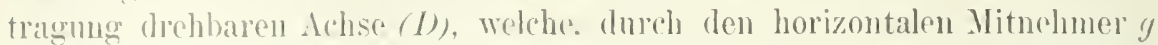
an den an der muteren fiäche der Scheibe angebrachten Stiften $(h)$ an-

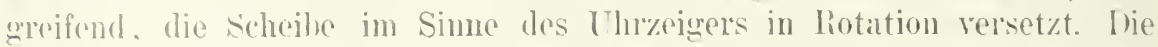
an dem ans weichem Fisongub helogetellten. recht roh greabeiteten Fabrikate befindliche Kubbel fiu Handbetricl) wurle durch eine mit Schwungrad $(h)$ verbundene Schumscheibe (Sch) ersetzt. Wolehe die Verwendung eines Motor's

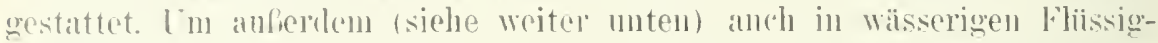
keiten malnlen zn kännen, olne von liosthildnug gestiint zn werden. wurde

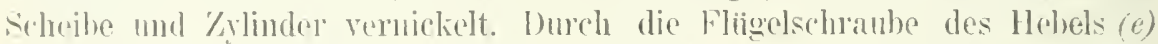
lasien sich die schleifenden Flächen von scheibe und Yylinder so weit nähern. dab zwischen heiden eine in den Kylinder gegossene. selhst sehr

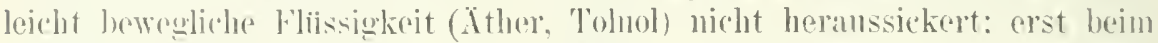

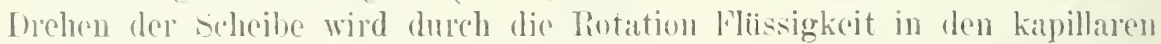
liaum, den die schleifenden Flächen hilden. gesogen mul arscheint als fouchter stroifun auf dem änferen zyhindrishom Mantel der Scheiho (m). Ion hion wird dic liissigkeit durch eine anf dem scheibemmantel sohleifende Fedor $(f)$ anfoemommen, rimut an dieser herunter und tropft in ein mintergestelltos (iefaib. Trotz mannigfaltiger, verbescerungsäuligor Fehler arbeitet der Ipparat zufriedenstellend. Er wirl derart in Gang gesetzt, dab man in don \%ylinder Toluol gieft und die Scheilye so weit hebt, dal' dieses eben nicht melır heranssickert, hierauf setzt man den Jotor in Gang und beobarhtet dic Abfluligeschwindigkeit des Toluols. Dieses soll nicht im Strahl, sondorn in mäbig rascher Tropfenfolge von der schleifenden Fabler flieben, was dneh Verstellen der Fligelschranbe a anch bei lanfender Maschine leicht zu eryelen ist. Hienanf erst lringt man das getrockuete organ portionsweise in den \%ylinder. indem man daranf achtet, daf dic Mischung im 'schlindol nicht zu dickflüssig welde: tritt dieses ein, so hat man sukzessive kleine Mengen Tolnol nachzugielien, bis alles vermahlen ist und roines lobluol ablänft. Ije so erhaltenen Suspensionen oder Emulsionen sind

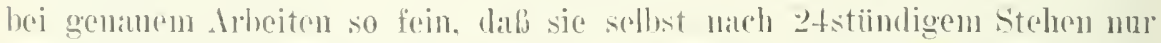
wenig Bodensatz absot\%cn mod, wie hereits erwähnt, nur langsan (wenn anch

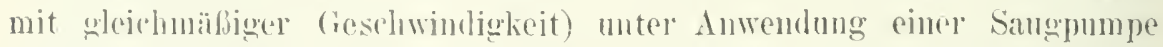
filtreren. Vereibt man angetrocknete 'Tropfen solcher Fumbionen mit

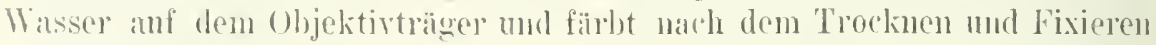
mit Methylenhlan, so findet man in gelungenen Fïllen ïberhaupt keine intaktan \%ellkernc. sondern mu eine oglehmäbig gefürlite, von feinsten Chomatinsplittem duchsotzte Flïche. Es ist zu hemerken. dab dieses liesultat un mit getrockuctem Material zu crziclen ist. Frische \%ellen schlüpfen lurch jencu kapillar'n Ramm, ohme zeroluibkt zu werden, inshesondere anch Erythroeyten. Frische Hofo und Stäkekörmer worlent num

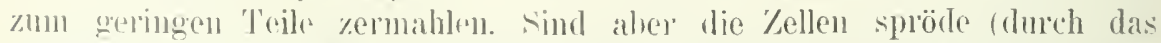
T'orknens und bedingt die Mahlfiissigkeit keine Erweichmg. so geht dic \%erkleindermong vout vonstatten; daher werden auch entfettete \%ellen sicherer 
zermahlen als nicht extrahierte, wenn auch lierluei das Mahlen mangels

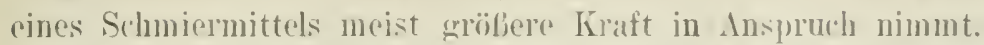

So werden sclilieblich die ibberlebenden orouse unverindert je nach Wunsch: lipoidhaltien odro frei, mit intakten oder zertriimmerten Zellen als wägbares, lingere Zeit haltbares Ausgangsmatrial arhalten, welches sich zu allen folgenden Fraktionierungen eignet. I)er yuantitativo Vergleich heterologer wie lomologer ()rowne des gleichen orler verschiedener Individuen derselben und rorschiedenen Art in Bewg anf Eiweil. Ferment und Lipoidbestand. ist ermöglicht. Desgleichen die Fewinnung unlöslicher organfraktionen. Dic Aufteilung durch Filtration ist infolge der Entfettung quantitativ und rasch durchfuhrbar. Vorbereitet zur weitcren Verarbeitung wird dieses Material am hesten durch Vermahlen abgewogener Mengen mit Wasser in der Farbenmiihle, wodurch feine und geniigend stabile Suspensionen erzielt werden, nm hequem mit Pipetten verteilt werden $z u$ können oder die Benutzung aliquoter Filtratsteile zu gestatten. Die Verarbeitung solcher Aufschwommungen mo Filtrate auf Fermente und Eiweilköirper siehe unter F. und G.

\section{E. Die Herstellung von Alkohol-(Aceton-) Material.}

Das Bestreben, für Fermentrersuche ein konserviertes und wäglares Ausgangsmaterial zu haben, verbunden mit dem Wrunsche, die koagulablen Eiweibkörper für die folgenden Extraktionen unlöslich zu machen, ohne die Fumente zu schädigen, hat zu dieser Yethode grefiihnt, die wohl nur in ganz bestimmten Fillen ohne Nachteil angewondet werden kam. Mafgehend fuir sie war die durchaus nicht für alle Fälle zntreffende Annahme, das die Orwanfermente durch Alkoholeinwirkung auf frische, d. h. stark wasselhaltige (Jorane keine Schädigung erfahren. In Gegenteile. die meisten Fermente werden partiell oder röllig durch längere Einwirkung starken Alkohols (in eiweibfällenden Konzentrationen) zerstört (siehe weiter unter G. und H.). auberdem kommt eine Alt Fixierung der Fermente an die koagulablen Eiweißkörper zustande. so dal' die Löslichkeit der Fermente oft ganz verloren geht. Dagegen wirkt der Ilkohol bei Wasserabwesenheit nicht koagulierend auf Eiweilj und nicht fermentschädigend.

Battelli) hält Iscoresco²) entgegen, dah beim Behandeln ruit .llkohol oder Aceton und nachfolgendem Trocknen die frischen Organe den gröbten Teil ihrer katalytischen Fähigkeit oder der Löslichkeit ler Katalase einbülen. (Im Gegensatze zur Alkoholfällung von gelösten Fraktionen siehe unter $(\dot{r}$ )

Die zerbleinerten (Irgane (meist sand-Kieselgur. aber anch einfach gehacktes Material) werden bis zur deutlichen Koagulation der Eiweif-

1) M. F. Battelli, La présence de la catalase dans les tissus animaux. Compt. rend. soc. biolog. T. ј9. p. 300 (1905).

") M. H. Iscoicsco, De la présence de la catalase dans les différents nrganes. Compt. rent. soc. biolog. T. 58. p. 1054 (1905). 
kürper mit dem melnfiachen Volmmen Alkohot oder Aceton remischt. Nach meist 2 stmuden. jedenfalls aber niclit länger als 24 stmolen wird ahfiltriert oder ahgesungt, mit Xther machgewachen. anf Filtrierpapier getrocknet mol gepulvert. Zn lange Einwirkmg des Alkolnols ist in allen Füllen schïdlich. Sulloresti fand die Aldehydase nach :) Tagen Alkoholeinwirkmo zerstört,

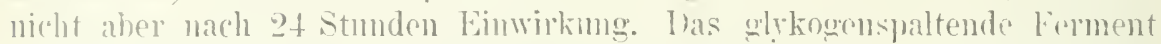

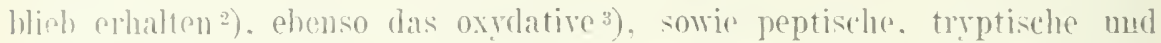

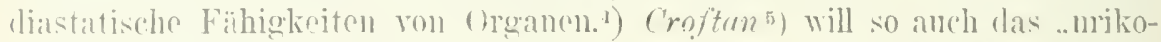
lytische" Forment konserviert haben. wiewohl durch Wierhoushi und

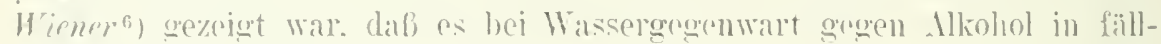
baren Konzentrationen selur empfindlich ist.

(1) die an Alkolsoluaterial heobachteten Framentleistungen quantitativ denen der rerwendeten Jengen frischer () rwane ont:prechen oder nur cinen Raest des urspriunglichen Funktionsansmalies darstrllen, ist ststematisch nicht untersucht. Xach zahlueichen literaturangaben ist, wie gesagt, das letztere anzunelumen. A. Joqueti) fand den Xa ('l-extrakt ron Alkoholmaterial berlentend geringer oxydativ wirkend als den liochsalzanszug der

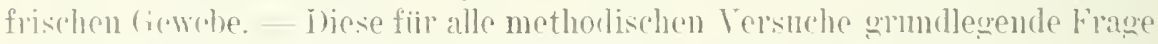
ist nur durch vergleichende Ermittlung jener kleinsten IJaterialmengen zu chtscheiden. Wedche gerade noch ein bestimmtes Ausmal an Leistmen

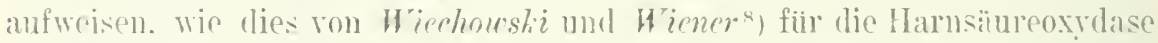

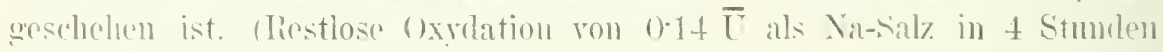
hei $40^{\circ}$ unter sichuitteln mit Inft.)

\section{F. Weitere Verarbeitung der zerkleinerten Organe.}

\section{prefosifte und Fitrakte.}

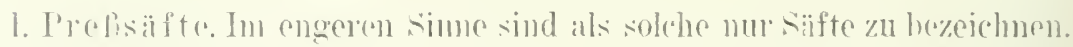

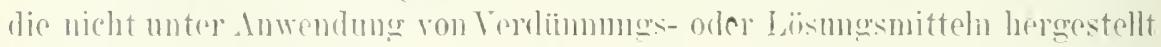
werden: sic stellen den fliissigen Anteil der (troune dar nud sollen klar. inshrondere zollfrei sein. Las nach dersolben Jethode rormuelmende Anspressen von irgendwie mit hismosmittoh hehandalen (hamen liefert

1) E. sellemesi, Zur Tiemntnis des Oxydationsfermentes der Gewehe. Tirchous Areh. Ba. 147. S. 1 (1897).

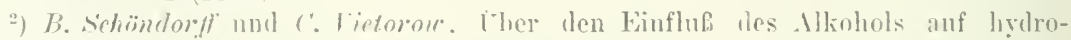
lysierende Enzyme. I'flïgris Arch. Bal. 116. S. 495 (1907).

$\left.{ }^{3}\right)$.J. I'ohl. Zur Kenntuis des oxylativen Fermentes. Arch. f. experim. Pathol. u. l'harm. Bu. 38. ํ. 65 (1597).

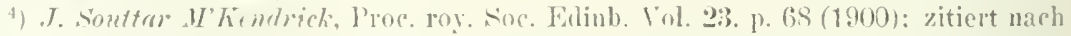
Malys . Tahrl). T. Bil. 31. S. 873 (1901).

5) ('roftun, I'flüyes Areh. Bid. 121. S. 377 (1908).

6) II. Mirchomstic und H. Wiener, 1. c.

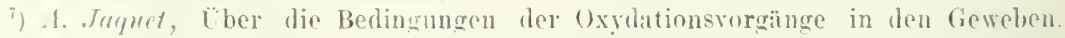
Areh. f. cxperim. J'athol. 11. Tharm. Bd. 29. S. 386 118.92).

a) II. Iriechomski und H. Hiener. l. c. 
Extrakte. Anch die oben erwähnten Collaturen haben mit den eigentlichen l'relisiften nichts zu tum. Gerwöhnlich werden I'relisifte so hergestollt, dill's

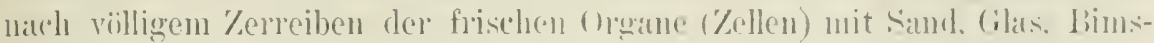
stein oder (guar\%pulver unter Zusit\% wn Kieselgmr. nach drm Vorbilde der

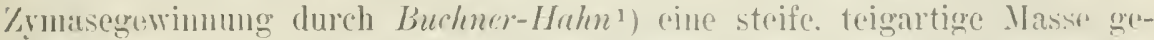
mischt wird, die in dinem doppelten l'relituche mit einer hydranlischen Presse bei hohem Druck (bis 50() Itm.) frei ansereprelit wird. Die l'ressung muls oft mehrere Stunden andanern, mn geniigend sift zu liefertı. Wer albfliebende Saft ist nur wenig trib. Die \%onsïtze wirken als Filter. Aulerer der klassischen Buchnerpresse sind zahlueiche audere Pressen und Filtrerpressen mit geschlossenem l'refraum ('zylinder) angegehen, die ehenfalls mittelst hydraulischen Inuckes oder aber mit Differenzialhebeh betrieben werden. Eine solehe Presse mit rerhesserter Ablaufrorrichtung hat WolffEisncr $\left.{ }^{2}\right)$ angegeben. Ein neuartiges I'rinzip henutzt die ()rgansaftpresse von H. H. Meyer. ${ }^{3}$ ) Ther Prebranm wird ron melneren ïhereinander gelegten Ringen sebildet. deren jeder an der unteren Flärche feine Rimnen führt. Durch diese tritt der Saft sofort ans, ohne das gresante Prefgut durchdringen zu miissen und sammelt sich in, von den lingen gedeckten, Zirkularkanälen an der Peripherie, ehe er endgiiltig die Presse verlïlit. Durch entsprechemle Wahl der Ringzahl läbt sich das Volumen des Zylinders bequem der Hasse des P'refontes anpassen. Yan kann anch zwirchen die Ringe Filtrierpapier legen. wodurch der Apparat als Filterpresse wirkt. Die röllig klare Säfte liefernden Filterpressen sind iiberhaupt rorznzichen. Für manche Zwecke (Fürths Muskelplasma*, z. P.) reichte schon das Anspressen mit einer gewölntichen Tinkturenpresse mit schraubenantrieb, der nur geringe Drucke zulälist, aus.

Die Methode der Prefisaifte hat den Vorteil, ganz kouzentricrten Organsaft zu liefern. gibt aber weder für Eiweilikörper noch fïr Fermente quantitative liesultate. Der Zusatz ron Kieselgm sollte womöglich rermieden werden, da diese, wie bereits erwähnt, Eiweil und Fermente, ja sogar Salze alsorbiert zuriickhält. Diese Erfahrung wurde schon ron Buchner-Huhn hei der'Zrmasedarstellung gemacht. - Der Eiweibhestand ier I'refsilfte ist bis auf den des Muskelsaftes nicht eingehend studiert, er dïrfte sich bis anf den Konzentrationsunterschied mit demjenigen des Organfiltrates ( I'ohls .. ()rgamplasma“, siehe unten) decken. Wurden die Zellen rorher zerrieben, so gehen wohl auch solche Fermente in den Saft ein, die dem einfachen Filtrat oder Saft fehlen. Doch scheint eine derartige Fermentgewinnmg nur wenig Ausbeute zu lieferu, da die meisten Erfahrungen dafür sprechen, daß nicht umittel-

1) E. Buchner, 1. c.

2) 1. Wolff-Eisncr, Iic Endotoxinlehre. Verh. d. physiol. Ges. zu Berlin. Areh. f. Physiol. Suppl. S. 430 (1906).

3) H. Meyer, Zwei neue Laboratoriumsapparate. Areh. f. cxp. I'athol. u. Pharm. Bd. 47. S. 430 (1902).

4) O. r. Fürth, Üher die Eiweißkörper des Muskelplasmas. Arch. f. exp. Pathol. u. P'harm. Bı. 36. S. 231 (1895). 
bar lïslicho ()roanfermente anch aus den zeltriinmerten Zellen erst durch ein mutsprechendes Lijsung-oder Aufschlichungsverfahren in guter Ausbente zu gewinnen sind (offenbar erst nach liswng ilner wahrscheinlich adsorptiven Bindung an unlösliche Organfraktionen).

Vielfach sind in der Literatur unter l'refsäften auch im obigen sinne durch Pressen harestellte Extrakte gemeint.

Prelbsifte von Lymphdriisen. Milz. Leber enthielten ein mit Alkohol fiallhares, $H_{2}(1)$ spaltundes ('ytoglobulin. ${ }^{1}$ ) Stoklusa. ${ }^{2}$ ) glykolytisches Ferment wurde mit Nkohol mod Xther ans l'rersäften gewomnen. Foinschmidt, der Sitoklasu hostatigt, arbeitete mit dev liudmerprosse. ${ }^{3}$ ) Hedin mul Rouland $\left.{ }^{4}\right)$ fandru in dem mit einer Filterpresse ans zerkteinerter Nilz (siche oben ihren Zerkleinerungsapparat) gewonnenen saft proteolytische Enzyne. die später x- mol (j-Lienase genannt wurden. F. Sachs ${ }^{5}$ ) fand uach dem Buchnerschen Verfahren im Organsaft Nuklease; L. Brunton und J. K. Kihodes ${ }^{6}$ ) im Muskelsaft glykolytische Fühigkeiten. Fürths Muskelplasma ist bereits erwiihnt.

II. Wxtrakte. Kur Darstellung dersetben kann jerles nach einer der in den rorigen Abschnitten beschriebenen Methorlen gewommenes Material verwendet werlen: O'ganbrei, Kollaturen, mit Fliissigkeit angeriebene Pulver. Alkohol-1cetommaterial. Die Extraktion erfolgt durch Digestion mit indiffelenten Lïsungsmitteln orler durch Aufschlieliung, sie ergibt aulier den fliissigen Zellhestandteilen dio iu den betreffenden Flissigkeiten löslichen. Die Abtremung des (ielisten vom lingelösten erfolgt durch Filtration oder Zentrifugieren. Beide Trenumosverfaluen könmen mit Pressen (siehe oben) komhiniert werden. In allgemeinen ist die Extraktion mit dem mgelösten Riickstand bis zur Erschöpfung an dor lïslichen Fraktion zu wiederholen. Fïr die Filtration sind die rerschiedenen Papiersorten sohr ungleich geeignet; oft wirl anch durch anfuesehlemmten Papierbrei filtriert. Im allgemeinen geht die Filtration mur sch: langsam vonstatten und stockt oft gan\%, so dal) Waschen anf dem Filter unmöglich ist. Nach D. her-

1) W. Demme, Ein nener eiweißliefernder Bestandteil des Protoplasmas. Ing.-Diss. Dorpat 1890. Zentralll. f. med. Wiss. S. 483 (1891); zit. nach Malys Jabrb. 'l. Bd. 21. S. $3(1891)$.

$\left.{ }^{2}\right)$.J. Stoklasa mul $F$. ('zerny, Beiträge zur Kenntuis der ans der Zelle höher organisierter Tiere isolierten Gïrnng erzeugenden Enzyme. B. B. Bd. 36. S. 4055 (1903) und Zentrallil. f. Physiol. lid. 17. S. 463 (1903).

$\left.{ }^{3}\right)$ J. Feinschmidt, Ober das zuckerzerstörende Ferment in den Organen. Beitr. z. chem. Physiol. u. Pathol. Bd. 4. S. 511 (1903) und Fortschr. d. Med. Bd. 21. S. 729 (1903).

4) S. G. Hedin und S. Roulamd, On the presence of proteolytic enzymes in the organs and tissues of the hody. Proc. phys. soc. Jouru. of phys. Vol. 26. p. 48 (1901). Weiters: ¿̈her ein proteolytisches Ferment in der Milz. Zeitschr. f. physiol. Chemie. 134. 32. S. 341 (1901) unl Untersuchungen üher das Yorkommen von protenlytischen Enzymen im Tierkörper. Ehenda. S. 531 und S. G. Hedin, Investigations on the proteolytic enzymes of the spleen of the ox. Journ. of phys. Vol. 30. p. 155 (1905).

5) F. Srachs, Uber die Nuklease. Zeitschr. f. physiol. (hem. Bal. 46. S. 337 (190氵)).

$\left.{ }^{\circ}\right)$ T. Lauder Brunton und J. H. Shodes, Uher ein glykolytisches Enzym in den Muskclin. Zentralbl. f. Physiol. Bd. 12. S. 353 (1899). 
gestelltes lipoidfreies Material lïßt sich dagegen gut filtrieren und waschen. Kieselgur h\%w. P'orzellanfiltration ist nicht anwendhar. dagegen kann man Watte mele Filzfilter versuchen. Indem die lixtraktion die (rgane in lösliche und unlösliche Anteile zerlegt. stellt sio gleichzeitig einen weiteren Schritt in der Organfraktionierung dar. die durch die Entfernung der Lipoide und Extraktirstoffe nach Methode D. heconnen werden konnte. Wiinschenswert wäre es aber auch für manche \%wecke, dlese Fraktionierung so durchzufuibren, daß zunächst die \%ellkerne rom l'rotoplasmateil getrennt werden. Dies scheint, wie mich Versuche gelehrt hahen. durch physiologische Salzlösung einigermalien möglich zn scin. Auf dem Filter oder der Zentrifuge kann man z. B. Leberzellen eiweilfrei waschen, ohne die Form und Fürbharkeit der Kerne zu schädigen. I)as Zentrifugat ist opaleszent, das Filtrat klar. Außer diesen nicht filtrablen. im Zentrifugat enthaltenen Anteilen muissen noch unlösliche Bestandteile im Protoplasma vorhanden sein. denn die so erhaltenen gut färbbaren Kerne sind noch in eine diffus gefärbte, fetzige Hasse eingelagert.

1. Indifferente Extraktion.

Fiir dieselbe kommt nur Material mit intakten Zellen in Betracht.

Un die aufschließende Wirkung der Autolyse zu rerhindern, ist die Extraktion in der Kälte eventuell durch Schiitteln und nur durch kurze Zeit (bis 24 Stunden) fortzufïhren. As indifferente Lösungsmittel wurden meist Wasser und Kochsalzlösungen niedriger, bis $1^{0}{ }_{0}$ iger Konzentration, sowie Glyzerin rerwendet. Fiir Fermente kïme auch Alkohol in Betracht. Doch können auch andere Lösungen versucht werden (etwa Zucker oder Na-Acetat); es sind in dieser Richtung noch zahlreiche Varianten möglich. Gewöhnlich wird die doppelte rewichtsmenge des frischen oder die 10-50fache des nach D. getrockneten Iaterials an Lösungsmittel rerwendet.

ж) Kochsalzlösung bzw. Wasser. Das klare Filtrat (Pohls Organplasma) enthält als charakteristischen Bestandteil den voll Pohl entdeckten, hei $37^{\circ}$ koagnlierenden Eiweißkörper neben anderen Proteinen. ${ }^{1}$ ) Als solche wurden in den betreffenden Extrakten Albumin aus Muskeln ${ }^{2}$ ) und anderen Organen, Nukleoproteid und Nukleohiston aus Thymus ${ }^{3,4,5,6}$ ) gefunden, auch

1) J. Poht, I'ber Organeiweiß. Beitr. z. chem. Physiol. u. Pathol. Bd. 7. S. 381 (1905); hier auch ältere Literatur über Organeiweiß.

$\left.{ }^{2}\right)$ W. Krautschenko, Die Menge des Nukleinkomplexes in Globulinen und Strominen rerschiedener Organe. Inang.-Diss. Petersburg 1904. Zit. nach Malys Jahrb. T. S. 39 (190t).

s) J. Bang, Chemisehe Lutersuchungen der lymphatischen Organe. Beitr. z. chem. Physiol. u. Pathol. Bd.4. S. 105, 331. 362 (1904). (1901).

4) H.Cociti, Úber das Nukleoproteid der Placenta. Lo Sperimentale. Vol.j̃̄. p.503

5) W. Huiskamp, Über die Eireißkörper der Thymusdrüse. Zeitschr. f. physiol. Chemie. Bd. 32. S. 145 (1901). - A. Ostuald, Die Eiweißkörper der Schilddrüse. Zeitschr. f. physiol. Chemie. Bd. 27. S. 14 (1899).

$\left.{ }^{6}\right)$ W. Jones, t'ber die Selbstrerdauung ron Nukleoproteiden. Zeitschr. f. phrsiol. Chemie. Bd. 42. S. 35 (190t). 


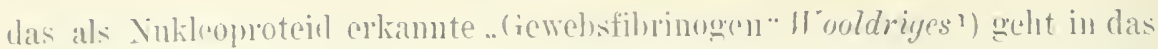
II asserextrakt iilure

fon Fermenten wurden in dieser Fraktion gofunden: das Erepsin

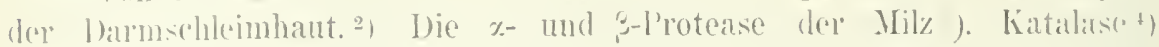
ans relshiedenen (Jounen: 'lrypsin und amylolytisches ferment des

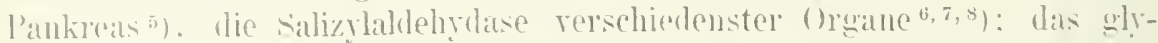
kolytische buzsm. dic .oxydierenden Sukleoproteide", sowic dic l'unin-

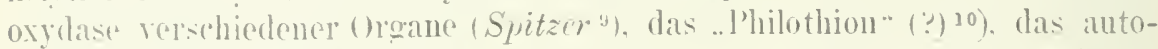

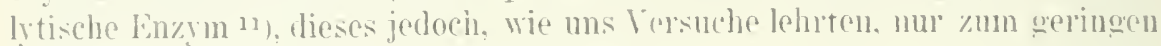
'Teil, ehenso nul trilweise die Aroinase. ${ }^{12}$ )

lowegen whrlen in frischen Extrakten nicht gefunden: die Ilarnsiareoxydase ${ }^{3}$ ) und die Laktase der Dammshleimbant ${ }^{44}$ ), letzt(re dagegen in Iarerationsfiltraten (siche weiter unten).

Jie Extrakte sind insofern nicht halthar, als sie auch bei Timmertempelatur: antiseptisch hewahrt, nach einiger \%oit jenen leicht koandublen Eiwerßlïrpur ansflocken lassen. Durch diese besonder's in del Wärme lasch eintretende Koagulation können auch formente niederoweshlagen werden.

( ) (ilyzerin. liese Extraktionsmethode stammt ron Wittirh, der

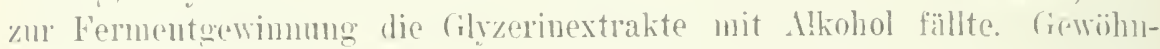

1) A. E. Wright, On Hooldriges Hethod of producing immunity against anthrax ly the injuction of solutions of tissue fibrinugen. Brit. Med. Jomrn. p. 12 (1891).

2) (). ('ohnheim, Die I'mwandlung des Eiweibes dureh die Darmwant. Zeitsihr. t. physiol. ('hemic. Bu. 33. S. 451 (1901).

$\left.{ }^{3}\right)$ s. (i. Hedin und s. lioulumel.

i) J. L. Abelous, sur la présence dans lorganisue animal d'un ferment soluhle déromposaut l'au oxygénéc. Compt. rend. soe. biolog. T. 51. p. 328 (1s!)!1).

5) X. Kromlour. Fine allgemeine Methole zur barstellung unorganisierter Fermente

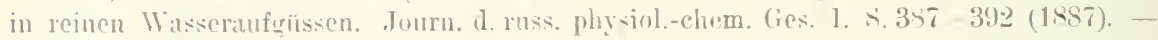
lieter. in B. B. Bal, 20. … 785 (1857).

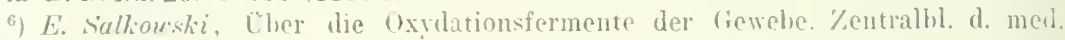
Wissensch. Nr. je 2 (1594).

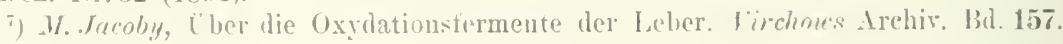
S. $235(1899)$.

8) 1. Januet, 1. e.

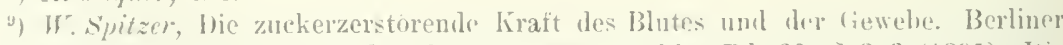

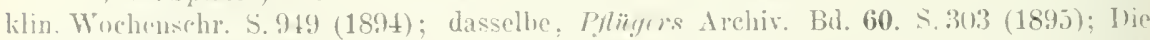

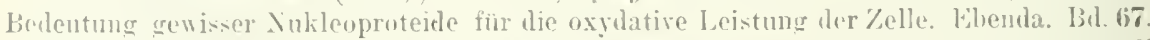

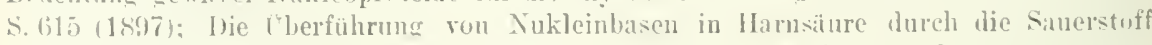
ïhertragende Wirkung rou Gewehsauszingen. Ehenda. Bul. 76. S. 1920 (1899).

10) E. Pozzi-Lsecot. Clee das Philothion ete. Bulletin de la soc. chim. de Paris. T. 29. p. 1232 (19031: zit. wach Malys .Jahrls. '1. 131. 33 (1904).

if $\mathrm{H}^{\mathrm{r}}$.Jones, ther die Sellstverdaung von Xikleoproteiden. Keitschr. f. physiol. (hemie. I31. 4\%. S. 35 (1904).

12) A. Liossel mul II. D. Inkin, thber die Arginase. Zeitschr. f. physiol. ('hemie. Bd.41. S. $321(1904)$.

13) H. Wiechoushi und H. Wiener, l. c.

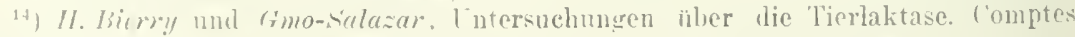
rent. 'T. 139. p. 381 (1904): zit. nach Valys Jahrl, T. Bu. 34. S. 941 (1905). 
lich wird kouzuntriertes :300 Glyzerin mit dem ()reranmaterial unemischt, nach verschieden langer Eimwirkung gewinnt man das Extrakt durch Wasserverdiumume mul Filtration oder besser ohne Verdiunnng durch Auspressen. Verwendet wurde diese Methode zur liereitung von T'estikelextrakt, zill Extraktion von glykolytischem IInskelenzym ${ }^{1}$ ), doch war hier der Frfolg geringer als bei der Wasserextraktion. - Erepsin wurde extrahiert $\left.{ }^{2}\right)$; desgleichen Katalase. $\left.{ }^{3}\right)$ Aus Alkoholmaterial wurden Extrakte mit peptischen, tryptischen mul diastatischen Eigenschaften gewonnen. $\left.{ }^{4}\right)$ Nicht in das Glyzerinextrakt gingen ijher die Harnsïnreoxydase ${ }^{5}$ ) und das oxydative Ferment Jaquets. ${ }^{6}$ )

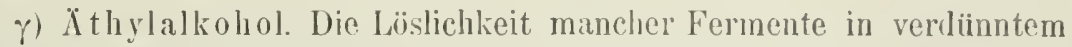
Alkohol ${ }^{7,8}$ ) kam gelegentlich \%u deren Extraktion versucht werlen. So wurde nach Fällung von Leber und Nierenmazerationen mit Alkohol die esterspaltende und Glykogen sowie Laktose hydrolysierende Poten\% vollständig im Filtrat erhalten.

\section{Extraktion durch $\Lambda$ ufschließung (Entmischung) der Organ- zellen.}

Die Extraktion geschieht hier nach oder gleichzeitig mit einer Zerstörung des Bestandes der eilnzelnen Zelle, wodurch bezweckt wird, sonst unlösliche Fermente oder Organproteine zu erhalten. Ian erhält nach Vollendung der indifferenten Extraktion neue Anteile in Lösung. Für derartige Versuche, die Zellen zu lösen, könnte die reiche Erfahrung, die man beim Studium der Hämolyse gemacht hat, Anwendung finden. Doch ist im Gegensatz zur Hümolyse über die Auflösung von Organzellen kaum systematisch gearbeitet worden. Man kann die benutzten Aufschließungsmethoden in solche mechanisch-physikalischer Natur und solche chemischer Natur einteilen.

๔) Mechanisch-physikalische Aufschließungsmethoden (Gefrieren, Zertrümmern, Dialyse, Entmischung durch Alkohol, Auskochen).

a) Gefrieren und wieder Auftauen. Das Verfahren ist zur Aufschliefung von Erythrozyten seit langem benntzt. Buchner wandte es zur

1) T. Lauder Brunton, On a probable glycolytic ferment in Muscle on raw meat and the treatment of diabetes. Zeitschr. f. Biologie. Bil. 34. S. 487 (1896).

2) Elsa Raubitschek, Erfahruugen über Erepsin. Zeitschr. f. exper. Pathol. u. Ther.

Bd. 4. S. 657 (1907).

3) E. Lepinois, Sur les ferments solubles décomposant l'eau oxygénée. Comptes rend. soc. biolog. T. 51. p. 401 (1899).

4) J. Souttar W'Kendrick, l. c.

5) Wr. Wiechowski und H. Wiener, l. c. Nr. 2 (1895).

${ }^{6)}$ Abclous et Biernè, Mecanisme des oxydations organiques. Archir de physiol.

$\left.{ }^{7}\right)$ A.J. A. Lambert, Contributiou à l'étude de l'action biologique du rein et du foie vis-à-vis de certains composés chimiques et médicaments. Thèse de Lille 1903. E. Gérard, 53 pages.

$\left.{ }^{8}\right)$ U. A. Dastre, Solubilité relatice des ferments solubles dans l'alcool. Comptes rend. soc. biolog. T. 47. p. 414 (1895); dort auch ältere Literatur. 
Jarstullung von Lanko\%tenstoffen an. In der (lromanalyse ist es nur selten benutzt worden, Weslualh kaum Erfahrungen dariber zu referieren

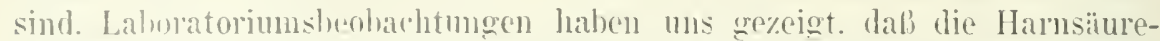

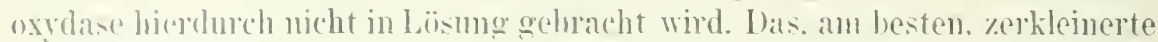
(1) ran wiol in einem metallenen (enaillierten) Gefäli ciner Käiltemischung

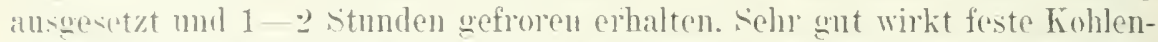
süure. die in Jolzkistehen ofler einen Filzhecher rehracht wirl. Man läßt langsam bei Kimmertemperatur anftunen und stellt hierauf Prefsaifte oder indifferente Extrakte her. Inf krrthro\%ten wirkt das Trocknen in analoger Weist rill.

b) Die \%ertrimmerung der \%ellen mit uachträglicher indifferenter Fxtraktion ist anch hiorlep zn rechuen. Wie elfolgt durch Zorreiben der spröle gemachten (fieforefromen oder getrockneten und entfetteten) Zellen olne Zusatz, oder der nativen /eden mittelst versehiedener Zusätze (Glas. bimsstein etc.). Cber diese Anfschlichmesart ist hereits in Abschnitt (" mol D) berichtet. Ins mit Glas zerriebener I'lazenta gring in 0.90/0 Na('llösung (in escigsinefällbares Nukleopnoteid iiber.') Die Harnsïnreoxydase

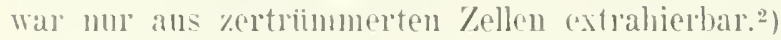

c) Jie Dialyse gegendestilliejtes Wasser. Sie bewirkt insoferne eine Entmischmog der Zellen. als die kerne ilne Strnktur und Fäbbarkeit verlieren. Trenut man nach nelutiogiger Dialyse durch Zentrifngieren das Gelïste rom Lngelösten, so erhiilt man eine weilie opaleszente. nicht litzekoagulahle Flïssigkeit, die nur dureh Mineralsinuren (nicht durch Essigsäure) ausgeflockt wird. Nach wochenlangen Stehen scheidet sich ein grober T'eil des Ejweifes spontan flockig aus. Der Zentrifugierrïckstand gibt an komzentrierter Kochsalylïsung noch reichlich Eiweil alo und lüst sich glatt in starker Essigsainre, welehe loisung bei der Dialrse völlig wieder ansfockt. Manche Fermente sind nach der Dialyse infolge des Mangels an Elektrolyt oder anderer aktivierender stoffe (Crallensal\%e ${ }^{3)}$ unwirksam. lassen sieh abor durch die entsprechenden Zusäte wieder aktiviren. Inuche Fermente passicren iibrigens manche Dialssiernembranen. Zur lialyse sind sehr verschiodene Materialien angergeben worden. I)ie meist gehanchten Perganentpapierschläuche haben viele Nachteile. Für kleine Flisssigkeitsmengen $\left(8-10 \mathrm{~cm}^{3}\right)$ sind die sogenannten sehilfschlinnche (v. l'huranites (ommmis) mit grobem Vorteil angewendet worden. ${ }^{4}$ l(d) benutze als Ilialysatoren sogrname Fischblasenkondome. die angeblich ans dem blinddarm ron schafen hergestellt werden. vie sind ein ausgezeichuetes Material, welches wegen seiner I)imuleit und muten ge-

1) H. Cociti, 1. e.

2) W. Wiechouski und H. Wiener, 1. e.

$\left.{ }^{3}\right)$ A. S. Loevenhart, On the so called ('oferment of Lipase. Journ. of hiolog. Chemist. Yol. 2. p. $391(1 ! 07)$.

4) P. Philipson, Ủber die Verwendharkeit der Schilfschläuche zur Dialyse. Beitr. z. chem. Physiol. 11. Pathol. Bd. 1. s. 80 (1902). 
schlossenen Form sehr rasch dialysieren läbt. I)ie Prifmo auf Jichtigkeit erfordert einen kleinen limustgriff, weil das Material so diinn ist, dali beim Anfiillen mit Wasser infolge des starken Inruckes nach einiger Zeit auch

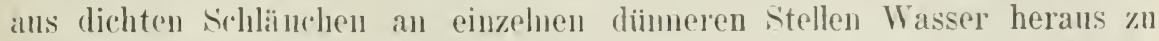
sickern beginnt. İei dieser gewöhnlichen Art der I'riifung findet man nur solten ein branchbares stiick. Da die Schlïnche aber während der Dialyse keinen Drurk ansmlialten haben, nehme ich die I'ruifung so vor, dali die in Wasser eintanchenden Schtäuche mit Lackmuslösung gefïllt werden und lïngere Zeit sich selhst ïberlassen bleiben. An wirklich undichten Stellen tritt der kolloide $\mathrm{F}$ arbstoff heraus und die Fürbung der Aufenfliissigkeit zeigrt die Unbranchharkeit des Stiickes an. Auf diese Weise geprüft, zeigen sich unter den besseren Sorten die meisten stiicke brauchbar. Der Raum-

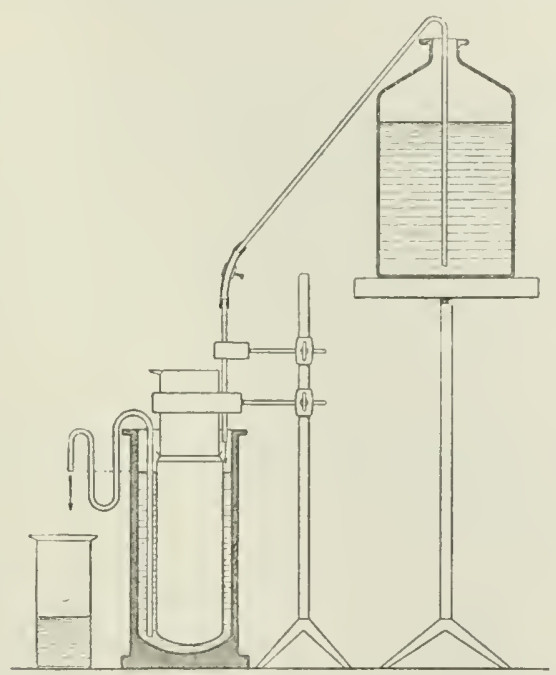

Fig. 90 .

inhalt der Schläuche beträg bis $400 \mathrm{~cm}^{3}$. Um mit möglichst menig Fliissigkeit auszukommen, den Fortgang der Dialrse bequem beurteilen zu kïnnen und auch die Verarbeitung der Dialysationsflüssigkeit zu erleichtern. werden die Glaszylinder, in welchen die Schliuche bis auf den Boden tauchen, so eng gewählt, daß diese ehen I'latz haben, ohne die Wïnde zu berïhren; hierdurch wird die Aufenflïssigkeit auf ctwa $1 / 5$ des Volumens des Schlauchinhaltes reduziert und ihr Wechsel erfolgt auch bei langsamem Zuflusse relativ rasch. Der Ahflul wird durch eine dreimal U-förmig gebogene Röhre, die bis an den Boden des Zylinder's reicht, so geregelt, daß immer genau soviel Fliissigkeit vom Boden des Zylinders abläuft, als oben zu'fliebt (vgl. Fig. 90). Das freie Ende des Abflußrohres lïlit sich durch Ansetzen von Schlauchstiicken beliebig verlängem, so daß das Flüssigkeitsniveau im Zylinder reguliert werden kann. Die (reschwindigkeit des Zuflusses 
richtet sich nach der Schnelligkeit der Diffusion, im Anfange lïlit man schneller flieben. bis cine Reaktion im bialysat (\%. B. die ('hlorreaktion) nicht mehr positiv ausfällt. Im allgemeinen braucht der Zuflub, der durch eine kleine schraubenklemme geregelt wird, nicht rascher zu erfolgen als etwa $2 l$ in 24 stunden. Bei diesem Vorgehen wird halbgesittigte Ammonsulfatlösung in 24 Stunden sulfatfrei, Menschenharn chlorfrei.

d) Fntmischung durch Zusat\% geringer. nicht eiweilifallen(ler Nengen Athylalkohol zu indifferenten Extraktionsmitteln. In geringen Konzentrationsgraden koaguliert Ïthylalkohol die Eiweifkörper nicht nnd schädigt anch die meisten Fermente nicht (\%. B. blieb die Harnsäureoxydase bei $05 \%$ wirksam ${ }^{1}$ ), gleichwohl ist er befïhigt, durch Lösung wassermü̈slicher Stoffe eine Entmischung von Organsuspensionen zu bewirken. analog seiner hämolysierenden Wirknugr. dualog kimm Cihe! n. a. wirken.

e) Anfschließen durch Auskochen der Oreane. 'Zum Teil zur Entfermung koagnlabler Eiweißkörper, aber auch zwecks Abtrennung solcher aus gröferen, unlöslichen Proteinekomplexen werden die zerkleinerten ()rgane bei nativer oder alkalischer Reaktion mit Wasser ausgrekocht. In den filtrierten Dekokten hat man namentlich die Nukleoproteide durch Säurefällung abgeschieden. Die Ausbeuten scheinen aber sehr gering zu sein, $0 \% 3-0.4^{\circ} \%$ des Ausgangsmateriales. Das Dekokt des Milzsaftes lieferte mit Essigsïnce ein Nukleoproteid 2), (lesgleichen das Pankreas ${ }^{3}$ ) und die Leher $\left.{ }^{4}\right)$ u. a.

(3) Chemische Anfschließungsmethoden (proteolytische Enzyme. Salzlösungen, Alkalien, Sïuren). Eine Bemorkung über die Fäulnis siehe Abschnitt H. S. 317. Fulbute 9.

a) Mazerationen und länger danernde Antolyse. Das Material wird durch kürzere oder lingere Zeit unter antiseptischem Zusat\% bei Bruttemperatur gelalten. Die hierbei nach wenigen stunden einsetzende, durch H'-Ionen geförderte. durch OH'-Ionen gehemmte und die Salzkonzentration beeinflußte ${ }^{5}$ ) Antolyse zerstört zunïchst die Zellen (die Kerne zerfallen) und hydrolysiert schlieblich auch die Eiweißkörper. Das Verfahren kamn daher nur zur Gewinnmug von Fermenten oder bindenden Gruppen dienen. /n erwähnen ist aber, dab manche Fermente durch das autolytische wie andere proteolytische Fermente zerstört werden.

$\left.{ }^{1}\right) W$. Wiechowski und $I$. Wiener, 1. c. p. $488(1896)$.

2) F. Bottazzi, Glialbuminoidi della milza. Ann. di chim. e I. tarm. Vol. 22.

s) O. Hammarsten, Till Kännedomen om Nukleoproteiderum. Upsala Lïkareförenings förhandl. Bd. 22 (1893).

4) J. Wohlgemuth, Uber das Nukieoproteid der Leber. Zeitschr. f. physiol. Chemie. Bd. 37. S. 475 (1903).

5) H. M. Vernon, The rute of tissue disintegration and its relation to the chemical constitution of Protoplasma. Zeitschr. f. allg. Phys. Bd. 6. S. 393 (1908). 
1)as Filtrat nach "4stiindiger Antolyse von Leber und Niere des I'ferdes und Hundes versoifte Ester, hydrolysiorte Laktose und Glykogen, die gesamte I'oten\% ging in das Filtrat der Alkoholfällnng ${ }^{-1}$, dic Aldelaydase wird durch Autolyse nicht zerstïrt ${ }^{2}$ ), frische Extrakte von Darmschleimbaut enthielten keine Laktase, lagegen war das Filtrat von 24stiindigen Mazerationen bei $: 7^{0}$ wirksam. ${ }^{3}{ }^{4}$ ) ()xydatives und nitratreduzierendes Ferment der IJaut widerstand einer stägigen Autolyse. ${ }^{6}$ ) Während die Pefunde für das oxvlative Ferment allgemein bestätigt werden, wird uach anderen Autoren das nitratreduzierende ${ }^{6}$ ) durch proteolytische Fermente zerstort. Das glykolytische Linzym Stoliasas ${ }^{7}$ wurde durch proteolytische Organfermente vernichtet, ehenso die Harnsäureoxydase. ${ }^{8}$ )

b) Papain. Die Inwendung dieses Fermentes zum Aufschliefen ron ()rganzellen stammt von Dastre und Floresco. ${ }^{9}$ ) Die Auflösung des Organes erfolgt nur langsam. Die Wirkung geht bei neutraler, besser schwach alkalischer Reaktion, vor sich. Ob die Iutolyse konkurriert, ist nicht untersucht. Papainverdaute Milz lieferte mit Alkohol wirksame Niederschläge (Lipase, Laktase. Diastase ${ }^{1}$ ), die Riickstände einer solchen Terdauung von Milz und Fibrin lösten sich teilweise in $8 \%$ igem Kalisalpeter. Die Lösung bäute Guajaktinktur. ${ }^{10}$ ) Die Harnsämreoxydase wurde zerstört. ${ }^{8}$ )

c) Trypsin. Es erwies sirh zur Isolierung der Harnsäureoxydase nicht geeignet, da es rlieselbe zerstörte.

d) l'epsin. Die P'epsinverdaumg wade nur zur Gewinnung hzw. Abspaltung der Organnukleine aus den Nukleoproteiden verwendet. Die Verdaumg mub lange Zeit fortgesetzt werden, am besten unter zeitweisem Frsatz des Gelösten durch neues Verdauungsgenisch $(0 \cdot 2 \% \mathrm{HCl}$, $0.5 \%$ Pepsin) oder Hundemagensaft (durch Scheinfiitterung erhalten). Die unverdauten Riückstände sind die Nukleine.

1) A. J. A. Lambert, 1. c.

2) M. Jacoby, Über die fermentatice Eiweißspaltung und Ammoniakbildung in der Leber. Zeitschr. f. phı̣siol. Chemie. Bd. 30. S. 149 (1900).

s) H. Bierry und Gmo Salazer, 1. c.

4) H. Bierry et $G$. Schäffer, Dialyse et filtration sur sac de Collodion de la lactase et de l'émulsine animales. Compt. rend. soc. biolog. T. 62. p. $723(1907)$.

5) H. Ch. Schmitt, Existence de ferments oxydants et réducteurs dans la peau. Leurs rapports arec la formation des pigments. Compt. rend. soc. biolog. T. 56. p. 678 (1904).

$\left.{ }^{6}\right)$ E. Abelous et E. Gérard, Sur la présence, daus l'organisme animal, d'un ferment soluble réduisant les nitrates. Compt. rend. T. 129 . p. $56,164,1023$ und T. 130 . p. 420 (1900).

$\left.{ }^{7}\right)$.J. Stoklasa und F. Cerny. l. c.

8) W. Wiechoushi und H. Wiener, l. c.

9) Hastre et Floresco, Méthode de la digestion papaïnique etc. Compt. rend. soc. biolog. T. 50. p. 20 (1898).

$\left.{ }^{10}\right) J . E$. Abelous et $G$. Biarnés, Sur l'existence chez les mammifères de globulines possédant les propriétés des ferments solubles oxydants. Compt. rend. soc. biolog. T. 49. p. 576 (1897). 
e) Salzlisungen. Starke Salzlösungen bringen. wie man sich muter dem Mikmskop ibbereuen kamn, die \%ellkerne zum \%erfall. I)ie Wirkung nähert sich der durch latugen gesetzten, wie die konzentrierter salzlismugen anf lebendes fiewebe. Die neutralen Salze der Alkali- und Erolalkalimetalle verhalten sich den (J)ganen gegenibber in starkel lösmg entweler lïsend oder fällend, manche vielleicht auch indifferent, manche (z. Ю. Kochsalz) gleichzeitiog lösend mol fïllend. systematisch sind diese Verhäluisse nicht studiert. Finges nur ist bekannt: $10^{0}{ }_{0}$ ige und stärkere Kodhsalzlïsmo wirkt lïsend, während Fraktionen rom filobulincharakter durch Sättigen mit Na('l ausgeflockt werlen kömmen. Ammonchlorid wirlit sehy stark lösend. Ammonsulfat schon hei relatir niedrigen Konzentrationen fällend. Na-Aeotat löst oder ist indifferent. Kaliumacetat fäll. Natrimmsulfat scheint indifferent zu sein. Kaliumnitrat wirkt lösend, ebenso Magnosiumsulfat, weleh letzteres aber auch Globuline fällt. Wie fällenden Salze sind im närlısten Mbschnitt behandelt. Von den lösenden wurden meist starke Kochsalzlismngen (5)-10-30\%o), starke Ka-

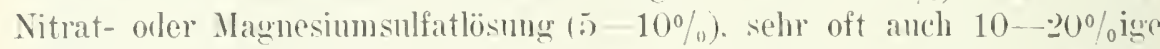
Ammonchloridlösung benutzt. Ihe Wirkung des Ammonchlorids antspricht wie anch die des zu derartigen Zwecken noch nicht vorwendeten Harnstoffes einel Allouninatbildung (Spirn, Ramsden"). Dio Anfschliebung durch die Salze bedingt es, daß mit indiff(renten Lösungen erschöpfte (organe, insbesondere an komzentriertere Kochsalz- und Ammonchlorillismugen noch Eiweili abgeben. Es bleibt zu untersuchen, ob die so erhaltenen lroteine unverinderte \%ellbestandteile darstellen.

Aus Kalbshirn wmrle mit to Ammonchlorid sämpefillhares Nukleoproteid extrahiert. ${ }^{2}$ Slowzow extrahicrte aus leber mit Wasser Mlbumine. dann mit $10 \%$ liochsal\% und $8 \%$ Ammonehlorid Gilohuline. ${ }^{3}$ ) Der mit $15 \%$ Ammonchlorid ans Muskel hergestellte Extrakt wab bei der Dialyse eine gelatinöse Masse. ${ }^{4}$ ) $0 \%$ ige Kochsalzhisung extrahierte aus ()rganen das säurefällbare ., Gewebsfibrimogen". ${ }^{5}$ ) las mit $10-20 \%$ Ammonchlorid hergestellte Muskelextrakt lïbt beim Lingicljen in Wasser Myosin ausfallen. $\left.{ }^{6}\right)$ Huliburton ${ }^{7}$ ) extrahierte mit 5\% Magnesium sulfuricum, Globulin und .. Nukleoalbumin" ans Niere und Ieber. Er verrieb auch die frischen ()rone mit

1) K. Spiro, Crber die Beeinflussung der EiweiBkoagulation durch N-haltige Substanzen. Zcitschr. f. physiol. Chem. Bil.30. S. 182 (1900). - Ramsden, some new properties of min. Joum. of physiol. Vol. 28. p. $23-26$ (1902).

2) I'. A. Levene, On the nucleoproteid of the hrain (Cerebronnelenproteid). Arch. of Neurolog. and Psychopath. Vol. 2. p. 3 (1899).

$\left.{ }^{3}\right)$ B. Slouran, Uher die Bindung des Arseniks durch das Lebergewebe bei chrouischer Arsenvergiftung. Wratsch. 1900. Nr. 44; zit. n. Malys Jhrb. Bil. 30. S. 433 (1901).

4) W. Kühue und K. II. Chittenden, Myosin und Hyosinosen. Zeitschr. f. Biologie. Bd. 25. S. $358(1889)$.

5) A. E. Wright, 1. c.

$\left.{ }^{6}\right)$ Ianiterskiy, l"ber das Myosin. Zeitschr. f. physiol. ('hem. Bd. j. S. 158.

7) W. I. Halliburton, The proteids of kidney and liver cells. Areh, de physiol. T. 13. p. 806 (1893) und ther den ehemischen Charakter des Nukleoalbumins. Ebenda. p. $11-13$. 
dem gleichen Gewicht Kódhsal\% (Mg-oder Nit-Sulfat), das hierdurch erziclte schleimige Gemisch wurde in Wasser gegossen, es elfolgt Fällung, die

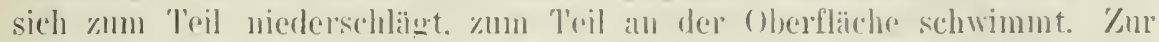
Gewimnung des Muskelstronas wurden Muskeh nit 10-20\% Ammonchlorid erschöpft." Nachdem Wasser aus l'leisch $12 \%$ grclisst hatte, brachte $10 \%$ Na (ll noch weitere $1 ; \%$ Eiweili in Lösung. ${ }^{2}$ ) S(axl ${ }^{3}$ ) fand im Kochsalz-(1\%)extrakt nur einen kleinen 'T'eil der löslichen Musheleiweilie. 10\% Ammonsulfat lïste mehr, $10 \%$ Salmiak am meisten. - Die Harnsäureoxydase mul das antolytische Ferment werden durch starke Salzlösungen gehemmt.

f) Alkalien. Sic extrahieren noch mehr als konzentrierte Salzlösungen und werden meist nach Erschöpfung des Iaterials mit diesem angewendet. Stärkere Laugen lösen insbesondere bei Salzabwesenheit die Urgane iiberhaupt völlig auf. Die Lïsung erfolgt natïrlich unter Denaturierung. Selbst die schwächsten Konzentrationen bewirken Alkalialbuminatbildung (so Dialyse gegen $(0.05 \%$ Soda. wie uns Versuche gezeigt hahen). Durch solche schwache Konzentrationen lassen sich insbesondere durch Dialyse sonst unlösliche Fermente ohne Schädigung in Lösung bringen (z. B. die Harnsä̈rreoxydase ${ }^{4}$ ). Stärkere Alkalikonzentrationen, insbesondere von Laugen, zerstören hingegen die meisten Fermente: die Katalase ${ }^{5}$ ) wird durch Alkali gehemmt, ebenso das autolytische Enzym und die Salizylaldehydase $\left.{ }^{6}\right)$, die Harnsäureoxydase. ${ }^{4}$ )

'/nr Darstellung der Nukleinsäuren wurden dic frischen Gewebe mit $5 \%$ Na OH orler $8 \% \mathrm{~N} \mathrm{H}_{3} 1$ - 2. Stunden ausge $\% 0 g e n .{ }^{7}$ ) Aus Muskeln wurde mit schwach alkalischem Wasser essigsämrefällbares Nukleoproteid extrahiert. ${ }^{8}$ ) Nach Wasserextraktion wing aus Nierengewebe in $0.5-1 \% \mathrm{NaOH}$ ein „Nukleoalbumin" in Lösung. - Nachdem mit Kochsalzlösung und Essigsäure extrahiert worden war, wurden ans Muskel und anderen ()rganen mit $0 \% \%$ Na (OH ..Stromine" ausgezogen ${ }^{9}$, desgleichen aus mit $20 \% \mathrm{NaCl}$ erschöpften Muskeln mit $0 \cdot 1-0^{\cdot 00}{ }_{0} \mathrm{Na}\left(\mathrm{HH} .{ }^{10}\right)$ Von Muskeleiweif ging nach vorläufiger Behandlung mit Wasser, Kochsalzlösung und Salzsäure noch

1) J.F. l. Holmgrecn, Studier öfer muskelstromats natur och quantitativa hestämmande jemte närlinggande frảgor. L psala, Läkareförnings förhandlingar. Bt. 28 (1893).

2) II. S. Grindley, Die X-haltigen Bestandteile des Fleisches. Journ. Amer. chem. Soc. Vol. 26. p. 1086 (1904); Chem. Zentralbl. Bcl. 2. S. 1335 (1904).

s) P.Sarl, Ưber die Mengenverhältnisse der Muskeleiweißkärper unter physiologischen und pathologischen Bedingungen. Beitrïge z. Physiol. und Pathol. Bd.9. S. 1 (1907).

4) Wr. Wiechortsi und H. Wiener, 1. e.

$\left.{ }^{5}\right)$ E. Lepinois, 1. e.

${ }^{6)}$.H. Jacoby, l. c.

$\left.{ }^{7}\right)$ I'. A. Lerene, Uther die Darstellung von Nukleinsäuren. Journ. Amer. chem. Soe. Yol. 22. p. 329 (1902); (hem. Zentralbl. Bil. 2. S. 386 (1902).

${ }^{8)}$ C. Peckelharing. C̈ber clas Vortandensein eines Vukleoproteids in den Muskeln.

Zeitschr. f. physiol. Chen. Bi. 22. S. 245.

9) Wr. Kroutschenko, 1. e.

10) J.F. $v$. Holmyreen, l. e. 
$2 \cdot 880$, Eiweilikörper in alkalische Lïsmng. ${ }^{1}$ ) $0 \cdot 2 \%$ Na(OI löste aus mit $\mathrm{NH}_{4}$ ('l extrahierter Gehiminde ..Nemrostromin ".2)

a) Säuren. Verwendet wurlen zur Extraktion von kiweibiörpern und Fermenten meist schwache Essig- oder Salzsïure. Starke Iineralsänren fïllen (auch bei Salzabwesenheit), Essigsälure lagegen, auch starke, fällt nur bei Salzanwesenheit, in salzfreien Lösungen schlägt sie nichts nieder, im Gegenteil, sie löst unter diesen liedingnngen. Der liiickstand nach der Wasserdialyse ist glatt löslich in Essigsäure, ebenso das gesamte Organ nach Dialyse gegen 0.05\% Karbonat. ${ }^{7}$ ) ('ber die Fällungen der Organextrakte mit Fssigsäure siehe das nüichste Kapitel.

Die meisten Fermente werden durch Sïnren, anch schwache, gehemmt oder zerstört: die Katalase ${ }^{3}$ ), die Harnsäureoxydase ${ }^{*}$ ) und Salizylaldehydase ${ }^{5}$ ). l)ie Arginase ${ }^{6}$ ) war nur unvollstindig durch verdiinnte Essigsinure extrahierbar. Nach Txtraktion von Muskeln mit Salzlösung wurden mit $0.5-0.75 \%$ Essigsäture ..(ilobuline" 8, 9) und mit $0.15 \% \% \mathrm{H} \mathrm{(l} \mathrm{noch} 2 \% 5 \%$ Eiweiß extrahiert. ${ }^{10}$ )

So gelingt es schlieflich, die Organe sukzessive auch muter Yermeidung ganz starker Laugen bis auf geringe, als Stromine (bzw. Neurokeratin) bezeichuete Reste, miter denen sich wohl auch Trile der Bindesulstanzen, Gefäße und Ausfiihrmngsgänge befinden mögen, in lösung zu bringen. Wie aus den mitgeteilten Erfahrungen aber hervorgeht, fehlt es noch an systematischen Untersuchungen, welehe Becientung die verschiedenen Extraktionsmethoden haben. (l. h. welche Anteile der (1)rane in die einzelnen Lösungsmittel ibergehen. Ferner ergilht sich die grolie Labilität der ()rganeiweile sowie der Fermente, welche es rigentlich erfordert, nur die im vorstehenden als völlig unschuldig befundenen IIttel zu verwenden. Daß hierbei ein Nittel oft nicht für fermente und kiweil gleichzeitign geeignet ist, zeigt das Verhalten der Organe gegen $0.05 \%$ Sodalösung; die Fiweißkörper werden denaturiert, die Harnsäureoxydase dagegen voll erhalten und gelöst.

\section{G. Fraktionierung der Extrakte, Preßsäfte oder Kollaturen.}

Die Fraktionierung bezweckt die möglichste lsolierung der Fermente von den Eiweilokörpern und die Tremnung dieser voneinander. sie wurde

1) H. S. Grindley, 1. c.

2) A. N. Schlarim, ¿̈her den Gehalt der Gehipurinde an rerschiedenen Eiweißkirpern ete. Ing.-Diss. St. Petersburg 1902 (russisch). Zitiert nach Malys Jahrb. Bd. 32. S. 529 (1903).

8) H. Wiechouski, 1. c.

${ }^{4}$ E. Lepinois, 1. c.

5) W. Wiechorski und II. Wiener, 1. (".

$\left.{ }^{6}\right)$ I. Jacoling, 1. c.

7) A. Liossiel und II. D. Daliin, 1. ('.

8) H. hrawtschenlio, l. c.

9) H. Iljin, Die organisierten Kiweißkörper der ILuskelfaser. Ing.-I)iss. Petersburg 1900. (Bei I)anileusky) (russisch). Zitiert nach Yalys Jahrb. Bd. 30. S. 471 (1901).

$\left.{ }^{10}\right)$ H. S. Grindley, l. c. 
üherwiegend durch Erzengung ron Niederschlägen rersucht (Salzfällung, Dialyse), daun durch líagulation der Fiweilikirper mit Alkohol, durch Abrerdanen dersethen und durch Alsorption, wozn nourdings anch rlie Kolloidfällnng gezïlnlt werden mul.

1. Salzfïllung. a) $\Lambda \mathrm{mmonsulfat.} \mathrm{Orgelmeister}{ }^{1}$ teilte indifferente Organfiltrate durch $A$ mmonsulfat in :S Fraktionen, desen Mencenverhälnis er in der Norm und bei Entzindung bestimmte. Aus 'Thyreoideaextrakt wurde durch Vlalbsättigung Thyreoglohulin, durch darauffolgende Canzsättigung ein Nukleoproteid erhalten. ${ }^{2}$ ) Alle Fermente werrlen gefillt. Las autolytische Fesment fällt hei sättionng ${ }^{3}$ ), die Aldehydase bei ${ }^{6} / 10^{-S a ̈ t t i g u n g}{ }^{3}$ ), die Fermente des Nukleinstoffwechels bei $2 / 3-5$ ittigun $\left.{ }^{4}\right)$. die Nuklease bei Süttigung ${ }^{5}$ ), anch die Arginase ${ }^{6}$, die ... Antikatalase ${ }^{-i}$ ) und die Harnsïureoxydase werden durch Ammonsulfat gefüllt, letztere aber meist gleichzeitig zerstört. $\left.{ }^{8}\right)$ - Iurch Wasserdialyse lassen sich die Fällungen nicht immer völlig in Lïsung bringen. Krork kou ${ }^{9}$ ) hat die Ammonsulfatfällung in Wasseranfgiissen zu einer allgemeinen Mcthode der Organfermentdarstellung verwendet (siehe unter \%) Alkohol).

(3) Calciumchiorid (gewöhnlich in 10\% iger Lösung) fällt ans Wasserextrakten der Thymus Nukleohiston ${ }^{10}$ ), aus Zentrifugaten nach Sodadialyse die Harnsäureoxydase. ${ }^{11}$ Letzterer Niederschlag löst sich in Soda.

Y) Kaliumacetat (in Wasser zu gleichen Teilen) füllt einfache Wasserextrakte (Plasmen) in gleichem Volumen noch nicht, $0.05 \%$ ige Soda dialysierte und zentrifugierte oder filtrierte Organextrakte oft schon bei Zusatz von $1 / 2{ }^{-1} / 25$ Volumen; Fällungen bis $1 / 2-1 / 10$ Volumen enthalten die Harnsäureoxydase. ${ }^{11}$ ) Die Fällungen sind durch $0.05 \%$ ige Sodadialyse röllig in Lösung $\mathrm{zu}$ bringen.

$\delta$ ) Uranylacetat (allgemeine Methode zum Nachwcise intrazellılärer Fermente von Jacoby ${ }^{12}$ )-Rosell. ${ }^{13}$ ) ... Die ()rgane werden mit der Fleischhack-

1) F. Orgelmcister, Änderung des Eiweißbestandes der Niere durch Entzündung. Zeitschr. f. experim. Y'uthol. u. Therap. Bd. 3. S. 219 (1906).

2) W. Huiskamy, 1. c. - A. Ostuald. 1. c.

3) M. Jacoby, l. c.

4) A. Schittenhelm, Über die Fermente des Nukleinstoffwechsels. Zeitschr. f. physiol. Chem. Bd. 43. S. 228 (1901/5).

5) F. Sachs, l. c.

$\left.{ }^{6}\right)$ A. Kossel und H, D. Datin, I. c.

7) F. Battelli et L. Stern, Lanticatalase dins les différents tissus animaux et la philocatalase et l'anticatalase dans les tissus animaux. Compt. rend. soc. Biolog. T. 58. p. 235 et 758 (1905).

$\left.{ }^{8}\right)$ W. Wiechoushi und $H$. Wiener, l. c.

9) N. Kratriou, l. c.

$\left.{ }^{10}\right)$ J. Bang, 1. e.

11) Wr. Wiechouski und H. Wiener, l. c.

12) M. Jacoby, C'ber das Aldebyde oxydierende Ferment der Leber und Nebenniere.

Zeitschr. f. physiol. Chemie. Bd. 3). S. 135 (1900).

13) M. Rosell, Üher Nachweis und Verbreitung intrazellularer Fermente. In.-Diss. Straßburg 1901, Jos. Singer. $25 \mathrm{~S}$. 


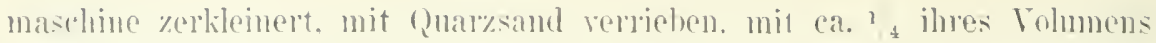

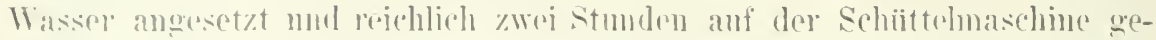

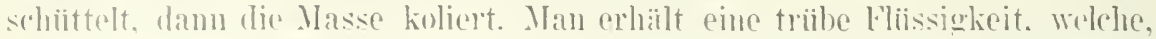
ohne filtriert \%n werlen, mit einer gesätigten Liosumg von Iranylacetat versutzt wird. Wälurend des Zusatzes wirl sie durch Zufiigen einer Mischung ron Satrimm karhonat uml Satriumphosphat alkalisch gehalten. Das Natriumphosphat dient da\%n, die schlieflich resultiepende Fermentlösung frei von

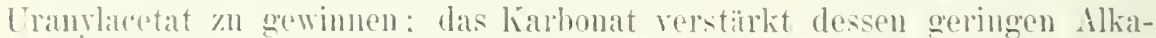

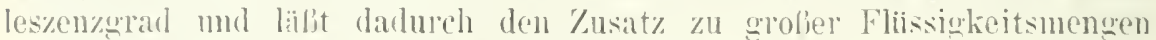
verumeiden. Man fïgt so lange [ranylacetat hinzu. bis sich grobe Flocken] bilden, welche in kiluzester \%eit sich abzusetzen beommen. dekantiert und

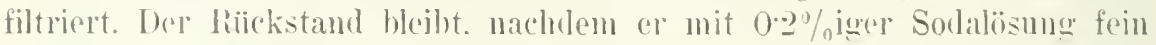
verieben ist, mindestens 12 Stunden stehen. woranf el filtriert wirl. So gewinnt man eine klare. eiweibarme Fliissigkeit, in welcher die Fermente in wirksaner form enthalten sind. Wiinseht man reinere l'äparate. so kann man Fïllen und Ansziehen wiederholen. \%weckmöligerweise setzt man behufs Lomservermeg elst jetzt Toluol hinzu. da dessen Anwesemheit soust den Verlauf der einzolnen (Operationen zu sehr verlanesant. Schmelligheit des Irbeitrus ist nämlich wegen der auch bei /usaty antiseptischer Vittel drohenden Fïnlnis zu empfehlen. Ferner wird die Fernentausbente desto geringer, je später die knzyme aus dem [ranylniederschlage ausgezogen werlen, wie sehon Jacoby in seiner Arbeit betont." Anfschliefinng des Materiak ducch mohrtigige bigestion mit Tolnolwasser hoi 40 " ergab keine hessuen liesultate. Mit dieser Mothode wurden folgende Resultate erhalten.

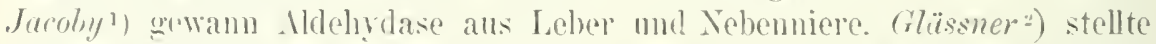
die l'ofermente der Magensehleimhaut dal'. Srhittenhelm ${ }^{3}$ ) gewam (alleldings nicht in allen Versuchen) mikolỵtisch wirksame fermentlïsungen. Rosell stellt seine Ergebnisse in lor folgenden 'Tabelle zusammen. Diastase. luvertase. Guajakoxylase. Lab und steapsin kounte er nie mit sicherhejt nachweisen. An geeignetsten erwies sich die Methode zum Nachweise der Adrhylase. dep proteolytisehen Fermente mul der Katalase. Nach den Fr-

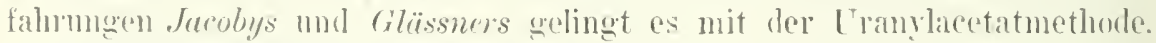
die Fermentu eiweilifrei darzustellen.

... Mit Ansualune der rom l'ferde hergenommenen Muskeln stammiten alle ()ronge rom limd." (()h die ()rome blutfrei gespiilt waren, ist nicht angegelo(')

ह) Sämren. siehe oben Siuren als Extraktiousmittel. Inem dort Gesagten

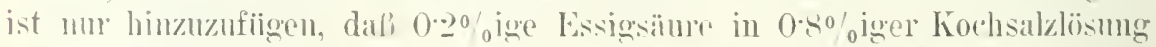
die homologen Kochsalzextrakte sämtlicher Orome fällt (l'ohl). L)icse Fällumgr

1) W. Jacoly. Üher das Aldehyde oxvdierende Ferment der leber und Nebennieren. Zeitschr. f. physiol. (hemie. Bul.30. 5.135 (190()).

2) K. Cilässner, Uther die Vorstufen der Magenfermente. Beitr. z. chem. Physiol. u. l'athol, Bil. 1. S. 1 (1902).

3) A. Schittenhelm, Uher das urikolytische Ferment. Zeitschr. f. physiol. Chemic. Bd. 45. s. 161. 


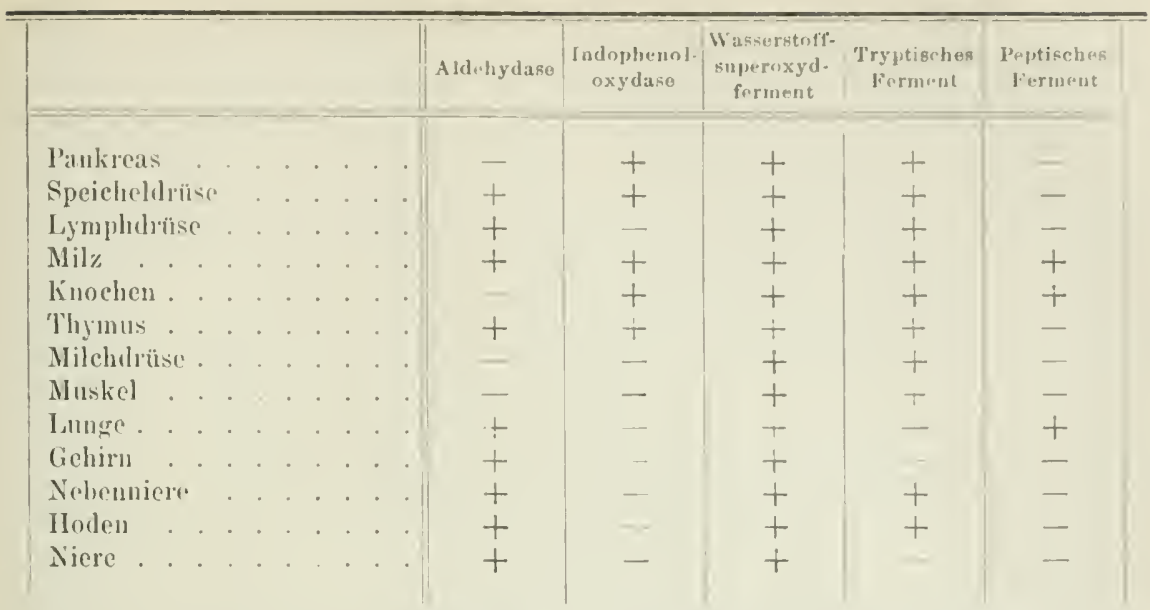

ist jedorh zm Fermentgewimmmo nur ausnahmsweise zu cebrandurn, weil die meisten Fermente selbst durch diese schwache Säurekonzentration ge-

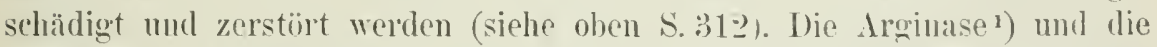
sogenamte .. Antikatalase* ${ }^{2}$ ) wurden ïbrigens durch Essigsimre nicht gefällt. J)agegen ist die Essigsiume zum Iusfällen der Nukleoproteide aus Extrakten vielfach benutzt worden: Aus dem Sodadekokt des Pankreas ${ }^{3}$ ), ans dem Lochsalzextrakt der Plazenta*), aus dem salmiakextrakt des (rehirns ${ }^{5}$, dem Alkaliextrakt der Mnskeln ${ }^{6}$ ), (lem Dekokt des Milzsaftes ${ }^{7}$ ). dem Dekokt (les Pankreas'), dem Wasser-orler Kochsalzextrakt der (organe iiberhaupt (.. (iewebsfibrimogen": 10).

ל) Athylalkohol. ['refisafte orler Extrakte wurlen sehr häufig zwecks Entfermung koagulabler Eiweißkörper aus Fermentlösungen mit Alkohol und meist anch. unter einem mit Ather gefällt, die Fïllumg alogenutscht. mit Ather gewaschen und bei niedriger 'Temperatur gotrocknot. Extrakte solcher Pulver enthalten je nach der Einwirkungszoit des Alkohols noch mehr weniger Eiweib, aber viel weniger als die Ansgangsextrakte. Von den Fermenten wurde alloemein angenommen, daß sie hierbei mngeschmälert in die Extrakto iiberohen, was sozusagen mit als Charakteristikum der Fermente angeschen wurde. Die P'rozedur läbt sich, allerdings unter starken Verlusten an Ferment, wiederholen und so immer Eiweiß entfernen. Wittich

1) 1. Kosscl und II. D. Jakin, 1. c.

2) F. Battelli et L. Stern, l. c.

s) T. A. Lerenc und J. B. Stookey, Notiz üher das Pankreasnukleoprotejd. Zeitschr. f. physiol. Chem. Bd. 41 . S. 404 (1904).

*) II. ('ociti, I. c.

b) I'. A. Lerene, 1. c.

$\left.{ }^{6}\right)$ ('. Pechelharing, 1. c.

i) F. Bolfazzi. 1. c.

8) O. Hammarsten, 1. c.

9) A. E. Wright, l. c.

10) Wr. D. Halliburton, l. c. 
stellte F'anentlömngen allgemein dar durch Alkoholfällung des Glyzerin"xtraktes und Auszichen der getrockneten Fällung mit Wasser. ${ }^{3}$ Krawlow $\left.{ }^{2}\right)$ fïllt Wasseranfoisse mit Ammoniumsulfat, bringt die Fillumg für 1 bis 1'. 'Tace moner absolutem Alkohol, trocknet bei $30^{\circ}$ und extrahiert mit Wascr. Dir Extrakte enthielten kein Eiweib, verzucherten Stinkr; in dersollen Weise wmole Nuklease gewomn('n."3) Ius Hundepankreas ließ sich so 'Trypsin gewimnen. Aus Papain verdauter Milz wurden mit Alkohol fermentativ wirkisme Nierlorschlïge erziclt.4) Aus Proßsiffen von Lrmphdriisen. Lobel. Mil\% wurde durels Alkohol Kitalase gefällt. ${ }^{5}$ ) Stolilusas gryolytisches ferment wirl aus den Prefsiften mit Mlkohol med Ither

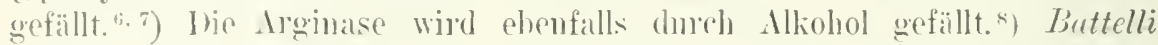
und Strm ${ }^{9.10}$ ) fällten Leberkollaturen mit 2 Volumen Alkohol, der Niederschlag worde mit : Volumen Wasser erechiittelt und filtriert, das Filtrat wiofler gefallt. Wie fällung, abgepreft und getrocknet, zeigt mächtige Katalasuwirnug. '/ur Kritili der Alkoholanwendung vol. anch das bei der Herstcllumger ron Mlkoholmaterial (resagte (S. 29!)).

r) Idsorbentien. Fermente, aber auch Eiwciblörper werden durch mamnigfathe Stoffe adsolbiert und kïmmon dadmeh aus Loisungen abereschieden werden. l)iese stoffe haben moist liolloidcharakter und es ist wahrscheinlich, gemacht11), daf das Wesentliche hierbei cin zwischen entgegengesetzt geladenen Kolloiden statffindender Vorowng ist, soweit es sich nicht um mechanische Adsorption handelt. \%m Isoliermo eloktropositiver Fermente wären daher die Eiwoibkörper gleichfalls duch ein clektropositives Kolloid, wolches jene nicht fällon diurfte, ausmflocken. Die Kolloidfällmo als Enteiweifmosmittel wurde von Michnelis mol hom ${ }^{12}$ ) studiert und eingefiilnt; fiir die Darstollung wirkamer Oroanextrakte wurde sie noch nicht ver-

1) $r$. Wittich, ther eine nene Methode zul. Darstellung kïnstlicher Verdamungflüssigkeiten. I'flügers Mrchiv. Bd. 2.. S. 193 (1869).

2) N. hrantiou, 1. e.

$\left.{ }^{3}\right)$ F. siache, l. c.

4) A.J.A. Lambert, l. e.

5)

$\left.{ }^{6}\right)$ J. Noklasa und $F$. ('scrny, I. c.

i) J. Finsthmidt, 1. e.

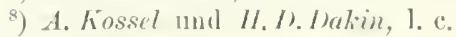

${ }^{9} \mathrm{r}$. Baffelli et $L$. stern. Préparation de la catalase animale. Compt. rend. soc. hiol. T. 57. p. 374 (1904).

10) J. E. Alelous, l. c.

11) L. Widutis, Elektrische Uberführung von Fermenten. Biochem. Keitschr. Bal. 16. S. 81 (19(19); vgl. auch L. Jichaflis und I'. liona, Thtersuchungen ïlser Ailsorption. Biochemische Keitsclur. Bd. 1.). S. 196 (1908), - L. Michaclis, Ite Adsorptionsaffinitäten des IIefe-invertins. Ehenda. Bil. 7. \$. 488 (1908).

12) L. Vichaflis und I'. Rona, Wine Methode zar Entfernung ron Kolloiden ans ihren Loismgen. inshesondere zur Enteiweißung ron Blutserum. Bischem. Zeitsehr. Bi. 2. S. 219 (1907). - Dieselben. Beitrag zur Frage nach der kolloidalen Natur von Albumoselösungen. Ehenda. Bit. 3. S 108 (1908) nut l'ntersuchungen ibler den Blutzucker. Ebenda. Bil. 7. . 329 (1908). 


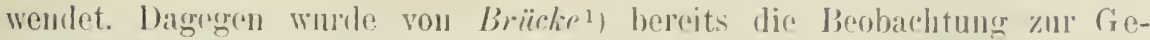

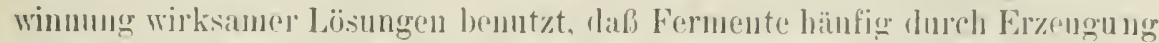

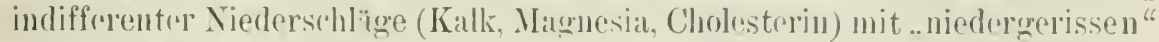
werden. Ton anderen ist zu nennen: Ticrkohle adsorbirerte ans den verschiedensten wïsserigon ()rganextrakten dic Fiweibstoffe. ohur dic Kiatalase zu alsonbieren. $\left.{ }^{2}\right)$ Kieselgm adsorbiert Eiweif, aber hiclt anch die Harnsäureoxylase \%uriok. $\left.{ }^{3}\right)$ Anch die Fixicrung welöster Fermute an Fibrin-

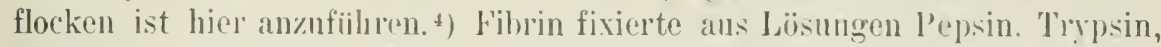
Diastase, glykolytisches Enzym 11 a., die Fermente wurden damn wieder an Wasser, weniger gut an Glyzerin ahgegebm.

i) Dialyse gegen destilliertos Wasser. Thulich wie lurch Wasserdialyse das Englobulin des Serums in cine feste l'hase iiberoeht, lassen sich aus Organextrakten anf diese Weise Eiweiskörper abscheiden. Wie sich im einzelnen die verschiedenen Extrakto rerhalten, ist nur zum Teil bekannt und auch iber Fermentgewimmmg anf diesem Wege ist wenig berichtet. Daß der Salmiakextrakt der Muskeln beim Dialysieren gelatinös wirl, ist bereits erwihnt5), elenso daf (lie mit Salmiak in Lösung ${ }^{6}$ ), oder Kochsalz in Substanz ${ }^{\text {) }}$ verriebeneu Muskeln bzw. andere Organe heim Eingiefen in Wasser flockige Abscheidungen geben. Unveröffentlichte Versuche haben mir auch gezejgt, daß die nach Wasserextraktion durch konzentrierte Kochsalzlösung gelösten Organeiweißkörper bei der Dialyse so gut wie vollständig ausflocken. Fitrate von Darnschleimhautmazeration liefien bei der Dialyse unter Druck einen voluniuösen Niederschlag fallen, die klare Flïssigkeit enthielt die Laktase. ${ }^{8}$ )

\section{H. Konservierung des Materiales während der Arbeit.}

(Antiseptika, Reaktion, Temperatur, schädigende Stoffe.)

Die iibergroße Labilität del Organe und deren Extrakte erfordert wăhrend der Arbeit und zur Erhaltung etwa gewonnener Produkte die dauernde Einhaltum ron Maßnahınen, welche die bakterielle ${ }^{9}$ ) und .. spontane “* Zersetzung des Materiales verhindern und die Fernhaltung oder Entfernung

1) Brïcke, Vorlesıng über Physiol. Bı. 1. S. 44 (1874). Vgl. auch Maly, Pflügers Arch. Bd. 9. S. $592(1874)$.

2) J.E. Abelous, 1. c.

3) W. Wiechowski und H. Wiener, l. c.

4) Stanislav de Szumou'ski, Über die Fixierung von Enzymen durch das Fibrin. Arch. de Physiol. T. 3\% p. 160 (1898); zit. nach Malys Jahrb. Bd. 29. S. T2t (1S99).

$\left.{ }^{5}\right)$ W. Külne und R.H. Chittenden, l. c.

6) Danileusky, 1. c.

7) W. D. Halliburton, I. c.

$\left.{ }^{8}\right)$ H. Bierry et G. Schätfer, l. c.

$\left.{ }^{9}\right)$ Nenestens teilt Sulkoushi (Zeitschr. f. physiol. Chem. Bd.61. S. 124 [1909]) mit, daß das Hefe-Invertiu der Fiulnis völlig widersteht. Dus Verhalten der Organfermente bei der Fäuluis ist nucht untersucht; sollten sie sich d :m Invertin analog verhalten. so wäre hierdurch ein Weg zu ihrer Trenunng von den Organproteineu gewiesen. 
aller als sobäblich crkamnter stoffe. Anlierdem gilt es aber immer zu rerhinderu, dali pine Fermentleistumg durch Bakterientitigkeit verogetäuscht werde.

1. Antiseptika. Steriles Arbeiten mit den einen voriigliehen Nähr-

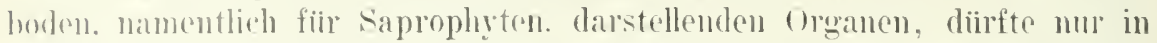
Ansmalınefällen, namentlich aber nm mit geringe!n Substanzmengen möglich

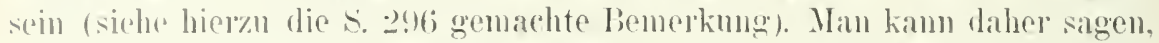
dal, Intersuchungen. denen die rorstehend bohandelten Methorlen dienen, (est dureh dio Entrleckmo des Chloroformwassers als muschädichen Ver-

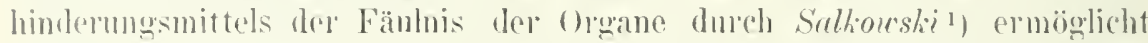
wmolen, wie dem tatsïchlich Fermentstudien an ()’ancen in ansgedehnterem Malie erst seit daher datioren. Auber dem ('hlowoform, weklhes bis \%ur siittigm den Extraktions- oder Verdiummosmitteln zumsetzon ist, werden

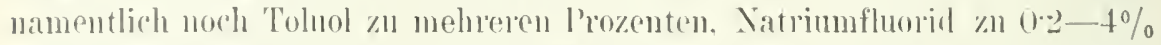
mul Thymol zu etwa $\theta^{\cdot} 1^{0}$ o verwendet. Wässerige Thymollösmogen bis etwa $0^{*} 1^{\circ} \%$ lassen sich am beguemsten so herstellen. dab nach Zusat\% dey berechneten Menge einer 50\% lang heftig geschiittelt mud dam eventuell aufwefïllt wirk. Im lichte werden die lösungon alluählich gelblich und triilse, doch findet bei derartiger Ilerstethmg keine Abscheidung von Thymol statt. Nenestens wird eine $: \% /$ ige lïsmng rom dodoform in Iceton empfohlen, die unschädlich mod sehr antiseptisch sein soll. ${ }^{2}$ ) ln Be\%g anf sichese Sterilisation ist das 'Tohol oder 'Thymol wohl am wirksamsten. Cliloroform mul Natrimufluorid hindern bej niedrigen Konzentrationen mel längeren Versuehen die Füuhis nicht immer. Es ist daher zweckmälitg, vom chlowoform einen therschul (d. h. melu als gelöst wurde) zuzufiigen. I)as Fluorid wird jet\%t nicht mehr so answedehnt verwendef, es wirkt nur in 2- $-4 \%$ iger Konzentration sicher. In Bezng anf die Unschädlichkeit Fernenten mu Fiweibkörpern argeniber verhalten sich diese antiseptischen /usitze und die verschiedenen Fermente nicht gleichartig. 1\% l'lnomatrimmlösmng beeinflufite etwas die Antolyses), Chlorolom hemmte in grobem lobersenuli die salizylaldehydas(2,5), Fluornatrimm zerstionte die Katalase $\left.{ }^{6}\right)$ und hemmt die Lipase ${ }^{7}$, das Thymol und Fhormatrium elwies sich als nicht gam\% gleichgiiltig fuir die Harnsänreoxydas(2.8) Das glykolytische Enzym ist fiir alle Antiseptika

1) E. Salkouski, ther Fermentprozesse in den Gerreben. Areh. f. l'hysiol. (Du Boislipymond). S. 5ist (18(10). (Verh. d. plyysiol. (ies. z. Berlin.)

2) I. J. J. I'anderelde, Uher die Anwendung antiseptiseher Mittel bei Untersuchung üher Enzyme. Biochem. Keitsehr. Bd. 3. S. 315) (1907).

$\left.{ }^{3}\right)$ C' Biondi, Beitrige zur Lohre ler fermentativen Prozesse in den Organen. I'ivehous Areh. Bd. 14t. S. 373 (1896).

1) I. Jacoly, l. c.

5) 11. Sehwirning, iner fermentative Prozesse in den Organen. Irivchou's Arch. Bil. 136. S. 444 (1894).

$\left.{ }^{6}\right)$ F. Ballelli et $L$. Stom, l. c.

$\left.{ }^{7}\right)$ A. L. Loerenhart und G. P'irce, Der Hemmungswert des Fluornatriums anf die Wirkung der Lipase. Juurn. of hiolog. chem. Bd. ¿. S. 397 (1907); Chem. \%entralbl. Bd. 1. ค. 1209 (1907).

${ }^{8}$ ) W. Wiechourski und II. Wiener, 1. с. 


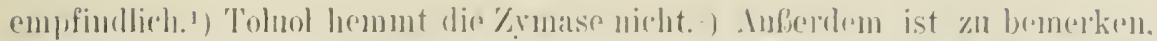

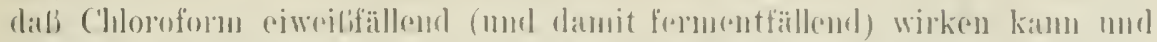

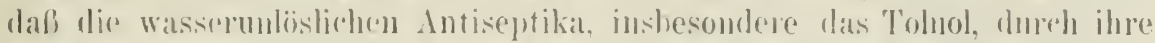

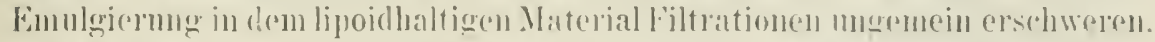

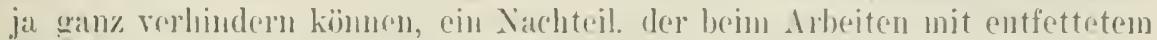

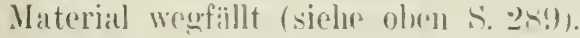

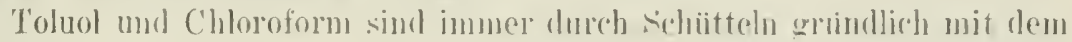

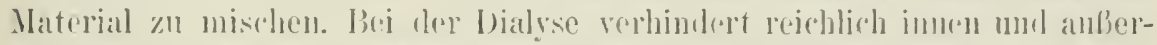

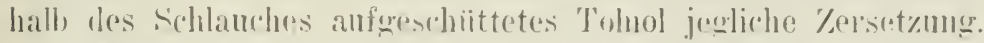

2. Die Reaktion. Fiir die mositen (1) reanfermento ist nentrale oder

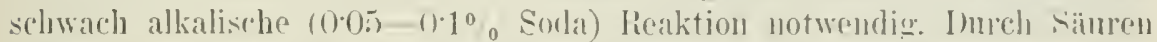
selbst in schwächster Konzentration werden alle Fermente bis ani das autolvtische, für welches eine geringe [H-Ioncnkonzentration optimal ist, zerstört. Höhere Alkali-, jnsbesondere Laum(nkonzentrationen zorstiren ebenfalls alle Organfromente in kimzer \%eit. Säuren füllen übrigess die indifferenten Organextrakte. Ilie spontankoagulation derselben kann durch wenig Alkali gehindert werlen, doch wirkt dieses wieder loicht albuminatbildend (siche oben S.::11).

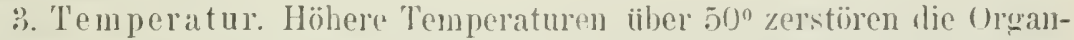
fermente; alle Schädlichkeiten, insliesondere anch die bathterielle Zersetzung und die Intiseptika wirken bei Bruttemperatur schneller; indifferente Organextrakte koagulieren, die Koanula ruben Fermente nieder. Viele Fermente sind gegen das bei Bruttemperatur wirkende autolytische Ferment nicht widerstandsfïhig. I) Aufbewahrumg des Materiales hat also stets in der Kälte im Eiskasten. eventuell in gefrorenem Zustande im Ipjarat .Figigo" zu erfolgen.

4. Scliäligende Stoffr.

(1) In den () roanen gelegen('. Inshesondere das allenthalben rorhandene antolytische Ferment ist befähigt, nicht nur die oraneiweibe. sondern anch viele Organfermente zu zerstören (siehe ob(un Autolyse, S.:30<,9). Aber es können auch kochbeständige, alkohol- und wasserlisliche, nicht näher untersuchte Organbestandteile (Extraktirstoffe) manche Fermente, \%. B. die Harnsäureoxydase, hemmen und zerstioreu. ${ }^{3}$ ) Jas blutsernm hemmt die Autolyse. - Jer Einflul\} der Iutolyse kann durch Alkalizusatz (0.0:) bis $0 \cdot 0^{0}$ Soda) aufgehoben werden. I) he hmenden Fxtraktirstoffe können nach Methode $\mathrm{D}$ oder durch Dialyse bescitiont werden.

b) Ton aubien eingebrachte st offe. Hierzu sind auch die bakterielle Infektion und die zu ihrer Verhiitmog angewendeten Antiseptika zu rechnen. Die Auswahl der letzteren hat daher fiu jede Fermentleistung besonders 7n weschehen. Cus hat sich das 'Tohnol fiir alle Zwecke als das indifferenteste ergeben. Fiu Eiweilhörper sind alle bis auf das Chloroform gleich-

1) J. Feinschmidt, 1. c.

2) E. Buchuer, 1. c.

3) W. Wichowsti und H. Wiener, 1. c. 
giiltig. Auferdem sind viele zur Fraktionierung der Fxtrakte benutzten Stoffr schịdlinge ron Fermenten und ()rganeiweiß: Salze, Alkalien. Säuren, Alkohol, Harnstoff. Hieriiber ist das hei der Fraktionierung Gesagte (S. S1으.) nachzusehen.

Im Anschlul, hieran sei noch erwähnt, daß nicht nur höhore Konzentrationen sonst indifferenter Salze manche Fermentfunktion zu hemmen imstande sind. sondern didl anlrerseits anch absolute Elektrolytfreiheit die Tïitigkeit von Fermenten beeintrïchtigen kann. Die Dialyse kamn so, allerding: reparabel, Fermentleistungen beeinträchtigen. es könuen aber durch Dialyse auch Formentaktivatoren spezifischer Natur verloren gehen (siche (rallensalze für die Lipase').

Da sich die Organfermente gegenïher den besprochenen schädigrenden Einfliissen durchans nicht grleichnäßjig verhalten, sollte es als liegel gelten, in quantitativen Versuchen jedes Ferment zmnächst auf seine Empfindlichkeiten und insbesondere die beabsichtigten Zusätze auf ihre Indifferenz zu prifen. Ierartige Versuche sind allemal mit jenen minimalen Naterialmengen anzustellen. welche ehen noch ein bestimmtes Ausmali vou Leistung aufweisen, weil nur auf diese Weise geringrgadige schädigungen entdecht werden können. Hierzı sind die obenerwähnten (Organkollaturen, verdïnutes gesiebtes Material, welche sich beide bequem mit Pipetten messen lassen. insbesondere aber die haltharen und wägbaren nach .. I) erlaltenen Organpulver geeignet. - Die iibrigen Bedingungen solcher Fermentversuche sind optimal zu wählen, also insbesondere die Temperatur und bei Oxydasen die Durchliiftung. Die Art der letzteren ist durchans nicht gleichgiiltig: in gleichen Zeiten zersetzten z. Ii. gleiche Mengen Harnsäureoxydase absteigende Mengen Harusilure: beim Schïtteh mit Luft, beim Dnrehleiten von luft, heim bloßen Stehen. Die innigste Mischnng mit Luft wird jedenfalls durch dauerndes schiitteln in halbvollen Flaschen erzielt. Anch für andere nicht oxydative Fermente kann das Schiittehn von Vorteil sein, wenn das Ferment z. B. in einer unlöslichen. rasch sedimentierenden Organfraktion enthalten ist. Bedeutet der Luftsanerstoff für ein Ferment eine Hemmung, dann kann man mit Wasserstoff, Kohlensüure oder im Vakuum schütteln.

1) A. S. Loevenhart, 1. c. 


\section{B. Die künstliche Durchblutıng resp. Durchspülıng von Organen.}

\section{Von Franz Müller, Berlin.}

Bidder, Alexander Schmidt und Ludwig verdanken wir die ersten Kenntnisse ïber die Durchströmung frisch ausgeschnittener Tierorgane. In den letzten Jalnzehnten ist die Technik der Durchspïlungen in ganz auferordentlichem Maße vervollkommet worden ${ }^{\text {) }}$ und hat in rer Wiederbelebung des menschlichen Herzens und dem Studium der in der überlebenden Leber sich vollziehenden synthesen ihre crößten Triumphe gefeiert.

\section{Vorbereitung des Tieres.}

Handelt es sich um Organe von Kaltbliitern, so hat man nur dafiir zu sorgen. da\} die Tiere zuvor möglichst kïhl gehalten werden und das betreffende Organ nach Tötung des Tieres nicht allzu lange undurchströmt bleibt. Es kommt aher auf oder 10 Yinuten dabei nicht an. Erheblich gröbere Vorsicht muf man bein Warmbliiter anwenden. Nan tötet bei Verwendung des Organs zum Studium biochemischer Fragen die Tiere in Xthernarkose durch Verbluten aus beiden Karotiden und Femoralarterien, bei Verwendung des Organs zur Priifung der Vasomotorentïtigkeit oder ähnlichem an besten ohne Narkotikum durch schlag oder schnelles Zerstören des verlängerten Marks mittelst eines scharf zugespitzten, $0.5 \mathrm{~mm}$ starken eisernen Stichels (einer Schusterahle), den man im Atlanto-(Okzipitalgelenk einstößt, entblutet darauf möglichst schell (Durchschneiden des Halses) und defibriniert das Blut durch Schlagen vermittelst Glasstabs oder Schiitteln mit Glasperlen in Glas- oder Porzellangefäßen. Beriihrung mit Metall ist möglichst zu vermeiden. Während ein Assistent dies alles besorgt, operiert man das gewünschte Organ so, daß es, wenn angängig, im Körper des toten Tieres verbleibt und wïhrend der Operation so viel als möglich vor Abkiihlung geschïtzt ist. Nur bei Verwendung des Langendorffschen Herzapparates (siehe später) oder ähnlicher Anordnungen, bei denen

1) Eine große Anzahl der veroffentlichten Apparate, größtenteils Modifikationen der im folgenden ausführlich beschriebenen, siehe bei Skutul: Über Durchströmungsapparate. Pfügers Archiv. Bd. 123. S. 249 (1908). 
das (Hoan an der Arterienkaniile frei hängt. wird es ganz ans dem liörper entfrut. Man hindet nach Abklemmung des Blutgefüßes zum Oroan hin eine lianible in dio llanptarterie mol cinc zweite in tie wichtigste abfïhrencle Vene. wïhrend alle anderen ciefälie sorgfältig unterbunden werden. Das ist oft z. 1). bei den Hintersehenkeln relativ cinfach, oft aber auch z. B. bei der Niere oder Leher des Kaninchens oder der Katze recht schwierig. Man nulj sich je nach dem anatomischen Ban, der ja bei den Venen sehr wechselt. iiberlegen. an welcher stelle man die abfïhrende Kaniile an richtigsten einlindet (s. ()perationstechnik).

Im allocmeinen soll man, wie cresigt, so schnell als möglich mach Aufhören der Zirknlation mit der Dmelispülung beginnen. da die Cefahr der Gerimselbildmog bei längerem liegen erhöht wird, fermer manche Grgane, wie das ller\%, nach starker Abkiilhlung nur schwer wieder funktionsfïltig werden, andere, wie die Extremitäten und die Lmoge, nach länger diuernder Panse hai der Durchspiilung allzu schnell ödematös werlen.

Die. Kínüle soll nicht zu eng sein. la sie sich sonst leicht rerstopft. Sic darf aber anch nicht mit grober Fewalt in die Gefübe eingedrückt werden, da diese sich dam kmy dahinter stark verengern nnd doch nur wenig Flissigkeit hindurehlassen. Kurz vor Vereinigung der Arterienkauiile mit dem bilntzufïhrungsroh des Apparates entfernt man die in der Kaniile oder der Arterie steckenden Gerimsel durch Einfiilnen einer weichen Federpose oder eines nitht zol dimnen Fadens, an deren bei mehratchem Hermmdrehen das Gerimnsel anhaftet mol herausgezogen wird. beim Herzen entfernt man nach Langendor/fs Torschbag die in den Höhlen

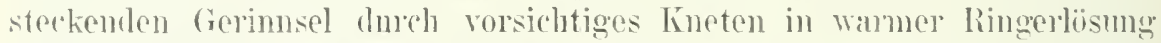
und Ausspritzen mit erwärnter Ringerlismug. 'T'rotzlem muB noch der bintritt von auch kleinsten Gerinnseh oder luftlasen in die Gefäbbahn verhindert werden. Man bïlt die Lösung kirr vor Eintritt in die Arterie lles Organs ein km\%es lioh (etwas weiter als die anderen Leitmoen) mit locker gestopfter Glaswolle, einen , Gerinnselfänger.., passieren, in den sich kleme Häserchen immer ansammeln, selbst wenn das defibrinierte Blut vor dem Einfüllen mehrfach durch Gaze oder Glaswolle filtriert war. Es miissen auberlem die noch in dem Oroan befindlichen Gerimnseheste zum lieginn der Durchspiilmng ansgespiilt werden. Man hat laher die ersten Portionen der austretenlen Flüssigkeit gesondert anfzufangen, neu zu defibrinieren und nochmals durch Gaze oler Glaswolle zu filtriereu, beror man sic wieler cinlaufen lïlt.

\section{Operationstechnik.}

\section{Leber.}

Man fiihrt an entbluteten Tiel einen rom liehlkopf bis zum Becken reichenden Schnitt in der Mittellinie des lïurpers, trennt die Hant des Brustkorbes nach beilen seiten ab, so dak das Brustbein freiliegt und eröffnet den Brnstraun durch Entfernen des Brustbeins. Dabei werden die Rippen von unten 
nach oben fortschreitend recht weit seitlich an der Knoryel-Kunochengrenze, das. schliissolbein an siterno-('laviculargelenk jewrils unter Aufheloen des Brustheins und Schommg der darunter liegenden 'Teile, besonders der halswärts und zu den vorderen Extrenititen verlanfenden Venen ohne Blutung dureh-

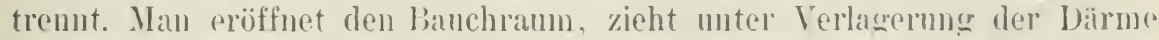
mach links die lober nach oben und unterbindet die Ant. hepatica, die Gallengänge doppelt. durchschmeidet zwischen deil Liwatmen. führt in die $V$. portae möglichst nahe zur Leber aine weite Kanile, (rentuchl unter Ibklemmum der Vene zur Leher hin mit einer weichen. durch (iummi armierten Klemme mit langen Branchen (Darmklenme del Chirurgen). Die oft kur\% vor Eintritt in die Lebur eimuindenden Seitenäste sind doppelt unterbunden zu durchtremen. '/ur [uterbindung mul' ein weicher. nicht schneidender Wollfaden benutzt werden. Damn mutephindrot man die V.ava inferior dicht unter der Leber (nach I)urchtrmung des zur Niere fiihrenden straffen Bandes) und bindet voun Brustraum ans oberhalb des /werchfells eine weite haniile in die V. cava ein. Man durchtrennt nach Anlemmng von Massenligaturen alle zur Leber fïhrenden länder, durchschneidet, wenn das Organ aus dem Körper entfernt werlen soll, das $/$ werchfell an seimen seitlichen Ansatzstellen und bringt Leber mit \%werchfell in die Wärmekammer des Apparats.

\section{Niere.}

Nach Eröffumg der Bauchhöhle und nach Seitwärtsschlagen der I)ämo fïhrt man. an besten nach Abklemmen zur Niere hin, die Kianïle in den Stanm dee Aorta thoraciea nahe zur Abzwejomg der Nierenarterien. Man hat die ku\% ror Eintritt in die Nierr teils rom Stamm der dorta. teils ron der Art. renalis selbst abgehenden Aste (Art. spermatica, Nierenkapselarterien, Art. suprarenalis) sorgfältio zu untrrbinden. Die Venenkanile füht man in die V. cara, wleichalls untel genaner Beachtmng der I. spermatica, suprarenalis u. a. m. eill. Bisweilen empfichlt es sich, eine lange. dïnne Kaniile in den Lreteren his ins Nierenhechen hinein romzuschieben. Die Nieren bleiben in ihrer Kapsel. Das Vordertier und die Beine werden entfernt.

\section{Lunge.}

Man führt eine Kaniile in dic Trachea, eröffnet den Thorax beirlerscits ganz seitlich. entfernt die Rippen möglichst ausgiebig, bindet die rechte Lunge durch eine Jassenligatur an der Wurzel ab, legt eine feste Ligatur, die nicht schneidet, $1 \mathrm{~m}$ die Mitte der Ventrikel nach vorheriger Entfernung des l'erikards und schniirt die Ligatur fest zu. Als Ausflußkanille dient ein recht weites liohr an der äußersten spitze des linken Herzohres. Der Einschnitt mul\} sehr klein sein, da der Riß leicht weiterreißt und die Kaniile dann nicht mehe zu befestigen ist. Als Zuflulibahn dient eine in die Art. pulmonalis eingefïhrte hanuile: Man legt die Arterie neben der Aorta eine kleine Strecke weit frei und geht mit dem Kaniilenfaden zwischen Aorta und Pulmomalis an einer leicht durchgingigen stelle 
mittelst durhlochten. stumpfen Fiuders durch. Damn schuncidet man au und bindet ein. Lm Blutrerluste zu vermeiden. bindet man die 1. anonyma. Corotis sinistra und Aorta am Areus ab.

Sollen die Kaniilen direkt in den Lungengefüben liegen und die beiden Lungen durehspiilt wrelen, so führt man die eine Rïhle rom linken Ventrikal ans durch das Ostium atrioventriculare in den linken Vorhof. die zweite wie oben in den sinus arteriosus der l'ulmonalarteric und ritfernt alie anderen Teile.

\section{Darm.}

Nach Eröffnume der lianchhoihle unterhindet man den loum unterhall, des Pankleaskopfes etwa an der Grenze rom Duodenum mud Jejumm sowie an der Heocökalklappe (etwa $1 \mathrm{~m}$ langes stück beju groben Hund). Ian surht ron der Aorta ans die Art. mesenterica superior und von der V. portae aus die $V$. mesenterica superior, bindet Kaniilen ein und entfernt, eventuell nach vorheriger Interbindung und Durchschneidung. die anderen Dirmteile, die stïren.

Will man den Tarm aulierhalh des hörpers durchströmen. so sind dic Mesenterien zwisehen ligaturen zu durchtremen und endlich an der liadix mesenterii zn durchschneiden.

\section{Bein.}

Man entfernt nach Eröfnumg der bau(hhöhle den ganzen baun nehst Magen. indem zuerst ganz tief im Bechen unter vorsidhtiger Schommg der Vinen in becken das licktum unterbunden und durchtrenut wird, dann die Y. und Alt. mesenterica inferior. die Mesenterien und oberen Gefäße. der Magen an der Kardia kurz muterhalb des /worchfells. Anfangend rom Rektum. entfernt man dann l)arm, Magen mit Milz. Kur\% oberhalb der 'leilungsstelle der Art. iliaca hindet man die zufiilnende Kaniile. die ahfïhrende möglichst weit herwäils in den stamm der V. cava ein. und unterhindet die seitlichen Aste sorgfältigst. Damn wird oberhalb der Nieren die Bauchwand mit Ansnahme der ämberen Haut schichtweise unter Luterbindung der gröberen Gefäle his anf die Wirbelkörper durchtremut. die letzten Rippen durchschnitten und unterhall, der Nieren zwischen Hant und liickenmuskeh ain fester Bindfaden zweinal hindurehoführt. kr wirl an scincu Enden mit Holzknebeln armiert und mit aller Kraft ron heiden Seiten um die Wirbelsäule herum zugezogen und fost rerknotet. Dann kneift man mit ciner groben Knochenzange die Wirbel oherhallh der Ligatur duroh, entfornt so das Vordertice und stopft den Wirhelkanal fest mit Watte aus. Trotzden wird man im Anfang der Inuchspiilung norh Vorluste aus den Sehnitten der liatlchwand haben, da die zu den Banchmuskch führenden Venen oft tief men von der $V$. femoralis ansgehru. Yan mub damn neu muterbinden. Oft blutet es auch in becken aus deu Hämorrhoidalgefaßen, die durch Massenligaturen mu die Harnblase herum gefaßt und unterbunden werden. 


\section{Herz.}

Nach der Verblutme mul Firlischen der Atembewammen entfernt man das lirusthein (siche vorher) mod dic lippen weit nach der Seite hin. öfinet das I'erikarl und fiihrt in die Aorta eine weite Kaniile ein. die dicht oberhallh der Semilunarklappen enden mus. Man hebt das Her\% an der Kinüle hoch mod schmeidlet es von den longen ab, füllt in einer schale mit erwärmter lingerlösung die Kaniile. Wïscht die Gerinnsel ans dem Stamm der Jorta ans mod entfernt durch leichtes Kneten, olne Luftblasen zuzulassen. die Gerimmsel ans dem Ilerzen. rerbindet daranf luftfrei mit demi Apparat.

\section{Uterus.}

I)ic (iebärmutter von Katzen, IHunden. Meerschweinchen oder Kaninehen wird verwendet. Sie ist sehr empfindlich gegen Temperaturschwankmuen, so dals schnell operiert werden mus.') Nach Eröffnung der Bauchhöhle entfernt man L'terus, Vagina und alle Ligamente, an der neben der Wirbelsäule gelegenen spitze des Horns heginnend. Soll die ganze Vagina benutzt werden. so mul beiderseitige Pubiotomie vorgenommen und der 'leil nach vorn geklappt werden. Man soll möglichst die Muskulatur gar nicht. nur die Jigamente beriihren.

\section{Zusammensetzung der Durchspiilungsflïssigkeit.}

Während man friiher glaubte. nur mit Blut die Funktionen des ()rgane des Warmbliiters extra corpus wiederbeleben zo können, weiß man heute, daf nicht bloß die Organe des Kaltbliiters. sondern auch dic höherstehender Tiere durch geeignete Lösmngen wieder belebt und in ihrer Funktion eine Zeitlang erhalten werden.

Beim Froschherzen sind besonders eingehende Untersuchungen dariiber angestellt worden. welche kiinstliche Lösung sich am meisten eignet. wemn nicht mit dem doppelten Volumen $0.7{ }_{0}^{\circ}$ iger Kochsalzösung verdiinntes Sïugetierblut vorhanden ist. Es hat sich heransgestellt. daf di Lösung. folgende Zusammensetzung habell soll 2):

$$
\begin{aligned}
& 06 \% \text { NaCl } \\
& 0.0: 3 \% \mathrm{~K} \mathrm{Cl} \\
& 0.00 \% \quad \mathrm{C}^{\circ} \mathrm{ilC} \mathrm{Cl}_{2} \\
& 0.020_{0} \quad \mathrm{NaH}\left(\mathrm{C}_{3}\right. \\
& 0 \cdot 1 \% \text { Traubenzucker (Locke). }
\end{aligned}
$$

Bei lange dauernden Durchspülungen muf darauf geachtet werden, dal das zur Verwendung kommende destillierte Wasser. das meist aus

$\left.{ }^{1}\right)$ E. Kehrer, Der üherleliende I'terus als Testohjekt. Arch. f. exp. Pathol. u. Pharm Bd. 58. S. 366 (1908). - Dersel be, Physiologische und pharmakologische I'ntersuchungen an den überlebenden und lebendeu Genitalien. Arch. f. Gṛnäkologie. Bd. 81. \$. 160 (1908).

*) Historische Darstellung ler Frage siehe bei: Langendortf, Eruebuisse der Physiologie von Asher-Spiro. I. Jg. II. Teil. S. 302 (1902) und IV. Jg. S. 750 (1905). 
Kupferblasen destilliert wird. zuletzt kurz vor dem Gebrauch noeh eimmal aus sehr sut gereinigten Glasgefirition destilliert wird und mur mit Glas in lertihrung kommt. Es darf ror dem Gehrauch nicht lange in cilasgefäben, die ja Alkali abgeben, stehen, sondern wird zweckmäßig in Kübeln von innen glasiertem Ton ohne Na H ( $\left.{ }^{\prime}\right)_{3}$ und T'ranbenzucker anfbewahrt. I liese werden erst kur vor dem Gehranch hinzugefiigt. Sanerstoffdurchleitung dureh die Ringer-Lockesche Lösung erhöht den liffekt anlierordentlich, ebenso der Kusatz von $0 \cdot 1^{\circ}$ o Traubenzucker. Eine Keitlang nahm man an, dali die Innehspoilumgsflüssigkeit beim Froschloez die gleiche Viskosität wie Blut haben solle und empfahl Zusatz von $2 \%$ Gummi arabicum. Lis hat sirls aber gezeigt, dak es nieht die Viskositiit, sondern der Gehalt an ('a" und $\mathrm{K}^{\prime}$ ist, der beim Gummizusatz wirkt. Wichtig ist, wemn man nicht reine Salzlösung. sondern Blut vermischt mit dieser verwendet, daf die Blutkörperchen sich nicht gelöst haben. Denn heim Lïsen der Erythrocrten treten Kaliumionen aus, und diese sind starke Her\%gifte. Durch Zusat\% ron Caleium hebt man diesen Effekt his yu einem gewissen Grade auf.

Beim Warmbliter verwendet man an hesten das defibrinierte Blut desselben 'Tieres orler derselben Tierart zmm mindesten, vermischt mit

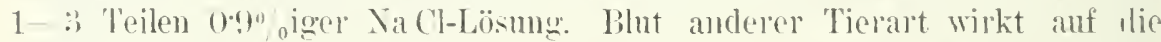
Gefibe oft giftig: sie riehen sich znsammen mul machen eine Durchblntung unmöglich. Doch gibt selbst defibriniertes Blut bei manchen ()romen, wie der Niere, oft schlechte Resultate, vielleicht weil beim Schlacen immer eine gewisse Zahl von Bhutkärperehen zer'stört wird und Blutfarbstoff. sowie Kalimm-lonen in Lïsung gehen. Ian macht die in artfremden Surum rorhandenen oefäfiverengenden Substanzen (Vasokonstriktine) durch Eiwärmen anf $5 f^{\circ}$ muschädlich. $\left.{ }^{1}\right)$ Vleist darf man das Blut rom gleichen 'Tier oder des" gleichen 'Tierart mit der gleichen Menge Ringerscher Lösung ohne schaden verdünnen: im Gegenteil geht die Durchspiilmug damn noch (twas leichter. weil beim muerdünten Blut oft Verlegung der loinsten Lispillaren cintritt.

Hlat man bei der Entnahme ans dem hiorper das orean sehr sorefailtig auspräpariert und alle Nebenwege nuterbumbens. so wird man boi nicht zu hohem In'urek Verluste an Durchspiilumgsfliissigkeit leicht rermeiden können. wenigstens zu Anfang des Tersuches. Nach ciniger \%eit, und zwar bei den verschiedenen Tierarten verschieden schnell (besonders schnell heim Kaninchen, später hei der Katze nud beim Inumd), werden die Gefälie anch bei Verwendung vou mrerdiuntem Bhut durehlissig. allerdings:

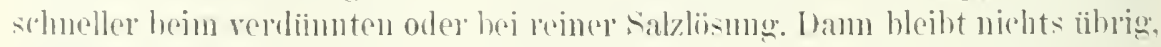

1) Ballelli (Butfolli, Recherches sur les vasoconstrietines des sérums sanguins. Jour'n. physiul, path. gén. P. 625 et 651 [1903]) zeigte. wir infolgedessen Meerschweinchenorgaue dureh l3ht oder Serum rom Rind. Hammel. IIund oder Kaninehen nicht durehstromt werdel können, wiblurend l'ferdeserum wenig schällich ist. Andrerseits sah

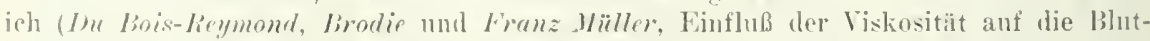

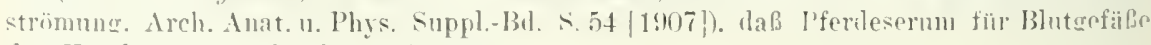
des Humies anBerondentliel giftig ist. 
als die Flïssigkeit in einer untergestellten Srhale aufyusammelu. Bei der lunge tritt durch verdiunntes blut schuell, durch defibriniertes unverdünntes aher auch nach $1-2$ Stunden Ödem ein. Auch für die Extremitäten sowie die Niere darf nicht zu stark mit Pingerlïsung verdünntes Bhut benutyt werden, da sonst allzn schnell Öden und Versagen des Stromes erfolgt. Diese Durchlässigkeit tritt schmeller auf, wemn die Arterialisierung nicht ansieichend ist.

Die Intersuchungen von Langendorff und seinen Schïlem sowie vou Locke hahen gezeigt. daf folgende /usanmensetzung fiir die organe von Wamblitem, insbesondere das 11 er\%, an geeignetsten ist:
$0.8 \%$ Na Cl
ocler:
$0 \cdot(9 \% \mathrm{NaCl}$
$0.01 \% \quad \mathrm{Cal} \mathrm{Cl}_{2}$
$0.0075 \%$ li Cl
$0 \cdot() \cdot 2+\% \quad \mathrm{CaCl}_{2}$
$0.01 \% \mathrm{NaHC(O}$
$0.042,1 \mathrm{KCl}$
$0.01-0.03 \%$ Nall $(0)$, eventuell mit $0 \cdot 1 \%$ Traubsizncker.

Nanche Iutoren empfehlen, der Ringerschen Lïsung Blutserum im Verhältuis ㄹ: 100 hinzuzufügen.

\section{Prinzip der Durchspülungsapparate.}

Man wïnscht ein System zu konstruieren, in dem bei Verbrauch ron möglichst wenig Spülfliissigkeit eine der normalen Blutstrongeschwindigkeit möglichst entsprechende Zirkulation ohne Verlust hei gut regulierbarem Druck ohne Unterlorechung fortdauernd stattfindet. Um Flïssigkeit zn sparen, mïssen daher die Verbindungsröhren so kurz wie möglich sein, und die als Druckgefäl dienende, in einer gewissen Höhe angebrachte Flasche mit konstantem Niveau (1/ariottesche Flasche als Blutreservoir) respektive die den Druck liefernde mit komprimiertem sauerstoff gefuillte Bombe leicht zu handhabende Iähne besitzen. Weun man lïnger dauernde Inurchspiilungen ansfiihrt sowie heim Intakterhalten des Herzens und der (iefülie des Warmbliiters, soll die Beriihrung der I)urchspülumgsfliissigkeit. hesonders des Blıtes, mit Kautschuk, Metallteilen oder Korkstopfen rermieden werdeu und nur ausgekochte (iummistopfen, Glas odler Porzcrllan zur Anwendmug kommen. Itie Verbindungsstiicke schlieben Glas an Glas.

Der bei niederer Temperatur langsamer, bei $: 37^{0}$ sehr merklich eintretende Sauerstoffrerbrauch im Organ (besonders stark in muskulösen (trganen und der Niere) mul durch reichliche Arterialisierung der ausflielienden Lösung ausweglichen werden. Bei Salzlösungen, in denen sich nur wenig Sauer'stoff, zumal bei $: 37^{\circ}$. löst, ist das nur in sehr beschränkten Maßje durchführbar. Vielleicht heruht gerade darin der Vorzug, den Blutzusatz zur Ringerlösung ror reiner Salzlösung besitzt, daß der Blutfarbstoff so viel mehr Sauerstoff locker zu binden rermag. Der Sauerstoff muli bei geschlossenem Srstem, in dem die renöse Fliissigkeit zum Anfangspunkt zuriorkflieft und wieder verwendet wird, eine möglichst hohe Schicht passieren, also von unten einströmen. Inahei schü̈mnt das lilut stark auf. 
Irer Blutkolben muli infolgedessen ziemlich erhebliche Dimensionen besitzen und mit cinem sicherheitsgefäli, einer odel zwei Vorlagen zum Luffangen des schammes verbmulen sein. Wem man nicht die Arterialisierung anlierhall, des Apparates durch schiitteln romimmt. Man empfichlt anch. Limssteinstiichehen auf die Blutoherflïche zu bringen, un das Schiumen zu

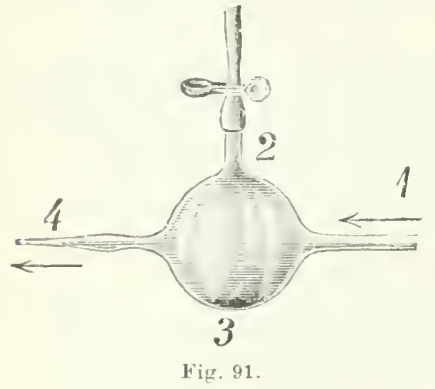
verhindern; das gelingt aber hei starkem sanerstoffstrom nur in geringem labie.

Resomlere Vorsidht ist daranf zu rerwenden, dali keine Lufthlasen in die Arterien gelangen. Man bringt daher hinter dem Gerimselfünger direkt ror der Arterie einen Luftfinger an in ciestalt eines seitenrohres mit birejterme, das senkrecht mach oben steht und dureh das die angesammelte Luft lejeht mach aulien herausgeprebit wird. Sehr zweckmällig sind A'terienkanïlen. wie Brodic sie verwentet. von der folwenden Form (Fig. 91):

Bei 1 tritt die Flissigkeit ein. -) ist der seitenamslab mit (inmmi-

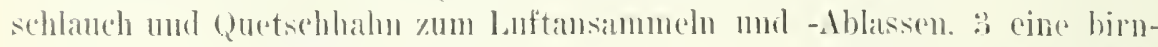

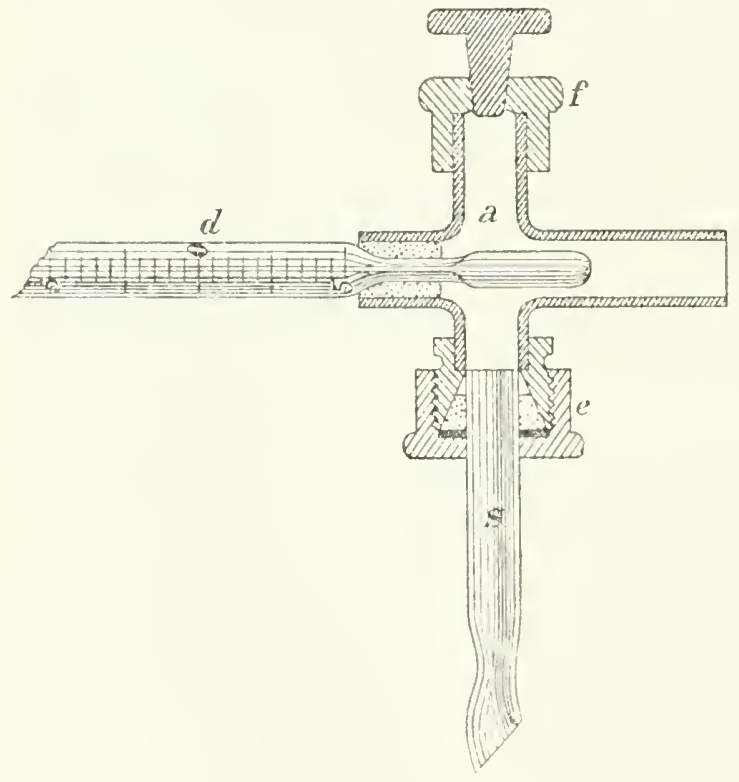

Fig. 92 förmige Erweiterung. 4 die eigentliche Kaniile mit abgeschrägter, gerundeter, spitze. Will man die Wirkung ron Giften studieren. so sint diese in die arterielle 8 Bahn kur\% vor fintritt जा die Arterie zu injizieren. damit man die Giftkonzentration and den Moment des bintretens in das Grgan geniigend schasf beurteilen kamm, efwa bei :in der kaniile (Fig. 91) Meist wirl es sich empfehlen, das Orwan in einem Wälmekasten bei koustauter 'Temperatur zu halten. Auf jeelen lall ist aber Sorge zu tragen, dalb die Inurchspiilungsfliissigkeit beim Eintritt in das Organ konstante 'Temperatur besitzt, die sich anch bei starkem Wechsel der Stromgesehwindigkeit um nicht mehr als vinige Zehntelgrade (beim Herzen nur $\left(01^{\circ}\right)$ indert. Nan erielt das dadur(h. dafi man vor der Arteris ein 
Schlangenolu in rinem Wasserbal ron konstanter 'Temperatur einsehaltet und die Temperatur durch ein Thermometer direkt vor Fintritt des Iblutes in die Arterie kontrolliert. und zwar so, dali die 'Thermoneterkugel auch wirklich rom strom umspiilt wird (siche Lemgendorff's Inschlubiantiile ans Motall. Fị. !)

Endlich hat sich herauserestellt. dali Inuchspiilungen sehr viel hesser bei rhythmischem Ginlanf als bei kontinuierlichou strom montatten gehen. Daher rerwendet man nur noch in bestimmten Fällen die urspringliche, einfachste Einrichtung, bei der das blut aus einer loch iber dem Organ hängenden Mariotteschen Flasche dauernd zuflieft. sondern schaltet in das system Irucksaupumpen in verschiedenster Form ein (siehe (lie Spezialapparate). Nan muli bei der Inockregulierung daranf halten. dal' der Inuck zu Beginn des Versuches nicht gar zu hoch ist, da sonst leicht sofort vollkommener Verschlul) der arteriellen Jiahn eintritt. Es cmpfiehlt sich, fuir das Froschhel\% den Inuck bis etwa $1.5 \mathrm{~cm}$ Wasser. für das Sïugetierherz bis etwa $30 \mathrm{~mm} \mathrm{Hg}$, hei der Leber his :i. - $40 \mathrm{~mm} \mathrm{Hg}$ (Blutstrom etwa $80 \mathrm{~cm}^{3}$ pro Minute), bei del Niele, dem Inarm. del Vilz

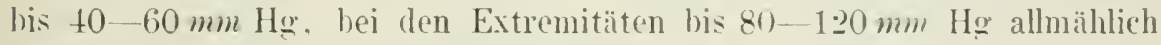
ansteigen $z$ lassen und so zu erhalten.

\section{Die einzelnen Apparate.}

\section{Froschherzapparate. ${ }^{1}$ )}

"1) Nach Williams-Lrescr. ?) Besonders für pharmakologische \%wecke ist im Schmiedebergschen Institut ron Williams ein einfacher Apparat zur I) urchspülung des aus dem Körper entfernten Froschherzens mit Iilut oder Ringerlösung konstruiert worlen. Fa besteht aus zwej je etwa $20 \mathrm{~cm}^{3}$ fassenden Glasgefäßen, die etwa $20 \mathrm{~cm}$ ïber dem Herzen stehen. unten eng zulaufen und jederseits zu einem lentil führen.

Die Ventile (Fig. 9:3) bestuhen aus einem weiteren. sich unten verengenden Rohr. in dem ein etwas engeres, sich stark rerjüngendes und am Ende geschlossenes Rohr durch schliff wasserdicht feststeclit. I)ieses innere Rohr hat einen Schlitz. den man mit Goldschlägrerhaut (chafmesenterium. Fischblase, locker rerschliebt. Ier Larun wird ober- und unterhalb des Schlitzes durch Ligaturen hefestigt. In clen neueren Ipparaten sind die Ventile durch Glaskngeh gebildet. Sie werden so geschaltet. daß sie auf der einen Seite nur mach dem Herzen him, auf der anderen nur rom Herzen weg den Durchgang der Flïssigkeit gestatten. Sie stehen beide unten durch ein Y-förmiges Metall’ohr. an dem die in die Aorta einzuführende, etwas

$\left.{ }^{1}\right)$ Nüheres siehe bei Langendorff, Ergebnisse der Phșsiologie ron Asher-sipiro. I. 2. Abtlg. S. $275(1902)$.

2) Williams, Utber die Ursachen der Blutdrucksteigerung bei der Digitalinwirkung. Arch. f. exp. Path. u. Pharm. Bd. 13. S. 11 (1877). - Perles, Beitrïge zur Kenntnis der Wirkung des Solanins. Ehenda. Bu. 26. S. 95 (1890). - Dreser, Cber Herzarbeit und Herzgifte. Ebenda. Bd. 24. S. 223 (1858). 
gebogene Metallkaniile sitzt, in Verbindung. Ins gerale Stück des Y-rohres ist doppellinfig. Tor lieginn des Versuches füllt man den ganzen Apparat lufterei mit Ringerscher Lisung und hat das Y-rohr. an dem spïter die Kinuile hefestigt wird, durch einen Gummischlanch mit Klemme verschlossen. Lamn präpariert man an Frosch das IIer\% herans, fïhrt, ohne das Her\% ans dem Körper zn (ntfernen, in den liogen der Aorta die mit Kochsalzlösung

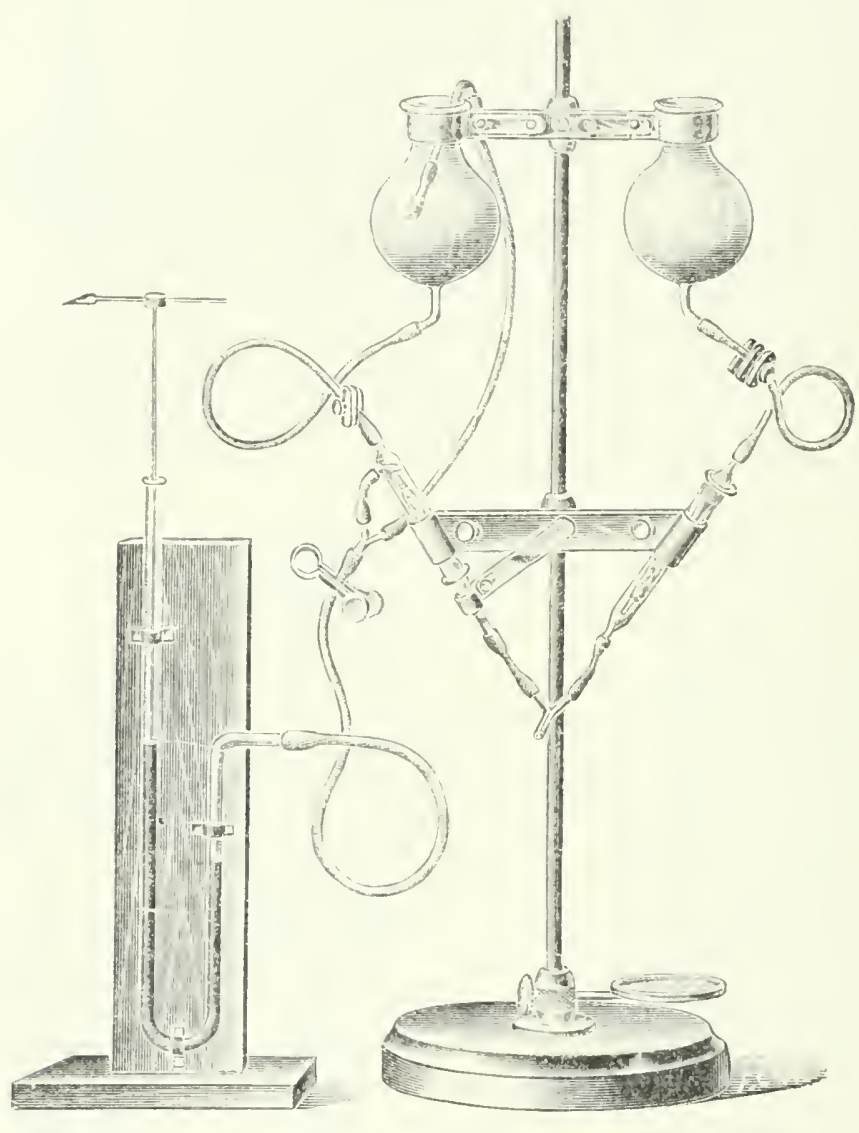

Fig. 93.

luftfrei grefiillte Kintile ein. deren zwei seitliche Ansïtze zm hesseren Handhabmng und zm Refestigung der Kaniilenfäiden dienen, damit das Her\% während des Torsuches nicht abgleitet. miterhindet die anderen groben Gefälsstämme, schneidet das Her\% los und rerbindet mit dem Metallrohr. I)ie Fliissigkeit strönt nun von der einen Seite dureh das eine Ventil nach abwärts in dats Her\% hinein und wird durch den Schlag der IIerzkammer nach der anderen lichtung hin in die Höhe werlriickt, $10 m$ den I)ruck an einem seitlich angesetyten Nanometer anznzeigen oder durch eine nicht allzu hoch 


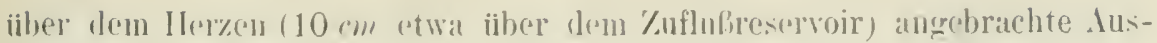
laufspit\%e allsutropfen.

\section{b) Der Jakobjoche Apparat') (lig. 94):}

In die linkr Hohlvene wird - unter linterbindung der anderen zum Herzen fïhrenden Venen - eine Glaskinuile eingeffilurt. Elonso wird in die linke Aorta rino feine (ilaskaniide ringebmenden und diese his in den Bulbus arteriosus roroeschoben; die andere Lorta wird unterbundern. I)ie beiden Kaniilen sind gefïllt; sie weren unter Vermeidnug von Luftblasen auf die anf einem liork fixiorten, mit kuren (iummischliurben rersehenen Iiöhrehen, die der 'Zn- bzw. Ableitung der Nährlösung dienen, anferesteckt. " fïhrt mittelst (;ummischlauches zu einem der beiden die Nährlösung, law.

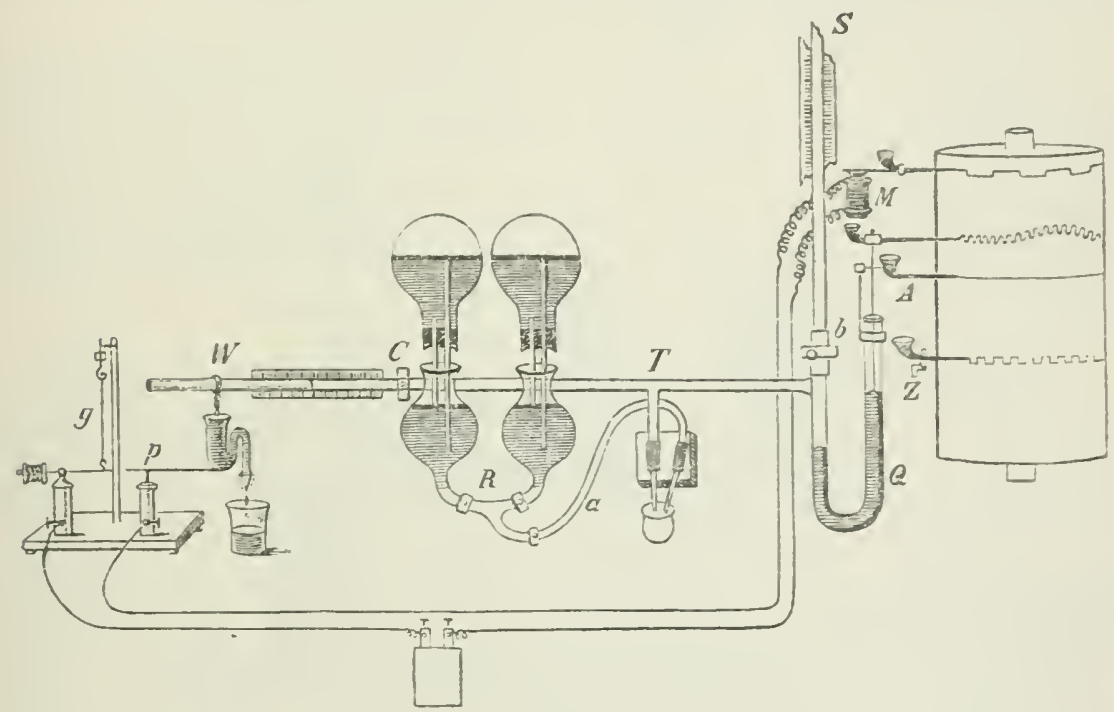

Fig. 94 .

die (ifflösung enthaltenden Reservoise $R$ (Arariottesche Flaschent. In die Leitung sind drei Hähne eingeschaltet (s. Fig. 94). l)as wegführende Rohr wird mit einem T-Rohr verbunden. Es fiihrt auf der einen seite zu einem kleinen Hg-Iranometer, auf dessen frei endendem Zuflufischenkel cin steigrohr S anfgesetzt ist. Auf der anderen Sejte ist das T-Rolur mit rimer geraden Cilasiölne $I$ rerbunden. in die cin das Lumen grerarle ausfiillender Glasstab eingeschoben ist. so dab nur ein feiner zylindrischer Kapillarspalt iibrig bleibt. Ein an Ende dieser Röhre um den herrorragenden Glasstah geschlungener feuchter Wollfaden gestattet der durch den Spalt austretenden Fluissigkeit gleichmälig abzutropfen. Roh $\|^{r}$ ist horizontal, einige

${ }_{1}^{1}$ Nach R. Hcinz, Handl, exper. Pathol. Jena 1905. Bd. 1. Teil II. S. 836. Dort auch genaue Beschreihung des Apparates rnn ". Frank, ler für hiochemische Fragen wohl nicht in Betracht kommt. 


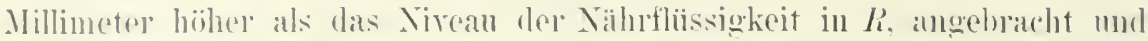

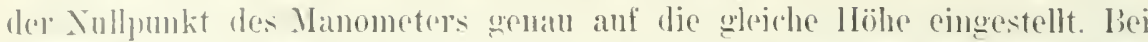

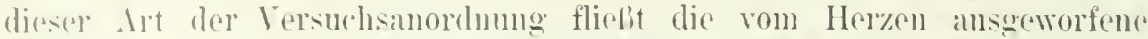
Flissigkeit durch die Kapillare. Wird nun dee Widerstand des liapillarspaltes durch Einschiehen des cilasstabes allmablirh gesteigret. inden die

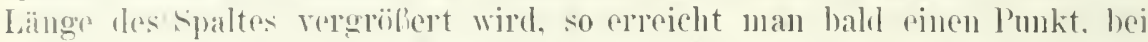
welehem nur ein Teil der l'liissigheit ansflicht, wïhrend der andere. zum Manoneter stromend. die steiguöhre zu füllen beginnt und damit das Her\% zwingt, gegen rinen sioh allmällich steigernden I) luck zu arbeiten. I)ieser kanm mit Ililfe des lIg-Nanometers $Q$ anf dem Kymographion, neben einer

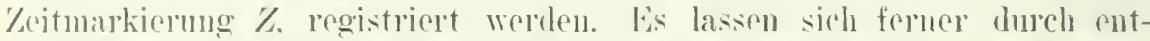
sprechende Verengerung des Hahnes b anch dic einzehnen l’ulsselnwankmogen zur I)arstellung Iningen.

lient das Fliissighejtsnivean in $R$ anch $111 \mathrm{l} 10 \quad 20 \mathrm{~mm}$ iiber der Atrioventrikularorenze des Her\%ens. so beginnt das Her\% kräftig zur alheiten. Man wählt die Inuckhöhe je nach der Weite der in dic Veme eiug(bundenem Kantile so, dab die Fiillung des Vorhofes möglichst gremau wie im 'Tiure selbst verlianft, so dab jedesmal in der Zait der Diastole sich der Vorhof (ben fiillt, ohne dafi eine l)ehnung soiner Wand eintritt. Man wïhle die in die Vone einzulburlande Kaniile so weit wie möglich: je writer die kianiile. desto weringer kann der ln'uck seiu.

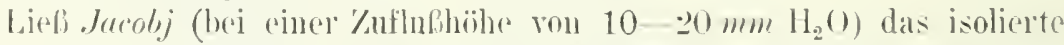
Herz arbeiten, so triel der Ventrikel die Flissiokeit in der Strigröhre auf $50-60 \mathrm{~cm}$, ja bis anf $80 \mathrm{~cm}$ Wasserhöhe, während gleichzeitig ans dem

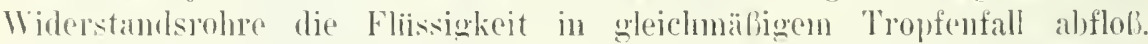
Inoh dusziehen dos Glasstabes komnte nach einigrm Probieren derjenige l'mkt gefunden werden. bei welchem der Widerstand des Kapillarspaltes offenbar gerade dem des ciefiibsystems im Tiere entsprach, so dab trot\% beständigen Abflieliens der rom Herzen ausgeworfenen Flüssigkeit der bruck sich auf der im libutdrurkersuch am Frosch grandenen Höhe hielt. Indem das Her\% gegen diesen l)puck amarbeitete. warf es mit jeder sistole zwej his drei Tropfen, mit 10 l'ulsen also $10-15 \mathrm{~g}$ aus, was bei einer Hubhöhe von $50 \mathrm{~cm} \mathrm{H}_{2}()$ einer Albeitsleistung von $50-75$ y

In die aus dem Widerstandspohr ahfliefende Flïssigkeitsmenge messen b\%. die Werte graphisch registrieren zu kiinnen, stellte Jacobj folgende Finriehtung her:

Jie vom Wollfaten bei $\|^{r}$ ahfliefiende Flissigkejt wird in ein kleines

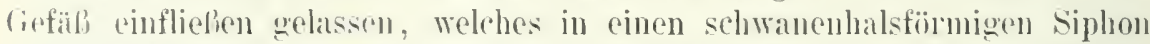
ansliutt. Sobald es sich his zur Höle des Hebers gefiillt hat, wird es durch diesen plïtzlich entleert. Das ciefäli ist an Ende eines Hehels befestigt und durch ein verstellbares Gegengewicht nahezu äquilibriert. Gleichzeitio wird dieser Hebel durch einen Gummifaden g getrageu, so dab er, wemn das refaili leer ist. ctwas iber dic horizontale Lage gehohen wird, hei Fiillung des (iefälies aber nach einiger Zeit unter Dehnung des Gummifadens mit der Platinspitze p dic mit einer kleinen l'latinplatte belegte 
Stiitze in horizontaler Lage beriilnt. Wiase stiitze einerseits und der Hobel andrerseits sind in einen Stromkere eingeschaltet. Fiillt sich das Ireligefoild, so wird in dem Voment des Niedarsinkens des llebels der liontakt zwischen der Platinspit\% p und dem Platimplittchen der stiitze geschlossen, mm in dem Voment, wo die dureh den Ilober bewirkte kntlectung de's liefälies

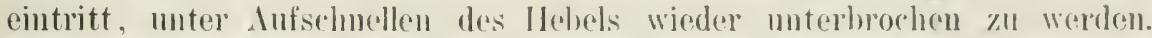

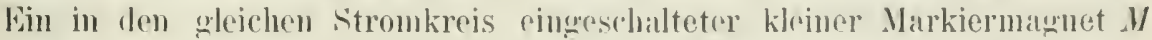
registriort den Schlof mol die öffmum des stromes iiber der Bhntdruckund \%eitkurve anf dem Kómographion. so dals hierelurch anch die Mrenge der in der \%eitemheit abgeflossenen l'bissigkeit in jedem lugenblick genan neben dem Bluttruck mul der l'nlszahl bestimmt werden kinn.

\section{Apparate für das Säugetierherz.}

a) Der Langendorf'sche Ipparat.

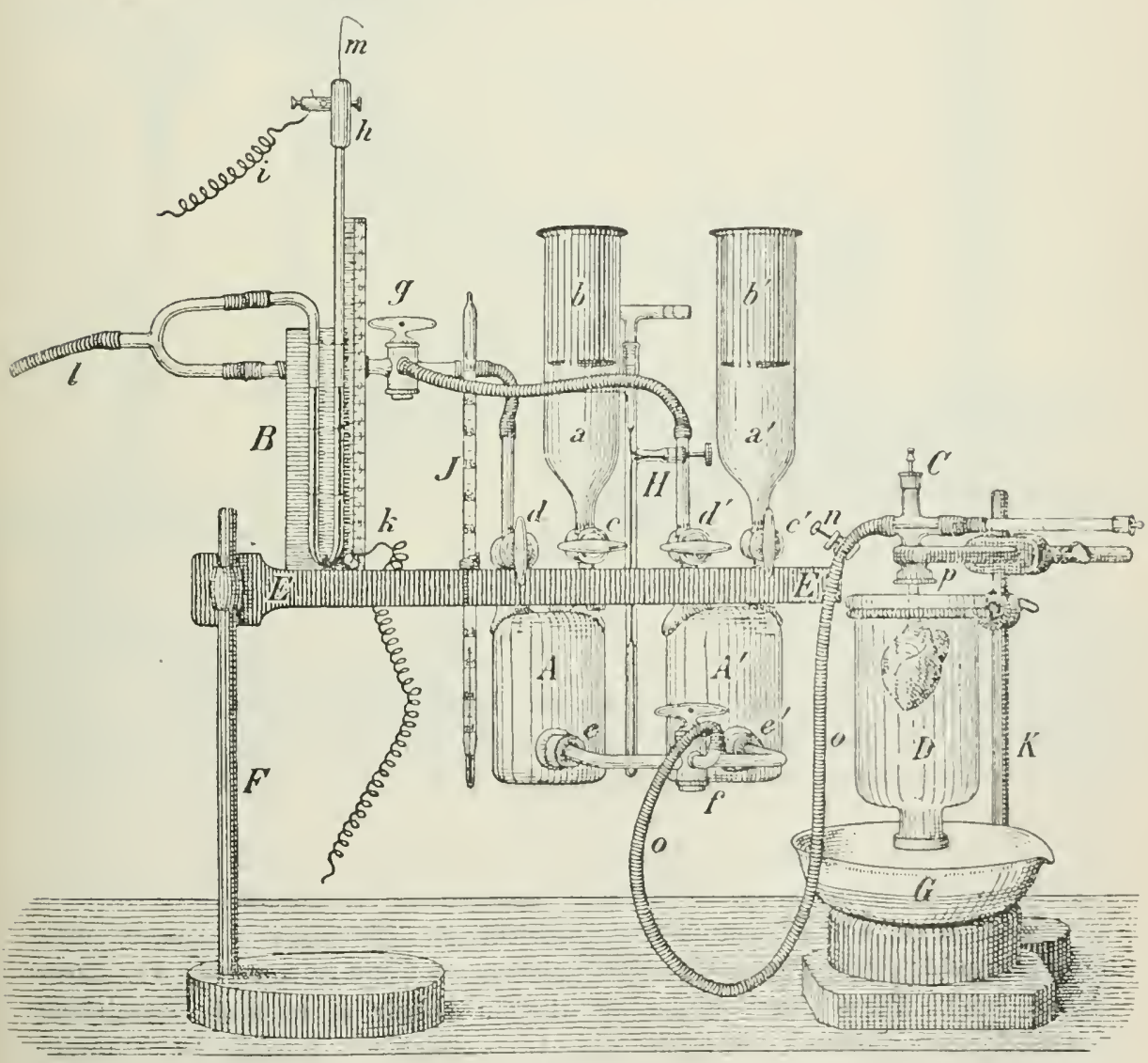

Fig. 95 .

Das Blut befindet sich bei diesem Apparat in einem Srstem ron zwei Flaschen $A$ und $A^{\prime}$ (Fig. 95), die durch eine Zuleitung mit eingeschaltetem 
Kontaktmanometer $B$ mit einer grolien Druckflasche in Verbindung stehen. bie burckflasche ron etwa $17 l$ steht ohen (Fig. 9ti) mit der Wassprleitung in Vephindung und hat unten einen Auslab. Jas Manometer $B$ (Fig. 95) besitzt an seinem freien sichenkel cinen Metallanfsatz $h$, der dureh $i$ mit einer Stromquelle, dunch den steifun Platindraht m mit der Quecksilberfliche in Verhindung steht. Der loraht $k$ führt zu einer Kilemmschraube und steht gleichfalls mit dem l'atindraht $m$ in Verbindung. Ein 1)oppelwoghalun g gestattet durch llahn doder d' die Verhindung mit einem der heilen Blutreservoire (A und $A^{\prime}$ ), deren jedes einen Bluteinfüllungstrichter ( bohrung ist gerade, die andere knieförmig, so daß $A$ oder $A_{1}$ entweder mit dem 'Trichter oder der äuberen Luft verbunden oder gegen beide ab-

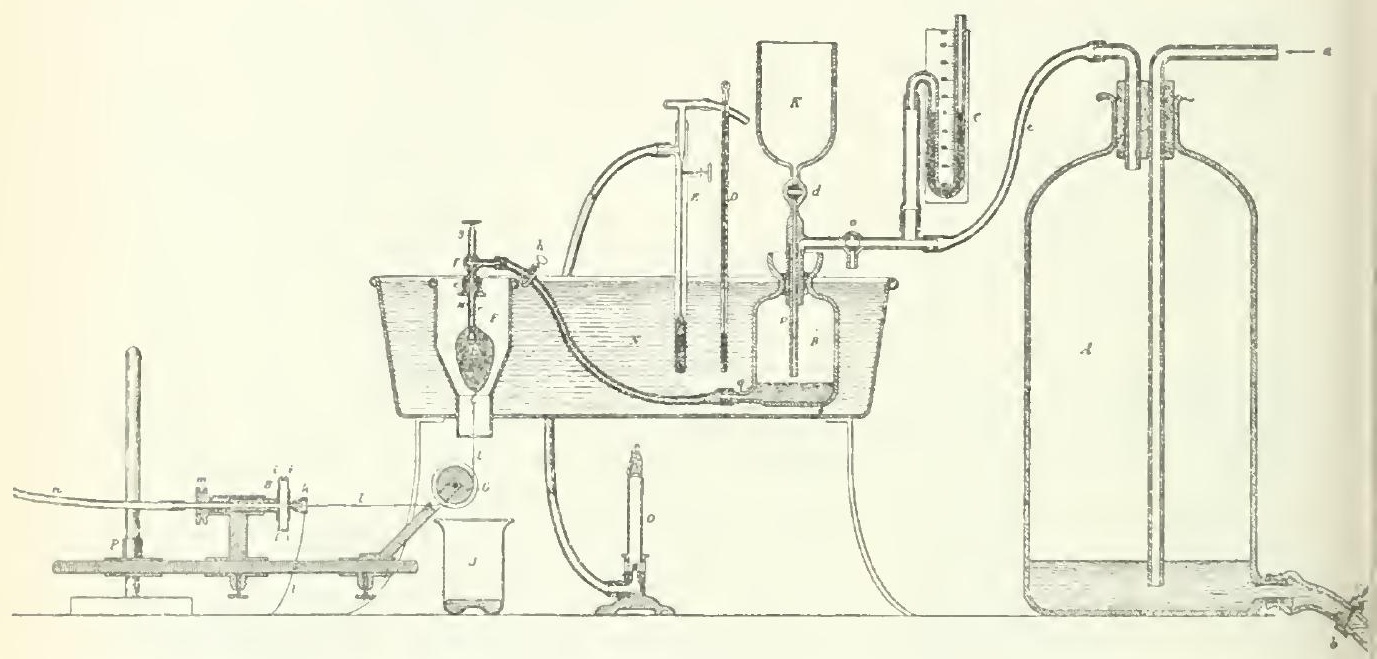

Fig. 96.

geschlossen sind. Man kann die eine der beiden Flaschen füllen, während die andere zur speisung des Ilerzens benutzt wird, ohne daf beim Wechseln eine merkliche Iruckschwankung entsteht. Auf die Einfuilltrichter setzt man mit Sieben rersehene 'T'richter (b und $\left.b^{\prime}\right)$, die die Gerinnsel des einzufüllenden Blutes zuriicklalten. Die Leitumg o führt zu der .Anschlulkaniile*. Diese (Fig. 97) besteht aus einem viersehenkeligen Rohr $a$, in dessen Mitte ein 'Thermometer $d$ hineinlagt. Oben ist es durch einen aufoeschraubten IIetallstïpsel $f$ rerschlossen, der zur Entfernung von luftblasen dient, unten dureh einen metallenen Insatz $e$, in dem rermittelst durchbohrten Kautschukstopfens die dortenkaniile $s$ steckt. Der Metallansatz $e$ ist mit einem Gewinde versehen, auf das eine Muttru paßt (in Fig. 97 ist sie aufgeschraubt, in Fig. 92 nur von außen sichtbar). Ist die Intter losgescliraubt, so steckt man die Herzkaniile in den liautschuk- 
stöpsel hinein. Sehraubt man daun die Mutter anf, so drïckt diese den Stöpsel stärker in die Hïhlung hinein und fredit iln so fest um das Glasrohr, dal) es dadurch absolut dicht in der Inschlulikaniile festsityt.

In Fig. 97 ist auch das Her\% selbst ohne das es beherbercende Ciefaili, nelost dem an seiner spitye mittelst des Häkchens y befestigten Fadens dargestellt. Der Faden läuft 1 m die Rollo $h$ zur L Infuahmekapsel (i). lie Rolle ist zugleich mit dem ganzen dufnahneapparat auf einem viorseitig-prismatischen Stahlstab (n) angehracht. der durch eincul Fortsatz,

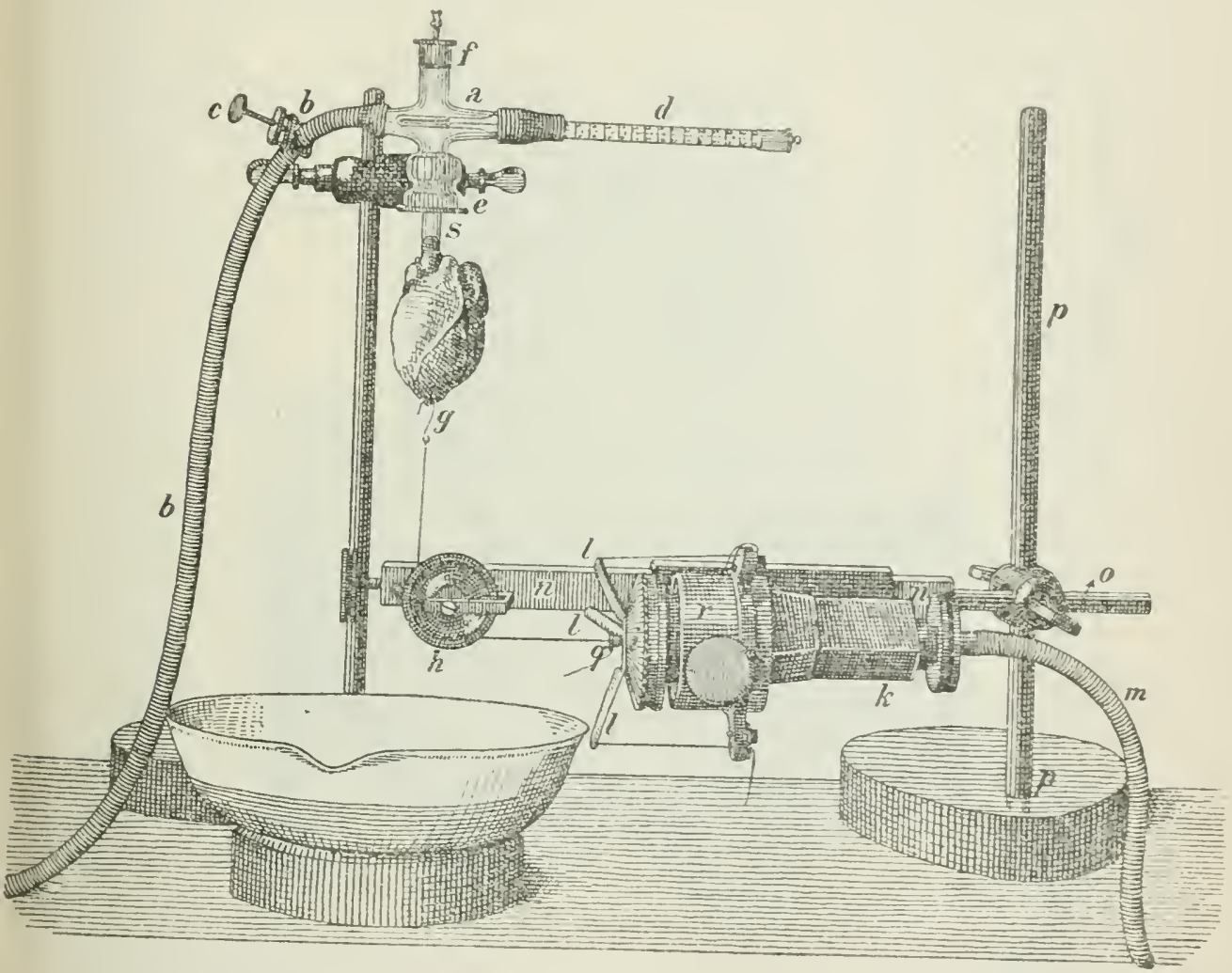

Fig. 97

an dem schweren Stativ $p$ verstellbar befestigt ist. Die Rolle kann so eingestellt werden, daß der Faden jedesmal genau senkrecht an der Doppelmembrankapsel $i$ angreift. Auf der Aluminiumscheibe, die der vorderen Membran der Kiapsel aufgeleimt ist, hefinden sich aufer einer Vorrichtung zur Befestigung des Fadens $(q)$ drei duimne. aus Aluminium verfertigte Streben $(l, l, l)$; an ihnen sind drei Gummifäden befestigt, die rückwärts zu dem die Kiapsel tragenden Metallring $r$ ziehen. Durch Verschiebung dieses hinteren Ansatzes der drei Fäden wird ein rariabler elastischer 
\%ug ansgciibt, der zu starke Anfangsspannumgen der beiden Membranen verhindert. Ihe elastischen Fïden wirken also wie eine Feder, die sich der Itervorwöthung der Kapselmembranen widersetzt. Fs ist leicht einzusehen,

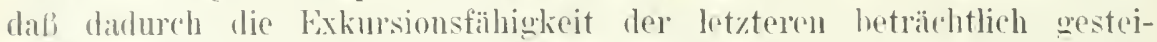
gert wirl.

I) Anfuahmekapsel (deren hintere Membran in der Abhildnng 97 nicht sichthar ist) ist anf dem Stalhtprisma $n n$ grob verstellbar und läbt sich durch die Vorrichtung $h_{i}$, die der Feinstellung des Vikroskops nachgebiidet ist, auch mikrometrisch einstellen; durch an die Vikrometervorrichtung

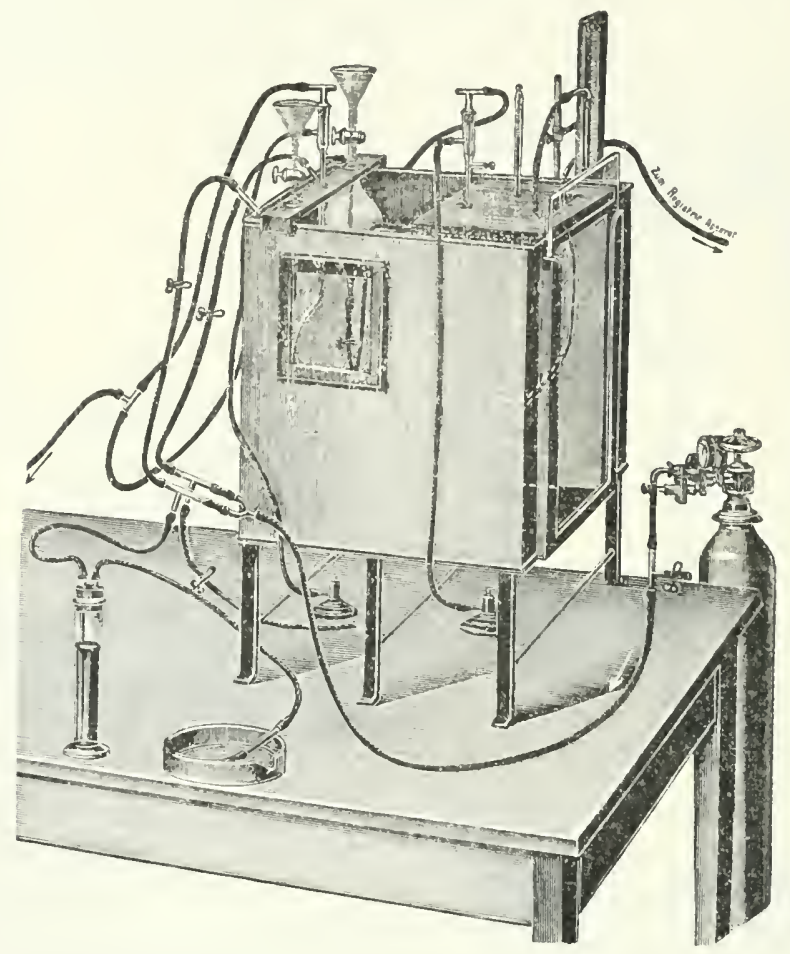

Fig. 98.

durchsetzendes Abzngsrohr steht sie mit tem \%ur sichreibkapsel ziehenden Schlanche $m$ in Verbindung.

Alle Flaschen, Leitungen usw. sitzen in einem Wärmekasten mit 'Thermoregulator' (Fig. 96), der zwei Abteilnngen enthält (vgl. Fig. 98). Die hintere. mit Wasser gefiillte ist fuir die Blntflaschen $A$ und $A_{1}$ nebst Schlauchverbindungen. ein kleiner vorderer Luftraum fïr die Anschlubkaniile nehst Her\%. Die vordere Kammer wird vorne durch einen dicken Glasschicher abgeschlossen und besitzt unten eine Öffnung, durch die der Faden von $y$ zn der liolle $h$ führt und anferdem das IBlut aus dem Herzen in eine darunterstehende schale abtropft. 
Der Apparat von Lanyendorff hat sich so bewihnt, daff es nicht mehr nötigr erscheint, einen ähnlichen von Neuell-1/artin zu beschreiben. Einen etwas einfacheren Apparat '), auch fuir andere ()roane, zeiggt Fig. !s.1) Ije Temperatur und der Druck sind in ihm für lïngere \%eit nicht so konstant zu erlaalten $\left( \pm 3^{0}\right)$. Will man vergiftetes Plut dem Organ zufiilıren und den Zeitpunkt genau kennen, in den es ins Organ gelangt, so kann man kurz vor der Arterienkanüle einen '/weiweghahn mit Querbohrung einschalten, der von anfen durch einen langen Hebel reguliert wird. Man läßt so den toten Raum sich schnell durch Verbindung mit der Aufenluft mit dem (iiftblut fiillen und schaltet schnell um. Die Hahmumschaltung erfordert nur wenige Sekunden. ${ }^{2}$ )

b) Der Brodiesche Herzapparat. $\left.{ }^{3}\right)$

Um die Temperatur noch sicherer innerhalb) $0 \cdot 1-0 \cdot 20$ durch viele Stunden konstant z:11 erhalten und den Zufluf der Lockelösung so gleichmäßig als möglich zu machen, um außerdem geringe Flüssigkeitsmengen $\mathrm{zu}$ benutzen, so daß Änderungen der Zusammensetzung oder Giftbeimischungen sich sehr schnell benıerkbar machen, ist der folgende, sehr kompendiöse, nur aus Jenaer Glas bestehende Apparat konstruiert worden (Fig. 99).

Die Kammer $A$ sitzt durch Schliff $D$ fest im oben offenen Wassermantel $C$. Oben bei $E$ steckt in $A$, durch ein Stiick Schlauch befestigt, Rohr $B$.

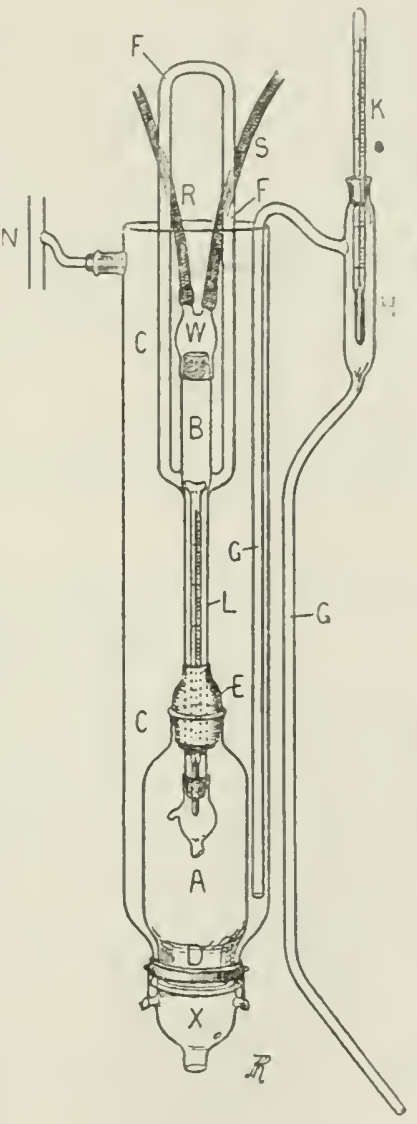

Fig. 99 .

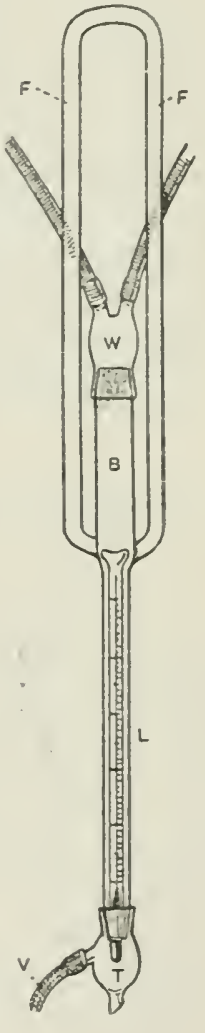

Fig. 100.

Dieses ist bei $E$ leicht beweglich mit Hilfe des U-förmigen Halters ${ }^{*} F$ aus kompaktem Glas (siehe auch Fig. 100). Lnten sitzt an $B$ die AnschlußS. 38 (1904).

${ }^{1)}$ Gottlieb und Magmus, Digitalis und Herzarbeit. Arch.f. exper. Path. Bd. 51.

$\left.{ }^{2}\right)$ J. Wohlgemuth, Zur Methodik der Herzdurchblutung. Zentralbl. f. Pbrsiol. Bd. 21. Nr. 25 (1907).

s) T. G. Brodie und W. C. Cullis, An apparatus for the perfusion of the isolated Mammalian heart. Jouru. of Phṛsiol. Vol. 37. p. 337 (1908). 
kaniile ' $T$ ' für das Herz mit seitlicher öffunme $T$ zur Entfernum von Lufthlasen. B) wird oben mittelst schliff rerschlossen duch eine Glaskappr $\|$, in die zwei Röhren. $R$ mnd $S$. einminrlen. Sie fiihren zu zwei Muriotteschun Flaschen. Ier lange 'leil von $b$ wind fast wanz dureh das 'Thermonetel' $I$ erfiillt, so dab die Lösung nu' in timmer schicht an ihn

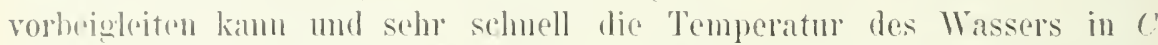
ammimmt. Das Wasser in (' woll anf konstantem Niveau durch Rohr $H$

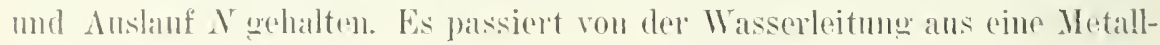
heispirale. Im Anslanfrohr $/ 1$ sitzt ein 'Thermometer.

Zum Gebranch hringt man $C$ anf $: 35^{\circ}$. fiillt die immeren Teile mit Salzlösung. befestiont dam das Hor\% an der Aoltenkiumile und diese (nath Eutfernung der Gerinusel dmoh Auswaselen der Herzhöhlen) an $b$,

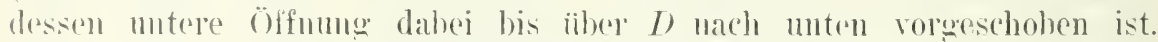
Damn rioht man $B$ hoch (wie in dep Fig. !!!) mol schlielit die Kammer A durch eino unten durchbohrte (ilaskappe $\mathrm{X}$ bei $I$ ) ab). Sie wird durch zwei iiber Gashäkchen geleyte Gimmibändor festgehalten. Duch die öffnum tropft die ausfichende Lösun巛 ab), oventudl unter liegistrierung der Tropfenzahl. mol weht die Verbindum von dem in der Hermpitze befestigten llaken zum schreiber.

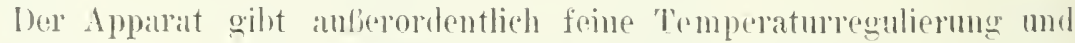
diufte auch fiur Versuche am Muskel. [terus u. aihul. von Nutzen sein.

\section{Apparate zur künstlichen Durchblutung anderer Organe als des Herzens.}

bie ron Ludury ansogedalde Anorlunug, wie sie zuenst von Cyon benutzt wurde. ist in Laufe der Jahe zuerst in Ludurigschen, später anch im Schmiedebrgschen Laboratorium nach den verschiedensten Richtmmen verbessert mod modifizicrt worden, so dab gnte Druckrogulisung, Gewälı fiil lionstanz der Temperatur sowie die Möglichkeit. dak das durehgeflossene blut immer wieder zu dem blutrescrvoir zurückströnt, erreicht sind. So geniogt oft für hiochenische Fragestellmgen folgende Anordnung '):

bas Blut flieft abwechselud ans cincm von zwoi soheidetrichtern durch eine aut $40^{\circ}$ gehaltene Wämmeschlange in das Oroan. Die Trichter werden ron oben aus durch Vephindung mit ler Inuckleitung eines Mänkeschen Masserstrahlgobläses untror Iruck gesetzt. Die Druckleitung passiert vor Fintritt in die Blutreservoire ein Quecksilber-Maximmmrentil. Ein Manometre zeigt den Inruck an. Jas renöse lilut fliebt durch einen 'lrichter in eine Flasche ab, ans der es durch den sanghahu einer Wasserstrahlpmupe abesanget wirl. I)ie iiberschiissige simgluft arterialisiert das blut unter Schämen, der scham wird in einer Vorlegeflasche wesammelt. Allerelings

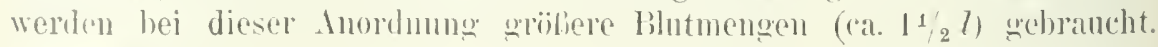

$\left.{ }^{1}\right)$ Vgl.: Embden und Gläfiner, ỉher den (1rt der Ätherschwefelsäurelilduug. Ilofmeisters Beiträge. I. ¿. 313 (1902). 
r. Frey und Gruber ${ }^{1}$ ) haben zur besseren Irterialisierume als in der ältoren dnordnung eine sogenannte kïnstliche Iange. d. h. einen Glaszylinder, in dem das Blut in diinnor Sichicht an cincon Innenzrlinder herablïuft und

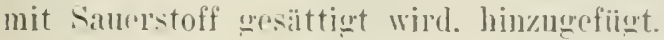

\section{(1) Ipparat von Jarobj.}

ln Inlehnumg an diese Einrichtung konstruiertw dann Jacolj seinen Durchblutungsapparat, der wohl fiir vicle \%wecke das Vollkommenste darstellt. was wir zurzeit besitzen, wemn man auch nicht lenguen kann, daf. die verwendete blutmenge immer noch ziemlich erheblich ist $1800\left(\mathrm{~cm}^{3}\right)$, daß man hei Hunden das blut also verdimmen mul' und dadurch die Möglichkeit der Ausdehnmug der Versuche ïber mohr als etwa 4 Stunden aufuibt (ödembildum!), solbst wenu man die Tiere nach dem Vorbluten eventuell mit hirudiuhaltiger Kochsalzlösung ausspült. dab ferner rlie ganze Anordnung grobe Kosten. sehr erhehliche Einibung sowie gute Assistenz verlangt. Jucolij hat seine ursprimgliche Inordumnor verbsest und in dieser For'm soll der Apparat jetzt nach dem ()riginal ziemlich rorteretreu beschrieben 2) werden (Fig. 101):

Der Apparat besteht aus zwei Hälften. von denen dic cine den Blutstrom in dem zu durchströmenden ()roan unterhält. die andere den kleinen Kreislauf nachahmt, in den das Blut durch eine kïnstlich geatmete natiirliche Lunge greleitet wirl.

Jede Hälfte des Apparates kann. wie man aus der Keichnung Fig. 101 sieht, einen in sich abgeschlossenen Kireislauf ditstellen. Beiden Kireisen gemeinsam ist der doppellänfige Doppelhahn $H$. wie ihn Fig. $101 a$ und $b$ in horizontalen Querschnitt zeigt. Der Hahn ist ans Messing hergestellt. Er besteht aus einem würfelförmigen Mantel. der je zwei zuführende und zwei abführende Röhren trïgt, welche in einer horizontalen, durch die Achse des Hahmes gehenden Ebene liegen. In diesem Mantel bewegt sich der Kern des Hahnes, der zwei Bohrungspare besitzt. Das eine Bohrungspaar durchsetzt den Kern derart, daß die beiden Bohrungen miteinander parallellaufend bei Einstellung ihrer Öffnungen anf dicjeniggen des Mantels die geradlini@ gegenüberliegenden Röhren des Mantels miteinander verbinden und dementsprechend das durch das rechte Zulcitungsrohr tretende Blut zur rechtseitigen, das durch das linke Zuleitungsrohr eintretende zur linkseitigen Ibflußröhre führen, so daß beide Ströme also parallel gerichtet den Hahn passieren, wie die Fig. 101 a veranschaulicht.

Bei dieser Stellung, des Hahnes bildet das Rohrsystem jeder Hälfte des Apparates cinen in sich abgeschlossenen Kireis. In eimer mit der Ebene der eben beschriebenen Bohrungen des Hahnkanals einen rechten

1) $x$. Frey und Gruber, Untersuchuugen über den Stoffrechsel isolierter Organe. Du Bois' Archiv. S. 519 (1S85) und $x$. Frey, Versuche über den Stoffrechsel des Muskels. S. อ33 (1885).

$\left.{ }^{3}\right)$ C.Jacobj, Ein Beitrag zur Technik der künstlichen Durchblutung überleben(ler Organe. Arch. f. exper. Path. Bd. 36. S. 330 (189a). 


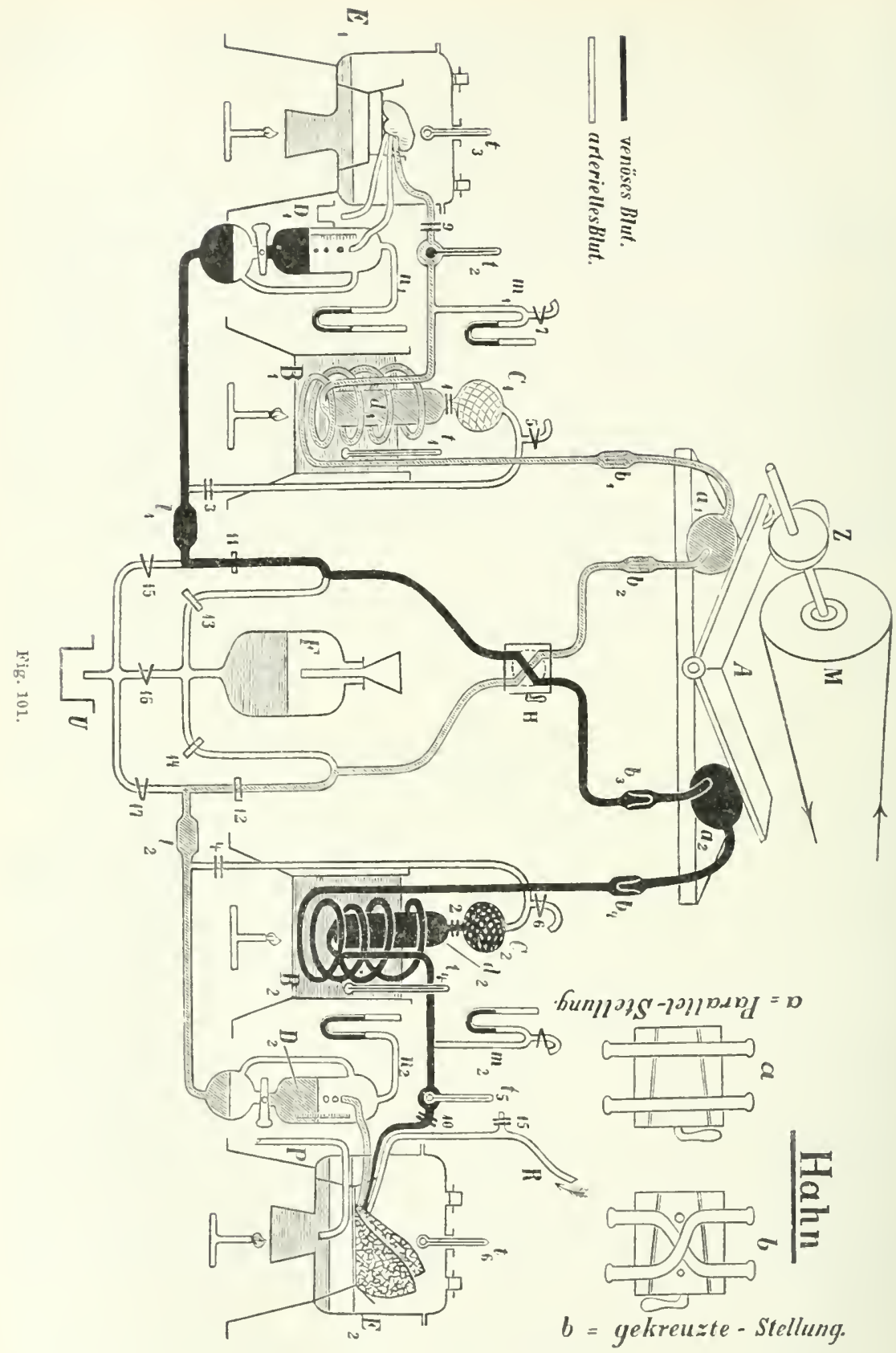

Winkel bildenden Ebene befinden sich zwei weitere Bohrungen, welche in einem leichten Bogen ancinander vorbeigehend sich derart iberkreuzen, 
dall bei Einstellung ihrer vier Öfnumgen auf die des Nantels durch Drehung des Hahmes linken Abflußrohr. das des linken Zuflubrohess aber zum rechten Abfurrohre geleitet wird. sich also bei dieser Stellung die Ströme in Hahnkerne kreuzen, wie die Fig. 1016 veranschaulicht.

Bei der Jetzteren Stellung des Hahnes werden die beiden Hälften des Apparates demnach in der auf Fig. 101 angedenteten Weise miteinander so verbmuden, dali das Blut in einem großen Kreise sowohl dir Lunge als das Orgatl passiert.

Entsprechend den beiden Herzen in organismus des Warmblïters, welche den groljen und kleinen lireislauf mit blut versorgen, haben wir anch in dem Apparate (vol. Fig. 101) zwei mit den stromrichtenden Ventilen $b_{1}, b_{2}, b_{3}, b_{4}$ versehene' Her\%pumpen $a_{1}$ und $a_{2}$. Welche abwechsehd von der Wippe $A$ zusammengeprebt werden: die Wippe wird mittelst einer mit einem Votor verhumdenen Exzenterscheibe $Z$ auf- und niederhewegt.

Es entspricht $a_{1}$ dem linken, $a_{2}$ dem rechten Ilerzen (venös schwar\%, arteriell hell). Die Herzpumpen saugen das Blut durch die Tentile $b_{2}$ und $b_{3}$ an, un dassellse durch die Ventile $b_{1}$ und $b_{4}$ den in einem Gefuif mit Wasser von etwa $40^{\circ}$ befindlichen Wärmespiralen $B_{1}$ und $b_{2}$ zuzutreiben. Im Ende dieser Spiralen befinden sich die Blasenfänger $d_{1}$ and $d_{2}$, welche in dem Blut befindliche Luftblasen zuriekhalten und zu entfernen erlauben. Der von der Luft völlig befreite Blutstrom. dessen Iruck und Temperatur an den Manometern $m_{1}$ und $m_{2}$ und den Thermometern $t_{2}$ und $t_{5}$ abgelesen werden kann, tritt nun linker Hand in las zu durchströmende Organ, rechter Hand in die Lunge, beide Teile befinden sich in den Rezipienten $E_{1}$ und $E_{2}$ in einer auf Körpertemperatur erhaltenen, mit Wasserdampf gesättigten Atmosphäre auf entsprechenden tellerförmigen Unterlagen, in welchen sich das Blut bei eventuell eintretender Blutung der Organe sammelt, so dal es wieder in die Zirkulation zuriickgebracht werden kamn. Jus den Venen der Oroane tritt das Blut beiderseits in die Meßgefäße $D_{1}$ und $D_{2}$, Zylinder mit unterem weiten Hahn nnd lingelansatz, hei dem (b)er- und Unterteil noch eine seitliche Verbindung haben, so daf auch nach Verschlul des IIahnes keine Irruckänderung bei Füllung des Zylinders eintritt.

Diese Meligefäße können durch die alsbald eingehender zu schildernde .Zirkulationswage" ersetzt werden, welche die sie durchströmende Blutmenge unter völligem Abschluls der Luft fortlaufend genau zu registrieren erlaubt. Lus den Veliapparaten wird das Blut durch die den Nulldruck in den Venen konstant erhaltenden Ventile $l_{1}$ und $l_{2}{ }^{1}$ ) wieder ron den Herzen $a_{1}$ und $a_{2}$ abgesangt. In jedem stromkreis ist je eine Nebenschliefiung eingeschaltet, welche von den Luftfängern $d_{1}$ und $d_{2}$ abzweigend und vor den Ventilen $l_{1}$ und $l_{2}$ miindend, durch öffnen oder schließen

1) Vgl.: C. Jacolj, Über das Funktionsrermögen der künstlich durchbluteten Niere. Arch. f. exp. Path. u. Pharm. Bd. 29. S. 27 (1891). 


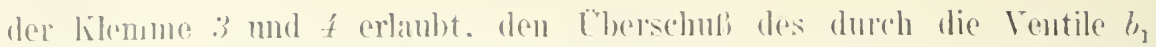

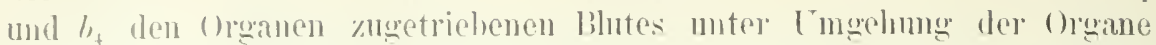

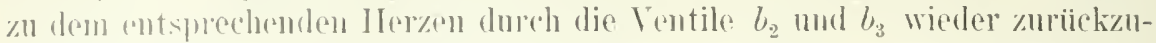

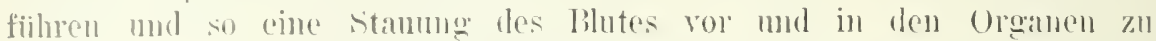

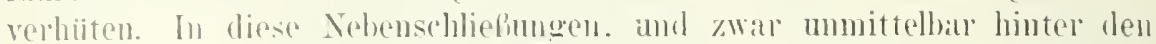
luftfïngen. sind zwoi elastische (immmiballons $C_{1}$ und $C_{2}$ mit nicht allzu dicker Wand eingesclaltet. I)ieselben haben in zusammengefallenem Zu-

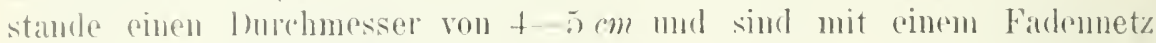
äherspannt. welehes sie bei ibermabiger siteigermug des blutdruckes ror

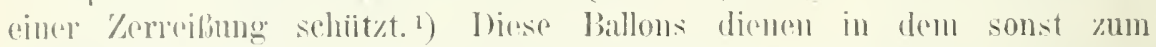
gröiliten 'Toile ans (ilasöhren bestehenden staren liohrsysteme als clastische Troik. entsmorchend der elastischen Wand des natiolichen Arteriensystems, aleichzeifig dienen sie aber anch als Reservoile, welehr ein zu plötzliches

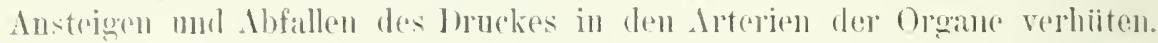

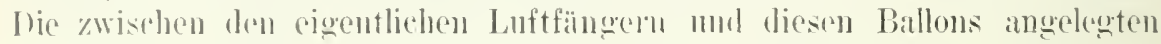
lỉemmen 1 mul : ermöglichen die elastische Wirkung des Ballons zu rognlieren un! durch öffnen und schlieben nach Beliehen einen hïrteren

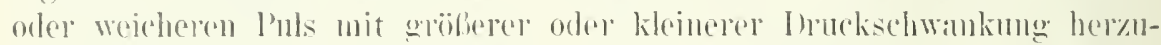
stellen. Da man aurh die bei der emzelnen Kompression ron den ller\%ballons atsoeworfonen bilutmengen durch das Versehioben der bibllons $a_{1}$ mud $a_{2}$ mnter dor Herswippe und ebenso den Blutdruek dureh die Menge des in das system ans dem Libservoir $F$ allgesaugten Blutes zu varieren verman. so ist man in der lage, jede beliebige drt des l'nlsos bei beliebigem liluthruck kiinstlich \%u ar\%engen.

\section{Fiillnllg des Appalutes.}

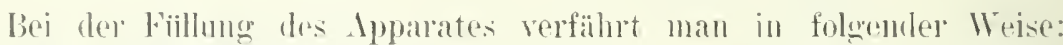
bie in don liezipienten $E_{1}$ und $E_{2}$ endenden. das Hhut den Oreanen

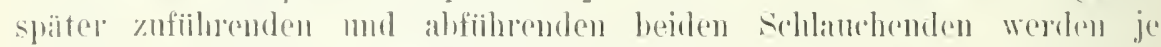

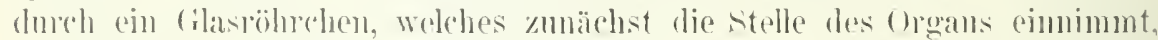
mitrimander vorhmolen, diurunf werden bei l'arallelstellumg des Hahnes $H$ (Fig. 101) die Kilommen 16; und 3-5, die Hähne an den Mrbagefïlen und

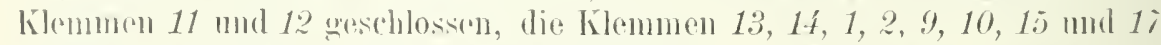

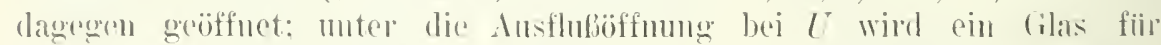
das dort austretendr Bhut gestallt. Die num in Bewegumg gresetzte Wippe a läbt dic ballons $a_{1}$ nnd $a_{2}$ ans dem Reservoir $F^{\prime}$ das Bhut

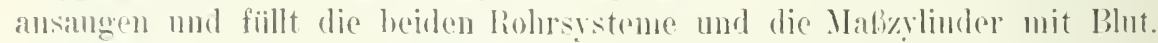

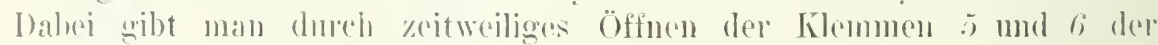

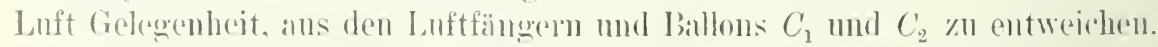

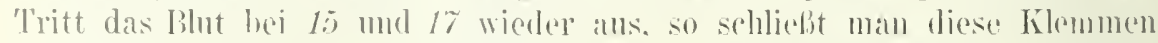

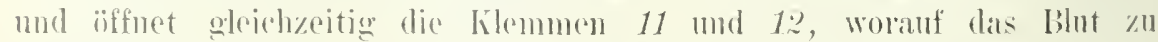

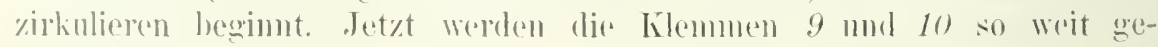

t) Man bringt diese Ballons zweckmäßig so an, daß sio senkrecht hängen. damit die sich in ihnen ansammelude Luft durch die Klemme 5 und 6 leicht antweichen und aus der Zirkulation entfernt werden kann. 
schlossen, dafi nus noch ein swhwacher Strom hindurchtritt, wobuj der Hruck an den Manometern $m_{1}$ und $m_{2}$ entsprechend der ans dem lieservoir $F$ angesaugten Butmenge strigt. Das in dem oberen 'Teil der Maligrefäße

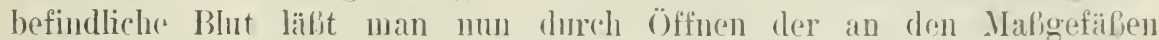
befindlichen Hähne in die kleinen unteren lieservoirc (eintreten, so dafj diese bei späteren Messungen, soforn nicht die Kirkulationswage eingeschaltet werlen soll, sich nie wanz entleeren kömnen.

lst der bruck an den Manometern $m_{1}$ und $m_{2}$ auf etwa 60 ( 80 mm gestiegen, so schlielit man 1.3 und 14 und lälit durch burzes öffnen der Klemmen $\sigma$ und 8 das Blut in die Manometer eintreten. Bei entsprechender Lagerung der Ballons $a_{1}$ und $a_{2}$ und ihrer Ventile grelingt es leicht, alle noch im Apparat befindliche Luft den Luftfängern $d_{2}$ und $d_{2}$ zuzutreiben, ron wo aus man sie durch die Ballons $C_{1}$ und $C_{2}$ ans den Krlemmen 5 und 6 entweichen lälit. Ist das ganze fohrsystem bis auf den in den Maßgefälen nötigen Luftraum in der beschriebenen Weise sologfältig ron Luft befreit, wobei der Druck wieler hcrabsinkt, so öffnet man zunächst die Klemme 1; wioler und lälit aus den lieservoir $F$ noch so riel Blut ansaugen, bis der Illuck am Nanometer $m_{1} 100-120 \mathrm{~mm}$ beträgt. daun schließt man dieselbe und läßt durch Öffnch von Kilemme $1 \dot{t}$ den Druck in der rechten Hälfte des Apparates so weit steigen. dab das Manometer ma 20-30 mm zeint. Del Ipparat. in dessen beiden Teilen das Blut cinstweilen noch getrennt und unter den angegebenen Druchverhältnissen zirkuliert, ist num zul dufualume der ()rame bereit.

Beim Einsetzen der Organe beginnt man mit der Lunge, in deren Arterie. Vene und Trachea vorher je eine Kanile gut eingebunden ist. Sie wird in den rechten Kreislauf. dessen Iruck. wie erwähnt, nicht iiber $30 \mathrm{~mm}$ betragen darf. eingeschaltet. $/ 11$ diesem $/$ weck schließt man zunächst die Klemme 10 und öffuet lilemme 4 so weit, daf das Blut durch die Nebenschliebung ungestïrt wierler zirkulieren kann. Das an Stelle des Organs interimistisch eingeschaltete liöhrchen wird sodann entfernt, und an die mit Blut gefüllte Arterienkaniile der Lunge der clas Blut zuführende Schlauch unter Vermeidung ron Lufteintritt angesetzt, die Klemme 10 langsam geöffnet, Klemme $\&$ dahingegen wieder ganz, K’lemme ¿ aber so weit geschlossen, daf das Manometer $m$, einen Ilruck ron $20 \mathrm{~mm}$ mit einer Pulsschwankung ron $10 \mathrm{~mm}$ Ho zeigit.

Es tritt nun das Blut in die Lunge ein und fuillt deren Gefälie. Sobald das Pilut ans der Venenkanile zu treten beginnt, wird diese mit dem zum Maligefäls fuilurenden schlauche verbunden, so daß das aus der Vene abfließende Blut vom Herzen $a_{2}$ wieler angesaugt werden hann. Da beim Fïllen der Gefïlie der Lunge der Blutdruck meist stark absinkt. so muf nun durch Öffnen ron Klemme 14 fuir Zufuhr nenen Blutes gresorot werden. doch ist stets darauf zu achten, dali der Blutdruck nicht uiber $30 \mathrm{~mm}$ steigt. da es sonst leicht zu Hämorrhagien in del Lunge kommt. Jetzt wird lic 'Trachealkaniile mit der für die kïnstliche Atmung bestimmten Vorrichtung durch das Rohr $R$ in Verbindung gesetzt. Man kann sich 
2u1 Herstellung der kïnstliehen Atmung der Lunge aines Müncheschen Trommelgehlïses hedienen. in dessen Luftstrom ein Mieschersher Item-

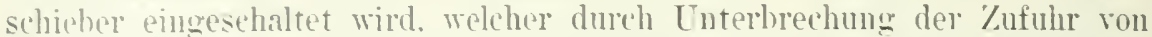
komprinierter Luft die Lunge in heliehigen Zeitintervallen ahwechselnd anfblist und ihr damn untel Entwoichen der luft durch die Klemme 15 wieder zusammenzufallen gestattet. Die Stïrke der Lufteintreibung wird in diesem Falle durch die an dem T-Rohr befindliche Klemme 15, wie bei der rewöhnlichen hinstlehen Atmung reguliert. und es ist zwechmärig, bei dieser Art der Itmung die Lunge zwar ergiebig. aber loch nicht ad maximum aufzublasen und die exspiratorischen Pansen so einzurichten. dab lie Lunge Zeit hat, wioler so weit zusammenzufallen, dab einerseits ein eroiehiger Luftwechsel. andrerseits aber keine I'berdehnung derselben stattindet. Während der Itmung nimmt bei ihrer Entfaltung die Lumge meist weiturs Blut auf. so dab eine nene Zufuhr aus dem Reserroir nötig wird.

In Stelle dieser die Lmoen leicht etwas schädigenden Lufteinblasung kann man eine der natürlichen Itmung ỉhnliche Ventilierung der Lunge

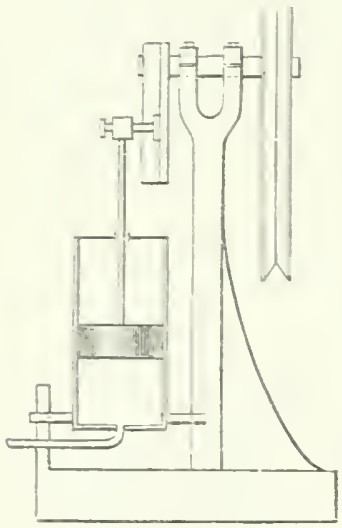

l.ig. 102 treten lassen. bei welcher die Luft wie im Brustraume des lehenden Tieres unter newativem Druck einströmt. wenm man folgentermaien rerfïhrt: Jan bringt die Inuge in eine Schale, wie sie Fig. $10 t E_{2}$ zoigt. deren anfoeschliffener Dechel einen luftdiehten Verschlub erlaubt, und hei welcher die das Blut führenden Laitungsröhren ehenso wie das die Trachealhaniile mit der äuleren Luft rerbindende und endlich das in das Wisser der schale eintauchente woite Rohr $P$ luftdicht eingesetzt sind.

Man rerhindet dann dieses letztgenannte Roln $P$ mit einel rentillosen Pumpe (Fig. 102), welche hei der Anf- und Nielerbewegung ilnes stempels abwehselnd Wasser ans der schale ansaugt und wielel in dieselhe zurichtreibt. Beim Ansaugen les Wassers wird ein negativer Druck in der schale entstehen, weleher zur Folge hat, dab durch das mit der "Trachea rerbundene Rohr von aufen Luft in die Lunge einströmt unt dieselbe entfaltet. Wird dann nach dieser Inspiration das Wasser wieler in die Schale zurtickgetrieben. so wird dmch die nun in derselben eintretente Terminderung des negativen Inuckes die Luft aus der Imnge rerdringt und unter Kollabieren der Lunge wird es zu einer Exspiration derselben homment.

I le Pumpe ham man ron dem gleichen Jotor treiben lassen. weleher dir Herzwippe bewert. Ist iln stempel mit der seme Auf- und Niederbewoung bewirkenden Exzenterscheibe so rerbunden. dab seine Exkursion variert werden kamn. so ist man atuh in der Lage. die Gröfe der Atem-

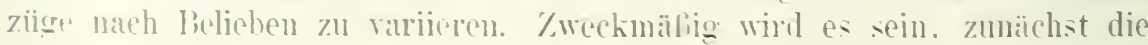


Lunge sich etwas cutfalten zu lassen. inlem man bei geschlossener Schale eine entsprechende Menge Wasser abfliefen läl't und rlann erst die die Atemschwankungen erzeugende Pumpe ansctzt. Yan kann selbstrerständlich eine solche l'umpe auch \%ur Atmung mittelst (infacher Eimblasung henutzen, wenn man sie mit den entsprerhenden Ventilen versieht.

Ist die Lungenzirkulation instand resetyt. so wird in das linke sistem in gleicher Weise das betreffende organ eingeschaltet. Sobald anch hier die Zirkulation hergestellt und der Blutdruck auf $100-120 \mathrm{~mm}$ gebracht ist, wird der Hahn $H$ mm $90^{\circ}$ gedreht, was durch eine am Hahngriff angehrachte sperrorrichtung ohne schwierigkeit zu erzielen ist. Hierdurch werden die beilen Systeme in der oben beschriebenen Weise derart rerbunden. daß das aus der Vene des Organs austretende dunkel renöse Blut ron der Herzpunpe $a_{2}$ der Lunge, das aus der Lungenrene fließende, schön hellrote arterialisierte Blut ron der Herzpumpe $a_{1}$ angesaugt dem (1)gane wieder zugeführt wird, wie dies auf Fig. 101 durch die Schraffierung angedentet ist. Fs hleibt nun nur noch die Regulierung der Pulse und des Blutdrucks übrig durch Öfnen oder schliefien der Klemmen 1, 2, 3, f. Wenn nicht Blutrerluste eintreten. zirkuliert die eingebrachte Blutmenge stundenlang durch beide Organe. indem die dunkel auf der Zeichnung gehaltenen Teile mit renösen, die heller schraffierten mit schön arteriellisiertem Blute gefüllt sind. Es hann ein geringes Absinken des Blutdruckes anch eintreten, wenn es sich mm Durchblutung einer Viere handelt, sofern aus den stets mit Kanuilen zu versehenden Creteren gröbere Flïsigkeitsmengen austreten. auch durch die Atmung scheint das Blut etwas Wasser zu rerlieren, wodurch ebenfalls ein Sinken des Blutdruckes eintreten kann. Alle diese Verluste hönnen ohne Störung dadurch ergänzt werden. dal man durch öfnen der klemme 1:3 aus dem Reservoir $F$ entsprechende Blutmengen in den Lungenkreislauf ansaugen läft. In dieses Reservoir kann auch das durch Blutung aus den troanen verloren gegangene und auf Interlagen aufgefangene Blut wieder zurïckgebracht werden. Sollen Lösungen dem Blute zugesetzt werden. so injiziert man dieselben am besten mit einer Injektionsspritze ron Klemme 1.5 aus in das zirkulierende Blut.

Soll der Apparat nach beendetem Versuche und behufs Lntersuchung des Blutes entleert werden. so werden. nachdem der Hahn $H$ wierler in die Parallelstellung (Fig. 101a) grobracht ist. zunächst nach sihliefen der Kilemmen 9 und 10 an stelle der Organe wieder die schaltröhrchen eingesetzt. Yan öffnet dam die Klemmen 9. 10, 15. 1\%, 13 und 1t sorie die Hähne an den Yaßgefäßen $D_{1}$ und $D_{2}$ und schlielit Klemme 11 und 12. Unter den Abfluf $L$ wird das für die Aufnahme des abfliefenden Blutes bestimmte Gefïl gesetzt. Es saugen nun die Herzpumpen zunächst den eventuell im Reservoir $F$ enthaltenen Rest des Blutes ${ }^{1}$ ) und dann Luft an

1) Soll derselbe hesonders ahgelassen werden. so geschieht dies rorher. indem bei VerschluB der Kilemmen $13,14,15,1$ i lilemme 16 geöffnet wird, worauf sich bej 1 * der Inhalt ron $F$ entleert. 


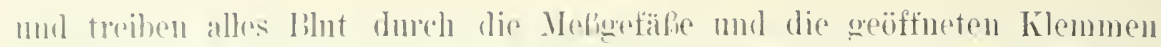

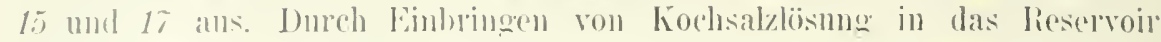
mul zoitwoiliges (offuen von 3 mol 4 sowic 11 und 12 lassen sich die

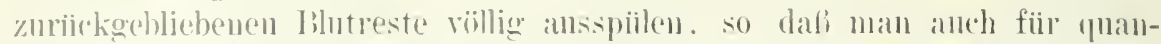

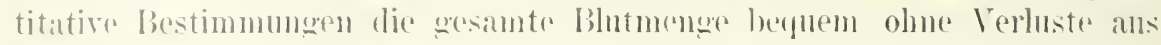
dom Apparate wieder gewinmen kimm.

Ist das lihut durch korhsalylösme auspespiilt. so kamm man dem

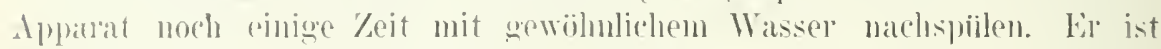

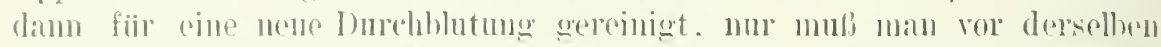

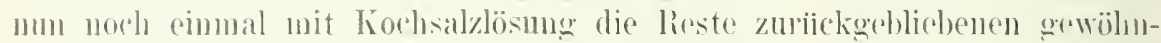

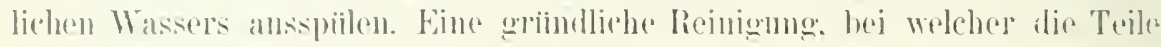

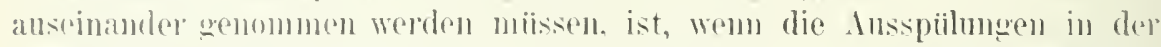

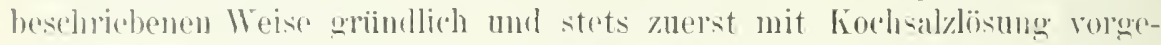

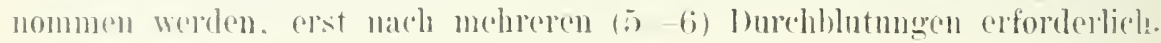

\section{l) Ze Zirkulationswage.}

Fs wird jede liorihlume des Blutes mit Inft. zumal bej der Messumu

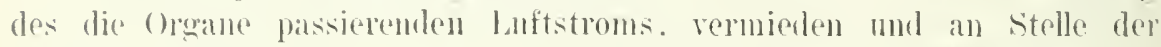

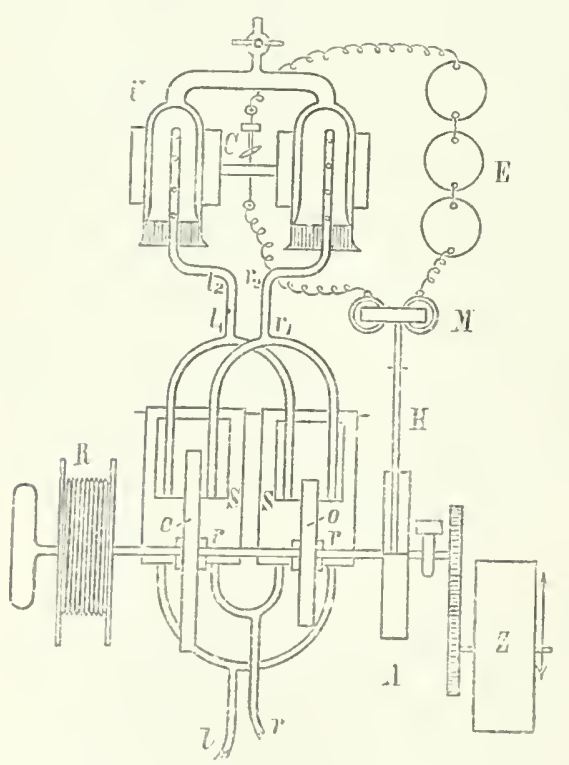

Fig. 103. bishrel angewandten Mefogefälie $I_{1}$ mud /), aine Vorrichtmug gesetzt, diu drall Blutstrom nuter vïlligem Abschlub der Luft kontinuierlial zu messen und zu louistrieren gestattrot.

her Ipparat, wie ihn Fin. 10:) voll olven geschen reranschaulicht, bestuht ass e Hauptteileu, welche in Fig. 104 mol 106 antrennt shomattisch in Seitenansioht wielerogereben sind. Iten ainen 'Teil bildet rin Strommender mit einer moppelklemme (Fig. 104). welehe vier mebencinamder lanfende Gummisobläuche patrweise abwechsohd dureh liompression \%u verschliefiem und zu iffunem crlanlit. Hieve schlänche sind in der anf Fig. 105 veranschanlichten Weise so miteinander verbunden. daf bej lessohlub des Tatares I Zuleitungsohr $r$ und $r_{1}$

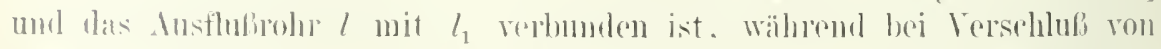
Patu // $r$ mif $l_{1}$ mol $/$ mit $r_{1}$, also beide iiber Kenz verbumlen sind.

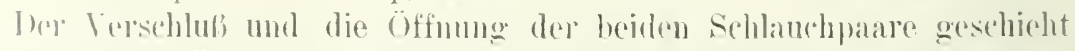
durch dis zwei anf Fig. 104 sichtbaren, in ilnen freien Enden mit alyermuletru

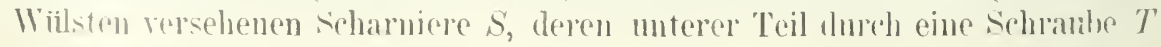


in beliebiger stellung fixierbar, deren (Bherteil je mit einer Rolle $r$ versehen ist. üher welche die heiden. an einer gemeinsamen Achse befestigten ovalen Scheiben $O O$ lanfen, so dalf sir die hewerglichen sohenkel der Scharniere alwechselnd niederdriicken und wieder durch die likstizität der zwischen

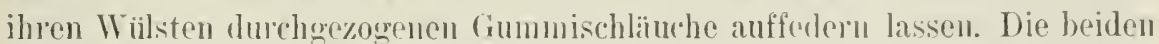
ovalen Scheiben sind an der gemeinselaftlichen Adher so bofestigrt. dal die langen dehsen der (Vale senkereht \%urinander stehen mol also jedesmal, wenu das eine (Nal mit dor zugehörigen Scharnierklemme das eine Schlauchpaar durch liompression rerschlielit, das andere () val dem zol ihm gehörigen Scharnier erlaubt, sich zu hehen, so dal' das betreffende schlauchpaar dadurch für den Strom durehgïngig wird.

An der glcichen Adhse wie die ovale ist eine mit vier /ahneinschnitten versehene runde scheibe $A$ (lig. 104) so befestigt. dal die vier Einschnitte

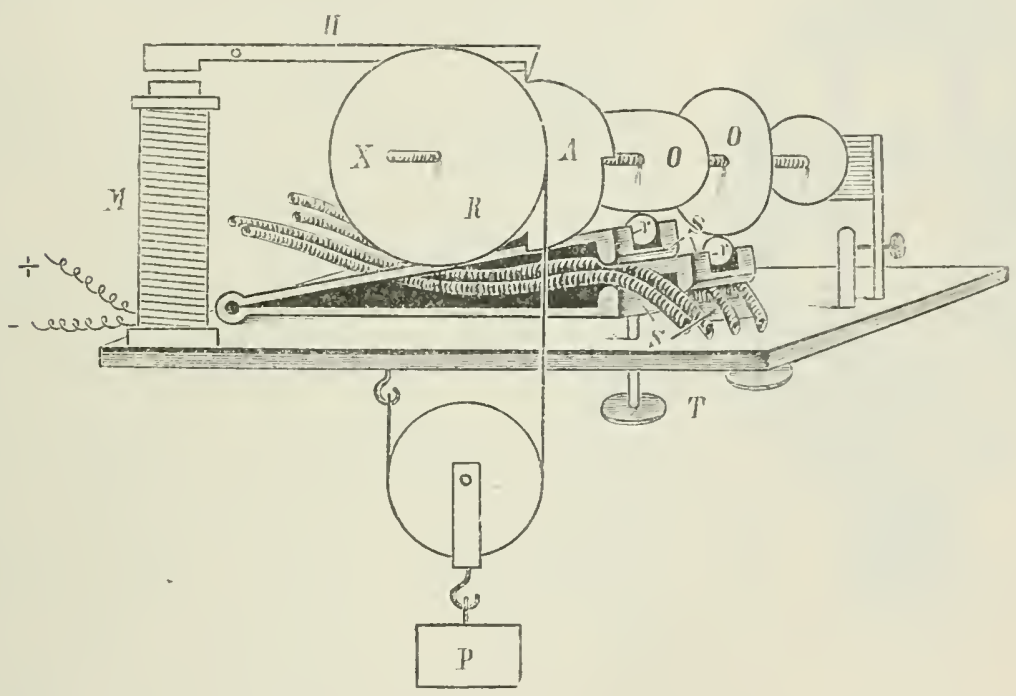

Fig. 104 .

den vier Enden der beiden langen Achsen der Ovale, d. h. den stellungen entsprechen, bei welchen je ein Schlanchpaar ad maximum geöffnet. das andere geschlossen ist. C'ber djeser letzten Scheibe scllleift ein Sperrhaken $H$, welcher an dem Anker eines Elcktromagneten $M$ befestigt ist so daß. sobald der Magnet den Anker anzicht, der Sperrhaken aus dem Einschnitt der Scheibe gehohen wird mud sich die Achse durch den Zug eines Gewichts $P$, das anf die an ihr hefestigten Rolle $R$ einwirkt, zu drehen begimnt und erst zum Stehen kommut, wenn der Sperrhaken $H$ wieder in einen Einschnitt des Arretierungsrades $A$ einfällt.

Da bei jeder Irehung der Iclse um $90^{\circ}$ die Verbindung der beiden Röhrenpare $r l$ und $r_{1} l_{1}$ derart geändert wird, daß eimmal die gleichseitigen Röhren $r$ und $r_{1}, l$ mo $l_{1}$ parallel, damn wieder die moleichseitigen 
$r$ mul $l_{1}$ mud / mul $r_{1}$ ïberkienz verbundon werlen. so bietet rliese Volrohtung (ielegenheit, hei 'mluitung eines konstanten Fliissigkeitsstromes von zwei getrenuten lieservonen abwechselnd gleichzeitig das eine zu fïllen, das mulere zu entleeron. Wenn jedesmal in dem Moment, in dem das cino lieservoir sich gefüllt und das andere sich gleichzeitig entleert

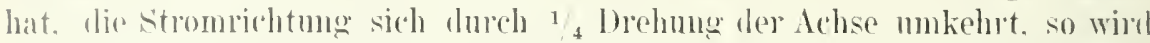
der 'muflub mit drom leeren. der Abflub aber mit dem vollen lieservoir verbunden.

Dies zu erreichen. dient dex zweite. anf Fin. 106 wiedergegehene 'Teil les Ipparats. Welcher ans einer $U$-fömogen blasöhre $U$ hesteht, die mit

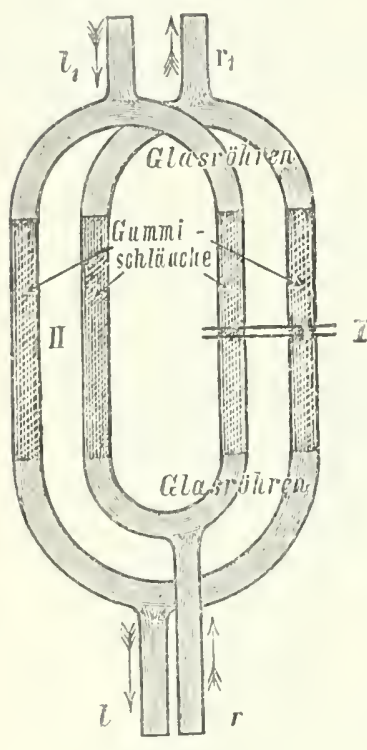

Fig. 105 , ihren beiden parallelen schenkeln auf den viereckigen Schalen einer kleinen Inilikenwage $W^{r}$ rubt. Die Ränder der schalen sind rechtwinklig in die Höhe gehogen und stellen olen in scharte Kante anslaufend je zuei seluneidreare dar anf denen sich dio Rioblera bei der Anf- und Niederberegung der daboi ihre horizontale Stellung beibehaltenden Wassohalen ohne Riejhmug abzurollen vernögent.

Dic U-Röhre von etwal : $4 \mathrm{~mm}$ I)mehmesser ist an iluen heiden Enden durch je einen Gummikorken geshlossen. welcher in der Mifte eine liöhre durchtreten läbt, die im lumern des Rohnes einen nit melneren Seitruöffungen vorsehenen Sehlanch vou etwa $10 \mathrm{~cm}$ hänge trägt. ber diese beiden schlänche ist beiderseits ein am Cimmmikork fost anliegender länglicher Beutel aus ganz dimnem, woilhem (iummi ge\%ogen, weleher nach dem Ëinsetzen der Korke in das Rohr die durch den surchloehten sehlauch rintrotende Fliissigkrit immorhalb des U-liohres abspert, sich abor entsprechend dem /an-oder Abflub von Flisssigkrit ohne indend anen nennenswelten Widerstand zu bioten, entfalten mul zusammenlogen kann. Iner zwischen den beiden ballons liogronde liamm läbt sich num von einem an der Vittr der Krimmmun des U-liohres gelegenen und mit pinem kleinem Hahn versehenen Ansatzröhrohen ans mit cinm kalt gesättignten Chlorcalciumlösmng fiillen. Wind diese Fiillung des lỏohres

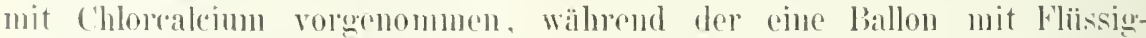

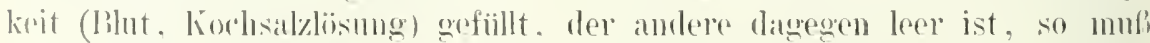
mun zunächst beim Anflegen des U-liohres anf die Wage die mit dom fas Chloraloim enthaltenden schenkel helastete Wawschale infolge des

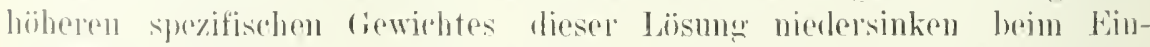
trriben von fliissigheit in den bisher leeren ballon mud bei dessen Entfaltmog winl dis (hlorealcimmlösung in den anderen schenkel der U-Röhre

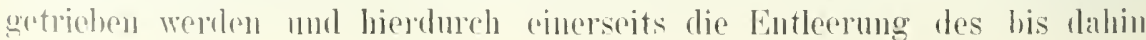


gefüllten Ballons herbeiführen, andrerseits aber nun anch infolge ihres höheren spezifischen Gewichtes die andere Wagschale zum sinken bringen.

I) ie beiden aus jenen Gummiballons durch die beiden Korke austretenden liöhren $r_{2}$ und $l_{2}$ (Fig. 106), welche zunächst in horizontaler Ebene nach innen rechtwinkelig gebogen sind, dann aber nach beilerseitiger abermaliger rechtwinkliger Biegung hart nebeneinander parallel mol horizontal verlaufen, sind mit den beiden in gleicher horizontaler Ehene sich befindenden Röhren $r_{1}$ und $l_{1}$ des den Strom wendenden liompressoriums (Fig. 105) durch zwei etwa $20 \mathrm{~cm}$ lange Gummischläuche beweglich verbunden.

Fließst z. B. bei Kompression des Schlauchpaares $l$ (Fig. 105) durch die Röhren $r, r_{1} . r_{2}$ das Blut zum rechten (iummiballon des U-Rohres, so wird es lierbei die Chlorcalcimmlösung in den linken Schenkel des U-Rohres hinäbertreiben, und es muls entsprechend dem Zuflul auf dieser Seite gleichzeitig zu einem Abflub der Fluissigkeit aus dem linken Gummibentel durch die Röhren $l_{2}, l_{1}, \quad l$ kommen. Bei dieser Entleerung des Ballons auf der linken Seite und bei dem damit verbundenen Übertritt der Chlorcalciumlösung in diesen Schenkel des U-Rohres nimmt aber entsprechend der Differenz der spezifischen Gewichte des Blutes und jener gesïttigten Chlorcalciumlösung

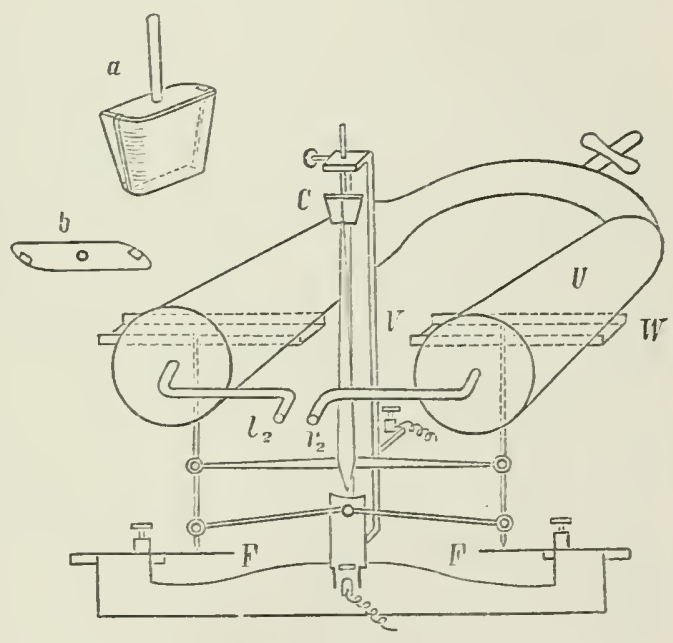

Fig. 106. das Gewicht auf dieser Seite zu, auf jener sich mit Blut füllenden ab, es wird also entsprechend der Entleerung des linken Ballons die Schale dieser Seite niedersinken und die Zunge der Wage einen Ausschlag nach links bekommen. Es befindet sich in der Ebene, in welcher sich das obere Ende der aus einem feinen federnden Stahlstreifen hergestellten Wagezunge soust frei hin- und herbewegt, eine nach unten keilförmig zulaufende, etra $1-1.5 \mathrm{~mm}$ dicke Hartgummiplatte, wie sie Fig. 106 a schräg von vorn, Fig. $106 b$ von oben zeigt. An ihrer seitlichen, in der aus Fig. 106 a ersichtlichen abgerundeten Kante sind in der Rundung beiderseits Platinstreifen, einen Teil der glatten Rundung bildend, eingelassen. Diese etwa $05 \mathrm{~mm}$ breiten Streifen stehen in leitender Verbindung mit dem in der Mitte der Platte befindlichen Messingstifte, der seinerseits bestimmt ist, die Platte mittelst einer Schraube in entsprechender Stellung an der kleinen Messingsäule $V^{\prime}$ (Fig. 106) zu fixieren. 
biese Platte wird zur eigentlichen Schwingmogsebene der Wagenzinge

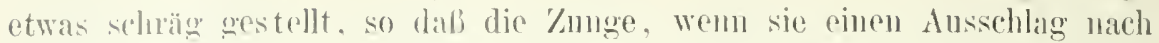
jenel seite macht, auf woleher die l'hatte ihre schwimgmesebene schmedet, gezwmmen wird, an der Ilatemmmiplatte ferlernd entlang zu gleiten, wobei sie ans ihrer eigrufliehen Palun goodrängt wird. Sobald sie aher mit ihrer Spitze das Ende der l'atte erredeht hat, gleitet sie iiber die ahgerundete Ebeno in ihre urspringliche Schwingungsehene, also anf die anderes seite der Platte ab mol streift dabei ibler den dort angebrachten latinstreifen. Verhindet man die Wage mit der an ilu leitend befestigten

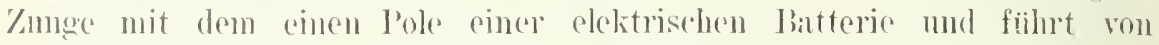
dem anderen l'ole dieser batterie die Leitung dureh den Elektromaneten des stromwenders zu dem isolierten, die Richtungsplatte tragenden Metall-

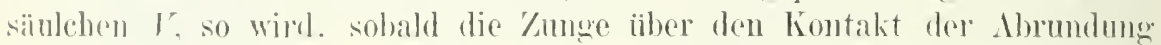
der Hartgummiplate abgleitet, fiir einen Moment der Strombreis areschlosson soin und es genïgt dies, nm ron dem Elektromagneten durch das Amzichen seines Inkrus den Sperohaken $H$ auslösen zu lassen, so dath die die ovalun seheiben $O$ tragende Achse durch das Gewicht in bewegung versetzt wird. biese bewegmng wird aber sehom nach ener

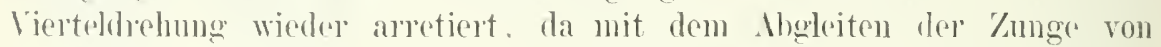
der Hartgummiplatte der Strom anch sogleich wieder geöfnet wird, so din der Magnet den Inker frei gribt und der sperrhaken durch rine Feder in don nächsten Einschnitt des sperrades rinfïllt. Da durch die

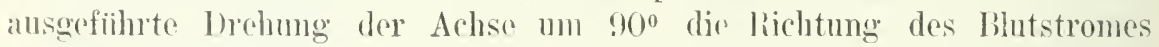
mogeledut worden ist, so wird es jetzt zur Fiillumg des aben entleerten biallons und zu ciner Austreibung dos lnhaltes des vorher gefïllten Ballous kommen, bis infolgo des hierdureh wieder nach dor anderen seite hin Whegtru Therowichts jene Wagsehale sowroit hinalogesunken ist, dab die Wagenzunge mun auf der anderen Seite der Kontaktplatte aligleitend von neuem die I'mschaltumg des Stromes durch Auslösumg riner weiterou Viertedichung bewirkt.

lis ist klar, dal bei der Wage, wio diesollse bisher beschriehen wurde, der die Sitrommmschaltumg bedingende Kontakt jedesmal zustande kommen wind, sobald dio Gewiohtsdifferenz auf beiden Sciten genügt, um die verschiedrnen, durch die Anordnung des Apparates bedingten konstanten Wirlestände. wie die Reibung der Wagenzunge durch den liontalit, den 'Porsionswiderstand der das U-liohr mit dem Lompressorim verbindenden sehlïuchr usw., zu ïberwinden.

Da 1 m diese Widerstände verhältnismäBig klein sind. so wiorle die C'midaltung jedesmal schon durch den Eintritt geringerer Flïssigkeitsmengen eintreten, als fiir deu Zweck ciner längeren strommessung erwiunscht ist, wo die einzelno [msehaltung am besten nach einem Volnmenwechsel von $5\left(1 \mathrm{~m}^{3}\right.$ erfolgt, anferlem aber gleitet die Zunge, wem sie die Kante iiberschriten und der durch ihre federwirkmog gesetzte Widerstand damit plitzlich nachliabt, loicht zu schmell ab, um einen fïr die Auslösmog des Sperrhakens geniigenden Stromschlub herzustellen. I'm diesen Thelständen ab- 
zuhalfen. Wurden unter den Wagschalen die beiden Federn $F$ (Fiğ. 1065) angebracht. anf welche der Fiihrmugsitab der Wagsehalen heim Viedersinken stöbt. Diese Federn bilden eincu weiteren Wirlerstand. dor jo nach der Stärke der henutzten Federn und nach der variierbaren Länge derselben beliebig repröbert onder veringert werden kann. Hirdurch wird es möglich. dir Wage so pin\%nstellen. dab die Umschaltung des Stromes jedesmal bei einer ganz hestimmten Venge des eingeflossenen Bhutes eintritt, und damit ist die Miiglichkeit einer Messung getraben.

La die Zahl der ansgeführten [mdrehungen dor die oralen scheiben tragenden lchse durch Thertragung auf ein \%eigerwerk dort ahofesen werden kann. so ist ohne Sichwierigkeit die Menge des durch den Apparat geflossenen Blutes am schlusse eines Versuches zu bestimmon. Yan brancht un dic Zahl der ausgefiihrten Vierteldrehmgen mit der jeder Tmschaltung entsprechenden Blutmenge \%u multiplizieren. Es erlaubt aber die Inorduung auch, die Stromgeschwindigkeit graphisch darzustellen und ihre Verindermugen hierdurch genau zu kontrollieren. Zu diesem Zwecke schaltet man in den Stromkieis. wacher den Elektromagneten rersorgt, norh ein elehtrisches signal ein. dessen Feder die jedesmaligen Unschaltungen nehen einer die Zeit markinenden Schreibrorrichtung anf den laufenden Papierstreifen eines Ludwigschen Krmographion markiert. I)a sich fermer an dem gleichen Krmographion die Blutdruck- und P'ulskurve nittclst eines Manometers auftragen libit, so ist Gelegenheit grehoten, bei der künstlichen Durchblutung die Abhängigkeit der Stromgeschwindigkeit ron dem Blutdruck und der Art der ['ulsschwankmingen in objektiver Weise rlarzustellen. Da die Zirkulationswage dem Strome keinerlei Widerstand bietet, und da die Pulsschwankung und der Druck sich durch dieselbe fortzusetzen vermögen, so wird durch den Apparat an sich der Strom nicht wesentlich rerändert werden. und es können vielleicht gröbere Schwankungen in der Nenge des durchfliefenden Blutrs anf diese Weise nachgewiesen werden.

\section{b) Durchblutungsapparat ron Brodic. ${ }^{1}$ )}

Dieser Apparat ist sehr riel einfacher und billiger als der Jacobjsche, besitzt aber trotzdem, soweit mir hekannt, riele der lorzüge. allerdings mit Ausnahme der weniger ausgiebigen Arterialisierung. Dieser Utbelstand tritt störend bei Durchblutung ron Extremitäten hervor. während für die Niere, den Darm, die Leher usw. die Sauerstoffrer'sorgung rollkommen ansreicht. Die Druckregulierung. die Temperaturkonstanz des einströmenden Blutes, die Mïglichkeit der Messung der stromgeschwindigkeit ist jedoch in rollhommenster Weise erreichbar. Seine Grenzeu findet der Apparat weniger in Yängeln der Konstruktion. als in der eben bei Durchblutung mit defibriniertem Blut oder Salzlösung nach einigen Stunden stets auftretenden Gefäßschädigung. Iler Apparat (skizze Fị. 107) besteht aus

1) T. G. Brodie, The perfusion of surriring organs. Journ. of Physiol. Vol. 29. p. 267 (1903). 
einem Blutreservoir A von etwa $.500 \mathrm{~cm}^{3}$ Fassungspaum, in welches der den Druck liefornde Sauerstoff aus einer Bombe nnten einströmt. Das Gas passiert dann eine Schämmungsvorlage ( $W$, Fig. 108) und durch eine T-Leitung. deren Höhe verstellbar, ein Maximumventil $X$ in fiestalt eines mit quecksilber gefïllten schmalen Zylinders, an das sich ein Manometer anschließt. I)as Blutresuroir steht in cinem auf konstanter Temperatur gehaltenen Wälmekasten: eine möglichst kurze Leitung (:-4 $\mathrm{mm}$ weit) fiihrt zu der Arterie des ()rgans. In sie ist (in Fig. 107 weggelassen, in Fig. 108 vorhanden) ein T-liohr $R$ eingeschaltet, das mit Quetschhähnen abschließbar direkt unter Lingehung des (Howns zur venösen Leitung führt. Auferdem befindet sich ror del Arterie ein etwa $6 \mathrm{~cm}$ langes mol $1 \mathrm{~cm}$ weites Rohr $T$ mit Glaswolle zum dbfangen der Gerinnsel und eine kleine, birnförmige Fr-

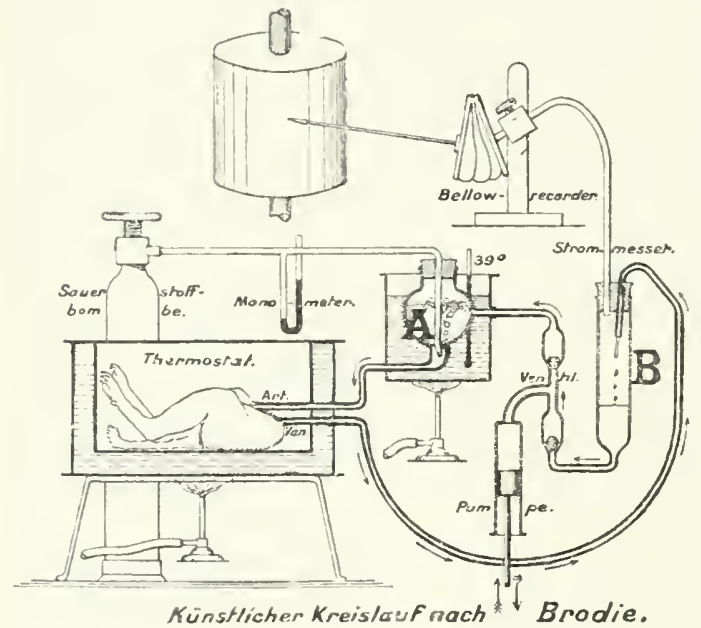

Fig. 107 weiterma $U$ mit seitlicher Öfunng zum Alsfangen und Entleeren der Luftblasen, beide kurz bevor das Blut in das Organ eintritt. Lio zufiihrende Bahn $S$ kann an verschiedenen Stellen durch Quctschhähne abgeschlossen werden. Aus der Vene strömt das Blut in einer Glasleitung zu einem Zylinder (B. Fig. 107. resp. X. Fig. 108) ron etwa $10 \mathrm{~cm}$ Höhe und $2 \mathrm{~cm}$ Weite. der oben luftdicht durch einen dreifach durchbohrten Gummistopfen verschlossen ist reine öffnung fehlt in der rigur 108). Wurch die cine bohrung führt das soeben genannte, das venöse Blut zufïhrende fiohr Q. lurch die zweite ein kurzes Rohr, das durch einen Gummischlauch mit dem T-Rohr $R$ und der Zuflukleitung $S$ in Verbindung steht. Durch di dritte Öffnung geht ein Gasrohr $O$, das zu einem zuvol geeichten Rekorder

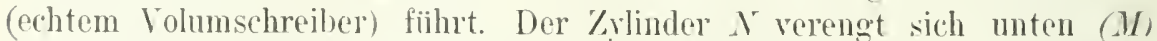
nnd mündet in die eine Hälfte eines Ventilapparates ein. Dieser besteht aus einem kurzen T-Rohr, an das sich jellerseits ein etwas weiteres liohr (5-7 mm weit. 2- $3 \mathrm{~cm}^{-}$lang*) anschließt, das auf der einen Seite konisch zugeht. In die konische Öffnung paßt ein konisch zugeschliffenes Glasstiickchen. Die Ventile miissen so gearbeitet sein. laß sie auferordentlich leicht gehen und auch ohne Flüssigkeit fast vollkommen luftdicht, mit Fliissigkeit absolut wasserdicht schlicßen. Das T-Rohr des Ventils ( $H$ in Fig. 108) steht mit einer kleinen Pumpenvorrichtung in Verbindung, etwa einer $10 \mathrm{~cm}^{3}$ fassenden spritze $(G)$, die behufs Heinigung vollkommen aus(inander zu nehmen ist, und in der sich ein (am besten Metall in Metall 
oder auch (ilas in Glas gehender) auch ohne Dichtung mit Vaseline luftelicht schließender Stempel auf- mol abbewegt. Die Kolbenstange des Stempels trägt einen Kopf $F$, welcher durch zwei seitliche Verschraubungen in einer hall)kreisförmigen Metallspange D) hefestigt wird. Diese Spange wird durch eine Stange $C$, lie an einer etwa $10 \mathrm{~cm}$ lingen, um eine horizontale Achse drehbaren Spindel sityt und ihrerseits von dem Exzenter eines Elektro-

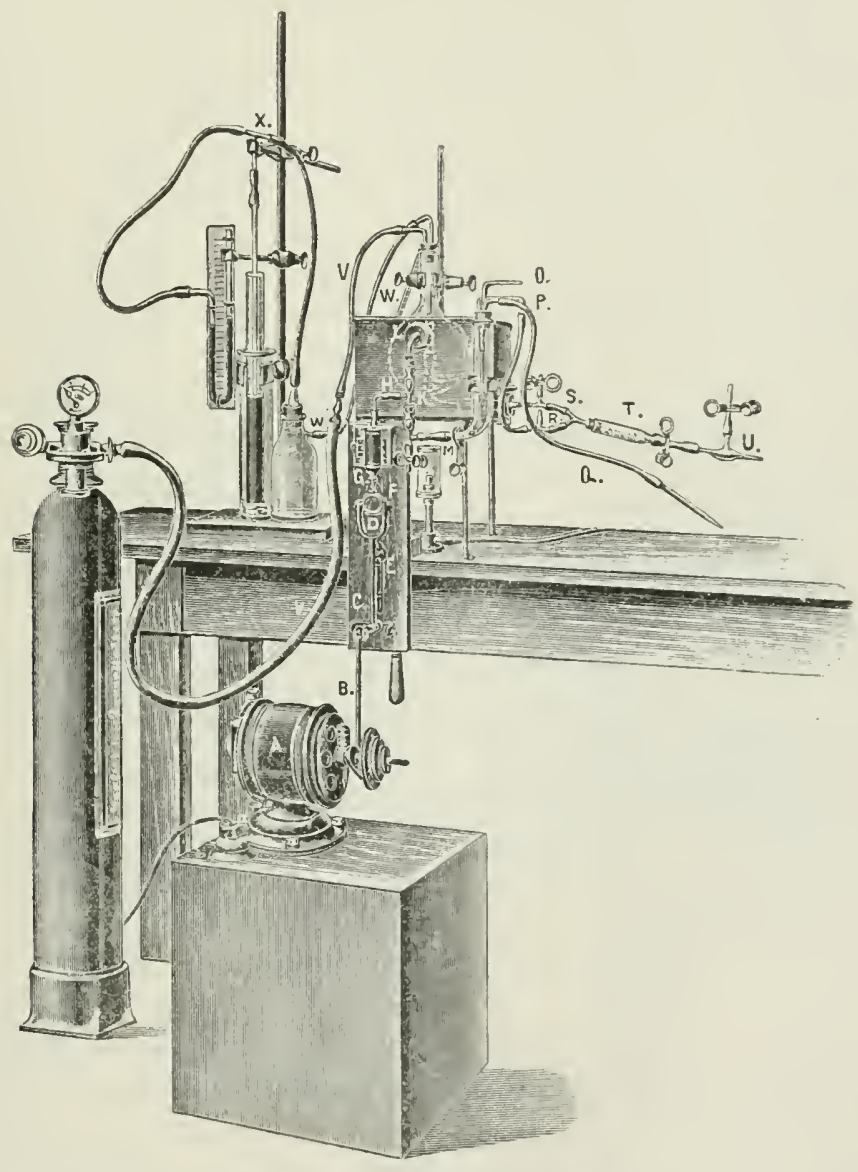

Fig. 10 .

motors $A$ und Stange $B$ bewegt wird, in rertikaler Richtung auf- und abbewegt (s. Fig. 108).

Die Spritze wird durch zwei Metallspangen $G$ auf einem Holzklotz festgehalten, der an dem Tischrand in vertikaler Richtmig verschieden hoch angeschraubt worden kam (E). Grobe Verschiebungen des Pumpenhubes erzielt man durch Versetzen dieses Laufbrettes, die feineren durch Schrauben an 
der schrambe der sjoindel $C$. die sich unter der vertikalen Drehachse leicht zugänglich befindet. Es ist ein ganz besonderer Vor\%ng des . Ipparates, dali man das spiel dep Pumpe und danit die Inurehhutme mit Hilfe diesel Viknometerpindel sehr fein regulieren kann, ohne dab dabei die burchblutung nuterbrochen zu werden brancht. Die Pumpe treibt das Blut in der in der skizge (Fig. 107) dureh Pfeile angedenteten Richtung dured das eine Ventil heraus nach $A$ zurïck und erhöht den Druck in A periodisch. so dab das Bhlut stobweise ansfliefit. Je nachden die P'mme den Zylinder $B$ schneller cntleert als Blut von oben in ilun himeintroptt, wird der luftranm ïher dem Iblut in $B$ wachsen oder abnehmen. Dementsprechend \%eigt der liekorder. der mit dem Luftraun ron $B$ luftdicht verbunden ist (O) in Fig. 108), einen Anstieg bei stärlierer Blutzufuhr als Abful der Pumpe. einen Fall bei schwicherem Zutropfen mol relatir stärkermu Arbeiten der P'unpe. Das (Organ selbst befindet sich in einem anf konstanter Temperatur gehaltenen Wärmekasten. Man hraucht bei den heschriebenen Dimensionen und möglichst ku1\% gehaltenen Leitungen aus Glas mit Gummi-\%wischenstïcken etwa :30- $35 \mathrm{rm}^{3}$ Bhnt für Durchströmung der hinteren lixtremitäten oder der Niere von Kaninchen oder Katze bei einem Inruck ron otwa so $\mathrm{mm} \mathrm{Hg}$. fiir die Lunge und den I)arm etwa ebensoviel bei einem Iruck ron :30 mm Hg. fiir die Leber etwas mehr. Da man von einer Katze brquem $60-80 \mathrm{~cm}^{3}$ lilut bei einem Körpergewicht von 1\%) kg gewinnt. so kann man mit dieser Menge, die man aber noch ein wenig durch Kochsalzłösung erhöhen kann, auf das beruemste auskommen.

Will man die Stromgeschwindigkeit messen, so eicht man den lickorder zmächst in der Art. dal' man auf der 'Trommel des Kimographions

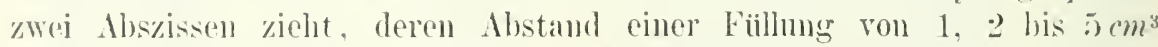
Luft in dem liekorder entspricht. LäBt man dam wïhrend der Dourchblutmg das Kymographion lanfen und verzeichnet das Zuflioben des Blutes in den ' $/$ ylinder $B$ bei bestinmtem, koustant gehaltenen l'umpenhub oder bei Stillstand del' P'umpe unter gleichzeitiger legistriermug der Zeit, so beschreibt der Iiekorter, wem die l'mmpe angehalten war. eine je nach der sichnelligkeit der Imolrehming der Trommel und des Einlaufs des Blutes verschichen steil ansteigenle gerade Linie, oder wenn die P'mue arbeitete, cine ansteigende, mit Pulsen versehene Linie. Lälit man sie die zuvor gezogenen Abzissen schneiden, so weif man, nuter lenutznng der Zeitmarken. in welcher Zeit die dureh die Absissenentfernumg gegebene Blutmenge aus (lem ()rgan bei dem herrschenden Drulek ankgeflossen ist. Die Messung ist bei scheller Umdrehung der 'Trommel anberordentlich genan.

Handelt es sich darmm, chemische Unsetynngen in durchbluteten ()roan zu studieren. so kimn der brodiesche Apparat leicht entsprechend modilizicrt werden. Fis bedarf dann keiner so feinen Terstellvorrichtung an der I'mupe. Eine an Votor angebrachte Friktionsscheibe mit rerstellbarem Uthertragungspunkt nach Art der lbertragung am Trommelkymoeraphion reicht ans. I)ie l'umpe wird anf einem horizontalen brett neben dem Motor fest montiert und kann, wenn man etwas mehr Blut zur V'er- 
fiigung hat. von dem Ventilapparat entfernt aufgestellt und durch eine längere Leitung rerbunden werden. Ferner mul die Arterialisierung besonders ausgiebig sein. Man leitet den sauerstoff sehr gut durch ein nach unten mugebogenes seitenrohr in das Rohr $N$ ein, legt noch eine zweite Vorlegeflasche von Gestalt des lihtreservoirs I. (Fig. 108) in horizontaler Lage жwiselien $L$ und $W^{\prime}$ vor, so dali auch starkes schäumen keine Verluste bringt, und sorgt besonder's fiil restlose (iewinnung von so übergehendem orler sonst austretridem Blut. so versieht man den im Wasser

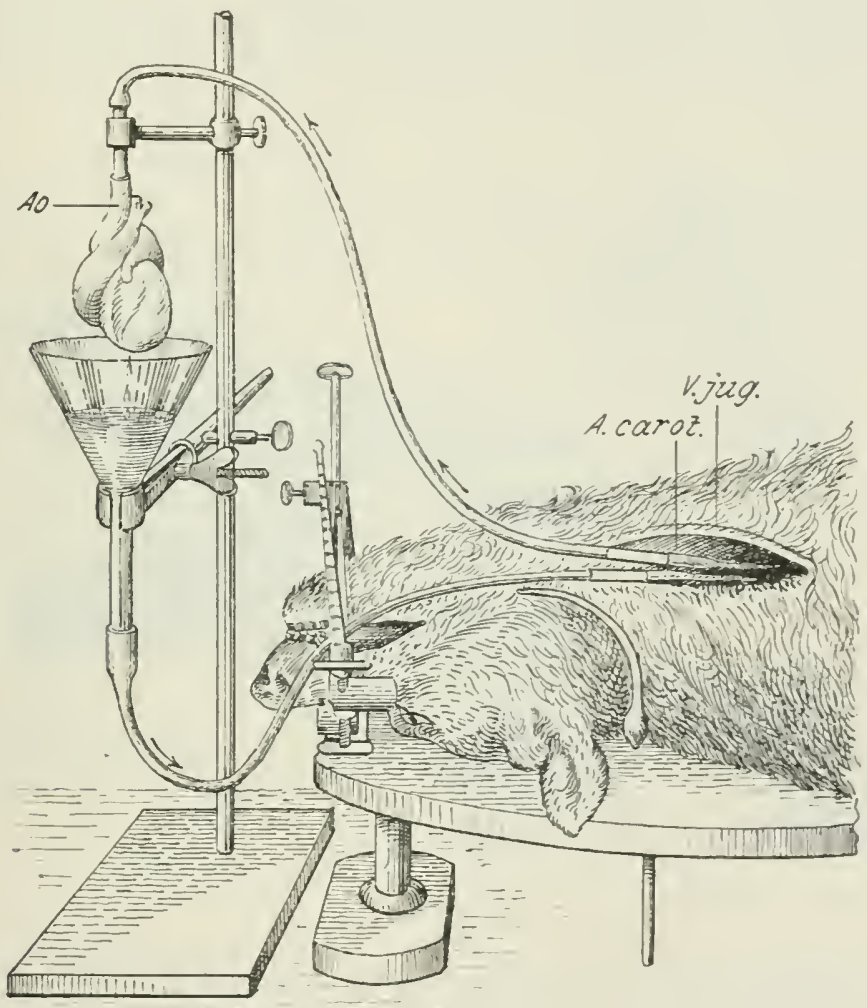

Fig. 109.

von $37^{0}$ stehenden Kasten. in dem das Organ lient, mit schrägem Boden und leitet das abfließende Blut durch saugpumpwirkung in das Blutreservoir zurtick. Iuch mehrere Pumpen fiir mehrere nebencinander zu durchblutende Organe lassen sich leiclut eng nebeneinander anbringen. Weiter kann man die Ventile enthehren. wenn man mit 2 Pumpenstiefeln arbeitet, von denen der eine driickt. der andere saugt.

Bisweilen empfiehlt es sich. das Blut in $Y$ und $L$ auf kleine Siebe aus Gaze tropfen zu lassen. an denen feine Gerinnsel hängen bleiben. 


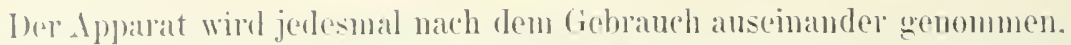

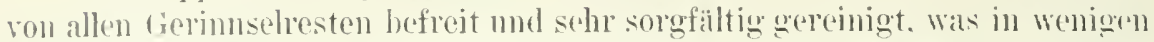
Minnten geschelien ist, anch mub stets frisehe. mit Wasser durehspülte Glaswolle (zur Entfernung kleiner Fäserehen) in klon Gerimselfänger $T$ vor

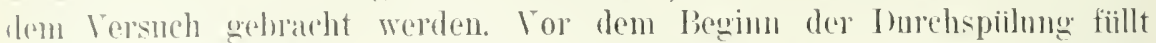
man alle 'leile zunïlhst Inftfoei mit Kochsalzlösume, die man durch Iilut verdringt.

c) Durehblutungsvelfahlen von Heymans und Korhmann. ${ }^{1}$,

bei diesen dient das eine von zwei Tiepen der gleichen drt als Bhlutspender, während das oroan des zweiten (dieses zweite Tier mulj etwa

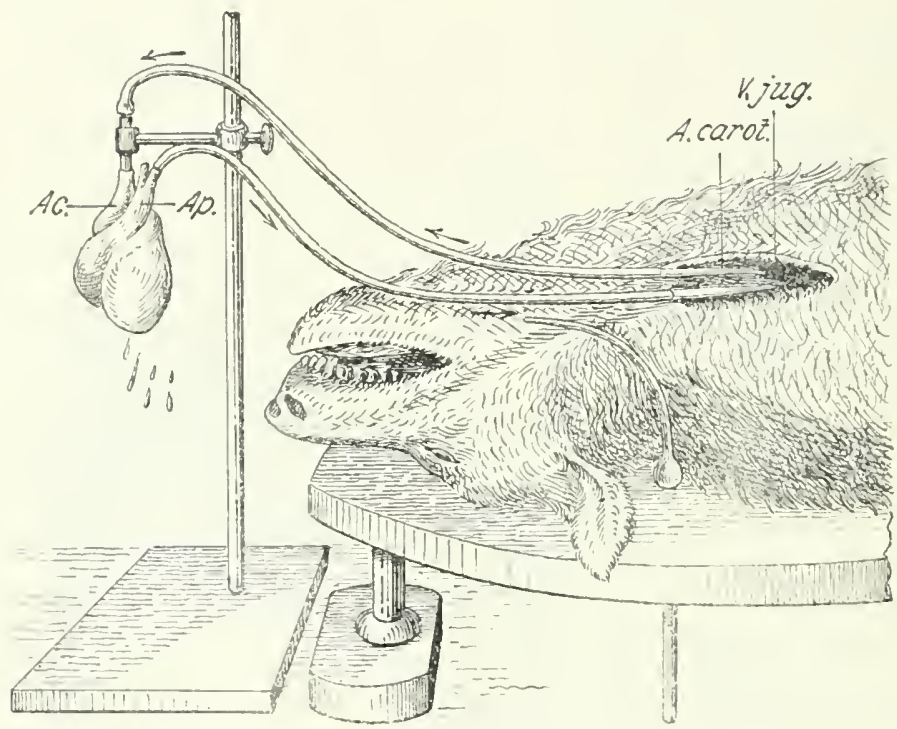

Fig. 110 .

${ }^{1}$ mall so selwer sein wie das erste) durch seine Arterie mit der liarotis des rrsten in Verbindung stoht und das abtropfende Bhut (boim Herzen) durch einen 'rophter oder das ans den Venen ausstrïnende direkt in die Jugularis des Blutspenders zun ziickfliebt. Nan tïtet das 'Tier, dessen ()igan man benutzen will, durch einen Stich in das verlängerte Mark, leitet kimstliche Atmung ain, bindet Kaniilen beim Ilerzen etwa in dic Aorta mol die Arteria pulnomalis und unterbindet allw anderen Gefäbe sorgfaltig. bas blutliefermde Tier ist inzwischen narkotisiert, anfochnden und bei ihm dic liarotis und Jugularis in ihren zentralen Teilen mit Kaniilon versehen. Die Kaniilen sind

1) Une nouvelle méthole de circulation artificielle a travers le coeur isolé de mammifere. Archives internat. de pharmacodynamie. T. 13. p. 379 (1904). 
aufs sorgfältigste luftfrei mit Ringerscher Lösung gefüllt, ebenso die Vorbindungsschlänche (Fig. 109. 110). Will man die Wirkung von Giften studieren. so hindet man eine kaniile in die lieinvene, will man arterielle Blutproben entuchmen, eine solche in die Beinarterie.

Man muf hei dieser Methodr besonders genan darauf achten, dafi keine Luft in das Organ hineingelangt, mub also die zufiihrenden Gefübe ror der Verbindung mit dem organ des anderen Tieres absperren und die Verbindungen aufs sorgfaltigste gefuillt haltem. Dann gelingt es oft, wenn anch nicht immer, eine sehr regelmälige Tätigkeit zu erzielen. Bisweilen aber milingt der Versuch doch. da nach kurzer Zeit ohne bestimmten Grund Gerinnselmassen sich bilden oder, wenn das Herz henutzt wird, Flimnern anf tritt.

Dieses Herzflimmern, das sich auch bei der Langendorffschen Anordnung störend bemerkbar machen kann, legt sich bisweilen durch plötzliche. kurzdauernde, starke Erhöhung des Iruckes, durch Injektion einiger Kubikzentimeter Kampferöl. oder nach Langendorti durch kurz dauernde Absperrung der Blutzufuhr. 


\title{
C. Stoffivechseluntersuchungen an ïberlebenden Organen.
}

\author{
lon S. Baslioni, líon.
}

In der folgenden /usammenstellumg sind nur Organe der Warmbliter berioksichtigt, and zwar deshall. weil sie fast ansschließlich fïr die rolliegonden [ntersuchmonen in Betracht ackommen sind mol wohl auch kommen werden. Fine dusnahme bildet mu das Kentralnervensystem der Amphibien, von dem die Methode der Isolierum und der Erhaltmon im iiberlebenden \%ustande deswegen beschrieben ist. weil as bisher noch nicht golingen wollte (die Möglichkeit ist nicht answeschlossen), es anch beim Warmbliiter in iherlebenden /ustande zu erlalten.

\section{A. Allgemeines.}

\section{Theoretische Begründung.}

Ine in ihrer (iosintheit hetrachteten rhomischen Vorginge. Welche sich in Inuen der lebenden ( hoanismen abspiclen. zejehmen sich besonders durch ein Mcrkmal ans: nämlich durch ihre änberst verwickelte lionpliziertheit. Fin nicht mwiehtiger Grmod dieser Erschoinmo ist in dem Imstande zu erblicken. dab die einzehnen Toroinge die Resultanten mehrerer chemischer l'rozesse dastellen, die sich znoleich in den einzehen, ringoremalien zorlogharen mol als homogen zu betrablenden (weil ans gleichen \%ellelementen bestohenden) liestandteilen (organe oder Gewebo) des Gesantkörpers abspiclen. Hat man mm rou, die gesanten Stoffwechselerschejnmogen,

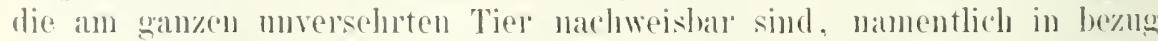
anf jhre Betriebstätte, zu amalysieren, so ist es maheliegend, ja geralezu weboten. die einzehen (Hoane heranszuschneiden und mit ihnen allen weiter zи experimentieren.

Die erste Bedingung. die erfiillt werden muh, mm einwandfreie liesultate zu erhalten, ist natiolich die, dab die vom Ciesantorganismus losgelösten ()rome tatsächlich ..ibesleben*. d. h. Eigensehaften oder Merkmale zeigen. die ohne weiteres der Peilıe der lebenserscheinmoen angehören. Infolgelessen hat man hei den einzelnen oroanen nach einem leicht zugänģlichon. einwandfreien und womöglich in semer Intensität oder seinem Umfang 
melbaren ..Lebenszeichen* (Judikator des Lobensustandes) zu suchen. an der IIand dessen man imstande ist, zu verschiedenen Zciten navh der

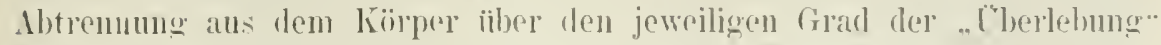
des betreffenden Organs ein Irteil zn croblten. Hicse Iufogabe ist num bei

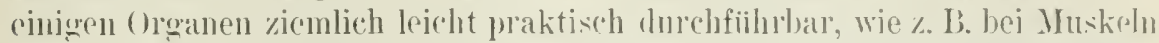
orler \%entren, bei denen man die Prifung der Kontraktionstätigkeit bzw. der lieflextätigkeit zur Verfïgmmg hat. Bei anderen isolierharen Organen hingegen ist ein derartiger Nachweis mit schwer iiberwindlehen schwierigkeiten rerbunden, wie $\%$. b. bei Iriusennrganen, ganz hesonders bei jenen. deren normale Funktion eine sogenannte innores Sekretion ist.

Aus dem Bestreben, diuse (Jrgane tunlichst lange Yeit und unter normal'n inneren Bedingungen zu erhatten, kam man auf len naheliegenden fredanken, die normalen Verhältnisse, welche die Organe in Kürper anfweisen, kïnstlich wieder herzustellen. Juf diese Weise entstanden die zahlpeichen. bisher beschriebenen Iurchströmungs- oder Durchblutungsapnarate (vergl. das vorhergehende Kapitel). Sie suchen den normalen Blutkreislauf nachzuahmen und namentlich die schädlichen Folgen del Asphyxie zu braseitigen. 'Trotz aller Bermiihungen ist es jerloch einstweilen nicht möglich, die isolierten Oroane länger als einige Stunden im branchbaren ..ïherlebenden* /ustand zu erhalten. Ja man ist sogar nach dieser Richtung nicht eimmal berechtigt anzunchmen, dah die Erscheinungen, die bei der Melurzahl der so behandelten (brgane festzustellen sind, ohne weiteres mit denjenigen identisch sind, die dieselben mit lem iibrigen kürper noch im Zusammenhang stehenden Orwane normalerwase zeigen. Es spricht im Gegenteil vieles dafür, dab es sich dabei um Tberbleibsel oder .. Reste* von normalen Lebenserscheinungen handelt, die zudem anch nicht lange \%eit unverïndert fortbestehen. Es tritt jedoch auch nicht sofort der Tod ein. Der Cbergang rom Leben zum Tode ist ein allmählicher. In diesem Chergangsstadium treten Vorgänge auf, die als ..nekrobiotische oder Absterbeerscheinungen bezeichnet werden. Es waire aber auch irro anzunchunen, daß die durch dicse nekrobiotischen Vorö̈nge erzeugten Erscheinungen ohne jede Bedentung für die theoretische Erforschung der Lebensvorgänge wären, dem sie schließen das liätsel der biochemischen Prozesse in sich ein. In Gegenteil erscheinen sie sogar von romherein von einem gröferen Werte fiir die methodische Analyse des Stoffwechsels deswegen, weil sie rermutlich nur wenige Glieder der sonst so komplizierten Kette der Lebensvoroünge darstellen. Diese theoretische Anschaumg wird durch die bisherigen unter Anwendung dieser Methodik er\%ielten Versuchsergebnisse hestätigt.

\section{Allgemeiner Versuchsplan.}

Abgesehen von den biophrsikalischen Lntersuchungen, die an überlebenden (Organen ausgeführt worlen sind und ron denen hier nicht die Rede sein kann, wurlen mehrere biochemische Fragen (Stoffwechselunter- 
smchungen im weiteren simme des Wortes) unte Anwendung iiberlebendel () rgane zn lisen versurht. Der allecemein verfolete Versuchsplan besteht ptwa in Folgendrin:

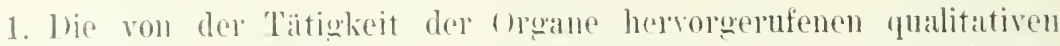

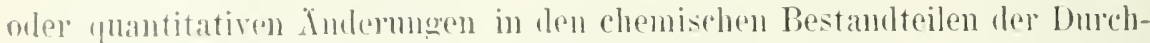

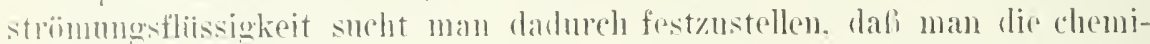

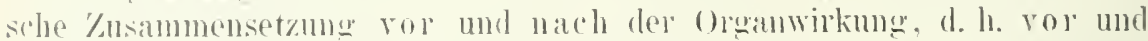

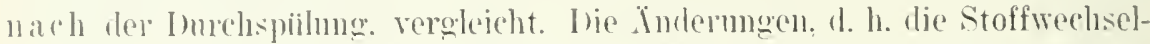
cracheinumene die hierbei theorotisch in betracht kommen. sind atwa:

(1) I)as Anftroton neuer Stoffe meist komplizierterer struktur. die

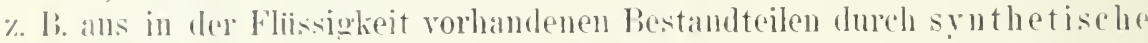

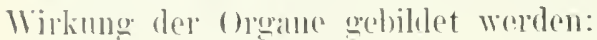

b) das Virshwinden in der Fliissigkeit rorhandener Stoffe. die durch die 'laitiokeit der Oroanc irondwie mugewandelt werelen.

sowohl in ersteren, wie im zweiten Falle kömmen qualitative, ebenso wio quantitative lontersuchungen angestellt werden. bei denen die iiblichen analytisclen Methoden anzuwenden sind.

2. Ua momalerweise einerseits nicht alle Lmwandlungspodukte in die durhströmende lissigkeit abgegeben werden, weil sie im lnnern

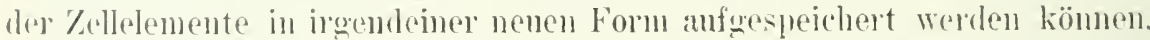
und anderseits nicht alle ron der orountaitiokeit verarbeiteten Stoffe ans der "rnährenden zirkulierenden Fliissigkoit weschöpft werden. da sio anch im lmmern der Zellelemente vorhanden soin kïmen. so erstreckt sich die lufoube anch anf die analytische Verabeitung der Orwane selbst. derru \%usammensetzmmer vol und nach der experimentellen Behandlung ehenfalls dureh die iblichen Methoden zu ermittrhn ist. (Vol. z. B. dic nenerding

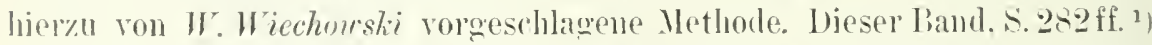

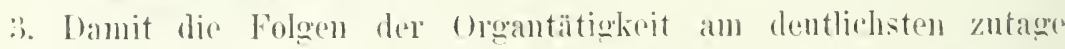
treten. werden anige kumstoriffe angewendet, die dahin riclen. dir 'Tïigliejt der oroane selbst zu erhöhen oder die bauer ilner Itherlobung zu verlingern. In ersterem Falle werlen alle die Mittel verwendet, die bekanntlich die Lebensvorgäne steigern. sie sind:

a) Kïustlicho Raize. Hierher gehörem manentich die olektrisehen Reize und die chemischen lieize, wolch letztere meist in Form ron (iffen gegehenenfalls gute I)ienste leisten kömurn.

b) Temperatur. Es ist eine nummeln bekannte latsache, dabi die Wärme bei stoffwechselerscheinungen eine aussehlaggehende liolle spielt. Man sollte also meinen. dab fïr solche Versuche eine hohe T'emperatur (wie rowa : $28-f 0^{\circ} C^{\prime}$ ansuahmslos die heste Bedingmg darstelle. Die Vortrile der holen 'Temperatur werten jedoeh durch den Umstand eingeschränkt.

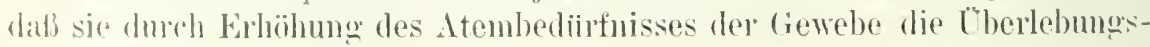

1) W. Wiechouski, Fine Methode zur chemischen und biologischen Intersuchung ïherlchender (Irgane. Hofmeisters Beitrïge z. chem. Physiol. Bil. 9. S. 232-246 (1907). 
daurer dere isolierten (Mrgane verkïrt. Wir werden in der 'Tat sphen. daf' man neuerdings bei einigen ()rganen bessere Ergebnisse dadurch aryielt hat. dafi man solche Untersuchungen hei Zimmertemperatur $(15-20)^{\circ} \mathrm{C}$ ) ausfiihrte.

4. Zu demselhen praktischen 'Zwecke, die in der burchströmungsfliissigkeit nachweisharen lolgen der ()rgantätigkeit hesser zutage zu fördern. dient schtieblich der Kunsteriff. dieselbe, möglichst kleine Menge Emährungsflïssigkeit mehrere Nale durch das Organ durchströmen zn lassen. Beziiglich der \%usammensetzung dieser Fliissigkeit ist noch hervorzuheben, dalf man im Verlauf solcher Untersuchung'm allmählich die Notwendigkeit erkannt hat. das friiher mit Vorliebe hierzu gebrauchte defibrinierte I3lut durch die Ringersche Lösung zu ersetzen. Der Grund hicron liegt wohl in dem l'mstande. daf letztere Fliissigkeit weyen ihrer einficheren und bekinnten Zusammensetzung der chemischen Inalyse unvergleichlich geringere scluwierigkeiten bietet als Blut.

5. Man sucht schlieblich zur Erkenntnis der Art der Lebensvorgünge der Zellen selbst, für die ihre normale Struktur eine mausbleibliche Bedingnng darstellt, im Cregensatz zu den Vorgäingen. welche die Zellen mittelst chemischer ron ihnen zwar erzeugten, aber auch von ilmen isolierbaren Agenzien (Fermente) bewirken, dadurch zu gelangen, dah man die Stoffwechselerscheinungen der isolierten Organe mit denjenigen vergleicht, die man in den durch Zcrreihung und Jusziehung aus den Grganen gewonnenen Säften wahrninmmt.

\section{Einige allgemeine praktische Winke.}

I. G. Brodie') gilut im Anschluf an die Beschreibung des ron ihm erfundenen Durchblutungsapparates einige allgemeine Winke ïber die Isolicrung der verschiedenen Organe und den Versuchsgang. die ich hier zum Teil wiedergeben möchte.

Mittel zur L'nterhaltung der Körpertemperatur. Das Gefäb. welches das Inurchspiilungsblut enthält. wird in einem passenden und konstant erwärmten Wasserbad für sich gehalten, während die Organe je nach der verschiedenen Durchblutungsgeschwindigkeit verschieden behandelt werden. Fließt eine beträchtliche Flüssigkeitsmenge durch das Organ hindurch, wie es z. B. bei der Leber der Fall ist, so braucht man das Organ ror Abkiihlung nur mittelst Umwicklung durch warme, feuchte Leintiicher oder Banmwollbauschen zu schiitzen. In den Fillen jedoch, bei denen die Durchspiilung langsam ror sich geht, ist es notwendig, das Organ in einen fiir jeden Fall besonders gebauten Wärmekasten zu legen. In den Fällen, bei denen das durchflieliende Blut ohne Verlust aus einer einzigen Vene

1) T. G. Brodie, The perfusion of surviring organs. Journal of Physiol. Vol. 29. p. $266-275(1903)$. 


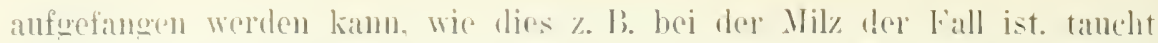

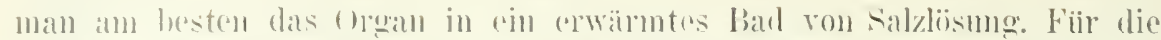

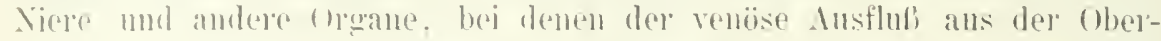

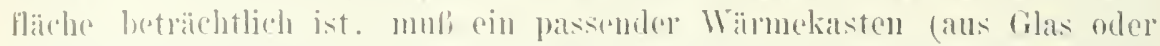

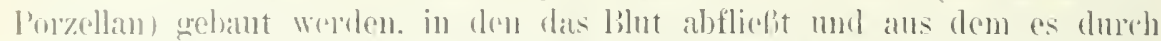

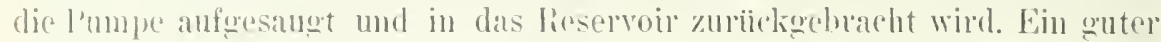

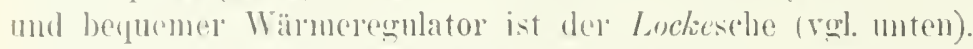

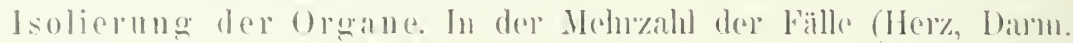

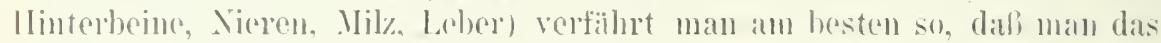

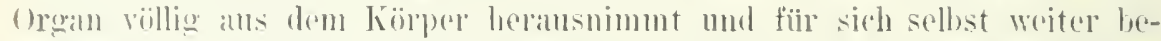

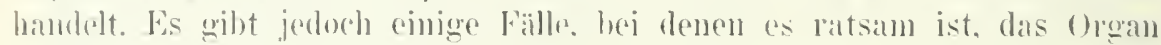
in sitn liegen zu lassen. Dies trifft namentlich für die Lumgen oder die

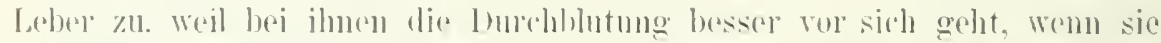

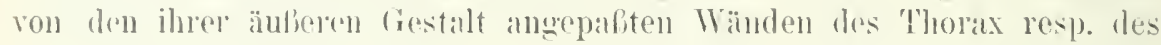

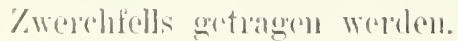

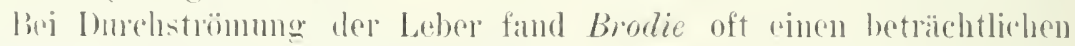
Blutverlust, wemu das ausfliebende bilut aus der V. cara inforior dieht oher-

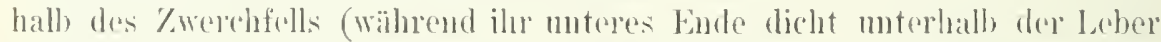

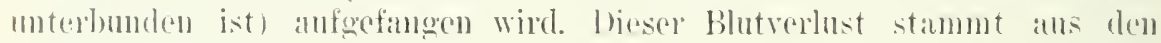
freien Anastomosen der Lebervenen mit Venen des \%worehfells oder mit anderen Venen. I'm diesen Verlust zu vermeiden, fängt man das blut an

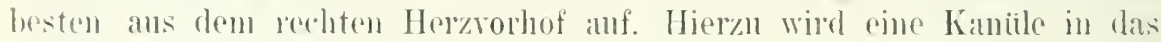

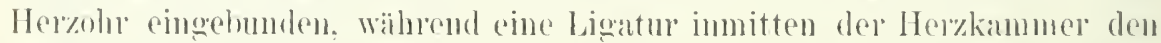

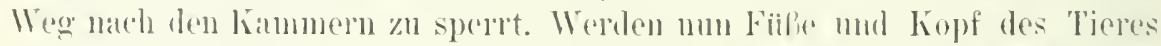

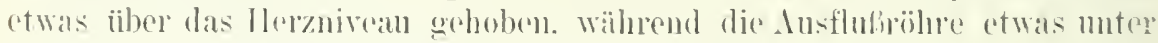
dem Herzvorhof gröffuet wird, so fliebt das Blut leicht und fast olume Terlust horans. '/u diesem \%wecke sind weder die V. cava inferion unteralb

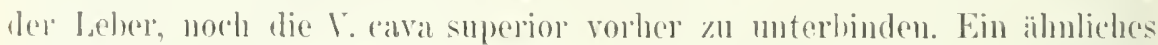

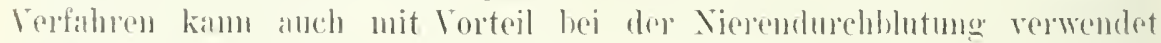
werden, zmmal wemn heide Nieren zugleich perfundiert werien. Iaci der Leberdurchlibutung durch die V. portae ist es von wesentlicher liedeutmen, die Lehrearterion zu unterbinden. Fs ist ratsan, Lumgen mol fedäme zu nutfermon. Ist dic Durehströmune im Gang. so ist das 'Tier in ein Bad warmer Salzlösung zn relsetzen. oder es wird ceinfachele mud doch mit gutem

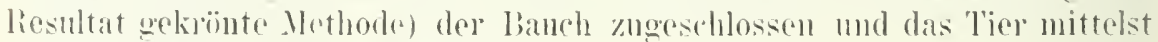
batumwollhatusche wallm gehalten.

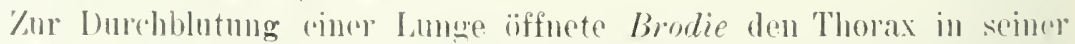
linken Sisite, besonders daranf achtend, den rechten l'lemralsack nicht zu rerlotzen. Fine Kanile wird dam in die erste strecke del Art. pulmonais

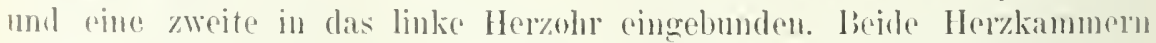

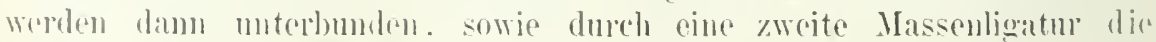

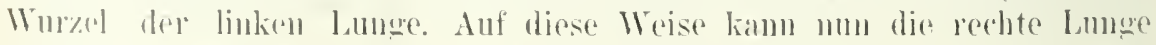

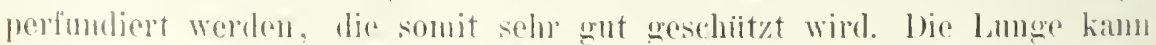

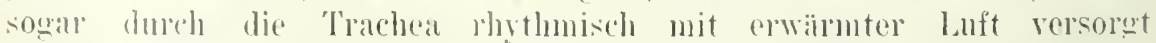
wreilent. 


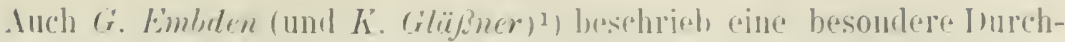

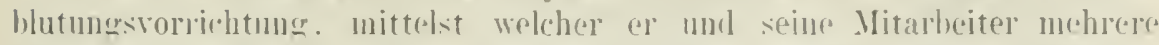

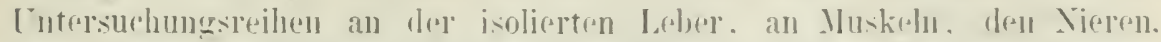
den Lungen und dem Ininndarm ausefefiihrt haben. Isei ihren sümtlirhen Vrathen wurden fast ansuahmslos zwei Hunde verwendet. rin

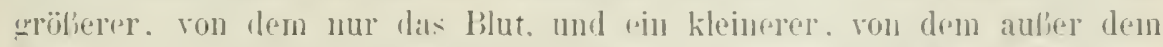

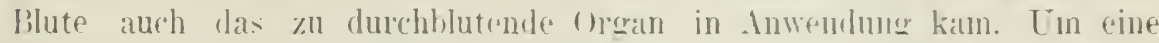
mörglichst grobe Blutmenge zu gewinuen, wurden die Hunde in Sthernarkose aus beiden liarotiden oleichzeitio entblutet nud furner geuren Ende der Entblutung Thorax und Abdomen stark komprimiert. lerer verwendete ()perationstisch gestattete auch. das liopfende drs lieres stark zu senken. Las gewonnene Blut wurde defibriniert und durch einen unten spitz zulaufenden Leinwandsack koliert. Wo es nötig war. wurde das Blut nochmals koliert, wenn es zum erstemmal das ()rgan passiert hatte. I,ei der Füllung des Apparates wurde natiolich sorufültig darauf exeachtet. dali nirgends luftblasen vorhanden waren.

\section{B. Spezielles.}

\section{Lunge.}

IDie Vethode von Brodie wurde olen hesprochen (siehe s. 362).

G. Embden und $K$. Gläknor ${ }^{1}$ ) relfahren folgendermafen. L'nmittelbar nach der Entblutung aus beiden Karotiden wird die Trachea freigelegt, eine Crlaskaniile eingebunden und alsdann nach breiter Eröffnung des Thorax eine lianüle rom linken Ventrikel ans durch das Ostium atriorentriculare in den linken Vorhof rorgeschoben und hier eingebunden. Die zweite Kaniile wird rom rechten Ventrikel aus in den sinus arteriosus der Pulmonalarterie eingeführt. Nachdem nummehr die Trachea dicht unter dem liehlkopf yuer durchtrennt worden ist. werden die Lungen aus dem Kö̈rper entfernt und in einem weiten zylindrischen Gefäf an der Trachea aufgehängt. Es folgt die Verbindung der Pulmonalarterienkaniile mit der Blut zufiihrenden. der Kanüle im linken Vorhof mit der Blut abführenden Leitung und der Trachealkaniile mit einem Handgebläse. I)as unter ziemlich feringem Druck ( $40 \mathrm{~mm}$ ) zugeleitete Blut durchströmt die Lungen sehr rasch. es fliefit in äuberst krïtigem strahl aus der Vorhofkanüle. gleichzeitig erfolgt die kiinstliche liespiration der Lunge durch das Handgebläse. Im weiteren Verlaufe des Versuches trat (wahrseheinlich infolge einer Blutdrucksteigermang eine Blutung in das Bronchiallumen auf: es wurde deshalb die Trachea unterhalh der Kanïle abgebunden, und das Blut ron

1) G. Embden und $K$. Filïkner, C̈ber den Ort der Atherschwefelsäurebihlung im Tierkorper. Hofmeisters Beitrïge z. chem. Physiol. Bd. 1. S. 310-327 (1902). 
mun an, ebenso wio hei den iblrgen Versuchen, arterialisiert. (lbrigens

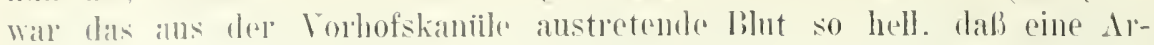
terialisiolnum kilum nötio war.) In weiteden Verlanfe des Versuches war

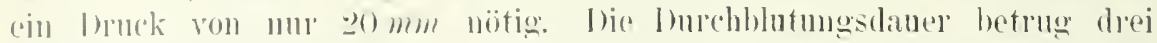

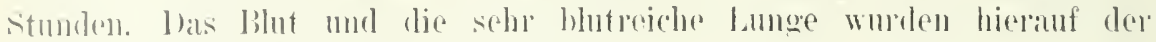
cheminsolen Analyse unterworfen.

\section{Leber.}

\section{Wetholle vou Saluslin.}

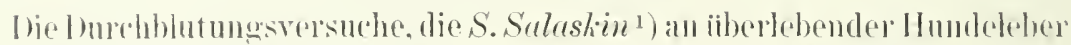

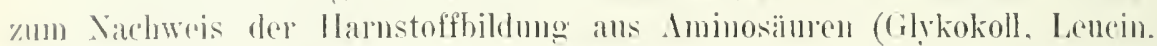

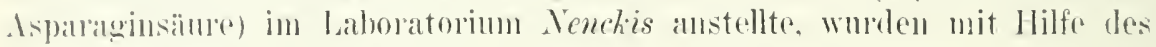

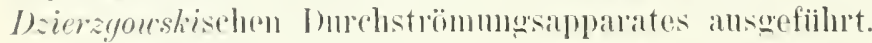

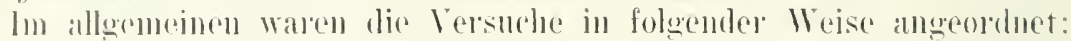

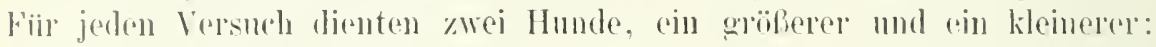
(inceseits mm mugeführ $1-1^{1}{ }_{2} l$ Blut zu bekommen, andrelseits um nicht mit ainel zu unfangreichen l,ober zn manipulieren. Fine Jeber vou 150 bis 300 g apeist sich fï diesen Zweck an meisten passend. bie Humbe walen volue mit in Himblick anf die Lutersuchungen passend ansge-

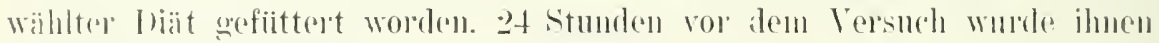
jerle Sillulumg ant\%ogene.

Sofort maleh der Yerhlutmog des Hundes wurde die Banch- und Brust-

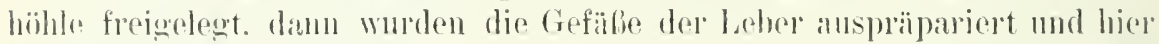

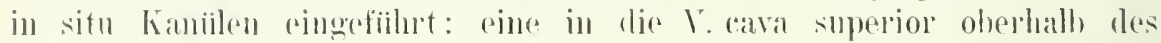
\%wrethfells, die andere in die V. portae; V. cava inferior, A. hepatical,

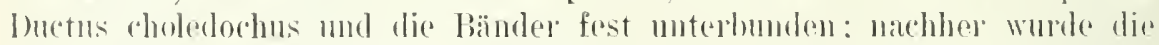

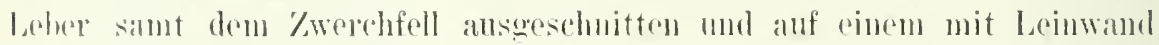

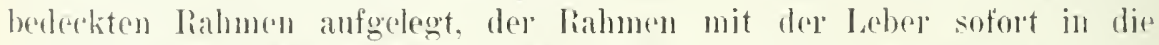

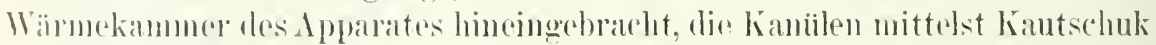
mit den entsprechenden Triben des Ipparates in Verbindung gasetzt und

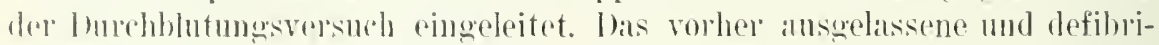
nientr bilut wild inzwischen durch dimne Leinwand filtriert und sofort in

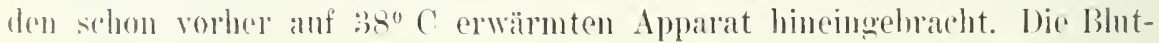
monge, div zu Versuchszwecken gebraucht wirl. schwankt zwishen 1300)

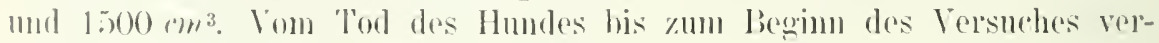

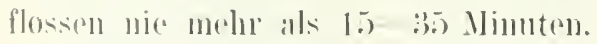

Silch der ersten Durehleitung wird las Iblut stets ans item Apluarat

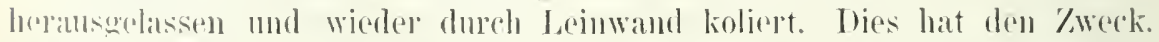
die ans dor Leber ansgewasehenen Fibringerinnsel zn entfermen, sonst werden dio Iolorkapillaren durch die Gerimnsel rerstopft und bei der darauf fol-

$\left.{ }^{2}\right)$ S. Salaskin, ther die Bildung ron Harnstoff in der Leber der Sängetiere ans Amidosäuren der Fettreihe, Keitschr. f. physiol. Chem. Bd. 25. S. 128-151 (1898). 
genden Burchleitung fliebt das Bhut nur tropfenwoise ab und dies nur hei

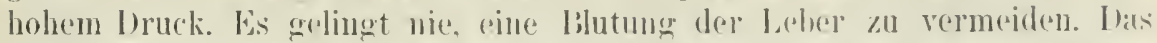

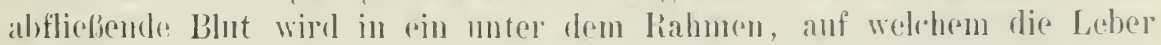
ruht anfgestelltes (iefail) gesimnout und wieder in den Apparat hineingebracht. Die Blutung beginnt gewöhnlich erst einge \%eit nach dem leginn des Versuches.

Der positive Druck, unter welchem das IBlut flof, schwankte zwischen $10-50 \mathrm{~mm} \mathrm{Hg}$, der negative (da der lunrecströmungsaparat auch aus einem blutaspirierenden 'Teil besteht) zwischen $10-20 \mathrm{~mm}$, wobei das blut aus der V. cava in ununterlorochenem strome abflof.

Der Durchblutungsversuch wnrle gewöhnlich ca. 4 stunden fortgesetzt. Jede Inuchleitung nahm etwa 10 Minuten in Anspruch. so dalo die gesamte Blutmasse etwa :2ómal durch die Leber geleitet wurle. Ilie ersten :i-5 I)urchleitungen geschahen ohne jeden Zusatz. nachher wurde die erste Blutprobe, ea. $150 \mathrm{em}^{3}$. entnommen und dam erst allnällich die zu untersuchende Substanz in Lösung heigemengt. An Endr wurde dann das durchgeleitete Blut analysiert.

\section{Vetlode vou Kraus.}

Mit einem besonderen kompendiösen Durchblutungsapparat, der von E. Freund konstruiert und in dessen Laboratorium seit mehreren Jahren in Verwendung ist, stellte $F r$. Krous ${ }^{2}$ ) seine Inurchblutungsversuche an der Leber von Hunden an, un die Frage ter Znckerbildung durch die iiberlehende Leber zn erforschen. Behufs Isolierung des Organs wurden die Hunde in Aorphimm-Chloroformnarkose rasch enthlutet. Abdomen und Thorax geöffuet, die Vena cava descendens knapp anferhalb der Leber unterbunden. ebenso die Art. hepatica, die Vena portae frei präpariert, ein Hauptast derselben durch Abbindungen isoliert und mit der zuführenden Kaniile des l)urchblutungsapparates armiert, in die Vena cava ascendens oberhalb des Zwerchfelles die abfiihrende (venöse) Kanuile des Apparates eingehunden. Zur Durchblutumg, die meist 2 Stunden dauerte. wurde defibriniertes Hundeb) verwendet und die Temperatur von Blutmischung und Organ auf $: 36^{\circ}$ bis $38^{0}$ gehalten.

\section{Wethode von G. Embden und $K$. Gläßner. $\left.{ }^{2}\right)$}

Sie verfuhren bei ilren Durchbiutungsversuchen an der Leber folgendermaken. Zunächst wird das Abdomen des Hundes seitlich ion der Linea alba, unter möglichster schonung des Zwerchfells, in seiner ganzen Länge eröffnet und ebenso das Thoraxinnere durch Heraustrennen des Brusthcins und der Rippenknorpel in grofier Ausdehnung freigelegt. Nun wird die Leber

1) Fr. Kraus, Uber Zuckerbildung in der Leber bei Durchblutungstersuchen. Pflïgers Archiv. Bd.90. S. $630-63 \pm$ (1902).

2) 1. c. S. 363 . Note 1 11. 2. 


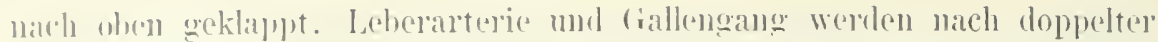

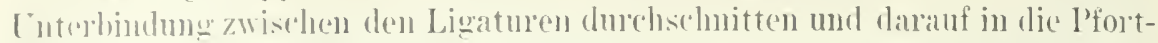

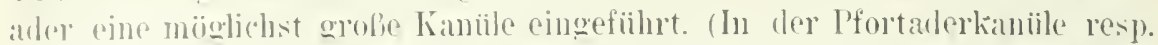
im Hanptaste dor I'fortadel bildet sich sehr leicht ein änlerst störendes lierimnsel. In dieses sicher beseitigen zu kïmnen. wird von der Kantile aus mmittalbar. nachdem sie eingebmen ist. ein dicker Faden möghchst tief in die Toua portar cingefiilnt. Las äubere Ende des Fadens wird zunälehst an der kaniile festebunden. Der Faden wird erst unmittelhar ror der Vurbindung der lianiile mit dem bhtzuführenden schlanch entfermt und

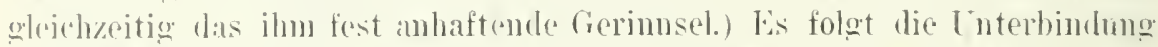

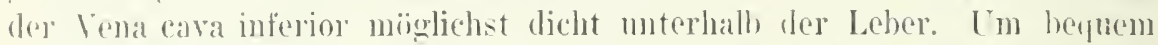
an die stelle gelangen zu können. wo die Hohlvene hinter die Leber tritt. ist w zweckmäbion. rorher die ron der Leber zur rechten Niere zichende T'ritonealfalte zu durchtrennen. Asdann wirl in die Vena rava oberhalh des \% werehfolls cine recht dicke Kimiile eingefuiht. Nun werlen die noch ïbrigen liänder der Leber — soweit nötig, nach vorheriger Anlegung von Massuligaturen - durchtremit. clas /werehfell ringsum unmittelhar an seinem Ansatze an der 'Thoraxwand abgeschnitten und jetzt Leber und \%werchfell gemeinsam unter Durehtremnmer aller Verbindungsstränge ans drun 'Tierkïrper entfernt.

leber und / werehfell werden damn in eine feuchte Kammer, die dureh (in Wascerhad auf atwa $39-40^{\circ}$ gehalten wird, gehacht, die Pfortaderkaniile unter den iblichen Kiautelen mit dem hlutzufiihrenden Schlanche. die Hohlvenenkaniile mit dem blutabführenden Schlauche verbunden. I)am wird (lel burehströmungsaplarat in Tätigkejt gesetzt.

bemorkuner. Was die theoretische Verwertumg dor an der aus-

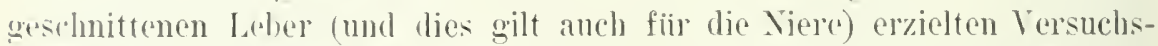
elobnisse anbelangt, ylutube ich, dab man den folgenden Linstand nicht unberileksichtigt lassen darf. Ian besitzt bisher kein änlieres hequemes Kenmzeichen, das nns iiber den wirklichen Lebenszustand der I)riisenelemente benachrichtigen kann, wie dies \%. B. beim Herzen durch l'rüfung scinel lirizharkeit (luckung) ler Fall ist. Fs lïge in dieser Hinsicht nahe, die (iallenabsonderung als Indikator zu benntzen. Dabei stöbt man aber elstens

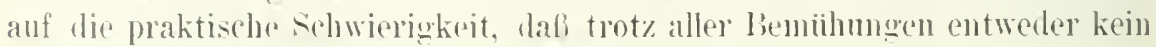
Sekret mehr oder nur ein "pathologisches" Sekret (wie es hei der Niere

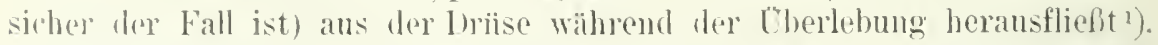
und zwejtens auf die theoretische sehwierigkeit. dal uach unseren heutigen Linntnissen über die Funktionen der Leberdriise die äubere sekretion der (rallu eine vielleicht nur sokundäre Leistmug darstellt.

Fine Folge dieses Tmstandes ist lic, dali man bei solchen Untersurhungen im regensatz zu denjenigen an isolierten Muskeln oder Nerven

1) Xach ilteron Angaben ron Asp (1873) hoirt die Gallensekretion 10 Minuten nach sistiernng des Blutkreisluufes anf (zitiert nach $K$. Grube). 


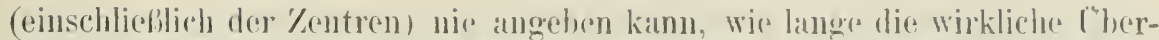

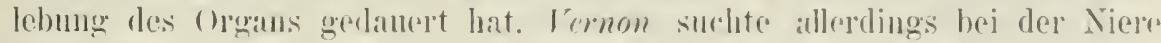
nowerdings letztere Schwierigheit dadurch zu ïberwinden, dalj al als Lebrnszeichen der ibberlobenden Driise den (iaswerhsol benutzt (regl. unten).

(bige Kritik berïhrt jedoch nicht in geringsten die allogmoine prinzipielle liedcutumg der mit diesen Methorlen nachgraiesonen mud eventuell nachweisbaren spezifischen chemischen Vorgïnge isolierter Organe, von denen man weif, dal\} sic auch in Cresantkörper stattfinden, wje z. I’. dice Marnstoffhildung. Ja \%m Lösump derartiger Fragen ist die Inurchspülungsmethorle der isolierten ()roane die einzig gebotene. Fiir ahnliche lragen ist aber auch einigermaljen mleichgialtig: ol sich in den Zellen normale physiologische oder nur nekrobiotische Vorgänge abspielen (rgl. oben s. :is)!).

Nach den Versuchsergehnissen, dic K. Grube untes Anwendung des Brodieschen Durchströmungsipparates an der kïnstlich perfundierten Katzenleber erhalten hat, scheint jedoch die Iöglichkeit nicht ausgeschlossen, auch diese Driise durch kiinstliche Durchblutung im wahren überlebenden '/ustande zu erhalten. I) wesentliche liedingung scheint in dem Umstand zu liegen. zwischen der Blutspersung des normalen Kroislaufes und dem Beginn der kïnstlichen Inrchströmung möglichst kmrze 'Zeit verstreichen zu lassen. 'Tatsïchlich fand Grube, dab, wenn el so rasch, wie nur möglich, die Dnrchblutung begann, die sekretion ron unlsutiger Galle wieder auftrat und sich sogar nene Mengen Glykogen aus dem zuckerhaltigen, durchströmenden Blut in dem Leberparenchym bildeten, und dies trotz dem ungiunstigen Imstande, daß zum Teil heterogenes Bhut (vom Schaf) zur Durchströmung diente.

\section{Ilethode voul K. Grube.}

Zur möglichst raschen. Iusfïhrung seines Versuches verfuhr $K$. Grube in folgender Weise. Der (unter Anwendung der von Engliundern oft gebrauchten Alkoholchloroformäthermischmng) narkotisierten Katze wird der Bauch längs ler mittleren Linie geöffnet und eine Kaniile in die Vilzvene eingebunden und mit dem Durehströmmngsapparat rerbunden, während eiue Ligatu unterhalb der $\mathrm{V}$. portae. unterlalh der Eimmindung der Milzrene angebracht wird, ohne sie jedoch rorlïufig festzuzichen. Damn wird ein Lïppchen der Leber unterbunden. ausgeschnitten, hicraf gewogen und zur chemischen Analyse (behufs Glykogenbestimmung) in Alkohol aufhewahrt. Sodann wirl der Thorax geöffnet und rasch eine Kanile in dic V. cava inferior eingefuihrt; unmittelbar darauf beginnt die kiunstliche Durchspiilung und zur gleichen Keit wird die Ligatur um die V. portae festgezogen. Dann werden Herz und Lungen entfernt. Nun wird zum Auffangen der von hier ausfließenden Blutmenge eine Kantile in die Aorta eingebunden. Auf diese Weise verstreicht nur wenig Zeit zwischen der sistierung des normalen

$\left.{ }^{2}\right) K$. Grube, On the formation of Glykogen in the artificially perfused liver. Journ. of Physiol. Tol. 29. p. 276-281 (1903). 


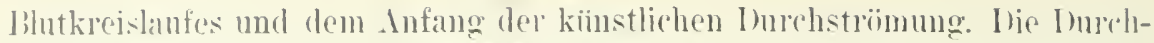
strïmung selhst dauerte atwa g- Stunden mud ging unter einem Inruck von 20-30 mm Ho voustatten.

\section{Darmschlinge.}

\section{Methode vou G. Sulrioli.')}

Nach dem letzten Atemzug des durch Verbutmmg getöteten 'lieres (kininchen oder Hund) wird die lianchlöhle eröffnet und unter sorofuiltierer

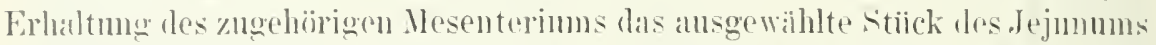

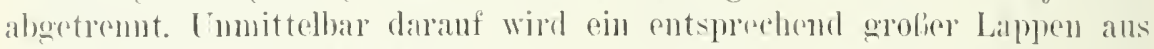
den Bauchdecken heransgeschnitten. nach Entfrommg des Fells auf einer starken Korkplatte das Peritonemm uach oben ansogrbreitet mo festersteckt.

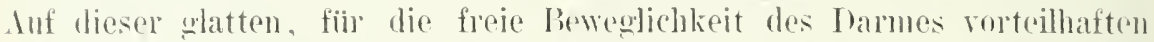
Fläche wird das letztere entfaltet mol elonfalls mit Nadeh befestigt. Inan

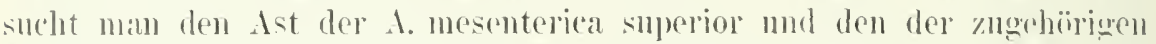
Vene auf, die sich in dor isolierten barms(hlinge verzweigron, rersieht bejele

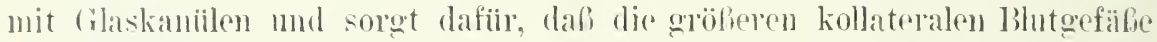
muterbunden werden. Bhtmugen aus kleineren fitchen werlen erst später nach de bindeitung des kïnstlichan stromes gestillt.

Will man öbem nud Bluterouli in mol ans der sohleimbant rermeiden, so darf die Hähe des lunckes im Inrchblutmosapparat nicht

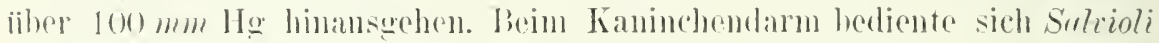

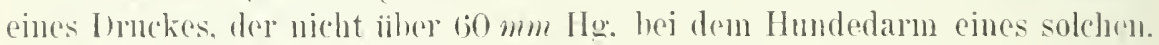
der nicht iiber $75 \mathrm{~mm}$ IIg himansging.

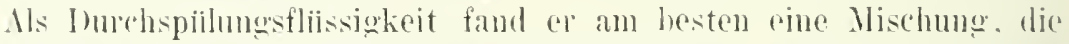

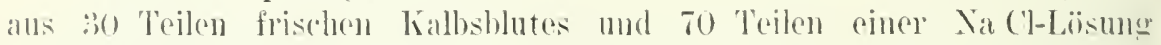
voll $11.7 .5 \%$ bestand.

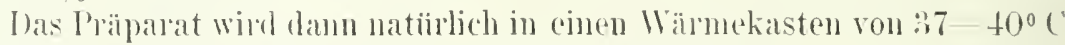
geblacht und darin während des Versuches gellalten.

Ehe man in die larmböhle die zu untersuchenden Stoffe einfïhrt,

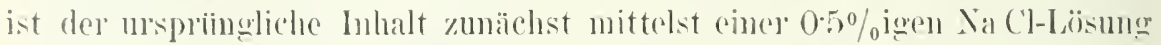
von to (' anszuspiilen. Sach Finfiillung der Versuchsstoffe miissen dic beiden diindungen tes Dammohres zugehunden werden. Fei der Fiillung des Jarnes ist darauf zu achten, dab die Wand nicht gespannt wird, es

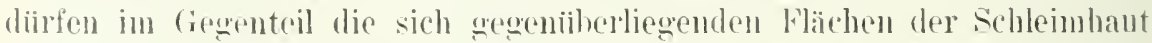
nicht allyn weit voneinander entfernt sein, so dal der Quersehnitt del Hïhle eine elliptische Form belailt.

Überlebungsdaner. Die Absterbererinderungen erfolgen verhiltuismälige langsam. so dak man bei sorofiltiger Wahrung der beschriebenen Nabrogehn 4-5 stunden hindurde keine merklichen Abwcichungen in den lersuchsergehnissen zu hefürchten hat. Dies bezieht sich jedoch haupt-

1) Gr. Sulrioli, Eine uene Methode für die Cntersuchung der Funktionen des Dümndarms. Arch. f. (Anat. n.) l'hysiol. Suppl-Bd. S. $95-112$ (1880)). 
sächlich auf die Lehensvorgänge der Muskelschichten (deren Bewegungen Salvioli aufzeichnete). Die Ćberlebungsdauer der Schleimhautorgane (Darmzotten), worauf es bei diesen Versuchen besonders ankommt, scheint dagegen geringer zu sein. Aus der Betrachtung der Schleimhaut gewann Salvioli die Utherzeugung, daß sie sich bei längerer Dauer des künstlichen Blutstromes wesentlich ändert. ..In der liegel rötet sich dieselbe, oft wird sie von Ödem geschwellt und ihr Epithel ahgestoßen. Immerhin ist auch gegenwärtig der Resorptionsversuch nicht ganz hoffnungslos."

Durch Analyse der Durchspuilungsflüssigkeit vor und nach dessen Durchströmen, sowie der in die Darmhöhle eingeführten Stoffe und des Darmes selbst kann man die biochemischen Vorgänge der iiberlebenden Darmschlinge (hauptsächlich Sekretions- und Resorptionserscheinungen, sowie Erscheinungen von Umformung der resorbierten Stoffe) erforschen.

\section{Methode von Embden und Gläßner. $\left.{ }^{1}\right)$}

Bei einem kleineren Hunde (vgl. oben S. 363) wird nach breiter Eröffnung der Bauchhöhle zunächst der Darm an der Grenze von Duodenum und Jejunum und ebenso etwa $1 \mathrm{~m}$ weiter abwärts doppelt unterbunden. Nunmehr wird die A. mesenterica superior von der Aorta abdominalis und ebenso die entsprechende Vene von der Pfortader aus aufgesucht. Es werden in beide Gefäße Kanïlen eingebunden. Das Darmstiick wird oben und unten abgetrennt. Dann wird das Mesenterium von den benachbarten Darmteilen ebenfalls unter vorheriger Anlegung von Ligaturen losgelöst und schließlich an der Radix mesenterii abgeschnitten. Das Ganze wird jetzt in eine feuchte Kammer von $40^{\circ} \mathrm{C}$ gebracht und nach Verbindung der Kanülen die Durchblutung eingeleitet. Das Blut entströmt der Venenkaniile in rasch aufeinander folgenden, stark venösen Tropfen. Der anfangs bewregungslose Darm geriet bei den. Versuchen etwa zehn Minuten nach Beginn der Durchblutung in die lebhaftesten Bewegungen. Sie dauerten etwa $1 \frac{1}{2}$ Stunden, um dann allmählich zu erlöschen. Die Durchblutungsdauer betrug 3 Stunden. Eine nennenswerte Blutung nach außen hatte nicht stattgefunden.

\section{Niere.}

\section{Methode von Bunge und Schmiedeberg. ${ }^{2}$ )}

Der Methode, der sich Bunge und Schmiedeberg bei ihren bekannten Untersuchungen iiber die Bildung der Hippursäure aus Benzoësäure und Glykokoll durch die Tätigkeit der ausgeschnittenen überlebenden Niere bedienten, war in ihren Hauptlinien die folgende:

1) G. Embden und $K$. Gläßner, Über den Ort der Atherschwefelsäurebildung im Tierkörper. Hofmeisters Beiträge. Bd.1. S. 310-327 (1902).

$\left.{ }^{2}\right)$ G. Bunge und O.Schmiedeberg, Die Bildung der Hippursäure. Arch. f. exper. Pathol. u. Pharm. Bd. 6. S. $233-255$ (1876). 
Jic Tiere (neist Hunde) wurden durch Verhlutung aus der Karotis gretötet. Das gesammelte lilut wurde defibriniert und koliert fund mit Benzorisinte und Glykokoll versetzt). Damm wurden die Nieren mit der Fotthapsel zusammen ausogeschniten mo in die Arterie. in die Vene mul in den Lrotur filaskaniilen engebunden. Hie Arterienkaniile war mit dem

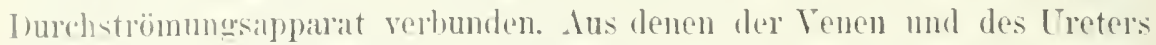
murlen die herausfledienden Flissigkeiten anfoefangen und chemisch unterisucht.

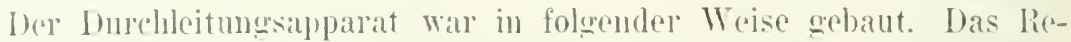
servoil fïl das durehzuleitende Bhut bildete ein Glashallon. der ra. 1 l blut anfuahm, oben tubuliert wall und unten in eine mit einem Glashahn verselnene Röhre auslief. Dun Inuck fiir die Durchleitung des Bhtes licferte die Wasserleitumg. I)as Wasser flob in einen gewöhnlichen fasometer und komprimierte in demselhen die Luft: der Druck dieser komprinierten Luft wurke auf das blut in dem Reservoir ïlertragen, indem der Luftraum in dem (iasoneter mit dem über dem Blute in dem Reservoir hefindlichen Luftrame kommmizierte. Durch den Hahn der Hasserleitung konnte der Druck beguem und genau regnliert werden. 1)as Bhutreservoir hefand sich in einer lilerlwanne. Welche mit Wassel von hörpertemperatur gefüllt war und auf dieser 'Temperatur dureh eine darmuter gestulle Gasflamme erlaalten wurde. Die ans dem Rescrvoir austretende Giasröhre war mit der (ilaskaniile der Nierenarterie in Verbindung gesetzt. Unmittelhar vor dem Eintritte in die Niere kommunizierte die Röhre mit einem seitlich angebracht'n Queckilhermanometer. Tm etwage Lufthlasen aus dem Blute zu entfernen, waren in die Vepbindungsühre zwischen dem Blutreservoir und dor Niere zwei T-lïibren eingeschaltet, an denen der dine schenkel senkrecht nach oben ererichtet und durch ein Stiick liautschukschlanch und cino Lilommschranbe geschlossen war. In diesen Schenkel sammelten sich alle mitrerissenen Infthlïschen und komnten nötigenfalls durch vorsichtiges Öffnen dor kilemuschraube fortgeschafft werden.

Niemals lief es sich rollständig vermeiden, dab eine geringe Venge blut anch anf anderem Wege als durch dic arolie Vene die Kitpsel durchrlrang. Soweit als möglich wurden solche Blutungen durch sorofültige Unterlindungerell gestillt.

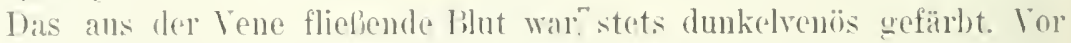
dem Zurijekeriefien in das Reservoir wurde dasselbe stets so lange mit atmosphärischer Luft geschiittelt. bis es vieder die hellrote arterielle Fïroung angenommen hatte und daranf durch lecinwand koliert.

Die Iburchleituneren dauerten immer mehrere stunden (von :) bis 8 stundenl. Aus dem Lreter flofen mitunter spärliche Mengen eiuer anfangs klaren. alkalischen, achlichen Fliissigkeit, die Eiweil enthielt und zuletzt eine rötliche Färbung (Hh) annahm. In anderen Fällen floßen nur wenig̨r Tropfen ..einer serumähulichen" Flissigkeit ah.

Der am Manometer abgelesene Durchströmungsdruck schwankte zwischen 100-1:0 $\mathrm{mm}$ IJg. 
bie gebildeto Hippursäure wurde sowoll in dem ..venüsen" Blut, wie in rer Ireterfliissigkeit. wic in Nierenparenchym gefunden.

Vou den Methorlen, die man nenordings fiir Sitoffwechseluntersuchungen an isolierten Warmbliternicren vorgeschlagen und zum Teil angewendet hat, seien noch die folgenden erwähnt:

\section{Methode rou Jarobj und $v$. Sobieranslit. ${ }^{1}$ )}

Die Methode der Nierenisolierung, deren sich C. Jacolij und v. Srolieranski zu ihren 1)uchblutumgsversuchen hedienten, war die folgende. sie wurle ausschlieblich an frischen Hundenieren ausgefiihrt. Ins einer in die Carotis des l'lues eingefïhrten Kanüle lïlit man die zum fiillen des hesonderen, ron $C$. Jacobj erfundenen Durchströmungsapparates erforderliche blutmenge (meist :300-400 $\mathrm{cm}^{3}$ ) ausflichen. Dann klemmt man das Gefäf wieder ab und stellt mit dem aufgefangenen, gut defibrinierten und kolierten nnverdiinnten Blute den Apparat zur Anfnahme des Organs völlig fertig. Sodann entzicht man dem 'Tiere vou nenem so viel Blut, bis es röllig bewubtlos wird. Jetzt wird die Banchhöhle durch einen Schnitt in der Linea alha greöffnet. bei noch erhaltener '/irkulation die Niere durch Massenligaturen mit der Fettkapsel von der Lmgehumg getrennt, die Arterie und Tene präpariert, die zum Abbinden der zentralen Gefäfienden und zum Einbinden der Ḱanüle nötigen Ligaturen vorbereitet, sowie der Ureter mit ciner Kanüle versehen. Ist dies alles geschehen, so läbt man das Tier entweder schmell röllig verbluten, oder es werden bei noch erhaltenem Leben nach zentraler Interbindung der Nierengefïbe in das periphere Ende derselben die Kanïlen eingebunden, die der Arterie mit Blut gefüllt und nun sehmell die Niere rölig losgetrenut und in den Apparat eingeschaltet. Die Temperatur des Blutes und des Organs wmile etwa bei $37-38^{\circ} \mathrm{C}$ gehalten.

\section{Terfalien voll Skutul. $\left.{ }^{2}\right)$}

Die Tiere (Hund. Katze. Kaninchen) werden durch Verbluten getötet. Durch die eröfnete Brusthöhle wird cine Kanüle in die Aorta thoracica und eine zweite in die Vena cara inferior cingefiihrt. Durch die erstere wird das 'lier mit auf $39^{\circ} \mathrm{C}$ erwïmter. mit (), gesättigter Lockescher Lösung so lange durchgespiilt, bis die aus der Vene fließende Fliissigkeit ganz klar ist. Darauf wird die Banclıhöhle in der Linea alba eröffnet. Die Darmschlingen werden so weit seitlich rerzogen, his das Organ frei zutage liegt. Danach wird es stumpf oder mit cinem Messer von dem umliegenden Fettgewebe samt der liapsel und einem Teil des anhängenden Fettes losgelöst und die A. resp. V. renalis gleich nach dem Abgang ron der Lorta ab-

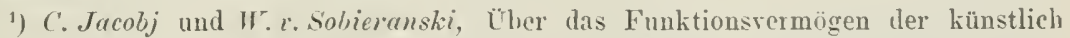
durchbluteten Niere. Arch. f. exper. Path. u. Pharmak. Bd. 29. S. 25-40 (1892). $273(1908)$.

2) K. skutul, Über Durchströmungsapparate. Ifflügcrs Arch. Bd.123. S. 249 bis 
dominalis resp. der Vena cava durchschnitten. um die Kaniilen noch ror des Teilung der Gefäße im Hilus der Niere bequem einführen zu kömnen. Die Kanüle in der A. renalis wird unter Beobachtung der ïblichen Vorsichtsmaßregeln, die für die Vermeidung von Luftembolien unumgänglich sind, eiıgeführt. Zur Untersuchung wurde stets die linke Niere bevorzugt, weil ihre Gefälje länger sind und das Einfiihren der Kanülen daher leichter ausführbar ist. Als Durchströmungsapparat diente der von Skutul neu konstruierte Apparat. Es fehlen Angaben ïher die damit erzielten Versuchsergebnisse, die ein Urteil über den Wert der angewandten Methode gestatten kömten.

Bemerkung. Muf die Sekretion eines, wenn auch verdiinnten. sonst aber doch nur normale Harnbestandteile enthaltenden Nierensekretes das Richtmaß sein. nach dem die Lebenstätigkeit einer isolierten Niere beurteilt werden soll, so ist man bis jetzt nach I'faff' und I'ejnx-Tyrode') noch nicht dazu gelangt, mittelst künstlicher Durchblutung aus der isolierten Niere ein wirklich normales Sekretionsprodukt zu erhalten. Sie suchten selbst durch zahlreiche Versuche dieses Ziel zu erreichen. Sie sahen nur, daß defibriniertes Blut ein fiir die Ernährung der Niere ungeeignetes Material ist. und daß man dazu kiinftig vielmehr durch Blutegelextrakt ungerinnbar gemachtes Blut mit Aussicht auf Erfolg anwenden sollte. Auch sie hielten die Temperatur des Blutes und des Organs auf etwa $38-40^{\circ}$.

Die Unzulänglichkeit der bisherigen Durchblutungsmethoden an der isolierten Niere, wenn man vorhat, mittelst derselben physiologisch normal Lebensvorgänge dieser Drüse zu erforschen, erkennen übrigens auch Brodie und Cullis ${ }^{2}$ ) in ihren Untersuchungen iiber die Harnsekretion an.

Eine anscheinend vorteilhafte, jedenfalls mit geringeren praktischen Schwierigkeiten verbundene Anderung in der Methodik für Stoffwechseluntersuchungen an ausgeschnittenen Warmbliiternieren haben T. Sollmann ${ }^{3}$ ) und H.M. Vernon ${ }^{4}$ ) bei ihren zahlreichen Versuchen eingefiilırt.

Sie bedienten sich einerseits zur Durchströmung des isolierten Organes (anstatt des Blutes) der sauerstoffhaltigen Ringerschen Salzlösung, und andrerseits stellten sie ihre Versuche nicht bei Körpertemperatur, sondern bei Zimmertemperatur $\left(15-20^{\circ} \mathrm{C}\right)$ an. Der Flüssigkeitsdruck war fermer ein konstanter.

1) E. I'faff und M. Vejnr-Tyrode, Uber Durehblutung isolierter Nieren und den EinfluB defihrinierten Blutes anf die Sekretion der Nieren. Areh. f. exper. Path. und Pharmak. Bd. 49. S. 324-341 (1903).

2) T. G. Brodie and W.C.Cullis, On the seeretion of urine. Journal of Physiol. Vol. 34. p. $222-249$ (1906).

3) T. Sollmam, Perfusion experiments on exeised kidneys. The American Journal of Physiol. Vol. 13. p. $241-303$ (1905); Vol. 19. p. 233-254 (1907); Vol. 21. p. 37 bis 50 (1908).

$\left.{ }^{4}\right)$ H. M. Vernon, The Rate of Tissue Disintegration, and its Relation to the Chemical Constitution of Protoplasm. Keitschr. f. allgem. P'hysiol. Bd. 6. S. 393-441 (1907). - Derselhe, The Conditions of Tissue Respiration. Journ. of Physiol. Vol. 35. p. 53-87 (1906-1907) und Vol. 36 p. 81-92 (1907). 


\section{Methorde vou Siollmann. ${ }^{1}$ )}

Sollmann verfihrt folgondermafien. Die 'Tiere (Hunde) werden znnảchst durch Morphium und Ither narkotisiert. Inuch einen medianen Länersschnitt und einen zweiten Querschnitt (unterhalh des lippensaumes) dureh rlie Bauchwand werlen die Nieren bloforelert. Ihre Fetthiille wird entfernt, ohne Verletzung der filorösen Kapsel. Ereter und Nierengefälie werden isoliert und freipripariert. Eine Kantile wird in den Ureter eingefuihrt und ihr freies Ende mit einel gebogenen susflubrölue verbunden, die zu einer Öffnung von etwa $1 \mathrm{~mm}$ Iurchmesser ausuezogen wird. Die Nierenarterie wird dann dicht neben der Aorta unterlunden und in ihr peripheres Ende eine Cilaskaniile cingebunden. Diese Crlaskaniile, nit der Sal\%lösung gefüllt, wird dann mit dem Rohr des Inrchströmungsapparates verbunden, der inzwischen rorbereitet war. indem er mit der (im allgemeinen $1 \%$ Va Cl) Salzlisung gefiillt und auf (inen Inuck von $100-140 \mathrm{~cm}$ Wasser eingestellt wurde. Ohne weiteres wird nun die Durchströmung hegonnen und so langre fortgesetzt, bis die Flissigkeit aus der Tene fast farblos erscheint. Diese vorläufige Durchströmung hat den /weck. die intravasal. Blntgerinnung zu verhindern. Wird diese Mafregel nicht retroffen, so danert es dann lange \%cit. ehe sich rin konstanter Ausflul; einstellt. Hierauf wird die Jurchströmung sistiert und die Vierenvene dicht neben der V. cava unterbunden und in deren Lichtung, wegen die Niere zu, eine andere Glaskaniile eingefïhrt. Sodann werden die Gefäbe unterhall) der Kaniilen durchschnitten. die Niere herausgenommen und anf ein kleines Stativ gelegt. Eine kurze gebogene (ilasıöhre, die zu einer öffnung von etwa :3 mm Durchmesser ansläuft. wird zum Auffangen der ausfließenden Flissigkeit mit der Venenkaniile verlounden. Die Arterienkaniile wird unter Termeirlung jeglicher Knickung der Gefäfe mittelst einer Klemme befestigt. Iie Niere wird ror Austrocknumg dadurel geschiitzt, daf sie mach Munk mit einem aus der Bauchwand herausgeschnittenen Hautmuskellappen berleckt wird.

Die aus der Vene und dem Ereter ausflefend Flissigkeit wirl in Bechern aufgefangen und dabei schätzt man die Durchströmungstreschwindigkeit entweder durch Zählung der ausfliefenden 'Tropfen oder durch Messung der \%eit, die notwendig ist, damit sich eine bestimmte Menge (gewöhnlich - $15 \mathrm{~cm}^{3}$ ) gesammelt hat. Dabei ist der [umstand zu berieksichtiren, daff wegen der geringeren Lichtung des Ausflubrohres die aus dem Ureter stammenden Tropfen ein I)rittel his cine Hälfte der (iröbe derjenigen haben. die aus der Vene herauskommen.

Während der Durchstrionung sickert immer etwas Fliissirkeit aus der Vierenoherfläche durch die Kollateralgefäbe. was jedoch keinen weiteren Einfluli auf die Versuchserobebisse hat.

1) T. Sollmann, Perfusion experiments on excised kidneys. The American Journal of Physiol. Vol. 13. p. 241-303 (1905): Tol. 19. p. 233-254 (1907): Vol. 21. p. 37 bis jo (1908). 
Manchmal teilt sich die Nierenaterie so nahe der Iorta. dab es unmöglich ist, in den fiesamtstamm eine Kinnile rinzufüluren. Bei solchen seltenen Fällen wurle die Kaniile in den Hauptzweig eingebunden und der andere nuterbunden.

Ganz besonders mub man damuf achten, dab keine Luft in die Nierengefälie hineingelaugt. Sie hat sonst eine plïtzliche Terminderung des lenen- mul I reteransflusses zur lolge und macht die Viere für etwa cine Stunde unbranchliar.

I) ron Sollmum bei seinen Untersuchungen angewendete burhströmungsapparat ist äuberst einfacher und bepmemer Ilandhabmog. wie aus der nebenstehenden Fig. 111 zu entuehmen ist. Das lieservour hat eine liapazitat ron $100 \mathrm{~cm}^{3}$ bis 27 , nnd wird otwa $1 \% \mathrm{~m}$ oberhalb der Niere mittelst einer liolle suspendiert. Der Imorehströmumgsdruck wird zwischen der Niere und dem mnteran Ende des im liservoir befindlichen mud in die Fliissigkeit tauchenden Glasrohres, das bei der Anordnung Luft durch die Flïssigkeit hindurchperlen lifft, gemosson. Das Verbindungsohr zwischen dem Reservoir und der Niere hesteht aus sich ahwechselnd folgenden Stiicken Kautschulischlaurh und Glasrohr, damit etwaige Luftblasen loicht enteleckt werlen. Das T-Rohr neben der Viere gestattet die Entfernung dieser Blasen, sowic das erentuello Wechseln der Inuchspiilungsfliissigkeit.

Dir auf diese Weise duroliströnte Niere kamn nach Sollmam einen Tag lang in eincm \%ustand erhalten werlen. der einige Erscheinumen gewisser lieste von Vitalitait dor Intisanelemente erkemen lälit. Inose Bufunde sind: 1. gewisse Tutersehiede in der \%usammensetzung der Durchspiilungsflissigkeit und der Treterflissigkeit; 2. synthese der Hippursüure: 2. l'iementexketion: t. Reduktion des Hämoglobins. Andre lobenserscheinungen bezichen sich nicht anf die eigentlichen Driisen-

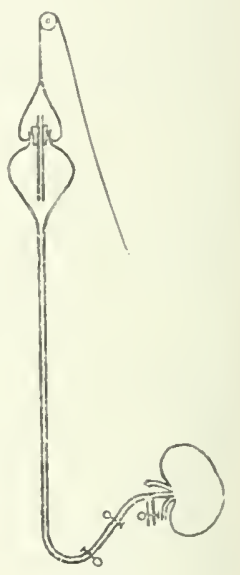

Fig. 111 remente. sondern anf diofrefäle. wio \% l). Adrenalinwirkung.

Ternon fuilut norh andere Momente zur Kontrolle der Vitalitiit dele \%ellen an. z. I. die Verfoleung des rasstoffweelsols.

\section{Muskelsystem: Herz.}

Als das fiur Stoffwechseluntersurhungen an isolierten iiberlabenden

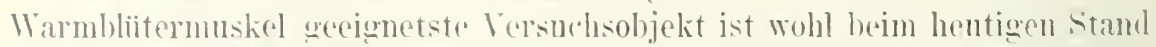
der Wissenschaft der isolierte Hermuskel (von Kaninchen, Katze. IJund) zu bryeichnen. bie Vorteile dieses Verfahrens sind in den folgenden Imständen zu erblickeru:

1. Diø vorhälnismäsig einfach und schmell ansfibrbare Isolirmun! des ( ) logins.

2. I) le lange I"berlebungsdanes: Wemn man die Methode Langendorfts 


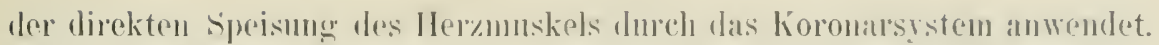
(I)abei schlägt das Her\% le(r).)

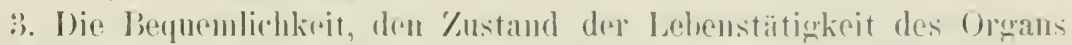

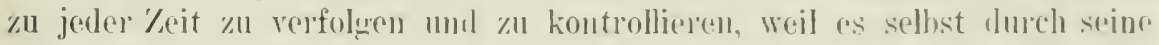

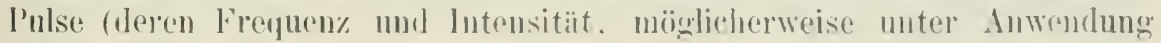
der graphischen Methoden vor allem zu beriicksichtiscoln sind) den jewriligen

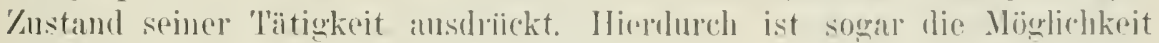
gegeben, die Bezichungen des Stoffwechsels zun Kraftwohsel experimentell z.ll ermittelı.

4. Die leichte Ausfiihrung der Inrehstrimmun, sei es hinsichtlich der geeignetsten Nährflüssigkeit (die einfache limyer-Lockesche Lösungr), sei es hinsichtlich der dazu nötigen Ipparate. hei denon die Totwendioreit wegfïllt, den Fliissigkeitsstrom rhrthmisch z,l unterhalten.

Zwecks der 'Trennung des Herzens ron den iibrigen lïrperhestandteilen (namentlich suchte man hierbei das Her\% rom Einflusse des Vervensystems zu befreien) wurden von den Phrsiologen mehrere Methoden angegeben. Von diesen kommen aber hier niu diejenigen in lietracht. die das vollständige Isolieren des Herzens von allen ïbrigen Geweben erielen.

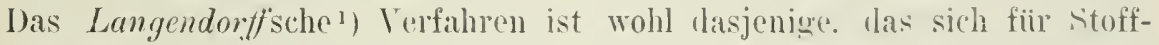
wechseluntersuchungen an isolierten Herzen wanz hesonders eignet. was auch aus den bisher schon ausgefiihnten [ntersuchungen [(.Joh. Miiller ${ }^{2}$ ), Locke und Rosenheim ${ }^{3}$ ), M. Camist)] hervorweht.

\section{Langendorffs lerfahren.}

Die Versuchstiere (Kaninchen odel liatzen) werlen aus der Carotis entblutet. Während oder nach Ablauf der terminalen Atembeweormngen wird das Herz durch Entfernen des Brustheines froigelegt, wobei im ersteren Falle eine Verletzung der Venen wegen der (iefahr ciner Luftembolie zu rermeiden ist. Nach Spaltumer des l'erikards wird um die Aorta eine Sohlinge gelegt, eine Öffnung in die Aortenwand geschnitten, durch welche zunächst die Blutreste fortgespiilt werten. llann wird die an den schlauch einer warme Ringersche Lösung enthaltenden spülflasche angesteckte cinfache Glaskaniile, deren Lumen dem der Lorta entspricht, mter einem schrachen Fliissigkeitsstrahl in die Aorta cingefüht und festerebunden. Dabei ist - larauf zu achten, daß die Spitze der Kaniile nicht zu nahe an die Klappen geschoben wird, weil dadurch deren schlubfälnigkeit leiden könnte. Das durch einige Scherenschnitte loswetremte Herz wird sorlann in eine Schale mit wamer Ringer-lösmme relegt und durch leichtes lineten vou dem

$\left.{ }^{1}\right)$ O. Langendorff', Untersuchungen an überlebenden Süngetierherzen. Pflügers Arch. B(1.61. S. $291-332$ (1895).

$\left.{ }^{2}\right)$ Joh. Mäller, Studien üher die Quelle der Muskelkraft. Zeitschr. f. allø. l'hysiol.

Bd. 3. S. $282-302(1904)$.

$\left.{ }^{3}\right)$ s. Locke and O. Rovenheim, Contributions to the I'hysiology of the isolated Heart. Journal of Physiol. Vol. 36. p. $205-220$ (1907).

4) M. Camis, Sul consumo di idrati di carhonio nel cuore isolato funzionante. Zeitschr. f. allg. Physiol. Bu. 8. S. 371-40t (1908). 
Blutinhalte möglichst hefreit $\left[\left(J\right.\right.$. Mäller $\left.{ }^{1}\right), H$. Winterstein $\left.\left.{ }^{2}\right)\right]$. Hieranf wirl das [Ierz mit dem Durchströmungsapparat rerbunden.

Von allen bisher beschriebenen Inrchströmungsapparaten für das isolierte Her\% scheint mir derjenige. (den nenerdings Locke und Rosenheim ${ }^{3}$ ) angewendet haben, am besten für stoffwechseluntersuchungen geeignet zil sein, namentlich wenn es sich ( was wohl im hïnfigsten zutreffen wirl) mu Bildung oder un Verschwinden bestimmter stoffe in resp. ans der Durchspiilungsfliissigkeit dured die Her\%titigkeit landelt, dil bej der Ilethorte dieselbe Fliissigkeitsmenge zu viederloblten Malen das Herzoewebe passicet.

Vebenstehende

Fig. 112 veranschanlicht das Verfahren. Ans dem lieservoir $C$ flient die Inrchströmmugslii.siokeit infolge ihres hydrostatischen Inuckes durch das sehlamerenrohı zimm Her\%en Hachdem sio durch lortal bunl coronargefoulio durchestroimt ist, tropft sic in den das Ifer\% $\mathrm{mm-}$ sebenten zylindrischen 'l'richtes $H$ ab, 1113 von hied dureh das senkrechte Rohr A ( A lusflub roln') hinunterzufliefien.

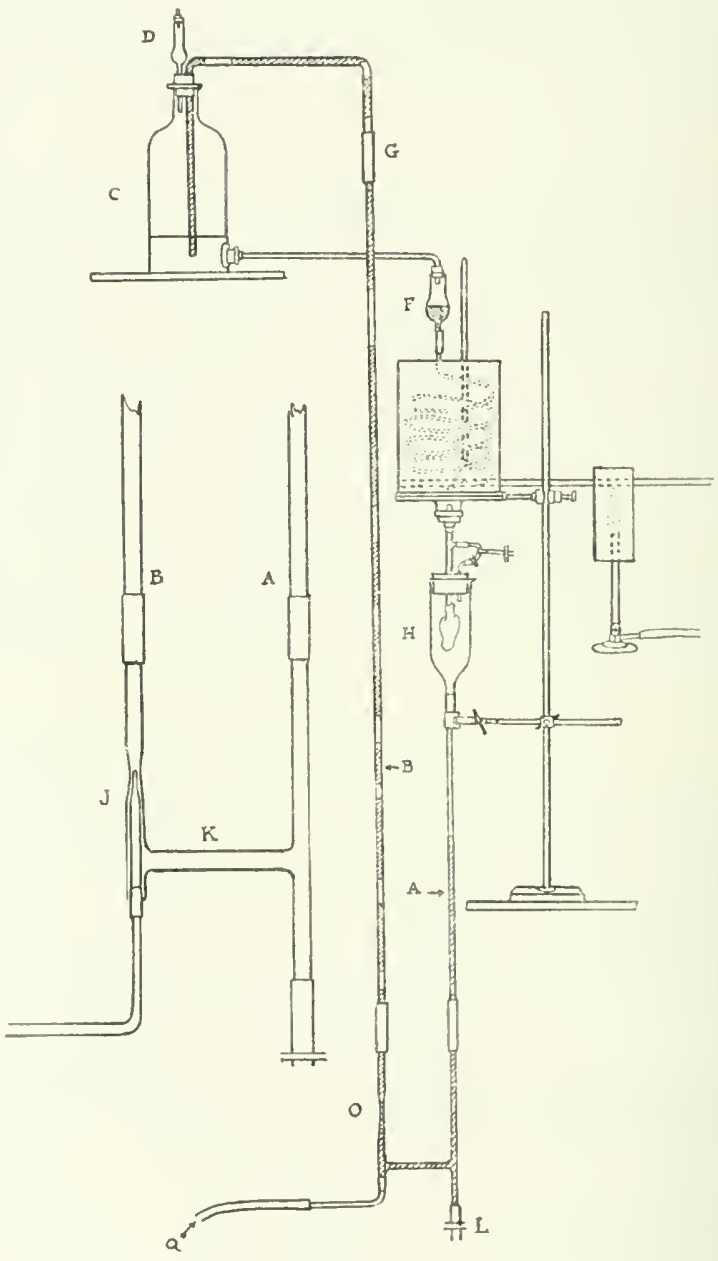

Fig. 11 ?

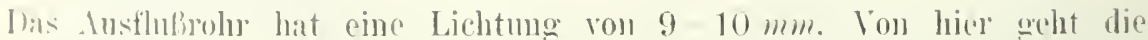
Fhiissigkejt zmuächst dured das wagerechte Verbindungsroh zur samer-

1) Joh. Vialler, l. e.

2) 11. Winterstein, Wher die Saucrstoffatmung des isulierten Süngetierherzens. \%eitschr. f. allg. Physiol. Bel. 4. S. 333-3.88 (19)-4).

3) S. Locher and 1). Rosenheim, 1. c. 
stoffpumpe 0 . dureh welche der komprimierte Sauerstoff als eine langsame mud reachnälig kontinuierliche lieihe ron Gashlasen hinaufsteigt. Las aufsteigende (ias reilit durch das Aufsteiglohp (B) rou $7 \mathrm{~mm}$ Lichtung die Flissigkeit als eine lieihe von kumen silulen verschiedener Lïnge mit sich, bis es schlieblich in das lisservoir zurickfliel.j. Hicromeh wird offenbar nicht nuy das /,uriekstrümen dej Flïssigkeit, sondern auch deren oxygenation an besten bewilkt.

Bei ihrem flurchgang vom Reservoir zum Herzen flieft die Flissigheit zunächst durch einen Filter ans filaswolle $(F)$ und hierauf durch das Schlangenrohr, wo sie sich erwarmt. Das kupferne Wasserbad. in den das Schlangenrohr enthalten ist, wirl mittelst eines in seine Wand gelüteten, $1 \mathrm{~cm}$ dicken Kupferstabes, dessen froies Ende durcl cinen an ihm befestigten Bunsen-Brenner erwärmt wird, auf annihernd konstanter Temperatur (:G6-;80) erhalten. Durch passende Änderung des Abstandes des brenners vom had ist man imstande. dessen 'lemperatur bequem mod gut zu regulieren. Der Wärmegrad wird an einem in Wasserbad rersenkten Thermometer ahoelesen.

I)ie Lianiile, die das Ende des Schlangenrohres mit der Lorta verhindet. hat $\&$ mm Lichtung und wird lurch den paraffinierten Pfropfen gresteckt. der den zylindrischen Herztrichter zuschlieft. I)as der Helzkaniile angeschlosscne Scitenröhrchen, das ebenfalls durch den Pfropfen durcheführt wird, ermöglicht das Entweichen etwaiger Glasblasen ohne Verlust dor Unuchströmungsflissinkeit.

bie Höhe des Ansflubohres, vom unteren Ende des zylindrischen Trichters $H$ bis zum Verhindungsrohr gemessen, hetrïgt $65-70 \mathrm{~cm}$. Die Höhe des Aufsteigrohres, rom lejbindmusstiick zum Niveau der Rescrvoirflüssigheit, betrigt hingegen $11 \bar{\partial}-120 \mathrm{~cm}$.

Der komprimierte Sancrstoff strömt ans scinem Bchälter zunächst durch eine (in der Figur nicht gezeichnete) Woulffsche Flasche, die Wasser cnthält. I)as Gas wild hithei gewaschen und olleichzeitio sättigt es sich mit Wasserdampf. Dieser l'rozel dient zur Vermindermo des Wasserverlustes. der während der Inurhleitung infolge der Vordanpfunw entsteht. Zwischen der IVoulf'schen Flasche und der Pumpe wird zur Vermeidmo von eventueller Zuriekströmmog der 1)urchleitmosfliissigkeit ein Glasventil eingeschaltet.

Einige Zentimeter oberhalb des Verhindmustohres $K$ (rol. die nehen der Hauptahbildung einzeln gezeichnete Gauerstoffpmupe) rerengt sich die Lichtung des Aufsteigrohres von 7 mm zu etwa : mm. In dieser Stelle befindet sich die Sauerstoffspritze (J), die $1 \mathrm{~mm}$ Lichtung besitzt. Dic Flissigkeitssäule im Ausfubrohr zeigt eine um so geringere Höhe, je melu die P'umpe arbeitet.

Die Durehspuilungsflissigkeit hat folgende /usammensetzmng: Na Cl

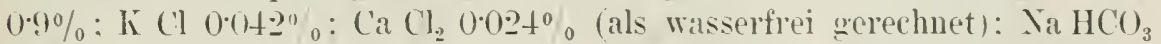
$0 \cdot 0.2 \%$. Beim Beginn des Versuchs wird das $\mathrm{NaHCO}_{3}$ allein zur Lösmı zugesetzt, mu dic schwache Fällung ron $\mathrm{CaCO}, 3$ möglichst einzuschränken 
Die Liismng enthiilt anferdem (ilukose von $\left(1 \cdot 1-(1 \cdot 25)_{0}\right.$, die immer frisch heim Beginn des Versudes limzngufiigt wird.

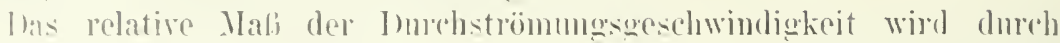
Zailulung der Tropfen geschätzt, die in jeder Minute durch den Cilasfilter passicren. der gewöhulich efwas Luft enthält. Im wiederwegehenen Versuch

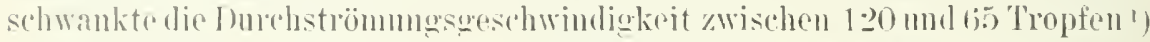

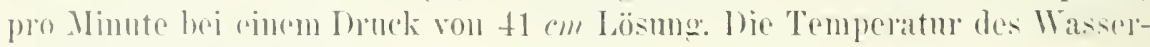
basles wall :36-1 - $37^{0}$.

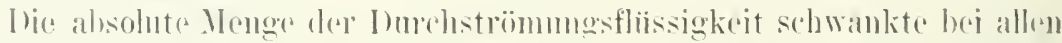
Vorsuchen zwischen 100 mul $250 \mathrm{rm}^{3}$. Thas isolierte Kaninchenher\% sehho unter diesen Versuchshedingungen während der ganzen Versuehsdaner. die

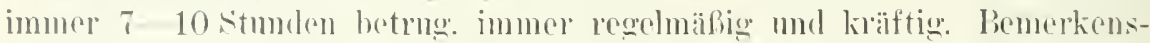
wert ist noch der Imstand, dali in keinem Fall IIer\%schwäche den Giruml der rersuchsunterhechung darstellte.

\section{Skelettmuskeln.}

Von den Beobachtungen ansgehend, daf die bis dahin des Stoffwechsels isolierter (Troune ersommenen Vethoden stets nui eimen Teil des l'rozesses der Mlesinng zngingelich machen. indem man entweder nme den Ciasanstansch oder sonst bloh den Wechsel ron nicht fliichtigen

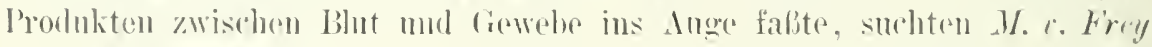

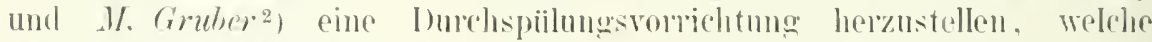

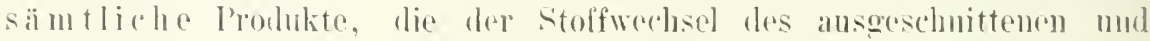
kiinstlich durchegeleiteton ()roanes liefert. der Untersuchumg zugänglich

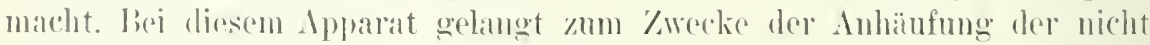
gasförmigen l'rodukte nur oine midrige Menge Blut zu oft wiederholten Maten zm lonrdheitung. Ihre Arterialisierung wird abor stetig und in solcher Weiso bewerkstelligt. dath die gesanten ansgetausehten Gasmengen

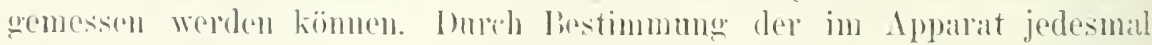
kreisenden bilutmenge mod dured Analyer der an schlub des Versuches

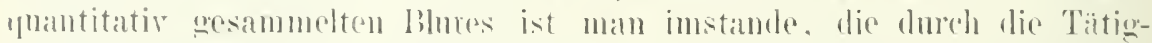

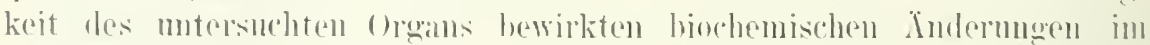

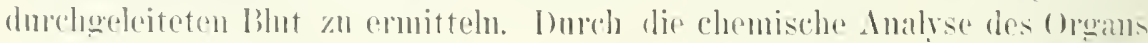
selbst kamm man andrerseits die in ihm stattorefundenen chemischen Cinderungen feststellen.

I ie Branchbarkeit des Apparates wurde von H. r. Frey am isolierten

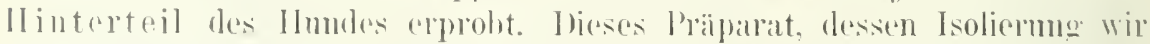

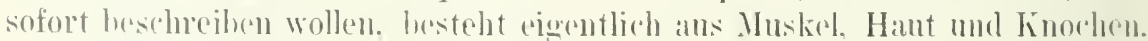

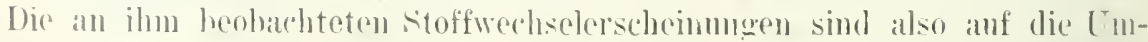

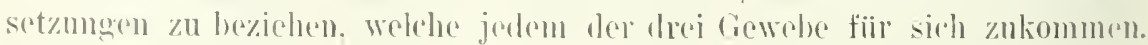

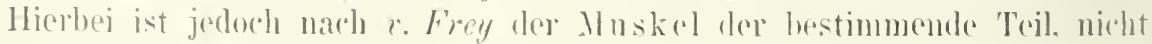

1) 100 Trepfen $=9 \mathrm{~cm}^{3}$.

2) K. L. Frey und M. Combre, Untersuchungen über den Stoffwechocl isolierter Organe. Arehir f. (Anat. 11.) Physiol. S. 519-562 (1885). 
mur, wril a in Ciesamterewicht des l'räparates mit denn gröblen Anteil $660 \%$ und dariiluer) vertreten ist, sondurn weil er auberdem am reichlichsten vom Iblut durdiströint wird. Die Haut zeigt ein werbselndes Verhalten. Bei Körperwärne ist sie gerötet: Einschnitte füluren zu kleinen blutungen. muter Kö̈rperwäirme ist sic blah und so blutillm, dali man grefahrlos cinschneiden darf. bihenso sind aus durchschnittencon Knodhen die Blutungen änferst geringfïgig. Immerhin wird man aher. namentlich be hïrperwärme.

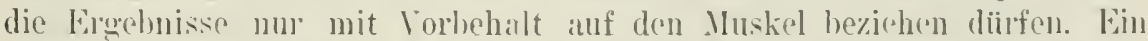
Torteil bei dem l'rëparat ist jedoch in dem I'mstand zur crblicken. dal' die Muskeln in iler unversehnten Hautereke gearen Gaskliffusion nach auben geschriit\%t werden. I)ieser Schut\% wirl norh erhöht und zugleich ein Wittel

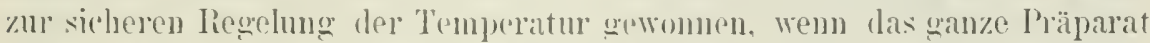
unter. Wasser rersenkt wird. Weitere Vorteile des I'räparates gegeniber anderen Methoden, bei denen die Inskeln wan\% isoliert werden, sind ferner 1. die leichte Crewinnum grolier Vluskemassen, ‥ die rasche und sichere Art, sie in die Durchleitung aufzunchmen. :) die Möglichleit, die Muskelnerven selbst in den stimmen und Turzeln reizhar zu crhalten.

Einwandfreie Erogehnisse sind an diesem l'rïparat in den Fällen wohl zu erhalten (d. h. bei der Mohrzahl der an den Muskeln angestellten Lntersuchungen dieser (rt), bei dencn es sich um Veroleiche zwischen Puhe und Arbeit handelt. Es ist mzweifelhaft zuliissig. dic Verändermgen. die sich infolge ron Tieizungen des Inskek im Stoffwechsel einstellen, auf das crereizte Gewebe zu bezichen.

Behufs der Isolierung seines Hinterteiles wirl der Versuchshnud durch Verblutung getïtet. Emmittelhar nach dem Herzstillstand werden die Bauchdecken dicht am Pippenrande durchtrennt. die Eingeweide in die Höhlung des Zwerchfells gredringt und mit Jusnahme des untersten von der Art. mesenterica inf. versorwten stiickes des Iastdarms von ihrem Mesenterium abgelöst: der Stmupf des Mastdarms wird unterbunden. Endlich wird die Wirbelsïule simt ihren Muskehnasson zwischen Brust- und Lendenteil. oberhalb der Nieren durchschnitten. I as Präparat ist hierdureh vollkommen abgetrennt und enthiilt an Eingeweiden nur noch die Nieren und die im kleinen Becken hefindlichen Teile. Irel nïchste $\mathrm{Akt}$ ist die Einsetzung je einer Glaskaniile in die Vena cava und dorta, und zwar dicht mnterhalb des Ahganges der Nierengefüfe. Die Nieren werden also nicht in den kïnstlichen Lreislauf aufgenommen: ihre rollkommene dusschlieliung erfolgt durch eine Fadenschlinge, welche die durchschnittenen Muskehn der Lendenwirhelsiule ungreift und zwischen den Nieren und den Glaskaniilen durchgezogren wird. Emmittelhar darauf. d. h. 10-15 Ninuten nach dem Tode des Tieres, beyinnt die Einleitung von defibriniertem Blut des Durchspülungwapparates. I as Blut, das zun̈̈chst aus der Vene des l'rïparates kommt, liblit man herausflieben. Es wird nicht weiter rerwendet.

Resomlere Sorofalt ist der Stillung des aus allen iibrigen durchschnittenen Hilutgefïlien des Präparates herausfliefenden Blutes zu widmen. Drei Massenligaturen reichen aus, um sämtliche Gefäße der Schnittwunde 
rollkommen sicher zu verschliefon. Die erste derselben ist für die durchschniftenen lenen des Wirbelkanals und wird hergestellt durch einen kleinen liork. der nath Ibtragung eines kmmen stïckes laiickenmark otwa 5) $\mathrm{mm}$ weit in die Höhlung ringesteckt wird. (Aus den Gefälien des litickenmarks selbst entsteht keine blutung.) Die zweite (iesantligatur hat die ganze Nuskehnasse zu umgreifen, welche den Stumpf der Lendenwirbelsänlo einhiillt. In dieser bezichumg kamn die oben erwïhnte Fadenschlinge, die unterhalb der Niere durehgezogen worden ist. um als eine provisorische

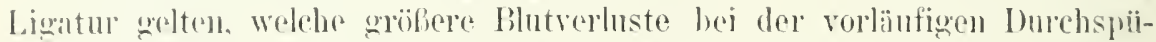
lung rerhindern soll. lie vollständige stillung der libutmog gelingt nur durch sehr kräftige lompression. Hierzm wirl der Wirbelstumpt sunt Inskeln und Rïrkenhant ron den A'men einer starken ejsernen Zange unfatit und durch Anziehen von schrauhen eingeschniirt. 1)ie Nieren werden hichanf entferut. Dire dritte Massenligatur hat sehliedilich die Jufgabe, blutungen ans den durehsehnittenen Gefïhen der banchwand zn verhindern.

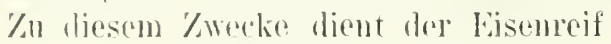
(lep nebenstehenden Abbildung (Fig. 113) ats sicheres mol borpuemes Hilfsmittel.

Lel' licif muli voll ciner cirölic sein. dals ar sich in die Batuchhöhle. des l'raipatrates berguem einfiihren lälbt. Labed sollen die baurehwandungen iiber den lieif zn liweren kommen. Die narls inmen gebogenen Enden ruhen auf den (Querfortsiitzen der Wirhel; es bleibt somit nur der Irithelkörper mit den auf ilum liegenden grofien Gefälien frei. Wird num ein statrel Mraht iiber den Weichteilen in die kible des lieifes gedriickt, hinter der Wirbelsïule hertumgefiilurt. und

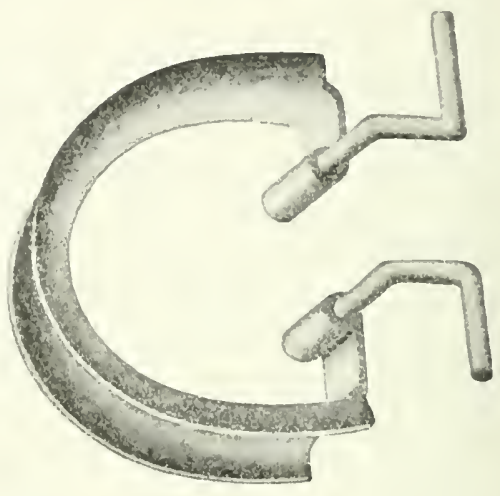

Fig. 113.

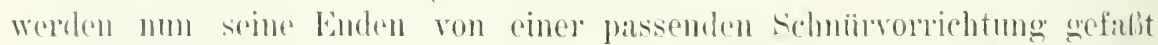
und ingerogen. so sind sïntliche Weichteile - Haut und Muskeln dureh die aine soldinge umfalbt und deren Gefälie unterbunden. Nur fuir die Arterien der tiefen Rïekemmuskulatur ist diese Ligatur zuweilen nicht

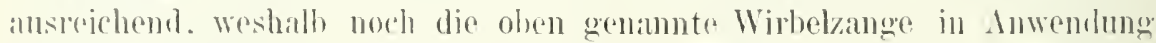

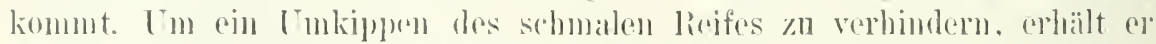

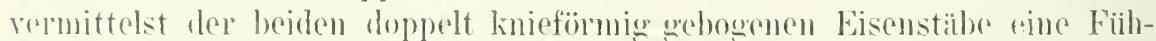
rmog in der Wiblatuge, in der er sich wie in einem scharnier bewegen

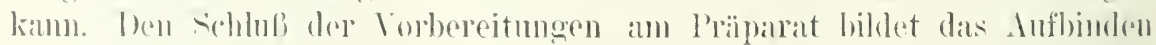

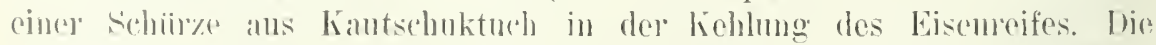

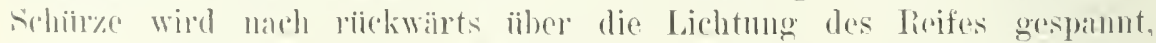

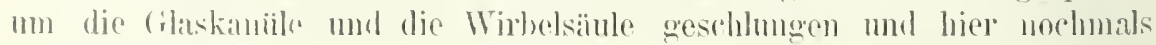

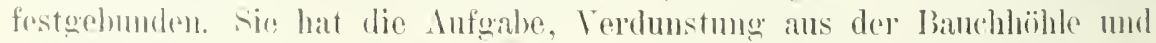

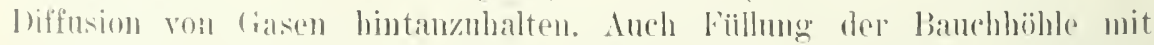

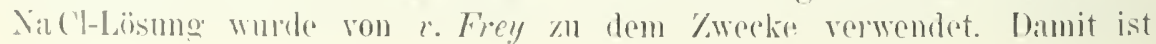


das l'räparat zur Anfuahme in den Apparat fertig. Das Präparat wird nun bis an den Eisenreif in das Wasserbad versenkt und in dieser Stellung festgehalten. Die Káanilen der Aorta und der Cava werden mit den Enden der Blutleitung verbunden.

Die Lebenstätigkeit der Muskeln kann man durch elektrische Reizung der zugehörenden Nerven feststellen und verfolgen. Lm alle motorischen Nerven zusammen zugleich reizen zn können, führt man die eine Elektrode in Gestalt einer langen und schmalen Drahtschlinge in den Rückenmarkskanal ein, so dal3 sie zwischen Dura und Wirbelbögen zu liegen kommt. Die Schlinge schmiegt sich also, indem sie den Körper des Ruickenmarks zwischen sich nimmt, an die hintere Fläche der austretenden Wurzelpaare an. Als zweite Elektrode dient der oben erwähnte Umschnürungsreif, dessen Enden fest gegen die Querfortsätze der Wirbel drücken. Beide Elektroden lassen sich ohne neue Verletzungen dem Präparate anlegen nnd die Reizung trifft sämtliche Nerven, die aus dem Lendenmark entspringen. Ihre Wirksamkeit beweist, daß, wenn nicht dem Rückenmark, so doch den Nervenwurzeln die Reizbarkeit erhalten bleibt. Am besten läßt sich dies bei den "kalten" Versuchen, wo sie selbst nach istündiger Versuchsdauer noch ungeschwächt befunden wird, beweisen. Aber anch bei den ..warmen" Versuchen, bei denen die Reizbarkeit rascher abnimmt, läßt sich durch vergleichende Prüfung der direkten Muskelreizbarkeit zeigen, daß der Grund des geringeren Erfolges im Muskel und nicht im Nerven zu suchen ist.

Die von Frey angewendeten Reizungen waren meist tetanisch. Die dadurch ausgelösten Bewegungen betreffen alle Muskeln zu gleicher Zeit. Das Ergebnis ist aber infolge des Utherwiegens der Mm. extensores eine Streckbewegung. Sie geht in dem Wasserbade vor sich. Um sie beobachten zu können und gleichzeitig ein Maß für den Betrag der Streckung und damit für die Wirksamkeit des Reizes zu gewinnen, wird an jede Pfote eine Schnur mit Gewicht (meist $500 \mathrm{~g}$ ) gebunden, welche derart über Rollen läuft, daß während der Ruhe die Beine an den Leib angezogen werden. Jede Streckung wickelt einen Teil der Schnur ab und es können die Längen an einer Millimeterskala abgelesen werden. Die Arbeit jedoch, welche die Streckmuskeln leisten, ist, da sie den Widerstand der Antagonisten zu überwinden haben, viel größer als der sichtbare äußere Effekt.

\section{Überlebungsdauer.}

Es wurde schon betont, daß die Utberlebungsdauer in enger Beziehung zur Temperatur steht. $v$. Frey unterscheidet in bezug auf die Temperatur drei Versuchsreihen: 1. Kalte Versuche, bei denen Blut nnd Präparat auf Zimmertemperatur, ca. $20^{\circ} \mathrm{C}$, gehalten werden. 2. Halbwarme Versuche, bei denen das arterielle, auf Körpertemperatur vorgewärmte Blut in einen Muskel gelangt, der sich in einem Wasserbade ron ca. $20^{\circ}$ befindet, wodurch das venöse Blut anf 32 bis $34^{0}$ abgekihlt wird. 3. Warme Versuche, bei denen die Bluttemperatur zwischen 36 und $39^{\circ} \mathrm{C}$ schwankt. 
Vit der 'J'emperatur ändert sich matiirlich nicht nur die İberlebmendauer,

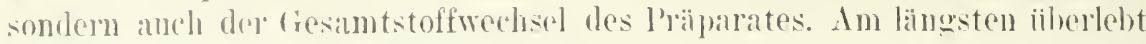

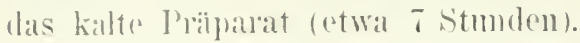

bie 'lechnik der I)mehleitmogen ist. madel $e$. Frey, also immer noch

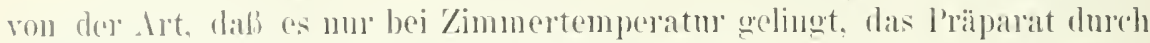

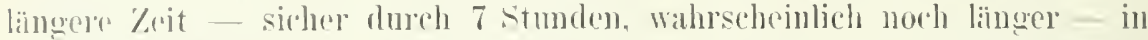
eincu konstanten. dem normalen ähndichen Zustande zn crhalten. Enter diesar Einschüunkmo biotet aber der Versuch schon jetzt ein zuverlässiges

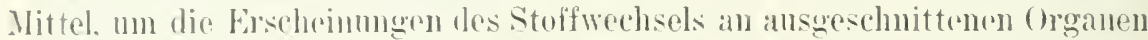
\%11 stmdieren. Handelt es sich dagegent mu die Frage, welehe Gröbe der Lmsat\% an isoliertun ()rgan mer den gïnstigsten berlingungen ereichen kann. so kimnen nur dic warmen Versuche in Retracht kommen.

\section{Ilothode ron Embden mnd Gläßner. $\left.{ }^{1}\right)$}

Dic Vethorle ist einfacher. Bei dem zu durchblutenden, klemeren Humle wird munittelbar nach der Entblutmo ans heiden karotiden die Bauchhöhle in del Linea alha vom l'rocessus xiphoideus etwa e. om nach abwärts cröffnet. das liektum möglichst tief doppelt mutcrbmolen mod zwischen hoiden Ligatmen durehtremut, alsdamn des Magen an der Cardia ohenfalls zwischen zwei Ligaturen durchsohnitten. Nm werden Magen und 1)arm entfornt: auch die Leber wird herausenommen.

Es folet die Freilegung der Aorta und Vena cava an ihrem muterhalb

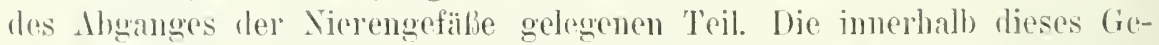
birotes abgelenden Seitenïste verden mnterbunden und alschan in die dorta und die Vena cava möglichst kmz ïber ihrer Gabmung Kaniilen eingebunden. Längs lor boiden seitumänder der banchwmde wird je cine Jassenligatur angelent, anferdem noch anf jeder Suite in der Höhe des unteren Nierenpols (ine quelanfende ligatur, welche Hant mo Mluskulatme mufalit. Der hintere

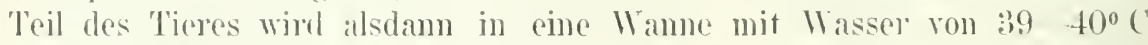
geleracht derant. dab die hinteren Extremitäten zwa völlo eintauchten, aber kein Wasser in dis Banchhöhle liof. Nummelu werden Arterien- und Tenenkaniile mit den zulïhrenden resp. abfiilnenden Sohlauch in Verbindung gebracht und die Inurhleitung in Gang gresetzt.

\section{Zentralnervensystem.}

stoffwechselmutersuchungen in engeren sime wurden bis jetzt an isolierten \%entren der Imphibien. ahgesehen vom Ciaswechsel (H. Winterstein 2 ), noch nicht ansgeliihrt. Ine bisher nach dieser lichtmug ansgefiihrten biochemischen Untersuchmeen beschüinkten sich nur darauf. diejenigen änkeren rhemischen liedingungen festzustellen, bei denen eine lange und normale Crberlebung del Zentren möglich ist.

1) 1. c. S. 363 , Finnote 1.

H. Wintrostrin, Cther den Mechanismus der (iewchsatmung. Keitschr. f. allgem. Physiol. B3. 6. S. 315-392 (19C7). 
Indessen seheint mir besonders das zuletzt ron mir beschrichene

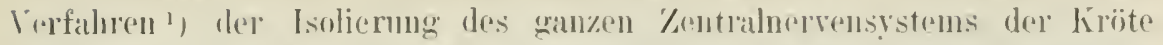

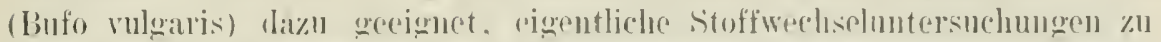
Eestatten. Deshall) (rolumbe irh mir: in folgenden die Vlethode seiner Isolicrung kur\% \%u besprechen.

Das 'Tier wird mit dem liijoken nateh oben und anserstreckten Extremitäten auf eine dicke liorkplatte anfoenunden. Instatt dep iiblichen Irothorle, die Fiilie mit stecknadeh durch\%ustechon, swhlingt man um den llals jedes Fulies ein stiick juns biessamen und budechten Kupferdrahtes, der zur elektrischen Leitung der gewöhnlichen kleinen Induktorien dient. und befestigt dann die suhlinge an den ("Istsprechenden, für sich allein fixierten sterkualeh.

Mittelst einel kleinen Schere wirel die Haut zunächst am Hüftegelenk dicht oberhalb der Drahtschlinge heransgeschnitten und ron da ab bis zum Kopf abgetragen. Ilie Hinterfüfe werlen nicht abgehäutet, denn ihre Haut dient zur I'riifung der Reflextätigkeit. Besondere Sorgfalt ist schon heim Beginn des Versuches der Durchschneidnng der Haut zu widmen, damit ein Ausdricken der zahlreichen Hautdrisen rerhindert wird. Ihr sames milchiges siekret darf nicht mit den Nerven des Präparates in Berihhung kommen, weil es auf diese eine äulerst schädliche Wirkung ausiibt.

Durch Abtragung der seitlichen Muskehmassen des Rïickens wird dann die dorsale Fläche der Wirbelsäule in ihrer çanzen Anslelnung blofigelegt. Sachdem man den dorsalen Umfanc des Wirbelkanals zwischen dem \&. und dem 9. Wirbel quer gespalten hat, beginnt man nnter Anrendung einer kleinen kräftigen kurzen Knochenschere die Wirbelringe beiderseits kopfwärts zu (lurchtremen. Dabei hält man die Wirbelsäule mit den Fingern der linken Hand fest und achtet ganz besonders darauf, dab mit der Schere niemals das Rückenmark herihrt wird. Die \%entren sind nämlich ungemein empfindlich gegen die auch äußerst geringen mechanischen Mißhandlungen. Ist ein solcher mechanischer Reiz erfolgt, so äubert sich die dadurch erzeugte Frrewng der \%entren als langdanerude tetanische bzw. fibrilläre \%uckungen der entsprechenden Muskeh des Körpers. Meist folgt eine unwiederrufliche Lähmung der Zentren und mithin ein Unbrauchbalwerden des Prïparates.

In gleicher Weise wird das Schädeldach entfernt. Fewöhnlich ist man damn gezwungen, die Längsöffnung der so entstandenen Zentralrinne seitlich weiter zu erweitern und die lïuder zu regulieren. Hierauf schreitet man zur eigentlichen Bloblegung der Zentren, indem man unter Beachtung der Vorsichtsregel, die Zentren selhst kaum oder gar nicht zu berihlen, diese mittelst einer feinen gebogenen l'inzette ron der schwiirzlich gefärbten und kalkreichen Dura befreit.

1) s. Baglioni, contributi alla fisiologia generale dei centri nerrosi. Zeitschr.f. allgem. Physiol. Bd. 9. S. 1-54 (1909). 
Mittelst eines kleinen stumpfen Schlingenfuihrers wird dann ein vorher mit Ringerscher Lösung hefeuchteter Fadell unter die bei der Kröte so eigentiimlich lange Cauda equina durchzogen, ohne jedoch die höher liegende Int. post. irrendwie zu zerren. I)ie anatomische Besondertreit, eine so lange Strecke ron intraspinal verlaufenden Nervenbiindeln ohne Beimengung von Gauglienmassen, im Gegensatz zum Frosche. zu besitzen, ist eben der Grund, weshalb die rollständige Isolierung der Zerebrospinalachse nur beim Bufo gelingt.

Sodann werden beide Unterschenkel, sowie beide $\mathrm{Nn}$. ischiadici bis zu ihren Austrittstellen aus dem Wirbelkanal präpariert. Hierauf schiebt man volsichtig unterhalb der mittelst des Fadens gehobenen Cauda die eine Klinge der kleinen Knochenschere und trennt hier die Wirbelrinne durch. Mit der linken Hand hebt man nun beide Hinterfüle des Präparates und zicht hierdurch schwach die Zerebrospinalachse, die aus der Wirbelrime schlieflich herausgeholt wird, indem die von den '/entren abgehenden Nerven kopfwärts, und

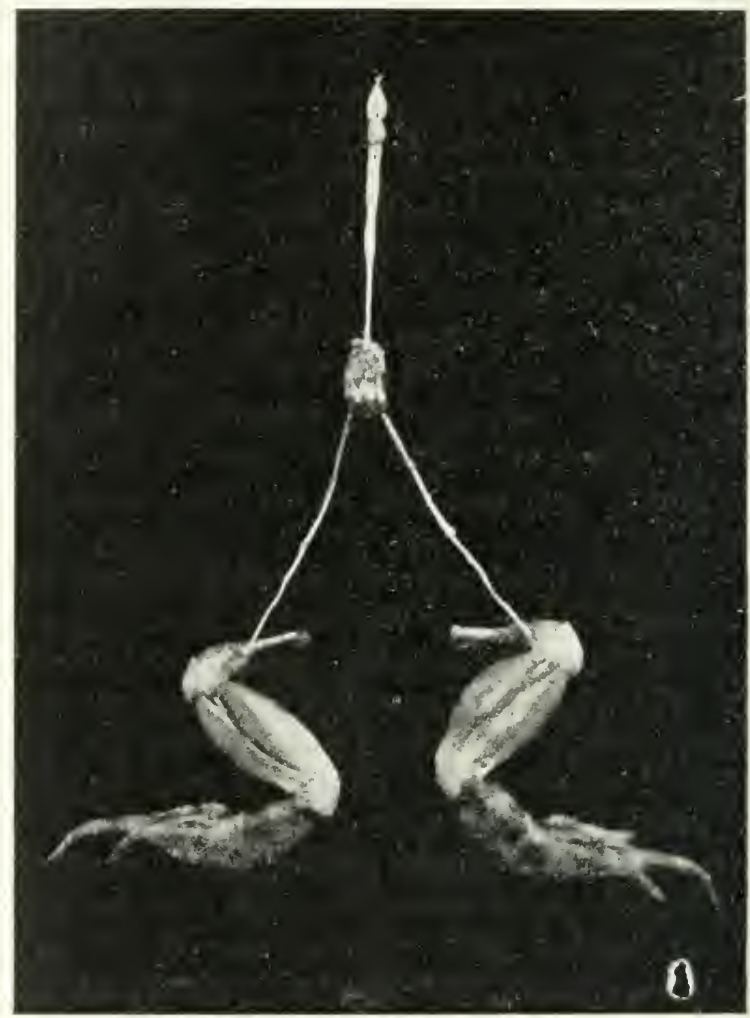

Fig. 114. zwar vou den Spinalwurzeh an his zu den Nin. olfactorii durchschnitten werden. Auf diese Weise erhält man das in der obenstehenden Fig. $11+$ abgebildete \%entrenpräparat. Seine Uberlebung, die durch die Fußreflexe leicht zu priifen ist, steht nun vor allem in direkter Bezichung zur äuferen Temperatur, sowie zum Umgebungssauerstoff. Aus meiner bisherigen Erfahrung geht hervor, daß ein solches l'räparat in einer feuchten Kammer dem Luftsauerstoff frei ausgesetzt, hei Zimmertemperatur ron $8-10^{\circ} \mathrm{C}$ bis mehr als $2+$ Stunden, bei Zimmertemperatur vou $20^{\circ}$ hingegen etwa 8 Stunden imstande ist, zu iiberleben. 


\title{
D. Die Fermente des Kohlehydratstoffivechsels in Tier- und Pflanzenwelt.
}

\author{
Von M. Jacohy, Berlin.
}

I)ie tierischen Zellen speichern liollehydrate als Glykogen und bediirfen daher eines Fermentes, welches (ilykogen spaltet. F'. Pick ${ }^{1}$ ) hat die Isolierung und das Arbeiten mit diesem Ferment eingehend studiert.

Die lebenswarm entnommene Leber wurde von der l'fortader aus so lange mit Leitungswasser durchgespïlt, bis dieses aus den Lebervenen fariblos abflof, dann zerhackt und mit dem fiinffachen Volumen $96 \%$ igen Alkohols $2+$ oder mehr Stmolen stehen gelassen, dann abgeprefit und das nach vorherigem 'Trocknen bei '/immertemperatur oder bei $38^{\circ}$ erhaltene Leberpulver mit einer Lösung von $0 \cong \mathrm{g}$ Fluornatrium auf $100 \mathrm{~g}$ physiol. Kochsalzlösung ausgezogen. Die Extraktion erfolgte in einem bei $38^{\circ}$ grehaltenen Schiittelapparat. Nach 24stiindiger Digestion wurde das fremisch koliert, die abgeprelite Fermentlösung im Falle des Bedarfes filtriert und dann eine abgemessene Nenge zu ebenfalls in Kochsalz-Fluornatrium getöstem Glykogen zugesetzt. Vergleichsproben wurden stets auf ein grleiches Volumen gebracht.

Man kann dann bei der I'riifung der Wirksamkeit des Fermentes entweder das der Spaltung entgangene Gilykogen oder den gebildeten Traubenzucker bestimmen. In dieser Beziehung muß auf andere Teile des Handbuches verwiesen werden.

Kisch ${ }^{2}$ ) hat dann die Vethode bearbeitet, deren man bedarf, um die fermentative Zersetzung des Glykogens in den Organen zu studieren, ohne das Ferment zu isolieren. Seln zweckmäßig ist das von Kisch benutzte Verfahren, dem Organbrei jedesmal Glykogen im Überschuß zuzusetzen, wodurch man einmal unahhängig von dem Glykogengehalt der Gewehe wird, sodann immer über einen so großen Glykogenuiberschuß verfiigt, daß

1) Friedel Pick, Über das glykogenspaltende Ferment der Leber. Hofmeisters Beitr. Bd. 3. S. 163-183 (1903).

2) Franz Kisch, Über den postmortalen Glykogenschwund in den Mnskeln und seine Abhängigkeit ron physiologischen Bedingungen. Hofmeisters Beitr. Bd. 8. S. 210 bis 237 (1906).

Abderhalden, Handbnch der biochemischen Arbeitsmethoden. III. 


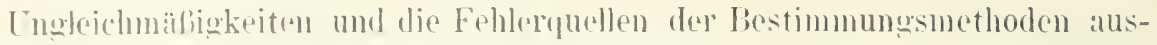

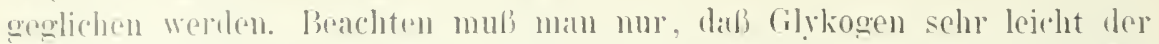

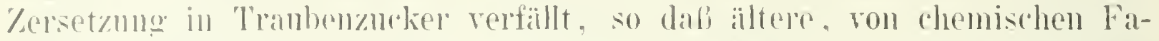

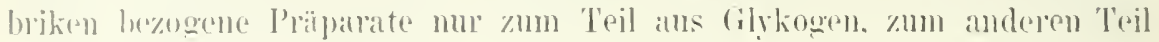
ans 'Trauberizuckele bestuhen.

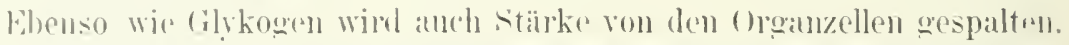

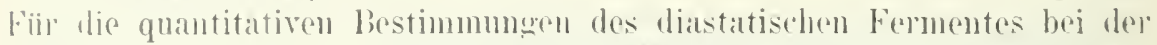
l'rifung mittelst stärle hat neuerdings Wohlyemuth ${ }^{1)}$ eine beyueme Irthoele heschrieben:

Man beschicht aine lieihe licanen\%gläser mit absteigenden Mengen

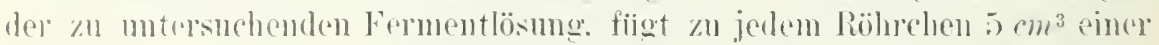

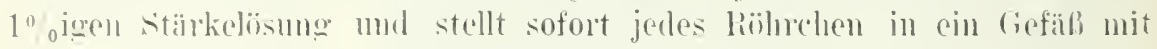

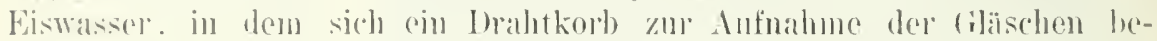
findet. Ho Anwendung les Eiswassers hat den \%weck. jede Feronentwir-

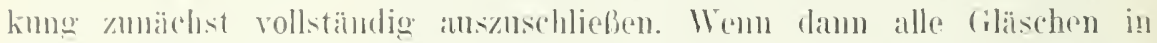
dieser Woise vorbereitet simd. wiol der Drahthorb mit sïmtlichen diläschen

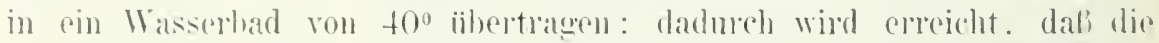
Wiokung des Firments in allen P'ortionen zu wenan dem gleichen zeitpunkt cinsetzt. Bei dieser. Temperatur hleibt der Inalitkorb 30 60 Minuten, je nachdem man den Versuch ausdehnen will. und wirl nach Mbanf der ent-

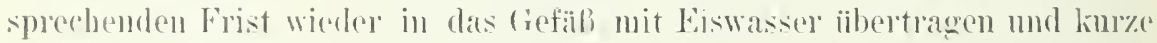
\%eit darin belassen: anf dieso Weise wirl dio Fermentwiokmo wiederum

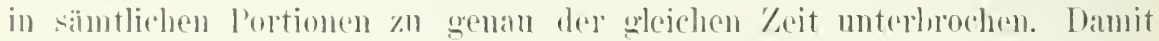
ist die aigentlieho Ausfiihrung des Versuches beroulet.

I m num festzustellen. wie stank die Fermentlosmug war. Wird folgenelormaben woiter rorfaluren:

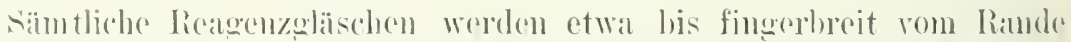

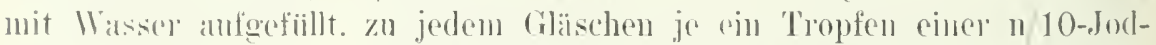

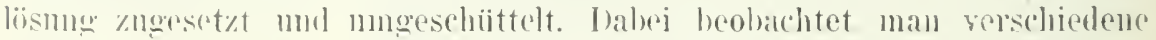

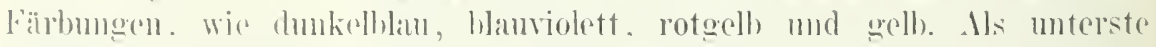

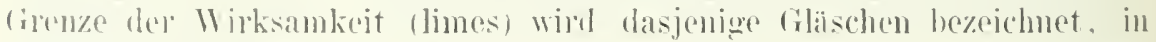
dem zam arsten Male die blane Farlo muerkemball anflitt, das ist also

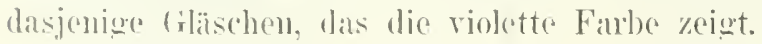

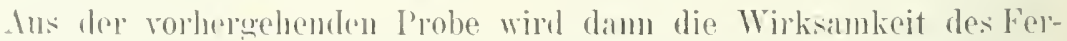
ments so herechnet. dak die Anzahl Kubikzentimeter eimer $1 \%$ oigen Stärlislïsme bestimmt wird. dic durch $1 \mathrm{~cm}^{3}$ der Fermentlösung in der fiir den Versuch angewanden \%eit lis zmm loxtrin total ahgebaut wirl. Hat man \%. Ib. dirse (iponzwilkmug dureh $0.1 \mathrm{~cm}^{3}$ einer lösung erhalten. so wïrde

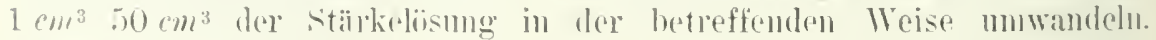

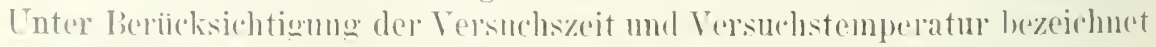
Wohlyemuth damn dic diastatische Kaft der Lösmo mit 1$)_{30^{\circ}}^{400}=50$.

$\left.{ }^{1}\right)$ Johlyemuth, Uher eine neue Methode zur quantitativen Bestimmung des diastatischen Ferments. Binchem. Zeitschr. Bd. 9. S. 1-9) (19018). 


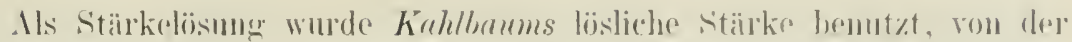
man möglichst frische lösungen velwendet. Jo nach der Intensitit der zu

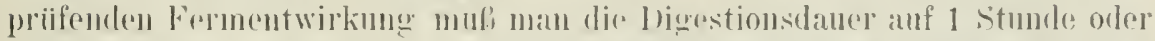

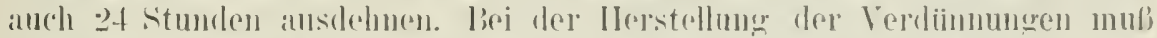
beachtet wroden, daf die Chloridr dio Diastasewirkme verstäken.

bici ()rounsäften stönt die lientrilung der Farbenreaktionen. dali die

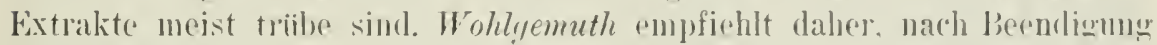

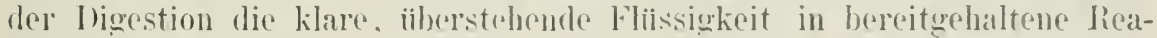

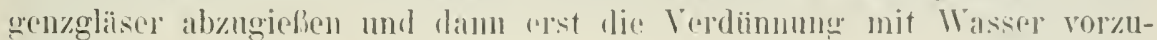
nelimen.

In manchen Reihen begrencet man bisweilen Riohrchen, in denen noben (2inem starken Rot ein leichter blauer Farbenton vorhanden ist. Wenn man schwankt, ob dieses biohuchen schon als unterste firenze aufmfassen ist nder nicht, so tut man wut, noch 1 Tropfen Jodlissmg in dieses Röhrchen zu tun und beobachtet nun beim Tmschiatteln. ob der blane Farbenton bestehen bleibt oder durch eine rotbraune Farhe verdringt wird. In ersteren Falle wäre das liöhrolen tatsäcllich schon als limes aufzufissen. im letzteren Falle dagegen erst das nächst tiefere. Nach Erfahrumeren, die Hata in meinem Lahoratorium gesammelt hat, erleichtert es die Bestimmung der Grenze, wenn man dir Proben mit Chloroform schiittelt. Man erkennt dann ohne Viihe, in welcher Probe zuerst ein blaner Ton liestand hat.

(1) das Glykogen erst mach der Spaltung oder auch direkt verbrannt werden kam, wie Pary vermutet, ist zweifelhaft. Da in ()ronismus sehr rerbreitet sich Diastasen finden. so ist anzmuchmen, daf im allgemeinen der Verbrennung die spaltmo in Traubenzucher vorangeht, elienso wie der (oroanismus ja auch das Glykogen aus Traubenzucker aufbant. ()b dabei 'wwischenprodukte entstehen und sich dazu gecignete Fermente in den ()ranen finden, ist noch unsiches: Da die oroane jedoch nicht nur Gilykogen, sondern auch Stärke spalten kömuen, so ist zu vermuten, daß auch dabei entstehende Dextrine gespalten werden, also Dextrinasen vorhanden sind (P. Mayer $\left.{ }^{-1}\right)$.

Die Isolierungsmethorlen der diastatischen Yellfermente sind bei den Pflanzenenzymen weiter rorgeschritten als bei den tierischen Enzynen. Das kommt wohl daher, dab diese Enzyme weniger labil und intensiver wirksam sind.

Ihie Malz-Diastase haben St. Fränkel und Hamlunrg') in wirksamer Form und sehr gereinigt nach einer allerdings ziemlich schwierigen Methode erhalten. Das Terfahren beruht darauf, daß das Enzym in Lösung

1) I'aul Mayer, Uber das Verhalten von Dextrin und Glykogen im Tierkörper. Fortschr. d. Med. Nr. 13 (1903).

2) Sigmund Fränkel und Mar Hamburg, Üher Diastase. Erste Mitteilung. Versuche zur Herstellung ron Reindiastase und deren Eigenselıaften. Iofmeisters Beiträge. Bu. 8. S. 389-398 (1906). 
gehalten wird, während Beimengungen zmiïchst ausgefüllt werden: sodann wird das Ferment durch Tonfilter filtriert. In der Hauptsache wird dats ferment dadurch gereinigt. dal) es aus eiweibarmen lösungen gewonnen wird, in denen der 'bucker verworen wird.

Es werden j $\mathrm{kg}$ Jalzschrot ron sehr diastasereichem Malz mit 1 is $l$

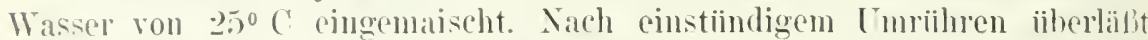
man die Maisehe einer halbstiindigen Ruhe, woranf man koliert und den Rïckstand ausprebt. Hie Kolatur wird zum Mbsetzen des mitgegamgenen dalzmehles in der Kälte sedimentieren gelassen nul hierauf vorsichtiy ahgeprefit.

Nun wirl folgendes Verfahren eingeschlagen: Man hestimmt in ahgemessenen Vengen des wässerigen Auszuges die diastatische Kraft in hezur anf Verflissigung und Verzuckermng und setzt anderen Proben derselben llenge des wïsserigen Auszuges gemessene Quantitäten einer lïsung ron basisch essigsaurem Blei so lange zu, als die diastatische Kiraft keine merkliche Veränderung erfährt. Jetzt mift man die Hauptmenge ab und setzt ihr die bereclmetr llenge derselben bleiessiglösung zu. Isei diesem Verfahren iiberzengt man sich. laf im Filtrat nach der Birifïllung Schwefelammon keine Bleireaktion zeigt. Man liblit absitzen. filtriert dureh Papier, zieht die gesamte Lïsung durch grolie, sterile Pukalfilter rasch in sterile Flaschen und läbt nach Impfen mit einer geringen Menge eincr Reinkultur von Frohberghefe, die man vorerst an zuckerarme. diastasereiche Nährböden gewöhnt hat. hei $28^{\circ} \mathrm{C}$ in 'Thermostaten vergüren. Sobald die Gärung zu Ende. zieht man wieder durch P'ukalfilter in einen vorher sterilisierten Vakummapparat ein, destilliert die Lösung hei cinem Druck von $10 \mathrm{~mm}$ Hg uml engt etwal auf $500 \mathrm{~cm}^{3}$ ein. Ist die I.̈̈sung saner geworden, so ist es notwendig, mit etwas kohlensaturem Kalk zu neutralisieren. Es ist dabei notwendig, auch den kohleusituren kalk. der dabei eingetragen wirl. zu sterilisieren. Nun wird die lösmo mit sehr wenig einer Vlischkultur ron Frohberg- mul logoshefe, die in oben erwähnter Wrise vorbehandelt ist, geimpft und einer neuerlichen Gärung unterzogen. Bei der zweiten Gärung empfichlt es sich schr, die Hefen vorerst stickstoffhungrig zu machen. Nun suelit man mögliclst den Fndvergärnngsgrad zu errejchen, engt wieder die Lösung nach dem Filtrieren furch l'ukalfilter im Vakumm ein und erhält unter giinstigen Arbeitsumstanden eine sirupöse Fliissigkeit. die durch Finengen im absoluten Vakum iibel schwefelsäure in ein l'ulver verwandelt werden kann.

Das so erhaltene Diastaseprïparat ist im Gecrensatze zu den gewöhnlichen mneinen I)iastasepräparaten chemischen Einfliissen gegeniiber moemein empfindlich. Löst man das Präparat in wenig Wasser unt versetyt es mit Alkohol, so geht nach kurzer \%ejt die liastase zugrunde. wenn man nicht sehr rasch die Fällung der weiteren Einwirkung des Alkohols entzieht. In wleicher Weise wirkt Aceton.

1)is I'riparat stellt ein lichtgelbes. in Wasser leicht lösliches, in Alkohol mulösliches Pulver vor. Welches die Binretreaktion sowie die Xantho- 
moteinreaktion nicht mehr gibt, mit alkalischer bileilösung gekocht, keine Schwal\%firbung zoigt. Hingegen zoigt es meist spurenweise Millonsche lieaktion. I)ic Lösumg reduziert Fehlingsche lösung nicht, zoigrt aber rinen positiven Ausfall der Molischschen lieaktion. ferner schwache l'entosenreaktion. Die Seliucenoffsche lieaktion auf Lärulose fällt negativ aus. lic wässerioge lösung läbit sich zum kleinen 'Teil sowohl durch liochsalz, Ammonsulfat und Magnesiasulfat anssalyen. I)ie Niederschläge zeigen starke diastatische Eigenschaften. aber auch die salzgesättigte lösung. salzsïure, Schwefelsämre und l'hosphorsiure bewirken in der wïsserigen Jisung schwache 'l'ribung, ebenso essigsaures blei und basischl essigsaures Bilei.

Tehen der l)iastase ist das Invertin, welches den liohrzucker in 'Traubenzucker und Fruchtzucker sjaltet. wohl das wichtigste Polyaccharide spaltende Enzym der Pflanzenzellen. Die Isolierung des Invertins aus der Hefezelle hat Hafner ${ }^{1}$ ) im Laboratorium von Häfner sorofältig ausgreabeitet; seine Angaben enthalten viele Winke, die bei Isolierungrversuchen allgemein verwerthar sein diurften.

5) ky reine l'reßhefe, die von der Hefezuchtanstalt des Voreines deutscher spiritusfabrikanten geliefert war, wurde nach Osborne mit 5 $795-96^{\circ} \%$ igen Alkohols in einer grolien lieibschale gut angerieben, sodann, nachdem man den Brei einen 'T'ag lang ruhig hat stehen lassen. der Alkohol durch Filtration entfernt, die zurïkbleibende Hefe wieder einige Tage lang in einem großen Becherglase bei ziemlich kiihler 'Temperatur mit etwa $6 l$ Wasser, am hesten unter beständigem Umrïhren mittelst eines Riihrwerkes digeriert und am Ende anf mehrere große Faltenfilter gebracht. um rom wïsserigen Auszuge getrennt zu werden: diese Extraktion wird wiederholt. his eine Probe des Extraktes kaum noch invertierend wirkt.

Nun fï@t man immoniak hinzu, bis die Lösung deutlich danach riecht, der entstehende Niederschlag wirl bald nach dem Absetzen abfiltriert. das Filtrat eventuell noch durch einen Pukalschen Tonfilter zur kiärung geschickt. endlich bei höchstens $40^{\circ} \mathrm{im}$ Vakuum eingeengt. Aus dem zuriickbleibenden Sirup wird das Invertiu durch absoluten Alkohol ausgefällt.

Das so erhaltene Rohpräiparat wird zunächst mit absolutem Alkohol gewaschen, hierauf mit lawarmem Wasser in eine Reibschale gespiilt und darin zu einem dünnen Brei angerieben. den man in einem Becherglase noch weiter verdünnt und einige Stunden stehen lält. Nunmehr wirl wieder ein schleimiger Niederschlag durch Filtration entfernt. das Filtrat wiederum durch Ammoniakausfällung gereinigt, endlich die Eliissigkeit einer längeren Dialyse unterworfen, bei der das vorher unwirksame Invertin wieder aktiv wurde. Man dialrsiert in einem gröferen lialysierapparat, möglichst indem man die Flïssigkeit dabei dauernd be-

1) B. Hafner, Einige Beiträge zur Kenutnis des Invertins. Zeitschr. f. phỵs. Chem. Bil. 42. S. $1-34$ (1904). 


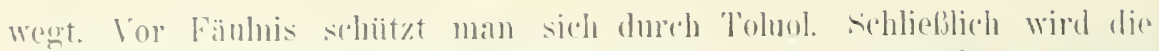

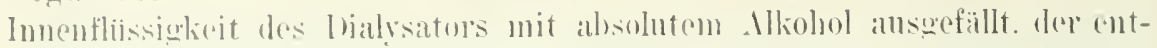

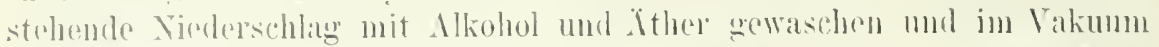

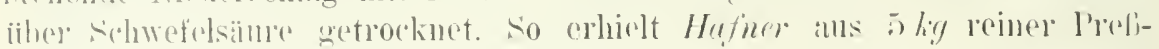
hele $: 3 \cdot 1$ y solu wirkamen Invertins.

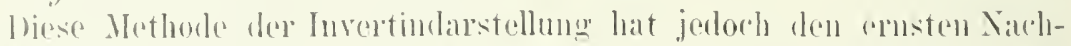

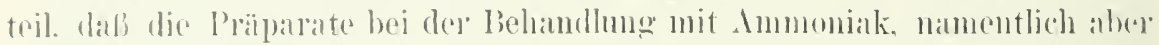

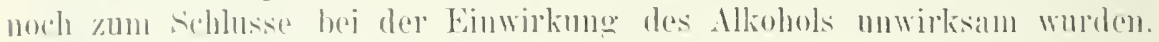
Hofner moint, dali diese Empfindlichkeit der reinen Hefo mit ihrer Reinzolde in innerem \%usammenhange steht, jedenfalls hatte el bessele bud

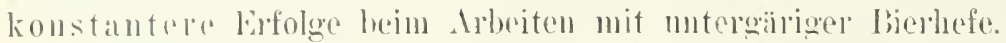

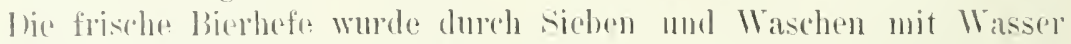

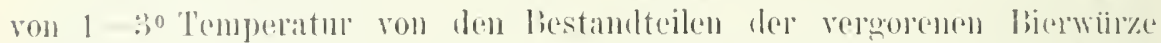

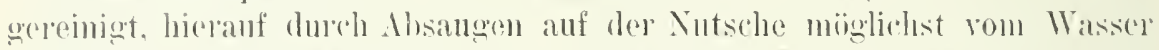

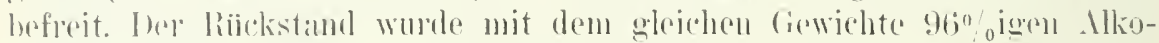

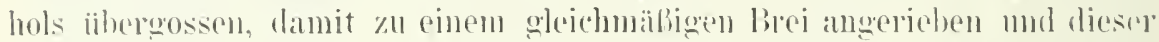
2) Stmuden side sellst iiberlass(n). Damm wirel der Alkohol durch rin Flanell-

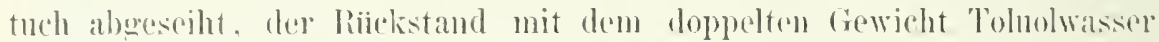

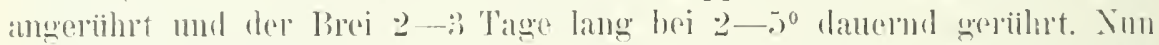

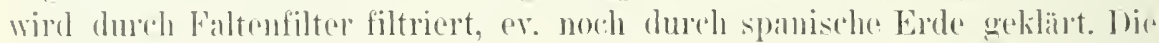

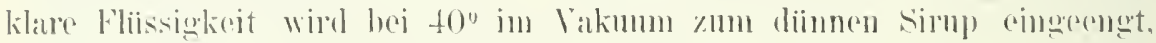

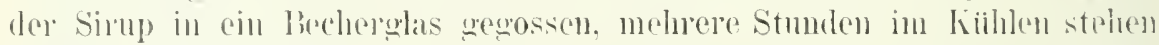

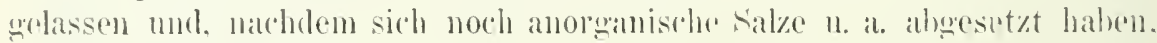
wieder filtriert.

Nummehr wird zu Portionen von $50 \mathrm{~cm}^{3}$ otwats moln als $50 \mathrm{~cm}^{3}$ al)-

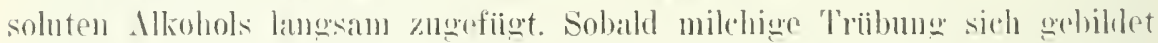

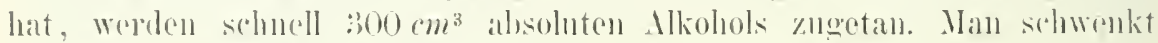

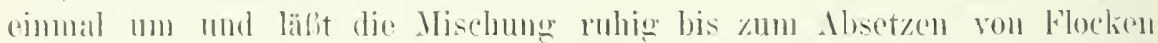

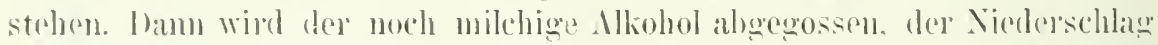
nochmals mit $200-300 \mathrm{~cm}^{3}$ absoluten Mkohols iihersehiittot. $\%$ ll l'l-

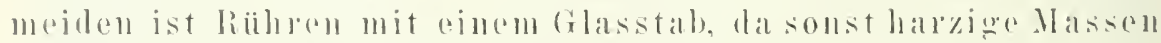

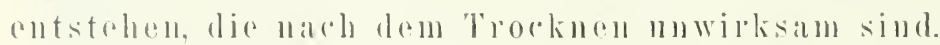

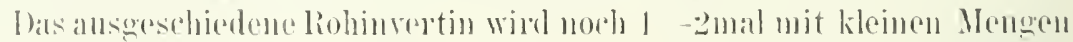

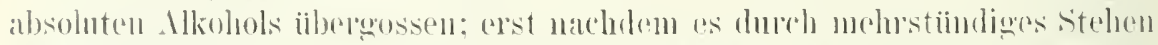

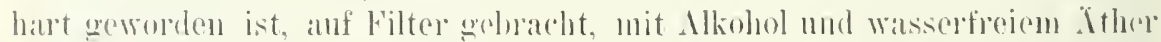

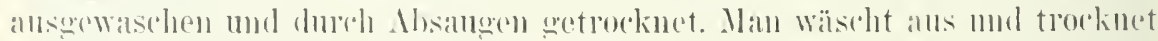
all besten anf mehrepent kleinen Filtern. Ans dem milchieren Alkohol ar-

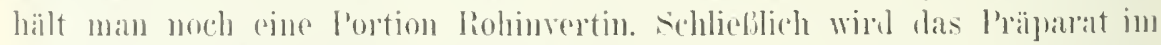
Vakumm iiber sichwefolsiure wetrockinet.

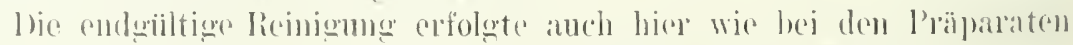

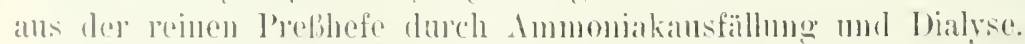

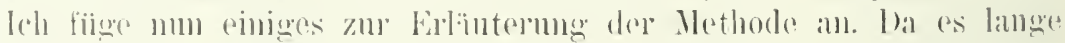

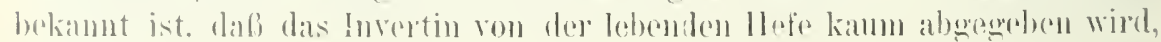

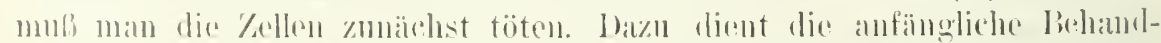

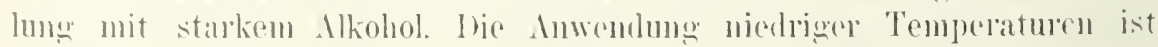


zweckmäliig, un die Entstehung von Eiweilispaltungsprodukten durch die Ein-

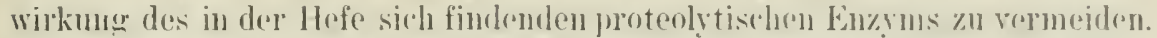

Wie ans Versuchen von li. Fissher u. a. hervorgeht, kann man die

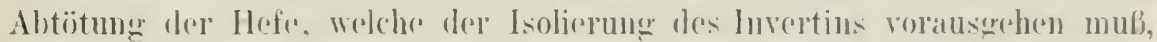
auch durch mochanisches terreiben bewerkstelligen.

Es ist nicht nötig, alle Fermente, welche Polysaccharide spalten, be-

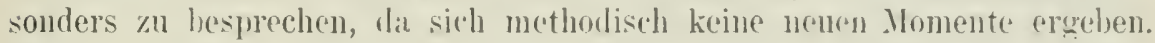
Jedoch soll norh einiges iiber die glnkosidspaltenden Fermente und insbesondere iiber das wichtige Fimulsin angefiigt werden.

Das Emulsin, welches ans den Kernen der bitteren llandeln gewonnen wird, ist bei Kahlhaum, Schucharlt und Jerck in gut wirksamer Form zu haben. Es spaltet Amygdalin in zwei Holekiile Tranbenzucker, in Blausiure und Benzaldehyd, andere Aldehyde entsprechend. Yan erhält z. B. nach Beitzke und Neubery ${ }^{2}$ ene Fernentlïsung, welche Amygrdalin sehr kriftig spaltet, wenn man das käufliche Kahlbaumsche I'rïlparat ¿o Stunden bei $38^{\circ}$ mit 'Toluolwasser extrahiert und damn filtriert. Das fast klare Filtrat ist sehr wirksam. Amygdalin wird durch einen wïsserigen Extrakt aus Bierhefe in Tranbenzucher und Mandelnitrilglukosid gespalten, welches sich nur durch das Fehlen eines Molekiils Traubenzucker vom Amygdalin unterscheidet. ${ }^{2}$ ) Aus diesem Mandelnitrilg]ukosicl sualtet Emulsin danu das zweite Molekiil 'Traubenzucker ab.

Am übersichtlichsten sind die Versuche Emil Fïschers ïber die Spaltung von synthetisch dargestellten Glukosiden durch Fermente. ${ }^{3)}$ Als Beispiel erwähnen wir die Versuche mit den Methylglukosiden. I) Methylglukoside werden nach Emil Fischers Vorschrift dargestellt. ${ }^{+}$) Folgendes Schema gibt ihre struktur und ihre Konfiguration wieder:

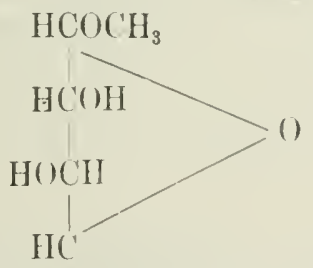

$\mathrm{HCOH}$

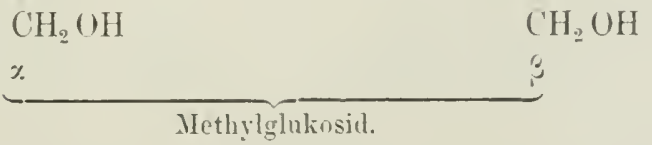

$\left.\mathrm{CII}_{3} \mathrm{C}\right) \mathrm{C} \mathrm{H}$

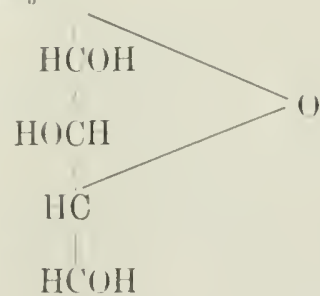

$\mathrm{CH}_{2} \mathrm{OH}$

1) H. Beitzke und ('. Neubery, Zur Kenntnis der Antifermente. Firehors Archir. B3. 183. S. $169-179(1906)$.

2) Emil Fischer, Uher ein neues, lem Amygdalin ühnliches filukosid. (hem. Berichte. Bd. 23. S. 1.09 (1895).

3) Emil Fischer. Betleumng der Stereochemie für die Physiologic. Zeitschx. f. physiol. Chem. Bd. 26. S. 60-8T (1898).

4) Emil Fischer, Ǐber die Verbindungen der Zucker mit den Alkoholen und lietonen. Chem. Berichte. Bd. 28. S. 1145 (1895). 
Fiigt man 1 Teil Emulsin zu 2) Teilen G-Glukosid in 20 Teilen Wassel' und belälist das Gemisch 15 - 20 Stunden bei $30-35^{0}$. so kamn man $90^{0} 0$ des 'Traubenzuckers dmeh Titration mit Felulingscher Lösung als abgespalten nachweisen, wijhend das $x$-Glukosid unverandert bleibt. Umgekehrt greift Invertin nur das $x$-Glukosid an. Fischer stellte sich das Invertin selbst dar, da kiäufliche Priplarate keine guten Resultate erouben. 1 Teil luftrockene Hefe (Saccharonyces cerevisiae. Typ. Frohberg-Reinkultur) wird 15 Stunden mit 15 Teilen Wassel bei $30-35^{\circ}$ digeriert. Tou dem ж-Cilukosid wurde durch dieses buzym etwa $50 \%$ abgespalten.

Anscheinend sehr bedeutsame Feststellungen iber das Emusin hat in nenester Zeit Rosenthaler gemacht. $\left.{ }^{1}\right)$ Danach besitzt das Emulsin außer den (iJukoside spaltenden Fermentwirkungen noch andere Funktionen, die sich von der eigentlichen Emulsinwirkung unterscheiden. Zu den Versuchen diente das Schuchardtsche Präparat, dem das Mercksche in dieser Hinsicht nachsteht. Nach Rosenthaler entsteht unter dem Einfluß von limulsin aus Benzaldehyd und Blausäure d-Benzaldehydeyanhylrin, das durch Salzsäure in L-Mandelsäure iibergefïhrt welden kann. Zum Benzaldehyd wird die wässerige Emulsinlösmng hinzugefïgt. damn sofort die gewöhulich 5\% 5 ige Blausäure und nit Wasser auf $100 \mathrm{~cm}^{3}$ (roänzt. Nach der Einwirkung des Emulsins wird mit Chloroform ausaeschiittelt. die Chloroformlösung wird mit entwässertem Natriumsulfat und, wenn zur Klärung nötig, noch mit Kieselgur behandelt. damn abfiltriert nud nach Vereinigung mit dem Waschchloroform in die l’olarisationsröhre eingefüllt. Im die aus dem d-Benzaldehydcyanhydrin zu erhaltende l-Mandelsänre zu bestimmen, wird die Chloroformlösung zunächst mit $25 \mathrm{~g}$ lauchender Salzsäure 1/2 Stunde stehen crelassen, dann wurde das Chloroform abdestilliert. der Riickstand unter Nachwaschen mit 15g ranchender Salzsäue in eine Schale gespiilt und diese auf dem Dampfbad bis zum Auftreten ron Kristallen erwärmt. Sach dem Erkalten wurden die Kristalle in Wasser gelöst und das Filtrat durch Nachwaschen auf $100 \mathrm{~cm}^{3}$ gel)racht. Diese lösung wird dann am Polarisationsapparat untersucht.

Wird das Gemisch bei der Einwirkmug des Emulsins regelmälig geschïttelt, so erhält man gröbere Lmsetzungen. Einstiundiges Erhitzen des Emulsins anf $80^{\circ}$ macht das Emulsin unwirksam. Der hydrolysierende Anteil des Emulsins geht bei lïngerer Erhitzung anf $40^{\circ}$ verloren. wïhrend der synthesen befördernde teilweise erhalten bleibt. Den letzteren neunt

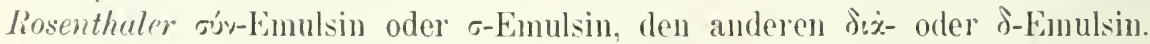
Anch aus inderen Aldehyden worden unter dem Einfluß des o-Emulsins aktive Nitrile erhalten.

Bei Halbsättigung von Kmulsinlösumgen mit Ammonsulfat geht ø-Emulsin in den Niederschlag, das Filtrat enthält nur $\delta$-Emulsin. ${ }^{2}$ (Ehenso

$\left.{ }^{1}\right)$ L. Rosenthaler, Durch Enzyme bewirkte asymmetrische Synthesen. Biochem. Keitschr. Bd. 14. S. 238- 253 (1908).

2) L. Rosenthaler, Durch Enzyme bewirkte asymmetrische Sunthesen. 2. Mitteilung. Biochem. Zeitschr. Bu. 17. S. 257-269 (1909). 
verhält es sich bei Ganzsïttigung mit Maunesiumsulfat, indem man auch hier im Niedersehlag das r-Emulsin-, in Filtrat das $\delta$-Limulsin findet. 1)abei erhält man aber in beiden fällen nur das $\delta$-Emulsin frei von -Emulsin, während die s-Emulsinfraktion immer noch $\delta$-Emulsin enthält.

Endlich findet sich in Emulsin noch eine dritte katalytische Substan\% ${ }^{1}$ ), welche die Anlagerung von Blausäure an Aldchỵde beschlennigt, ohne anf die Entstehung der optischen Aktivität von Ë̈nflng zu sein. Sie wirkt anch da, wo optisch inaktive Nitrile entstehen. I)iese Substanz widersteht längerer Einwirkmog der Siedehitze. Wahrscheinlich handelt es sich Imm C'alcium-Nagnesiun- und kaliumrerbindungen.

Die IIethodik der 'Zellfermente, welche den 'Traubenzucker vergären. baut sich auf Buchners Entdeckung, der 'Mymase, auf. Wer sich mit experimentellen Studien iiber fermentative Traubenzuckervergärung beschäftigen will, muß unbedingt die wichtige IIonographie von Buchner und Hahn 2) über die Zymasevergärung genau durcharbeiten. Wenn wir auch versuchen werden, hier möglichst alles wesentliche der Buchnerschen Methodik wiederzugeben, so $m 118$ doch fiir zahlreiche Details auf das Original verwiesen werdell.

Als Vaterial für die \%wmasedarstellung diente untergärige Bierhefe, die entweder ans Brauereien oder ans der Hefefabrik von A. Schroder in Viunchen stammte. Oberoürige Hefe liefert auch Kymase; doch sind die Frfahrungen mit ihr bei weitem weniger zahlreich.

Die Herstellung des Hefeprelssaftes zerfällt in folgende Alschnitte:

1. Waschen der Brauereihefe, 2. Entwässern der gewaschenen Hefe, :D. Vischen mit Quarzsand und Kieselgur, 4. Zerreiben unter Zerreibung der Zellmembranen, 5. Auspressen der erhaltenen teigförmigen Masse, 4. und 5. werden nochmals wiederholt.

Das Waschen der Brauereihefe und Entwässern der gewaschenen Hefe. Die aus der Brauerei bezogene Hefe wirl zunächst gewaschen: man bringt dieselhe anf ein Haarsieb und schwemmt sie mittelst aufgegossenen Wassers durch das Sieb hindureh in hohe Gefälie (25) $l$ hnhalt) mit Wasser. Nun wird auf den boden der grolien Gefäle mittelst eines langen Schlauches Wasser unter Druck geleitet. Das schliebiich oben iiber den Rand des Gefïßses abfliebende Wasser nimmt die Verunreinigungen und auch einen grolien Teil der toten und der ... wilden" Hefezellen mit, die im Gegensatz zu den .. Kulturhefen" meistens kleineren Rassen angehören.

Die gewaschene Hefe muß sodann möglichst entwässert werden. wozu man sie am besten in ein beutelförmigr gefaltetes und oben zusammengebundenes Koliertuch und hierauf noch in ein Preßtuch einschlägt und in der hydraulischen Presse einem schließlich 5 Minuten anhaltenden Druck

$\left.{ }^{1}\right)$ L. Rosenthaler, Uber katalysierende Emulsinbestandteile. Biochem. Zeitschr. Bd. 19. S. 186-190 (1909).

2) Eduard Buchner, Hans Buchner und Martin Hahn, Die Zymasegärung. Untersuchungen über den Inbalt der Hefezellen und die biologische Seite des Gärungsproblems. Nü̈nchen und Berlin 1903, Verlag von Oldenbourg. 


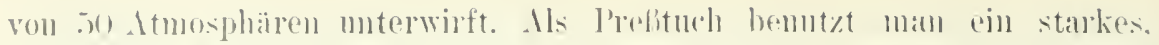

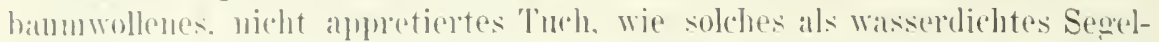

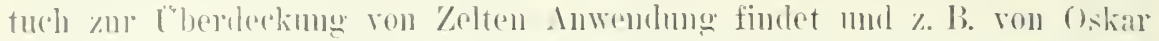

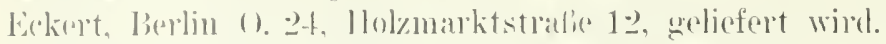

Mischen mit Qual\%sand und Kiesolgur - \%erroihen muter

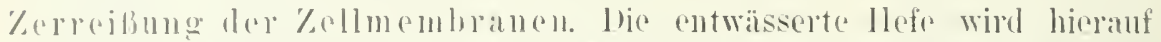
in einer wrofien sobale mit frinsm Quarzsand, der dureh ein Siob ron

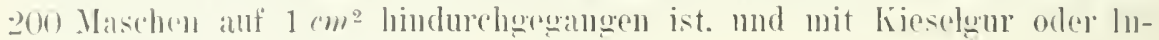
fusorienerele im Verlülthis vou

$$
\begin{aligned}
& 1000 \text { y entwisserte Hefo. }
\end{aligned}
$$

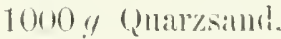

$$
\begin{aligned}
& 2000-3000 \text { \% Kieselyur }
\end{aligned}
$$

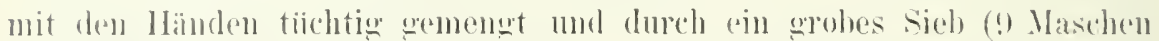

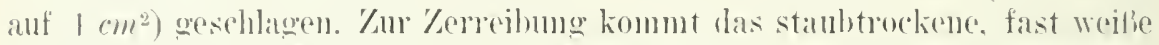
l'ulver hieranf in Toptionen von 300 - $400 \mathrm{~g}$ in eine grobe Porzellameib-

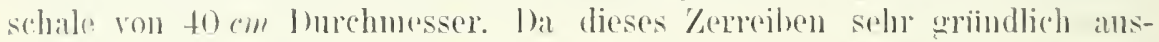

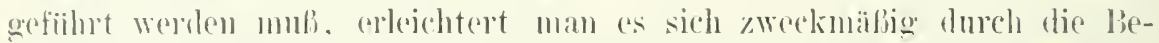

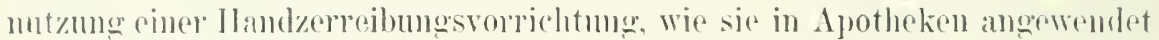

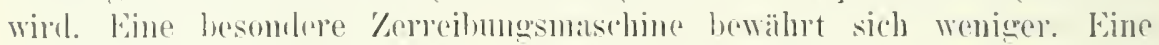

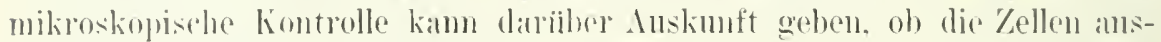
ginabe \%ertrimmert worden sind.

Iusplessen der orhaltenen teigförmigen Masse. Kum Zwecke des Anspressens wirl die teigformige Masse entsprechend 1 liof Hefe munmehr in das ohen beschriehene Prefituch ringeschlagen. Inas Tuch wirl

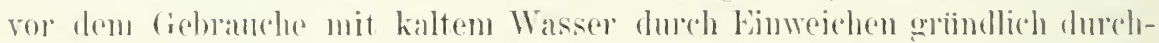

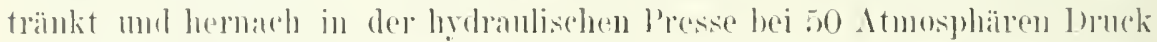

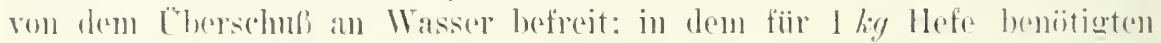

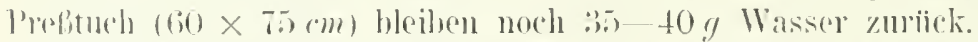

As Terese berlient man sich eined hydanliselen Jandpresse. wie sie

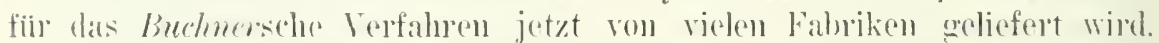

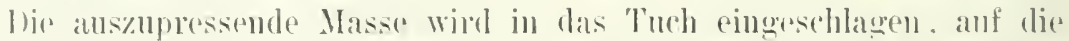

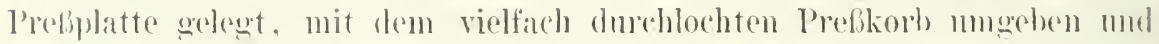

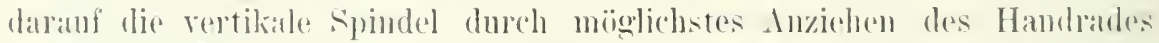
andeprebt. Sodam setzt man auch die horizontale Spindel dureh loreden

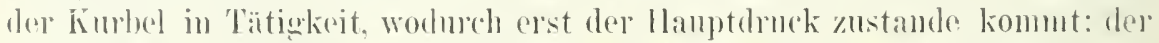

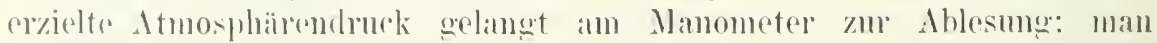
strigert denselben langsam, damit das Profitmeh nicht reilit, von jo \%u

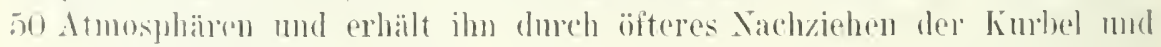
anch des llandraldes konstant.

Xachelem die zerriebene Hofo eimmal ausereprefit ist, was aus 1 lig

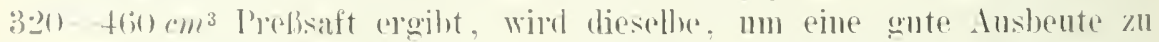

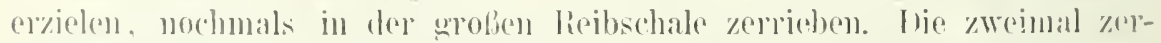
riohene Hefe kommt mun abermals in die l'resse bei einem Inuck von ?() ky allf $1 \mathrm{~cm}^{2}$. 


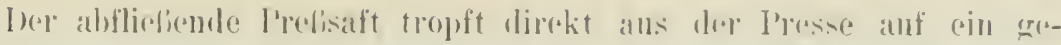

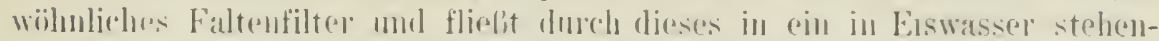

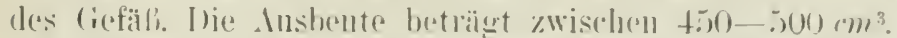

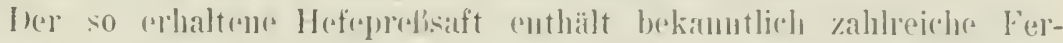

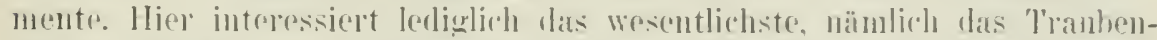

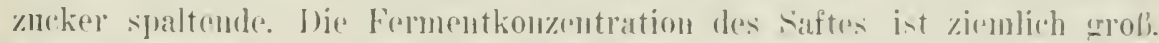

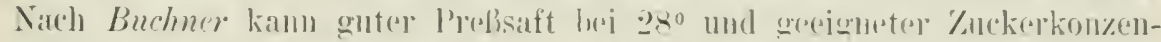

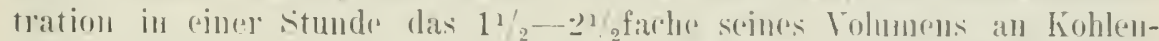

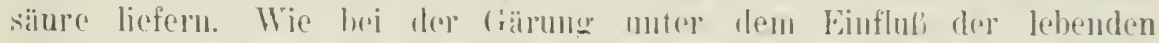

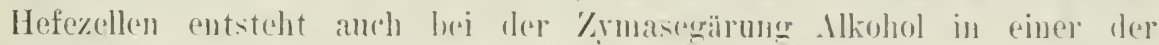
liohlensäure entsprenenden Menge.

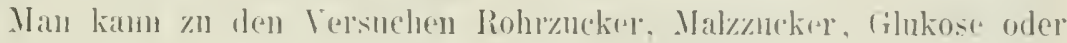
Fruktose bemutzen. als Antiseptikmm genügt Toluol.

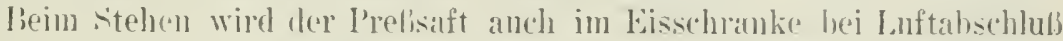
and unter aseptischroll hautrelen bald mowirkam, die \%yndse ist nur mäbier

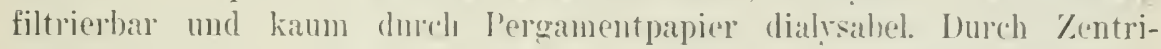
fugieron wirel sie nicht alogeschieden. wohl abel kinn man durch Ausfrieren die Fermenthonzentration steigern.

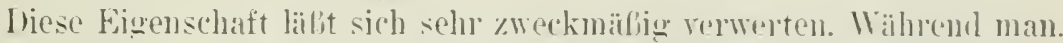

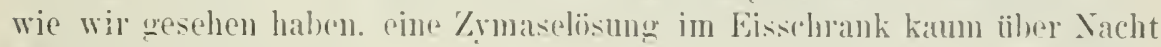
wirkam erhalten kann, hewahrt die \%ymase nicht nur ihre Aktivitait. sondern lälit sich sogar konzentrierter wiedergewimnen. wenn man das Ge-

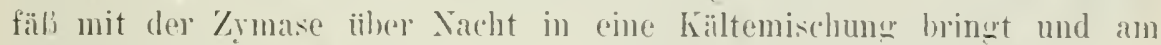
nächsten 'Tage in Wasser vol 2 - 50 langsitm wiedel anftauen lälit.

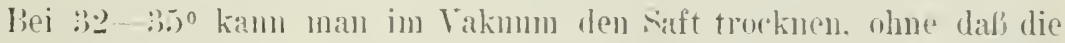
Zymase scharden leilet. Jedoch mul' man dahei sehr vorsichtig sem. besonders die Zeit des Eindampfens muli sehr kurz bemessen werden.

Trägt man $50 \mathrm{~cm}^{3}$ I'relisaft untel' starken 'Turbinielen in ein fe-

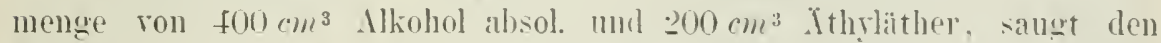
Niederschlag sofort ab, wäscht ihn rasch mit Alkohol und damm mit Ither mud trocknet ihn im Vakummexsikator ïher sohwefelsïures, so erhält mau ein wirksames Zymasepulver. das mam am besten in Glyerinwaser auflost. Anch mit Iceton ist die \%rmase fällhar. Diese Eigenschaft der Zymase wurde benutzt, um ein wirksames Daucr-Trockenpräparat fiir den Handel helzustellen.

Frische, ausgewaschene braucreiunterhefe wird bei einem Iruck von 15-:30 ky auf $1 \mathrm{~cm}^{2}$ entwäsert. Was hei der verwendeten hydraulisehen Presse $50-100$ Itmosphïren lluck und einem Wassergehalt del Hefe von $72 \quad 66 \%$ (bestimmt duroh Trocknen hei 10.50) entspricht. 500 g daron, zwischen den Händen zu einem grohen Pulver zerrieh('n. werden auf einem Siel, (100 Maschen auf $1 \mathrm{~cm}^{2}$ ) in einer flachen schale in : $l$. leeton eingetaucht und dureh Hehen und Senken des Siphes in der Flïssigkeit unter Nachhilfe mit einem Bïrstchen :- Minuten durch die angen Maschen geschwemmt. Die Hefe bleibt nach dem Eintragen nutel häufigen Lml'ïhren noch 10 Minuten in Aceton liegen. Hierauf wird nach kurzem Absetzen die Flïssigheit grölitenteils ahgegossen und die Hefe in einer Nutsche 
anf grehäretem Filtrierpapier muter kräfigem Anpressen mit einem greeigueten stempel möglichst trocken abgesangt. Wen numehr grob zerkleinerten Hofeknchen ïbergiefit man anfs neue in der schale mit 1 l

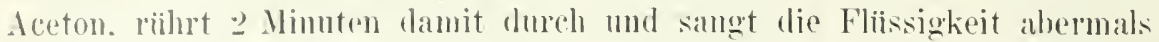
dureh Juplessen ler Masse an die Sutsche möglichst vollständiog ab. Die Masse wirl sodam grob gepmlvert und in einer kleinen schale mit $250 \mathrm{~cm}^{3}$

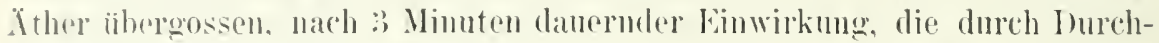
kmeten moterstiitzt wird, filtriert man vour Ither anf der Nutsche mutro kräftigem Salten ab und mreitert die zu feinem Pulver zerricbene Hefo direkt oder noch hesser. nachden man sie dureh ein mittelfeines siob geschlagen hat. in diimer schicht anf mit Filtrierpapier belegten Hiirlen ans. Nach 1/2 - 1 Stunde Lagem an der Luft, wobei tler Xther grölitenteils verdampft, schieht man die Hiinden, weil sonst die Hefe wieder Wasser

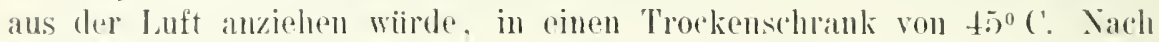
2tstiundien Verweilen ist das l'rijparat fertig.

Jieses l'riparat wird unter dem Samen Krmin von schroder in lliunchen verkatlft.

Trennung vom Ferment nud coferment deromase.

Wem ain Prebsaft einge Zeit Zucker vergoren hat, wird er unwirksam. Es hat sieh herausgestellt, dab das aus dem \%ugrumdegehen eines ('ofermentes zu erklären ist, weldhes neben der ejgentlichen Zymase zur Wirkmng nötig ist. Das rou Harden mol Young ') anteleckte ('oferment ist leichter filtrierbar als das Ferment, wirl durch die sielehitze nicht zerstört, mnterseheidet sich aber anch sonst in mamnigfaltiger Weise vom Ferment. Wahrscheinlich ist es eine organische Phosphorverbindung, welche dureh Lipasen und dureh Verseifung nuwirkam wird.

Buchner und Ducharek ${ }^{2}$ ) haben begonnen. oin 'Trennungsverfahren des Ferments von dem Coferment anszuaruiten, welches I)ifferenzen in der Fällbarkeit der beiden substanzen verwertet.

Ier sog. liochsaft. der das coferment enthilt, wirl foigendermalien bereitet:

$1 \mathrm{lg}$ abgeprelite. Hefe wird auf dem Dampflad, wemn nötig, unter Wasserzusat\% erhityt, his sich ein diinnel Brei gebildet hat. Mischt man damm Kieselgur zu, bis las fanze fest geworlen ist. und bringt die Masse, in ein lorbtuch eingeschlagen, in eine hydranlische l'resse, so resultient bei :300 Atmosphïren Druck eine gelblich klare Flïssignkeit, die nur aufgekoeht und filtriert zu werelen braucht.

Diesel Lochsaft pegeneriert ain nicht mehr wirksames Kymase\%uckeromisch nur, wemn es hald nach dem bröischen der Gärwirkmug yugesetzt wirl. bor liochsaft selbst ist sehr halthar.

1) Arthur Ifarden und William John Young, Der linfluB von Phosphaten anf die Gïrung der dilukose durch Ilefesaft. Proceedings C'lem. Soc. Vol. 21. p. 189-190: nach Chem. \%entralbl. Bit. ‥ S. 347 (1905).

${ }^{2}$ E. Bnchur. mud $r$. Duchack, Ther fraktionierte Fällung des Hefepreßsaftes. Biochem. \%eitsclur. Bd. 15. S. $221-253$ (1909). 
Burher und Duchurel haben mit IJilfe von Aceton eine gewisse Fationirerum von Ferment und ('oferment erreicht. Quantitativ sind die Resultate noch wenig befriedigend. I)as liegt aber nicht etwa daran, dali Areton die Substanzen zerstört. Frührer wurle ja schon erwälnnt, dab man ein wirksames Trochenpräparat herstellen kann. wemn man I'refsaft in Aceton eintriufelt. Tm aher Fraktionen zu erhalten, welehe sich scharf durch eine verschiedene Fallharkeit durch Aceton unterscheiden. muls man das Aceton in den Prefsaft eintracren. Ienu nur so kann vermiclen werden. dafs voriberwehend die Acetonkonzentration zu boch ist. bei diesen Vortrehen entstehen aber stark wasserhaltige Niederschläge, in denen viellejcht die wirksamen Substanzen durch Fermentwirkungen greschädigrt werden. Lediglich auf Verzettelung läßt dir mangelhafte Ausbeute sich nicht zuriickführen. I)enn auch die vereinigten Niederschläge erreichen nicht die Wirksamkeit eines I'räparates. welches durch Eintragen des I'rebsaftes in das Acetou gewonnen wird.

Tm durch schnelles Arbeiten die einwirkenden Schädiquungren möglichst abzuschwächen, werden die Niederschläge durch Ausschleudern auf einer Zentrifuge abgetrennt, welche in der Vimute 3000 Cmdrehungen macht, woriuf die iiberstehende Flüssigkeit einfach abgregossen werden kann.

Im einzelnen gestaltet sich ein 'Trennungsversuch etwa wie folgt: In $100 \mathrm{~cm}^{3}$ frischen Preßsaftes aus Berliner Unterhefe, der durch Zentrifugieren moch von Kieselgursplittern und Hefezellresten befreit wird, wird unter starkem Turbinieren eine Mischung von $50 \mathrm{~cm}^{3}$ Aceton und $50 \mathrm{~cm}^{3}$ Wasser eingetragen. Die entstandene erste Fällung trenut man durch Zentrifugrieren rom Niederschlag. Zur Herstellung der zweiten Fällung wird die abgegrossene Lösung abermals mit $100 \mathrm{~cm}^{3}$ Aceton versetzt. Fleichzeitig wird die erste Fällumg mit $100 \mathrm{~cm}^{3}$ Aceton angerührt. Die Niederschläge werden sodann wiederum abzentrifugiert. In die von der zweiten Fällung abgegossene Lösung wird hierauf ron neuem $200 \mathrm{~cm}^{3}$ Aceton eingetropft. worauf sich die dritte Fällung heim \%entrifugieren als flockiger, aber halbschmieriger Yiederschlag am Boden des Gefälies absetzt. Zu gleicher Zeit werden wiederum die erste und die zweite Fällung mit je $100 \mathrm{~cm}^{3}$ Aceton aufgeschwemmt und sodann zentrifugiert. Endlich werden alle drei Fällungen nochmals mit je $100 \mathrm{~cm}^{3}$ Aceton und init je $100 \mathrm{~cm}^{3}$ Ather durchgeriihrt, jedesmal hermach zentrifugiert und die Niederschläge schließlich im Vakuum iber Schwefelsiure getrocknet. Die erste Fällung stellt nun ein feines, weilies Pulver, die zweite ein gelbliches, gröberes Mehl dar, während die dritte eine gelbe. feste und zerreibbare Masse bildet, die sehr zerfließlich ist.

Die ganze Operation dauert 2 Stunden. Das Verfahren ist so eingerichtet. daß alle :3 Fällungen die gleiche Zeit mit dem Aceton in Beriihrung bleiben. werden:

Der Gang des Versuches kann etwa so tabellarisch wiedergegeben 
Angewandt : $100 \mathrm{~cm}^{3}$ Ilefeprobsaft.

Fiste Fibllung aryelt lunch ein Gemisch von $.00 \mathrm{~cm}^{3}$ Aceton $+.50 \mathrm{~cm}^{3}$ Wassel, gewaschen sohrittweise mit $100+100 \mathrm{~cm}^{3}$ Iceton $+100 \mathrm{~cm}^{3}$ Ither:

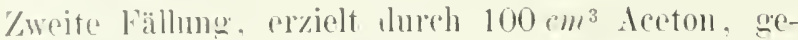
Waschen mit $100+100 \mathrm{~cm}^{3}$ Accon $+100 \mathrm{~cm}^{3}$ Ither:

Dritte faillung, rmielt durch $200 \mathrm{~cm}^{3}$ Areton, gewaschen mit 100 cm $^{3}$ Acoton $+100 \mathrm{~cm}^{3}$ ither:

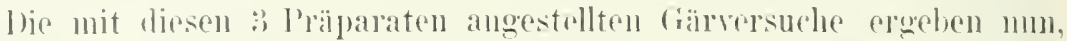

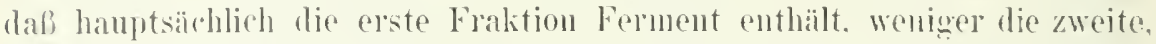
die dritte iblerhanpt nicht, währoul in dieser dritten Fraktion cofermont sielı findot.

liei der 'Traubenzuchervergärung durch die Hefezmatse entsteht als Neben- oder Zwisehemprodukt Milchsäure. Anch die Mildhsilure wird durch tierisehe nud pflanzliche Enzyme zerstört. Burluer mul Meisenheimer, welehe das Enzym in der Hefezelle, das die Milehsäme spaltut. Laktacidase nemuen, haben anch eine Nethoule zum Xachwejs der lixistenz einer

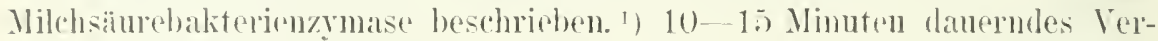
weilen muter Acoton mul mehrmaliges Iuswaschen mit Xther tötet die durch Alorntrifugieren aus der Nïhrösung isolirrten, 15-20 Stunden auf Tou an dre lıft gotrockneten Milchsäurebakterien (Bacillus l)ellniicki) vollkommen zuverlässig. In flen Prefsaft geht das kn\%m nicht iiber, man han es vielmehr nach dem Anspressen aus dem Riölistand durch Acetonansfällung frei von lebenden Bakterien gewinnen.

Jie abgetöteten Bakterion werden mit Rohrzucker oder Maltose mnter 'Toluolzusatz zusammenowbracht. Offenbar sind neben den Milehsäureferment gledehzeitio stets hrdrolytische Enzyme vorhanden. wie darans

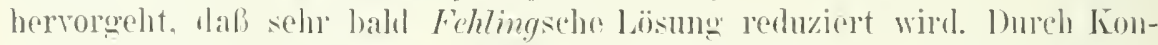
trollen wurle nacherwieson. dah weder die bahtorien vor der Fermenteinwirkmog Milchsium enthalten, noch unter dem Einflusse (rhitzter Fermentlïmug Milchsiume entsteht. Es wurle immer inaktive Milchsäure gefunilen.

Cber das luftroten und den Nachweis von fermentativ entstandenel

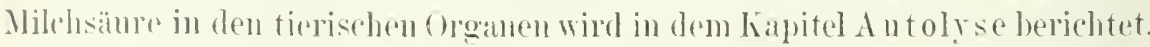

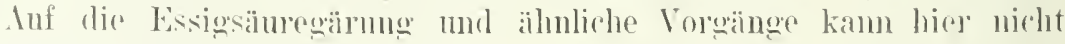
aingegangen wejten. da es sich hiej un die Wirkung von Gxylasen handelt, zum 'Teil auch die Isolierumg der Fermente noch aussteht.

b) a urh in (roanismus der höheren Tiere dir Verbenmumg des Tranlenzuckers eine orobe liolle spielt, so ist es kamm anders möglich, als dally die tierischen Kellen auch olykolytische Fermente bositzen.

1) Eduard Jinchner und Jakob Mcisenheimer, Über die Milehsäuregärung. Liebigs Annalen. Bu. 349. S. 125-139 (1906). Die Autoren reservieren die Bezcichung "Zymase" für die Fermente. welche direkt den Zncker angreifen. 


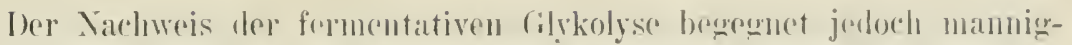

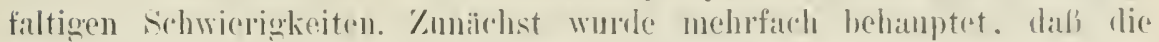

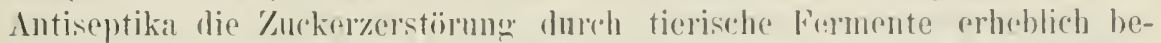

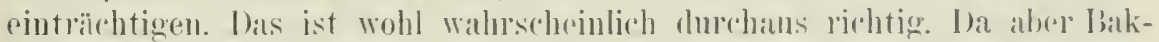
terien bekanntlich sehr stark /urker \%ersetmen. aseptisch sich dieso lersuche kanm in erobloren I'mfange durchfiiluen lassen, so werelen aben nur Mothoden sich verworten lassen, die nicht anf Intiseptikil zu verzichten manchen. Hier ist inshesondere das von Cohmheim ansogebildete Vorfahren zu efwähnen. Wir worden sofort sehen, was fï mmollicho Schwierighejen sich hier störend hemerkhar machen, schwicrigkriten, die in don verschiodensten I'mständen hedinet sind. Foluende l'mukte seien hervorgehoben :

1. Das Vorkommen rou Gilykogen in den fieweben. das während der Vorsuche durch gleichzeitig vorhandene diastatisehe Euzyme zersetzt wirl. So kann Zerstörung des 'Tlanbenzuckers durch Veubilimg aus Gilyogren verdeckt werden.

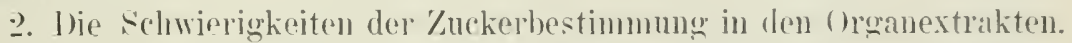
I lieser Ubelstand ist anscheinend ron Gohnheim durch dic Verwertung von Parys Methode iberwumblen worlens.

3. Die Abhängigkeit dor Fuzrmwirkmng rom Milieu.

t. Die Abhängigkeit der Wirkmg von der Mengr des vorhankenen Enzyms und speziell von dem Verhältnis. in dem die zul Wirkmo notwendigen Faktoren zmeinander stehen.

Cohnheim ${ }^{3}$ ) hat allmälnlich folgend'n methodischen Gang vorgeschrieben:

Die zu den Versuchen dionenden Katzen wurden durch Ither betäuht und durch Durchschneiden des Halses getötet. wobei eine erhebliche Menge Blut in den Gefäben zuriublbleibt. Jas Rindfleisch, meist vom Vorlerbein stammend, wurde frisch vom Schlachthaus geholt und kam uoch vor stïrkerer Abkïhlung und vor Eintritt der Totenstare zur Verarbeitung. Мeist zuckten die Muskeh noch beim Durchschneiden. Das Fleisch wurde zweimal durch eine Flejschhackmaschine gegehen und kam dam sofort in das riskalte Wasser. Dem Fis und Wassel wird 1-1.2y oxalsaures Natron füi $: 300-500 \mathrm{~g}$ Muskeln zugesetzt, auberdem etwas Magnesiumkarbonat.

Die Menge der Fxtraktionsfliissigkeit kam in weiten (irenzen schwanken, 170 und $600 \mathrm{~cm}^{3}$ pro 100 y Muskel macht keinen Lnterschied. Die Extraktionsdauer betrïgt $1 \%-4$ Stunden. ehenfalls ohne erkenmbaren Lnterschied. Man fügt soviel Fis hinzu, dali am Schlusse der Fxtraktion noch reichlich Eis da ist. Nach schlul der Extraktion wird soviel Chlorcaleium zugesetzt, daß gerade alles 1)xalat ausgefält ist. I)amn wirl gut durchgeschiittelt, endlich das Extrakt durch Gaze mit der Hand ausgepreßt.

bie erhaltene Flissigkeit wird zwecks Mischung gut geschïtelt und dam in gleichen Portionen, die immer ziemlich genau je $100 \mathrm{~g}$ Muskelu

1) Otto Cohnheim, Coer Glykolyse. IV. Mitteil. Zeitschr. f. phys, Chemie. Bd. $\mathbf{4}$. S. $253-285$ (19ง6). 
entsprechen, untersucht. I'ro Tortion wird genan $1 \mathrm{~g}$ 'Traubenzucker. Maunesiumkarhonat, $20 \mathrm{~cm}^{3}$ 'Toluol mol am besten alleh noch $6-10 \mathrm{~cm}^{3}$ Chloroform hinzugefïgt. Ins Chloroform wird vor der Reduktions]nrifung durch geniigend langes líochen wieder entferut. Die l'estinmung der Reduktion erfolgt mach I'uxy.

Im geforenon /ustande bewahrt das Muskelextrakt seime grlykolytische Fähigkeit, in Eisschrank verliert sie sich balel.

Bei Hunden seheint die Anwendung des (oxalats bei dep Methode vorläufi@ mostatthaft.

Nicht alle Katzemmuskeh sind glykolytisch wirksam. Will man starke Glykolyse finden, so setzt man die Katzen in ein kaltes Zimmer und yibt ihnen mit /ucker versetzte Jilch. Soll die Glykolyse fehlen, ermiidet nan die Latzen dureh Morphin oder durch Arbeiten im Tretrade und läbt sie dann im warmen liamm humgern oder füttert sie mit speck, Butter und öl.

Nach Cohnheim besitzt das l'ankreas einen Aktivator, der die Glykolyse der Muskeln rerstäkt, ohme selbst 'l'aubenzucker zu verändern. Im ibn ans Kitzenpankreas in möglichst wirksamel und reiner Form zu gewimen, wird der (Organbei frisch in kechendes Wasser gretan, dureh Gaze ahgeprefit, der liickstand mehrumals mit Alkohol vou $96^{\circ}$ extrahielt, die Extrakte mit dem ersten Wasserextrakt vereinigt und anf dem stark siedenden Wasserbad zur Trockene eingedampft. I)abei mul man zu starkes Eintrocknen vermeiden. Der Riickstand wird mit $96 \%$ igem Alkohol aufgenommen und filtriert. Diese alkoholische Lösung wird direkt den Muskelextrakten znosetzt. Bunchteile eines kibbikzentimeters geniigen fiir den lixtrakt von $100 \mathrm{~g}$ Muskeln. I'berschub des Aktivators hemut die Glykolyse mol muli daher rermierlen werden, eventuell muls man fiir die besonderen Versuchshedingmaten die gehörige Menge ausprobieren. Meistens ist Extrakt, das $0 \cdot 0: 3$ y Pankreas entspricht, die richtige Menge.

liir las elykolytische Enzym der lö̆leren l'flanzen gehen wir Stoklasas ${ }^{2}$ ) und seiner Mitarbeiter Methorle wieder:

/ar Isolierung der Rohenzyme werolen gewöhnlich 5-6 kg junge und frische P'flanzensubstanz relwendet. Ino frische I'flanzenmaterie, welche keinerlei \%ersetzmng lurch Fänlnis aufweisen darf, wurle zerstiickelt und der saft aus der so crbaltenen Masse unter cinem lorucke von 300 bis 400 Atmosphären ausgeprelit. Jem so gewomnenen Saft wird ein Gemisch von Alkohol und Cther zugesetzt, worauf ein an Eiweilistoffen reicher Niederschlag sich absetzt.

loiese Operation geschieht in einem hohen, sterilisierten /ylinder. Auf $200 \mathrm{~cm}^{3}$ des zollfreion Saftes kommen $600 \mathrm{~cm}^{3}$ eines Gemenges von $400 \mathrm{~cm}^{3}$ Alkohol und $200 \mathrm{~cm}^{3}$ Xther. Naleh einem Augenblicke setzt man Athor im I'berschuli zu und die oberhalb des Niederschlages aus Alkohol mol ither hestehende Flissinkeit wird sofort abgebcbert. Nun wirl nener-

1) Julius Stoklasu, Adolf Ernest und Karl Chocensky, Uther die glykolytischen Enzyme im lfflanzenorganismus. Keitschr. f. phys. Chem. Bd.50. S.303-360 (1907). 
dings Xther anfgegossen und sodann sofort die iiberstehende Fliiscirtreit abgehehert.

Ier ¿ranze Vorgangr bei Fällung des l'flanzensaftes muli rasch rorgrenommen werden. so dab . Ilkohol und Sther nur möglichst kurze Ze.jt auf das Enzym rinzuwirken repmö̈gen und infolgedessen seinr Aktivitit nicht abschwächell. Die Fliissigkeit iiber dem Niedersehlag wird deshalh rasch ahgegossen oder ahgehwhert und der so gewommene das grimugsrregende Enzgm enthaltende Niederschlag sofort abfiltricrt. Ibie Filtration läbt sich am schmellstrn mittust Lainwand bewerkstelligen. Auf die sterile Leinwand wird die erhaltene Yasse anfgeschüttet und grut abegepreft.

Das so gewonnene Rohenzom wurde entwerler in Vakuum oder in sterilen. zn diesem /wecke besonders arrangierten liolben getrocknet.

l)iese liolben waren wie folgt zusammengrestellt: In dem Hals jedes der Kolben war ein dreifach gebohrter Kautschukstïpsel eingepalit. Durch die eine dieser Öffunngen gring eine ziemlich hreite. knieförmig gehogene Riöhre, welche bis fast an den Boden des liolbens reichte und mit Watte gefuillt war. In die zweite Öffunng des Stopfens war eine kurze, gerade Röhre gesteckt, die ebenfalls mit Watte gefïllt war und kuapp unter dem Stopfen mündete. Die dritte Öffung war mittelst einer lilasstanger rerschlossen, welche, sobald die Kolben einer dreifachen, fraktionierten Sterilisation unterworfen waren, durch ein Thermometer ersetzt wurde. Das Thermometer wurde, hevor man es in den hetreffenden liolhen eingelassen hatte, wrïndlich mit einer sublimatlösung abgewaschen und dann auf die Weise ahgesengt, dab es in Alkohol getancht und die sehr schwache 11koholschichte angeziundet wurde.

Sodamn erfolgt die Wïgung jedes der Kolben. Lnter. Beobachtung aller Kautelen gegen die Inrasion ron Mikroben wurde hierauf in die Kolben ein hestimmtes Quantum des auswesibten Viederschlages eingetragen und dessen Trocknung durchgeführt. Die liolben mit dem Enzrm wurden nämlich in kupferne Trockenapparate getan, in welchen eine Temperatur von ea. 36--38 $\mathrm{C}$ erhalten und sterilisierte Luft in starkem Strome in der Weise durehgetrieben wurde, daf die kurze, unterhalb des Stopfens in den Kiolbenhals miindende Röhre mit einer Wasserpumpe in Verbindung gebracht wurde, während die längere Röhre. welche fast bis an den Boden des Kolbens reichte, mit etlichen Waschflaschen, die oine konzentrierte Lösung ron Sublimat enthielten, und mit etlichen \%slindern. in deren mit steriler Watte gefuilltem Lnern mehrere iibereinander geschichtete Lagen feinkörnigen Thrmols untergebracht waren. verbunden ist.

Mit $6-10 \mathrm{~g}$ dieses Enzrms werden damn $50 \mathrm{~cm}^{3}$ einer $15{ }^{\circ}$ igren Traubenzuckerlösung $0 \% \mathrm{~K}_{3} \mathrm{PO}_{4}$ unter ascptischen Kantelen und unter $\mathrm{Zn}$ satz ron Thymol zusammengebracht und dam der Verlust an Zucker und die gebildeten Produkte bestimmt. 


\title{
F. Ine Fermente des Fettstofinechsels in Tier- mond Pflanzenwelt.
}

\author{
Ton M. Jacoby, lierlin.
}

Iej intermediäre Fettstoffwechsed mol seine Beeinflussumg durch Fer:mente beginut mit dem Ingenblick, in dem das fort in jrogend eince Form

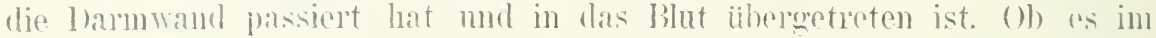

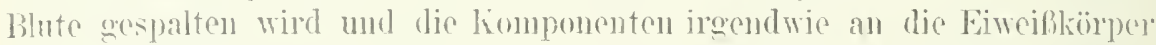
ackuppelt werlem odel wie somst das Fott dem direkten Nachweis outzogen

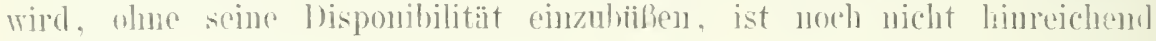
ตeklält.

Nach dre Methorie ron Comnstein ${ }^{1}$ ) nud Micharlis kamn man jedenfalls mathweisen, dal. Fett. welches man dem? lilute zusetzt, seine Itherlïslichkeit vellort. Als Antiseptikum bewährte sich Fluornatrinm: die ständige \%ufulu von Samerstoff ist mentbehlich.

Ein derartiger lersuch gestaltote sich dam folgendermalian:

lis werten gemischt:

$157 \because y$ Hint, enthaltend $0 \cdot 400^{\circ}$ \% Fett, mit

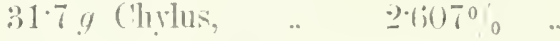

Dor Foftgehalt dos Gemenges berechmet sich somit anf (1-8s?g; statt

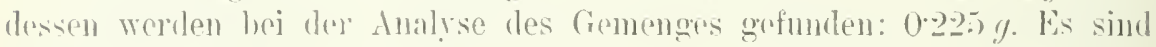

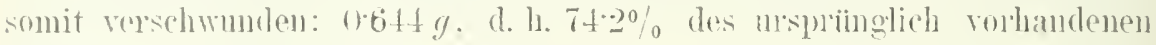
Fettes.

Inwiereit hier das atherösliche Fett abgrommonn hat und mit welchem Anteil lecithin mol andere fipoide betriligt sind, ist nicht ganz sicher(ger.tellt.

Wälurall cine fermentative Spaltung dow Körperfotte durelı libutserum bishor nicht nachgewiesen und nicht cimmal wahrscheinlich gemacht

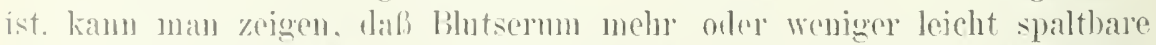
Ester, wie \%. I). das Monobutruin, in gewissem Infange zerlegt. Man stellt das nach dem lerfahren ron Hamriot ${ }^{2}$ ) fest, das darin besteht, dak man

1) Fithelm (omnstein, Uther fermentative Fettspaltung. Krgebnisse d. Physiologie. B1. 3. 1. S. $194-2322(1904)$.

2) Vgl. Withrlm Connstcin, Ergehnisse der Physiologie. Ba. 3. I (1904). 
Monobutgrin zu blutserum zusot\%t und sich nach einiger \%oit dureh Ti-

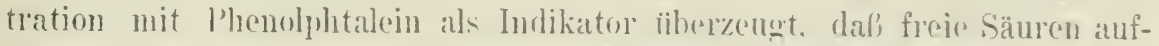

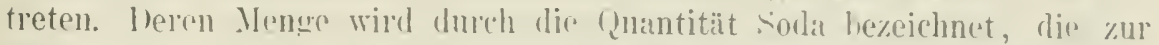

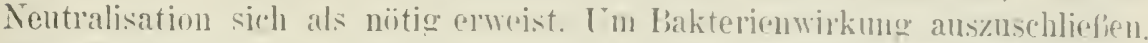

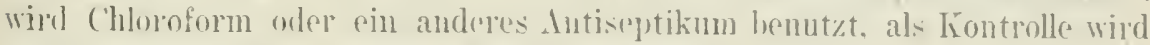
auf mindestens (ji) erhitztes sirum vorwandt.

biese Fsterspaltume findet mun auch in den Geweben statt und num kanu esterspaltende Fermente alus den ()rganzellen extrahieren. sohr leicht

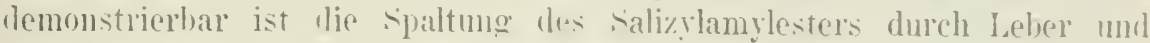

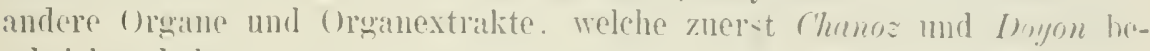
schricben halsen.

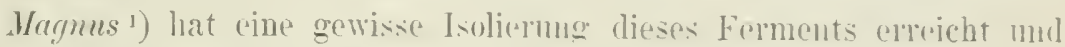
einige bemalienswerte methodische I'mulitr hervorgeholen.

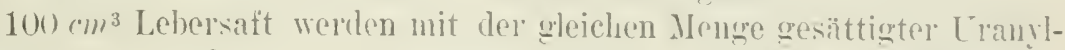
acetatlösmg ausgefält, mit gesättigrter Lösung ron soda und Natrimmphosphat mentralisiert und noch so viel Natrimphosphatliisung zugrafigt. bis im Filtrat mit Natrimphosphat kin Nieldershlag melu zu erzicten ist. I)arauf wird sofort abfiltri(ret, der Niederschlas :-2) Stmulen mnter $100 \mathrm{~cm}^{3}$

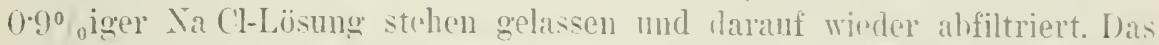
Filtrat, welches schwarh alkilisch reagiert. wird nit $n-20-1 l_{2},-0$ rersetzt.

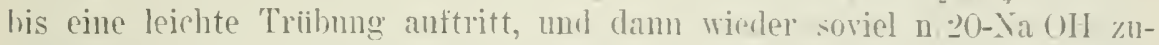

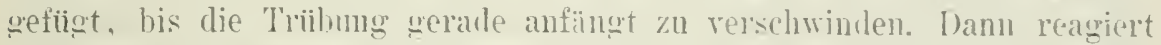
die Flïsigkeit gegen Lackmus nentral nud wird unter 'I'olnol anfhewahnt.

so gewonnene Lösungen sind in den meisten Fällen aulierorlentlich wirksam. unter Cmstänlen pnantitatir chenso wirksan wio eine entsprr(hende Menge des Lebersuftes $120 \mathrm{~cm}^{3}$ spalten in 4 Tacen bei $1 \mathrm{~cm}^{3}$ Ester so viel, dab die gerromnene salizylsiume noch in einer lerdiinnung 1: 20.000 mit Eisenchlorid nachweisbar ist: das entspricht nach

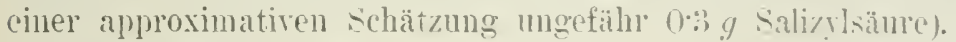

Der Eiweiligehalt diescr lösungen ist rin weringer, aber weehsehnder. In einer Darstellung. Welche stark wirksam war. lieli sich Eiweif nur in Spuren nachweisen (Biuretprobe unsicher. Kochprobe und Xanthoproteinreaktion ganz minimal. Hillons, Adamlicuicss und Molischs lieaktion negativ).

(ianz eiweibfreie Lösmgen sind stets unwirkan. Sach mehrtägiger Dialyse gewen fliebendes Hassel werdon die fermenthaltigen Flissigheiten stets murirsam. Sie werden anch nicht wieder wirksan. Wonn man sie nach der Dialyse wieder auf einen Fehalt ron $0^{\circ} y^{\prime \prime} \mathrm{Nil}$ ('l hringt. Die alte Wirksamkeit kehrt jedoch sofort zunich. Wenn zu der murirkamen Fermentlisung einige Knhikentimeter gekochten lebersaftes gesetzt werden. der fiur sich allein ehenso vïllig mwirkam ist. Statt des grochten Lebersaftes kann man eine entsprechende Menge einer gehochten Fermentlösung nehmen, welche mit Uranylfälung gewonnen, aher nicht dialysiert worden ist.

1) R. Magmus, Zur Wirkungsweise des esterspaltenden Ferments (Lipase) der Leber. Zeitschr. f. phys. (hemie. Bul. t2. S. $149-15 t$ (1904). 
Es clhält also rine dialysierte unwirksame Fermentlösmug durch \%usatz der fiir sich ebenfalls unwirksmen, nicht dialysierten, aber gekochten lösung ihre esterspaltende Eigenschaft murick.

Dialysielt man $100 \mathrm{~cm}^{3}$ Fermentlösumg gegen ca. $1 \mathrm{l}$ Wasser, das am

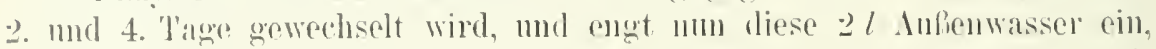
so erhält man rine Fliissigheit, Welche nentralisient atuch nach dem dufkochen die Fähgkeit hesitzt, oine mowirkame dialysierte Formentlïsmug wieder wirksam zol machen.

Das Coferment. das also durch Cranylacetat fällbar. dialysiert und kochbestiundig ist, ist alkohollöslich, mulïslich in Xther, wild ilureh nentrales essigsames Blei nicht gefällt und dum Velaschen zerstört.

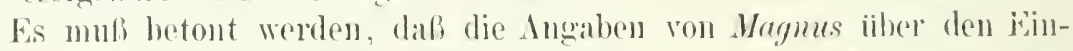
flub der Dialyse anf die Wirkung des Ferments und las Coferment sich lediglich anf die Spaltung des Amylsalizylesters beziehen. Ersetzt man den Amylsalizylester durch den Ithylbuttersïmester, so wird die lermentwirkung weder dureh l)ialyse anfgehoben, noch durch entsprechende $/ 11-$ sütze verstälit.

Sard $\left.{ }^{1}\right)$ ledet kritisch gegeniber manchen anderen Angaben hervor: daf man Organextrakte mit riniger Exaktheit anf den Gelaalt an Sïmren,

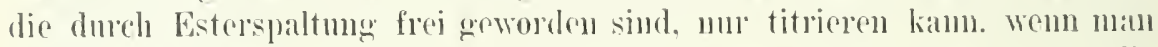
die Eiweibiörper zuror durch lioagulation entfernt, wem man ferner die Prohen mit den Estor nidht zn lange im linutschranke beläbt. Bei längerer Antolyse rntstehen nämlich ans dem rigenen Material der organe zu viel sance Proulukte, welche die Fohler dor Methode zu sehr vergröbern.

Saxls rigenes Vorgehen gestalteto sich folgendonnaben:

Frische Groane wurden fein gehackt und l'ortionen ron je $5 \mathrm{~g}$ davon ahgewourn; dieso wuden in Pulvergläser mit eingeschliffenem Stïpsel ge-

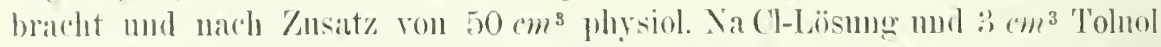
gnt durchgeschiittelt; die Gläsor wmelen sodam in den Bintofen gestellt,

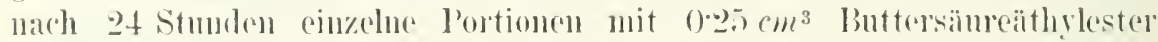
versetzt, wähend andere als Vougleichsportionen olne Ester\%usat\% verblieben; mmn whrden die Proben noch 1 stunde im linentofon golassen, sodam alle anfgekocht mud filtrielt, nachdem den P'roben ohne Esterzusatz munittelhal vor dom Anfkochen norh $0.25 \mathrm{~cm}^{3}$ Ester zugesetzt worlen war. I) Fo Filtrate wurden mit $11 / 10-\mathrm{Na}$ ()II (Lackmustinktur als Indikator) titriert: die Intrerseluede der mit Ester\%usat\% im Brutofen beschickten Portionen und der

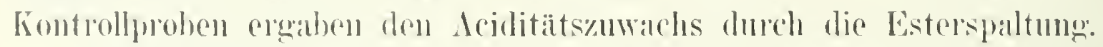

Die Erfahrungen iiber die Spaltmong von Neutralfetten, welche mit den

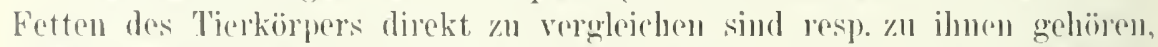
sind noch gering. Wir verweisen anch hiel anf die von Saxl verwandte l'echnik.

Melnere I'ortionen zn je $10 \mathrm{~g}$ Leber mod zu je $10 \mathrm{~g}$ Lunge wurlen

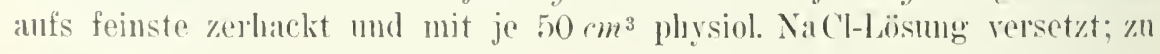

1) Paul Suarl, ther Fett- und Fsterspaltung in den Geweben. Biochem. Zeitsehr. Bil. 12. ‥ $343-360(1908)$. 
den einzelnen Iuneren- und Leberportioness wurle je 1 g Kuhbutter. diw gegen Lackmus neutral reagrerte. hinzugefingt, alle Prohen mit $: \mathrm{cm}^{3} \mathrm{To}$ luol versetzt, gut verhorkt, durchgeschïtelt und in den lirutofen gestellt. Sach einiger \%eit wrirden diese (1)ganportionen dem brutofen entnommen. aufrekocht, filtriert, die Filter nacherewaschen und die Filtrate mit n/10Lauge titriert. wobei I'henolphtalein als Indikator diente.

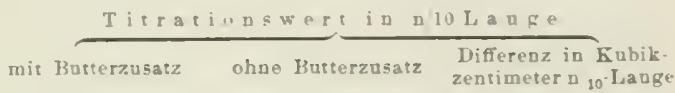

Je $10 \mathrm{~g}$

I. u $n \perp e$ :

Nach 2fstündigem Verweilen im Brutofen.

$7 \cdot 0$

S.0

L e b e r :

$41 \cdot 0$

$51 \cdot 0$
$4 \cdot 1$

4.7

$37 \cdot 0$

$39 \div$
$4 \cdot 0$

$11 \%$

ach 7 -2tïndigem Verweilen im Brutofen

Wenn die spaltung erst spät einen gröferen L'mfang ammimmt, so beruht das vielleicht auf dem Einflusse der erst allmählich durch die Antolyse zunehmenden sauren Reaktion der Gemische. Denn wir werden gleich erfahren. daß entsprechende Erscheinungen Connstein und seine Mitarbeiter hei dem Studium der fettspaltenden Enzyme der Pflanzen beohachtet haben. Ilese Vethodit muf jelenfalls fuil Versuche mit tierischen (Irganen noch nach verschiedenen Richtungen ausgebaut werden. ${ }^{1}$ )

Von den lipolytischen Enzrmen der Pflanzen sind am genanesten dic Methoden der Darstellung und die Prifungsrerfahren fuir das fettspaltende Ferment des Rizinussamens auscearbeitet. Diese felmentative Fettspaltung ist ron Connstein und seinen Yiturbeitern für die \% weche der Technik verwertet worden. Die Ingaben heziehen sich daher eigentlich auf das Irheiten mit grofen Mengen. Es ist aber nicht schwierig, sich danach auch bei Laboratoriumsstudien zu richten. Wir grehen hier aine schilderung, die sich an die Arbeit ron Hoyer $\left.{ }^{2}\right)$ anschliebt:

Der geschälte oder auch ungeschiilte Rizinussamen wird in einer ron Friedrich Kirupp. Grusonwerh. Magdeburg-Buchau, gelicferten Exzelsiormühle

1) S. Bondi und Th. Frankl, ťber Lipoproteïle und die Deutung der degenerativen Zellrerfettung IV. (Biochem. Zeitschr. Bu. 17. S. 555-561 [1909]) haben gefunden. daB sog. Lipopeptide (Laurylglycin und Laurylalanin) durch Leber- und besonders Nierenbrei des Kaninchens, aher nicbt dureh Magen-Darmfermente gespalten rerden. Eine Isolierung des wirksamen Fermentes gelang bisher nicht. I'ber die Darstellung der Lipopeptide rgl. S. Bondi, ťber Lipoproteide und die Deutung der degenerativen Zellrerfettung II (Biochem. Zeitsehr. Bd. 17. S. j43-552 [1909]). Die Methode der Fermentspaltungsrersuche findet sich in der rierten Mitteilung.

¿) E. Hoyer, ther fermentatire Fettspaltung. Zeitsehr. f. phys. Chemic. Bd. 50. S. $414-439(1907)$. 
mit Wasser fein vermalilen. Jie gebildete Samenmilch passiert eine Uthellanf\%entrifuge rou hoher Lmodrehungszahl, in der alle lipolytisch muricksamen liestandteile des Rizinussamens zurüekgehalten werden. wäluend das

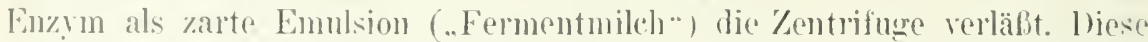

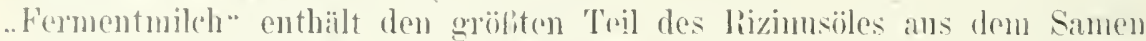
emulsioniert mit den müislichen liweibstoffen des l'rotoplasmas; darmer anch das fettspaltumle Fuzm. Das Emulsionswasser hat alle wasserlislichen Bestandteile, worniter aurh das simmbildende Fonzm, anfoenommen. Diesp

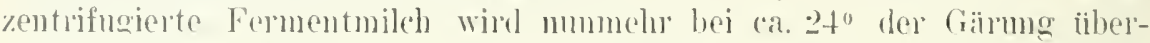
lassen. llierbei sotzt sich die fermenthaltige Emulsion als dicke .. Sahne* an der oherflädhe des samon Lnterwassers ab und kamm so lejoht gewomnen werlen. Diese Sahne enthält das Ferment. Die Lüsung enthält ituler dem Euzym etwa

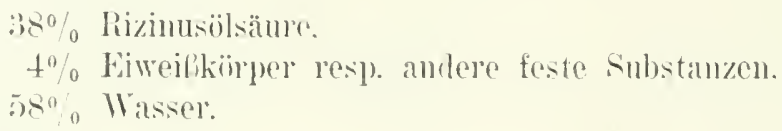

Bekanmtlich wiol das Enzym durch Simre, an hesten - weil am muschädlichsten - durch Lssigsiture. Buttersïure oder Vilchsïure in seinel Wirksankeit rerstairkt, aktiviert. In I"berschub ist aber Sïure für das Ferment schädlich. Inas nato der eben beschriebenen Mothode dargestelle Ferment bedarf keinos sümeznsatzes, os mub vielmeln 'Zusatz von weiterer Sïure vermieden werden. Die Wirkung des Enzyms wird verstälst dureh kleine Zusïtze von Manganoxydulsulfat; $0 \cdot 15-0 \cdot 5$ y Mangauoxylulsulfat auf 100 y l'almkernöl mol 7 g Ferment waren die gorigneten Dosen.

Das Ferment ist cinigermafen halthar, wenn man steril arbeitet mud die l'rifuarate kiihl aufbewahrt. Doch anch dam ist eine Mbuahme der Wirksamkeit morerkembar, wie folgende 'Tabelle loht.

Je $100 \mathrm{~g}$ Leinöl wmolen mit $4 \mathrm{~g}$ Ferment mo fo $\mathrm{cm}^{3}$ einer $(1.50 \% 0$ igen Maneansulfatlösung zusammengeriihrt und der Spaltung iiberlassen.

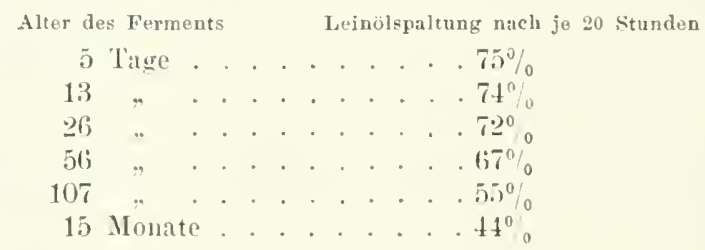




\title{
F. Die Fermente des Fiweilistoffirechsels in Tier- nnd Pflanzenwelt.
}

\author{
Vou M. Jacoly, Tierhin.
}

Ine Figenart der Methodik fiir die Fermente des Eiweifstoffwechsels der 'Tier- und Pflanzenwelt beschrïnlet sich anf die Isolierung der Fermente.

A. Tierische Formente. Fs ist hisher erst in wenigen Fïllen mäglich, die Einwirkng der proteolytischen (1) ranfermente anf isolierte Suhstanzen zu untersuchen. Wenm man nämlich mit einem ()ranextrakt odej einem ans einem (Hoanextrakt hergestellten Fermentpulver liweilirirper, wie z. B. Gelatine, Kasein orler Edestin resp. duch syntlese grewonnene Verbindungen. wie l'olypeptide, zusammenhringt. so hann man in allgemeinen die Wirkung der Fermente nicht ohne weiteres durch Abuahme der Menge des Eiweibkürpers oder durch den Nachweis des Iuftretens der Spaltungsprodukte feststellen. Denn die Organpräparate enthalteu selbst Eiweih, dessen Menge sich bei der Verdaumg vormindert und an dessen Stelle dam Spaltungsprodukte anftreten, die nicht immer ron den spaltungsprodukten der zugefiugten Eiweibsubstanzen rerschieden sind. Man ist damn auf sogenannte Kontrollrersnche angewicsen. Kin Beispiel möge das erlüutern: Es soll festgestellt werden, ob Edestin durch Lehersaft verdaut wird. Man lringt dann in melnere Gefäße gleiche Vengen des Lebersaftes. Zu einer Probe des Lehersaftes fügt man eine hestimmte Menge Elestin. Anberdem setzt man ein (iefïß allein mit dem gleichen Volumen Lebersaft an. ein weiteres mit der oben benutzten Quantität rles Edestins. Selhstverständlich werden ron allen diesen verschiedenen Prohen mehrere Parallelrersuche verwandt. Sun iiberläst man alle l'roben im Brutschranke rer Verdaumo fiur einge Tage. Wenige stunden genïgen nicht. da hei del geringen Intensität dev Fermentwirkngen die dusschlïge dann zu klein sind. Un Bakterienwirkungen zu vermeiden. fügt man von Anfang an dem Organsaft, aber auch del rinzeln angesetzten Eiweiliosung. also in unserem Beispiel dem Edestin, ein Antiseptikum zu, am häufigsten Chloroform, das sehr energisch antibaktericll wirht, aber vielleicht auch besonders schädlich für die Enzrme ist, oder Toluol, das weniger wirksam in erwïnschten und unerwinschten sinne ist. 
Waren dic Flaschen himeichend lange im Brutschranke, so erfolgt die Aufurbeitung in der Art. daf der Kiweibgehalt der Lösungen bestimmt wird. Auf ule hierbei zweckmäbiog verwandten Verfahren gehen wir an dieser stelle nicht cin. hier kommt es zunächst daranf an, auseinanderzusotzon, wir die Einzelproben retrennt resp. rereint rerabeitet werden misisen, mn beweisendr liesultate zu argelen. Den Mittelpunkt der Versuchserihe bildet dio Probe, in der des Lehersaft und die Eiweibkörper

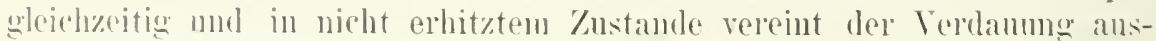
geserty waren. Indem man diese l'ortion enteiweilit molden Stickstoffgehalt des ciweibfreien Filtrates hestimmt. erhält man cin Kriterium, wioviel Terdaumgsprodukte von Giweißkïrpern in wanzen vorhanden sind. l'm nun \%u elfaluen, weriel daron ans der Verdammo der Lebereiweibkörper stammen, vereinigt man von den in den Brutschrank gestellten l'ortionen je cine, die nur lebersaft enthielt, mit einer, die mur ans Edestin besteht, und enteiweibt das Gemenge sofort nach dem Mischen. Bei dieser Kontuolle war dann die Möglichkeit der verlanenden Finwirkun des Leberfermentes auf das Edestin ausgeschaltet, andrerseits die Möglichkeit escichert, Vüunderungen der Leher sowohl wie des Edestins, die in buntschrank auftreten, zur Geltung kommen zu lassen. I)ie Differenz der beiden Versuchsreihen kimm dam als Resultat der upensentigen Beeinflussung der bejclen Faktoren ansgesprochen werden. Ienn der eine Faktor ein gereinigrer Eiweibkörper wie das Erlestin ist, bei dem verdamende Wirkungen nicht anzunchmen sind, so kann man eine aktive Wirkmng des lebersaftes resp. cines in ilun enthaltenen proteolytischen Fermonts als beriesen ansehen.

Ia die ()ranextrakte die in ihmen entlaltenen Eiwcibkörper bei ihrer nativen lieaktion verdauen, so kamn man bei der prifung anf Proteolyse

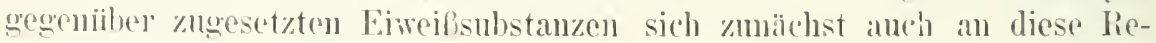
aktionen halten. birelt man negative Resultate oder will man genauer foststellen. ob das verumtete Enzym der Gruppe der lepsine oder der Trypsine nahesteht, so kamm man dieselben Versuche natiurlich anch mit abgeänlelter liaktion, also bei verschiedenen Graden der sauren oder alkalischen lieaktion wiederholen.

Ganz bedeutend rareinfachen wiirle sich dic Lntersuchung auf proteolytische Oruanfermente. Woun man optische mol andere physikaliselue

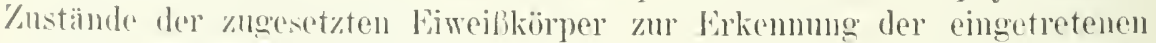
llikkung rerwerten könnte, weun man also untersuchen kömnte, oh fibrin-

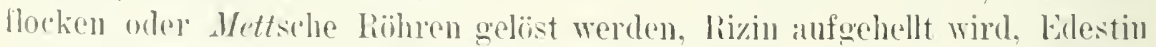
rexp. Kasein nicht mehr ansfillhar ist. Solche Versuche wiuren cimmal zur Orientierung sehr bequem sein. daun anch für puantitative Reihenversuche

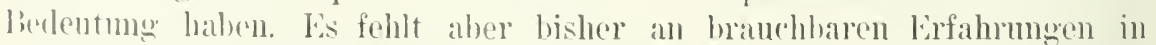

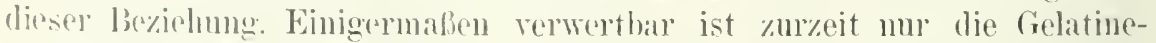
methode ron firmi. Man lereitet sich eine 5-8\% ige Felatine, der man Chloroform zusetzt, mul bringt davon 5-10 $\mathrm{c}^{3}$ in lieagenzgläser mud mutersucht, ob lie felatime noch erstart, nachdem sie mit (organsuhstan\% oder ()roncitrakten zusammen im Brutschrank gewesen war. 
An griustigsten liegen die Terhïltnisie bei don Versuchen mit synthetischen l'olypeptiden, die Abderhalden und seine Mitabeiter angestellt haben. Wenn hier Aminosïuren abgespalten werden, dir bei der Selbstrerdaumng des betreffenden ()roanes, z. R. der laber. nicht gebildet werlen, so ist mau sicher. dali die zugefiigte substanz gespalten worden ist.

Aus alledem weht aher hervor, dali es sehr wïnschenswert wäre, müglichst reine oter wenigstens so gut wie eiweilfreie, proteolytische organfermente zur Verfuignum zu haben. Hine Isolierung der Fermente schüzt anch am sichersten davor, dab Hemmungsitoffe und Intifermente dem Spaltmugsprozen stioren. Bisher ist man aber noch sehr wenig in der Isolierung dieser Fermente rorwärts gekommen. I) wir rorläufig noch nichts hesseres hesitzen, werde ich hier das Verfahren von liosell beschreiben. Nachdem ich mit dem [ranylacetat hei ler Isolierung der Allehydase ded Leber branchbare Resultate erhalten hatte, hat Rosell ${ }^{1}$ ) tas Iranylacetat ganz allgemein benutzt, um wirksame Fermentlösungen aus Orøamen herzustellen. Seine Fermentlösungen hatten vielfach auch dentlich peptische und tryptische Wirkungen. Anf einen L'mstand muß aber labei aufmerksam gemacht werten. Als Magmus zu seinen im rorigen dbschnitt geschilderten Versuchen iber fermentative Esterspaltung die Iranylacetatmethode benutzte, hatte er stets gute Resultate. Bei Benutzung eines neuen Präparates, das ebenso wie die friiheren ron Merck als I ranglacetut purissimmu bezogen war, bekan er keine spur des Ferments in den Niederschlag, wilhrend thas alte Priparat stets auch in Zukunft sich als wirksam erwies. Eine Anfrage bei der Fabrik ergab, daß das Reinigungsverfahren rerbessert war. Mugnus und ich haben tann zusammen versucht, die ['rsache der Terschiedenheit der beiden Präparate aufzuklären, die Versuche aber rorzeitig abgebrochen. Radium schien keine Rolle zu spielen. ob die von Neubery gefundene katalytische Lranwirknng bei dem Phänomen beteiligt ist, wiire noch zu untersuchen. Jedenfalls ist aber bei Fehlversuchen an diese eigenartigen Erscheinungen zu denken.

Das Rosellsche Verfahren gestaltet sich nun nach den Argaben des Verfassers folgendermalien:

Die Gewebe werten mit der Fleischhatkmaschine zerkleinert, mit Quarzsand rerrieben, mit zirka einem Viertel ilues Volumens Wasser angesetzt und reichlich ¿ Stunden auf der schiittelnaschine geschüttelt, dann die Masse koliert. Man erhält dabei eine trübe Flüssigkeit, welche, ohne filtriert zu werden, mit einer gesiittigten Lösmng von Lranylacetat versetzt wird. Während des Zusatzes wird sie durch Zufiigen einel Mischung von Natriumkarbonat und Natriumphosphat alkaliseh gehalten. Las Natriumphosphat dient dazu, lie schlieblich resultierende Fermentlösmng frei ron Lranylacetat zu gewimen; das Karbonat rerstiukt dessen geriugeren Al-

1) Max Rosell, Ủber Nachweis und Verbreitung intrazellulärer Fermente. Dissert. Straßburg i. E. 1901, Josef Singer. 


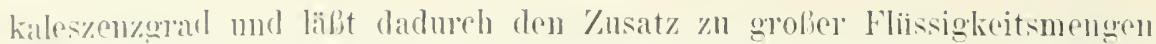
rermeiden. llan fügt solange tramylacetat hinzu. bis sich grobe flocken bilden wolde in kiirzester Zeit sich alynsetzen beginnen, dekintiert und filtriert. Ih libekstand hleibt. nachdem er mit $0 \% 0 \%$ iger Sodalösmer fein verrieben ist, mindestens 12 Stmolen stehen, worauf er filtriert wird. So gewimnt man whe klare. eiweilarme Flissigkeit, in welcher die Fermente in wirksamer form enthalten sind. Wïnseht man reincre l'äparate. so kimn man ['ällen und Anszichen wiederholen. Zweckmälingerweise sct»t man hehnfs honservierung erst jetzt Tolnol himzu. da desson Anwesenheit sonst

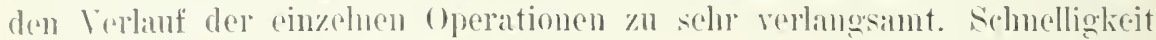
des. Arheitens ist nämlich wegen der anch bei /nsatz antiseptischer Vittel drohonden fämhis zu empfehlen. Ferner wirl die Fermentansbente desto seringer, je später die knzyme aus dem Uranylacetatniederschlag ansogerocerem werden.

Nenerdings hat in meinem Laboratorinun Huta ${ }^{1}$ ) eine Nethode der Isolierung eines proteolytischen Leberfermentes ansgearbeitet. die zunächst nach folgenden Angaben ansgefïht wurde:

Möglichst fein zerhackte Leber wird mit physiologischer Kochsal\%lïsmog (1 $\mathrm{cm}^{3}$ furo $\left.1 \mathrm{~g}\right)$ versetzt. gut geschiittelt mil bleibt cine Nacht anf Fis. Dann wird koliert und der Saft abgeprebt nud noelnmals filtriert. Das Filtrat wird mit (hloroform im Eissehrank anflewalut. Die ganze Darstellung bis zu diesem l'unkt mub loei mögliehst niedriger Temperatur erfolgen. (ieht man so vor, so erhält man bessere Iusbenten und ebenso wirksamen sift, wie wenn man die Leher nit Quarsand und Kiesolgur rerarheitet. Dieses arste lixtrakt ist triib und sehr eiweibrich.

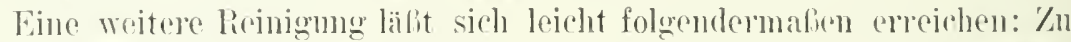
einen Volumen des lixtrakts fiigt man $1 / 10$ Volumen Normalsalzsïnre. Man wartet, ohne den entstehenden Niederschlag alzufiltrieren, eine stunde mud fïgt num Sudalösmng soviel hinzn. dab die sïnre fast vollkommen neutralisiert ist. Inam wird filtriert. Man erhält so eine likare nnd proteolytiseh gut wirksame Fliissigkeit.

Djeses Verfallurem habe ich hier geschildert. weil die Kemutnis dieses Vorgehens das Verstindnis eines noch vorteilhafteren Verfahrens erleichtert, das ebenfills Hate in meinem Jaboratorimm ansegearleitet hat.

100 g Pferdeleber werden in einer Reibsehale tiichtig zerrieben und damn mit $100 \mathrm{~cm}^{3} \mathrm{n} / 20$ ()-Salzsïne versetzt, die zugleich $0.85 \%$ Kochsalt

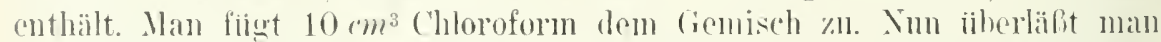
las Gemisch sich selbst, schiittelt nur ron \%eit \%, \%eit dureh. Braucht man die Fermentlösung hade, so führt man den Versuch $2+$ stunden bei :3" dureh. lun anderen Falle belifit man das fiemisch 7 Tage bei Zimmertemperatur. Nach Beendignug der Digestion wird dureh (raze isoliert, mit Normal-Sodalïsung nentralisiert mol filtriert. Jam erhält dam ca. 125 $\mathrm{cm}^{3}$

1) s. Hata, Zur Isoliernng der Leberfermente, insbesondere des gelatinolytischen I.elerfermentes. Biochem. Zeitschr. Bd. 16. S. 383-39) (1909). 


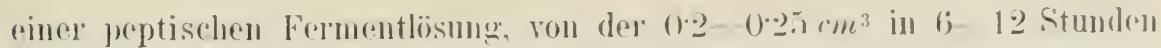

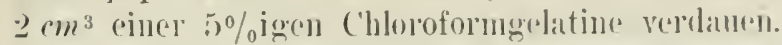

Ijese lermentlösmog lälit sirh damn mit Ammonsulfat norh weiter

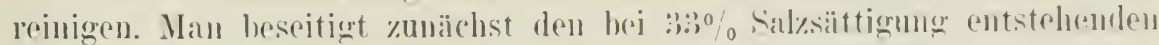
Niedersehlag mul hrimgt dann die Siittigung mit Ammonsulfat anf 7()$^{0}{ }_{0}$. Dann erhält man das Eumyn im Niederschlagn.

Aus Leukozyten stellten Jochmann und Locliemumn ") mach folgender Methode ein puoteolytisches Ferment dar:

Kuochenmark wurde durch Auspressen vou mensehlichen Rïckrnwirbeln am sohraubstock gewommen, Eiter wurle erhalten. indem entwedur Kokkenabszesse benut\%t wurden oder beim Ilenschen steriler Eiter durch Terpentininjektion angesimmelt wurde.

Das Ausgangsmaterial wurde 24 - tr Stmulen der Autolyse im Brutschrink bei 5.50 ausgesetyt. Das Iutolysat wurde mit der nimgeähr fünffachen Menge eines Ciemisches von 2 T'eilen Alkohol und einem Teil Ither veruihrt, mm die fettartigen stoffe herausmlisen bzw. die eiweilartigen Verbindungen zu fällen. Nach eintägigem Stehen wurde filtriert, der Riickstand zunächst zur Verdunstung ron Alkohol und Ither aluf Ton ausgebreitet und dann mit einer entsprechenden Menge (hei flïssigem Insgangsmaterial mit etwa $1 / 4$ Volumen) Glyzerin und der gleichen Menge Wasser innig verrieben, lach ein-bis zweitigigem Stehen in Dunkeln wurde auf einem Büchnerschen Trichter abgesaugt und das klare Filtrat

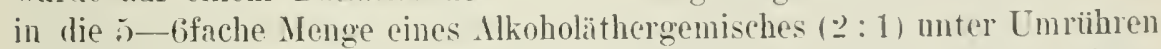
allmählich eingegossen. Der dabei entstehende weibliche Niederschlag, welcher sich allmählich an dem Borlen des Hecherolases ziemlich fest absetzt, wurde nach dem Ahgielien der dariber stehenden Mlkoholïtherlösung auf 'Ton gebracht und in Vakuumexsikkator iiber konzentrierter Schwefelsiure getrocknet. Dabei fïrbt er sich gelbbraun und geht nur, besonders in dickeren Schichten, sehr allmählich in trockenen. zerreibharen Zustand iiber. Das so gewonnene l'rodukt, welches das Enzym enthält, ist etwas hygroskopisch. Fs löst sich beim /erreiben mit Wasser oder physiologischer Kochsalzlösung mit bräunlicher Farbe.

Die Prifung auf fermentative Wirkmng kann nach der Müller-Jochmannschen Methode vorgenommen werden. Man bringt auf cine LöfflerSerumplatte, wie sie in der Bakteriologie für liulturzecke benutzt wird. ein 'Tröpfehen der zu priffenden Fermentlösung und belïßt die l'latte 2t Stunden bei $55^{\circ}$. Dann bildet sich, wenn ein aktires, proteolytisches Ferment rorhanden ist, in der l'latte eine tiefe Delle.

Das Leukozytenferment löst anch Fibrinflocken, erstarrte Gelatine und erstarrtes Blutserum. verdaut Kasein und spaltet aus I'eptonen 'Tyrosin, Tryptophan und Ammoniak ab.

1) G. Jochmann und (: Lockemamn, Darstellung und Eigenschaften des proteolytischen Leukozytenfermentes. Hofmeisters Beitr. Bu. 11. S. $449-457$ (1908). 
Hat man die ()ranfermente himeichend isoliert. Was mit der Zeit immer besser gelingen wird. so wirl man sich zur gualitativen und quantitativen Untersuchung der proteolvtischen ()rganfermente sehr vorteilhaft dep Abrrohaldensehen Methoden bedienen können. Abderhalden ${ }^{1}$ ) setzt zu den Fermentlösungen synthetisch hergestellte I'olypeptide und untersucht, ob und wieviel ron den spaltungspodukten anftreten. Sehr cinfach gostalten sich die yuantitativen Bestimmungen, wenn man das Drehumgsvermögen der Aminosïnren verwerten kamn. so ist \%. B. d-Alanyl-d-Alanin sehr greeignet, weil das d-ilanin sich im Drehungsvermögen scharf von dem (-I)ipeptid unterscheidet. Das nähere iiber dic Methode findet sich an anderer Stelle des Handbuches. Hier sei nur ein Versuchsbrispiel wiederwereben, das den Effekt gut demonstriert:

(1) 6 y d-Alauyl-d-Alanin in $7.6 \mathrm{~cm}^{3}$ Hefepreßsaft $+04 \mathrm{~cm}^{3}$ physiologischer Kochsalzlösung ge]öst :

\begin{tabular}{|c|c|c|c|c|c|}
\hline Irehung & nach 5 & linuten & & . & $-1.08^{\circ}$ \\
\hline . & $\because 12$ & .. & . & & $-0.85^{\circ}$ \\
\hline - & $\because \quad 19$ & .. & . & & $-059^{0}$ \\
\hline .. &.$\quad 26$ & $"$ & . & . & $-0.23^{0}$ \\
\hline r & ,. 30 & .. & . & . & $-0.09^{0}$ \\
\hline .. & $" 35$ & .. & & . & $+0.05^{0}$ \\
\hline " & . 40 & , & & & $+0 \cdot 10^{\circ}$ \\
\hline
\end{tabular}

B. Pflanzenfermente. Die in den Jflanzenzellen tätigen proteolytischen Fermente hat man sowohl in ruhenden lieimen wie in gekeimten I'flanzen untersucht. In beiden Fillen hat man eimmal mit antolytischen Methoden lie Voroünge rerfolgt, aulierdem aber auch die Enzyme ans den \%cllen extrahiert. Wir geben zunächst wieder. wie man bei der T'ntersuchung' dor ruhenden Pflanzenteile, wie sie als Futternittel in betracht kommen, volyenangen ist. Grimmer hat die Autolse der Futtermittel studiert. Die Mrthoden der Autolyse werden später noch besonders beschrichen, hier sei nur hervorgehoben, dab wir unter autolytischen Methoden die Verfahren verstehen. welche ditrauf verzichten, isolierte Enzrmlösungen auf zu fermentierendes Material einwirken zu lassen, die vielmehr sich daranf beschränken, die Judernung der Zusammensetzung von Granen oder Organaxtrakten bei bestimmten 'lemperaturen unter Bedingungen zu mtersnchen. hei denen Enzymwirkungen in Frage kommen.

Grimmer ${ }^{2}$ ) ging folgendermaßen vor:

$100 \mathrm{~g}$ der zu untersuchenden Futtermittel: Pferdebohnen. Wicken, Gerste und llafer, wurden mit $1000 \mathrm{~cm}^{3} \quad 0 \% 0 / 0$ iger Salzsälme oder Wasser

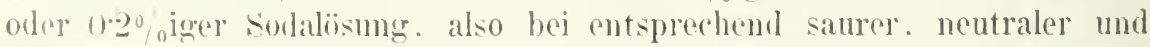

$\left.{ }^{1}\right)$ Emil Aluderhalden nud A. H. hoolker, Die Verwendung optisch aktirer Polypeptide zur Priffung der Wirksunkeit proteolytischer Fermente. Zeitschr. f. phys. Chemie. Bil. 51. S. $294-310$ (1907).

2) W. Grimmer, Kur Kenntnis der Wirkung der proteolytisehen Euzyme der Nahrungsmiltel. Biochem. Zeitschr. Bd. 4. S. 80-98 (1907). 
alkalischer Reaktion $(i, 12$ und ef Stumblen im Thermostaten bei körjertemperatur (:370 C) belassen. Nach dieser Zeit wmedon durch Kolieren und Filtrieren die festrn und fliissigen Anteile des I)igestionsenemisches vonrinander getrennt und dis Filtrat anf $1500 \mathrm{~cm}^{3}$ gebracht. In 2.5 $\mathrm{cm}^{3}$ des Filtrates wurde die Gesamtmenge des gelisten sitickstoffes bestimmt, in weiteren $50 \mathrm{rm}^{3}$ durch Dufkochen mit Essigsiure und nachfolgendes Nentralisieren koagulables lïweili unl sintonin entfernt und in Filtrat die Menge des iibrigen gelïsten Stickstoffes bestimmt. Zur Ermittlung des an Albumosen gehundenen stickstoffes wurlon $1000 \mathrm{rm}^{3}$ nach Eutfermung des koagulablen Eiweibes anf $200 \mathrm{~cm}^{3}$ eingeengt und die Venge der Albumosen in schwefelsamrer Lösung durch Kinksulfat nach Zunz gefällt. Ein Teil des Filtrates wurde zur bestimmung des nummehr darin remblebenen stickstoffes benutzt, während in dinem anderen die mit l'hosphorwolframsänre fïllbareu Anteile gefüllt mol deren Stickstoffgehalt ermittelt wmode. I'm die Menge des Stirkstoffes festzustellen, der vor der Jutolyse vorlanden war, wurden $100 \mathrm{~g}$ der hetreffenden Futtermittel mit eiskaltem Wasser ca. 10 Minuten in Beriihrung gelassen, dam im Fisschranke filtriert und das Filtrat in der aben beschriebench Weise untersucht. Kieht man die Menge des ursprïnglich rorhandenen löslichen Stickstoffes ron der Menge (les bei den Digestionsversuchen gefundenen ab, so erhält man die Menge des durch die Enzyme relösten Stickstoffes. die zmm Teil sehr betrïchtlich ist.

Aron und Klempin ${ }^{1}$ ) wandten bei ähnlichen Versuchen die ron Lionn und Mirhaelis angegebone Fnteiweibnng mit Hilfe von Mastix in, ein fiir die Autolyserersuche gewilj vielfach anwendbares Verfahren.

Im zu beweisen, daß im Hafer mehr proteolytisches Enzym vorhanden ist, als dureh die antolytische spaltung des Hafereiweibes direkt zur Erscheiunng kommt. setzten sic bestimmten Quantitäten lohen Hafers (z. B. 15) g und 55 y) noch 15 resp. $20 \%$ g gekochten Hafer zu. Inic Inoudnumg der Versuche geht ron folgenden krwägungen ans. Man kennt die ans $15 \mathrm{~g}$ wekochtem Hafer zu erwartende Menge löslichen Stickstoffes und ebenso die in 15y rohem Hafer vorhandene Nence löslichen und durch das Ferment löslich gemachten Sickstoffes.

Ist die Meuge des inkoagulablen Stickstoffes gröber geworden, so mub das in 15y rohem Hafer enthaltene Ferment - da es ja erfahrumesgemäß von dessen Eiweif nichts mohr lösen kann - das biweil des gekochten Hafers angegriffen haben.

Mit entsprechender Versuchsanordnumg liof sich auth prifen. ob das Ferment einer Getreideart anch die Eiweiliörper anderer Gotreidearten zu spalten vermag. Es war nur nötiy, mgekochten Hafer anf gekochte Wicken und gekochte Gerste muter den nötigen Kiontrollen einwirken zu lassen oder ungekochte Gerste auf andere gotiochte Getreidesorten. Natiir-

1) Hans Aron und Paul Klempin, Studien üher die proteolytischen Enzyme in einigeı pflanzlichen Nahrungsmittelı. Biochem. Zeitschr. Bd.9. S. 163-184 (1908). 


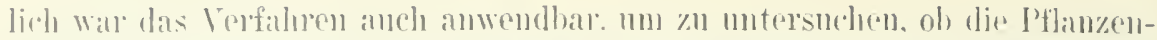

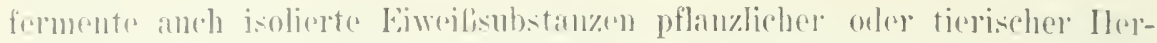
kunlt zil spalten rermügen. Aron und Klempin priften mit positivenn Ergehnic die I'flanzenpuliparate .. Roborat" und .. Laktagol", von tierischen

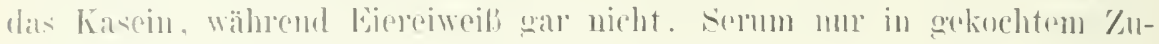
stimde verdaut wurle.

Zur Isolicrung des Hafertermentes gingen Aron mol Klompin folgendermalien vor":

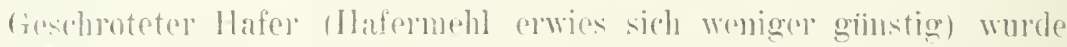

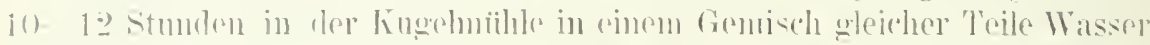

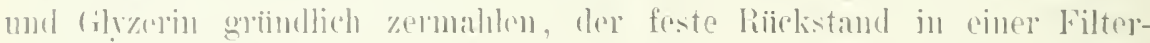

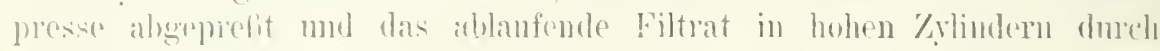

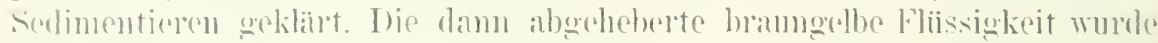
schliebilich noch mehrmals filtriert.

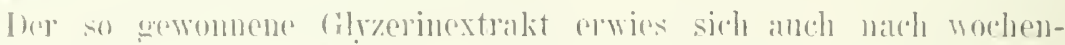

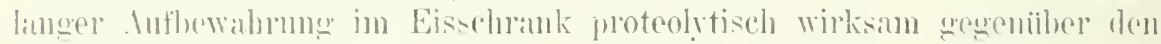

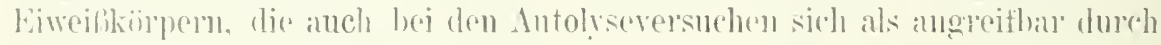
diss lateryerment erwiesen batten.

Fiir alle diese Vorsuche sei hervorgehohen. dab diese Fermente am

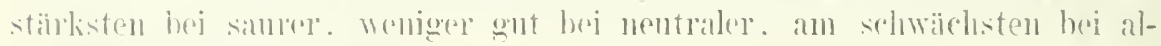
kialiselarer laviktion wirkem.

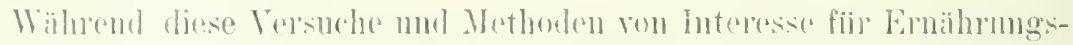

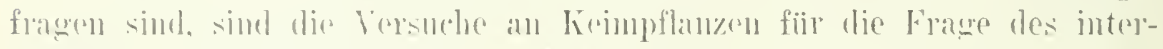

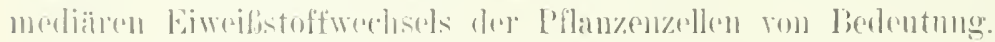

I) betreffenden Versuchsanordnumgen haben sich im wesenthehen

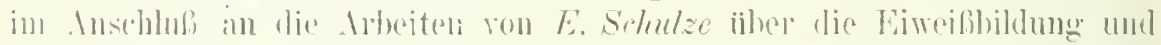

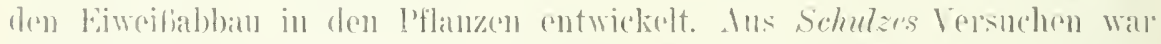

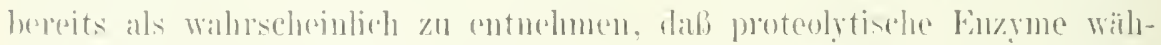

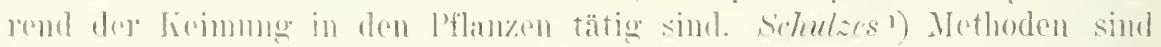

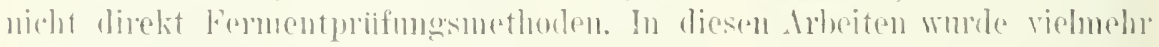

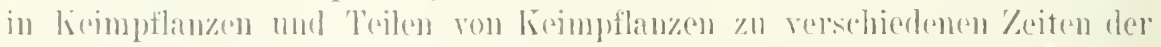

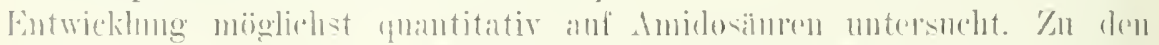

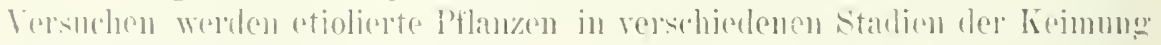

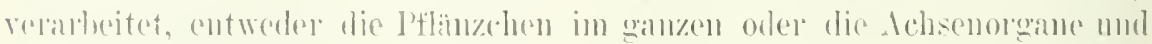

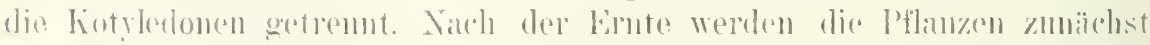

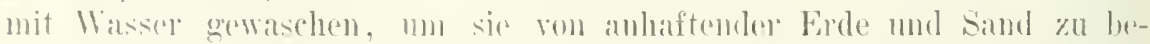

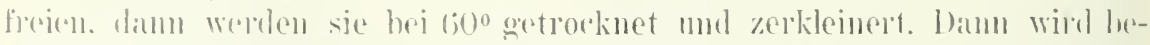

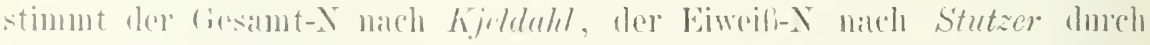

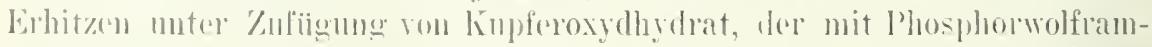

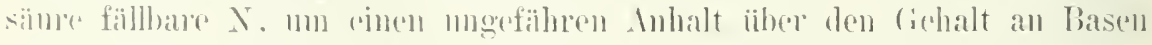
2.4 erhalten, endlich der Amidstiekstoff dureh Bestimmung des $x$, der

1) E. schulze, Uber den Imsitz der biweißstoffe in der lebenden l'tlanze. Zeitschrift f. physiol. (hemic. Bu. 24. S. 18 (1898) mu 2. Ahhandl. Bet. 30. S. 241-312 (1900). 


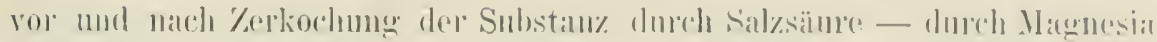
austrobbal ist. Der llauptwert wird aber bei diesen drheiten anf dir möz-

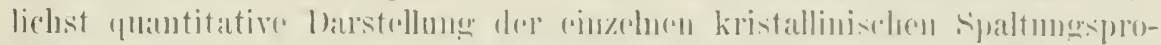

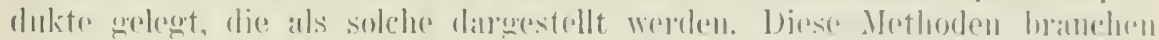

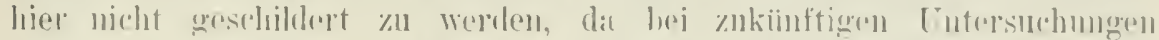

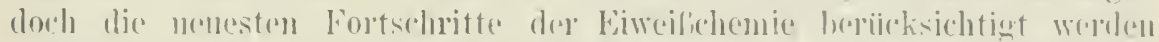

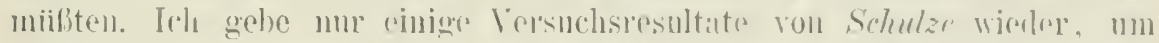

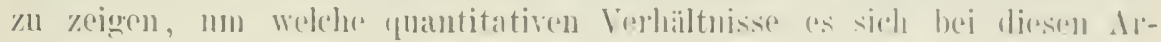
briten landudelt.

Tom Giesant-N entfallen in l'rozonten auf:

\section{Lupims lutens:}

lingekeimter Samen

litïgige licimptlanz'n

15

24

"

L.upinus angustifulius:

Ungekeimter simen

3türige lieimpflanzen

$\begin{array}{rl}6 & " \\ 9 & " \\ 12 & " \\ 15 & " \\ 18 & "\end{array}$

$"$

"

"

"

$"$

Zea-Mrais:

Ungekeinter Samen
9795

9582

9162

8530

66.67

nicht protinartige Verlsinduneren

\begin{abstract}
1938;
.589

$18 \%(1$

18.96
\end{abstract}

9289

$8+13$

4831

3473

2867

2.2. 33

22.78

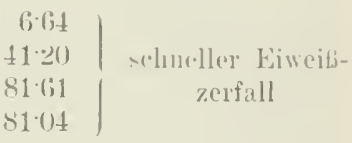

$7 \cdot 11$

15.87

$51 \cdot 69$

(i.) 27

71:33

77.177

75.2.

schmeller Fineißzerfall

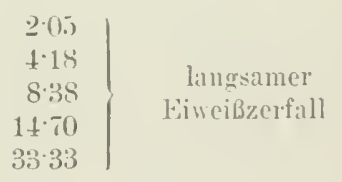

In ungekeinten samen wulden koine Aminosïuren, in 6 itägigen Keimpflanzen $0 \cdot 6 \%$.minosïmen bei umolliommener Inshente gefunden.

Butliewitsch ${ }^{1}$ ) hat dam die Versuche von Schulze mit einel direkten antolytischen Methode weitergefiihrt. Zunächst wurden die gekeinten Samen bei :j- $-40^{\circ}$ getrocknet, dam das Pflumenpulver mit ither getrockmet. Damn wird das Pulver nit Wasser mol Thymol Jei Brutschranktemperatur einige Zeit gehalten. In einem Kontrollversuch wurde die Wasseranfschwemmung des l'ulvers am Begim zmm Sieden thitzt. Lie Lutersuchmon der entstandenen Spaltungsprodukte entspricht dem Vorgang ron Schulze.

Das proteolytische Enzyn läßt sicls durch (ilyorin extrahieren und ist in dem Alkohohiederschiag des Extrahtes enthalten. Setzt man das Enzym zu Konglutin, so konnte Lencin und 'Tyrosin nach Finwirkung des Enzyms nachgewiesen werden.

1) W' . Butkewitsch, Über das Vorkommen eines proteolytischen Enzyms in gekeimten Samen und über seine Wirkung. Zeitschr. f. physiol. Chemie. Bd. 32. S. 1 (1901). 
Heis") hat ein peptisches Enzrm ans Gerstenkörnem dargestellt. Fertio gekeimte fierstenkörner werden in einer Fleischlackmaschine zu einem dicken Brei zerquetselit und : Trile Malz mit 4 Teilen Wasser angerihrt. Jach einiger '/eit, in welcher mehrfach umgerihnt wirl, filtriert man durch Faltenfilter mnd gieft die Flissigkeit so lange durch dasselbe Jilter, his sie völlig klar ist. bei $0^{0}$ ist das Ferment ca. \& Tage halthal. boi der Eimwirkmo anf Weizenghtin wirl die Wirkmg dalurch nachgewiesen, dal' die mit 'Jamuin nicht fällbaren sinbstanzen zumchmen. Wurde bei alkalischer Reaktion anf die Gegenwart einer Tryptase gempift, so komnte mit dersulhen Methode nachgewiesen werden, dab mehr spaltumgsprodukte rntstehen, die mit Tammin nicht fällhar sind.

Da offenhar viole Pflanzenfernente bei ihrer Wirliung ans dem Fiweif Tryptophan abspalten, benutzt Tines ${ }^{2}$ ) die Bromwassereaktion, mm sich schmell zu orientieren, of in l'flanzen ein proteolytisches Euzyn vorhanden ist. '/u diesen Versuchen kann als Eiweibkioper anch Fibrin herangezogen werlen. Die lieaktion ist anch benutabar. um die Schnelligkeit der Euzrmwirkme zu studieren, da man leicht ihr erstes Anftreten in den Vordamungsgemischen feststellen kamm.

Abderhalden ${ }^{3}$ ) hat in Gemeinsehaft mit Schittenhelm und Dammhahn in keimenden simen anch peptolytische Fepmente nachgewiesen. Im ruhenden Simnen sind sio vielleicht ju juaktiver Form vorhanden, da der ans mop-

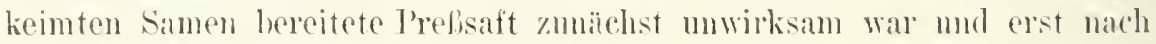
längerem Stehen bej :;To wirksam wurde.

Die Versuche wmden mit Impinensamen, Weizensamen, Masklörmern und Gerstensamen angestellt. Dic samen wurden vor ihrel Verwendung

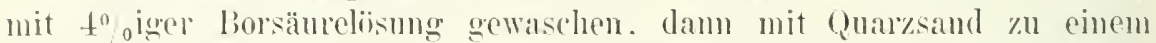
leinen brei zerrieben und mit soviel Kieselgur remengt, bis das Ganze eine plastische Masse bildete. Dirse Masse wmode mm in fostes líoliertueh cingepackt und zmäichst bei 1 i) 1 tmosphiben Iruck anscreprelit. Eine weitere Fraktion an Prelisaft worde unter Anwendumg ron 150-300 Atmosphären Druck gewomnen, diese letzte Fraktion zn den Versuchen benutzt.

Damm wmole zu dem Prebsaft eine bestimmte Nenge Gilycyl-l-tyrosin hinzngefïgt. nach Je(dndigmng der bigestion entweder die Spaltmugspodukte isoliert oder die Hydrolyse ilureh Beobachtung des Drehungsvermögens der Lïsung verfolgt. Wie Fersuche miblingen hei Anwendmug tyrosinhaltiger l'olypeptide oft, weil alie lösungen sich dureh Oxylation von Tyrosin dunkel

1) Fr. Whis, ther das proteolytisehe und ein ciweißkongulierndes knzym in keimenler (ierste (Malz). Zeitsehr. f. physiol. Chemie. Bd. 31. S. 79 (1900).

2) s. II. Vines, I'roteolytische Enzyme in Pflanzen. Annal. of hot. Vol. 17. p. 237 lis 264 (1903), zitiert nach Ialy, Bericht üher 1903.

s) Emil Abderhalden und Alfred schittenhelm, l)ie Wirkung der protenlytischen Fermente keimenter Sumen des Weizens und der Lupinen. Zeitsehr. f. physiol. Chemie. Bit. 49. S. 26 (1906) und Emil. Ibderhalden und Dammhahn, Ther den Gehalt ungekeimter und gelicimter Samen rersehiedener I'flanzenarten an peptolyticelien Fermenten. \%eitschr. f. physiol. Chemie. Bu. 57. S 332-335 (1908). 
färben. '/ur Kontrolle werden Proben von l'refsaft ohne l'olypeptidzusat\% untersurht.

l'raktisch wohl das wichtigste proteolytische Pflanzenenym ist das Japayotin. das aus den Friichten des Ilelonenbaunes, ('arica papaya. dargestellt wird. Scine I alrstellung bietet nichts besonderes, aurh ist das Felment in snt wirkamer Form als Handelspraparat zugänglich. Man weili seit langer /ceit. daf das buzrm biweil) hri sell verschiedener liraktion zu spalten scheint. Aber es schien die Wirtung des Fuzyms eine begrenzte. indem mter seinem Einflul nur Albumosen und P'eptone, aber nicht dis lutzten spaltungsprodukte, die Iminosämen, entstelıen sollten. Emmerling sowie Kutscher und Lohmann haben mun die Methode so gestaltet, daf auch hei der Papayotinverdaumer die Iminosäuren untro den Spaltungsprodukten nachgewiesen werden künnen. Das Papayotin entfaltet seine Wirkung anseheinend nur seho lanesam; man mulj daher die Versuche selır ansdehuen. Mlmählich verliert aher das Enzyn seine Wirksankeit; es ist infolgedossen notwendig, von Zeit zu \%eit lerment von neuem dem Verdaumosarmisch zuzuführen. lie Aminosäuren wurden von Emmerling uach der Fischerschen Methode der Veresterung und fraktionierten Iestillation, Arginin nach Kossel dargestellt.

Die Verdaume wurde ron Emmerling ${ }^{1}$, im einzelnen folgendermal'en lurehgefïhrt:

In ? Kolben wurden 1000 y trockenes Blutfibrin mit schwach alkalisehem Wasser ïbergossen und nach Tolnolzusatz zunälchst einen Tag bei gewöhnlicher' 'Temperatur stehen gelassen. Die nun stark aufgerpullene Masse wurde mit Wassel (ben bedeckt und mit je $20 \mathrm{~g}$ l'apayotin rersetzt. Hie gut rerschlossenen Kolben kamen in einen konstant auf $34^{\circ}$ gehaltenen Raum. Nach 14 Tagen wurden abermals je $10 \mathrm{y}$ und mach + Wochen weitere $10 \mathrm{~g}$ Papayotin zugesetzt. Almählich erfolgt lösung.

Kutscher und Lohmann ${ }^{2}$ ) lielien das Paparotin 10 Joule auf Fibrin einwirken und entfernten das noch rorhandene Ëweiß und die Albumosen durch Ausfällung mit Tamnin.

Sehr (rigenartige methodische Verhältnisse leiten sich aus Beohachtungen ab, welche Delezenne, Mouton, Posershi iiber die Einwirkung ron l'apain (Merck), das dem Papayotin nahesteht, auf Hühnereiweib und Hammelserum gemacht haben. ${ }^{3}$ )

Versetzt man frisches Iliihnereiweili ouler Hammelserum mit einer grolien Jlenge Papain und läßt gleiche Proben rerschieden lange \%eit im Brutschrank orler hei Zimmertemperatur. sïuert dann mit Essigsäure an und kocht auf, so nimmt mit Zunahme der Digestionsdaner die Menge des

1) O. Emmerling, Über die Eiweißspaltung durch Papayotin. Chem. Berichte. S. $69 \check{0}-699$ (1902).

2) Kuntscher und Lohmann, Zur Kenutnis der Papaşotinverdaunng. Zeitschr. für physiol. Chemie. Bd. 46. S. 383-386 (1905).

s) Literatur hei Fritz Sachs, Uher die Verdanung ron rohem HühnereiweiB durch l'apain. Zeitschr. f. physiol. Chemie. Bd. j1. S. 488-505 (1907). 


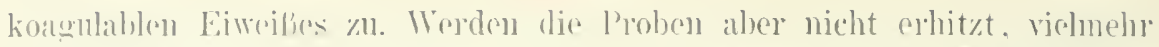
das liweilf durch dlkohol oder mit Trichloressgeäme an Sohlusse des Versuches answefällt, so wird disselhe Eiwcibmenge gefunden wie in den hontrollyersuchen, in denen die Felmentwirkung ansgeschaltet war. l)ir

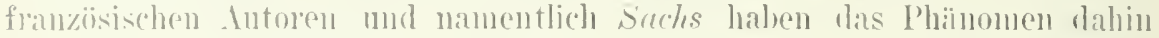

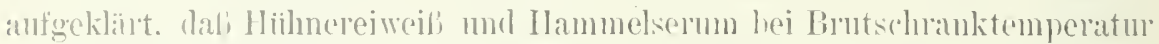
vont I'apain ialherhaupt nicht nachweisbar angegriffen werden mul die Veldanung erst während der steigerung der 'T'mperatur beim Aufkochen ganz plïtzlich stattfindet. Iali die T'rohen, welche länger bei mittlerer Tempelatur gehalten waren. mehr Eiweils nach dem Anfkochen enthielten, komint dadureh zustande. daf das Ferment durch längeres Zusammensein mit den Eiwcils in sciner Mlitivitit alogeschwächt wird, demnach dam beim stärkoren Erhitzen woniger altives Fuzym disponibel ist.

Nach Abderhalden und Terunchi ') werden aurh l'olypeptide durell I'aparotin gespalten. W'mn das in Wasser glatt löslicle Glycyl-l-trosin de' Linwirkung des Ferments ausgesetat wird, so kimm man die eingetreene spaltmug daran erkemnen. daf das in Wasser kamm kösliche Tyrosin alıs der Lösung ausfällt.

\section{ANHANG. \\ Das Sekretin. ${ }^{2}$ )}

Nach Versuchen von Bayliss und Sturliny kann man das P'ankreas zu reichlicher Sekretion veranlassen, wem man einen besonders prïparierten I) ünndarmanszug Versuchstiereu intravenös einspritzt. Die substanz wird Sekretin henannt und folgendermafen dargestellt. Nan schaht die schleimlatut des buodenums und der oberen Teile des Diinndarms al, zerreibt sie in cinem Mürser mit sand unter Zusatz ron $0 \% \%$ Silzsäure, kocht die Mischung anf freien Feur und nentralisiert die gekochte Flïssigkeit mit Kalilauge. Man filtriert einen Niederschlag als und hat damn ein eiweibfreies, klares Filtrat, welches das rekretin enthïlt. Diese liösung kann man noch weiter reinigen, wenn man in ihr mit . Ilkoholn̈ther Niederschläge erzelugt. Das seliretiu bleibt dabei in Lösung und kamm aus ihr durch Findampfen gewomen werten.

Will man die Wirksankeit eines Sekretimprïparates priffen. so spritz.t man rinice Kubikzentimeter in die V'ane eines rersuchstiores ( $\%$. B. Katze oder Kaninchen), bindet rolher eine Kaniile in den Ausfiihmugsgang der Driise und beobachtet die Zunahme des sekrets unter dem Finfluf der Sokretinzufuhr. Was sokretin kamn ron den rersehiedensten Wirheltieren stammen, seine Wirksimkeit ist nirht an dieselbe speries oder Art gebunlen.

1) Emil Abderhalden und Futaka Trunchi, Vergleichende T'utersuchungen über einige proteolytische Fermente pflanzlicher Herkunt. Keitschr. f. phys. Chemie. Bu. 49. S. $20-24(1906)$.

$\left.{ }^{2}\right)$ W. M. Bayliss und I. H. Starling, Ilie chemisehe Loordination der Funktionen des Liorpers. Ergehnisise der I'hysiologie. 5. Jahrgang. S. 670-676 (1906). 


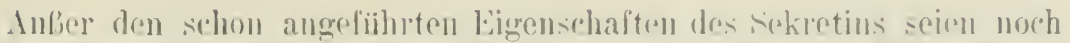

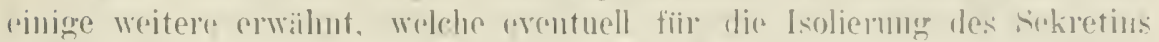

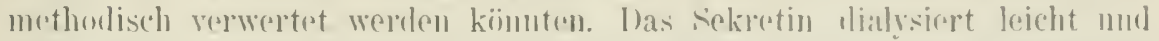
wird weder durch (ierbsiimre noch durch l'hosphorwolframsämre anserofällt. In alkalisehen Medimm mud beim stehen an dol luft wirel das ciekretiu

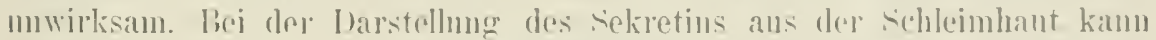

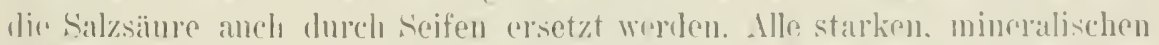

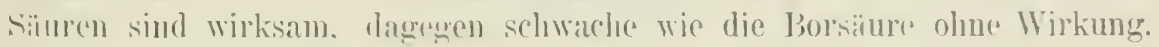
Trypuin zerstürt das cekretin.

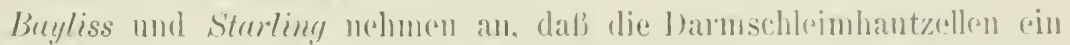
l'rosekretin enthalten, aus welchem hydrolytische docuzien subretin abspalten. lojese Vurstufe ist mulïslich.

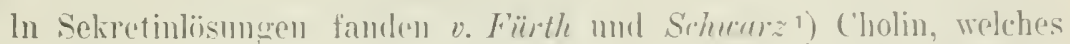
auch an mul fiir sioh die rekretion des Pankreas anlent. Jedoch ist lle seksetinwirkung niclıt ohno writres mit der des cholius zu identifizieren.

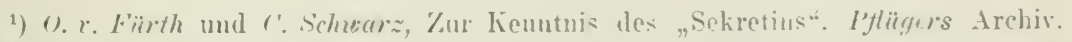
bi. 124. II. 9--10; zit. n. Binchem. Zentralbl. Bil, 7. S. 920 (19)心). 


\section{G. I)ie Fermente des Nukleinstoffiwechsels und deren IVirliumg.}

Yon Alfred Schittenheh, kirlangen.

Während in Magen-Darmkanal nuter dem Einflusse der Verdaumugsfermente die Nukleinsämre ans den Nukleoproteiden in Freiheit gesetzt und damn, offenbar ohne eine tiefere Aufspaltung zo erleilen, in rine resorptionsfähige Form gehraht wird ${ }^{1}$ ), nuterliegt sie jenseits des Vordannng'straktus der Wirkmg einer Reihe von Fermenten. Welche sie aufspalten und lie spaltprodukte weiter verändern. Unsere Kemntnis bezicht sich nur anf diejenigen Fermente, welche die Nukleinsiure anfspalten und die einzelnen Bansteine in Freiheit setzen; wir hezeichnen sie als Nukleasen.

Wir kennen ferner eine lieihe von Fermenten. Welche die ans der Nukleinsiure freigewordenen Purinbasen repänlern. Dieselben stellen sich im einzelnen als folgende dar:

P'm rindesamidasen (Guanase, Adenase). L'nter der Finwirkmu dieser Fermentstufe wirl das Adenin in Hypoxanthin und das Guanin in Xanthin tmgewandelt.

Xanthinoxylasen. Sie bewirken eine Oxydation des Hypoxanthins zn Xanthin und des Xanthins zu Harnsïnre.

I) Harnsinne endlich mnterliegt der Einwirkmg ron urikolrtischen Fermenten. Dahei antsteht beim Tiere (Hund, Kaninchen, Schwein ete.) aus der Harnsïnre Mlautom, welehes nicht weiter zersetzt wird. ()b noch andere Abbanprodukte der Harnsïure existieren, steht noch dahin. Bein Jenschen gelingt der direkte Xachweis urikolytischer Fermente in Organextrakten nicht mit Sicherheit. Der stoffwechselversurh zeigt jedoch. dalb die Clarnsiure abgebant wird, und zwar bis zum Harmstoff. Es finden sieh auch klone Hengen von Allantoin im menschlichen Urin. Jessen Herkmuft jerlorh noch zin erforschen ist.

1) E. Abdorhalden und A. Schittenhelm, Der Ab-und Anfhan der Nukleinsimen in tierischen Organismus. Zeitschr. f. physiol. (hemie. Bd. 47. S. 45z (1906). 


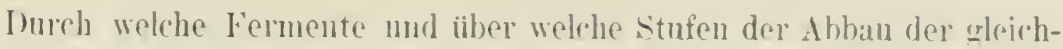
falls im Nukleinsäuremolekül cuthaltenen Prrinidiubasen. Thymin. Cytosin und lareil, wor sich geht. wissen wir nicht. Sireher ist nur nach drom stoffwechselversuch, daf anch diese auferespalten werden. Vielleicht wird dabei ans dem Thymin sowohl wie aus dem Crosin zunälchst Iravil gebililet.

\section{Nuklease.}

Allgemeiner Nukleasenachweis durch $x$-thrmonukleinsaures Natrium.

\%um allgemeinen-Nachweis eimer Nukleasewirkng hat es sich als praktisch erwiesen ${ }^{1}$ ). cine $3-50$ oige Lisung ron -thynomukleinsaurem Satrium, welchem bekanntlich die Eigenschaft, in dieser Konzentration zu gelatinieren. zukommt, in kleinen filäsern prstarren zu lassen und nun auf die Oberfläche der gelatinierten Nukleinsäure das auf die Nukleasewirkung zu prifende Material zu geben. Die Gegenwart von Nuklease wird durch die Verflüssigung der gelatinierten Nukleinsäure angezeigt. Man tut jedoch nach Sachs (l. c.) gut. stets zu rersuchell, ob sich nicht noch rorhandene gelatinierende Substanz nachweisen läfit. Dazu wird das Tersuchsgemenge heif filtriert und dann mit Alkohol und etwas Natriumacetat rersetzt. wodurch etwa noch rorhandenes $x$-thymonukleinsaures Natrium aus der Wässerigen Lösmg ausgefällt wird. Dieses kamn. in wenig heibem Wassel geliist. nach dem Erkalten der Lösung selbst in geringer Menge als gelatinicrende substanz erkannt werdell.

Diese Methode des Nachweises der Nuklease besagt natiulich über die Art ihrer Wirkung nichts weiter. als dab sie grelatinierende Nukleinsïure verfliissigt. Dieselbe Wirkung kamu aber sowohl mit reinen Verdaumgssäften (Hundepankreassaft aus Paulouscher Fistel ${ }^{2}$ ). wie mit intrazellulälen Fermenten aller Art (Extrakten von Ilarm, I.eber. Milz. Pankieas etc.) erreicht werden. Zur genaneren Feststellung muls man daher Versuche ansetzen. welche zeigen. ob die Nukleinsïure bei der Verflissigung auch zerlegt wird. Es hat sich dabei herausgestellt. daf es ein Ferment gibt. welches das $\boldsymbol{\alpha}$-thymomukleinsaure Natrium rerfliissigt und dessen kolloidale Form dabei in eine dialrsierbare unzuwandeln scheint, ohne dali jedoch eine tiefere Aufspaltung exfolgt; diese Form der Nuklease findet sich in dem in den Darm sich ergiefenden Pankreassekret. Denıcgenuiber steht die echte Nuklease. welche die Nukleinsäure in ilne Bestandteile zerschlägt und zum Auftreten freier Phosphorsäure. freier I'urimbasen etc. führt: diese Form findet sich

1) T. Araki, Uher enzymatische Zersetzung der Nukleinsäure. Zeitschr. f. phrsiol. Chemie. Bd. 38. S. $8+$ (1903). - H. Plenge. Ľber die $x$-nukleinsaures Yatron lösende Wirkung einiger Mikroorganismen. Zeitschr. f. physiol. Chemie. Bd. 39. S. 190 (1904). M. Nakuyama, Über das Erepsin. Zeitschr. f. phrsiol. Chemie. Bd. 41. S. 348 (1904). F. Sachs, Utber die Nuklease. Zeitschr. f. phrsiol. Chemie. Bd.46. S. 337 (1905). F. Abderhalden und A. Schittenhelm, l. c.

2) E. Abderhalden und A. Schittenhelm, 1. c. 
nicht muter deu Verdammosfermonten, sonderm nur intrazelluliir: sie wird nicht nach anlien swerniegt. somlern kann nur nachowiesen werden. indem man die \%ellen selbst resp. ihne kiumstlichen Extrakte zmm Velsuche verwendet.

Spezioller Nabueis der anfspaltenden Tuliease und Lsolierung ler Abbanprodulete.

Kahlecich sind die Versuche. Iurch Antolrse der Hefo und tierischer

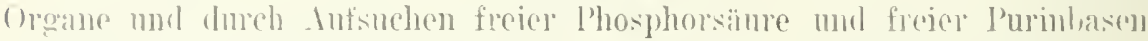
muter den Autolyseprodukten eine durch formente bewirkte Sulsinsmaltuner zu beweisen. Es bedarf besomblerer Erwähmmg. daf bei bigestion des Buchmenchen Hefeprebsaftes Purinhasen und Phosphorsiume als Abbanprodukte nachowiesen werlen komuten. $\left.{ }^{1}\right)$ Iner exakte Nachwois der Xuklease ist jedoch erst nach Verwendmug ron Nukleinsäme erfolgt.

Nukloasenachwois in ()reanextrakten $\left.{ }^{2}\right)$ : Fine to igo losmug

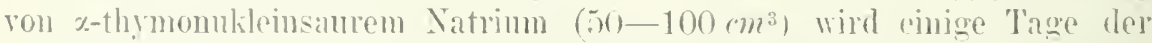

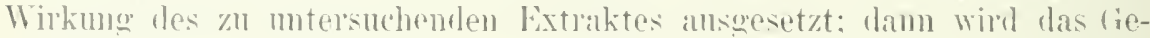
misch filtriert und das Filtrat zm lieseitignn etwa noch vorhandener Nukleinsiame mit schwefolsiure versetzt. 1)er dabri etwa anserefallene Nienlelschlag wird abfiltrielt: aus drm Filtrat werden die I'urinbasen mit Quechsilbersulfatlösung ausofällt. Hel so erhaltene Niederschlag wird ab-

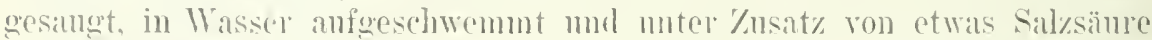
mit Schmefelwaserstoff zerlort. Damn wird wielermu filtriert und das Filtrat durch burchleiten vou Lnft rom Schwefelwasserstoff helreit. Num wird as mit ammoniakalischer silberlissune grefillt, dor eutstandene silberniederschlag abfiltriert, gut anserwaschen. in Vasser anfueschwemut und unter \%usatz vou salzsäure in der Wälme zelegt. Tom ('hlorsilber wird abfiltriert, durch das Filtuat noch einigr Hasen sehwefelwasserstoff gelejtet und dimn wiedermu filtiert. Das letzte Filtrat wird zwerks Abseheidmug

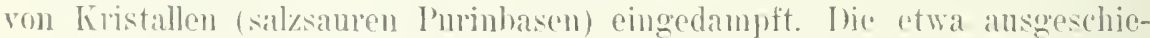
denon Liristalle werden samt dem liiekstand in salzsïmehaltigem Wassel gelöst, die Lösung filtriert mu wiedermm bis zmm völligen Anskistallisieren eingedampft. Hie Kistalle werden mit Ilkohol mol Cther getoocknet und gewogen. Will man den Beweis. dali man freie J'mrimbasen ror sich hat, noch weiterführen, so prifft man dic Kristalle mit Hilfe der rom Burian ${ }^{3}$,

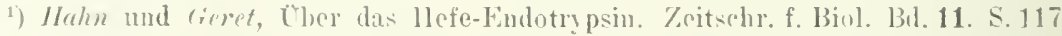
(1900)

2) Fr. Sarhe, Üher dir Nuklease. Zeitschr. f. physiol. Chemic. Ba. 46. S. 337 (1965).

$\left.{ }^{8}\right)$ IR. Burian. Diazoaminoverlindungen der Amidazole und der Purinsubstanzen. (hem. Berichte. Bd.37. S. 696 (1904). - I)erselbe, Zur lemutus der Bindung der l'urinbasen im Nulileinsäuremolekül. Chem. Berichte. Bd.37. S. 708 (1904). - 1)r.rselhe. Weitere Beiträge zur Kenutnis der biazoaminoverbindungen der l'uriubasen. Zeitschr, f. phrsiol. Chemie. 1Bil. 51. S. 4050 (1907). 


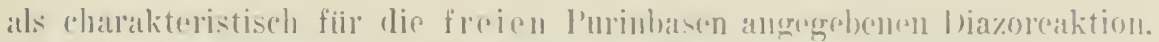

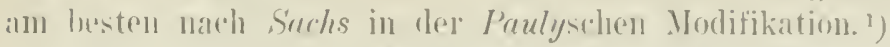

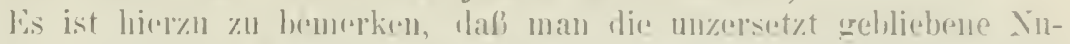

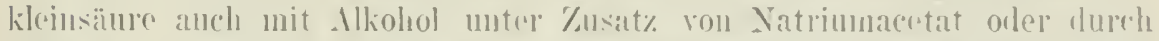

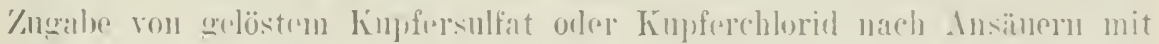

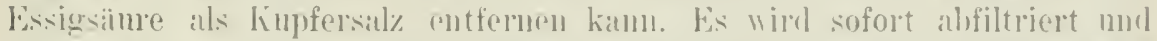

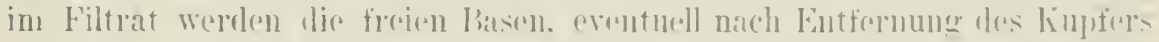
mit $H_{2} s$, mit ammoniakilischer vilberlisumer oder mit ler Künfersulfatbisulfitmethode isolirert.

In stelle der 'Thỵmonnklpinsïnre kamm man natiolich auch jexle all-

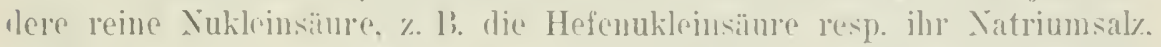

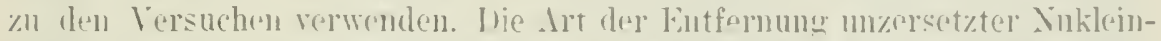
sime und dic beschrobene Methode der fievimmong der l'mrinbatsen bleibt

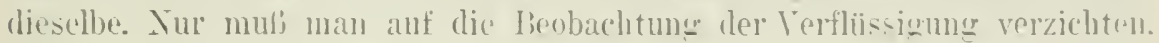
da die Hefenukleinsianu nicht gedatinint.

Iufel anf freie l'urinhasen kinn man im Firaktion:remisch noch nach

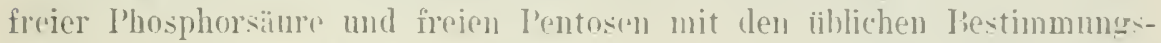

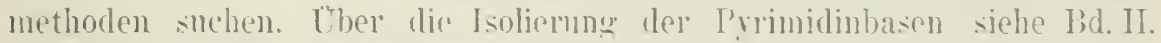

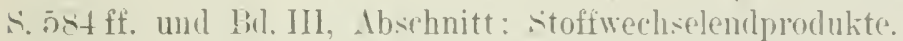

Vachweis der Nuklease iu Srhimmelpilzen und Lakterien: Auf der zur (ielatine crstarrten lismugr von \%-thymonnkleinsaurem Natrimm ziichtet man die zu untersuchenden schimmelpilze -) und Bakterion. ${ }^{3}$ ) [ntel Verflissigum tritt melı oder weniger schnell die Zersetzung ein, welche man, wic oben heschricben, feststellt.

Zur Verfolgung der hakteriellen spaltung*) der Nukleinsïure kamn man anch eine Xährlösung beuntzen, welche zwechmibigerweise folgendermafen zusammengesctzt ist: Nukleinsaures Yatrimm 150) g. (hlornatrum

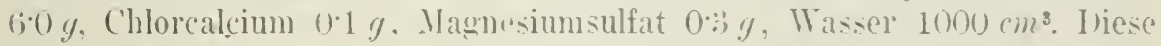
lösung wird in lhanpftopf sterilisient und dann tätich mit deu entspre-

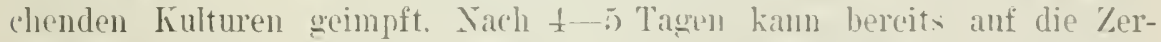
setzungsprolukte untersucht werlen. Habei kïnnen anler den genannten lï̈pern noch eine Reihe anderel (Ammoniak. Alkohol. ()xalsäure. Ameisensäure etc.) gefunden werden, la die \%ersetzung weitergeht und die Bakterien \%. B, auch die I'urinbasen angreifen und zerlegen.

1) II. Pauly, Cher die Konstitution des Ilistidins. I. Mitteil. Zeitschr. f. physiol. Chemie. Bt. 42. S. $516(1904)$.

2) Cntersucht sind Aspergillus niger, Mneor stolonifer mil Penicillinm glaueum. siehe L. Iwanofi", Uher die fermentatice Zersetzung der Thymonukleinsüure durch Schimmelpilze. Zeitschr. f. phrsiol. Chrmie. Bd. 39. S. 31 (1903).

$\left.{ }^{3}\right)$ Untersucht sind Bact. coli. Base. Typhi hominis u. a.. siche II. Plenge, I’ber die «-nukleinsaures Matron lösende Wirkung pinger Mikrnorganismen. Zeitschr. f. physiol. Chemic. Bd. 39. S. 190 (1904).

4) A. Schittenhelm und $F$. schrötcr, (t)er dic Spaltung der Hefenukleinsäure durch Bakterien. Zcitschr. f. physsiol. Chemic. Bd. 39. S. 203 (1903); Bd. 40. \$. 62 und Bd. 41. S. $28 \pm$ (1904). Lntersucht sind Bact. coli. Staphylokokken und Fäzeshakterien. 


\section{I) arstellmog und Eigenschaften der Tukleasen.}

1)arstelhng: Man kann einen wässerigen Extrakt der Rindermilz ${ }^{1}$ ) oder limderleher ${ }^{1}$ ), (ler Pankreas- ${ }^{2}$ ) oder Thrmusdrise ${ }^{2}$ ) nehmen, und zwar macht man ihn zweokmibig' so, dali man 1 'Teil fein zerkleinertes und zer-

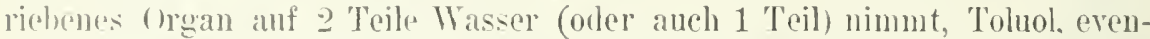
tuell auch etwas chloroform zusetzt, tiichtig miseht, mehrere stumben bis ${ }^{1}$. 'l'ag (nicht zu lange!) bei Yimmertemperatur stehen lülit, dann kolient und filtriert. I)er so rhaltene Extrakt ist direkt wirksam.

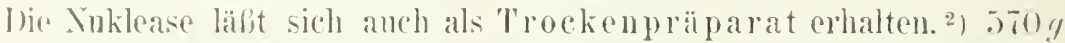
l'ankroas werden mit Sand und Kieselgur zerrichen und mit der Buchnerschen l'resse geprefit. Wer gewomnene saft $\left(100 \mathrm{~cm}^{3}\right)$ wird sofort mit Immonsulfat his zur sättigung versetzt. der entstandene Niederschlar abfiltrin't und mit Alkohol und Ither getrocknet. Der getrocknete vierlerschlag rerflibsigt, in destilliertem Wasser gelöst, nukleimsames Natriun vollkommen in wenigen Stunden. (l'robe auf Crelatinieren fïllt nachher negativ ans.) Das l'nlver hat seine Wirkung anch nach zweimonatlichem Lawern noch behalten.

Auch ans fichimmolpilzen ${ }^{3}$ ) und aus Lupinenteimlingen 4 kam man dureh Zerreiben derselhen und Auspressen des saftes cinen wirksane Niklease enthaltenden Fistrakt bekommen.

Eigensohaften: Die Nuklease wird durch aktives Trypsin allmählich zerstört. $\left.{ }^{5}\right)$ Schwach saure lieaktion, wie sie z. R. im frischen l'ankrasextrakt ron rornhereju besteht, ist fiir die Wirkung der Nuklease am ginstigsten: intensivere same lieaktion sowie alkalische lieaktion (Natrimmkirbonat) schwichen die Wirksamkeit ab resp. heben sie auf. loie Nuklease dialysiert nicht. Bureh längeres Kochen will sie zerstört: kurzes Eulhitzen anf s(1) schoint sie nur zur schädigen. $\left.{ }^{5}\right)$

\section{Purindesamidasen.}

Nachweis ler Fermontwirkung.6)

Derselbe geschieht durch den Nachweis der Unwandhun von Guanin in Xanthin und Adenin in Hypoxanthin.

$.500 \mathrm{~cm}^{3}$ lindermilzextrakt resp. Fermentlïsung (orler $500 \mathrm{~cm}^{3}$ Extrakt anderer (Organe, siehe miten) werden mit $0.5 \mathrm{~g}$ in möglichst wenig Nor-

1) A. Schittchhelm, Über die Itamsänrebildnng in Gewebsanszügen. Zeitschr, für physiol. Chemie. Bd. 42. S. 251 (1904).

2) Fr. Sachs, 1. e. Wahrscheiulich enthält nach Sachs auch die Kalbsniere Nuklease. nicht aber der Rindermuskel und das linderllut.

$\left.{ }^{3}\right)$ L. Iwanoffi, 1. c.

4) A. Schittenhelm. Noch nicht publizierte Versuche.

5) Fr. sachs, l. e.

6) 1. Schittenhelm, Uber die Fermente des Nukleinstoffwechsels. Zeitschr. f. phys. ('hemie. Bd. 43. S. 2.8 (1904) nud derselhe, Ther die Harusäurebildung und Harnsäurezersetzung in den Luszügen der Rinderorgane. Zeitschr. f. physiol. Chemie. Bi. 45. S. $121(1905)$ 
malnatronlange gelösten Guanims versetot und unter '/ugabe von Chloro-

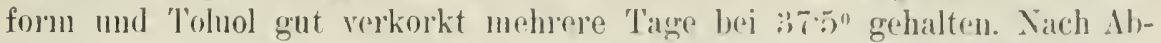
bruch des Versuches wirl die Jischmng entweder dircht anteiwoift: sie wird dazı erhit»t, leicht alkalisch gemacht, damn mit Fssigsiume schwach angesiunert, muter Zugabe vou cingen framm Kochsal\% anfoekocht und filtriert. \%weckuäbiger wird die Mischung jedoch zunächst mit $10-15 \mathrm{~cm}^{3}$ konzentrierter Schwefelsäme versetzt. 3 Stunden am liuickflubkïhler grokocht, dann erst mit Natronlange alkalisch. mit Essigsäure schwach sauer gemacht, kurz anfoekocht und filtriert. Wer zuridoheblichene biweipnierlesschlag wird dam nochmals in Wassel suspendiert, durch Mlkali in dej llitze gelöst und wieler gefällt. Ius den vereinigten Filtraten werden die l'urinkïrper mit der Kiupfersulfit-Bisulfitmethode (siche Iid. III, Ibschnitt: Stoffwechselendprodukte) gefält. Dir so erhalteneu Kupferoxydulverbindungen werden abfiltriert, mit heibem Wasser gut ausgewaschen, flann in (a. 500 $\mathrm{cm}^{3}$ heibem Wasser suspendiert und durch Schwefolwasserstoff zerlegt. Es wird kurz aufgekocht, sofort filtriert und salzsauer eingeengt. Am besten wird dam fer Riickstand zur weiteren Reinigung in $500 \mathrm{~cm}^{3}$ Wasser unter Zugabe von etwas Natronlauge heiß gelöst, mit Essigsäure neutralisiert und nun sofort die Kupfersulfat-Bisulfitfällung, wie beschriehen, nochmals durchgefïhrt. Das die Purinkörper enthaltende Endfiltıat ${ }^{1}$ ) wird schwach salzsaner eingedampft. Der Riickstand wirl in ea. $100 \mathrm{~cm}^{3}$ verdiinntem Ammoniak digeriert und mehrere Stunden kalt stehen gelassen. Dabei fillt Harnsäure und Guanin aus, welche durch verdiimte Salzsäure getremnt werden. In lösmg bleibt Ianthin. das durch Einengen in charakteristischen schollen erhalten wird. 1)ie weitere Identifizierung siehe Bd. III, Mbschmitt: Stoffwechselendprodukte.

Will man die Cmwandlung von Adenin in Hypoxanthin stulieren, so setzt man den Versuch mit $0 \% \mathrm{~g}$ in wenig Normalnatronlange gelösten Adenins an. Der Gang des Versuches und die weitere Verabeitung sind dieselben. Man erhält so nach Eindampfen des salzsanyen Filtrates eincon Riickstand. Dieser wird mit wenig Wasser $\left(60-80 \mathrm{~cm}^{3}\right)$ in der Wärme digeriert und das Gemisch einige stunden in der Kilte stehen gelassen. Das Ungelöste wird abfiltriert; es ist Xanthin und eventuell etwas Harnsäme, welche durch Ammoniak getremnt werden. Das in Lösung Gegangene wird heif mit Pikrinsänre $(1 g)$ in sulstan\% versetzt. Falls noch Adenin vorhanden ist. so fällt es beim Mbkiihlen sofort in nadelförmigen Kristallen ans und wird sogleich abfiltriert. Aus dem Filtrat, welches eventmell etwas emgeengt wird, kommt das Hypoxanthinpiklat bei lïngerem Stehen in der Kälte in großen tafelförmigen Kristallen heraus. Dieses Pikrat wird auf dem Filter gesammelt und mit wenig kaltem Wasser gewaschen. Zur weiteren Identifizierung wird es in ca. $100 \mathrm{~cm}^{3}$ Wasser unter \%usat\% von $4-\overline{5} \mathrm{~cm}^{3}$ Salpetersäure gelöst, die Lösung durch Ausschiitteln mit Benzol von Pikrin-

${ }^{1}$ ) Klärt sich nach dem Einleiten von Schwefelwasserstoff und Anfkochen die Lösung nicht genügend, so kaun man nach den Angaben ron Wiener einige Kubikzentimeter ciner gesättigten Alumininmacetatlösung zugehen und leicht essigsauer machen. Dadurch erhielt man ein klares Filtrat. 
sämre bofrejt, filtriert mul stark eingeenent. I)abei schejdet sich das Hypo-

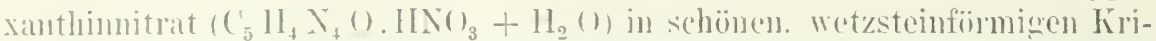
stallen ans. boi dell Meninrersuch findet man in der Regef neben dem Iypoxanthiu auch Xanthin, da das erstere durch lie in der Jösung gleichfalls vorlamblene (xwhase sofort zum 'Teil weitroxydiert wird.

Es muli ïhriens hier bemerkt werden, dali dice Tmwandlung der Aminopurine in ()xy)uruo bei dieser Versuchsamordnung: sobald Luft Jurel-

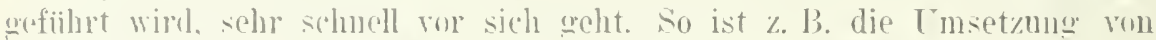

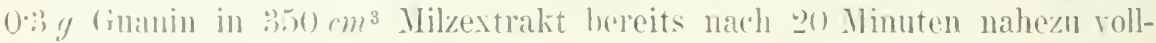
ständị erfolet. 1)

I)atrithung mud Kigenschaften der l'uriudesamidasen.

J) arstellune: Mau kan wisserige Fxtrakte von tierischen Organen

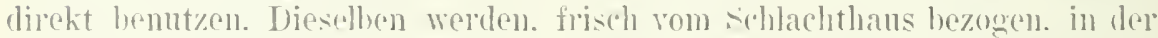
Fleischlackmaschine foin zorkleinert. Was fiir Mil\%, Leher mol Thymus zumeist geniigt, wïhrend hunge. Darm, Muskel, Nirre ete. zweckmälijgr noeh

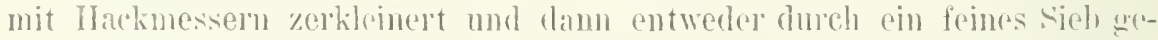
prefit ofler noch mit siand nud hieselgur im Mörser fein zerrieben werden.

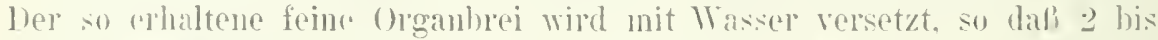
: 'Teile Wassel' auf 1 Teil Uroanbrei kommen. Dir Masse wird num unter' \%usatz vou ('hloroform tiichtig durehereribrt und greschiittelt und dimn mehrere stumleu stehen achasen. Helnach wirl koliert und unter Anwen-

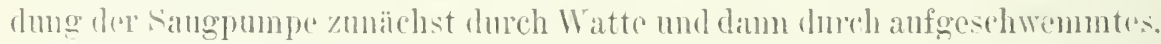
fein verteiltes Filtrierpapier filtriert. Dor so erhaltene Fxtrakt ist noch moh oder weniger getribt, enthält aber keine gröheren Bestandteile mud

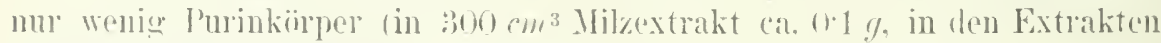
anderer (heane weniger). Die Extrakto sind stets gut wirksaun.

Es ist selhr bemerkenswert, daß man hei Verwendung ron Rinler- mol Pferileorganen in den Extrakten stets die Unsetzung von Guanin mu Adenin in gleich intensiver Weise nachweisen kium. Bei Verwendur ron bestimuten Urganen des Mensehen. des sehwoines, des llumdes und des haninchens dagegen geht die Umsetzung hïnfig scheinhar nur für den einen Körper; su vermag Menschenmuskel und Menschenleber elenso wir Kaniuchen- nul Ifundeleher un Guanin, Schweinemilz und Schwpineleher nur Adenin umzusetzen. Daher werden zwei versehiedene Fermente angenonmen, eine (inanase nul eine Adenase. ${ }^{2}$ ) Es hat sich aber gezeigt. daß die Unterschiede zumeist wahrseheinlich nur quantitative sind. indem anch tiese Organextralite zum Teil beile Wirkungen entfalten kimmen, nur die ane weniges shohell und weniger mnfangreich. Jan muß die Versuche ru allem lïnger gehen lassen. ${ }^{3}$ ) Ein Vercleich der im

1) A. Sithenhlm, ther die Fermente des Nukleinstuffwechsels. Zeitsilhr. f. physe ( hemie. Bu. 37. \&. 21 (1908).

$\Rightarrow$ W. Jones und ' '. I. Partridge, lher die Guanas". Zeitschr. f. phrsiol. Chemir. Bd. 42. S. 343 (1904). - W. Jomes und 1\%, ' Winternitz, Cher die Adenase. Zeitschr.

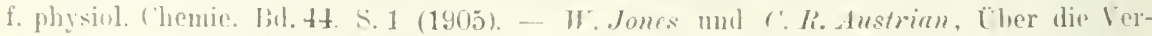
teilung der Fermente des Jnkleinstoffwerhsels. Zeitschr. f. physiol. Chemie. Bd. 48. $\therefore 110(190(5)$.

3) A. Schittenhelm, Der Nukleinstoffwechsel und seine Formente bei Nenseh mul l'ier. Zeitschr. f. physiol. ('hemie. Brl. 16. S. $35 \pm$ (1905). - 1. schittenhelm und .l. schmil, 


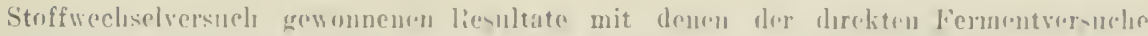

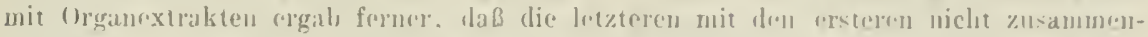

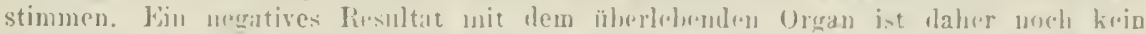

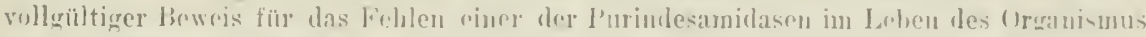
resp. im lebenten (1) ran. ')

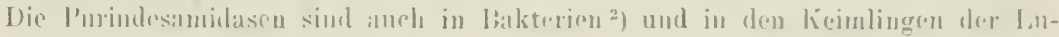

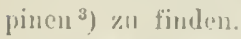

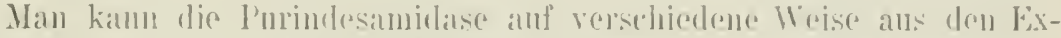

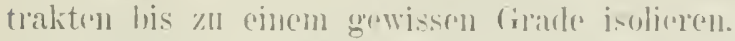

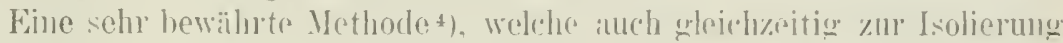

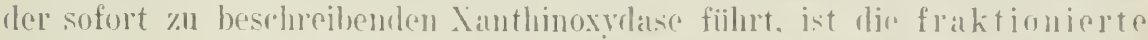
Aussalzung mit I mmonsulfat nach Juroloys Angabr. Mall vrepwendet dazn eincu mach den oben stehenden Angahrul dangestellten Extrakt

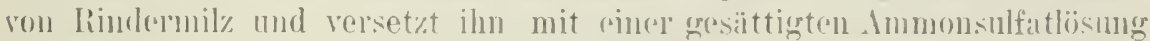

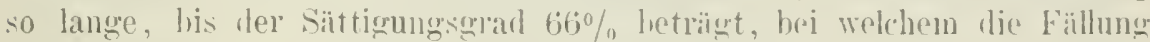
les Ferments am ergiehigsten ist. Mlan liilit mun otwas stehen, his sich der Niederschlaw dentlich alsetzt, filtrist nud suspendiert den Niralarschlag in Wassel (1 l bei Vewendung von 2 Vilzen als Iuseancsmaterial), rersetzt die Mischung mit otwas Chlorofolm und Toluol. schiittelt krätig durch und dialssiert nun rlas gan\% gegen flicfemeles Wasser. bis hein Ammoniak melr nachwrisbar ist. Was strets mehrere Tage crordert. Nun wird filtriert und das so erhaltene, leicht gelblich bramme liltrat. welches eventuell noch repliinnt werden kann. direkt zu den Versuchen verwandt. Diese Fermentlisinng ist stets hochwirksam: sie enthält mur noch wruig oroanische substanz $\left(3-t^{0}, 00\right)$ und Aschemrichstand $\left(1.5\right.$ bis $\left.1.00^{\circ}, 00\right)$ und ist so gut wis frei rou J'uriulïrperm.

Man ham weiterhin den wïsscriven Milzextrakt mit weichen Mengen Alkohol fïllen. Der dadurch erhaltene Niederschlaw wird nach liuzem

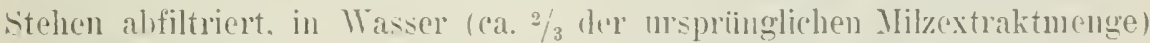
suspendiert mid einige stunden bei çewöhnlicher Temperatm geschiittelt. Nun wirl filtriert. Tha, Filtrat ist dio Fermentlösung, ron der der Alioholrest bei $f 0^{\circ}$ orler durch Infthurchleiten entfernt werlen kimu. Die Lösung entlält wie die obige auch die Xanthinosydase, ist aber nicht wan\% so wilksam.

Endlich kam man die J'urindesandase anch nach W'echoustis Methode konservieren. indem man ain Trockenpulver des ()romes herstellt. Diese Methode dient zngleich dazu, die Ianthinoxydase so zu schädigen,

Ober die Fermente des Nukleinsteffwechsels. Zeitichr. f. physiol. Clemie. Bu. j0. S. 30 (1906). - A. Schittenhelm und J. Schmid, Mhlauf des Nukleinstoffwechsels in der Schweineleler. Zeitsehr. f. experim. Path. u. Ther. Btl. 4. S. 432 (1907).

1) A. Shittenhelm, Uher die Fermente des dukleinstnffwechsels menschlicher Organe. Zeitsehr. f. physiol. Chemie. 1909. Bd. 63. S. 22.22.

2) Schittenhelm und schröter, l. e.

3) A. schittenhelm, Uher rlie Fermente res Nukleinstoffwecheds in Lupinenkeimlingen. Zeitschr. f. physiol, ('hem. 1909. Bd. 63. S. 26\%.

4) A. Schitfenhelm, Uber die Fermente des Jukleinstoffwechsels. Zeitschr. f. phrsiol. (hemie. Bil. 43. S. 228 (1904). 
dab ihre Wirkung wegfïllt oder erst bei tagelangem Gehen des Versuches wieder zun Vorschein kommt. Man kanm die Methode dadurch redeinfachen, dali man das (trgan anf Glasplatten trocknet mul nun sofort wässerige Auszige des Trockenpulvors macht. olue dasselhe weiter zu reinigen. (ribt man nun Adenin und Guanin. wie beschrichen, zu und leitet Luft durch. $\therefore$ a geht die besamidiermug hereits in einigen stunden vor sich.

lijecuschaften der lurindesamidasen: Dieselhen sind relativ wenig empfindlich. Nie halten sich in Lösung wochenlang. in l'ulver chenfills. Dureh Erhitzen werden sie dageen sofort zerstiirt. Sie dialisieren nirht. Ihe Wirkmug äufert sich gleich gut bei schwach samrer, nentraler mnd schwach alkalischer licaktion.

\section{Xanthinoxydase.}

\section{Nachweis des Ferments. ${ }^{1}$ )}

berselbe geschieht dureh die Lmwandhng von Hypoxanthin in Xanthin und rou Xanthin in Harusäne. ()h heide T'mwandlungen dureh ein mul dasselbe Ferment bewirkt werlen, odter ob es sich anch hier um zrei Fermente handelt, bedarf noch besonderes Untersuchung. Da die (rogane, welchr Xanthinoxylase enthalten, anch die l'urindesanidase in hochwirksamel Form besitzen, so kamm man die Cuwandlung der Aminopurine dirckt in ilarusïme erreichen. Bei ver Auswahl der (Organe mul) man jedoch berieksichtigen, dals in einzelnen nelen der Xinthinoxydase anch eine mikolytische Fermentation besteht mod dab die letztere, indem sie die frisch gehildete llansïure wieder zerstört, den Nachweis der ersteren elschweroul kimm. Sicher gelingt er stets in der Rimdermilz, welche keine mikolytische Fïhigkeit hat.

$50\left(1 \mathrm{~cm}^{3}\right.$ Rindermil\%extrakt werden mit $05 \mathrm{~g} \mathrm{~g}$ in wenig Normalnatronlange gelister l'mimbase (Alenin. (imanin, Santhin oder Hypoxanthin) und otwas Chloroform und Tolnol rersetzt: dis Mischung wird auf cine konstunto 'l'emperatur von $: 7^{\circ}$ gebracht und nun Lnft in kräfigem Strom durcheleitet. Nach wenigen Stmoden ist der Versuch beendet mod die zugenchene P'minbase quantitativ als llansäure wiederzufinden. Man verfïhrt dabei wie zul Tsoliedung der Purinbasen (S. 425), indem man zunähst enteiweilit mnd dann die Kujpersulfat-Bisulfitmethode verwendet. Das salzsaure Filtrat rom soluwefelkupfer wird anf dem Wasserbitle anf ca. $10 \mathrm{~cm}^{3}$ eingeenet und damn norlı 1 - - Stunden stehen gelassen. I)ie so gewonnene

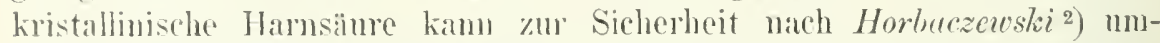
kristallisiut werden. Labei verführt man so, daf je $0 \cdot 1$ g Substanz in $2 \cdot 0 \mathrm{~cm}^{3}$ konzentrierter Schwefelsüure, eventuell unter ganz vorsichtigem schwachen Erwibnen gelöst und dam mit dem vierfachen Volmmen Wasser wieder

1) 1. Schittenhrlm, iber die Fermente des Nukleinstoffwechsels. Zeitschr. f. phys. Chemic. Bu. 57. \&. 21 (1908).

$\left.{ }^{2}\right)$ J. Horbarzerski, ther die Trennung der Harnsäure von den Xanthinbasen. Zeitschr. f. phys, Chem. Bil. 1s. S. 341 (1894). 
gefällt wird: dabei fïllt die Hallusïne quantitativ wieder aus. Wälnend atwa volhandene l'uriubasen in Lösmor bleiben.

Jarstrllung und Fierenschaften dev Xanthinoxydase.

barstellung: Man ham eine relatir einfach zusammengentote, ent wirksame Fermentlïsung durch Aussalzung mit Ammonsulfat, viel weniger gut wirksame durch Fällung mit Alkohol aus der wässerimen findermil\%extraktlösung herstellen. Jie genaue Ausfühung entspricht völlig den Antraben zur Isolierung der Purindesamidatsen.

Auber in der Iindermily ${ }^{1.2}$ ) ist die Santhinoxydase auch in den Ex-

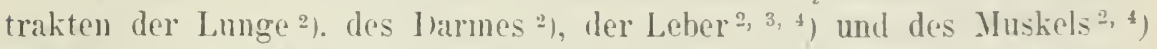
rom Rinde, (ler Mil\% vom I'ferte ${ }^{2}$ ), der Leber des Menschen ${ }^{5}$ ), der Leber des Schweines. (ler Milz ${ }^{6}$ ). des I)armes ${ }^{i}$ ) und der Lung( ${ }^{7}$ ) des Hundes aufgefunden. Bei Versuchen mit Rinderleber und lindermuskel ist jedoch darauf zu achten, dab die gebildete Harnsïure zum Teil durch die zurleich vorhandene Lrikolyse weiter zerstört wird.

Eigenschaften. Wie Xauthinoxidase ist vicl empfindlicher als die l'urindesamidasen. Sie wirl in der wässeligen Lösung langsam zerstört. Bei der Darstellung als Trockenpulver nimmt ihre Wirksamkeit bis zum völligen Verschwinden ab. Cberhaupt leidet sie bei jeder Art der Isolierung. indem dann der Vel'such längere \%eit bis zur quantitativen Harnsäulebildmo gehen mub, als wemn ein ganz frisch bereiteter, wässeriger Rindermilzextrakt genommen wird. Der letztere ist immer das am besten wirksame. Das Ferment ist nicht dialysabel und wird durch Aufkochen zerstürt. Es ist bei schwach saurer, neutraler und schwach alkalischer lieaktion gut wirksam. Stärkere Säuerung oder Alkaleszenz zerstört es jedoch.

Es mag-hier bemerkt werden, daß unter Umstinden bei der Cmvetzung der Aminopurine die Xanthinoxylase zuerst wirkt. Dann entsteht aus Adenin als Zwischen-

1) W. Spitzer, Die Üherführung vun Nukleiubasen in Harnsäure đurch die sauerstoffübertragende Wirkung von Gewebsauszügen. Archiv f. Physiol. Bd. 76. S. 1922 (1899).

3) A. Schittenhelm, 1. c.

3) H. Wicner, Ober Zersetzung und Bildung der Harnsäure im Tierkirper. Archiv f. experim. Path. и. Pharm. Bd. 42. S. 373 (1899).

4) R. Burian, Über die Oxydation und die rermeintliche synthetische Billung ron Harnsäure im Rinderleberauszug. Zeitsehr. f. physiol. Chemie. Bd. 43. S. 497 (1905). Derselbe, Die Herkunft der endogenen Harnpurine bei Mensch unl Säugetier. Ebenda. Bu. 43. S. 532 (1905).

5) A. Schittenhelm und W. Künzel, Zur Frage des Nukleiustoffwechsels beim Menschen. Zentralbl. f. d. ges. Physiol. u. Path. d. Stoffw. Nr. 19 (1908). - A. sichittenhelm, Uber die Fermente des Xucleinstoffiechsels menschlicher Organe. Zeitschr. f. phrsiol. Chem. Bd. 63. S. 222.2 (1909).

$\left.{ }^{6}\right)$ Wr. Jones und C.R. Austrian, 1. c.

i) A. schittenhelm, Über die Harnsäurebildung in Hundeorganen. Zentralbl. f. d. ges. Physiol. 11. Path. Nr. 21 (1909). 


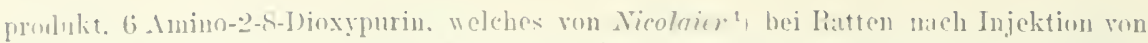
deleninlissung ans den Nieren isoliert werien konnte. Ans (inanin entsteht dahei

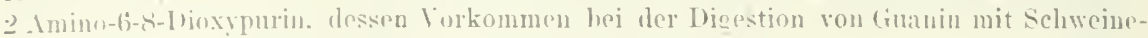

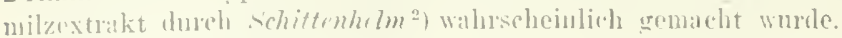

\section{Urikolytisches Ferment (Harnsäureoxydase).}

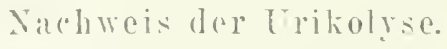

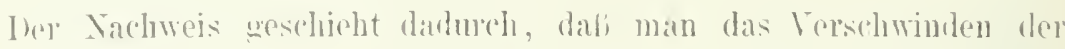
Hansiure konstatient ${ }^{3}$ ) und das Abbamprodukt derselben zn isolieren vorsucht, als welches Mlantoin ${ }^{4}$ erkannt worde. (Ob es nicht andere Mbhatuprodulite giht. muf zurzeit noch dahingestellt bleihen.

bie Harusiurezersetzung. esehieht in den "roshiedensten Wromen nud man kann zu deren Nachwois einfacl wisserige kxtrakte dersolben henutzen. die genan so herwestellt werden, wie oben für dio l'm rindesimidasen mol die Xanthinoxydase angegeben ist. Am greeignotsten ist die limderniome. Der Vorsuch geht dann folgondermafen:

:50) $\left(\mathrm{m}^{3}\right.$ limblerierenextrakt werden mit $0 \% \mathrm{y}$ in möglichst weng Sormalnatromlauge gelöstre Hamsïme rersetzt; lam wird otwas Toluol uml chloroform zugorgeben, gut gemischt und num das Gemisch hei :370 nuter standiger Lufturehleitung gehalten oder in der s.hihtelmaschine arschiittelt. Tach t-7 Stmolen ist alle Harnsänue rerschwumden. Dic Methorle der Harnsäneisoliermo ist hei der Xanthinoxydase angegeben.

Instatt Rindernjere ${ }^{5,6}$ ) kamn man anch Hundeleher ${ }^{5,7}$ ), Leber und Muskel des Rindes ${ }^{5,6,8}$, Schweineleber $\left.{ }^{5}, 9\right)$ und I'ferdeniere ${ }^{5}$ ), Leher und Niere von lianinchen ${ }^{20}$ ) sowie Leber ron kitzen ${ }^{10}$, nohmen. Mit monschlichen organen golinet os nicht, den cinwandsfreien Beweis ciner Lriko-

1) A. Nicolnitr, iber die Trmwanllung des Adenins in tierischen Organismus. \%oitselır. f. klin. Nerl. Bal. 4.j. S. $430(190)$ ).

2) A. schittenhelm, Der Nulkinstuffwerhsel und seine Fermente lei Ilensch und Tier. Zeitselur. f. plyssiol. (hemir. Bd. 46. S. 354 (1905): siehe anch A. Schittenhtm, bemerkungen üher den Nukleinstoffwechsel. Jentsehes Archiv t. klin. Med. Bol.89. \&. 266 $(1906)$.

s) A. Schittenhelm, Cher das urikolytisehe Ferment. Zeitschr. f. physinl. Chemie. Bit. 45. S. $161(1905)$.

4) Wr. Wiechousli, lie l'rolukte der fermentatiren Hansänrezetzung durch

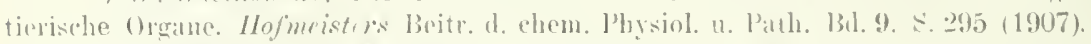

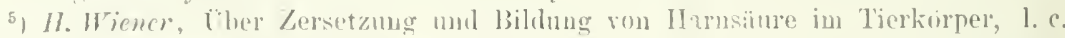

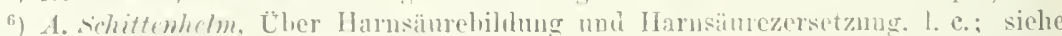
anch H. Könzel und A. Schitfenhem, Cher den zeitlichen Ablanf der l'rikolyse. Zeitschrift f. exprerim. Pith. u. Ther. Bd. 5 (1908).

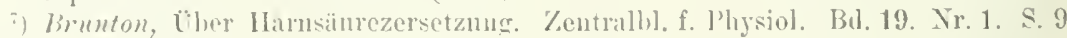
(1905)

$\left.{ }^{8}\right)$ R. limian, l. c.

9) A. Schittenhelm, Iter Nukleinstoffwechsel mo seine lermente bei Mensch unil Tier, 1. p.: sinhe auch A. Schittenhelm uml J. schimid, Ablanf des Nuklemstoff wechsels

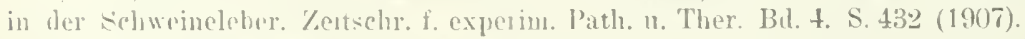

10) A. schittenhtlm und .J. schmid, ITher die Fermente des Nukleinstoffwechsels. \%eitschr. f. physiol. ('hemie. Bal. 50. S. 3.) (1906). 


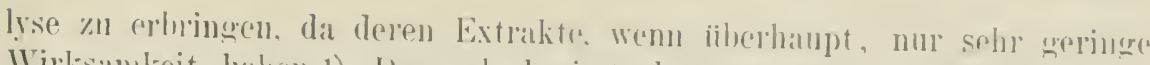

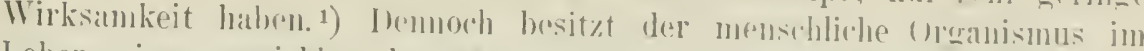

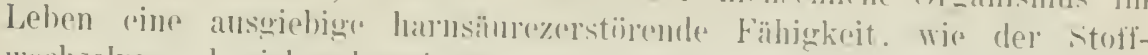
worluselversuch sicher heweist. ${ }^{2}$ )

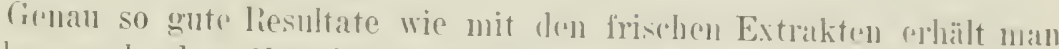

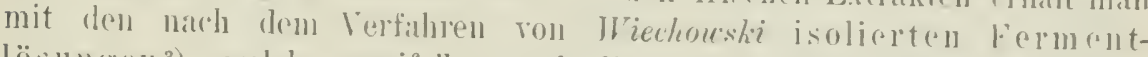

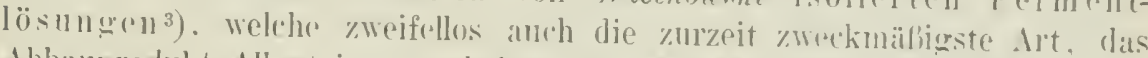
Abbauprodukt Mlantoin zu rithalten, ist. J)ic Methode jst mit Humbleber und Rinderniere durchofiilnt (senane Beschreibung siehe hei Wrierhoustiv, Bt. III. s. 28. ff.). Nie herult darauf, daß man sich rin ()roanpulver durch rasches, wenige Stumlen wälnendes Trockinen der blutfru gespilten, iilucrlobenden (Hoane in diunster Schicht boi :;0 darstellt. welches lange haltbar ist, und dicses ror dem Gehrauche durch ein hesonderes Verfahren (Vermalılen mit 'loluol in einer Farbrejhnihle, Ibuntschen und FarhstoffFreiwaschen mit Toluol auf llev Nutsche) reinigt. Inrch Dialyse grenen schwache sodalösungen werden dio zermahlenen Oroane so weit anforoschlosicen, daß das Ferment viillig in Lösmeg geht. I) meh Fällon soldher dialysierten Emulsionen mit niedrigen Konzentrationen von Kalinmacetat lassen sich die gelïsten Eiweifiörper ron riner nu opalosent lis lichen und eincr unlöslichen (lreanfraktion durels Filtration tremen. Die Fiillung enthält das Ferment, welches mach neuerlicher ldilyse dieser Fälnug in fast eiweibfreiel Lösung quantitativ in das Filtrat ibergeht (Hundeleber) oder ebenso rollständig dnech die Zentrifuge in opaleszenter Lösung erhalten werden kann (Rinderniere). IIan erbält so eine sehr wirksane und einfach zusammengesetzte Fermentlösume. welche der Isolierung des Allantoins keine schwierigkeiten bietet. Diese weschicht nach den fiir dic Isolierung des Allantoins ans lem Trin angegebenen I'rinzipjen (siche IBd. III, Abschnitt : Stoffwechselendprodukte.

Eine Isolierung des Ferments, welche jedoch weniger sicher ist, wie lie eben heschriebene. geht anch mittelst der won Rose $/ l^{4}$ ) augegehenen Methode (les Nachweises intrazellulär. Fermente. ${ }^{5}$ ) Dibei wird wässeriger Nierenextrakt mit einer gesättigten Lösung von Cranylacetat muter gleichzeitiger Zufügung einer Mischumg ron Vatriumkarbonat und Natrimphosphat. so llaß die Lösung stets alkalisch bleilit, so lange rersetzt. bis sich grobe Flocken hilden, welche vich dann weiterhin gut abietzen. Man dekantiert mul filtriert. Der Filterriblistand wirl in $600-800 \mathrm{~cm}^{3} 02$ wger Sodalösung fein zerriehen oder hesser einge stmulen geschüttelt und bleiht dann ca. 12 stmnden stehen. Nun wird extrahiert nud eventuell diialysiert. Liese Lösung enthält das Ferment.

1) Wr. Wiechouski, l'her alie Zersetzlichkeit der Ilarusäure im menschlichen Organismus. Arch. f. exper. l'ath. 12. Pharmak. Bil. 60. S. 185 (1909). - A. sehittenhelm, Über die Fermente des Nubleinstoffrechsels menschlicher Organe. l. c.

$\left.{ }^{2}\right)$ F. lrank und A. Schittenhlm, ther dio Lmsetzung verfütterter Nukleinsäure heim normalen Menschen. Zeitschr. f. physiol. Chem. Bd. 63. \&. 243 (1909).

s) Wr. Hiechoushi, l. e. und Wr. Wriechowshi und II. Wiener, Uher Eigenschaften und Darstellung des harnsäurezerstörenden Ferments der Rinderniere und Hundeleber. Llofmeisters Beitr. Bu. 9. S. $2 \pm 7$ (1907).

4) Rosell, UUber Nachweis und Verbreitung intrazellnlärer Fermente. Inaug.-Diss. Straßhurg 1 sol.

5) A. Schittenhelm, Über das miknlytische Ferment, 1. c. 


\section{Eigenschaften des Ferments. ${ }^{1}$,}

Das Ferment wirkt an besten bei Schïtteln mit Luft und bei LuftJurchleitung. I) Re Reaktion ist zweckmälbig schwach alkalisch $(0.05 \%$ Sorla): stärkere Alkaleszenz kann schaden; saure Reaktion schädigt. Die Furmentmenge ist ron wesentlichem Einfluf anf die selmelligkeit der Fermentreaktion. inden dieselhe un so geringer ist, je weniger Ferment angewandt wird. Antiseptische Zusätze (Toluol. Thromol. ('hloroform, 02-0.8\% iges Fhornatrium) haben keinen Einfluli: dagegen hemmt ein Cberschnli an salzen. Erhitzen des ferments in Lïsung und als Trockempulver zerstört das Ferment. Behandlung des Trockenpulvers mit 'Toluol mul Ithylalkolıol schädligen das Ferment nieht, während Xthylalkohol. der Fermentlösmng in grö̈berer Inenge zugesetzt, hemmt nul zerstört. I) proteolytischen l'ermente. llarnstoff schon zu $5 \%$ und Ammonsulfat. schädigen dis Ferment. Natives Kaninchenleberplasma (aus frischem, nicht wetrocknctem ()rgan gewonnen) zerstört das Ferment. Hemmend wirkt auch Znsatz von harnsänrebildenden Milzextrakten. Es ist nicht dialysahel.

1) W. Wirchowski und H. Wiener, 1. c. sowie A, s'chitfenhelm, 1. c. und H. Kün=el nud A. Schittemhelm, l. c. 


\title{
H. Weitere liermente des intermediären Stoffirechsels mit Finschluß der Methoden zur' Lntersuchung der Antolyse von Organen.
}

\author{
Von M. Jalcoling, lierlin.
}

Lnter Autolys im weitesten sinne des Wortes versteht man die fermentativen [msetzungen, die sich in Organcu ron Tieren mul l'flanzen nach dem Tode nachweisen lassc'n, olne dali Zusütze rou Fernnenten od(r ron Substanzen, welche durch Enzyme verändert werden. gemacht werden. Salkouski. der die Autolyse 'nttleckte und sie zuerst unter dem Namen Autodigestion beschrieben hat, hat genaue Augahen dariber gemacht, wie man sich von der Zerlegung der Eiweilbkirper, der Nukleine und des Glykogens bei der Autolyse ïherzengen und die Vorginge auch ynantitativ rerfolgen kinn. Wir geben zunïchst das rielfach angewandte Sallionshische ${ }^{1}$ ) Verfahren wieder:

Die Leber eines sochen durch Verbluten aus der ('arotis getöteten großen Hundes wird möglichst schnell zcrhackt und eine ahgewogene Quantität. etwa $250 \%$ mit Chloroformmasser remichen und in eine starkwandige Glasstöpselflasche gespiilt. Chloroformwasser wirl hergestellt, indem man destilliertes Wasser stark mit (hloroform schiittelt. \%um Verreiben und Nachspülen werden im ganzen $21 / 2 l$ vorher bereitgestelles Chloroformwasser verwendet, so dal das Verhältnis zwischen der Quantitït des Organes und dem Chloroformwasser etwa $1: 10$ ist. Das Volumverhältnis kann indessen ohme Schaden auch (rhebliclr enger sein; spitere Ieobachter haben sogar nur 1: :3 genommen. Dir Flasche wird so groli cremiilalt, dal's sie starkes Schuitteln gestattet. Zu der Vischung werlen dam noch $21 / 2 \mathrm{~cm}^{3}$ ('hloroform hinzugesetzt, um der sïttigung der Mischung mit C'bloroform sicher zu sein. wiederholt krïftig geschiittelt, die Flasche bu io stunden hindurch in Thermostaten bei ca. $40^{\circ}$ gehalten und öfer's geschiittelt. I) ie Verdauungszeit kann natiirlich auch länger oder kïrzer gewïhlt rerden. Zum Schlusse wird die Jischung enteiweißt und im Filtrat der Stichstoff bestimmt.

1) E. Salkoushi, l'ber Autolyse. Inie Deutsche Kilinik. Ba. 11 (1903). 
Don Kontrollversuch, welcher nötig ist. um festzustellen. inwieweit dio

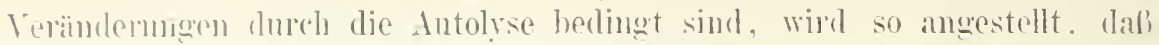
(benfalls 250 y Leber sofort mit der zehnfaclon Quantität Wasser zum sieden whitzt werden. Nach dem Erkalten hringt man alles in eino Flasehe,

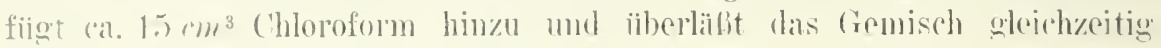
mit dem llanptrersuche der Verlanumg.

bie Autolyse der tierisehen (Jogane liblt sich auch nachweisen, indem man zunähost einen Preßsaft mit Hilfe der Buchnersehen Presso herstellt wler, falk solehe fohlt, imlen man das (Hoan anfach gelörig zerkleinert.

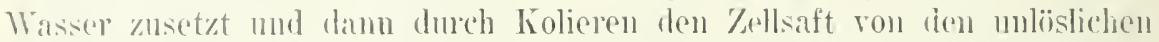
l'oilen ahtrenut. I'm deu \%ellbrei gehörig zu extrahieren. pflegt man hier we in ähnlichen Fällen das Gewehe-Flüssigkeitsonisch tiichtig miteinandev

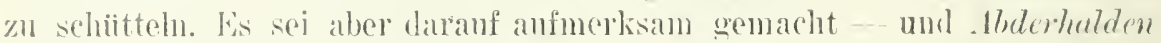
hat gelegentlich daranf besonders bingewiesen - , lab man durch zu ibtensives Schiitteln anf der Maschine muter Lmständen das Gegenteil des heabsichtigten '/weckes areicht. Eime vor lem Sohiitteln gut wirlesame Fermentlisume kinn dureh diese Prozedur ihre Wirksamkeit aimbiißen.

Die direkte Beolachtumg der Autolyso bietet auch oiniges Interessante. Jer vorhandene Brei nimmt ab, die Fliissigkeit fälot sich dunkler. Hat man Toluol als Antiseptikum angewandt, so sieht man das iberstehende Toluol allüihlich sich färben, inden Prorlukte entstehen. welche in Tolnol sich lïsen. Autolysiest nuan \%. B. Leber, so entsteht Trobilin. das sich im Toluol lijst. War die Fliissigkeit bei beginn des Versuches durch Glykogen milchig. so kiärt sie sich bei der Iutolyse.

Will man den Terlanf der Antolyse studieren, hesonders den binflul der lieaktion des Nediums, die Eimwirkung von rasen, pharmakolonisehen Agenzien und Giften auf die Antolyse nutersuchen, so bedarf man einel zuverlässigen quantitativen Jethodik. Eine solche ist in Sulloustis Vorfahren argehen. Jedoch hat sich fïr gewisso Vorhältuisse auch oin anderes

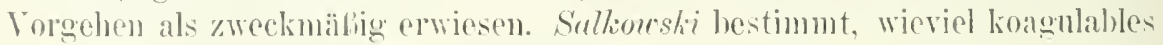
Eiveili am Infang des Versuches und nach bastimmten Fristen in den Antolysegemiscluen vorhathelen ist. Jie Gemischo missen also enteiweilit werden. Da hiej num matiulloh sols viel daraul ankommt, dab bei der Enteiweisung nieht etwa dureh die zngesetzte siinre liweib gespalten wird, so haben die Hofmeistersehen Schiiler vielfach die same lieaktion durch Mononatriumphosphat hergestellt, was in dor Tat ein sehr vorsichtiges und branchbares Verfahren ist.

Will man in einzelnen feststellen, Wats fiir sipaltungsprodnkte auf Kosten des liweib bei der Autolyse anftreten, so mub man die betreffenden Falitionen herstellen, deren Wert nicht gleichmäbig ist. Handelt es sich aher, wie das sehr häufig der Fall ist, nur um die quantitative Emonthung des Crades del Autolyse, so kann man die Tyemmmg zwischen komplizierten und einfachen Substanzen an sohr versohiedenen l'unkten vornehmen. Damn aenight es, dalf eine quantitative und gleichniblige Versuchsanordnung vorliegt. 


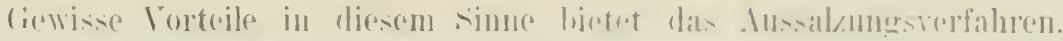

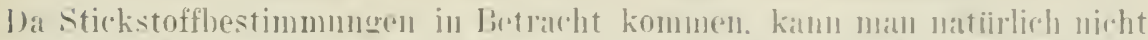

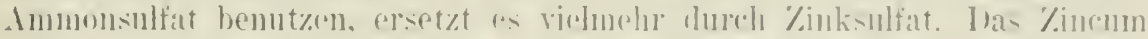

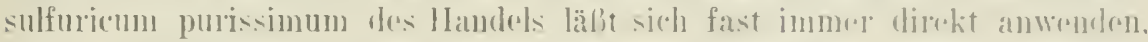

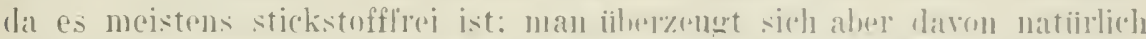

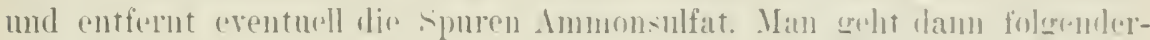
malien ror:

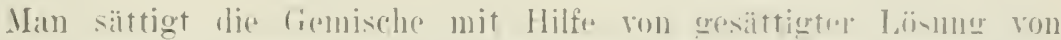

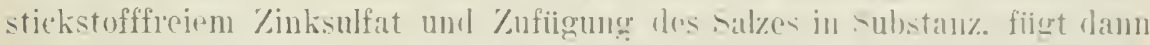

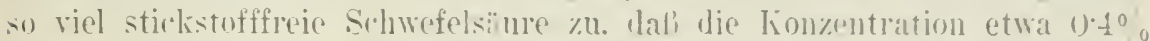

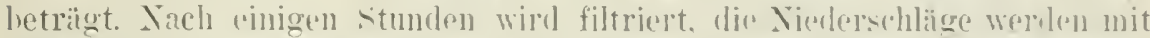

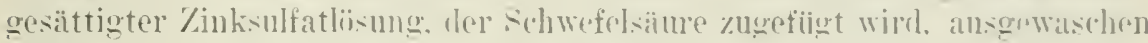
und in l'ortionen des Filtrates damn der I luestimmt. Vertreibt man das Wassel auf dem Wasserbade und sundhade mud zersetyt in Joncuser

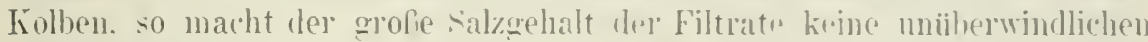
schwierigkeiten.

sehr hequem ist die Methorle nicht. woil die Stickitufflostimumugen in den honzentrierten Salzlisungen immer gewisse schwierigheiten hereiten. Es stehen aber auch norh andere Verfahren zur Vorfïgung. Dat ich gezejgt habe. dafi der Ammoniakstickstoff bei der Iutolyse zunimmt. so kann anch dieser Stickstoff als Mah der Autolyse henutzt werolen. Die Schlësinysche Methode und ihre Nodifikationen sind weniger geeignet. la die Apparatur meistens zu platzraubend ist. Zu brauchbaren Resultaten gelangt man. wonn man die Magnesia-Destillationsmethode anwendet. Auch sis hann zwechmälig num bei Leberextrakten mud nirht mit Leberbrei benntzt werlen. Das Verfahren gestaltet sich sehr cinfach, inden man dis zu untersuchende Flussigkeit mit Wasser relüunt. mit Maqnesia usta rersetzt. die man zur Sicherheit vorher in einer Nickekchale noch eimual gliht. mm sie von Inmoniakspuren zu befreien und dam direlit in die rorgelente Silure destilliert. Noch sicherer ist os. wem man in den liolhen zmä̈chst destilliertes Wassel und die Magnesia hringt und leel destilliert und dann mach dem Abkïhlen den Organsaft zusetzt. Ein Mifstand bei der Methode ist, dab der schluf der Destillation asrmptotisch elreicht wirl, so dafi man nur im Einzelfall durch die Erfahrung feststellon kann. wann man die Destillation abschlielien darf.

Branchbar ist auch das Verfahren ron Hedin und Roulund 1), die Tamninfällung anwenden. Man fällt den Lebersaft mit einer mit etwas Essigsäure versetzten $T^{0}{ }_{0}$ igen fierbsïurelösung und bestimmt im Filtrat dell Stickstoff.

Endlich sei auf eine ron mir praktisch noch nicht erprobte Methode aufmerksam gemacht. auf das Mastis-Terfahren von Michuelis und Rona, welches sich wohl auch für autolytische Zwecke ausarheiten lassen wird.

1) S. G. Hedin und S. Rouland, ther ein proteolytisches Enzym in der Milz und Intersuchungen über das Vorkommen ron protenlytichen Enzymen im Tierkörper. Zeitschr. f. phrsiol. Chemie. Bd. 320. S. 341-349 und $531-540$ (1901). 


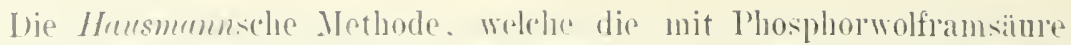
fällharen sulsstamen ron den nicht fällbaren trenut. hietet fiir die Lntersnchung der Antolyse keine Vortejle die direkto Bestimmump de basischen

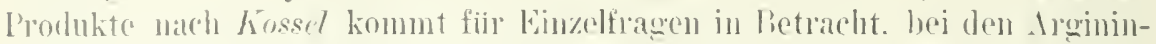
wertan ist anf die Existru\% der Iroinase liürsicht zu nehmen.

An diese Mothoden. Welche bestimmen. wiovich biweib in einfarbere

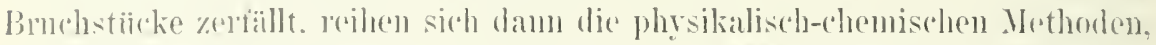
weleho daranf himauslaufen, die Zmualnue der Nolekiile hei der Autolyse fostzustollen. Es moteliogt keinem \%weifel, dabi derartige Mothoden eventurell fiir gribere heihenversuche Vortril hieten.

bisher hemut worlen ist die Kryoskopie und die bestimmmun dep

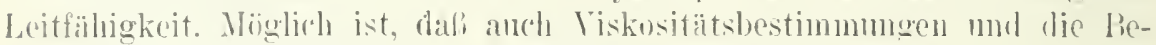
stimmmmo der liefraktion sieh vortrilhaft verwenden lassen.

Anch histologisch lat man das Verhalten dere aseptisch antolytischen Gewrobe studiert.

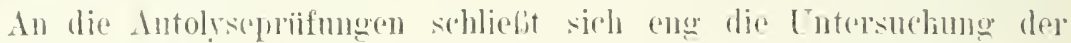
lloterolyse an. Ms Hetelolyse hahe ioh die Fimwirkme del Fermente rines

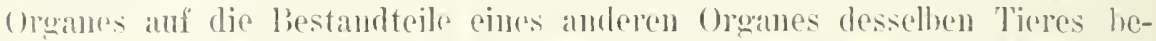
\%(eichnet. 1)as Verfahren gestaltete sich in meinen Versuchen folgenulermilliemil $\left.{ }^{1}\right)$ :

Fiir dir einzelnen Varsuche wurden immer ain oder zwei Hunde dureh

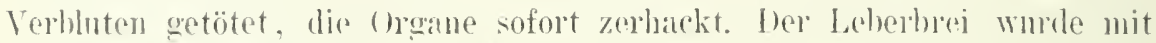
destilliertem Wasser oder $0 \cdot y^{0}$ ige! Kochsalzlïsung muter 'Toluolzusaty so

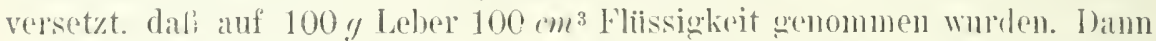

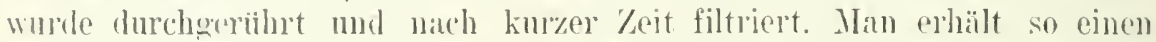
diinnen Lobersaft, der moben anderen substanzen Eiwoiblörper und fernente, darunter anch das lebereiweib spaltende ferment enthält.

Vom Lumernbrei wurlen Portionen (in den einzehen Versuchen von

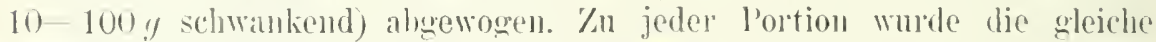

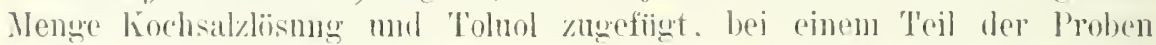
wurlen einige Kulikzentineter der Kochsalzlisung (in den einzeluen Versuchen schwankte las zwischen 10 mol $25 \mathrm{~cm}^{3}$ ) durch Lebersaft ersetzt.

Von dem behersift wude auberdem eine Reihe entsprechender Proben besomders abgemessen.

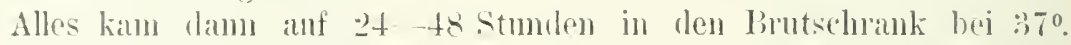
bann wurden die Proben ohme Lebersaft nit den besonders digerierten

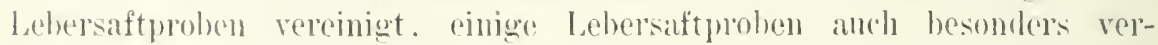
allicitet.

In einigen l'ortionen wurde mun der nit '/inksulfat nicht aussalzhare stickstoff, in anderen der nicht koagulable stickstoff bestimmt.

\%nsat\% ron Lebersaft vermehrt nicht den nicht koagulablen Stickstoff bej der cyaltumg des Lungengewebes, wohl aber den nicht ans-

1) Wratin. Jucoly, Zur Frage dor spezifischen Wirkung der intrazellularen Fermente. Ilofmeistes Beitr. Bd. 3 \& $440-450$ (1903). 
sialzbalen Stickstolf. Es wiol also infolge Eimwirkmog dos lobersaftes nicht

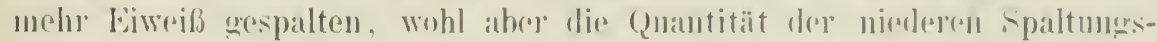
produkte vermehet. also moble Allumose weitej gespalten als in der nolmalen Lungeruantolrse.

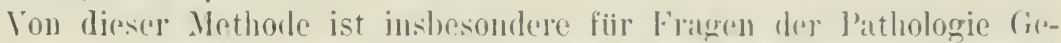
branch gematht worlen, namentlich hat man Ibwoichungen von der Norm

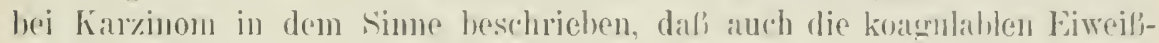
kïrper heterolytisch zersetzt wurden.

In Anschluls an die antiseptische Intolyse habs ich nuch untersucht. ob die antolytischen spaltumgen auch vor sich gehen, wrun die ()rganstiicke ohne jede I'rozedur aus dem lïirper genommen werden und die

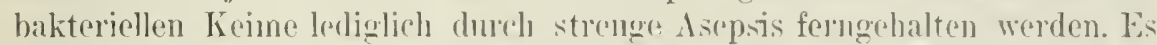
sollte damit möglichst jode sekmuläre lieaktion ansqeschlossen werden.

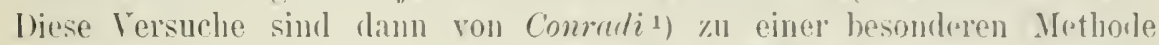
der aseptischen Intolyse entwickelt wordru. Mngnus-Levy hat die aseptische Autolyse besonders in seiner Arbrit über die antolytische süur(bildung henutzt. Die aseptische Autolyse lat deshalb einen Wert, weil die autolytischen Prozesse offenbar durch die Antiseptika crehemunt werden und man daher bei antiseptischem Torgehen nicht len vollen I'mfang des I'rozesses kemen lerut. Trotzdem wirl das Verfahren nur fiil ganz hestimmte Fïlle zu empfehlen seiu, da den Vorteileu grobe Schwierirkeiten gegeniibersteh('n. Denn nur hei gröbter Vorsicht kann natiolich lua einem Material, das emen so ausgezeichneten Vährboden für liakterien rlarstellt. Infektion rermieden werden. Inch darf man nicht iibursehen. dab Bakterien unter Conständen auch der bakterioskopischen und allenfalls anch der kulturellen Prïfung entgehen könneı. Man darf sich iibrigens bei aseptischor Autolyse nicht dureh den Geruch rerleiten lassen, einen Tersuch zu verwerfen. Ton stinkender Fïnhis ist zwal der Geruch einer aseptischen Autolyse durchans zu unterscheiden, wohl aber riphen die fremische sehr unangenehm. insbesondere wohl wegen des Auftretens ron Fettsïuren. Bei del antiseptischen Antolyse sind diese Nubstanzen nicht nur yuantitativ weniger vertreten, ihr Geruch wird auch durch den der Antiseptika rerderki.

Wir lassen nun Conradis Angaben iibel die Versuchsanordnumg bei der aseptischen Autolyse folgen:

$\mathrm{Zu}$ einem Versuche ubel aseptische Autolyse ist auliel dem Operateur ein Assistent erforlerlich. Was Versuchstier (Hund orler líaninchen), das 2t Stunden gefastet hat, wird durch Chloroform oder Genickschlag getötet. Von dem Assistenten wirl nnmittelbar nach erfolgtem Tode die Haut ron der Symphyse bis zum Jugulum freigeleart und möglichst weit zuriickpräpariert. I)ie freigelegte Fläche wird mit Sublimat iiberspiilt und mit Sublimat durchtränkten Tüchern ringsum bedeckt. Der ()perateur. der besser

1) H. Comradi, tber die Bezichung der Autolyse zur Blutgerinung. Hofmeisters Beitr. Bd. 1. S. 136-182 (1901). 


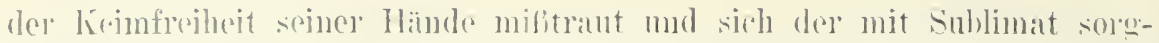

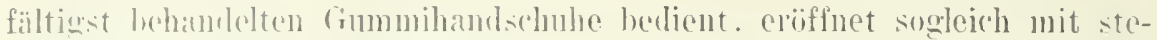

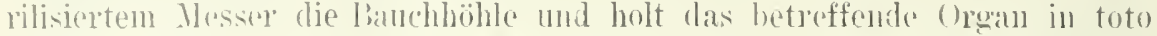

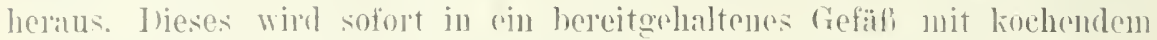

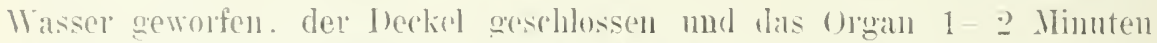
lang im kochenden Wassel gehalten. Mittelst einer wolien sterilen l'inzette wird dann das (Mrgan in ein a. $10 l$ fassendes Crefaif mit sterili-

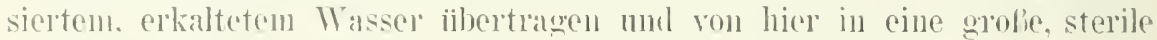
Hoppelschale eingeloracht. Vor dor Sterilisation war in dieselle ejn kleines

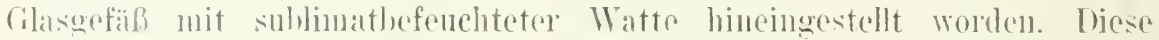

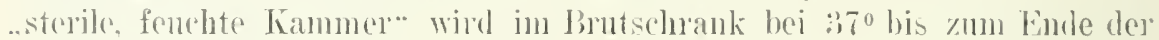
Autolyse rewialut.

lieabsichtigt man, statt an laboratoriumstieren die aseptische Into-

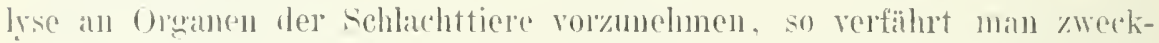
mäbio folgendermalien: D)as betreffende ( )ronan wiled in toto heransgeschnitten mul in an rerschliefibares. mit $1 \%$ igel sublimatlösug gefiilltes refüh gebacht. In Labolatorim wird das in sublimat befindliche orwan mit sterilem Messer, Wenn nötig in kleinere r'ortionen zorteilt. Ins

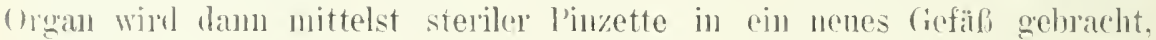
wolches ca. $10 \mathrm{l}$ hochencles Wassele enthält. Nach 1-2 Minnten langem Aufenthalte in kochendem Wasser kommt das orean in steriles, kaltes IVasser, dem vor dem Konchen schwefolanmonimu oder selowefelnatriun zugesetzt wurle; ernoute Chertragung in sterilisiertes, kaltes Wassel nsw. wie oben. Nach Beherrschung dieser Methode gelang os in den meisten Fälen, eine aseptische Antolyso der meisten tiorischen ()rane durchzufiihren. An schwierigsten ist hei der Ideher die Autolsse aseptisch aus\%ufiihuen.

Liei dieser aseptischen Antolyse, die iblrogens schneller ror sich geht wie die antiseptische, findet man, soweit das hisher nutersucht worden ist,

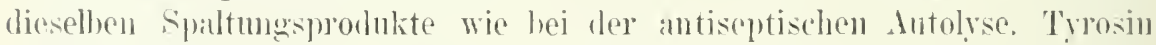
kanı man sehr ball auskristallisieren sehen. Natïrlich läbt sich die Yersuchsanorlunug in sehr weiten Grenzen valuopen. man kinn Sillerstoff

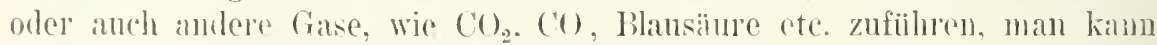
den Wassergehalt der nmerebenden luft verandern u. a. 11.

bie aseptische dutolyse ist gewissemaben ein Grenzegehiot zwischen Chemir mul Histologie. Denn man kann das Gewebe, das ja hierbei me-

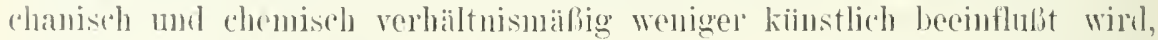
als bei dem antiseptischen Vorgehen, anch mikroskopiseh mutrisuchen. Diese Lutersuchmgen diinfen aber nicht zu chemischen schluffolgermugen herangezogen werden. Wonn man \%. R. in cin leberstiick nach dem Tode T'hosphoröl injiziont und es dann der aseptischen Autolyse iiberlälit, so entsteht allmällich das histologische Bild der Verfettumg. Wie chemische Priifung weist aber nach. daf aine bonahme des Fottes nicht eingetreten ist, das vorher volhanden gewesene Fett ist nur sichtbar geworlen, weil die iil) liogen (iewebsbestandeile sich verïndert hahen. 


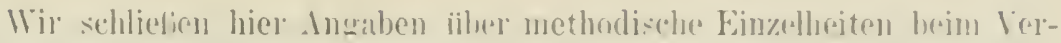
arbeiten antolytischer (ieminiche an.

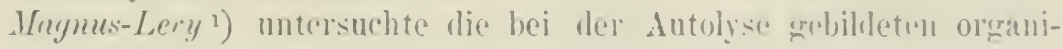

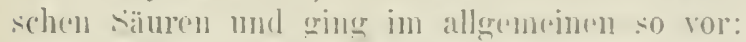

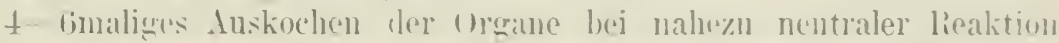
(Zusatz von Kalimulisulfat bei frischen, von Natrimmbikarbonat bi antolysierten (Mrganen), Eindampfen. Znsat\% von Annoniumsulfat und schneforsïme, nach lingerem stehen fbfiltrieren ron ausgeschiedenem Eiweili. Albumosen, Fetten und höheren fottsäuren: Erschöpfung des Filtrates nint Ither. Kontrollversuche, in denen die saure nit Ither orschöpfte Liisnng neuerdings mit Alkohol-ithernisehune behandelt wurde. zeigten. dali due

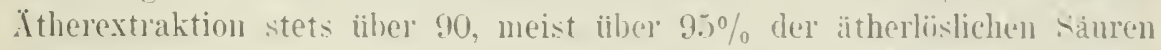
aufrenommen hatte. Die ätherische Lösung wurde zur Befreimng ron an!organischen sïmen mit wenig Wasser gewaschen, dem Walseluwassor die geringen ron ihm aufgenommenen Itengen organischer siuren durch ernente .itherbehandlung wieder entzogen. . o behandelt, war das Itherextrakt stets frei ron Mineralsäuren. Der Cther wurde unter möglichster lermeidung ron Verlusten an orwanischen siiuren abdestilliert, der Riuckstam in Wasser gelöst. die flürhtignen süuren mit Wasserdampf abgretrichen und mit Natronlauge titriert. Auch die Menge der nichtflïchticren säuren im Destillationslïehstand wurle (an einem Bruchteil) titrimetrisch bestimmt. So war die Yenge der gesanten s̈̈uren wie auch das Verhältnis zwischen flüchtigen und nichtflüchtigen stets bekamnt. Die höheren Fettsäuren wurden bei dieser Behandlung nicht mitbestimmt. T'berall wurden die gefundenen Zahlen auf $100 \mathrm{~g}$ ursprïnglicher Lobersuhstanz umgerechnet.

Von besonderem Interesse ist vielleicht das Vorkommen der Yilchsiume unter den Produkten der Autolyse. Jedoch bietet die Gerinnung des Zinhsalzes der Milchsäure keine besonderen schwierigkeiten. Mochizuki und Arima ${ }^{2}$, erhitzen zu dem Zweche die digerierte Flissigheit zunächst zum sieden, behandeln sie erst mit Barytwassel, dann mit Kohlensäure. dimpfen die Lösung ein, ziehen den Sirup mit Alkohol ans. Der Extraktrückstand wird dann mit Phosphorsïure angesiucrt, mit Ither ausgeschüttelt, aus dem ditherrïckstand wird das Bleisalz und aus ihm das Zinksalz dargestellt.

Inouye und Kondo ${ }^{3}$ ) konnteu iibrigens das Ferment, welches bei del Autolyse die Milchsäure bildet, auch im Prefsaft nacluweisen. wie folgendes Beispiel erläutert:

$425 \mathrm{~g}$ frische, zerkleinerte lianinchenmuskehn wurden mit Quarzand fein zerrieben, mit $425 \mathrm{~cm}^{3}$ Chloroformwasser durchgeriihrt und mittelst

1) Adolf Magnus-Lery, ther die siturehildung bei der Autolyse ler Leber. Hofmeisters Beitr. Bu. 2. S. $261-296$ (1902).

2) J. Mochizuki und R. Arima. Lber die Bildung ron Rechtsmilchsäure bei der Autolyse der tierischen Organe. Zeitschr. f. physiol. ihemie. Bd. 49. S. 108-112 (1906).

3) Katsuji Inonye und K. Fondo. Üloer die Bildung ron Rechtsmilchsäure bei der Autolyse der tierischen Organe. III. Mitteilung. Die Milchsäurebildung bei der Autnlyse des Muskels. Keitschr. f. physiol. Chemie. Bu. jł. \$ 4\$1-500 (1908). 
piner l'ressu atusepuelit. Das Extrakt lieforte nach Filtration eine Fliissigkeit. die sich muter dem Mikroskop als frei ron Zelldetritus erwies: diese

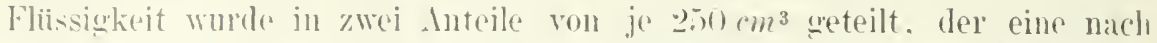
dem liochen, der andere sofort hei Gegenwart von 'Toluol, bei Bruttemperatm digeriert. Nach ttägiger Digestion wurlen dir beiden Anteile auf Mlibhsäure verarbeitet. Es wmblen gefumden:

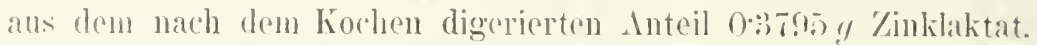

aus dem sofort digerierten Inteil 05123, / 'inklaktat.

bie angwandten Methoden der Milchsäuredarstollnus sind natiuldich keine wirklich quantitativen. jeloch sind die erhaltenen Iusschlïge atuferhalb der Fehlerpuellen der Methodik. Zu wirklich exakten Kahlon kann man hoffentlich mit Hilfe den von Jerusulem auscrearbeiteten Methode der quantitativen Bestimumug der Milchsäure in tierischen Oroanen gehangen.

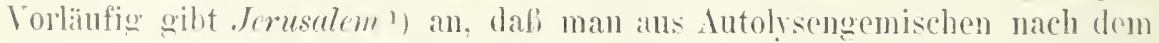
Inskoanulieren die liweibreste mit l'hosplorwolframsämre ansfällen soll. Dic Milchs̈̈mphestimmmon soll nach seiner Methode in diesen Flissigkeiten dann zwar selu miihselig soin. dafiur aber anscheinend manche Fehlerupellen vermeiden.

Mugmes-Lery hat anch die Gasbihlume bei der Autolyse nutroucht. Gabbildnug findet in reichlichem Malie bei des Iutolsce der Leber. in geringerm anch bei der einzelner anderer ()roane statt. licj antiseptischer Autolyse ist sie nicht so bedentend. dagegen liefert die aseptisch behandolte Hundeleher sehr viol Gas. Die Anwesenheit geringer Mengen von schwefelwasserstoff, die sich dem Geruch entziehen. ist leicht nachwoishal. Papier oder Watte, lie, mit sublimat od rer Bleiacetat getrinkt. in kleinen (iläschen in dis groben Intolsierschalen ringel)racht wurden. zeigten ans-

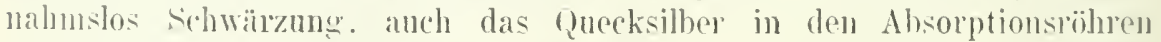
wurle dunkel gefübt. Magnus-Lery brachte miter aseptisehen Kantelen ein Leberstick in ein trichterförmiges, mit antiseptischer Flïssigkoit gefiilltes Gefäl). Aus ainen Halbliterkolben wurle der borlen ansgesprengt. der Hals zn einer feinen liöhre ausgezogen. die duch einen kapillaren Gummischlath mit Bunsenschen Gummiventilen verschlossen werden komnte. Dieses zur Aufnahme der Lebel bestimmte frefül kam in ein grolies bucherglas $\%$ strhen. Dic beiden wurlen nach trockener siterilisation mit Toluolwasser und reichlichem iiberschiissigen 'Ioluol grefiillt. Das sterile

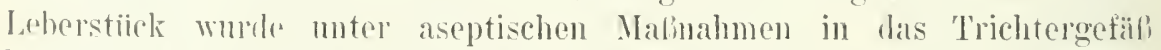
hineingebracht und dieses damn durch Ansaugen mit dem 'Toluolwasser guefiilt, mol zwar so. daß anch hier iiberschiissiges Toluol an der oberfläthe schwanm. Bei der Autolsse war somit die Anbenschicht des Leberstickes und der ansfliefiende saft einel etwaigen bakterienwirkung entzogen, aber auch die Autolyse und Gasbildung dieses Anteiles sehr beschränkt. Der imnere kern des Organstiickes, der der 'Tiefenwirkung des

1) Ernst Jerusulem, ither ein noues Verfahren zur quantitativen Bestimmung der. Milchsäure in Organen nul tierischen Flüssigkeiten. Biochem. Keitschr. Bd. 12. S. 361 bis 389 (1908). 
Antiseptikums nicht unterlag. mulite hier das Gas liefern. Im Schlusse dieser Vorsuche wurle die Laber mit hesonderer Sorofalt hakteriologiscll mutersuchte. las an der sipitze des T'richters sich sammelnde lias komute zul belieligen \%eiten entnommen nnd zur Messung und dualyse benutzt werden.

Die Gasbildung begrimut erst nacle fi Stunden. nebrol Kiohlensäure wurde Wasserstoff gefunden.

In den (reganzellen findet man neben den antolyticheren fermenten. welche das Eiweif zerlegen. anch fermente. wriche dis primäien sipaltungsprodukte weiter zerlegen. Hier ist besonder's die Arginase von Kossel und Dation ${ }^{1}$ zu nennen. Wolche das Arginin in Grnithin und Harnstoff spaltet. I) Arginase geht in den l'refsaft über. sie kann, wenn auch nurollständigr. aus dem Leberbrei durch Wasser oder verliumte lssigsänre extrahiert mol aus der Lösung durch Ammonsulfat sowie dureh Alkohol und Ither gefällt werden. Ein Trockenpripalrat kann man sich aus dem leberprefsaft herstellen. wenn man ihn mit einer Nlischung aus ? Teilen Alkohol und einem Teil ther ausfillt und den Viederschlag vorsichtig trocknet.

Die Spaltung des Arginins durch die Arginase erfolgt schnell. die Spaltmosprodukte kümnen durch dic Analyse sichergestellt werden. Iurch die Existenz der Arginase ist es wohl bedingt, dalf man in Autolysengenischen meistens das Aroinin rermilit oder nur in geringer Menge antrifft.

Die stärkste Aroinasewirkmng hat die Leber. wirksan sind auch Niere. 1)inndarmschleimhat, Thrmus und Lrmphdriisen, zweifelhaft ist die Wirksamkeit der Muskeln und des Blutes. Yebenniere und Mil\% des Hunde: spalten nicht Arginin. ${ }^{21}$

Nach Gottlieb und Stangassinger ${ }^{3}$ ) wird bei del Autolyse líreatin in Kreatinin umgewandelt. aufierdem lireatin aus unbekannten Vorstufen gebildet und endlich Kreatin und Kreatinin noch weiter zerstört. Dies. Intersuchungen erfordern cine Methode der Kreatin- und lireatininhestimmung in den Organextrakten. Das hreatinin wird nach Folin bestimmt. Die Folinsche Methode rerwertet kolorimetrisch die Jaffésche I'ikrinsäurereaktion. Ihr Prinzip beruht in der lieduktion ron alkalischer Pikrinsäure z.1 der roten Pikraminsïure durch lireatinin. Nit Hilfe eines Kolorimeters wird die erhaltene rote Fliissigkeit mit einer n/2-Kaliumbichromatlösung

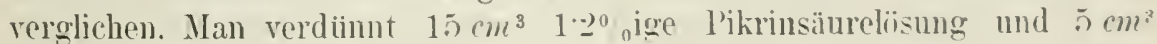
$10 \%$ ige Natronlauge anf $500 \mathrm{~cm}^{3}$. Gottlieb und Stankfassinger haben in der

1) A. Kossel und II. D. Dakin, Uher die Arginase. Zeitschr. f. physiol. Chemie. Bd. 41. S. 321-331 (190t) und Weitere Untersuchungen über fermentatire Harnstofflildung. Zeitschr. f. phrsiol. (hemie. Bd. 42. S. 181-158 (1904).

$\left.{ }^{2}\right)$ Über die peptolytischen Orgimfermente rgl. das Yotwendige bei den Fermenten des Eiweißstoffwechsels.

3) R. Gottlieb und R. sitangassinger, Über das Verhalten des lireatins bei der Autolyse. Zeitschr. f. physiol. Chemie. Bd. 52. S. 1-41 (190i). - R. stangassinger, II. Mitteilung. Zeitschr. f. physiol. ('hemie. Bd. 55. S. 295-321 (1908). 


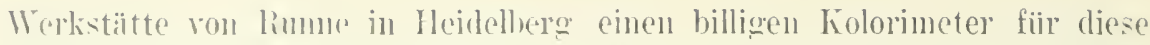
Methorle besonders anfentigen lassen. Wrenen der Fimpfindlichleit del Re-

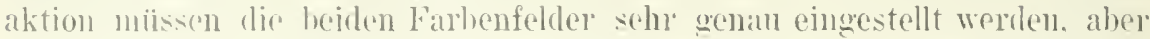
anch sonst ist the Mothorle sebr vorsichtig ausufülulen. inshesondere, da dio in den Oromextrakten enthaltenen substanzen leicht Störungen verurvirchen.

IIir besprerhen anerst die Kreatininbrstimumng in den organextrikt('), lann erst die Kreatinbestimmung. welche indirekt erfolgt. Gottlieb und stangassinger hahen urspringlich die Intolysegemischo zur heatimblostimmmng unter Znsatz von Kochsalz und Essigsime koanuliert, dam dio Flissigkeit cingedampft. l)jese Inothode hat nenerdings Foth-

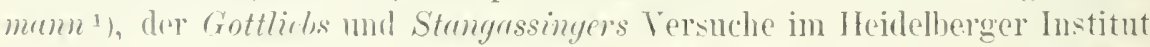
fortgesetzt hat, Marh dem Vorgango von Mrllonby auferegeben. Melianby mol Rothumm koasmlioren mit Alkohol mol dampten das filtrat hei einer

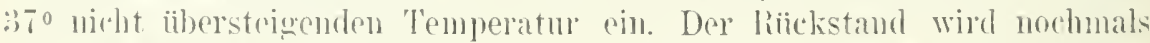

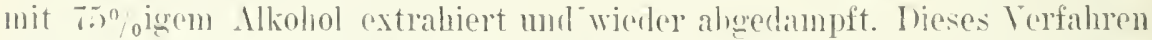
vermoilet den Fehlor, dal beim Eindampfen bej höherer Temperatur Kreatinin ans lireatin entsteht.

Mitunter geben längere Zeit antolysierte Extraktlïungen auch ohne

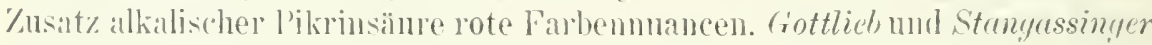
halfen sirb, indem sie lixtraktproben olme Kreatin- orler Kéreatininzusaty parallel mit den Ilauptversuchen behandelten mol die durch lie rote Firhe lamn vororotiluschte Kroatininmenge feststellten. Diese Zahlen wurden dann von den Zahlen des Hanptrelsuches abgrogen. Abasehen ron diesem Ililfsmittel verringerou sich die Fehler anch dadurch, daf man wegen des Feimheit dor Methorle in sehr starken Verdimnungen arbeiten kam. woulurh man allerdings zu gröberen Inltiplikationen genötigt ist.

In einer anderen J'ortion des Antolysegennisebes wird rlas líreatinin bestimmt. nachdem das danehen volhandene lireatin in Lreatinin ib)ere-

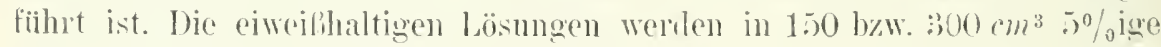
sindendo (hlornatriumlösung eingegrossen, his zum Anftreten eben samrer Reaktion mit reoliunter Essigsiure versetzt mud rasch anfgekocht. [as amskoagulierte Eiwoils wird abfiltriert mol mit siedendem Wasser gut nachgewaschen. Die gesante Flïssigkeit wird eingeengt und auf $100 \mathrm{~cm}^{3}$ mit dem (iehalt ron $2 \cdot 2 \%$ salzsänr celoracht. Dieses Loagulationsverfahren, das urspriinglich anch bei der Kreatininbestimmung benutzt wurle, wurde beim Ciesantkreatinin beibohalten, weil es hier ja nichts ansmacht, wemn Kratin in Kreatinin ïbergeht. Dem suater wirl ja doch alles in Kreatinin musedwatudelt.

Die salzsane liosmug wird nun in einem Erlenmeyerkolben zur L'msetzung des rollandencun Kreatius : stunden anf eincm lebhaft siedenden Wascorbade erwïmt. Dann wird der liolbeninhalt, ohne die Lösmg zu

1) L. Rothmonn, Uher das Verhalten des Kreatins bei der Autolyse. III. Nitteilung. Keitschr. f. physinl. Chemie. Bd. 37. S. 131-142 (190s). 


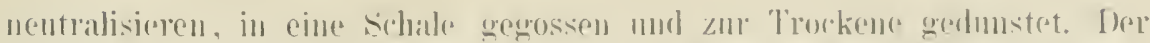

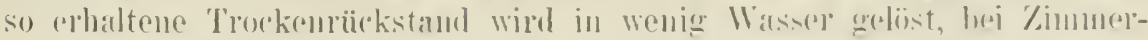

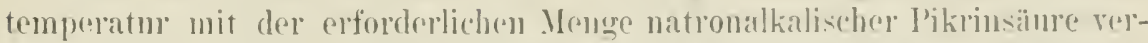

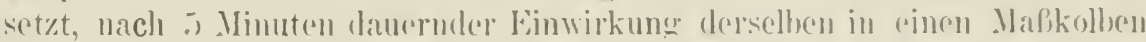
gespiilt und anf das erfordorliche Volumen verbiunt: von den anceresche-

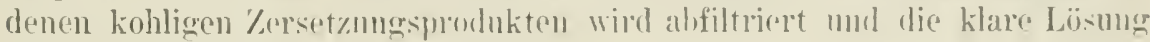
auf den Gesantgrhalt mitcrisuldt.

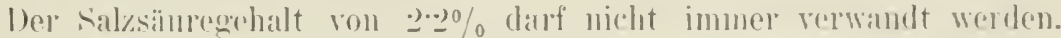
Ilie zur quantitativen I'mwandlung von Kreatin in Kreatinin nötige ciouremenge schwankt nämlich je nach dem chemischen Milien, in dem sich das Kreatin befinder. Bei den Intolyeversuchen bewährte sich in Versuchen liothmanns die lionzentration vour ?-200.

Die fuir die Tersuche notwendigen orwanextrakte wurden folgendermalien bereitet: Die (Organe wurden durch die Fleischbackmaschino ge-

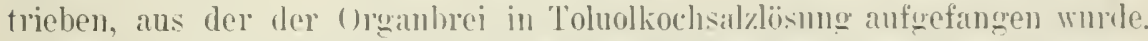
sodam wurde der (1rwanbrei mit Mmarzsand griumdlich verrieben und dicier diunfliissige Brei blieb 1-2 stunden im Eisschrank: danach wurle er durch Tücher koliert. Ine Menge zugesetzter Flüsigheit betrug im Vurhältuis zum ()rgangewicht $1: 1$. 


\title{
I. Methoden zur Bestimmung der Atmung tierischer Gewebe.
}

\author{
Von F. Battelli und Lina Stern, fienf.
}

Isei allen hiorher gehörigen Methoden handelt es sich darum. entweder die suncrstoffunfnahme oder die Kohlensämeabgabe oder beides zugleich zu bestimmen.

Die gasanalytischen Vethoden werden an anderer stelle hesehrieben. Hier sollen hauptsärhlich die Bedimgungen. unter denen der respiratorische Gaswerdsal der zu untersuchenden (iewebe gemessen werden kann, anscimanderesestzt werden.

\section{Der Gaswechsel in Gegenwart von Sauerstoff.}

\section{A. Untersuchungsmethoden des respiratorischen Gaswechsels ganzer Organe.}

1. I) (Je rane oder Fewebe sind in situ am lebenden Tier: die Nervarerbindung und die natioliche Zirkulation sind intakt.

Die zu dieser (iruppe gehörenden Irothoden bezweeken den Gaswerhsel der verschiedenen frewebe unter möglichst normalen Bedingungen sowie den Finflul verschiedener Faktoren: Ruhe oder Täitigkeit, Wirkung verschiedene? Sibstanzen usw. auf den respiratorischen Gaswechsel der versehierlenen (iewebe studieren zu kömmen. Das allgemeine Prinzip dieser Methoden besteht darin, das arterielde Blut mit dem vom 7.1 mtersuchenden (iewebe oder Grgan kommenden renösen biht in bezng auf ihren Gehalt an () $)_{2}$ und ('( $)_{2}$ 2.1 repgleichen.

In einigen Fällen gentigt es. die P'roportion dieser (rase im arteriellen mul renösen lilut zu bestimmen. Diese Untersuchung bietet koine weiteren schiwierigkeiten.

In der Mehryalul der lälle handelt es sich jedoch darum. die Mengen des aufgenommenen Sanerstoffes und der abgegebenen Kohlensäure in der Zeiteinheit zu messen mul zugleich die plysiologisehen Bedingungen, unter 
demen das zu mutersuchroule firwehe oder ()rgan siell befinulet, festzustellen.

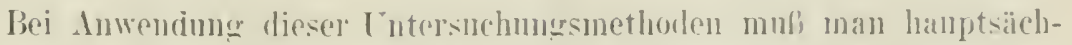
lich folgende I'unkte herieksichtigran: 1. dir lorbereitung dos Jieres, lwi dem der Gaswechsel rines ()ranes oder Gewobes studiert warden soll, 2. die Blutentnahme ans dru Arterien mud Vinen und die dnalyse dej darin enthaltenen Gase, :). die Menge des in der \%eiteinheit in ()rgane zirkulierenden Islutes, to das Verfahren, m die Funktion des J roanes nach Belieben zir steigem oder herabzusetzen.

a) Die Vorbereitung dos Versuchstieres.

Dic allgremeine Vorberejtune des Tieres, d. h. die Fessclum, die Varkose usw.. weist keine besonderheiten auf. Dic Vorbereitung des zu untersuchenden Organes odel trewehes. der ans demselhen kommenden lene sowie des Verven. dessen Einflul auf den Ciaswechsel des hetreffenden Gewebes studiert werden soll. wird natiirlich je nach lem in Betracht kommenden fiewbe rerschieden sein (siehe weiter unten). Was das arterielle Blut betrifft, so kann dasselhe einer beliebigen Arterie des Körpers entnommen werden: Karotis. Femoralis nsw. da die Znsammensetzung des arteriellen Blutes in allen lilutgefülien dieselbe ist. In manchen Versuchen ist es vorteilhaft. das Blut rorher ungerinnbar zu machen. I) ie Engerinubarkeit des Blutes ist am besten durch eine intravenöse Einspritzung von Hirudin (1)01 g Hirudin pro $1 \mathrm{~kg}$ Tier' zu creielen.

\section{b) Die Blutentnahme und die Gasanalyse.}

Bei der Blutentnalme zur (iasanalise ist ror allen lingen darauf zu achten, dab das Blut nicht mit der Luft in Beriihrung kommt. Zu dem Zwecke wird das Blut unter einer Ölschicht aufgefangen und mit Quecksilber defibrimiert, wenn es nicht rorler ungerimnlar wemacht worden war. Andrerseits kann das Blut mit Hilfe einer Spritze entnommen werden, die $1 \mathrm{~cm}^{3}$ einer $1^{0}{ }_{0}$ igen Oxalatlösung fiir $9 \mathrm{~cm}^{3}$ Jilut enthïlt. In letzterem Falle ist es notwendig, die /irkulationsgeschwindigkeit im betreffenden ()roan bereits zu kennen.

Die Analyse der Gase des arteriellen und renösen Blutes kann wach irgend einer der jetzt angewandten Methoden (siehe das entsprechende hapitel) vorgenommen werden.

\section{c) Bestimmung der im Organ zirkuljerenden Blutmenge.}

Die im Organ zirkulierende Blutmenge wird aus der Venge des in einer gewissen Zeit aus der Vene kommenden Blntes berechnet. Diese Blutmenge ändert sich natiirlich, wenn der Druck in der aus dem or⿳ạn kommenden Vene geändert wirl. Es ist also notwendig, das blut unter Beibehaltung des normaleu Widerstaudes aufzufangen, d.h. der Widerstand. den das aus der Tene kommende blut bezwingen mub, soll dem in der 


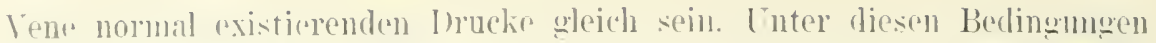

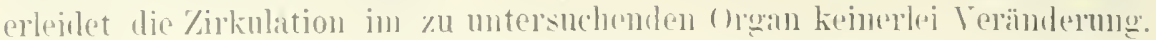

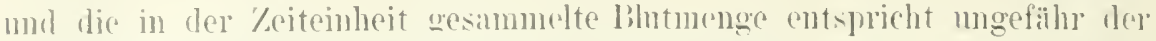
normal in der \%oitrinheit zirkulieronlen Bhtmenge.

Wenn es sioh darmm bandelt. eine gawisse l'bizision zu beobachten. dart malu die Kaniile nicht direkt in die rom (l)gan kommende Vene rinfïhren. weil dadurch der Blutstrom behindert wäre. In diesem Falle nuli mall dine andele Methode anwenden. Wem die anatomische Disposition as gestattet, kamn man die Kanile in eine grofe kollaterale lene einfuihren. so bindet man \%. li. bei Lntrusulumg des respiratorischen Gaswechsols: dor Muskeln der hinterou Extremität des Hundes nach dem Verfahren von Zunt: ${ }^{1}$ ) die Kanible in die Vena femoralis profunda mmitelbar vor der Vereingung mit dor Vena femoralis superficialis ein. ()herhalb der Verringong dieser beiden Venen wird ame Srluleife angolegt. Solange die

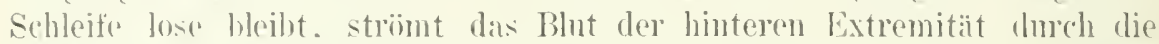
Vona femolalis smperfiejalis unhehindert dem Herzen zu. Will man nun das Hint zur Gasamalyse anffungeu, so hebt man die schleifo empor; das Blut fliefit damn durch die kimiile der Vena femoralis profunda und wird in

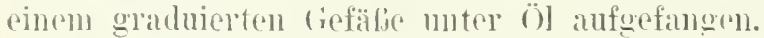

Wenn keine gröbere kollaterale Vene vorhanden ist. so bindet man die Kiniile in die Vene cin. in welche die aus dem zu untersuchenden Organ kommende niindet. nald vorheriger sorgfiltiger Unterbindung der aus anderen leilen kommenden Venen. so führt man z. B., weun man das aus den Niere kommende venöse Blut anffangen will, eine weitr Kaniile in die untero Hohlvens, unmittalhar ror der Finmiindumer der Nierenvene ein. I)ie Aorta abdominalis wird oleich nach dem Austritte der Nierenarterio unterbunden. Ferner. werden alle die in lie Cava einniindenden Venen, mit Aus-

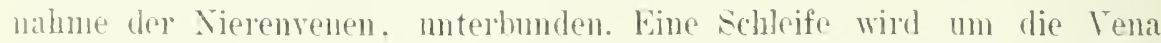
cava mmittedhar oberhalh der Eimmindung der Nierenvene welegt. ${ }^{2}$ ) Will man nun das ans der Niejenvene kommende blut anfangen. so zieht man die schleife zu; das Blut fliebt damn durde die Kiunile. Man kamn auf diese Weise zugleich anch die Nenge des in der \%eiteinheit in der Niere zirkulirrenden Bhutes bestimmen. Wenn es sich $m$ m das Nierenblut bandelt, darf man die in der Zeiteinheit sezernierte Harmmenge nicht auliel achit lassen. ${ }^{2}$ )

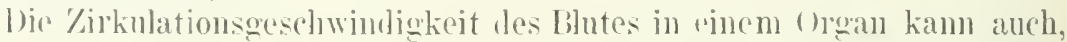
wenn die anatomischen Verhälnisse es gestatten. durch die Volunenvergröberung des in einem Plethrsmogruphen eingeschlosinen Oroans gemessen worden. indem man die abfülnenden Gefäße fiir eine kurze Zeit

) V.Zuniz, C̈ber den Finflub der Innervation anf den Stoffwechsel ruhender MIuskeln. Berliner klin. Wochenselır. S. 141 (1878).

$\left.{ }^{2}\right)$ Barcroft anul Brodir, The gazeous metalolism of the kidney. Journ. of Physinl. lol. 32. p. 18 -2S (1905); Vol. 33. p. 52-69 (1905-1906). 


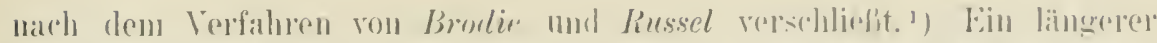

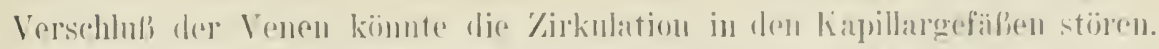

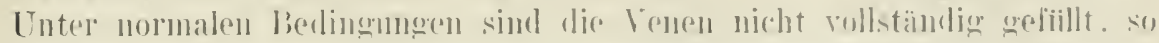

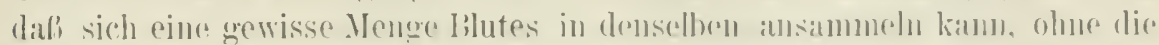

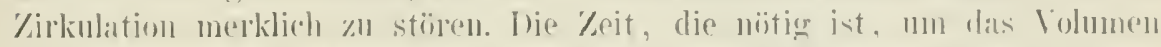

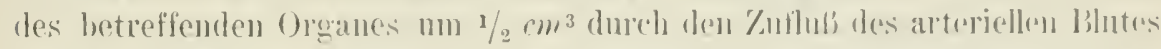

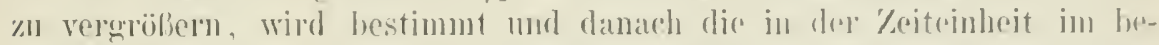

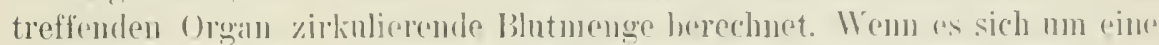
Driise handelt (wie J'ankreas, Speicheldriise, Niele usw.). muli einc lior-

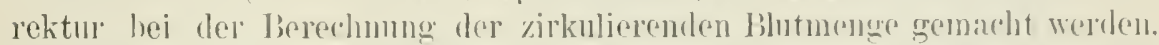

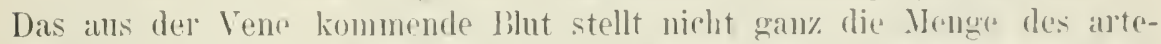
riellen Blutes vor, indem ein Teil des Wassers durels die rekrotion entzogen wird. Nan muli also dom aus den Venen aufgefangenen Bhlute diexo bei der Sekretion verhranchte Wassermenge hinzmechnen. Nan kann die nötige Korrektur in der Weise bestimmen, daf man dic 'aalıl der roten

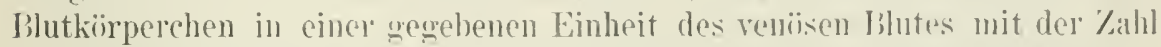
der roten Blutkörperchen im arteriellen lihte veroleicht. wie es Barroft $\left.{ }^{2}\right)$ getall. Man kamn ehensogut die hämatometrische Methode anwenden. I. h. man vergleicht das venöse blut mit dem arteriellen in burng auf jhuren Hämoglobingehalt. Nan bemerlit auf diese Mreise, dali das venöso lilut reicher an anatomischen Elementen und ärmer an Wasser ist als dis arterielle Blut. Die fehlende Wassermenge findet sich zum gröfiten 'l'eile in der Sekretionsflüssigkeit (Speichel. Harn usw:), zum Teil aber auch in der Lymphe wieder. Fiil die Submaxillaris findet Barcoftt, dali man zmm aufwefangenen Venenblut dio in ter \%eiteinheit sezernierte Speichelmenese. mit 1.2 multiplizient, hinzufïgen muli. Wan darf auch nicht auber acht lassen, daß in der sekretionsflisisigkeit eine mehr oder minder wrofe Irenge ('O) enthalten sein kann, die man bei der Brrechnung des respiratorischen Gaswechsels nicht remachlissigen darf, falls es sich un genane Ingaben handelt.

d) Verfahren, um die Tätigkeit des zu nutersuchonden lloganes zu beeinflussen.

Die zu dem Zwecke zn benutzenden Methoden kïmmen je nach dem in Betracht kommenden ()roan rerschieden sein. Die Tätigheit eines Organes kamn durch Durchschneidung der Terven oder durch Zufuhr ron giftigen Substanzen herahgesetzt werden. Durch Reizung der entsprechenden Nerven oder durch Anregung der physiologischen läitigkeit des (1rganes oder auch durch Einführung gewisser reizender substanzen kann die Tätinkeit des (organes verstinkt werlen (siehe weiter monten).

1) Brodie anc Russel, (In the determination of the rate of hlood-flow trongh an organ. Proceedings of the Physiological Society, Mai 1905. Joum. of Physiol. Vol. 32.

${ }^{2}$ ) Barcroft, The gazeous metaholism of the submaxillary gland. Journ. of Physiology. Yol. 25. p. $479-487$ (1900). 
Beispicle zur kiäuterung der Lutersuchungmothodendes respiratorischen faswechsels an den in situ belassenen (1)ganen am lebenden 'lier. Eine wrobe Anzall von Oroanen sind ant ihren respiratorischen Gaswechsel untersucht worden (Niere, Darm. Nebenniere, J'ankreas, speicheldriisen. Hirn. Muskeln usw.).

Die Muskru bieten ein wanz besonderes Interesse, weil der wribite l'eil des respiratorischen Gaswechsels in den Muslieli stattfindet, namentlich, wenu man die grobe Masse des Mnskelsystems - ungefïhr die llälfte les liölpergewichtes in betracht zicht.

Zum studium des respiratorischen Gaswechsels in den Muskeln kann man die Muskelı der hinteren Extremität benutzen, wie es Zuntz') an! Hunde rersucht hat, indem man eine Kaniile in die Vena femoralis cinbindet (siehe oben). Man entnimme zu jeder Analyse $10 \mathrm{~cm}^{3}$ venöses und arterielles blut. Der (rasgehalt des arteriellen und renösen Bhotes giht. Wran die Jluskeh in völiger liuhe rerharen, Anfsehluls iiber den respiratorischen Gaswechsed des tonischen Muskels. Durch Lieizung des entsprechenden Nerven, Ischiadicus oder Cruralis, tetanisiert nan den Muskel. Man kan so den Gaswechsel wälnend der Muskelkontraktion studieren. Durch Durchschneidung der cutsprechenden Verven hebt man den Muskitonus aut, und man kann nummehr den Gaswechsel des erschlaffen Muskels untersuchen. Der respibatorische Gaswechsel des tonischen Muskels ist doppelt so grols wie der des schlaffen Muskels. Wïhend der Muskelkontraktion wird der biswechsel hedeutend gesteigert.

Der Einflub der frewilligen Muskelkontraktion liann \%. B. während

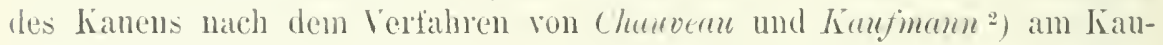
muskel des l'ferdes und der liuh studiert werden, inden man eine kianiile in die Vena maxillo-muscularis cinführt. Es ist rorteillatter, zu dem /wecke den Mlusculus lerator labii superioris heim l'ferde nach dem Verfahren der genamnten gutoren $^{3}$ ) zu verwenden, weil die anatomische I)isposition dieses Muskels bein l'ferde es gestattet. durch Einfiihren einer Kaniile in die abfuhrende Muskelrene alles und ansschließlich das ans diesem Muskel kommende blut anfzufangen. Wälnend dos Kanens wirl die Zirkulation bedeutend stärker und zugleich steigert sich der respiratorische Gaswechsel des betreffenden Muskels.

Drïsen. Der respiratorische Gaswechsel der l'arotis kann in liuhezustande und wälnend der funktionellen physiologivehen l'ätigkeit, die durch

1) $/ u n t z, 1 . c$.

$\left.{ }^{2}\right)$ Chaucuu et haufimann, la glycose, le glycogine, lat glycogénie en rapport avee la production de la chalen et lu travail mécanigue dans l'eronomie animale. leuxieme étude: Calorifications dans les organes en travail. Compt. lend. de l'Aeal. des siences. 'l' 10:3. p. 1057 (1886).

3) Chumeau et liaufmam, Souveaux documents sur les relations qui existeut entre le traval chinique et le travail nucanique du tissu musculaire. De l'activite nutritive et respiratoire des nuscles qui fouctionent physiologiquement sans produire de travail micanique. (omple rend. de l"Acad. des Sciences. T'. 104. p. 1763 (1857). 


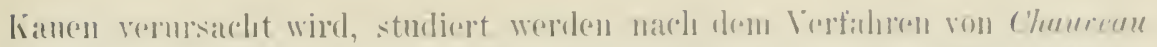

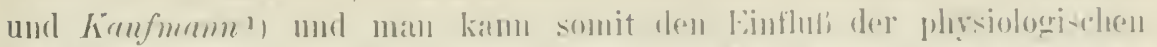

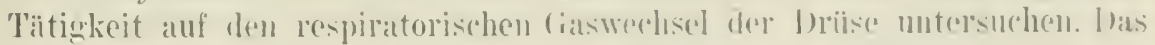

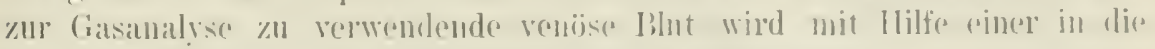

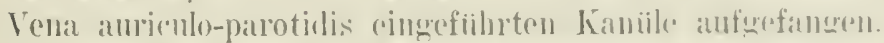

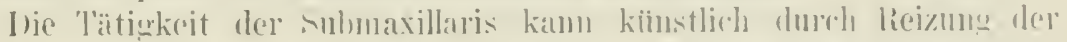

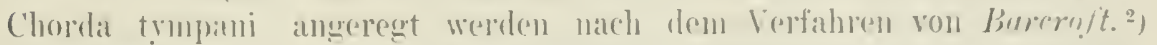

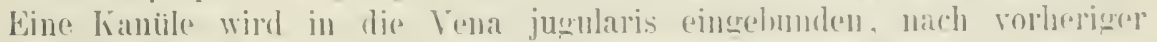
Enterhindme aller in die Jugnlaris eimmïndenden frefülic.

Ine Taitigkeit des I'ankleras kann nach dem Verfahren ron Borrouft

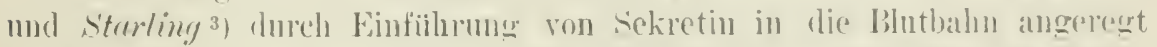
werlen. Eine Kaniile wird in dir Vene des l'ankreasthwanzes wingebunden. Las aus dieser Vene kommende libut stellt ungeffible ${ }^{1}$ o der liesantmenge des in P'ankreas zirkulierenden blutes dar. Dep respiratoris he (iaswechsel ist währoud der sekretorisehen läitigheit des l'ankreas ugesteigrelt.

Die Niere kamn nach (lem Vorfahren von Bureroft und Broli, t) durch Einspritzung ron dimetischen vubstamzen zur Tätigkeit angeregt wrolen. Man beobachtet auf diese Weise, dali der vauerstoffuerbranch während der 'Täitigkeit der Nier’ bedeutend zunimmt, die Kohlensäurebildung hingeren ziemlich konstant bloilit.

I'm die Tätigkeit des Darmes zu steigern, kann man nach dem Verfaluen ron Barcroft ${ }^{5}$ ) in die zu untersuchende Harms(hlinge eine leicht absorbierbare Substanz. wie Pepton, einfuiluren. Die Blutzirhulation wird berleutend lebhafter. Zugleich nimmt die sauerstoffzehrung stark zu. wïhrend die hohlensämreentwicklnng keine Inderung erfïlnt.

Das Gehirn. Die Untersuchung der Blutwase des aus dem (iehirn kommenden Blutes bietet grofe schwierigheiten, weil es sehr schwer ist, aussehlieblich áus dem Gehirn kommendes venöses Blut zu ('ntnehmen mnd zu weicher Zeit die Geschwindigkeit der Blutzirkulation des rehirms zu bestimmen.

Bisher hat man sich darauf beschränken miissen, die Torinderuntren des Gasgehaltes des lilutes in den Hirnvenen zu bestimmen. mach der Methorle von Hill und Nabarro. ${ }^{6}$ ) I)iese Lutoren trepanieren den sichïdel an der Torcula Herophili. Eine Kanüle wird in die Trepanöffnung einge-

1) Chanceau und Kicufinann, 1. c.

2) Barcroft, The gaseous metaloolism of the submaxillury glaud. Journ. of Physiology. Tol. 25. p. 265̃-283 und $479-487$ (1899-1900).

3) Burcroft and storling, The oxygen exchange of the pancreas. Journ. of Physiol. Vol. 31. p. 491 (1904).

4) Burcroft und Birorlic, 1. c.

5) Barcroft, The gaseous exchange of the small intestine during absorption of Uitte's peptone. VII. Internat. I'hysiologenkongreB. Heidelberg 1907. Arehires internat. de Plirsiol. T. j. p. 86 (1907).

$\left.{ }^{6}\right)$ Hill and Tabarro, On the exchange of blood-gases in brain and muscle during statr's of rest and activity. Journ. of Physiol. Tol. 18. p. 218 (1895). 
fiihnt. Man fänent anf diese Weise das aus dem vinus longitudinalis superiuris lommente bhut anf. Inie Tätigkeit des Hirus kann durch lieizung

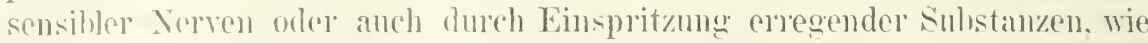
Absinth z. 13. (Hill und Vaburro). asesteigert werden. Jan kann unter diesen Unständon ein Anwachsen des respiratorisohen (iasweohsels. namentlich was die Saucrstoffanfuahme betrifft. beobachten. I)och sind die auf diese Weiso anthaltenen Kahlen von Hill nnd Vabarro recht niedriog. Was anf

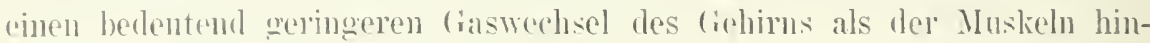
denten winde. J) bisherigen [ntersuchungen iiber den respilatorischen faswechsel des dehins sind im allgemeinen unzulängliclı.

2. I) ie kifustliche Inurhblutung ganzer. vour Käpor losgetrenluter () reane.

Dir allgemeinen Methoden der kimstliehen Durahblutung sind beroits im entsprechemden Kiapitel S. SO2 Iff. beschricben worden. Hier sollen nur alie heim studium des rospiratorischen Gaswechsels zn beachtenden l'unkte auscinanderosetzt worden. I)je Anwendung der kiinstlichen Durehblutume hictet den Vorteil, dalf die Vorsuchshedingmenen nach Belieben varieren kömmen. Jie Dnrchblutungstiissigke it ham heliohig zusammengesotzt und dieso Zusammensetzung konstant gehalten werlen. I ${ }^{\top} m$ den Gaswerbsel des zn untersuchenden Orownes zu messen, genïgt es. den Sanerstoff-und Kohlen-

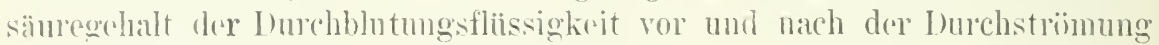
iles betreffenden ()rganes zu vergleichen.

Die kibustliche Inuchblutung muli so schuell wie möglich nach der

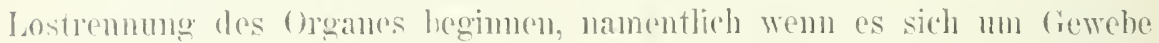
hamdelt. doren Atmungsähigkeit sehr schnell nach dem Todo des 'Tieres ahnimmt, wie \%. li, die Leber, das Herz, das Gehirn usw. (siche weiter unten). Anferdenu zeight das (iewebe, wenn es längere Zeit ohne Zirlanlation grobliaben ist, eine gröbrere Neigumg zul ödemen.

Man wird also dio Vorsicht gebrauchen, das zu untersuchende Organ (rst in letzten Angenblicke. W('mn alle Vorbereitumgen bereits getroffen

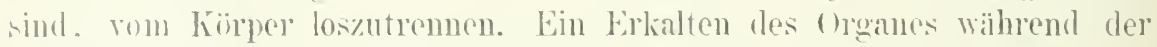
Vorbreitmugen soll womöglich rormieten werlen. Falls die Versuchsbedingungen es micht durhans crfordern, soll das Waschen des Organes mit plysiologischer liochsalzlösung vermieden werlen, weil man anf diese Weise

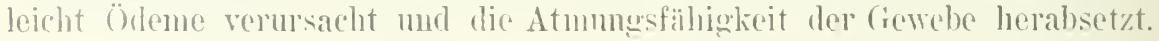

I) Ifurchhlutmosflissigkeit kann ans blut odel ans isotonischen, sanerstofforättigten salzlösungen, wie sir T trmon $\left.^{1}\right)$ verwendet, bestehen.

Man vorwondet gewöhnlich aine Ringresche lösung nach dem V'r-

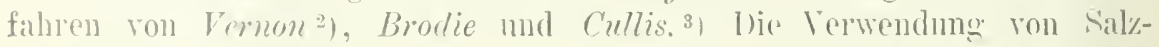
lösungen liin die kiunstliche Inuchblutung woist mehreve Tachteile anf. Die

1) Temon, The conditions of tissue respiration. Journ. of l'hỵsiol. Vol. 35. p. 53 his $87(1906 / 07)$.

2) I'rnon, l. c.

3) Brodie and Cullis, The analysis of oxygen and carbonic acid in small rolmmes of saline solutions. Journ. of I'hysiol. Yol.36. p. 405 (19/9/(08). 
wichtigsten darmer sind vor allen die häufigen ödeme sonio der l'instand, dali mehrere in den (ieweben enthaltene substanzen in Lüsung gredeen und fortgesdowement werden. Auferdem ist der Sauerstoffigehalt diesere Lïsungen recht gering. so dali sie mit kifolg nur beim smolinm des respiratorischen Giswechsels vou kalthlïtern benutzt werden kïnnen. Wremn es sich aher um Wambliiterorgane handelt, sind die in dies'll sialzlizungen enthaltenen Saucrstoffmenten röllig ungenïgend. Die Santrstoffipannung kann allerdings erhöht werden dadurch, dal, man die Jurrhblutung bei niedriger 'Temperatur (18-200) rornimmt. Doch brdeutend emplehtenswerter ist es, zur I) urchbiutungsfliissigkeit gewaschenr pote lilutkörperchen. die in der Salzlij:mng suspendiert bleiben, hinzuzuniigen.

In den Durchblutungsversuchen mit Ringerseher salzlösung nimunt der respiratoriscle (iaswechsel allmïhlich ab. I"m diesinn lohelstande alzuhelfen, empfiehlt Vernon, zur Jingersehen liosung etwas libsterum in einer Proportion ron 20 ". auferdem hleine Jengen jo nach den zu untersuchenden Organen rerschiedener substanz'n (Harustoft für die Yiere. Dextrose für das IJerz usw.) hinzizufïgen.

I) Temperatur des Blutes und des das ()roan enthaltenden Ciefillies

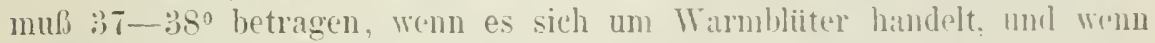
man einen möglichst hohen Gaswechsel cracelen will. Bei der l'ntersuchunw ron Kaltblïterorganen begnïgt man sich mit der gewïhnlichen Zimmertemperatur $\left.(18-2-2)^{\circ}\right)$.

All diese soeben beschriebenen Irothonen grhen recht mulutrieligende Resultate in bezug auf den Gaswechsel. liedentend lesinere liesultate erziclt man mit der I) mrehblutungsmethorle rou Heymun: und forkmann wiehe diesen Band, S. 35.5), die sich am meisten den normalen Bedingungen des: 'Tierorganismus nähert.

so beträgt z. B. in den Versudhen ron Luduig und Sehmidt 1), ron r. Frey ${ }^{2}$ ) und Gruber die simerstoffaufnahme des llushels $11.2 \mathrm{~cm}^{3}$ für $100 \mathrm{~g}$ und 1 Minute, während in den Versuchen von Burroft mol I)icon $3 \%$ die die Methode von Heymans und hochmann benutzen. iler Harmuskel mindestens $1 \mathrm{~cm}^{3} \mathrm{O}_{2}$ für 100 g und 1 Vinute aufnimmt.

\section{B. Untersuchung des Gaswechsels fragmentierter Gewebe.}

Diese Methode ist s(it Spallmauni*) ron einer (rroben Inzahl ron Forschern angewandt worden. sije hesteht darin. die fiewrotingmente in

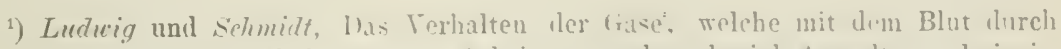
den reizbaren Siugetiermuskel strömen. Arheiten aus ter plysiol. Anstalt zu leipzic. S. $1-61$ (1S68).

$\left.{ }^{2}\right)$ r. Frey, Tersuche über den Stotfwechsel des Muskels. Arch. f. l'hysinl. S. $73: 3$ bis 562 (1885).

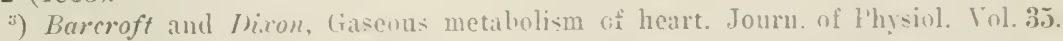
p. $182-204(190607)$.

4) spallanzani, Ménoires sur la respiration. Franzö-ische l゙hersetzung ron J. Senebier. Genf 1803. 
Gefälie von branmtem Ramminhalt. die mit Luft oder Samerstoff wrifullt sind, zu bringen und nade ciner bestimmten \%eit die verhranchte sancr-

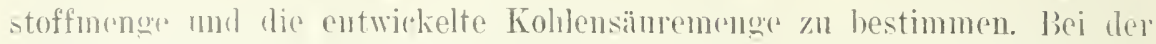

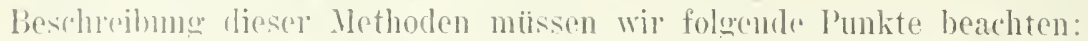

1. I) Kubereitmo der Gewebeframonte und

2. die Ipparate zur Lntersuchung des respiratorischen Gasuecelsols dor liewehofragmente.

\section{1. 'ubereitung der liewebeframente.}

bie Vorbereituno des Tieres, dessen Gewobe nutersucht werlen sollen. biotet keine besondere Eigentiimlichkeit. I)ie Gewehe miissen so schnell wie möglich nach dem Torle des Tieres varwendet werdan. Wem die Tntersuchung längere Zeit (mohrere Stunden) dancru soll, ist darauf zu alehten. dab keme Fäulnisprozesse eintreten, und man wind daher bei allen Manipulationen so aseptisch wie möglich verfahren. Eine wrofe Zahl friberer Lntrisurhmon laben keinen Wert, oben weil die Forscher keine Malinahmen zor Verhiitmug von Bakterienwirkung getroffen hatten. Fs ist allerdings nicht immer möglich, völlog Isepsic \%n erzielen, namentlich wemln os sich um gewisse Orone. wie I.unge oder I)arm, handelt. Andrerseits ist das l'rïparat oft trotz aller Torsichtsmabregehn durch die Mikroorganisnen der luft infiziert.

Die Cröbe der (Oberfläche, die mit dej Gasatmosphäre in Beriihrung kommt, ist von grolier Wichtigkeit fiur dic Intensität des Gaswerhsels.

In den valoleichenden Untersuchmogen niiscen die (iewebefragmente von einem brstimmten Gewicht dieselhe oberflächenauslehumm besitzen.

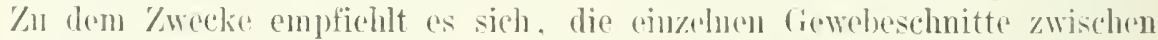
zwei Metalluctze ans rerzinntem oder lackiorten Messing oder Kunpter auszulneiten, wie es Lussuma ${ }^{1}$ ) getan hat. Dnueh rine Metillferler worden die Metallnetze ancinandergeprest, so daf die Fliche des Gewebes eine weichmäBig ehene ist. Wem das zu untersuchende Gewebe zorrieben wirl. kann man den (iewebehroi in kleine höhrehen ans lackiortem Metalldraht mach den Verfahren von Garnier und Lambert ${ }^{2}$ ) bringen. Letztere Methode eignet sich besonders. wenn man die Wirkmog verschiedenel Suhstanzen anf den respiratorisehen Gaswechsel des fragmentierten Gewebes studieren will.

-2. Ipparate zur Lutersuchung des respiratorischen Stoffwechsels fragmenticrter Gewebe.

Wenn es sich nm gröhere fiewichtsmengen eines fiewebes handelt. 10 oder ״̈() g \%. B.. kinn man zur Intersuchnng des respiratorischm (ias-

1) Luscente, Sugli scamli respiratori del fegato e sul loro valoro in rapport all'amilolisi epatica. Areh. di fisiol. Vol. 2. p. 445 (1905).

$\left.{ }^{2}\right)$ Cramior et Letmbert, Action du chlorture de sodium sur lactivité cellulaire. Areh, de Ihysisol. p. 421 (1898). 


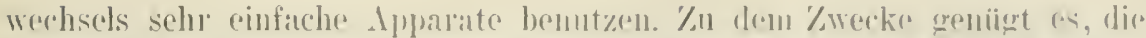

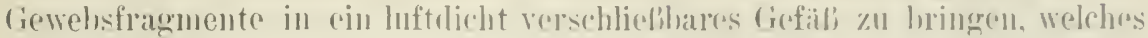

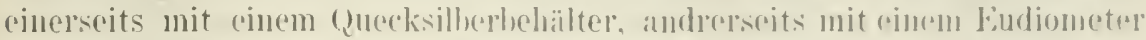
in Verhindung grebracht werden kamm. I)as (quecksilber dient dazu, dio zun

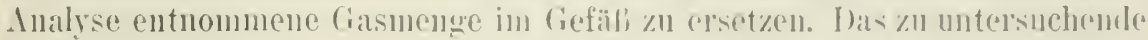

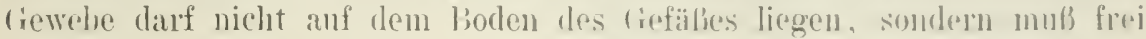

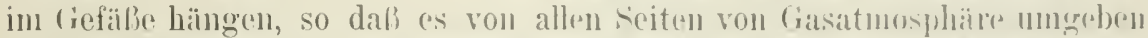
ist. Iner liamminhalt des frefülies darf nicht zu klein sein, 10)(o) cm min-

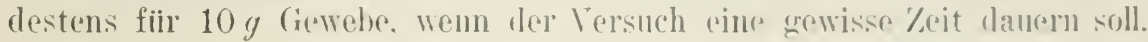

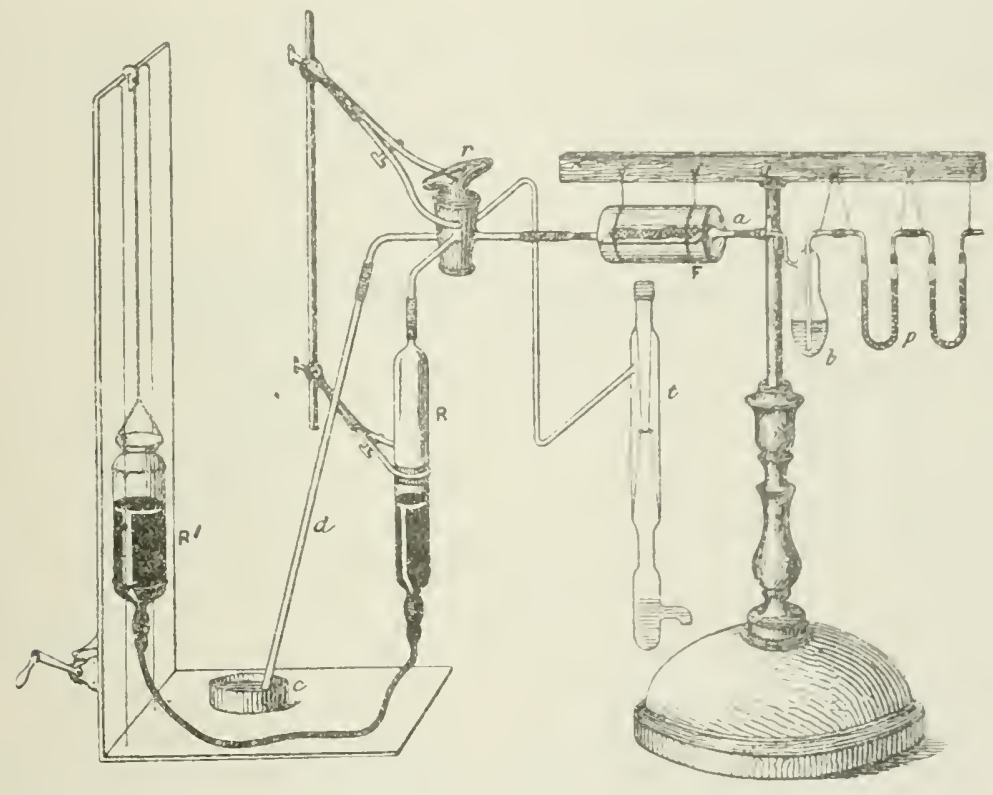

Fig. 115

Es empfiehlt sich, die Luft durch reinen Sauerstoff zu erset\%on. Weil dadurch der (iaswechsel der Gewebe gesteigert wird.

Der Apparat ron Tissot fii länger dauerude Cutersuchungen des respiratorischen Gaswechsels überlebonder Gewebe. Wenn man den respiratorischen Gaswechsel eines uiherlobenden Gurebes lïngere Zeit verfolgen will, kann nan den 'Tissotschen Ipparat') (Fig. 115) benutzen, der den Vor\%ug hat, nicht kompliziert zu sein. Das fiewebe wird so aseptisch wie möglich rom Körper losgetrennt und in die sorgfältig sterilisierte Flasche $F$ gehracht.

$\left.{ }^{1}\right)$ Tissot, Recherches sur la respiration musculaire. Arehives de Physiologie normale et pathologique. T. 6. p. 838 (1894). 
Diese Flasehe hat zwei Hälse, von len+n der eine mit einen liepweghahn verbunden ist. Die eine ler Bohrumgen steht mit dem Aspirator $t$ in Verbindung, eine andere hommuniziert mit dem liohre d. das in die Quecksiberschale $c$ mündet, die dritte Bohrum steht mit dem (unecksilherereservoir $R$ in Verbindung und dio vierte kinn mit den Kaliflaselen $p$ unu der Barytflasche 7 verbunden werden.

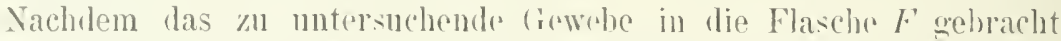
worden ist, stellt man die Verbindung dre Fasche mit dem Ispirator her. Ein durch Kalilauge von Kohlensäne befreiter Luftstrom wirl dureh die

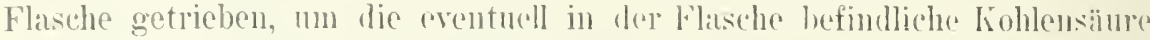
auszutreiben. Der Hahn wird geschlosien sowie anch das liohr a, welches zu den Baryt- nud Kaliflaselien fiihnt. Wenn nan num das in der Flasche $F$ enthaltene Gas analysieren will, so beginnt man damit, dals man die Velhindung des Quechsilberbehälters $R$ mit dem Glaslohr d herstellt und letzteres vollstünlig mit Quecksilber füllt. Man verbindet daranf den (Duecksilberbehälter $h^{\prime}$ mit der Flasche $F$. Durch senken des Reservoirs $R^{t}$ füln’t man in $R$ eine gewisse Monge Gas ein. welches man durol das liohr $d$ in einen Mefaylinder, der auf der (Quecksilberschale ruht, iiberleitet. Ins (ras wird dann amalysiert. Wem man den Ramminhalt der Fasche $F$ kennt, ist es leicht, die Gesantmenge des relubulden Sauerstoffs und der entwickelten Kóhlensäure zu berechnen. Wenn man mun den Versuch fortsetzen will, läbt man die Flasche $F$ mit dem Aspirator $t$ kommmnizieren und ernenert so die Luft der Flasche. Man rerfïlut im übrigen wie rolher. Diese Manipulationen kömen so lange fortgesetzt werlen, his die Gasatmosphäre der Flasche $F$ keine Anderung mohr anfweist. d. h. lis der Gaswechsel röllig aufgehöt hat. Will man len Versuch hei (aner bestimmten T'emperatur ausfiihren, so kann man die Flascho $F$ in ein Wasserbad vou konstanter 'T'emperatur versenken.

Das Gindringen ron Mikroben in die Flascho $F$ wälnend der Velsuchsdaner muf möglichst verhindert werlen. \%u dem /wecke wird ein sterilisierter Wattebausch in die Miundungen der Flasche $F$ gesteckt. Der Luftstrom mul, diesen Wattebanseh passicren, bevor er ins Immere der Flasche gelangt.

Mikrorespirometer vou Thunberg. Wem man len respiratorischen Gaswechsel sehr kleiner Mengen (iewebes nntersuchen will, kamn man sich mit gutem Erfolge des Thunbergschen Mikrorespirometers (Fig. 116) berlienen.

Mit Milfe des kleinen Mikrorespirometers') bestimmt man blop die Saucrstoffzehrung oder den respiratorischen Quotienten. wibrenul das grobe Mikrorespirometer 2) zur Bestimmung der verbranchten Sanerstoffmenge sowie der gebildeten liohlensänre benutzt werilen kann.

$\left.{ }^{1}\right)$ Thunberg, Eine einfache Anorthung, un die Sauerstoffzehrung kleinerer Organismen orler (Oreane zu demonstrieren. Zentralhl. f. I'hysiol. Bd. 19). S. 308 (1905).

") Thunberg, Ein Nikrorespirometer. Skaud. Archir f. Physiol. Bit. 17. S. It (1905). 


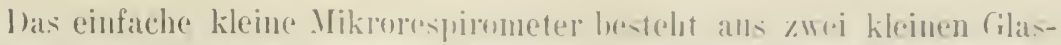

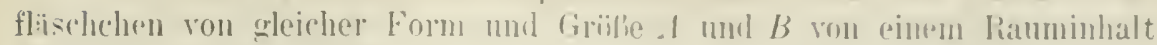

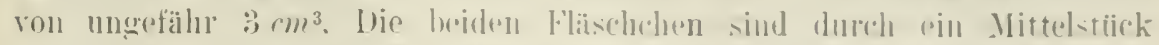
miteinander rerbunden. Thas Mittelstirrk ist eine weite, dickwandige liapillare, die ein wenig nach unten sorbogr'm ist. An den briden Emlen der Kiapillare befindet sich jo ein Drejweghahu, so dali die entsprechenden Flischchen nach Beliehen mit der Aubenluft oder mit der Kapillare oder anch mit beiden zugleich verbunden werden kömnen. In der liapillare hefinlet sich ein leicht beweglicher Petroleuntropfen $I$. der als Index dient und sich längs einer Millimetereinteilung beweogen kann. Durch Vorrersurhe bestimmt man die Kapazitït. lie einem Villimeter der Shala dler Kapillare entspricht. I)ie Biegung der Kippillare dient dazu. die einzelnen Teikchen des Tropfens sich in der Vitte sammeln zu lasisen, wenn der Tropfen durch eine plötzliche Druckschwankung zersprengt worden war.

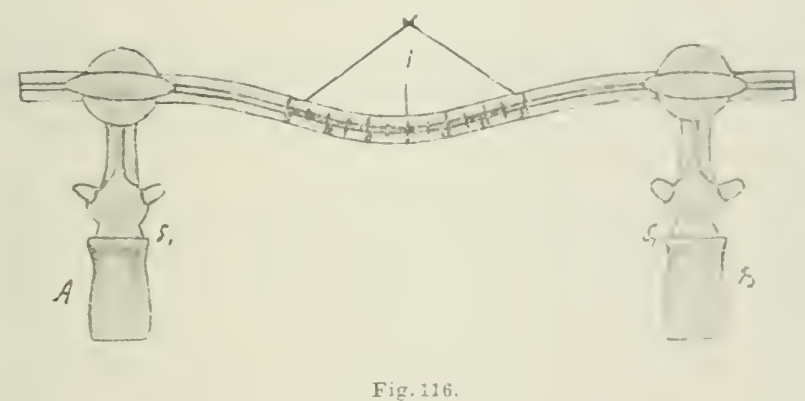

Las zu untersuchende Gewebe wird in eines der Fläschelen gebracht. Der atmosphärische Druck wird in heiden Flïschchen hergestellt, indem man durch geeignete Stellung des Hahns das Innere der Flischchen mit der Aulienluft hommunizieren laift: daranf werden die Flissehehen mit der Indexkapillare rereinigt. Die Temperatur wird dureh Versenken des Ipparates in einen Wasserthermostaten konstant erhalten.

Der Thunhergsche Apparat hildet somit ein in sich geschlosienes Srstem und die Anderung des Gasvolums in dem Analysenfläsehehen wird durch Verschiebung des Petroleuntröpfehens angedentet. Pringt man etwas Kalilauge in das Fläschchen. welches das Gewehe enthält. so wird die gebildete Kohlensïure absorbiert und die Verschiehnung des Trüpfchens nach dem Organ hin zeigt die Nenge des anfgenommenen siunerstoffes an. Lin die Absorption der Kohlensäure durch die Kalilange zu erleichtern. empfiehlt es sich. die Flïschehen von Zeit zu Zeit leicht zu schiitteln.

Lülit man die Kalilauge fort, so zeigt die Verschiebung des Petrolemutröpfchens nach der einen oder anderen Seite des Apparates den respiratorischen Quotienten an: del Quotient ist kleiner als 1 . wenn das Tröpfehen sich nach dem Organ zu rerschieht: er ist grölier als 1, wenn 
das 'Tröpfehen sich nach der entgegengesetzten reite rorschieht, und der (puotiont ist gleich 1. wenn der Tropfen seine Infangsstellung bewahrt hat.

bie stellungsäudermug des Indextröpfehens zeigt nicht dir alsolute reelle Gröbe des absorlielten odel entwickelten (iasts an, denn die Volumverinderung in einem aeschlossenen system wird durch die respektive D)uckinderung in den beiden Fläschchen becinflubt. Nach rler Berechnmm von Winterstein erlült man die absolnte Gröfe der Gasvolumenverinderung des das Gewehe enthaltenden Fläschehens, iudeun man den an der Skala res Kapillan'ohres angegebenen Wert mit உ2 multipliziert.

ber Apparat ist selu' empfindlich und erfordert daher grobe Vorsicht bei der Ilantierung, da verschiodone Fahtoren die liesultate

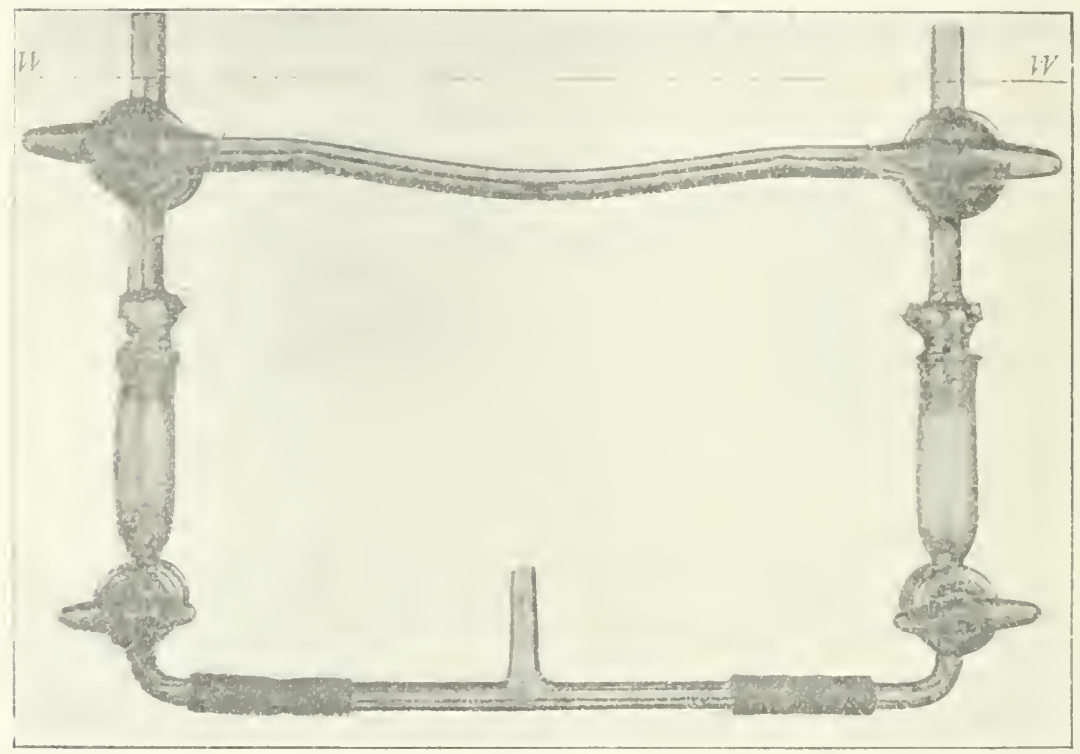

Fig. 117 .

triiben kïnnen. Eine Hauptbedingung ist, daf die Temperatur im ganzen System eine gleichmäßige sei. Man wird also einige llinuten abwarten miisien, bevor man den Tersuch beginnt, damit dic verschiedenen T'eile des Apparates sich mit der mogebenden Temperatur ins Gleichgewicht

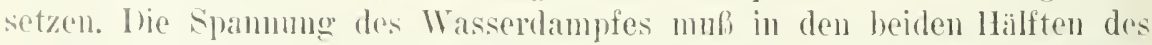
1ppanates eine gleiche soin. Man wirl deshalb in die beiden Flaschehen otwas Flissigkeit bringen.

"Interstein ') hat diesen soeben heschricbenen Thunbergschen Mikrorepoinometer etwas abgeäludert (Fig. 117), so dab der respiratorische tias-

1) Winterstrin, Uber den Mechanismus der (ieweleatmung. Zeitschr. f. allgem. l'hiciol. Bd. 6. S. $315(1905)$. 


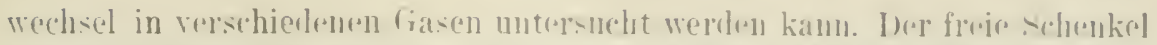

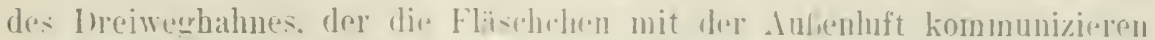
lïlit. ist nach oben gethogren. statt wis in Thunhry-chen Aluarate narh Irer seite. so dab der wanze Appourat his iiber die Hähus einschliefulieh

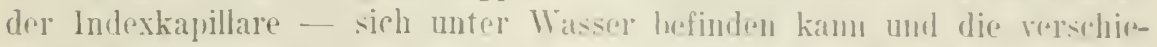
denen Manipulationen rolgenommen werelen hënmen. olne den Ippatrat ans dem Wasser zu heben. Jofles der Fläshohen kann aulierdem an seinem

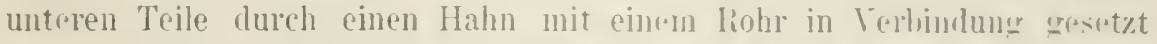

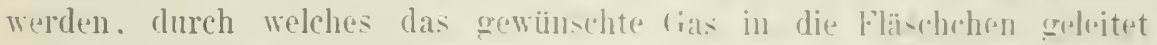
werden kann. Jeder 'leilstrich der Indexkapillare entspricht einem lianminhalt ron $2 \cdot 1 \mathrm{~mm}^{3}$. Eine lerschichnne des Tröptehens un ${ }^{1}{ }_{3}$ rines Teilstriches hann noch genau bestimmt werden. Da dic roullo ciriblie der gesamten Vohmveränderung des rases in dom Fläschehen doppelt so rrof ist wie die an der Indexstiala abgelesene (siehe ohen). so folgt raraus, dal'

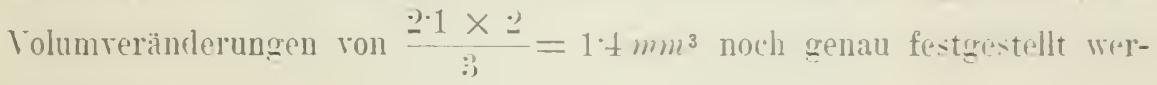
dell könmen.

Das eigentliche Mikrorespirometer von Thunbery ist durch folgende Fig. 11s darrestellt.

bie Pipetten A. B. C sind in ein Wasserhad Wr ron konstanter lemperatur versenkt, das gehohen und gesenht meloden kimn. Das zu untrsuchende Gewebe wird in die Pipette 1 gebracht. Pipette $B$ dient als liompensationspipette. Die beiden Pipetten $A$ und $B$ stehen an ihrem unteren Teile mit Kapillarröhren. die mit (ueckilber gefiillt sind und eine Millimetereinteilung tragen, in Verbindung. An ihrem oberen Teile kïnnen die Pipetten durch die Hähne I und $Y^{\prime}$ mit der Infenluft ofler mit der Indeskapillarröhre $I$. welche ein leicht hewegliches Petroleumtröpfohin enthïlt kommunizieren. Die Analssenpipette A kann auberdem durch ten Hahn $D$ mit dem Kaliapparat $C$ rerbunden werden.

Lie Analrsenpipette $A$ mit dem entsprechenden (quecksilberohr hann an den Punkten s und $T$ losgetrennt werilen. um das [ntersuchungsobjekt in die Pipette einzufïhren.

Dit Quecksilber enthaltenden Kapillarröhren können mit Hilfu der Quetschhähne $E$ und $F$ mit den Querksilberbehältern $I$ ' und $Q$ und mit Hilfe der Hähne $G$ und $H$ mit der Anlenluft rerbunden rerden. Die Hähne $G$ und $H$ haben zugleich den Zwech, die bei der Füllung der liöhren mit quecksiber zurïchą)bliebenen Luftblasen beseitigen zu künnen.

Der Rauminhalt der liompensationspipette $B$ ist ungefähr $5.5-70 \mathrm{~cm}^{3}$; das Volumen der Analrsenpipette $A$ ist $6.5-70 \mathrm{~cm}^{3}$. Die Kapillaroüren $m$ und $n$ haben eine Linge ron 20 ( $m$ und besitzen eine Millimetereinteilung, $1 \mathrm{~mm}$ entspricht in den resschiedenen ron Thunlierg rerwandten Röhren einen Fauminhalt ron $14-30 \mathrm{~mm}^{3}$.

Die Versuchsanordnung ist folgende: Man beginut mit der Einführung des zu untersuchenden Gewebes in die Analysenpipette $A$. das Gewebe wird in rie Mitte der Pipette placiert. Ilie Pipette wird sodann eingestzt und 
sorgfïltig befestigt. Das Wasserbad wird gehoben. Wenn die Atmung des Gewebes in ciner Luftatmosphäre stattfinden soll, so lält man die l'ipetten I und $B$, mit der dulienluft kommunizieren und führt durch Emporheben

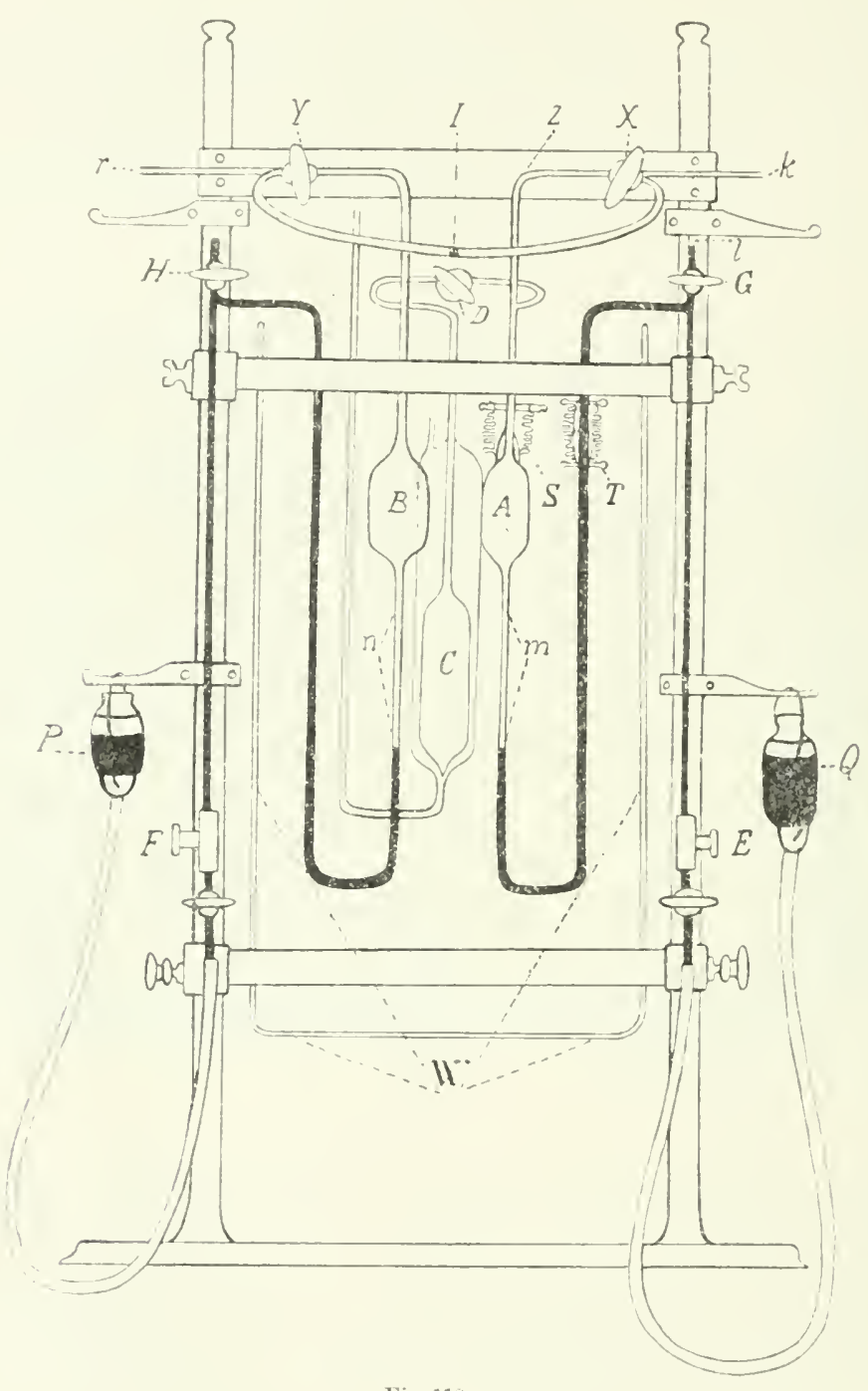

Fig. 118.

der (Quecksilherbehälter $P$ und $Q$ das Quceksilber in die Kapillarröhren $m$ und $n$ his zur gewiinschten Höhe. Nachdem der Ipparat sich mit der Temperatur des Wasserhades ins Gleichgewicht gesetzt hat, werden die Pipetten $A$ und $B$ mit der Indexkapillare $I$ vereingt. Man verzeichnet die Stellung des 


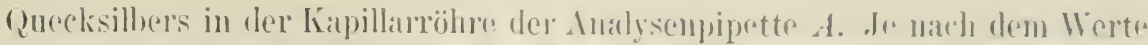

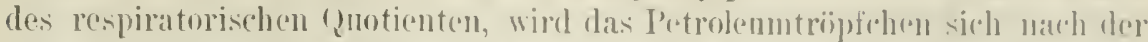
lipette $A$ oder der l'ijette $B$ rerschichem. Wenn man nun das bej dee

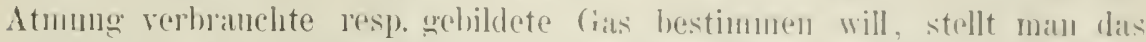

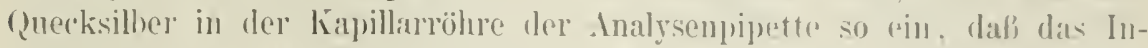

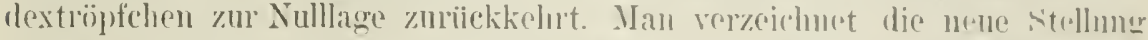

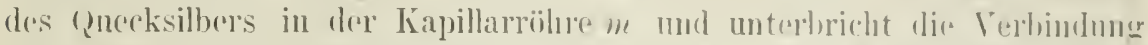

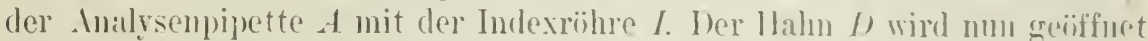
und durch Emporhehen des Quecksilberhehälters Q wird das (ias der dualysempipette $A$ in den Kaliapparat $C$ iibergefiihrt. Das (rals wirl sodimn ron nenem in die Analysenpipette geleitet und die Kommunikation mit der Indexü̈hre wieder hergestellt. Iit Hilfe des Queckiblherhehilter's wird das

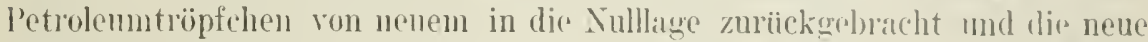
Stellung des Quecksilhers in der Kapillarröhre $m$ rel\%eichnet. Iner Tnterschied zwischen der Anfangsstelhng des Quecksilher's und der stellung nach dem Durchleiten des Gases in den Kaliapparit zeigt die Vlenge des verbrauchten sauerstoffes au. Die gebildete Kohlensïure wird durch den Interschied des Gasrolumens vor und nach der Einfiihrung des Gasgemisches in den Kaliapparat angegeloen.

Wenn man zur Atmung des Gewehes ein anderes Gas als atmosphärische Luft verwenden will, ( $)_{2}$ z. P., so beginnt nan diunit. daf man das Quecksilber nur bis unterhalb des Hahnes $G$ einführt. I)as zn untersuchende (iewebe wird sodam in die Analysenpipette $A$ gebracht. Dir Röhrenmiindung $l_{i}$ wird mit einem Sauerstoffeasometer rerbunden und ein kraftiger strom des eutsprechenden Gases durch die Analysenpipette gretrieben. bis alle in der I'ipette rorhanden gewesene Luft verdrängt worden ist. Las Gas strönt durch die Dbugsmiindnug $/$ aus. Die Hähue $G$ und $X$ werlen sodamn geschlossen, das Quecksiber wirl in das Kapillarrohr $m$ bis zur gewïnschten Höhe eingefiihrt und die an dor Lmbiegungsstelle des (nnechsilberrohres eventuell vorhandenen Lnftblïschen werden durch öfnen des Rohres $G$ entfernt. Ilie l'ipetten $A$ und $B$ werden dureh geeignete Einstellung der Hähne $I$ und $Y$ mit der Aulienluft verbnulden. darauf wird die Verbindung mit der Indexröhre hergestellt. Im ïbrigen verfährt man in der früher angegehenc'u Wcise.

Der Beqnemlichkeit wegen nimmt man an, dali das Gewebe und die umgebende Gisatmosphärn in hezug auf den Stickstoff sich im Inffusionsgleichgewicht befinden und daf das entwickelte Gas ausschlieflieh (' ( $)_{2}$ und das absorbierte Gas ansschlieblich $\mathrm{O}_{2}$ sei.

Um die durch die verschierlene spannung des Wasserdanpfes ('ntstehende Veränderung des Gasvolumens zu rermeiden. empfiehlt es sich. die verschiedenen Teile des Apparates mit Wasserdampf zu sättigen. Zun den Zwecke wird dwas Wasser anf den Boden der heiden I'ipetten . I und $B$ gegossen.

liei der Bestimmung der Kohlensänre ist es hesser. das Quecksilber in die Analysenpipette $A$ nicht bis in die obere Kapillarröhre zn treiben. 
Inan vermeidet anf diese Weise das Zurüekhleiben ron Flissigkeitsteilehen in der liapillarrihre und die ladmeh bedingte Verbinderme der Konmunikation der Analysenpipette mit der Indexkapillare. Es empfiehlt sich also. das l'berfiihnen des basemenges der Analysenpipette $A$ in den Kaliapparat zwemal roumulumen, wohei jedesmal das quecksilberniveau die Ansat\%stelle der oberen hápillarröhre nicht ïberschereiten darf. Man wird auch daranf achten. dau keine Quecksilbertü̈pfehen am Gewebe haften bleiben nund dali das Queckilber nicht isolierte Tropfen bildet.

l)ie sechnelligkeit. mit der das Gaswemenge ans der l'ipette $A$ in den Kaliapparat geleitet mol aus letzterem in die l'ipette $A$ zuriickgefiihrt

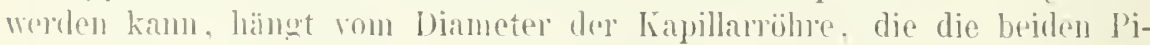
petten rerbindet. ah. bei einem I hurchnesser der Kapillarröhre ron $1.9 \mathrm{~mm}$ kann die Gasanalyse in : -4 Minuten vollendet sein. Während bei einem 1)urehmesser ron $1+4 \mathrm{~mm}$ die Traner der Gasanalyse 5-6 Vinnten betrïgt.

\section{Atmung der in Flüssigkeiten suspendierten Gewebe.}

Tiese von Bruttrlii und Stern ringeführte Methode besityt gegeniiber den friiher beschniebenen einige Vorzige. Sie gestattet vor allem. den Mechanismus der (ieweheatmung hesser zu analysieren, sowie den Einflub der Zusammensetzung der suspensionsfliissigkeit zu stulieren und zugleich einen schr enerwischen diawechsel zu aryolen. Ilie fein zerriebenen, in

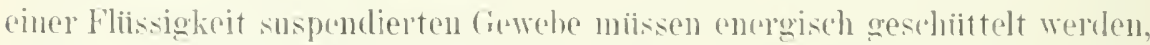
damit inmer norne sanerstoffmengen in der Flissigkeit sich lösen und so den von den Gewehen rerzehrten Sanerstoff ersetzen.

Bei Antrendung dieser Methode ist folgendes in Retracht zu ziehen:

1. Die zum sehiitteln diemenden Apparate.

2. die Galsamalyse,

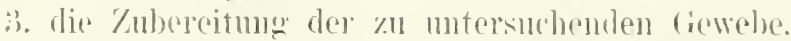

t. die Zusammensetzung der suspensinnsflissigkeit.

万. die Hauptatmung.

6. die akzessuriselle Itmung.

7. der Linflub des verschiedenen Substanzen.

1. Dey Subiittelapparat. The zerriebenen Gewebe miissen, sobald sio in die die Flibsigkeit enthaltenden Flasehen eingefuihnt sind, energisch seschïttelt werden. Zn diesem \%wecke kann man sich des von Buttelli und Stem ') bemutzten Apparates. der in Fig. 119 alogebildet ist, bedienen.

bie delse des Rades $A$ ist mit der Achse einer Riemensolheihe, die durch einen Elektromotor in Bewegme gesetzt wird, rerbunden. Das Rad A ist nit einer Exzentrik $E$ versehen. In dieser Fazentrik ist die horizontale Kimbelstange $B-B$, die ilnerseits in die rertikale stange (' eingefiigt ist, befostigt. C' ist an ihrem unteren Ende in der Metallplatte $P$ hefestigt. lectztere weist eine zirkuläre liohrung anf. durch welche eine horizontale

1) F. Battrlli of yne L. sitern, Recherches sur la respiration élémentaire des tissus. 1'r mémoire. Journ. de l'hysiol. of P'athol. générale. p. 1 (1907). 


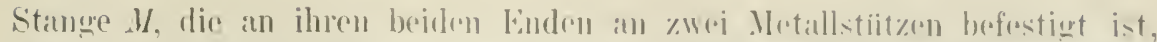

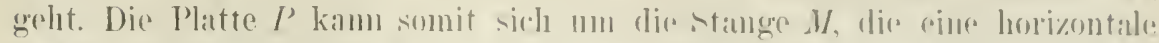

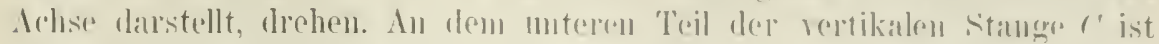

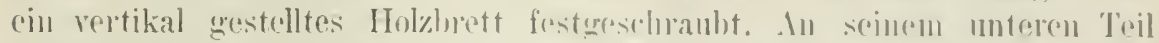

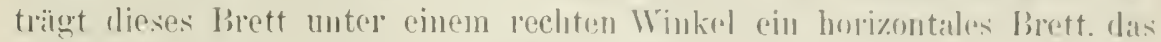
zur Iufuahme der Flaschen $F^{\prime}$ bestimnt ist.

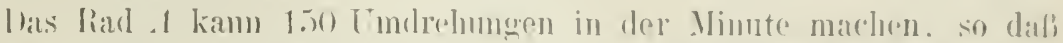

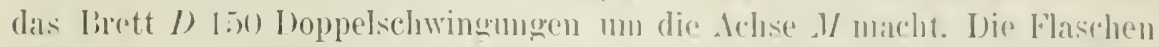

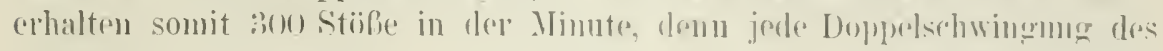

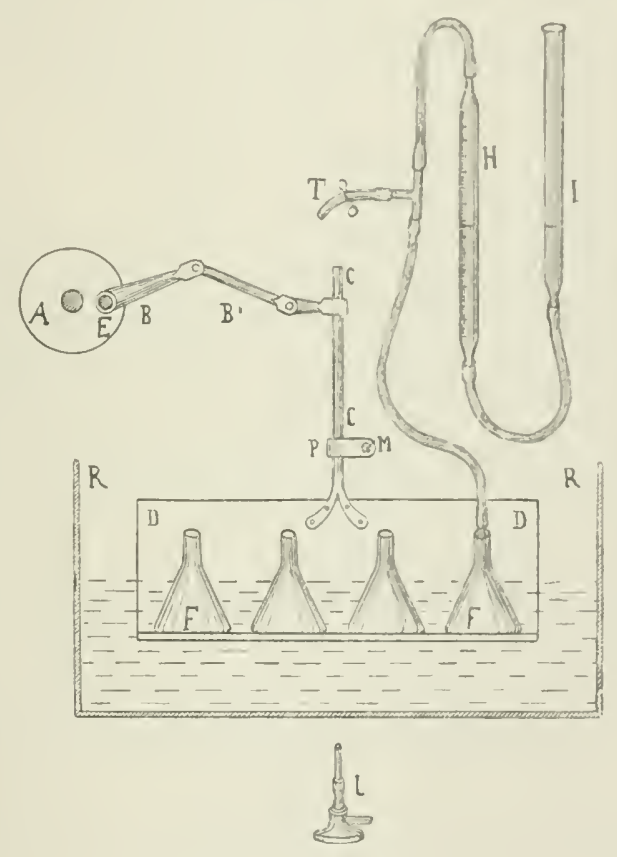

l.ig. 119 .

Brettes ruft in den Flaschen ein Hin- und Herstofien herror. Die in den Flaschen enthaltene Fliissigkeit wird anf diese Weise kräftig geschiittelt. Das Brett und die darauf hefindlichen Flasehen können mehr od wer weniger tief ins Wasser des Thermostaten $R$ versenkt werrlen. Wihrend des Schiittelns sind die Flaschen nur 2-:3 cm tief unter Wasser"; wenn man sie tiefer senken wollte, wïrde man das Schiitteln stark erschweren. Die Temperatur des Thermostaten muß ungefüh :38- $40^{\circ}$ betragen. wenn man die maximale Atmungstiitigkeit erzielen will. ()berhalb und unterhall, dieser Temperaturgrenze ist der respiratorische Gaswechsel geringer.

2. Einleiten der Gase in die Flaschen. Vessung der rase. Der respiratorische Gaswechsel iler Gewebe ist in einer Santstoffatmo- 
sphäre berlentem stärkel als in einer Luftatmosphär ${ }^{\star}$. namentlinh wem die

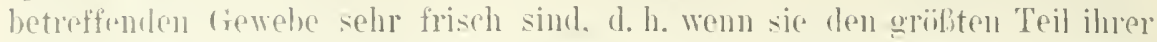
respuratorischen Fäligkeit unch bowaht baben. Wenn aber die Ciewebe mehrere stunden nach dem 'l'ode des Tieres untersucht wrolen, zul einer \%eit, wo die respiratorische Täitigkeit derselben hereits stark herabgesotzt ist. ist der Tuterschied des Gaswechsels in einer simerstoffatmosphibe

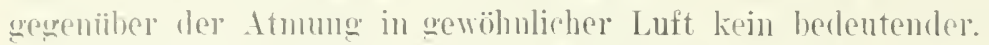

Wenu der Versuch in einer Sauerstoffatmosphäre gemacht werlen soll, füht man das zu metresuchende zerriobene Gewabe und die gewiinschte Fiissolorit in die Flasche pin, daranf wirl mit Hilfe eines energisehen Aspriratols die in der Flasche vorhandene Luft ansgepumpt, his zul dem Angemblicke. wo die Flijsigkeit zu schäunen begimt. Die Torbindung mit dem Aspirator wird sodamu unterbrochen mol die Flasche mit einem sanerstoffwasometer reremigt. Sach vollendeter Fiillumg der Flasche wird die Velhindumg mit dem sanerstoffbehälter ahgebounen und die Flasche wird auf dem sohiittelaplualut hefestigt.

IV ruil die Flasche mit Luft grofïllt ist. wird die Bestimmung des Sumerstoffes mul der Kohlensiture. die ju dem fiscremenge der Flasche am Ende des Versurhes onthalten simel. nach den gewöhulichen gasanalytischen Methoden

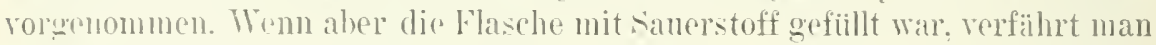
anf folgende Weise. Jede Flasche wird duch dinen Gimmischlauth mit einer Hempelsehen Bürette. die als Wassermanometer dient, velbumlen. Vor dem Bexinne des lorsuches wird die Flasche vollständig ju das Wasser des Themostaten reremkt mud darin so lange gelassen, bis das (rasrolumen in Innern Jer Flasche konstant beibt. Das 'T-Rohr wird num geöffnet und die Flijssigkeit in lon lioihnen $H$ und $I$ stellt sichl anf dasselbe Nivean ein. Das T-liohr wirel mun geschlosson. Die Flasche wird sodann teilweise ans dem Wasser gehohen und der schiittelapparat in Bewegung gesetzt. Nach Beomdigung

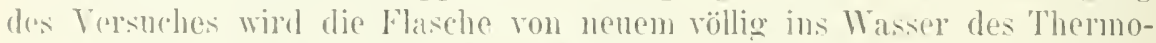
staten versenkt. Man wartet 2-:) Minuten, das ist die /rait, die nötig ist, um das Temperaturalojchewicht zwischen der Flasche mol dem Thermostaten her\%nstellen und stellt darauf dulch Heben oder Senken der Löhlur I die Flissigkeit in den liobren $H$ und $I$ anf glpobes Vivean ein. In der

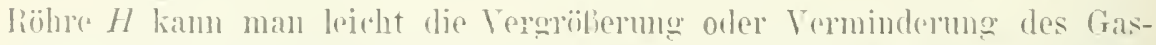
rolnmens in Kubikzentimetern ablesen. Man milit die in der (iasatmosphäre voihandene Kohlensïnemenge nach den wewöhnlichen Methoden. Eine einfarhe Leredhung wibt die Menge des verbranchten sauerstoffes an. Es bleiht mu noch iibrig, die in dex das vewehe euthaltenden Fliissigkeit gelöstru (jase zu messen. Jie in Lïsung befindliche sanerstoffmenge kiann ohne reiteres veruablissigt werden. namentlich wem man bei $38^{\circ}$ operient mul wemm das (iewebe einen enrorgischen Gasmerhsel anfweist. In der Tat nimmt das Gewebe wihlend der wenigen Minuten, die das Ablesen au der biinotte $K$ erfordert, allen in der Fliissiokeit gelösten sauerstoff auf. Imo dic in der Fliissigheit grelöste Kohlensäure zu mos:ou, wird die Flïssiçkeit mit l'hosphorsiure angesäuert und die fiohlensäme mit Hilfe der 


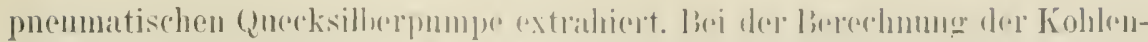

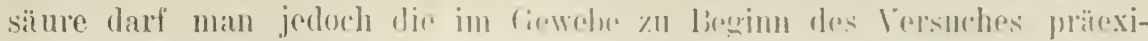

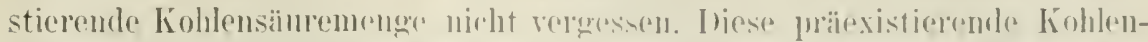

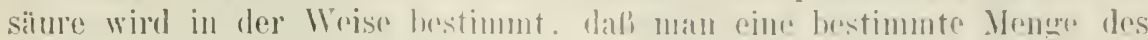

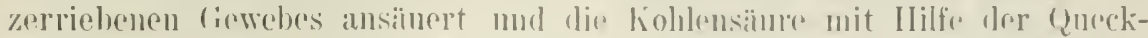

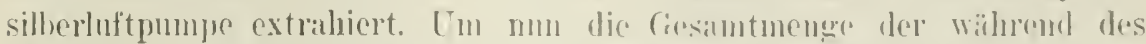
Versuches gehildeten Köhlousiime zu herechnon, hrancht man nur zu der

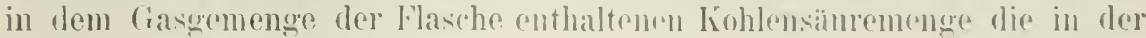
rliissigkeit gelöste hinzuzufïgen mm von der erhaltenen smmme die prii-

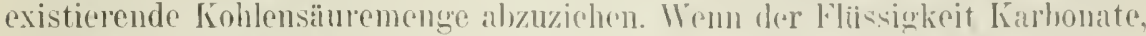
z. B. Natrimmbikabonat. him\%ngesetzt worden waren, wird die Mlessumg der durch das (iewehe entwickelten Kohlensïure munigrlich, es sei denu. dals man die rom Bikarbonat stammendo liohlensiimennenge vorlep bestimust.

Will man die Saucrstoffanfualume fortaufend rorfolowe so ist es nötig, die Kolılensïure in dem Mafe, wie sir sich hillot, zu entfornen. Zu dem Zwerlie kamn man folgendes lerfahren benutzen (Brattclli und Stem):

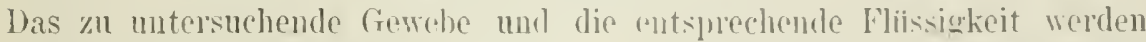

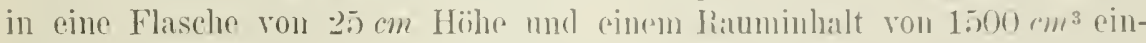
gefiilut. Die Flasche hesitzt eine weite öffumo, die durch einen (immuipfropfen verschlossen werden kann. Ter (immimipfoufen hat ״̈ lohrungen. Durch eine dieser Bohrungen geht cin (ilasrohr $r^{r}$, das mit der graduierten

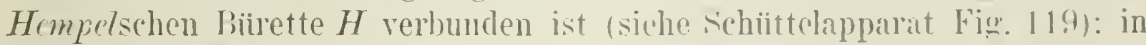
der anderen Bohrung befindet sicl ein Messingstah $T$. der den Kialiapparat trïgt. Der Kaliapparat besteht aus 2) Messingzylindern von verschielenem Durchmesser, die ineimander gestellt, an ihrem oberen Eudu offen und an ihrem unteren Ende geschlossen sind (Fig. 120). Die /, linder sind $10 \mathrm{~cm}$ hoch.

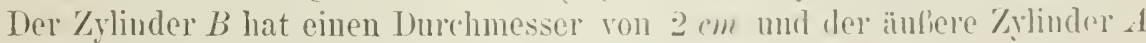
einen Durchnesser von $3: 5 \mathrm{~cm}$. 1)er innere $7 . y$ linder ist in seiner ganzen Ausdehnumg durchlöchert, während der anfere \%ylinder nur in seinem oberen 'Teile in einer Ausdehnumg von $7 \mathrm{~cm}$ von Lïichern durchsetzt ist, der untere $: 3 \mathrm{~cm}$. hohe Teil des /sylinders hat keine Öffnungen. An der Vereinigung dieser hejelen Toile hefindet sill cin zirkulïrer ling $C$, der nach innen mol unten gehogen ist mol his zum immeren Zylinder reicht. Dic Löcher sind sehr zahlreich, dicht heirinander mal haben einen Inuchmesser ron $4 \mathrm{~mm}$. In den imneren $/ y \operatorname{lind} \mathrm{B}$ führt man die Kíalistangen, die bis an den oberen Teil des Zylinders reichen, ein.

Die Flasche wird in der friiher beschriebenen Vejse mit sauerstoff gefiillt und energisch geschïtelt. Die bei der Itmmg des rewehes entstehende Kohlensäme wirel schuell durch die im \%ylinder $B$ befindlichen Kralistäbe absorbiert. Iläufig spritzt wïhrend dos schiittelus etwas Fliissigkeit auf den Kaliapparat. Fin Teil diescr 'Tö̈pehen wind durch den äuferen Zylinder A zuriickgehalten, ein Teil aber gelangt zum imnereu Zylinder und zu den darin enthaltenen Kalistäben: von da ans welangt die Fliiscigkeit ins Innere des Zylinders und sammelt sich im unteren 'leile des \%ylin- 
der: A. Iler zirkuläre ling C rerhindert das Austreten der Fliissigkeit ans dem Zylinder wihrend des solittelns.

Tiemu man num die Jenge des bei der 1 tmung aufgenommenen Sanerstoffs bestimmen will, senkt man die Flasche rollständig ins Wasser des Thermostaten und wartet 2 -3 Minuten, his das Temperaturgleichoewicht heroestellt sei, d. h. his das Gaswolumen unverändert bleibt. Ihie verbranchte samerstoffmenge wird mmittellar an der wraduierten Biirettr $H$ ablelesent.

2. Die \%ubereitung der (iowebe. Das zu untersuchende Gewebe wird in einer gewöhnlichen Fleischmühle fein zerrieben. Die Löcher tler

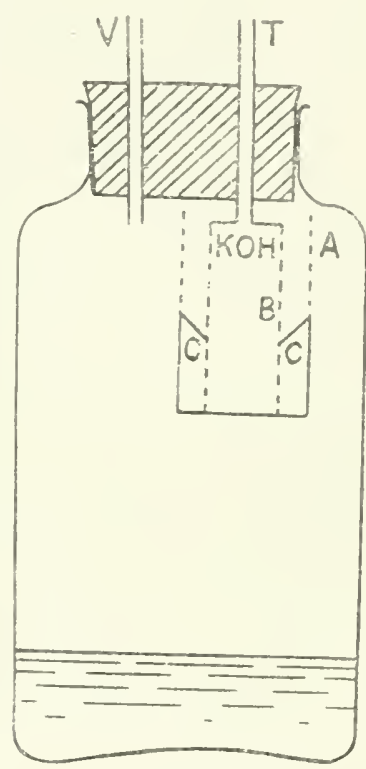

Fig. 1:0.

Fleischmiihle missen einen Durchmesser von ungefïhr 22 $\mathrm{mm}$ hesitzen. Sind

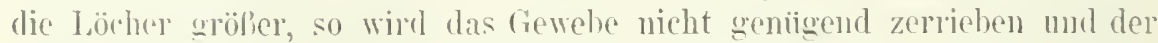
Gaswechsel wird dadurch herabgesetzt. Sind hingegen die Lörher kleiner, so kann das zerrichene (iewebe nur schwer hindurehtreten. namentlich wemm es sich $11 n$ Drïsenoroane handelt. Das so zerriebene (iewebe wird

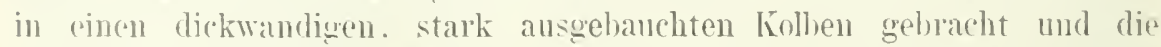
Fliissigkeit von hestimnter Znsammensetzung hinzugefïgt. I lie Menge derselhen muf grof genug sein, damit das fiewebe in derselhen schwimmen kann. Nan kamm o $\mathrm{cm}^{3}$ zu je 1 g (iewebe himzusetzen. Man erhält anf diese Weise eine Gewebeanfschwemmmng. Wenn es möglich ist. ist as ratsann, gröliere (iewebemengen zu benutzen, $40 \mathrm{~g}$ \%. B. In dem Falle muf der liollon einen Rauminhalt ron mindestens 10 ou $\mathrm{cm}^{3}$ besitzen, wenn der- 


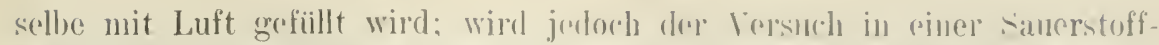

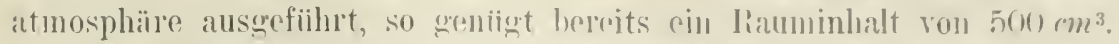

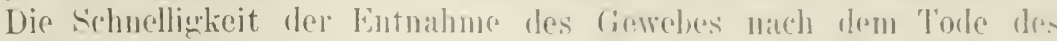

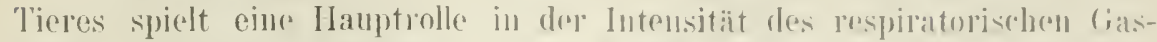

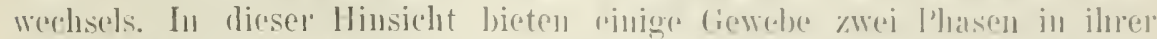
Atmungsfähgkeit. Während der rosten l'hase nimmt die lntrmsität des Gaswechsels allmählich ab. Während der zweiten J'hase hingureng hleiht diw Itmmostätigkeit mindestens cinige Tage lang konstant. Ino erste l'hase

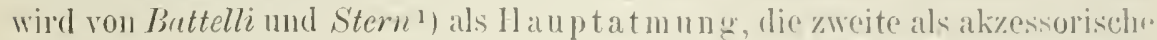
Itmung bezeichnet. I)er Atmunesprozeli der arstell Thase ist an die litalitit der zellen gebunden, während der l'rozef' der zweiten l'hase auch in einem von \%ellen vällig befreiten Anszuge vor sich grehen kann. ${ }^{2}$ )

Die Danel der Hauptatmung (erste Pliase) ist in den verschiedenen

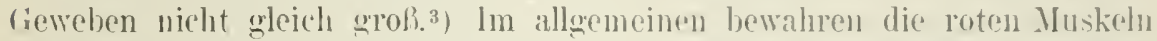
des Rindes. des Iferdes, ler 'Janhe u. a. ilne Itmungstätokeit riemlich lange, so dal, man diese Fewehe zun Studium der Lauptatmung 1 stunde und mehr nach dem 'Tode des 'lieres verwenden kann. l)ie Niere des Iundes und des Kaninchens besitzen in diesel Rezichung obenfalls eine aroke Widerstandsfähigkeit. Hingegen weisen die leher, das Herz, dic Banchspeicheldrise 11 a. eine seln schnelle Vermindorung ihrer itmungrtiitigkeit auf. So besitzt \%. B. die Leber des Hundes eine Stunde nach den Tode des Tieres oft nur ein Drittel orler Vicrtel der Atmungsfühigherit. welche sie gleich nach dem Tode des lieres anfweist. Das Gehirn do: Hundes weist eine grole Trobeständigheit in der Daure der Hauptatmung auf.

Ile Hauptatmumg der fewebe lewahrt sich un so besser, je niedriger die nmgehende Temperatur ist. Wenn man also die Hauptatmung in einem Gewebe, zum Beispiel in der Leber, einige stunden nach dem 'lode hewahren will, so selnneidet man das betreffende Gewele in Stiicke von unacfuhr :; - $+\mathrm{cm}$ Höhe und bringt sie in ein ron lis umgehenes Iristallisiergefäl. Aber selbst bei einer 'Temperatur ron $0^{0}$ verlioren gewisse (iewehe mach 12-2t stunden den größten 'Teil ihrel Itmungsfïhigkeit.

Einzelne Gewehe, wie der Herzmuskel, die Slielettnuskel des Ilundes und des Kaninchens u. a., besitzen keine akzessoristhe Itmung. Wenn man also diese frewehe einige Stunden nach dem Toule des Tieres untersucht. beobachtet man keine oder mur eine sehr weringe sauerstoffatuahme. Dic akzessorische ist hingegen in der Leher und der Niere stark ausceprägt. Diese Organe hewahren folglich, nachlem die Hauptatmung auforörort, cinen zienlich bedeutenden Ciswerhsel wïhrend mehrerer Tage unrerändert.

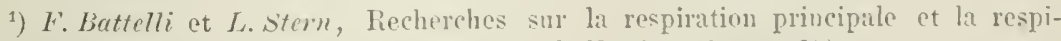
lution accessoire des tissus animaux. Soc de Biol. T. 66. p. 372 (1909).

$\left.{ }^{2}\right)$ Buttelli und stron, Die alizessorische Atilumg in den Tiergewchen. Bioch. Zeitschr. Vol. 21. p. 487. 1909.

3) Battelli et stern, Recherches sur Ia conservation de lactivité respiratoire dius les différents tissus animaux après la mort. Jouru. de Plyysiul. et de I'athol. géuérale p. 410 (1907). 
Jer Grad der Frische des Gewehes ist nicht nur ron Bedentung fiin die Intensitit des respinatorischen Gaswechsels. sondern beeinflubt anch stark die Wirkmo der velschiedenen substanzen auf die Atmmngsä̈higkoit.

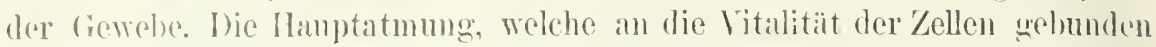
ist, wind durelo gewisse giftige substanzen, selbst in minimalen Dosis, stark herabgesetzt oder günzlich rernichtet (arsenge süure. Hansäure, Fluorsïnte usw.). so dali der (raswechsel anf ein Fïnftel oder ein Zehntel herabsinkt. Diesulben substanzen, selbst in bedentend stälkerer Dosis, beeinfhusen nur unbelentend die Itmmngstätigkeit der Leber, der Niere, des (iehin'ns usw. wenu diese Organc anderthalb oder zwei Stunden nach den 'Toulo des T'ieres untersucht werden, d. h. wenn sie nur noch die akzessorischo Atmung besitzen. I as l'nein (siche weiter muten) rerstälit nur die Hauptatmung und ist ohno Einflut anf die akzessorische Atmung. Infolgedessen bleilet das T'nein olne Wirkmug auf den Gaswechsel der Gewebe, wenn dieselben zu spät naclu dem 'Tode des 'lieres benutzt werden.

Wenu es sich darum handelt. die Hauptatnumg allein, getremut ron dey akzessolischen $\Lambda t m m$, zu mutersuchen, so kamm man die Muskeln des Ilundes, des limdes, des Hammels nsw. verwenden. Die Leber der verschiedenen Tiere (Hund, Pferd, Rind, Schaf usw.), einige Stunden nach dem Tode des Tieres entnommen. eignet sich vorzighlich zum Studimu der akzessorisehen Atmung. Wemn man die Leber, die Niere, das Gehim usw. gleich mach dem Tode des Tieres mutersucht, erhält man die Gesamtmenge des respiratorischen Gaswechsels, der zum weitaus größten 'Teile der Hanptatmung zuzusehreihen ist, während ein kloinerer Teil desselben durch die akzessorische Itmung verusacht wird.

bie verschiedenen (iewebe, selbst wenn sic sofort mach dem 'Tode des l'ieres verwandt werden, besitzen nicht die gleiche Atmmugstäigkeit; mehrere fewehe weisen einen nur geringen Gaswechsel auf. Wenn man (inen chorgischen Gaswechsel erzielen will, so kinn man die roten Muskeh ler versehiedenen 'Tiere benutzen; die Iluskehn der 'Taube eignen sich hierzu ebenfalls, doch muf man darauf achten, daß die Taube sich in einem guten Gesundheitszustande befinde und nicht durch längeren Aufenthalt in Käifige abgenagent sei. Die Muskeln des Kianinchens besitzen eine zienlich geringe Atmungstätigkeit. Die leher und dic Niere des Hunles oder des Kanimehens eiwnen sich ebenfalls sehr gut zu den verschiedenen Untersuchungen, betreffend den respiratorischen Gaswechsel. Das Gehirn des Hundes gibt unregelmäbige Resultate. Die Lunge, die Milz und der l'ankreas des Hundes oder des Kaniuchens weisen einen sehr schwachen Gaswechsel anf. Ibie ibloren Organe der Laboratoriumstiere, wie die Thyroidea, dio Nebennicre, dic ()varien u. a., sind zu klein, 1 m zu ähnlichen Lntersuchungen benutzt werlen zu können. Inter den Geweben, die rom Schlachtlofe bezogen werden kïmmen, eignen sich die Muskelı sehr gut zum Studimm der Hauptatmung. Dje anderen ()rgane oder Gewebe können nur zum Studium ler akzessorischen 1 tmmng dienen, da sie, bevor sie ins Laboratorium gelangen. den grobiten Teil ihrer Hauptatmung bereits eingebüit haben. 
4. Die Zusammensetyung der suspensionsflissigkeit. Die Zusammensetzung der Flissigkeit, in der das zu mutersuchende zerriebene (iewebe suspendiert wirl, hat einen grofien Einflul) auf ilen respiratorischen Gaswechsel der fiewebe, falls dieselben den grölitrn Teil ihrer Hauptatmung noch nicht eingebüßt haben. Ist jedoch die llanptatmung verschwunden, so daß nur die akzessorisclie Atmung in betracht zu zielıen ist, so ist die Zusammensetzung der Suspensionsfliissigkeit ebenso wio all die verschiedenen anderen Faktoren ron wenigr Wichtigkeit.

Die Ienge der Flüssigkeit muli grols genug sein. Im das Schütteln des (iewebes zu ermöglichen: sif darf anderseits nicht zu grofi sein, weil dadurch der Gaswechsel stark herabgesetzt werlen kann. Ginte Resultate exzielt man bei Auwendung ron 2.5 - :3 $\mathrm{cm}^{3}$ Fliissigkeit (Blut orler alkalische Lösung) für je $1 g$ (iewebe.

Die Reaktion des Mediuns spielt in der /usammensetzung der Suspensionsfliissigkeit die Hauptrolle. Dieselbe muli schwach alkalisch reagieren. Die gewünschte Alkalinität erhält man durch Hinzufïigen von $\mathrm{Na}_{2} \mathrm{CO}_{3} .10 \mathrm{H}_{2} \mathrm{O}$ in einer Konzentration von $0.4-0 \% \%$, oder ron $\mathrm{XaHC} \mathrm{CO}_{3}$ in einer lionzentration ron $0.2 \%$, oder besser noch ron $\left.\mathrm{Na}_{2} \mathrm{HP(}\right)_{4} \cdot 1 \cdot 2 \mathrm{H}_{2}(\mathrm{l})$ in einer Konzentration von $1 \%$. Wenn man blof die Sauerstoffaufuahme bestimmen will, kann man mit Erfolg folgende Mischung benutzen: Ëne Lösung von $\mathrm{Na}_{2} \mathrm{HPO}_{4} 12 \mathrm{H}_{2} \mathrm{O}$ wird durch Hinznfiigen von H('l gegen Lackmus amphoterisch und darauf dureh Hinzufiigen voll $\mathrm{Ta}_{2}\left(\mathrm{C}_{3} .10 \mathrm{H}_{2}()\right.$ in einer Proportion von $5: 1000$ alkalisch genacht.

Die äuferst giinstige Wirkung der phosphorsauren Salze hängt wahrseheinlich von der dreifachen dreibasischen Funktion der Phosphorsäure, wodurch eine Regulierung der Alkalinität des Mediums erzielt wird, ab.

Der respiratorische Gaswechsel rollzieht sich ebensognt in einer hypotonischen, wie in einer isotonischen Flüssigkeit. Es ist also iiberflüssig, $\mathrm{NaCl}$ oder ein anderes Salz hinzuzusetzen, un die Fliissigkeit isotonisch zu machen. Die Hauptatmung wird bei Anwendung hypertonischer Fluissigkeiten stark herabgesetzt; auf die akzessorische Atmung ist die Wirkung dieser Flüssigkeiten bedeutend geringer.

Das Blut verstärkt bedeutend die Hauptatmung. Diese hegiinstigende Wirkung ist zum weitaus größten Teile durch die Bluthörperchen bedingt. Das Serum uibt häufig vielmehr eine inhibitonische Wirkung aus. Es ist nicht notwendig, daß die Bluthörperchen intakt seien; man kann mit gleichem Erfolge eine wässerige Lösung hämolysierter Blutkörperchen verwenden. Die guinstige Wirkung der gewaschenen Blutkörperchen wird noch verstärkt, wenn die Fliissigkeit in der vorher angegebenen Weise alkalisch gemacht wird. Es ist nicht notwendig, das Illut der gleichen Tierart zu verwenden: die begiunstigende Wirkung der verschicdenen Blutarten ist ziemlich die gleiche.

Verwendet man als Suspensionsfliissigkeit Blut oder eine $1^{0}{ }^{\prime}$ ige $\mathrm{Na}_{2} \mathrm{HPO}_{4}$-Lösung und führt man den Versuch in einer Sauerstoffatmosphäre aus, so erzielt man einen äuferst energischen fiaswechsel. wenn die Ge- 
wehe recht frisch sind. So kamn zum beispiel der Muskel oder die Leber des Hundes moter diesen borlingmugen pro $100 \mathrm{~g}$ Gewbe in der ersten stund $400 \mathrm{~cm}^{3}$ sanerstoff aufnchmen und :00 $400 \mathrm{~cm}^{3}$ Kohlensäure abwehen. Her fiaswechsel nimmt mit der Daner des lersuchs herlentend al).

5. Die Hauptatmung. Ier fundamentale Atmungsprozeli; das l'nein; dir hommenden Substanzen in den Geweben. Die Hauptatmmog reschwindet in den feweben mohr oder weniger schmell mach dem 'Tode des Tieres und ist an die Vitalität der \%ellen eng gebund('n (siche weiter oben). Alle Einfliisse, die rlie Vitalität der \%ellen herabsctzen, hemunen zugloich die Hauptatmung. Es ist wahrseheinlich, dak dic Hauptatmung allen Geweben znkomme. Hn einzelnen Geweben. wie in den roten Muskehn des Hundes und des Rimles, ist der respiratorische Gaswophscel gänzlich durch die Hamptatmung bedingt. In llor Leber, der Viere, dem fiehirn 11, a, wenn dieschen gleich nach dem Tode des Tieres untersucht werden, gesellt sich zur Hauptatmung auch die akzessorische It $11111 \mathrm{ng}$.

In der Lauptatmung kanu man das Zusammenwirken zweiel Faktoren unterscheiden: das l'noin und den fundamentalen Itmungsprozel.

Aus den firmeben lassen sich mit Wasser eine oder mehrere substamzen extrahieren, die die Fihigkeit besitzen, den respiratorischen Gaswechsel der (iewehe zu steigem. ${ }^{1}$ ) Diese Substanzen sind bisher nicht isoliert worden. Battelli und Stern haben angenommen, laf es sich um cinc cinzigr Substan\% handelt und hahen dieselbe Pnein genannt. ${ }^{2}$ ) Die von Pnein mit Hilfe von Wasser befreiten Grewebe hesitzen nm sehr weringen orler keinen respiratorischen Gaswechsel mehr, aber wenn man ilnen das l'nein hinzusetzt. steigt dor Gaswerhsel wieder an. Tnter iler Bezeichnumg .fundamentaler respiratorischer Prozessus" versteht man den l'rozessus, der dem im Wasser unlöslichen Teile des Gewebes zukommt und welcher nach Hinzufiigen von Pnein die respiratorischen Erseheinungen aufwoist (Battelli und Sterm).

Das Pnein ist nicht in gleiches Menge in den verschiedenen fewoben morhanden: die wässcrigen Iusziige del Muskoln vom Rimd oder vom I'ferol hesitzen dic äroten Mengen disser. Substanz: in zweiter linie kommen dic Ansziige der Leher und der Milz und erst in dritter linie die Ausziige der Nire, der hunge, des Pankreas, des Hirus, des Thrmus. J)as blutserum, die Milch, der Harn scheinen kein l'nein zu hesitzen. lhas l’nein erfïhrt in den Geweben keine Verminderung nach dem Tode; man kann (x) ef stunden wach dem 'tode aus den Muskeln extrahioren.

h1 mehreren Gereben kann das Vorhandensein von P’nein durch gleivhzoitiges Vorhandensein von lemmenden substanzen maskiert sein.

1) Buttelli et Strm, Activation de la respiration tissulaire par l'extrait des llifférents organes et par les liquules de l’organisme. Arehives internationales de Physiol. T. 5. p. $262(1907)$.

${ }^{2}$ ) Butfelli et siturn, Pecherches sur la pnëine et le processus respiratoire foulamental. Soe. de Biol. Bd. 6.j. p. 489 (1908). 


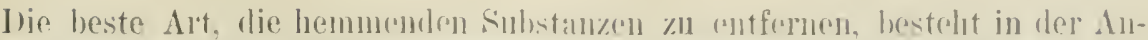

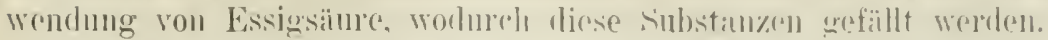

Um rinc an l'nein reiche lösung zu rphaltron, riihrt man foin zel'-

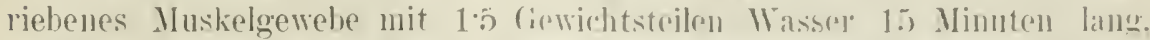

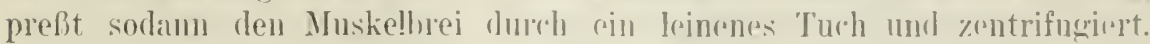
IIII die Lisung von eventuell vollandemen griheren Trilchen zu befreien. Jie etwas tribe Lösmng, die man anf diesc Wpise phöilt. kamn ohne woiteres benutzt werden, aber wenn man cine klare, durhsirhtige Fliisigkeit haben will. fiigt man etwas Essig-orler Salsä̈ure in eincr I'roportion von 0-1.): 100

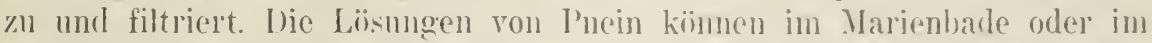
Vakuum bis \%u sirnpöser Konsisten\% eingeengt werden. ohne ihre ak1vierenden Eigenschaften $\%$ verlieren. T)as l'nein wird durch Siedehitz. nicht zerstört; aber wem man die his auf sirupösc Konsistenz eingeengtr I'neinlösung anf $200^{\circ}$ erhitzt, wird das l'nein zersetzt. l)as l'nein dialysiert.

Jas Pnein wird weder durch süuren noch durch Alkalien einschlieflich des Baryts gefällt. Wenn man eine bis zu riner I)ensitit von 12.50 konzentrierte Pneinlösung mit : Volumen 95grädigen . Mkohols behandelt. wird der größste 'Teil des P'neins gefällt; das Filtrat anthält nur geringe Mengen dieser Substanz. Inuch sieden mit $\mathrm{Cl}_{3} \mathrm{Fe}$ wird kas I'ncin nicht gefïllt.

1)as I'nein ist nicht autoxydabel; eine an I'noin reiche Lösung nimmt keinen Samerstoff auf. Das Wassustoffsuperoxyd ruft keine Verinderung der aktivierenden Fähigkeit dieser substanz hervor.

Jie Wirkung des Pueins ist durch keine andere bis jetyt bekannte Substanz des tiurischen Oroanismus erzielt worden.

Ym die Wirkung des Pneins zu studieren, kam man entweder die rerschiedenen zerriebenen, aber sonst umeränderten fiewebe, oder die roten Muskeln, die rorher mit Wasser behandelt worlen waren. benutzen. Das letztere Verfahren eignet sich berlentend besser. Wenn man das I'nein anf die nicht rorher gewaschenen Gewehe einwirken lassen will, kimn man die Leber, die Niere, das Gehim usw. henntzen. Die Gewehe miissen schnell nach dem Tode des Tieres zur Verwendung gelangen. Wemn man \%wei oder drei stunden oder noch weniger mach dem Tode des Tieres verstreichen läBt, bleibt das Pnein ohne Wirkung auf den respiratorischen Gaswechsel dieser Gewebe, weil der fundamentale T'rozessus eine Alschwächung erfahren hat (sieho weiter unten).

Wenn man rote, nicht gewaschene Mnskeln benut\%. nul man dieselben im Gogenteil erst drei bis vier stunden nach dem Torle des Tieres verwenden: gleich nach dem Tode des Tieres bieten die Muskeln häufig das Maximum ihres respiratorischen Gaswechsels und das hinzugrofigte Pnein bleibt in diesen Falle wirkungslos. Wartet man jerloch einige stunden ab, so ist die respiratorische Fähigheit der Muskeln rermindert und das Pnein kamn alsdamn soine aktivierende Wirkung zur fieltung bringen.

Der Gaswechsel eines Prïparates. Welches den fundamentalen ['rozessus hesitzt. steigert sich anfangs mit del zunehmenden Ironge des hin- 
zugefügten I'neins his zu eincen gewissen Maximum, das durch Hinzufügen von nenen Mlonen Pneins nicht iiherschriten wirl.

bieses Maxinnm wird llälfig erzielt, wenn man zu :30 g frischen (iewebes oder wewaschenen Muskelrickstandes (siehe weiter moten) das Puein von megefille 50 \% Muskel hinzufiignt.

Zur Intersudume des fundamentalen respiratorischen l'rozessus wählt man die Muskeln von lind oder I'ferd: das /werchfell eignet sich ganz besonders zu dem \%werk. Mer fundanentale Prozessus der anderen (iewebr ist zu labil und wird durch Behandeln mit IVasser vollständig vernichtot. l) Muskel wird wie gewiihnlich mit Hilfe einer Hackmaschine zerrieben, wiblend o Mimten mit Wasser verrilnt und dureh ein Tuch unted Anwendumg einer Handpresse geprelit. Man erhält anf diese Weise eincu Muskeldidektand, der zum studium der Eigenschaften des fundanentalun l'pozesisus dienen kann.

Lis ist riemlich schwer zu entscheiden. eine wie glohe Menge Wasser zur licreitung des Muskelriuckstandes benutzt werden mul3. Wem die hinzugefiigte Wassermenge zu grol ist, erhält man einen Muskelruckstand. der alloin genommen keine lespiratorische Tiitigkeit mehr anfweist. aber oft sich mu schwach durch das Pnein aktivieren läBt. Ist hingegen die hinzngefïgte Wassermenge zu klein, so erhält man einen Muskelriekstand. dessen respiratorische Tätigkeit noch sehr encogisch ist: das Hinzufïgen rom P'nein hat in diescm Fall ane mbedeutende Wirkmo. Die zu reswendende Wassernenge mub sich nach der Reizhalieit des Muskels ridhten. [on diese livizhalkeit zn prifon, versetyt man den Mnske] einen harten Sehlag. Ist dio Reizbarkeit grob, so bemerkt man eine starke Kontraktion des gamzen Muskelliindels. In dem Falle fügt man $2-4$ Gewichtsteile Wasiel dem Muskel von Rind. nnd 5- 6 Gewidhtsteile Wasser, wemn es sich um Muskohn von Pfenol landelt, zu. Ist die Reizbarkeit des Muskels etwas gelingel, so fiint man o) (iewichtsteile Masseg zu dem Muskel vou Pind und $\frac{1}{4}$ fewichtsteile Wassel zu dem Mnskel von Pferd. Fndlich, wenn die limeglankeit des Mukels nur gering ist, begnijgt man sich mit 1\%) Gewichtsteilen Wisser fiir den Muskel ron lind mo :3 (iewichtsteilen Wasser fiir den Musked von l'ferd. Der Muskel ron lind liefert einen weniger feuchten und weniger gefühten Rïrkstand als der Mushel von J'ferd. Das Gewicht des Muskehörkstandes ist gewöhnlich geringer als das fewicht des ganzen Muskels. Der (iewiehtsverlust betrïgt je nach der behandlung des Muskels 1/4 - 1/3 des Gesantgewichts. Der Mluskelriickstand muli so schmell wie möglich nach seiner /mbereitung benutzt werden. $/ u$ je 1 g

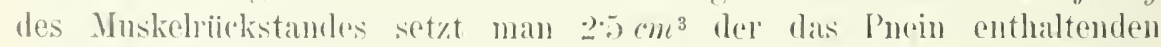
Fliissigkeit himzn.

Der Muskel des Hundes eignet sich weniger an dieser I'räjaration; der respiratorische Gaswechsel dieses Muskeluidkstandes wird durch das I'nein mur wenig aktiviert.

Der funlanentale respiratorische Prozessus besitzt in den verschiedenen Gevehen eine ungleiche Stabilitiit. Ev ist an widerstandsfähigsten in den 
Muskeln rou lind und von Pferd, wäluend er in der Labere, im Herzen nsw: änlierst labil ist; letztere (iewebe verlinen den gribliten teil ihrer respiratorischen Fähigkeit sehr bald nach dem 'Todr dwi Tiures. Diese zerriebenen Orwane, mit Wasser hohandelt, licferm einen liiek-iand, der durch das Puein fast nicht aktiviert wrorlen kanı.

I) respiratorischen Eigrenschaften des fundannentalen respiratorischen I'rozesses werden durch Sieden in allen (irweben röllig vernichtet.

Iehrere fiewehe enthalten eine oder mehrere die Itmung der Gewebe hemmende Substanzen. ${ }^{1}$, Dieses Substanzen sind hauptsïrhlich in der Milz, den Lymphdrisen rou Pferd und Riml, der Lunge von Hamnel und P'ferd, den Hoden ron Hammel mul Ilund enthaltroln. Das Blntserum wirkt ebenfalls häufig hemmend.

Die hemmende substanz ist in Wasser löslich: sie wird aus ihren wässerigen Lösungen durch schwache sänren gefällt. I'u diese substanz zn bereiten, zerreibt man fein Milz oder Hoden usw. und riihrt das ciewebe mit 15 Gewichtsteilen Wasser 10 Minuten lang mun. Nan prefit hernach den ferrebebrei durch ein dickes Thch und erhält auf diece Weise eine trïhe Flïssigkeit, die häufig den respiratorischen laswechsel der (iewebe stark herabsetzt. Wenn man die hemmende substanz in konzentrierterer Form erhalten will, so säuert man den wässerigen Iıs\%ng der Yil\% der Hoden usw. mit Fssigsäure in einer l'roportion ron 0)15:100 an und zentrifugiert. Der Niederschlag ist reich an hemmender substanz, während der flïssige Teil keine hemmende Wirkung mehr besitzt.

Die hemmende substanz wird durch sieden zerstört; sie dialysiert nicht.

Wenn man den Einflun der hemmenden substanz auf den respiratorischen Gaswechsel der Gewebe untersuchen will, wällt man ein Gewebe. dessen Caswechsel sehr energisch sei, zum Beispiel die IIuskin der Taube. Zu $20 \mathrm{~g}$ Yuskel setzt man $20 \mathrm{~cm}^{3}$ eines Anszugs aus Yilz oder Hoden, $25 \mathrm{~cm}^{3}$ Wasser und die nötige Ienge $\mathrm{Na}_{2} 1 \mathrm{II}^{\prime}()_{4} \cdot 1 \cdot 2 \mathrm{H}_{2}()_{\text {. }}$ um eine Konzentration ron 1:100 zu erzielen, hinzu. In dem Kontrollversuche wird der Gewebeanszug durch eine entsprechende Menge Wasser ersetzt. Die beiden mit Sauerstoff gefüllten Flaschen werden eine laalbe stunde lang energisch geschiittelt und darauf die verbrauchte Sauerstoffmenge und dic entwickelte Kohlensäure in der oben beschriebenen Weise gemessen. Wenn die zum Versuche angewandte Milz, Hoden usw. reich an hemmender Substanz waren, kann der Gaswechsel um die Hïlfte und noch mehr vermindert sein.

Die Ienge der hemmenden Substan\% in einem bestimmten (iewebe variiert von einem Tier zum anderen in derselhen Tiergattung. In cinigen Fällen scheint diese Substanz in den Geweben. die gewöhnlich die gröbten Mengen derselben enthalten, gïnzlich zu fehlen.

1) F. Battelli et Mne $L$. stern, Vinuelles recherches sur laction que les différents tissus animaux exercent vis-à-ris de la respiration musenlaire. Snciete de Biol. T. 62. p. $832(1907)$. 
(i. Die akzessorische Itmmng. Lnter akzessonischer Itmmog versteht man den Atmungsumozeli, der längere \%oil nach dem loudr des Tieres

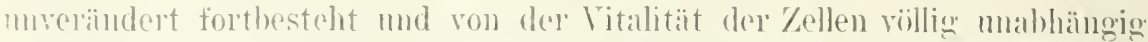

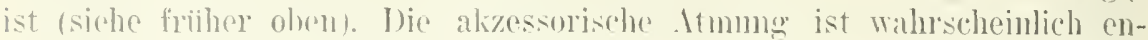
\%ymatischer Xatur mul ist mamentlich in der Leber und in der Niere

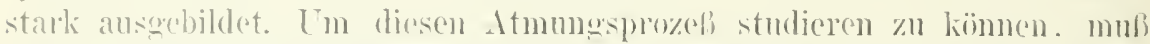
man die betreffenden Crowbe mehrere Stmoden mach dem Todo des theres. womn die Hauptatmmo bereits vïlig erloselien ist, relwenden.

I) Sulestankn (Enzyme u. a.), die hej der akzessorischen $11 \mathrm{mung}$ zusanmenwirken, kïmen als trockenes l'nlver oder anch als lisue. von

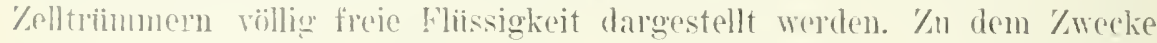
wird dis Leber (oder die Niere) wie gewïhnlich zerrieban, mit : Volumen

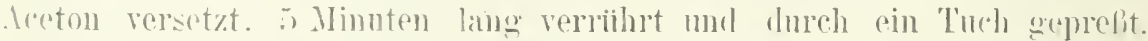

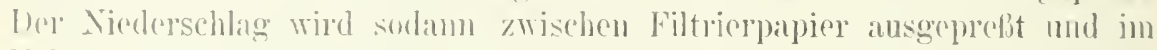

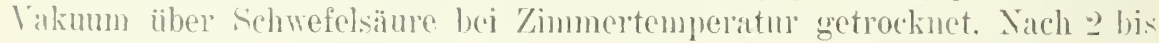
:) stmulen ist der Nioderschlag trocken genng, um zu den Versuchen varwaindt zil werden.

Es genigt nun. diesen Niederschlag in Wasser zn hringen. Worin ('1 eine suspension bildet. Will man eine klare Flïssigkeit, die die akzesso-

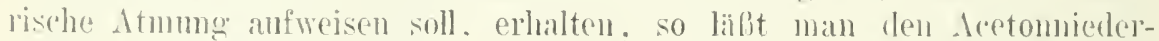
schlag unter Luftansishlul in einel $0.07 \%$ igen Ammoniaklösmos unter ïferem schiitteln digerioren. Die Fliissigkeit wird dam alogehoben mul zentrifugiert, venn man dirselbe völlig klar herstellen will. Die Alkalinität

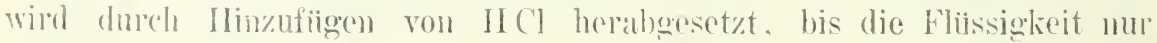
schwach alkalisch reagrert. Die anf dicse Weise bereitete Fliissigkeit wind

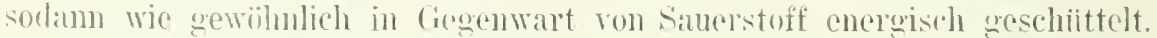

l) Exhaltung der akzessorischen Atmmug in den Aretomiederschlienen varielt jo nach dem P'rïpalat. In einigen Fällen nimmt dic ak-

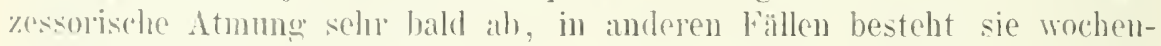
lang unvoriundert fort.

Anstatt des Acetons könnte man zur Fällme der Gewebe anch $\mathbf{\text { I- }}$ kohol benutzen. Hoch hat man in diesen Falle den Nacheil, dab der Alkohol dnech die in melueren Gemelon enthalteme Alkoholase oxydient

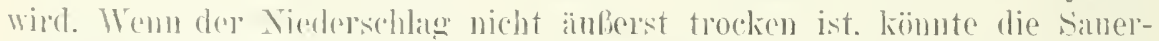
stoffanfuahme dureh die Oxylation des Mhohols mol nicht nur eler in den

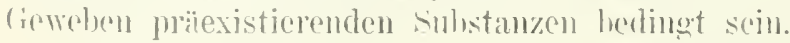

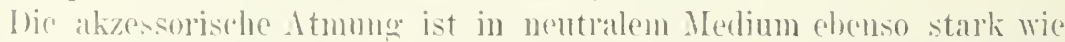

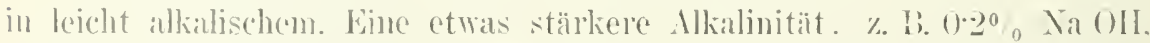

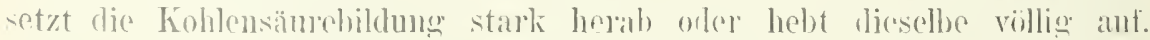

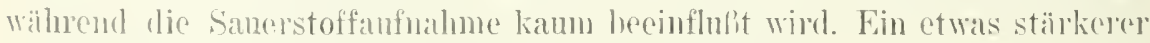
siumereral hebt die akzessorische Atmung röllig auf.

1)as T'omperaturoptimum der akzessorischen Atmung jst in nemtralcm

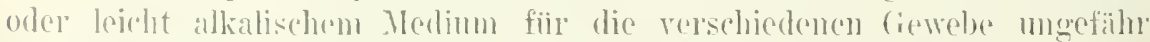

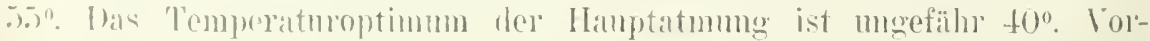

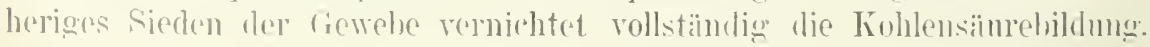


Die Samerstoffaufnahme besteht. Wrin anch in sehr garingem Mal'e. fort, namentlich in der Leber. Es handest sich hier wahrscheinlich um autroxydable Substanzen.

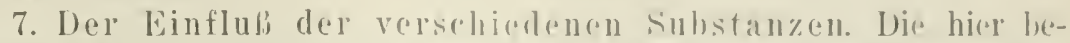
schriebene Vlethode eignet sich rorzïglich zum studium des Linflusses der

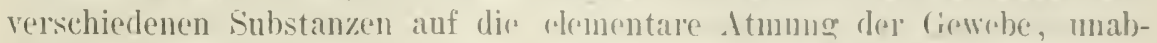
Jä̈ngig vom Nervensystem, von dru Zirkulationsändremegen nsw. Jan kann auf diese Weise die direkte Wirkung der rersehiedenen (iffe. der Xinkotika, flel Antiprretika usw., wie es Senta $\left.{ }^{1}\right)$ uretan. mutersurben.

Ian kann den Einfluf der verschienlenen substan\%en, sei es auf die Hauptatmung (frischer roter Muskel), sei es anf die alzes:orische $A$ tmung (Leber, einige stunden nach rem Tode des Tieres entnomment) studieren. Wenn man die Lebel oder die Niere unmittelbar nach den Tode des Tieres verwendet, so wird die zu untersuchendr Substanz sowohl die Hauptatmung als auch die akzessorische Itmung becinflussen kömnen.

Die Wirkung der hemmenden substanzen ist bedoutend stïrkel auf die Hanptatmung als auf die akzessorische Atmung. lis empfiehlt sich also, zu ïhnlichen Intersuchungen recht frische Gewehe, die einen sohr energischen Gaswechsel aufweisen, zu verwenten. Ilie Muskeln der Tanhe eignen sich hierzu vorzüglich.

Es gilst eine orofe Inzahl ron Substanzen, die die Itmungsfälnigkeit der Gewebe herabsetzen. Unter den in der Hinsicht wirksamsten substanzen sind vor allem die arsenige Säure (die Arsensiume besitzt eine ziemlich schwach hemmeude Wirkung), die Blansäure. die Aldehyle, und zwar das: Salizyl- und das Formaldehyd zu nennen. l)as Natriumarsenik z. P. beeinfluft die Hauptatnung bereits in einer Konzentration ron $1: 50.1100$. In einer Konzentration von 1:2000 setzt diese Substanz die Itmungstaitigkeit der Muskeln auf ein Minimum herab. I)ie Anästhetika, wie C'hloroform, Ather, Chloralhydrat, schwächen ehenfalls bedentend die Itmung:taitigkeit der Gewebe. Die Aminosämen (Cilykokoll, Iencin, 'Jyrosin) setzen nach Lussana den Gaswechsel der (iewebe ehenfalls herab).

Unter den Substanzen, die aine stark hemmende Wirkung auf die Atmung ausiilen, mus man auch die Calle nennen; ihre Wirkung ist auf die darin enthaltenen Gallensïuren zuriekzufiiluren.

Die Zahl der Suhstanzen, die die Itmmgstätigkeit steigern, ist änßerst gering. Außer den Substanzen. die durch ihre allatische Reaktion wirken, wie die Karbonate und I'hosphate. kann man nur das Hämoglobin und das l'nein nennen. Der (iesantaustansch des ron I'nein befreiten Muskelrïckstandes wird durch das Hämoglobin nicht gestrigert.

Ein besonderer Platz gebihn't der Harnsäure, die durch das in rerschiedenen Geweben enthaltene urikolytische Ferment orler die Crikase unter Kohlensäurehildung und sauerstoffaufnahme zu Allantoin oxydier't

1) sicnta, Action des autipyretiques et des alcaloiles sur la respiration de's tissus , in ritro“. Arch. internationales de Pharmacolynamic et de Therapie. T. 18. pag. 217 (1!108). 
wird. ${ }^{1}$ ) Inie Niere des Rindes und die Leher des I'ferdes oder des Hundes sind die an Trikase reichsten Organe. Die Oxydation der Harnsäure vollzicht sich sehr schnell in Gegenwart dieser sochen genannten Organe.

Bei Anwendung frischer Organe nühert sich der respiratorische Quntient, der durel die Oxydation der Harnsäure bedingt ist, der Zahl 2. Die Aufnahme von (1), und die Entwicklung ron $\mathrm{C}_{2} \mathrm{O}_{2}$ summiert sich mit der (igenen Atmung des (iewebes. $\left.{ }^{2}\right)$ Die Steigermug der Kohlensïureabgabe entspricht den theoretischen Werten. So crhält man z. B. bei der Oxydation von $1 \mathrm{~g}$ Harnsilure $1335 \mathrm{~cm}^{3} \quad\left(\mathrm{C}_{2}\right.$ mehr als in der Kontrollflasche, wo das Gerebe allein. ohme Hamsïure geatmet hat.

I)ic (ilukose, mehrere organische Salze, wie ameisensaures, essigsaures mul milchsanres Natrimm oder Calcium, desgleichen Aceton, die l'minbasen. Haurnstoff usw. hahen keinen dentliehen Einfluls auf den respiratorischen Gaswechsel der Gewebe, es sej demn. dak man diese Substanzen in sehr starker Konzentration rerwendet. In dem Falle setzen sie die Atmungstitigkeit herab. In X der Leber verschiedener Tierarten bedeutend. Ilese Wirkmog ist durch ein besonderes Ferment, die Alkoholase 2). welehe den Alkohol zu Aldehrd oder zu Essigsiure oxydiert, bedingt. Die laber des I'ferdes ist das an Alkoholase reichste ()roan.

\section{Entwicklung von Kohlensäure in Abwesenheit von Sauer- stoff.}

I)iese I'ntersuchungen bezweeken hanptsächlich, zu entscheiden, ol) die in einem diewehe gebildete lohlensänre in enger Bezichung zum anfgenommenen Sinerstoff steht oder mehr oder weniger mabhängig von den Oxydationsvorgängen ist. Nehr oder minder grobe Nengen Kohlensäure präexisticren in allen Geweben; daher die Yotwendigkeit, die in den zu untersuchenden Geweben präexistierende kohlensïmemenge bestimmen zu kiimnen.

Mehrere der weiter oben heschriebenen Methoden können zum Studium der Kohlensïmrebildung unter Jusschluß von Siucrstoff angewandt werden. In diesen Untersuchungsmethoden hat man folgemde ['unkte zn beachten:

1. I) kiinstliehe Durchblutumg ganzel iiberlebender (Organe,

2 . dic kïnstliche Durchhlutung des ganzen Tierkiorpers,

$\therefore$. the Untersuchung fragmentierter (Mrgaue,

t. die liestimmung der prïexistierenden kohlensïme.

1. Die kiinstliche Durchblutung ganzer iiberlebender (1rwane. Ilic kiinstliche Durchblutung muter Iusschlub von samerstoff kamn mit Hilfe einer der oben beschriebenen Methoden rorgenommen werden.

1) Battelli mul stern, Untersuchungen über die Trikase in den Tiergewelnen. Bioch. \%eitschr. Bil. 19. S. 219. 1909.

2) Buttelli et stem, L'alcoolase dans les tissus auimaux. Soc. le Biol. Vol. 67. p. 419,1909 . 
Die Flüssigheit, die zur burchblutung diencell soll, wilrl von den darin enthaltenen sanerstoff furch xierlen lufreit; oder man lälit dureh dic Fliissigkeit einen strom eines inerten Gases länere \%eit streichen. Die Gefälie, die zur Aufuahme des betreffenden organes nud dor Fliisisgkeit hestimmt sind, müssen ebenfalls ron dem darin enthaltenen sauerstoff bef reit sein. Die Vorbereitung des zu untersuchenden ()rones, die Messung der entwickelten Kohlensäure nsw, bieten keinerlei spowelle Figentïnlichkeiten.

2. Die kinstliche 1)urchblutung des ganzen Tierkïrpers unter Ausschluh ron sauerstoff. In dieser ron Battelli ${ }^{1}$ ) angergebenen Methode wird der ganze Tierkörper kïustlich durchblutet, indem das Her\% massiert wird, und die durch die Junge entweichende Kohlensïure gresammelt. Außer ihrer groken Einfachleit bietat diese Irethode den Vor-

Fig. 121.

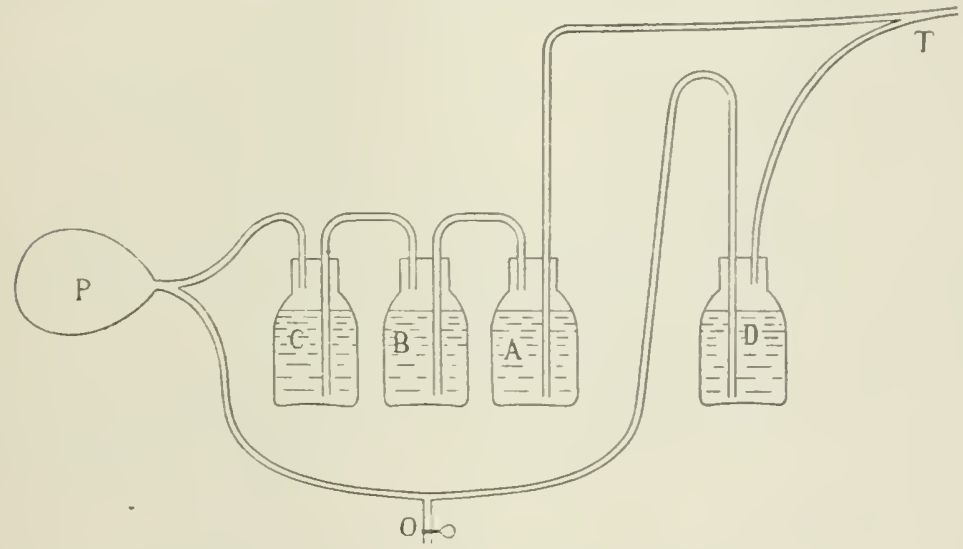

teil, die Organe intakt unter den soust während des Lebens herrschenden Bedingungen zu lassen. Diese Methode kann sehr gut heim Hunde angewandt werden; die Kaninchen sowie die Meerschweinchen eignen sich nicht lecht dazu, weil bei diesen Tieren das Herz sehr bald blutleer wird.

Um die aus der Lunge entweichende Kohlensäure aufzufangen. wird die kiinstliche Atmung mit Stickstoff rorgenommen. Zu dem Zwecke benutzt man die in der Fig. 121 dargestellte Anordnung.

Die Röhre $T$ kam einerseits mit der Trachealkaniile und andrerseits mit den als Müllersche Ventile funktionierenden, mit einer Bartlösumg gefïllten Flaschen in Terbindung gesetzt werden. Ilie Flaschen sind mit einem dickwandigen (rummiballon $I^{\prime}$ rou $600 \mathrm{~cm}^{3}$ Rauminhalt, welcher als Saug- und Druckpumpe funktioniert, rerbunden. Bei jeden Zusammen-

1) F. Battelli, Contribution à l'étude du métaholisme en cas de circulation artificielle. Arch. internationales de I'hysiologie. T. 1. p. $\neq i \quad(190 \neq 1$. 


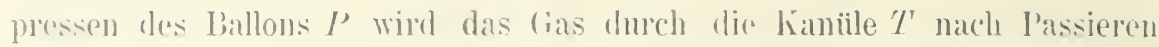
der Flasche $B$ in die Lunge getrieben. Sobald die Kompression des Ballons anfhiirt. sucht lotzterer sein friberes Volumen wieder zu gewinnen und sangt das Gas, welches die Flaschen $1, B$, $C^{+}$passieren mub, an. Der Gummiballon sowie die Flasdhen nuissan natiulich vorher von Luft vïllig befreit und mit stickstoff gefiillt werden. Man wird molnere Roihen Barytflaschen, die in der gleichen Weise angeordnet sind, bereit halten, um im gegebenen Angenblicke dir bereits benutzten zu arsetzen.

Dic Versurhanordmung ist folgende: J)as Versuchstier wird gofesselt. tracheotomiert und eine Kaniile in die 'l'rachea eingelunden. lie Trachealkimiile virel mit dem Rolır $T$ verbunden.

Die spontanen Itembewpermeen werden durch rythmisches \%usammenpressen drs Gummiballons rerstärkt. Nach ander gewissen \%eit versolminden lie lieflexe. Man öffnet alslann dic Bimsthöhle, legt das Herz bloh und massiert os kräftion. Während die kïnstliche $\Lambda$ tmung mit stickstoff fortdanert. Die '/irkulation vollzieht sich sehr gut während der ersten Viertelstunde, später aber wird das Her\% infolge der eintretenden Laihmung der Tasomotoren allmählich blutleer. Man helt dann den hinteren Teil des 'Tieres empor und führt auberlem ron \%eit zu \%eit eine isotonische, auf t0 erwïnnte Kochsal\%lösung in die Tena femoralis ein.

l'm das Ablïhlen des Tieres soweit wie möglich zu verhindern. wird dassolbe auf eine mit Wasser gefiillte und auf tho erwämte Zinkkiste gelegt und mit Wolldecken sorgfältig bedeckt. Man kamn das Ticr auch in rin Salzwasserbad, das auf :30 erwärmt wird, bringen.

Wenn die Lunge durch das Gas, welches in dem zum kiinstlichen Atmung dienenden system cuthalten ist, nicht genigend erweitert ist, kann man einc mehr oder minder globe Menge stickstoff durch das hohr $O$ in lie Lunge ainfiiluren.

Wenn man es fïr nötig findet, werden die zur Mbsorption der Kohlensïne wilhend einer gewissen Zeit benutzten blaschen entfernt und durch rine andere Reihe mit titrierter liartlösung gefüllter Flaschen ersetzt. ber Versuch wird bis zu dem dugenblicke fortgesetzt, wo die Barytlösung keine merkbare 'Tribung mehr anfweist, was ungefïhr nach ¿ Stmoinden der Fall ist. Man voreingt die in den verschiedenen blaschen enthaltene Baryt-

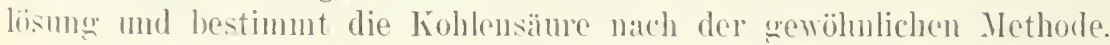

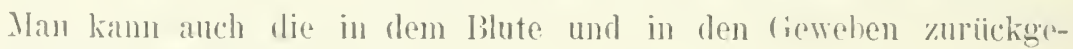
bliebene Kuhlensïuremenge messen.

Mit Ililfe dieser Methode kann man konstatieren. dab die Mbabe vou kohlensäure durch die Jumge wïluend der ersten 15) Minuten der kiinstlichen Jurchblutung unter Iusschlug vou sianerstoff bedentend ab-

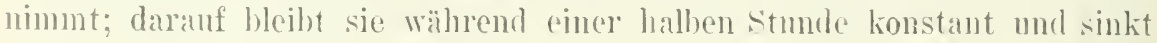
dam aufs neue. Nach 90 Minuten erhält man nur geringe Mengen Kohlen-

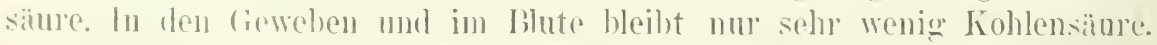
Dic Tiaktion des bilutes und der fiewebe ist ansesprochen saurr. 
Die Menge der wïhrend der zwastiundigen kiinstlichen Dorchllutung

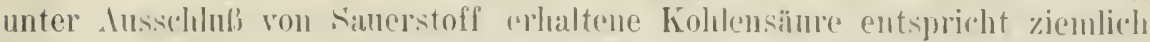

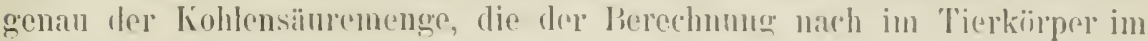
Inerenblicke des 'Torles durch Ersticken rexistieren mulitr.

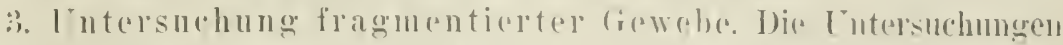

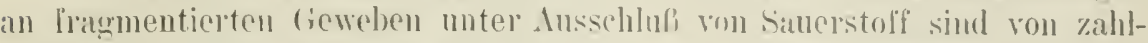
reichen forsehern gemacht worlen. Die verschiedenon Methoden, die zाm Intersuchung des respiratorischen faswechsols fragnentierter fiewebe in (iegenwart von Sanerstoff angewandt werden nnd die weiter oben beschrielen worden sind, kömnen anch benutzt werden, wenn man die fiewche in ciner Stickstoff- oder Wasserstoffatmosphïre atmen lassen will. Nachdem das z.I motersuchende (iewche in den Apuarat gebracht worden ist, treilit man einen starken Strom des entsprechenden Gases, Nichstoff oder Wasserstoff, durch das das (ievehe enthaltende Gefïf. Del Appalat ron Tissot. eignet sich sehr gut zu diesen Untersuchungen. Die Kaliflaschen p (siehe Fig. 1 5 ) sind mit einem das betreffende incrte (ias enthaltenden (iasometer verbmulen mol die Aspiration des rases wird mit Hilfe eimes Wasseraspirators erziclt.

Ijic Zubereitung des Gewebes, die Messung der entwickelten Kohlensïure bieten keinerlei Besonderheiten.

4. Bestimmung der in den Geweben prïformierten línlensïnre. Wenn man erfahren will, ob ein gegebenes Gewebc in Abwesenheit von Saucrstoff Kohleusïure produziert hat, mub man ror allen Ibingen die Kohlensïuremenge, die in Augenblicke des Lostrennens rom Tierhörper im Crewebe existiert lat, bestimmen. Ilieser Umstand ist ron den meisten Forscherm, die sich nit dieser Frage heschiftigt hahen, nicht in Betracht gezogren worden.

Mehrere. Methoden kïnnen zu dem Zwecke angewandt werelen. Dic cinfachste drt besteht in folgendem: Man wiegt schnell das zu mntersuchende Gewebe und bringt es sofort in ein hermetisch schlielindes fiefüb, welches 10 frewichtseinheiten auf $20^{\circ}$ erhitztes, alier nicht siedendes Wasser enthilt. Die Flasche wird sodann vollständig mit Wasser gefuilt und mit einem mit einem Hahn verschenen Glasstöpsel rersehen. Alle luft kann durch den Hahn entferut werden. Der Hahn wird geschlossen und die Flasehe bleibt ungefiln 5 Minuten lang bei einer 'Temperatur von $90^{\circ}$. Man lïbt abkïhlen mo schïttelt die Flasche, um etwaige Gasbläschen, die an den Wäuden der Flasche haften geblieben sind, zu lösen. Ian öffnet mun die Flasche und zerschneidet schucll das Fewebe in kleine sitichchen mit Hilfe einer Schere, ohne das Gewebe ans dem Irasser zu hehen. Das Ganze wird nun in einen Ballon gebracht, mit Plosphorsäure in einer Proportion ron 1:100 angesäuert und das Gas mit Hilfe der Quecksilberluftpumpe extrahiert, wobei man das (ianze leicht erwïrmt. Die Kohleusäuro wird in der gewöhnlichen Weise gemessen.

Man kaun anch die Kohlensälure aus dem Gewebe extrahieren, ohne letzteres zuerst zu erhitzen, demn man kam annehmen, dali infolge der 
starken Azidität der Fliissigkeit jede Veubildung von Kohlensïure völlig unmiglich wemacht wird. I)as fowebe wird schnell gewogen. in 10 Gewichtsteile kalten Wassers getan und nntel Wasser rasch in kleine Stiickchen zerschnitten. Das Ganze wirl schnell in den I'allon gebracht, die nötige Ienge l'hosphorsåne, um eine Gesamtkonzentration vou 로 $100 \mathrm{zu}$ erzielen, hinzugefiigt und das Gas mit Hilfe der Quecksilberpumpe extrahiert.

bic in den feweben enthaltene Kohlensïure kann auch durch andanerules sieden extrahiert werden nach dem Verfahren von Stintzing. ${ }^{1}$ ) Die mit Hilfe der letzteren Methode erhaltenen Werte sind etwas höhel als die mit den anderen Methoden erhaltenen.

Dit in den verschiedenen freweben gefundenen Kohlensäuremengen sind verschieden. In den Muskeln der Säugetiere findet man gewöhnlich 15-20 Volumprozente Kiohlensä̈ure.

Das Vakumm allein geniigt nicht. um sämtliche in den Gewcben enthaltene liohlensïure extrahieren zu könmen. Ein Gewehe, dem durch das Vakum Kohlensïure entzogen worden ist, setzt seine Kohlensämreabgabe fort, wic es Hermam ²) gezeigt hat. Diese Frscheinung könnte dadurch bedingt sein. daff das Gewcbe nach dem 'Torle immer mehr sauer wird und somit neue Mengen gebundener liohlensäure in Freiheit setzt.

$\left.{ }^{1}\right)$ Stintzing, Fortgesetzte Untersuchungen über die Fohlensänre der Muskeln. Arch. f. d. ges. Phiysiol. Bd. 20. S. 189 (1879).

2) Hermam, Untersuchungen über den Stoffwechsel der Muskeln. Berlin 1867. 




QH Abderhalden, Emil

324 Handbuch der biochemischen

A3 Arbeitsmethoden

$\mathrm{Bd} .3$

Spez.T.I

BioMed

PLEASE DO NOT REMOVE CARDS OR SLIPS FROM THIS POCKET 
